\title{
REGULATION OF TOBACCO PRODUCTS
}

\section{(Part 1)}

Y 4. EN 2/3: 103-149

Regulation of Tobacco Products, (Pa...

\author{
HEARINGS \\ BEFORE THE \\ SUBCOMMITTEE ON \\ HEALTH AND THE ENVIRONMENT \\ OF THE \\ COMMITTEE ON \\ ENERGY AND COMMERCE \\ HOUSE OF REPRESENTATIVES \\ ONE HUNDRED THIRD CONGRESS \\ SECOND SESSION \\ MARCH 25 AND APRIL 14, 1994 \\ Serial No. 103-149
}

Printed for the use of the Committee on Energy and Commerce

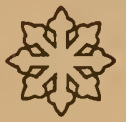


.

\section{(n)}

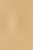

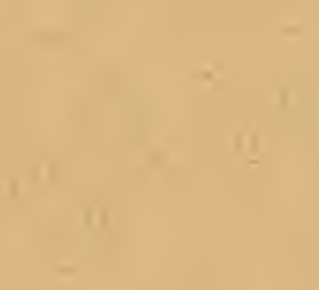




\section{REGULATION OF TOBACCO PRODUCTS (Part 1)}

\section{HEARINGS}

BEFORE THE

SUBCOMMITTEE ON

HEALTH AND THE ENVIRONMENT

OF THE

\section{COMMITTEE ON \\ ENERGY AND COMMERCE \\ HOUSE OF REPRESENTATIVES}

ONE HUNDRED THIRD CONGRESS

SECOND SESSION

MARCH 25 AND APRIL 14, 1994

\section{Serial No. 103-149}

Printed for the use of the Committee on Energy and Commerce

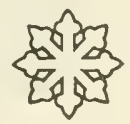




\section{COMMITTEE ON ENERGY AND COMMERCE}

HENRY A. WAXMAN, California

PHILIP R. SHARP, Indiana

EDWARD J. MARKEY, Massachusetts

AL SWIFT, Washington

CARDISS COLLINS, Illinois

MIKE SYNAR, Oklahoma

W.J. "BILLY" TAUZIN, Louisiana

RON WYDEN, Oregon

RALPH M. HALL, Texas

BILL RICHARDSON, New Mexico

JIM SLATTERY, Kansas

JOHN BRYANT, Texas

RICK BOUCHER, Virginia

JIM COOPEK, Tennessee

J. ROY ROWLAND, Georgia

THOMAS J. MANTON, New York

EDOLPHUS TOWNS, New York

GERRY E. STUDDS, Massachusetts

RICHARD H. LEHMAN, California

FRANK PALLONE, JR., New Jersey

CRAIG A. WASHINGTON, Texas

LYNN SCHENK, California

SHERROD BROWN, Ohio

MIKE KREIDLER, Washington

MARJORIE MARGOLIES-MEZVINSKY,

Pennsylvania

BLANCHE M. LAMBERT, Arkansas

\author{
CARLOS J. MOORHEAD, California \\ THOMAS J. BLILEY, JR., Virginia \\ JACK FIELDS, Texas \\ MICHAEL G. OXLEY, Ohio \\ MICHAEL BILIRAKIS, Florida \\ DAN SCHAEFER, Colorado \\ JOE BARTON, Texas \\ ALEX MCMILLAN, North Carolina \\ J. DENNIS HASTERT, Illinois \\ FRED UPTON, Michigan \\ CLIFF STEARNS, Florida \\ BILL PAXON, New York \\ PAUL E. GILLMOR, Ohio \\ SCOTT KLUG, Wisconsin \\ GARY A. FRANKS, Connecticut \\ JAMES C. GREENWOOD, Pennsylvania \\ MICHAEL D. CRAPO, Idaho
}

AlaN J. RoTh, Staff Director and Chief Counsel

Dennis B. FitzaibBons, Deputy Staff Director

Margaret A. Durbin, Minority Chief Counsel and Staff Director

\section{SubcommitTeE on Health aND THE ENVIRONMENT}

HENRY A. WAXMAN, California, Chairman

MIKE SYNAR, Oklahoma

RON WYDEN, Oregon

RALPH M. HALL, Texas

BILL RICHARDSON, New Mexico

JOHN BRYANT, Texas

J. ROY ROWLAND, Georgia

EDOLPHUS TOWNS, New York

GERRY E. STUDDS, Massachusetts

JIM SLATTERY, Kansas

JIM COOPER, Tennessee

FRANK PALLONE, JR., New Jersey

CRAIG A. WASHINGTON, Texas

SHERROD BROWN, Ohio

MIKE KREIDLER, Washington

JOHN D. DINGELL, Michigan

(Ex Officio)
THOMAS J. BLILEY, JR., Virginia MICHAEL BILIRAKIS, Florida ALEX MCMILLAN, North Carolina J. DENNIS HASTERT, Illinois FRED UPTON, Michigan BILL PAXON, New York SCOTT KLUG, Wisconsin GARY A. FRANKS, Connecticut JAMES C. GREENWOOD, Pennsylvania CARLOS J. MOORHEAD, California (Ex Officio)

\footnotetext{
KAREN Nelson, Staff Director

E. RIPLEY FORBES, Senior Staff Associate

WILlLAM SCHULTZ, Counsel

Howard COHEN, Minority Counsel
} 


\section{CONTENTS}

Hearings held on:

March 25, 1994

April 14, 1994

Testimony of:

Ballin, Scott D., vice president, American Heart Association, on behalf of Coalition on Smoking OR Health

Campbell, William I., president, Philip Morris U.S.A.

Clyburn, Hon. James E., a Representative in Congress from the State of South Carolina

Connolly, Gregory N., on behalf of American Public Health Association ....

Cooper, Richard, counsel, RJ Reynolds Tobacco Co

Durbin, Hon. Richard J., a Representative in Congress from the State of Illinois

Ellis, Kathy, director of research, Philip Morris U.S.A.

Frenchis, Robert, student, AMT Elementary School, Lake Ridge, Va. .........

Gardner, Sherwin, on behalf of Philip Morris U.S.A.

Henningfield, Jack E., Chief, Clinical Pharmacology Branch, National Institute on Drug Abuse

Horrigan, Edward A., Jr., chairman, Liggett Group, Inc.

Johnston, Donald S., president, American Tobacco Co

Johnston, James W., chairman, RJ Reynolds Tobacco Co

Kessler, David A., Commissioner, Food and Drug Administration

Lancaster, Hon. H. Martin, a Representative in Congress from the State of North Carolina.

Raffle, Stephen N., on behalf of the Tobacco Institute ..................................

Riehl, Tilford F., vice president, Brown \& Williamson Tobacco Corp. .........

Schindler, Andy, head of manufacturing, RJ Reynolds Tobacco Co. .............

Slade, John, on behalf of American Society of Addiction Medicine ................

Spears, Alexander W., III, vice chairman, Lorillard Tobacco Co.................143,

Taddeo, Joseph, president, U.S. Tobacco Co.

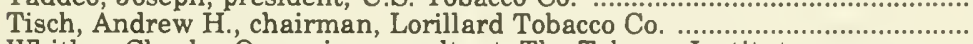

Whitley, Charles O., senior consultant, The Tobacco Institute

Prepared statements of witnesses submitted for the record for March 25, 1994 hearing:

Ballin, Scott D.

Connolly, Gregory N.

Gardner, Sherwin

Raffle, Stephen N.

Slade, John

Spears, Alexander W., III.

Whitley, Charles O.

Material submitted for the record by:

American Dental Association, statement

Coble, Hon. Howard, a Representative in Congress from the State of North Carolina, statement

Hansen, Hon. James V., a Representative in Congress from the State of Utah

Shepherd, Hon. Karen, a Representatve in Congress from the State of Utah

Taylor Quinn Consulting Inc., statement 



\title{
REGULATION OF TOBACCO PRODUCTS
}

\author{
FRIDAY, MARCH 25, 1994
}

\author{
HOUSE OF REPRESENTATIVES, \\ COMMITTEE ON ENERGY AND COMMERCE, \\ SubCOMmitTeE ON HEALTH AND THE ENVIRONMENT, \\ Washington, $D C$.
}

The subcommittee met, pursuant to notice, at 9:45 a.m., in room 2123, Rayburn House Office Building, Hon. Henry A. Waxman (chairman) presiding.

Mr. WAXMAN. This morning the subcommittee will hear testimony about a drug addiction which claims the lives of 430,000 Americans each year. The drug is nicotine and Americans ingest it by smoking.

In 1988 the Surgeon General concluded that nicotine addiction was one of the most important health consequences of smoking. The 1988 report concluded that cigarettes and other forms of tobacco are addicting, nicotine is the ingredient in tobacco that causes addiction, tobacco addiction shares important similarities to addiction to drugs such as heroin and cocaine.

Four weeks ago, the Commissioner of the Food and Drug Administration announced evidence exists that tobacco manufacturers have engaged in the deliberate manipulation of nicotine content in order "to satisfy an addiction on the part of their customers."

If substantiated, the implications of such a finding are profound and could dramatically impact the availability of tobacco products in the United States. According to Commissioner Kessler, the classification of nicotine in tobacco products as "drugs" could result in removal from the market of tobacco products containing nicotine.

This morning, we have asked Dr. Kessler to elaborate on the possible application of the Federal Food, Drug and Cosmetic Act to tobacco products.

We will also hear from the Coalition on Smoking OR Health which has formally petitioned the FDA to classify all cigarette products as drugs under the Food, Drug and Cosmetic Act and from several representatives of the tobacco industry.

We will not hear, however, from individuals at the center of this controversy because they have declined to testify at this hearing. These individuals set the standards for industry conduct. They set the limits on company practices. They know how much nicotine is added to cigarettes and why. The subcommittee extended an invitation to Michael Miles, the chairman and CEO of Philip Morris and other top tobacco company officials.

Without objection I would ask that letters from Mr. Miles, James Johnson of RJ Reynolds, and T.E. Sandefur, Jr. of Brown and 
Williamson be printed in the record at the conclusion of my opening statement.

Mr. Miles had the time to hold a press conference and announce a lawsuit yesterday, but he wouldn't find the time to come before the Congress of the United States and talk about this very issue.

The tobacco industry denies the adverse health effects of smoking. They deny that advertising promotes smoking. They deny that their cartoon characters are appealing to children. They deny that nicotine is addictive. Today their representatives will deny that tobacco companies enhance or fortify tobacco with nicotine. They will ask the Congress to take them at their word.

I don't think so.

The evidence that FDA will present today makes three critical points: One, nicotine is a powerfully addicting substance; two, nicotine is the reason people smoke; and three, tobacco companies have the capability of removing all nicotine from cigarettes.

What the American people want to ask the cigarette industry is this: "If nicotine is addicting, why won't you remove it from cigarettes?"

We have had legislation in the Congress for a number of years introduced by my colleague Mike Synar and others to ask the FDA to have jurisdiction to regulate tobacco. They are now unregulated by the Food and Drug Administration, the Consumer Product Safety Commission or any other Federal regulatory agency.

Perhaps we need to ask ourselves why we should leave this product, which does so much harm to the American people, completely unregulated.

I want to commend Congressman Synar for his leadership in raising this issue year after year. Now it is time for us to take a hard look at his proposal.

[The letters referred to follow:] 


\section{PHILIP MORRIS}

COMPANIES INC.

THE COLORADO BUILDING • 1341 G STREET, N.W - SUITE 900

WASKINGTON, D.C. $20005 \cdot 202 \cdot 637 \cdot 1500$

The Honorable Henry A. Waxman

Chairman

Health and Environment Subcommittee of the House Energy and Commerce Committee 2415 Rayburn House Office Building Washington, D.C. 20515

Dear Representative Waxman:

Michael Miles, the Chairman and Chief Executive Officer of Philip Morris Companies Inc., has asked that I respond to your letter dated March 16, 1994 inviting him to testify before your Subcommittee on March 25. I regret to inform you that Mr. Miles is unable to accept your invitation. However. industry representatives should be able to adequately address at your hearing the issues you describe in your invitation.

With best regards,

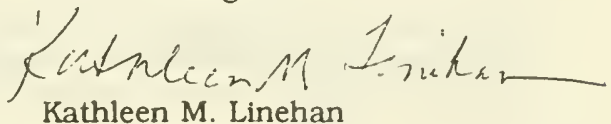

Kathleen M. Linehan 


\section{RIReynotds}

March 21, 1994

JAMES W JOHNSTON

Charman and

Chief Executive Officer

Winston-Salem, N.C. 27102 919.741 .7925

The Honorable Henry Waxman

U.S. House of Representatives

Committee on Energy and Commerce

Subcommittee on Health and the Environment

2415 Rayburn Hoise office Building

washington, DC 20515

Dear Mr. Chairman:

Thank you for your letter of March 15, 1994 and your invitation to testify at hearings scheduled before your subcomittee on March 25, 1994.

From your letter, it is apparent that these hearings will focus on technical aspects of the cigarette manufacturing process as well as the policy implications of FDA regulation. I firmly believe that these are issues which the experts on our industry panel of witnesses are more qualified to address. Accordingly, I respectfully decline your invitation to appear before your subcommittee on March 25, 1994.

Very truly yours,

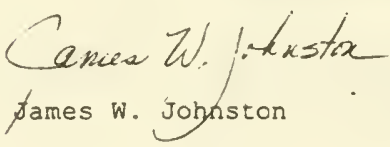

"We work for smokers." 
The Honorable Renry A. Wexman

Chairmen, Subcommittee on Healch and the Environment

Committoc on Enersy and Commerce

2415 Rayburn Howto Office Building

Washington, DC 20515-6118

Dear Mr. Chairman:

Thank you for inviting Brown \& Willianson to testify before your subeommittee on March 25, 1994. Brown \& Williamson will participat through induntry

representative Mr. Charlea $\mathrm{O}$. Whitley, Senior Consulant to The Tobacoo Institute, and Dr. Alerander W. Spears, II, Vice Chairman and Chief Operating Officer of the Lorlllard Tobacos Company.

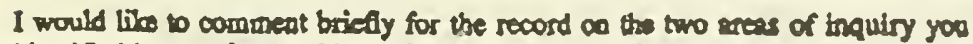
identified in your low of invintion: nemely, edjusting nicotine lovals in the cigarette manufacturios proses, and whether Congress should wuthorize the Rood and Drug Administrabion to regulato ntootios.

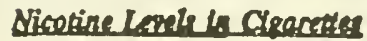

The media, bogether with the Commissioner of the Food und Drug Administation, have survetted that clparetre menufacturers, in the words of one report, "cynically meanipales alootine bevels to keep their customens booked." This conteation in sbourd.

Browa \& Williameon does nox believe the addiction claims of the Surgeon Centeral and the FDA Commiesioner, nor do we "epibs" our cigaretts with niootion Our

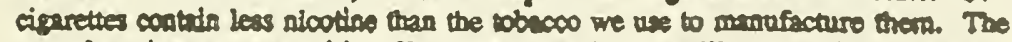
manufecturtag process and it effoct regarding nicotine will be described is greater detail in testimony before your Subcommittee by industry representutives. But I repeat we do sot "spike" our cigarettes with nicotine, and ciparettes never contain more micotine than the tobscos we use to make them. 
The Honorable Henry A. Wexman

Page 2

March 23, 1994

There has been a dramalle drop in the average nicotine content of cirarattas since the 1950's. Acoording to The N/y Rnolund Jorme / of Medicine, the avernge njootine delivery dropped from 2 milligrams to 0.9 millinms between 1955 and 1987. [Editorial, p. 1619, July 15, 1989.]

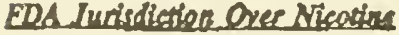

In responding to recent petitions submitted by the Coslition on Smoking OR Kealth seking FDA regulation of low "tar" and low nicotine cigaretter and de-nlootized oigaretter, the FDA Commledioner has expressly deferred jurisdiction over cigarettes to Congress. The legisiative history of the Foderl Food, Drug and Cosmetic Act as amended, and cares interpreting that Act, clearly stand for the proposition thas tobaco and alcotine aro not "drugs" and aro, therefore, not subject to FDA regulation. We are pleased the Commissioner recognizes what the law is and acknowledges the need for Congress to provide direction to his aganoy.

Coneress should lnstruct FDA not to expend further time, energy and finunch resourcss seeking authority to regulut tobecco or nicotine. We also oppose any effor by Congress to extend the FDA's Jurisdiction to tobacco or nicotian. Cigarettes ere alrendy hichly regulated. There is no need or justification for FDA to regulate cireretes. Whatever policy decisions need to be made relating to tobacos and nicotine cas best be made by Congress.

Wo would appreciate your including this letter in the hearing recond.

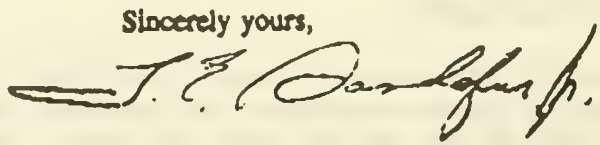

TES/dlb 
Mr. WAXMAN. Mr. Bliley.

Mr. BLILEY. Thank you, Mr. Chairman.

Mr. Chairman, we are here today to consider issues raised by the Food and Drug Administration Commissioner, David Kessler. In his February 25, 1994 letter to the Coalition on Smoking OR Health-and similarly aired in the media relating to nicotine in cigarettes-in his letter, Dr. Kessler suggested that the cigart manufacturers may be spiking their cigarettes with nicotine order to keep their customers hooked.

This proposition was advanced in even more sensational form a television news magazine program called Day One on February 28. In the uproar that followed, The New York Times said in an editorial that the FDA's allegations about nicotine manipulation, if true, would be a crime of unconscionable dimensions.

Last week Philip R. Lee, Assistant Secretary of the Public Health Service announced dramatically, but incorrectly, it turned out, that FDA had asked the Justice Department to investigate these allegations. What was the basis for these grave allegations against the cigarette industry? What is the evidence now available, as Dr. Kessler puts it, that could support a change in FDA's long-standing policy toward tobacco? Is it evident that cigarettes today contain more nicotine than ever before? That could not be.

If Dr. Kessler had consulted the 1989 Surgeon General's report, he would have noted a chart on page 88 that shows a decline in average nicotine content of about two-thirds between 1957 and 1987. The decline in the nicotine content of cigarettes has been common knowledge for years. Is nicotine being added through a tobacco reconstitution process?

The reconstitution process has been in use for over 30 years. Manufacturers have explained to the Department of Health and Human Services in correspondence last year that this process results in no increase in nicotine. The New England Journal of Medicine in a 1989 article said that the reconstitution process is one of the ways in which cigarette manufacturers reduce the amount of nicotine in cigarettes. Three Surgeon Generals' reports made this same point.

Is the use of tobacco extract aiding nicotine? Tobacco extracts have long and well-documented use in tobacco products. The manufacturers told the Office of Smoking and Health that the nicotine indirectly added by the use to tobacco extracts is less than onethree thousandths of a percent by weight of the tobacco blends.

Is the use of denatured alcohol adding nicotine? Denatured alcohol has been used for over 40 years. The manufacturers told HHS that the quantity of nicotine indirectly added to tobacco from denatured alcohol is less than one-one thousandth of a percent by weight of tobacco blends. Yes, I said one-three thousandths of a percent from tobacco extracts and one-one thousandth of a percent from denatured alcohol.

Manufacturers pointed out to HHS that 2 to 3 percent of tobacco is nicotine by weight. When someone talks about the nicotine indirectly added by extracts and denatured alcohol, it reminds me of the old pictures of a mouse standing next to an elephant or a man standing next to the Empire State Building. 
Did the Commissioner and his staff fail to consult with the Office of Smoking and Health before he unloaded his heavy artillery against the tobacco industry? Did he and his staff fail to consult the relevant Surgeon General's reports and the relevant literature on the reconstitution process? Obviously he failed to consult with the manufacturers themselves.

In short, Dr. Kessler failed to do his homework. He chose to shoot first and ask questions later. In a similar vein, I have noted Assistant Secretary Lee announced last week in a congressional hearing that the FDA had asked the Department of Justice to investigate the alleged manipulation of nicotine in cigarettes, only to have HHS issue a correction explaining that no such referral had occurred.

I know the tobacco industry is not very popular in some quarters, but that does not excuse Federal officials from their duty to proceed cautiously and responsibly before leveling serious accusations. Commissioner Kessler has not done so in this instance.

I view this hearing as an opportunity for Dr. Kessler to explain his precipitous and reckless conduct and to set the record straight. Thank you, Mr. Chairman.

[The article from the New England Journal of Medicine follows:] 


\section{The New England Journal of Medicine}

Owned and Published by the Massachuserts Medical Societ)

$$
\begin{gathered}
\text { William G. Laveile, M.D. } \\
\text { Presidens }
\end{gathered}
$$

William $\mathrm{M}$ McDermoth Ir., Executioe Vice President

Charles S. Amorosino, Jr. Execulice Secritay

Thz Commtter on Puanchtons of the Mnesachusetts Medical SOCIETY

Henry H. Banks, M. D

James F. McDonough, M.D., Chaimen Frank E. Bixby, Jr., M.D.

Howard M. Ecker, M.D.

Howard Epstein, M.D.
Edward E. Jacobs, Jr., M.D. Daniel Miller M. Percy W. Wadman, M.D.

Arnold S. Relman, M.D., Eorrok-tr-Chis: Marcia Angell, M.D. Exucurrve Eprrok Edwin W. Salzman, M.D., Deputr Edrox Gregory D. Curfman, M.D., Derutr Edrton Edward W. Camplon, M.D., Deputy Eorrox Robert D. Utiger, M.D., Derurr Eorrox

\section{Assocutz Edrons}

Jane F. Desforges, M.D. Norman K. Hollenberg, M.D., Pb.D. Ronald A. Malt, M.D. Morton N. Swart, M.D.

Franklin H. Epstein, M.D.

Francis D. Moore, M.D., Book Review Esror

John C. Bailar, III, M.D., Walter Willeth, M.D., Statistral Consuztarts

John K. Iglehart, National Comersmondent

Marlene A. Thayer, Eorronuc Ornex Marnoes Stephen E. Cinto, Maraoes or Epronul Production Lorraine W. Loviglio, Maraoza of Maruscum Eprmwo

\section{Eotroneac Boaro}

Eugene Braunwald, M.D. Aram V. Chobanian, M.D. Theodore Coleon, SC.D. Richard H. Esdahl, M.D. John T. Harrington, M.D. Homayoun Kneeni, M.D.
Robert J. Mayer, M.D. Kennet MeIner, M.D. David G. Nathen, M.D. Lawrence G. Raip, M.D. Kennech J. Rothman, Dr.P.H Thomes J. Ryan, M.D.

\section{Eomorus Omas}

Nancy A. Bracty, Editurial Production Assistant; Helen Connors, Research Asvistant; Keren M. Daly, Editorial Assistant; Brians Doherty, Editorial Assistant; Rathieen Eagan, Manuscript Aasistant; Dale R. Golden, Editorial Assistant; Kate L. Hess, Editorial Production Assistant; Chriatie L. Hages, Editoria Assistant; Rebecc H. Hale, Editorial Assistant; Susen L. Keplan, Editorial Probeca $H$. Hale, Editorial Astistant; Susan L. Kaplan, Editorial Pro-
duction Layout Artist; David F. March, Manuscript Editor, Sandra duction Layout Artist; David F. March, Manuscript Editor, Sandra S. MeLean, Manuscript Editor; Brien Middleton, Editorial Assist-
ant; Henry S. Miller, Jr., Manuscript Editor, Stephen Morrisey, Menuscript Editor; Sylvia L. Parons, Ediorial Auistant; Marilyn Seaquist, Receptionist; Deborah A. Stone, Senior Editoria Production Coordinator.

Frederick Bowes, 111, Dinecton of Pusushmo Opzumons Ann Reinke Stronk, Deruty Diancton

\section{HEALTH AND PUBLIC POLICY IMPLICATIONS OF THE "LOW YIELD" CIGARETTE}

BETWEen 1955 and 1987 the average tar and nicotine yield of American cigarettes declined substantially. The average tar yield (weighted for the volume of sales of the cigarette) fell from 34 to $13 \mathrm{mg}$, and the average nicotine yield declined from 2 to $0.9 \mathrm{mg}$. Advertisements for "low yield" cigarettes often imply that the health hazards associated with smoking these cigarettes are less than the hazards associated with higher-yield cigarettes.

The case-control study by Palmer and coworkers reported in this issue of the Joumal shows that modern low-yield cigarettes do not reduce the risk of nonfata myocardial infarction among women smokers under 65 years old.' Similar data have been reported for men. ${ }^{2}$ It seems cleat that the hazards of coronary heart disease are not reduced by smoking low-yield rather than high-yield agarettes. However, there is evidence that smoking the low-yield cigarette may af fect the overall risks of adverse health effects in a population of smokers. The implications of these findings for physicians and public policy makers are the subject of this editorial.

Yields are determined by analyzing the smoke produced when a machine consumes a cigarette, using specific "puffing" characteristics. In the United States, a 35-mi pufi is taken over a period of two seconds, and one puff is taken every minute until the cigarette has burned to a specific length. Cigarette testing was performed by the Federal Trade Commission between 1967 and 1987. The commission began testing to deal with the competing advertising claims of tobacco companies concerning tar yields. Governmental testing was discontinued for economic and other reasons. Cigarette manufacturers, overseen by the Federal Trade Commission, now undertake testing on a voluntary basis.

Historically, the first and most imsortant step in reducing tar and nicotine yields was the addition to cigarettes of a filter tip that selectively removes

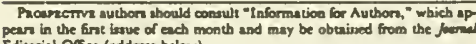
Editoris Offec (addreas below).

Anrraxs witb original muterial are scocpted for considention with the underianding thas except for abarnceu, no part of the dau has been pub. lished, or will be mubmitted for publication elecwhere, before appearing here. Notrces ahould be went at leant 30 daye before publication date.

Trs , mond does not hold itell responsible for statemesta made by any contributer. Statement or opirions apressed in the fened refleet the virm of the author(s) and not the official policy of the Massuchuert Medica Society unless so stated.

Asmoven all advertiting material is expected to conform wo ethical ttand. ande, screptance does not imply endorsement by the fhomel.

Marzaul printed in the Junel is covered by copyright. No part of this publiavion may be reprodued of tmensined in any form without written permistion.

Foa information on subscriptions, permiayione, repriats, and acher services ee the "Butines Information for Readen" pare preceding the Classified Advertising section.

Esrronul Omas: 10 Shattuck St., Boston, MA 02115-6094.

(617) 734 (44)

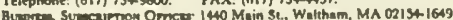


these elements (but not carbon monoxide or other gascous components) from tobacco smoke. More recent engineering refinements to decrease tar and nicotine yields include the use of reconstituted sheet tobacco containing larger amounts of stems, which has less nicotine; expanded or puffed tobacco, which results in less tobacco per cigarette; faster burning times, more porous paper, and longer filter overwraps, which cause the sinoking machine to take fewer puffs per cigarette; and ventilated filters that allow dilution of the tobacco smoke with air. It is important to recognize that modern low-yield cigarettes contain the same type of tobacco and the same amount of nicotine by weight as higher-yield cigarettes. ${ }^{3}$ Thus, the lowyield cigarette is not low in yield because it contains less of anything, but because it is engineered to make less smoke available to the smoker (or at least to the smoking machine).

However, people do not smoke the way machines do. Most smokers are addicted to nicotine; they tend to compensate for their lower-yield cigarettes by smoking them in such a way as to optimize the intake of nicotine. ${ }^{4}$ By taking more frequent puffs, inhaling more deeply, occluding the ventilation holes with lips or fingers, and smoking more cigarettes, people take in considerably more tar, nicotine, and carbon monoxide than would be predicted by smoking machines. Studies of people who smoked their own selected brands of higher- or lower-yield cigarettes indicate similar or only sligbtly lower levels of cotinine (a metabolite of nicotine commonly used as a marker of nicotine intake) or carbon monoxide in smokers of all but possibly the lowest-yield cigarette ( $1 \mathrm{mg}$ of tar) $0^{3,3-6} \mathrm{De}$ spite a great deal of promotion and advertising, very-low-yield cigarettes ( 1 to $3 \mathrm{mg}$ of tar) are not very popular and account for only a small percentage of sales, ${ }^{9}$ presumably because most smokers do not obtain enougb nicotine to find them satisfying. In general, low-yield cigarettes do have a lower ratio of tar to nicotine yield as tested by smoking machines, which has suggested that even if smokers compensate for nicotine, their exposure to tar will be reduced. 'Unfor tunately, intensively smoking low-yield cigarettes increases the tar-to-nicotine ratio and reduces or even negates any possible benefit of selective differences in yield. ${ }^{3}$

Epidemiologic data indicate that low-yield cigarettes are less hazardous than high-yield cigarettes with respect to lung, laryngeal, esophageal, and other cancers and possibly chronic obstructive lung disease. ${ }^{10-12}$ However, it is important to recognize that the definition of "low yield" has changed over the years. A low-yidd cigarette in the $1960 \mathrm{~s}$ (18 $\mathrm{mg}$ of tar or less) would be a high-yield cigarette today. Many of the older cigureties were unfiltered. Not only was their yield of tar much greater, but the tar was also qualitatively more toxic than that in modern cigarettes. As is appropriate when one is studying diseases that may take 20 years or longer to develop, most epidemiologic studies of cancer and lung disease bave used the older cigarettes in their comparisons. Studies indicate that the risk of lung cancer is reduced substantially (by 20 to 40 percent) in smokers of the old-style low-yield as compared with the old-style high-yield cigarettes; however, that risk is still markedly higher than the risk in nonsmokers. ${ }^{10-12}$ Similar results have recently been reported for laryngeal, esophageal, and other cancers. 11 The data on chronic lung disease are less clear. Some studies suggest a reduction in cough and phlegm, fewer deaths due to emphysema, or slightly less seriously impaired pulmonary function in smokers of filtered as compared with unfiltered cigarettes. ${ }^{10,11}$ Other studies find no difference in lung function as related to cigarette yield. ${ }^{13}$ It is notewortiny that the greatest reduction in lung cancer among people who switch from unfiltered to filtered cigarettes is among those who do not increase the number of cigarettes they smoke per day. ${ }^{14}$ The risk in those who compensaic by smoking more than 10 additional filtered cigarettes a day is as great as or greater than their risk when they smoked unfiltered cigarettes.

For myocardial infarction, studies comparing smokers of high-yield and low-yield cigarettes, either old style or modern, show no evidence of a difference in disease risk. $1,2,10,11$ We can draw valid conclusions concerning modern cigarettes and the risk of acute myocardial infarction or sudden deach, because these events are closely related to current smoking habits. The risk of these events diminishes within a year or less of stopping smoking, so the brand most recently smoked is likely to influence disease risk. Although conclusions about the relative risks of modern highyield and low-yield cigarettes cannot yet be reached for cancer or chronic lung disease, studies using biochemical markers of nicotine or smoke intake in people who smoke various brands indicate only small differences in exposure to the toxins of tobacco smoke. The expected reduction in disease risk for a person who smokes a low-yield cigarette is small, although the consequences of a small reduction in a population of smokers could be considerable.

On balance, the movement toward low-yield cigarettes has been worthwhile, although in reducing the risk of discase it may have reached the limit. There are, however, potential risks in encouraging the smoking of low-yjeld cigarettes. The availability of lowyield cigarettes may make it easier for adolescents to begin smoking. Additives, which enhance the flavor of low-yield cigarettes, may be harmful, although no data concerning this issue are available. Most important, information about low-yield cigarettes may be used to convince people that smoking is not as hazardous as it once was. As a result, some smokers may switch to low-yield cigarettes rather than quit.

The implications of the low-yield cigarette differ for physicians and public bealth planners. The benefits for any person of smoking low-yield rather than highyield cigarettes are small, and the benefits of quitting are great. Physicians should give their patients tie unequivocal message that low-yield cigarettes are not safe cigarettes. The only reliable way to reduce the adverse health consequences of smoking is to stop. 
From the perspective of public health, however, the movement toward low-yield cigarettes makes sense. There has been considerable progress in reducing the prevalence of smoking in the United States, Canada, and many European countries, but smoking rates are much nigher in other parts of the world, and the cigarettes smoked in many other countries have a much higher yield than their American counterparts. A worldwide attempt should be made to reduce the yields of toxic substances and to make the yield of all cigarettes as low as possible. Public health policy should encourage smokers who have not yet quit to smoke cigarettes with the lowest possible yield. The yields of American cigaretzes should not be allowed to drift higher as research finds that low-yield cigarettes are not less hazardous. Mandated ceilings for tar, carbon monoxide, and other toxic components of tobacco smoke that could be lowered gradually over the years, or a progressive tax on higher-yield cigarettes, are logical ways to implement such goals.

Sen Francisco General Hospital

San Francisco. CA 94410

Neal L. Benowtrz, M.D.

\section{REFERENCES}

1. Palmer JR, Rosenberg L, Shapiro S. "Low yiejo" cigaretes and the risk of

nonfatal myocardial inf arction in women. N Engl J Med 1989; 320:1569-73.

2. Koufman DW. Helmuich SP. Rosenberg L. Mietinen OS, Shapiro S. Nico ane and eatron monoude contest of eigarette snoke and the risk of myocardial infaretron in young men. N Engl Med 1983; 308.409-13.

3. Benowiz NL, Hall SM, Herning RI, Jacob P II, Jones RT, Osmen A-L. Smokers of low.yeld cagaretes do not consume kes nucotine. N Engl I Med $1983 ; 309: 139-42$.

4. Benowiz NL. Pharmacologic sepers of cizantere smoking and niconne addiction. N Engl J Med 1988: 319:1318-30.

5. Benowiz NL, J coob P III. Yu L. Tuloot R. Hall S. Jones RT. Redaced tar ricacine. and eartoe monoxide exposure while inotung ultrilow but not low-yield cigiones. JAMA 1986: 236:241-6.

6. Gori GB, Lymch CI. Andyrical cigurear yields as protictors of smote biosvailability. Regul Toxucol Furmoucol 1985: 5:314-26.

7. Russell MA, Javis MJ. Feyerabend C. Sabojice Y. Rectuction of tur, nico-

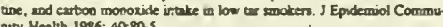
arty Healch 1986; 4080-5.

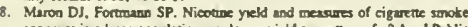

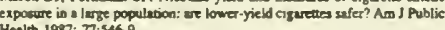
Heal 1987: $77: 546$.

9. Kozlowski LT. Evidence for limit on the soctpability of lowest-ar cigarear. Am I Pablic Heal't 1959, 79:19\%-9.

19. Depertmeat of Health and Human Services. The health consequenoes of srooting the changing elares: a report of the Surgewn Generd. Weshing-

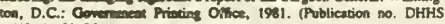
(PHS) 81-S015.)

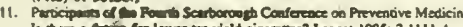

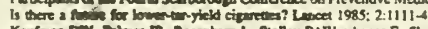

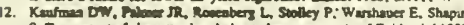

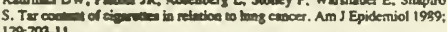
129.700-11.

13. Sparrow D, Seffos T, Baved R, Wein ST. The relationehip of ur content 10 declioe in pulmoning furction in cigarete smoter. Am Rev Respir Dis 1983; $127.56-8$

14. Augusane A, Harns RE, Wynder EL. Compensation as a nsk factor for lung etwoer in smokers who switsb from nonfiler to filter cigurettes. Am J Public Hewth 1989, 79.188.91.

\section{PREDNISONE THERAPY FOR DUCHEINNE'S MUSCULAR DYSTROPHY}

In the past five years, progress in understanding the molecular basis of Duchenne's muscular dystrophy has heen substantial. 'The affected gene in this discase has been cloned, and its protein product, dystrophin, characterized.' The importance of dystrophin in the pathogenesis of this disorder has been defined: dystrophin is absent from muscle in Duchenne's muscular dystrophy and is usually present but of abnormal size in Becker's muscular dystrophy, a milder variant. ${ }^{2}$ Unfortunately, these dramatic advances have not yet had an effect on the clinical management of muscular dystrophy. Duchenne's muscular dystrophy remains invariably fatal. The disease is common, occurring in approximately $]$ in 3000 male infants. A third of the cases resuit from new mutations in the dystrophin gene. It is therefore essential to develop effective treatment for this disorder.

In this issue of the Journal, Mendell and colleagues report that the administration of prednisone in single doses each day over a six-month period improved the strength of patients with Duchenne's muscular dystrophy. ${ }^{3}$ This confirms the results of three previous unrandomized, unblinded studies. ${ }^{4-6}$ In an earlier study, these investigators found prednisone effective in such patients as compared with historical controls who were only observed. "They now repor similar results of a randomized, blinded trial. Several factors were evaluated to gauge muscle status, including strength in several muscles, joint contraciures, timed functional tests (e.g., the time needed to climb four stairs), overall functional grading of the limbs, and pulmonary-function tests. In all ca:egories except joint contractures, progressive improvement was detected at one, two, and three months; the improvement in muscle function was maintained for three to six months.

Several points commend this report. It demonstrates benefit from a therapy for Duchenne's muscular dystrophy in a double-blind, controlled trial. It exemplifies the valie of well-executed multicenter collaboration for rapid, statistically accurate drug trials. It is also a tribute to the Muscular Dystrophy Association, which has been a dominant force promoting research into the pathogeriesis and treatment of the disease.

These points notwithstanding, the paper raises several questions. Perhaps most important, can any trial of steroids at these doses remain truly blinded and free of a placebo effect? The answer is not clear. Certainly, it is unlikely that observer bias explains the significant clinical improvement at one month in this study, since the cushingoid appearance induced by steroids had not developed in most of the prednisone-treated pa. tients by that time. Alchough the results of many of the functional tests might have been influenced by a placebo effect, it is doubeful that this alone would have accounted for the overall pactern of improvement in the prednisone groups. Twenty-four-hour urinary creatinine levels, which reflect total muscle mass, increased during prednisone treatment. This observation is objective and presumably independent of any placebo effect. Furthermore, some trials of drugs have not benefited patients with Duchenne's muscular dystroplyy. indicating that placelon ellects 
Mr. Waxman. Thank you Mr. Bliley.

Mr. Synar.

Mr. SYNAR. Thank you, Mr. Chairman, and thank you for this opportunity to focus on $a$ very important health issue for all of us.

Ladies and gentlemen, the tobacco industry is perpetrating a fraud on the American people. Tobacco companies put Lord knows what in their tobacco and they do not believe that they should in any way be accountable to the American people who buy their products.

Americans have the right to know what is in cheese through the ingredients on the back of the package. Americans have the right to know what is in NyQuil and other drugs. Americans do not have the right to know what is in this cigarette package. Yet 7 out of every 10 Americans believe that tobacco products should be regulated. Nine out of 10 Americans believe that manufacturers should disclose the additives used in tobacco products.

Why isn't it happening? It could be because of the increasing amount of attention that has been drawn to the means and the influence that the tobacco industry yields in this town and across this country. Their lobbyists are some of the wiliest and best compensated in America.

Let me share with you a quote from a former tobacco industry lobbyist in the Maryland State legislature, Victor Crawford, which appeared in The New York Times on March 20, 1994. "I am not proud of having lobbied for them, the tobacco industry. I think it is ironic and just desserts, because in my heart, I knew better. But I rationalized and denied because the money was so good and because I could always rationalize it. That is how you make a living, by rationalizing that black is not black. It is white; it is green; it is yellow.

"But I knew in my heart that what the Surgeon General said was right. I think these people know that. Do I feel guilty about what I did? Yes. Would I do it again knowing what I know now? No. Would I do it again not knowing what I know now? Yes. Why? Because it might be unhealthy but it will never again happen to me and, after all, there is freedom of choice and it is a free country. If you want to make an ass out of yourself, you have that right. Sounds good, but the fact of the matter is that it is a killer."

My colleagues, friends, fellow Americans, it is time, long overdue to force this tobacco industry to show some respect for the health of the American people.

Mr. WAXMAN. Thank you Mr. Synar.

Mr. Wyden.

Mr. WYDEN. I want to start by congratulating you and Congressman Synar for your many years of leadership on this issue and I also want to commend Dr. Kessler for his courage and his efforts in the public interest to examine the question of regulating tobacco products as drugs.

This is an extremely important hearing. We are going to be examining today whether cigarettes are indeed a delivery system for the addictive drug nicotine and, therefore, should be regulated like other drugs under the Food, Drug and Cosmetic Act of 1938.

We see many representatives of the tobacco industry in the audience. They are here, I believe, because they are concerned, con- 
cerned that government may eventually be getting around to doing the right thing. Dr. Kessler's scrutiny of tobacco has set off warning alarms throughout the industry because this drug, the drug of choice to many millions of addicted Americans and the basis for a $\$ 50$ billion per year industry, may have to be proven safe under FDA regulation in order to stay on the market. How many on this panel or in this country would want to try to represent that side of the case?

Mr. Chairman, this hearing is not about freedom of choice or alleged government intrusion on matters of personal habits. It is about an addiction that drains billions of American health care dollars, kills many of our fellow citizens, and threatens the security of our children. It is also about what is or isn't in tobacco and blatant tobacco industry efforts to withhold information from the American people, about a variety of agents and chemicals in tobacco which may pose serious health threats.

Today I have a three-ring binder that contains lists of chemicals and other agents in tobacco products. Under a 10-year-old law, the lawyers for the industry have to submit these lists each year under strict confidentiality to the Centers for Disease Control. According to these lists, cigarettes contain ingredients so toxic that you could not dump them in a landfill under the Federal environmental laws.

These lists show that the Federal Government is allowing toxins to be delivered directly to the bloodstream via the lungs, the most efficient delivery system that nature has ever devised. Under the law, public health officials have the right to review these lists and decide whether specific agents may require changes to cigarette package labels warning of health risks.

I won't tell you what we had to do to get this binder. The industry objected. It wasn't easy. But I will tell you, citizens of this country aren't going to get to see this binder because of the incredible argument by the cigarette makers that these lists contain trade secrets. Apparently one of those secrets may be that some manufacturers are juicing up their products by adding extra amounts of nicotine. What else?

I would like the American people to know exactly what is in these lists, but I am bound from telling them by the confidentiality provision of the law. I can say that my perusal of the documents shows that these lists contain heavy metals, active agents and pesticides and insecticides. It contains at least 13 ingredients that, by FDA law, are not allowed in the foods that Americans eat.

Possibly these are items that belong on warning labels. We will never know, because the staff has found that for years no public health official with access to these lists has even bothered to ask for it in order to make even a cursory review.

Mr. Chairman and colleagues, this industry has had its own way for too long. It is time this list got a review. Therefore, at the appropriate time, I would like to propose that this subcommittee convene a special executive session if need be to review all 700 items on this list with the health officials of our country.

We ought to lift the cloud of tobacco smoke that has hovered over these documents. These documents are not atomic secrets. They aren't even confidential provisions of a trade treaty. It isn't even the secret formula for Coca-Cola. These are matters of real con- 
sequence to the health and safety of our citizens, and our consideration should not be waylaid by specious industry claims that trade secrets are being jeopardized.

Mr. Chairman, I congratulate you and Mike Synar and Dr. Kessler for pressing forward with this inquiry and look forward to our witnesses.
[The prepared statement of Hon. Gary A. Franks follows:]

\section{STATEMENT OF HoN. Gary A. Franks}

Thank you, Mr. Chairman. This morning we will consider the issue of FDA regulation of tobacco products. I appreciate the opportunity to comment on this matter. Mr. Chairman, I have very serious concerns about the impact this action would have on the FDA's current responsibilities and our economy.

I have seen no evidence that their is a need for such action. The tobacco industry is already regulated by the Federal Government from the day the seeds are planted to the purchase of a product. Tobacco also is subject to exceptionally heavy regulation by taxation. Because of this regulation, cigarette manufacturers have been publicly reporting "tar" and nicotine levels for more than 20 years. The manufacturing process for cigarettes are not new and have not been hidden from the Government. The Department of Health and Human Services has been receiving cigarette ingredients lists since the early 1980 's and has never given any indication that these ingredients were harmful or that the manufacturing process was suspect in any way.

I am concerned that the FDA's primary function, to test pharmaceutical to ensure their safety for the public is not being handled in a timely manner. An increasing number of new drugs await approval while staff and monetary resources diminish. It is no secret that approval of new drugs to treat ailments such as asthma, cancer, arthritis, Alzheimers and AIDS are way behind schedule. Those citizens in critical stages of diseases (and who can afford it) often go out of the country to receive treatment with drugs that have been widely accepted for years in other countries, but have not received approval by the FDA. Given this unfortunate scenario, why would we want to burden an alregdy overburdened Agency with the enormous and unnecessary task of regulating and policing the manufacture, labeling and advertising of tobacco products and the use of tobacco additives.

The impact on our economy and the tobacco industry would be equally devastated by the FDA's decision to ban the cultivation and consumption of tobacco. FDA Commissioner Kessler has stated publicly that the FDA would "have no choice under current law" to do so if the FDA rules nicotine a drug.

Thousands of jobs and entire economies could be wiped out with this decision. State and Federal treasuries would be severely impacted. Even President Clinton would have to re-think the financing of his health care plan if this decision were to become law.

We all know that a scenario like this would also ignite the largest black inarket we have seen in this country since prohibition.

The regulation of cigarettes by the FDA would cause irrevocable damage to our economy and society, not just in the southern States represented by my colleagues here today, but across the United States. I strongly urge all of my colleagues to reject this plan of action.

Mr. WAXMAN. Thank you. Our first witnesses this morning are colleagues with long-standing interest in tobacco. Richard Durbin of Illinois is chairman of the House Appropriations Subcommittee of Agriculture, Rural Development, Food and Drug Administration, and related agencies. Martin Lancaster is a member from North Carolina, James Clyburn is a member from South Carolina. 
Welcome to our hearing today. Without objection, your testimony will be printed in the record in its entirety and we would like to ask you to limit your oral statements because we do have a long list of witnesses to hear today.

Mr. Durbin.

\section{STATEMENT OF HON. RICHARD J. DURBIN, A REPRESENTA- TIVE IN CONGRESS FROM THE STATE OF ILLINOIS}

Mr. DuRBIN. Thank you, Mr. Chairman. I appreciate the opportunity to testify today regarding the recent revelations about the role of nicotine in tobacco manufacturing and marketing. I appreciate your leadership as well as the leadership of Mr. Synar and $\mathrm{Mr}$. Wyden in dealing with the tobacco issues we face.

Even in this town of upside down thinking, how can we continue to exempt tobacco and its products from FDA regulation? Even accepting the tobacco industry's lame explanation, it is clear that the so-called tobacco scientists manufacture a witch's brew of nicotine and lethal chemicals to stuff into those white paper cylinders.

If the tobacco companies can remove addictive nicotine from a cigarette, why do they put it back in? And how do they decide what level of nicotine to add? Imagine a business where these so-called tobacco scientists are calculating the proper level of nicotine to keep African-Americans hooked on Kools, women hooked on Virginia Slims, and children addicted to Camels. Do these same socalled scientists cram more nicotine into cigarettes popular with America's children so they can become addicted for life?

When the Colombian drug cartel formulates its products to meet the demands of addicted cocaine users in the United States, Members of Congress don't invite them to their fundraisers. But when the tobacco companies monkey with their deadly nicotine formula to keep smokers addicted in our country, we judge them model businessmen.

Lest we forget, the deaths attributable to tobacco in the United States are 100 times as many as those attributable to cocaine. The Food and Drug Administration, which my subcommittee funds, spends hundreds of millions of dollars to test the safety of food and drugs, many of which are used by only a handful of Americans. Why in God's name do we not test and disclose the contents of cigarettes and spit tobacco which account for more deaths than any product, legal or otherwise, sold in the United States?

I believe tobacco content should be regulated not so as to ban the product but to ensure that all harmful ingredients can be removed. That is why I have joined Congressman Mike Synar in sponsoring the Fairness in Tobacco and Nicotine Regulation Act.

Our legislation would bring tobacco content under the regulation of FDA and put an end to the industry's free rein in advertising, labeling, promoting and selling cigarettes and other tobacco products. Our legislation would give the FDA the authority to regulate not only nicotine but all ingredients added to tobacco, and to establish rules for labeling and marketing tobacco products to put an end to some of the egregious practices of the tobacco industry.

We must subject tobacco to comprehensive regulation as we do foods, drugs, cosmetics, and other consumer products. Tobacco is a deadly product. It is not only legal to sell tobacco, we must always 
remember it is lethal. It should not be exempt from sensible regulation. We must do what we can to protect the public as much as we can without a prohibition-style ban.

The legislation I have cosponsored with Mike Synar would replace ignorance with knowledge and expose any and all harmful practices of the tobacco companies.

Thank you.

Mr. WAXMAN. Thank you.

[The prepared statement of Mr. Durbin follows:] 
RICHARO J. DURBIN 2014 Dastact cumas

AT LAAGE WHIP

COMMitTeE ON NMROMLATIONS Suncompurres on Acarcul ruber ne

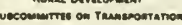

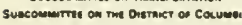

\title{
Eongress of the 2anited States kouse of Representatioes Washington, $B C$ 20515-1320
}

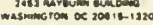 \\ (202) 212-02? \\ 135 soutm 8 sm sment \\ a in 4ev-4002 \\ 400 st coves staken sumet \\ ith e0z-1002 \\ 131 Gest caocowar surte elot \\ in $132 \rightarrow 306$
}

TESTIMONY OF

THE HONORABLE RICHARD J. DURBIN

BEPORE THE

SUBCOMITTEE ON HEALTH AND THE ENVXRONWFI COMITTEE ON ENERGY AND COMRERCE

MARCH 25, 1994

Mr. Chairman. I thank you for the opportunity to testify today regarding the recent revelations about the role of nicotine in tobacco anufacturing and marketing. I appreclate your leadership in dealing with the tobacco issues we face.

TOBACCO COKPANIES ARE OUR MATION'S MURBER ONE DRUG PUSHERS

Today, In a cocaine lab in Columbla, a clandeatine drug manufacturer is carefully formulating his product to supply the demands of addicted cocaine usera in the United States.

Today, In a cigarette factory in the Southeast United States, a clgarette manufacturer is carefully formulating his product to supply the demands of addicted amokers in the United States and around the world.

The first supplier carefully manipulates the ingredients of his product to ensure the delivery of the addicting hit in a way that will help maintain the addiction.

According to the Food and Drug Administration, the second supplier also carefully manipulates special ingredlent .. nicotine - - to ensure the delivery of the addicting hit in a way that will help maintain the addiction.

The first product kills a few thousand Americans every year.

The second product kills one hundred times as many Americans every year.

The flrst product is 11legal, and the supplier is denounced for the deaplcable crime of purveying a dangerous product to people who find it difficult to escape 1 ts addictive grip. 
The second product is legal, and the supplier is welcomed here on Capitol $\mathrm{H} 11 \mathrm{l}$ and almost everywhere as a responsible corporate citizen, even though this supplier is also purveying a dangerous product to people who find it difficult to escape its addictive grip.

Since the first product is 1 llegal, the U.S. government is engaged in a massive effort to stop the delivery of cocaine to prospective users.

Since the second product is legal, the U.S. government does not stop deliveries of cigarettes.

I am not advocating that tobacco be made 1 llegal 1 ike cocaine, but I think the point must be made that tobacco companies are peddling harmful drugs. Tobacco companies are our nation's number one drug pushers.

THE CONTENT OF DEADLY TOBACCO PRODUCTS IS NOT REGULATED

"But surely," one might ask, "sinca the second product is known to be dangerous, surely the U.S. government carefully monitors and regulates the content of cigarettes, right?"

Unfortunately, the answer is no. Tobacco, the single most preventable cause of death in Anerica today, has almost completely escaped regulation of its content.

Hopefully, the FDA's recent revelations will change this fact. But today. no one regulates tha content of cigarettes except the tobacco companies themselves, and they have apparently chosen to manipulate nicotine levels not to protect their customers but to strengthen their addiction.

If this is true, it is scandalous and outrageous. That American companies might intentionally hook their customers on a deadly product is astounding. Yet the FDA has advised us that it is true.

REYOVING AN ADDIGTIVE AND DANGEROUS INGREDIENT - - THE EXAMPLE OF COCA-COLA VS. THE SHAMELESSNESS OF THE TOBACCO COMPANIES

What would any cther upstanding, responsible corporation do, if it was revealed that the corporation's product contained a harmful ingredient that could be removed? It would remove the dangerous additive.

Consider, as a case in point, the Coca-Cola Company.

In 1860, cocalne was first extracted from coca leaf. By 1884, purified cocaine was commercially avallable, and at first cocalne was seen as a wonder drug, a harmless or even beneficial stimulant that enhanced the quality of $11 \mathrm{fe}$.

In 1886, Coca-Cola was introduced as a drink that was far better than alcohol, offering the advantages of the coca leaf and the cola nut without the intoxicating effects of alcohol.

But people began to discover that cccaine was addictive. Long-term use tended to have adverse social and behavioral effects. Regular use seemed to be linked with violence and paranoia in some users. The wonder drug turned out to have more troubling side effects than people first thought. 
Coca-Cola was not immune from these concerns. The company says it never Intentionally added coceine to Coca-Cola, and whatever amount of cocalne was present in Coca-Cola was not present in large quantities. But in the early days, the company did not actively remove the cocalne from the coca extracts it used in producing Coca-Cola. People began to wonder if Coca-Cola was a safe beverage.

In response to the growing public concern about cocaine, the Coca-Cola Company took action. Around 1900 , the company voluntarlly began to remove all cocalne from the coca extract it used in producing Coca-Cola.

That was a clear demonstration of ethical and social responsibility.

(Incidentally, today, there atill exists a manufncturing company in New Jersey that takes imported coca leaves from Peru and Bollvia and processes them into a non-narcotic flavor extract for use in Coca-Cola as well as a cocalne extract that has pharwaceutical uses. The process is carefully monitored by the U.S. Drug Enforcement Agency.)

Long before federal regulation of cocalne was considered, years before federal regulation of cocalne was enacted. Coca-Cola did the right thing and removed all cocalne from ita product. A federal ban on the non-prescription usa of cocaine did not take effact unt 11 14 years 1 ater, in 1914.

The parallel ahould be obvious. Tobacco contains an addictive product, nicotine, which we now have been advised can be removed from tobacco. The obvious, socially responsible act would be for tobacco companies to

voluntarily remove this dangerous ingredient from their products. But not the tobacco companies. They don't seem to have the slightest interest in doing what Coca-Cola did. And that is a clear demonstration of how shameless these nicotine pushers are.

\section{THE NEED TO REGULATE ALL INGREDIENTS IN TOBACCO}

Mr. Chatrman, I look forward to the findings of this hearing regarding nicotine manipulation in tobacco products. The allegations in the media and the statements by the Food and Drug Administration are alarming. I hope that you will get to the botton of this matter and allow the American public to know the full truth about the role and handling of nicotine in the manufacturing of tobacco products.

I hope that you won't stop there. We need to investigate, and expose to public scrutiny, the facts about all tobacco ingredients, not just nicotine. All aspects of tobacco product manufacturing must be regulated, not just nicotine in clgarettes.

How do we know that the Coca-Cola Company doesn't add harmful Ingredients to Coca-Cola and other beverages it sells? We know Coca-Cola and other soft drinka are safe because, $11 \mathrm{ke}$ any other foods, these products are subject to federal regulation to protect the public from any potential adverse effects associated with their consumption. The Food and Drug Administration provides an Invaluable service to the American people by regulating the content of thase products. 
I belleve tobacco content should be regulated too .. not so as to ban the product, but to ensure that all harmful ingredients that can be removed are removed.

That is why I jolned Congressman Mike Synar in sponsoring the Fairness in Tobacco and Nicotine Regulation Act. Our legislation would bring tobacco content under the regulation of the Food and Drug Administration and put an end to the tobacco Industry's free rein in advertising, labeling, and selling clgarettes and other tobacco products. Our leglslation would give FDA the authority to regulate not only nicotine but all ingredients added to tobacco, and to establish rules for labeling and marketing tobacco products to put an end to some of the more egreglous practices of the tobacco Industry.

I cannot emphasize enough the Importance of not stopping with the subject of nicotine in cigarettes. This hearing should be only the beginning of a series of hearings looking at tobacco content and how we should sensibly regulate this industry.

If, as a result of the recent revelations, we were to regulate only the nicotine content of cigarettas, how would we know whether cigarette manufacturers were starting to add some other ingredient to maintain their hold on smokers? We would have no way of knowing.

How would we know whether there may be other ingredients added to cigarettes that are equally dangerous? We would have no way of knowing

How would we know whether smokeless tobacco products contain harmful additives? We would have no way of knowing.

We must subject tobacco to comprehensive regulation, as we do foods, drugs, cosmetics, and other consumer products. Tobacco is a deadly product. It should not be exempt from sensible regulation. We must do what we can to protect the pubilc as much as we can without a Prohibition-style ban. The legislation introduced by Mike Symar would replace ignorance with knowledge and expose any and all harmful practices of the tobacco companies.

So I say to you, Mr. Chalrman, thank you for your interest in this subject. I hope you will pursue it tenaciously and comprehensively. I hope that we can work together to address this issue so that, one day, if people choose to smoke they will at least do so with full knowledge of what they are putting into their bodies and with an assurance that any harmful ingredients that can be removed have been removed. Thank you. 
Mr. WaXman. Mr. Clyburn.

STATEMENT OF HON. JAMES E. CLYBURN, A REPRESENTATIVE IN CONGRESS FROM THE STATE OF SOUTH CAROLINA

Mr. Clyburn. Thank you, Mr. Chairman. I wish to commend you for calling this hearing today and thank you very much for allowing me to testify.

The issues that have been raised by Commissioner Kessler regarding nicotine and cigarettes are very serious, but first let's consider the timing of his letter to the Coalition on Smoking OR Health. His ietter was issued the Friday before the Monday that ABC's Day One program aired its segment on the same subject. It appears that Dr. Kessler's rush to accuse the cigarette manufacturers of misconduct may have been to avoid being beaten to the punch by a tabloid news program.

Second, let's consider the evidence that Dr. Kessler suggests has become available to the FDA that supposedly supports a reversal of its long-standing policies toward tobacco.

Is there anything new about the tobacco reconstitution process? No. It has been in use for at least 30 years. Is there anything new about the use of denatured alcohol? No. It has been used for over 40 years. The same is true for tobacco extracts.

Is there anything new about the notion that particular nicotine is "addictive"? No. The Surgeon General's report claiming that nicotine in cigarettes is addicting was issued 6 years ago. Is there anything new about plans that some individuals associated with the tobacco industry have said that smokers enjoy the nicotine in cigarettes? Again, the answer is no.

What then is new?

What is new, Mr. Chairman, is the feeling on the part of some that the tobacco industry and all who make up that industry can be bashed and battered with impunity and that the consequences for all those whose livelihoods depend on this industry do not matter because the anti-smoking cause is just.

Many of my constituents do not see it this way and neither do I. We take strong exception to the scare-mongering at our expense by Dr. Kessler and the tabloid journalists that have joined with him in making nicotine the issue of the day in the war against tobacco.

I hope, Mr. Chairman, that this hearing which has been called in response to Dr. Kessler's allegations will help put those allegations to rest and I applaud you for having this hearing.

Mr. WAXMAN. Thank you.

Mr. Lancaster.

STATEMENT OF HON. H. MARTIN LANCASTER, A REPRESENTATIVE IN CONGRESS FROM THE STATE OF NORTH CAROLINA

Mr. LANCASTER. Thank you, Mr. Chairman. I appreciate the opportunity to address the members of this subcommittee on the issue of nicotine and tobacco.

FDA's recent actions on this issue of nicotine in cigarettes suggests to me that the Agency, in its eagerness to come after the tobacco industry with both barrels blazing, has in fact run off with its pistols half-cocked and its barrels loaded with blanks. 
To provide one illustration of FDA's tendency to speak first and think later I note, as Mr. Bliley already has, that Philip R. Lee announced last week at a recent House appropriation subcommittee hearing the FDA had asked the Justice Department to investigate allegations that tobacco manufacturers manipulate nicotine levels of their products.

In fact, no such referral has taken place and shortly thereafter, it was necessary for HHS to retract Dr. Lee's statements.

I also question the startling suggestion that FDA should perhaps regulate cigarettes as drugs. One would think, to hear the talk of nicotine "spiking," that cigarette manufacturers are increasing the nicotine levels in their cigarettes. But the only alteration over the years in the nicotine content of cigarettes of which I am aware has been to lower nicotine levels in response to changing consumer taste preferences.

I wonder if this subcommittee has considered where this line of reasoning takes us. If the FDA should regulate or even ban cigarettes based on nicotine, because nicotine has been deemed "addictive," why shouldn't the FDA regulate wine, beer, distilled spirits on the same basis-that is because alcohol is deemed addictive too.

Certainly there is evidence that alcohol has "addictive" properties for some individuals. Assistant Secretary Lee himself acknowledged as much at the FDA-Appropriations Subcommittee hearing on March 16. Based on the logic of Commissioner Kessler's letter, it is difficult to see why the FDA is not also taking immediate steps to regulate the alcohol content of the excellent wines produced by West Coast wineries. And what about the fortified wines which are indisputably "spiked"?

Mr. Chairman, it would be foolish for the FDA to assume, or for Congress to give this Agency, any significant new responsibilities, whether they relate to tobacco or not. FDA is seriously underfunded and understaffed. The Agency is hard pressed as it is to get new drugs and food additives approved in a timely fashion and to enforce the laws that apply to millions of food, drug and cosmetic products currently on the market.

FDA's existing mandate is extraordinarily broad. It encompasses the regulation of foods, prescription and over-the-counter pharmaceuticals, animal drugs, cosmetics, medical devices, radiological products, and Congress imposes more every year. FDA staff already is stretched beyond endurance, a fact that has prevented the Agency from completing in a timely manner many of its existing, central responsibilities.

Let's insist that the Agency meet its current mandates before we give it additional assignments. And let's hope our regulators proceed more thoughtfully in the future on the issue of nicotine in cigarettes than they have to date.

Mr. Chairman, may I request that a "dear colleague" letter I circulated early this year be included in the record at this point.

Mr. WAXMAN. Without objection, we will receive the letter for inclusion in the record.

[The letter follows:] 


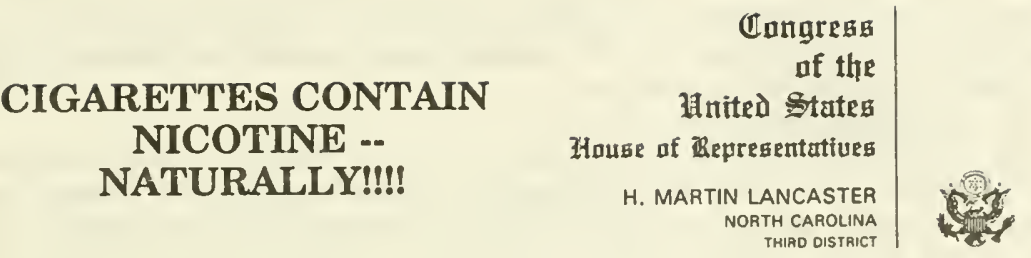

Dear Colleague:

The media is at it again - trying to create "entertainment" by distorting and sensationalizing the facts.

The National Enquirer of television entertainment, Day One, aired a show on Feb. 28,1994 suggesting that tobacco companies "spike" cigarettes with vicotine. This is an absolute falsehood. Cigarettes naturally contain nicotine, but there is nothing in the processing of tobacco or the manufacture of cigarettes that increases nicotine levels above what naturally occurs. At no point in the production of cigarettes, from the tobacco fields to the completion of the manufacturing process, is any amount of nicotine added to "spike" cigarettes and the finished product actually contains less nicotine than cured tobacco.

The facts show that the level of nicotine delivered by cigarettes has been dramatically reduced since 1950. Since 1950, the addition of filters, differences in the paper used to wrap the tobacco, and other changes bave resulted in a $69 \%$ decrease in the average amount of nicotine yields.

Consistency in the level of nicotine is demanded by consumers and the Federal Trade Commission for advertising purposes. As a result, the nicotine yields of all cigarettes, determined by testing ruethods required by the FTC, have appeared in cigarette advertising for over 20 years. From year-to-year, nicotine levels in the tobacco crop vary primarily due to climatic differences, but the demanded consistency in nicotine levels is achieved by mixing tobacco from different crop years, not by adding nicotine.

During its piece on nicotine, Day One implied that nicotine is added during the process of making sheets of reconstituted tobacco. Simply stated, no additional nicotine is added to the sheets. Zcro. None.

There are at least two reconstituting processes which are patented and used today. The processes are similar and neither include the addition of extraneous nicotine. Scrap tobacco, including iraproperly cut tobacco, tobacco stems, and the like, are placed into water. Components which are water soluble, including some nicotine and tobacco flavoring, are dissolved into the water. The water is extracted from the mixture and the remaining tobacco fibers are rolled into a sheet. The water, which does contain naturally occurring nicotine and tobacco flavors, is returned to the sheets and the sheets are left to dry. Only nicotine present at the beginning of the process is present at the end of the process. At least 3 Surgeon General reports and 5 reports by the National Cancer Institute document this process, and all conclude that the use of reconstituted tobacco results in reduced nicotine levels in the final tobacco blend.

Day One indicated that cigarettes are also "spiked" with nicotine from two other sources - denatured alcohol and tobacco extracts. This too is demonstrably untrue. Day One chose to ignore readily available information which shows that the use of these substances does not measurably increase nicotine levels in cigarettes.

I trust that this information helps to clear up some of the misinformation being broadcast on our public airwaves. Please do not hesitate to contact my office if you would like further information.

With kindest regards, I am

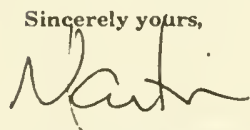

H. Martin Lancaster Mcmbcr of Congress 
Mr. WAXMAN. I want to thank the three of you for your testimony today. I don't have any particular questions to ask of you but I will ask if any of the others do. Mr. Bliley? Mr. Synar? Mr. Wyden?

Thank you for being with us.

Mr. LANCASTER. Thank you.

Mr. Waxman. Our next witness is David Kessler, Commissioner of the Food and Drug Administration. Last month, Dr. Kessler released a letter which sent shock waves through the tobacco industry. That letter raised serious questions regarding the tobacco industry's precise manipulation of the nicotine levels present in cigarettes. The Commissioner suggested that the Agency might have the legal basis to regulate cigarettes under the Federal Food, Drug and Cosmetic Act.

Dr. Kessler, welcome to our hearing. I commend you for the courage and commitment to public health you have demonstrated in bringing this matter to public attention.

Without objection, a copy of your February 25, 1994 letter to the Coalition on Smoking Or Health will be printed in the record and, without objection, your statement submitted to the subcommittee today will be in the record.

Please proceed.

[The letter follows:] 
Scott D. Ballin, Esq.

Chairman, Coalition on Smoking oR Health

Vice President for Public Affairs

American Heart Association

1150 Connectlcut Avenue, NW., Suite 810

washington, D.C. 20036

Dear Mr. Ballin:

As you know, the Food and Drug Administration (FDA) has before it several petitions from the coalition on Smoking OR Health seeking to have FDA regulate low-tar and low-nicotine cigarettes and denicotinized cigarettes as drugs. Rather than respond formally to the petitions at this time, I think it more appropriate to frame the issues for the broader public debate that will be necessary to resolve them.

In its consideration of the petitions, the agency has examined the current data and information on the effects of nicotine in cigarettes. The current data on the highly addictive nature of nicotine and other evidence now avallable to SDA lead the agency to take a different approach from that urged in the petitions. The structure of the Federal Food, Drug, and cosmetic Act (the Act), and sound public health policy, suggest that the focus should be on the presence of nicotine in clgarettes in amounts associated with addiction.

As you note in your petitions, FDA has traditionally refrained from asserting jurisdiction over most cigarette products. This has not been based on an interpretation of the Act that cigarettes cannot be regulated as drugs. There is no exemption for cigarettes from the Act's definition of a "drug," and some cigarette products have besn regulated as drugs. See United Staten y. 16 cartons. . Fairfax cigarettes, 113 F. Supp. 336 (D.N.J. 1953); United States $V_{\text {. }} 354$ Bulk Cartons Trim Reducing-Add clgarettes, 178 F. Supp. 847 (D.K.J. 1959).

Under the Act, products are subject to regulation as drugs based on the intent of the product vendor. If the vendor intende that the products be used as drugs (for therapeutic or diagnostic use or to affect the structure or function of the body), FDA may regulate them as drugs. See National Nutritional Foods Ass'n $y$. Mathews, 557 F.2d 325, 334-6 (2d Cif. 1977). Although 1t has been well-known for many years that some people smoke for the drug effects of nicotine (for example, for stimulation and/or to satisfy a dependence on nicotine), cigarette vendors have in the past been given the benefit of the doubt as to whether they 
Coalition on Smoking OR Health

February 25, 1994

Page 2

intend cigarettes to be used for this purpose, because some people smoke for reasons other than the drug effect. See Action on smoking and Health V. Harris, 655 F.2d 236, 239 (D.C. Cir. $1980)$.

Evidence brought to our attention is accumulating that suggests that cigarette manufacturers may intend that their products contain nicotine to satisfy an addiction on the part of some of their customers. The possible inference that cigarette vendors intend cigarettes to achieve drug effects in some smokers is based on mounting evidence we have received that: (1) the nicotine ingredient in cigarettes is a powerfully addictive agent and (2) cigarette vendors control the levels of nicotine that satisfy this addiction.

The coalition is well aware of the large body of scientific evidence documenting the highly addictive nature of nicotine. Most of this evidence is summarized in the 1988 surgeon General's Report and in the Department of Health and Human Services' 1991 "Triennial Report to Congress on Drug Abuse and Drug Abuse Research." The evidence demonstrates that cigarettes cause an addiction. The current evidence suggests that nicotine, when delivered by cigarettes, produces physiological dependence resulting in withdrawal symptoms when smokers are deprived of nicotine. It also appears that cigarettes enjoy a market that is based in part on the need of smokers to satisfy that addiction. A Canadian survey suggests that 80 percent of smokers believe they are addlcted to cigarettes. Other data suggest that a comparable percentage of smokers are, in fact, addicted.

Moreover, the public knows that cigarettes are harmful and many smokers desire to quit. Research has revealed that 77 percent of smokers desire to quit but cannot primarily because of nicotine addiction. At FDA we have approved a number of pharmaceutical therapies for treating nicotine addiction and many more are under development. These therapies, which include nicotine patiches and nicotine gum, are essentially, nicotinedelivery gyetems. There is a growing market for these, as well as non-pharmaceutical, behavioral therapies.

Although technology was developed years ago to remove nicotine from cigarettes and to control with precision the amount of nicotine in cigarettes, cigarettes are still marketed with levels of nicotine that are sufficient to produce and sustain addiction. In fact, it is our understanding that manufacturers commonly add nicotine to cigarettes to deliver specific amounts of nicotine. There is also evidence discovered in recent litigation that some individuals involved in the manufacture of cigarettes in the $1970 \mathrm{~s}$ regarded their products as nicotinedelivery systems. 
Coalition on Smoking OR Health February 25, 1994

Page 3

This evidence, along with the growing body of data related to new products proposed for the treatment of nicotine addiction from smoking, suggests that cigarette vendors intend the obvious - that many people buy cigarettes to satisfy their nicotine addiction. Should the agency make this finding based on an appropriate record or be able to prove these facts in court, it would have a legal basis on which to regulate these products under the drug provisions of the Act.

A strict application of these provisions could mean, ultimately, removal from the market of tobacco products containing nicotine at levels that cause or satisfy addiction. only those tobacco products from which the nicotine had been removed or, possibly, tobacco products approved by FDA for nicotine-replacement therapy would then remain on the market.

Given the widespread use of cigarettes and the prevalence of nicotine addiction, such a regulatory action could have dramatic effects on our society. One must consider the possible effects of the loss of this source of nicotine on the health of some people who are addicted to nicotine and the possible need for a weaning period. It is also important to consider the potential for a black market in nicotine-containing cigarettes.

We recognize that the regulation of cigarettes raises societal issues of great complexity and magnitude. It is vital in this context that Congress provide clear direction to the agency. We intend therefore to work with congress to resolve, once and for all, the regulatory status of cigarettes under the Food, Drug, and Cospetic Act. Few public health issues are more important.

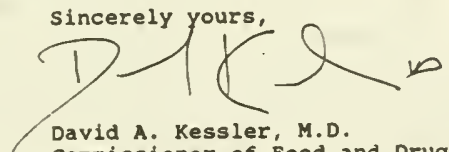

Commissioner of Food and Drugs

cc: Michael F. Heron, American Cancer Society Fran Du Melle, American Lung Association Matthew L. Myers, Asbill, Junkin, and Myers 
STATEMENT OF DAVID A. KESSLER, COMMISSIONER OF FOOD AND DRUGS, FOOD AND DRUG ADMINISTRATION, ACCOMPANIED BY JACK E. HENNINGFIELD, CHIEF, CLINICAL PHARMACOLOGY BRANCH, NATIONAL INSTITUTE ON DRUG ABUSE

\section{Mr. KESSLER. Thank you very much, Mr. Chairman.}

The cigarette industry has attempted to frame the debate on smoking as the right of each American to choose. The question we must ask is whether smokers really have that choice. Consider these facts. Two-thirds of adults who smoke say they wish they could quit. Seventeen million try to quit each year, but for every one who quits, at least nine try and fail. Three out of four adult smokers say they are addicted. By some estimates, as many as 74 to 90 percent are addicted. Eight out of 10 smokers say they wish they had never started smoking.

Mr. Chairman, the issue I will address today is simple: Whose choice is actually driving the demand for cigarettes in this country? Is it a choice by consumers to continue smoking? Or is it a choice by cigarette companies to maintain addictive levels of nicotine in their cigarettes?

FDA has not regulated most tobacco products as drugs. One of the obstacles has been a legal one. The law requires an intent that the product be used either in relation to a disease or to affect the structure or function of the human body. Intent is a key word in our statute. We have not had sufficient evidence of such intent with regard to nicotine in tobacco products. The assumption has been that the nicotine in cigarettes is present solely because it is a natural and unavoidable component of tobacco.

Mr. Chairman, that assumption needs to be re-examined. The amount of nicotine in a cigarette may be there by design. Cigarette companies must answer the question, what is the real intent of this design? In my testimony this morning, I will describe some of the information that has prompted our re-examination.

First, I want to address the addictive nature of nicotine. Second, I will talk in some detail about the apparent ability of cigarette companies to control nicotine levels in cigarettes.

My first point is that the nicotine delivered by tobacco products is highly addictive. As the chart shows, that fact is acknowledged by the world's preeminent medical organizations. As with any addictive substance, some people can break their addiction, but I suspect that everyone in this country has seen a friend or relative struggle to extricate himself or herself from a dependence on cigarettes and the nicotine they contain.

Remarkably, we see that nicotine exerts its grip even on patients for whom the dangers of smoking could not be starker. After surgery for lung cancer, almost half of the smokers resume smoking. Even when a smoker has his or her larynx removed, 40 percent try smoking again.

I am equally struck by the statistics about our young people. Seven out of 10 teenage smokers say they believe that they are already dependent on cigarettes. About 4 out of 10 high school seniors who smoke have tried to quit and failed. Most adult smokers today began smoking as teenagers. 
It is fair to argue that a decision to start smoking may be a matter of choice. But once people start smoking regularly, most in effect are deprived of the choice to stop smoking. My concern is that the choice that people make at a young age quickly becomes little or no choice at all and it will be very difficult to reverse over the course of their lives.

The primary criteria of addictive substances are compulsive use, a psychoactive effect; that is a direct chemical effect in the brain, and reinforcing behavior that conditions continued use.

Mr. Chairman, nicotine reaches the brain within seconds. This contributes greatly to its reinforcing effect. Nicotine meets all the criteria for an addictive substance. We have learned a great deal about addictive drugs by studying laboratory animals. It is intriguing that with very few exceptions, animals will press levers and do other things to give themselves those drugs that are considered highly addictive in humans, but will not generally self-administer nonaddictive drugs.

Despite being very different chemically, almost all addictive drugs affect the parts of the brain that are important to emotion and motivation. Specifically they affect the regulation of the brain chemical dopamine which produces psychoactive sensation and reinforces drug use behavior.

Animal self-administration is considered a hallmark of a drug with a potential to addict. Nicotine has been shown to affect dopamine release and it has been further shown that animals will self-administer nicotine.

Tobacco industry officials have denied that nicotine is addictive. They use euphemisms-satisfaction, impact, strength to describe the effects of nicotine. But one company states in a quote, "It also has been generally recognized that the smoker's perception of "strength" of the cigarette is directly related to the amount of nicotine contained in the cigarette smoke during each puff."

Euphemisms aside, smokers crave nicotine pure and simple because of its psychoactive effects and its drug dependence qualities. Mr. Chairman, nicotine levels in a cigarettes are more than sufficient to create and sustain addiction in the vast majority of smokers.

Let me turn to my second point today, which involves the control of nicotine levels exercised by the tobacco industry. Mr. Chairman, I do not have all the facts or all the answers today. Certainly practices differ within the industry and the technology available to one company may not be available to another. It is important to keep this in mind. But a picture is beginning to emerge.

The public may think of cigarettes as no more than blended tobacco rolled in paper. But they are more than that. Some of today's cigarettes may in fact qualify as high technology nicotine delivery systerns that deliver nicotine in quantities sufficient to create and to sustain addiction in the vast majority of individuals who smoke regularly.

But you don't have to take it from me. Just listen to the words written by a supervisor of research at one of the Nation's largest tobacco companies in 1972. And I quote, "Think of the cigarette pack as a storage container for a day's supply of nicotine. Think of the cigarette as a dispenser for a dose unit of nicotine. Think of a 
puff of smoke as the vehicle for nicotine. Smoke is beyond question the most optimized vehicle of nicotine and the cigarette the most optimized dispenser of smoke."

How does the cigarette industry design cigarettes? Several decades ago, the industry began to recognize that nicotine is the psychoactive ingredient in tobacco smoke. Numerous patents since then illustrate how the industry has worked hard to sustain the psychoactive effects of nicotine in cigarettes.

These charts I will show you show examples from several categories of patents. I recognize you can't read them all now, but I wanted to give you a feel for the kinds of patents we are seeing.

Eight patents on the first chart (B) increased nicotine content by adding nicotine to the tobacco rod.

On the next chart (C) five patents are listed to increase nicotine content by adding nicotine to filters, wrappers and other parts of the cigarette.

The next chart (D) shows three patents that use advanced technology to manipulate the levels of nicotine in tobacco.

On the next chart (E) there are eight patents for the extraction of nicotine from tobacco. The next chart (F) shows nine patents to develop new chemical variants of nicotine.

Patents not only describe a specific invention but they can do much more. They speak to the industry's capabilities and research and they provide insight into what industry may be attempting to achieve with its products. At the same time, however, it is prudent to keep in mind that patents do not tell us what processes are currently in use. Nevertheless, the number and pattern of these patents leaves little doubt that the cigarette industry has developed enormously sophisticated methods for manipulating nicotine levels in cigarettes.

Look at the industry's own words in these patents. Let me read the key words from a number of patents. The industry is interested in "maintaining the nicotine content at a sufficiently high level to provide the desired physiological activity, taste, and odor."

These are the words of the patents. "Add nicotine." "Maintaining or increasing the nicotine content." "The release in controlled amounts of nicotine." "Nicotine released in controlled amounts." "Manipulation of the nicotine." "Provide various nicotine levels." "Varying levels of endogenous and exogenous nicotine." "Maintenance of the proper amount of nicotine." "Delivers a larger amount of nicotine." "Nicotine donor." "A process for the migration of nicotine." "Nicotine can be incorporated." "Nicotine-enhanced smoking device." "The application of nicotine components." "Incorporated within the filler material applied to the wrapper, applied within the glue line of the wrapper."

Let me briefly describe how a few of these technologies work. U.S. Patent number $4,830,028$ (Chart G) describes a way to increase the nicotine content of low yield cigarettes from 1.66 percent to 2.9 percent nicotine by spraying on a 1,3 or 5 percent nicotine salt.

The patent states the nicotine salt is used because added nicotine alone is unacceptably harsh or irritating to the user. Notice that great care is paid to the $\mathrm{pH}$ of the smoke because $\mathrm{pH}$ affects ab- 
sorption of nicotine into tissues. This technology can increase content of tobacco by up to 76 percent and lower the $\mathrm{pH}$ in the process.

The next chart. U.S. Patent number 5,065,775 (Chart I) describes chemical methods using chlorofluorocarbons that can be used, among other things, to bring the tobacco blend containing 2.3 percent nicotine up to 5.2 percent nicotine. This technology increases the nicotine content in tobacco by more than 100 percent.

The next chart. U.S. Patent number 4,898,188 (Chart J) shows how to transfer nicotine by supercritical fluid extraction involving liquid carbon dioxide. An example in the patent shows that the technology can reduce the Burley tobacco from 3.56 percent nicotine to 0.88 percent nicotine and increase the flue-cured tobacco from 2.59 percent to 4.83 percent. This patent demonstrates that nicotine can be transferred in significant amounts from one type of tobacco filler to another.

Mr. Chairman, these patents illustrate that the cigarette industry has developed technologies that allow it to add or subtract nicotine from tobacco. The amount of nicotine present in cigarettes may therefore be a matter of choice, not chance.

Mr. Chairman, that prompts me to ask: How does the industry determine nicotine levels in various products? More importantly, why does the amount of nicotine in cigarettes remain at addictive levels? In fact, since the technology apparently exists to remove nicotine from cigarettes to insignificant levels, why does the industry keep nicotine in cigarettes at all?

The cigarette industry would like you to believe that it simply returns the nicotine that is removed when reconstituted tobacco is produced. It should be clear from what I have described that the technology that the industry may have available goes beyond such efforts. The industry may also tell you that it is adjusting nicotine levels to be consistent with established FTC yields. These are the amounts of tar, nicotine, and carbon monoxide that are measured for each cigarette product by a smoking machine. But in fact, patents were granted for adjusting nicotine levels before those FTC measurements were adopted. No measurements would prevent the industry from reducing nicotine below addicting levels or eliminating it all together.

Nicotine levels may be dictated in part by marketing strategies and demographics. Let me show you a reproduced copy of one smokeless tobacco company's marketing strategy. The products with the lower nicotine yield are found on the bottom and marketed as "starter" products. As you go up the chart, nicotine yields increase. And through advertising, the users are encouraged to "graduate"-their word, not mine-to products with higher levels of nicotine, marketing on the basis of nicotine delivery.

Why develop such a strategy? The cigarette industry may tell you that the purpose of nicotine is to provide flavor. Information suggests otherwise. A company's own book on flavoring tobacco lists about a thousand flavorants, but nicotine is not one of them. Some industry patents specifically distinguish nicotine from flavorants.

As we saw earlier, technologies have been developed specifically to mask the unacceptably harsh and irritating flavor of added nicotine. In fact, U.S. patent $4,620,554$ uses the word "hazardous" to 
describe the taste of nicotine. It shouldn't come as a surprise to anyone, the Merck Index, the authoritative encyclopedia of chemicals, describes nicotine as having an acrid, burning taste. Smokers apparently do associate the burning in the throat with nicotine's psychoactive effects and thus look for those sensory signals in a cigarette, but nonaddictive substances have been shown to produce those effects.

Why doesn't the industry use them instead? Why is nicotine in cigarettes? The research undertaken by the cigarette industry is more and more resembling drug development. I mentioned earlier the focus on controlling the $\mathrm{pH}$ of tobacco smoke because it affects absorption of nicotine. The cigarette industry has also studied the activity of added nicotine versus nicotine that occurs naturally and it has studied the potentially beneficial effects of nicotine on anxiety, heart rate, and behavioral performance tasks. Such research on the physiological effects of an active ingredient is a standard part of drug development.

Perhaps the most striking research undertaken by the industry is the quest for new nicotine-like chemicals with pharmacological properties that, and I quote from a patent, "are intended for utility as potential psychotherapeutic agents." The chart shows one patent that summarizes the effect of nicotine-like chemicals on tranquilization, sedation, and body tone of mammals.

Mr. Chairman, I would like to move on to the actual nicotine levels in cigarettes. FDA laboratories measured the amount of nicotine in several types of cigarettes. We analyzed three varieties of one brand; for example, highest, medium, and lowest. What surprised us was that the lowest one in fact had the highest concentration of nicotine in the cigarettes. Let me repeat that. The lowest one in fact had the highest concentration of nicotine in the cigarette.

I have read with interest the testimony that Mr. Spears, Vice Chairman of Lorillard Tobacco Company, will give this morning. He states that, and I assume he is speaking for the industry, we do not set nicotine levels for particular brands of cigarettes. He goes on to say that nicotine levels follow the tar levels.

The easy proof, according to Mr. Spears, is that both tar and nicotine on a sales weighted basis have decreased in the same fashion and in the same amount over the years. One question: If there is no manipulation of nicotine going on, why does the lowest yield cigarette I just showed you have the highest percentage of nicotine in it? If Mr. Spears is right, wouldn't the lowest yield cigarette have the lowest concentration of nicotine in it?

Furthermore, Mr. Spears says that the fact that tar and nicotine have decreased in parallel fashion over this time period, and I quote, "by the same amount" indicates that there has been no manipulation of nicotine levels. But when you look closely at the numbers from FTC's database for tar and nicotine levels in smoke since 1982, the earliest year for which the FTC-computed database is available, we do not see that kind of tar and nicotine content occurring in a parallel fashion and by a proportional amount over the last decade.

Let me show you the graphs describing the nicotine and tar changes from 1982 to 1991 , the years for which the database is available. You will see from the chart $(\mathrm{T})$ that the proportional 
change in nicotine has not been the same as the proportional change in tar for each of the years from 1982 to 1991. In fact, these data suggest that the amount of tar over this time period has remained relatively flat while the proportional amount of nicotine has not. Rather, nicotine levels in smoke appear to increase over the last decade.

The next graph $(Q)$ shows percent changes in nicotine and tar levels from their average 198i levels for low-tar cigarettes. The next graph $(R)$ displays the information for high-tar cigarettes. And the next graph $(\mathrm{S})$ provides similar information for ultra low-tar cigarettes.

All three categories clearly suggest that tar and nicotine levels in smoke are not following parallel patterns over the last decade.

The final graph (U) summarizes in a different fashion the previous graphs by showing the nicotine/tar ratios are not identical in the three categories of cigarettes. Why not?

We feel these data call into question Mr. Spears's conclusion and require further explanation.

Mr. Chairman, the evidence I have presented today suggests that cigarette makers may intend the obvious, that most smokers buy cigarettes to satisfy their nicotine addiction. We do not yet have all the evidence necessary to establish cigarette manufacturers's intent. As we reconsider our traditional assumptions about nicotine in cigarettes, we will need to determine whether nicotine-containing cigarettes meet the statutory definition of a drug.

As I mentioned earlier, intent is a key issue. It should be clear, however, that in determining intent, what cigarette manufacturers say can be less important than what they do. The fact that the technology is available to reduce the nicotine to less than addictive levels is relevant in determining manufacturers's intent.

Clearly, the possibility of FDA exerting jurisdiction over cigarettes raises many broader social issues for Congress to contemplate. It could lead to the possible removal of nicotine-containing cigarettes from the market, the limiting of the amount of nicotine in cigarettes to levels that are not addictive, or restricting access to them, unless the industry could show that nicotine-containing cigarettes are safe and effective.

If nicotine were removed precipitously, millions of Americans would experience addiction withdrawal. Of course, a black market in cigarettes could develop.

On these issues we seek guidance from the Congress.

Thank you.

[The prepared statement of Dr. Kessler begins on p. 71.]

Mr. WAXMaN. Thank you, Mr. Commissioner. Dr. Kessler, without objection, I am going to recognize each member on this first round for 10 minutes; any subsequent round, for 5 minutes if it is necessary.

Dr. Kessler, you have laid out a really astounding picture, not only of the tobacco companies manipulating the levels of nicotine, but by doing that, manipulating the American people who take up cigarette smoking. We are not talking about a choice any longer if it is an addiction. They have the ability to manipulate the nicotine which evidently causes the addiction to smoking itself. 
One of our colleagues said we have known for some time that they could deal with the nicotine levels in cigarettes, but I don't think any of us have any idea of the sophisticated techniques that the tobacco industry has had at its disposal to play around with these nicotine levels. They could figure out exactly the level needed to hook people, to get them addicted so that most people will find it very difficult to quit.

I found that astounding when you think 400,000-plus people die every year from cigarette smoking, all which that involves in terms of pain and suffering for the people and their families, and all the costs that are incurred for health care costs to treat them, to try to save them and prolong their lives, sometimes with some misery.

I really don't know what to say about such a thing. I guess we have to go through the technical questions of legality, whether this was intended or not for you to decide whether you have jurisdiction. It is a question also for those of us who are here as people's representatives, whether we should leave this industry on its own to be so cynical in manipulating the nicotine levels.

Let me just lay some things out to understand clearly what we are talking about.

Tobacco is an extremely serious health hazard. It killed 430,000 people last year; is that correct?

Mr. KESSLER. That is correct.

Mr. WAXMAN. Second, nicotine and tobacco is an addictive substance. It has all the hallmarks of addiction. Nicotine is why people who want to quit smoking can't quit; is that correct?

Mr. KESSLER. That is correct.

Mr. WAXMAN. Third, nicotine has drug-like qualities, it has physiological effects. In the words of the Food, Drug and Cosmetic Act, it affects the structure and function of the body; is that correct?

Mr. KESSLER. It certainly has those physiological effects.

Mr. WAXMAN. Until 1902, the Coca-Cola Company added cocaine to coke. Today, such a company would not think of adding cocaine or any other addictive substance to soft drinks.

Isn't it true that the Food and Drug Administration would not approve addictive levels of nicotine as an additive which could be added to food?

Mr. Kessler. Right, Mr. Chairman. The Coca-Cola Company in that time period sent their coca leaves to the Shaffer Alkaloid Works in Maywood, N.J. to have them decocainized. We would not allow addictive substances to be in any product that we regulate without the most tight regulation.

Mr. WAXMAN. Coca-Cola Company removed cocaine-

Mr. KESSLER. Right before the 1906 Act.

Mr. WAXMAN. You testified that nicotine could be removed from cigarettes, and it is possible to duplicate the taste of nicotine.

I realize you are not ready to make a final decision, but are you aware of any significant, reliable evidence that would support the proposition that the manufacturers leave nicotine in cigarettes for any reason other than addiction?

Mr. KESSLER. No.

Mr. WaXman. Dr. Kessler, on the critical issue of the industry's intent, have you found any studies by the tobacco industry that 
would support the proposition that nicotine is retained in tobacco for addictive purposes?

Mr. Kessler. Mr. Chairman, I mentioned earlier about self-administration studies in animals that show that, in fact, nicotine is addictive. Self-administration, as I mentioned, in laboratory animals is a hallmark of a drug that has the potential to addict.

We have recently learned that a team of industry researchers carried out studies in the 1980's and reached similar conclusions several years before. The results were actually published by other scientists in the late 1980's. We understand that two manuscripts from industry scientists were submitted to a well-respected independent journal in 1983 and 1986 and accepted for publication.

The first was entitled, "Nicotine Is a Positive Reinforcer in Rats: Effects of Infusion Dose in Fixed Ratio Size." I will let Dr. Henningfield describe what that means in a second.

The second was entitled, "Intravenous Nicotine Administration in Rats: Effects of Mecamylamine Hexamethonium and Naloxone." The titles of these studies alone tell you the important criteria in determining that the rats self-administer nicotine; and again that is an important criteria-one of the imfortant criterias in determining whether a substance is addictive.

Mr. WAXMAN. Are you saying, in other words, that the tobacco industry sponsored studies of animals that would indicate that nicotine was addictive to these animals, and that is the way we find out whether anything is addictive?

Mr. KESSLER. It is one of the hallmarks of whether a drug is addictive.

Mr. WAXMAN. What happened to these studies?

Mr. KESSLER. We have been told that both manuscripts were withdrawn by the researchers before publication. We have a copy of a letter from an editor of the journal to the researcher acknowledging the withdrawal of the second manuscript, and in that letter the editor repeats what he has been told by the researcher, that the manuscript is being withdrawn because the company has issued an injunction against publication of this paper.

Mr. WAXMAN. In other words, the tobacco industry sponsored studies on their own where they found out that nicotine was addictive; and before the public could know about it, they acted to suppress those studies?

Mr. Kessler. Again, from the title, it says "Nicotine Is a Positive Reinforcer in Rats." That suggests positive findings that nicotine was self-administered in rats.

Mr. WAXMAN. The tobacco industry officials have stated over and over again they don't believe that tobacco is addictive. What you are telling us is that they knew from their own studies that tobacco-nicotine has an addictive quality, and they tried to suppress that information.

Mr. KESSLER. Mr. Chairman, I am not drawing any conclusions. I am telling you what we have learned about what studies were undertaken and what happened to those studies.

Let me let Dr. Henningfield-

Mr. WAXMAN. I have a limited period of time. Could you tell us what company sponsored those studies? 
Mr. Kessler. Mr. Chairman, I would be very happy to work with the committee. I am reluctant to do this today. Certainly if the committee so instructs, we will be happy to provide you with information.

The issues that we are addressing today are general issues about nicotine in cigarettes. I certainly don't want to-I understand the problem of not releasing the name is that I may, unfortunately, cast aspersions on other companies; and again, we will be happy to provide all the information to you, Mr. Chairman. I think that it is for your review. You can investigate further. You can see what the facts that we have are, and determine whatever intent may follow.

Mr. WAXMAN. We will work with you to receive that material, but you know of a study. You didn't learn of this through a confidential means, did you? You know of a study that was sponsored by the tobacco industry that was supposed to go into publication and wasn't?

Mr. KESSLER. We have a letter from an editor that states what I told you.

Let me also just allow Dr. Henningfield-we also have Mr. WAXMAN. Dr. Kessler, was this sponsored by the industry or was it sponsored by a cigarette company?

Mr. KESSLER. It was a cigarette company.

Mr. WAXMAN. And why can't we know the name of that company?

Mr. Kessler. Again, Mr. Chairman, I would be happy to work with you and give you our documents. I am not prepared at this time to do that. I don't want today-I cannot come here to talk about it. I was very careful in my presentation not to focus on specific brands or specific companies, and I would really rather not get into that today.

Again, we would be happy to give the committee the information, and certainly you can do whatever the committee would like to do with it.

Mr. WAXMAN. I have run out of time. Do you have something briefly to add? Maybe we will come back to you.

Mr. HENNINGFIELD. I could just confirm that in fact in the early 1980 's a number of us in the field were aware that one of the tobacco companies was sponsoring such drug self-administration research. One of the tobacco company investigators sent me one of the resulting manuscripts. This is something that is often done by scientists; they exchange manuscripts and to let others know what they are doing in the field.

I had marked it in my files as an unpublished manuscript, and therefore would not have cited the manuscript in my own literature reviews. When I called the investigator to ask him what the status of it is and if I could cite it in my literature reviews, he told me that he would not be able to publish it, so that I would not be able to cite it. Furthermore his words, to the best of my recollection, were that the lawyers of the company had discovered that the investigators and colleagues were doing this work and that it showed that nicotine looked like heroin, and therefore that such work shouldn't be going on and it should not be published. 
Mr. WAXMAN. Was this in any way illegal for a company, that you know of?

Mr. HENNINGFIELD. I am not familiar with any of the legalities, just the basic science. This was a good basic science study. It did demonstrate that nicotine served as a reinforcer for the rats. The proper experimental controls were done. These included the interesting standard manipulations to look at the dose and see how much the animals would work for each dose.

[The following letter was received:]

DEPARTMENT OF HEALTH \& HuMAN SERVICES, Baltimore, MD, May 3, 1994

Hon. HENRY A. WAXMAN,

Chairman, Subcommittee on Health and the Environment,

Committee on Energy and Commerce, House of Representatives,

Washington, $D C$.

DEAR CONGRESSMAN WAXMAN: With reference to the unpublished manuscript by Dr. Victor J. DeNoble, et al., entitled "Nicotine as a positive reinforcer in rats: Effects of infusion dose and fixed ratio size," I made an error that I would like to correct for the record. During the March 25 hearing I stated that I had not cited the DeNoble et al. paper in my own literature reviews. However, I have recently been reminded that 1 did make reference to the DeNoble work in a book chapter that I wrote.

Upon receiving the manuscript from Dr. DeNoble in 1983, I made reference to his important finding in several papers that I was working on at the time. Later, upon learning from Dr. DeNoble that his paper would not be published, I deleted reference to it from manuscripts that had been submitted (or were to be submitted) to scientific journals for publication. What I had quite simply forgotten about was that I had also made reference to the DeNoble work in a book chapter entitled "Behavioral pharmacology of cigarette smoking," published in Advances in Behavioral Pharmacology, edited by T. Thompson, P.B. Dews and J.E. Barrett, Academic Press, Inc., 1984. I apologize for this oversight.

Sincerely,

JaCK E. HenNingfield, PH.D., Chief, Clinical Pharmacology Branch.

Mr. WAXMAN. Do you know any reason why we shouldn't know the name of the company that sponsored that study?

Mr. HENNINGFIELD. I defer to Dr. Kessler.

Mr. WAXMAN. Is there any reason why we shouldn't know that information?

Mr. KeSSLER. Mr. Chairman, we would be happy to work with you.

Mr. WAXMAN. If you are going to give it to us later, why not give it to us now?

Mr. KESSLER. I would prefer to present to the committee the information, and then you can do what you would like with it.

Mr. WAXMaN. Mr. Bliley.

Mr. BLILEY. Dr. Kessler, in your February 25th letter you state, and I quote, "In fact, it is our understanding that manufacturers commonly add nicotine to cigarettes to deliver specific amounts of nicotine," unquote.

Dr. Kessler, this statement is unequivocally false. In fact, in the processing of raw tobacco into cigarettes, the nicotine levels in cigarettes are reduced as compared to the raw unprocessed tobacco product. In the manufacturing process, there is no replacement of lost nicotine.

Let's first address the question of whether cigarette manufacturers spike or add nicotine to their product.

Chart two, I would like you to examine this graph which is taken from the 1989 Surgeon General's report. This graph documents the 
decline of nicotine and tar from the 1950's to the 1990's; for both tar and nicotine there has been a 69 percent reduction.

This graph also shows that nicotine levels are a function of the tar levels in tobacco. When tar levels are set, nicotine levels follow. As manufacturers have reduced tar levels over the years, nicotine levels have concurrently fallen. That is why tar and nicotine levels have been reduced by exactly the same amount, 69 percent.

Therefore, this graph demonstrates correlation between the reduction of tar and nicotine levels.

As I am sure you know, correlation is a very common statistical measure of the dependence between two factors. For example, Scholastic Aptitude Test scores are strongly correlated with firstyear grades in college. In other words, a high SAT test score is an excellent predictor of success in college.

In statistics, correlation coefficients of 0.50 are evidence of significantly strong relationships. In this graph, the correlation is very close to one, meaning that the relationship between tar and nicotine is very, very strong.

What does this mean? First, that nicotine levels follow tar levels; second, that no nicotine manipulation has occurred in the manufacture and process. Why? Because if nicotine was being added back into cigarettes the data would have shown one of three things: Nicotine levels would have remained relatively constant over the 40year period while tar levels would have declined significantly; second, nicotine levels actually have declined very little compared to the 69 percent reduction in tar levels; finally, nicotine levels could have increased while tar levels declined.

In all these cases, the correlation between the levels of nicotine and tar would be very weak or even negative. Instead, this data shows an almost perfect positive correlation. In other words, nicotine is not being added.

Chart three, what about the tar and nicotine levels in 1994? This table presents the correlation analysis of the latest tar and nicotine results to be reported by the Federal Trade Commission. The correlation coefficient of the amount of tar and nicotine in domestic brands is 0.975 . This is essentially a perfect correlation between the levels of nicotine and tar. Again, this is very strong statistical evidence that nicotine is not being manipulated.

[The charts follow:] 


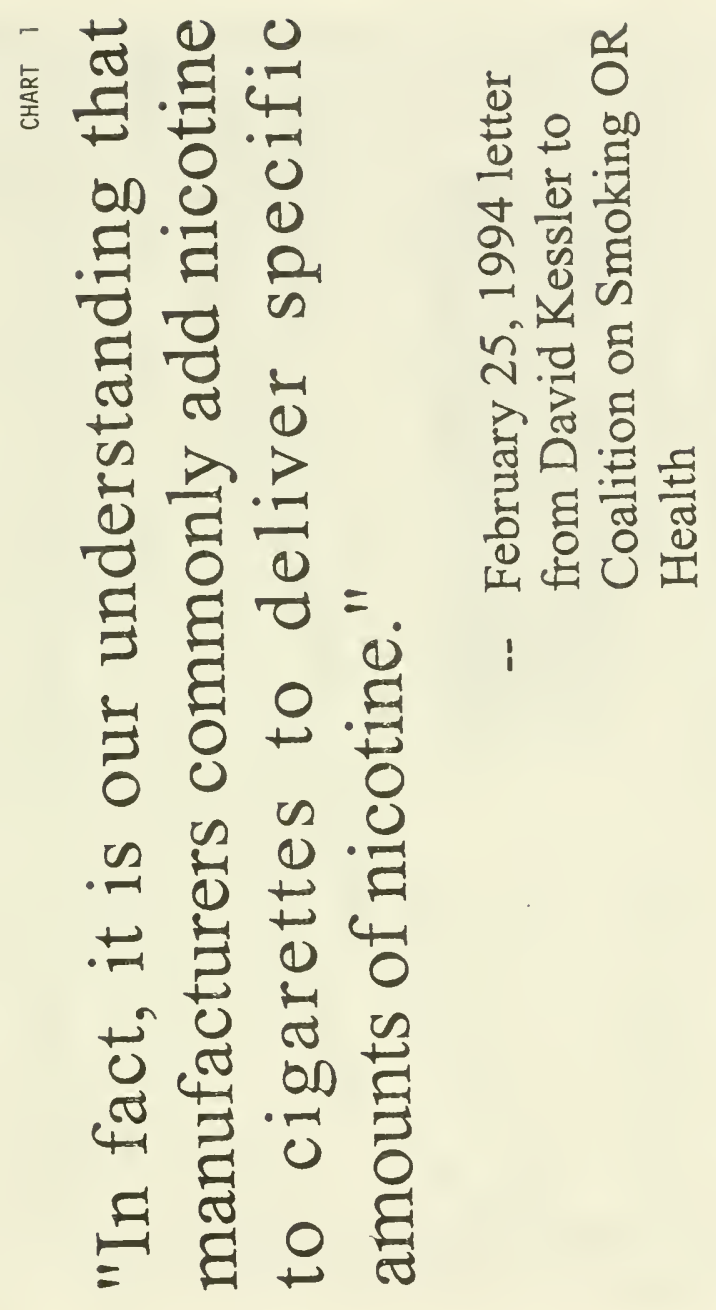




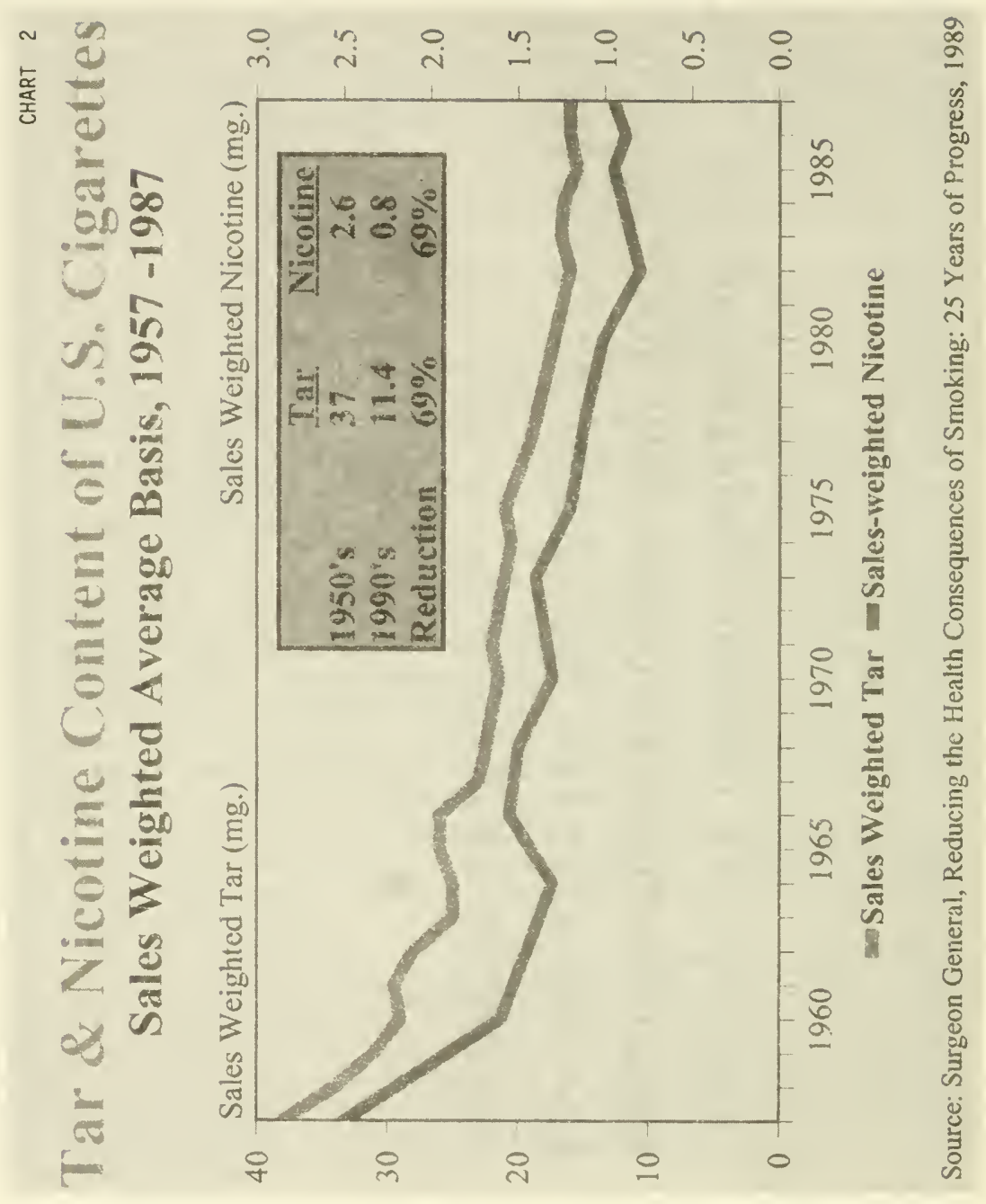




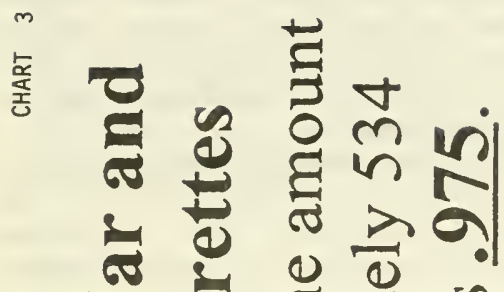

एव

- Dी 4 E

(2) 0 + 0.

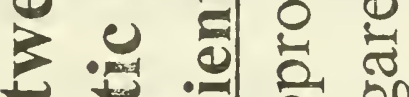

(1) थ थ 다.

a (1) उ

$=000$

- 0 e 0 U

$\leftrightarrow$ 일 ह

$\approx$.

(2) (1)

$-10=0$

$0+2$ \&

() 0 है ब

(4) $U$ Uा

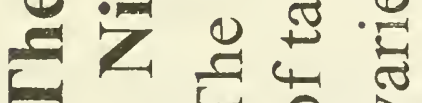

En 50 \%

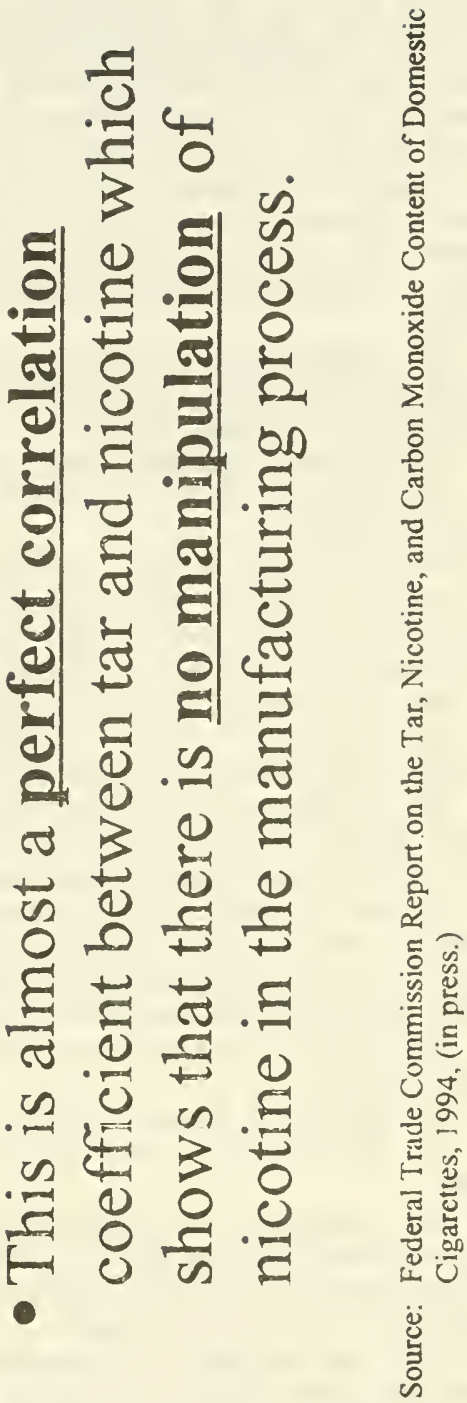


Mr. Bliley. Dr. Kessler, these charts present 40 years of longitudinal data on tar and nicotine levels, as well as the latest Federal Trade Commission data. In both cases, correlation between tar and nicotine levels demonstrates almost perfect correlation. In other words, this is conclusive statistical evidence that is there is no nicotine manipulation in the manufacturing process.

Would you explain to us why this data, which shows an essentially perfect correlation between tar and nicotine levels for the past 40 years, does not categorically contradict your contention that nicotine is added to cigarettes to produce and sustain addiction?

Mr. Kessler. I would be happy to, Congressman. I would be happy to explain why, in fact, the data that we see do not support what you have just stated.

If you could put back your previous graph, I would appreciate it.

Mr. BlileY. This isn't my data. This is the Federal Trade Commission data.

Mr. KESSLER. I know a little about the data; and if you look at a graph-first of all, when you see two vertical axes on a single graph, you see one axis for tar, and one axis for nicotine, always be suspicious. You can change axes just like changing scales, and if we could go back to the graphs-Congressman, you asked-

Mr. BLILEY. I point-I will let you answer the question-this graph was taken from the Surgeon General's report.

Mr. KESSLER. This graph, if you look-if you look between 1980 and 1992-and I will show you that the graphs for that period, I can't read that graph. There are no data points on that graph.

We can go back to the average of all brands with the data points, and if you look from 1982 to 1991 and you plot-and we plotted the FTC computer database-I think when you see that in fact the percent change from that time period is not parallel.

Mr. BLILEY. Are you contradicting the FTC and the Surgeon General's data?

Mr. KESSLER. I used the FTC's data.

Mr. Bliley. How did you get a different conclusion than they did?

Mr. KessLer. You can ask the FTC what conclusion is drawn. I have talked to the FTC. I have shown them our data. They have great questions in my conversations when you look about why-in fact, what is going on here.

I am not saying, Congressman, that I fully understand what it means when nicotine is going up and tar is staying relatively flat, but it raises questions. And I think it really does go to the heart of whether there is, in your words, "manipulation of nicotine."

Let me just respond to your previous question. You used words like "spiking" and other words. The issue to us at the Food and Drug Administration is whether the nicotine is being controlled to sustain and support an addiction. You can do that two ways. You can do that exogenously with nicotine or endogenously with nicotine. 
Mr. BLILEY. We have never seen this data before, and I would request that you submit it to this committee so we can look at it. Mr. KESSLER. We would be very happy to, Congressman.

Mr. BLILEY. Thank you very much.

Thank you, Mr. Chairman.

[Testimony resumes on p. 60.]

[The information referred to by Mr. Bliley follows:] 
Food and Drug Administration Rockville MD 20857

The Honorable Thomas J. Bliley, Jr.

Ranking Minority Member

Subcommittee on Health and the Environment

Committee on Energy and Commerce

House of Representatives

Washington, D.C. 20515-4607

Dear Mr. Bliley:

This is in response to your request to commissioner Kessler at

the nicotine hearing on March 25, 1994, for the Federal Trade

Commission's (FTC) data on which FDA relied to plot its charts on

nicotine and tar levels.

Enclosed is a copy of the FTC data. I hope this information is helpful.

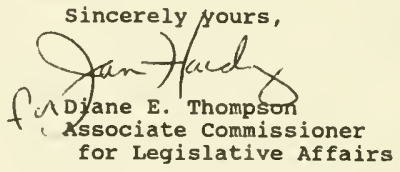

Enclosure 
(NB: We excluded all ratings data for car and nicotine where tar $=0$ or nicotine $=0$. In 1982, the zero's accounted for 5\% of daca; in 1983, the zero's accounted for 7t of data; and in 1984, they accounted for $8 \%$ of data. From 1985 to the present, the zero's were not significanc. The zero's, we believe, were the result of unreported daca, and may or may not be randomly distributed among all tar and nicotine categories. We do not know.

In 2985, the standard deviation on the ricotine/tar ratio appears to be anomolous .. again, we have no theory.l

- tab tarx

$\tan \operatorname{ta}_{\text {| }}$

Ereg.

Percent

Cum.

\begin{tabular}{|c|c|c|c|}
\hline $\begin{array}{r}\text { high } \\
\text { low } \\
\text { uleralow }\end{array}$ & $\begin{array}{r}994 \\
2206 \\
454\end{array}$ & $\begin{array}{l}25.15 \\
62.07 \\
12.77\end{array}$ & $\begin{array}{r}25.15 \\
87.23 \\
100.00\end{array}$ \\
\hline Total & 3554 & 100.00 & $\cdots-\cdot$ \\
\hline
\end{tabular}

Tar, Micotin and Tar/Nicotire totio By Year (weighted by eales)

\begin{tabular}{|c|c|c|c|c|c|c|}
\hline$\Rightarrow$ year= & $\mathrm{B2}$ & & & & & \\
\hline variable ! & obs & Weight & Mean & sed. Dev. & Min & Max \\
\hline \begin{tabular}{r|} 
rar \\
nic \\
nictar \\
earnic
\end{tabular} & $\begin{array}{l}197 \\
197 \\
197 \\
197\end{array}$ & $\begin{array}{l}602301260 \\
692001260 \\
602801260 \\
602301260\end{array}$ & $\begin{array}{r}13.5 \\
0.89 \\
3.068 \\
15.0\end{array}$ & $\begin{array}{r}4.9 \\
0.28 \\
0.012 \\
2.6\end{array}$ & $\begin{array}{r}1.0 \\
0.10 \\
0.033 \\
6.3\end{array}$ & $\begin{array}{r}28.0 \\
2.10 \\
0.160 \\
30.0\end{array}$ \\
\hline $\begin{array}{l}->\text { yeara } \\
\text { Variable ! }\end{array}$ & $\frac{83}{\text { Oba }}$ & Weishe & Meen & sed. Dev. & Min & Mex \\
\hline $\begin{array}{r}\text { tar } \\
\text { nic } \\
\text { rictar } \\
\text { tarnic }\end{array}$ & $\begin{array}{l}206 \\
206 \\
206 \\
206\end{array}$ & $\begin{array}{l}561079389 \\
561079389 \\
561079389 \\
56107 \% 389\end{array}$ & $\begin{array}{r}13.4 \\
0.88 \\
0.069 \\
15.0\end{array}$ & $\begin{array}{r}5.0 \\
0.28 \\
0.012 \\
2.5\end{array}$ & $\begin{array}{r}1.0 \\
0.10 \\
0.032 \\
5.3\end{array}$ & $\begin{array}{r}28.0 \\
2.10 \\
0.160 \\
31.3\end{array}$ \\
\hline $\begin{array}{l}\Rightarrow \text { year } \\
\text { Varisble I }\end{array}$ & ats & Neight & Mean & sted. Dev. & min & Max \\
\hline $\begin{array}{r}\text { ear } \\
\text { nic } \\
\text { nictar } \\
\text { Earnic }\end{array}$ & $\begin{array}{l}211 \\
211 \\
211 \\
211\end{array}$ & $\begin{array}{l}561675181 \\
561655191 \\
561675181 \\
561675181\end{array}$ & $\begin{array}{l}13.0 \\
0.80 \\
0.071 \\
14.4\end{array}$ & $\begin{array}{r}4.7 \\
0.20 \\
0.010 \\
1.7\end{array}$ & $\begin{array}{l}1.0 \\
0.10 \\
0.050 \\
10.0\end{array}$ & $\begin{array}{r}28.0 \\
2.10 \\
0.100 \\
20.0\end{array}$ \\
\hline $\begin{array}{l}\text { - }>\text { year= } \\
\text { variable ! }\end{array}$ & ${ }_{\infty}^{85}$ & Waight & Mean & Std. Dev. & win & $\operatorname{Max}$ \\
\hline $\begin{array}{r}\text { ear } \\
\text { nie } \\
\text { nictar } \\
\text { tarnic }\end{array}$ & $\begin{array}{l}267 \\
267 \\
267 \\
267\end{array}$ & $\begin{array}{l}556502651 \\
554502651 \\
556502651 \\
554502651\end{array}$ & $\begin{array}{l}13.0 \\
0.96 \\
0.077 \\
13.5\end{array}$ & $\begin{array}{r}4.7 \\
0.29 \\
0.031 \\
6.2\end{array}$ & $\begin{array}{r}1.0 \\
0.10 \\
0.013 \\
0.5\end{array}$ & $\begin{array}{r}28.0 \\
2.00 \\
2.000 \\
80.0\end{array}$ \\
\hline
\end{tabular}

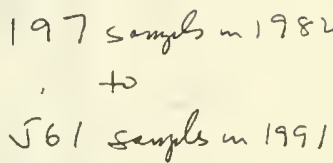

197 sanges m 1982

561 sempls m 1991

$\rightarrow$ yeure

86 


\begin{tabular}{|c|c|c|c|c|c|c|}
\hline Varrade i & cbs & Height & Mean & sid, Gev. & Kin & $\max$ \\
\hline $\begin{array}{r}\text { rar } \\
\text { nic } \\
\text { nictor } \\
\text { rarnic }\end{array}$ & $\begin{array}{l}334 \\
336 \\
336 \\
336\end{array}$ & $\begin{array}{l}582516102 \\
582516102 \\
582516102 \\
582516102\end{array}$ & $\begin{array}{l}13.6 \\
0.92 \\
0.072 \\
16.2\end{array}$ & $\begin{array}{r}4.8 \\
0.28 \\
0.011 \\
1.8\end{array}$ & $\begin{array}{r}1.0 \\
0.10 \\
0.046 \\
2.0\end{array}$ & $\begin{array}{r}29.0 \\
1.90 \\
0.500 \\
22.7\end{array}$ \\
\hline $\begin{array}{l}\text { Pyears } \\
\text { variable! }\end{array}$ & $\begin{array}{l}87 \\
0 \infty\end{array}$ & Vofighe & Moon & std. Dev. & Min & $\operatorname{Max}$ \\
\hline $\begin{array}{r}\text { tar } \\
\text { nie } \\
\text { nictar } \\
\text { tarnic }\end{array}$ & $\begin{array}{l}381 \\
381 \\
381 \\
381\end{array}$ & $\begin{array}{l}576074836 \\
576074036 \\
57607 \angle 836 \\
57607 \angle 836\end{array}$ & $\begin{array}{r}13.3 \\
0.94 \\
0.073 \\
13.9\end{array}$ & $\begin{array}{r}6.7 \\
0.29 \\
0.011 \\
1.7\end{array}$ & $\begin{array}{r}9.0 \\
0.10 \\
0.050 \\
6.0\end{array}$ & $\begin{array}{r}27.0 \\
1.90 \\
0.167 \\
20.0\end{array}$ \\
\hline $\begin{array}{l}\rightarrow \text { yearz } \\
\text { Variable }\end{array}$ & 88 & Weight & Mean & Std. Der. & Min & Mex \\
\hline $\begin{array}{r}\text { tor } \\
\text { nic } \\
\text { nictar } \\
\text { tarnic }\end{array}$ & $\begin{array}{l}392 \\
392 \\
392 \\
392\end{array}$ & $\begin{array}{l}559602793 \\
559602793 \\
99902793 \\
559602703\end{array}$ & $\begin{array}{r}13.3 \\
0.96 \\
0.073 \\
13.9\end{array}$ & $\begin{array}{r}6.8 \\
0.30 \\
0.010 \\
1.7\end{array}$ & $\begin{array}{r}1.0 \\
0.10 \\
0.050 \\
2.5\end{array}$ & $\begin{array}{r}27.0 \\
1.00 \\
0.400 \\
20.0\end{array}$ \\
\hline $\begin{array}{l}\rightarrow>\text { yeare } \\
\text { Variable i }\end{array}$ & $\begin{array}{l}89 \\
\text { Obs }\end{array}$ & Veigh: & Maan & s:d. Oav, & Min & Max \\
\hline \begin{tabular}{r|} 
rar \\
nic \\
niczar \\
rarnic
\end{tabular} & $\begin{array}{l}6 \pi 7 \\
6 \pi 7 \\
6 \pi \\
4 \pi\end{array}$ & $\begin{array}{l}522753708 \\
522753708 \\
522753708 \\
522753708\end{array}$ & $\begin{array}{r}13.2 \\
0.97 \\
0.976 \\
13.3\end{array}$ & $\begin{array}{r}4.8 \\
0.30 \\
0.010 \\
1.6\end{array}$ & $\begin{array}{r}1.0 \\
0.10 \\
0.011 \\
7.5\end{array}$ & $\begin{array}{r}26.0 \\
1.80 \\
0.133 \\
90.0\end{array}$ \\
\hline $\begin{array}{l}\rightarrow \text { year= } \\
\text { variable i }\end{array}$ & $\begin{array}{l}90 \\
\text { ODs }\end{array}$ & Height & Mean & sid. Dev. & Min & $\operatorname{Max}$ \\
\hline \begin{tabular}{r|} 
far \\
nie \\
nlcrar \\
tarnic
\end{tabular} & $\begin{array}{l}528 \\
528 \\
528 \\
528\end{array}$ & $\begin{array}{l}523616272 \\
523616272 \\
523416272 \\
523416272\end{array}$ & $\begin{array}{r}12.5 \\
0.93 \\
0.07 \\
13.1\end{array}$ & $\begin{array}{r}6.7 \\
0.30 \\
0.010 \\
1.7\end{array}$ & $\begin{array}{r}1.0 \\
0.10 \\
0.010 \\
8.0\end{array}$ & $\begin{array}{l}26.0 \\
1.90 \\
0.125 \\
100.0\end{array}$ \\
\hline $\begin{array}{l}\Rightarrow \text { year= } \\
\text { variablo i }\end{array}$ & $\begin{array}{l}91 \\
\text { obs }\end{array}$ & Weight & Mean & std. Dav. & $\min$ & Max \\
\hline $\begin{array}{r}\text { rar } \\
\text { nic } \\
\text { nicter } \\
\text { rapnic }\end{array}$ & $\begin{array}{l}561 \\
561 \\
561 \\
561\end{array}$ & $\begin{array}{l}510706031 \\
590706031 \\
590706031 \\
510705031\end{array}$ & $\begin{array}{r}12.6 \\
0.96 \\
0.077 \\
13.5\end{array}$ & $\begin{array}{r}6.8 \\
0.31 \\
0.011 \\
5.6\end{array}$ & $\begin{array}{r}1.0 \\
0.10 \\
0.009 \\
5.0\end{array}$ & $\begin{array}{r}27.0 \\
1.90 \\
0.200 \\
110.0\end{array}$ \\
\hline
\end{tabular}

Ter, Mleotine end Tarmicotine antice oy vear (weipted of sales)

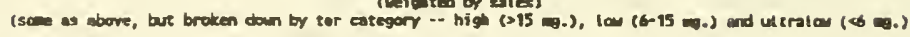

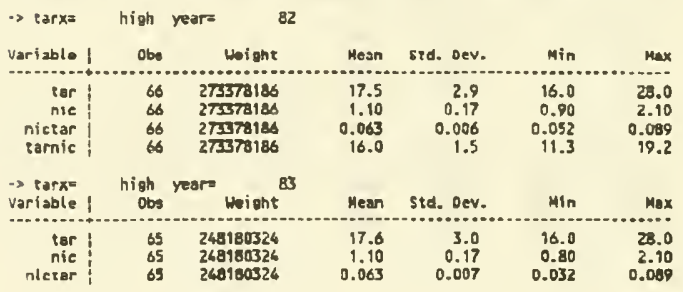




\begin{tabular}{|c|c|c|c|c|c|c|}
\hline rarnic : & 65 & 248180324 & 16.1 & 2.1 & 11.3 & 31.3 \\
\hline$\rightarrow \operatorname{tar} x=$ & nigh & vear $=86$ & & & & \\
\hline variable : & abs & weight & Mean & sed. Dev. & $\min$ & $\max$ \\
\hline $\begin{array}{r}\text { iar } \\
\text { nie } \\
\text { nictar } \\
\text { cornic }\end{array}$ & $\begin{array}{l}58 \\
58 \\
58 \\
58\end{array}$ & $\begin{array}{l}277542537 \\
277542537 \\
277562537 \\
2 \pi 7542537\end{array}$ & $\begin{array}{r}17.0 \\
1.11 \\
0.065 \\
15.6\end{array}$ & $\begin{array}{r}2.2 \\
0.15 \\
0.005 \\
1.1\end{array}$ & $\begin{array}{r}16.0 \\
0.90 \\
0.056 \\
12.7\end{array}$ & $\begin{array}{r}28.0 \\
2.10 \\
0.079 \\
17.9\end{array}$ \\
\hline$\Rightarrow \operatorname{tar} x=$ & high & year $=\quad 85$ & & & & \\
\hline variable & obs & elght & Sean & Stc. Dev. & $\min$ & $\max$ \\
\hline $\begin{array}{r}\text { nic } \\
\text { nic } \\
\text { nictar } \\
\text { ta-nic }\end{array}$ & $\begin{array}{l}99 \\
69 \\
69 \\
69\end{array}$ & $\begin{array}{l}266479082 \\
206670002 \\
266679082 \\
266479002\end{array}$ & $\begin{array}{r}17.0 \\
1.19 \\
0.071 \\
16.3\end{array}$ & $\begin{array}{r}2.2 \\
0.15 \\
0.007 \\
1.6\end{array}$ & $\begin{array}{r}16.0 \\
0.90 \\
0.050 \\
11.4\end{array}$ & $\begin{array}{r}28.0 \\
1.00 \\
0.087 \\
20.0\end{array}$ \\
\hline$\rightarrow \operatorname{tar} x=$ & high & yeares $\quad 06$ & & & & \\
\hline variable ! & abs & weight & Mcon & sed. Dev. & Min & $\operatorname{Max}$ \\
\hline $\begin{array}{r}\text { tar } \\
\text { nic } \\
\text { nictar } \\
\text { earnie }\end{array}$ & $\begin{array}{l}89 \\
89 \\
89 \\
89\end{array}$ & $\begin{array}{l}277855762 \\
277825762 \\
277825762 \\
277825762\end{array}$ & $\begin{array}{r}17.5 \\
1.15 \\
0.066 \\
15.3\end{array}$ & $\begin{array}{r}2.5 \\
0.16 \\
0.005 \\
1.9\end{array}$ & $\begin{array}{r}18.0 \\
1.00 \\
0.044 \\
12.0\end{array}$ & $\begin{array}{r}29.0 \\
1.90 \\
0.003 \\
22.7\end{array}$ \\
\hline$\rightarrow$ ear $x=$ & nigh & year= & & & & \\
\hline Variable & obs & Weight & Mean & Sid. Der. & Min & Max \\
\hline $\begin{array}{r}\text { ear } \\
\text { nie } \\
\text { nictar } \\
\text { tamic }\end{array}$ & $\begin{array}{l}96 \\
96 \\
94 \\
94\end{array}$ & $\begin{array}{l}256757785 \\
286737755 \\
256757745 \\
256757785\end{array}$ & $\begin{array}{r}17.5 \\
1.19 \\
0.069 \\
16.8\end{array}$ & $\begin{array}{l}2.2 \\
0.14 \\
0.005 \\
1.1\end{array}$ & $\begin{array}{r}16.0 \\
0.90 \\
0.050 \\
11.9\end{array}$ & $\begin{array}{r}27.0 \\
1.90 \\
0.084 \\
20.0\end{array}$ \\
\hline 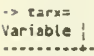 & $\begin{array}{l}\text { high } \\
\text { Coss }\end{array}$ & year= Weight & Mean & std. Der. & Min & $\operatorname{Max}$ \\
\hline $\begin{array}{r}\text { tor } \\
\text { nic } \\
\text { nictar } \\
\text { tornic }\end{array}$ & $\begin{array}{l}94 \\
94 \\
94 \\
36\end{array}$ & $\begin{array}{l}256995824 \\
256995824 \\
256995824 \\
256995824\end{array}$ & $\begin{array}{r}17.6 \\
1.19 \\
0.868 \\
16.8\end{array}$ & $\begin{array}{r}2.2 \\
0.15 \\
0.005 \\
1.0\end{array}$ & $\begin{array}{l}16.0 \\
0.90 \\
0.053 \\
11.3\end{array}$ & $\begin{array}{r}27.0 \\
1.90 \\
0.089 \\
18.9\end{array}$ \\
\hline $\begin{array}{l}\rightarrow \overrightarrow{c a r x}= \\
\text { variable }\end{array}$ & $\begin{array}{l}\text { high } \\
\text { Obs }\end{array}$ & year ${ }_{\text {Weight }}^{89}$ & Mean & sid. Der. & $\min$ & $\operatorname{Max}$ \\
\hline $\begin{array}{r}\text { tar } \\
\text { nie } \\
\text { nictar } \\
\text { rarnic }\end{array}$ & $\begin{array}{l}121 \\
121 \\
121 \\
121\end{array}$ & $\begin{array}{l}234205688 \\
234205688 \\
234205888 \\
234205688\end{array}$ & $\begin{array}{r}17.5 \\
1.23 \\
0.070 \\
16.3\end{array}$ & $\begin{array}{l}2.2 \\
0.16 \\
0.006 \\
3.8\end{array}$ & $\begin{array}{l}18.0 \\
1.00 \\
0.050 \\
11.3\end{array}$ & $\begin{array}{r}26.0 \\
1.80 \\
0.009 \\
20.0\end{array}$ \\
\hline $\begin{array}{l}\because \operatorname{tarx}= \\
\text { variable }\end{array}$ & $\begin{array}{l}\text { high } \\
\text { obs }\end{array}$ & yeur= ${ }_{\text {Height }}^{90}$ & Mean & Std. Dev. & Min & $\max$ \\
\hline $\begin{array}{r}\text { tar } \\
\text { nie } \\
\text { nietar } \\
\text { ternie }\end{array}$ & $\begin{array}{l}117 \\
117 \\
117 \\
917\end{array}$ & $\begin{array}{l}20469059 \\
206499999 \\
206499959 \\
206490959\end{array}$ & $\begin{array}{r}16.9 \\
1.20 \\
0.071 \\
16.2\end{array}$ & $\begin{array}{r}2.3 \\
0.15 \\
0.006 \\
0.9\end{array}$ & $\begin{array}{r}16.0 \\
1.00 \\
0.056 \\
11.3\end{array}$ & $\begin{array}{r}26.0 \\
1.90 \\
0.089 \\
18.5\end{array}$ \\
\hline $\begin{array}{l}\Rightarrow \operatorname{tarx}= \\
\text { varlable । }\end{array}$ & $\underset{\text { Tbs }}{\text { high }}$ & year= welant & Mean & std. Dev. & MIn & $\operatorname{Max}$ \\
\hline \begin{tabular}{r|} 
ar \\
nic \\
nictar \\
tarnic
\end{tabular} & $\begin{array}{l}121 \\
121 \\
121 \\
121\end{array}$ & $\begin{array}{l}201613003 \\
201613003 \\
201613003 \\
201613003\end{array}$ & $\begin{array}{l}17.2 \\
1.23 \\
0.071 \\
16.1\end{array}$ & $\begin{array}{r}2.5 \\
0.19 \\
0.006 \\
1.2\end{array}$ & $\begin{array}{r}16.0 \\
0.60 \\
0.025 \\
11.6\end{array}$ & $\begin{array}{l}27.0 \\
1.00 \\
0.087 \\
40.0\end{array}$ \\
\hline & & & 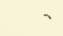 & & & \\
\hline$\rightarrow \operatorname{tar} x=$ & low & year= & & & & \\
\hline
\end{tabular}




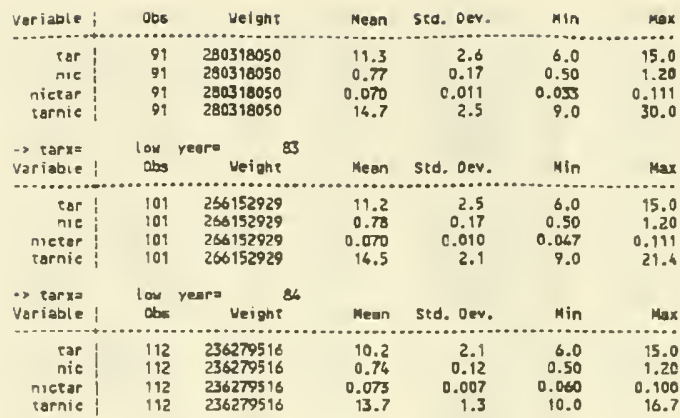

\begin{tabular}{|c|c|c|c|c|c|c|}
\hline $\begin{array}{l}\Rightarrow \operatorname{tar} x= \\
\operatorname{var} 1 \theta 0 \text { le }\end{array}$ & $\begin{array}{l}\text { low } \\
\text { cos }\end{array}$ & yaar $={ }_{\text {veight }}^{85}$ & Neen & St6. Dev. & Min & $\max$ \\
\hline $\begin{array}{r}\text { tar } \\
\text { nic } \\
\text { nietar } \\
\text { tarnic }\end{array}$ & $\begin{array}{l}159 \\
159 \\
159 \\
159\end{array}$ & $\begin{array}{l}242269205 \\
242269205 \\
242269205 \\
262269205\end{array}$ & $\begin{array}{r}10.3 \\
0.81 \\
0.079 \\
13.2\end{array}$ & $\begin{array}{r}2.1 \\
0.14 \\
0.011 \\
6.0\end{array}$ & $\begin{array}{r}6.0 \\
0.10 \\
0.013 \\
8.8\end{array}$ & $\begin{array}{r}15.0 \\
1.30 \\
0.116 \\
80.0\end{array}$ \\
\hline
\end{tabular}

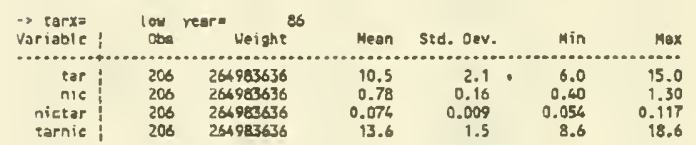

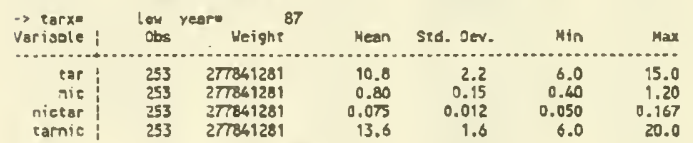

\begin{tabular}{|c|c|c|c|c|c|c|}
\hline $\begin{array}{l}\rightarrow \text { rarnz } \\
\text { Variaole ! }\end{array}$ & tou & year= Weight & Mean & Std, Dev. & Nin & $\max$ \\
\hline $\begin{array}{r}\text { tar } \\
\text { nic } \\
\text { nfesar } \\
\text { sarnic }\end{array}$ & $\begin{array}{l}259 \\
259 \\
259 \\
259\end{array}$ & $\begin{array}{l}257249404 \\
257269404 \\
257249404 \\
257269606\end{array}$ & $\begin{array}{r}10.7 \\
0.79 \\
0.076 \\
13.6\end{array}$ & $\begin{array}{r}2.0 \\
0.16 \\
0.008 \\
1.4\end{array}$ & $\begin{array}{r}6.0 \\
0.40 \\
0.050 \\
8.6\end{array}$ & $\begin{array}{r}15.0 \\
1.30 \\
0.117 \\
20.0\end{array}$ \\
\hline
\end{tabular}

\begin{tabular}{|c|c|c|c|c|c|c|}
\hline $\begin{array}{l}\Rightarrow \text { tarx }= \\
\text { Variable ! }\end{array}$ & low & yoar" weight & mean & sed. Dev. & Min & $\operatorname{Max}$ \\
\hline tar $r$ & 307 & 238072608 & 10.7 & 2.0 & 6.0 & 15.0 \\
\hline nic & 307 & 238072600 & 0.86 & 0.15 & 0.10 & 1.30 \\
\hline nictor & 307 & 238072408 & 0.070 & 0.007 & 0.011 & 0.117 \\
\hline tarnic & 307 & 258072608 & 12.9 & 9.6 & 8.6 & 90 \\
\hline
\end{tabular}

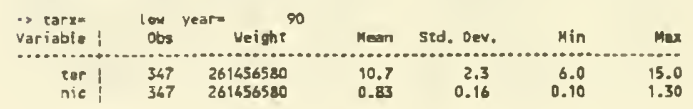




\begin{tabular}{|c|c|c|c|c|c|c|}
\hline $\begin{array}{l}\text { nictar ! } \\
\text { earnie }\end{array}$ & $\begin{array}{l}347 \\
367\end{array}$ & $\begin{array}{l}261456580 \\
261656580\end{array}$ & $\begin{array}{l}0.070 \\
12.8\end{array}$ & $\begin{array}{r}0.008 \\
1.6\end{array}$ & $\begin{array}{r}0.010 \\
8.6\end{array}$ & $\begin{array}{l}0.117 \\
100.0\end{array}$ \\
\hline $\begin{array}{l}\text {-) tarx= } \\
\text { Variable I }\end{array}$ & low & yeare Weight? & Han & Std. Dev. & Min & $\mathrm{Ma}$ \\
\hline $\begin{array}{r}\text { tar } \\
\text { nic } \\
\text { nictar } \\
\text { tarnie }\end{array}$ & $\begin{array}{l}371 \\
371 \\
371 \\
371\end{array}$ & $\begin{array}{l}259402107 \\
259402107 \\
259402107 \\
259402107\end{array}$ & $\begin{array}{r}10.7 \\
0.82 \\
0.077 \\
13.7\end{array}$ & $\begin{array}{r}2.2 \\
0.16 \\
0.009 \\
7.7\end{array}$ & $\begin{array}{r}6.0 \\
0.10 \\
0.009 \\
8.6\end{array}$ & $\begin{array}{l}19.0 \\
1.20 \\
0.117 \\
110.0\end{array}$ \\
\hline
\end{tabular}

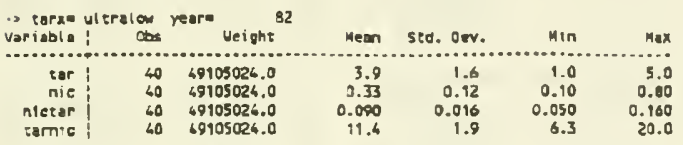

\begin{tabular}{|c|c|c|c|c|c|c|}
\hline $\begin{array}{l}* \text { tarx }= \\
\text { Variable I }\end{array}$ & low & rear= Ueight ${ }^{8}$ & Mean & std. Dev. & Mín & Max \\
\hline $\begin{array}{r}\text { tar } \\
\text { nie } \\
\text { nietar } \\
\text { tamie }\end{array}$ & $\begin{array}{l}60 \\
40 \\
40 \\
40\end{array}$ & $\begin{array}{l}46746136.0 \\
46746136.0 \\
46746136.0 \\
16746138.0\end{array}$ & $\begin{array}{r}3.9 \\
0.3 \% \\
0.091 \\
11.3\end{array}$ & $\begin{array}{r}1.5 \\
0.12 \\
0.016 \\
1.9\end{array}$ & $\begin{array}{r}1.0 \\
0.10 \\
0.050 \\
6.3\end{array}$ & $\begin{array}{l}5.0 \\
0.80 \\
0.160 \\
20.0\end{array}$ \\
\hline $\begin{array}{l}\Rightarrow \text { tares } \\
\text { Veriable }\end{array}$ & law & veare Weight & Mean & Std. Dev. & Min & $\operatorname{Max}$ \\
\hline $\begin{array}{r}\text { tar } \\
\text { nie } \\
\text { nictar } \\
\text { tamic }\end{array}$ & $\begin{array}{l}61 \\
41 \\
61 \\
61\end{array}$ & $\begin{array}{l}67853128.0 \\
47053128.0 \\
47853128.0 \\
47853128.0\end{array}$ & $\begin{array}{r}6.0 \\
0.35 \\
0.088 \\
11.6\end{array}$ & $\begin{array}{r}1.4 \\
0.12 \\
0.011 \\
1.6\end{array}$ & $\begin{array}{r}1.0 \\
0.10 \\
0.050 \\
10.0\end{array}$ & $\begin{array}{r}5.0 \\
0.50 \\
0.100 \\
20.0\end{array}$ \\
\hline
\end{tabular}

\begin{tabular}{|c|c|c|c|c|c|c|}
\hline variable i & $\infty$ & Wefghe & Mean & sed. Dev. & Min & Mes \\
\hline $\begin{array}{r}\text { tar } \\
\text { nic } \\
\text { nictar } \\
\text { tomic }\end{array}$ & $\begin{array}{l}39 \\
39 \\
39 \\
39\end{array}$ & $\begin{array}{l}45754364.0 \\
45756366.0 \\
45756366.0 \\
45754364.0\end{array}$ & $\begin{array}{r}6.9 \\
0.38 \\
0.099 \\
10.8\end{array}$ & $\begin{array}{l}1.5 \\
0.15 \\
0.102 \\
1.5\end{array}$ & $\begin{array}{l}1.0 \\
0.10 \\
0.075 \\
0.5\end{array}$ & $\begin{array}{r}5.0 \\
2.00 \\
2.000 \\
13.3\end{array}$ \\
\hline
\end{tabular}

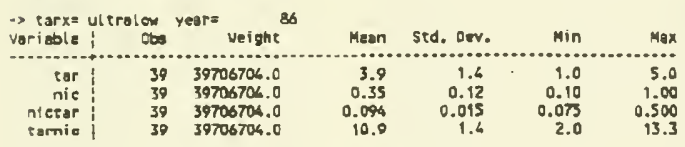

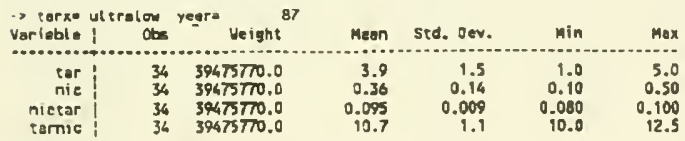

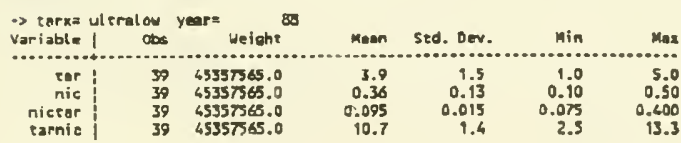




\begin{tabular}{|c|c|c|c|c|c|c|}
\hline $\begin{array}{l}\rightarrow \operatorname{tar} x=u \\
\text { Yartade }\end{array}$ & $\operatorname{los}_{1}$ & year $=\underset{\text { Veignt }}{89}$ & Mean & std. Dev. & $\min$ & $\operatorname{Max}$ \\
\hline tar & 49 & 50475612.0 & 4.2 & 1.3 & 1.0 & 5.0 \\
\hline nie & 69 & 50475612.0 & 0.60 & 0.12 & 0.10 & 0.60 \\
\hline nictar & 40 & 50675612.0 & 0.096 & 0.000 & 0.08 & 0.133 \\
\hline tarnic & 49 & $504 \pi 5612.0$ & 10.6 & 1.2 & 7.5 & 40.0 \\
\hline$\rightarrow$ tara $=u$ & lam & year- & & & & \\
\hline Variable & cos & Weight & Haen & sed. Dev. & Min & Max \\
\hline tar & $\infty$ & $5 \$ 459733.0$ & 6.0 & 1.6 & 1.0 & 5.0 \\
\hline nie & 66 & 55459733.0 & 0.38 & 0.93 & 0.10 & 0.50 \\
\hline nictar & 64 & 55459733.0 & 0.096 & 0.000 & 0.020 & 0.125 \\
\hline sarnic & 66 & 55659733.0 & 10.5 & 9.1 & 8.0 & 50.0 \\
\hline$\Rightarrow \operatorname{tar} z=u$ & ion & year= & & & & \\
\hline Verieble & $\infty$ & Weignt & Mesn & Std. Dev. & Min & $\operatorname{Max}$ \\
\hline tor & 69 & 49690921.0 & 6.0 & 1.5 & 1.0 & 5.0 \\
\hline nie & 69 & 49590921.0 & 0.38 & 0.16 & 0.10 & 0.50 \\
\hline nictar & 69 & 49690921.0 & 0.006 & 0.011 & 0.020 & 0.200 \\
\hline tarnic & 69 & 69690921.0 & 10.5 & 1.2 & 5.0 & 50.0 \\
\hline
\end{tabular}




\begin{tabular}{|c|c|c|c|c|c|c|c|c|c|}
\hline Tar & & & nber & Tar & & $\mathrm{Nicot}$ & & . & I Rat \\
\hline Level & Year & Sales & sted & Mean & sd & Mean & sd & Mean & sd \\
\hline h & 82 & 273378186 & 66 & 17.5 & 2.9 & 1.1 & 0.17 & 0.063 & 0.006 \\
\hline h & 83 & 248180324 & 65 & 17.6 & 3 & 1.1 & 0.17 & 0.063 & 0.007 \\
\hline h & 84 & 277542537 & 58 & 17 & 2.2 & 1.11 & 0.15 & 0.065 & 0.005 \\
\hline h & 85 & 266479082 & 69 & 17 & 2.2 & 1.19 & 0.15 & 0.071 & 0.007 \\
\hline h & 86 & $277825 T 62$ & 89 & 17.5 & 2.5 & 1.15 & 0.16 & 0.066 & 0.005 \\
\hline h & 87 & 256757785 & 94 & 17.5 & 2.2 & 1.19 & 0.14 & .068 & 0.005 \\
\hline $\mathrm{n}$ & 88 & 256995824 & 94 & 17.6 & 2.2 & 1.19 & 0.15 & 0.068 & 0.005 \\
\hline h & 89 & 234205688 & 121 & 17.5 & 2.2 & 1.23 & 0.14 & 0.07 & 0.004 \\
\hline n & 90 & 206499959 & 117 & 16.9 & 2.3 & 1.2 & 0.15 & 0.071 & 0.004 \\
\hline n & 91 & 201613003 & 121 & 17.2 & 2.5 & 1.23 & 0.19 & 0.071 & 0.006 \\
\hline 1 & 82 & 8050 & 91 & 11.3 & 2.6 & 0.77 & 0.17 & 0.07 & 0.011 \\
\hline 1 & 83 & 52929 & 101 & 11.2 & 2.5 & 0.78 & 0.17 & 0.07 & 0.01 \\
\hline 1 & 84 & 236279516 & 112 & 10.2 & 2.1 & 0.74 & 0.12 & 0.073 & 0.007 \\
\hline 1 & 85 & 69205 & 159 & 10.3 & 2.1 & 0.81 & 0.14 & 0.079 & 0.012 \\
\hline 1 & 86 & 33636 & 206 & 10.5 & 2.1 & 0.78 & 0.16 & 0.074 & 0.009 \\
\hline 1 & 87 & 1281 & 253 & 10.8 & .2 & 0.8 & 0.15 & 0.075 & 0.012 \\
\hline 1 & 88 & 19404 & 259 & 10.7 & 2 & 0.79 & 0.14 & 0.074 & 0.008 \\
\hline 1 & 89 & 2408 & 307 & 10.7 & 2 & 0.84 & 0.15 & 0.078 & 0.007 \\
\hline 1 & 90 & 6580 & 347 & 10.7 & 2.3 & 0.83 & 0.16 & 0.079 & 0.008 \\
\hline 1 & 91 & 259402107 & 371 & 10.7 & 2.2 & 0.82 & 0.16 & 0.078 & .017 \\
\hline 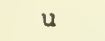 & 82 & 5024 & $4 C$ & 3.9 & 1.0 & 0.33 & 0.12 & 0.09 & 0.016 \\
\hline . & 83 & 46136 & 40 & 3.9 & 1.5 & 0.34 & 0.12 & 0.091 & 0.016 \\
\hline $\mathrm{u}$ & 84 & 53128 & 42 & 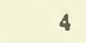 & 1.4 & 0.35 & 0.12 & 0.089 & 0.011 \\
\hline-2 & 85 & 45754364 & 3 & 4 & 1.5 & 0.38. & 0.15 & 0.099 & 0.102 \\
\hline u & 86 & 39706704 & 39 & 3 & 1.4 & 0.35 & 0.12 & 0.094 & 0.015 \\
\hline $\mathrm{u}$ & 87 & 39475770 & 34 & 3.9 & 1.5 & 0.36 & 0.14 & 0.095 & 0.009 \\
\hline $\mathrm{u}$ & 88 & 45357565 & 39 & 3.9 & 1.5 & 0.36 & 0.13 & 0.095 & 0.015 \\
\hline $\mathrm{u}$ & 89 & 50475612 & 49 & 4.2 & 1.3 & 0.4 & 0.12 & 0.096 & 0.009 \\
\hline 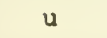 & 90 & 55459733 & 64 & 4 & 1.4 & 0.38 & 0.13 & 0.096 & 0.009 \\
\hline & & & 60 & & 1.5 & 38 & .14 & 696 & .011 \\
\hline
\end{tabular}


Summary:

1. Nicotine Levels:

When one looks at average nicotine levels over the years 1982-1991, one finds that the levels are trending upward. This is true both within each of the three categories (high tar, low tar, and ultra low tar), and averaged across all brands.

Within each of the three categories based on tar level, the upward trend in nicotine levels is statistically significant. This does not appear to be an artifact of a particular method of statistical analysis. The upward trends remain significant when any of several analyses are used.

When one looks at the average over all brands, the trend is marginally statistically significant. Depending on the method of analysis, the trend is significant with a p-value between .07 and .024 . The analysis with the higher p-value is a weighted regression which puts substantially more weight on the later years. As the graphs show, nicotine levels are somewhat flatter in the years 1987-91 than in the whole time period 1982-91. This may account for the diminished statistical significance.)

\section{Tar Levels:}

As was done with nicotine, one can also look at trend in average tar levels over time. If one looks at average tar levels within the three categories of high, low and ultra low tar cigarettes, one does not find any statistically significant trend upward or downward over the time period 1982-91. Since this analysis is stratifying on tar levels, it may be an artifact that no trend is found.

A more relevant analysis for tar levels over the time period 1982-91 is the tar level averaged over all varieties of cigarettes. This average tar level has been trending downward to a statistically significant extent. (The p-value for a downward trend is between .0248 and .0425 , depending on the method of analysis chosen.)

An apparent explanation of the downward trend in average tar levels is increasing market share of low tar and ultra low tar cigarettes. (Ultra low tar cigarettes have increased from 8.18 
to 9.78 of the market; low tar cigarettes have increased from 478 to 518 of the market.)

\section{Nicotine/Tar Ratios:}

The ratio of nicotine divided by tar is higher in low tar cigarettes than in high tar cigarettes and is higher in ultra low tar cigarettes than in low tar cigarettes. These differences are all statistically significant, at simultaneous levels below .05 . The differences remain statistically significant, whether one averages all 10 years of data together or performs an analysis that adjusts for possible effects of year.

Furthermore, within each of the categories high tar, low tar, and ultra low tar, the ratio of nicotine to tar has been trending upward over the period 1982-91. In each category, the upward trend is statistically significant.

During this period, the differences among the three categories in nicotine/tar ratio have not changed. The upward trends in the three categories are parallel. 
Analyses Performed:

1. Analyses of the Trend of Nicotine Level on Year:

The nicotine data provided by the FTC consisted of four vectors: 1) $\mathrm{Nic}(i, j)=$ mean nicotine level of cigarettes tested in year $i$, tar category $j ; 2) \operatorname{SDN}(i, j)=$ std. dev. of Nicotine in year $i$, tar category $j ; 3) N(i, j)$ = number of cigarettes tested in year $i$, tar category $j ; 4) s(i, j)=$ number of cigarettes sold in year $i$, tar category $j$. In this data, the mean and the std. dev. were computed, according to Joe Mulholland, by taking sales weighted means and sd's of all of the varieties tested within a given year and tar category.

We did six analyses of the trend of Nicotine Level on Year, from 1982 through 1991. These were as follows:

1) weighted least squares regression of nicotine, $N i c(i, j)$ on year $i$, stratifled by tar category $j=$ (high, low, and ultra-low). The weights were proportional to reciprocals of the variances of the sample means $=1 / \operatorname{VarN}(i, j)=$ $N(i, j) / \operatorname{SDN}(i, j) \wedge 2$.

2) weighted least squares regression of average nicotine on year, ignoring tar category. In this regression, the dependent variable was the sales weighted average of nicotine of all varieties tested in year $i$. This was computed from the FTC data as $N i c(i)=\Sigma(S(i, j) \star N i c(i, j))$ /IS $(i, j)$ where the sums were over $f=$ ultra-low to high. The weights in this regression were again proportional to reciprocals of variances of the Nic(i). Specifically, the weights were $w(i) \propto \Sigma(S(i, j) \wedge 2) / \Sigma(\operatorname{VarN}(i, j) \star S(i, j) \wedge 2)=$ $\Sigma(S(i, j) \wedge 2\} / \Sigma(S(i, j) \wedge 2 * \operatorname{SDN}(i, j) \wedge 2 / N(i, j)\}$. In all cases, the sums are over $j=u l$ tra to high.

3) ordinary (unweighted) least squares regression of nicotine on year, stratified by tar category. (This was the same as analysis 1 except the weights were now $=1 / 10$.)

4) ordinary least squares regression of average nicotine on year, ignoring tar category. (This was the same as analysis 2 except the weights were $1 / 10^{.}$) 
5) Spearman rank correlation of nicotine and year, stratified by tar category.

6) Spearman rank correlation of average nicotine and year, ignoring tar category. (Average nicotine is defined exactly as in analyses 2 and 4. .)

Findings were usually that nicotine was increasing with time to a statistically significant extent. Ten out of 12 two-sided p-values were smaller than .05 . The two marginal findings were wLS and Spearman's correlation, both computed for all categories averaged together. P-values for $H_{0}$ : There is no change in nicotine level over time are tabled as follows:

\begin{tabular}{|c|c|c|c|c|c|}
\hline \multirow{6}{*}{ Tar } & Category & WLS & OLS & Spearman & \\
\hline & High & $.0005 \star$ & $.0003 \star$ & $.0001 \star$ & \\
\hline & Low & $.0109 *$ & $.0101 \star$ & $.0041 \star$ & \\
\hline & Ultra & $.0032 \star$ & $.0067 \star$ & $.0041 *$ & \\
\hline & Al1 & .0718 & $.0244 *$ & .0667 & \\
\hline & & $1000 *$ & & * & \\
\hline \multirow[t]{5}{*}{ Tar } & Category & WLS slope & & slope & Spearman R \\
\hline & High & 14.82 & & & .938 \\
\hline & Low & 8.34 & & 54 & .815 \\
\hline & Ultra & 5.84 & & & .815 \\
\hline & All & 5.88 & & 13 & .938 \\
\hline
\end{tabular}


2. Analyses of the Trend of Tar Level on Year:

The tar data provided by the FTC was parallel to that for the nicotine, consisting of two additional vectors: 1$) \operatorname{Tar}(i, j)=$ mean tar level of cigarettes tested in year $i$, tar category $j$; and 2$) \operatorname{SDT}(i, j)=$ std. dev. of tar in year $i$, tar category $j$. In this data, the mean and the std. dev. were computed, according to Joe Mulholland by taking sales weighted means and sd's of all of the varieties tested within a given year and tar category.

We did four analyses of the trend of Tar Level on year, from 1982 through 1991. These were as follows:

1) weighted least squares regression of $\operatorname{tar}, \operatorname{Tar}(i, j)$ on year $i$, stratified by tar category $j=$ (high, low, and ultra-low). The weights were proportional to reciprocals of the variances of the sample means $=1 / \operatorname{Var} T(i, j)=$ $N(i, j) / \operatorname{SDT}(i, j) \wedge 2$.

2) weighted least squares regression of average tar on year, ignoring tar category. In this regression, the dependent variable was the sales weighted average of tar of all varieties tested in year $i$. This was computed from the FTC data as $\operatorname{Tar}(i)=\Sigma(S(i, j) * \operatorname{Tar}(i, j)) / \Sigma S(i, j)$ where the sums were over $j=$ ultra-low to high. The weights in this regression were agair proportional to reciprocals of variances of the $\operatorname{Tar}(i)$. Specifically, the weights were $w(i) \propto \Sigma(S(1, j) \wedge 2\} / \Sigma(\operatorname{Var} T(1, j) * S(1, j) \wedge 2\}=$ $\Sigma(S(i, j) \wedge 2\} / \Sigma(S(i, j) \wedge 2 * \operatorname{SDT}(i, j) \wedge 2 / N(i, j)\}$. In all cases, the sums are over $f=u l t r a$ to high.

3) Spearman rank correlation of tar and year, stratified by tar category.

4) Spearman rank correlation of average tar and year, ignoring tar category. (Average tar is defined exactly as in analysis 2.)

Findings were that tar was statistically indistinguishable from being flat within tar categories. This may be because varieties within a tar category retain a deliberately maintained chemical identity, with lowering of tar in the marketplace occurring by proliferation and increased sales of lower tar brands. It may also be an artifact, since the association found 
in a bivariate scatterplot generally decreases when one stratifies on either variable. When the overall average tar, based on the sales weighted average of all varieties tested by the FTC was examined, both the wLS regression on time and the spearman rank correlation showed a statistically significant decrease in tar over time. P-values for $\mathrm{H}_{0}$ : There is no change in tar level over time are tabled as follows:

Tar Category High

Low Ultra

All

Tar Category $\mathrm{High}$

Low Ultra All

\section{P-values}

WLS

.6233

.8630

.2966

.0248 *

1000 *

WLS Slope

$-17.9$

5.61

12.6

$-9.64$
Spearman

.4716

.6410

.2522

$.0425 *$

Spearman $R$

$-.258$

$-.169$

.3999

$-.648$ 
3. Analyses of Nicotine/Tar Ratios:

The nicotine/tar ratio data provided by the FTC was parallel to that for the nicotine and tar, consisting of two additional vectors: 1) Ratio $(i, j)=$ mean ratio of nicotine/tar in cigarettes tested in year $i$, tar category $j$; and 2$) \operatorname{SDR}(i, j)=$ std. dev. of that ratio in year $i$, tar category $j$. In other words, the ratio is computed for each tested cigarette, providing a mean and a std dev. of the ratio. The mean ratio is not just computed as the ratio of mean nicotine over mean tar. In this data, the mean and the std. dev. were computed, according to Joe Mulholland by taking sales weighted means and sd's of all of the varieties tested within a given year and tar category.

We did five analyses of the nicotine/tar ratio. These were as follows:

1) Weighted least squares regression of the ratio, Ratio $(i, j)$ on year $i$, stratified by tar category $j=$ (high, low, and ultra-low). The weights were proportional to reciprocals of the variances of the sample means = $1 / \operatorname{Var} R(i, j)=N(i, j) / \operatorname{SDR}(i, j) \wedge 2$.

2) ordinary (unweighted) least squares regression of the ratio on year, stratified by tar category. (This was the same as analysis 1 except the weights were now $=1 / 10$.)

3) Spearman rank correlation of the ratio and year, stratified by tar category.

4) Analysis of Covariance, using tar category as the class variable and year as a continuous covariate. Tukey tests were run at simultaneous level .05 to determine which tar categories had significantly different nicotine/tar ratios when adjusted for year.This analysis treated the 30 observed Ratio(i,j) as single points with equal weights.

5) Analysis of Covariance, using tar category as the class variable and year as a continuous covariate. Again, Tukey tests were run at simultaneous level .05 to determine which tar categories had significantly different nicotine/tar ratios when adjusted for year. This analysis gave the 30 observed Ratio $(i, j)$ weights proportional to the reciprocals 
of their variances: $w(i, j) \propto N(i, j) / \operatorname{SDR}(i, j) \wedge 2$. (These are not quite the same weights as in analysis 1 because in that analysis, the final weights are scaled to add up to 1 over the 10 years within each tar category; in this analysis, the weights are scaled so that the sum of all 30 weights over year and categories is 1.)

Findings were that nicotine/tar ratio was increasing with time in all three tar categories to a statistically significant extent. The three tar categories also had statistically significantly different mean nicotine/tar ratios when adjusted for year.

p-values for $H_{0}$ : There is no change in the ratio over time, are tabled as follows:

\begin{tabular}{|c|c|c|c|c|}
\hline \multirow[t]{3}{*}{ Tar } & Category & WLS & OLS & Spearman \\
\hline & High & $.0004 *$ & $.0026 *$ & $.0046 *$ \\
\hline & Low & .0058 & $.0077 \star$ & .0165 \\
\hline \multirow{2}{*}{\multicolumn{2}{|c|}{ Ultra }} & $.0004 *$ & $.0379 *$ & $.0274 \star$ \\
\hline & & 1000 & 1000 & • \\
\hline & Category & WLS Slope & OLs & Slope \\
\hline & High & .919 & .885 & \\
\hline & Low & .928 & .885 & \\
\hline & ultra & .807 & .685 & \\
\hline & Ratios, Adjus & eed for year & & \\
\hline & Tar Category & Ultra-Low & Low & High \\
\hline & ighted Mean & .0942 & .0750 & .0676 \\
\hline e & hted Mean & .0945 & .0761 & .0686 \\
\hline
\end{tabular}


Mr. WAXMan. Thank you, Mr. Bliley.

Before calling on Mr. Synar to go through his questions, I want to recognize the distinguished Chairman of the Energy and Commerce Committee, Mr. Dingell.

Mr. Dingell. Thank you, Mr. Chairman, for this courtesy. Mr. Chairman, I came down to ask no questions, but I wanted to commend you for having this hearing. I think you are going into an extremely important question, one which is a matter within the responsibility of this committee and one which is a major public health concern.

And Dr. Kessler, I want to commend you and your associates at the table there for your assistance to us. You have approached an extremely important question, in what I think is a highly professional, scientific, and decent way. I want to express my commendations to you, as I do to the chairman for holding this hearing today. This is an important question, and I will be following it very closely as the committee proceeds with its business on this matter.

And Mr. Chairman, I thank you, and I thank you, Doctor, for your kindness to us today.

Mr. WAXMAN. Mr. Synar.

Mr. SYNAR. Thank you, Mr. Chairman.

And Dr. Kessler, thank you. I think, as the chairman of our full committee just said, this is very important. I don't think I would be exaggerating to suggest that we have just witnessed some of the most historic testimony in the history of Congress on any subject. And you and your staff who have been working on this, not just in the last month but in the last year, are to be commended for the courage and the leadership that you are taking on this.

I want to go back to something Chairman Waxman said: whether or not nicotine is a drug will somehow be determined on looking at the manufacturer's intent. You also go on to say that you are concerned about the industry's manipulation of that nicotine.

That does not mean, does it, strictly speaking that they spiked it to higher or more pure levels, but that they just changed the level? Is that not correct?

Mr. Kesslen. That is correct, Congressman. Our concern is the control over the nicotine levels and why those levels are being set the way they are.

Again, you can change nicotine levels either by adjusting endogenous amount of nicotine or you can achieve adding exogenous nicotine. In the end, it is irrelevant how you increase the nicotine.

It is almost irrelevant. There is some tobacco industry research that I have seen that suggests exogenous-suggests-it is old; it is in the literature that suggests that exogenous nicotine may, in fact, be a little more active. I would be interested in seeing that data, but it makes no differences for the purposes of the Food and Drug Administration.

Mr. SYNAR. The chairman asked me to ask you what those two terms mean.

Mr. WAXMAN. Will the gentleman yield?

Mr. KESSLER. Let me use an analogy. It is something that has been in the news lately. It is the Big Bertha example, BST, which has been in the news. 
You can take the genetically derived bST and add it to a cow, or you can breed a cow like Big Bertha that just has more bST in the animal. Exogenous has to do with applied from without; endogenous has to do with applied from within.

Mr. WAXMAN. Will the gentleman yield?

In other words, whether it is sprayed on and added to the tobacco or whether it is a mixture of a high-nicotine blend with a low-nicotine blend; is that what we are talking about?

Mr. KESSLER. Absolutely.

But biologically, Mr. Chairman, the nicotine-the nicotine that ends up in the bloodstream is what we are concerned about. You can raise nicotine levels either way, so its effect on structure and function obviously can be affected either way.

Mr. SynAR. Second, Dr. Kessler, could you tell us how the FDA regulates nicotine in other products, such as nicotine gum or nicotine patches or other things that it appears in?

Mr. KESSLER. Andrew, if I could have the chart on the products that we have approved.

Congressman Synar, I think this chart will show you the names of the products that we have approved, the ingredient base, the strength, the dosing intervals. We have approved those under the drug provisions of the Act.

Mr. SYNAR. That, I think, is an important point because, as you know, one of the things that the industry would have us believe is that the only option available to us is to ban the product. But we are presently regulating nicotine in many products, which is something very short of the kind of ban which they claim is the only alternative.

Mr. KeSSLER. Congressman, those products have nicotine for a therapeutic effect, obviously to prevent the withdrawal symptoms that can occur from smoking cessation. I guess you can view the cigarette as the same, having nicotine to prevent the withdrawal symptoms, so there are similarities. But I should also make sure that the subcommittee understands that there are differences.

Certainly these products have the therapeutic claim that is attached to them.

Mr. SYNAR. I would like to go back to one chart that you used in your presentation. I think it is this one right here where you show examples of the highest, middle, and lowest 100's and the percentage of nicotine in each one of those products.

Mr. KESSLER. It is an example of three different varieties from one brand family. Our lab ran those numbers. We actually had several labs run those numbers; depending on how many hours of the extraction, you can get somewhat different numbers, but they are all in the same proportion. And all the numbers we have seen have the lowest-yield product having the highest concentration of nicotine. And that surprised me, Congressman.

Mr. SYNAR. That surprised me, too, because it flies in the face of industry statements that they don't put in different levels of nicotine with respect to different levels of cigarettes within a chain.

Mr. KESSLER. This is concentration.

Mr. SYNAR. I understand that.

What disturbs me even more is if one takes that chart and crosstabs it with the type of advertising for those various products, one 
would be led to believe by the industry that the smoking of the lower tar and nicotine cigarettes is safer.

And yet, this chart flies in the face of that, that you may, indeed, be subject to even more nicotine in a low-tar cigarette that has been advertised as being safer.

Mr. KESSLER. The lowest-tar cigarettes usually have less tobacco in them. The absolute amount of nicotine, the nicotine may be the same in the highest, medium or low, but the concentration is highest in the lowest tar cigarette so there is more nicotine proportionally in that tobacco versus in the highest brand.

But you raise a most important question, and that is, what is a consumer who wants to reduce levels supposed to do? Dr. Henningfield -in talking about this, he draws a analogy to food labeling and what does "lite" mean? And unfortunately, there is not a correlation between FTC yield numbers and what is actually absorbed in the body.

And if I could just have the FTC charts, the reason for thatit is not that the machine isn't working and it is not that the FTC is not doing and overseeing the tests correctly. They are. They are doing a good job.

The issue is that the humans don't smoke like the machines, the ones at the FTC.

Mr. SYNAR. The one that Mr. Bliley put up there.

Mr. KESSLER. There are a number of reasons why the low-yield cigarette really in many ways is a myth. One, the serving size; if you hold the analogy, the puff volume, is not the same. Smokers compensate.

There are also certain ways that the manufacturers can-under the manufacturer's control that can reduce the level below the rating for which the FTC rates cigarettes. For example, the placement of ventilation holes on the cigarette. I don't think most people even know that there are ventilation holes, and when you put the cigarette in the machine, the machine doesn't cover the ventilation holes.

But, in fact-I think there is a picture, Andrew, of the actual ventilation holes. The cigarette with the holes, if you can find it. The machine doesn't cover those holes. You can see the cigarette, and there is a magnification. This is one of the ways you get a lowyield cigarette it is not by reducing the nicotine in the tobacco rod necessarily.

One of the major advances, one of the technologies is to increase the air dilution. And these holes are one of the ways to increase, put more air into the smoke, thereby reducing the amount of active ingredients in the smoke. But the machine doesn't cover those holes.

Kozlowski in the early 1980's did a number of studies, and he found that between 30 and 60 percent of people cover those holes with either their lips or their fingers. And some don't even know that they are doing it; and when you cover those holes, you end up getting more of the nicotine that is in that tobacco rod.

Mr. SYNAR. So the physical building of the cigarette, which then can take advantage of the advertising that it is lower tar and nicotine, is defeated by the mere using of the fingers and the lips.

Mr. KESSLER. Let me show you another one. 
There is another way to get a lower FTC rating than smokers actually get.

Part of the filter paper-and Grunberg has done this work-extends out over the smoking rod. It is called the overwrap. There is actually tobacco under that overwrap. And the smoking machine, the instructions are to stop three millimeters before that overwrap. But smokers can smoke that tobacco.

If you are a cigarette manufacturer and you wanted to have a yield that was low, but still had enough tobacco in there for whatever reason, what would you do? That overwrap, as Grunberg has documented in the Surgeon General's reports, has increased.

The FTC described this as sort of a Type 2 error. It is not that there is anything wrong with the smoking machine; it is just that there is technology that has been advanced for whatever reason that undermines the usefulness of the machine measurements.

One other technology is to increase the burning rate, which decreases the number of puffs the machine takes. All those technologies basically mean that what you are getting in your body doesn't correlate, and Benowitz did very eloquent work in 1983 and subsequent years that shows what you are getting in your body doesn't correlate with the FTC yields; and I think there is room for improvement so that people who want information can get reliable information.

Mr. SYNAR. Thank you, Dr. Kessler.

Mr. WAXMAN. Mr. Wyden.

Mr. WyDEN. Thank you, Mr. Chairman.

And, Dr. Kessler, let me commend you, as my colleagues have done, for an excellent job. I suspect folks at home in Oregon are not following all the nuances of exogenous and endogenous and the like, but I want to tell you what is the bottom line for me and see if you agree with this proposition.

The bottom line to me is that it appears that nicotine is taken out during the production process and then deliberately put back in later on. And when it is deliberately put back in, it, in effect, hooks the American public and hooks the smokers of our country. Would you agree with that?

Mr. KESSLER. You can hook someone, Congressman, just by taking 10 different tobacco blends and adjusting the levels. There is no difference whether it is reconstituted, or tobacco extract, or you are mixing the blends. In the end, the issue is how are those levels being controlled? You can increase levels, you can decrease levels many different ways.

What concerns us is that the levels of nicotine in cigarettes is in excess of what is necessary to create and sustain an addiction. It is irrelevant to our analysis how the nicotine-whether it is the reconstituted tobacco, or whether it is the blend, the issue is how is that level set and why is that level set in such a way that it is in excess of what is necessary to addict-to sustain and support an addiction?

Mr. WYDEN. In today's Washington Post, Steven Parrish, the Vice President of Philip Morris, makes the admission that Philip Morris is adding nicotine to cigarettes. Is this, on its face, an admission that cigarette manufacturers are in the drug business and therefore subject to regulation under the 1938 Act? 
Mr. Kessler. Congressman, I tried very hard not to deal with specific companies today, but to respond to this comment-

Mr. WYDEN. Let's set aside then Philip Morris, even though they said it in The Washington Post.

If a drug company admits that they are adding nicotine to cigarettes-this is what I am asking, in a hypothetical case-isn't that an admission that they are in the drug business and therefore subject to regulation under the 1938 Act?

Mr. KESSLER. I am sorry, if you can ask the question again.

Mr. WYDEN. If a drug company admits that they are adding nicotine to cigarettes is that an admission that they are in the drug business and therefore subject to regulation?

Mr. KESSLER. Andrew, if I could get the definition of drug, this is what it comes down to. There are three parts of the definition of drug. One has to do the formularies; that is not at issue here. The relevant two sections-something is a drug either of two ways, for all practical purposes: an article intended for use in the diagnosis, cure, mitigation, treatment, or prevention of disease. Does that apply to nicotine in cigarettes?

It certainly is possible to argue addiction is a disease. And then the question is, is the article intended for the mitigation of a disease?

But I think the harder question for the Agency to deal with is the third definition. And that is-something can be a drug if it is an article other than food intended to affect the structure or function of the body.

So is a psychoactive effect affecting the structure and function of the body? Is an addictive effect from the psychoactive effect affecting the structure and function the body? Again, it is that word "intended" that the Agency pays a lot of attention to.

Mr. WYDEN. If it looks like a drug and acts like a drug, it sounds to me like a drug. And I think that is essentially what you have spelled out for us today.

Now Philip Morris is quoted in the papers this morning as saying that no powerful extract containing nicotine is added in its manufacturing process. Can you tell us again in a generic way, apart from any company, what kinds of powerful tobacco extracts are added in the manufacturing process?

Mr. KESSLER. Congressman, I had an option and I declined that option; I had an option to sign a confidentiality agreement and to see what substances are actually in cigarettes, to see the list. I declined to exercise that option. I did not want to be bound by information that I could not share with the American public.

Mr. WYDEN. Well, you know, this industry says that it has got nothing to hide. Why don't we just change the law and make that ingredient list that I held up public? Wouldn't that be in the public interest?

Mr. Kessler. Congressman, I think that is for the Congress obviously to decide.

Mr. WYDEN. What would be your personal opinion?

Mr. KESSLER. I worked very hard. I spent 3 years of my life trying to let people know what is in food, to give them the whole story. I think we have to be careful, though. Nothing is more dan- 
gerous than what is occurring naturally that I know about in cigarettes.

Yes, I understand the focus on any additives, but I can't think of any substances more dangerous than what is occurring there naturally.

I think you also, Congressman, need to look, and I think one of the questions that requires evaluation is, what about manipulation of natural ingredients? Because in the end, natural ingredients could be - certainly in cigarettes there are very few things that are more toxic.

Mr. WYDEN. You make a good point. What I am concerned about is this pattern of secrecy and pattern of nondisclosure, and I am going to push to make this list public.

Over the years, the tobacco industry has spent substantial sums, millions, to fund research to dispute the kinds of health risk claims that you are making today. Are you aware of research done by the tobacco industry that disputes your claims, and what is your opinion of the quality of tobacco industry research, again in a general sort of way?

Mr. KESSLER. Congressman, I referred to the chairman about two studies that were undertaken that were not published. Dr. Henningfield, who saw the paper that indicated that nicotine is a positive reinforcer, thought-I don't want to speak for you, Jack. Our understanding is that those papers were accepted by a prestigious, independent journal. They were never published, unfortunately. It is very hard to comment broadly.

There is-Andrew, do you have the chart on the myths about tobacco? There are some myths, Congressman. And I just think, again, everyone needs to understand that these are myths.

One, tobacco is not dangerous; two, nicotine is not addictive; three, people who smoke low-nicotine cigarettes get less nicotine than people who smoke high-nicotine cigarettes. That a cigarette is natural tobacco rolled in a paper sleeve. Smokers know what they are smoking. Those are myths about tobacco. I can go on, but you can read the list.

Mr. WYDEN. Let me just wrap up with some questions that were asked in the press recently that I think really summarize it for me.

You have said that nicotine has been deliberately added to tobacco products; have you not?

Mr. KESSLER. Congressman Bliley has talked about tobacco extract. He has talked about other processes. The issue before us is the significance of whatever tobacco is in there. I don't think anyone is disputing the fact that tobacco extract is used. We have seen it sold. Tobacco extract has nicotine, and it is being used.

Mr. WYDEN. Let me finish just with this, then.

So nicotine is being deliberately added, and it is being added, in your opinion, at levels that are known to be addictive; isn't that correct?

Mr. KESSLER. The issue for the Agency is the control and manipulation of the nicotine level. I think that needs to be reiterated and reiterated, over and over again. The issue is whether the levels of nicotine -ither added from tobacco extract or other means, or naturally-are being manipulated to sustain an addiction. That level that we see in cigarettes is in excess of the addictive level. 
Mr. WydEN. Thank you, Mr. Chairman.

Mr. WAXMAN. Thank you, Mr. Wyden. I am going to follow up on that and take a second round.

It is obvious that the level is being controlled and manipulated. If we know that nicotine can be removed from tobacco completely, if we know it can be removed and it is not being removed and we know that the tobacco industry, or at least one company, did a study that told them that nicotine was the addictive quality in their product, if there is no reason for nicotine other than for addiction, then all this manipulation is to addict people to smoking.

People are being manipulated. I don't see that there is any other conclusion that we could reach.

Isn't that true, Dr. Kessler, at that point?

Mr. KESSLER. Why is nicotine at levels that are addictive in cigarettes? That is the question that needs to be answered.

Mr. WAXMAN. And I want to commend you on your testimony. This is really very powerful testimony. I think it is historic. Never in this country have we understood what was going on with the tobacco industry, and we are only getting a little whiff of it, so to speak, a little bit that we are seeing from your testimony.

We know the tobacco companies have tobacco that has nicotine in it. We have always thought that. But the tobacco companies can exogenously, endogenously manipulate and play with those levels. They spray it on.

Mr. KESSLER. Andrew, do you have the reference cigarettes over the last number of years, over a period of time? You think that it is just tobacco leaves in a cigarette. These are just four examples, and they are done as reference cigarettes. And you can see that you can achieve, you have a lot of different tools to achieve whatever level of nicotine you want.

There is lamina, there is stem, there is puff, there is reconstituted. There are different types of tobacco. You can set nicotine levels with great care.

Mr. WAXMAN. So they can do this-let me ask you about some of these points, because those patents are really astounding. You indicated they can change the blend. You indicated that they can take nicotine and spray it on later.

Mr. KESSLER. Patents shows that they can do that, yes.

Mr. WAXMAN. The patents show that they can do something with the filter; isn't that correct? They can add nicotine to the filter itself?

Mr. KESSLER. Andrew, do you have the chart of the patent on the filter? I was a little surprised to see patents that actually had as their purpose to add nicotine to other parts of the cigarette. Why would you want to add nicotine to the filter? Why would you want to add nicotine to the wrapper? I think it raises questions.

Again, Mr. Chairman, it is very important that we be careful. These are patents. And I cannot sit here today and tell you which patents are

Mr. WAXMan. The point is, you can't tell us whether they use these patents, but it shows that the industry has carefully looked for ways of playing around with the nicotine levels in their products and they have even added it potentially through the filter paper itself. 
No one could argue that there is a natural occurrence of nicotine in the paper, they may say that for the tobacco.

They can spray it on. They can add it to the filter paper, they can enhance the contents with a liquid. They can take an extract. This, to me, is absolutely astounding.

Mr. Kessler. Again, I just need to be careful that these are patents. I want to underscore that.

Mr. WAXMAN. It shows the capability. But it shows that they were interested in developing that capability.

You have indicated that there is a company that you know of that did studies in the 1980's that must have led them to understand that nicotine is addicting.

Mr. KESSLER. Self-reinforcing in rats.

Mr. WAXMAN. Self-reinforcing in rats is the way that we decide whether a substance is addicting. If they knew that nicotine was addicting and they could add and play with the nicotine levels, they knew that they could get people hooked on tobacco.

You are going to give us that information about the name of the company, and unless you can give me a reason not to reveal that publicly, I plan to make that public because I think we ought to know a company that may well be telling us they never knew about tobacco nicotine being addicting. I would like to have their response as to whether they knew it or not, based on the fact they funded a study and then suppressed that very study.

Mr. Kessler. Again, we will give you the facts that we have, and you can assess them and do any investigation.

Mr. WAXMAN. Thank you Dr. Kessler.

Mr. Bliley.

Mr. BLILEY. Dr. Kessler, it may be well known that denatured alcohol, number 4, SD-4 trade name, and certain tobacco flavors used during the manufacturing process contain minuscule quantities of nicotine. However, the total contribution of nicotine from these two sources is so small that it cannot be detected in the tobacco by standard laboratory methods and has no effect whatsoever on the nicotine delivery as determined by the Federal Trade Commission.

Let's first examine the effect of alcohol. Alcohol is used as a solvent and carrier for flavors in the cigarette industry as well as in the food and beverage industry. The denatured alcohol used is specifically denatured alcohol number 4 , which is specifically approved by the Bureau of Alcohol, Tobacco and Firearms under the Federal regulation 27 CFR section 21.38 .

The alcohol is denatured with small amounts of nicotine sulphate for the sole purpose to render it undrinkable. The graph shows the relative quantity of nicotine indirectly added to tobacco from the use of SD-4 alcohol. In processed tobacco, there are approximately 15,000 parts per million of nicotine. The contribution from alcohol is on the order of two parts per million; two parts per million of nicotine is too small to be measured in the final product.

Dr. Kessler, does FDA consider the use of denatured alcohol to be adding nicotine to the final cigarette? Is your suggestion that manufacturers may be spiking their cigarettes based on the use of denatured alcohol? 
Mr. KESSLER. I have never said that, Congressman. I have never used the word "spiking." I have never even talked about denatured alcohol.

Mr. Bliley. Then how did you arrive at your statement to the smoking people on February the 25th that the manufacturers may be spiking their cigarettes?

Mr. KESSLER. First of all, I didn't use the word "spiking," Congressman, and I would be happy to go through my testimony again, but it was rather lengthy.

Mr. BLILEY. All right, I will go through it, too; and if I find it, I will be back in touch with you.

When you were-at the invitation of Philip Morris, when you sent your people down to their plant in Richmond, did they observe anybody adding nicotine to the cigarettes?

Mr. KESSLER. Mr. Chairman, if you would like me to talk about one company, I would be happy to do that, but I am trying to stay away from talking specifically about individual companies. Philip Morris was very kind. They allowed us in for a courtesy visit. Our people sat and talked and learned a lot about the tobacco industry. I would be happy to share that with you. But again I am not prepared to do that today.

We have taken certain samples, we have learned certain things and talked to certain people. I think it is very important before we reach any conclusions to the questions that we raise today, we need not to just talk to any one company. We need to know what is going on in the industry across the board.

Mr. BlileY. Thank you, Mr. Chairman.

Mr. WAXMan. Thank you, Mr. Bliley.

Mr. Synar.

Mr. SYNAR. I might remind all of those that are listening, who think that we are beating up on the industry, that the chairman of this subcommittee invited both Philip Morris and R.J. Reynolds to be with us; and as the chairman pointed out, they chose not to do so, which speaks volumes about their interest and sincerity in the issue.

Dr. Kessler, you said on the very last page of your testimony, and I think it is a very important statement, "in these issues we seek guidance from Congress."

Let's summarize, if we can, really what this debate has come down to. You really have two options if you determine nicotine is a drug. You will have to ban the product unless it can be shown that it can be applied safely and effectively in curing some type of disease, or you will be able to regulate it; is that correct?

Mr. KESSLER. The tools are limited. Yes.

Mr. SYNAR. And so what you need from us is some guidance on what we think is appropriate for this product?

Mr. KESSLER. We have asked for that guidance, Congressman.

Mr. SYNAR. Many of us who have been engaged in this issue, Mr. Waxman and Mr. Durbin and Mr. Wyden and I have said that banning this product would be cruel and unusual punishment to the 50 million smokers in this country, to tobacco users, because the evidence-unsurmountable evidence now, is that they are addicted to a very serious drug. That is why we have favored the legislation 
that Mr. Waxman and I, and Mr. Wyden and Mr. Durbin have been involved in.

Could I get your opinion on that legislation and whether or not you favor the basic principles that are behind it? Do you favor listing ingredients and chemical additives on the product of tobacco?

Mr. Kessler. Congressman, I apologize for this, but as you know, the Food and Drug Administration, our job is to deal with the questions within our jurisdiction. Commenting on legislation is not something that I do as an Agency head. That is left, obviously, to the Secretary. So I apologize; I am not trying to not be as forthcoming. I am just not able to comment on any specific legislation.

Mr. SYNAR. Let me ask you this, then. Clearly if you do find nicotine to be a drug, it is probably, based upon the evidence that you presented today and other evidence that is available, going to be impossible to prove that it can be consumed safely. We know that the mere consumption of two cigarettes a day increases the chance of heart disease and cancer by 50 percent.

We have favored an approach for the FDA that would not define it as a drug or food product, but create a new, unique status. Is that a way to accomplish the goal of avoiding a ban, but getting the type of regulatory authority that we need in order to protect the public?

Mr. KESSLER. We understand the enormous social consequences that could attach to a decision to exert jurisdiction. And it is because of those enormous social consequences that we are seeking guidance.

There are those at the Agency, I must tell you, Congressman, that have a hard time believing that an Agency that is charged with making sure that there are safe and effective products on the market would ever find nicotine-containing cigarettes for anyone to establish that they are safe and effective. Maybe that could happen. Maybe there are levels below which the nicotine is not addictive and there can be an argument made.

But you are right. There are enormous social consequences. And that is why we are here today to seek your guidance.

Mr. SYNAR. Thank you, Mr. Chairman.

Mr. WAXMaN. Thank you, Mr. Synar.

Mr. Wyden.

Mr. WYDEN. Thank you, Mr. Chairman.

Dr. Kessler, just one other area I am interested in, and that is this matter of clear direction from the Congress. You have said, for example, and I quote, "Should the Agency make this finding based on an appropriate record or be able to prove these facts in court, it would have a legal basis to regulate these products."

Now, is that something you are going to go ahead with anyway? Or does Congress have to pass a law and say, Dr. Kessler, this is a drug, have at it?

Mr. KESSLER. Congressman, my job is to enforce the statute and the statute has the FDA making the decision of whether to exert jurisdiction. Let me be clear though that I think there are a lot of questions. I have shown you some data.

There are many issues that we don't fully understand. Philip Morris was very kind to allow us in for a day and a half, but there are many companies and there are still a lot of questions that need 
to be answered. A lot more fact-finding. I hear Congressman Bliley using words like spiking-there is a lot more information that this Agency needs to understand and a lot more data.

Once we have that data, we need to assess. Also, I don't think we have the answers yet on what the public health consequences would be of reducing or eliminating nicotine. We need to understand that issue. If the Agency were hypothetically to exert jurisdiction, how should nicotine be regulated? What is the right way?

If you lower the dose of nicotine just a little, people may end up smoking more cigarettes. If you lower it below addictive levels, maybe no one will smoke. So the question becomes how should nicotine be regulated, and I don't think that we have thought through that or the public health community or the regulators or the Congress. I think we need to do work in that area.

Mr. WYDEN. My only point here is that I think it is a mistake for the Food, Drug and Cosmetic Act to be silent on this issue. I would rather see us pass a Synar bill and say regulate. If we can't get that passed, I hope you will go forward and try to build a record, play out the facts to show that this is a drug, and let me commend you on a first-rate job.

I think this is a hearing that the country is going to look back on in the next century and say this is a hearing that made a difference for our kids and grandkids and I commend you for it.

Mr. WAXMAN. I want to thank you as well. I want to close this part of our hearing today by playing the following statement out for maybe later witnesses to cornment.

What you have told us very clearly without any controversy is that nicotine is addicting, it is the reason people continue to smoke. When kids get started, they get hooked. We have over 400,000 people die each year from smoking tobacco. This nicotine addiction is something we now know that at least one tobacco company knew about, and I believe they all knew about it. They carefully regulate the amount of nicotine in this cigarette product, and it seems that the major reason this manipulation of nicotine takes place is to assure there is enough there to addict people.

I can't understand why we allow cigarettes with nicotine at all if it doesn't add to the flavor, and it only adds to the addiction of it. You may or may not have the legal authority to insist that nicotine be removed.

We certainly have the legal authority to impose that on the industry, and I would like to know from them why they would insist on having nicotine in their product at any level if it only serves the purpose of addicting people to that product.

I wish the tobacco company executives were here so we could ask them directly. I would like to know from the Philip Morris Company that filed a lawsuit yesterday charging that $A B C$ television should pay them $\$ 10$ million in damages because they reported the fact that nicotine is manipulated in tobacco.

I would like to know from Philip Morris, and I wish the head of Philip Morris had accepted our invitation, why they allow any levels of nicotine whatsoever, and I want to hear from other witnesses today what they have to say about this issue because it seems to me that is one of the core questions that is before us. You have 
given us incredibly powerful testimony, and I very much appreciate your being here.

Mr. KESSLER. Thank you, Mr. Chairman.

[Testimony resumes on p. 138.]

[The prepared statement and supplemental charts of Dr. Kessler follow:] 


\section{statement on Nicotine-Containing Cigarettes}

by

\section{David A. Kessier, M.D. Commissioner of Food and Drugs}

Mr. Chairman, the cigarette industry has attempted to frame the debate on smoking as the right of each American to choose. The question we must ask is whether smokers really have that choice.

Consider these facts:

- Two-thirds of aduits who smoke say they wish they could quit ${ }^{2}$.

- Seventeen million try to quit each year, but fewer than one out of ten succeed ${ }^{2}$. For every smoker who quits, nine try and fail.

- Three out of four adult smokers say that they are addicted $^{3}$. By some estimates, as many as 74 to 90 percent are addicted ${ }^{4}$.

- Eight out of ten smokers say they wish they had never started smoking ${ }^{5}$.

Accumulating evidence suggests that cigarette manufacturers may intend this result -- that they may be controlling smokers' choice by controlling the levels of nicotine in their products in a manner that creates and sustains an addiction in the vast majority of smokers.

That is the issue I am here to address. Whether it is a choice by cigarette companies to maintain addictive levels of nicotine in their cigarettes, rather than a choice by consumers to continue smoking, that in the end is driving the demand for cigarettes in this country.

Although FDA has long recognized that the nicotine in 
tobacco produces drug-like effects, we never stepped in to regulate most tobacco products as drugs. One of the obstacles has been a legal one. A product is subject to regulation as a drug based primarily on its intended use. Generally, there must be an intent that the product be used either in relation to a disease or to affect the structure or function of the body. With certain exceptions ${ }^{6}$, we have not had sufficient evidence of such intent with regard to nicotine in tobacco products. Most people assume that the nicotine in cigarettes is present solely because it is a natural and unavoidable component of tobacco.

Mr. Chairman, we now have cause to reconsider this historical view. The question now before us all is whether nicotine-containing cigarettes should be regulated as drugs. We seek guidance from the congress on the public health and social issues that arise once the question is posed. This question arises today because of an accumulation of information in recent months and years. In my testimony today, I will describe some of that information.

The first body of information concerns the highly addictive nature of nicotine. The second body of information I will be talking about -- in some detail -- concerns the apparent ability of cigarette companies to control nicotine levels in cigarettes. We have information strongly suggesting that the amount of nicotine in a cigarette is there by design. Cigarette companies must answer the question: what is the real intent of this design? 
I. NICOTINE IS A HIGHLY ADDICTIVE SUBSTANCE

Let me turn then to my first point about the addictive nature of nicotine.

The nicotine delivered by tobacco products is highly addictive. This was carefully documented in the 1988 surgeon General's report. You can find nicotine's addictive properties described in numerous scientific papers?

As with any addictive substance, some people can break their addiction to nicotine. But I doubt there is a person in this room who hasn't either gone to great pains to quit smoking, or watched a friend or relative struggle to extricate himself or herself from a dependence on cigarettes.

Remarkably, we see the grip of nicotine even among patients for whom the dangers of smoking could not be starker. After surgery for lung cancer, almost half of smokers resume smokinga. Among smokers who suffer a heart attack, 38 percent resume smoking while they are still in the hospital ${ }^{9}$. Even when a smoker has his or her larynx removed, 40 percent try smoking again:?

When a smoker sleeps, blood levels of nicotine decrease significantly. But the smoker doesn't need to be an expert on the concept of nicotine blood levels to know full well what that means. More than one-third of smokers reach for their first cigarette within 10 minutes of awakening ${ }^{11}$ nearly two-thirds smoke within the first half houri2. Experts in the field tell us that smoking the first cigarette of the day within 30 minutes 
of waking is a meaningful measure of addiction ${ }^{13}$.

I am struck especially by the statistics about our young people. A majority of adult smokers begin smoking as teenagers ${ }^{14}$. Unfortunately, 70 percent of young people ages 1218 who smoke say that they believe that they are already dependent on cigarettes ${ }^{15}$. About 40 percent of high school seniors who smoke regularly have tried to quit and failed ${ }^{16}$.

It is fair to argue that the decision to start smoking may be a matter of choice. But once they have started smoking regularly, most smokers are in effect deprived of the choice to stop smoking. Recall one of the statistics I recited earlier. Seventeen million Americans try to quit smoking each year. But more than $15,000,000$ individuals are unable to exercise that choice because they cannot break their addiction to cigarettes. My concern is that the choice that they are making at a young age quickly becomes little or no choice at all and will be very difficult to undo for the rest of their lives.

Mr. Chairman, nicotine is recognized as an addictive substance by such major medical organizations as the office of U.S. Surgeon General, the World Health Organization ${ }^{17}$, the American Medical Association ${ }^{18}$, the American Psychiatric Association ${ }^{19}$, the American Psychological Association ${ }^{20}$, the American Society of Addiction Medicine ${ }^{21}$, and the Medical Research Council in the United Kingdom ${ }^{22}$. All of these organizations acknowledge tobacco use as a form of drug dependence or addiction with severe adverse health consequences. 
Definitions of an addictive substance may vary slightly, but they all embody some key criteria: first, compulsive use, often despite knowing the substance is harmful; second, a psychoactive effect -- that is, a direct chemical effect in the brain; third, what researchers call reinforcing behavior that conditions continued use ${ }^{27}$. (Chart A) In addition, withdrawal symptoms occur with many drugs and occur in many cigarette smokers who try to quit. These are hallmarks of an addictive substance and nicotine meets them all.

When a smoker inhales, once absorbed in the bloodstream, nicotine is carried to the brain in only 7-9 seconds ${ }^{23}$, setting off a biological chain reaction that is critical in establishing and reinforcing addiction.

Over the past few years, scientists have generated a tremendous amount of information on the similarities among different addictive substances. Some crucial information has come from the fact that, in a laboratory setting, animals will self-administer addictive substances. This self-administration may involve the animal pushing a lever or engaging in other actions to get repeated doses of the addictive substance. With very few exceptions, animals will self-administer those drugs that are considered highly addictive in humans, including morphine and cocaine, and will not self-administer those drugs that are not considered addictive ${ }^{24},{ }^{25}$.

Understanding that animals will self-administer addictive substances has fundamentally changed the way that scientists view 
addiction in humans ${ }^{24}$. It has turned attention away from the concept of an "addictive personality" to a realization that addictive drugs share common chemical effects in the brain ${ }^{24}$.

Despite the wide chemical diversity among different addictive substances, a property that most of them share is the ability to affect the regulation of a chemical called dopamine in parts of the brain that are important to emotion and motivation ${ }^{26}$. It is now believed that it is the effect of addictive substances on dopamine that is responsible for driving animals to self-administer these substances and for causing humans to develop addictions ${ }^{24}$.

Regulation of dopamine, rewards the activity, and causes the animal or person to repeat the activity that produced that reward 24,25 . The process by which the regulation of dopamine leads an animal or a human to repeat the behavior is known as "reinforcement ${ }^{24}$." Drugs that have the ability to directly modify dopamine levels can produce powerfully ingrained addictive behavior ${ }^{24}$."

One of the ways that researchers now test the addictive properties of drugs is to determine whether animals will selfadminister that substance and then to determine whether the animals will stop self-administering if the chemical action of the substance is blocked by the simultaneous administration of another drug that prevents the first substance from acting in the brain. Data gathered over the past 15 years have documented that laboratory animals will voluntarily self-administer nicotine ${ }^{25}$, 
${ }^{27}$; that nicotine does stimulate the release of dopamine ${ }^{28}$; and that laboratory animals will decrease self-administration of nicotine if the action of nicotine, or the release of dopamine, in the brain is blocked ${ }^{29},{ }^{30}$.

A number of top tobacco industry officials have stated that they do not believe that tobacco is addictive ${ }^{31}$. They may tell you that smokers smoke for "pleasure," not to satisfy a nicotine craving. Experts tell us that their patients report that only a small minority of the cigarettes they smoke in a day are highly pleasurable $e^{32}$. Experts believe that the remainder are smoked to primarily sustain nicotine blood levels and to avoid withdrawal symptoms ${ }^{32}$.

The industry couches nicotine's effects in euphemisms such as "satisfaction" or "impact" or "strength." Listen to what they say in one company's patent:

It also has been generally recognized that the smcker's perception of the "strength" of the cigarette is directly related to the amount of nicotine contained in the cigarette smoke during each puff $f^{33}$.

-patent no. 4,595,024 C1:33-36

But these terms only sidestep the fact that the companies are marketing a powerfully addictive agent. Despite the buzzwords used by industry, what smokers are addicted to is not "rich aroma" or "pleasure" or "satisfaction." What they are addicted to is nicotine, pure and simple, because of its psychoactive effects and its drug dependence qualities.

To smokers who know that they are addicted, to those who have buried a loved one who was addicted, it is simply no longer 
credible to deny the highly addictive nature of nicotine.

\section{CONTROLLING THE LEVEL OF NICOTINE IN CIGARETTES}

My second point today involves a growing body of information about the control of nicotine levels exercised by the tobacco industry. Mr. Chairman, I do not have all the facts or all the answers today. The picture is still incomplete. But from a number of pieces of information, from a number of sources, a picture of tobacco company practices is beginning to emerge.

The public thinks of cigarettes as simply blended tobacco rolled in paper. But they are much more than that. Some of today's cigarettes may, in fact, qualify as high technology nicotine delivery systems that deliver nicotine in precisely calculated quantities -- quantities that are more than sufficient to create and to sustain addiction in the vast majority of individuals who smoke regularly.

But you don't have to take it from me. Consider how people in the tobacco industry itself view cigarettes.

Just take a moment to look at the excerpts from an internal

memorandum written by a supervisor of research that circulated in the Philip Morris Company in 1972:

Think of the cigarette pack as a storage container for a day's supply of nicotine. . . Think of the cigarette as a dispenser for a dose unit of nicotine. . . . Think of a puff of smoke as the vehicle for nicotine. . . Smoke is beyond question the most optimized vehicle of nicotine and the cigarette the most optimized dispenser of smoke.

"Dispensers of smoke... which is a vehicle for delivering 
nicotine." This quote is a revealing self-portrait.

Or Iisten to the words in one tobacco company patent:

Medical research has established that nicotine is the active ingredient in tobacco. Small doses of nicotine provide the user with certain pleasurable effects resulting in the desire for additional doses ${ }^{34}$. -patent no. 4,676,259 C1:21-24

\section{The Design of Cigarettes}

How does this industry design cigarettes?

The history of the tobacco industry is a story of how a product that may at one time have been a simple agricultural commodity appears to have become a nicotine delivery system. Prior to the 1940's, the waste products from cigarettes -- the stems, the scraps, and the dust -- were discarded. The tobacco industry had identified no use for these materials in the cigarette manufacturing process.

Then, in the $1940 \mathrm{~s}$ and '50s, the industry created reconstituted tobacco from the previously unusable tobacco stems, scraps, and dust. This gave cigarette makers the ability to reduce the cost of producing cigarettes by using fewer tobacco leaves and making up the difference by using reconstituted tobacco. While the motive appeared to be purely economic, the reconstitution process was nevertheless a critical development that started the industry down the path toward controlling and manipulating nicotine levels. The ability to control and manipulate nicotine levels becomes important in light of another key realization. Industry patents show that the industry recognized that nicotine is the active ingredient in tobacco 
smoke. It is what produces the psychoactive effects that lead smokers to crave cigarettes.

Numerous patents illustrate how the industry has been working to sustain the psychoactive effects of nicotine in cigarettes. These charts show samples from several categories of patents: eight patents to increase nicotine content by adding nicotine to the tobacco rod (Chart B); five patents to increase nicotine content by adding nicotine to filters, wrappers and other parts of the cigarette (Chart C); three patents that use advanced technology to manipulate the levels of nicotine in tobacco (Chart D); eight patents on extraction of nicotine from tobacco (Chart E); and nine patents to develop new chemical variants of nicotine (Chart F).

patents not only describe a specific invention. They also speak to the industry's capabilities, to its research, and provide insight into what it may be attempting to achieve with its products.

It is prudent to keep in mind that patents do not necessarily tell us what processes are currently being used in manufacturing cigarettes. Nevertheless, the number and pattern of these patents leaves little doubt that the cigarette industry has developed enormously sophisticated methods for manipulating ricotine levels in cigarettes. Today, a cigarette company can add or subtract nicotine from tobacco. It can set nicotine levels. In many cigarettes today, the amount of nicotine present is a result of choice, not chance. 
Let me show you the language in some of these patents. This is in the industry's own words.

Listen to what industry says it wants to be able to do with nicotine.

First, the industry wants precise control of the amount of nicotine in cigarettes to provide desired physiological effects:

Maintaining the nicotine content at a sufficiently high level to provide the desired physiological activity, taste, and odor...can thus be seen to be a significant problem in the tobacco art ${ }^{35}$. -patent no. $3,280,823$ C1:43-48

Second, the industry wants to increase the amount of nicotine in some cigarettes.

...the perceived taste or strength of the cigarettes classified as having lower levels of "tar" and nicotine are progressively less than that of the cigarettes which are classified as approaching the characteristics of the "full flavor" cigarettes. It has been proposed to add nicotine and other flavorants to the cut filler of the lower "tar" cigarettes to enhance the taste, strength, and satisfaction of such cigarettes ${ }^{36}$. -patent no. 4,830,028 C1:40-47

This invention...concerns the problem of maintaining or increasing the nicotine content of the smoke whilst avoiding an undesirable level of particulate matter in the smoke ${ }^{37} \ldots$.

-patent no. 3,861,400 Cl:1-10

Now listen to what the industry says it can do, right now, at least for patent purposes, with the nicotine in cigarettes:

It can precisely manipulate nicotine levels in cigarettes:

This invention permits the release into tobacco smoke, in controlled amounts, of desirable flavorants, as well as the release, in controlled amounts and when desired, of nicotine into tobacco smoke ${ }^{38}$. 
-patent no. $3,280,823 \quad$ C2:37-40

It is another object of the invention to provide an agent for the treatment of tobacco smoke whereby nicotine is easily released thereinto in controlled amounts ${ }^{39}$.

-patent no. $3,584,630$ C2:69-71

[I]t can be seen that the process...enables the manipulation of the nicotine content of tobacco material, such as cut leaf and reconstituted leaf, by removal of nicotine from a suitable nicotine tobacco source or by the addition of nicotine to a low nicotine tobacco material ${ }^{40}$.

-patent no. 4,215,706 C3:6_-66

...processed tobaccos can be manufactured under conditions suitable to provide products having various nicotine level $\mathrm{s}^{41}$.

-patent no. 5,031,646 C5:63-65

Examples of suitable tobacco materials

include...processed tobacco materials such as

expanded tobaccos, processed tobacco stems, reconstituted tobacco materials or reconstituted tobacco materials having varying levels of endogenous and exogenous nicotine ${ }^{42} \ldots$. -patent no. 5,031,646 C5:21-27

...the present invention... is particularly useful for the maintenance of the proper amount of nicotine in tobacco smoke.

...previous efforts have been made to add nicotine to tobacco products wherein the nicotine level in the tobacco was undesirably $10 w^{43}$.

-patent no. $3,584,630$ C2:5-15

It can precisely manipulate the rate at which the nicotine is delivered in the cigarette:

It is a further object of this invention to provide a cigarette which delivers a larger amount of nicotine in the first few puffs of the cigarette than in the last few puffs ${ }^{44}$. -patent no. $4,595,024$ C2:23-26 

will:

It can transfer nicotine from one material to another at

Moreover, the process is useful for transferring naturally occurring nicotine from tobacco having a generally high nicotine content to a nicotine deficient tobacco, tobacco filler materials, or RL (reconstituted leaf) which are used in the production of cigarettes and other smoking products... [A] low nicotine tobacco... can also be used as the nicotine donor ${ }^{45}$... -patent no. 4,215,706 C1:40-48

It is another object of this invention to provide a process for the migration of nicotine from one tobacco substrate (leaf material or reconstituted leaf) to a second tobacco substrate (leaf material, reconstituted leaf material or tobacco stems) or to a non-tobacco substrate ${ }^{46}$. -patent no. 5,018,540 C2:39-43

It can increase the amount of nicotine in cigarettes:

If desired, nicotine can be incorporated into the expansion solvents used to provide a volume expanded processed tobacco material having a high nicotine content ${ }^{4}$. -patent no. 5,031,646 C5:65-68

The present invention provides a nicotine-enhanced smoking device with a high nicotine release efficiency.... Thus, the smoker is provided with more nicotine from the nicotine-enhanced device than from a similar smoking device which does not contain the nicotine solution or from a comparable cigarette $e^{48}$.

-patent no. $4,676,259$ C2:30-33, 53-56

The present invention is concerned with the application of additives, such as...

physiologically active agents such as nicotine components to the smoking rod, in order to improve or help to improve the satisfaction provided to the smoker ${ }^{49}$.

$$
\text { -patent no. } 4,236,532 \mathrm{Cl}: 35-40
$$

It can add nicotine to any part of the cigarette:

The salts [nicotine levulinate] can be incorporated into the smoking article in a variety of places or sites. For example, the salt can be applied to the filler material, 


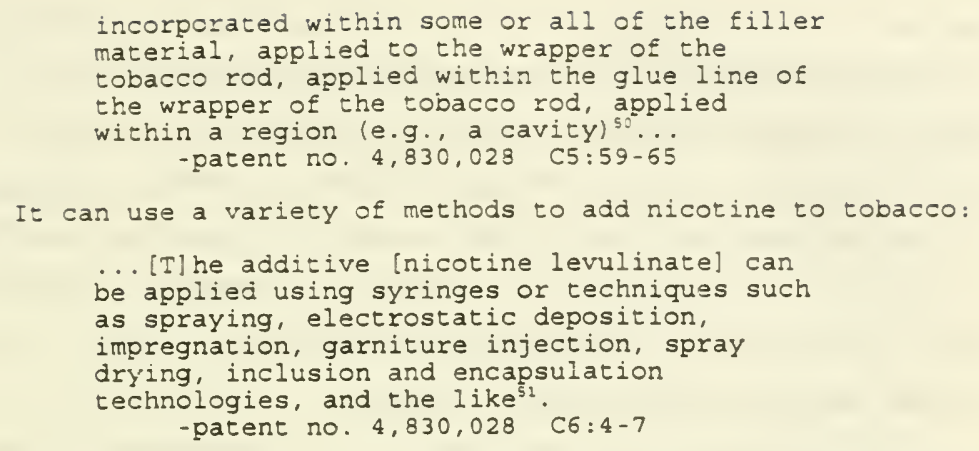

Let me describe in some detail how some of the technologies can be used to increase or control the nicotine level of tobacco.

The industry had to tackle a new problem beginning in the 1960 s as public concern about the health consequences of smoking intensified. The industry began to market cigarettes it described as low yield. It faced a major challenge, however, because in the words of patent no. $4,830,028$, "the perceived taste or strength of the cigarettes classified as having lower levels of 'tar' and nicotine are progressively less than that of the cigarettes which are classified as approaching the characteristics of the "full flavor" cigarettes."

The patent then describes a way to add nicotine to the "low yield" cigarettes. If nicotine alone is sprayed on a blend of tobacco, the patent states that the smoke that results will be unacceptably harsh or irritating to the user. So, instead of just spraying nicotine on the tobacco blend, the patent combines nicotine with another compound, an organic acid called levulinic acid, to form a salt that masks the irritating qualities of 
nicotine. (Chart $G$ and $H$ ) The patent demonstrates that different percentages of the nicotine salt can be added to blends of tobacco to produce different nicotine concentrations. The control cigarette, the one without any added nicotine, contains 1.66 percent nicotine. Adding one percent nicotine salt results in a cigarette with 2.05 percent nicotine. As one increases the amount of nicotine salt sprayed on the tobacco blend, the nicotine content of the tobacco increases.

In this process, great care is paid to the $\mathrm{pH}$ of the smoke because $\mathrm{pH}$ affects the bioavailability of nicotine - that is, how much the body absorbs. The patent demonstrates the technology to increase nicotine content in tobacco by up to 76 percent.

U.S. paient no. 5, 065,775 (Chart I) describes another technology that can control the nicotine content of tobacco filler. This involves a process for "modifying the alkaloid content of a tobacco material and, in particular, for providing a processed tobacco material having a controlled nicotine content." (C2:57-60) In the words of the patent "[t]he process of the present invention provides a skilled artisan with an efficient and effective method for changing the character of a tobacco material le.g., rearranging components of a tobacco material or altering the chemical nature or composition of a tobacco material) in a controlled manner. That is, the process...can be employed in a way such that changes in the chemical composition of tobacco can be monitored as to occur to a desired degree." 
$(C 3: 55-63)$

The patent allows for the removal of selected substances from tobacco, and incorporating controlled amounts of substances into tobacco. Example 4 within this patent shows how a tobacco blend that starts off with a 2.3 percent nicotine content can end up with a 5.2 percent nicotine content. A highly concentrated nicotine solution is created by subjecting a tobacco blend to a series of chemical steps, including adding water, removing solids, increasing the $\mathrm{pH}$, and mixing this substance with chlorofluorocarbon (CFC) 11 and then evaporating off that CFC 11. This concentrate is then added to water-washed tobacco to increase its nicotine content. This patent demonstrates the technology to increase the nicotine content in tobacco by more than 100 percent.

A third example of sophisticated technology involves the direct transfer of nicotine from one type of tobacco to another type of tobacco. (Chart J) U.S. patent no. 4,898,188 utilizes supercritical fluid extraction. In example 2 in the patent, liquid carbon dioxide is used to transfer nicotine from Burley cut tobacco filler to flue-cured cut tobacco. The flue-cured cut filler starts off with a nicotine content of 2.59 percent and ends up with a nicotine content of 4.83 percent. The Burley cut filler starts off with a nicotine content of 3.56 percent and ends with a nicotine content of 0.88 pezcent. This patent demonstrates that nicotine can be transferred in significant amounts from one type of tobacco filler to another. 
Additional information about the ability to set nicotine content at varying levels comes from the following ad, headlined "More Nicotine or Less," which appeared in an international tobacco trade publication: (Chart $K$ )

\begin{abstract}
Nicotine levels are becoming a growing concern to the designers of modern cigarettes, particularly those with lower "tar" deliveries. The Kimberly-Clark tobacco reconstitution process used by LTR INDUSTRIES permits adjustments of nicotine to your exact requirements. These adjustments will not affect the other important properties of customized reconstituted tobacco produced at LTR Industries: low tar delivery, high filling power, high yield, and the flexibility to convey organoleptic modifications. We can help you control your tobacco.
\end{abstract}

In fact the process described in this advertisement can raise the level of nicotine beyond what is naturally found in tobacco materials, especially the stems and scraps. A 1985 tobacco journal article describing the LTR process states

Though standard reconstituted tobacco products contain 0.7 1.0 percent nicotine, LTR Industries offers the possibility of increasing the nicotine content of the final sheet to a maximum of 3.5 percent...

A dramatic increase in tobacco taste and smoke body is noted in the nicotine-fortified reconstituted tobacco ${ }^{52}$.

All of this apparent technology for manipulating nicotine in tobacco products raises the question of how the industry determines how much nicotine should be in various products. More importantly, since the technology apparently exists to reduce nicotine in cigarettes to insignificant levels, ${ }^{53}, 54$ why, one is led to ask, does the industry keep nicotine in cigarettes at all? 
The tobacco industry would like you to believe that all it is doing is returning the nicotine that is removed during the process of producing reconstituted tobacco. It should be clear from what I have described thus far that the technology the industry may have available goes beyond such modest efforts.

The industry may also tell you that it is adjusting nicotine levels to be consistent with established "FTC yields" -- these are the amounts of tar, nicotine, and carbon monoxide that are measured for each cigarette product by smoking machines, and disclosed under a voluntary agreement with the Federal Trade Commission. In fact, the control of nicotine levels in cigarettes, dating back at least to patents granted in 1966 for adjusting nicotine levels, preceded the first rules adopted by the FTC on disclosing tar and nicotine yields. Moreover, there is nothing about the FTC yields that would require tobacco companies to increase nicotine in low tar cigarettes, as the industry patents suggest they do. There are no FTC restrictions on nicotine levels, and the FTC guidelines take into account crop variability by sampling completed cigarettes from 50 retail outlets across the country. Indeed, there is no FTC restriction that would prevent the industry from reducing nicotine below addicting levels or eliminating it altogether.

In fact, the technology reflected in the cigarette industry's patents appears to be intended to allow the industry to set the nicotine content of tobacco products at defined levels that have little to do with either the amount of nicotine that 
was removed during the processing of the tobacco, or with the simple goal of maintaining consistency with established FTC yields. The technology may exist to allow the industry to set nicotine levels wherever it want, or, in fact to remove nicotine entirely. With all the apparent advances in technology, why do the nicotine levels found in the vast majority of cigarettes remain at addictive levels?

Nicotine levels may be dictated in part by marketing strategies and demographics. A blatant example comes from information on the marketing of smokeless tobacco. There is evidence that smokeless tobacco products with lower amounts of nicotine are marketed as "starter" products for new users, and that advertising is used to encourage users to "graduate" to products with higher levels of nicotine. (Chart L) The evidence was developed in lawsuits brought against one manufacturer of smokeless tobacco.

The tobacco industry may tell you that nicotine is important in cigarettes solely for "flavor." There is a great deal of information that suggests otherwise. Some of the patents specifically distinguish nicotine from flavorants ${ }^{55}$. An RJR book on flavoring tobacco, while listing around a thousand flavorants, fails to list nicotine as a flavoring agent ${ }^{56}$. Even research scientists from the same company acknowledge that the nicotine in cigarettes provides pharmacological and psychological effects to smokers in addition to any mere sensory effects ${ }^{57}$.

Moreover, the available information shows that the industry 
has gone to significant lengths to develop technologies to mask the flavor of increased levels in cigarettes. As I have already noted, the industry's own patents reveal that increasing nicotine in fact usually produces an unacceptably harsh and irritating product, and that the industry has had to take special steps to mask the flavor of increased nicotine in low tar cigarettes.

This should not come as a surprise. The Merck Index, the authoritative encyclopedia of chemicals, describes nicotine as having "an acrid, burning taste." Webster's 7th New Collegiate Dictionary defines acrid as "sharp and harsh or unpleasantly pungent in taste or odor; irritating, corrosive." In fact, U.S. patent 4,620,554 uses the word "hazardous" to describe the taste of nicotine.

What appears to be true is that smokers become accustomed to, and associate, the sensory impact of nicotine (burning in the throat) with the resulting psychoactive effects of nicotine, and thus look for those sensory signals in a cigarette; this is called "conditioned reinforcement ${ }^{58}$."

Moreover, if nicotine is just another flavorant in tobacco, why not use a substitute ingredient with comparable flavor, but without the addictive potential? For example, it has been repeatedly shown that substitute ingredients, such as hot pepper (capsaicin) ${ }^{59}$ and citric acid ${ }^{60}$, have similar irritating sensory effects. 


\section{Similarities to the Pharmaceutical Industry}

Mr. Chairman, this kind of sophistication in setting levels of a physiologically active substance suggests that what we are seeing in the cigarette industry more and more resembles the actions of a pharmaceutical manufacturer. Besides controlling the amount of a physiologically active ingredient, there are a number of other similarities.

One similarity between the cigarette industry and the pharmaceutical industry is the focus on bicavailability. Bioavailability is the rate and extent that pharmacologically active substances get into the bloodstream. For example, the pH of tobacco smoke affects the bioavailability of nicotine ${ }^{61}$. The tobacco industry has conducted research on the $\mathrm{pH}$ of $\mathrm{smoke}^{62}$ and has undertaken to control the $\mathrm{pH}$ in tobacco smoke. In patent examples, chemicals have been added to tobacco to affect the $\mathrm{pH}$ of tobacco smoke ${ }^{63}$. The industry has even performed bioavailability and pharmacokinetic studies on conventional and novel cigarettes ${ }^{64}$.

The cigarette industry has undertaken research to look at the specific activity of added versus naturally occurring nicotine ${ }^{65}$. Additional research looked at the differences between spiking, spraying and blending compounds into cigarettes ${ }^{66}$.

Development of an "express" cigarette, a shorter, faster burning cigarette with the same amount of tar and nicotine, has been reported in the lay press recently. This is another example 
of how cigarette companies appear to be controlling the amounts of nicotine to deliver set levels ${ }^{67}$.

The cigarette industry has also undertaken a significant amount of research looking at the potential "beneficial" effects of nicotine. It has studied the effects of nicotine on anxiety, heart rate, electroencephalographs (EEG's), and behavioral performance tasks. Such research on the physiological effects of an active ingredient is a common part of pharmaceutical drug development ${ }^{68}, 69,70,71,72,73,74,75$.

Perhaps the most striking aspect of the research undertaken by the tobacco industry is its search for, and its patenting of, new nicotine-like chemicals that exhibit pharmacological properties which, in their own words, "are indicated for utility as potential psychotherapeutic agents ${ }^{76} . "$ One patent describes nicotine-like chemicals which

exhibit tranquilizing and muscle-relaxing properties when administered to mammals. The nicotine analogs do not exhibit nicotine-like properties, such as tachycardia, hypertension, gastrointestinal effects, emesis in dogs, and the like.

Example XXIX in the patent

illustrates the pharmacological properties of nicotine analogs....

The tranquilizing effects of invention nicotine compounds are measured after intraperitoneal (IP) and intraventricular (IVC) administration in the form of hydrochloride salts.

Sedation is determined by measuring locomotion in an open field maze, and the response to noxious (air blast) stimuli. Body tone is estimated by handling rats and by the ability to hang from a rotating rod.

Tranquilization after intraventricular (IVC injection) is estimated from muscle weakness in all four limbs, body tone and general activity ${ }^{77}$. 
Chart $M$ illustrates the results.

\section{The Problem of the Low-yield Cigarette}

We, at the Food and Drug Administration, are concerned not only about the control over nicotine levels exercised by the cigarette industry, we are also concerned that the problems associated with nicotine are aggravated by significant limitations in consumer's ability to reduce their exposure to nicotine by selecting "low" nicotine cigarettes.

Most people who smoke low yield or "light" cigarettes believe that they are getting less nicotine and tar by smoking these cigarettes. For the last 25 years the American public has relied on FTC ratings of tar and nicotine in advertising to tell them what they will be consuming. The "FTC method" utilizes a machine that tests cigarettes in a process involving a twosecond, 35 milliliter puff each minute until a predetermined butt length is reached ${ }^{78}$.

Most people don't realize that low yield cigarettes, as determined by the FTC method, do not usually result in proportionally less nicotine being absorbed when compared to high yield cigarettes ${ }^{79}$. Furthermore, there is little correlation between low yield FTC ratings and the total amount of nicotine in cigarettes ${ }^{80}$.

It is a myth that people who smoke low nicotine cigarettes are necessarily going to get less nicotine than people who smoke high nicotine cigarettes. There are several reasons for this. 
One reason is that there are differences between the smoking habits of a machine and a human. The way in which a cigarette is smoked is probably the most important determinant of how much tar and nicotine is inhaled. Humans can compensate - - and do compensate -- when smoking low yield cigarettes, by altering puff volume, puff duration, inhalation frequency, depth of inhalation, and the number of cigarettes smoked ${ }^{81},{ }^{82},{ }^{83},{ }^{84},{ }^{85},{ }^{86},{ }^{87}$. As a result of these compensatory mechanisms, a low yield cigarette can actually result in a relatively high intake of nicotine ${ }^{88}$.

Beyond the human compensatory mechanisms, several other factors under manufacturers' control contribute to a lowering of machine ratings. These factors include the positioning of ventilation holes, how fast the cigarette paper burns, and the length of the filter paper overwrap ${ }^{91}$.

To understand how the position of ventilation holes in a cigarette can confound the FTC ratings, it is important to recognize that the main determinants of whether a cigarette has a high or low yield in machine testing are the cigarette's ventilation and burning characteristics ${ }^{89}$. Most low yield cigarettes achieve their low ratings because of filter characteristics and also because the smoke is diluted with air. The air dilution is accomplished in part by placing ventilation holes in the filter. What scientists have demonstrated is that "although smoking machines which measure tar and nicotine do not occlude the perforations," 32-69 percent of low tar smokers have blocked the holes with their fingers or lips, resulting in larger 
nicotine yields ${ }^{30}$. The ventilation holes are sometimes laser generated and can be hard for the smoker to see. Not all smokers are aware of the existence of these holes or that the smoker may be blocking them. (Chart $\mathrm{N}$ )

Two other factors that are under manufacturers' control can also confound the usefulness of the FTC ratings. The FTC method smokes a cigarette down to within 3 millimeters of the tipping paper overwrap. According to one study, "between 1967 and 1978, 18 brands of filter cigarettes underwent increases in overwrap width that reduced the amount of tobacco smoked in the cigarettes on the machine, even though the remaining tobacco is still smokeable $e^{91}$ " (Chart 0) Another way that the FTC numbers can be confounded is by "increasing the rate at which cigarettes burn." A faster burning cigarette lowers the puff count. Manufacturers can increase the rate at which a cigarette burns by controling the porosity of the cigarette paper. The machine takes a puff every minute, but humans can adjust their smoking rate ${ }^{91}$.

Because of all these confounding factors we are concerned that consumers may assume that low yield cigarettes in fact deliver low tar and nicotine when in reality they do not.

\section{Actual Nicotine Levels in Cigarettes}

To assess the levels of nicotine in cigarettes, we did two things. First, FDA laboratories measured the amount of nicotine actually in several types of cigarettes. We analyzed three varieties of one brand family of cigarettes; one that is regular, 
one that is low tar, and one that is ultra low. What surprised us was that the variety advertised as having the lowest yield in fact had the highest concentration of nicotine in the cigarette. (Chart P)

Second, we formally requested from our colleagues at the Federal Trade Commission summary information derived from their data base on the levels of nicotine in cigarettes. What we found was that since 1982 (the earliest year for which the computer data base is available), the sales weighted levels of FTC nicotine in cigarettes appear to increase. (Charts Q, R, S, and $T$ ) What was equally striking was that when we segmented sales into high tar, low tar, and ultra low tar cigarettes, the nicotine/tar ratio was higher in the ultra low tar group. (Chart U) We would not have expected to see these differences because high tar has usually been associated with high nicotine, low tar has usually been associated with low nicotine. It has often been said that tar and nicotine travel together in the cigarette smoke. The disparities in the nicotine/tar ratios among these varieties raise the question as to how this can occur.

\section{FDA REGULATION OF NICOTINE IN CIGARETTES}

The next task facing the FDA is to determine whether nicotine-containing cigarettes are "drugs" within the meaning of the Federal Food, Drug, and cosmetic Act.

Our inquiry is necessarily shaped by the definition of "drug" in the Act. It is a definition that focuses on "vendor 
intent." More specifically, it focuses primarily on whether the vendor intends the product to, "affect the structure or any function of the body."

Mr. Chairman, the evidence we have presented today suggests that cigarette manufacturers may intend that most smokers buy cigarettes to satisfy their nicotine addiction.

We do not yet have all the evidence necessary to establish cigarette manufacturers' intent. It should be clear, however, that in determining intent what cigarette manufacturers say can be less important than what they do. The fact that the technology may be available to reduce the nicotine to less than addictive levels is relevant in determining manufacturer intent.

It is important to note that the possibility of FDA exerting jurisdiction over cigarettes raises many broader public health and social issues for Congress to contemplate. There is the possibility that regulation of the nicotine in cigarettes as drugs would result in the removal of nicotine-containing cigarettes from the market, limiting the amount of nicotine in cigarettes to levels that are not addictive, or otherwise restricting access to them, unless the industry could show that nicotine containing cigarettes are safe and effective. If nicotine were removed, the nation would face a host of issues involving the withdrawal from addiction that would be experienced by millions of Americans who smoke.

There is, of course, the issue of black market cigarettes. With nicotine, as with other powerfully addicting substances, a black market could develop.

In these issues, we seek guidance from Congress.

The one thing that I think is certain is that it is time for all of us -- for the FDA, for the Congress, for the American public -- to learn more about the way cigarettes are designed today and the results of the tobacco industry's own research on the addictive properties of nicotine.

Thank you. 
1. Thomas, R.M., Larsen M.D. Smoking Prevalence, Beliefs, and Activities by Gender and other Demographic Indicators. Princeton, NJ: The Gallup Organization, Inc., 1993.

2. MMWR. JulY 9, 1993.

3. Thomas R.M., Larsen M.D. Smoking Prevalence, Beliefs, and Activities by Gender and Other Demographic Indicators. Frinceton, NJ: The Gallup Organization, Inc., 1993.

4. Hughes et al. Prevalence of tobacco dependence and withdrawal. $1987 ; 205-208$.

5. Thomas R.M., Larsen, M.D. Smoking Prevalence, Beliefs, and Activities by Gender and other Demographic Indicators. Princeton, NJ: The Gallup Organization, Inc., 1993.

6. United States v. 46 Cartons... Fairfax Cigarettes, 113 F. Supp. 336 (D.N.J. 1953); United States v. 354 Bulk Cartons Trim Reducing-Aid Cigarettes, 178 F. Supp. 847 (D. N. J. 1959).

7. 1994 Surgeon General's Report. Nicotine Addiction in Adolescence. Health Consequences.

Benowitz M.D., N.L. Pharmacologic Aspects of Cigarette Smoking and Nicotine Addiction. NEJM 1988 No. 17:1318.

Benowitz M.D., N.I. Cigarette Sroking and Nicotine Addiction. Medical Clinics of North America. Vol.76:No. 2. March 1992.

Henningfield Ph.D., J.E., Nemeth-Coslett Ph.D., R. Nicotine Dependence: Interface between Tobacco and Tobacco-related Disease. Chest: Vol. 93.pp.37s-55S 1988.

U.S. Department of Health and Human Services. Drug Abuse and Drug Abuse Research: The Third Triennial Report to Congress from the Secretary, Department of Health and Human Services. 1991.

Schelling, T.C. Addictive Drugs: The Cigarette Experience. Science : Vol : 255 .

Jones, R.T., Tobacco Dependence. Psychopharmacology: The Third Generation of Progress. pg.1589. 1987.

8. Davison and Duffy. Smoking habits of long term survivors of surgery for lung cancer. Thorax 1982;37:331-333.

9. Bigelow et al. Smoking cessation and relapse among cardiac patients. Relapse and Recovery in Drug Abuse; NIDA Research Moncgraph 72 1986:167-171. 
10. West and Himbury. Smoking habits after laryngectomy. Br. Med Journal. 1985;291:514-515.

11. Gary Giovino. Report to FDA from CDC National Center for Health Statistics. National health interview survey. 1987.

12. Gary Giovino. Report to FDA from CDC National Center for Health Statistics. National health interview survey. 1987.

13. Gary Giovino. FDA interview with CDC. March 1994. Hughes et al. Prevalence of tobacco dependence and withdrawal. Am J Psychiatry. $1987 ; 205-208$.

14. U.S. Department of Health and Human Services, Public Health Service, Centers for Disease Control and Prevention, National Center for Chronic Disease Prevention and Health Promotion, office on Smoking and Health. Preventing Tobacco Use Among Young People: A Report of the Surgeon General. 1994;pg. 67.

15. U.S. Department of Health and Human Services. Preventing tobacco use among young people: A report of the surgeon General. 1994. pg. 95.

16. U.S. Department of Health and Human Srvices. Preventing Tobacco use Among Young People; A Report of the Surgeon General. 1994.

17. World Health organization. Smokeless tobacco control. Technical Report Series 773. 1988.

World Health Organization. Women and tobacco. 1992. pp.33-34.

18. American Medical Association. 1993 AMA Policy Compendium. $30.958 . \mathrm{pg} .35$.

19. American Psychiatric Association. Diagnostic and Statistical Manual of Mental Disorders. Third edition revised. 1987. pp. 150-51 and 181-82.

20. The American Psychological Association. Statement before the U.S. House of Representatives Committee on Energy and Commerce Subcommittee on Health and the Environment. July 29, 1988.

21. The Royal Society of Canada. Tobacco, Nicotine and Addiction. The Health Protection Branch Health and Welfare Canada. August $31,1989$.

22. Medical Research Council Field Review. The basis of drug dependence. January 1994 pp.1-13. 
23. Henningfield et al. Drug and alcohol dependence. 1993:23-29 citing Benowitz $\mathrm{N}$. National Institute of Drug Abuse Research Monograph pp.12-29.

24. Gardner, Eliot L. Brain Reward Mechanisms. Substance Abuse: A Comprehensive Textbook. Second Edition. William and Wilkens. 1992.

25. Yokel, Ra. Intravenous self-administration: Response rates, the effects of pharmacological challenges, and drug preference: Methods of Assessing the Reinforcing Properties of Abused Drugs. Spring-Verlag. 1987.

26. Dichiara, G. and Imperato, A. Drugs abused by humans preferentially increase synaptic dopamine concentrations in the mesolimbic system of freely moving rats. Proceedings of the National Academy of Sciences. Vol.85:July 1988:5274-78.

27. Department of Health and Human Services, Public Health Service. The Health Consequences of Smoking: Nicotine Addiction. A report of the Surgeon General. DHHS (CDC) 1988 . Publication no: $88-8406$.

28. Imperato, A., Mulas A., and DiChiara, G. Nicotine preferentially stimulates dopamine release in the limbic system of freely moving rats. European Journal of Pharmacology. $1986 ; 132: 337-338$.

29. Corrigall, WA., Franklin, KBJ., Coen, KM. and PBS Clarke. The mesolimbic dopaminergic system is implicated in the reinforcing effects of nicotine. Psychopharmacology. $1992 ; 107: 285-289$.

30. Corrigall, WA. and Coen, KM. Selective dopamine antagonists reduce nicotine self-administration. Psychopharmacology. $1991 ; 104: 171-176$.

31. Robinson JH. and Pritchard, WS. The role of nicotine in tobacco use. Psychopharmacology. 1992;108:397-407.

Rosenblatt, R. How do they live with themselves? New York Times Magazine. March 20, 1994.

32. Henningfield Ph.D., J.E., Schiffman Ph.D., S. Informal communications.

33. U.S. patent no. 4,595,024 C1:33-36.

34. U.S. patent no. 4,676,259 C1:21-24.

35. U.S. patent no. 3,280,823 C1:43-48. 
36. U.S. patent no. 4,830,028 C1:40-47.

37. U.S. patent no. 3,861,400 C1:1-10.

38. U.S. patent no. $3,280,823 \quad 22: 37-40$.

39. U.S. patent no. $3,584,630$ C2:69-71.

40. U.S. patent no. 4,215,706 C3:61-66.

41. U.S. patent no. 5,031,646 C5:63-65.

42. U.S. patent no. 5,031,646 C5:21-27.

43. U.S. patent no. $3,584,630 \mathrm{C2}: 5-15$.

44. U.S. patent no. 4,595,024 C2:23-26.

45. U.S. patent no. 4,215,706 C1:40-48.

46. U.S. patent no. 5,018,540 C2:39-43.

47. U.S. patent no. 5,031,646 C5:65-68.

48. U.S. patent no. 4,676,259 C2:30-33, 53-56.

49. U.S. patent no. 4,236,532 C1:35-40.

50. U.S. patent no. 4,830,028 C5:59-65.

51. U.S. patent no. 4,830,028 C6:4-7.

52. Silberstein, D.A. Flavouring reconstituted tobacco. Tobacco Journal International. 1985. Vol.1:26-29

53. Method of removing nicotine from tobacco using organic solvent. Philip Morris Incorporated. Patent number $3,046,997$. July 31,1962 .

54. Denicotinize tobacco by rapid drying of an alkaline aqueous dispersion of tobacco. Patent number 4,068,671. AMF Incorporated. January 17, 1978.

55. U.S. Patent No. 3,584,630. p. 1:57-58.

56. Leffingwell, J.C., Yound, H.J., Tobacco Flavoring for Smoking Products published by $R$ J Reynolds Tobacco Co. 1972.

57. Robinson J.H. and Pritchard, W.S. The role of nicotine in tobacco use. Psychopharmacology. 1992;108:405. 
58. Rose, J.E., Levin, E.D. Inter-relationships between conditioned and primary reinforcement in the maintenance of cigarette smoking. British Journal of Addiction. 1991;86:605609.

59. Blanc, P. et al. Cough in hot pepper workers. 1991 Chest. Vol. 99 January pg. 27.

60. Levin et al. Clinical Evaluation of a Citric Acid Inhaler for Smoking Cessation. Drug and Alcohol Dependence. 1993; 131-138.

61. Gori, Gio B., Benowitz, NL., and Lynch, CJ. Mouth versus deep airways absorption of nicotine in cigarette smoker. Pharmacology, Biochemistry \& Behavior. 1986. Vol.24:1181-1184.

62. Harris, J., and Hayes, L. A method for measuring the pH value of whole smoke. Tobacco Science. 1977. Vol. XXI.

63. U.S. patent no. 4,830,028. May 16, 1989.

64. R. J. Reynolds Tobacco Company. Chemical and Biological Studies: New Cigarette Prototypes that Heat instead of Burn Tobacco. 1988. pp. 455-557.

65. Jenkins, R.W., Comes, R.A. Exogenous vs endogenous transfer of nicotine during smoking. The International Journal of Applied Radiation and Physics. 1976. Vol. 27:323-324.

66. Jenkins, R.W., Bass, R.T., Newell, G.C., Jr., Segura, G., Newman, R.H. Recommendations for the standardized preparation of carbon-14 labeled cigarets. Tobacco $177(20): 35-38$.

67. Newsweek March 21, 1994. pp 52-53 and Sunday Times of London. September 19, 1993.

68. Gelbert DG, Robinson JH, Chamberlin CL, Speilberger CD. Effects of smoking/nicotine on anxiety, heart rate, and lateralization of EEG during a stressful movie. Psychophysiology. 1989;26(3):311-320.

69. Pritchard WS. Electroencephalographic effects of cigarette smoking. Psychopharmacology 1991;104:485-490.

70. Pritchard WS, Duke DW, Coburn KL, Robinson JH. Nonlinear dynamical electroencephalographic analysis applied to nicotine psychopharmacology and Alzheimer's disease. In Lippiello PM, Collins AC, Gray JA, Robinson JH, editors. The Biology of Nicotine. New York. Raven Press. 1992;195-214.

71. Pritchard WS, Duke DW. Modulation of EEG dimensional complexity by smoking. Journal of Psychophysiology $1992 ; 6(1): 1-10$. 
72. Pritchard WS, Robinson JH, Guy TD. Enhancement of continuous performance task reaction time by smoking in nondeprived smokers. Psychopharmacology. 1992;108:437-442.

73. Pritchard WS, Robinson JH. The meaning of addiction: reply to West. Psychopharmacology. 1992;108:411-416.

74. Robinson JH, Pritchard WS, Davis RA. Psychopharmacological effects of smoking a cigarette with typical "tar" and carbon monoxide yields but minimal nicotine. Psychopharmacology. $1992 ; 108: 466-472$.

75. Pritchard WS, Gilbert DG, Duke DW. Flexible effects of quantified cigarette-smoke delivery on EEG dimensional complexity. Psychopharmacology in press, 1993.

76. U.S. Patent no. 5,138,062 C4:41-48.

77. U.S. Patent no. 5,138,062 C18 1:11.

78. Pillsbury, C., Bright, K., O'Connor J., and Irish, F.W. Tobacco: Tar and nicotine in Cigarette Smoke. Journal of the Association of official Analytical Chemists. 1969:Vol. $52: 3: p p .458-462$.

79. Benowitz et al. Smokers of low yield cigarettes do not consume less nicotine. New England Journal of Medicine. 1983;309:139142 .

Benowitz NL and Jacob P. Daily intake of nicotine during cigarette smoking. Clin. Pharmacol. Ther. 1984;35:4:499-504.

80. Benowitz et al. Smokers of low yield cigarettes do not consume less nicotine. NEJM 1983;309:139-142.

81. Gust and Pickens. Does cigarette nicotine yield affect puff volume? Clin. Pharmacol. Ther. 1982;32:4:418-422.

82. Herning et al. Puff volume increase when low-nicotine cigarettes are smoked. Br. Med. J. 1981;283:187-189.

83. Sutton et al. Relationship between cigarette yield, puffing patterns, and smoke intake: evidence for tar compensation? British Med. J. 1982;285:600-603.

84. Wald et al. Relative intakes of tar, nicotine, and carbon monoxide from cigarettes of different yields. Thorax. $1984 ; 39: 361-364$.

85. Goldfarb et al. Reactions to cigarettes as a function of nicotine and tar. Clinical Pharmacology Ther. 1976;19:6:767772 . 
86. Maron and Fortman. Nicotine yield and measures of cigarette smoke exposure in a large population: Are lower-yield cigarettes safer? AJPH. 1987;77:546-549.

87. Stepney $R$. Consumption of Cigarettes of reduced tar and nicotine delivery. British Journal of Addiction. 1980;75:8188 .

88. Benowitz NL and Jacob P. Daily intake of nicotine during cigarette smoking. Clin. Pharmacol. Ther. 1984;35:4:499-504.

89. Benowitz et al. Smokers of low yield cigarettes do not consume less nicotine. NEJM. 1983;309:139-142.

90. Kozlowski et al. The misuse of "less-hazardous" cigarettes and its detection: Hole-blocking of ventilated filters. American journal of Public Health. 1980; Vol.70:11November:1202-03.

91. Grunberg, Neil E. et al., Changes in overwrap and butt length of American filter cigarettes. NY State $J$ of Med. July 1985:310-12. 


\section{Criteria for Drug Dependence}

Primary Criteria

- highly controlled or compulsive use

- psychoactive effects

- drug-reinforced behavior

\section{Additional Criteria}

Addictive behavior often involves:

- stereotypic patterns of use

- use despite harmful effects

- relapse following abstinence

- recurrent drug cravings

Dependence-producing drugs often produce:

- tolerance

- physical dependence

- pleasant (euphoric) effects

(Source: U.S. Surgeon General's Report, 1988) 


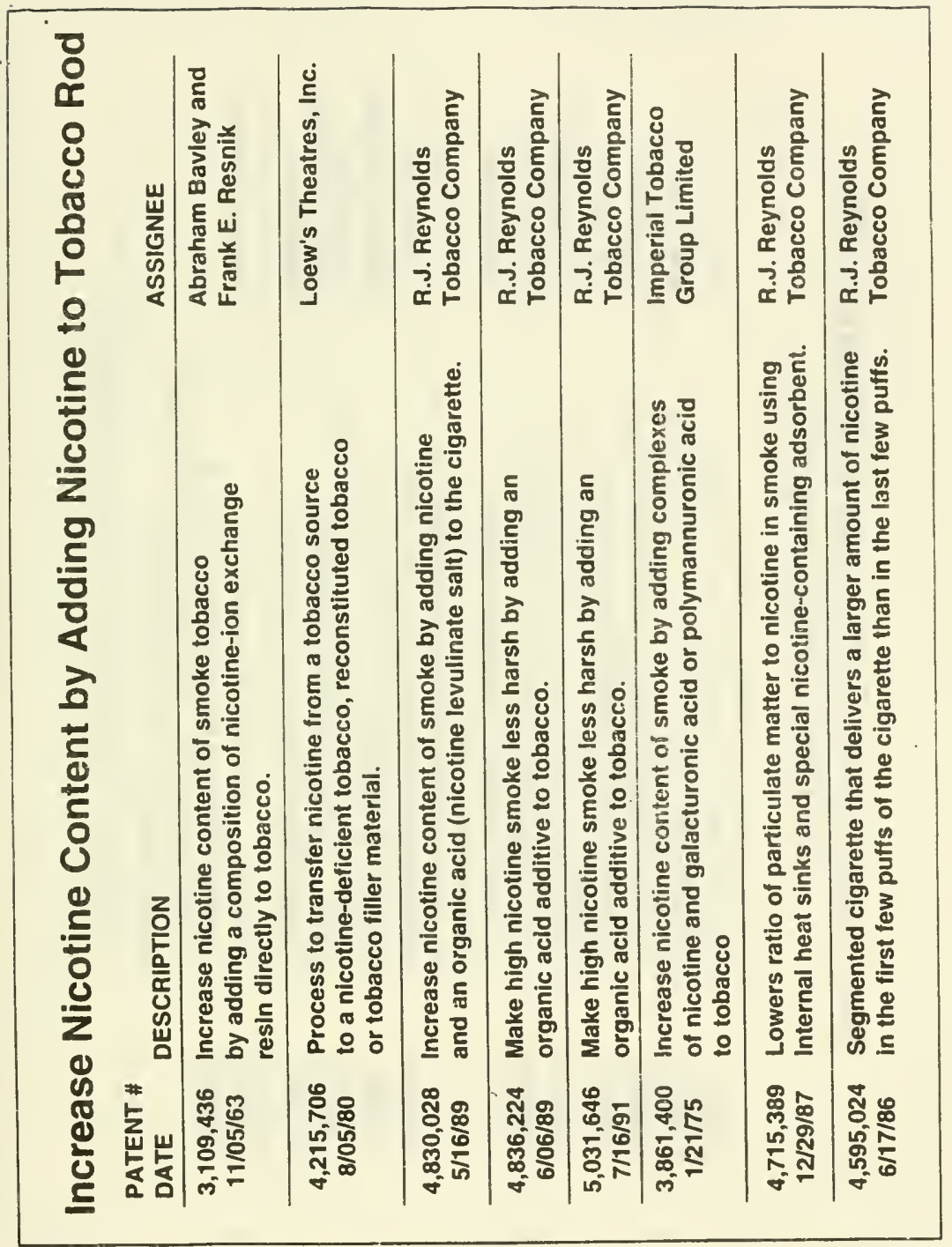

Chart B 


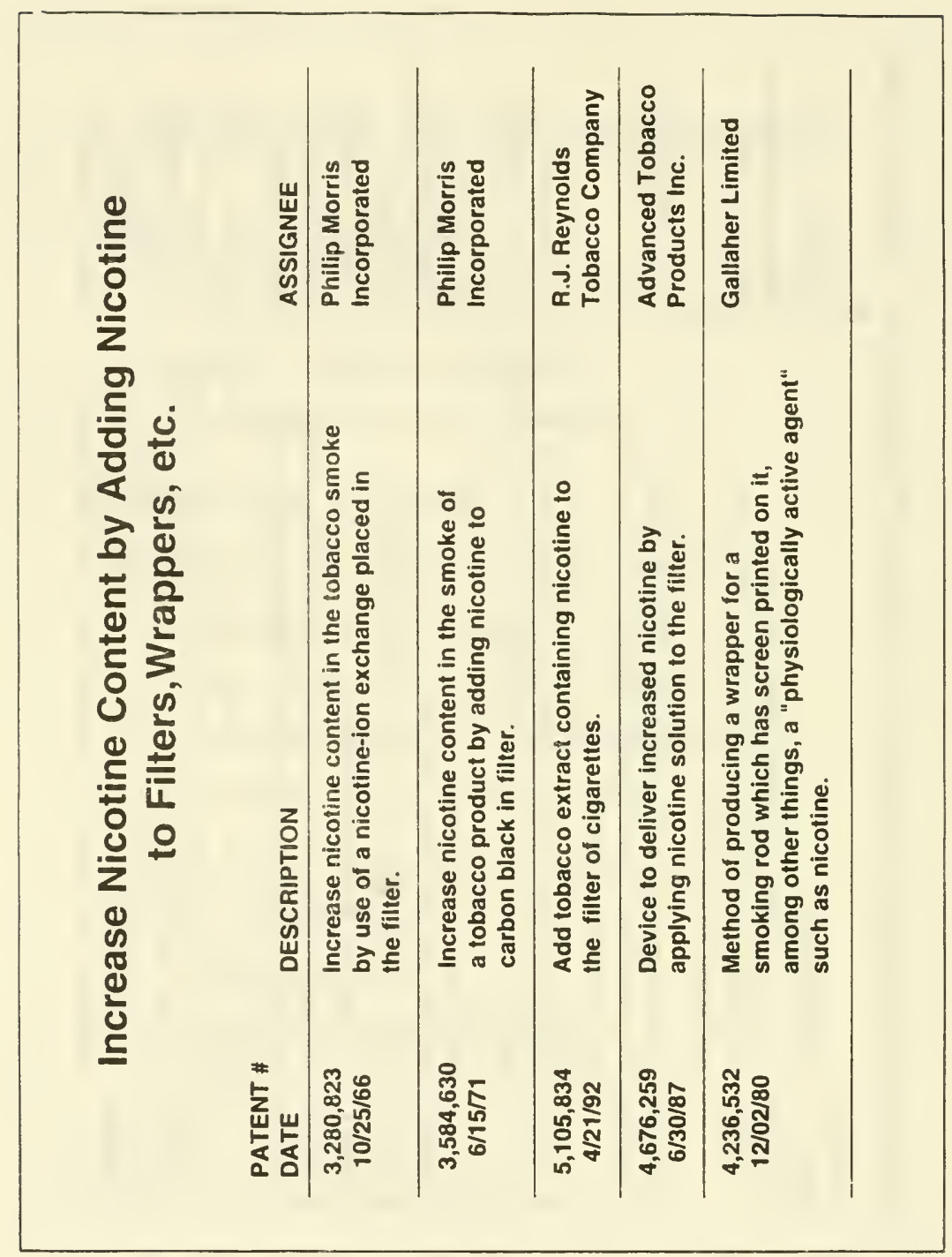




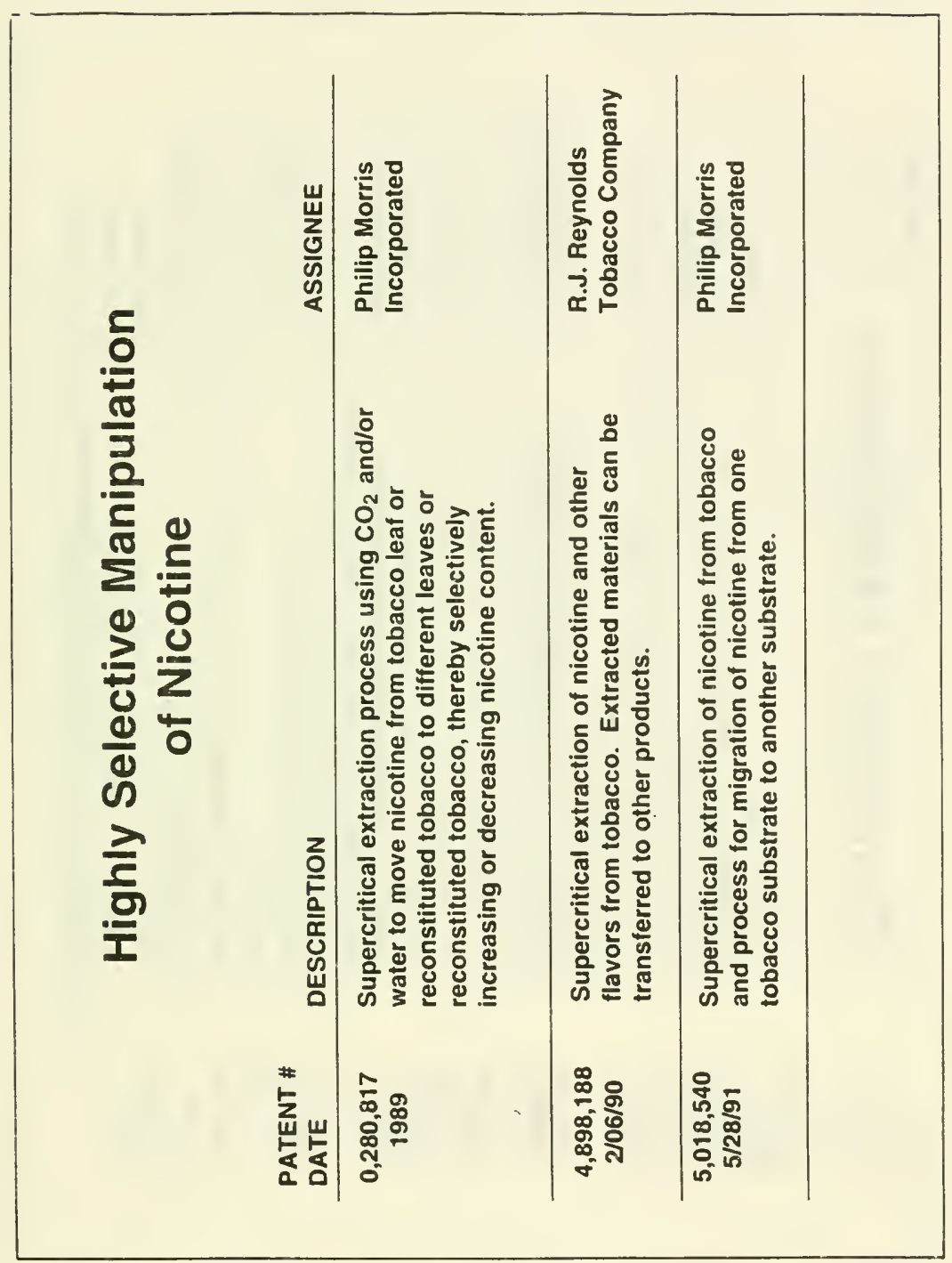

Chart D 


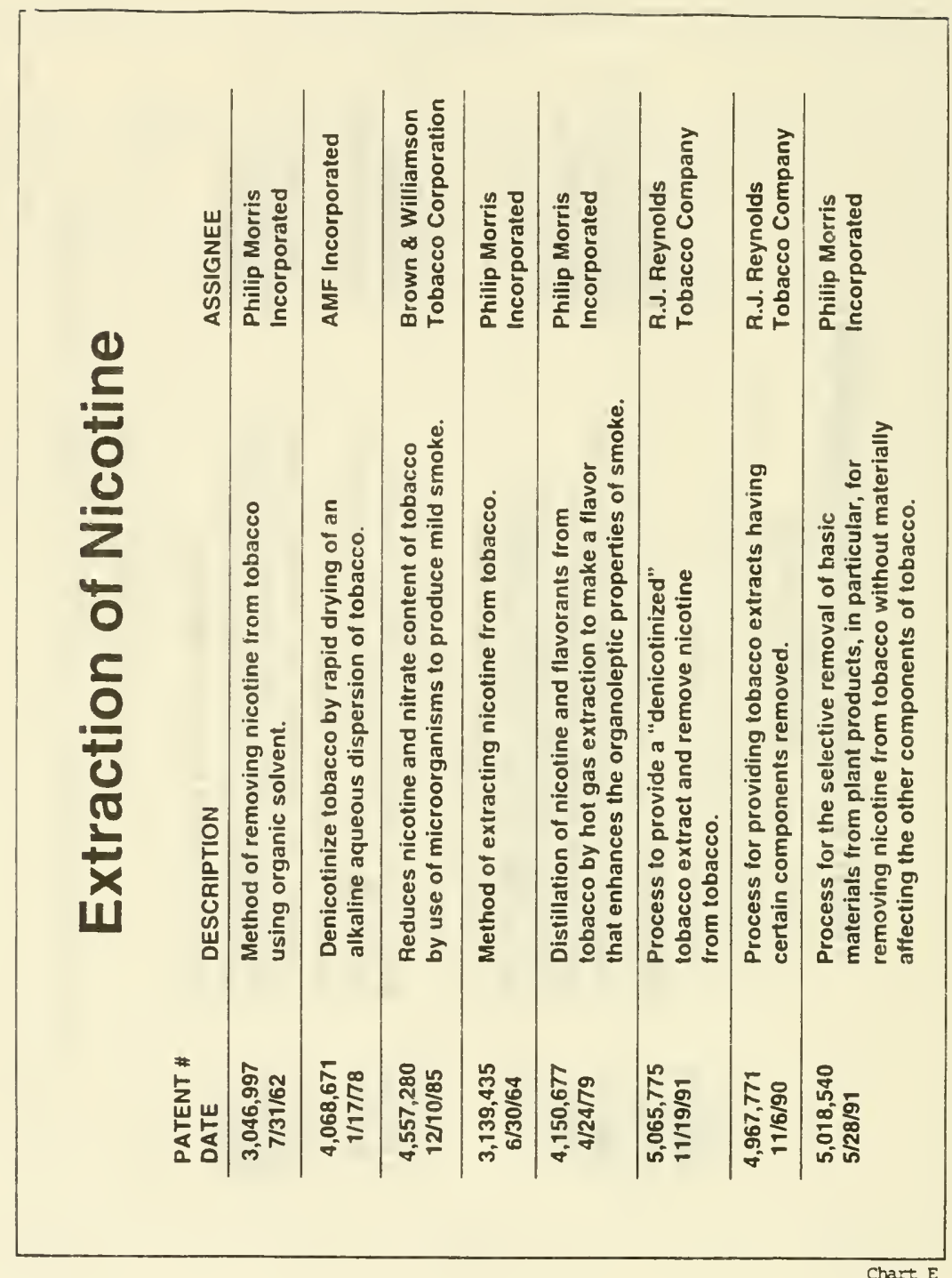




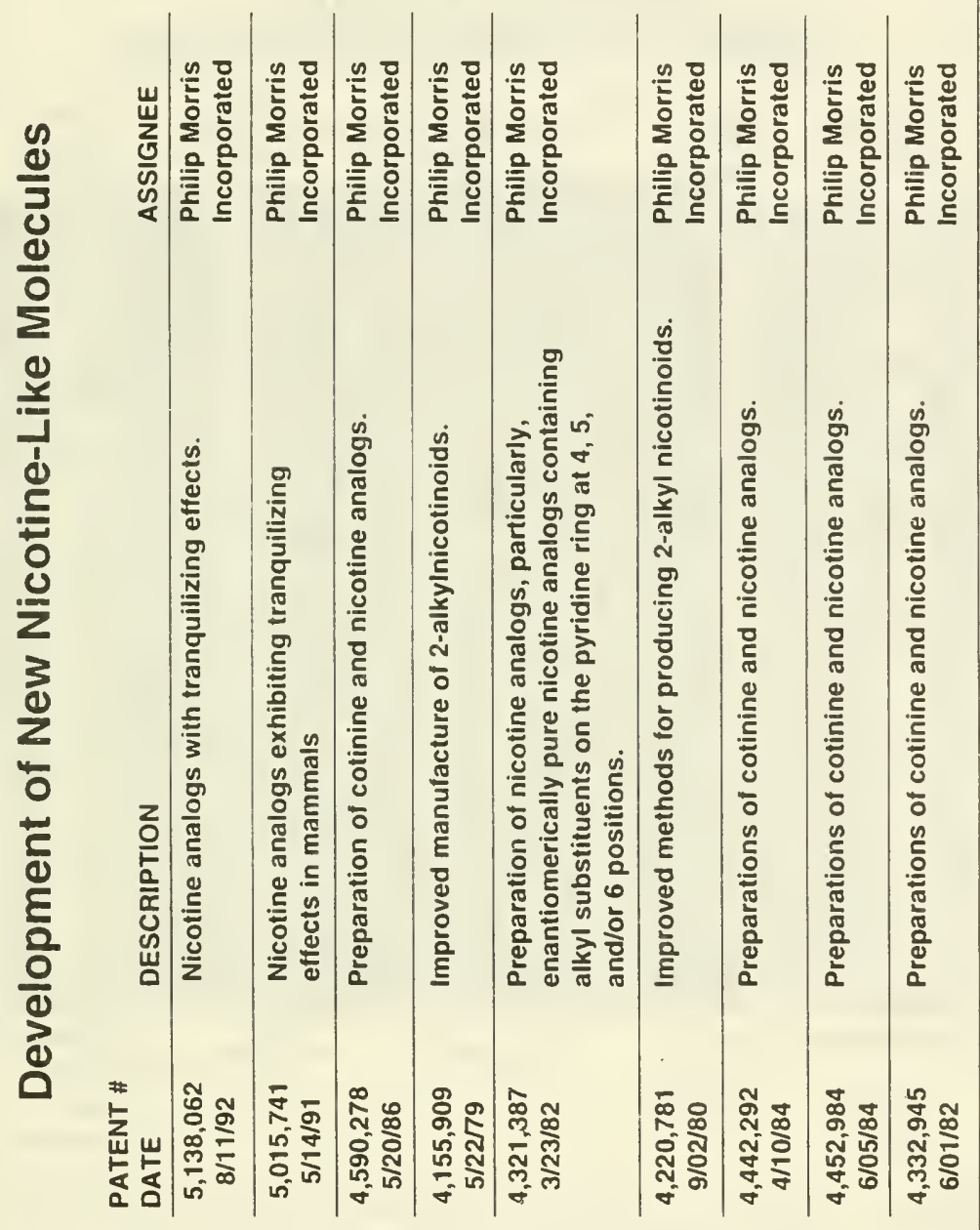




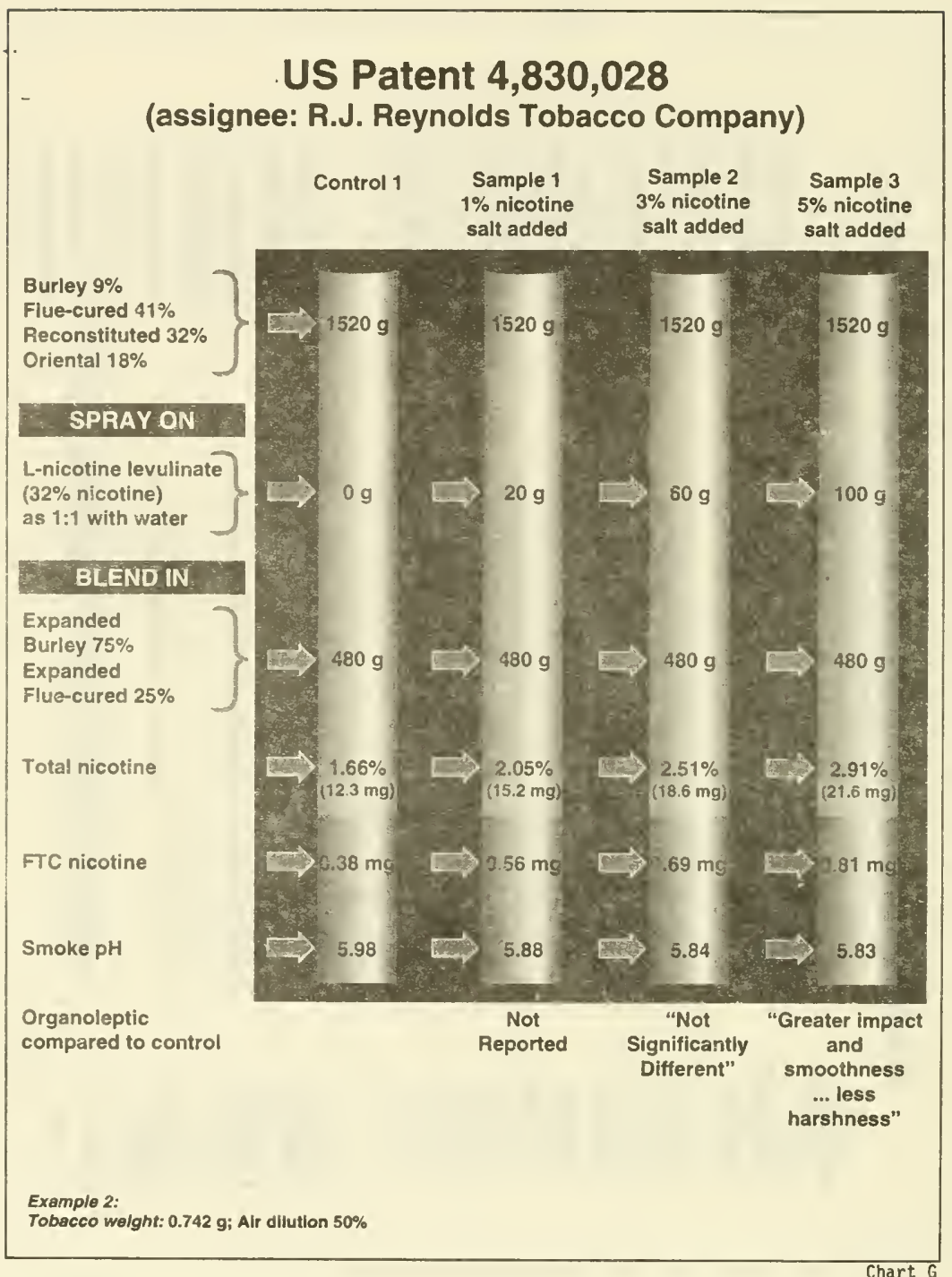




\section{US Patent 4,830,028 (assignee: R.J. Reynolds Tobacco Company)}

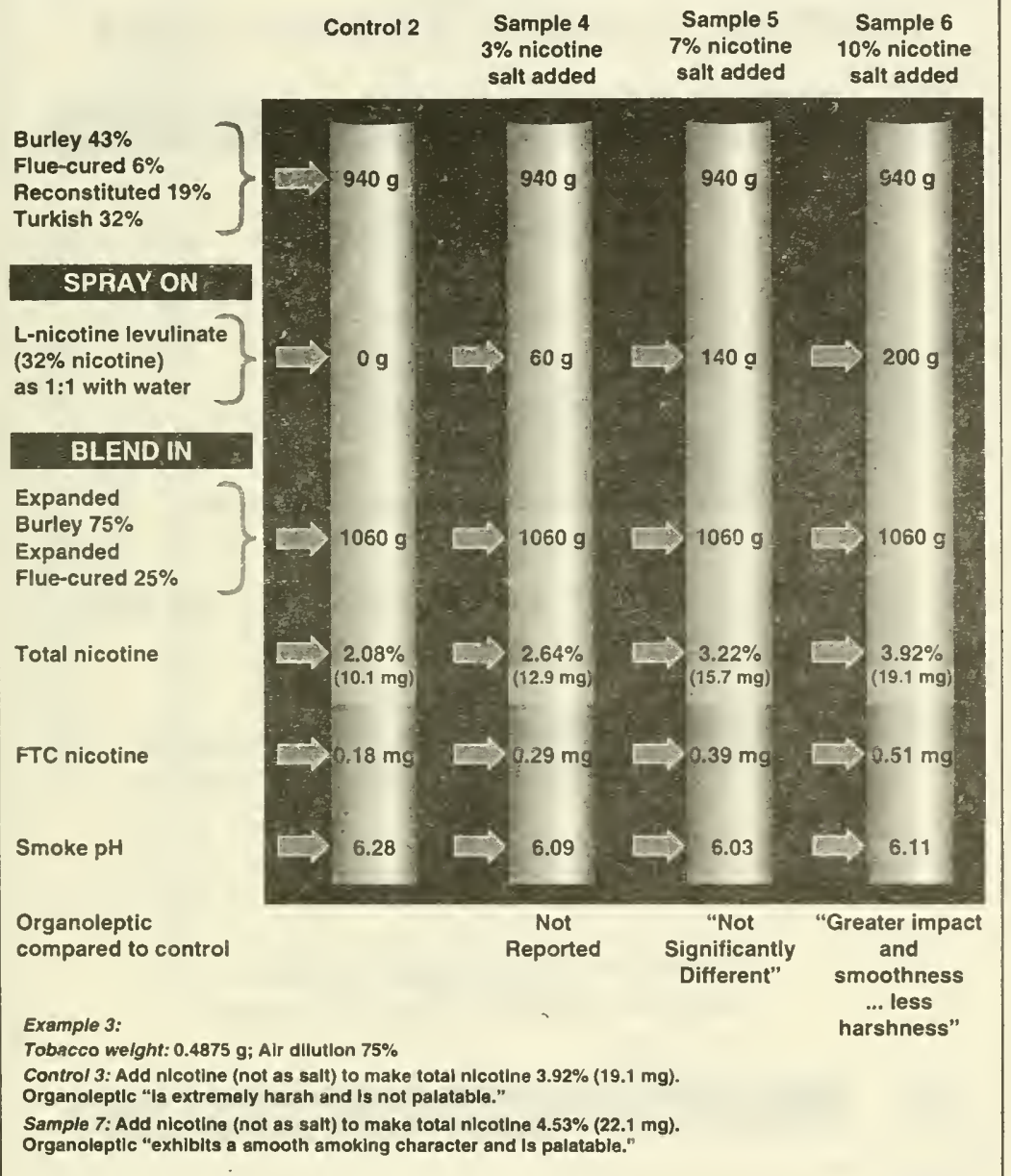




\section{U.S.Patent No. 5,065,775}

Example 4

\section{Increases nicotine in a tobacco blend}

\section{Start} with a:

\section{3\% Nicotine-Containing Tobacco Blend}

$\bullet$

Mix with water

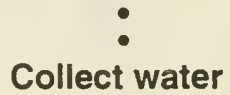

$:$

Adjust $\mathrm{pH}$ to 10

:

Mix with Chlorofluorohydrocarbon \#11

:

Evaporate Chlorofluorohydrocarbon \#11 and water

:

Results in:

1. a liquid containing about $60 \%$ nicotine

2. a solid containing about $.01 \%$ nicotine

Mix $1+2$ with water

:

Add to another batch of $2.3 \%$

nicotine-containing tobacco blend

End with a:

$5.2 \%$ Nicotine-Containing Tobacco Blend 


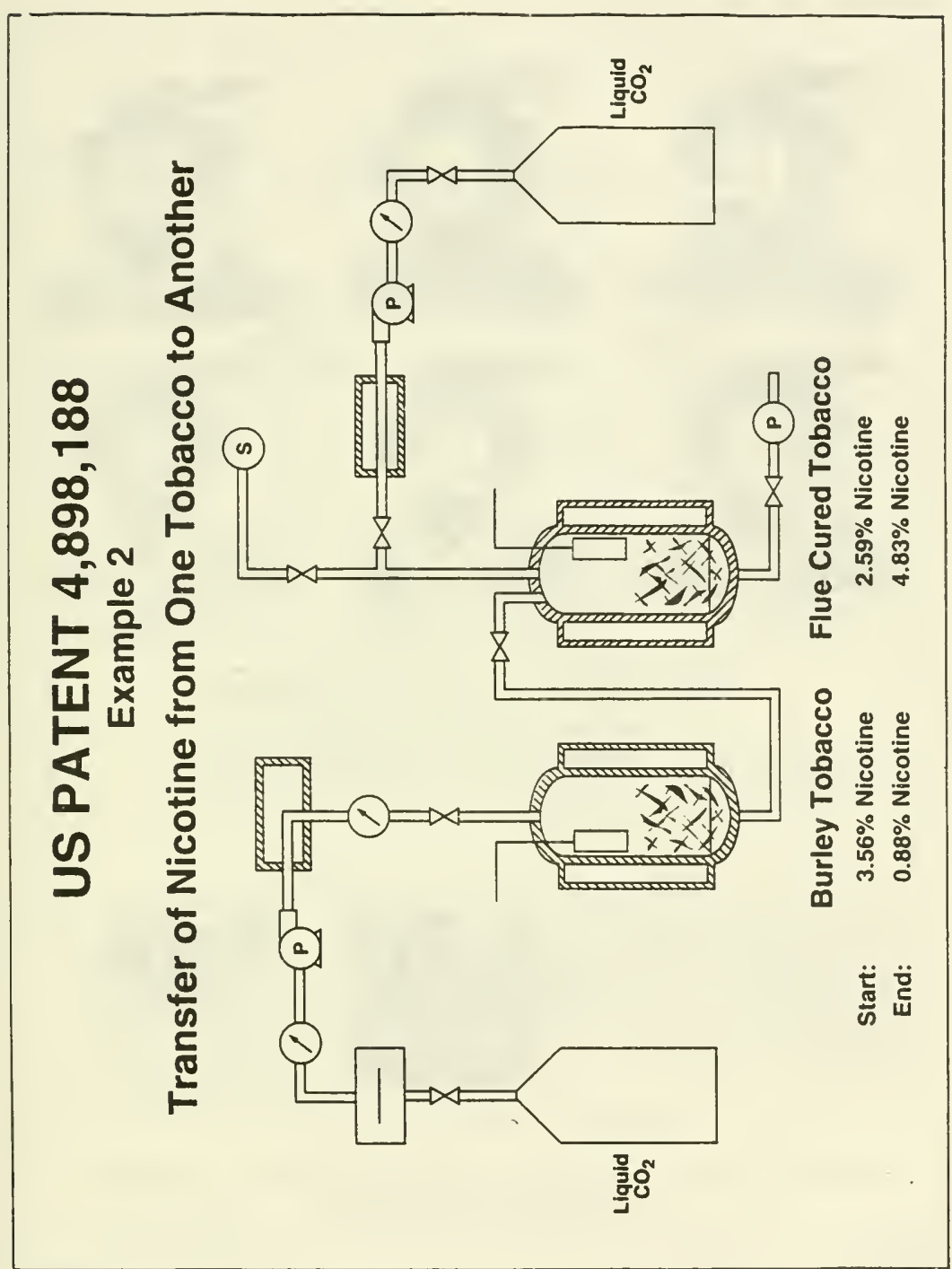




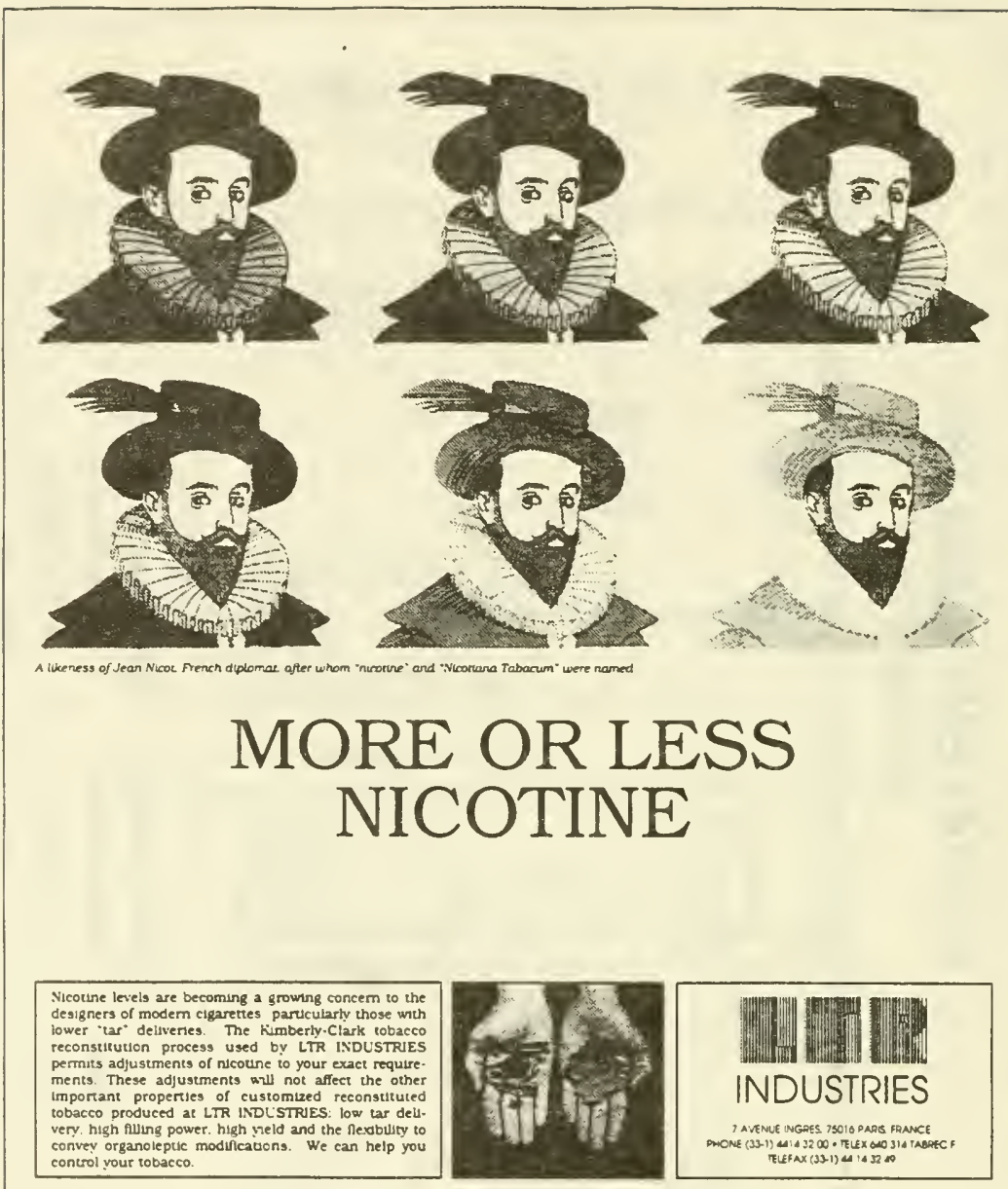

Get more tobacco from all your tobacco

LTR INDUSTRES, a subsidiary in France of 37 KIMBERLY-CLARK Corporotion 


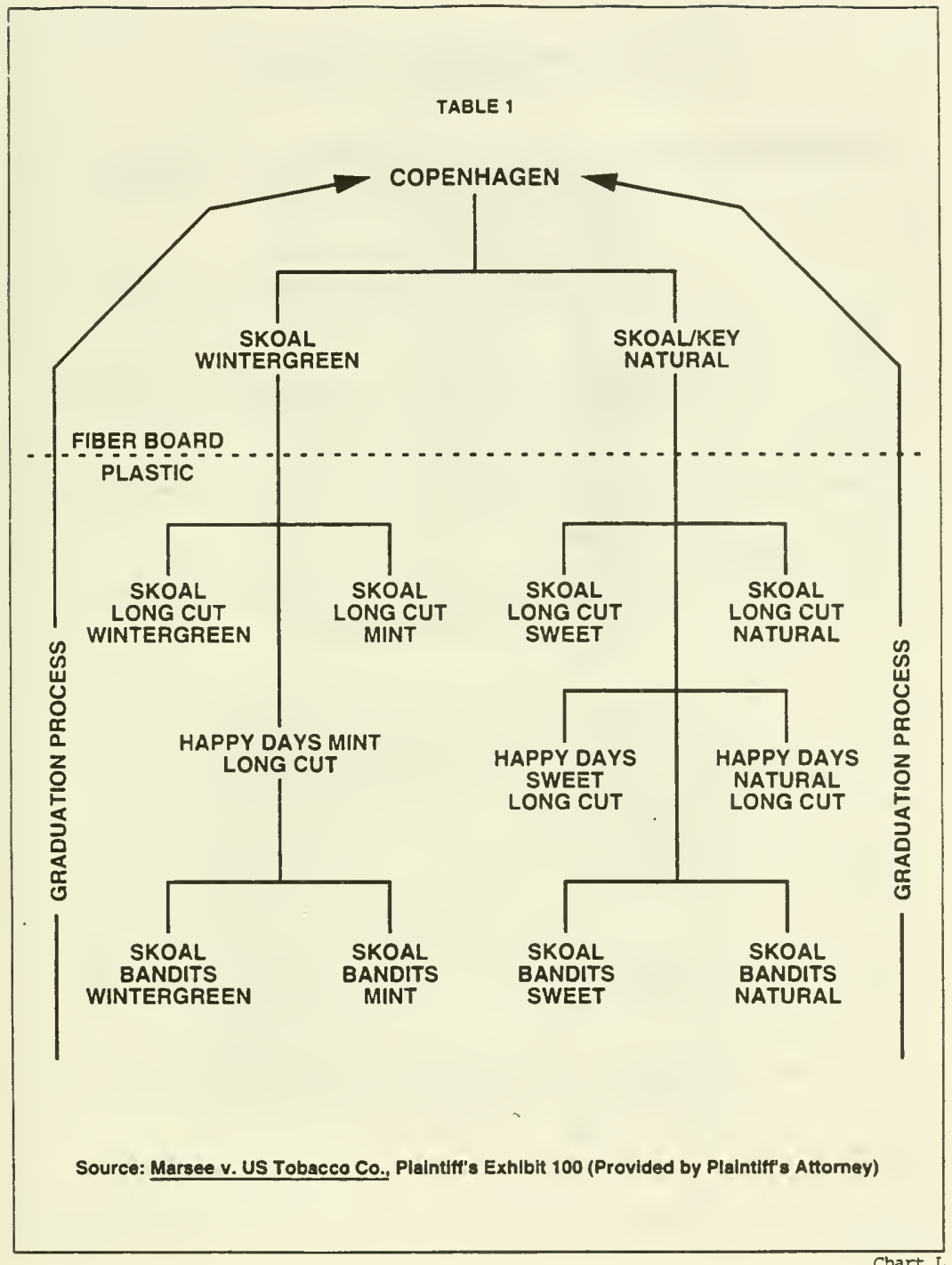

Chart L 


\section{Psychotherapeutic Agents}

(Patent 5,138,062)

\begin{tabular}{|c|c|c|c|c|}
\hline Nicotine Analogues & $\begin{array}{c}\text { Dose (IP) } \\
\mathrm{mg} / \mathrm{kg}\end{array}$ & Sedation & $\begin{array}{l}\text { Body } \\
\text { Tone }\end{array}$ & $\begin{array}{l}\text { Tranquilization } \\
\text { (IVC) } 50 \mathrm{ug}\end{array}$ \\
\hline${ }^{0} \mathrm{R}-\left(\mathrm{CH}_{2}\right)_{2}-\mathrm{N}_{\mathrm{CH}_{3}}^{-\mathrm{CH}_{3}}$ & $\begin{array}{l}10 \\
20\end{array}$ & $\begin{array}{c}+ \\
++\end{array}$ & + & +++ \\
\hline (2) $\mathrm{R}-\left(\mathrm{CH}_{2}\right)_{3}-\mathrm{N}^{\prime}$ & $\begin{array}{c}5 \\
10 \\
20\end{array}$ & $\begin{array}{c}+ \\
++ \\
+++\end{array}$ & $\begin{array}{l}+ \\
+ \\
++\end{array}$ & ++++ \\
\hline${ }^{3} \mathrm{R}-\left(\mathrm{CH}_{2}\right)_{4}-\mathrm{N}{ }_{\mathrm{CH}_{3}}^{\mathrm{CH}_{3}}$ & $\begin{array}{l}10 \\
20\end{array}$ & $\begin{array}{l}+ \\
+\end{array}$ & + & +++ \\
\hline (4) $\mathrm{R}-\left(\mathrm{CH}_{2}\right)_{5}-\mathrm{N}$ & 40 & ++ & ++ & +++ \\
\hline${ }^{6} \mathrm{R}-\left(\mathrm{CH}_{2}\right)_{3}-\mathrm{NH}_{2}$ & $\begin{array}{l}10 \\
20\end{array}$ & $\begin{array}{l}0 \\
+\end{array}$ & $\begin{array}{l}0 \\
0\end{array}$ & +++ \\
\hline${ }_{\mathrm{R}}^{8}-\left(\mathrm{CH}_{2}\right)_{4}-\mathrm{NH}_{2}$ & $\begin{array}{l}10 \\
20\end{array}$ & $\begin{array}{l}0 \\
+\end{array}$ & $\begin{array}{l}0 \\
0\end{array}$ & +++ \\
\hline $\mathrm{B}-\left(\mathrm{CH}_{2}\right)_{3}-$ & $\begin{array}{l}10 \\
20\end{array}$ & $\begin{array}{c}+ \\
++\end{array}$ & $\begin{array}{c}0 \\
++\end{array}$ & +++ \\
\hline$\stackrel{9}{\mathrm{R}-\left(\mathrm{CH}_{2}\right)_{3}-}$ & $\begin{array}{l}10 \\
20\end{array}$ & $\begin{array}{c}0 \\
++\end{array}$ & $\begin{array}{l}0 \\
+\end{array}$ & ++ \\
\hline $\mathrm{A}-\left(\mathrm{CH}_{2}\right)_{2}-$ & $\begin{array}{l}10 \\
20\end{array}$ & $\begin{array}{l}0 \\
+\end{array}$ & $\begin{array}{l}0 \\
+\end{array}$ & + \\
\hline$\stackrel{\text { (1) }}{\mathrm{R}}-\mathbf{1 C H}$ & $H_{3} \begin{array}{l}20 \\
40\end{array}$ & $\begin{array}{c}++ \\
+++\end{array}$ & $\begin{array}{c}+ \\
++\end{array}$ & ++++ \\
\hline
\end{tabular}

$A=\pi$ NICOTINE $=$

(Data from Rats) 

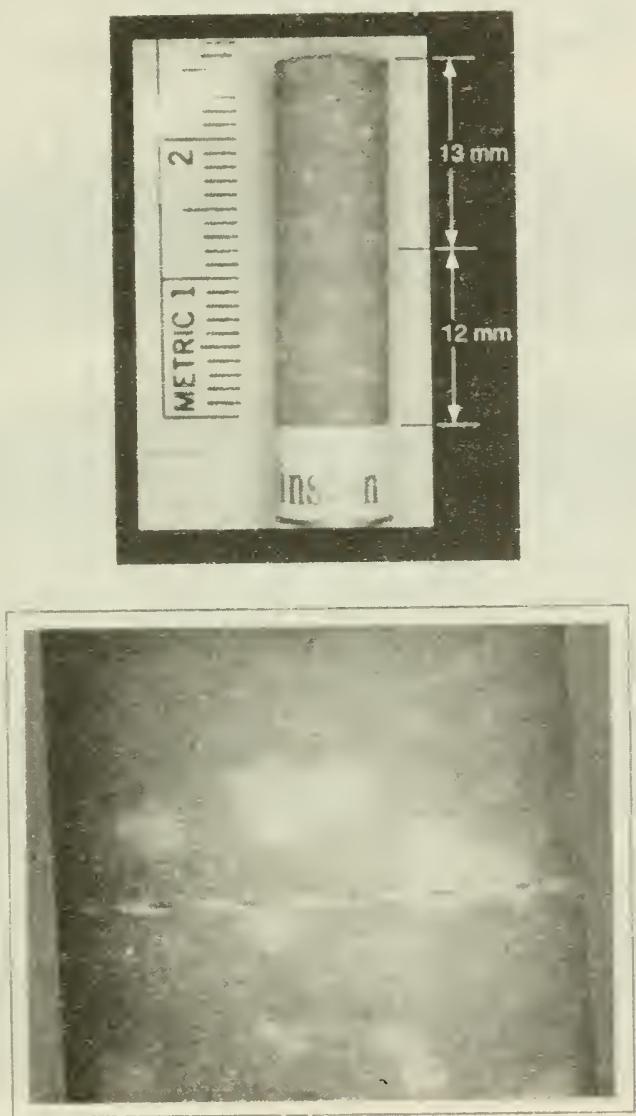


\section{Cross Sectional Diagram of A Filter Cigarette Demonstrating Overwrap}
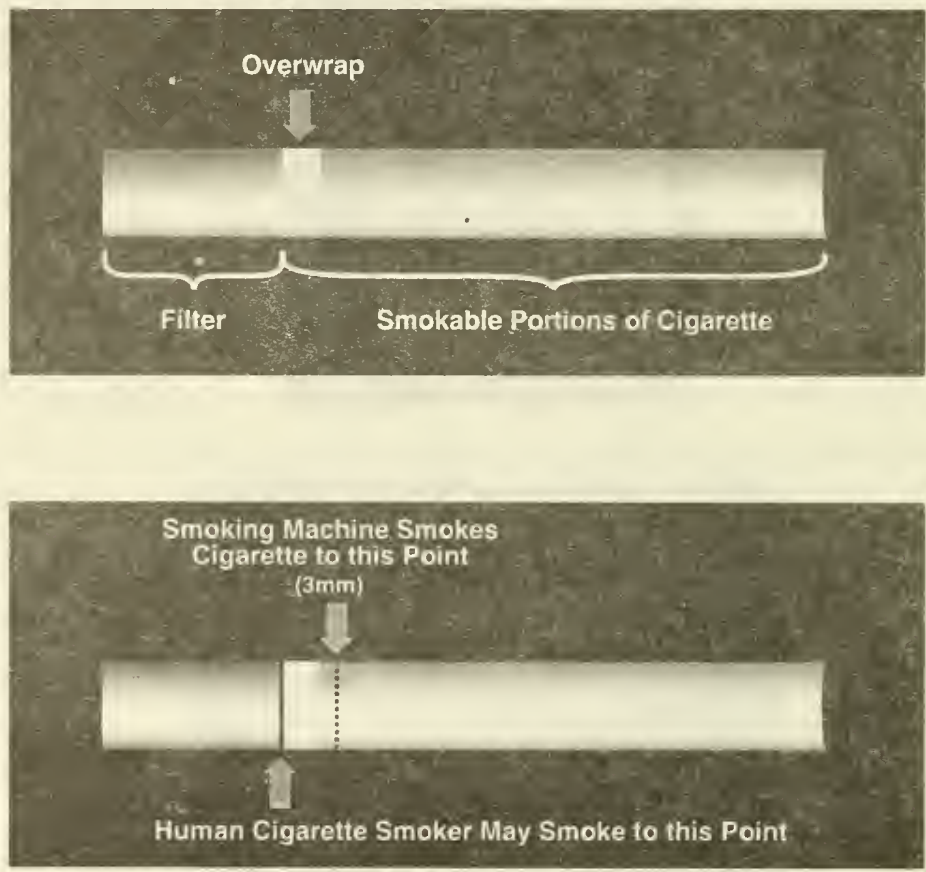

(Source: Grunberg,1985) 


\section{$\%$ Nicotine in \\ One Brand Family}

Variety

Regular

100 's

Low Tar

100 's

Uitra

Low Tar

100 's
$\%$ Nicotine

(mg/grams)

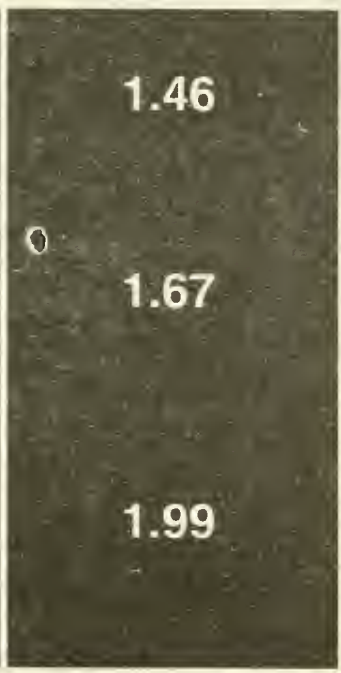




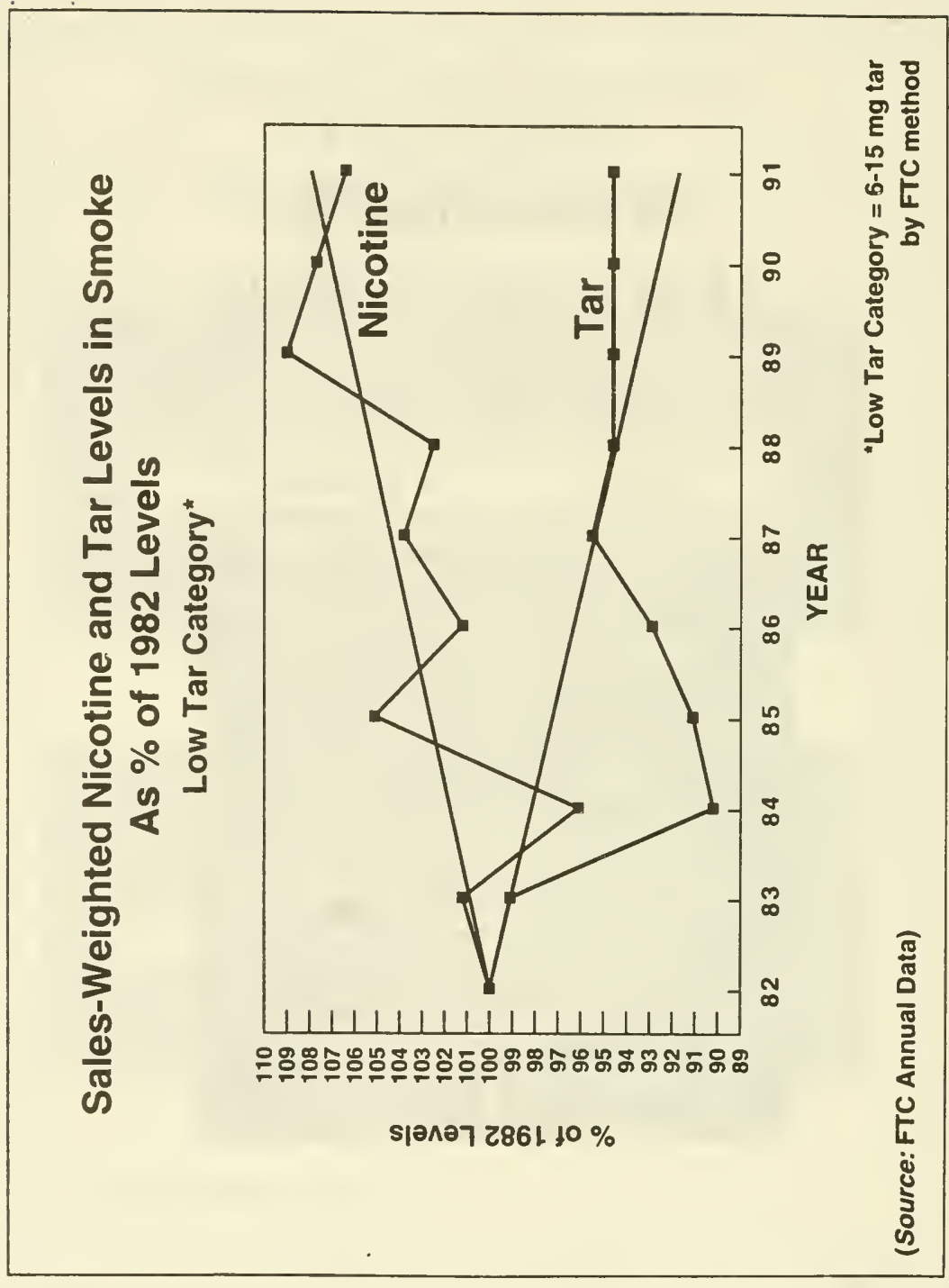

Chart $Q$ 

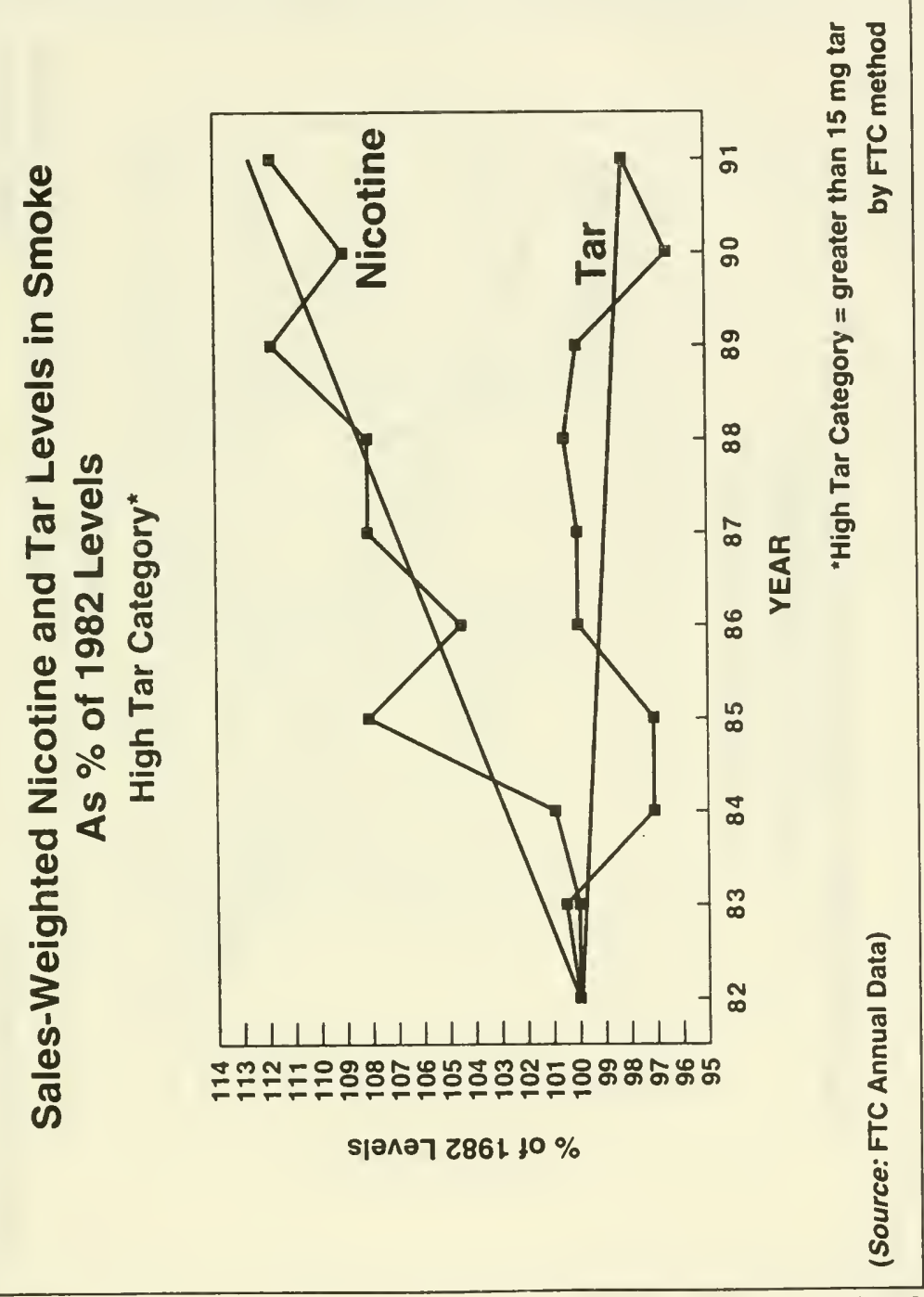

Chart $\mathrm{R}$ 


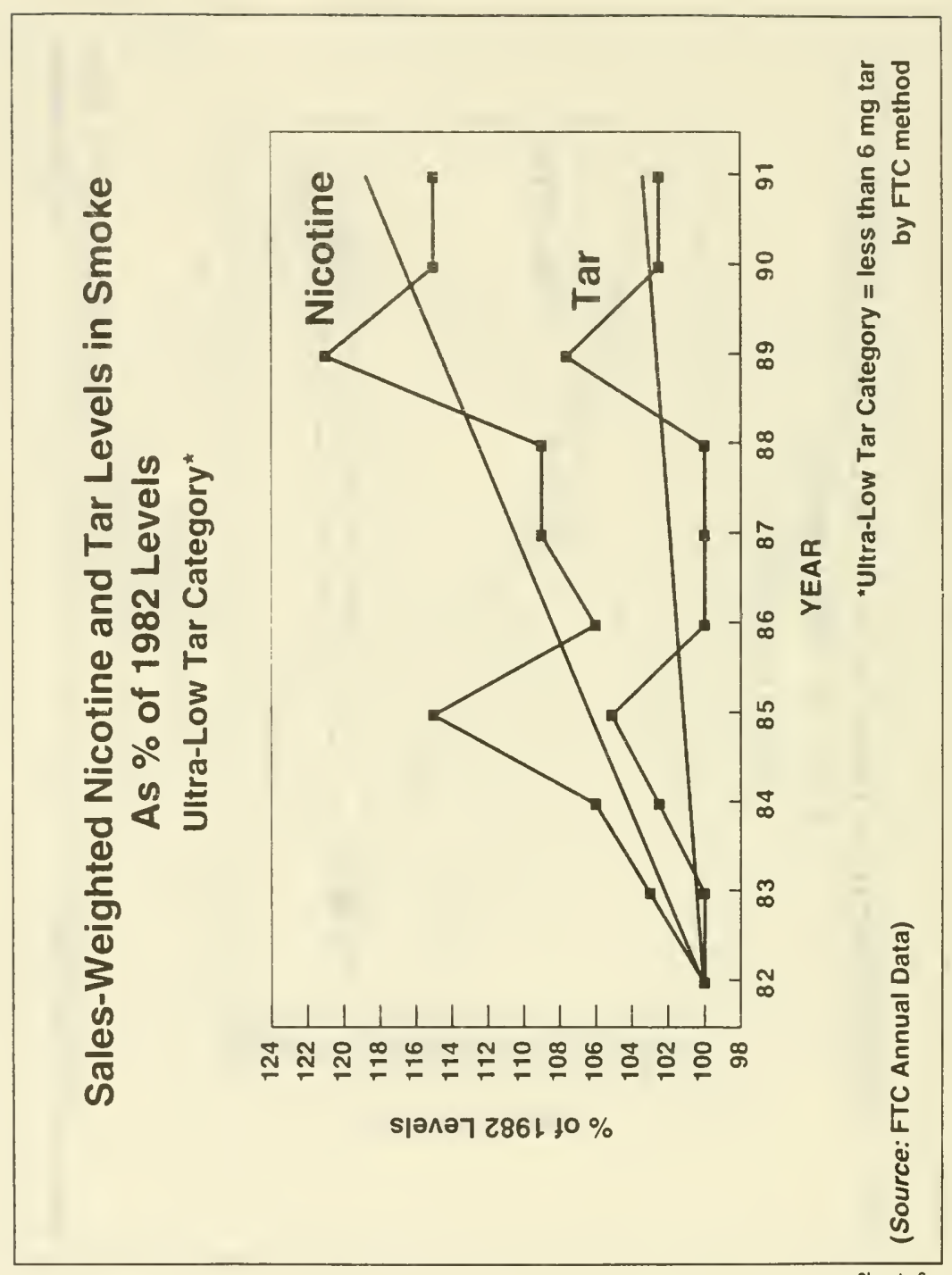




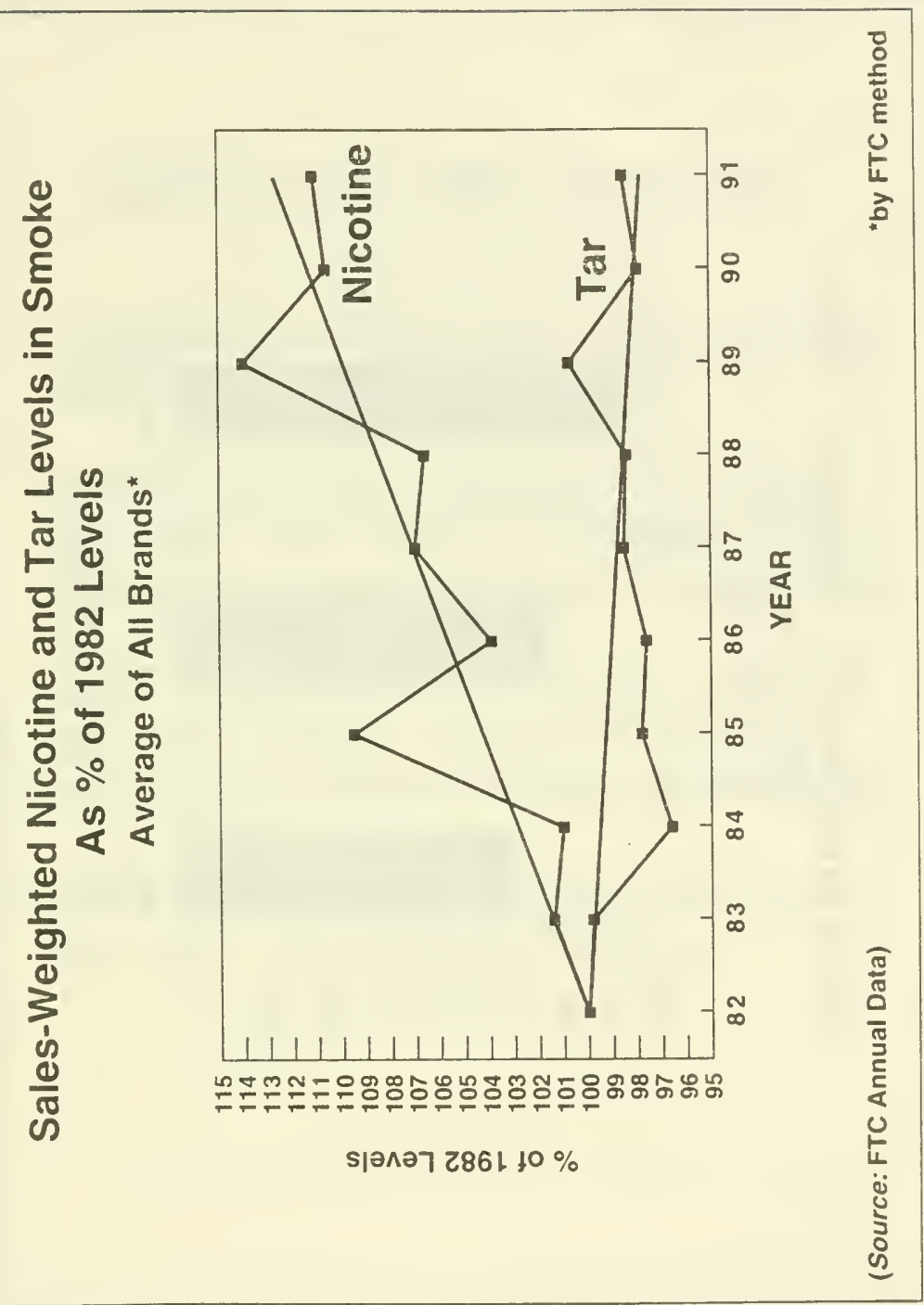



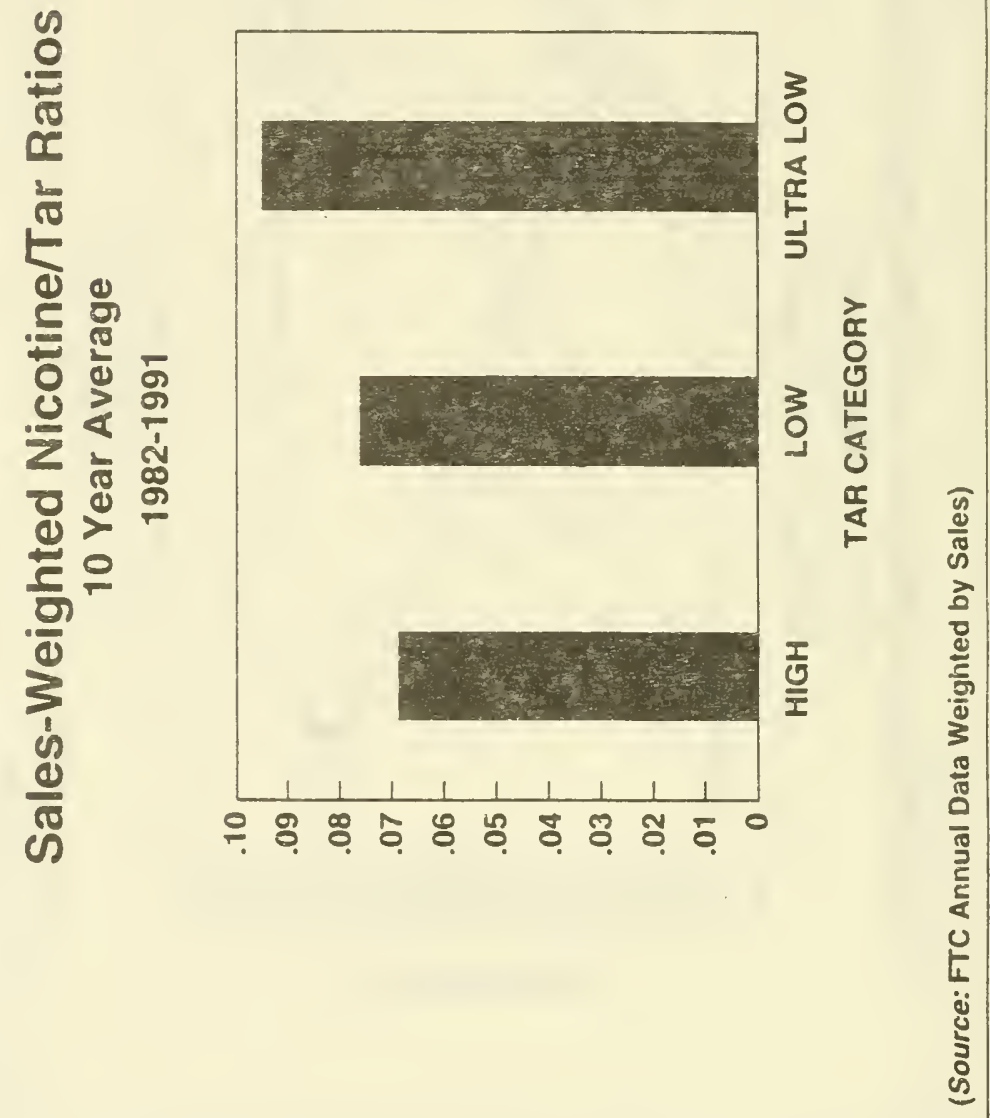


\section{Addiction: The Numbers}

- Two-thirds of adults who smoke say they wish they could quit.

- Seventeen million try to quit each year, but fewer than 1 out of 10 succeed. For every smoker who quits, 9 try and fail.

- Three out of four adult smokers say that they are addicted. By some estimates, as many as 74 to 90 percent are addicted.

- Eight out of ten smokers say they wish they had never started smoking. 


\title{
Major health authorities acknowledge tobacco use as a form of drug dependence or addiction with severe adverse health consequences.
}

\author{
U.S. Surgeon General 1986 - Smokeless tobacco \\ U.S. Surgeon General 1988 - Cigarettes and other \\ forms of tobacco \\ U.S. Surgeon General 1994 - Tobacco and youth \\ World Health Organization \\ American Medical Association \\ American Psychiatric Association \\ American Psychological Association \\ American Society of Addiction Medicine \\ Royal Society of Canada \\ Medical Research Council, United Kingdom
}




\section{A demonstration of} positive reinforcement in intravenous self administration studies is a hallmark of a drug that has addiction potential. 


\section{The Nicotine Effect}

Psychoactive Agent

i

Receptor Sites in Brain

3

Chemical Release in Brain

圈

Psychoactive Effect

息

Tolerance

Physical Dependence Reinforcement Cognitive Benefit

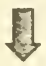

Addictive Behavior

\section{Industry \\ Euphemisms}

Impact

Satisfaction

Strength

Pleasure 
"Think of the cigarette pack as a storage container for a day's supply of nicotine."

"Think of the cigarette as a dispenser for a dose unit of nicotine."

William L. Dunn Jr. 1972 
"Think of a puff of smoke as the vehicle for nicotine."

"Smoke is beyond question the most optimized vehicle of nicotine ..."

William L. Dunn Jr.

1972 


\section{Quotes from Industry Patents}

Maintaining the nicotine content at a sufficiently high level to provide the desired physiological activity, taste, and odor...can thus be seen to be a significant problem in the tobacco art.

-patent no. 3,280,823 C1:53-59

... the perceived taste or strength of the cigarettes classified as having lower levels of "tar" and nicotine are progressively less than that of the cigarettes which are classified as approaching the characteristics of the "full flavor" cigarettes. It has been proposed to add nicotine and other flavorants to the cut filler of the lower tar cigarettes to enhance the taste, strength, and satisfaction of such cigarettes. -patent no. 4,830,028 C1:47-50

This invention...concerns the problem of maintaining or increasing the nicotine content of the smoke whilst avoiding an undesirable level of particulate matter in the smoke....

-patent no. 3,861,400 C1:1-10

This invention permits the release into tobacco smoke, in controlled amounts, of desirable flavorants, as well as the release, in controlled amounts and when desired, of nicotine into tobacco smoke.

-patent no. 3,280,823 C2:37-41 


\section{Quotes from Industry Patents}

It is another object of the invention to provide an agent for the treatment of tobacco smoke whereby nicotine is easily released thereinto in controlled amounts. -patent no. 3,584,630 C2:69-71

It can be seen that the process...enables the manipulation of the nicotine content of tobacco material, such as cut leaf and reconstituted leaf, by removal of nicotine from a suitable nicotine tobacco source or by the addition of nicotine to a low nicotine tobacco material.

-patent no. 4,215,706 C3:61-66

...processed tobaccos can be manufactured under conditions suitable to provide products having various nicotine levels.

-patent no. 5,031,646 C5:63-65

Examples of suitable tobacco materials include... processed tobacco materials such as expanded tobaccos, processed tobacco stems, reconstituted tobacco materials, or reconstituted tobacco materials having varying levels of endogenous and exogenous nicotine.... [emphasis added]

-patent no. 5,031,646 C:21-27 


\section{Quotes from Industry Patents}

...the present invention...is particularly useful for the maintenance of the proper amount of nicotine in tobacco smoke. ...previous efforts have been made to add nicotine to tobacco products wherein the nicotine level in the tobacco was undesirably low.

-patent no. 3,584,630 C2:5-17

.....object of this invention to provide a cigarette which delivers a larger amount of nicotine in the first few puffs of the cigarette than in the last few puffs.

-patent no. 4,595,024 C2:23-2

Moreover, the process is useful for transferring naturally occurring nicotine from tobacco having a generally high nicotine content to a nicotine-deficient tobacco, tobacco filler materials, or RL (reconstituted leaf) which are used in the production of cigarettes and other smoking products... a low nicotine tobacco ...can also be used as the nicotine donor...

-patent no. 4,215,706 C1:40-48

It is another object of this invention to provide a process for the migration of nicotine from one tobacco substrate (leaf material or reconstituted leaf) to a second tobacco substrate (leaf material, reconstituted leaf material or tobacco stems) or to a non-tobacco substrate.

-patent no. 5,018,540 C2:39-43 


\section{Quotes from Industry Patents}

If desired, nicotine can be incorporated into the expansion solvents used to provide a volume expanded processed tobacco material having a high nicotine content.

-patent no. 5,031,646 C5:65-68

The present invention provides a nicotine-enhanced smoking device with a high nicotine release efficiency... Thus, the smoker is provided with more nicotine from the nicotine-enhanced device than from a similar smoking device which does not contain the nicotine solution or from a comparable cigarette.

-patent no. 4,676,259 C2:30-33, 53-56

The present invention is concerned with the application of additives...and physiologicaliy active agents such as nicotine components to the smoking rod, in order to improve or help to improve the satisiaction provided to the smoker.

-patent no. 4,236,532 C1:35-40

The salts [nicotine levulinate] can be incorporated into the smoking article in a variety of places or sites.

For example, the sait can be applied to the filler material, incorporated within some or all of the filler material... applied to the wrapper of the tobacco rod, applied within the glue line of the wrapper of the tobacco rod, applied within a region (e.g., a cavity)....

-patent no. 4,830,028 C5:59-65 


\section{Definition of a Drug}

The term "drug" means

(A) articles recognized in [compendia]

$(B)$ articles intended for use in the diagnosis, cure, mitigation, treatment, or prevention of disease ...

(C) articles (other than food) intended to affect the structure or any function of the body ... 
Mr. WAXMAN. We have a number of witnesses that we are going to ask to come up together and testify as a panel. Obviously these witnesses have a diversity of opinion. We want to call Scott Ballin, Legislative Counsel of the American Heart Association appearing on behalf of the Coalition on Smoking OR Health. Charles Whitley, Senior Consultant to the Tobacco Institute, Steven Raffle, a physician appearing at the request of the Tobacco Institute, John Slade, a physician and chairman of the Committee on Nicotine Dependence of the American Society of Addiction Medicine, Alexander Spears, Vice Chairman and Chief Operating Officer of the Lorillard Tobacco Company, Sherwin Gardner, Consultant to Philip Morris, USA, and Gregory N. Connolly, Director of the Massachusetts Tobacco Control Program, appearing on behalf of the American Public Health Association.

We want to welcome you to our hearing today. Your prepared statements will be in the record in full. We would like to ask you to limit your oral presentation to 5 minutes. We will start with $\mathrm{Mr}$. Ballin.

STATEMENTS OF SCOTT D. BALLIN, VICE PRESIDENT, AMER-

ICAN HEART ASSOCLATION, ON BEHALF OF COALITION ON SMOKING OR HEALTH; CHARLES O. WHITLEY, SENIOR CONSULTANT, THE TOBACCO INSTITUTE; ALEXANDER $W$. SPEARS III, VICE CHAIRMAN, LORILLARD TOBACCO CO.; STEPHEN N. RAFFLE, ON BEHALF OF THE TOBACCO INSTITUTE; JOHN SLADE, ON BEHALF OF AMERICAN SOCIETY OF ADDICTION MEDICINE; SHERWIN GARDNER, ON BEHALF OF PHILIP MORRIS USA; AND GREGORY N. CONNOLLY, ON BEHALF OF AMERICAN PUBLIC HEALTH ASSOCIATION

Mr. Ballin. Thank you, Mr. Chairman. Good morning, Mr. Chairman and members of the subcommittee.

Today is indeed an historic hearing, a potential significant turning point of the health of the American public. Since the first Surgeon General's report was released 30 years ago this past January, the tobacco industry and the deadly products that it sells have escaped regulation under all major health and safety laws enacted by Congress designed to protect the American public health.

Applying any of those laws to tobacco products would probably have resulted in the products being removed from the marketplace. That is how dangerous and how hazardous these products have been and are to the American public.

The epidemic of tobacco-related diseases and deaths wili continue until the tobacco industry is forced to adhere to regulations and standards that are designed to protect the health of the American public rather than the profits of the tobacco industry.

While tobacco products have been exempted from regulation under most health and safety statutes, there is one health and safety act that does not include a specific exemption for tobacco products, and that is the Food, Drug and Cosmetic Act.

As this subcommittee is well aware, the Food and Drug Administration is the primary Agency charged with insuring that products which the public ingests, implants or applies to its skin are safe, effective, properly packaged, dispensed properly, labeled, and properly marketed. 
How is it that a product which is a cause of cancer, cardiovascular disease, emphysema, stroke, chronic obstructive lung disease, premature births, osteoporosis and is addictive virtually unregulated at the Federal level of government in the way in which it is manufactured, distributed, sold, labeled, advertised, and promoted?

Part of the reason lies with Congress' mistake and failure in 1964 to give the FDA the authority it needed even back then to regulate tobacco as a significant public health problem. It also stems in large measure from the tobacco industry's continued assurances to Congress and the American public that it was a responsible industry that would do the right thing if it were proven that smoking caused disease.

The promises and assurances that the industry made to the American public as far back as 1950, that it would put public health above all corporate interests were nothing but public relations ploys designed to buy the industry time to find ways to keep its products on the market.

What other industry could or would have in spite of 23 Surgeon General reports and over 60,000 scientific studies continued to sell addictive killer virtually unfettered from government oversight and regulation? In 1988 the Coalition on Smoking OR Health, after taking a careful look at the history of how tobacco products are regulated, realized that the Food and Drug Administration and the act that that administration implements could be applied against tobacco products under certain circumstances.

It became clear to us that if and when the tobacco industry sold. its products with the intent of mitigating or preventing disease or with the intent to affect function or structure of the body, that the industry was no longer selling merely tobacco products, they were in the business of selling drugs.

Based on this analysis, the Coalition filed a petition with the FDA seeking to classify all low tar and low nicotine cigarettes as drugs under that act. Last spring the coalition contracted with a Gallop organization to determine what the public's perceptions were about these products.

When we asked what message the industry was trying to get across by using such terms as low tar, low nicotine or low yield, two-thiras of those surveyed believed that the products were in some way safer and less addictive.

The tobacco industry manufactures and the public buys these cigarettes for an overwhelming reason that they believe these products are safer. These products are in our view drugs under the Food, Drug and Cosmetic Act.

Since we filed that petition seeking to classify all low tar, low nicotine cigarettes as drugs, additional evidence has come to light that we believe justifies the FDA taking jurisdiction over all cigarette products under the act.

Documents released as part of the Cipollone liability have given us a glimpse into the industry's past and present practices. These documents have pointed to the fact that even before 1964, the industry was investing millions and millions of dollars into developing highly technical products, products which indeed are drugs. Are we surprised by these revelations? Not really. 
I would like to request that our March 7 th petition be included in today's hearing record and would like to highlight several statements, some of which were made by Dr. Kessler in his presentation. [See p. 28.]

As far back as 1961, the industry knew that the cigarettes they sold were cancer promoting and poisonous. They knew that they had to develop techniques to determine and to find ways to remove nicotine, phenal, polynuclear hydrocarbons and nitrosamines.

Mr. Chairman, the patents speak clearly that Dr. Kessler outlined, and we have reviewed those as well. It is time, Mr. Chairman, for Congress to act. Your leadership and the leadership of many members of this subcommittee must be commended, but it is time for the other members of this subcommittee to put the American public's health first.

To that we pledge to work with you and to work with the FDA to bring tobacco under FDA jurisdiction and to support the American public's health for the first time in 30 years.

Thank you.

Mr. WAXMaN. Thank you, Mr. Ballin.

[The prepared statements of this panel of witnesses begin on $p$. 170.]

Mr. WaXMan. Mr. Whitley.

\section{STATEMENT OF CHARLES O. WHITLEY}

Mr. Whithey. Mr. Chairman, I would like to ask your indulgence inasmuch as Dr. Kessler testified for considerably more than an hour that Dr. Spears and I as principal witnesses for the industry be given a little more leeway than being held strictly to 5 minutes.

Mr. WAXMAN. I think that is reasonable, please proceed.

Mr. WHITLEY. I am here as a representative of the Tobacco Institute, a trade association for major cigarette companies.

It has been mentioned that three chief executives from our companies were invited to testify in person and that they are not here. I have attached to my statement a written statement from five of the six cigarette manufacturers in the country and ask that they be included for the record.

I am accompanied by Dr. Alexander Spears, who is the Chief Operating Officer of the sixth company, Lorillard Tobacco Company. It was felt that he was the most appropriate witness on this issue for a number of reasons. The first is that he is a research chemist, has a Ph.D. in chemistry. He has worked with Lorillard since 1959 and is their Chief Operating Officer.

$\mathrm{He}$ is uniquely qualified in what the testimony has shown is a highly technical field. Most CEO's of our companies, as most other companies in this country, have a marketing background as opposed to a scientific and manufacturing background, which Dr. Spears has.

$\mathrm{He}$ is the most well versed and qualified person in the tobacco industry on the subject of the chemistry of tobacco and the manufacturing process, and that is the primary reason why I am accompanied by Dr. Spears this morning.

There are several points that we want to make in our testimony, Mr. Chairman. The first one is that we do not add nicotine to cigarettes. I will not use the word spike. I agree with Dr. Kessler, I 
don't believe he used it either, but he did say in so many words that we add nicotine. That is not true.

We do not add nicotine to cigarettes. There is not a cigarette marketed in the U.S. today by an American manufacturer which contains more nicotine than the nicotine level which occurs naturally in leaf tobacco, not one.

The second point, nicotine levels are a function of tar levels. Over the last 30 years or so, the consumer demand for lighter cigarettes has led the tobacco manufacturers to reduce tar levels in cigarettes, and when they have, the nicotine levels have dropped correspondingly.

The word manipulate suggests something sinister or ulterior. Nicotine levels have been reduced, they have been changed, but not with any sinister motives, but because they have followed the tar levels and the tar levels have been reduced to reflect the taste of American consumers for a lighter cigarette.

The third point I would like to make is that today the nicotine level in the average cigarette is lower than it has ever been. Between 1954 and 1993, the average nicotine level fell from 2.6 milligrams to 0.89 , a two-thirds decline.

The next point I want to emphasize, and we have a witness to testify specifically to that issue, is that it is irresponsible to equate cigarettes with hard drugs. The suggestion that has been made by some that nicotine is as addictive as heroin and cocaine and other hard drugs trivializes the serious narcotic and other hard drug problems faced by our society and undermines efforts to combat drug use.

The irony over the latest controversy over nicotine is striking. I will have to admit that we are somewhat at a loss to understand what is supposed to be new and startling about the latest developments. The points I have just made are very specific and are very accurate, that we do not add nicotine, have not added nicotine, we do not manipulate nicotine, nicotine levels have dropped as we have manufactured lighter cigarettes to reflect American taste.

So the irony of this latest controversy is truly striking when after reducing the average nicotine levels of cigarettes by over two-thirds in the last 40 years, we are now accused of adding nicotine. In fact the original petition that was filed with FDA by the Coalition on Smoking OR Health was based on the theory that we were reducing tar and nicotine in order to make health claims about smoking. Now, it is ironic that they are saying that, anti-smoking petitions are saying that we are adding nicotine.

The reconstituted tobacco process which has been discussed here this morning and which Dr. Spears will discuss in more detail, has been in use for at least 30 years and it has been mentioned in the literature, including three different Surgeon General reports. There is nothing new about that. This has been known for a long time.

The next point is that the use of denatured alcohol, and that has been discussed, has been known for a long time and the amount of nicotine in denatured alcohol is minuscule. The fact that it is used doesn't leave any significant addition in the level of nicotine in the manufacture of cigarettes. These processes are not new, have not been hidden from government, they do not add measurable nicotine to the final product. 
During all this time Mr. Chairman, FDA has never suggested, and this has been here again with nothing new, has never suggested that cigarettes ought to be regulated by FDA. Now, he suggests that evidence now available-I listened carefully, as you did, Mr. Chairman, and other members of the panel to the new evidence that, to see what new evidence Dr. Kessler had.

About the only thing I heard was a long lengthy description of patents. There was not a single allegation that any of these patents were in use, that even the technology to put them into use had been developed.

You made a statement, Mr. Chairman, that we don't take the words of the companies for what they do. Neither did Dr. Kessler. He sent 10 men this week to Philip Morris-I mention that one company because that is the only one he made the request to to send people at that time-and they responded positively.

He sent a whole team including scientists, lawyers and others. They were received, all their questions were answered, they were taken through the plant, they were told that anything they wanted to see, they could see, nothing was withheld from them. There are not any secrets.

The companies are doing what they say they are doing and all six have either appeared here in person or filed statements describing their manufacturing process and verifying that nobody is adding nicotine, manipulating nicotine, that the cigarette manufacturing process is what it has been all the time and there is nothing new or startling that should provide a basis for Dr. Kessler and the FDA suddenly to decide to classify cigarettes as a drug and for the FDA to assume jurisdiction.

The cigarette manufacturers address the issues raised in Dr. Kessler's letter in a recent exchange of correspondence with HHS' office on smoking and health. As Mr. Synar knows pursuant to a law that he helped to author in 1984, we have provided to HHS for the last 9 years a complete list of all ingredients. We have responded to any and all questions and concerns that they raised.

We got a letter from Dr. Louis Sullivan in 1990 asking for some quantitative information about ingredients. We responded promptly, we provided that information, we assured him that we would give him additional information that he might need, and we promised cooperation with him, and that remains our position, that we are ready, willing and able to cooperate with him and to provide him with any further information in that regard.

So we are not hiding anything. It was written into that law, and again I think Mr. Synar had a good deal to do with the drafting of that law that brand specific ingredients and quantities would not be revealed to protect confidentiality; but the ingredients are there and the manner in which they are used is available.

If the Office of Smoking and Health and HHS thinks there are problems with those ingredients, they are free to raise those questions, and we stand ready to provide them with information and with the benefit of detailed research that we have done in connection with those ingredients.

Dr. Sullivan testified in the Senate in 1990 regarding additives that further regulation regarding additives is "unnecessary". $\mathrm{He}$, as you know, Mr. Chairman, certainly was no friend of tobacco. 
We would also make the point that FDA is an overburdened Agency now. I think this committee knows probably better than anybody else in Congress what a track they have of doing the things that they are already directed to do without getting into this area of trying to regulate cigarettes and trying to regulate ingredients.

My entire written statement refers to other provisions of the Synar bill that I will not go into because they haven't been the subject of this hearing. I will stop now and if the chairman would indulge us, I would like to ask that Dr. Spears be permitted to follow me.

Again, I would like to make the point that Dr. Spears has a Ph.D. in chemistry, has been a research chemist, he is Chief of Operations for Lorillard Tobacco Company and has been in the cigarette manufacturing business since 1959.

Mr. WAXMAN. Thank you Mr. Whitley.

Dr. Spears? If you would pull the microphone closer to you.

\section{STATEMENT OF ALEXANDER W. SPEARS III}

Mr. SpEARS. Thank you, Mr. Chairman, members of the subcommittee, my name is Alexander Spears and I am Vice chairman and Chief Operating Officer for Lorillard Tobacco Company.

Within the last few weeks the ABC's Day One show has featured two cigarette-related programs alleging that the tobacco industry adds nicotine to cigarette tobacco for the purpose of manipulating the dose of nicotine to the consumer. These statements are completely false.

David Kessler, Commissioner of the FDA, who testified here earlier, stated in a letter to Scott Ballin of the Coalition on Smoking OR Health dated February 25, 1994, that manufacturers commonly add nicotine to cigarettes to deliver specific amounts of nicotine. This letter was released to the media perpetuating its false assertions.

The level of nicotine in tobacco products is solely determined by the tobacco we buy and the blending of the different tobaccos during manufacturing. Tar and nicotine yields of our products are determined by a combination of the tobacco blend and the construction of the cigarette; for example the length, circumference, filter, tip, ventilation, tobacco density.

The Federal Trade Commission has reported the results of tar and nicotine analysis by brand for years. We do not set levels of nicotine for particular brands of cigarettes. Nicotine follows the tar level. The easy proof that no nicotine manipulation has occurred may be found in the tar and nicotine data from the 1950's to 1990's.

If I could have the first chart please. This grafh comes from the Surgeon General's report and it depicts the change in tar and nicotine from the 1950's until the 1990's. It also depicts the change in nicotine from the 1950's to 1990 's, and the insert indicates that tar has decreased in this period of time by 69 percent and that nicotine has decreased by a similar amount of 69 percent.

I could not help but notice in Dr. Kessler's testimony that he presented some graphs which might suggest something different, and 
I might say what he has done is to take only a short period of time relative to this graph, that is the last 10 years.

This graph covers 40 years and changed the scaling to expand it so that a small secondary effect was magnified. The small secondary effect that he is talking about which he found surprising should not have been. It has been well documented, it is in the literature and in 1974 was reported by one of the investigators in our laboratory.

That is simply, if you ventilate a cigarette by the tip, tip ventilation, all the constituents of the smoke do not behave in the same fashion. And there is a slight lesser decrease in nicotine and other similar substances, it is not alone in that respect, then there is tar, but there is also a selective decrease in other components which decrease beyond that of tar and one is carbon monoxide. This has been around for a long time and is well known.

I think what he has done is to magnify a small portion of this graph to try to raise a question about it. I think it clearly shows that these do go parallel over this period of time.

The second chart that I have is the current tar and nicotine data on 483 brands, again the Federal Trade Commission method of measuring the tar and nicotine. And what we have done here is simply run a simple correlation between tar and nicotine over all 483 brands with a near perfect correlation between tar and nicotine of 0.975 .

I do find this easy and convincing proof that there is not some sort of manipulation of nicotine occurring that is independent of tar, but rather that they co-vary over all these brands in a remarkable fashion, that is tar and nicotine co-vary, nicotine follows tar.

We do not add nicotine to our products except in two insignificant and incidental cases, and these have been raised by other individuals in some of the $\mathrm{ABC}$ programming that the use of denatured alcohol was a significant source of nicotine and a method of replacing nicotine in tobacco. That is not true.

The formula for denatured alcohol indicates that it contains 200 parts per 1 million nicotine and with the amounts that are typically used as a vehicle in the flavoring of tobacco, you would expect as much as 2 parts to 3 parts per 1 million in tobacco, something that is insignificant and incidental.

The amount of nicotine from those sources and tobacco extracts which are occasionally used to enhance the flavor characteristic of a certain type of tobacco, which do contain some nicotine, but in the amounts used as a source of nicotine, totally insignificant.

The two together produce levels on products that are too small to be measured by any conventional measuring process.

One of the processes for the production of reconstituted sheet which is used to manufacture cigarettes does involve a temporary separation and reapplication of water soluble components including nicotine. This process which is well described in the published literature, including three Surgeon General report results in a nicotine reduction in the finished product.

This occurs due to both losses of nicotine in the process and the materials that are used to make the reconstituted sheet which in part incorporates stems and veins of the leave which are much, much lower in nicotine than is the leaf laminate. 
Other processes that are described in the literature result in a similar product, but do not involve the temporary separation of water-soluable products and tobacco. Again, with this process, some nicotine is lost during the manufacture of reconstituted sheet with the sheet containing much less nicotine than leaf tobacco.

I would like to repeat that the allegations of Day One and David Kessler concerning nicotine manipulation are false and inconsistent with the reported data and nicotine on commercial brands.

I would also add, in listening to Dr. Kessler's testimony, that I believe he has changed what he was saying in the letter that he wrote. He seems to no longer be saying that nicotine is being added to tobacco. I heard the words, it doesn't matter from his perspective whether he is talking about endogenous or exogenous nicotine, this is a reversal of where he was before saying nicotine was definitely being added.

Another part of what he said relates to patent and innuendos from existence of those patents. The patents that you saw represent I believe a tiny fraction of patents awarded to tobacco companies over time. There are thousands of patents that have been awarded.

This appears to be a small selective group that was picked out. This does not imply that an individual company is using a patent. Many times patents are sought and awarded by investigators and are permitted by the companies as a form of incentive for continuing work in a field, a kind of recognition. They may be useful in the future, they may also be sought for defensive reasons, you might have an idea that has value in another field-there are all kinds of reasons, but I think these are indeed just innuendos made and you will remember that he clearly said "may" in every instance.

But nonetheless let me say that to my knowledge these patents are not being used, certainly none that are owned by this company are in use that he cited, and they go along the line that I am suggesting, that they are trivia with respect to the matter of manipulating nicotine.

Thank you, Mr. Chairman.

Mr. WAXMAN. Thank you, Dr. Speàrs.

Let's go to Mr. Raffle.

\section{STATEMENT OF STEPHEN N. RAFFLE}

Mr. RAFFLE. Thank you. I am Steven Raffle, a physician and board certified psychiatrist from Oakland, Calif.

For 17 years I served as an assistant clinical professor of psychiatry, and for 10 years as an assistant professor of orthopedic surgery at the University of California, School of Medicine, San Francisco.

In the course of more than 20 years of clinical practice, I have evaluated and/or treated many patients with various drug addictions and drug intoxication, and I have worked with many people with weight problems and other habitual and compulsive behaviors.

I have reviewed H.R. 1247 as well as the related Surgeon General report and other pertinent scientific literature. 
I appear before you today to address the proposition that cigarette smoking is addictive and a proposed label warning that once a person has started smoking, he or she may not be able to quit, and that cigarette smoking is as addictive as heroin or cocaine.

Cigarette smoking behavior is not the same as seeing an actual hard drug addiction. The only reason smoking became an addiction in 1988 is because the Surgeon General changed the definition of addiction, not because of any new scientific discoveries.

I do not appear here as an apologist or promoter of cigarette smoking. Fundamentally I believe it is a risk factor in the development of some diseases. What is it about truly addicting drugs that differentiates them from habitual behaviors such as cigarette smoking, coffee drinking, eating, or exercise?

First, is the effect produced by ingestion. A person on hard drugs is intoxicated. The person's state of consciousness is altered, reasoning is impaired, coordination is affected, and memory and concentration are substantially altered. Mood is visibly changed, judgment is warped and delusions and/or hallucinations may occur. Overdose may cause death.

Intoxication does not occur with cigarette smoking. Cigarette smoking is similar to the effect produced by drinking a cup of coffee and very dissimilar from the effect produced by hard drugs. People who smoke think clearly and make reasoned decisions.

The second difference occurs upon cessation of drug use. Abrupt cessation of a hard drug following a regular use will inevitably and predictably result in a classic withdrawal syndrome including rapid blood pressure changes, muscle cramps, nausea, hallucinations or delusions. Withdrawal from hard drugs is so severe as to render the addict incapable of making or carrying out reasoned decisions.

Cigarettes and nicotine cessation is not really withdrawal because it produces none of these signs or symptoms. It is impossible to predict whether or not a smoker will have any discomfort based upon cigarettes smoked per day or the duration that person has smoked, that is to say the number of years they have smoked.

The clinical complaints associated with cigarette abstinence are a far cry from hard drug withdrawal. Abstaining smokers continue to meet their responsibilities without significant disruptions of reasoning, judgment, concentration or efficiency. It may not be pleasant, but the symptoms are no different than those experienced when dieting.

The pharmocologic of hard drugs lead to a change of personality and pursuit of a lifestyle which is dominated by the drug. Nicotine does not. Active smokers can and do abstain for long periods without untoward effect if external circumstances dictate it.

Since 1964, more than 40 million people have stopped smoking permanently without any outside intervention or assistance. The overwhelming majority have quit on their own. With hard drug addiction, self-help quitting or spontaneous remission, to borrow the Surgeon General's term, is an extremely rare occurrence.

As with successful dieting, the smoker must abandon a pleasurable activity and modify a behavior in order to obtain a greater long-term benefit. The smoker need not rebuild his life to succeed, nor does he face perpetual struggle requiring therapeutic support. 
Calling smokers hard drug addicts tends to destroy those components that are necessary to successful quitting. It makes smokers feel like victims who must receive treatment to be successful nonsmokers. Calling smoking an addiction provides some smokers a convenient external excuse for not initiating cessation or giving up too easily.

Perhaps of greater importance is the effect on young people of the message that smoking is just like heroin and cocaine. Every day they see smokers who are productive, sober and fulfill their responsibilities. They also see adults giving up smoking without great difficulty, hospitalization or lifelong therapeutic suppert.

To tell these young people that smoking crack/cocaine or taking heroin will not affect them in a different way than smoking cigarettes encourages experimentation with these hard drugs.

Finally, does the addiction label frighten away potential smokers? Actually it makes cigarettes more controversial and creates in certain groups an invitation to defy authority by smoking. The proposed addiction warning and the assumption upon which it is founded are based neither in science nor fact, and will have unintended harmful results.

Thank you, Mr. Chairman and members of the committee. I will be happy to respond to any questions you may have.

Mr. WAXMAN. Thank you.

Mr. Slade.

\section{STATEMENT OF JOHN SLADE}

Mr. SLADE. Thank you, Mr. Chairman. I appreciate the invitation to being invited to speak at this hearing.

I am an internist, a specialist in addiction medicine testifying on behalf of the American Society of Addiction Medicine. My testimony will present evidence that cigarette manufacturers intend to affect the structure and function of the body.

A couple of comments about the FTC method nicotine, sales weighted averages of nicotine delivery. What I have charted on the graph are the data from the Federal Trade Commission from 1968 through 1991 because on review of the Surgeon General's report, it turns out that the data prior to 1968 aren't published, are not in the public domain, and I can't determine whether the methods used to measure tar and nicotine were the same as those used by the FTC.

Average nicotine levels are unchanged since 1981. As Dr. Kessler mentioned this morning, the test does not accurately predict the bioavailability of nicotine. People smoke quite differently from the machine, and several studies in the literature, including one conducted by a tobacco company, showed substantially more ingestion of nicotine than the test predicts.

In short, the FTC tests results don't predict nicotine levels in smokers, and I believe the test is a fraud when looked at by a consumer and should be abandoned in cigarette advertising.

The next chart is taken from a Philip Morris patent in 1971 that describes the way nicotine is controlled in cigarettes. In 1950, the Federal Trade Commission found that cigarette manufacturers were unable to control nicotine delivery with any great precision because of the inherent variability in their raw materials. 
But by 1994, as discussed this morning, the industry has been able to achieve enormous control over nicotine delivery through advances in technology. This patent shows that, and I will read from a couple of items in the patent.

"It has long been known in the tobacco industry that in order to provide a satisfying smoke, it is desirable to maintain the nicotine contents of tobacco products at a uniform level. However, it is difficult to accomplish this result since nicotine content of tobacco varies widely depending on the type of tobacco and the conditions under which the tobacco is grown."

It discusses the importance of nicotine to give the desired physiologic activity of smoking, and it says it is desirable to add nicotine in a way that allows accurate control of nicotine in tobacco smoke.

The other materials I submitted with my statement provide some of the patents on the technology that is available to the industry about adding nicotine to filters, to paper, to other smoking material besides tobacco. One of the materials used in the industry is tobacco extract. And this is a sample of flue-cured tobacco extract that has about 1 percent nicotine in it.

Mr. Wyden had discussed earlier this morning the additive list, and I quote from the Comprehensive Smoking Education Act of 1984 that directs the companies to provide information. The information that is directed is information on ingredients added to tobacco in the manufacture of cigarettes.

My reading of that is that there is no requirement in the law that the companies have to divulge additives to paper or to filters or to any non-tobacco smokable material that may be in the tobacco rod so your list of 700 ingredients may not be complete and exhaustive. Besides, I don't believe the companies regard this as an ingredient.

Cigarette companies intend that their customers inhale mainstream tobacco smoke and absorb the nicotine. Advertising for Camels and Lucky Strikes in the 1930's mentions inhalation as a specific feature of their products.

Claims about reduced throat irritation are predicated on inhalation and cigarette manufacturers have never said that inhaling was a misuse of their products and never tried to design their products so they were difficult to inhale. They have conducted secret research through the special projects on the toxicity of inhalation. R.J. Reynolds in fact used an inhalation study as the gold standard of how well Premier functioned as a cigarette.

Cigarette companies also intend specific pharmocologic effects from their cigarettes. This is a study from laboratories at R.J. Reynolds showing that relaxation and stimulation specifically come from smoking cigarettes. In this case, they compared smoking a conventional cigarette with smoking a nicotine-free Next cigarette.

The chart on the left demonstrates that nicotine is not absorbed from the Next while it is from the regular cigarette. The charts on the right show that EEG changes associated with relaxation and stimulation come from the nicotine-containing cigarette, but not from the nicotine-free cigarette.

Mr. WAXMAN. Thank you. We will have the rest of the charts in testimony in the record.

Mr. Gardner. 


\section{STATEMENT OF SHERWIN GARDNER}

Mr. GARDNER. Thank you, Mr. Chairman.

I will summarize my statement, if it could be included in its entirety in the record.

My name is Sherwin Gardner. I am an independent consultant to industry specializing in issues arising from the regulation of food and other products by FDA.

I am here today at the request of Philip Morris USA, which retained me to review its tobacco processing and cigarette manufacturing practices in light of recent allegations regarding manipulation of the nicotine content of cigarettes.

To do this I visited several Philip Morris manufacturing facilities in the Richmond, Va. area and was accompanied by two consultants who are expert in auditing FDA facilities in the United States.

We did not find any basis for concluding that Philip Morris manipulates or intentionally adds measurably to the nicotine content of cigarettes through its processing and manufacturing.

Two of the facilities we inspected manufacture reconstituted tobacco products known as blended leaf and reconstituted leaf respectively. In the blended leaf process from 30 to 40 percent of the nicotine is lost and 20 to 25 percent is lost in the reconstituted leaf process.

During our inspections of these facilities, we were able to see manufacturing records of the controls used in producing these reconstituted tobacco products. We did not observe any manufacturing controls in reconstituted tobacco production for nicotine content.

We also inspected the flavor center which prepares the content rates for application to tobacco prior to cigarette making and also the cigarette manufacturing facility, with the same results.

In conclusion, the interviews and inspections at these four Philip Morris facilities provided us with the information to find that the nicotine content of cigarettes is not intentionally controlled by the manufacturing processes, nor is nicotine added during the process of preparing reconstituted tobacco nor as part of a flavoring agent.

The inspections of Philip Morris that I describe further did not disclose any facts that would support regulation of cigarettes as drugs under current law. Clearly the question of FDA's authority to regulate tobacco products is a legal matter. It hinges on a marketer's intent and representation to consumers.

The definitive court holding on this issue was in the case of Action on Smoking and Health versus Harris in 1980. Nothing I have learned during my service at FDA or since changes my understanding of the act and its application in this area.

Certainly the Congress in its wisdom may decide to change the legal standards under which cigarettes are regulated. The question is whether FDA should be burdened with the implementation of another major regulatory program. The Agency already is responsible for the regulation of about 25 percent of consumer purchases and Congress has added important new regulatory responsibilities over the past 15 years without significant additional resources to carry these out.

The regulation of cigarettes in the Agency's responsibility can only jeopardize its ability to serve the public through the approval 
of new drugs, biologicals, and devices and to monitor the safety of the food supply.

Thank you. I will be pleased to respond to questions.

Mr. WAXMAN. Thank you.

Dr. Connolly.

\section{STATEMENT OF GREGORY N. CONNOLLY}

Mr. CONNOLLY. Thank you very much, Mr. Chairman.

I am Gregory Connolly, Director of the Massachusetts Tobacco Control Program representing the American Public Health Association.

We are a $\$ 52$ million State agency to curb smoking in Massachusetts. That is three times the amount of money CDC receives to curb smoking nationally, just in our State.

Having heard the resource problems at FDA, we are prepared to give FDA a grant to regulate tobacco. It will be the first time in the history of the country that a State gave the Federal Government a grant.

I was here 9 years ago before Mr. Waxman and Congressman Synar with a widow from Oklahoma whose son tragically died of smokeless tobacco use. We worked and got a bill through Congress that dealt with the advertising, not the regulation of the product. The regulations for that bill went through in 1987.

If you look at that chart, we failed; smokeless tobacco use is going up. Why? Because the tobacco industry and U.S. tobacco in particular has conducted very detailed research on the action of nicotine on humans. This is a study summarized in the Marcy court case where they took naive tobacco users, gave them snuff, precisely measured their blood yields and compared that to what they called habituated smokers.

In the court record, their vice president read, taste and strength-that is nicotine-should be medium, recognizing the fact that routinely all tobacco use is based upon nicotine, the kick. That is directly from the industry documents.

They took this knowledge and created new products to hook a generation of young Americans. They called for three brands in their graduation strategy, a high nicotine brand, a medium brand, and low brand. What they designed for the low brand was the Skoal Bandit. They said it is for age groups 15 to $35-15$ to $35-$ and they called it nicotine satisfaction.

They developed what they call a graduation strategy. And the graduation strategy was that after a period of time, there was a natural progression to products switching to brands that are more full bodied, less flavored, and more concentrated tobacco.

As far as entering into a new market-this is from the vice president of the company-Skoal Bandit is the introductory product. Then we look toward establishing the normal graduation process. The bottom line is the Bandit is the vehicle by which we are going to expand consumption.

We can look at their advertising. This is where they put their ad dollars. In 1983 about half of ad dollars went for this brand, yet it only had 2 percent of market. No advertising has been done of any appreciable measure for the higher nicotine brand, Copenha- 
gen. Why? You don't have to advertise it. The nicotine does it all for you. Easy to use, convenient, and they have a free sample.

In the free sample, they provide youngsters information how to use it, and the question posed to the new users, how long should I keep the pouch in my mouth? If you haven't tried Skoal Bandit before, we recommend that you keep the first one for about a minute, then remove. Like your first beer, Skoal Bandit can be a taste that takes time to acquire and get the most out of.

After four or five Skoal Bandits, you will find you develop quite a taste for them, and you will want to keep in the pouch as long as the flavors last.

What you see for the Copenhagen, the highest brand, is no free samples; only sooner or later it is Copenhagen. And down below it says it satisfies. If you go back to the document, it is nicotine. It is not a tobacco extract, it is a chemical. Calling nicotine a tobacco extract is like calling morphine an extract of poppy seed oil.

I have listened to individuals after hundreds of thousands of Americans have died from smoking. I was in Canada in the Canadian Parliament just a month ago testifying. People with the same education as us, they go to the same churches, they dress like we do, and they are treating this like a drug.

We need leadership of Congressman Kessler all around this room. Believe me, when I leave this room, I am going back and looking at the Massachusetts food and drug act and make sure we are not preempted and see what we can do to protect the health of our children.

If other States want to have their chairman walking around smoking Camel cigarettes barefoot and enjoying it, so be it, but don't preempt us.

This is the sale of the starter brand, the bottom. It didn't go anywhere. What went up was Copenhagen. What was the impact? That is what that individual graduated to. People say you can't compare it to heroin or cocaine. I have never seen heroin or cocaine commit that level of violence on an individual and that individual's only sin was he got a free sample as a 13-year-old and he couldn't quit because he was addicted to nicotire.

What is the impact on our society? In 1970, the highest rates of oral snuff in our Nation were old men, 2.7 percent post age 50. For 1991 it is up to 8 percent among young males. They didn't do that through advertising but through knowledge of nicotine, applying that nicotine in a marketing strategy with the intent to graduate youngsters up to higher brands over time, 15-year-olds, and they created a market.

Any business would do in the country. These people aren't acting immorally or unethically; they are just good businessmen. The problem is that the Congress and the Food and Drug Administration hasn't treated these people the way they should be treated.

Today 1,200 Americans will die of smoking. Today 3,500 youngsters will start smoking. The tobacco industry says that is not our problem. It is about time we made it their problem.

Thank you.

Mr. WAXMAN. Thank you very much, Dr. Connolly. 
Mr. WAXMAN. I would like to start off the questions. As I indicated, we invited the chief executive officers of the major tobacco companies. They absolutely refused.

We have a letter Mr. Whitley indicates attached to his statement. Let me tell you, we cannot question a letter. We can question witnesses.

Mr. Whitley, you are here on behalf of the trade association, the Tobacco Institute. Is it your position that tobacco is non-addictive?

Mr. Whithey. That is correct. I subscribe to the testimony Mr. Raffle just gave.

Mr. WAXMAN. It is your position that no additional nicotine is being added?

Mr. WhITLEy. Absolutely. That is absolutely, unequivocally our position and that of all of our companies-

Mr. WAXMAN. Why should anybody care in your industry if you are accused of adding nicotine if nicotine is not addictive? Your industry has been accused of adding nicotine.

Philip Morris filed a $\$ 10$ million lawsuit saying that is just not true. Why should anybody care if you are accused of adding nicotine-does it do harm?

Mr. WHITLEY. We are being accused of something we are not doing, and we are being accused of it for the purpose of creating addiction. We don't do it.

Mr. WAXMAN. I understand your position; it is non-addictive, and you are not adding more. If somebody accused you of adding more of a particular substance that doesn't do harm, why should you care? Does it do any harm?

Mr. WHITLEY. We don't think so.

Mr. WAXMan. Dr. Spears, does it do harm to add nicotine to a product?

Mr. SPEARS. There are points beyond which a product is not acceptable in terms of nicotine levels.

Mr. WAXMAN. Why?

Mr. SpEARS. Tobaccos that contain high nicotine level are very unpleasant.

Mr. WAXMAN. So you think that the industry is reacting to the attack that you are adding nicotine which means your products are more unpleasant?

Mr. SPEARS. No, to the fact that addition of nicotine was cast in the view of some sinister motive and some sinister activity, that it was cast in that way.

Mr. Waxman. Dr. Spears, you said you don't know to your knowledge whether any of those patented products are being used. That just means you don't know?

Mr. SPEARS. I have seen those patents for the first time today. My company does not use any of those patents.

Mr. WAXMAN. Mr. Whitley, I guess that is why your company was selected to have a witness here today and not the others who have the patents?

Mr. WHITLEY. The use of the patents mentioned this morning would be totally inconsistent with the manufacture and process that is subscribed in the written statements that we submitted for the record. 
Mr. WAXMAN. Your position is that none of your companies are using those patents?

Mr. WhitLey. My position is that use of those patents would be totally inconsistent with the manufacturing process that each of the companies has described as what it follows in the written statements that were submitted for the record today.

Mr. WAXMAN. If the Chief Executive Officer of Philip Morris were here, we could ask him about these patents, we could ask whether R.J. Reynolds, Philip Morris do things like adding a proportion of nicotine indirectly to the tobacco.

Mr. WhitLEY. Mr. Chairman, if you would care to submit those, we would be glad to submit those to the companies and let them respond.

Mr. WaXman. Come on. You knew we were holding this hearing today on the issue of whether nicotine is being manipulated.

You don't know the answer to this question? You don't know whether they are manipulating it because you don't know whether they are using these patents. Is that your testimony?

Mr. SPEARS. May I respond to that, Mr. Chairman?

You are citing patents that involve the addition of nicotine. You have statements from each company, and I made the statement with respect to my company, that there is no addition of nicotine. That would indicate that none of those patents you are citing is being used.

Mr. WAXMAN. Do you know whether the nicotine levels can be manipulated from what would otherwise be in the blend or the product itself?

Mr. SPEARS. By blending tobacco is the only method of manipulation that is being used, yes.

Mr. WAXMAN. Do you know whether the nicotine levels can be adjusted upward?

Mr. SPEARS. By blending?

Mr. WAXMAN. By blending, by spraying, by any other changes in the tobacco product itself.

Mr. SPEARS. They cannot be adjusted upward except by blending different tobacco types. I don't know what you mean by upward.

Mr. WAXMAN. We have patents by other companies, not by your company, but by Philip Morris and others, where they can add nicotine even to the filter and the paper. Why would they want to do that?

Mr. Spears. That is a patent. They are not doing that. If they were doing it, if would be counter to the statements that they have made that they are not doing it.

Mr. WAXMAN. Why would they want to study it?

$\mathrm{Mr}$. SPEARS. I have already explained that there are individuals in laboratories who carry out all kinds of work for all kinds of purposes, and we would need to examine the specific patent and talk to the investigators and the individual who applied for the patent as to why.

Mr. WAXMAN. I can't believe your answer to me. That is just so insincere. They are doing this because they are in business to make money. Why would they want to have all these patents that allow them to manipulate the nicotine level unless they wanted that opportunity to manipulate the nicotine level? 
Mr. SPEARS. We have patents that we have never used.

Mr. WAXMAN. So it is your testimony

Mr. SPEARS. The patent does not imply commercial use or even commercial feasibility.

Mr. WAXMAN. Is it, to your knowledge, or can you give us absolute assurance that none of these patents are being used by the companies?

Mr. SPEARS. I am giving you assurance that none of the patents that represent addition could be used or it would be inconsistent with the statements that you have.

Mr. WAXMAN. What you are saying to me is either you know what they are doing with their patents, so it is an anticompetitive situation since you are presumably a competitor, or you are saying they couldn't be used because they said they are not adding the nicotine.

Mr. SpEars. Couldn't be used because they say in statements to you, to this committee, that they are not adding nicotine.

Mr. WAXMAN. Well, I am going to come back, but I want to call on Mr. Synar, next.

Mr. SYNAR. Thank you, Mr. Chairman. I would ask unanimous consent to enter into the record a confidential memo that was revealed in the discovery process of the Cipollone case: Motives and Incentives in Cigarette Smoking, William L. Dunn, Jr., Philip Morris Research Center, Richmond, Va.

Mr. WAXMAN. Without objection, it will be entered in the record. [The information follows:]

\section{Motives and Incentives IN Cigareite SMOKIng}

(William L. Dunn, Jr., Philip Morris Research Center, Richmond, Virginia)

There is a lovely little island lying about 150 miles east of the Virgin Islands. It is at the northern end of the Antilles, that string of islands flung out crescent-like across the blue Caribbean waters. Legend has it that in the 16 th century, both the Dutch and the French lay claim to possession of this tiny body of land. Rather than fight it out as was their wont in those days, they showed a surprising and exemplary willingness to apply human reason. A Frenchman and a Dutchman were placed back to back on the beach and told to walk along the beach until they met again on the opposite side. They did so, and a line was drawn between the points of start and finish, dividing the island into the French half called St. Martin, and the Dutch half called San Marteen.

It seems that the Frenchman walked faster than the Dutchman, because the French got the bigger half. Some say this was because the Frenchman was drinking French champagne and the Dutchman was drinking Dutch whiskey. However true all this may be, the two colonies continue to live peacefully under these 16th century terms.

In January, 1972, the Dutch side of St. Martin was invaded by an unlikely party of 25 scientists. There were pharmacologists, sociologists, anthropologists and a preponderance of psychologists. They came from England, Canada and the United States. Each brought with him a carefully prepared scientific paper which represented his best efforts at attacking the question "Why do people smoke cigarettes?"

Inspired by the rare 16th century display of human reason shown by the French and Dutch colonists, and while not sunning on the beach, they listened to and reflected upon each other's ideas.

You've heard many explanations for cigarette smoking. These were reviewed at the St. Martin conference. I think it appropriate that we list the more commonly proposed explanations here: (1) For social acceptance or ego-enhancement; (2) For pleasure of the senses (taste, smell); (3) For oral gratification in the psychoanalytic 
sense; (4) A psychmotor habit for the release of body tension; and (5) For the pharmacological effect of smoke constituents.

I might mention one other explanation, not because anybody believes it but as an example of how distorted one's reasoning can become when under the influence of psychoanalytic theory. Smoking according to this argument, is the consequence of pulmonary eroticism. Translated, this means the lungs have become sexualized and smoking is but another form of the sexual act.

If one asks the smoker himself why he smokes, he is most likely to say "Its a habit." If he is intelligent enough, he might be more to the point and say either one of two things: "It stimulates me", or "It relaxes me". And now we are already deep into our topic. The polarity of these two observations has plagued investigators for 50 years. The challenge to any theory as to why people smoke lies in the theory's ability to resolve this paradoxical duality of effect.

The St. Martin conference was called by the Council for Tobacco Research, U.S.A., in an effort to goad the scientific community into having another go at the problem. And go at it they did. Much of what follows in this presentation comes from that St. Martin conference.

Most of the conferees would agree with this proposition: The primary incentive to cigarette smoking is the immediate salutory effect of inhaled smoke upon body function. This not to suggest that this effect is the only incentive. Cigarette smoking is so pervasive of life style that it is inevitable that other secondary incentives should become operative. The conference summarizer, Prof. Seymour Katy of Harvard, used eating as an analogy. Elaborate behavioral rituals, taste preferences, and social institutions have been built around the elemental act of eating, to such an extent that we find pleasure in eating even when not hungry.

It would be difficult for any of us to imagine the fate of eating, were there not ever any nutritive gain involved. It would be even more provocative to speculate about the fate of sex without orgasm. I'd rather not think about it.

As with eating and copulating, so it is with smoking. The physiological effect serves as the primary incentive; all other incentives are secondary.

The majority of the conferees would go even further and accept the proposition that nicotine is the active constituent of cigarette smoke. Without nicotine, the argument goes, there would be no smoking. Some strong evidence can be marshalled to support this argument:

(1) No one has ever become a cigarette smoker by smoking cigarettes without nicotine.

(2) Most of the physiological responses to inhaled smoke have been shown to be nicotine-related.

(3) Despite many low nicotine brand entries into the marketplace, none of them have captured a substantial segment of the market. In fact, critics of the industry would do well to reflect upon the indifference of the consumer to the industry's efforts to sell low-delivery brands. 94 percent of the cigarettes sold in the U.S. deliver more than $1 \mathrm{mg}$. of nicotine. 98.5 percent deliver more than $.9 \mathrm{mg}$. The physiological response to nicotine can readily be elicited by cigarettes delivering in the range of $1 \mathrm{mg}$. of nicotine.

I hope our English friends who are developing the synthetic nicotineless cigarette arent going to be too disturbed by all this.

Why then is there not a market for nicotine per se, to be eaten, sucked, drunk, injected, inserted or inhaled as a pure aerosol? The answer, and I feel quite strongly about this, is that the cigarette is in fact among the most awe-inspiring examples of the ingenuity of man. Let me explain my conviction.

The cigarette should be conceived not as a product but as a package. The product is nicotine. The cigarette is but one of many package layers. There is the carton, which contains the pack, which contains the cigarette, which contains the smoke. The smoke is the final package. The smoker must strip off all these package layers to get to that which he seeks.

But consider for a moment what 200 years of trial and error designing has brought in the way of nicotine packaging:

Think of the cigarette pack as a storage container for a day's supply of nicotine:

(1) It is unobtrusively portable.

(2) Its contents are instantly accessible. Think of the cigarette as a dispenser for a dose unit of nicotine:

(1) It is readily prepped for dispensing nicotine.

(2) Its rate of combustion meters the dispensing rate, setting an upper safe limit for a substance that can be toxic in large doses.

(3) Dispensing is unobtrusive to most ongoing behavior.

Think of a puff of smoke as the vehicle of nicotine: 
(1) A convenient $35 \mathrm{cc}$ mouthful contains approximately the right amount of nicotine.

(2) The smoker has wide latitude in further calibration: puff volume, puff interval, depth and duration of inhalation. We have recorded wide variability in intake among smokers. Among a group of pack-a-day smokers, some will take in less than the average half-pack smoker, some will take in more than the average two-packa-day smoker.

(3) Highly absorbable: 97 percent nicotine retention.

(4) Rapid transfer: nicotine delivered to blood stream in 1 to 3 minutes.

(5) Non-noxious administration.

Smoke is beyond question the most optimized vehicle of nicotine and the cigarette the most optimized dispenser of smoke.

Lest anyone be made unduly apprehensive about this drug-like conceptualization of the cigarette, let me hasten to point out that there are many other vehicies of sought-after agents which dispense in dose units: wine is the vehicle and dispenser of alcohol, tea and coffee are the vehicles and dispensers of caffeine, matches dispense dose units of heat, and money is the storage container, vehicle and dose-dispenser of many things.

So much for extolling the virtues of the rod. Let us go back now and pick up our discussion of the motivational aspects of smoking. If we accept the premise that nicotine is what the smoker seeks, we've still not answered the question "Why do people smoke"? We've merely reformulated it to read "Why does the smoker take nicotine into his system?"

Systematic research on the question dates back some 50 years to the time when American Tobacco Co. funded the work of a psychologist later to become the most prominent American psychologist of his time. His name was Clark L. Hull. His question then was "Wherein lies the charm of tobacco for those accustomed to its use?"

In order to review the data that has been collected over these intervening 50 years, I have organized it under three headings:

(1) Differences between smokers and nonsmokers.

(2) Human physiological responses to inhaled smoke.

(3) Situational variables related to smoking behavior.

First, then, let us quickly review what is known about the differences between smokers and nonsmokers.

\section{TABle 1-INDIVIdUal Traits and Group Characteristics By Which a GRoup of SMOKERS CAN BE DISTINGUISHED FROM A GROUP OF NONSMOKERS}

\section{Personality Traits:}

More independent (Pflaum, 1965); Greater anti-social tendencies (Smith, 1970); More active, energetic (Schubert, 1959; Straits, 1965); Higher mean extroversion rating (Smith, 1970); "Happy-go-lucky" (Smith, 1969); Higher mean measure of "orality" (Smith, 1970); Poorer mental health (Smith, 1970); Less rigid, less orderly, more impulsive (Smith, 1970); Greater reliance on "external" than "internal" controls (Smith); More chance-oriented (Straits, 1963); More emotional (Smith, 1967); Less agreeable (Smith, 1969); "Type A" personality (More time-conscious, competitive, etc.) (Rosenman, 1966); Less "strength of character"; (Smith, 1969); and Higher anxiety level (Walker, 1969; Srole, 1968; Thomas, 1968).

\section{Life Style Characteristics:}

More business-oriented in occupation (Seltzer, 1964); Poorer academic performance (Veldman and Bown, 1969; Pumroy, 1967; Salber, 1962); More users of alcohol (Higgins, Kjelsberg, \& Metzner, 1967; Lilienfeld, 1969); More users of coffee and tea (Lilienfeld, 1959); Religious service attendance less frequent (Cattell, 1967; Straits and Schrest, 1963); Proportionately higher frequency of marriages and job changes (Lilienfeld, 1959); Higher incidence of prior hospitalizations (Lilienfeld, 1959); Higher incidence of smoking among parents (Salber and Abelin, 1967); More active participation in sports (Lilienfeld, 1959); and, More auto accidents (Ianni and Boek, 1958).

Morphological Traits:

Greater body weight (Seltzer, 1963); Greater height (Seltzer, 1963; Baer, 1966); Thinner (Higgins and Kjelsberg, 1967); Higher height/(cube root of weight) ratio (Damon, 1961); and, Thinner skin folds (triceps and subscapular) (Higgins and Kjelsberg, 1967). 
Demographic Characteristics:

More men (Public Health Service Publication No. 1000, 1970); Proportionately more 25-45 year-olds (Public Health Service Publication No. 1000, 1970); Lower mean socio-economic class (Salber and MacMahon, 1961); Proportionately fewer college men (Higgins, Kjelsberg \& Metzner, 1967; Lilianfeld, 1959); and, More urban residents (Higgins, Kjelsberg \& Metzner, 1967).

Many of these characteristics have little meaning without considerably greater explanation than is appropriate for this presentation. Suffice it to say that the list does summarize our state of knowledge on the smoker-nonsmoker differences. As for the relevance of this knowledge to the question of motivation in smoking, I would say that it is a rich source of hypotheses and hunches, but unfortunately, that is about as far as it can take us. And I regret to say that the major effort of psychologists has been to search for these differences. Hull warned us 50 years ago that the difference approach was a primrose path, but only recently have psychologists begun to appreciate Hull's warning.

The pharmacologists and physiologists have done much better, which leads us to the second body of fact; the human physiological response to smoke. The list in Table 2 again is a summary of our knowledge. To be sure there are other responses, some of which have been noted in the literature, some likely yet to be discovered but those listed have been reported by at least two non-related laboratories.

\section{Table 2-Transient Physiological Responses to Smoke Inhalation}

(1) Elevated heart rate; (2) Elevated coronary flow; (3) Elevated blood sugar level; (4) Lowered cutaneous temperature in the extremities; (5) Increased blood flow in skeletal musculature; (6) A reactive release of adrenalin; (7) Alterations in electrical potential patterns of the brain involving alpha wave suppression; and (8) Inhibition of patellar reflex.

Where these responses have been plotted over time, they have been observed to have their onset within several minutes of smoke inhalation, and they are shortlived, having a decay function with a half-life of about 30 minutes. Onset and decay, roughly parallel the coincident plotting of nicotine in the bloodstream. (Isaacs \& Rand, 1972).

These facts are considerably more relevant to the motivation question than are the facts about smoker-nonsmoker differences. In psychology, when we talk about motivation we refer to a force which impels one to act, and the action is goal-oriented. Hunger, for example, is a motive which impels one to the action of ingesting food. The goal is a state of satiety. Reaching the goal is the reward, and the behavior which is instrumental in reaching the goal is reinforced.

With this in mind, we can now ask several questions "Are any of the listed physiological reactions sought after by the smoker?", "Are these physiological reactions symptomatic of a body state which is the goal of smoking behavior?

One feature of the list which has impressed many investigators is its close resemblance to the physiological response pattern accompanying emotional arousal, such as fear, anger, even joy. Is this perhaps the goal of the smoker, to achieve a body state which mimics emotional arousal?

In the context of this question, let us now turn to the third body of fact, the situational variables related to smoking behavior. So as not to bore you with references and the recitation of all the evidence, permit me to present this body of fact in the form of a summary statement: The rate and incidence of smoking varies as a function of external conditions which influence the emotional state of the smoker. The evidence at hand permits us to go one step further; the rate and incidence of smoking is highest at the extremes of the arousal continuum.

If one were to plot smoking rate against some measure of the smoker's level of bodily arousal, one would observe a nice U-shaped distribution. This observation brings us full circle, for you will recall that at the outset of this presentation I quoted the smoker as explaining his smoking in paradoxical terms: It calms me, it stimulates me.

You may also recall that I stated that the challenge to any explanatory theory of smoking is to resolve this paradoxical duality of effect. At the St. Martin conference, Professor Stanley Schachter, a psychologist at Columbia University, labeled this as the Nesbitt paradox; Nesbitt being a student of Schachter's who called the paradox to his attention.

Let me state this paradox as clearly and succinctly as I can: The known physiological effects of smoking are those that we consider as indicating body activation or arousal. This fits in nicely with the smoker's statement "It stimulates me". But it is highly discordant with the polar explanation which the smoker provides per- 
haps even more often- "It calms me". And why should an already aroused, excited person seek further physiological arousal?

Summarizing the known facts pertinent to the question of motivation:

(1) Smoking is relatable to personality variables.

(2) Smoke inhalation induces documented physiological responses similar to those induced by emotional arousal.

(3) Smoking rate varies as a parabolic function of body activation level.

I will end this presentation by summarizing the two major theoretical explanations proposed at the St. Martin conference. We shall see how each attempts to cope with the Nesbitt paradox.

The first is that of Hans Eysenck. To appreciate his explanation of smoking, you must sit still for me to give you a skeletal outline of his theory of personality. Eysenck contends that there are two major dimensions of personality. He uses the poles of the dimensions to label them: extroversion-introversion and neuroticism-stability. He states that the evidence shows no relationship between smoking and the neuroticism-stability dimension. There is, however, abundant evidence of a relationship between smoking and the extroversion-introversion dimension. His explanation for smoking proceeds as follows: Under identical external conditions of low-sensory input, extroverts will have a low level of cortical arousal and introverts a high level of cortical arousal. For every individual there is an optimum level of arousal. Since arousal varies with the level of sensory input, one can visualize as in Figure 1 the relationship of sensory input and hedonic tone, or sense of well-being. It can be seen that, in these terms, too much stimulation is to be avoided, and also too little. Introverts and extroverts require different levels of input for optimum arousal; the extrovert needs more, the introvert less. Extroverts will become stimulus seekers, introverts stimulus avoiders. Drugs are used to alter the level of sensory input. Nicotine is also used to alter the level of sensory input. Now we shall see how he resolves the paradox: He acknowledges that nicotine has an arousal. Activating effect, and reasons that extroverts therefore should smoke more than introverts. And happily this is true. But what now does he do with his smoking introverts? Surprisingly, he does not attempt to resolve the Nesbitt paradox. He invokes it, pointing out that nicotine can have both arousing and sedating effects. He cites the well-known biphasic action of nicotine as documented by neuropharmacological research. At low concentrations, nicotine activates neural function, at high concentrations, it depresses neural function.

Two serious flaws in Eysenck's reasoning must be pointed out:

(1) The neuropharmacological evidence for the biphasic action of nicotine is based upon observations of neeural tissue response to the local application of nicotine in animal studies. Stimulation occurred at low concentrations of nicotine, depression at high concentration levels. It is absolutely impossible for the concentration level required to induce neural depression to be attaired by means of smoke inhalation.

(2) To postulate both activating and sedating effects is to defy the documented universality of the activating physiological effect of smoke inhalation.

Eysenck, then, has not dealt effectively with the Nesbitt paradox. And I would remark in passing that the theory of Sylvan Tomkins, widely acclaimed in some circles, suffers from the same criticism. Tomkins has proposed that there are different types of smokers each type seeking different effects from smoking. Tomkins, too, has chosen to overlook the universality of smoke-induced physiological arousal, agreeing with Eysenck that smoking can be either arousing or sedating, depending upon the person and the situation.

The second theoretical explanation from the St. Martin conference is that proposed by Professor Schachter, whom I have already mentioned for coining the phrase "the Nexbitt paradox". Schachter offers an ingenious resolution of the paradox, and an explanation of smoking which you will most certainly find novel and possibly noncredible. Again you must first be briefed on Schachter's theory covering all kinds of affective or emotional experience.

The bodily arousal accompanying emotion is the same for all emotions: fear, anger, joy, etc. The person interprets the bodily emotional state in terms of the circumstances under which the emotion is experienced. Sometimes there are faulty interpretation. These can be dramatically demonstrated in a laboratory setting. An example: A male college student is given adrenaline without his knowledge and under pretext that makes him unsuspecting. All this takes place in the presence of a very attractive female lab assistant. At about the time that the adrenaline begins to take effect the young woman crosses her legs provocatively and lets her hand linger a bit too long on his arm. The subject invariably interprets the adrenaline-induced arousal as an erotic arousal and behaves accordingly. The lab assistant threatened to quit if the experiment were to continue. 
Now how does Schachter apply this theory to resolving the Nexbitt paradox? There is no paradox, of course, in the smoker seeking arousal when at the low end of the arousal continuum, but why seek arousal through smoking when excited, as is so often the case?

I quote him: "As we all know, disturbing and frightening events are presumed to throw the autonomic nervous system into action, epinephrine is released, heart rate goes up, blood pressure goes up, blood sugar increases, and so on. Now notice that many of these physiological changes are precisely those changes that we're told are produced by smoking a cigarette. What happens, then, to the smoking smoker in a frightening situation? He feels the way he usually does when he's frightened but he also feels the way he usually does when he's smoking a cigarette. Does he label his feelings as fright or as smoking a cigarette? I would suggest, of course, that to the extent that he attributes these physiological changes to smoking, he will not be frightened. And this, I propose, is a possible explanation for the strikingly calming effect that smoking a cigarette had on the chronic smokers in Nesbitt's experiments."

There is a variant on the Schachter hypothesis that should properly be ascribed to Frank Ryan, one of my psychologist colleagues at the Philip Morris Research Center.

Ryan suggests that arousal by smoking is perhaps a means of muting or damping an arousal response to exciting or disturbing circumstances. There are limits within which a person will operate on the arousal continuum. If pushed up toward the upper limit by smoke inhalation, there is little room left for further arousal by external events. Thus the smoker can prep himself against the disturbing effect of anxiety or fear, or anger or whatever.

This is the end of my presentation. If you have been intrigued by any of these ideas, I recommend the recently published volume entitled "Smoking Behavior: Motives and Incentives", a compendium of papers presented at the St. Martin Conference, published by V.H. Winston \& Sons of Washington, D.C.

Mr. SYNAR. Mr. Whitley, I would like to read you a portion of this internal Philip Morris memo from 20 years ago. Let me read it to you.

Without nicotine, there would be no smoking and strong evidence can be marshalled to support this argument. No one has ever become a cigarette smoker by smoking cigarettes without nicotine. Most of the psychological responses to inhaled smoke have been seen to be nicotine related.

Do you deny that memo of 20 years ago?

Mr. Whitley. Mr. Synar, I have heard that memo referred to a number of times in the past, and I assume it is authentic.

Mr. SYNAR. Do you deny the statement within that memo, Mr. Whitley?

Mr. WHITLEY. I think the statement that is in that memo, if you read the entire memo, represented the opinion of the person who expressed that view.

Mr. SYNAR. It is the position of the Tobacco Institute that this memo is false?

Mr. WhitLEy. No. I think that memo, to the best of my knowledge and belief, is an authentic memo and it reflects the views of the person who made that statement.

Mr. SYNAR. Do you deny the merits of that statement; just yes or no, Mr. Whitley?

Mr. Whitley. Well, I don't-tell me what you think the merit is, and I will answer your question.

Mr. SYNAR. Mr. Whitley, in your written testimony you state that H.R. 2147 would, quote, "produce an instant ban on tobacco products currently on the market," end quote. You later assert if the bill contemplates that FDA must find current tobacco additives to be safe before they can be used, "the result would be an instant 
ban on all tobacco products currently on the market, pending a review of all additives by the Agency," unquote.

Do you deny that cigarette ingredients cause cancer and are not safe?

Mr. Whitley. Yes, I deny that they cause cancer and are not safe.

Mr. SYNAR. So it is your position that after an FDA review, cigarettes would be allowed back on the market?

Mr. Whitley. Mr. Synar, as we read your bill, before we could sell cigarettes, the FDA would have to review the ingredients and determine if they are safe, and during the course of that review, I assume the cigarettes would be kept off the market.

Mr. SYNAR. Is the industry's only objection then that during that 6-month period or window of review that cigarettes would be off the market? Because I will be more than happy to allow that ban to be lifted during that period.

Mr. WhitLey. That is not our only objection. We don't think the FDA needs to be regulating ingredients. The office of

Mr. SYNAR. Mr. Whitley-Mr. Whitley, you said that it is safe enough and effective enough to get back on the market; and yet you then said the reason you are concerned that it would not get on the market is because of the ban. Is it your position that after FDA reviews, cigarettes would or would not be allowed back on the market?

Mr. WhITLEy. It is my opinion that they will be allowed back on the market when they complete the review process, but that still doesn't mean we want to be regulated by the FDA.

Mr. SYNAR. Mr. Whitley, the Cigarette Labeling and Advertising Act of 1984 requires tobacco companies to disclose the ingredients to the Secretary of HHS and not to the public.

Again, in your testimony, you claim that nothing has occurred since 1984 to change these requirements, and I want to just ask you where you have been since 1984 .

Are you aware that direct smoking of cigarettes has resulted in 419,000 deaths per year?

Mr. WhITLEY. I am aware that those figures have been repeated a number of times.

Mr. SYNAR. Are you aware, Mr. Whitley, that environmental tobacco smoke causes 3,000 deaths a year?

Mr. WHITLEY. I am aware that those figures have been repeated.

Mr. SyNAR. Are you aware, Mr. Whitley, that the AMA has found that smoke is found in the hair of newborn children whose mothers smoke during pregnancy?

Mr. WHITLEY. I am aware of that-that has been said.

Mr. SYNAR. Mr. Whitley, are you aware that EPA has classified nicotine as a Class I carcinogen?

Mr. WHITLEY. Yes, and that was a gross mistake.

Mr. WAXMAN. Mr. Whitley, are you aware that all food and drug ingredients must be on package labels other than cigarettes?

Mr. WhITLEY. No, that is not the case.

Mr. SYNAR. So there have been changes since 1984, have there not, Mr. Whitley?

Mr. WhitLEY. Not in our product. Not in the manufacture and marketing of our product. 
Mr. SYNAR. Dr. Raffle, you say in your testimony, quote, "it is impossible to predict whether or not a smoker will have any tobacco abstinence discomfort based on the number of cigarettes smoked per day or the duration of smoking," unquote.

Now, Doctor, that flies in the face of the American Psychological Association and also the Surgeon General's report where they found that cigarette and other forms of tobacco are addicting. They also found that nicotine is a drug in tobacco that causes addiction. And it also flies in the face of the American Medical Association's position, which was delivered to the offices of the members of this subcommittee today, that our experience in dealing with tobacco results - that tobacco smoke is a deadly result that cannot be denied.

So you are in some ways a maverick against every reputable medical institution and association in the county, are you not?

Mr. RAFFLE. Nothing you have read to me just now goes counter to the statement that I made that the predictability of the difficulty in stopping smoking has anything to do whatsoever with the number of cigarettes smoked per day or the number of years a person smokes.

Mr. SYNAR. That is not the position of AMA or the American Psychological Association, is it?

Mr. RAFFLE. No, you misstated their position, sir.

Mr. SYNAR. No, I have not.

Mr. Gardner-if I could have one more question-you were the Deputy Commissioner of the Food and Drug Administration; is that correct?

Mr. GARDNER. Yes, sir.

Mr. SYNAR. And during that period of time you assisted in setting ingredients for cheeses and other food products; is that correct?

Mr. GARDNER. Yes, sir.

Mr. SYNAR. And you were also involved in putting ingredients on Nyquil and other drugs that are currently on the market; is that correct?

Mr. GARDNER. That is correct.

Mr. SYNAR. Can you explain to this subcommittee and this member how you can justify having worked down there and actively sought the listing for ingredients on those products, but you will not find any ingredients on this product which has so clearly affected so many millions of Americans lives?

Mr. GARDNER. Mr. Synar, if the concern is over the safety of ingredients, then I think there are many ways to go about dealing with that question other than putting them on the label. And what I think is necessary, if that is a concern, is to look for ways that are the least burdensome on the Agency and on the industry.

Mr. SYNAR. Mr. Gardner, did you see Dr. Kyle said that he would recruit States to finance any burdens that the FDA might have?

One final question, Mr. Gardner, are you being paid to consult with the tobacco industry?

Mr. GARDNER. I am being paid for my consultation to do the job that I described, that I visited the Philip Morris facilities for, yes, sir.

Mr. SYNAR. Thank you.

Mr. WAXMAN. Paid by the tobacco industry? 
Mr. Gardner. Paid by Philip Morris USA.

Mr. WAXMAN. Mr. Wyden.

Mr. WYDEN. Dr. Spears, let me tell you that the central concern I have is that it seems to me that the industry is constantly saying that concerns like we are expressing today are kind of trivial and no big deal, and then goes to such extraordinary lengths to try to keep secret what is in tobacco.

I have here - under the confidentiality laws, I am not allowed to go into detail-I have a letter here from the Centers for Disease Control. And what this letter says is that 13 of the ingredients that are known to be added to tobacco in the manufacture of cigarettes cannot be used in food under the Food and Drug Administration statute.

My question to you is, again in the name of openness and in the name of disclosure, can you tell us from your knowledge what items are included in tobacco products now that cannot be used in food in our country?

Mr. SPEARS. I am familiar with the list that you are talking about-

Mr. WYDEN. You are familiar.

Mr. SPEARS [continuing]. But I am under a confidentiality agreement, as well, and I cannot discuss the items on the list.

However, let me say that from my perspective, this list has been available to scientists within HHS who are willing to sign a confidentiality agreement for review for a 10-year period or a 9-year period. To my knowledge, until this date, there have not been any questions raised about individual items that are part of that list.

My only knowledge is that-and I think this has been said already-that Secretary Sullivan in 1990 said to the Congress that that list of ingredients was not a priority for his organization.

Mr. WYDEN. Well, we know for a fact, because we have worked on trying to obtain this list, that essentially nobody has looked. Frankly, I think that is one of the most powerful indictments of the way government has regulated tobacco is that here we have a 1984 law so that at least public health officials could know what dangerous ingredients were in tobacco and virtually nobody looked.

I gather that you know the answer to my question. You know what is not allowed in food, and yet turns up in tobacco.

I am just curious, do you feel any obligation to the customers that buy your products to give them that kind of information? I think Oregonians would like to know that. My constituents would like to know if something isn't allowed in food that is in your cigarettes. I am curious whether you think there is any obligation to consumers in my State and elsewhere to tell them that?

Mr. SPEARS. I think you are making the implication that there is something significantly wrong with something on a list that is not approved for food-

Mr. WYDEN. I just said, why don't you tell them? Let them choose it. Why don't you give them the truth?

Mr. SPEARS. As far as I am concerned, you have scientists who have access to the information in government who can look at this list and make any determination they wish. They can talk to the industry about it. They can talk about the individual companies about it, the scientists in those companies. 
There is no secret about this list in the sense that there is adequate opportunity for government employees with proper backgrounds to review this list. And I am simply saying that your suggestion that there is something on a list that is not approved for food, that in itself is no indictment that there is anything wrong with that particular ingredient.

Mr. WydEN. I have looked at the list and there are things on that list that are so toxic you can't put them in landfills, and they are very serious ingredients, and I guess you want to wash your hands of your responsibility to the consumers of this country by saying maybe somebody else in government ought to take a look. But I want you to know that I think that is a breach of responsibility to your consumers, and it seems to me that if the industry had nothing to hide, which has been at the heart of your arguments to this Congress now for many years, you would be willing to put it out. But you are not.

You are willing to really, as far as I can tell, go to great lengths to kind of keep it out of the public's view; and I think that is unfortunate.

\section{$\mathrm{ABC}$ reported-}

Mr. SPEARS. Could I just say one other thing?

Mr. WYDEN. My time is short and you have already told me that you are not interested in the public getting the information.

Dr. Spears, the ABC program Day One recently reported that some tobacco companies use a substance called nicotine sulphate. Is that a toxic compound?

Mr. SPEARS. Nicotine sulphate is a salt of nicotine.

Mr. WYDEN. Is it toxic?

Mr. SPEARS. At what concentration?

Mr. WYDEN. Again, I would like to hear from you whether or not you all use that kind of ingredient and whether or not it is toxic? Do you use nicotine sulphate?

Mr. SPEARS. We do not use nicotine sulphate.

Mr. WYDEN. Not in any quantity?

Mr. SPEARS. I would say this, however, that I believe that the denaturing agent in the SDA-4 alcohol may be nicotine sulphate.

Mr. WYDEN. So you may use nicotine sulphate?

Mr. SPEARS. It may be. As I have already disclosed to you and mentioned to you, the fact that we use denatured alcohol and the amount of nicotine or nicotine sulphate in denatured alcohol would be insignificant and trivial.

Mr. WydEN. Mr. Chairman, I know my time has expired, but why would a company use a substance like this in manufacturing cigarettes?

Mr. SPEARS. I don't know, and I don't think you can get an intelligent answer until someone raises the question with the company that may have reported nicotine sulphate.

Mr. WYDEN. You told me it may be used in your cigarettes. That is what you just told me.

Mr. SPEARS. What I told you was that we use SDA-4 alcohol, and that the denaturing agent is nicotine. And nicotine sulphate is the same as nicotine; it is a salt.

Mr. WYDEN. Mr. Chairman, my time has expired, but nicotine sulphate has been characterized by the Centers for Disease Control 
as an extremely toxic compound which is easily absorbed by the human body; and I think this is an additional area we ought to be following up.

Mr. WAXMAN. Thank you, Mr. Wyden.

Dr. Raffle, this is your second appearance before our committee. You were here in 1988 and you testified then that-on behalf of the tobacco industry, in opposition to the Surgeon General's finding that nicotine was addictive, and apparently your views and your client haven't changed in 5 years; is that correct?

Mr. RAFFLE. My views haven't changed. I don't have a client.

Mr. WAXMAN. You not being paid a consulting fee for your appearance today?

Mr. RAFFLE. I am only being paid the amount of money that I am losing in my practice today.

Mr. WAXMAN. And who is paying you that amount?

Mr. RAFFLE. The people who asked me-Mr. Whitley is.

Mr. WAXMAN. Mr. Whitley, Dr. Raffle is here at your request to tell us that he doesn't think that nicotine in cigarettes is addicting. You stated on the record that you don't believe cigarettes are addictive and nicotine is addictive. Do you know which company it was that did the studies in the 1980's that indicated that nicotine was addictive, and which company suppressed that study from being published?

Mr. WhitLeY. Mr. Chairman, what was said here this morning by $\mathrm{Dr}$. Kessler is the first suggestion I have ever heard of anything like that.

Mr. WAXMAN. So you would have no knowledge of -

Mr. WHITLEY. I have no knowledge of the incident that he referred to.

Mr. WAXMAN. Dr. Spears, do you have any knowledge of that?

Mr. SPEARS. I am sorry. Would you repeat the question?

Mr. WAXMan. Dr. Kessler said that he had information of a company that did some studying about the nicotine addictive qualities, and once they found out, through looking at whether the animals seemed to respond to that addiction, they suppressed that study. Do you know which company that was?

Mr. SPEARS. I have no information.

Mr. WAXMAN. We are going to get that information, and unless there is a strong reason, as I indicated earlier, to keep that from being made public, we are going to make it public; and perhaps we will get the people from that company here to talk about it.

But it would seem to me that if that study did take place and at least one company knew that nicotine was addictive, they might have told the rest of the industry about it as well; or they might have acted on that by trying to manipulate the nicotine levels in order to make people addicted to that cigarette product.

Now, Dr. Spears, you said that nicotine is not being manipulated, but in the manufacturing process, is there ever a time when nicotine is added?

Mr. SPEARS. Added means additional?

Mr. WAXMAN. No, nicotine levels are in the manufacturing process, is there a time when nicotine is reduced to the point where they add nicotine to where it would have been otherwise in the tobacco? 
Mr. SPEARs. Well, I have described in my statement the manufacture of reconstituted sheet if that is what you are referring to.

Mr. WAXMAN. Reconstituted what?

Mr. SPEARS. Reconstituted sheet.

Mr. WAXMAN. What is that? Is that when they add all the stems and the leaves that otherwise don't have the same virility?

Mr. SPEARS. Small parts of tobacco are formulated into a sheet. In order to make the sheet, one of the processes is to contact these materials with water.

Mr. WAXMAN. I don't really want to know that much about it in the time that I have. What I want to know is, in that manufacturing process, is there nicotine brought into it so that it is reconstituted to what it might have otherwise been?

Mr. SpeARS. As I explained, this is a continuous process. Some nicotine would go into the water. Water is placed back on the fibrous material after they have been separated and made into a sheet. I do not consider that an addition.

Mr. WAXMAN. I gather that is the distinction that we are getting from the tobacco industry, that it is not an addition of nicotine if it was brought to the levels it would have been otherwise.

Why do we need nicotine in cigarettes at all if we have the ability to take it out?

Mr. SPEARS. I think-it is an important flavor to me.

Mr. WAXMAN. You think it is a flavor?

Mr. SPEARS. Undoubtedly.

Mr. WAXMAN. Dr. Kessler seemed to question it was a flavor. You even indicated if you had too much nicotine it is a pretty acid and unpleasant taste.

Mr. SPEARS. I am referring to certain types of tobaccos, yes.

Mr. WAXMAN. Well, I thank you all for your testimony.

Mr. SPEARS. Could I correct one thing you said a minute ago? And that is that Dr. Kessler said that this experiment that was not reported was proof of addiction. I think he did not say that.

$\mathrm{He}$ said it showed that the animals pressed a lever for nicotine administration.

Mr. WAXMAN. He indicated that is one of the hallmarks of finding out whether a quality or a chemical or whatever is addictive.

Mr. SPEARS. That was one of his criteria, but he didn't say that was it.

Mr. WAXMAN. It is a test that is used to determine an addiction, isn't it?

Mr. Spears. It is a test that is used in terms of his definition of addiction, yes.

Mr. WAXMAN. How about your definition of addiction? You are a scientist. Isn't this a test that is used to determine addiction?

Mr. SPEARS. Let me explain. I think if you look at the literature on this, you will find that there are many, many tests-

Mr. WAXMAN. I am sure there are many tests. Isn't this one test that is used to see whether it is a hallmark of addiction?

Mr. SPEARS. There are many reports of this one test in the literature, and-

Mr. WAXMAN. Listen to my question and give me a yes-or-no answer, if you can. 
Isn't this a test that is used to determine whether-it is a hallmark test for looking at addiction?

Mr. SPEARS. That was his position.

Mr. WAXMAN. Do you deny it?

Mr. SPEARS. I don't think so.

Mr. WAXMAN. Pardon?

Mr. SPEARS. It depends on the strength of the experiment and a lot of things.

Mr. WAXMAN. But if you are going to determine addiction, isn't this one of the tests that is used?

Mr. SPEARS. Look, it is a test that is used.

Mr. SYNAR. Did the company make a mistake using that test as a barometer?

Mr. SPEARS. I don't know any more about it. I am just trying to say that Dr. Kessler did not call this addition-addiction.

Mr. SYNAR. Mr. Whitley, the patents that Dr. Kessler presented are interesting. You saw them. Do you have any information on whether any of those patents were actually used by the industry?

Mr. WHITLEY. Let me go back to what I said previously, Mr. Synar. If you will look at the written statements that each of the companies submitted today, every single one of them says that we do not add nicotine. I do not believe-

Mr. SYNAR. I would like to ask you-

Mr. WHITLEY. I do not believe-if you would let me finish, please.

Mr. SynAR. No. Mr. Whitley, I have asked you, on behalf of this subcommittee, if you would go back to the various companies and as a sign of good faith report back whether or not any of the patents that Dr. Kessler talked about have been applied by the industry.

Dr. Raffle, first your testimony states that you see patients with various drug addictions and drug intoxications, including heroin, alcohol and other things. I do not see from your testimony that you have dealt with patients who are not able to stop smoking. Do you?

Mr. RAFFLE. In the course of my practice, I sometimes have patients who also smoke and ask me for their-for my guidance in doing so. I then tell them that smoking is not a big deal. That 40 million Americans have stopped smoking, not to start again. That none of them-none-maybe 95 percent of those

Mr. SYNAR. So your experience is limited to that kind of advice and limited readings?

Mr. RAFFLE. I have more answer to give you, sir. Can I tell you what else I tell my patients?

Mr. SYNAR. Yes.

Mr. RAFFLE. Good. I also tell them that when they stop smoking they are going to experience a loss of a well-liked and entrenched habit. And that they will feel a yearning for it. They will also have probably some restlessness, some fidgeting, but that it has nothing at all to do with the kind of detoxification that occurs with drug addictions such as heroin and cocaine, which I have described in my report to you.

Mr. SYNAR. So you don't specialize in a stop-smoking type of-

Mr. RAFFLE. You don't need to specialize in stopping smoking to help people stop smoking. It is easy. All you have to do is want it. 
Mr. SYNAR. I hope that you get a tape of this so that you can watch it.

Mr. RAFFLE. It is a behavior, Mr. Synar.

Mr. SYNAR. Mr. Ballin, the Tobacco Institute has claimed that the bill that I have introduced, a number of the associations that you represent support-singles out tobacco products which are, quote, already highly regulated and therefore it would be punitive treatment of this product. How do you respond to that?

Mr. BALLIN. I think tobacco products have already been singled out for special treatment. They are the only products that are exempt from Federal regulation in the way they are manufactured, sold, labeled, advertised and promoted. And for the industry to claim that they, in fact, are overregulated, I think does a disservice to the public health's interest.

Mr. SYNAR. Thank you.

Thank you, Mr. Chairman.

Mr. WAXMAN. Thank you, Mr. Synar.

Dr. Raffle, maybe I should ask this question of you.

I recently received a copy of a letter sent to the Tobacco Institute last month following the Institute's denial that nicotine was addicting. The letter was sent by a Pat McGlothlin of Hollywood, Fla.; and I don't know whether the Institute even responded to Ms. McGlothlin or not, but I would like you to respond to her today.

She writes, quote: "I must comment on your statement that cigarettes are not addictive. Let me tell you about my father's death from emphysema. His death was not the bad part. His life was the real horror story. My earliest childhood memories include hearing my dad's persistent, constant, hacking cough, watching him continually spit up phlegm into a coffee can which he had by his side 24 hours a day.

"I also remember my dad being in the hospital once or twice each year for a lengthy stay while his lungs were being pumped of the poisons from nicotine.

"My most vivid memories were my dad's unforgettable words of despair. Not one day went by when he didn't say, 'I know these damn cigarettes are killing me, but I can't quit.' I remember his being under the oxygen tent begging for a cigarette. Does this sound like a pleasurable, nonaddicting hobby or a disgusting, addicting disease? Do you think a person would choose this lifestyle?

"My dad never got the chance to meet his three grandchildren, and he died with a cigarette in his hand. It is too late for my dad, but please be honest for the sake of our young people today who still have a chance to just say no to this harmful drug called nicotine," end quote.

How would you respond to Pat McGlothlin, Hollywood, Fla?

Mr. RAFFLE. I would first express my condolences to her. I would then explain to her that a person who is smoking, such as her father, had the capability of stopping if he believed he could stop and if he wanted to stop and if someone didn't tell him that he was addicted to cigarettes.

Mr. WAXMAN. You mean someone told him he was addicted and therefore he believed it?

Mr. RAFFLE. I think that is a component, and that is really the reason I am here today. I don't want you to put an addiction label 
on cigarettes because there are people who want to smoke, who if you tell them they are addicted and they believe they are addicted, it is going to make it harder for them to believe they can stop.

Mr. WAXMAN. That must be why that company suppressed the study that indicated that perhaps cigarettes are addicting. They didn't want people to hear it because they might in fact become addicted if they heard it.

Do you think that might be the case?

Mr. RAFFLE. I am trying to answer your other question, sir; then I could come back to that one. I would be glad to.

Mr. WAXMAN. Why don't you answer the second one first?

Mr. RAFFLE. I am trying to keep the questions straight, Mr. Waxman.

In terms of Ms. McGlothlin's very troubling letter, to me, that when smokers are in a hospital and the doctor says, this is not a smoking hospital, people stop smoking. If they have addictions to real drugs like heroin and cocaine; and you say, this is not a hospital where you can get heroin and cocaine, they are not able to stop because they go into the withdrawal that I described in my report to you today.

Smokers who are in social situations or in situations where they have to not smoke stop smoking, and they do it for long periods of time and they are able to without going into withdrawal.

Mr. WAXMAN. I want to hear from Dr. Slade. You are an expert on addiction.

Mr. SLADE. I am not sure that Dr. Raffle has been in an acute care hospital recently where smoking has been banned. In my hospital and other facilities, smoking is frequently confined now to the bathrooms where patients go to avoid getting scolded by the staff. They are not able to stop. And it is actually another issue.

Our physicians are not treating nicotine withdrawal, not recognizing it as often as it exists. And there are other ways to treat it besides letting people go into the bathroom to smoke.

Mr. WAXMan. You don't believe, Dr. Slade, that people are addicted to cigarettes because somebody told them they are addicted and therefore they talked themselves into it, do you?

Mr. SLADE. That is nonsense. Nicotine causes-

Mr. WAXMaN. Absolute nonsense.

Dr. Raffle, I am just really astounded to hear a person come here and say that-who has presumably some scientific background.

Mr. SYNAR. Mr. Chairman.

Mr. Spears, I want to correct something. Did you say nicotine is used only for flavor by the tobacco industry?

Mr. SPEARS. I said nicotine is an important flavor to the tobacco product.

Mr. SYNAR. Is that the reason nicotine is used?

Mr. SPEARS. Nicotine is a natural ingredient of tobacco.

Mr. SYNAR. What is it used for? Is it for flavor?

Mr. SPEARS. It is present. It is not used for anything. It is an ingredient of tobacco.

Mr. SYNAR. But is its purpose flavor?

Mr. SPEARS. Its purpose is-make a cigarette that contains tobacco, and it automatically contains nicotine; and nicotine is an integral part of the flavor of that cigarette. 
Mr. SYNAR. Is it an active ingredient, Dr. Spears?

Mr. SPEARS. Active in what sense?

Mr. SYNAR. In the sense that you put it back in after you have taken some of it out?

Mr. SPEARS. Only in what I have described to you previously in my statement.

Mr. SYNAR. What I find hard to believe in this argument by the industry is that nicotine is used for flavor. If that is the reason, why don't you add a substitute flavor, if that is the reason, given the serious problems of nicotine?

Mr. SpearS. I have already explained to you that tobacco is grown and it has varying levels of nicotine depending on where in the stock it is harvested from and the different grades. People purchase tobacco by grade. The grades are set.

Mr. SYNAR. Dr. Spears, do you like being here and having to answer these questions?

Mr. SPEARS. I don't mind.

Mr. SYNAR. You know, we wouldn't have to be here if you would just take the nicotine out of the product, if it is just flavor. We could get this issue over real quick. Why don't you do that and end the controversy?

Mr. SPEARS. Why should we take the nicotine out of product? It is integral to the product.

Mr. SYNAR. Yes, it is. As we learned today, it is hooking Americans. Thank you, I think that is a good conclusion.

Mr. WAXMAN. Thank you all for your testimony. We have gone over this issue, and we are going to continue to go over this issue; and I hope we will get some people who will come here and give us very specific answers from the companies themselves, particularly from that company, that we will find out about, who did that report.

We stand adjourned.

[Whereupon, at 1:25 p.m., the subcommittee was adjourned, to reconvene at the call of the Chair.]

[The following statements were submitted:] 
Good Moming Mr. Chairman and members of the Subcommittee. My name is Scott Ballin, Vice President for Public Affairs for the American Heart Association. I am speaking on behalf of the American Cancer Society, American Heart Association, and American Lung Association, united as the Coalition on Smoking OR Health. Thank you for holding this hearing today to discuss the need for regulation of tobacco products by the Food and Drug Administration.

Today, Mr. Chairman, is in many respects an historic hearing, a potential significant turning point for the health of the American public. Since the first Surgeon General's report was released thirty years ago this January, the tobacco industry and the deadly products it sells have escaped regulation under all of the major health and safety laws enacted by Congress designed to protect public health. These laws include the Consumer Product Safety Act, the Toxic Substances Act, the Fair Labeling and Packaging Act, and the Federal Hazardous Substances Act. Applying any of these laws to tobacco products would probably have resulted in the products being removed from the market place. That is how dangerous and hazardous these products have been and are to the health of the American public. Instead, we have a product that is virtually unregulated for health and safety. These special protections for tobacco products have conservatively resulted in the premature deaths of over 10 million Americans. And the epidemic of tobacco related deaths continues and will continue until the tobacco industry is forced to adhere to regulation standards that are designed to protect the health of Americans rather than the profits of the tobacco industry.

While tobacco products have been exempted from regulation under most health and safety statutes, there is one health and safety act that does not include a specific exemption for tobacco products. That is the Federal Food, Drug and Cosmetic Act. As this subcommittee is well aware, the Food and Drug Administration is the primary agency in 
the federal government charged with ensuring that products which the public ingests, implants or applies to the skin are safe, effective, properly packaged and dispensed, properly labeled, and properly marketed. How is it that a product which is a cause of cancer, cardiovascular disease, emphysema, stroke, chronic obstructive lung disease, premature births, osteoporosis, and is addictive remains virtually unregulated at the federal level of govemment in the way in which it is manufactured, distributed, sold, labeled, advertised and promoted? Why has this unacceptable lack of health and safety controls over tobacco been allowed to perpetuate? Several reasons come to mind.

Part of the reason lies with Congress's mistake and failure in 1964 to give the FDA the authority it needed even back then to regulate tobacco products as a significant public health problem. We would not be here today talking about the tobacco industry's manipulation of its products if the proper authorities had been vested in the FDA in 1964. Congress's failure to act on the recommendations of then Secretary of Health, Education, and Welfare Celebreeze, to give FDA jurisdiction, stems also in large measure from the tobacco industry's continued assurances to Congress and the American public that it was a responsible industry that would do the "right thing" if it were proven that smoking caused disease. We know now in retrospect that there were no good intentions on the part of the tobacco industry, nor are there today. The promises and assurances that the industry made to the American public as far back as the 1950s, that it would put the public's health above all corporate interests, were nothing but public relations ploys designed to buy the industry time to find ways to keep its products on the market. A confidential internal tobacco institute document in 1972, released to the public during the Cipollone products liability trial, portrays the tobacco industry "holding" strategies to dupe the public and the Congress and to keep its products on the market as "brilliantly conceived and executed." 
Edward T. Ned Brethitt, former Governor of Kentucky (1964), in a recent interview with a Kentucky Newspaper, indicated that the strategy of Senator Earle Clements back in the 1960 s was to make tobacco regulation the province of Congress, where the industry had influence and could keep the issue out of the hands of unelected regulators.

And Mr. Chairman, the strategies were brilliantly conceived and brilliantly executed. What other industry could, in spite of 23 Surgeon General's Reports and over 60,000 scientific studies, continue to sell an addictive killer virtually unfettered from government oversight and regulation? What other industry could so flagrantly target our children with seductive advertising of an addictive product that kills?

In 1988, the Coalition on Smoking OR Health, after taking a careful look at the history of how tobacco products have been regulated (or should I say unregulated), realized that the Federal Food, Drug and Cosmetic Act could be applied against tobacco products under certain circumstances. It became clear to us that if and when the tobacco industry sold its products with the intent of "mitigating or preventing disease" or with an intent to "affect the structure and/or function of the body of man, " the industry was no longer merely selling tobacco products for smoking pleasure only, it was selling "drugs" under section 201 of the FDC Act. Based on this analysis, the Coalition filed a petition in April of 1988 asking the FDA to classify low tar and low nicotine cigareftes as "drugs" under the FDC Act. That petition is attached to your copy of this testimony for inclusion in the record.

The legislative history of these two sections of the Act, added in 1938, makes their purpose clear - to ensure that products that did not appear on the U.S. Pharmacopoeia list, and which had drug like effects and/or were intended to mitigate and or prevent disease, were to be treated as "drugs" under the Act. Do today's tobacco products meet these definitions? The answer must be a resounding yes. 
It was clear to us several years ago that the tobacco industry's entire low tar and low nicotine market was and should be subject to section 201 of the FDC Act, in that these products were developed, manufactured, and marketed with an intended purpose to both "mitigate and prevent disease," as well as to "affect structure and function of the body." Last spring, the Coalition contracted with the Gallup Organization to determine what the public's perceptions were about these products. When asked what message the industry was trying to get across by using such terms as low tar, low nicotine, and lower yield, almost two-thirds of those surveyed (including both smokers and nonsmokers) believed that these products were in some way safer and/or less addictive.

I think the message is clear. The tobacco industry manufactures and the public buys these cigarettes for the overwhelming reason that they believe these products are safer. These products are, in our view, "drugs" under the Food, Drug and Cosmetic Act. Such a conclusion is consistent with all the legislative history of the Act, the FDA decisions, as well as the case law on when cigarettes can or should be treated as drugs.

As Judge Meany stated so eloquently in a 1953 FDA/cigarette case:

If claimants' [tobacco companies] labeling was such that it created in the mind of the public the idea that these cigarettes could be used for the mitigation or prevention of the various named diseases, claimant cannot now be heard to say that it is selling only cigarettes and not drugs.... The ultimate impression upon the mind of the reader arises from the sum total of not only what is said, but also all that is reasonably implied. If claimant wishes to reap the reward of such claims let it bear the responsibility as Congress has seen fit to impose on 


\section{it. United States v, 46 Carton, More or Less, Containing Fairfax Cigarettes,} 113 F.Supp. 336 (D.N.J. 1953).

Since we filed that petition with the FDA seeking to classify all low tar and low nicotine cigarettes as drugs under the FDC Act, additional evidence has come to light that we believe justifies the FDA taking jurisdiction over all cigarette products under the Act. The tobacco industry has in our view crossed over the statutory line and is now in the business of selling "drugs" and not just conventional cigarettes. These activities have been going on for some time but because there is no federal agency that has access into the internal workings of the tobacco industry, its activities, its strategies and its manufacturing processes have remained virtually a heavily guarded secret. Documents released as part of the Cipollone liability case have given us a glimpse into the industry's past and present practices. These documents have pointed to the fact that beginning even before 1964 , the tobacco industry was investing millions and millions of dollars into developing highly technological products - products which no longer consisted of just blended tobaccos, but rather products in which the nicotine was controlled, products which had sophisticated, elaborate filters to remove so-called toxins from tobacco, and products which contained chemical additives to provide flavor and to control the bum of the cigarette so it would burn faster and smoother. Interestingly enough, all of this was being done at break neck speed while the industry categorically denied that its products caused disease. A review of the evidence that has come to our attention is distressing, to say the least, and prompted our Coalition to file a more recent petition with the FDA seeking to classify all cigarette products on the market as drugs under section 201 of the FDC Act.

Are we surprised by these findings and revelations? Not really. Should the public be outraged by the tobacco industry's secretive efforts to do everything feasible to make huge 
profits at the expense of the public's health and its right to know about how these products are being manufactured and marketed? Absolutely!

I would like to request, Mr. Chairman, that our March 7th petition be included in today's hearing record. I would like to highlight several statements from the petition to give the members of this subcommittee an idea of the kind of actions and deceptions the tobacco industry was engaging in that subjects them to FDA authorities. As far back as 1961 the industry knew it had a real dilemma on its hands. A Ligget and Myers document of March 1961 from its consultant Arthur D. Little began with the statement, "There are biologically active materials present in cigarette tobacco. These are a) cancer causing, b) cancer promoting, c) poisonous, d) stimulating, pleasurable and flavorful. The document talks about the 'disassembling and 'reassembling' of the cigarette using a process designed to 'minimize the biological effect'."

A 1962 Philip Morris document talks about speeding up activities on the solvent extraction of tobacco for the purpose of reducing "the quantity of TPM, nicotine, and gas phase materials." Another 1964 confidential document talks about the need to develop a "medically acceptable cigarette in light of the present health attitude." The research benchmarks were defined as:

\section{- Nicotine removal \\ - Phenal removal \\ - Polynuclear hydrocarbon removal \\ - Nitrosamine removal}

A 1968 Ligget Myers memorandum refers to a meeting in 1968 of the top scientific directors of the tobacco companies in which strategies were discussed on product research 
and development to deal with the problems facing the tobacco industry, particularly in the area of tobacco and health. A 1973 Philip Morris document discusses in depth the reasons why people smoke cigarettes, with emphasis on the affects of nicotine on body function.

A 1981 Philip Morris document noted that "Nicotine is a powerful pharmacological agent with multiple sites of action and may be the most important component of cigarette smoke. Nicotine and an understanding of its properties are important to the continued well being of our cigarette business since this alkaloid has been cited often as the 'reason for smoking' and theories have been advanced for 'nicotine titration' by the smoker. Nicotine is known to have effects on the central nervous system as well as influencing memory, learning, pain perception, response to stress and level of arousal."

A review of the tobacco industry patents that have been filed for the last several decades also establishes a documented intent on the part of the tobacco industry to research and develop products that are designed to both "mitigate and prevent disease" as well as designed to affect function and structure of the body.

A 1971 Philip Morris patent, for example, talks about maintaining the nicotine content at a sufficiently high level to provide the desired physiological activity... without raising the nicotine to an undesirably high level. The patent also says by employing the nicotine releasing agents and methods... it is possible to incorporate exact amounts of nicotine in tobacco composition, which will remain constant over extended periods and will ultimately yield a smoke containing a controlled amount of nicotine.

A 1985 Brown and Willianson patent talks about a process "for treating tobacco to reduce nitrate and nicotine contents thereof which when incorporated into a tobacco smoking product, yields smoke with reduced nitrogen oxides, hydrogen cyanide and nicotine 
deliveries...." And an R.J. Reynolds patent discusses a process that results in a "cigarette having a puff by puff nicotine delivery curve radically different from that of a conventional cigarette."

There are, Mr. Chairman, many, many more.

Just prior to the submission of our petition to the FDA, the Coalition received a letter from Commissioner David Kessler. A copy of that letter is attached to our testimony. The letter was in response to our 1988 low tar and low nicotine petition, but in fact went much further, reaching some of the same general conclusions that we had reached and which are contained in our March 7th filing. The letter also indicated that FDA jurisdiction over cigarettes would probably result in the products being banned under the "drug" provisions of the FDC Act and that the FDA wanted to work with Congress in finding solutions once and for all for the way in which tobacco products should be dealt with in the future. The FDA letter, in our view, changes the dynamics of the tobacco control and tobacco regulation debate. It recognizes that the industry by its own volition has skirted and violated the law. It indicates that the FDA will enforce the law if necessary and if Congress fails to act. The tobacco industry's free lunch, Mr. Chairman, must come to an end.

Mr. Chairman, it is high time that Congress act. Your leadership and the leadership of many members of this subcommitiee must be commended. But it is time for the other members of this subcommittee to put the American public's heaith first. Thirty years of tobacco industry domination at the expense of miliions and millions of American lives is too high a price to pay. What hypocrisy it is to talk about health care and ignore our biggest preventable cause of disease and death, tobacco use. This is not the subcommittee on tobacco, this is the subcommittee on health. 
Why shouldn't tobacco be treated as the addictive drug it is when all other nicotine products are strictly regulated by the FDA?

Why shouldn't tobacco products be regulated when they are known to cause cancer, heart disease, emphysema, birth defects and many other medical conditions?

Why should the tobacco industry be allowed to make misleading and deceptive advertising and labeling claims to keep smokers and nonsmokers believing that certain products are safer and less addictive?

Why should the tobacco industry be allowed to add hundreds if not thousands of chemicals to its products without disclosing them to the public or providing the FDA with the scientific data that ensures the additives are in fact safe when used in the products?

Why shouldn't the tobacco industry be required by an agency like the FDA to disclose dangerous chemical constituents in tobacco smoke such as arsenic, benzine, and cyanide, to name just a few of several thousand?

Why shouldn't the tobacco industry be required to provide wamings about environmental tobacco smoke, or addiction, or stroke, or osteoporosis, to name just a few?

Why shouldn't the tobacco industry's advertising and marketing practices be held to the same or comparable standards that other legal products, such as pharmaceutical products, are held?

And why, Mr. Chairman, are there no federal enforcement mechanisms to ensure that tobacco products are not being given out as free samples or sold to minors? 
For thirty years we have heard from the tobacco industry that "voluntary" efforts are the best way to deal with the smoking and health problem. Let's be frank. Its voluntary efforts are nothing but a part of its elaborate public relations scheme to sell itself as an industry of good, responsible corporate citizens. The thirty year record of this industry speaks for itself. Even today, the CEOs of the major tobacco companies deny that their products cause disease and death. They are, as many have said, "merchants of death."

Congress must now have the political will that Dr. Kessler and the FDA have shown in their willingness to take the tobacco industry head on, to enforce the law when the law has been violated. The political will starts right here with this subcommittee. Can this subcommittee continue to bury its head in the sand and avoid dealing with the regulation of this nation's single most preventable cause of death, as it has done for the last thirty years? Or will the members of this subcommittee support what the public has demanded for some time, accountability of an industry that manufactures and markets a product that the federal government and every medical organization has recognized as a major addictive killer? Go ask your constituents what they believe appropriate. Our survey of smokers and nonsmokers alike shows the public believes FDA regulation is both appropriate and necessary. As former Surgeon General Dr. Antonio Novello so aptly put it, the time for studying the issue is over, the time for action is now.

Mr. Chairman and members of this subcommittee, on behalf of the millions and millions of Americans whom our organizations represent, I implore you to end the vicious cycle of disease, addiction, and death. If tobacco products are to remain on the market, then the American public deserves better protection. Our children have a right to better protection. The special protections given to the tobacco industry must end. These products should at a minimum be held to regulatory standards comparable to those that all other legal products are held. FDA must be given full authority over the regulation of the manufacture, distribution, sale, labeling, and advertising of these products. To that end, we have enthusiastically endorsed H.R. 2147 the "Faimess in Tobacco and Nicotine Regulation Act," which we believe creates the necessary regulatory structure to bring the naiion's single most preventable cause of death under control for the first time. 
BEFORE THE FOOD A.DD DRLG ADMILISTRATIO. WASHLNGTON, D.C.

Petition of

the American Heart Association,

the American Lung Association,

the American Cancer Society,

acting as

the Coalition on Smoking OR Health

and members of

the Coalition's Legislative Advisory Committee seeking

Classification of all cigarette products

as Drugs under Section 201 of the

Federal Food, Drug, and Cosmetic Act

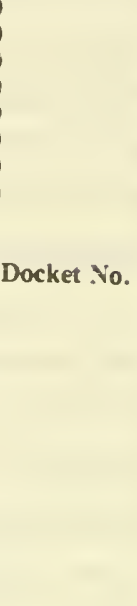

March 7, 1994 


\section{TABLE OF CONTENTS}

I. PRELIIINARY STATEMIENT

I. STATEMENT OF LEGAL GROLYDS page 6

A. Cigarettes are "drugs within the meaning of the Federal Food. Drug and Cosmetic Act.

B. Legal requirements for establishing intent.

C. FTC $v$. Liggett is consistent with the legal arguments made by petitioners to classify all cigarettes as drugs under Section 201(g)(I)(C) of the Food, Drug. and Cosmetic Act.

D. FDA has on numerous occasions regulated as drugs and/or food other nicotine or tobacco containing products.

E. FDA's failure to take action against tobacco products is arbitrary and capricious.

III. STATEMENT OF FACTUAL GROLNDS .page 23

A. Tobacco products are a major cause of disease in the United States and are addictive. Nicotine is the drug in tobacco that causes addiction.

B. The tobacco industry has conducted extensive research on the important role that nicotine plays in the addiction to cigarettes, has intentionally manipulated the nicotine levels in tobacco products designed to affect the "functions and structure of the body," and has used this knowledge as part of its product developmeat and marketing strategies. 


\section{PRELIIINARY STATEMIEYT}

In 1906. the first Food and Drug Act was enacted into law. The starute banned from interstate commerce any trafficking of adulterated and/or misbranded foods or drugs. Since that time the Food and Drug Administration (FDA) has. under starutory direction from the U. S. Congress, continued to enforce the laws designed to ensure that foods and drugs are safe and effective. The Act also now govems cosmetics and medical devices. All of the products covered by the Act are products that are either ingested by man, applied to the skin or implanted into the body. Food and Drug Administration regulation of these products govems the composition of the products and their sale, distribution, advertising and promotion.

The underiying purpose of the Federal Food, Drug and Cosmetic Act (FDCA) is to ensure the protection of consumers from hazardous substances. There is one product that has, afthough it has attributes similar to foods and drugs, traditionally not been regulated by the FDA and has escaped regulation by statutory exemption under the Consumer Product Safety Act, the Fair Labeling and Packaging Act, the Toxic Substances Act and the Federal Hazardous Substances Act; that product is tobacco.

There can be no question by any person reviewing the health hazards posed by cigarettes that this is a product that logically warrants regulation in the same manner that foods, drugs and other harmful products are regulated. There can be no question by anyone reviewing the medical literature on nicotine and its addictive effects that this is a product that should be considered a dangerous drug. As the Surgeon General has frequently stated, cigarette smoking is this nation's 
number one pretentable sause of death and disability accounting for approximately $\$ 20.000$ deaths annually. Cigarette smoking:

- Is the leading cause of death in the United States, accounting for approximately $20 \%$ of all deaths each year.

- Is the number one cause of lung cancer in the United States, accountung for an estimated 120,000 deaths annually.

- Is a major cause of respiratory disease, accounting for approximately 84.000 deaths each year.

- Is a major cause of cardiovascular disease, accounting for approximately 180.000 annual deaths.

- By pregnant women increases the risk of spontaneous abortions. miscarriages, and premanre birhs. Pregnant women who smoke are more likely than nonsmokers to have low birth weight babies -- a leading cause of death and disease among infants. In addition. Sudden Infant Death Syndrome (SDS) occurs 2 1/2 times more frequently among babies of smoking mothers.

- Is harmful to nonsmokers as well as smokers. Each year. Environmental Tobacco Smoke (ETS) causes 3,000 lung cancer deaths, between 30.000 and 40,000 hear disease deaths, and up to 300,000 cases of bronchitis in children. A recent study in the Joumal of the American Medical Association (JAMA) found that ETS can affect the fetus of a nonsmoking woman who is regularly exposed to such smoke.

(See, for example: Reports of the Surgeon General on the Health Consequences of Smoking, 1979, 1980, 1981, 1982, 1983, 1984, 1985, 1986, 1987, 1988, 1989. 1990, 1991, and 1992.)

The National Institute on Drug Abuse (NIDA) has called cigarette smoking the most common example of drug dependence in the United States. The World Health Organization (WHO), the American Psychiatric Association, the Harvard School of Public Health and others have declared tobacco use to be a form of addiction similar to cocaine and heroin.

More importantly, in 1988, the Surgeon General of the United States released a comprehensive scientific report on nicotine addiction concluding that: 
- Cigarettes and other forms of tobacco are addicting.

- Nicotine is the drug in tobacco that causes addiction.

- The pharmacological and behavioral processes that determine tobacco addiction are similar to those that determine addiction to drugs such as heroin and cocaine.

Because of the lack of regulation of tobacco products due to specific statutory exemptions or to interpretations of the limits of the FDCA, as well as lack of action on the part of the FDA, the tobacco industry has remained free to continue to manufacture, promote and advertise their products without meaningful regulation, so long as their only purpose was to sell the product for smoking pleasure only. Each year the tobacco industry spends over $\$ 4$ billion dollars to market their products, making the number one preventable cause of death also this nation's most heavily marketed consumer product. Free samples of cigarettes and other tobacco products are routinely handed out to young people on streets, at rock concerts, at sporting events and through the mail. Rarely is there verification from the tobacco manufacturer that the tobacco product has been given out to someone of legal buying age - 18 or above in all states. No federal agency has taken the responsibility to ensure the proper labeling, distribution, sale and advertising of these products.

The Food and Drug Administration, charged with protecting the public from misbranded and adulterated products, would obviously not allow such practices to be carried out for a prescription dng such as "valium" or for nicotine-containing drugs such as Nicorette gum and the transdermal nicotine patches. Such allowances would amount to the sanctioning and promoting of drug abuse -- an absurd notion by any standard. Yet, that is exactiy what has been allowed to occur with tobacco products. 
Tobacco products have traditionally not been subject to the Food. Drug. and Cosmetic Act unless they have been determined to meet the legal standards of the Act under Section $201(\mathrm{~g})(\mathrm{l}),(\mathrm{B})$, and (C). The petitioners were pleased to recelve your letter of February 25, 1994, recognizing that cigarette products can. in the view of the FDA, fall under the agency's jurisdiction as "drugs" and that evidence exists that clearly points to the fact that these products are being sold to mitigate and prevent disease and to affect function and structure of the body.

As long as tobacco products and particularly cigarettes were sold merely for smoking pleasure only and were not intended to affect function and structure of the body or to mitigate or prevent disease, the FDA has not viewed itself as having jurisdiction over cigarettes or other tobacco products. The history of the food and drug statutes and case law, as well as testimony and other FDA actions governing tobacco products do, however, make it clear beyond doubt that tobacco products, like any other product, can be subject to the act when the manufacture, sale. labeling, and promotion of the product is deemed to meet the legal requirements of the Act.

The earliest cases which affirmed FDA jurisdiction over cigarettes as "drugs" were decided in the 19503. Those cases remain the law today, supplemented by numerous other cases that have reaffirmed the FDA's statutory authority.

Petitioners believe that there is now more than ample evidence to establish that today's cigarettes and other tobacco products are "drugs" within the meaning of Section 201 of the FDC Act.

This proposition to regulate all cigarettes under the FDC Act was first advocated by the Action on Smoking and Health (ASH) in the late 1970s in a petition to the 
FDA seeking to classify all nicowne containing cigarette products as drugs. While the petition was denied, it was denied on the basis that ASH had failed to show any evidence of vendor intent, that these products were being sold as products intended to affect function and or structure of the body. ASH had relied solely on consumer intent. While consumer intent was useful evidence to bolster "intent," it was in and of itself insufficient for the FDA to assume jurisdiction absent a showing of any vendor intent.

Petitioners believe that after a review of evidence that has come to light since the ASH petition was decided, a clear and convincing argument can now be made to establish that cigarette manufacturers have in fact been selling cigarettes not "merely for smoking plẹasure only," but have for some time embarked on a calculated, intended strategy to alter the fundamental characteristics of tobacco products, including but not limited to, the manipulation of nicotine. The tobacco industry has tumed its research endeavors into the implementation of marketing strategies in order to sell a product that is designed to "affect functions and structure of the body," as well as "mitigate and prevent disease." The industry's extensive research, its development and manipulation of the cigarette and the nicotine in its products, its calculated labeling and advertising campaigns to convince smokers and nonsmokers that there are safer, less addictive products, and its deliberate efforts to withhold important health related information from the public warrant FDA jurisdiction over all cigarette products. 
ए. STATEIIEYT OF LEGAL GROL IDS

A. CIGARETTES ARE "DRLGS" WITHLV THE VIEAILVG OF THE FEDERAL FOOD, DRCG ALD COSIIETIC ACT

Section $201(\mathrm{~g})(1)$ of the Food. Drug and Cosmetic Act (21 U.S.C. of $32 !(\mathrm{g})(1))$

defines a "drug" as:

(A) articles recognized in the official United States Pharmacopeia. official Homeopathic Phamnacopeia of the United States, or official National Formulary, or any supplement to any of them:

(B) articles intended for use in the diagnosis, cure, mitigation, treatment or prevention of disease in man or other animals;

(C) articles (other than food) intended to affact the structure or any function of the body of man or other animals; and

(D) aricles intended for use as a component of any articles specified in clauses (A), (B) or (C) of this paragraph; but does not include devices or their parts, or accessories.

The manufacturing, advertising, promoting and marketing of cigarettes on the market today, fall squarely within the definitions of drugs under clauses (B) and (C) and of Sec. $201(\mathrm{~g})(1)$ which defines drugs as articles intended "for use in the diagnosis, cure, mitigation treatment or prevention of disease," and "articles (other than food) intended to affect the structure or any function of the body of man or other animals."

Petitioners contend (and have contended in previous petitions filed with the FDA) that the manufacturing, adverising, selling and promoting of low yield products will lead consumers to believe that use of many of these products will mitigate and prevent diseases caused by the use of the higher tar and nicotine cigarettes and that the marketing of cigarettes is conducted in a calculated manner with the intent of affecting the function and structure of the body of man. Thus, for reasons set out in this petition, as well as reasons set out in prior 
pettions by the Coalition. the FDA should take action against all cigarente products as "drugs."

Petitioners are not embarking into unexplored territory in contending that tobacco products should be regulated as "drugs" under the Food, Drug and Cosmetic Act. In appropriate circumstances, such actions have been brought by the FDA and upheld by various courts.

For example, the courts have routinely held that if "there is an indication of intent to use the article for the cure or mitigation or treatment or prevention of disease in man, then clearly the subject matter of the libel is to be considered a drug within the meaning of the [Food, Drug and Cosmetic] Act." United States V. 46 Cartons More or Less containine Fairfax Cigarettes, 113 F.Supp. 336, 337 (D.N.J. 1953). Similarly, in United States v. 354 Bulk Cartons: . Trim Reducing - AID Cigarettes, 178 F.Supp. 847 (D.N.J. 1959), Action on Smoking and Health v. Harris, 655 F.2d 236 D.C. (Cir. 1980), cigarettes were acknowledged to be drugs when they were intended to affect the function and structure of the body of man.

The Food and Drug Administration's jurisdiction over tobacco products in appropriate circumstances has also been reaffirmed by the FDA in testimony before the Congress. In 1972, then FDA Commissioner Charles C. Edwards testified to the Consumer Subcommittee before the Senate Committee on Commerce as follows:

Cigaretres and other tobacco products would be drigs subject to the Federal Food, Drug and Cosmetic Act if medical claims are made for the product.... We have on occasion proceeded against cigarettes recommended for use in controlling appetite or otherwise recommended as a weight reducing aid.... However cigarettes recommended for smoking pleasure are beyond the Federal Food, Drug and Cosmetic Act. (Hearings: "Public Health Cigarette Amendments of 1971 ", Senate Commerce, Science and Transporzation Committee, Subcommittee on the Consumer, 92 nd Congress, 1972. Serial No 92-82 page 239.) 
This position was reiterated in December 1977 by then FDA Commissioner Donald Kennedy in a letter of denial to a petution filed by Action on Smoking and Health et.al., which requested that the FDA exercise jurisdiction over cigarenes containing nicotine as a "drug" under the Food, Drug and Cosmetic Act and in the altemative. as "devices" under the Act. In his letter, Commissioner Kennedy concluded that the judicial opinions stood for the proposition that cigarettes are "intended to affect the structure or any function of the body of man" within the meaning of the Food. Drug and Cosmetic Act only where manufacturers or vendors of cigarettes intend such effects (emphasis added) and that such intent must be shown by health claims or other representations by cigarette manufacturers or vendors. (Brief of Action on Smoking and Health v. Joseph Califano, Case No. 79-1397, U.S. Court of Appeals for the District of Columbia p. 2-3).

To date, the FDA has brought action against traditional cigarette products as "drugs" on two occasions. A third case, relevant to this petition and discussed in greater detail eisewhere, concems an action brought by the Federal Trade Commission which employed the Food and Drug Administration's definitional standards for "drugs."

The first case relevant to this portion of the petition. United States $v$. 46 Carton. More or Less. Containing Fairfax Cigarentes, 113 F. Supp. 336 (D.N.J. 1953). involved the introduction into interstate commerce of 46 cartons of "Fairfax" Cigarettes. The cartons were accompanied with 51 leaflets entitled, "How Cigarettes May Help You." A libel action was brought by the United States alleging that the cigarettes were drugs and, as such, were misbranded. The issue addressed by the court was whether or not "the seized article is a drug within the meaning of the Food, Drug and Cosmetic Act." The Court noted that "in a field 
where generally speaking competition is met by advertising and labeling rather than by price or even perhaps by substantial differences in quality, such conflicts [between the FDA and tobacco companies] are almost inevitable as manufacturers tread near the statutory boundary." (113 F. Supp. at 337.)

In ruling that the cigarette products were drugs, the court concluded that, contrary to the claimant's assertions that the leaflets were intended only to promote and increase one's smoking pleasure, "if there be an indication of intent to use the article for the cure or mitigation or treatment or prevention of disease in man then clearly the subject matter of the libel is to be considered a drug within the meaning of the act." (Id. at 337.) Similarly, the manufacture, promotion, and sale of today's cigarettes mislead the public "by a subtle appeal to a natural and powerful desire on the part of all of us to avoid" disease and addiction to a deadly product. (Id. at 337.)

In the Irim cigarette case the court held that cigarettes "promoted as weight reducing cigarettes and which contained combustible tartacic acid, constituted an article intended to affect, and contained a component which affected structure or functions of the body, and therefore, constituted 'drugs' within the meaning of the Food, Drug and Cosmetic Act." Petitioners will establish that the tobacco industry research, knowledge, and deliberate manipulation of nicotine and other components in tobacco products constitutes "an article intended to affect" and contains a component intended to "affect structure and functions of the body."

Materials released as a result of discoveries in the Cipollene case, as well as other newly discovered industry documents, etc., provide an extensive record of the tobacco industry's research activities and recognition of the effects of nicotine as part of the smoking habit. Documents also show the industry's intended purpose 
to manipulate nicotine levels of iggarettes through investigatıng new scienturic procedures and techniques designed to influence smoking behaviors and addiction levels.

The robacco industry's marketing practices of reducing tar and nicotine content and its extensive research and actual intended manipulation of the nicotine content in cigarettes "would appear to have" - in the words of the Federal Court in Fairfax - "no other purpose than to mislead the unwary, " whose hope in buying and smoking such cigarettes is to improve their prospects for avoiding, mitigating and/or preventing cigarette caused disease, as well as intending to assure continuing addiction to the product thereby affecting structure and function of the body. (Id. at 337.) (Emphasis added.)

In the Fairfax case, Judge Meany pointed out that the Food, Drug and Cosmetic Act was intended and must be constructed so as "to effectuate the purpose of protecting the buying public which is largely beyond self protection in the circumstances of modem life." (Citizen 62 Cases of JAM v. United States, 1951 340 U.S. 593, 596, 71 S.Ct. 515, 95 L. Ed. S66; Kerdel v. United States, 335 U.S. 345, 69 S.Cl. 106, 93 L.Ed. 52; United States V. Dotterweich 1943, 320 U.S. 277. 280. 64 S.Ct. 134, 88 L.Ed. 48 1943.) 113 F. Supp. at 337. This was further reiterated in United States V. Aricle-Sudden Change, 409 F.2d 734, 740 (2d Cir. 1969) and United States v. An Article of Drigr. Bacto - Unidisk, 394 U.S. 784, 22

L.Ed. 2 d. 726,733 , in which the court stated:

At the outset, it is clest from Sec. 201 that the word "drug" is a term of an for the purposes of the Act, encompassing far more than the strict medical definition of the word. If Congress had intended to limit the statutory definition to the medical one it could have so stated explicilly, or simply have made reference to the official United States Pharmacopoeia, or the National Formulary, as it did in the first of the three sections of Sec. 201 (g)(l) and let the definition rest there. The historical expansion of the stanute's definition, furthermore clearly points out Congress' intention of going beyond the medical usage. 
This construction of the broad scope for the uord "drugs" under the Food. Drug and Cosmetic Act was set out by the Congress beginning in 1935. It was under the legislation first considered dunng the 74th Congress and enacted in 1938 under the Food. Drug and Cosmetic Act of 1938 (Copeland Act) (52 Stat. 1046, 75th Congress, 3d Session, June 25, 1938) that the definition of "drug" was expanded to be broadly interpreted. The Senate Committee Report to the 1935 Act stated:

The definition of "drug" has been expanded to include, first substances and preparations recognized in the Homeopathic Pharmacopoeia of the United States; second devices intended for use in the cure, mitigation, treatment or prevention of disease; third substances, preparations and devices intended for diagnostic purposes, and fourth such articles other than food and cosmetics intended to affect the structure or function of the body. Such expansion of the definition of the term "dng" is essential if the consumer is to be protected against a multiplicity of devices and such preparations as "slenderizers." many of which are worhless at best and some of which are distinctly dangerous to health. (Senate Report 74-361 "Food, Drugs and Cosmetics," 74th Congress Ist Session, 1935, p.3.) (Emphasis added.)

The fact that tobacco products "sold for smoking pleasure only" are not considered to be drugs does not limit the FDA's authority to regulate those that do fall under the statutory definition of "drugs." It was also Congress' intent that product definitions not be mutually exclusive. As the Senate Report to S.5 further noted in 1935:

The use to which the product is to be put will determine the category into which it will fall. If it is used only as a food it will come under the definition of food or none other. If it contains nutritive ingredients but is sold for drug use only, as shown by labeling and advertising, it will come under the definition of drug but not that of food. If it is sold to be used both as a food and for the prevention or treatment of disease it would satisfy both definitions and be subject to the substantive requirements of both. The manufacturer of the article, through his representations in connection with its sale can determine the use to which the article is to be put. (Senate Report 74-361, 74th Congress 1st Session, 1935 p. 4. See also, U.S. v. Article---Sudden Change, 409 F.2d 734, 739, 1969.)

Both the Congress and the courts have clearly spoken and the tobacco industry cannot legally claim that their manufacturing, advertising, promoting and selling 
of cigarettes. Intended to affect the sinucture and function of the body or containung implied or direct health claims, are purely for smoking pleasure.

What the Federal District Cour said in Fairfax some 30 years ago. in applying the provisions of the Food, Drug and Cosmetic Act, remains fully applicable today and should be applied with the full force of the law against all cigaretre products. The Cour in Fairfax observed:

If claimants labeling was such that it created in the mind of the public the idea that these cigarettes could be used for the mitigation or prevention of the various named diseases, claimant cannot now be heard to say that it is selling only cigarettes and not drugs.... The ultimate impression upon the mind of the reader arises from the sum total of not only what is said, but also all that is reasonably implied. If claimant wishes to reap the reward of such claims let it bear the responsibility as Congress has seen fit to impose on it. (113 F.Supp. at 338-339.) (Emphasis added.)

\section{B. LEGAL REOUTREMENTS FOR ESTABLISHING INTENT}

Petitioners have established that cigarettes and other tobacco products can and have been legally classified as "drugs" under the Food, Drug and Cosmetic Act when they are manufactured and marketed with an intended purpose to affect the structure and function of the body, or when they are marketed to mitigate or prevent disease. Additional attention, however, should be given to the legal requirements needed to establish "intent" under section $20 \mathrm{l}(\mathrm{g})$ of the Act. It was Action on Smoking and Health's failure to show any "vendor intent" that led to FDA's denial of ASH's petition to classify all nicotine containing cigarettes as "drugs." The legal authorities most frequently cited for establishing "intent" under section 20l(g) of the FDC Act include:

Action on Smoking and Health v, Hamis, 655 F.2d 236 (1980)

U.S. v. Donterwich, 320 U.S. $277,280,64$ S.Cl. 134,88 L.Ed. 48 (1943) U.S. v. An Article of Drue. Bacto-Unidisk, 394 U.S. 784, 22 L. Ed.2d 726. 89 S.Ct 1410, reh den 395 U.S. 954, 23 L.Ed.2d 473, 89 S.Ct. 2013 (1969) U.S. v. Hohensee, 234 F. 2d 367,370 (3 Cir. 1957), cert. den., U.S. 967, 77 S.Ct. 1058, 1 L.Ed.2d 1136 (1957) 


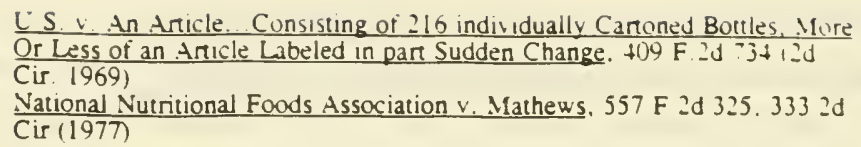

The Supreme Cour has also explicitly determined that commercial speech is inherenily calculated, intended speech, because commercial speakers "have extensive knowledge of both the market and their products." See Central Hudson Gas \& Electric Corporation v. Public Service Commission of New York, 447 U.S. 557,564 n.6, 100 S.Ct. 2343, 65 L.Ed.2d 341 (1980). The tobacco companies fully understand the health ramifications and the addictive nature of nicotine in tobacco, and carefully research, develop, and market their products to encourage consumers to use so-called safer products as well as to ensure their continued addiction. Since the commercial speech of the tobacco industry is calculated to foster the public's use of this product, which they often perceive as safer and less addictive, the tobacco companies should be held accountable for development and marketing of their products with such intent. In addition, a 1993 survey conducted by the Gallup Organization showed that over 75 percent of those surveyed (smokers and nonsmokers) believe terms like "low tar," "low nicotine," and "low yield" mean the product is safer, less cancerous and less addictive.

In Sudden Change the court said that the question of whether a product is intended to affect function or structure of the body is to be answered by considering first how the claim might be understood by the "ignorant, unthinking. or credulous consumer and second, whether the claim as so understood may fairly be said to constitute a representation that the product will affect structure of the body..." (p.734). Citing Hohense, the cour in Sudden Change explains the ways in which "intent" is to be ascertained stating that: "It is well established that the 
Intended use of a product may be determined from its labeling, accompanving labeling promotional matenal, advertising, or any other relevant source temphasis added) The cour notes that "intent" has been established in statements made in a "disclaimer letter, magazine testimonials, as well as lectures. and in "Class Notes on Health and Nutrition." Obviously the manner in which intent can be established and ascertained is very broad and flexible. The court continues (citing Hohensee, Fairfax, and Irim) finding that "regardless of the actual physical effect of a product, it will be deemed a drug for purposes of the Act where the labeling and promotional claims show intended uses to bring it within the drug definition." And finally the court discusses the issue "by what standards are these claims to be evaluated? Or to put it another way, what degree of sophistication or vulnerability is to be ascribed to the hypothetical consumer in order to understand how these claims are understood by the buying public?" Citing U.S. v. Dorterwich, the court states that, "Considering the remedial purposes of the Act and particularly of the 1938 amendments, the Supreme Coun declared: 'The purroses of this lezislation thus touch phase of the lives and health of people which, in circumstances of modern industrialism, are largely beyond self-protection. Reand for these purposes should infuse construction of the leqislation if it is to be treated as a working instrument of gevernment and not merely as a collection of English words. Accepting this admonition, we conclude that the purposes of the Act will best be effected by postulating a consuming public which includes the 'ignorant, the unthinking and the credulous... $\because$ " (p. 277) (Emphasis added.)

The cumulative legal basis upon which "intent" and particularly "vendor intent" is required to be established was again summarized and confirmed in both National Nutritional Foods Associations v, Mathews, 557 F.2d $3252 \mathrm{~d} \mathrm{Cir.} \mathrm{(1977)} \mathrm{and} \mathrm{in}$ ASH V Harris, 655 F.2d 236 (1980), the latrer case being directly related to and 
most relevant to this petition. As the Cour in National Nutrinonal Foods noted in finding that the FDA had failed to show any vendor intent:

The main issue on this appeal is whether the evidence of the extensive use of larger doses of Vitamins $A$ and $D$ to treat or prevent diseases and the promotion of such usage by persons not associated with the manufacturers or vendors establishes such widespread therapeutic use at the regulated levels as to overcome the plaintiffs' claim of the lack of an intended use to cure or prevent disease.... (p.335)

In the ASH case, Action on Smoking and Health (ASH) had contended that the mere presence of nicotine in a tobacco product coupled with the "intent" of the consuming public to buy these products to affect structure and function of the body made these products "drugs" subject to the FDC Act. FDA denied the petition. In affirming the FDA's decision the District Court noted that ASH, by failing to introduce any evidence of vendor's intent - whether based upon subjective vendor claims or objective evidence such as labeling, promotion material and advertising, placed itself in a position of having to meet the high standards established in cases where statutory "intent" is derived from consumer intent alone. Whetber consumer intent is a "relevant source for these purposes depends upon whether such evidence is strong enough to justify an inference as to vendor's intent."

Petitioners believe that there is far more than sufficient evidence now available on vendor's intent (complemented by well established consumer intent) to warrant the FDA assuming jurisdiction over all cigarette products under Section $201(\mathrm{~g})(\mathrm{l})(\mathrm{B})$ and $(\mathrm{C})$. 
As the Agency is atuare. the Coalıtion on Smoking OR Health has already tiled petitions which have relied prmanly on Section $201(g)(1)(B)$ and have shou $n$ that the marketing of cigarenes using low tar and low nicetine labeling and advertising have no other purpose than to promote cigareties as safer and less addictive. We will also present evidence in the Factual Statement Section of this petition that clearly shows that the public's perception (smokers and nonsmokers alike) is that low tar and low nicotine cigarettes are marketed as safer and less addictive. and that the industry has designed today's cigarettes to affect functions and structure of the body.

In ASH v, hanris the court specifically noted that in deciding whether a cigarette was to be classified as a "drug" under Section $20 \mathrm{l}(\mathrm{g})(1)(C)$ (intended to affect function or structure of the body), the case law to be consulted was FTC $v$. Liegert \& Myers Tobacco Co. decided in 1952. As the court specifically noted, "...the court's remarks in FTC $v$. Liggett \& Mvers Tobacco Co, seern as relevant today as they were in 1952."

The petitioners therefore have given Ligzert particular attention not only because of its legal significance in ASH v . Harris but because it is also the case most often cited by the tobacco industry for advocating that the FDA has no jurisdiction over cigarette products. A review of this case will clearly show that the facts of the case and the courr's rationale are boch distinguishable and legally consistent with the basis of this petition. 


\section{FTC $\checkmark$. LIGGETT IS CONSISTEYT WITH THE LEGAL ARGLIENTS ILADE BY PETITIONERS TO CLASSIFY ALL CIGARETTES AS DRLGS L.NDER SECTION 201 (g)(1)(C) OF THE FOOD, DRLG, AND COSMETIC ACT}

In Liggett the cour found that cigarettes which claimed to be less "irritating" than other cigarettes were not deemed to be drugs under section section $20 \mathrm{l}(\mathrm{g})(1)(\mathrm{C})$. The decision in the case, the statutory definition that the cour was concemed with (clause $(\mathrm{C})$ ), and the rationale and conclusions of the cour must be put into perspective to understand the important distinctions between what the cour said in 1952, and how it is applied to today's scientific and medical knowledge about tobacco products. This includes how the tobacco industry has deliberately and intentionally embarked on research, product development and manipulation, and advertising campaigns that now clearly establish that they are selling products "intended to affect the structure and function of the body." When one reviews this overall picture including the case law, it is difficult to arrive at any conclusion other than that the tobacco industry is selling "drugs." The decision in the Liggett case is completely consistent with and supports the premises upon which this petition is being filed. The court in Liggett was correct when it said:

As times and conditions change it is fitting that an administrative agency, before resorting to the legislarure, seek to invoke new means of coping with still unresolved problems, but in its zeal the agency must not exceed the bounds of its statute.

It is clear to even the casual observer that the cigarette industry and its manufacturing processes and marketing practices have continued to dramatically change and that the FDA should invoke "new means of coping with still unresolved problems." In spite of its broad statutory authorities, the FDA has, however, been anything but over zealous in the use of its authorities to regulate tobacco products when they are sold as drugs. Its unwillingness to act has resulted 
In the deaths of millions of Amencans since the first Surgeon General's Repon was released in 1964.

Thus the Liggen decision must be reviewed in light of what has transpired since it was decided in 1952. In Liggett, the court was confronted with the question of whether or not cigarette products which claimed to be less irritating were intended to affect the structure or any function of the body of man.

The court ruled that the FTC allegations that the product was a "drug" and intended to affect function and structure of the body (Section $201(\mathrm{~g})(1)(\mathrm{C})$ ) were faulty in that the claims focused on the cigarette being less "irritating" and thus had non-adverse effects rather than having "beneficial effects." Claiming that something is "less irritating," "better tasting," "smoother," or "soothing" is far different from a claim that a product is safer, less addictive, and will have beneficial effects toward the reduction of the health consequences of cigarette smoking. (Consequences that were not yet known or accepted in 1952.)

The cour in Ligeen further noted that:

Anything that stimulates any of the senses may be said in some perhaps insienificant degree, to affect the functions of the body of man. Consequently an aricle, which used in the manner anticipated by the manufacturer thereof, comes into contact with any of the senses may be said to be an article "intended to affect functions of the body man."

Surely the legislators did not mean to be as all-inclusive as a literal interpretation of this clause would compel us to be.

The Commission asserts that the defendant alleges a "soothing" property and that cigarettes are adverised and bought with this soothing property in mind. But many things soothe the troubled mind of modern man and I do not feel that this is the type of effect which the stante contemplates. (emphasis added) 
As we uill clearly establish in the Statement of Factual Grounds. the Surgeon General's Reports (particularly the 1988 Report on Nicotine Addiction), the FDA's own actions in regulating nicotine containing products as drugs, as well as the industry's own research, documents, and marketing strategies, reveal a component of the tobacco product (nicotine) which is today recognized as a powerful and significant determinant on smoking behaviors, and one that has significant intended effects on functions and structure of the body. The tobacco industry's deliberate attempts to remove other dangerous substances in the cigarette product is further evidence of its efforts to produce products intended to effect structure and function of the body, and/or to mitigate or prevent disease.

Clearly the health claims, research, and development of nicotine and cigarette products in general, which have been and continue to be conducted by the industry are the primary result of scientifically and medically established health dangers (including nicotine addiction), associated with cigarette smoking, that were obviously nos known in 1952 or more importantly not cited in the 1952 Liggett case. It was not until 1953 that the first significant scientific evidence that cigarette smoking was causally connected with cancer came to public attention. It was not until 1964 that the first Surgeon General's report on cigarette smoking and cancer was released to the public. The scientific and medical knowledge about the dangers of tobacco, coupled with the tobacco industry's strategic responses to such knowledge, have changed so dramatically and significantly since the 1952 decision that we are obviously no longer dealing with a product that merely "stimulates" in some insignificant degree, but which is a proven cause of major chronic diseases and is as addictive as cocaine and heroin -- issues which were obviously far from the mind of the court when they considered and ruled in Liggen. The basis upon which petitioners seek action on the part of the FDA under section $201(\mathrm{~g})(1)(C)$ is therefore wholly consistent with the Liggen decision. 


\section{FDA HAS ON IT IIEROLS OCCASIONS REGLLATED AS DRLGS AND/OR FOOD OTHER MCOTIE OR TOBACCO CONT ANITG PRODLCTS}

In addition to the legal authorities to regulate cigarettes as drugs under the FDC Act. the FDA has also brought numerous actions against a number of nicotine and/or tobacco containing products.

In 1987 the Food and Drug Administration found that a cigarette-like product. FAVOR, was a nicotine delivery system intended to satisfy a nicotine dependence and to affect the structure of one or more functions of the body. The FDA reached its decision to classify the product as a drug after reviewing promotional materials filed with the Securities and Exchange Commission (SEC).

In 1989 the FDA issued a regulatory letter against Masterpiece Tobacs. This time the product was being sold as a chewing gum. The manufacturer had argued that the product was outside the FDA's jurisdiction because the product contained tobacco. The FDA disagread and ruled that because the product was a chewing gum, it therefore fell under the jurisdiction of the FDA under the definition of "foods." Because the product contained a dangerous substance - tobacco - the product was deemed to be adulterated and removed from the market place.

Arguments that the product was a tobacco product for "chewing pleasure only" did not even eater the FDA's decision to remove the product from the marketplace.

In 1989 the FDA issued a regulatory letter against C.A. Blockers, Inc. indicating that a cigarette additive, "N-Bloctin," was a "drug" subject to regulation by the FDA. "N-Bloctin" according to the regulatory letter, "is an alcohol containing cigarette additive, the intended uses of which include, through action at the tissue cells, to inhibit the accumulation in the lungs of nitrosamines present in 
cont entional cigarette smoke and thereby prevent lung cancer." The regulatory letter goes on to state that "Cigarettes marketed as containing the 'N-Bloctin. additive such as Optima and Spectra Brands are also 'drugs' under Section $201(\mathrm{~g})(1)(B)$ and (C) of the FDC Act. When one or more of these uses for cigarettes containing ' $\mathrm{N}$-Bloctin' is recommended or suggested in the labeling they would be 'new drugs' as defined in Section 201 (p)...." This case is analogous to the situation in the case of low tar and nicotine claims in that the product that is being used is also the product that causes the diseases to be avoided, an issue that, in spite of tobacco industry assertions, is obviously not relevant in the application of Section 201 (g). (Emphasis added.)

The Food and Drug Administration has reviewed and approved new drug applications for a variety of nicotine containing products including gums and patches which are designed to assist the public in reducing their risks of disease and addiction caused by cigarette smoking.

And most recently, the FDA sent a regulatory letter to the maker of JAZZ cigarettes indicating that the claims made by the manufacturer constituted "drug" claims under the FDC Act and since the product is a new drug for which no approval of an application has been filed, the product was prohibited from being sold in interstate commerce. JAZZ was advertised as a revolutionary product nicotine fres, tar free, and noncancerous, a message clearly analogous to the tobacco industry's messages in their low tar and nicotine promotions, and clearly comparable to the industry research and development initiatives to develop safer, less addictive products. 


\section{E. FDA'S FARLRE TO TAKE ACTION AGANST TOBACCO PRODLCTS IS ARBITRARY AYD CAPRICIOLS}

The FDA's failure to regutate all tobacco products under the drug provisions of the Food. Drug. and Cosmetic Act is in the view of the Coalition clearly artitrary and capricious and not in accordance with the law. (See for example. National Nutrition Foods Association v. Mathews, 557 F.2d 325, (333,336 2d Cir.(1977).) Petitioners have clearly shown that the tobacco industry long ago abandoned the premise that cigarettes are sold for smoking pleasure only and that they have consciously and consistently conducted research and developed marketing strategies that clearly fall within the legal parameters of Section 201. We have shown under Section D that the FDA has in fact proceeded against a myriad of other products which have been marketed in a fashion similar to that in which today's cigarettes are developed, marketed, and sold.

The double standard, which literally affects the health of millions of Americans each and every year, must end. All nicotine contairing products, and all cigarette products which are marketed with an intent to affect function or structure of the body or which are intended to mitigate or prevent disease, must be consistently regulated as required by law. 
III. STATEIENT OF FACTLAL GROLYDS

\section{A. TOBACCO PRODLCTS ARE A MAJOR CALSE OF DISEASE N THE T.TTED STATES AVD ARE ADDICTIVE. NICOTLNE IS THE DRLG IV TOBACCO THAT CACSES ADDICTION.}

It is now well established and accepted that tobacco products are a major cause of cancer, heart disease, emphysema, stroke, and many other diseases. It is also well established that tobacco products are addictive. Tobacco products contain nicotine which is readily absorbed into the body both in the form of tobacco smoke, as in the case for cigarettes, as well as through the mouth and nose as in the case for smokeless tobacco products.

The 1988 Report of the Surgeon General, "Nicotine Addiction, " provides the most in depth and extensive review of the scientific literature on the powerful role that nicotine plays in causing and maintaining addiction. Prior to this repor, however. numerous other reports and studies had made similar findings and conclusions.

As the report notes:

For example, numerous monographs prepared in the 1970 s by the National Institute on Drug Abuse (NIDA) considered tobacco use as a form of drug dependence. In 1980, the American Psychiatric Association. in its Diagnostic and Statistical Manual of Mental Disorders, included tobacco dependence as a substance abuse disorder and tobacco withdrawal as an organic mental disorder (APA 1980). The 1987 revised edition of this manual (APA 1987), in recognition of the role of nicotine, changed "tobacco withdrawal" to "nicotine withdrawal." In 1982, the Director of NIDA testified to Congress that the position of NDDA was that tobacco use could lead to dependence and that nicotine was a prototypic dependence-producing drug. In a 1983 publication, "Why People Smoke Cigarettes," the U.S. Public Health Service supported this position of NIDA regarding tobacco and nicotine (US DHHS 1983b). In the 1984 NIDA Triennial Report to Congress, nicotine was labeled a prototypic dependence-producing drug and the role of nicotine in tobacco use was considered to be analogous to the roles of morphine, cocaine, and ethanol, in the use of opium, coca-derived products, and alcoholic beverages, respectively (US DHIHS 1984b). In 1986, a consensus conference of the National Institutes of Health and the Report of the Advisory Committee to the Surgeon General on the health consequences of using smokeless tobacco concluded that smokeless tobacco can be addicting and that nicotine is a dependence-producing (i.e., addicting) drug (US DHHS 1986b). 
Source Health Consequences of Smoking: Vicolıne tddiction. A Repon of the Surgeon General. 1988, pp. 12-13.

Petuioners have atrached as an exhibit the Executwe Summary of the report

What follows are some of the numerous significant findings and conclusions of the report. The conclusions of the report are based upon the concepts of drug dependence (addiction) developed by expert committes of the World Health Organization (WHO), as well as publication of the National Institute on Drug Abuse (NIDA) and the American Psychiatric Association. As the repon notes. "These concepts were used to develop a set of criteria to determine whether tobacco-delivered nicotine is addictive. The criteria for drug dependence (addiction) includes primary and additional indices and are summarized below:

\section{Criteria for Drug Dependence}

\section{Primary Criteria}

o Highly controlled or compulsive use

- Psychoactive effects

o Drug-reinforced behavior

\section{Additional Criteria}

Addictive behavior often involves:

- stereotypic patterns of use

o use despite harmful effects

o relapse following abstinence

- recurrent drug cravings

Dependence-producing drugs often produce:

0 tolerance

- physical dependence

- pleasant (euphoriant) effects. (p.T)

What follows are conclusions of the report. Petitioners recommend that additional discussion, details, and fundings of the report be made by consulting the appropriate chapter of the report.

\section{Nicotine: Pharmacokinetics, Metabolism, and Pharnacodynamics}

1. All tobacco products contain substantial amounts of nicotine and other alkaloids. Tobaccos from low-yield and high-yield cigarettes contain sirnilar amounts of nicotine.

2. Nicotine is absorbed readily from tobacco smoke in the lungs and from smokeless tobacco in the mouth or nose. Levels of nicotine in the blood are similar in magnitude in people using different forms of tobacco. With regular use, levels of nicotine accumulate in the body 
duning the day and persist ovemight. Thus. daily tobacco users are exposed to the effects of nicotine for 24 hours each day.

3. Nicotine that enters the blood is rapidly distributed to the brain. As a result. effects of nicotine on the central nervous system occur rapidly after a puff of cigarette smoke or after absorption of nicotine from other routes of administration.

4. Acute and chronic tolerance develops to many effects of nicotine. Such tolerance is consistent with reports that initial use of tobacco products. such as in adolescents first beginning to smoke. is usually accompanied by a number of unpleasant symptoms which disappear following chronic tobacco use.

\section{Nicotine: Sites and Mechanisms of Actions}

1. Nicotine is a powerful pharmacologic agent that acts in the brain and throughout the body. Actions include electrocortical activation, skeletal muscle relaxation, and cardiovascular and endocrine effects. The many biochemical and electrocortical effects of nicotine may act in concert to reinforce tobacco use

2. Nicotine acts on specific binding sites or receptors throughout the nervous system. Nicotine readily crosses the blood-brain barrier and accumulates in the brain shorly after it enters the body. Once in the brain, it interacts with specific receptors and alters brain energy metabolism in a pattern consistent with the distribution of specific binding sites for the drug.

3. Nicotine and smoking exert effects on nearly all components of the endocrine and neuroendocrine systems (including catecholamines. serotionin, corricosteroids, pituitary hormones). Some of these endocrine effects are mediated by actions of nicotine on brain neurotransmitter systems (e.g. hypothalamic-pinitary axis). In addition, nicotine has direct peripherally mediated effects (e.g.. on the adrenal medulla and the adrenal cortex).

\section{Tobacco Use as Drug Dependence}

1. Cigarettes and other forms of tobacco are addicting. Partems of tobacco use are regular and compulsive, and a withdrawal syndrome usually accompanies tobacco abstinence.

2. Nicotine is the drug in tobacco that causes addiction. Specifically, nicotine is psychoactive ("mood altering") and can provide pleasurable effects. Nicotine can serve as a reinforcer to motivate tobaccoseeking and tobacco-using behavior. Tolerance develops to actions of nicotine such that repeated use results in diminished effects and can be accompanied by increased intake. Nicotine also causes physical dependence characterized by a withdrawal syndrome that usually accompanies nicotine abstinence.

3. The physical characteristics of nicotine delivery systems can affect their toxicity and addictiveness. Therefore, new nicotine delivery systems should be evaluated for their toxic and addictive effects.

\section{Tobacco Use Compared to Other Drug Dependeacies}

1. The phannacologic and behavioral processes that determine tobacco addiction are similar to those that determine addiction to drugs such as heroin and cocaine. 
2. Environmental factors including drug-associated stimuli and social pressure are important influences of inttation. patterns of use. quitting. and relapse to use of opioids. alcohol. nicotine. and other addicting drugs.

3. Many persons dependent upon opioids, alcohol. nicotine. or other drugs are able to give up their drug use outside the context of treatment programs; other persons, however, require the assistance of formal cessation programs to achieve lasting drug abstinence.

4. Relapse to drug use often occurs among persons who have achieved abstinence from opioids, alcohol, nicotine, or other drugs.

5. Behavioral and phamacologic intervention techniques with demonstrated efficacy are available for the treatment of addiction to opioids, alcohol, nicotine, and other drugs.

\section{Effects of Nicotine That May Promote Tobacco Dependence}

1. After smoking cigarettes or receiving nicotine, smokers perform better on some cognitive tasks (including sustained attention and selective attention) than they do when deprived of cigarettes or nicotine. However, smoking and nicotine do not improve general leaming.

2. Stress increases cigarette consumption among smokers. Furher, stress has been identified as a risk factor for initiation of smoking in adolescence.

3. In general, cigarette smokers weigh less (approximately $7 \mathrm{lb}$ less on average) than nonsmokers. Many smokers who quit smoking gain weight.

4. Food intake and probably metabolic factors are involved in the inverse relationship between smoking and body weight. There is evidence that nicotine plays an important role in the relationship between smoking and body weight.

\section{Treatment of Tobacco Dependence}

1. Tobacco dependence can be treated successfully.

2. Effective interventions include behavioral approaches alone and behavioral approaches with adjunctive pharmacologic treatment.

3. Behavioral interventions are most effective when they include multiple components (procedures such as aversive smoking, skills training, group support, and self-reward). Inclusion of too many treatment procedures can lead to less successful outcome.

4. Nicotine replacement can reduce tobacco withdrawal symptoms and may enhance the efficacy of behavioral treatment.

Source: The Health Consequences of Smoking: Nicotine Addiction, A Reporn of the Surgeon General, 1988, pp. 13-15. 
B. THE TOBACCO NDLSTRY HAS CONDLCTED EXTENSIVE RESEARCH INTO THE IIEDIC AL RALUFICATIO. OF CIGARETTES AS WELL AS ON THE IMIPORTAIT ROLE THAT NTCOTIE PLAYS IV THE ADDICTION TO CIGARETTES, HAS INTENTIONALLY MANTPLZATED THE NTCOTIVE LEVELS IN TOBACCO PRODLCTS DESIG.NED TO AFFECT THE "FUNCTIONS AND STRLCTLRE OF THE BODY." AND HAS LSED THIS KNOWLEDGE AS PART OF ITS PRODCCT DEVELOPMENT AND MARKETLNG STRATEGIES

Petitioners have already established that tobacco products can be "drugs" under Section 201 of the FDC Act. This section will provide factual evidence that the tobacco industry is no longer selling cigarettes for "smoking pleasure only." but has for some time in fact conducted extensive research and marketing activities on nicotine, and cigarette products in general, including developing sophisticated processes for extracting nicotine from tobacco products, and adding the nicotine back into the product (Reconstitution processes). This calculated, scientifically based effor to "control" the nicotine delivery of a cigarette product, coupled with a marketing strategy often designed to promote low nicotine cigarenes as safer and less addictive, warrants FDA expeditious action to classify all tobacco products as drugs under Section $201(\mathrm{~g})(1)(B)$ and (C) of the Act.

Over the last several years, new evidence and documentation has been brought to light which establishes that the cigarette industry has for many years recognized the central role that nicotine plays as par of the smoking habit, and that it deliberately and intentionally conducted (and continues) extensive research into nicotine, its effects on functions and structure of the body, and has used such research to develop and market new cigarettes designed to both affect functions and structure of the body and to mitigate and prevent disease (addiction).

In addition, tobacco industry documents made public in the case of Cipollone $v$. Ligeett Group. Inc., Civil Action No. 83-2864 (D.N.J. 1988), a product liability action brought in the U. S. District Court in New Jersey, reveal cigarette 
companies efforts to mislead and contuse the public regarding the health hazards of smoking. In the Cipollone case. Judge H. Lee Sarokin stated that the jury could reasonably conclude that "advenising of the industry created a consistent message of purity, health, safety, reduced tars and nicotine...to create doubt in the minds of the consumer as to smoking dangers. and played on the weakness of those who were either addicted and/or dependent," and, further, that the defendant cigarette companies "made affumative health claims which were untrue." (Id. at 8, 11-12.) In Haines, Judge Sarokin went even further stating:

All too often in the choice between the physical health of consumers and the financial well-being of business, concealment is chosen over disclosure. sales over safety, and money over morality. Who are these persons who knowingly and secretly decide to put the buying public at risk solely for the purpose of making profits and who believe that illness and death of consumers is an appropriate cost of their own prosperity.

The evidence from Cipollone, some of which is cited specifically in the petition, dates as far back as the 1960s. In March 1961, Arthur D. Little provided Liggett and Myers with a "Perspective Review" of the problems and solutions facing the industry. The document began by stating that: "There are biologically active matenals present in cigarette tobacco. These are: a)cancer causing b)cancer promoting c)poisonous d)stimulating, pleasurable, and flavorful." This memorandum is revealing in that it sets out some of the basic challenges to the industry on the smoking and health issue which were to be pursued for thirty five years. Several points in the review are worth noting:

There are many forces which continue to emphasize that $L \& M$ is in the tobacco business not the pleasure business. Any shift from being in the tobacco business will have to be accomplished by avoiding these major pressures. A means is emerging -- is it correct? Can it be accelerated?

The use of C.T.S. not as a product but as a concept opens a way of having a "tobacco" cigarette and at the same time exploring a great deal about the "causative factors" in cigarettes and at the same time not having to face major opposition for not using tobacco.

Are we not on the march to a "disassembled" tobacco cigarette that we "reassemble" via the C.T.S. process to minimize the biological effect? 
In an tpnl 20. 19h2 memorandum. senıor scienust $H$. Wakeman of Philip . $110 \mathrm{~m}$, latd out his thoughts on a "policy the company might follow as a result of the reopening of the smoking and health question..."

if the "Tar Derby" stans up again in the United States. I think we should try to be the first to market a cigarene delivering considerably less... of one or more of those substances that have been reported to be irritating to human skin or mucous membrane.

Let's speed up our activities on the solvent extraction of tobacco for the purpose of reducing the quantity of TPM, nicotine and gas phase materials delivered from the cigarette blend.

Finally. let's hasten our search for an additive (catalyst) that might be incorporated into the cigarette blend for the purpose of reducing the irritating substances in smoke.

On October 24, 1963 in a personal and confidential memorandum, H. Wakeham

of Philip Morris provided a "Technical Forecast" to Mr. Hugh Cullman. It read,

You have requested a "technical forecast outlining those areas where the cigarette industry might be most subject to criticism and suggesting those elements in smoke which might be most accused by either the medical profession or exploited by our competitors." We now have accumulated a good deal of documentation on this subject. Rather than to subject you to all this I will present here our considered judgement in the matter. If you should wish to go into further detail. It might be more practical to give you an oral review.

We believe that the health critics are following three main lines of antack:

(1) Chemical carcinogenesis of the lungs by smoke constituents;

(2) Irritation from smoke components leading to chronic bronchitis and emphyserna; and

(3) Cardiovascular effects due mainly to nicotine in the smoke.

...The Cardiovascular Effects in smoke are believed to be mainly due to nicotine and have been thoroughly explored in literature and conference. We do not believe this will be a specific area of attack. If forced to, we could produce a fairly tasty low nicotine product.

On November 21, 1963, Mr. R.H. Blackmore sent a confidential memo to Dr. A. Bavley concerming "Project 0100." The memo summarizes a planning meeting to "establish the major objectives for Project 0100 during 1964. The following excerpt is worth noting.

Dr. Bavley prefaced the meeting with the statement that the major objective of the Research Division for 1964 is to develop a "Medically 
Acceptable" sigarette in light of the present heaith artitude. The aims of the smoke chemistry group should be more specitic than in the past. We must not forget the major goals of the Division and become bogged down in procedures on analytical methodologies. For example. one of our major purposes is to remove polynuclear hydrocartons from cigarette smoke. not just to develop a method of detecting benzola)pyrene in smoke.

Dr. Bavley then stated that we should approach the problem with definite "bench marks" in mind.

What are the "bench marks" in the Smoke Chemistry Problem?

1. Vicotine removal. Accomplisbed - using low nicotine tobacco and/or extracted tobacco to remove nicotine selectivity from tobacco.

2. Removal of phenol. Accomplished by means of the cellulose acetate filter with plasticizers.

3. Polynuclear hydrocarbons removal. We should have this completed during 1964 - major effort.

4. Vitrosamines removal. We should also have this completed during 1964.

\section{Stans of Polynuclear Hydrocarton Removal from Smoke.}

An improved analytical method for the determination of benzo(a)pyrene and several other polynuclear hydrocarbons should be completely worked out by January 31,1964 . This will enable screening of various chemical additives and/or treatments of cigarettes for polynuclear hydrocartons delivery.

A 1968 Liggett and Myers internal memorandum summarized the results of an important meeting of the scientific directors of all of the major tobacco companies, held in Hilton Head, South Carolina, February 14-16. Attending the meeting were: E. Harlow, American Tobacco Co.; R.E. Griffith. Brown and Williamson; M. Senkus, R.J. Reynolds; H. Wakchat. Philip Morris: A. Spears. P. Lorillard; and W. Bates, Liggett and Myers. The memorandum from W.W. Bates to M.E. Harrington contained the following statements:

Our primary purpose was to discuss the scientific aspects of the problems facing the tobacco industry with specific emphasis on tobacco and health. If a consensus could be reached on this point, we were to discuss and attempt to reach a consensus as to an acceptable way to atrempt to solve these problems.

Shortly after lunch on the second day of our conference I insisted upon discussing what I considered to be the major scientific problems facing 
the industry. After a brief discussion the remainıng tive sientitic directors quickly arrived at (illegible) that:

1. There is general agreement that it is desirable (I feel it is necessary) to establish the scientific facts which will put smoking and health into the proper perspective. These problems are of such magnitude that they are beyond the capability of any one company to attack with the expectation of making the needed progress within reasonable tume limits.

2. In order to do this it will require an extensive and broadly based program which includes epidemiology, pharmacology, toxicology. chemistry and the necessary interactions of components of cigarette smoke with biological systems of animals and where necessary humans. My thoughts expressed here may in fact go somew hat beyond my fellow conferees.)

3. The organization discussed above contains the essential elements to underake the kind of program which is required.

4. In addition we reached general agreement that in many areas of basic research such as the isolation and identification of components of cigarette smoke and other problems with non-competitive implications, work should be jointly planned and divided between individual industry labs so as to eliminate unnecessary duplication and to generate more information faster without an increase in funds needed to do the work.

A 1973 internal Philip Morris (William Dunn Jr.) memorandum on "Motives and Incentives in Cigarette Smoking" describes the conclusions of a 1972 Council for

Tobacco Research scientific conference in St. Martin on the question of "Why do people smoke cigarettes?" The conference concluded that:

The primary incentive to cigarette smoking is the immediate salutary effect of inhaled smoke upon body function...that nicotine is the active constituent of cigarette smoke. Without nicotine, the argument goes. there would be no smoking.... Think of the cigarette pack as a storage container for a day's supply of nicotine.... Think of the cigarette as a dispenser for a dose unit of nicotine.... Think of a puff of smoke as the vehicle for nicotine.... Smoke is beyond question the most optimized vehicle of nicotine and the cigarette the most optimized dispenser of smoke.

An October 1978 presentation (revised draft) made by $\mathrm{H}$. Wakeman of Philip

Morris described the company's plan and activities as follows:

I have been given five minutes to describe a five-year plan for Research and Development.... Firstly, we would like you to think of Research and Development as a originator, developer, and tester of the technological weapons system that underlies and protects company policies, particularly 
in the area of smoking and health Obviously. without an adequate ueapons system. strategy is severely limited. Where the weapon, inventon contains applications of scientific and engineering methods to solve our technical problems. it becomes part of our offensive strateg Where the arsenal contains protective shields against economic. competitive. and political pressures. it is part of our defenstve strateg. As Mr. Goldsmith expresses it. "We must keep all bases covered."

Our most important defensive weapons are in the category of product development. Here the company and industry are facing two clearly discernable trends, both of them arising from the smoking and health controversy. The first of these is the continuing demand to make cigarets milder and milder, in effect to lower the tar and nicotine delivery per cigaret. Milder cigarets have lower taste impact, and our challenge is to maintain and improve customer acceptance in the face of this trend.

The second trend is the intensifying pressure to develop a "safe" cigaret... The definition of cigaret "safeness" centers around a battery of bio-essay tests. currently with animals but eventually with humans. Our current program is to use a limited number of such tests to evaluate fiiter combinations. blend components, and even non-tobacco substitute materials. We are working to be in a position to design a cigaret which will meet "less hazardous" specifications if they are ever imposed on us and at the same time to make a product which is attractive to the smoker. I am pleased to report that we already have a number of such prototypes on our shelves, with more to come in the future.

Research and Development provides the Philip Morris weapons system: your insurance against surprises that may undermine the pre-emunence of our business.

A Philip Morris interoffice correspondence dated March 24, 1981. noted the

following:

Nicotine is a powerful pharmacological agent with multiple sites of action and may be the most imporant component of cigarette smoke. Vicotine and an understanding of its properties are important to the continued well being of our cigarette business since this alkaloid bas been cited often as 'the reason for smoking' and theories bave been advanced for 'nicotine titration' by the smoker. Nicotine is known to have effects on the central and peripheral nervous system as well as influencing memory. leaming, pain perception, response to stress and level of arousal.

It is not surprising that a compound with such a multitude of effects would have properties which are considered undesirable by the antismoking forces. Claims are made that nicotine in cigarette smoke can induce chest pain and irregularities in cardiac thythm when a person with a compromised cardiovascular system smokes or when persons with cardiac disease are exposed to high concentrations of side stream smoke.

For these reasons our ability to ascerain the structural features of the nicotine molecule which are responsible for its various pharmacological properties can lead to the design of compounds with enhanced desirable properties (central nervous system effects) and minimized suspect 
propenies (peripheral nen ous systems effects) There are many oppomunities for acquiring propnetary compounds which can sine as $J$ tirm foundation for new and innovative products in the future.

The program is justified in my view as a defensive response to the antismoking forces criticisms of nicotine and also as fundamental research into the nature of our product and how it affects our customers, the smokers. This entire program involves complex technological problems and the benefits to be derived from the program will not be realized immediately. Indeed the benefits will necessarily be of a long-term nature and may have direct bearing on our market position in a 10-15 year time frame. However, if we do not have the basic research resulis this program will provide we will not be in a position to respond if and when the pressures to change do occur. (Emphasis added.)

In addition to the internal documents that have become available, of which we have cited only a few, there is extensive evidence about the tobacco industry's inten: to manipulate its products and particularly the nicotine content of the cigarettes contained in patent applications. A preliminary review by petitioners indicates that the patents filed both here in the United States as well as in Europe are numerous. The patents go back well into the 1960 s, indicating the tobacco industry's ongoing efforts to manipulate the tobacco product. A few examples are noted below. A 1971 Philip Morris patent $(\$ 3,584,630)$ reflects the technological applications of the strategies revealed in the tobacco industry's intemal confidential documents.

This invention relates to a tobacco product containing a nicotinereleasing agent and to a method for releasing a controlled amount of nicotine into tobacco smoke. More particularly, the invention relates to tobacco products containing an agent for releasing nicotine into tobacco smoke which agent permits storage of tobacco products containing said agent for prolonged periods of time, without substantial loss of the nicotine associated with said agent. The agent provides for the release of nicotine in controlled amounts, when tobacco smoke is passed in contact with the nicotine-containing agent.

It has long been known in the tobacco industry that in order to provide a satisfactory smoke, it is desirable to maintain the nicotine content of tobacco products at a uniform level. However, it is difficult to accomplish this result since the nicotine content of tobacco varies widely, depending on the type of tobacco and the conditions under which the tobacco is grown.

Maintaining the nicotine content at a sufficiently bigh level to provide the desired physiological activity, taste, and odor which this material imparts to the smoke, without raising the nicotine content to an 
undesirably high leiel. can thus be seen to be a significant problem in the tobacco ari. The addition of nicotine to tobacco in such a uav that it remains iner and stable in the product and yet is released in a controlled amount into the smoke aerosol when the tobacco is pyrolyzed. Is a result which is greatly desirable.

The present invention provides a solution to this longstanding problem and results in accurate control of the nicotine which is released in tobacco smoke. By employing the nicotine-releasing agents and methods of the present invention, it is possible to incorporate exact amounts of nicotine in a tobacco composition, which ill remain constant over extended periods of time and which will ultimately yield a smoke containing a controlled amount of nicotine.

With regard to the above-discussed problems of maintaining the nicotine content of tobacco products to the proper level to provide the desired qualities in tobacco smoke. previous efforts have been made to add nicotine to tobacco products wherein the nicotine level in the tobacco was undesirably low.

Such efforts have included adding nicotine per se to the tobacco. However, it has not been found feasible to add nicotine per se to tobacco products. For one thing, the nicotine can be absorbed through intact skin and is, thus, difficult and hazardous to handle in processing operations. In addition, free nicotine is a very volatile material and will volatilize readily at room conditions. Therefore, the addition of nicotine into a tobacco product as the free material could readily result in a substantial loss of the nicotine during storage of the tobacco product. Even though the nicotine content of tobacco products could, by the addition of nicotine content of tobacco products could, by the addition of nicotine under conditions involving considerable effort, be made initially uniform, the volatization losses attending storage of the product would not provide smoke containing a uniform amount of nicotine.

A 1985 U.S. patent $(\$ 4,557,280)$ fuled by Brown and Williamson conceming the process for reduction of nitrate and nicotine content of tobacco by microbial treatment states:

The present invention relates to a process of reducing the nitrate and nicotine contents of tobacco by treating the tobacco with a culture of a microorganism. More specifically, the invention relates to a process for treating tobacco to reduce the nitrate and nicotine contents thereof, which, when incorporated into a tobacco smoking product, yields smoke with reduced nitrogen oxides, hydrogen cyanide and nicotine deliveries without loss of desirable flavor and taste properties or other smoking qualities.

Using the culture of the present invention, it is practical to treat tobacco lamina or stem and remove nitrate and nicotine simultaneously or to make a water extract of either material and remove nitrate and nicotine and then reapply treated extract to the original tobacco materials or a reconstituted tobacco. The capability of ireating the extract and then reapplying it to the original tobacco avoids the solubles weight loss 
encountered when using water extraction and discard as a behile for removing nitrate and nicotıne. It also atoids the loss of other desirable tobacco components encountered in water extraction and discard. The process of the present invention also offers potential for removing both nitrate and nicotine in reconstituted tobacco production systems. wherein the tobacco is extracted and the extract is added back in subsequent process steps, since this enzyme (microbial) system functions efficiently in a liquid system.

A 1986 R.J. Reynolds patent ( $\$ 4.595 .024)$ contained the following statements:

A significant problem facing the cigarette industry is the development of new products.

Another area for significant improvement would be the development of a cigarette that delivers full smoking "satisfaction" at "tar" and nicotine levels below those made possible by current technology.

This is an object of this invention to provide a cigarette baving a puff-bypuff nicotine delivery curve radically different from that of a conventional cigarette.

It is a further object of this invention to provide a cigarette which delivers a larger amount of nicotine in the first few puffs of the cigarette than in the last few puffs.

A European patent application (Application \#8731143.0) filed by Philip Morris

Products, Inc. in December of 1987 also provides a good indication of the continuing intent of the tobacco company in developing processes and techniques

for nicotine removal and nicotine manipulation. As the patent specifically states:

A process is provided for the selective removal of basic materials from plant products, in particular, for removing nicotine from tobacco without materially affecting the content of other components of the tobacco product.

The patent goes on to state:

This invention provides a process for removing nicotine from tobacco without also removing the desirable aroma generating components. Tobacco is extracted with a solvent either in the supercritical state or in the liquid state. Thereafter, nicotine is selectively removed from the enriched solvent by passing the solvent through a trap containing a nonvolatile acid which is not soluble in the extraction solvent. The trap may be contained on a support medium. The solvent, depleted of nicotine and enriched in the other components, is then recycled to the tobacco to extract nicotine again.

It is an object of this invention to provide a process for selectively reducing the level of nicotine in tobacco using a single state extraction process with or without separate entrapment vessels. 
It is another object of this intention to provide a process for the migration of nicotine from one tobacco substrate lleaf matenal or reconstituted leaf) to a second tobacco substrate (leat matenal reconstituted leaf materal or tobacco stems) or to a non-tobacco substrate.

It is a further object of this invention to provide a process using absorption media (full flavor tobacco filler, reconstituted leaf matenais. tobacco stems. cotton cloth, cellulose. carbon, coca shells. or other plant by-products. porous ceramic, porous metal, etc.) to facilitate the selective removal of nicotine.

It is a further object of this invention to provide a process using aqueous absorption media (water, aqueous acid, aqueous salt, etc.) to facilitate the selective removal of nicotine.

It is a further object of this invention to provide a process for the extraction of nicotine from tobacco under relatively mild conditions.

In 1987, R.J. Reynolds Tobacco Company introduced a new cigarette called Premier, the so-called cigarette that heated but did not bum. It is clear from Reynold's own documents and press statements that the purpose of the cigarette was to intentionally respond to the evidence that had been released as part of the Surgeon General's report on environmental tobacco smoke. At a September 14, 1987 press conference Mr. Edward Horrigan, CEO of RR Tobacco, stated:

As you know smokers have been facing many challenges over the past several years ranging from the smoking and health controversy to the social acceptability of smoking.

In response to these we began to develop a cigarette that would help smokers address many issues they face as they exercise their choice and right to smoke.

Since the tobacco does not burn, a majority of the compounds produced by buming tobacco are eliminated or greatly reduced, including most compounds that are often associated with the smoking and health controversy.... We believe it will be well received by those people who object to tobacco smoke.

And since this cigarette eliminates or greatly reduces most of the compounds often associated with the smoking and health controversy... we feel this product address the desires and perceptions of many of today's smokers.

The Coalition on Smoking OR Health along with the American Medical

Association filed petitions with the FDA seeking to classify these products as 
drugs and or devices under the Food. Drug and Cosmelic Act. Because Reynolds decided not to go forward with the marketing of the product. the petitions were never acted upon. In attempting to convince the public that this product should have been allowed on the market. Reynolds produced a 743 page monograph entitled. "New Cigarette Prototypes that Heat Instead of Bum Tobacco." This document reflects the intensive research of the industry to develop and manufacture a product that clearly should be considered a drug under the FDC Act. Segments of the study included discussion of "nicotine-free particulate." "nicotine elimination," "nicotine absorption," "inhalation studies," and other topics related to the chemical and toxic effects of cigarette smoking. The intended objectives of the development of the cigarette were stated in the monograph as follows:

- to simplify the chemical composition of mainstream and sidestream smoke emitted by the new cigarette.

- To minimize the biological activity of the mainstream and sidestream smoke emitted by the new cigarette.

- To achieve significant reduction of environnental tobacco smoke from the new cigarette.

While being touted by Reynolds as a "cleaner" cigarette, Premier was known to contain carbon monoxide as well as nicotine. Concern was expressed by the public health community that if the product escaped regulation, the industry would have been free to add any chemical additives to the flavor chamber as a.ell as adding or subtracting levels of nicotine at will without the FDA having any federal regulatory oversight. Premier was just one more example of how the tobacco industry has been intensifying its research and development activities to develop and promote products that are not sold for smoking pleasure only but are in fact drugs under the Act, designed to affect function and structure of the body and designed to mitigate and prevent disease. 
The March 1992 edition of the tobacco industry's trade joumal. TR Tobacco

Reporter provides further evidence that nicotine research. development. and manipulation continue to be a major focus for the tobacco industry. As an advertisement by LTR Industries (a subsidiary of Kimberly-Clark Corporation) specifically points out:

Nicotine levels are becoming a growing concern to the designers of modem cigarettes. particularly those with lower "tar" deliveries. The Kimberly-Clark tobacco reconstitution process used by LTR Industries permits adjustments of nicotine to your exact requirements. These adjustments will not affect the other important properties of customized reconstituted tobacco produced at LTR Industries: low tar delivery, high filling power, high yield and the flexibility to convey organoleptic modifications. We can help you control your tobacco.

The factual evidence from a variety of sources, coupled with the evidence provided by petitioners as part of an earlier filing seeking to classify all low tar and nicotine cigarettes as "drugs" under the Food, Drug and Cosmetic Act, clearly establishes that for many years the tobacco industry has intentionally and deliberately engaged in the research, development and marketing of products subject to drug provisions of the FDC Act. 


\section{CONCLLSION}

It has been thirty years since the release of the first Surgeon General's Repor implicating cigarente smoking as a cause of cancer. Since then. there have been more than 20 additional reports issued by the Office of the Surgeon General. The messages and conclusions of those reports are clear -- cigarette smoking is the single most preventable cause of death in our society.

While the medical evidence about tobacco and its effects on human health has grown. the manufacturing and marketing strategies of the tobacco industry have developed and grown concurrently. At one time, cigarettes were products marketed and produced merely for smoking pleasure only, products which consisted primarily of a roll of tobacco wrapped in paper. As the concems about the health consequences of tobacco use grew over the years, so did the tobacco industry's antempt to develop and market products which would allay the fears of disease and death and addiction. Not only did the industry market and label its products with low tar and low nicotine claims, but confidential documents only recently made available to the public show an industry that had a well planned out and calculated strategy designed to develop, produce, and market products which were intended to both "affect structure and function of the body" and also to "mitigate and prevent" the onset of disease. The industry was no longer in the business of marketing and selling products sold for smoking pleasure only, but was in the business of selling "drugs" as they have been defined by the Food. Drug and Cosmetic Act.

In producing and marketing "drugs" the tobacco industry should be held to the same standards as other businesses whose products are marketed and sold with intended "drug" related effects. 
The federal govemment has for the last 30 years ialled in us policy responsibuities to protect the Amencan public from adulterated and misbranded products in the form of tobacco products. For too long the federal govemment has side-stepped the issue of regulating this nations leading cause of disease and disability. It seems almost inconceivable that a public health issue of this magnitude can be virtually ignored by our policy makers.

The evidence of tobacco manufacturer intent to sell tobacco products as drugs under the Food. Drug and Cosmetic Act is clear and convincing. The Food and Drug Administration can no longer afford to sit idle while hundreds of thousands of Americans die each year, and while 3,000 children try this addictive drug for the first time each and every day. 


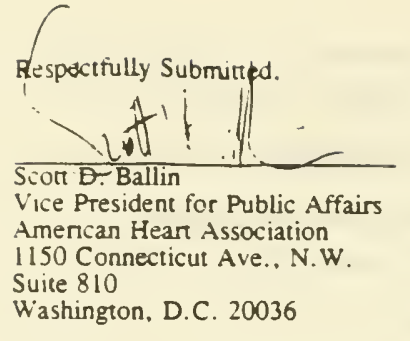

Fran Du Melle
Deputy Managing Director
American Lung Association
$1726 \mathrm{M}$ Street, N.W.
Suite 902
Washington, D.C. 20036
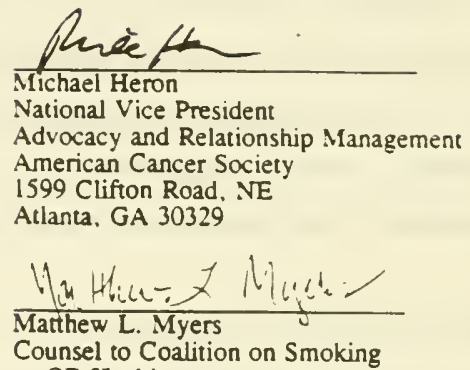

OR Health

1615 New Hampshire Ave., N.W.

Second Floor

Washington, D.C. 20009

\section{Legislative Advisory Council}

Douglas E. Henley, M.D.

Chairman of the Board

American Academy of Family Physician

Jane Delgado, Ph.D.

President and CEO

National Coalition of Hispanic Health and

Human Services Organizations (COSSMHO)

Deborah L. Cullen, Ed.D.

President

American Association of Respiratory Care

George K. Degnon

Executive Vice President

Association of State and Territorial

Health Officials
Ronald B. George, M.D., FCCP

President

American College of Chest Physicians

Fernando Trevino, Ph.D.. MPH

Executive Director

American Public Health Association

Gordon K. McLean, M.D.

President

Society of Cardiovascular \& Interventional Radiology 


\section{EIVTROMTIENT NL IIP.ACT}

Action requested by Petitioners does not require preparation of an environmental impact statement under the Food. Drug and Cosmetic Act.

The undersigned cerifies, that, to the best knowledge and belief of the undersigned. this petition includes all information and views on which the petition relies, and that it includes representative data and information known to the Petitioners ahich are unfavorable to the petition.

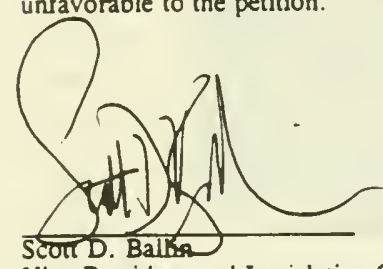

Vice President and Legislative Counsel

American Hear Association

1150 Connecticut Ave., N.W.

Suite 810

Washington. D.C. 20036

(202) 822.9380 


\section{Coalition on Smoking OR Health}

\section{GALLUP Poll}

Survey on:

The Public's Attitudes Toward

\section{THE REGULATION AND}

ADVERTISING OF

CIGARETTES

April 1993 


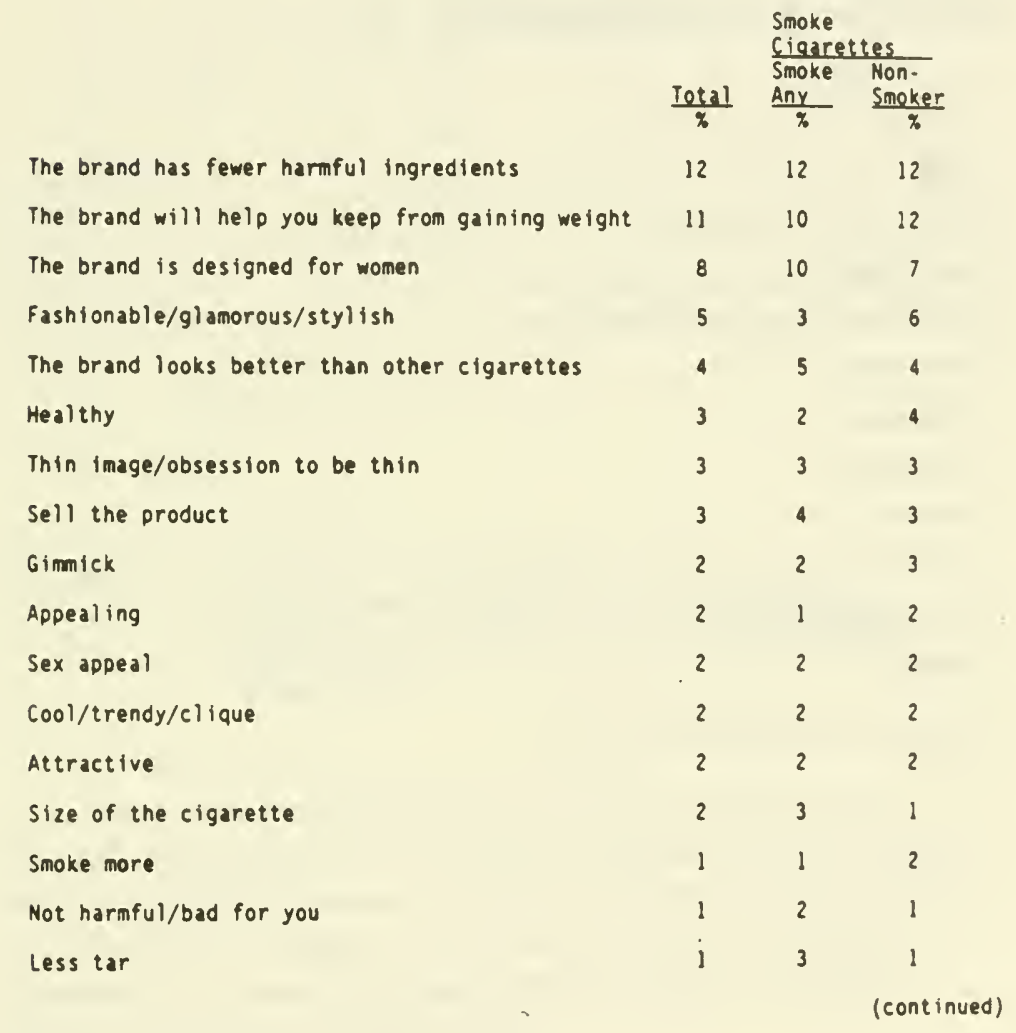




\begin{tabular}{|c|c|c|c|}
\hline & \multirow[b]{2}{*}{$\frac{\text { Iotal }}{\%}$} & \multicolumn{2}{|c|}{$\begin{array}{l}\text { Smoke } \\
\text { Ciaarettes }\end{array}$} \\
\hline & & $\begin{array}{l}\text { Smoke } \\
\frac{\text { Any }}{\%}\end{array}$ & $\begin{array}{l}\text { Non- } \\
\frac{\text { Smoker }}{\%}\end{array}$ \\
\hline Less calories/not fattening & 1 & 1 & 1 \\
\hline Okay to smoke & 1 & 0 & 1 \\
\hline Directed towards the younger generation & 1 & * & 1 \\
\hline Less nicotine & 1 & * & 1 \\
\hline The brand is easier to hold & 1 & 1 & 1 \\
\hline Safe & 1 & 1 & 1 \\
\hline Better value for the money & 1 & $\bullet$ & 1 \\
\hline Less tobacco & 1 & 1 & $*$ \\
\hline Better than other brands/competitors & 1 & • & 1 \\
\hline Don't smoke & $\bullet$ & $\bullet$ & 1 \\
\hline Propaganda & * & 0 & 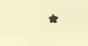 \\
\hline Acceptable & $\star$ & • & $\bullet$ \\
\hline Psychological & * & 0 & $\bullet$ \\
\hline Other & 2 & 2 & 2 \\
\hline Don't know/Refused & 31 & 32 & 31 \\
\hline Nothing & - & 1 & 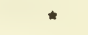 \\
\hline
\end{tabular}

-Less than one-half of one percent. 
Yes

No

Don't know/Refused

Total

Number of Interviews

\begin{tabular}{|c|c|c|c|c|c|c|c|}
\hline \multirow{3}{*}{$\frac{\text { Total }}{x}$} & & \multirow[b]{2}{*}{ Female } & & & & \multicolumn{2}{|l|}{ Smoke } \\
\hline & & & & 35.49 & $55+$ & $\begin{array}{l}\text { Smoke } \\
\text { Any }\end{array}$ & $\begin{array}{l}\text { Non- } \\
\text { Smoker }\end{array}$ \\
\hline & $x$ & $x$ & $\%$ & $\%$ & $\%$ & $\%$ & $\frac{10}{\%}$ \\
\hline 68 & 62 & 74 & 73 & 71 & 62 & 62 & 70 \\
\hline 27 & 34 & 20 & 24 & 25 & 30 & 33 & 24 \\
\hline 5 & 4 & 6 & 3 & 4 & 8 & 5 & 6 \\
\hline 100 & 100 & 100 & 100 & 100 & 100 & 100 & 100 \\
\hline$(1015)$ & (488) & (527) & (299) & (325) & $(391)$ & (267) & (748) \\
\hline
\end{tabular}

The Question: The Food and Drug Administrarion has regulanons that deal with the way many drugs are sold, labeled, adverrised, and promoted.

Currently there are no similar regulations for tobacco products. Do you think that tobacco products should be regulated in a similar manner or not?

Close to seven in ten adults $(68 \%)$ feel the FDA should regulate tobacco products in a manner similar to the way drugs are regulated. Women are more likely than men to favor FDA regulation. In addition, younger adults ar more likely than older adults to favor regulation. While smokers are somewhat less likely than nonsmokers to favor regulation of tobacco products by the FDA, nevertheless, a majority $(62 \%)$ do say they support regulation. 


\author{
The brand is safer \\ Trying to sell them \\ $\mathrm{False} / \mathrm{misleading}$ advertisement \\ Heal thier \\ Keep smoking/encourage you to smoke \\ Less hamful/dangerous \\ That it is not bad for you. \\ The brand is less addictive \\ It's okay to smoke \\ 8ad for your health/warnings \\ Less cancerous/won't cause cancer \\ Not to smoke/stop smoking \\ start smoking \\ Makes it look attractive/fashionable \\ Ignoring possible health risks \\ The brand tastes better \\ Low tar
}

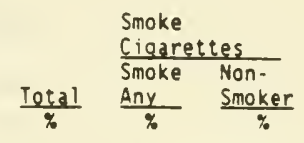

$\begin{array}{lll}49 & 46 & 49 \\ 5 & 8 & 4 \\ 4 & 4 & 4 \\ 4 & 3 & 5 \\ 3 & 2 & 3 \\ 2 & 2 & 3 \\ 2 & 2 & 2 \\ 2 & 1 & 2 \\ 2 & 2 & 2 \\ 2 & 3 & 1 \\ 1 & 3 & 1 \\ 1 & 1 & 1 \\ 1 & 1 & 1 \\ 1 & * & 1 \\ 1 & * & 1 \\ 1 & 0 & 1 \\ 1 & 1 & *\end{array}$

(cont inued. . .) 
Protecting themselves

Trying to make money

Encourages youths to smoke

The brand is milder

Lower nicotine

Favors smoking

other

Don't know/Refused

Number of Interviews

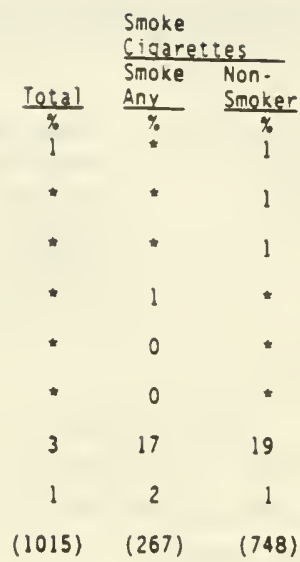

-Less than one-half of one percent. 
The Questions: Besides selling the product, what message do you think cigarette advertising is ming $10 \mathrm{get}$ across when it uses terms like low tar. low nicorine, or lower yield? What else?

And what message do you think cigarerte advertising is trying to get across when it uses words such as slim, uitrathin, no fat smoke. super slim? What else?

Slightly less than half $(49 \%)$ ) say cigarette advertising that uses terms such as "low tar," "low nicotine" or "low yield" is trying to convey the message that their cigarettes are safer. Both smokers and nonsmokers hold the same opinion with regard to this advertising.

There is less consensus regarding cigarette advertising that uses terms such as "slim," "ultrathin" or "no fat smoke." One in eight (12\%) say this type of statement tries to suggest the brand has fewer harmful ingredients. As many (11\%) say the message the advertising is trying to convey is that the cigarettes will help you keep from gaining weight. Again, there is little difference in opınion between smokers and nonsmokers. 


\begin{tabular}{|c|c|c|c|c|c|c|c|c|}
\hline & & & & & & & $\begin{array}{l}\text { Smoke } \\
\text { cigar }\end{array}$ & ettes \\
\hline & $\frac{\text { Total }}{\%}$ & $\frac{\frac{\text { Sex }}{\text { Male }}}{\%}$ & $\frac{\text { Eemale }}{x}$ & $\frac{\frac{A g e}{18-34}}{x}$ & $\frac{35 \cdot 49}{\%}$ & $\frac{55}{\%}$ & $\begin{array}{l}\text { Smoke } \\
\frac{\text { Any }}{\%}\end{array}$ & $\begin{array}{l}\text { Non- } \\
\text { Smoker } \\
\frac{\%}{\%}\end{array}$ \\
\hline Yes, should ban & 53 & 43 & 62 & 46 & 60 & 53 & 48 & 55 \\
\hline No, should not & 43 & 53 & 34 & 51 & 38 & 41 & 48 & 41 \\
\hline Don't know/Refused & 4 & 4 & 4 & 3 & 2 & 6 & 4 & 4 \\
\hline Total & 100 & 100 & 100 & 100 & 100 & 100 & 100 & 100 \\
\hline Number of Interviews & $(1015)$ & (488) & $(527)$ & (299) & (325) & $(391)$ & $(267)$ & $(748)$ \\
\hline
\end{tabular}

-Less than one-half of one percent.

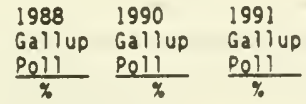

Yes, should ban

$55 \quad 49 \quad 47$

No, should not

$40 \quad 48 \quad 49$

Don't know/Refused

$5 \quad 3 \quad 4$

Total

$100 \quad 100 \quad 100$ 
The Question: Do you think there should or should not be a complete ban on cigarette adverising?

A majority ( $53 \%$ ) agree there should be a complete ban on cigarette advertising. About four in ten (43\%) feel advertising should not be banned. Women and older adults are more likely than men and younger adults to support a complete ban.

Compared to other Gallup Poll measures taken in the past. the $53 \%$ who favor a complete ban on cigarettes advernising is similar to the $55 \%$ who approved such a ban in 1988 and slightly higher than the $47 \%$ who favored a ban in 1991 .

FAVOR/OPPOSE RESTRICTIONS ON CIGARETTE ADVERTISING THAT - Appeal to children .

$\begin{array}{lrrrrrrrr}\text { Favor } & 76 & 78 & 75 & 74 & 84 & 73 & 74 & 77 \\ \text { Oppose } & 23 & 21 & 24 & 26 & 15 & 25 & 25 & 22 \\ \text { Don't know/Refused } & -1 & -1 & -1 & -10 & 1 & -2 & 1 & 1 \\ \text { Total } & 100 & 100 & 100 & 100 & 100 & 100 & 100 & 100 \\ \text { Number of Interviews } & (1015) & (488) & (527) & (299) & (325) & (391) & (267) & (748)\end{array}$

-Less than one-half of one percent. 
FAVOR,OPPOSE RESTRICTIONS ON CIGARETTE ADVERTISING THAT

$\begin{array}{lcccccccc}\text { Favor } & 64 & 63 & 65 & 59 & 71 & 63 & 59 & 66 \\ \text { Oppose } & 33 & 32 & 33 & 38 & 26 & 33 & 36 & 31 \\ \text { Don't know/Refused } & 3 & 5 & 2 & \frac{3}{3} & \frac{3}{3} & 4 & \frac{5}{100} & \frac{3}{100} \\ \text { Total } & 100 & 100 & 100 & 100 & 100 & 100 & 100 & 100 \\ \text { Number of Interviews } & (1015) & (488) & (527) & (299) & (325) & (391) & (267) & (748)\end{array}$

FAVOROPPOSE RESTRICTIONS ON CIGARETTE ADVERTISING THAT - Encourage people 10 smoke.

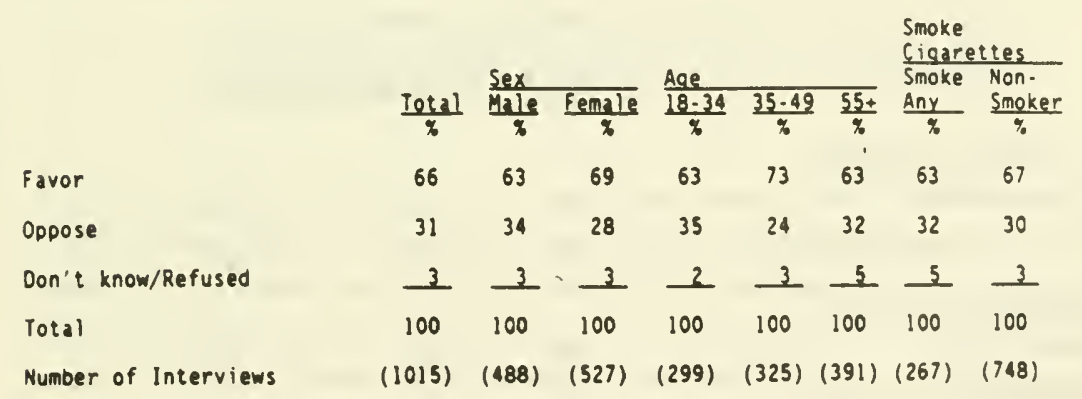


The Question: Would you favor or oppose restricrions on cigarette advertising that - Appeal to children?

- Make smoking appear glamorous?

- Encourage people to smoke?

Three out of four adults (76\%) favor restrictions of cigarette advertising that appeals to children. Approximately two in three $(66 \%)$ favor restrictions on advertusing that encourages people to smoke, and $64 \%$ favor restrictions on ads that make smoking appear glamorous. There is little difference of opinion of these matters between smokers and nonsmokers. Adults between the ages of 35 and 49 are more likely than others to favor, such restrictions.

ADDITIONAL INFORMATION TO WARNING LABEL

$(N=1015)$

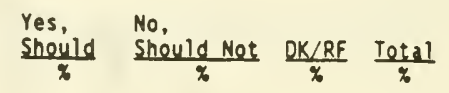

Increases health risk

for people with heart or lung problems

88

12

100

A warning about addiction

87

12

100

Increases health risk

for people with high

blood pressure

85

Increases risk of stroke

85

$\begin{array}{lll}13 & 2 & 100 \\ 14 & 1 & 100\end{array}$




$\begin{array}{lc}\frac{\text { Tot2l }}{4} & 76 \\ \text { Yes, should be added } & 23 \\ \text { No, should not } & 1 \\ \text { Don't know/Refused } & 100 \\ \text { Total } & \text { (1015) } \\ \text { Number of Interviews } & \\ \text { Additions to Cigarerse Warning Labels }\end{array}$

The Questions: Cigaretle packages currently carry a waming abous the risk of smoking. It has been suggested additional information be added to the waming label. As I read some of these suggestions, please tell me if this informarion should or should not be added to the waming label on cigarettes packages. Firt. . .
- Increases risk of stroke
- Increases healih risk for people with hight blood pressure
- Increases health risk for people with hears or lung problems
- A warning about addicrion

It has been suggested that cigarette packages include an additional waming about the effects of tobacco smoke on norl-smokers. Do you think this addinional information should or should not be added to cigarette packages?

The public appears to be highly in favor of adding information to cigaretie warning labels. Nearly nine in ten (88\%) feel a warning about the risk of heart disease should be added to the label. As many ( $87 \%$ ) favor adding a warning about the possibility of addiction related to smoking. A warning about the risk of smoking to people with high blood pressure is supported by $85 \%$ of all adults, and $85 \%$ also favor a warning about the risk of stroke.

Asked about attaching a warning on cigarette packages about the effect of robacco smoke on nonsmokers. three out of four ( $76 \%$ ) say such a warning should be added. 
The Question: Currently, there is no law that requires cigarette manufacturers to disclose the additives used in manufacturing tobacco products. Do you think cigarette manufacturess should be required to list the additives used in manufacturing cigarettes and other tobacco praducts or not?

Nine in ten aduits (89\%) are in favor of requiring manufacturers to disclose the additives used in tobacco products. There are no differences by demographic group in opinion on this issue. Smokers are as likely as non-smokers to support disclosure of additives.

\begin{tabular}{|c|c|c|c|c|c|c|c|c|}
\hline & & & & & & & $\begin{array}{l}\text { Smoke } \\
\text { Cigar }\end{array}$ & \\
\hline & $\frac{\text { Iotal }}{x}$ & $\frac{\text { Sex }}{\frac{\text { Male }}{\%}}$ & $\frac{\text { Female }}{\%}$ & $\frac{\frac{\text { Age }}{18-34}}{\%}$ & $\frac{35-49}{\%}$ & $\frac{55}{\%}$ & $\begin{array}{l}\text { Smoke } \\
\frac{\text { Any }}{\%}\end{array}$ & $\begin{array}{l}\text { Non- } \\
\text { Smoker } \\
\%\end{array}$ \\
\hline Yes, should be required & 89 & 87 & 91 & 90 & 95 & 84 & 87 & 90 \\
\hline No, should not & 8 & 11 & 6 & 8 & 4 & 11 & 11 & 7 \\
\hline Don't know/Refused & 3 & 2 & 3 & 2 & 1 & 5 & 2 & 3 \\
\hline Total & 100 & 100 & 100 & 100 & 100 & 100 & 100 & 100 \\
\hline Number of Interviews & $(1015)$ & (488) & $(527)$ & (299) & (325) & (391) & $(267)$ & $(748)$ \\
\hline
\end{tabular}


TABLE OF CONTENTS

111. TAME OF MTIDORITIES

1. PLLIMIMAY STATEMNT

11. STATEERT OF FACTUAL EROUMOS

A. Introduction

B. Cigarette Marketing Strategy and Health Clales

C. Historical Overview: A Chronology of Cigarette Advertising and the Development of Low Tar, and Low Micotine Cigarettes

1. Prior to the 1964 Surgeon General's Report on Saoking and Health

2. 1964 - 1967

d. Advertising Thens: Mid 1960s

b. Development of Law Yiels Clgarettes

c. Consunar Perceptions

d. FTC Testing

e. Falmess Doctrine

3. 1968 - 1970

a. Advertising Thenes: Late 1960s to Early 1970s

4. 1970s

a. Advertising Themes: Early to mid 1970s, Mid to Late 1970 s

b. Publiclty on "Safe" Sroking Levels Not Based on Fact

c. Claim "Lowest" Repeated By Various Brands

5. Late 1970s to Early $1980 \mathrm{~s}$

c. Public Impession of Reduced Tar and Nicotine

b. Advertising Theives: Late 1970s to Early 1980s

6. Eerly to Mid 1980 s

A. Mdvertising Theaes: Early to Mid 1980s

7. M1d to Late 1980 s

c. Aovertising Themes: Current

b. Current Advertising Practices

D. Mazands of Lor Tar and Lor M1cotine Cigarettes and thy Health Cleles are Misleading

1. Compensatory Swoking

2. Additives

3. Misrepresentation of Tar and Nicotine Content

4. Harnful Components of Tobacco Snoke Other Than Tar and Nicotine

5. No Reduction in Oisease Risk 
111. STATEENT OF LEGAL GROUNOS

A. Low Tar and Low Nicotine Cigarettes are "Orugs" with In the meaning of the Federal Food, Orug, and Cosettc Act.

1. The Food and Orug Administration has asserted jurisdiction over tobacco products where claims related to the treatment, cure, mitigation or prevention of disease have been indicated and where the tobacco product has been shown to be intended to affect the structure or function of the body.

2. Low tar/low nicotine cluarettes are marketed with the intent of creating in the mind of the public the 1dea that they will "mitigate," or "prevent" the onset of disease associated with the saoting hablt. thus meeting the definitional requirements of "drugs."

3. Comparative advertising and promotion activitles which distinguish varying levels of nicotin and tar dewonstrate the intent of the cigarette manufacturers to market these products as products intended to affect the structure or functions of the body thus meeting the definitional requirements of 'drugs."

8. Low Tar and Low Micotine Cigarettes are alisoranded under Section $201(n)$ and Section 502 of the food Ding and Cosmettc Act.

1. Low Tar and Low Nicotine cigarette labeling, advertising and pronotion falls to disclose that these products contatn chemical additives and other constitutents which are haraful and may increase risks to health.

2. Low Tar and Low Micotine clgarette labeling, advertising, and promtion falls to disclose contratndications. effectiveness, side effects. etc.

3. Low Tar and Low Nicotine cigarette labeling falls to provide directions for use and adequate labeling. including wernings that clgarettes are addictive.

C. Cigarette anmfacturers have falled to net the requirements of Section sos of the Food. Orug, and Cosnetic Act, "New Orugs."

IV. concusion 
TABLE of MTHORITIES

\section{CASES}

Action on Smoking and Health v. Joseph Callf ano, No. 79-1397, U.S.

Court of Appeals ror the ofstrict of Columbra...................67

Ash v. Herris 655 F.2d 236 D.C.(C1r. 1980)..................77, 80

Cippollone v. Liggett Group, Inc..............................90

United States v. An Article of Orug... Bacto-Unidisk, 394 U.S. 784, 89

5. CE. IAIO, 22 L.Ed. 20126 (Ig69) .......................85, 71

United States v. Article...Consisting of 216 Cartoned Bottles, More or

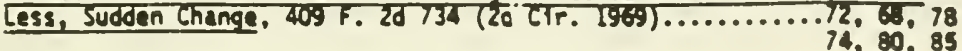

Aronberg $V$. FTC, .32 F. 28165 (7th C1r. 1842).................80

United States v. Articles of Orug, Etc., 263 F. Supp 212 (1967).....85

United States v. 354 sulk Cartons:... Trin Reducing-Ald Cigarettes, 178

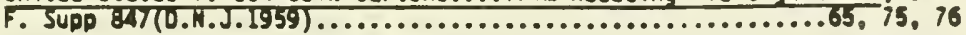

Untted States V. 46 Cartons, More or Less, Containing Fafrfax clgerettes, IIJ'F. Supp. 336 (0.A.J. I933).................65, 68-71, $85-86$

\section{STATUTE}

Food, Orug, and Cosmetic ACt, 21 U.S.C. 301 et seq..............passín 21 CFR Part 202 "Preseription Drug Advertising"................84

\section{LEGISUATI MLSTOM}

Public Heelth Cigarotte Amendients of 1971. Hearings before the Consuepr Subco ittee, Senate Conlttee on Comprce, 92nd Congress, Serlal No. 92-82, (1972)....................................66 
Reviewing Progress Made Toward The Development And Marketing of A Less Hazardous Cigarette. Hearings on S. 1803 before the Consumer Subcomittee, Senate Comittee on Commerce, 99th Cong.. Ist Sess.

(1967) ...........................................22, 23, 24, 48,55

Senate Report 74-361, "Food, Orugs, and Cosmetics," 74th Congress, 1st Sesston (1935).......................................72-73

\section{MISCELLANEOUS}

Eennett, "The Nicotine Fix," 66 Rhode Island Medical Journal 155, 158 1 1983).....................................................10

Benow:ttz et. d1.. "Smokers of Low-Yield Cigarettes Do Not Consune Less Nicctine," 309 Ner Eng. Journal of Medicine 139, 140, 141 (1983)...46, 54,

Blum, "When 'More doctors smoked Cameis': Cigarette advertising in the Journal," 83 N.Y. St. Journal of Medicine 1347, 1351, 1352 (1983)....6, 12

Burry. "Cigarette denand could decline; raw materials may gain from

legislation," 184 Tobacco International 28, 38 (1982)..............39, 40

Clgarette Report: "Low Tar In Comand," 185 (7) Tobacco International 68 (1983)....................................................

Cohn, "Some Cigarettes Now 'Tolerable," Doctor Says," Washington Post, Aug. 10, 1978 at $A 1, A 14 \ldots \ldots \ldots \ldots \ldots \ldots \ldots \ldots \ldots \ldots \ldots \ldots \ldots \ldots \ldots \ldots \ldots \ldots \ldots \ldots . \ldots . \ldots . \ldots 32$

Davis. "Current Trends In Cigarette Advertising and Marketing," 316 New Eng. Journal of Medicin $725,726,727,728,731(1987) \ldots \ldots \ldots \ldots . .34,36$, 49,50

Federal Tred Conission, Report to Congress Pursuant to the Federal Cigarette Labling and Advertising Act for the Year 1981, 98th Congress, 2nd Sess. (1S94)...........................................27

Federal Trade Conission, Report to Congress Pursuant to the Federal Cigarette Labeling and Advertising Act for the Year 1985, 99th Congress and Sess. (1988) 
Food and Orug Administration, Regulatory Letter to Advanced Tobacco

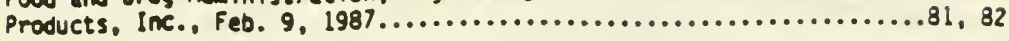

Ganagan, Swttch Down and Quft, Ten Speed Press, Berkeley, CA. (1987)... 24

Gahagan Research Associates, "Monograph on Snoker Attitudes Toward Low

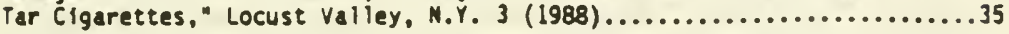

Harriman, "Do clgarettes cheat the tar tables?" 99 New Selentist 85, 86, 87 (1983)................................................ 53

Health Advocacy Center, Sixty Years of Deception: An Andiysis and Campllation of Clgarette Advertisements, 1925 to 1985 (1986) ........16, 17, $20,24,26$, 27. 28, 23, $30,31,33$. $34,36,37$. 41,42

Health Consequences of Smoking: Report of the U.S. Surgeon General, Cancer (1982)..........................................89, 90, 92

Health Consequences of Snoking: Report of the U.S. Surgeon General,

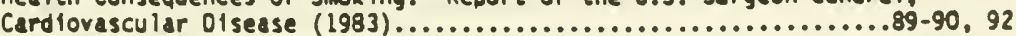
Health Consequences of Smoking: Report of the U.S. Surgeon General, The Changing C1garette (1981).................................... 48 , $50,51,56$ $75,87,92$

Health Consequences Of Saoking: Report of the U.S. Surgeon General, Chronle Obstructive Lung O1sease (1984)........................., 92

Houston, "Women who Smoke: An Equal Right To Ore," 29 Fantly Physictan 128, 131 (1984)............................................... 40.

Humphrles. "U.S. clgarettes: Uitras holding strong." 109 Tobacco

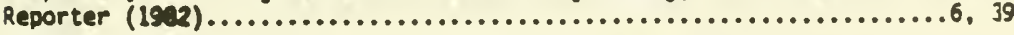

Interofflce Correspondence, Phllip Morr1s, USA, 100 Park Ave.. New York. N.Y. (Mar. 24, 1981)......................................... 38

Mennies, "Saoking. The Physiologic Effects." American Journal of Mursing 1143 (Aug. 1983) ...............................................

Miller. "The 'less hazardous' cigarette: a deadly delusion." 85 N.Y. St.

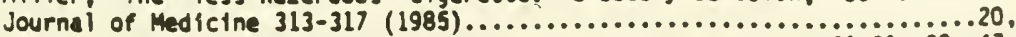
$21,31,32,47$.

M1ntz, J., "Low Tar, H1gh R1sk, " Mother Jones 55 (1983)............. 51 
Mintz, M., "Cigarette Ads and PR Misiead Public, Hitness Contends." Weshington Post, Mar. $11,1988, \ldots \ldots \ldots \ldots \ldots \ldots \ldots \ldots \ldots \ldots \ldots \ldots \ldots \ldots \ldots \ldots ., 8,14$

Mint2. M. "Clgarette Ads Sald Full of 'Healeh' Cues," Washington Post. Mar. 10, 19e ...............................................

Mintz, M.. "Meno States 'Holding Strategy' Of Tobacco Fimas," Washington

Post, Mer. 2, 1988...............................................9

Mintz, M., "Studies Sald to Cast Doubt On Use of Clgarette Filters," Hashington Post. Mar. 7, 1988.

National Acadeny of Sclences, "Reduced Tar and Nicotine CIgarettes:

Smoking sehavior and Health" (1982)..........................5,6, 46 $48,49,55,79$

Offlce of Oiseese Prevention and Health Frombtini., "Oi sease

Prevention/Heaith Promstion. The Facts." 1,9 (1988)................48, s0

Press Release: Tobacco Products Lidollity Profect, Mar. 26, 1983........91

Resesrch and Develupment Department, Operations Departant Presentation To Phillp Morr's Board of Directors, Oct. 28, 1964, 283-289.........18, 19

Rickert, "Less hazardous' cigarettes: fact or fiction?" 83 W. Y. St. Journal of Medicine 1269-1271 (1983).......................40,49, 54

Roper Organization, Inc. A Study of Public Attltudes Toward CIgarette Swoking and the Tobacco Industry in 1978, Vol. 1. Prepared for The Tobacco Institute $(1978) \ldots \ldots \ldots \ldots \ldots \ldots \ldots \ldots \ldots \ldots \ldots \ldots \ldots \ldots \ldots \ldots \ldots \ldots \ldots \ldots . \ldots \ldots \ldots$

Roper Orgenization, Inc.. Seoking Study (1980)......................38

Swoking and Health, A Report of the U.S. Surgeon General (1979).........35

Snoking and Health Report of the Advisory Comittee to the U.S. Surgeon

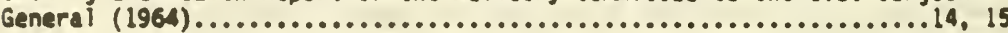

Tye, "Solling Deeth By Proising Health: Sixty Years OF Health Claims In Cigarete Avertising," I Tobacco Products Litigation Reporter 4.63, 4.64, $4.66(1986) \ldots \ldots \ldots \ldots \ldots \ldots \ldots \ldots \ldots \ldots \ldots \ldots \ldots \ldots \ldots \ldots \ldots \ldots \ldots \ldots \ldots \ldots \ldots \ldots .11,12,13,28$

Tye, Hamar and Glantz, "Tobacco Advertising and Consumption: Evidence of a Casuel Relationship," Journal of Public Health Pollcy 492, 501 (1987)..12,

U.S. Departame of Health and Human Services, "Snoking and Health," in The 1990 Health Objectives for the Nation: A Midcourse Review, 182-183

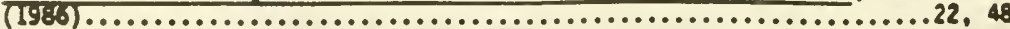

Warner, "Tobacco Industry Resoonse to Publlc Heaith Concern: A Content Analysis of Cigarette Ads," 12(2) Health Education Quarterly 115, 116, 117. $119(1985) \ldots \ldots \ldots \ldots \ldots \ldots \ldots \ldots \ldots \ldots \ldots \ldots \ldots \ldots \ldots \ldots \ldots \ldots \ldots \ldots \ldots \ldots \ldots 14,27,28$

Webster's Ninth New Colleglate Dictionary (1986) ....................67 


\section{BEFORE THE FOOO ANO ORUG AOMIMISTRATION}

WASHIMGTON, O.C.

Petition of
the American Heart Assoctation,
the American Lung Assoctation and
the Anerican Cancer Soctety.
acting as
the Coalition on Sinoking OR Health
requesting
Ciassifleation of Low Tar and Low Nicotine
Cigarettes as Orugs under the Food Orug
and Cosmetic Act

Apr11 25, 1988 
BEFORE THE FOOO ANO DRUG AOMINISTRATION WASHINGTON, O.C.

Petition of
the Anerican Heart Assoctation.
the American Lung Association and
the American Cancer Soctety,
acting as
the Coalition on Sanoking OR Health
requesting
Classiffcation of Low Tar and Low Nicotine
Cigarettes as Orugs under the Food Orug
and Cosmetic Act

\section{CITIZENS PETITION}

The undersigned organizations, the American Heart Association, Acerican Lung Assoctation and the American Cancer Soclety who comprise the Coalition on Snoking OR Health submit this petition pursuent to Sections $201(g) 1,201(n), 201(p), 502(a), 502(n)$ and 505 of the Federal Food, Orug, and Cosmetic ACt, 21 U.S.C. Sec. 321 et seg.

Pettionars request for reasons set out below that cigarettes whtch are manufacturad, advertised, promoted and marketed as low tar and low nicotine be classifted as "drugs" under the Food Orug and Cosmetic Act and that the food and Orug Adinintstration take action to enforce the requiremefts of the Act against these products. 


\section{PRELIMIMARY STATEMENT}

in 1906. the first food and Drug Act was enacted into law. That statute banned from interstate commerce any traffleking of adulterated and/or misbranded foods or drugs. Since that time the food and Orug Adainistration has, under statutory direction from the U.S. Congress, continued to enforce the laws destgned to ensure that not only are foods and drygs saie and effective but the Act also now governs cosatictes and medical devices. All of the products covered by the Act are products that are efther ingested by man, are applfed to the skin, or implanted into the body. Food and Drug Administration regulation of these products not only governs the composition of the products but also their sale, distribution, advertising and promotion.

The underlying purpose of the Food, Orug, and Cosmetic ACt (FDCA) has and continues to be to ensure the protection of consumers from hazardous substances. There is however, one product that, although it has attributes siaflar to foods and drugs, has esceped regulation not only under the Food, Drug, and Cosmetic Act but also the Consumer Product Safety Act, the Fatr Labeling and Packaging Act, the Toxic Substances Act, and the Federal Hezardous Substances Act. That product is of course tobacco. FDA has assumed jurisdtetton over tobacco produets under situations in wich a health clain has been made or fmplled about the product. But, the the FOA has not taken action against tobacco products as long as they are sold oniy for smoking pleasure. 
There can no question by any person reviewing the health hazards of cigarette sooking that this is a product that logically warrants regulation in the same manner that foods, drugs and other harmful products are regulated. As the Surgeon General has frequently stated, cigarette snoking is this nation's number one preventable cause of death and disabllity accounting for over 300,000 deaths annually. Cigarette swoking:

- is the number ans. caliss of 1."'s cancer in the United States accounting for over 100,000 erecths annually.

- Is the sajor cause of chronic obstructive lung disease (eaphyseas and chronic bronchitis).

- Is a major cause of coronary heart disease, accounting for approximately 170,000 deaths annually.

- by pregnant women increases the risk of spontaneous abortions, miscarrlages, and premature births. Sudden infant death syndrome (SIDS) occurs 2 1/2 tiaks more frequently among bables of sooking mothars.

(See for exaple: Reports of the Surgeon Generel on the Health Consequences of Swok1ng, 1979, 1980, 1981, 1982, 1983, and 1984.) 
The National Institute of Orug Abuse has called cigarette smoking the most comen exeple of drug dependence in the U.S. The NIOA. The Horld Health Organization, American Psychiatric Association, the Harvard School of Public Health and others have declared tobacco use to be a form of addiction siallar to cocaine and heroin.

The econoaic costs to soclety are also staggeringly high. The Office of Technology Assessient in an August 1985 Staff Memorandum. Smoking-Related Deaths and Financial Costs estimated inalth care and lost productivity costs to be $\$ 65$ b11110n a year in the United States.

Because of the lack of regulation of tobacco products due to specific statutory exemptions or fallure to meet definitional requireants under the FOCA, the tobacco Industry has remained free to continue to aanufacture, promote and advertise their products. Each year the tobacco Industry spends over $\$ 2$ billion dollars to market their products making the number one preventable cause of death also this nation's most heartly marketed consumer product. Free samples of cigarettes and other tobacco products are routinely handed out to people, Including young people, on our streets, it rock concerts, at sporting events, and through the nalls.

The Food and Orug Adainistration would not allow such practices to be carried out for a prescription drug such as "valium." Such allowances would asount to the sanctioning and promotion of drug abuse - an absurd notion by any standard. But for numerous reasons, some clearly politically notivated, others historically related, the federal government has turned its back when the product is tobacco. 
While the fou has not taken action against clgarette products when they are sold for smoking pleasure only. It has a clear statutory obligation to enforce the law when the marketing, advertising and promotion of tobacco products crosses over the line to become a drug.

The Food. Orug, and Cosmetic Act was enacted with that intent and the FOA has the responsfollity to carry out that intent. FOA's obligation becomes wore urgent in situations where the produrt his been deened isprisent a major health hazard, and where its cois:inued promotion is partially the result of luring consumers into a false sense of security.

The Food and Orug Adwintstration clearly has jurisdiction over low tar and low nicotine elgarettes as drugs, because they: (a) are manufactured, promoted and sold under the contention that they are safer and will nitigate and prevent the onset of diseases assoctated with the smoking habtt, and (b) are intended to affect the structure or function of the body. 
11. STATEMENT OF FACTUAL GROUNOS

\section{A. INTROOUCTION}

Tobacco companles market and promote low tar, low nicotine cigarettes with the purpese and Intint, si ireating in the rind of the public the Idea that these clgareites +111 i" Igate or pruvent the onset of disease associated with the smoking habit.

The tobacco industry manufactures many brands of low tar and low nicotine cigarettes. The production and marketing of these brands began after evidence was publicized linking exposure to tar and nicotine in cigarette snoke to disease. Clgarette companies have promoted these products as safer than clgarettes having higher tar and nlcotine levels. Aggressive marketing strategies, and the use of direct statements, suggestions and insinuations in cigarette advertisements, have led the public to belleve that tar and nicotine are the primary dangerous substances in cigarette soke and that low tar and nicotine cigarettes are "safer". As noted by the Mational Academy of Sciences,

-For the anufacturers, reducting tar and nlcotine has proved an important arketing tool to reach an increasingly health-consclous public and to reduce criticism in the blomedical comintey, withoyt serious economic loss to interests dependent on tobacco sales."

The cigarette industry has always trled to alleviate fears about dangers to health in order to sell its product, and the promotion of low tar and 
nicotine eigerattes represents a continuation of that strategy. The New York State Journal of Medictne is one source which has recognized this strategy:

"Even though the clgarette compantes have never publicly acknowledged any lasting harm attributed to thetr product, they have a lways attempteg to portray varlous brands as safer and healthier than others."

The reduction of tar and nicotine levels in cigarettes has been carrled out gradually by cigarettz manufacturers over tim. The average cigarett 8 swoked in Anerica in 1982 yielded 12.5 milligrans of tar and $.92 \mathrm{mg}$ nicotine, 3 while it had yielded $43 \mathrm{mg}$. ear and $2.8 \mathrm{mg}$. nicotine in 19554 . The average tar yield dropped to $23.1 \mathrm{mg}$ in 196. "when the first Surgeon General's Report on Saoking and Health was released, and has been falling consistently since, in response to consumer demand." (eiphasis added) 5

Because of health concerns, swokers over the years have purchased and soked low yield brands in increasing numbers, believing in the safer eigarette notion promoted in advertising. In 1983, the Tobacco Reporter noted that:

"The entet share held by low tar brands in the United States has been cliding in stairstep fashion, for about a decade. Rising from en averege share of seven percent in 1971/74 to 34 percent in 1978. these 15 g-or-less brands now hold an est fanted 65 percent of the market. (According to Tobacco International, In late 1982, lowtar clgarettes const ftuted 58.8 percent of the domest $1 \mathrm{c}$ market. while they had held only a 3 percent market share in 1970. ') such oranatic rise reflects a gain in popularity even more rapid than that of fliter-tipped cigarettes during the fiftles and Sixt1es." 
These figmes reflect the fact that the health clalms presented in low yfeld clgarette promotions and advertising have convinced the public that these brands are healthier.

\section{CIGARETTE MARKETIMG STRATEGY ANO HEALTH CLAIMS}

The tobacco industry has employed a long-standing public relattons and marketing strategy to dispel en-cern in consumsrs' minds arout the adverse health effects of siroking and tu coivince smoker. chat advertised brands are safe to smoke. Kuferences ic ine industry's publle relations and advertising strategles b.c. a hade oy ji..? 8. Cohen, dfiector of the Center for Consumer Research at the University of Floride, in recent testimony in the Rose 0 . Cipollone smoker-death lawsult, according to accounts in the Washington Post. Cohen, an expert on consuner behavior, testffled on March 10, 1988 that the clgarette Industry has dented the public:
"an adequate understanding of the health-consequences of smoking" and thet "for cost suokers, the public relations and ad campaigns effectively nullifled warnings that swoking could cause lung cancer."

The industry's public relations efforts in response to negative publiclty about the heith effects of smoking included the creation three decades ago of the Tobacco Industry Research Comittee (TIRC). According to the Post, this action was taken in response to what the industry viewed as a a public relations "cris1s" created in 1953 by researcher "Ernest L. Wynder's widely publfctzed finding that mice developed skin cancer when painted with tars condensed from elgarette smoke." 10 
"In a 1932 meso, J.M. Brady. TIRC's assoclate scientifle director, sald thet 'the (Wynder) emergency was handled effectively,' the Industry heving realized that to had 'a public relations problen that wust be solved for the self-preservation of the industry. TIRC, Brady wrote, 'has carried lts fair share of the public relations problen (which) was like the early symptoms of dlabetes.. certain dietary controls kept public opinton reasonably healthy. when some new symptom appeared, a snot of insulin in the way of a news release' was one of the devices that 'kept the pattent going.' Brady said in the meno. To 'improve the industry "1mage"', Brady urged o $\$ 5$ million annual budget for the TIRC... TIRC became the Counc il for Tobacco Research in 1964." is

Hill and Knowlton, the public relations fin: hired by the Tobacce Institute, played a major role in thi institui.'s creation of a publication called Tobacco and Hea?th (later. Tobacco ans Health Research). "A 1960 meno fron the ... firm shows d print order of 536,742 coptes, Including one for 204,000 U.S. Dhysteians, 3,181 county heelth officers and 1.655 'chief editorlal writers.'" 12 The 'Criteria for Selection' of articles for the publication included the exasple of a report in which the smoking-associated diseases are questloned." 13 The Industry's interest in the potential popularity of a perceived-ashealthier cigarette was reflected in a paper in the late $1960 \mathrm{~s}$ in which Helmut Wakehan, later vice president for research and development of Philip Morrts, Inc., told the company's board that one of the ReD wisstons of the company was:

"to learn wore about the psychology of suoking, hopefully to discover ways to exploit the benefits of saok.ing to, the advantage and profltabllity of our major camany business."

According to a memo written by Tobacco Institute Vice President Frederick R. Panzer In 1972, the tobacco industry's public relations strategy was 
to creata a malthier tmage for smoking. The memo was described in a

March 11. 1989 article in the Hashington Post:

"For 20 years the tobacco industry used a 'nolding strategy' to defend tiself against the charge that clgarette smoking causes disease, according to a confidential memo introduced ... in a smoker-death case. In a 1972 memo, Frederick R. Panzer, a vice president of the Tobacco Institute, sald that the 'ortlilantly concelved and executed' strategy consisted of: 'Creating doubt. about the health charge wlthout actually denying $\sqrt{t}$. (emohasts added) ... Panzer sent the memo to horace R. Kornegay, then president (and later chatrman) of tre insttute. The memc covered the time perfod during which, in 1953, an experiment by Ernest 1. Wynder showed that condensed tars from smoke, placed on the shaven backs of ice, calised a signifteant number of tumors and mallgnancles, and, in 1964, the syrgeon generai released his firsi report on smoking and healin."

According to the Post. Panzer also sald in the nemo that:

"the fndustry deployed the strategy 'on three najor fronts -. litigation, polltics and public opinion." On the public opinion front, the industry wanted to get the public to "accept that ' smoking may not be the heaith hazard that the ant issooking people say lt is (emphasts added) because other alternatives are at least as probable (as causes).' HIs examples were 'air pollution. viruses, food additives. Occupational hazards and stresses.' His chtef weapon was to be an elaborate survey. 'If the results are favorable, release then as a book' to counter the annual reports by the surgeon general on smoxing and health.' he advised. 'And best of all, it would only have to be seen -. not read -- to be belleved ... just like the surgeon general's report." "Panzer sald.

A Rhode Island Madical Journal article notes that the strategy behind the manufacture and promotion of lawer yleld cigarettes is not only to elininate sakers' health fears but also to increase the number of cigarettes sold by making a product that must be consumed in greater quantities in order for a smoker's addiction to be satisfled:

"Today, paradoxically, the healthiness of clgarettes has becone the dominant theme of advertising ... But there is something even more deceptive in this situation than the oovious deception: ... they 
(low yleld cigarettes) must. It appears, be smoked more heavily than orands higher in nicotine. The loy-tar smoker can be expected to buy and smoke more cigarettes."

Another part of the industry's publlc relations campalgn was is use of the advertising dollar not only to sell supposedly "safer" cigarettes but also as leverage to discourage publication of information about the health hazards of snoking. Thts aspect of tobacco public relations was noted in the March 1984 Family Physictan magazine:

\begin{abstract}
"An analysis of coverage of tooacco hazards in women's Mnn: pimge shows that the vast majority of the most popular magazin:- ' ' women have not published any articles on the health effects of buosing... This suggests that the tobacco industry discourages perlodicals that accept clgarette ads from publishing information on the hazards of cigarette smoking. It is curtous, for exaple, that the aujor news magazines. Tlase. Newsweek and U.S. News and World Report, heve not published anything resewbiling a comprehensive article on snoking and its effects on health. (All carry an average of six to eight pages of cigarette advertisements in each issue.) The only exception during the past few years was the June 6, 1983 issue of Newsweek. which carrled an article on nonsmokers' rights and how that wovement is gaining momentum. There were no tobacco advertisements in that particuląr issue." 18
\end{abstract}

Joe Tye, director of the Health Advocacy Center, in an article on health

claims in cigarette advertising. summed up the industry's marketing

efforts this way:

"The success of the U.S. cigarette industry in convincing nillitions of Narteans to start and continue smoking -- first in the face of a widespread comen sense perception that it was an unhealthy practice, and later in the face of increasingly convincing evidence linking smoking with lung cancer, heart disease, and emphysead -bears testimony to the power of modern advertising to manipulate people's att1tudes and behaviors. In order to create, expand, and maintain the market for cigarettes, Its promoters have used advertising to achleve two purposes. First, advertising has been used to create a powerful mental iagery linking smoking with healthy, glanourous, athletic, and successful lifestyles. Second, it has sought to assuage fears that smoking might be hazardous to 
health by attributing health protective, and even health prosoting, gualitics to particular cladette brands. ... For 60 years, ctarette promoters have used heat th claims to create an expectation aron consunars that smoking is reasonably safe, undermining the effectiveness of heath warnings provided by other sources. (emphasis added) In doing so, they have violated thelr Tegal and ethical responstblittles. They have been selling death by pronising health."

The manufacture and strategy for promotion of low tar and nicotine cigarettes constitutes a major aspect of the industry's long-standing progran to convince the public that smoking can be safe.

C. HISTORICAL OVERVIEH: A CHRONOLUGY OF CIGIRETTE AOVERTISIMG AMO THE OEVELOPAETT OF LOW TAR, LOW NICOTINE CIGARTEITES

Health claims have always appeared in cfgarette advertisenents. The tobacco industry has carried out a consistent campaign to quell public fears about snoking. Efforts in earifer years to smooth over saokers' health anxietfes have evolved into the more recent marketing strategles applied to low tar and nicotine cigarettes:

"Since the late 1920s, cigarette pronoters have used advertising to create in the minds of consumers an expectation that it is reasonably safe, if not outright salubrious, to smoke clgarettes. As public alari grew over the health hazards of smoking, the heaith assurances in these advertisements becase increasingly brazen. Cigarette ads invoked doctors and aedical science to convince people that roking a certain brand would not be haraful. After the Federel Trade Comission banned the most egreglous of these health clais in 1955. cigarette promoters became nore sophisticated in their aporoach, utilizing references to fliters designed by modern technology to provide velled assurance, a confusing numbers gase of tar and nicotine content levels, and lifestyle advertising to assoclate swoking with good health and athietic achlevement."

1. Prior to the 1964 Surgeon General's Report on Smoking and Health 
The tobacco industry responded to the public's fears about smoking decades ago through advertising. There are numerous examples of health clatms in cigarette advertisenents in the 1920s, 1930s and 1940s:

"In 1927 the Anerican Tobacco Company began a new advertising campalgn for the nation's leading clgarette brand, Lucky Strike, by clatwing that 11,105 ohysiclans endorsed Luckies as 'less 1ry tating to sensitive or tender throats than any other cigarettes."

"The first advertisement carried by the New York State Journal of Medicine for a fliter cigarette was for Viceroy (July 15, 1939): TILAST ... a clgarette that fllters each puff clean!' ('NC more tobacio in mouth or teeth')" 22

Erown 4 Wlllanson promoted old Gold "wifh the slogan "not a cough in a carload" in the 1930s and 1940s." 23

"In the early 1940s, Lucky Strikes began proaising that, In addition to removing 'eertain harsh throat irrttants found in all tobacco," Lucky Strlkes also had 12 percent less nicotine than the average of the other four leading brands. Although these ads did not thenselves explain why swokers would want to avoid ingesting nicotine, by 1940 there was a popular perception linking nicotine with heart disease. (As early as 1928, 'No Harm Clgars' used advertising to clain that they were safer than clgarettes because they did not contain nicotine, which the ad stated causes heart trouble.)"

In the early 1950s, several ador studies were published that left little doubt about cigarette smoking being the primary factor in the growing epideatc of lung cancer in men. In 1954, the International Cancer Congress first assoclated snoking with lung cancer.

Kent cigarettes were introduced in 1952 with a massive orint and television advertising campaign. The ads stated that "one out of three smokers were 'unduly sensitive to the nicotine and tars in tobacco. They really need real health protection." 25 "The Kent micronite filter was promised to provide 'the greatest hedith protection in cigarette history' 
28 . This conpalgn was described in the Decenber 1983 New York State Journal of modelne:

"Lortllard ... launched nationally televised 'scientific demonstrations to show the efficacy and implicit medical benefits of its Micronite fliter. This campaign was backed up by a heavy cose of advertising in medical publications. Although the advertisements never disclosed the composition of 'Micronite'.... Lorillard touted (Microntte) as 'so safe, so effective tt has been seleted to help fliter the atr in hospital operating roons' (May 15, 1954) and 'to purlfy the alr in igtomic energy plants of microscople impurities' (Feb 15, 1954)." 27

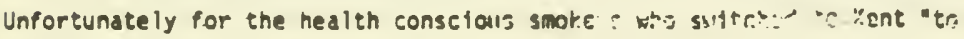
afford thenseives this great protection, the company incresen the nicotine level by 400 percent and the tar level by 600 percent between 1952 and 1955. This dranatic increase in tar and nicotine .. the substance from which sensitive smokers were clalued to need 'real health protection' -- was never announced to the public through advertising or warning labels. Furthermore, it is now known that in lts early years the Kent micronite pllter contained asbestos, a fact never disclosed to the smoking public." 28

Menos prepared by $\mathrm{HIII}$ and Knowlton for the Tobacco Institute showed that following Ermest L. Wynder's cancer finding in 1953 (that mice developed skin cancer wan painted with cigarette smoke tars), the firm recominended ways for clgarette compantes to deal with this "serfous problem of public relations ... one of extreme delfcacy." The firm suggested the formation of the Tobacco industry Research Comalttee (TIRC), which was announced on January 4, 1954 in newspaper ads entitled "A Frank Statement To Cigarette Snokers." 
- The stateant cast doubts on evidence that smoking is a cause of lung cancer, Implicated 'many other aspects of modern life.' acceoted 'an interest in people's health as ... paramount to every other consideration in our business.' clatmed tobacco products 'are not infurious to health.' and pledged ald 'to the research effort into all phases of tobacco use and health." 29

Ouring this perfod, cigarette manufacturers promoted new filtered products, attributing to fllters "unusual powers of selectivity which hold back elements that detract from the pleasure of saroking." and cigarette sales continued to rise. 30 The tobacco industry pushit filters hard as the way to avold disease.

"Filter-tipped cigarettes rapldly clalmed a majority market share. In 1952 only 1.3 percent of all aanufactured ctgarettes had fllters. By 1956 the fliter-tlpped market share exceeded a quarter, and only four years later filtered elgarettes became the dowinant product on the market. This cigarette consumption revolution was preceded, and encouraged, by a barrage of ads for flltered cigarettes, as seen in the percentage of Ttme ads for flltered cigarettes in 1951 and the years thereafter. Tn 1951, when less than 1 percent of all clgarettes sold had fllters, eight of the nine cigarette ads in the sampled issues of Time promoted filtered brands. It appears that the intent of the cTgirette compantes was to convey the message that plicers provided protection against the hazardous elements of ctgarette smoke responstble for lung cancer (emphasis added)." 31

Ouring the years from 1950-1960, statements based on the accumulated evidence about smoking were issued by various organizations. Including "the British Madical Research Councll: the cancer soctetfes of Denmark, Norway, Sumen, Finland and the Netherlands; the American Cancer Soctety; the Amertean Heart Assoctation; the Joint Tubereulosis Council of Great Britain; and the Canadian Kational Department of Health and Welfare. The consensus, publicly declared, was that smoking is an important health nazard, particularly with respect to lung cancer and cardlovascular diseese." 32 
In 1955. the FTC banned the most outright and egreglous health clalms. The U.S. Publite Health Service first became "officlally engaged in an appralsal of the avallable data on smoking and health in June 1956, when, under the instigation of the surgeon general, a scientific Study Group on the subject was established jointly by the Mational Cancer institute, the National Heart Institute, the American Cancer Society and the American Heart Assoctation. After appraising 16 Independent studies carrled on in Pive countries over a perlod of 18 years, this group concluc d th.? bil. is a causal relationship between excessive smoking of cigarettes $;:$ ling cancer." 33

The causative relationship between smoking and lung cancer was recognized by Surgeon General Leroy E. Burney in a statenent issued on July 12 , 1957. In 1959, an article published in the November 28 Journal of the American Medical Assoctation, entitled "Swoking and Lung Cancer -. A Statement of the Public Health Service," sald the Public Health Service belleved that:

"The weight of evidence at present imolicates smoking as the principal factor in the increased incidence of lung cancer," and that "cigarette smoking particularly is associated with an increased chance of developing lung cancer."

Early in 1962, the Comittee of the Royal College of Physiclans issued a report coneluding that:

"Cigarette smoking is a cause of lung cancer and bronchitis, and probably contributes to the development of coronary heart disease and various other less comion dfgeases. It delays healing of gastric and duodenal ulcers." 
On June 7. 1962, the surgeon general announced that he was "establishing an expert conittee to undertake a comprehensive review of all data on smoking and health." 36

Ouring the perfod from 1954 to 1963, television assumed a major role in elgarette promotion. Ouring the 1960s, the nation's two most popular medical shows. Or. Kildare and Ben Casey, were both sponsored by tobacco companles. Television was hearfly used in the introduction of Kerit cigarettes, with their promise of 'The Greatest Hedith Protection in Cigarette History.' 37

\section{1964-1967}

The Surgeon General's Advisory Comalttee on Suoking and Health was established and held its first meeting on Novenber 9, 1962. In 1964, the Report of the Advisory Comittee was released, containing signiffeant conclusions about the hedith consequences of smoking, including the following:

"Cigarette sooking is a health hazard of suffictent importance in the United States to warrant appropriate renedial action.

- Cigarate sooking is associated with a 70 percent increase in the age-spectfic death rates of males. .. cigarette smoking contributes substantialiy to mortality from certain specific diseases and to the overall death rate.

"Clgarette smoking is causally related to lung cancer in men: the magnitude of the effect of cigarette sanoking far outweighs all other factors. The data for women, though less extensive, point in the salie direction. The risk of developing lung cancer increases with duration of smoking and the number of cigarettes smoked per day, and is diainished by discontinuing smoking. In comparison with nonsmokers, average male smokers of cigarettes have approximately a 9- 
to 10-pold risk of developing lung eancer and heavy sanokers at least a 20-fold risk.

"Ctgarette saoking is the most important of the causes of chronic bronchitts in the United States, and increases the risk of dying fron chronte bronchitis and emphysema.

"A relationship exists between pulmonary emphyseme and clgarette smoking but it has not been established that the relationship is causal. The smoking of clgarettes is assoctated with an increased risk of dying from pulmonary emphysena.

"It is established that male clgarette snokers have a higher death rate from coronary artery disease tr.an non-saoking ales. "Women who smoke clgargttes during pregnancy tend to have bables of
lower birth welght." 38 to

In the months imnedlately following the issuance of the surgeon general's report, cigarette sales decilned by 20 percent, though they soon rose to previous levels. 39

In an attempt to "head off" regulations, the industry adopted a "voluntary cigarette advertising code" in 1964. It contalned the stipulation that advertising would not be included in media almed primarily at persons under age 21 . The provistons of the code included the following:

"Cigaritte advertising shall not represent that clgarette smoking is essential to social prominence, distinction, success, or sexual attraction. Ctgarette advertising shall not depict as a sinoker any person participating in, or obviously having just participated in, physical activity requiring stanina or athletic conditloning beyond

With the release of the 1964 report, cigarette manufacturers showed an upward trend in the emphasis on the health issue in their advertising, as discussed in a Washington Post article, excerpted below, describing a 
study presented recantly in a smoker-death trial. In the study, 567 advertisenents were surveyed, which appeared in 108 coples of Life magazine from 1938 to 1983, and in 26 coples of Look from 1962 to 1971:

"Richard W. Pollay, narketing professor at the Untyersity of Brttish Colunbia. tes: ifled about the (cigarette) ads' contribution to the 'cigarette information environient' and sald he combined data from three themes to determine the frequency of the 'healthiress' wessage: 1) 'Health/Safety': The consequences of swoking relating to 'positive ohysical effects.' cialms about coughs, endorsements by people in this medical comuntty, ares reduction tin tar and nicotine leve?: .... The range vas from zero percent in the four years precenting the flrst surgeon gener:l's report on smoking and health in 1964 to 76 percent in the peried from 1976 to 1983.

The text of a presentation mede by Phillp Morris' Operations Departaent to Its 8oard of Directors on October 28, 1964 outlines the company's considerations given at that time to "the principal proble of the Industry -- the question of Snoking and Health:"

"please recall that our number one objective is to develop products having maximum consumer appeal in the current and future health consclous market place. Two years ago. In anticlpation of health crisis to be precipitated by the Smoking and Health Report of the Surgeon General's Consittee, we undertook to develop a physically supertor product.... Our strategy here was that if we could define new acceptable criteria by infen ohyslological performance of a cigaretie would be Judged, and then develop a product or products meting these criterla, we stood an excellent chance of having our product be best in the market and recelve valuable outside endoresiant. ... Even though the Smoking and Healeh Report contained for us few surprises we gave it thorough study. From this came to several liportant conclusions whtch we expressed in a mesorandum to our top enageient last february.

-...It was now up to the eigarette compantes to prove that clgarettes are safe or that safe ones could be made. In this connection it is our opinion that the industry must sorahow find a way to make an effective technical rebuttal to the arguments of the anti-cigarette forces. Only in this way will the present burden be lifted from us.

Secondly the government and private agencies would intensify their technical activities on the swoking and health 
question to protect their monetary and political interests. The Industry to avold excessive regulation and to maintain its compettitive independence would have to do likewise.

Third, these research efforts would in all likelihood lead sooner or later to clgarettes generally regarded as 'less hanful' than others.... He would have to leapfrog forward in product design.

"...It behooves Phillp Morris to participate in sultable ways in this endeavor in order to learn the most from whatever knowledge is discovered and to be prepared to take commercial advantage of any developments from these prograns.... We are engaged in a research and developnent progran to deliver a cicarette line with supertor physiological performance, unique and effecttve fllter jystems attractive to marketing incerests, and with taste and flavor comparable to major fliter branis...

"In all this activity our aim is to 'Be Prepared.' He cannot know how the advertising code will be interpreted or adwinistered, or how the products we are developing can be merchandized in the market place. We do know that all the major cigarette compantes have now alled thenselves with blological research laboratorles and are actively working in these areas...

"In short, the Research and Development Department is working to establish a strong technological base with both defensive and offensive capabilities in the snoking and hedith situation. Our ohilosophy is not to $\mathrm{q}_{2}$ start a war, but if war comes, we a im to fight well and to win." 42

\section{d. Advertising Themes: Mid 1960s}

Below are descriptions of cigarette advertisements containing health

related masages which appeared during the mid 1960s:

"Kent elgarettes were promoted with the theme of pleasure, though references to Its 'highly absorptive' Micronite fliter undoubtedly brought back menorles to many sinokers of the advertising canodign with which kent cigarettes had been launched in 1952 prowising 'the greatest health protection in cigarette history. '... Health protection was still implied by ads like 'This is a filter that does its work... Today more than ever, to a smoker, tt's a Kent.'

"Philip Morris ads included an implifelt health reassurance:

'Activated Charcoal: highly absorbent of selected gases to smooth out flavor: Fresh-Air System: acetace flbers reduce tar whtle fresh air injection surrounds and freshens flavor.' 
"Lart introduced a 'fortifled' three plece activated charcoal fliter. The timplicit heaith reassurance in one ad sald 'each gravile (of charcoal) has 5 square feet of surface area. Each Lark filter contains wore surface area than 20 of anybody else's ordinary clgarettes. That's because Lark's charcoal is activated. This gives ti miles of microscoplc passageways and tiny pores where substances in smoke can stick. In about 1968, Lark began a major prosottonal campaign playing on the fear that 'gas' in cigarettes was a major health threat. One ad ran 'Gas in cigarette snoke may be a bigger problen than tar and nicotine... Only lark has the Gastrap fliter. Lark's patented fliter reduces certain harsh gases by nearly twice as much as any other popular brand."

"Parlfament continued to emphastze "he recessed filter, which "keeps the fllter neat, clean one quarter inch away.

"Carlton cigarettes were introduicd with an emphasis on low tar and nicotine content, actually listing tar and nicotine levels on the pack. Ads ceninued to refer to latest U.S. governient figures as proof of Cariton's low tar and nicotine levels. Later ads focused on the clgarette's lightness and wildness. Som Carlton ads falicltly compared the clgarette with another low tar clgarette on the market -- True. One woan is depicted as saying 'I thought ay clgarette was larest in 'tar' but it turned out not to be true." Another wonan, finding .1t wasn't 'true' seid ' 'm not kidding nyseif anymore.

"True used its low tar and nicotine flgures and easy draw to prongte its cigarettes as Anerica's most taiked aoout fliter clgarette.' 33

b. Development of Low Yield Cigarettes

The tobacco industry's efforts to develop and promote "safer" filter

cigarette wre evident following the 1964 report.

- Early rasearch was based on the assumption that reduction in tar and nicotine would lead to less hazardous cigarette. This thesis wes accepted by most health professlonals and the public. Soon clgarette compantes ... began dovertising nywerous brands that clatined to offer less tar and nicotine."

"The first major studies to develop a 'safer' clgarette were supported by the National Cancer Institute. The resedrchers reported findings that 
appeared to show lawer mortality rates with lower tar and nicotine levels." 45 This information was used as a basis for promoting cigarettes and was belfeved accurate by the public even though a close look at the studies produced many questions about thefr results, as explained in the following excerpt from an article by G.H. Miller:

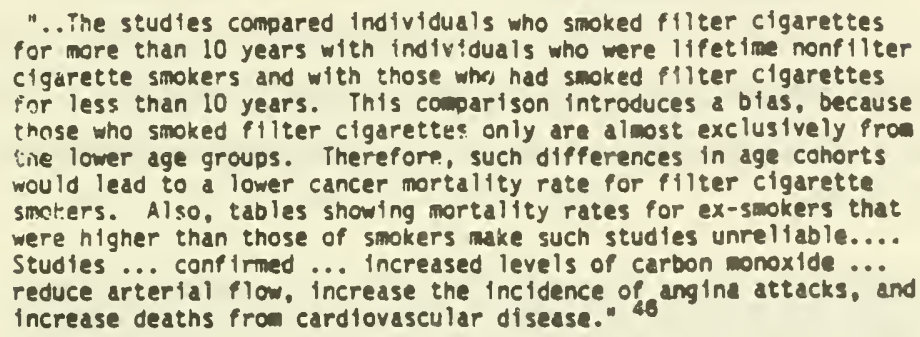

The Federal Clgarette Labeling and Advertising Act was aade law in 1965 , requiring on all cigarette packages the health warning. "Caution:

Cigarette Smoking May be Hazardous to Your Health." The law required regular reports from the Department of Health. Education and Welfare (HEW) on the health consequences of szoking as a way to monitor scientific developments. In 1965, the Mational Clearinghouse on Smoking and Health was created.

In June 1966, the Public Health Service issued a report of 14 proalnent scientific investigators tho met at the invitation of the surgeon general to review medical knowledge on the significance of the tar and nicotine content of c1garettes. The group reported that: "The preponderance of scientific evidence strongly suggests that the lower the tar and nicotine 
content of cigarette snoke, the less narmful would be the effect..." The group recamended to the surgeon general that "action be encouraged which will result in the progressive reduction of the tar and nicotine content of cigarette smoke." 47

\section{c. Consumer Perceptions}

ine 1966 announcement stimulated a substantfal change in the way consumers viewed cigarettes, as descrited in a 1986 report of the public hieaith Service:

"Consumer demand for low tar clgarettes has increased steadlly since this announcement was released. This change in consumer preference, coupled with stepped up advertising and promotional efforts of the clgarette compantes, led to a 39 percent decline in the average tar yield of cigarettes between 1968 and 1981. The decline in tar ylelds, thus far, has been accomplished by a reduction in yields in older brands as well as the-1ntroduction of new, 'low-tar' brands.

However, the Public Health Service had warned in 1966 about the danger of communicating to consumers the idea that saoking could be safe. The service urged that advertising statements be controlled and that the public be warned about the dangers of smoking in general:

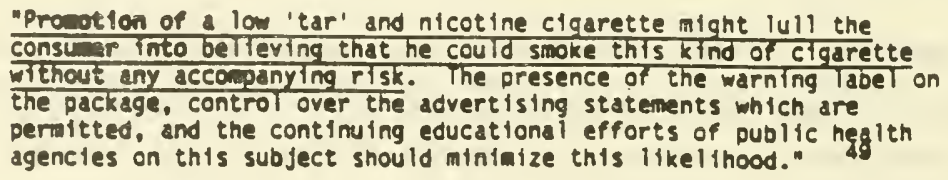

In May 1967, legislation was introduced to strengthen the Cigarette Labeling and Advertising Act of 1965 by requiring that all cigarette 
packages and advertisements disclose the tar and nicotine content of each cigarette as measured by a standard test.

Testifying sefore the Consumer Subcomititee of the Senate Comerce Comittee in August 1967. Or. Hilllan Stewart, then surgeon generd, noted that sakoks wanted to know the tar and nicotine levels of cigarette brands tecause they belfeved this information was relevant in choosing a "hesithier" eigarette. He also pointed out that, for health reasons, smokers warc likely to seler: brands ylelding lower levels of tar and ntcotine. Hits statement is excerpted below:

"A Public Health Service survey shows that 77 percent of people who were interviewed felt that cigarette compantes should be required to list tar and nicotine content on packages; among clgarette smokers. 71 percent favored such action. As other substances are found in cigarette smoke which contribute to the health hazard of smoking, the fdentity and quantity of such substances should be incldued a long wtth tar and nicotine in the package labeling and in advertising. The question is: Will tar and nicotine disclosure on cigarette packages and in advertisenents encourage wider use of the brands with lower levels? I belleve that a progressive reduction of tar and nicotine levels will result from such action because of public demand. The phenomenal increase in sales of filter cigarettes from only 2 percent in 1952 to nearly 70 percent today reflects the average smoker's concern in protecting himself as much as posstble against the hazards of smoking. Since it is obvious that seif-protection is wuch of the motivation for switching to flltars, it is important to insure that filters are effective in reducin the hariful ingredlents of the cigarette smoke. It is reasonele to assume that health-conscious smokers will shlft to an acccoteble low tar and ntcotine clgarette (emphas ts added) in the sase. Ind or greater, proportion as they have switehed to filter cigarettes."

In a Novenber 1967 letter from Secretary of Health, Education and Welfare John Gardner to Senator Warren G. Magnuson, the sponsor of the bill, the secretary noted that not smoking at all is the only way one can be protected from smoking's health hazards. The secretary sald: 
-I strongly support your view that these steps relating to the measuramt and labeling of 'tar' and nicotine in clgarette smoke are only part of our overall approach to this problem.... the only effective means avallable to eliminate the health hazards associated with smoking is an educational progran designed to inform people of the hazard and encourage people to stop or not to start smoking." 5

\section{d. FTC Testing}

The FTC operated its own testing program beginning in 1967 to analyze the tar, nicotine, and later the carbon monoxide content of cigarette smoke of all domestic cigarettes. The comession published tts test results at least once a year.

As noted by market researcher Frederick Gahagan in his book. Switch Down and Quit. "Light" cigarettes were marketed as a resconse to snoker's health anxieties:

"With all of the uorcar in the medla and government about the health hazards of smoking .... the cigarette companies realized that if they did not want to lose 'health concerned' smokers, they would have to produce an aiternate ... Thus, the birth of 'Light' cigarettes: Marlboro, Lights, Kool Lights, Hinston Lights, Kent Golden Lights, etc." 52

\section{e. Fairness Doctrine}

In 1967, the Federal Commntcations Comission, applled the Fairness Doctrine to cigarette advertising and ruled that television stations had to provide tine for antisnoking advertisments proportional to the anount of cigarette advertising they ran. An estimated 10 million Americans quit smoking between 1967 and 1970 as a result. 53 


\section{3. $1995-1970$}

The launching of the FTC's testing progran was followed by the tobacco industry's use of FTC findings -- which were later found to be Inaccurate (see section 0 ) -. for competitive advertising purposes, with each company trying to outdo the other by producing the larest yield but 'best tasting' cigarette on the market. This marketing strategy furthar relnfored the public bellef that low tar and ittex. ine ctgarettcs were safer.

\section{c. Advert1sing Thenes: Late 1960s to Early 1970s}

The following are descriptlons of advertisements which appeared between 1969 and 1971:

"Vantage addressed some of Its ads 'To every clgarette smoker who enjoys good taste but tho's concerned about 'tar.'

"Pall Mall asserted that 'U.S. Government figures show Pall Mall Gold 100 s (at $19 \mathrm{mg}$. ) lower in 'tar' than the best-selling fllter king (at $21 \mathrm{mg}$ ).'

"The Phtlip Morris Multifilter was clatined to be "lower in tar than 95 percent of ell cigarettes sold.'

"Lart continued Its reference to 'gas', pushing the health theme very hard with the phrase 'Tell soneone you like about Lark's GasTrap filter.' For examle, one ad showed wom kissing her husband's bulding head. In the text. it sald: Maybe your husband alreedy knows that alwost 90 percent of cigarette smoke is gas. And, that Lark's Gas-Trap fllter reduces not only 'tar' and nicotine, bus gases as well. But you can still tell him a thing or two. For instance: Lark's Gas-Trap fliter reduces certain of those harsh gases by nearly twice as much as any other filter on any other popular brand." " "Other Lark ads called te 'The Gas Mask:" showed scowling faces at the question 'Just what does gas in cigarette smoke taste like:" and called the fllter the 'S.S. Gas-Trap.' clatming that it uses the same type of charcoal to scrub sanke as a 
subarin uses to clean air." and stating that, "If you ilke the taste of gas, you'll hate the taste of Lark.

"True also focused on the health theme, stating that it was Amertca's most popular reduced tar and ntcotine cigarette. Like Lark, It stressed its patent. One ad clatmed that 'True is lowest In both tar and nicotine of the 20 best-selling brands. Lower, In fact, than 99 percent of 11 other clgarettes sold.'

"Carlton clatmed that 'Latest U.S. goverment figures show Carlton st11l lawest In 'tar' of all regular fllter kings tested.' Its advertising played a confusing numbers gase, wth clalms 11ke: Two packs of Carlton have less 'tar' then one pack of any leading filter king. Three packs of Carlton have 'ess 'tar' than one pack of the "i.. : " Tow tar' ctgarette. A whole carton of Carlton has less $\because$. Lhan three packs of the larjest selling fllter king. Four nar' of Carlin! have less 'tar' than one pack of the largest s.? iling fllter king.

"f 41 clgaretias were introduced by R.J. Reynolds ge having 'the fliter system you'd need a scientist to explein." 5

\section{1970 s}

Effective January 2, 1971 under the Public Health Clgarette Smoking Act of 1970. all radio and televiston advertising for clgarettes was banned. "An unintended consequence was that television stetions were relleved of their responsfbllity to provide time for Falrness Doctrine antismoking advertiseants. For a pertod of time, cigarette companies circumvented the ben by advertising 'little cigars' on television, causing sales to soer unt1 ents practice wes outlawed." 55

In 1970, Congress amended the Federal Cigarette Labeling and Advertising Act to require the cigarette package health warning to read: "Warning: The Surgeon General has Deterwined that Cigarette Smoking is Dangerous to Your Health." Under a voluntary agreement entered into by most of the 
major cigarette munufacturers, all clgarette advertising was to disclose the tar and nicotin content of the advertised brand as determined by the FTC. Beginning in 1972, the FTC required major clgarette manufacturers to Include the Surgeon General's warning in all advertising. 56

\section{a. Advertising Themes}

\section{Early to Mid 1970s}

In the 1970s, the cigarette comparites cont inued to focus their pronotional efforts on low tar and nicotine cigarettes, seeing within that product line the means of encouraging snokers to continue their habits and recrulting new smokers, especially teenage girls and young wowen. Kenneth Warner descrlbed the Industry strategy as using health concerns to promote so-called 'less hazardous' cigarettes." (emphasis added) 57

Below are descriptions of such advertisements:

- A Vantage agazin advertisenent portrayed a handsone sincerelooking ale codel with the message. 'If you smoke and are concerned about your heelth, switch to vantage... Tow in tar and you won't sacritice plavor.

"Vantage used many heaith reassurances during this perfod. Another ad said 'Instead of telling us not to sinoke. maybe they should be telling us what to smoke.' and went on to discuss low tar and nicotine levels in Vantage, said to be dellvered without reducing taste. An ad for Vantage stated: 'In most clgarettes, the more the flavor, the more the 'tar.' Except for Vantage ... what sepurates Vantage Menthol from ordinary menthois is that Vantage menthol gives you all the flavor you want. with a lot legs of the "tar and nicotine that you probably don't want." 
Another Vantage ad "depicted a woman saying. 'I smoke. And I'il not going to apologize for 1t.' She sald that, although she was concermat by 'all that stuff they say about high 'tar' and nicotine,' smoxing low tar clgarettes was like smoking a 'tootholck.' Vantage, she said, had tar and nicotlne levels low enough that she didn't 'have to make any excuses for smoking.' but not so low as to interfere with 'full tobacco taste."

"Cigarettes such as Carlton and Now have long been promoted as lawest in tar. with the heaith implication being quite direct." 61 "Other True ads spoke about the clgarette's tar and nicotine level. and then asked questlons like 'Shouldn't your next cigarette be True?" One ad ncknowledged that the fear-orlented advertising for Tru: was nc: d: :Ected at ne:y starte:'s, whic tended to smoke other clgarettes: "You don't si irt with True. You change to True.'

"Pall Mall ce:ıtinued to c?a1s that U.S. novernment flgures showed Pall Mall to be lower In tar than the best-salling fliter king.

"Lucky Ten was introduced as a way that smokers of the best-salling regular size cigarette could cut their tar in helf. Ads included tables comparing tar and nicotine content of Lucky Ten and other eigarettes.

"The Phillp Morris Multifliter was changed to be the Benson 4 Hedges mitifliter. It was bflled as 'The Moderate Smoke.' One ad sald 'It's the cigarette you can feel comfortable with. Enjoy. And stay with. Phllip Morris International was also introduced.

"Winston Lights were introduced.

"Parlianent continued to push the recessed fllter, which was sald to act as a cigarette holder.

"Cariton continued to push its tap and nicotine levels. Swokers were offered a free copy of the latest U.S. governant measureaents of cigarette tar levels.

"Ralolgh still pushed ... the theme 'spend a vilder moment with Relelgh.' Relelgh 'Extra Mllds' were introduced.

"Doral ads claled that the brand 'has flxed what you don't like about low 'tar' and nicotine saoking.' A cut-away photograph of Its fliter showed a recessed, baffled chamber.

"Iceberg 10 cigarettes were intrgguced with ads comparing the tar ratings of leading cigarettes." 62

\section{Mid to Late 1970 s}


- Varteres ads continued to play on the health fears of smokers. They featured every-day kinds of people explaining that they were very concerned about the 'controversy' over the tar and nicotine in clgarettes, but that they enjoyed smoking and didn't want to quit. The solution, these smokers had concluded, was to smoke Vantage. The authoritative volce of the ads stated that, although Vantage wasn't the lawest tar cigarette on the market, It was lower than 95 percent of all cigarettes, and the only low tar with good taste.

"Kent Golden Lights used comparison advertising to show that they were lower in tar than many other cigarette brands. Kent ads clained that they had ' $25 \%$ Less Tar.' without saying less than what. They also claimed that Kent was America's il selling low tar cigarette.

"True ads of the period uses a norif sianllar to that of the Vantage ads -- 1ntelligent per, e tiio, d:... Eu.sideratien of the facts had decided that, rather than quit, s:acy would saoke a cigarette leplled to be reasonably safe to smoke. One such ad featured a women on the tennis court with a cigarette in her hatis saying, 'Considering all I'd heard, I decided to either quit or smoke True. I swoke True.' The ad went on to say 'The low tar, low nicotine cigarette. Think about it.' True ads also engaged in comparison advertising. clatining to be

'lavest in tar.

"Merit ads relled upon both scientific and market research claims to sell eigarettes. The market research clain was that consumer opinion studfes had shown smokers to like Merit as well as or better than clgarettes containing 60 percent more tar. The scientific claim was that Merft had found a way of delivering flavor at lower tar levels: 'by isolating certain 'key' ingredients of tobacco in cigarette smoke, ingredlents that deliver taste way out of proportion to tar. researchers at Phillo Morris have developed an 'Enriched Flavor' process so successful at boosting flavor, the resulting cigarette actually delivers as mash -. or more -- iaste than orands having more tar.' Many Merit ads used a newspaper headline format to make it appear that a major sclentiffc oreakthrough had been announced.

"Carltan relled upon clafued results of government studies and comarisen edvertising to make the claim that 'Cariton is Lavest.' On claiad that, 'Based on latest U.S. govermment reports, ten packs of Carlton have less tar than one pack of ..." and then went on to list any of the popular law tar clgarettes of the day. Carlton ads ade no reference to taste -- the sole selling point was low tar.

"Now ads also clalmed that clgarette to be lowest in tar. In 1976. How had $2 \mathrm{mg}$ of tar. In 1977, ads claimed that the level had been reduced to $1 \mathrm{mg}$ (this is more than just "low tar'. This is ultrs-low 'tar'... If you want to be sure you're getting uitra-low 'tar.' count all the way down to Now's number $1 .^{\circ}$ ) In 1977 , however, the tar level was quietly increased back to $2 \mathrm{mg}$. There las no evident change in the cigarette package over this period. 
"Fact efgarettes took up where Lark left off by ralsing smokers" concerms about 'gas' in eigarettes. Its patented aldehyde-reducing 'Purite' fliter was clatned to remove 'spectfic gases in smoke that taste bad.' In a footnote, these gases were sald to include 'Forma idehyde, Crotonaldehyde, Acroletn.' One such ad read:

Fact: If you're concerned about snoking, you should know something about gas. You might not know th, but eigarette smoke is mostly gas --. many different kinds. Not just 'tar' and nicotine. And desplte what we tobacco people think, some critics of smoking say it's Just as important to cut down on some of the gases as it is to lower 'tar' and nicotine. No ordinary clgarette does both. But fact does.'

This ad reflects how the industry clalmed that the substances in cigarette sauke were not -. In th: industry's conjldired opintion .. harmful, while at the sane tine it alanied snokers with a clear implication that other credible sources believed ointerwise, and then offered the snoker a techinulogleal fla which would eri:ble hife or her to keep smoking with a clear consclence."

Doral swakers were depleted as endorsing the 'Doral Diet' In order to cut down on their tar consumption. One ad showed a suoker saying. "I' not too oig in the willpower department. But I lost 700 nilligrams of 'tar' in the flrst week on what I call 'the Doral Diet.' Mow I can still enjoy smoking and cut down on 'tar' and nicotine, too.

"Real clgarettes were clalaed to be the only cigarette not to enhance flavor artiffclally. Real's menthol was also clatined to be 'fresh, natural. Not synthetic.' Real ads also touted the cigarette's low tar levels, claining it was voted the best low tar elgarette in a national taste test.

"Lark ads abandoned the 'low gas' theme and featured hot atp balloons. The textual enphasis was on the technology of the filter: 'Our unique filter has two outer 'tar' and nicotine filters, pius an inner cheober of spectally treated charcoal granules."

"Lucky loos were clalmed to be the lowest tar of all fllter $100 \mathrm{~s}$.

"Ley used comparison advertising to make the clalm that it had 'less 'tar' than all leading longs.'

"Parflasent ads clalmed that smokers concerned about tar had to consider more than fust the tar levels of ctgarettes. Regular clgarettes with flush fliters were clalned to place tar bulld-up 'flat against your 11ps.' with the clear lawilication that this would be potentially harmful. Shokers could prevent this by sabking Parlfament, because its fllter was 'recessed to keep tar bulld-up from touching your 11ps. So there's no 'ftliter feedback'.' Parllament was said to be 'the thoughtful chotce in low-tar smoking.' 


\section{5}

"pall Mall used comparative advertising to clalm that 1t was 'lowest in tar of all the lights,' clalmed to have ' 45 percent less 'tar" than the best selling fliter king.' and that a smoker cou?d lose $2,800 \mathrm{mg}$. Of tar per week oy switehing to Pall Mall Extra Mild (based upon a two pack a day smoker)."

"Tareyton continued Its 'rather fight than switeh' advertising" campaign, and touted the filtering effictency of its activated charcoal fllter, noting that the same substance was used to filter alr in Horld War I gas masks, submarines, spacecraft and auto pollution control devices.

"Kool Super Lights were introduced, emphasizing 16. ter.

"Iceberg loos were clalmed to be 'lawest in te- of $8 !$ !l mertins? loos.

"Decade cigarettes were introducro as being thg first 'tota? systen' clgarette providing low tar and good taste." b.s

\section{b. Publictty on "Safe" Sinoking Levels hot Based on Fact}

Tobacco industry efforts to comannicate to the public the fdes that low yield cigarettes prevent the onset of disedse associated with sanoking received a boost frow two articles published in the late 1970s on supposedly safe smoking levels, woth authored by the deputy director of cancer prevention at the Rational Cancer Institute, Glo batta Gori. Published in Decenter 1976, Gori's article in Science magazine, entitled "Low Risk Cigarettes: A Prescription," "purported to estimate the safe levels of exposure to certain components in cigarette smoke." 64

In its Septeraber 15, 1978 issue. Jaka published another article oy Gorl. One month before tt appeared, the "purported results" were given broad publicity. The publicity was criticized by JAM's editor, Willian R. Barclay, MO, who described the finding as "of 'small benefit' to 
individuals who do not follow the medical profession's good advice not to smoke." 65 As noted by G.H. Miller below, the information was based on speculation rather than fact:

.... "The Jama article used 'critical values' to estimate the safety levels of six compounds found in cigarette swoke: carbon monoxide, tar, nicotine, nitrogen oxides, hydrogen cyanide, and acrolein. However, the statements concerning the possible safety of the less hezardous cigarettes were dependent upon assumptions of theoretical safety 11 mits if the estimates were correct and if the proposed reduction in these components could actually be made. These assumftions, as well as the handling of the data, were made without experimental substantiation. ... Due to (extensive) pre-pubilcation publicity, the public was presented with informetion assumed to be basegg on fact, whereas it was based on speculation. (enphasts added)

Subsequent "reports in the mass media on the safety levels of certain low tar-low nicotine cigarettes included tables listing the number of cigarettes of spectfic brands that could be smoked 'safely.' ... These tabies... were not contained in the original (JNAA) article... (and) (the 1 ).... source... realins unclear." 67

On August 10, 1978, the Washington Post published an article entitled "Some Cigarettes Now 'Tolerable,' Doctor Says." LIggett took advantage of the printed account and distributed the article in 1978 for use as a store display advertisement. The article stated that, according to Gorl, "some cigarettes now have so little tar, nicotine and other harmful elements that they can be called 'less hazardous' and can even be sinoked In 'tolerable' numbers without 'appreciable' 111 effects on the average smoker." 68 The article included a chart showing the number of clgarettes "the average smoker could consume dally without exceeding a 
"tolerable' level of risk of cancer or other disease." 69 The article pointed out, however, that Or. Arthur Upton, director of the cancer Instftute, issued a more "cautfous statement ... saying our present knowledge does not permit us to establish any levels below which smoking might be safe." 70 Gori, in the article, was quoted as saying, "I am not calling any cigarette safe. The only cigarette that is safe is the etgarette that is not 11t." 71

\section{Claim "Lowest" Repeated R/ Various Brands}

"The advertising of at least eight cigarette brands used the word 'lowest' proainently in their advertising... (Prom the wid 1970 s through the wid 1980s), referring to tar and nicotine content. ... These ads ... substantially contributed to consumer confusion over which cigarette really was lowest in tar and nicotine.... A confusing numbers gane was being played in which comparison advertising could be used to plck certain competitor brands to use the word 'lowest' and, in a technical sense, be telling the truth." 72

\section{Lete 1970 s to Early 1980 s}

Health clalms, while more discreet, have been prominently featured in cigarette advert1sements of the late 1970 s and the early 1980s.

"The advertising themes of this perlod were far more sophisticated than those of earlier eras. The onrase how is Lowest is much Tess drect than the promise Kent provides the greatest health 
protection in cigarette history.' It is, nonetheless, just as effective at conveying the message that it is reasonably safe to soke that brand of ctgarettes, given the widespread public attention given to the hamiful effects of the tar and nicotine in tobacco smoke. "(smphasis added)

\title{
a. Public Impression of "Reduced Tar and Nicotine"
}

According to Ronald M. Oavis, M.O., M.A., director of the Office on Snoking and Health,:

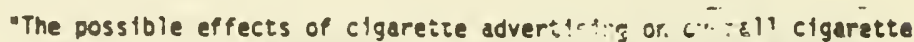
consuiption could be attributed to the $10 \cdots$ - ys. and isiogefy used in cigarette advertisements, which tend to undernine the effectiveness of the surgeon general's warnings. In tts report to Congress for the year 1978, the FTC noted that 'some ads use language which directly contradicts the required health warning and scientiflc evidence that smoking is dangerous to health and perhaps to life itself... A number of campigns imply that smoking a particular brand solves the health dilewans or at least mintatzes the problem. " The FTC report stated that advertising emphasizing tar and nicotine content may: "contain the fmplied representation that low tar and nicotine cigarettes are safe. Such teplled representations may nislead the reader about the safety of smoking reduced tar and nicotine brands." 74
\end{abstract}

A 1978 survey done for the Tobacco Institute by the Roper Organization reflects the public's concern about the health hazards of smoking. The report concluded that:

- 1. Wore than nine out of every 10 smokers belleve that smoking is hezardous to a smoker's health.

2. There is majority acceptance of the ldea that the clgarette warning label should be nace stronger and more specific.

3. Two-thirds of smokers would like to give up smoking."

In the report on the survey excerpted below, references are made to "low tar smokers" that indicate this group is more concerned about the health 
consequences of seoking than smokers of regular orands. This concern would dccount for their cholce of low-yield brands.

\begin{abstract}
"More than the average, (low tar smokers) have read something that worried then about saoking, they belleve it is definitely true that swokers have more of certain kinds of 11 linesses, that smoking is hazardous. And more of them than the average have tried to quit smoking. Since low tar suokers are an expanding share of the market. their greater destre "q, quit smoking poses a special problem for the cigarette industry."
\end{abstract}

The surgeon general's 1979 Report contalned signifteant conclusions about tar and nicotine, including the findiry that: "Compouncs in smoke wost likely to contribute to the health hazards of swoking are carbon monotice and nicotine and tar." 76

Two studies were conducted in 1979 and 1980 for The Brow and Wlllianson Tobacco Company by Gahagan Research Associates, Inc., a survey research firm. The major findings are indicative of the attitudes of low-yleld snokers:

1. Over 80 percent of respondents expressed health concern dbout seoking.

2. The degree of concern was directiy proporttonal to the tar/nicotine level of the cigarette brand smoked.

3. On average, snokers knew withir a tenth of a milligraw the tar/nicotine level of the elgarette brand they were smoking.

The findings clearly indicate that smokers concerned about the hedith effects of smoking were more likely to select the lower tar and nicotine orands. 
By emphasizing tar and nicotine content in advertising during the 1970s, the industry hoped to convince the public that the lower the tar and nicotine, the healthier the cigarette, and thereby to stop smokers concerned about health from quitting smoking. as noted in the December 15 , 1980 Business Week:

"Some (Industry executives) suggest that the explosion in low-tar brands ... has finally 7 done the job of stopping heaith-consclous

According to the FTC, the powerful hedith message thi. piking cou's be safe despite healin warnings was being conveyed in adves a?...int: fo. low tar and nicotine cigarettes:

"Many cigarette advertising techniques appear to denigrate or undercut the health warning. Information ootained from subpoenaed documents indlcates that, at least in the case of several advertising gampaigns, these techniques appear to have been carefully planned."

\section{b. Advertising Themes: Late 1970s to Early 1980s}

"Vantage ads continued the emphasis on low tar. Vantage Ultra Lights were introduced.

"Kent III was introduced in the low tar category. Kent Golden Lights (which had wore tar than Kent III) used comparison advertising to make it uppear that they were lowest in tar. One such ad sald 'Getting the rumuround trying to find a good tasting low tar?' with a picture of footsteps tracking around a group of cigarette packages.

Marit continued to use consumer market research claims to argue that 95 percent of current Merit smokers would not switch, and that smokers liked the tast of Merlt better than that of high tar cigarettes. Merit Uitra Lights were introduced.

"Carlton continued to use government test reports and mocked-up newspaper headlines to make the claim 'Carlton is lowest.'

"Now also used clatmed results of goverment studies and comparison advertising to make the claim that 'Now is Lowest.' In any of Its ads, Carlton was the target, as in 'which is the lowest 100s? (Hint: It's not (arlton)' 
"Doral contimued its clalm to be the best-tasting low tar cigarette.

"Real continued use of macho men, with the slogan 'the smoking man's low tar."

"Trlumph cigarettes were introduced with velled references to sclentific breakthroughs and comparison advertising to clalm to be best tasting low tar cigarette.

"Cambridge cigarettes were Introduced clatming 'No cigarette is lower in tar or nicotine.' and 'the lowest tar ever.'

"The claim was made that Barclay clgarettes were ' 994 tar free." (This clatm was protested by other igarette companies to th
Trade Commisston on the grounds that the 8 arclay f1lt.: testing devices because tis air lients were covered up by th 1 to: in human smokers, but were left ope.l on the machines.) The incinduction of Barclay was one of the most expensive product introdictions in cigarette nistory.

"One Canel ad depleted Camel Lights as being 'the solution' to the problen of reduced taste in low tar cigarettes.

"Ley continued to use government reports and comparison advertising to clala it was the lowest tar in its category.

"Parlianent continued the emphasis on its recessed fliter.

"Pall Mall promised 'a third less tar than the leading fllter 85s."

"Tareyton Lights were introduced with the thene 'Us Tareyton sanokers would rather light than fight'... Comparison advertising was used to make the point that Tareyton had the best filter, with its activated charcoal.

"Arctic Lights were introduced." 80

\section{Eerly to MId 1980s}

In 1980, a Roper survey showed that 36 percent of those questloned belleved that: "It has been proven that swoking low tar and low nicotine cigarettes does not significantly increase a person's risk of disease over that of a nonsmoker." Another 32 percent sald they weren't sure. Thus 
over 60 parcent of those questfoned efther belfeved that low yield efgarettes were "safe" or they weren't sure. 81

A confidential memo, written on Maren 24, 1981, fron J.J. Morgan to H. Culliman and J.C. Bowling, executives with Philip Morris, USA, described the following statement on the company's advertising strategles to be presented to the Comuntcations Comititee for review:

"The Comiunications Comittee is comitted to instituting national advertising to reinforce the imoker, his choice to swoke and the custom of smoking. This will be accomplished by:

--attacking bad research

--attacking researchers themselves, where vulnerable

--attacking the unreasonableness of legislative segregation

--exposing the bureaucracy and personal aggrandizement of certain anti-smoking organtzations.

In effect, the Commintcations Comalttee is readying advertising to stand uD to the Industry's detractors and by that means support our smoking population."

A 1981 review of public opinton surveys by the Federal Trade Comalsston concluded that:

"Many saokers falsely belfeve that smoxing is not dangerous to them If they swoke low'tar' and low-nicotine clgarettes. "... many seokers tho switched to new allegedly 'safer' clgarettes would have quit soling altogether had they not been influenced by advertising. In this way, advertising and promotion of etgarettes clained to provide 'heelth protection' or to be 'lowest' in dangerous constituents successfully offset the deand-decreasing 1 mpact $8 f$ publicity concerning the adverse health consequences of smoking."

In its an robacco Reporter, the tobacco Industry acknowledged that people were smoking lower yield clgarettes because of thelr bellef that these brands are healthier. The publication discussed the fact that the 
arketing of these cigarettes is an attempt to counter publicity about health harards:

\begin{abstract}
"Some may feel they can 'lessen the risk' by switehing to brands with much lower tar and nicotine ratings. Others may want to rid thenselves of feelings of guilt about smoking or about their inablifty to quit, and they figure the best way to do this is to smoke cigarettes with extremely low tar ratings. Certainly the industry-wide trend toward lower tar and nicotine deliveries represents a response to the continuing health attacks on smoking. If the attacks lead the public to belleve smoking is all that hanful and hazardous, obviously the industiy must respond..."
\end{abstract}

In the December 10, 1982 issue of iobacco International, the tobacco industry attributss growth in sales of low yield eigarettes to their healthier lagag:

"Cigarettes containing redused tar levels have substantially increased their share of the domestic market during the last 10 years... Because of the less negative health image (eaphas is added) assoctated with lower-tar brands and reduced nicotine leveis, the former repid growth of this segwent of the domestic cigarette market is belfeved to be at least partially responstible for the upward clgarette consumption trend of recent years..." 85

The article notes that a sharp increase in sales of longer 100 nam cigarettes "In recent months" may have occurred because anti-smoking forces had lessened pressure and the Tobacco Institute had increased its "educational" efforts, a clear acknowledgment that the public chooses laver yfald clgarettes for health reasons:

"Sales of longer $100 \mathrm{man}$ cigarettes have moved up sharply during recent months. This new trend... may have resulted from a lessening in pressure from anti-smoking forces and the effectiveness of the industry's recent 'educational' programs surrounding the hesith issue as effected by the Tobacco Institute." 86 (Tobacco international uses quotes around the word 'educational.' indlcating that these prograns are not truly educational, but have some other purpose, which is obviously commerclal.) 
The success of low yleid cigarettes due to their "healthier" image was again discussed in the Decenber 1983 New York State Journal of Medicine, along with the idea that cigarette manufacturers are taking advantage of this image to sell more of their product:

\begin{abstract}
"The critical factor with respect to any 'less hazardous' product is consuiner acceptance and, wth respect to the low-tar brands, consumer response has been extraordinary. Data from the Unlted States indicate that sales in the low-tar segient (that i3, trr less than or equal to $15 \mathrm{mg}$ ) have trippled from 17 percent in 1976 to 59 percent in 1982. A similar pattern has eccurred in Canada. There are several posstble explanations i:r this explostve jioviti, but the aujor contributor would seen to bs an increased public awareness that cigarette smoking, and in particular exposure to clgarette tar. is detrimental to health. Cigarette companies have capltalized on this perception by advertising tar levels as the basts for brand selection." (emphasis added)
\end{abstract}

A March 1984 editorlal in Santly Physictan noted that young wom in particular were buying the notton that low yield cigarettes are safer:

"The rise In cigarette sinoking among young women may a iso have been
encouraged by the increasing avallability of low-nicotine clgarettes.
since the advent of the low-nlcotine clgarette in 1968, teenagers in
this country have nearly doubled their smoting rate. The proportion
of teenage fenales who smoke has risen concurrently with the market
share of low-nicotine clgarettes.." The article attributes the
popularity of low-nlcotine clgarettes among women to: a "better
health image". 88 On October 12, 1984, the president signed into law the Comprehensive Soling Education Act of 1984, requiring that the single health warning be replaced with four rotating labels on cigarette packages and in cigarette advertising. Four warnings were mandated for cigarette advertisenents on outdoor blliboards which were slightly different versions of the sane nsages. 


\section{Advertising Themes: Early to Mid 1980s}

R.J. Reynolds carried out new marketing efforts in the 1980 s to counter consumers' health concerns about smoking, as described by Joe Tye:

"In early 1984, Reynolds began tes multi-ntllion dollar advertising campign with an ad headed 'Can we have an open debate about swoking?' This ad included the statement, 'Studies whtch concluded that swoking causes disease have regularly ignored significant evidence to the contrary ... During the coating months we will discuss a number of key issues relating to saoking and health. We will also explore other lmportant issues including relations between suggers and nonsmokers, snoking anong our youth, and 'passtve snoking. ing

Other advertising efforts for various brands during this period Included the following:

"Vantage ads featured young athletes engaged in strenuous activities, in deceptive attempt to convey the tmpression that sooking is comatible with the extraordinary conditioning of the heart and lungs required to participate in these activities, and in direct violation of the cigarette industry's own voluntary advertising code that prohibits the deptetion of sookers engaged in strenuous athletic activities.

-True cigarettes continued to be advertised with an emphasis on low tar and nicotine levels .... In late 1985 True Gold was entered Into the competition for younger swokers with iages of attractive young men on glanorous but mysterlous missions into exotic forelgn countries.

"Cariten bugan the period with its usual 'Carlton is Lowest' theme, a them mich continued in many of its advertisements. it also. homur. began the 'If you sioke, please try Carlton' theme. (which sees to say, If you are going to smoke please take care of your health by suoking Carlton) For certain audiences, the health theme seend to be more urgent than for others. In the magazine Working Wother, for example, the health these is strongly eaphasized, probably because the pregnant women and young mothers who read this agazine require serious rationalization to Justify their snoking.

"Now stayed with the 'Now is lowest' thene.

"Parllaeent continued to push tis recessed fliter with the slogan 'All's well that ends we 11.' In early 1986, a new ad campaign was inttlated with the slogan 'The perfect recess.' 
"Benson 4 Hedges Introduced Deluxe Ultra Lights. "Pall Mall usegothe slogan 'A step ahead. Step up in taste, step
down in tar."

\section{Mid to Late 1980 s}

in October 1985. the Federal Trade Comission deternined that its tectirn progran significantly underestimated the levels of tar, nicotire, and carbon monoxide that smokers recelved from smoking Brown williamsons Barclay cigarettes. The comission's announcenent sought coments on "proposed procedures or alternatives (to its testing method) and asked for 'suggestions' on possible designs that could improve the proposed modifications." 91

The FTC closed down its elgarette testing laboratory, leaving no federal agency to test for tar and nicotine levels and thus leaving it up to the industry to do the testing. The lack of government testing of cigarettes creates a greater need for regulation of tobacco under the FDA.

\section{a. Motvertising Thenes: Current}

The following quotations are taken from cigarette advertisenents published in 1987 and 1988: 


\section{Carlten:}

"U.S. Gov't. Test method confinas: Carlton is still lowest!"

"Carlton. It's lowest. And it's got the tast that's right for me. U.S. Gov't Test Method conf $1 \mathrm{rms} 17$ years of U.S. Gov't Reports: Cariton is still lowest!"

\section{Now:}

"A Closer Look Reveals who's Lowest. NOW IS STILL LOWEST By U.S. Gov't testing method."

"Sted Down to the Lowest. NOW IS LOWEST By U.S. Gor't testing nethod."

"Uncover the Lowest. MOW IS LOWEST 8y U.S. Gov't testing method." "The Lowest Overshadows Them All. NOW is LOWEST By U.S. Gov't testing method."

"Low Isn't... lowest. Now Menthol is lowest. By U.S. Gov't testing wethol.

\section{Merit:}

"Breakaway. Get the flavor of these leading brands, but less tar... Breakaway to flavor. Breakaway to Merlt. Great flavor, ress tar. Prove it yourself.

"O1scover an ultra light with real flavor. Merit Ultra Lights. Where today's swokers are heading."

"The world's first do-1t-yourself print ad. Close your eyes and inegin the most flavorful picture you can. Now, think "Merit." Congratulations! You've created the perfect Merit ad. Because flevor is what Merit is all about. Merit Enriched Flavor delivers real aking satisfaction with even less tar than leading lights. So thanks for your help. You created the perfect image for Merit. And you saved us a bundle on expensive photography. Enriched flavor, low tar. A solution with Merit."

"This cigarette is far more flavorful than trits ad. Rather than fllling this page with tasty pictures, we present you with some Interesting food for thought. Because of Enriched Flavor, Merit gives you all the smooth, safisfying taste you want in a cigarette, yet has even less tar than other leading 11 ghts. Now Isn't that an appetizing ided? Enpiched Flavor, low tar. A solution with Merit." 
"Strike it enriched! For smokers. Merit is a gold mine. Rich, smooth, safisfying flavor, yet even less tar than other leading light clgarettes. The secret is Enriched Flavor. Only Merit has it. Dig up a pack today. And stake your clatin to a mother lode of flacor. Enriched Flavor. low tar. A solution with Merlt."

\section{Newport:}

"Newport Lights. Alive with pleasure! Mewport pleasure comes to low tar menthols."

\section{Pari ianent:}

"P.:-ilanent Lights. The Perfect Pecess. Recess: A break from activity for rest or relaxation. Recess: A unique fllter for extra smonth taste and low tar enjoyment."

\section{Virginia Silims:}

"Ya gotta move with the style. New Virginia Silins Uitra Lights. Only $6 \mathrm{ng}$ tar. The lightest style of silas."

"New Virginta Slims Uitra Lights. Only $6 \mathrm{mg}$. tar. The lightest style of silms."

\section{Capri:}

"Today, you'11 discover the slimaest cigarette known to woman. And tomorrow you'll wonder how you ever smoked anything else. New Capri 100 's. Trin \& Light Menthol."

\section{Benson \& Hedges:}

"For popie who like to smoke... New Lights. The new case for the best-tasting Lights. Benson \& Hedges because quality matters."

"Benson 2 Hedges Deluxe Ultra Lights. Only $5 \mathrm{mg}$, yet rich enough to be called deluxe."

\section{b. Current Advertising Practices}

The editor of the New York State Journal of Medicine has provided the following comentary on the current advertising practices of the tobacco Industry: 
"It eay be too late to publish corrective advertising for promotions that ceased 30 years ago, but even in retrospect the credibllity of the publleation is harmed. The knowledge and common sense about clgarette smoking were there -- but so were the mass media to undermine knowledge and cultivate mass denial. One clear lesson is that physictans are not tmmune to propaganda. But the potnt of this article (and this entire issue) is that the situation in regard to promotion of saoking is even more pernictous today (emphasts adced). he old advertisements in the Journal may seed ride culous in their lmages and claims, and we can rationalize that we no longer acquiesce in the sale of eigarettes in a medical context. But do we? ... we as leaders in soctety are doing prectsely what the claarette advertsers want us to do: not become angry, but rather to beculte-iesigned or comnlacent (einphasis added). Advertising for a Wicuci ts not solely designed to sell to potential or current users, ojt also to assure the ccmulacency or tolerance of nonusers." 9 "

\section{HAZAROS OF "LOW TAR ANO NICOTIME" CIGARETTES AMO WHY HEALTH} CLIIAS IR AOVERTISEREENTS ARE MISLEROIHES

The message that low yield clgarettes are "safer" has been heard and heeded by the public even though low tar and nicotine cigarettes are not considered safer because of such factors as compensatory smoking behavior, which accompantes the smoking of low yleld brands, and hazardous agents in smoke other than tar and nicotine, including carbon monoxide. Various sources have recognized that advertisements for low yield cigarettes are misleading and that a "safer" cigarette cannot be nanuf actured.

\section{National Acadeny of Sctences:}

"The logic that lawer T/N yields equal less harmful smoking seems simple and persuasive. But there are two ways in which this logic may be misleading. First, the measurements of $T / N$ are performed, in the laboratories of the Federal Trade Comission (FTC) and others. by analyzing batches of smoke drawn by a machine that simulates smoking with a simple and unchanging progran. Muman smokers and their ctgarettes, however, are netther simple nor unchanging.... second, there is the complexity of the product itself. Tobacco smoke contains several thousand distinct compounds. While the particulate condensate we call tar is clearly carcinogentc, and pure 
nicotine has well-demonstrated effects on the cardlovascular system, the rated quantities of these two components cannot give all the information relevant to the potentlai toxictty of clgarettes. In particular, these ratings do not take into account the yield of gases .- such as carbon monoxide, hydrogen cyanide, and acrolein, in addition, flavorings are added."

"Sinokers who want to reduce the health hazards from their clgarettes are best advised to quit smoking entirely.

"For continuing smokers, exposure to the constitutents of smoke and attendant risks depend not only on the content, construction, and number of cigarettes, but also on the way they are smoksd.

"Therefore. the T/N yields may or may not correspond well to the actual hazerd exposure of differe-t smokers.

"Thus, the evi..ience for switching to laver T/N elgarettes is doubtful.... in our judgment, the degree of benef it most smokers can expect from switching to lower T/N brands, If any, is smell compared with the benefit of stopping smoking completely." 'si"

\section{New England Journal of Medictne:}

"Advertisements from cigarette manufacturers suggesting that smokers of low-yield cigarettes will be exposed to less tar and nicotine arg misleading. Patlents who smoke cigarettes should be so advised." 95 "He think that in the case of the habltual smoker for whom cutting down on nicotine and tar intake is considered to be medically Important, it is unlikely that changing the brand of clgarette w111 accomplish this goal. ... He ... found that people who wanted to stop smoking and who were smoking law-yleld clgarettes did not consume less nicotine, as judged by blood cotjnine concentration, than smokers of higher-yield eigarettes." 96

\section{New York State Journal of Medicine:}

In 1985, the Journal advised doctors against any relfance on low yield cigarettes as an alternative to quitting smoking, pointing out that these clgarettes are as deadly as the high yleld brands or are not safe:

"A review of research in 1983 and 1984 on low tar-low nicotine clgarettes, as reported in the Bibllography on Smoking and Health (Washington, $O C$. Office on Smoking and Heaith), shows that all experfmental studies presented evidence that the so-called less hazardous cigarettes are elther no less hazardous or are simply not 
safe.... The realities of the smoking process make the production of a 'less hazardous' cigarette highly improbable. The comoustion of any types of compounds that have been used in cigarettes will produce the following: carbon monoxide, which is detrimental to the cardtovascular system; tars, which are saturated with carcinogenic compounds; nitrogen oxides, which form acids capable of dissolving lung tissue and causing bronchitts and emphysema: and hundreds of other compounds such as cyanlde and acrolein which are potentially dangerous to the health of both snokers and the people around them. .. The less hazardous clgaretie is a hypothetical construct deve Toped from earliter unsubstant ated research and wishful thinking. (emphasts added) based on the optialstic pretiatnary reports, cigaretic companies began to echo these clatms and have cortini.ed to use this informatloul tis advertise the safety of clgareties based on the curtallment of tar and nicotine. The evidence oresented in this articl: show: that Inaccurate information is being used to advertise clgarettc: (criphas is added) The pollowing measures are recommended tö redress this situation:

- O All funding for the development of a 'less hazardous' cigarette should be discontinued.

- Funding for snoking machine research should also be discontinued since their data kave been shown to be highly inaccurate.

- Funding should be avallable from all levels of government to support and publictze 'stop smoking' clinics with verfflable success rates for those who wish to quit smoking.

- Funding should be made avallable for advertising to counter the advertising efforts of the cigarette industry espectally in regard to low tar-low nicotine clalms.

- The business comanity should expand efforts to encourage the workforce to stop smoking by providing funding to develop Its own prograns to assist in swoking cessation.

... It is Imperative that physiclans realize that there wlll never be a Tess hazardous cloarette (emphasis added). Instead of recominding that the smoker change to low tar-low nicotine cigarettes, phystcians should advise all patients to stop smcking. For those unable to stop on thetr own, phystclans should undertake to dovelep skills in better educating patients on how to stop saoking and andyze the methods and veriftable success rates of the vartous clinics before referring pattents to then. The evidence should now by clear: the 'less hazardous' ctgarette is a deadly delusion."

\section{Fanily Phystctan:}

"Whether the advertiser's substance or style is reviewed, the inescapable conglusion emerges that cigarette advertising is
misleading." 


\section{Compensatory Smoking}

It has been recognized repeatedly that low tar and nicotine cigarettes are not necessarily safer because the smoker tends to smoke more clgarettes to compensate for the lowered tar and nicotine content:

\section{Public Health Service:}

"...ntedth care providers should warn smokers switching to a low-tar and ilcotine cigarette not to increise their dosage, as many smokers increase the number of elgarettes they smoke and inhale more deeply aftar switching to a lower yleld-igarette. There is no safe cigarette, no safe level of consispotion, and such compensatory behxufor may negate any advantage of switching to lower yield product, and may even increase the health risk." 9 ?

"The potential benefit to the individual consumer who wight shift to the lower :ar and nicotine cigarette would be negated if this shift were accompanied by an increase in the number of clgarettes consumed..." 108

\section{Surgeon General:}

"...many snokers change their smoking behavior when they switch to the lower-yleld brand. In an attempt to satisfy nicotine or taste demands, however, they may compensate by smoking more cigarettes than before, puffing more frequently, Inhaling more deeply and for a longer period. This could lead to increased atherogenesis through the greater tntake of carbon monoxide, hydrogen, cyanide and nitrous oxide, all constituents of cigarette smoke."

"If the swoker compensated for reduced yield by increasing the number of cigarettes, the depth of Inhalation, or the volume or irequency of puffs, a reduction in 'tar' night not result in a reduced solke exposure. The possible increase in the average number of cigerettes smoked by each smoker and the possibllity that the depth of Inhalation and puff volume may also have increased as the average 'tar' yleld of the clgarette has declined raise a real concern that the shift to the use of lower 'tar' cigarettes pay not have resulted in a proportionate drop in smoker exposure."

\section{Nat fond Academy of Sciences:}

"The wefght of recent studles that we have reviewed supports the Idea that nicotine dependence is a very important component of smoking behavior and that most heavy cigarette smokers, regardless of brand, tend to maintain high nfcotine levels." 103 
"The laboratory and fleld studies of smoking generally but not uniformly show that a significant prodortion of smokers who switch to lower tar and nicotine cigarettes change the way they smoke them so as to compensate partially for the reductions in tar and nicotine yields, thus making the reduction in actual tar and nicotine absorption by smokers less substantial than the reduction in tar and nicotine ratings based on the FTC smoking machine method." 104

\section{New England Journal of Medicine:}

"... low-yield cigarettes may even increase the health risk, since smokers who switch to these cigarettes may compensate for the lower intake of nicotine by smoking more cigarettes per day, inliciling more deeply, puffing more frequently, or snoking cigarettes to a shorter butt length.

New York State Journal of Medicine:

"... The question of nicotine compensation also has been approached using volunteers who were made to switch to progressively loweryield brands. Measures of snoking exposure such as blood COHb, serua cotinine, and plasma thiocyanate all demonstrated that more snoke was absorbed than would have been predic:ed from the values on the packages. In fact, the lack of major differences between the treatment and control groups in this study suggested that most subjects obtained just as much nicotine from the so-called lesshazardous products as they did from their. original brand. For most subjects in these studies, switching to low-yield brands did not result in a significant decrease in the anount of smoke absorbed, due primarily to a tendency to increase puff volume and/or depth of inhalation when such products are smoked." 106

\section{Family Physictan:}

"Howerer, the advertised claim that the so-called low-nicotine cigarattes have less tar and nicotine than higher-yleld brands is not valld... nicotine concentration in cigarettes is inversely (ital) correlated with the concentration measured by Tsmoking machines' and government testing... studies have shown that on switching to a lower-nicotine brand, snokers will change their smoking behavior, altering the number of cigarettes smoked per day. the depth of Inhalation, and the anount of tobacco left in the butt."

\section{Additives}


In trying to manufacture a safer cigarette, companies found that removing the tar fram tobacco also removed "taste." In an effort to preserve taste, they use a wide array of additives with questionnable and potentially dangerous effects, as noted by the following sources:

\title{
Surgeon General:
}

\begin{abstract}
"I" order to enhaice consumer acceptability, flavoring substances in cuded to clgurettes; it may be ihat the lower the 'tar' yield,

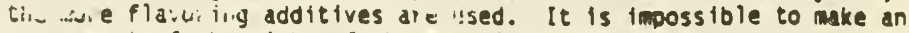
asisisment oi the risks of these sodtives, as cigarette maisfiri.ure:s are not requtrec $: \because$ sveal what additives they use.

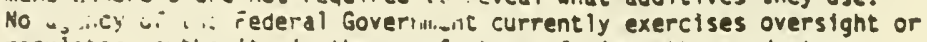
regulatory at thority in the manufacture of cigarette products. Further, no agency is empowered to require public or confidential disclosure of the additives actually in use by the cigarette manuf acturers."

"... the production of cigarettes with lower 'tar' and nicotine ylelds may involve the increasing use of additives for tobacco precessing or flavoring. Some additives avallable for use are either known or suspect careinogens or give rise to carcinogenic substances when burned. The use of these additives may negate beneficial effects of the reduction of 'tar' yield, or might pose increased or new and different disease risks. Therefore, the 'tar' yleld of cigarettes currently being manufactured probably cannot be used as a preclse measure of current smoke exposure risk, nor be compared quant tat tvely wth the smoke exposure risk of the odder higher tar' clgarettes." (eniphasls added)
\end{abstract}

"Another compllcating factor in determining the health hazards of the lawr-yleld brands is that additives for flavoring or other uses in these brands have not been adeguately identifled and tested for adverse blological potential"

\section{New England Journal of Medicine:}

"... cigarette additives are more cominnly introduced into loweryield cigarettes to enhance their 'taste. '; the Identity of these additives is not disclosed to consumers, and they present unknown risks to the smoker."

Mother Jones: 


\begin{abstract}
"The extra Ingredients could be making low-tars even riskler than the old-fashioned brands.... Cigarette makers have more than 1,400 such Ingredients to choose from; and the industry releases no figures on the ir use... In 1977 the industry spent $\$ 76$ million on flavorings and molstening agents; in 1979 it spent $\$ 113$ million. Even allowing for Inflation, purchases appear to have increased about 10 percent per year through the late 1970s." 112
\end{abstract}

\title{
3. Misrepresentation of Tar and Nicotine Content
}

The accuracy of eigarette tar tables has been disputed amd the FTC has terminated its tesitng program. The foilowing, including the tobacco industry, have noted the innaccuracy of the FTC's test findings:

\section{Public Health Service:}

"Cigarettes are easily manipulated, and scientific evidence suggests the tar and nicotine yields obtalned through current testing methods may not correspond to the dosages individual smokers actually receive. A cigarette advertised as being in the one to five ing tar range can turn into a 15 to $20 \mathrm{mg}$. tar cigarette if a smoker takes more and deeper puffs or even partlally blocks the yentilating holder or channels found in the clyarette fliter."

\section{Surgeon General:}

"There is evidence to suggest that the clgarette ylelds measured oy machine are very different from what the consumer actually obtains by saoking the cigarette, due in part to the difference in patferns of saoking between testing machines and individual smokers."

\section{New Sctentist:}

An article in the July 14, 1983 issue of New Sctentist discussed the inaccuracy of cigarette tar tables as $1 t$ was revealed in a controvery over Barelay elgarettes, which clalmed to be "99 percent tar free".

"Big differences have been found," it stated, "between smokers" habits and the way that machines test cigarettes." sThe article 
notes that the success of 8arclay cigarettes "is due in a large part to being advertised as ' 99 percent tar free"> R. J. Reynolds, British Auerican Tobacco (BAT's) big American competitor, became irate about the Barclay rating and complained, with Philip Morris, another compettor, formally to the FTC. "The FTC's machine drew in less than one milligram of tar when it smoked Barclay, that put the cigarette comfortably at the bottom of the American tar table. Not surprisingly the FTC's one milligram rating is touted widely in Barclay's advertising." The Barclay filter, patented under the name 'Actron'. has small rings of perforations around the fflter that allow air to be drawn in and dilute the smoke. It also has four fragile grooves which "run, Just under the paper wrapper, from between the tobacco and the perforations to the end of the fliter that goes in the mouth. So when t... it draws in some smoke and fuite a lnr, of :rejh : $i \cdot$ in: ough ti.s grooves. During the minute betraer : ich autsu... ri:, standardisr.o puff, the tobacco burns slowly in:3; The reeill: is the much prised on milligran tar rating." R.J. Reyiulds chargnd that "smokers crush the fragfle grooves with their fingere and it?. They then suck in a lot less fresh air and a lot more tars anc nicutine than does the FTC's smoking machine, or than Barclay's advertising claims." is"

\section{Tobacco Industry:}

Ernie Pepples, a Brown and Williamson vice president and general counsel. said, on a Chicago television program in 1982:

'They really ought to tell people that these numbers are developed by a robot, and nobody smokes like a robot.... People take different length puffs, hold the fllter elther further in or out of their mouth and smoke more or less frantically.'...

In November 1977. BAT's director of research. Or. Jim Green, said,

\footnotetext{
In som respects it is unfortunate that cigarettes have been tested for so long by simulated smoking ... it is doubly unfortunate that machine smoking under falrly arbitrary conditions, probably different from those of any known human smoker, should be so often and so wrongly regarded as equivalent to human smoking.... a change by only one puff would readlly reverse the positions of adjacent clgarettes (in the tar tables) and for those at the 599 and botton bands would shift cigarettes into different bands.' If
}

\section{FTC Consultants:}


Some of the FTC's consultants have published articles relating "to the measurement of low tar under their own names. Foremost among them is Or. Lynn Kozlowskt, and his colleagues working at the Addiction Research Foundation and the Department of Preventative Medicine, at the Unviersity of Toronto, in cooperation with the laboratory which does the Canadian tar tests:

'We belleve that a loophole exists in the standard smoking machine procadure in that it does not specify the number of puffs to be taker.' they wrote in 1980 . (SCience, vol 209, Dp 1550-51). 'The number of puffs taken per cigaratte for some brands declined signiflcantly from 1969 to 1974 , and we belleve that this change has enatributed to the reported reductions in their tar and ntcotine content. (emphasts added) This was followed by a paper reporting that more than half of a sample of smokers block the ventilation holes in filters, of ten inadvertently, when they draw. They added, 'Hole-blocking increases the yield of toxic products by 59 percent to 293 percent. (emphasts added) (American Journal of public health, November 1980, vol 70, pp 1202-3).. In The Lancet in 1981 (voll, p. 508) Kozlowskf sald. "Ultralow tar clgarettes do not deliver ultra-low-tar tobacco smoke -- they deliver less smoke and more air per puff ... some smokers defeat the vented filter by blocking poles with fingers, lips ... and can turn a $4 \mathrm{mg}$ cigarette into a $13 \mathrm{mg}$ one." 118 


\title{
New York State Journal of Medicine:
}

"Fifty percent of those who smoke low-tar cigarettes admit to blocking the holes: thus, there could be little, if any, change in the risk of smoking-related diseases... But although consumers can be warned of the danger of hole blocking, the vents on many brands are 11 but invisible to the human eye." 119

"... smoking machines report lower tar and nicotine content than that actually consumed by the smoker." (pg 315, Miller) Also, "the Federal Trade Commission noted in an injunction against Broan and Williamson Tobacco Company that the ventflation channels near the top of the clgarette, which were supposed to reduce tar and carbon monoxide intake, werg blocked by the smoker's lips but not by the smoking machtne." 120

\section{New England Journal of Medicine:}

The following is an abstract of a study which concluded that the FTC values do not reflect what is actually taken into the body of the cigarette smoker:

\begin{abstract}
"Advertisements suggest that smokers of cigarettes low in nicotine are exposed to less nicotine and tar. Nicotine ylelds are measured with smoking machines, but machines do not smoke cigarettes as people do. We therefore measured the actual nlcotine content of commerclal cigarettes with different nicotine and tar yields as determined with snoking machines, and also measured actual nicotine intake as indicated by blood concentratlons of its metabolite. cotinine, in 272 subjects smoking various brands of cigarettes. We found that low-yleld cigarette tobacco did not contain less nicotina: in fact, the nicotine concentration in tobacco inversely correlated $(r=-0.53, P<0.05)$ with the concentration measured by swoking achines. Blood cotinine concentrations correlated with the number of cigarettes smoked per day but not with the nicotine yteld measured by sinoking mechines. Only 3.8 to 5.0 percent of total variance in blood cotinine was contributed by nicotine yield. We conclude that smokers of low-nicotine cigarettes do not consune less nicotine." 121
\end{abstract}

\section{Harmful Components of Tobacco Smoke Other Than Tar and Nicotine}


The Federal Trade Comission and the Department of Health and Human Services have both called for legislation that would make the 11sting, on cigarette packages and promotional material, of tar. nicotine and carbon monoxide yields mandatory. ("8y 1985, elgarette companies were required to list tar and nicotine ylelds in all advertising but were not required to display elther value on cigarette packages. At the sane time, cigarette compantes were not required to, nor did they voluntarlly, display carbon monoxide ylelds on elther packages or pronotional materlais." ) 122

\section{National Academy of Sclences:}

"...the attempt to make clgarettes less hazardcus by reducing their tar and nicotine yteld is necessarlly a crude approach. corresponding to the uncertainty of knowledga about the differential effects of the thousands of components of ctgare:th smoke and the difficulties in independently manipulating them." 123

"It is possible for a cigarette to be altered in such a say that its 'tar' and nicotine content is reduced but certain other harmful effects, for exapple, the effect of the gaseous phase may be increased......

"... Investigators have reported that carbon monoxide levels are no different in suokers of low-yield clgarettes and smokers of higheryleld clgarettes." 125

\section{New Yort State Journal of Medicine:}

"When Inhaled, the carbon monoxide (CO) in tobacco smoke results in the formation of carboxyhenoglobin (COHb). so-that approximately 80 percent of persons stlll swoking have COHb levels of from 2 percent to 8 percent. COHb levels are better correlated than smoking history with the development of angina pector 1s, myocardlal infarction and intermittent claudication: the relative risk of developing coronary heart disease is about 20 times greater in individuals with COHb levels $9 f^{5}$ percent or greater than in those with levels below 3 percent." 126 
"Aldehydes such as accetaldehyde, are toxic to cllla as is hydrogen cyanide (HCN), which also interferes with respiration. A single cfgarette delivers 40 to 250 ug (symbol) of $\mathrm{HCM}$. In rats a dose of 170 to 230 ug per ktlogram of body weight causes unconsfjousness and 590 to 640 ug per ktlogram of body weight is lethal." 127

5. No Reduction in Oisease Risk

New England Journal of Medicfne:

"...a recent study showed that the risk of myocardial infarction increased with the number of cigarettes smoked but did not differ between smokers of low-yleld cigarettes and those of high-yleld cigarettes."

\section{Surgeon General:}

"... the absorption of carbon monoxide is more dependent on depth of Inhalation than is the absorption of ntcotine and, if the use of lower 'tar' products results in a compensatory increase in depth of inhalation, snoker exposure to carbon monoxide may remain unchanged or actually increase. The reallty of this concern is borne out by those studies that show no lowering of carboxyhemoglobin levels in smokers who switch to lower 'tar' ctgarettes. If carbon monoxide is an active etfologic agent for clgarette-related coronary heart disease, and if significant compensatory changes in the style of smoking occur with use of lower 'tar' cigarettes, then the risk of coronary heart disease with lower 'tar' cigarettes may be similar to, or posstblegreater than, the risk of smoking higher 'tar' cigarettes." 128

"... the risk of developing emphysena may not be related to the 'tar' yilid of the cigarette smoked. Even if the reduction in 'tar' results in a reduction in smoker exposure to 'tar,' a pattern of compensation that produces a deeper inhalation may deliver a greater dose of the gas phase of that smoke to the alveoll where it produces a pathogenic effect. In addition, the techniques used in formulation of the newer very low 'tar' cigarettes may result in an increase in the concentrations of etfologic agents in the smoke. Therefore, the relative risk for lower 'tar' clgarette usage in the developant of chronic obstructive lung disease is highly problematical." 130 


\section{Footrotes}

1 National Academy of Seiences, "Reduced Tar and Nicotine Cigarettes: Smoking Behavior and Health," 3 (1982)

2 Blum, "When 'More doctors smoked Camels': Cigarette advertising in the Journal" 83 N.Y. St. Journal of Medteine 1351 (1983)

3 Cigarette Report: "Low Tar in Command," $185(7)$ Tobacco International (1983)

4 National Academy of Sciences, supra note 1 at 2

5 Cigarette Report, supra note 3

6 Humphries, "U.S. Cigarettes: Uitrus holding strong," 109 Tobacco Reporter (1982)

7 Cigarette Report, supra note 3

8 Humphries, supra note 6

9 Mintz. M., "Cigarette Ads and PR Mislead Public, Witness Contends," Weshington Post, Mar. 11, 1988

10 ld.

11 Id.

12 Id.

13 id.

14 Mintz. M.. "Studies Sald to Cast Doubt On Use of Cigarette Fliters." Washington Post, Mar. 7, 1988

15 Mintz, M., "Meawo States 'Holding Strategy' of Tobacco Firms," Hashingotn Post, Mar. 2, 1988

16 Id.

17 Bennett, "The Kicotine Fix," 66 Rhode [s and Medical Journal 158 (1983)

18 Houston, "Women who Smoke: An Equal Right to Die", 29 Fanily Physician 128 (1984)

19 Tye, "Selling Death By Promising Health: Sixty Years of Health Claims in Cigarette Advertising," I Tobacco Products Litigat!on Reporter $4.66(1986)$ 
20 Id. at 4.63

21 Blum, supra note 2 at 1347

22 1d. at 1351

23 Id. at 1352

24 Tye, supra note 19 at 4.64

25 Id. at 4.66

26 Tye, Karriag and Giancz, "Tobacco Advertising and Consumption:

Evidence of : Crusal Reiationsh10." Jourral of Public Mealth Policy 501 (1987)

27 Blum, supris iste 2 at 1351, 1352

28 Tye, supra note 19

29 Mintz, supre note 9

30 Mennies, "Seoking, The Physlologtc Effects," American Jourral of Nursing 1143 (Aug. 1983)

31 Harner, "Tobacco Industry Response to Publlc Health Concern: A Content Analysis of Cigarette Ads," 12(2) Health Education Quarterly 119 (1985)

32 Snoking and Hesith Report of the Advisory Comittee to the Surgeon General of the Public Health Service 6 (1964)

33 Id. at 7

34 Id.

35 Id. at 8

36 id.

37 Health Mdrocacy Center, S1xty Years of Deception: An Analysis and Canpllation of C1garette Advertisements, 1925 to 1985 (Vo). 31954 to [963) 2 (I986)

38 Smoking and Health Report of the Advisory Comnittee to the Surgeon General of the Publtc Health Service, supra note 32 at 29, 31, 32, 33, 39

39 Health Advocacy Center, supra note 37 (Vol. 41964 to 1973) at 1

40 Id.

41 Mintz, M.. "Clgarette Ads Said Full of 'Kealen' Cues, "Washington Post, Mar. 10, 1988 at 08 col. 4 
42 Research and Development Department, Operations Department

Presentation to Philip Morris Board of Directors 283-288 (Oct. 28, 1964)

43 Health Advocacy Center, supra note 39 at 2, 3, 4, 5 ,

44 Miller, The "less hazardous" clgarette: a deadly deluston," $85 \mathrm{~N}$. Y. Se. Journal of Medicine 313 (1985)

45 id.

46 id.

47 Health Consequences of Smoking, ihe Changing Cigarette, A Report of the Surgeon General 5 (i981)

48 U.S. Department of Health and Humar Services, "Smoking and Health," in The 1990 Health Objectives for the *ation: A Midcourse Review 182, 183 (19़8)

49 Revfewing Progress Made Toward the Development and Marketing of a Less Hazardous Cigarette, Hearings on S. 1803 before the Consumer Subcomittee, Senate Comittee on Commerce, 9gth Cong., ist Sess. 8 (1967)

50 Stewart, Statement before Consumer Subconmittee, Senate Comiltee on Comerce, Reviewing Progress Made Toward the Development of a Less Hazardous Cigarette, 99th Cong.. lst Sess. 151 (1967)

51 Gardner, Letter to Senator Warren G. Magnuson, Consumer Subcomfittee, Senate Committee on Commerce, Reviewing Progress Made Toward the aevelopment of a Less Hazardous Clgarette, 99th Cong., 1st Sess. 6.7 (1967)

52 Gahagan. Switch Down and Qult, Ten Speed Press, Berkeley, Calif. 15 (1987)

53 Health Advocacy Center, supra note 39 at 1

54 Id. at 5, 6, 7, 8

55 Id. at 2

5 Federal Trade Comalssion, Report to Congress Pursuant to the Federal Cigarette Labeling and Advertising Act for the Year 1981, 98th Congress, 2nd Sess. 2 (1984)

57 Harner, supra note 31

$\$$ Id. at 116

P9 Health Advocacy Center, supra note 39 at 8 
60 Tye, supre note 19

61 Warner, supra note 31 at 116

62 Health Advocacy Center, supra note 39 at $7,8,9$

63 Health Advocacy Center, supra note 37 (Vol. 51974 to 1985) at 5, 6, $7.8,9$

64 Miller, supra note 44 at 313

65 Id.

66 Id. at 313,314

67 Id. at 313

68 Cohn, "Some Cigarettes Now Toleratile, Doctor Says, "Washington Post, Aug. 10, 1978 at AI

69 Id. at Al4

70 Id.

11 Id. at Al

12 Health Advocacy Center, supra note 63 at 4

13 id. at 5

14 Davis, "Current Trends in Cigarette Advertising and Marketing," 316 Eng. Journal of Medicine 725, 726, 727 (1987)

15 Roper Organization, Inc.. A Study of Public Attitudes Toward CIgarette Smoking and the Tobacco Industry in 1978, Vol. 1, Prepared for The Tobacco Institute, 41 (1978)

16 Swoking and Heelth, A Report of the U.S. Surgeon General 1-30.(1979)

$\pi$ Gahagen Research Assoctates, "Monograph on Snoker Attftudes Toward Lou Tar Cigarettes." Locust Valley. N.Y. 3 (1988)

70 Oavis, supra note 74 at 727

T) Health Advocacy Center, supra note 63 at 3

0 Id. at 9,10

4 Roper Organization, Ine., Smoking Study (1980)

2. Interoffice Correspondence, Philifo Morris, USA, 100 Park Ave., New lork, NY (Mar. 24, 1981) 
83 Tye, Warner and Glantz, supra note 26

84 Humphries, supra note 8

85 Burry, "Cigarette demand could decline; raw materials may gain from legislation," 184 Tobacco International 38 (1982)

86 id.

87 Rickert, "'Less hazardous' cigarettes: fact or fiction?" 83 N.Y. St. Journal of Medicine 1269 (1983)

88 Houston, "Women who Smoke: An Equal Right to Oie," 29 Fantly Physictan 131 (1984)

89 Health Advocacy Center, supra note 63 at 12

90 Id. at 13, 14

91 Federal Trade Comalssion, Report to Congress Pursuant to the Federal Cigarette Labeling and Advertising Act for the Year 1985, 99th Congress 2nd Sess. 5 (1988)

92 8lun, supra note 2 at 1352

93 National Academy of Sclences, supra note 1

94 Id. at 4,5

95 Benowitz et al., "Smokers of Low-Yield Cigarettes Do Not Consume Less Nicotine," 309 Hew Eng. Journal of Medtcine 141 (1983)

96 Id. at 140,141

97 Miller, supra note 44 at 316,317

98 Houston, supra note 18 at 131

99 U.S. Departaent of Health and Human Services, supra note 48 at 183

100 Reviewing Progress Made Toward the Development and Marketing of a Less Hazardous Cigarette, supra note 49 at 7

101 Office of Oisease Prevention and Health Promotion, "Disease Prevention/Health Promotion, The Facts," 9 (1988)

102 Health Consequences of Smoking, supra note 47 at 6

103 National Academy of Sciences, supra note 1 at 6

104 id. 


\section{6}

105 Davis. supra note 74 at 728

106 Rickert, supra note 87 at 1271

107 Houston, supra note 18

108 Health Consequences of Smoking, supra note 47 at 6

109 1d. at 8

110 Office of 01sease Prevention/and Health Promotion, supra note 101

111 Davts, supra note 74 at 728

112 Mintz, J.. "Low Tar, High R1sk," Mother Jones 54 (1983)

113 U.S. Department of Health and Hutan Services, supra note 48 at 183

114 Health Consecuences of Smoking, suprd nore if at 5

115 Harriman. "Do clgarettes cheat the tar tables?," 99 New Scientist 85. 86 (1983)

116 [d. at 87

117 Id.

118 Id.

119 Rickert, supra note 87 at 1270

120 Miller, supra note 44 at 315

121 Benowitz et. al., supra note 95 at 139

122 U.S. Department of Health and Human Services, supra note 48 at 188

123 National Acadeny of Sciences, supra note 1 at 6

124 Reviering Progress Made Toward The Development And Marketing of A Less Hezardous Cigarette, supra note 49 at 7

125 Benowttz et al.. supra note 95

126 Rickert, supra note 87 at 1269

127 Id.

128 Benowltz et al., supra note 95

129 Health Consequences of Smoking, supra note 47 at 10

130 Id. It 12 


\section{II1. STATEMENT OF LEGAL GROUMOS}

A. LOW TAR ANO LOW NICOTINE CIGARETTES ARE "ORUGS" WITHIN THE MEAMING OF THE FEOERAL FOOO, DRUG, ANO COSHETIC ACT

Section $201(g)(1)$ of the Food, Orug, and Cosmetic Act (21 U.S.C. of $321(g)(1))$ defines arug as:

"(A) articles recognized in the offlcial United States Phamacopeia, official Homeopath:: Phanacopela of the United States, or official formulating, or any supplement to any of then: and

(B) articles intended for use in the diagnosis, cure, attigation, treatment or prevention of disease in man or other animals; and

(C) articles (other than food) intended to affect the structure or any function of the body of man or other anials; and

(D) articles intended for use as a component of any articles specifled in clauses (A). (B) or (C) of this paragraph; but does not include devices or their parts, or accessories."

It is the intention of petitioners to establish that the manufacture, advertising, promotion and marketing of low tar and low nicotine cigarettes falls under the definition of drugs under clauses (B) and (C) and of Sec. $201(\mathrm{~g})(1)$ which defines drugs as articles intended "for use in the diagnosis, cure, mitigation treatment or prevention of disease," and "articles (other than food) intended to affect the structure or any function of the body of man or other animals."

Petitioners contend that the manufacturing, dovertising, sale and promotion of these products has led consumers into belleving that use of these products will mitigate and prevent diseases caused by the use of the higher tar and nicotine cigarettes and that the marketing of 
clgarettes, advertised and promoted as containing varying amounts of tar and nicotime is done with the intent of affecting the structure of the body of man. Thus, for reasons set out in Statement of Factual Grounds and for reasons to be presented in this section the FOA should take action against these products as "drugs."

\section{The Food and Orug Adainistration has asserted Jurisdiction over tobacco}

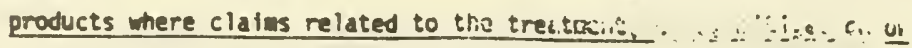

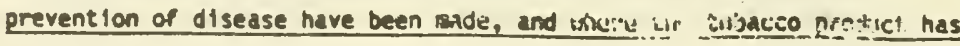

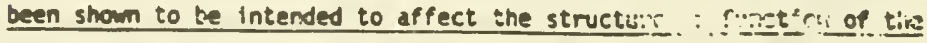
body.

Pettitoners are not embarking into unexplored territorles in contending that tobacco products should be regulated as "drugs" under the Food, Orug. and Cosmetic Act. In appropriate circumstances, such actions have been brought by the FOA and upheld by various courts.

For example the courts have held that if "there is an indication of intent to use the article for the cure or mitigation or treatment or prevention of disease in an, then clearly the subject matter of the libel is to be considered drug within the meaning of the [Food, Orug, and Cosmetfc] Act." U.S. $\vee 46$ Cartens More or Less containing Fairfax Cigarettes $113 \mathrm{~F}$ Supp. 336, 337 (O.N.J. 1953). Similarly, in U.S. v 354 8ulk Cartons:... Trin Reducing - AlO Cigarettes 178 F Supp. 847 (D.N.J. 1959), the court held that cigarettes "promoted as weight reducing cigarettes and which contained combustible tartacic actd, constituted an article intended to 
affect, and contained a component which affected structure or functions of the body, and therefore constituted "drugs" within the meaning of the Food. Drug, and Cosmetic Act."

The Food and Orug Administration's jurisdiction over tobacco products in appropriate circumstances has also been reaffirmed by the FDA in testimony before the Congress. In 1972, FOA then Comisstoner Charles C. Edwards testifled to the Consumer Subcomittee before the Seriate Coneittee on Commerce as follows:

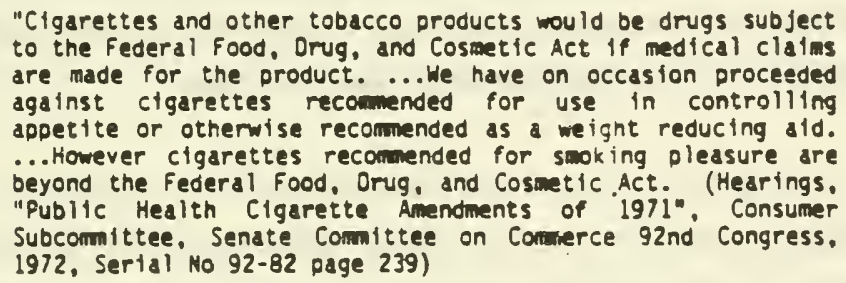

This position was refterated in December 1977 by then FOA Commissfoner Donald Kennedy in a letter of dental to a petition filed by Action on Seoking and Health et.al.. that had requested the FDA to exercise Jurisdiction over cigarettes containing nicotine as a "drug" under the Food. Orug, and Cosmetic Act and in the alternative, as "devices" under the Act. In his letter. Commissioner Kennedy concluded that the judiclal opinions stood for the proposition that cigarettes are "intended to affect the structure or any function of the body of man" within the meaning of the Food, Orug. and Cosmetic Act only where manufacturers or vendors of 
clgarettes Interd such effects and that such intent must be shown by health clatms or other representations by cigarettes manufacturers or vendors." The Comisstoner then went on to state that FOA did not regulate cigarettes except in situations where health claims are made, the very contention of this petition (Brief of Action on Smoking and Health $v$. Joseph Caltfano, Case No. 79-1397. U.S. Court of Appeals for the Oistrict of Columbia p. 2-3).

2. Low tar/low nicotine clgarettes are arketed with the Int:-i, if creating in the wind of the publtc the ldea that they will : jaite or "prevent" the onset of disease assoclated with the sooking habit. thus Eeeting the defintitional recuirements of "drugs".

The factual evidence concerning the purposes and intent of tobacco compantes to market low tar/low nicotine cigarettes has been thoroughly reviewed and documented under Section II, Statement of Factual Grounds of this petition and those arguments and detalls $w 111$ not be repeated here. This section $w 111$ review the legal requirements necessary to establish that tha tobacco companies have in fact marketed, advertised and promoted low tar and low nicotine cigarettes with the intention of creating in the wind of the public the ldea that such products w111 mitigate and prevent the onset of diseases associated with the snoking habit. Webster's Collegiate Oictionary (9th Edition) defines "mitigate" as follows:

"1. to cause to become less harsh or hostile ...

2. to make less severe or painful..." 
Weoster's Collegtate Dictlonary, defines "prevent" among other definitions:

"to forestall, to hold or keep back, to hinder."

Similar definitions and synonyms appear in other dictionarles and thesauruses.

Applying these definitions to low tar and nfcotine advertisements and promotions, it is clear that it has been the intent of the tobacco industry to promote a product designed "to cause to becone less harsh, to make less severe, to forestall, hold back, or inder."

Courts have relled on such definitions in determining the intent of statutes, and in particular, in interpreting the FDCA. See for example, US $\vee$ Sudden Change, 409 F. 2nd 734, 742 n.l (2d C1r. 1969).

To date the FOA has brought action against cigarette products as drugs on two occasions. A third case, relevant to this petition concerns actions brought by the Federal Trade Commission, an action which employed the food and Orug Adanistration's definitional standards for "drugs".

The flrst case relevant to this portion of the petition, United States $v$ 46 Cartons, More or Less, Containing Falrfax Cigarettes, 113 F. Supp. 336 (O.N.J. 1953), involved the introduction into interstate commerce of 46 
cartons of "Falrfax Clgarettes." The cartons were accompanied with 5! leaflets entitled, "How Cigarettes May Helo You." A libel action was brought by the United States alleging that the cigarettes were orugs and, as suck, were misbranded. The issue addressed by the court was whether or not "the seized article is a drug within the meaning of the food, Orug, and Cosmetic Act." The Court noted that "In a field where generally speaking competition is met by advertising and labeling rather than by price or even perhaps by substantial differences in quality, such conflicts [between the FOA and tobacrs companies] are almost inevitable as manufacturers treed near the statutory boundary." 113 F. Supp at 337.

In ruling that the cigarette oroducts were drugs, the court concluded that, contrary to the clalmants assertions that the leaflets were intended only to promote and increase one's smoking pleasure. "If there be an indication of intent to use the article for the cure or mitigation or treatment or prevention of disease in man then clearly the subject matter of the llbel is to be considered a drug within the meaning of the act." Id. at 337 .

The representations ade by the manufacturer in the circular accompanying the cigarettes suggested that falrfax cigarettes were effective in preventing respiratory and other diseases. Finding that these leaflets constituted labeling, the court held that the representations made in this labeling were spectous, that fairfax clgarettes had "none of the curative or preventive powers Implied in the leaflet," and that the cigarette manufacturer wisled the pubitc "by a subtle appeal to a natural and 
powerful desire on the part of us all to avold the infectious diseases or diments therein mentioned." Id. at 337, 338 (emphasis added).

In so holding, the court determined that on the basis of the implicit as well as explictt claims made in the labeling accompanying Fafrfax cigarettes, the public would buy falrfax cigarettes "wtth the hope of mitigating, curing or preventing disease." Id. at 338.

Similarly, tobacco manufacturers do make explictt reference to tar and nicotine figures in their labeling with the intent to "appeal to (the buying public's] natural and powerful desire... to avold" the health hazards widely acknowledged and understood to result from cigarette smoking. Id. at 338 (emphasis added).

The explicit references in such advertising to the tar and nicotine content of low tar and low nicotine cigarettes "would appear to have" - in the words of the Federal Court in Fairfax - "no other purpose than to mislead the unwary," whose hope in buying and smoking such cigarettes no doubt is to improve their prospects for avoiding, nitigating and/or preventing cigarette caused disease. Id. at 337.

The court went on to note that in attenpting to market their products manuf acturers:

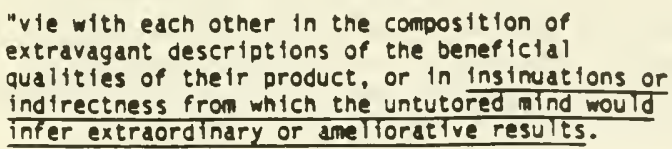


Exactness, completely truthful statements of objective versinfleude are frequently subordinated to blatant, spectacular, suggestive or dubtous representations in order to breakdown sales resistance or to create a demand for a product hitherto not found necessary to the happiness or the well-being of the generd public." (emphasts added) 1137 . Supp at 337

In developing these propositions even further, Oistrict Judge Meaney pointed out that in situations where conflict extsts between manufacturers and the public on advertising and labeling 1ssues, bin. Congress, in establishing statutory boundarles, clearly had in minu "that the public should be adequately and truthfully informed as to what it is purchasing." Thus he goes on, the Food, Orug, and Cosmetic Act must be constructed so as "to effectuate the purpose of protecting the buying public which is largely beyond self protection in the circumstances of modern 11fe. (Citizen 62 Cases of JAM V U.S. 1951340 U.S. 593,596, 71 S.CT.515, 95L.EO.S66 kordel v. U.S. 335 U.S. 345, 69 S. Ct. 106, 93 L.Ed. 52; U.S. v. Dotterweich 1943, 320 U.S. 277, 280, 64 S. Ct. 134, 88 L.ED. 48 1943)." 113 F. SUpp. at 337. See also U.S. v Article - Sudden Change, 409 F. 2d 734, 740 (2d C1r. 1969) and U.S. V. An Article of Orug....Becto - Untdisk 394 uS 784, 22 L. Ed 2d. 726, 733, in which the court stated:

At the outset, It is clear from Sec. 201 that the word "drug" is a term of art for the purposes of the Act, encompassing far more than the strict medical definttion of the word. If Congress had intended to linit the statutory definttion to the redical one tt could have so stated explicitly, or simply have made reference to the offtetal United States Pharmacopoefa, or the National formulary, as it did in the first of the three sections of Sec. $201(g)(1)$ and let the definition rest there. The nistortcal expansion of 
the statute's definition, furthemore clearly points out Congress' intention of going beyond the medical usage."

This construction of the definitional scope of "drugs" under the Food. Orug, and Cosmetic Act was set out by the Congress beginning in 1935 . It was under the iegislation first considered during the 74th Congress and enacted in 1938 under the Food, Orug, and Cosent 16 Act of 1938 (Copeland ACt)(52 Stat. 1046, 75th Congress, 3d Session, June 25, 1938) that the definition of drug was expandid to be oroadly interpreted. The Senate Comfttee Report to the 1935 Act stated:

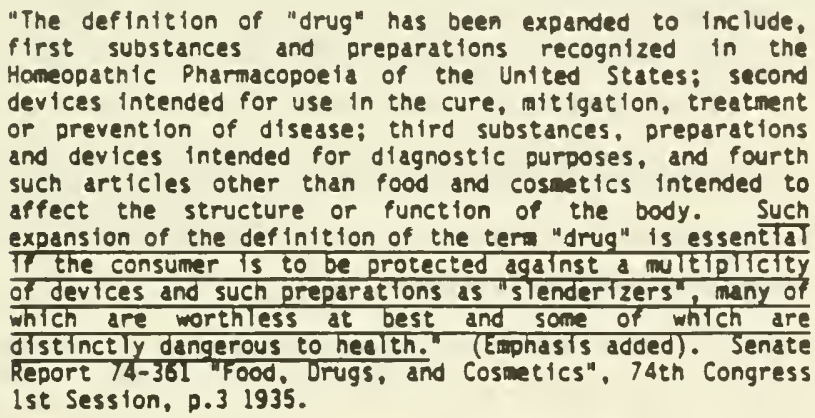

The fact that any tobacco products are not considered to be drugs does not linit fOA's authority to regulate those that do fall under the statutory definition of "drugs." It was also Congress' intent that product definitions not be mutually exclusive. As the Senate Report to S.5 further noted in 1935 . 


\begin{abstract}
"The use to which the product is to be put will determine the category into which it will fall. If it is used only as a food it will come under the definition of food or none other. If it contains nutrittve ingredtents but is sold for drug use only, as shown by labeling and advertising, it will come under the defintition of drug but not that of food. If it is sold to se used both as a food and for the prevention or treatment of disease tt would satisfy both definitions and be subject to the substantive requirements of both. The manufacturer of the article, through his representations in connection with its sale can determine the use to which the article is to be put." Senate Report 74-361, 74h Congress lst Session, 1935 p. 4. See also, U.S. v Article---Sudden Change, 409 F. $2 d 734,739$. (1969)
\end{abstract}

Both the Congress and the Courts have ilearly spoken and the tobacco industry cannot be heard to clalm that the manufacturing, advertising promotion and sale of low tar and low nicotine cigarettes is purely for snoking pleasure.

Low tar and low nicotine cigarettes elearly fit within the paraneters of what both the Congress and the courts intended when they deftned drugs. Tobacco companies anufacture, advertise, promote, and sell low tar and, nicotine cigarettes with the obvious intention of playing on the public's perception that use of these products will mitigate and prevent the onset of disease associated with smoking.

What the Federal O1strict Court sald in Fairfax some thirty years ago, in applying the provistons the Food, Orug, and Cosmetic Act, remains fully applicable today and should be applled with the full force of the law against low tar and low nicotine cigarettes. The Court in Fatrfax observed: 
"If claimants labeling was such that tt created in the nind of the public the ided that these cigaretres could be used for the mitigation or prevention of the vartous named diseases, claimant cannot now be heard to say that it is selling onty clgarettes and not drugs... The uttimate impression upon the mind of the reader artses from the sum total of not only what is said, but also all that is reasonably implied. If clainant wishes to reap the reward of such clatms tet it bear the responsibllity as Congress has seen fit to impose on it." (Emphasis added) IIJ F. Supp at 338339.

\section{Cocparative advertising and promotion activities witch}

distinguish varying levels of nicotine and tar deonstrate

the intent of the cigarette annufacturers to earket these

products as products intended to affect the structure or

functions of the body thus reeting the definitional

reguireents of 'drugs.'

In addition to meeting the definttional requtrements of Section 201 ( $g$ )

(1) (B), low tar and low nicotine cigarettes aiso clearly meet the definttional and legal requirements of Section 201 (g)(1) (C). "articles Intended to affect the structure or any function of the body of man or other animals."

There can be no question that for reasons noted elsewhere in this petition, today's low tar and nicotine cigarettes are not the same product that appeared on the market in the $20^{\prime} \mathrm{s}, 30^{\prime} \mathrm{s}$, and 40 's. 
Fliters of varying types have been introduced to reduce tar and nicotine delfvery, chentcal additives and flavorings of all kinds have been introduced into the product to restore flavor lost by tar reduction. Varlations in tar and nicotine levels, primarily for health reasons, have become important, If not critical consumer determinants on whether to quit smoking. (See "The Changing Cigarette," Report of the Surgeon General 1981.)

Today's low tar and nicotine cigarettes and the advertising and promotional materials that go into their marketing requires that the FOA classify these products as drugs under Section 201 (a)(1)(C) of the FOCA.

In U.S. v. 354 Bulk Cartons..........Trim Reducing Ald and Cigarettes, 178 F. Supp $847,($ O.N.J. 1959), the Government filled a libel action for the seizure and condemnation of articles alleged to be drugs which consisted of 354 bulk cartons (more or less) of cigarettes labeled "Trin Reducing-Afd Cigarettes." In ruling that the products were drugs ader the FoCA, the Federal District Court held that they were intended to affect the structure or functions of the body by reducing the epetite for the ingestion of food. Orawing from an earlier decision imoiving cigarettes (U.S. v. 46 Cartons, More or Less, Containing Falrfax (igarettes, supra) the Court stated:

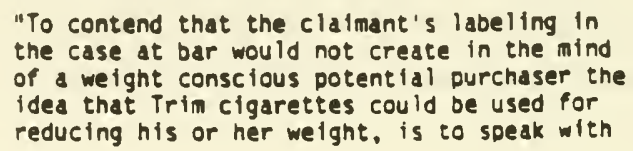


tongue in cheek, if not to display a most

extraordinary naivete." 178 F. Supp at 851.

Applying this same argument, to contend that advertising and promotion of low tar and nicotine cigarettes would not create in the mind of a health consctous purchaser the fdea that use of these clgarettes are less hazardous in that they contain low levels of substances known to affect the structure or functions of the body is again to speak with tongue in cheek, if not to display an exirsordinary naivete.

In determining whether low tar and nicotine cigarettes should be classifled as drugs under Section 201 (a) (1) (C), two wore recent actions by the FOA are also worth reviewing. One deals with FDA's dental of petition by Action on Smoking and Health which sought to classtfy all cigarette products as drugs because they contained nicotine. The other concerns the marketing of FAVOR smokeless cigarettes, "a cigarette like device consisting of a plug impregnated with a nicotine solution inserted with a simall tube - corresponding in appearance to a conventional cigarette."

In 1977. Action on Seoking and Health (ASH) and others, filed a petition with the Food and Orug Administration seeking to classify all cigarettes as drugs under Section 201 ( $g$ ) (C). as articles "Intended to affect the structure or any function of the body of man or other animals." The preatse on which the pettion was flled was that because all clgarettes contain nicotine "they fali eastly and squarely within the broad language of the act" (Petition of A.S.H. at D.13). In denying the 
petition (upheld in ASH V.Harris 655 F.2d 236 O.C. Cir. 1980) then Commissioner Donald Kennedy stated that petitfoners had falled to establish an fritent on the part of the manufacturer to sell a product which "affected the structure or function of the body." Speciffcally, the Comisussioner wrote:

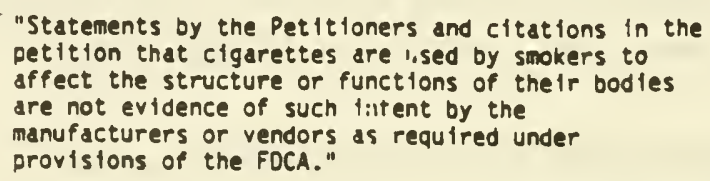

In denying the petition, FOA did not say that elgareties could not be classified as drugs under Sec. 201, the FOA merely sald that in the case of cigarettes in general. petitioners falled to provide sufficlent evidence to establish that manufacturers sell cigarettes with an intention of affecting the structure or functions of the body.

This is not the case for low tar and nicotine cigarettes. Evidence presented in the statement of Factual Grounds demonstrates that priearlly because of the well established scientific evidence that clgarettes cause cancer, emphysema, heart disease, etc., consumers have sought ways of efther quitting or reducing their risks by smoking what is belleved to be safer eigarettes. In order to meet this consumer concern for health, tobacco compantes have shifted their marketing strategles by manufacturing increasing numbers of low tar and nicotine cigarettes, which they have aggresstvely promoted in a manner, which suggests to the public that the lower tar and nicotine cigarettes 
mitigate the risks of the diseases about which consumers are concerned. In U.S. V. Article... Sudden Change (supra) 409 F. 20 at 742, the Court stated that "...the question of whether a product is "Intended to affect the structure of the body of man...." is to be answered by considering, first, how the claim might be understood by the "fgnorant, unthinking or credulous" consumer and second whether the claim as so understood may fairly be said to constitute a representation that the product will affect the structure of the body in some medical or drug-like fashion, 1.e., In some way other than merely "ditering the appearance." The public has been and is consistentiy bombarded with such massages as:

\footnotetext{
"A lot of cigarettes have fllters. Only True has this tar and nicotine reduction system so unique it's patented by the U.S. Government. True is lawest in both tar and icotine of the 20 best-selling brands. Lower, in fact, than $99 \%$ of all other clgarettes sold. Think about it. Doesn't it all add up to True?" (TRUE, 4/19/71 Sports Illustrated)
}

"Instead of tellng us not to smoke maybe they should tell us what to smoke.... Since the cigarette critics are concerned about high 'tar' and nicotine, we would like to offer a constructive proposa1.... For instance, perhaps they ought to recomend that the American pubilte smoke Vantage clgarettes." (VANTAGE, 1/8/73 TIME)

"Gas in cigaratte saoke may be a bigger problen than tar and nicotine.... Only Lark has a Gas-Trap filter. Lark's unique Gas-Trap fllter reduces-certain harsh gases by nearly twice as much as any other popular brand." (LARK. $7 / 12 / 68$ TIME)

"A closer look reveals tho's lowest. Now is still lowest oy U.S. Goverment testing methods." (NOW, April 1988 MASHIMTONIAM)

"Carlton It's Lowest. And it's got the taste that's right for me. U.S. Government test method confirms 17 
years of U.S. Government reports: Carlton is still lowest!" (CARLTON, 4/4/88 People Magazine)

The only logical reason for these advertisements to even discuss the low tar and nicotine issue is to encourage health consclous consumers to use these products. As the National Research Counctl of the Natlena' Acaderiy of Sclence concluded in tts 1982 Report, Reduced Tar and Iflcotine Clgarettes: Smoking Behaviur and Health: the focus of tie report was un the less hazardous c'garette:

a "first, because there are adequate sctentific reports to evaluate this method as a health strategy for snokers:

○ second, because it has unquestionably been the major direction of consumer interest, commerctal develogenent and governatental activity in this country... and findly.

0

because experinents with different types of cigarettes have provided the opportunity to assess the role of nicotine in the motivation to continue smoking." (p.2)

These types of promotions cited above and the conclusion of the WAS and other studies clearly demonstrate that the low tar and nicotine cigarettes are intended to affect the function and structure of the body. It is not necessary that the intended purposes be explicitiy stated. Both the FDCA and case law have established that "the intended use of the product is not limited to the label on the container but may extend to oral and written representations as well." As the U.S. Court of Appeals for the Seventh Circuit sald. "The ultimate Impression upon 
the mind of the reader arises from the sum total of not only what is sald but also of all that is reasonably implled. Aronberg V. FTC, 132 F. 2d 165, 167. (7th C1r. 1942)" See also U.S. V. Arttcle... Sudden Change (supra) in which the Court stated," it is well settled that the intended use of a product may be determined from its label, accompanying labeling, promotional material, advertising and any other relevant source." 409 F. $2 d$ at 739

So long as advertising and promotion of cigarettes (whether the level of tar and nicottie is low, medium or high) is geared towards "sanking pleasure" only, cigarettes remain outside the authority of the FDA. But when advertising and promotional activities for certain clgarette products go beyond the promotion of clgarette smoking for purely smoking pleasure and represent, Imply or reasonably give the impression that the low tar cigarette being advertised mitigates the normal health risks of smoking while still delivering the same physiological reactions, then the FOA is obliged to step in and take jurisdiction.

Thus petftioner's contentions that low tar and nfcotine cigarettes are articles intanded to affect the structure or function of the body are consistent with the FOA's determinations in Action on Smoking and Hedith. (upheid in ASH V. Harris, 655 Fed 20236 O.C. Circuit 1980)

Another example is provided by FDA's recent response to the introduction of FAVOR cigarettes. On February 9th, 1987, the FOA notifled Advanced Tobacco Products, Inc., that FAVOR could not be introduced into interstate 
comerce since FAVOR was new drug within the meaning of the FOCA and nad not been approved for use by the FOA.

In reaching its conclusion, the FOA reviewed numerous labeling and promotional materials, as well as registration material filed with the Securities and Exchange Comission (SEC). The materials, sald the FOA, regresent and sugciest. that FAVOR is a novel nicotine delivery systen; that each pouch of six will have a nicotine capacity intended to satisfy the average number of conventional cigare:ces for an entire day, that the quantity of nicot'ne required to produce the effect on the nervous system which nost smokers are accustomed to in relation to the anounts of other alkalotds regularly consumed by typical users, and that FAvOR is an alternative for conventinal cigarette smokers who desire nicotine pleasure.

in its regulatory letter, FOA points out that the medical literature clearly recognizes that nicotine is well absorbed from the lungs and that "it has potent phanmacologic effects. including effects on the nervous system and that nicotine is a drug of dependence." Upon that basis, the FOA then reaches the following significant conclusion:

\author{
It is our position that FAVOR is a \\ nicotine delivering systean intended to \\ satisfy a nicotine dependence and to \\ affect the structure of one or more \\ functions of the body. (Food and Jrug \\ Adaninistration Regulatory Letter to \\ Advanced Tobacco Products, inc., \\ February 9, 1987.)
}


Nothing in the FOA's opinton letter indicated that the presence or lack of tobacco in this product glayed a signifteant role in the FOA's conclusion. In fact, in the FOA's letter ordering that Advanced Tobacco Products, Inc., cease the marketing of FAVOR, there is absolutely no discussion of whether FAVOR was a tobacco product.

The legal and factual criteria applied by the FOA, in the case of FAVOR elgarettes, are both pertinent and relevant to the marketing of low tar and nicotine cigarettes.

The very role that nicotine was viewed as playing in FAVOR cigarettes, is the very role that $1 t$ plays in the promotion of low tar and low nicotine cigarettes. Just as FAVOR was determined to be an alternative for cigarette smokers who desire to fulfill their body's acquired need for nicotine without the risks assoclated with smoking, so too are all low nicotine cigarettes which are intentionally advertised and pronoted as products which reduce levels of tar and nicotine levels, important determinants to the health conscious smoker who wants to quit but can't.

As the factual section of this Petftion demonstrates, discussions by cigarette anufacturers in advertising and promotional materials and Information provided to government agencies and the public which references tar and nfcotine leveis of products, clearly demonstrates that those products are intended, as was FAVOR, to adjust and regulate the delivery of nicotine (and tar) to the body, thereby, affecting the "structure of the body." 
8. LOU TA ND LON MICOTINE CIGARTTES ARE MISBRNOED UNOER SECTION

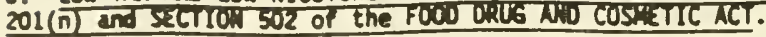

The Food, Orug, and Cosmetic Act, Section 301 (b) makes tt unlawful to adulterate or misbrand any food, drug, device, or cosmetic in interstate commerce. In determining if the product is misbranded the Food, Orug, and Cosmetic Act sets out specific statutory crileria. Section $201(n)$ of the Act states that in determining whether labeling or advertising is misleading:

\begin{abstract}
"there shall be taken into account anong other things, not only representations made or suggested by statenent, word, design. device or any combination thereof but also the extent to which the labeling or advertising falls to reveal facts matertal in the light of such representations or material wtth respect to the consequences which may result from the use of the article to which the labeling or advertising relates under the conditions of use prescribed in labeling or advertising thereof or under such conditions of use as are customary or usual."
\end{abstract}

Section $502(a),(f)$ and $(n)$ of the Act further state that a orug is misbranded:

"(a) If its labeling is false or misleading in any particular."

"(f) Unless its labeling bears ( 1 ) adequate directions for use: and (2) such adequate warnings against use in those pathological conditions or by chlldren where its use may be dangerous to health, or agatnst unsafe dosage or methods or duration of administration or application, In such manner and form, as are necessary for the protection of users: Provtded. That where any requitrement of clause ( 1 ) of this subsection, as applied to any drug or device, is not necessartly for the protection of the pubilic health, the Secretary shall promlgate regulations exempting such drug or device from such requirement." 
"(n) the case of any prescription drug distributed or offered for sale in any state, unless the manufacturer, packer, or distributor thereof includes in all advertisements and other descriptive printed matter issued or caused to be issued by the manufacturer, packer or ofstributor with respect to that drug a true statement of (1) the established name as defined in section 502(e). printed prominently and in type at least half as large as defined in Section 502(e) printed prominently and in type at least half as large as that used for any trade or brand nane, thereof (2) the formula showing guantitatively each ingredient of such drug to the extent required for labels under section $502(e)$. and (3) such information in brief sumary relative to the side effects, contra indleations, and effectlveness as shall be requited in regulations which shall be issued by the Secretary in accordance with the orocedure specifled in jection $701(e)$ of this Act..."

Pursuant to these sections FDA has also promulgated extensive regulations

governing the advertising of prescription drugs 21 CFR Part 202,

"Prescription Drug Advertising."

In addition to numerous other advertising restrictions and requirenients, subsection (d) 6 states that an advertisement for a prescription drug "Is false, lacking in falr balance, or other wise misleading or other wise in violation of section $502(n)$ of the act, if $1 t$ :

1) Contains a representation or suggestion not approved or peraitted for use in the labeling, that a drug is better, more effective, useful in a broader range of conditions or patients (as used in the section "Dattents" means humans), has fewer, or less incidence of, or less serious side effects or contraindications than has been demonstrated by substantial evidence or substantial clinical experfence whether or not such comparisons are made or not such comparisons are made with directly or through use of published or unpublished ilterature. quotations, or other references,

11) Contains a drug comparison that represents or suggests that a drug is safer or nore effective than another drug in some particular when th has not been demonstrated to be safer or more effective in such particular by substantial evidence or substantial clinical experience." 
Similarly, the courts have consistently applied a brodd interpretative standard in determining if labeling and advertisements are false and/or misleading. In Fairfax, supra, 113 F. Supp. 336, in discussing now consumers might be misled, the court employed such words as "insinuations" or "indirectness" "suggestive" or "dublous representation" from which the "untutored mind would infer extraordinary anelforative results."

In U.S. v Articles of Orug Etc.., 263 F Supp. 212 (1967), the court stated that "misleading" as used within the Act should be determined by the effect "the materiai [label and labeling] will have on the prospective purchasers to whom the claims are addressed. It would defeat the obvilous intentions of the ACt to hold such persons to spectal knowledge or doflity. Nor should the court assume that the buying public will exercise great selectivity and caution in what they choose to belfeve of what they hear or read ... The reaction of the average person is thus made the test. But allowance has also to be ade for the susceptibility to the publicity of the groups or types of people at whon it is peculiarly aimed." U.S. v Articles of Orugs Etc.. 263 F Supp. 212, 215, (1967). And in U.S. v Article... Sudden Change, 409 F $2 d 734,740$, (2d Cir. 1969) the Court concluded that "the purposes of the Act will best be effected by postulating a consuming public which includes the ignorant, the unthinking, and the credulous."

As has been clearly documented in the Statement of Factual Grounds the tobacco industry has, in a clear and calculated manner for the past twenty plus years, been reaping economic benefits as a result of increased sales 
of low tar and low nicotine clgarettes by putting into the mind of the public the Idee that low tar and nicotine clgarettes represent a safer alternative to high tar and nicotine cigarettes through "I nsinuations," "suggestive" or "1ndirect" statements from which the untutored mind would infer benefits that do not exist. The Industry has played upon the "susceptibility" of the smoking public, in particular, many (approximately 908) of whom have expressed an interest in quitting but sind it very difficult due to the addictive nature si the priciuct ani industry advertising and promotional ectivitlej. 0.0.jition oi is:. tar and nicotine

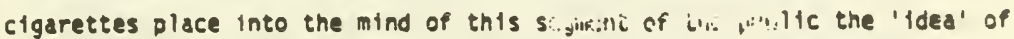
a lowering of risks or as an intermedlate step to quitting thus creating, "a demand for a product hitherto not found necessary to the happlness or will being of the general public". U.S. v. 46 Cartons, More or Less, Containing Falrfax Clgarettes, supra $113 \mathrm{~F}$. Supp. at 337.

In addition to these practices the tobacco industry has also violated other misbranding and misleading by sections of the act in falling to reveal other aspects of the product that may present risks or unknowns to the unsuspecting consuser.

1. Law Tar and Lar Micotine Cigarette Labeling, Advertising and Promotion falls to disclose that these products contain chealcal additives and other constituents inich are harmful and ay Increase risks to health. 
The tobacco industry presently is under no statutory obligation to disclose to the public any of the components of its cigarette products. As a drug it would be incumbent upon the industry to provide the food and Orug Administration and the public with detalls of the pharmacological properties of the low tar and low nicotine products as well as the ingredients.

While it is believed that reduction of :ar and nicotine will reduce some risks to health there are other properties of the product that present serfous health risks and in fact may, due to the industry's manipulation and alteration of the eigarette product, present increased risks.

The tobacco industry is suspected of using well over a thousand chemical additives as flavorings and fillers. While a list of many of these additives is now provided to the Departinent of HMS. the list is kept confident1al. (See, 15 U.S.C. Sec. 1335.) No federal agency has any statutory authority to require public disclosure or removal of additives found to be harmful. As the Surgeon General's Report, "The Changing Cigarette" noted in 1981:

\footnotetext{
"In order to enhance consumer acceptabllity flavoring substances are added to cigarettes: It may be that the lower the "tar" yfeld, the nore flavoring additives are used. It is impossible to make an assessment of the risks of these additives, as cigarette manufactures are not required to reveal what additives they use. No agency of the Federal Government currently exercises oversight or regulatory authority in the manufacture of efgarette products. Furthermore, no agency is empowered to require public or confidential disclosure of the additives actually in use by the cigarette manufacturers." (page 6)
} 
In the 1984 Report, "Chronic Obstructive Lung Disease," the Surgeon

General relterated the serfous concern about additives stating:

\begin{abstract}
"When initially introduced. lower yleld elgarettes lacked palatability and acceptablitity. Advertisements for the current low tar and nicotine cigarettes emphasize their flavor, presumably achieved by the use of additives in the processing of the tobacco. Additives employed may include artificial tobacco substitutes (Freedman and Fletcher 1976), flavor extracts of tobacco and other plants, exogenous enzymes, powderce t...isis (Gort 1977), and other synthette flavoring substinces. Pariibls more additives are being used in the new lewer tar and nirotitie cigarettes than in the older brantis, and new ageitrs may aiso be in use. Some of the substances, such as porderen cocoa. haie been shown to further increase the carcinogentclity of tar $! r .9 .1$ 1977), and otners may result in increased or new and different hesith risks. The pyrolytic products of these additive agents may product novel toxic constituents. A characterization of the chenical composition and adverse blologic potential of these additives is urgently required, but is currently impossible because cigarette compantes are not required to reves l what additives they eaploy in the manufacture of tobacco (USDHAS 1981). No government agency is empowered with supervisory authority in the manufacture of tobacco products. With this lack of bastc information and the usually prolonged latent Dertad before manifestation of the adverse effects of smokting. it is likely that a long time perlod will elapse before we know the hazards of the new eigarettes in current iss." (p. 352-353)
\end{abstract}

In addition to the chenical additives, tobacco smoke contains an estimated 4,000 constituents. One of the most well known is carbon monoxide, a potsonous gas. As the 1983 Surgeon General's report "Cardiovascular Oisease" concluded, "Research fundings suggest that carbon monoxide may act to precipitate cardiac symptonatology or ischentc episodes in Individuals already compromised by coronary disease." (D. 232) 
The 1983 Surgeon General's Report also concluded that: "One should not ignore the proportien of the population that continues to smcke, nor should one accept unchellenged the concept of a "safe" cigarette. The main objective is to reduce the hamful constituents present in tobacce smoke. It is probable that promotion of ultra-low-yleld products will not suffice, since compensatory mechanisas may be triggered by sensory needs for taste as well as for nicotine.

A cigarette considered less harmful for cancer etiology iligrit not resuce the risk for coronary disease. It appears to a formideble iask to develop product that sattsfles the smoker and does not increase disease risk through exposure to carbon nionoxide, cyanide, nitrous oxide, or still unknown agents." (D. 231-232)

Many of the constituents contained in tobacco smoke are known carcinogens or cocarcinogens. The following charts from the 1982 surgeon General's Report. "Cancer" Indicate how Imperative it is that the FOA regulate the low tar and nicotine products.

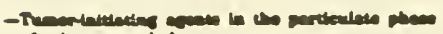
4 nimesos

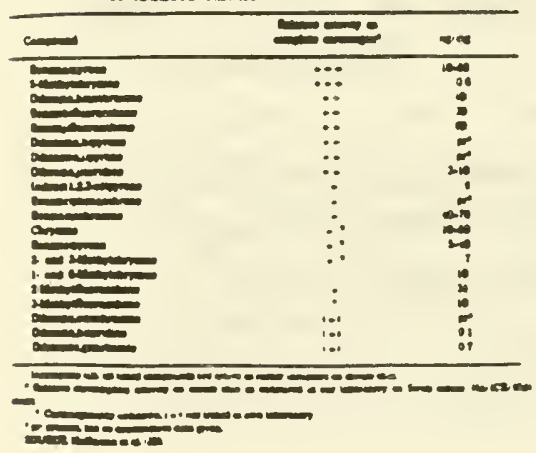

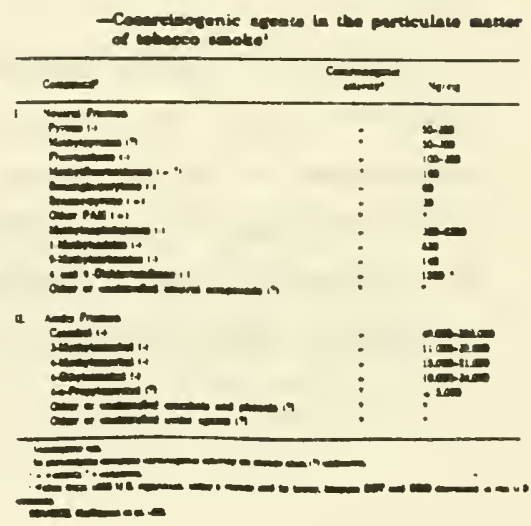


The 1982 Report of the Surgeon General diso noted the pressing concerns about the changing cigarette product and particularly the role of chemical additives in the production of harmful constituents.

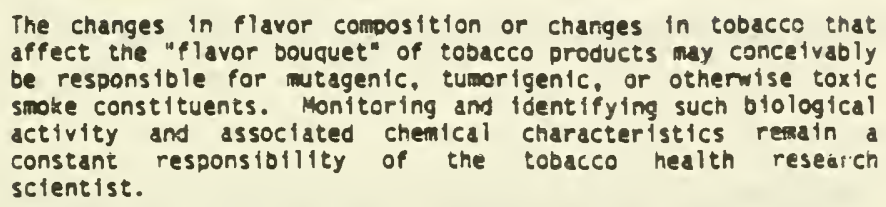

Evidence released at the Cipollone $r$. Liggett Group, Inc.. trial in New Jersey indicates that as early as 1959 Philip Morris had reason to be concerned about additives, and other constituents. A presentation made to the President's office of Phillp Morris noted that if the food and drug laws were ever applied to clgarettes "certain constituents, like arsentc and other insecticides and certain minor smoke constituents aight have to be controlled." A 1963 meno from Phtlip Morris' research director to a sentor executive indicated "We belleve that the next medical attack on cigarettes will be based on the cocarcinogen idea. With the hisoreds of campounds in snoke, this hypothests will be hard to contest.": (b) that irritation problems from efgarette smoke "are now recetving greater attention because of the general medical bellef that irritation leads to chrontc bronchitis and emphysema. These are serfous diseases involving millitons of people. Emphysema is often fatal efther directly or enrough other respiratory complications. A number of experts have predicted that the 
cigarette industry ultimately may be in greater trouble in this area than in the lung cancer fleld."; and (c), that "The Cardtovascular Effects in smoke are belfeved to be mainly due to nicotine and have been thoroughly explored in literature and conference." (Press Release - Tobacco Products Llabilitty Project, March 26, 1988, p. 3)

2. Los Tar and Los Micotine Cigarette Labeling, Avertising and Prowotion Fails to disclose contreindicatiens, effectiveness, side effects, etc.

As noted earlier, section $502(n)$ of the FDCA specifically requires that drug manufacturers disclose contraindications, side effects and the effectiveness of their product. Although a federally mandated warning label appears on the package and advertisements of clgarette products, the message contained is far from complete. If low tar/low nicotine cigarettes were treated as drugs it would be incumbent upon the FOA to require that proper labeling and disclosure be provided on all low tar and nicotine cigarettes to ensure that consumers are not mislead about the effects and or benafits of these products.

Consumers have a right to know the pharmacological effects of these products just as they do with respect to other drug products. The labeling for "Nicorette" gum for example, a prescription drug used as a tobacco substitute, contains a lengthy description of the product, its direction for use, contralndications, and side effects. The labeling requirements for oral contraceptives warns the consumer that use of 
cigarettes and oral contraceptives can increase risks to health. No such labeling appears on low tar and nicotine cigarettes.

The consumer has a right to know whether or not a product is effective for its intended purpose. Does it really reduce risks to health? If so under what conditions? There is evidence to suggest for example that some smokers who switch to the low tar and nicotine brands inhele wiore deciply, take more puffs and smoke more clgaret:es to compensate for the low:.i tar and nicotine levels. There are also indications that the filtering systems are altered when efgarettes are smoked by a person as opposed to a testing machine, also resulting in higher yfelds.

As the 1984 Surgeon General's Report on "Chronic Obstructive lung O1sease" suceinctly put it;

\begin{abstract}
"Low tar and nicotine cigarettes have gained considerable popularity among the smoking public, partly on the premise that a reduction in the nominal tar and nicotine yield results in a proportional reduction in the health hazards of cigarette smoking. The validity of this approach to cigarette smoking is contingent on the accuracy of smoking-machines in reflecting the actual anner of puffing and also on the smoker not altering swoking behavior to compensate for vartations in nominal tar and nicotin content. Should smokers develop compensatory alterations in their snoking behavior, this would not only reduce the relevance of the smoking-machine assays but might also alter the proportionate delivery of the different toxic substances in cigarette smoke and expose. the smoker to concentrations beyond those predicted by the smoking-machine." (p. 341)
\end{abstract}

See also Surgeon General's Reports of 1981, 1982, 1983 which reached similar conclusions. 
3. Low Ter and Low Micotine Cigarette Labeling falls to provide directions for use and adequate labeling, including warnings that clgareties are addictive.

As noted earller, a drug is deemed to be misbranded under Section $502(f)$ of the Food, Drug, and Cosmetic Act:

"( $f$ ) Unless its labeling bears (1) adequate directions for use: and (2) such adequate warnings against use in those pathological conditions or by chlldren where its use may be dangerous to health, or against unsafe dosage or methods or duration of adinistration or apolication, in such manner and form, as are necessary for the protection of users."

Current advertising and labeling practices for low tar and nicotine clgarettes do not provide any of the information (except the federally mandated warning labeling) required by this section. This is particularly of concern with respect to children, a segment of the population specifically addressed by the FOCA. NIOA estimates for example that $90 \%$ of the new uners in the Untted States are 19 years of age or under. Once saoking patterns are begun, it is very difficult for smokers to quit. It would be incumbent upon the FOA then to at the very least to requite warnings about the use of these products by chlldren, as well as adult consumers, that the product is addictive. 
C. CIGARETTE MANUFACTURERS HAVE FAILED TO MEET THE REQUIREMENTS OF SECTION 505 OF THE FOOD, ORUG, ANO COSMETIC ACT (21 U.S.C. SEC. 321(p)). "NEW ORUGS."

Section $201(p)$ of the Food, Drug, and Cosmetic Act (21 U.S.C. Sec. 321(D)) defines "new drug" as:

"(1) Any drug (exceot a new animal drug or an animal ric. bearing or containing a new animal drug) the composittor. uf which is such that such drug is not generally recognized, arivis: experts qualified by scientific training and expertence tc evaluate the safety and effectiveness of drugs, as safe bin effective for use under the conditions prescribed, reconmended, or suggested in the labeling thereof, except that such a drug not so recognized shall not be deened to be a "new drug" if an any time prior to the enactment of this Act it wes subject to the Food and Drugs Act of June 30, 1906, as anended, and if at such time 1ts labeling contained the same representations concerning the condtions of Its use: or

(2) Any drug (except a new animal drug or an animal feed bearing or containing a new animal drug) the composition of which is such that such drug, as a result of investigations to determine its safety and effectiveness for use under. such conditions, has becone so recognized, but which has not, otherwise than in such investigations, been used to a material extent or for a material time under such conditions."

Petitioners contend that manufacturers of low tar and nicotine clgarettes have falled to weet the statutory requirements governing the introduction or delivery of new drugs into Comierce under Section 505 of the food, Orug, and Cormetic ACt (21 U.S.C. Sec. 355). Section 505 requires among other things that prior to the introduction or delfvery of a new drug into interstate coanerce an applifation of approval be flled with the Secretary of the Department of HHS. Such application shall by statute include such information as: 
"(A) full reports of investigation which have been made to show whether or not such drug is safe for use and whether such drug is effective in use: (B) a full list of the articies used as components of such orug: (c) a full statement of the composition of such drug: (D) a full description of the methods used $1 \mathrm{n}$, and the factlities and controls used for, the manufacture, processing, and packing of such drug: (E) such samples of such drug and of the articles used components thereof as the Secretary may requtre; and (F) spectimens of the labeling proposal to be used for such drug..." 


\section{comcuustan}

Each year over 300,000 people continue to die as a result of cigarette smoking - an addictive habit which the Surgeon of the United States has called the single most preventable cause of death and disability in the United States.

One could rationally argue that if this product never existed and it was developed today. such a product would be prohiblted from being marketed on the sole basis of health and safety. Instead however, wave a product which reasins virtualy unregulated, a product which enjoys spectal statutory exemptions from the very laws designed to protect the public from unsafe consumer products, a product which is advertised and promoted at a cost of over $\$ 2$ billion a year.

The Food and Drug Administration has acknowledged and the Courts have concurred that tobacco products can in fact be regulated by the FOA if a determination is made that cigarettes meet the definitional requirements of "drugs" under the FoCA. The Act, (among other definitions) defines such products as:

\footnotetext{
"articles intended for the use in the dlagnosis, cure, nitigation, treatment or prevention of disease..." and "articles (other than food) intended to affect the structure or functions of the body...."
} 
The FDA cannot regulate cigarette products if those products are advertised and promoted for "smoking pleasure only," but where the industry implies and suggests that certain products (1.e.: low tar and nicotine cfgarettes) are safer and can reduce or mittgate risks to health, and that varying levels of tar and nicotine may "affect the structure or functions of the body," then the FOA has both the authortity and the obligation to step in.

In 1964, as a result of accumulated scientific and medical evidence. the Surgeon General of the United States, Or. Luther Terry released a landmark report fmplicating cigarettes as a major cause of cancer. The report was the result of an accumulation of scientific evidence of the fiftles and early sixtfes and sent shock waves not only through the public, but through the tobacco industry as well. This report, and many reports since then, sent a clear message to the public: clgarette snoking causes disease, those who smoke should quit, those who don't smoke shouldn't start.

In concluding that cigarettes caused disease, the scientific commonty, including the PHS determined that reduction of two components of the cigarette - tar and nicotine - might reduce some of the harmful effect. Faced with the prospects of losing its smoking clientel and profits, the tobacco industry, even before the release of the report, was quick to capltalize on these findings of the public Health Service. New marketing strategies energed from the industry designed to suggest that flitering mechantsms would miraculously 
reduce the risks of smoking by removing the tar and nicotine, and yet at the same time retain the flavor of the conventional styled cigarette.

Advertisements such as the Vantage ad below began appearing in the narket.

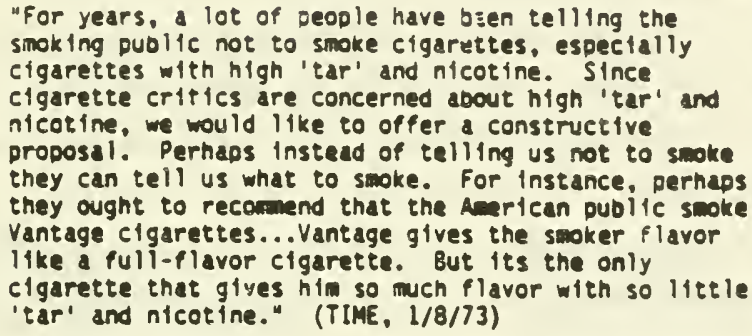

The common theme, whether stated overtly or whether lmplied was clear and remains clear today. If you are going to snoke or even if you are thinking of smoking and have concerns bout health risks, you can lower your risks both to your health and to beconing addicted by smoking low tar and nicotine cigarettes.

It was clearly the intention of the U.S. Congress that the definition of "drugs" under the food, Orug, and Cosmetic Act was designed to be expansive and flexible to guard and protect consumers against"a witiplicity of devices and such preparations as 'slenderizers,' many of which are worthless at best and some which are distinctly dangerous 
to health. Low tar and nicotine cigarette products clearly fall within these categories. It is because these products are distinctiy dangerous to health that FOA has even a higher responsibility to take dction. We are not dealing with product which has no adverse health effects and is being advertisfed as a beneflelal product. This is a product that is responsible for one out of every six deaths in the United states, is highly addictive, is rizadily avallable, and which is aggressively advertised and promoted. It is ironic enough that this product which kllis and debllitates, is also the least regulated product in the Untted States. Petitioners do not contest that when advertisements for the products are afeed at smoking pleasure only. the FOA has no jurisdiction. This has been clearly spelled out by the courts and the legislative history. But equally clear is that the FOA does have the authorlty to regulate cigarette products when those advertisements and promotions "suggest, imply or insinuate" that a health benefit, or a risk reduction can be obtained by smoking a particular brand.

Petitioners are not denying the legal rights of tobacco compantes to sell their products but we belleve those rights are contingent upon the public's right to be protected to the maxtmug extent posstble from products deened to be harmful. Enforcenent of the Food Orug and Cosinetic Act against the advertisting and pronotion of low tar and nlcotine cigarettes, therefore is essent1al. As we noted earlfer, what was said by Oistrict Judge Meaney in a case in which FDA was found to have Jurisdiction over clgarettes, realins the standard today: 
-If the claiants labeling was such that it created in the uind of the public the idee that these slgarettes could be used for the mitigation or prevention of the varfous nand diseases. clatmant cannot now be heard to clain thet it is only selling cigarettes and not drugs... The ultimate impression upon the aind of the reader arises from the sun totel of not only what is sald, but 1 isc 11 that is reasonably implied. If clalaant wishes to reap the rewerd of such clalas let it bedir the responsitility as Congress has seen fit to impose on 1t.

Respectiully Subaitted.

Scott 0. EaTth

Vica President for Public Affairs Ansican Heart Association 1250 Connect laut Ave., in Sulte 360

Washington, DC 20036 (202) $822-9300$

\author{
Fras or hite \\ Directos of Coverment Relations \\ Amrican Lung Association \\ 1029 Vernont Are.. int \\ Sulte 710 \\ Masnington, oc 20005 \\ (202) $393-1260$
}

\author{
ATan urs

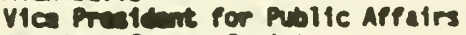

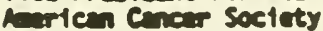 \\ 224 East centtol strut. SE \\ Hashington, of 20003 \\ (202) 516-9011
}

\author{
Watther nyers \\ Staff Diructor \\ coslition on Swoking on thalth \\ ia07 Nee Hepshire Ave., in \\ ith f floor \\ Washington, DC 20009 \\ (202) 234-9375
}




\section{Statement of Charles $\mathrm{O}$. Whitley}

on behalf of

\section{The Tobacco Institute}

\section{before the}

\section{Subcommittee on Health and the Environment House Energy and Commerce Committee}

\section{March 25, 1994}

Mr. Chairman and distinguished members of the Subcommittee, we appreciate this opportunity to address issues raised by FDA Commissioner David Kessler in his February 25, 1994, letter to the Coalition on Smoking OR Health, and by Rep. Synar's bill, H.R. 2147, the "Fairness in Tobacco and Nicotine Regulation Act of 1993." I am accompanied by Dr. Alexander W. Spears III, Vice Chairman and Chief Operating Officer of the Lorillard Tobacco Company, Sherwin Gardner, Deputy Commissioner of FDA from 1970 to 1979 , and Dr. Steven M. Raffle, a practicing psychiatrist with extensive experience in addiction treatment.

Dr. Spears, speaking on behalf of Lorillard, will describe the cigarette manufacturing process and, in particular, the use of reconstituted tobacco, tobacco extracts and denatured alcohol. Mr. Gardner will address the inappropriateness of regulating tobacco products under the Federal Food, Drug, and Cosmetic Act, while Dr. Raffle will address the inappropriateness of viewing smoking as an "addiction" and equating cigarettes with hard drugs. I wish to submit for the record statements provided by five of the six leading U.S. cigarette manufacturers -- Dr. Spears will speak for the sixth - concerning the nicotine in their cigarettes. 
In his February 25 letter, Commissioner Kessler suggested that the cigarette manufacturers "commonly add nicotine to cigarettes to deliver specific amounts of nicotine" and deliberately manipulate the ansount of nicotine in cigarettes in order to "produce and sustain addiction." Similar allegations have been aired in the media.

Mr. Chairman, I am here today to tell you -- unequivocally -- that these suggestions are false.

- The cigarette manufacturers do not "spike" their cigarettes with nicotine. In fact, nicotine is lost in the manufacturing process. There is not a single cigarette on the market in this country today that does not contain less nicotine than is found in the raw tobacco used in its manufacture.

- Generally, nicotine levels are a function of "tar" levels. When "tar" levels are set, nicotine levels follow. As manufacturers have reduced "tar" levels and yields over the years to satisfy changing consumer tastes, nicotine levels and yields have fallen correspondingly.

- The nicotine in the average cigarette today is lower than it has ever been. Between 1954 and 1993, the average nicotine level in cigarettes fell from 2.6 milligrams to 0.89 milligrams -- a two-thirds decline. The suggestion that nicotine is being "added" to cigarettes or "manipulated" to keep smokers "hooked" is absurd.

- It is irresponsible to equate cigarettes with hard drugs. The suggestion that nicotine is "as addictive as heroin, cocaine and other hard drugs" trivializes the serious narcotic and other hard drug problems faced by our society and undermines efforts to combat drug abuse. As the Indianapolis Star stated in a 1988 editorial, the analogy to hard drugs is "misguided zealotry" that "downgrades, even discredits, the nation's campaign against hard drugs."

Mr. Chairman, the irony of this latest controversy over nicotine is truly striking. The cigarette manufacturers, after reducing the average nicotine levels of their cigarettes by two-thirds over the last 40 years, now stand accused .- wrongly, as I already have stated -- of adding nicotine to their cigarettes in order to keep smokers 
"hooked." More ironic still, Dr. Kessler's letter accusing cigarette manufacturers of this practice came in response to petitions filed by antismoking groups alleging that the manufacturers have been reducing "tar" and nicotine levels in cigarettes in order to mollify the health concerns of smokers! The manufacturers clearly are damned if they do and damned if they don't. Dr. Kessler's letter and the antismokers' petitions, however, are equally inconsistent with the facts.

Despite the attention that Dr. Kessler and others are now calling to the issue of nicotine in cigarettes, the fact is that the cigarette manufacturers have been publicly reporting "tar" and nicotine yields for their advertised brands for over 20 years. The reconstituted tobacco process has been in use for at least 30 years, denatured alcohol has been used for over 40 years and tobacco extracts also have a long and welldocumented history of use in the manufacture of tobacco products.

These processes are not new. They have not been hidden from the government. And they do not add measurable amounts of nicotine to the final product. During all this time, FDA has never suggested that cigarettes should be subject to ongoing regulation as a drug. Yet Dr. Kessler suggests that "the evidence now available" to FDA could support "a different approach." We disagree. Nothing has occurred during this time to warrant a change in FDA's long-standing policy toward tobacco.

The cigarette manufacturers addressed the issues raised in Dr. Kessler's letter in a recent exchange of correspondence with HHS's Office on Smoking and Health. HHS asked the manufacturers to provide information with respect to whether nicotine is reintroduced or augmented in tobacco during the manufacture of cigarettes and with 
respect to the use of reconstituted tobacco in the cigarette manufacturing process. The manufacturers confirmed that there is less nicotine in cigarettes than is contained in the unprocessed tobacco used in their manufacture.

Dr. Kessler recognizes that subjecting cigarettes to FDA regulation as "drugs" would require his agency to ban the product. He said as much in his February 25 letter and in his March 16 testimony before the FDA Appropriations Subcommittee. But Dr. Kessler made clear that he has no intention of moving in this direction unless directed to do so by Congress. In short, Dr. Kessler has raised a "problem" that is not a problem at all, and he has left it to Congress to consider an appropriate "solution."

Before turning to Dr. Spears, I would like to touch on a number, though by no means all, of the objectionable features of Rep. Synar's bill, H.R. 2147.

H.R. 2147 is an omnibus antitobacco bill that would subject tobacco products to ongoing FDA regulation. Although Rep. Synar has portrayed his bill as being designed to treat tobacco products like other products, H.R. 2147 would single out tobacco products, which already are highly regulated, for inapposite and uniquely punitive treatment. Indeed, despite Rep. Synar's insistence that he does not mean to ban tobacco products, H.R. 2147 in fact could produce an instant ban on all tobacco products currently on the market.

The regulatory scheme that H.R. 2147 would establish regarding additives is one that HHS Secretary Louis Sullivan in 1990 told Congress is "unnecessary." It also would interfere, directly and indirectly, with FDA's performance of its core functions. The tobacco companies themselves would be forced to pay the cost of their regulation 
under the bill. Such an arrangement, despite Rep. Synar's assurances to the contrary, would be unprecedented and should trouble other industries deeply.

The labeling and advertising provisions of H.R. 2147 are both unnecessary and highly objectionable. Rep. Synar would add a great deal of extraneous information to cigarette packages, thus discouraging smokers from reading any of the information currently appearing there. He also would restrict cigarette advertising in ways that, in many respects, are the functional equivalent of an explicit ban. The advertising provisions of H.R. 2147 are every bit as objectionable as the explicit advertising ban proposals that Rep. Synar has offered in the past.

\section{PUNITIVE INGREDIENT REGULATION}

Instant ban. H.R. 2147 would direct FDA to issue regulations requiring that all additives (i.e., ingredients) used in tobacco products be "safe." If the bill contemplates that FDA must find current tobacco additives to be "safe" before they can be used, the result would be an instant ban on all tobacco products currently on the market pending a review of all additives by the agency. H.R. 2147 would impose elaborate regulatory requirements with respect to tobacco additives even though, as noted, former HHS Secretary Sullivan told Congress just four years ago that no additional regulatory authority in this area is required. Indeed, Secretary Sullivan stated that he considered tobacco product ingredients to be a "peripheral" concern.

For more than a decade, the cigarette manufacturers have submitted ingredient information to HHS - first on a voluntary basis and later pursuant to the ingredient reporting provisions added in 1984 to the Federal Cigarette Labeling and Advertising 
Act, 15 U.S.C. 1335a. The manufacturers have provided additional information, not required by law, on several occasions, when HHS has asked them to do so. The manufacturers repeatedly also have offered to make their scientists available to meet with HHS to consider any issues relating to cigarette ingredients. To date, HHS has given no indication that its review of cigarette ingredients has created any basis for concern.

When the statutory ingredient-reporting requirement was enacted in 1984, the responsible House committee stated that it provided "appropriate statutory authority" and would "permit the federal government to initiate the toxicologic research necessary to measure any health risk posed by the addition of additives and other ingredients to cigarettes during the manufacturing process." Rep. Synar, who claimed credit for "hammering out" the language of the 1984 law with then-Rep. Al Gore, praised the 1984 law as "the best example we have had in a long time of where honest negotiation and reasonable compromise can mean that we can have meaningful legislation for this country." 129 Cong. Rec. 24,626 (1984).

Nothing has occurred since 1984 to warrant the conclusion that the approach taken in 1984 was mistaken. Yet now, less than a decade after he pronounced the 1984 law not merely satisfactory but exemplary, Rep. Synar proposes to replace that law with an ingredient safety-finding requirement that would result in banning tobacco products overnight.

Trade secrets. H.R. 2147 would repeal the provision of the Federal Cigarette Labeling and Advertising Act that guarantees that the ingredient information provided 
to HHS shall be treated as confidential or trade secret information, with criminal penalties being provided for unauthorized disclosure.

The confidential treatment of cigarette ingredients is consistent with the treatment by Congress, the Food and Drug Administration and other federal agencies of proprietary information concerning the ingredients used in foods, drugs, cosmetics and other consumer products. Flavorings - which account for the vast majority of cigarette ingredients - are exempt from disclosure in connection with food and cosmetic products. Legislation sponsored by Senator Kennedy in the last two Congresses addressing cigarette ingredients (S. 2795 and S. 1088) likewise would have exempted flavorings from public disclosure.

The 1984 law allows the cigarette manufacturers to submit ingredient information to HHS on a composite rather than a brand-specific basis. This maintains the confidentiality of product formulas. There is no requirement to disclose product formulas for food and cosmetic products. Yet H.R. 2147 apparently would impose, without the slightest justification, such a requirement in the case of tobacco products.

In short, H.R. 2147, far from treating tobacco products like other products, would single out tobacco products for uniquely unfavorable treatment so far as additives are concerned. Ironically, Rep. Synar, in boasting of his authorship of the 1984 law that H.R. 2147 would replace, stressed that "[t]rade secret information will be protected but ingredient information will be available to Congress to review if it deems necessary." 129 Cong. Rec. 24,626 (1984). 


\section{UNJUSTIFLABLE ADVERTISING AND LABELING RESTRICTIONS}

H.R. 2147 would deal tobacco product labeling and advertising a triplewhammy. The bill would subject tobacco product labeling and advertising to regulatory requirements designed for prescription drugs, which are wholly inappropriate for tobacco products. Those requirements would make tobacco product advertising impossible in some media and inordinately expensive in others. The bill also would prohibit truthful statements about tobacco products unless approved as "health claims" by FDA, even though comparable statements about food are not regulated as health claims. Finally, the bill would pave the way for inconsistent or prohibitive state and local advertising restrictions.

Advertising and labeling. H.R. 2147 would treat tobacco like a prescription drug for purposes of labeling and advertising regulation. But the regulatory scheme for prescription drugs assumes a product for which therapeutic claims are made and that are available to consumers only on the advice, and under the supervision, of a treating physician. Applying prescription drug requirements to the labeling and advertising of a product for which therapeutic claims are not made would produce absurd results.

Under the requirements that apply to prescription drugs, tobacco advertising in outdoor and point-of-sale media would be practically impossible, and magazine advertisements would be inordinately expensive. In a briefing paper, moreover, the 
Coalition on Smoking OR Health has suggested that FDA could ban "image" advertising under the bill.

To be sure, H.R. 2147 is more subtle and indirect than Rep. Synar's earlier proposals, which date back to 1986 , to ban or restrict tobacco product advertising. But the effects of his most recent back-door approach would be the same as the effects of his earlier proposals and would be equally incompatible with the First Amendment. ${ }^{\prime \prime}$

Health claims. H.R. 2147 would prohibit truthful statements about or char-

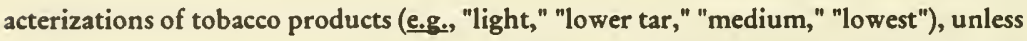
the FDA first determined that such statements and characterizations were justifiable as "health claims." But they are not health claims. They are descriptions of product characteristics, including taste, that distinguish one brand of cigarettes from another.

Advertising has little value if manufacturers cannot distinguish their brands from those of their competitors. The Federal Trade Commission has long recognized, moreover, that "it is in the public interest to promote the dissemination of truthful information concerning cigarettes which may be material and desired by the

1/ H.R. 2147 would ban outright the distribution of free tobacco product samples and coupons redeemable for free or discounted tobacco products. There is no justification for banning these promotional practices. The bill also would direct the Secretary of Health and Human Services to issue regulations prohibiting manufacturers from sponsoring any event or function open to the public at which the name or logo of one of the manufacturer's brands is displayed. The result of the latter prohibition would be a reduction in the amount of financial support for the arts and sporting events. The underlying assumption -- that people attending a sponsored event will be overcome with an urge to begin smoking -- obviously is untenable. 
consuming public." FTC Cigarette Advertising Guides, 4 Trade Reg. Rep. $(\mathrm{CCH})$ I $39,012.70$, p. 41,603 .

We note, in this connection, that comparable statements and characterizations about food products are not regulable as "health claims" by FDA. FDA regulates such descriptive terms in food labeling -- e.g., "light," "low fat" and "reduced fat" -- only as needed to resolve problems of inconsistent usage. See FD\&C Act, $\mathbb{\$} 403(\mathrm{r})(1), 21$

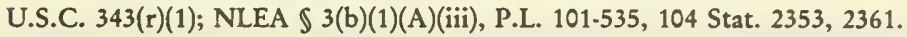

Preemption. H.R. 2147 would repeal the provision of the Federal Cigarette Labeling and Advertising Act, 15 U.S.C. 1334(b), that prohibits the states from regulating cigarette advertising and promotion based on smoking and health. It is widely recognized that repeal of this provision would generate inconsistent state and local requirements, or even outright bans. For this reason, among others, calls to repeal preemption have been opposed by groups as diverse as the American . Civil Liberties Union, Washington Legal Foundation, Freedom To Advertise Coalition, Association of National Advertisers, American Advertising Federation and American Association of Advertising Agencies.

Subjecting a nationally marketed product like cigarettes to a maze of potentially conflicting, non-uniform advertising and labeling regulations would undermine decisions that Congress has made over the years concerning cigarette advertising and labeling, would cause confusion among consumers and would involve nearly insuperable practical problems for cigarettes manufacturers. It seems to us no 
exaggeration to suggest that repeal of the preemption provision of the Federal Cigarette Labeling and Advertising Act would be purely punitive.

\section{WARNINGS}

H.R. 2147 would replace the carbon monoxide warning currently required by the Federal Cigarette Labeling and Advertising Act with an addiction warning. Tobacco products also would be required to carry "a warning and information about the dangers associated with environmental tobacco smoke." For the reasons that we have stated in connection with previous warning legislation, and for the reasons stated in Dr. Raffle's testimony today, these new warning requirements are unwarranted.

\section{FEDERAL TOBACCO POLICE FORCE}

H.R. 2147 would give HHS inappropriate responsibility for enforcing an 18year-old federal minimum sales age for tobacco products. Forty-seven states prohibit the sale or distribution of tobacco products to persons under 18 and three states prohibit sale or distribution to persons under 19. The responsibility for enforcing such prohibitions properly rests with the states, not the federal government. We are not aware that the states consider themselves incapable of enforcing their own laws in this regard or have asked the federal government to assume responsibility in this area. A federal police force is not needed to ensure that tobacco products are not sold or distributed to minors. 


\section{DISRUPTION OF FDA ACTIVITIES}

FDA already is hard pressed to perform its essential functions. As a result, approval of new medicines, for example, often is significantly delayed. H.R. 2147 would require FDA to assume broad additional responsibilities in areas in which it has no pertinent experience or expertise -- regulation and policing of the manufacture, labeling and advertising of tobacco products. Food and pharmaceutical regulators would be forced to become tobacco regulators as well. Even with extra funding, engrafting this wholly new set of responsibilities on administrators currently struggling to perform their agency's core functions would be disastrously disruptive.

\section{FUNDING MECHANISM A DANGEROUS PRECEDENT}

The funding mechanism provided by H.R. 2147 also would set a dangerous precedent. H.R. 2147 would require each tobacco company to pay an annual fee to defray the cost of implementing the bill. Rep. Synar has suggested that this fee is similar to the system of user fees established by Congress under the Prescription Drug User Fee Act of 1992. But the fees that H.R. 2147 would assess bear little resemblance to those assessed under the Prescription Drug User Fee Act.

The fees assessed under the Prescription Drug User Fee Act are designed to enable FDA to improve its process in a single area -- review and approval of applications for new drugs, antibiotics and biological products. The fees cannot be used to support general FDA activities and merely augment, rather than replace, appropriated monies. The fees are assessed only to the extent that total appropriations for FDA salaries and expenses exceed the 1992 appropriations level. 
The pharmaceutical industry acceded to the assessment of these fees because improving the drug approval process provides the pharmaceutical industry with tangible benefits - namely, expediting new drug approvals. H.R. 2147, by contrast, would require the tobacco industry to pay the full cost of FDA regulation under the bill -- regulation that HHS itself has declared to be unnecessary. The precedent that H.R. 2147 would set for other industries is obvious and ominous.

Before closing, Mr. Chairman, I would like to offer some personal remarks. Although I am here on behalf of The Tobacco Institute, I proudly served in this body for ten years. My perspective is broader than the particular interests on whose behalf I speak today.

A rabid antitobacco movement bent on Prohibition has made the tobacco industry the subject of an extraordinary campaign of vilification. Antitobacco sentiment has been stirred to such a point that almost any accusation against the industry is believed, regardless of whether it actually is true, while any refutation offered by the industry or anyone else for that matter -- however demonstrably based on certifiable fact -- is disbelieved or ignored. The more sensational the accusation, the more bizarre the allegation, the more attention it receives.

When the allegations that are at the heart of this hearing are viewed dispassionately, I am confident that they will be seen to be unfounded.

I would be glad to answer any questions. 


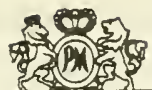 \\ PHILIP MORRIS}

COMPANIES INC.

THE COLORADO QUHLDING, 1341 G STREET. N W., SUITE 900 . WASHINGTON, D.C 20005 TELEPHONE: (202) 637-1500 FAX (202) 637.1505.6

\section{PHILIP MORRIS STATEMENT ON NICOTINE IN CIGARETTES}

Philip Morris does nothing in the processing of tobacco or the manufacture of cigarettes that increases the nicotine in our products above what is naturally found in tobacco. In fact, our manufacturing process results in less nicotine in the cigarettes we make than exists in the raw, unprocessed tobacco that enters the process. There is no replacement of the lost nicotine.

All cigarettes manufactured by Philip Morris contain some reconstituted tobacco. The production of reconstituted tobacco utilizes tobacco stems and small pieces of the leaf in what is essentially a paper making process. Large quantities of water are added to the stem and leaf material to create a pulp. The water soluble materials in tobacco, including nicotine, are dissolved in the water during this step. The water containing the solubles is then recombined with the fiber sheet. No nicotine whatsoever not found in the original tobacco is introduced in the production of reconstituted tobacco. Indeed, reconstituted tobacco sheet produced by Philip Morris contains approximately 20 to $25 \%$ less nicotine than the stems and leaf fragments that are used in the process. 
Denatured alcohol is used as a carrying agent for the application of certain flavorings that do not dissolve in water. The denatured alcohol used by Philip Morris has been denatured with small amounts of nicotine sulfate (SDA-4) to render it undrinkable. SDA-4 is specifically approved by the Bureau of Alcohol, Tobacco and Firearms as the denaturant to be used for alcohol in the processing and manufacturing of tobacco products, see 27 Code of Federal Regulations 21.38. The amount of nicotine remaining in cigarettes resulting from the use of denatured aicohol is so small as to be undetectable in the final product.

There are a number of flavorings sprayed onto tobacco in the manufacture of cigarettes. One of these flavorings is commonly referred to as tobacco extract. Tobacco extract appears as only one component of a flavoring package. The nicotine contribution from tobacco extract added to the finished products is negligible and does not measurably change the levels of nicotine in tobacco smoke. Philip Morris no longer uses tobacco extract in any of its brands. The fact that cigarette companies have used tobacco extract as a flavoring agent has long been a matter of public record.

Cigarette advertising has carried nicotine yield information since 1972. The nicotine yields reported in cigarette ads are measured pursuant to standard test methods prescribed by the Federal Trade Commission. Thus. consumers have information concerning the relative nicotine yields of products that permit them to make an informed choice. Consumers have expressed a growing demand for lower tar and nicotine products which has resulted in average nicotine yields decreasing by more than $50 \%$ over the last 40 years. 


\section{Statement of R.J. Reynolds Tobacco Company}

R.J. Reynolds Tobacco Co. welcomes this opportunity to correct three erroneous claims that have been made about Reynolds Tobacco and its products: 1) that cigarettes are "addictive"; 2) that Reynolds Tobacco adds nicotine to its products; and 3) that the company manipulates nicotine yields to create, maintain or satisfy "addiction."

Attached to this testimony are four documents that the committee might find helpful: 1) a February 28 letter from Reynolds Tobacco's chief executive officer to Dr David Kessler, the food and drug commissioner, informing him that RJR does not add nicotine to its products; 2) a March 3 letter from the company's general counsel to $A B C$ News, correcting misrepresentations about the company that were made during a recent "Day One" news report; 3) a March 22 preliminary report from Battelle Memorial Institute, through its Battelle Columbus Operations, documenting the fact that nicotine yields are not increased during RJR's tobacco reconstitution process (a final report will be available within a week); and 4) a chart that tracks the industrywide reductions that have occurred in cigarette "tar" and nicotine yields during the past 40 years.

\section{CLAIM: CIGARETTES ARE "ADDICTIVE"}

During the past several years, there have been a wide variety of attempts to convince the American public that cigarettes are "addictive," and some public officials have even gone so far as to put cigarettes in the same class as such truly addictive drugs as heroin and cocaine. One does not have to be a trained behavioral scientist to see this is not true. All one needs to do is simply ask, and honestly answer, the following question "Would an airline passenger rather board a plane piloted by someone who had just had a couple of beers, smoked crack, shot heroin, popped some pills or smoked some cigarettes?" 
The allegation that smoking cigarettes is "addictive" is part of a growing and disturbing trend that has destroyed the meaning of the term "addiction" by characterizing any enjoyable activity as "addictive," whether it is eating sweets, drinking coffee, exercising or playing video games. Under that very loose definition of "addiction," Americans are currently raising a new generation of "caffeine and sugar addicts" and "exercise and video junkies." This defies common sense.

The simple fact is, cigarettes do not meet the classic criteria for addiction, and to suggest that cigarettes are as "addictive" as cocaine or heroin, as anti-smokers frequently do, trivializes the very serious problem our nation faces in battling the use of truly addictive and illegal drugs.

The use of such addictive substances as cocaine, heroin, alcohol and barbiturates eventually leads to major lifestyle disruptions, and their use interferes with the user's ability to perform normal, routine functions such as working, driving or maintaining healthy relationships with family members. Truly addictive drugs invade every aspect of an addict's life. Overcoming an addiction to these substances, requires the addict to completely change his or her behavior, lifestyle and attitudes. In contrast, when a smoker quits smoking cigarettes, that is all that he or she needs to do.

Equating cigarette smoking with the use of heroin or cocaine could actually encourage experimentation with those drugs by suggesting that it is no more difficult to quit using cocaine or heroin than it is to quit smoking cigarettes. That is clearly not the case. 
The fact is, there are currently almost 43 million American adults who have quit smoking, and almost all of them did so on their own, without any help. According to statistics compiled by the Public Health Service for the National Center for Health Statistics, today there are more former smokers (almost 43 million) in the United States than there are adults who currently smoke cigarettes on a daily basis (41 million). And almost all of them quit without the aid of nicotine substitutes, counseling or other aids. That result would hardly have been achievable if cigarettes were truly addictive, or if they even began to approach the addictive nature of such substances as cocaine and heroin.

Ironically, suggestions that cigarettes are "addictive" also work against government efforts to encourage smokers to quit because by telling smokers that they are "addicted," they provide smokers with an excuse to avoid quitting. As a Scripps Howard columnist who happens to be a former smoker put it earlier this week:

"By pretending that smokers are helpless addicts, slaves to a tobacco conspiracy, drug addicts unable to control their own actions, the addictionconspiracy peddlers help make a very simple decision to stop become impossible.

"There's actually no conspiracy but there's a secret about smoking.

"To quit, you have to decide you want to quit.

"Then you quit."

\section{CLAIM: R.J. REYNOLDS ADDS NICOTINE TO ITS PRODUCTS}

Recent reports have claimed that R.J. Reynolds increases the level of nicotine in its products during the manufacturing process. That allegation is simply untrue, and the company has sent a letter (copy attached) to FDA Commissioner David Kessler informing him that Reynolds Tobacco does not spike the nicotine level in its products. In fact, the company's processes result in a reduction in the amount of nicotine in cigarettes when compared to unprocessed tobacco. 
The company has also sent a letter to $\mathrm{ABC}$ News (copy attached) concerning a "Day One" segment that clearly implied that Reynolds Tobacco "boosts" the nicotine content of its cigarettes by adding nicotine to reconstituted tobacco. This could not be farther from the truth. Nicotine is, in fact, lost during the process, so the reconstitution process actually results in tobacco with lower yields of nicotine than either 1) unprocessed tobacco leaf or 2) the small pieces of tobacco and tobacco stems used to manufacture the reconstituted sheets.

For the committee's information, the reconstitution process was developed to reduce raw material waste by making the most efficient use of the tobacco that is purchased without compromising the taste or smoking characteristics of the final product. The reconstitution process is similar to the process used to produce paper. Once the tobacco pulp is formed into sheets of tobacco, nicotine and other natural flavorings that were extracted with water from the tobacco during the process are returned to their original source

Battelle, a highly respected independent laboratory, recently reviewed RJR's reconstitution process and analyzed reconstituted tobacco produced by that process. Their tests confirmed that the process does not increase nicotine in the final tobacco sheet and that some nicotine is, in fact, lost during the process. A copy of Battelle's preliminary report is attached.

Contrary to statements made by Congressman Mike Synar in the "Day One" report, the tobacco industry has never hidden the fact that it uses reconstituted tobacco Had Congressman Synar or ABC's reporters conducted even a cursory review of the public information on reconstituted tobacco, they would have learned that the process has been extensively discussed in published documents by the National Cancer Institute (in at least five reports), the Surgeon General (in at least three Surgeon General's Reports) and others. The Surgeon General's Reports also document that the use of reconstituted tobacco results in a reduction of nicotine 


\section{CLAIM: REYNOLDS TOBACCO MANIPULATES THE NICOTINE IN ITS PRODUCTS TO CREATE, MAINTAIN OR SATISFY ADDICTION}

This claim is also false. The fact is, Reynolds Tobacco and the other tobacco companies do market a broad range of cigarette products in response to the demands and tastes of today's adult cigarette smokers; and within that range of products, there is also a range of "tar" and nicotine yields. The company does not, however, establish specific nicotine yields or manipulate nicotine to create, maintain or satisfy "addiction."

It is important to understand that nicotine plays an essential role in the taste and "mouthfeel" of cigarette smoke, which are variables that affect smokers' enjoyment. (It is also interesting to note that tobacco is not the only common source of nicotine. Nicotine naturally occurs in a variety of common vegetables including tomatoes, potatoes, eggplant and green peppers.)

A wide variety of cigarette brands and styles are available today largely as a result of blending techniques and other manufacturing processes that developed over many decades. In addition to using blending techniques, cigarette manufacturers reduce "tar" yields through the puffing of tobacco, filtration, air dilution and tobacco reconstitution. These developments help manufacturers provide smokers with the wide selection of tastes and "tar" yields that they demand.

It is a simple fact that reducing "tar" yields automatically results in proportional reductions in nicotine. So as American smokers have demanded lower "tar" products over the years, the average nicotine yields in American cigarettes have also declined (by more than 60 percent over past 40 years, as detailed in the attached chart). Since 1970, U.S. cigarette manufacturers have been required to disclose "tar" and nicotine yields in product advertising (as determined by a method established by the FTC). 


\section{4}

The committee should be aware of the fact that cigarettes are an agriculturally based commodity and that the quality and smoking characteristics of tobacco, the primary raw materiai, can vary greatly from farm to farm and year to year. To ensure that any particular brand of cigarette tastes and smokes the same from month to month and year to year, tobacco companies must blend their products for consistency.

The committee should also be aware that any suggestions - however erroneous that Reynolds Tobacco or any other manufacturer manipulates the nicotine levels in its products to create, maintain or satisfy an "addiction" would aiso indict, as drugs, a wide variety of consumer products industries that maintain product consistency and offer a variety of brand-style choices.

For example, soft drinks are available with varying caffeine levels, and caffeine-free versions are also available. Using the same logic that is being used to argue that cigarettes should be regulated as a drig, one could argue that the FDA should be regulating soft drinks as a drug, since: 1) unlike the practice of cigarette manufacturers with respect to nicotine, soft-drink manufacturers routinely add caffeine (a substance that so-called "caffeine addicts" seek because of its properties as a stimulant) to some of their products; and 2) soft-drink manufacturers have the ability to reduce or eliminate naturally occurring caffeine.

Similarly, American consumers can now buy beverages that have alcohol contents ranging from less than .05 percent (so-called "non-aicoholic" beer) to 190 proof (95 percent alcohol), with choices available for many proof levels in between. Alcohol is a physically addictive intoxicant that is often used to relieve stress and anxiety. Nonetheless, Reynolds Tobacco is not aware of any serious proposals for the FDA to regulate wine, beer or spirits as a drug.

The bottom line is, smokers are no different from other American consumers in their demand for variety and choice (as evidenced by the fact that, today, the average supermarket stocks 30,000 different items). American cigarette manufacturers currently produce more than 500 cigarette brand styles, and the fact that those styles offer a variety of tastes and "tar" yields, is entirely consistent with the American consumers' preference for variety and choice. 


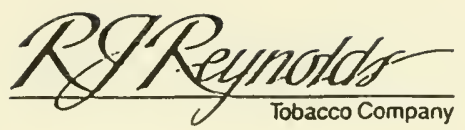

February 28, 1994

JAMES W. JOHNSTON

Chairman and

Chiet Executive Otficer

Winston-Salem, N.C. 27102 919.741 .7925

David A. Kessler, M.D.

Commissioner of Food and Drugs

Food and Drug Administration

Department of Health \& Human Services

Rockville, MD 20887

\section{Dear Dr. Kessler:}

This letter is intended to clarify one simple fact: that R.J. Reynolds Tobacco Company does not increase the nicotine in its cigarettes above what is found naturally in tobacco. In fact, our processes reduce the amount of nicotine in cigarettes when compared to unprocessed tobacco.

Reynolds manufactures and sells a broad range of cigarette products designed to appeal to the tastes of today's adult cigarette smokers. Smokers have increasingly demanded lower "tar" cigarettes. As a result of the processes used to lower "tar", nicotine has also been reduced. Over the past 40 years, the average "tar". and nicotine in cigarettes sold in the U.S. has declined by more than $60 \%$.

The variety of cigarettes available is, in large part, a result of blending techniques developed over a long history of cigarette manufacture and research. In addition to traditional tobacco blending techniques, various other techniques are available to cigarette manufacturers, including puffing of tobacco, filtration, air dilution, tobacco reconstitution and others, in order to enable manufacturers to reduce the "tar" and nicotine yields in their cigarettes. As a result of these various techniques, the sales weighted averages of "tar" and nicotine yields in the United States today are 11.5 milligrams and 0.8 milligram, respectively.

In the early 1950's the sales weighted averages of "tar" and nicotine yields were 36 milligrams and 27 milligrams, respectively. Most cigarette brands were in a narrow band around this average. Flue-cured tobacco naturally contains 2.5 to 3.5 percent nicotine, burley tobacco contains 2.75 to 4.0 percent nicotine, and Oriental tobacco contains 0.5 to 1.8 percent nicotine in the cured leaf. Finished cigarettes generally contain approximately 1.5 to $2.5 \%$ nicotine by weight, less than the natural cured leaf. 
Dr. David A. Kessler, M.D.

Page 2

February 28, 1994

The broad range of cigarette products available today provides smokers with a wide selection of tastes, "tar" and nicotine yiclds. The "tar" and nicotine yields in cigarettes are published by the Federal Trade Commission and the yiclds for each brand are provided in every advertisement for that brand in accordance with the law. The processing of certain tobaccos cnables us to manufacture cigarettes consistent with the published "tar" and nicotine levels despite the nicotine variations from Ieaf to leaf and crop to crop.

Let me repeat, so that it is absolutely clear. R.J. Reynolds Tobacco Company does not increase the nicotine in the tobacco we use in the manufacture of our cigarettes.

Sincerely,

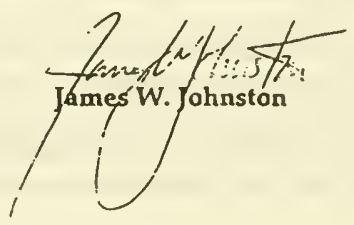




\section{REReynolde}

March 3, 1994

WAYNE W. JUCHATZ

Senior Vice President

General Counsel and Secretary

Winston-Salem, N.C. 27102 919.741-6378

\section{Mr. Richard C. Wald}

Senior Vice PresidentABC News

Capital Cities/ABC, Inc.

47 West 66th Street

New York, New York 10023

\section{Re: Day One $-2 / 28 / 94$}

\section{Dear Dick:}

Once again I find myself writing a letter calling your attention to another example of your network's biased and sensationalized reporting on a tobacco-related issue.

Had your reporters conducted even a cursory review of the public information on reconstituted tobacco they would have learned that in 1979, 1981, and 1989 three Surgeon General's Reports discussed this process. This is not a process, as reported, which has "never been disclosed" to the public or the government. It is also a process that was documented in these Surgeon General's Reports and elsewhere as resulting in a reduction of nicotine.

This lack of thorough research and biased reporting is particuiarly troublesome when $A B C$ decides to communicate with the American public on a controversial subject. Your viewers are entitled to receive all of the information and come to their own conclusions. This can only happen if the news report contains an unbiased presentation of all the facts and not a reckless reporting of information selected to support a predetermined conclusion.

There are some additional points I feel compelled to raise conceming this Day One segment:

(i) The clear (if not intended) implication of this segment was that Reynolds "boosts" the nicotine content of our cigarettes by adding nicotine to reconstituted tobacco. This couldn't be farther from the truth and should have been readily apparent to any conscientious reporter. The simple fact is that no nicotine is added and the reconstitution process actually results in tobacco with lower levels of nicotine than tobacco leaf.

Contrary to the impression created, our use of reconstituted tobacco has the net effect of reducing the nicotine yields of the cigarettes into which reconstituted tobacco is blended. The use of reconstituted tobacco and other mahufacturing processes have in fact reduced the sales weighted average "tar" and nicotine yields of U.S. cigarettes by more than 60 percent over the last 40 years. This is another relevant and readily available piece of information that your reporters could have obtained from Surgeon General's and FTC reports. Enclosed is a copy of a letter sent to Dr. Kessler on this subject. 
Mr. Richard C. Wald

March 3, 1994

Page 2

(ii) The segment included statements by Representative Mike Synar that the tobacco industry never disclosed to consumers or the government the tobacco reconstitution process or cigarette ingredients. If the producers had researched these issues or asked us these questions, they would have learned that cigarette manufacturers are required by law to supply a list of cigarette ingredients annually to the U.S. Department of Health and Human Services and have done so for the last nine years. The reconstituted tobacco process has been in use for at least 30 years and is widely known. As indicated above, it was even discussed in the 1979, 1981 and 1989 Surgeon General's Reports and is routinely addressed in trade publications. Any suggestion that the tobacco industry has been hiding this process from the Congress or the American public is absolutely ridiculous.

(iii) Perhaps the most shocking example of sensationalism in this segment was the unidentified former "Reynolds manager" whose appearance and voice were disguised ostensibly for his or her protection. Without knowing who this individual is, there is simply no way for us or your viewers to assess his or her level of knowledge, motivation or credibility or to determine whether he or she was in fact even a Reynolds employec.

It's a shame that once again $A B C$ has sacrificed objective, thorough reporing on issues of significance to our employees, customers and shareholders, and to the American public, in favor of entertainment value, sensationalism and "hype."

We can only hope that any plans you may have for continued coverage of this issue will reflect a higher standard of objectivity and thoroughness.

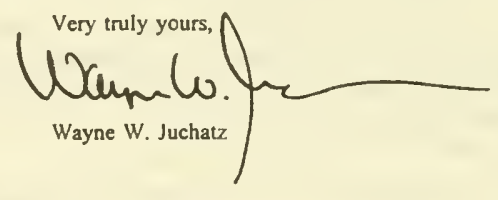

WWJ:jt

Enclosure

cc: Mr. Walt Bogdanich (w/e)

Mr. Roone Arledge (w/e) 


\section{Battelle \\ ... Putting tehnology 10 Work \\ saskerenue. \\ Colut of Ohe cerases

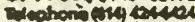

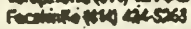

\section{Mirch 22, 1994}

\section{RAXYFEDERAL EXPRBSS}

\section{Jumes Ex Swarger, Ph.D.}

Suly Monitor

R. 3. Reprolde Tobscos Comparry

Bowning Oar Tochwical Center

P.0: B.0X 1487

Winstorstem, NC 27100-1487

\section{Deer. In:}

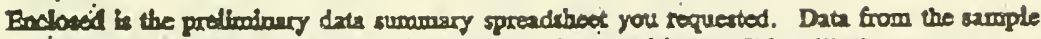
coti nol yet milyod on Friday are iocluded in this gpreudisher. This will givo you

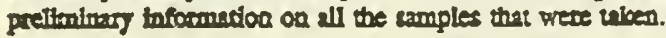

The rumples wero triben from the tobrceo procesring building aumber 90 an Mareh 11, 1994 between the hours of 09:00-13:00. Separabe samples were taben from the two sturtion

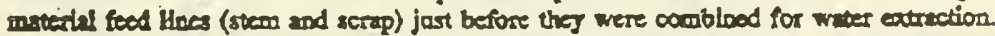

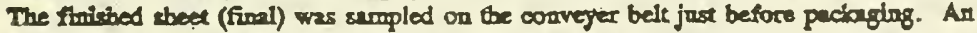

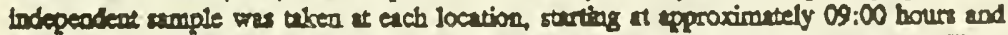
about ovecy bale bour thereafter, the last semple betog taken at about 13:00 hours. The

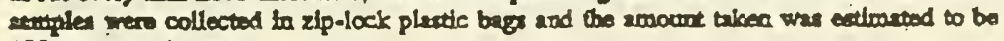
100 or lager.

The sampia were exractod and unalyzed fallowing the R. J. Regnolds anifyical method 2006, inctoding your rocommended modifleattons for CCIMSD ansivds for abootine. The cortiction atoo inchudod the sample prep bomogertization and dry down as dotalled to your mobod, excopt the samples were dried ather homogenirstion to ensure a more even diflag procoses foc all samplo types. In addition, a 1:100 difution la straight chloroform was 
Jamos B. Strugger, Ph.D.

March 22, 1994

Pago 2

performed on the samplo extructs just prior to amitysis. Baxicalty, the complete sample was

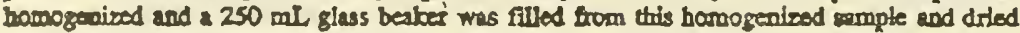
at $\sim 96^{\circ} \mathrm{C}$ for 2 hours. After drylug, samples were ettored in screw cap plartic boutles and asaled with Teflon sppe until extretion. To extract, duplieare 1 gram samples were velighed cut into reperates $60 \mathrm{mll}$ centrifuge tubes, wee with $10 \mathrm{mll}$ of water along with $10 \mathrm{ml}$ of a $10 \%$ sodino bydroxide soluthon and extractod with $20 \mathrm{~mL}$ of cbloroform containing $0.4 \mathrm{ppron}$

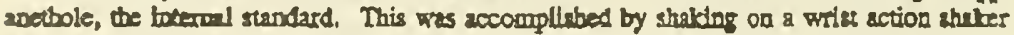
for 20 miloutes. The extract layes were then eppanted by centelfugution. A portion of the chloroforio layer was reonoved $(-5 \mathrm{ml})$ and a 1:100 dilution is straighe chloroform wes doxe. The asriples were then uniyzed along with celibretion staoderds by GCMSD ustag single ion monftoring for the prearance of nicotse.

A companathe andysis between the two staring materials (sten and serap) to the finishod shect (final) appess to indicate that over the time pectod we sampled the bevel of nleotloc in the tind product we inslyzed nover exceeded the sum of the gicotine levels fornd in the two rtarting murtals. The dach reported to date indicatod that the nicotine level to the finished abee is less than 50\% of the num of the picotine kevels forrod in the two startiog materials.

Derring the process overview given by R. J. Reypolds, it whe stated that the terget

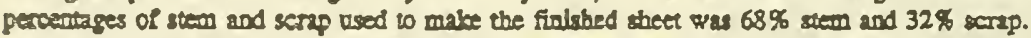
If that persentage was met for this final steet, then you would expect as average contribution of epproximatily $1730 \mathrm{ppm}$ nicotioe from the stem and la average contribution of $2774 \mathrm{ppm}$ from the scrap for a total averase of 4504 ppon.

These aumbers were crtimud using the preliminary average values for sem and scrap fornd in tho spreadsheet and multiplying by 0.68 and 0.32 respectively. When you compare these values to the prelinatary average for the finst sthect of upproximately 3963 ppon, these dets ise in good agreement with expected values. In fect the preliminary average for the finishod theet is slighaly less then the extimated value based on the stam and serap iverages.

As we discussed to detail before, these data still noed to go through a complete GLP revtet. The purpose of this review is to carch any acton leems thas would cause these mumbers to change or ceuse additional wark to be done, is well as to ensure that you recelve a quality product under the GLP guidelines that we followed throughoor this project. Until the full GLP roviow in omplese, these data cen only be cousidered prelimiasry. Aro ocher was of theac det it this time to considered the responsibility of the R. J. Reynolds Tobroco Compery.

4) tocus now will be on proparing the fimal report. If you heve wing questions about these dats, pleave don't betitute to call me at (614) $424-4190$ or thx me at (614) 424-3204.

Stincerely yours,

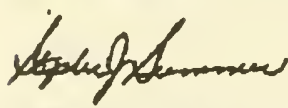

Stephen J. Srmmer

Manser Research Technician

Recibue and Product Cbemitry 


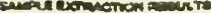

wormentre

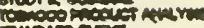

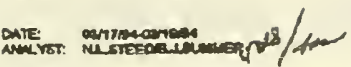

\begin{tabular}{|c|c|c|c|c|c|}
\hline wavenos & ces: & exth & heorice & 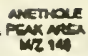 & $\begin{array}{l}\text { name } \\
\text { necturs } \\
\text { nestans }\end{array}$ \\
\hline $\begin{array}{r}8 \\
8 \\
8 \\
8 \\
2 \\
08 \\
08\end{array}$ & 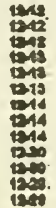 & $\begin{array}{l}3 \\
3 \\
13 \\
11 \\
1 \\
12 \\
0 \\
n \\
n \\
n\end{array}$ & 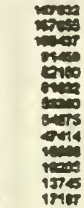 & 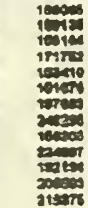 & 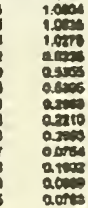 \\
\hline
\end{tabular}

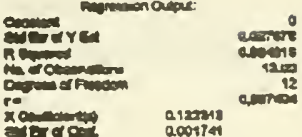

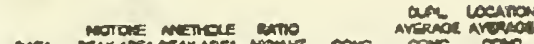

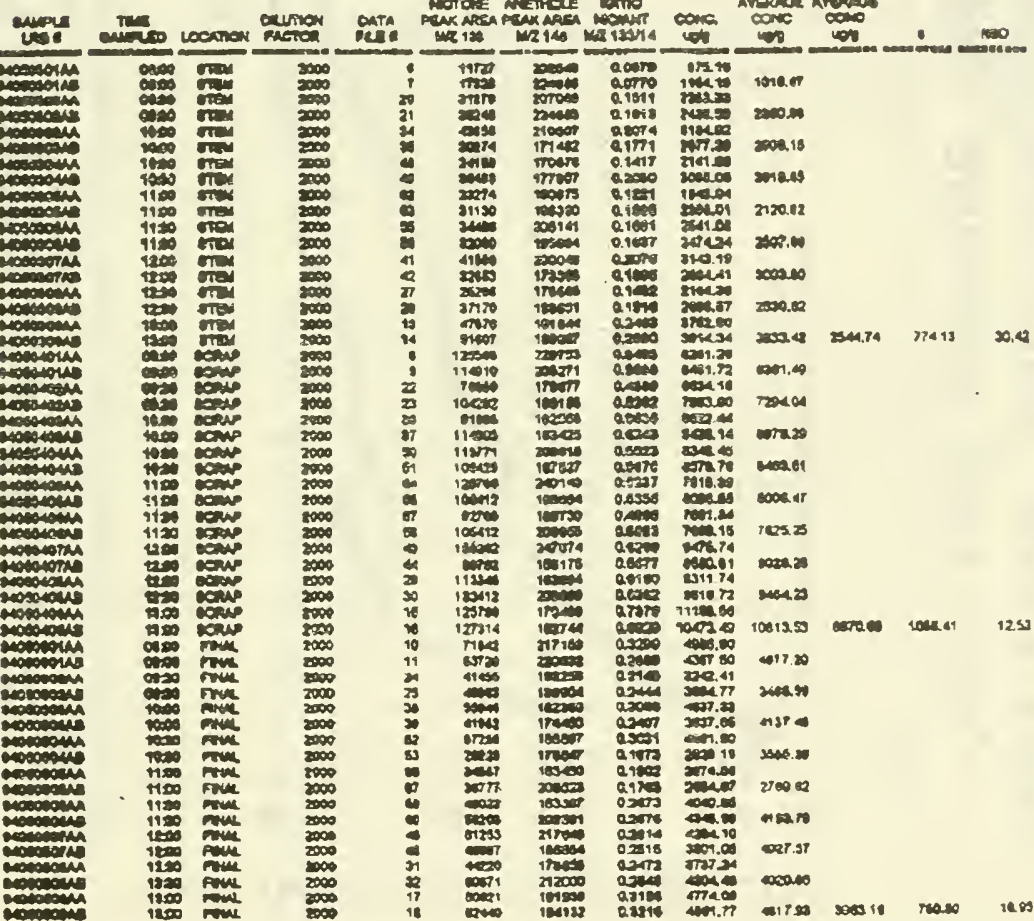

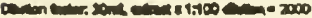


Nicotine delivery, $\mathrm{mg} / \mathrm{cigarette}$

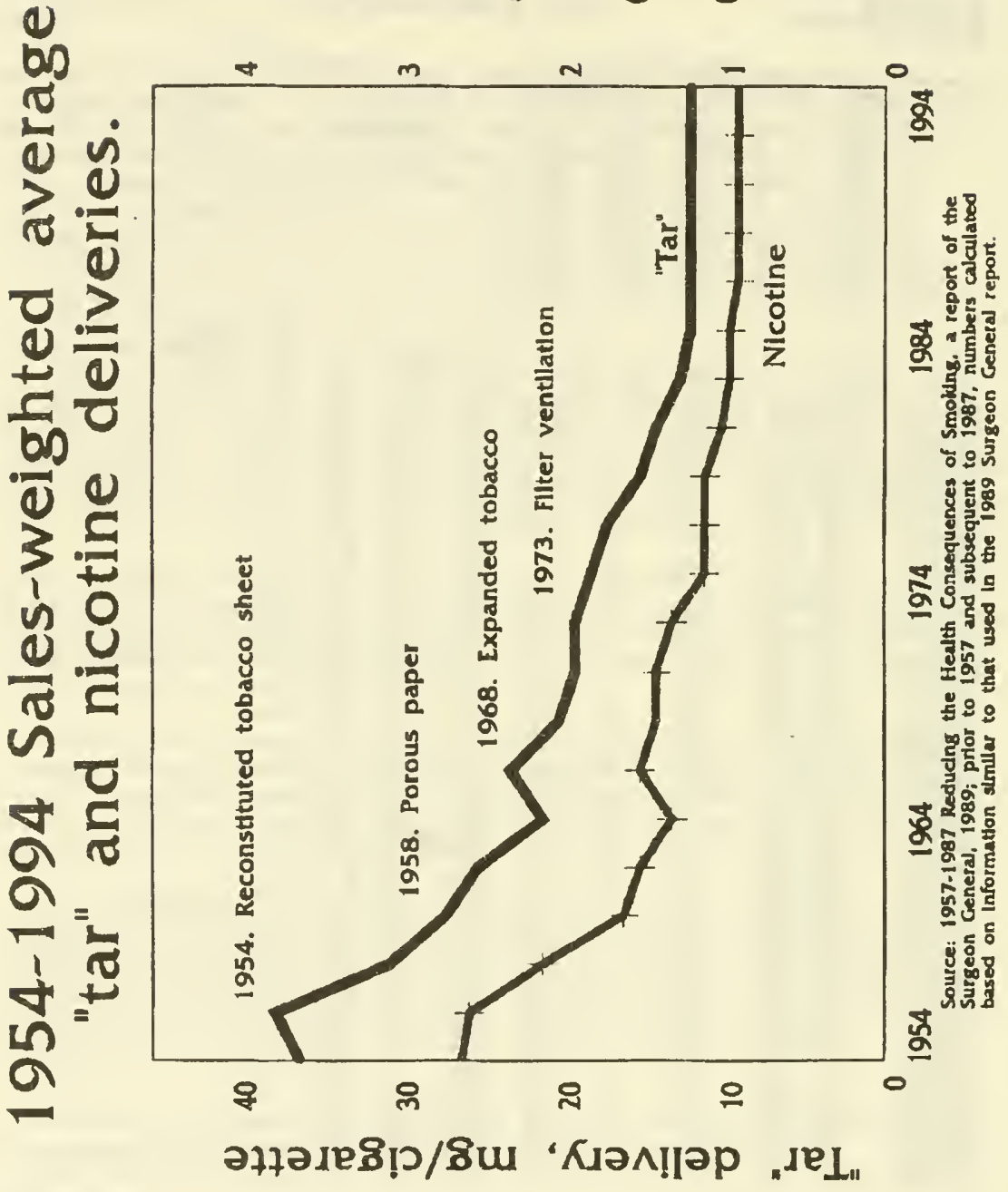


Statement of The American Tobacco Company

before the

House Energy and Commerce Committee

Subcommittee on Health and the Environment

March 25, 1994

THE AMERICAN TOBACCO COMPANY NICOTINE STATEMENT

Aside from tobacco itself and federally

authorized use of alcohol denatured with minute amounts of nicotine, The American Tobacco Company does not use

nicotine in the manufacture of its cigarettes.

The only source of nicotine other than that

naturally occurring in tobacco is introduced from specially Denatured Alcohol No. 4 used as a solvent for flavorings. SDA No. 4 is authorized for tobacco use in accordance with 27 Code of Federal Regulations, Alcohol, Tobacco Products and Fire Arms, revised as of April 1, 1993, Section 21.118 and 21.38 and is denatured by the alcohol manufacturer in accordance to the prescribed formula outlined in the regulations. The quantity of nicotine indirectly added to tobacco from use of SDA No. 4 is on the order of 3 ppm to 5 
$\mathrm{ppm}$, or $0.0003^{\circ}$ to $0.0005 \%$ by weight and is negligible in comparison to naturally occurring nicotine of tobacco blends that generally contain 28 to 2.58 by weight.

\section{Further, The American Tobacco Company}

manufactures reconstituted tobacco by the Fourdrinier paper making process that involves separation of water-soluble components from tobacco, formation of a tobacco cellulosic sheet and reapplication of the water-soluble components to the sheet. The end product is tobacco material that contains only the quantity of water soluble components including nicotine originally removed from the tobacco. In practice, the nicotine content of the finished reconstituted tobacco material is approximately $4 \%$ less than the nicotine content of the natural tobacco utilized in the reconstitution process.

The American Tobacco Company uses various types of natural tobaccos including reconstituted tobacco in the manufacture of its cigarettes. The percentages of natural tobacco types and reconstituted tobacco varies by cigarette brand; however, after processing of tobacco for cigarette manufacture, the nicotine content is on the order of 58 less than that of the various tobaccos entering the process.

In summary, nicotine involved in the federally regulated and authorized use of SDA No. 4 denatured alcohol is negligible and nothing is done in the tobacco processing or manufacture of cigarettes by The American Tobacco Company to increase nicotine beyond that naturally occurring in tobacco. 
700 West Main Street, Durham, NC 27702

\section{Statement of Liggett Group Inc.}

The purpose of this statement is to establish for the record the facts concerning the design of cigarettes manufactured by Liggett Group Inc.

Contrary to assertions that have been made in the press and elsewhere, we do not increase the nicotine level of our cigarettes beyond that found naturally in the tobacco from which our cigarettes are made.

Over time, and particularly since the advent of the cigarette filter, consumers have shown an increasing preference for "lighter" cigarettes. The "lighter" cigarette is achieved by lowering total smoke delivery. One effect of lowering smoke delivery is a reduction in the nicotine level. The nicotine level in smoke historically has been, and continues to be, approximately 10 percent or less of the "tar" level.

with that background in mind, we would like to address the specific factual allegations made against Liggett by ABC's "Day one" tabloid show. We do not artificially increase the level of nicotine in our cigarettes to allegedly "addict" or otherwise influence our consumers. Reconstituted tobacco, the manufacture and use of which have been publicly documented for decades, is used for the purpose of cost savings. Tobacco is the most expensive component of the cigarette and any loss of that tobacco would make the production of cigarettes that much more expensive.

The net effect of our use of reconstituted tobacco is a significant reduction in the nicotine level of the finished product. Indeed, reconstituted tobacco has been a significant factor in achieving the lower "tar" and nicotine products that have been increasingly preferred by consumers in recent years.

Alcohol and tobacco flavorants are the only other sources of nicotine in our cigarettes. The nicotine occurs naturally in the flavorants and is used as a denaturing agent in the alcohol. The Specially Denatured Alcohol No. 4 (SDA-4) that we use acts as a carrier for flavorants and dissipates after the flavorants are applied. SDA-4 is the only denatured alcohol that has been approved by the Bureau of Alcohol, Tobacco and Firearms for use in the cigarette manufacturing process. The amount of nicotine contributed via tobacco flavorants and denatured alcohol is so minuscule as to be not measurable in tobacco smoke using the accepted FTC method.

Any attempt purposely to elevate nicotine levels in cigarettes would be reflected in the "tar" and nicotine values that are published each year in the Pederal Register. In fact, as explained above, the nicotine content of cigarettes manufactured by Liggett is lower than the nicotine content of the tobacco that we use to make our cigarettes. 


\section{STATEMENT ON NICOTINE IN B\&W CIGARETTES}

The only direct source of nicotine in cigarettes manufactured by Brown \& Williamson Tobacco Corporation is the tobacco that is used in the cigarettes. In fact, as a result of the processing steps described below, the nicotine content of $\mathrm{B} \& \mathrm{~W}$ cigarettes is lower than the nicotine content of the tobacco used to produce them.

Cigarettes manufactured by B\&W contain varying amounts of reconstituted tobacco, which is produced by first adding water to the tobacco stock, a step that dissolves a number of substances including nicotine. The water solution is then drawn off, which allows the remaining tobacco cellulose to be formed into a sheet. The resulting water solution is subsequently reapplied to the tobacco sheet. Some of the dissolved nicotine as well as other dissolved substances are lost, which results in the reconstituted tobacco containing less nicotine than the tobacco stock from which the reconstituted tobacco was made.

Alcohol and certain other tobacco flavors used during the manufacturing process contain minuscule quantities of nicotine. The alcohol, known as SDA-4, is used as a processing agent and is the only form of alcohol that has been approved for that purpose by the Bureau of Alcohol, Tobacco and Firearms. B\&W also uses a few flavors containing a substance that is made from tobacco, which therefore incidentally contains trace amounts of nicotine. But the total indirect contribution of nicotine by alcohol and tobacco flavors is so small that it cannot be detected in the tobacco blend by standard laboratory methodologies and has no effect whatsoever on the nicotine delivery as determined by the Federal Trade Commission method.

The Federal Trade Commission began publishing in the late 1960's information concerning the "tar" and nicotine deliveries of cigarettes, including cigarettes manufactured by B\&W. The information was produced by the FTC pursuant to a standardized testing methodology that the FTC developed in consultation with a number of outside scientists, including scientists from Oak Ridge National Laboratory. In 1972, the FTC began to require cigarette manufacturers to include FTC "tar" and nicotine figures in cigarette advertisements.

Over the years, consumer preferences have resulted in a progressive lowering of average "tar" and nicotine deliveries. According to the 1989 Surgeon General's Report, the average nicotine delivery dropped from over 2 milligrams to 0.9 milligrams between 1957 and 1987. That reduction has been accomplished by companies like B\&W through tobacco selection and advances in cigarette manufacturing technology, primarily filters and ventilation.

The filtering and ventilation techniques that are utilized by $\mathrm{B} \& \mathrm{~W}$ result in the smoker's receiving only a small fraction of the nicotine contained in the tobacco that was used to produce the cigarette. In addition, because of the steps taken in processing reconstituted tobacco, the nicotine content of the cigarettes produced by B\&W is, in turn, lower than the nicotine content of the tobacco from which they are made. 


\title{
Statement of \\ Alexander W. Spears \\ Vice Chairman and Chief Operating Officer \\ Lorillard Tobacco Company
}

\author{
before the \\ Subcommittee on \\ Health and the Environment \\ of the \\ Committee on Energy and Commerce
}

U.S. House of Representatives

March 25, 1994

My name is Alexander W. Spears, and I am Vice Chairman and Chief Operating Officer for Lorillard Tobacco Company.

Within the last few weeks, ABC's DAY ONE show has featured two cigarette-related programs alleging that the tobacco industry adds nicotine to cigarette tobacco for the purpose of manipulating the dose of nicotine to the consumer. These statements are completely false.

David Kessler, Commissioner of the Food and Drug Administration, stated in a letter to Scott Ballin of the Coalition on Smoking or Health dated February 25, 1994, that manufacturers commonly add nicotine to cigarettes to deliver specific amounts of nicotine. This letter was released to the media, perpetuating its false assertions.

The level of nicotine in the tobacco of our products is solely determined by the tobacco that we buy and blending of the different tobaccos during manufacturing. The tar and 
nicotine yields of our products are determined by a combination of the tobacco blends and the construction of the cigarette, i.e., length, circumference, filter, tip ventilation, tobacco density, etc. The Federal Trade Commission has reported the results of tar and nicotine analysis by brand for years.

We do not set nicotine levels for particular brands of cigarettes. Nicotine levels follow the tar levels. The easy proof that no nicotine manipulation has occurred may be found in the temporal tar and nicotine data from the 1950's to the 1990's. As shown in Chart I, both tar and nicotine on a sales weighted basis have decreased in a parallel fashion and by the same amount, (reference, U.S. Department of Health and Human Services, "Reducing the Health Consequences of Smoking: A Report of the Surgeon General," at 88; 1988-1990 numbers based on information similar to that used in the 1989 Surgeon General's Report.) Chart II presents the results of a longirudinal analysis for the latest tar and nicotine results on 483 brands to be reported by the Federal Trade Commission. The correlation coefficient of 0.975 is essentially perfect correlation between tar and nicotine and shows that there is no manipulation of nicotine.

We do not add nicotine to our products, except in two insignificant and incidental cases: (1) through the use of denatured alcohol, which is required to contain small amounts of nicotine under regulation by the Bureau of Alcohol, Tobacco and Firearms; and (2) through the use of a few flavors which incorporate a tobacco extract that contains some nicotine. The combined amount of nicotine from these sources is too small to be measured in the final products. 


\section{$-3-$}

One of the processes for the production of reconstituted tobacco, which is used in the manufacture of cigarettes, involves temporary separation and reapplication of water-soluble components of tobacco, including nicotine. This process, which is well described in the published literature, including three Surgeon General's reports, results in a reduction of nicotine in the finished cigarette. Other processes which have been described in the literature result in similar products but do not involve the temporary separation of water soluble components of tobacco. Again, some nicotine is lost during the manufacture of reconstituted sheet with the sheet containing much less nicotine than leaf tobacco.

I repeat, the allegations of DAY ONE and David Kessler concerning nicotine manipulation are false and are inconsistent with reported tar and nicotine data on commercial cigarette brands. 


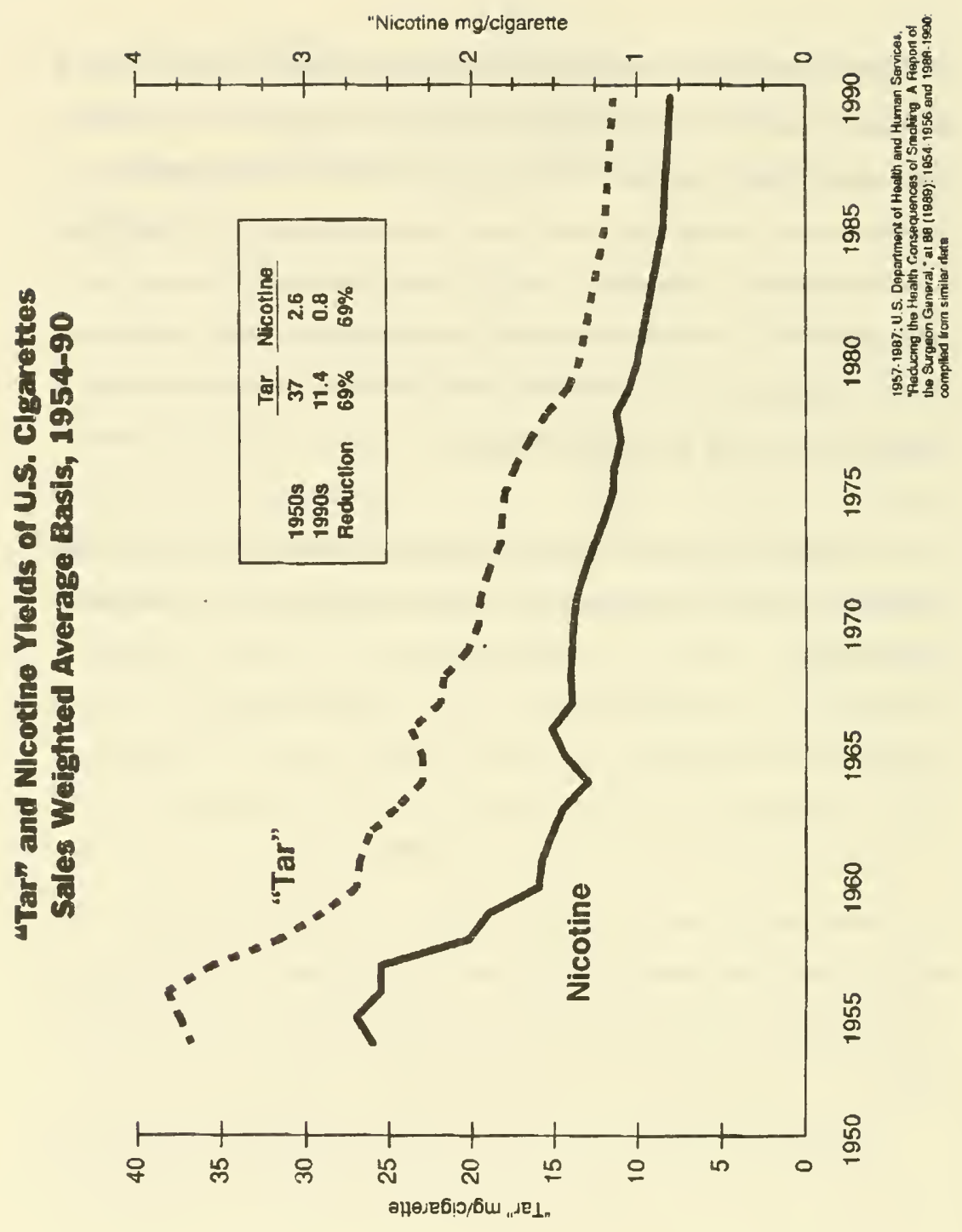




\section{Tar and Nicotine of the Smoke of Domestic Cigarettes}

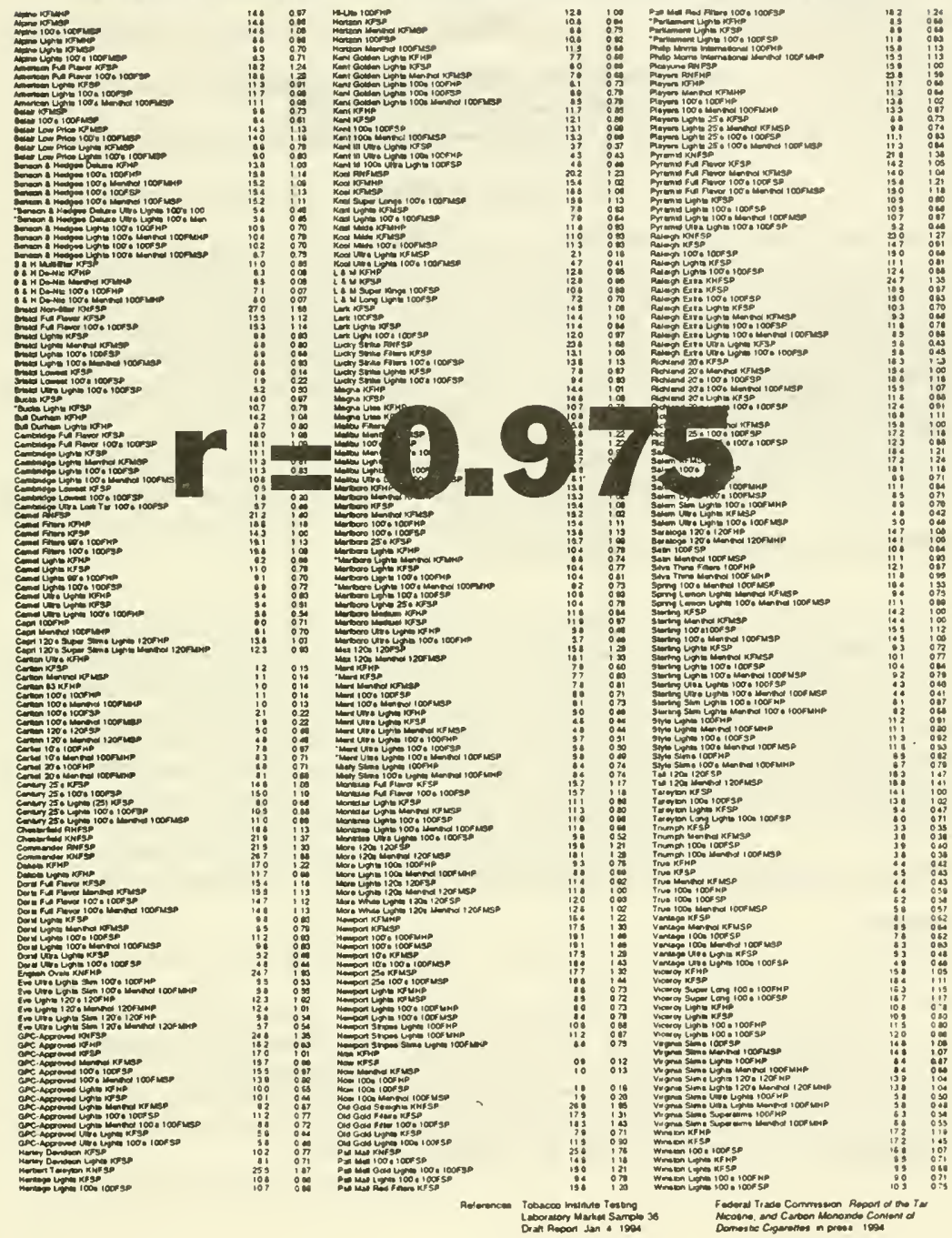




\title{
STATEMENT OF DR. STEPHEN M. RAFFLE
}

\author{
to the
}

\section{Subcommittee on Health and the Environment Committee on Energy and Commerce \\ United States House of Representatives}

\section{March 25, 1994}

I am Stephen Raffle, a physician who practices psychiatry in Oakland, California. For seventeen years I served as an Assistant Clinical Professor of Psychiatry and for ten years as an Assistant Clinical Professor of Orthopedic Surgery at the University of California School of Medicine, San Francisco. I hold a Diplomate in psychiatry with the American Board of Psychiatry and Neurology. My B.A. is in physiology from the University of California, Berkeley, and my medical degree is from the Chicago Medical School.

In the course of more than twenty years of clinical practice, I have evaluated and/or treated many patients with various drug addictions and drug intoxications. This includes heroin and other opiates, alcohol, amphetamines, barbiturates, and various forms of cocaine. Additionally, I have worked with many people with weight problems and other habitual and compulsive behaviors. Thus, I bring to you the perspective of a teacher and clinician with considerable first-hand patient treatment experience.

I have reviewed H.R.1247 as well as the related Surgeon General reports issued in 1964, 1979, 1988 and 1990. Additionally, I have read many source articles on cigarette smoking behavior, hard drug addictions, habitual behaviors, and compulsive behaviors. 
I appear before you today in order to address two parts of this bill, the proposition that cigarette smoking is addictive (indeed, as addictive as heroin and cocaine), and the proposed label warning that once a person has started smoking he or she may not be able to quit. From a practical, clinical and scientific perspective, cigarette smoking behavior is not the same as seen in actual hard drug addiction. In order to include smoking as an addiction, one must redefine that term, water down its meaning, and ignore critical differences involving every aspect of these behaviors. This is precisely what the Surgeon General did in his 1988 report to Congress. Smoking became an addiction because the Surgeon General changed its definition, not because of new scientific discoveries. The finding, therefore, rests solely on semantics. Further, the salient features of this new definition of addiction are shared by many other well-liked and common habits, such as eating, coffee drinking, exercise and even interpersonal relationships.

But more than semantics and labels are involved here. Presenting smoking as a hard drug addiction and warning that a person may not be able to quit has unintended negative ramifications. It victimizes smokers and makes the process of stopping seem more difficult than it really is. . It also sends the wrong message to young people about the true dangers of hard drug usage by equating the effects of heroin and cocaine with the behavioral effects of cigarettes.

I do not appear here as an apologist or promoter of cigarette smoking. Fundamentally, I believe it is a risk factor in the development of some diseases. For that reason, within the context of therapy, I help my patients examine their motives for smoking and, if they wish, help them to stop. This process is like that involved in losing weight or changing one's exercise pattern. It is a far cry from treating hard drug addiction. 
But what is it about truly addicting drugs that differentiates them from habitual behaviors such as cigarette smoking, coffee drinking, eating or exercise?

The differences are present in all phases of these behaviors. First is the effect produced by ingestion. A person on hard drugs is intoxicated. Intoxication is fundamentally an organic brain syndrome whereby the person's state of consciousness is altered, reasoning is impaired, coordination is affected and memory and concentration are substantially altered. Further, mood is visibly changed, judgment is warped, delusions and/or hallucinations may occur, and unconsciousness or sudden death will result from substantial overdose.

Intoxication does not occur with cigarette smoking. Measured and observed effects on mood and mental functioning of cigarette smoking reveal that it is similar to the effect produced by drinking a cup of coffee and very dissimilar from the effects produced by hard drugs. People who smoke think clearly and make reasoned decisions. Smokers perform with competence at the highest levels in their personal and professional lives. They make complex and difficult decisions without any interference from their cigarette smoking.

The second difference occurs upon cessation of drug use. Abrupt cessation of a hard drug following regular use will inevitably and predictably result in a "classic" withdrawal syndrome. This generally requires medical hospitalization for clinical management because drug withdrawal can be a life-threatening situation. The symptoms of withdrawal due to physiologic dependence include severe vasomotor instability (rapid blood pressure changes), muscle cramps and nausea, hallucinations and/or delusions (in alcohol withdrawal they are called delirium tremens or "DT's"), 
dangerous changes in body temperature, seizures, mood changes often accompanied by paranoia, and suicidal ideation and attempts. Death may ensue even if the patient is hospitalized and properly medically managed. Withdrawal with hard drugs is so severe as to render the addict incapable of making or carrying out reasoned decisions. In fact, mentation and judgment are impaired for months and even years following resolution of the acute withdrawal phase.

Cigarettes and nicotine cessation is not really withdrawal because it produces none of these signs or symptoms. It is impossible to predict whether or not a smoker will have any tobacco abstinence discomfort based on the number of cigarettes smoked per day or the duration of smoking. The clinical complaints associated with cigarette abstinence are a far cry from hard drug withdrawal. The most uncomfortable, complaining cigarette abstainer does not remotely resemble a person who is withdrawing from hard drugs. But they do resemble those of a dieter or other person giving up a well-liked habit or close relationship. The symptoms and complaints experienced by people changing these other well-liked habits are of the same magnitude and degree, and include mild apprehension, restlessness, periodic recurrent thoughts about the lost object or person and a repeated wish to reunite or resume the habit. But people changing common habits like cigarette smoking continue working while "withdrawing" and continue to meet their responsibilities without significant disruption of reasoning, judgment, concentration or efficiency.

In addition to the acute organic brain effects of intoxication, chronic administration of hard drugs may cause irreversible brain changes before or after the offending drug is withdrawn. The person may be left demented or psychotic. Long-term cigarette use does not produce this result. 
The pharmacological effects of hard drugs lead to a change in personality and pursuit of a lifestyle which is dominated by the drug. Obtaining drugs and getting "high" supplant all other values. Family responsibilities are shirked, employment becomes unpredictable, morality is eroded, illegal activity is often resorted to in order to obtain the hard drug, and marital discord is usually evident. Abuse and the emotional scarring which results can last for generations. On psychological tests the personality configuration of a hard drug addict is distinguishable from that of other patient groups.

Cigarette smokers do not suffer these psychological and sociological impairments. They are not behaviorally dominated by a drug-induced state. They can drive automobiles, fly airplanes, drive heavy machinery and even be members of Congress without mental impairment. In my experience, cigarette smokers are not different from the general run of normal, honest citizens. Nicotine does not govern their actions or decisions. Smokers can and do abstain for long periods without untoward effects if external circumstances dictate it (religious observances, hospitalization, work place, airplanes).

For the hard drug user following detoxification and stabilization, a new lifestyle must be established. The addict must rebuild nearly every aspect of his or her life, and rectify the emotional (and physical) damage to loved ones and family. He must learn to face life without being constantly intoxicated and must learn new values to supplant drug seeking. Often successful abstinence involves leaving behind old friends and haunts and establishing enduring relationships in support groups modeled on Alcoholics Anonymous. For many, it will be a life-long undertaking requiring ongoing reinforcement. 
None of these impediments are present when people stop smoking. Since 1964, more than 40 million people have stopped smoking permanently without any outside intervention or assistance. The overwhelming majority (approximately $95 \%$ of smokers) have quit on their own. With hard drug addiction, self-help quitting, or "spontaneous remission" to borrow the Surgeon General's term, is an extremely rare occurrence. For the cigarette smoker, my clinical experience and numerous studies have demonstrated that the components of successful abstinence are commitment, personal responsibility and self-efficacy. By self-efficacy I mean a person reasonably believing he can accomplish an undertaking. As with successful dieting, the smoker must abandon a pleasurable activity and modify a behavior in order to obtain a greater long term benefit. The smoker need not, however, rebuild his life to succeed. Neither does he face perpetual struggle requiring therapeutic support.

It is often claimed that the strength of the so-called addiction to tobacco is shown by the fact that when put on the spot, $80 \%$ of smokers claim to wish that they could stop. The same could be said of overweight people, those in need of exercise, or those engaging in any other habit that is frowned upon by others. It says nothing about addiction or the difficulty experienced in changing habits. As noted above, in order to change a habit, one must commit to change, have a positive attitude and follow through. This is precisely how the 40 million former smokers successfully stopped on their own when they chose to.

Labeling smokers as hard drug addicts tends to destroy those components that are necessary to successful quitting. It makes smokers feel like victims who must receive "treatment" to be successful non-smokers. The facts reveal this to be untrue. In reality, much of what I do when I 
counsel smokers is educate them regarding what is actually involved in smoking behavior and explain to them that they can choose to successfully stop without sophisticated treatment. Calling smoking an addiction provides some smokers a convenient, external excuse, an easy out if you will, for not initiating abstention or for giving up too easily at the first sign of discomfort. Many individuals who want to continue smoking have already created the personal myth that they are addicted, thereby feeling overwhelmed and excusing themselves for not trying to stop or persevering in the effort. Officially endorsing that myth perpetuates and exacerbates this situation. They are now officially forgiven their failure.

Perhaps of greater importance is the effect on young people of the message that smoking is just like heroin and cocaine. Every day they see smokers who are productive, upright citizens and who fulfill their responsibilities. They also see adults giving up smoking without great difficulty, hospitalization or lifelong therapeutic support. To tell these people that smoking crack cocaine or taking heroin will not effect them in a different way than smoking cigarettes encourages experimentation with these hard drugs. Such experimentation, as we all know, often leads to disastrous results.

Does the addiction label frighten away potertial smokers? Actually, it makes cigarettes more controversial and creates, in certain groups, an enticement to defy authority by smoking, or to treat smoking as a rite of passage into adulthood. I know of no adolescent who abstains from alcohol because it is an addicting substance (and that addiction is real!); I do know many who drink to defy authority or prove they are adults. (They also drink to get intoxicated.) For some, designating cigarettes as an addicting substance could well have a result opposite to the one desired. 
In my review of the literature regarding smoking behavior, I have been struck by the use of hyperbole and innuendo in reporting study results. Labeling smoking as an addiction provides a prime example. Another involves the claim that eigarette smoking is a "gateway drug" for the use of illicit drugs. It is claimed that cigarette smoking is a "powerful predictor" of future illicit drug use. Proponents appear to be arguing that cigarettes produce a "hunger" for more powerful drugs. Such could not be further from the truth. First, it should be noted that research underlying this argument reports smoking as a weak predictor at best, and finds it to be alcohol usage that predicts both cigarette smoking and illicit drug use. Secondly, the vast majority of cigarette smokers have obviously escaped the alleged gateway and never succumb to hard drug abuse.

The simple explanation for this supposed association shows it to be one of coincidence, rather than causality. Illicit drug users are often rebellious and have risk taking personalities. These types also represent a small percentage of those who choose to smoke cigarettes. Thus, as admitted in the 1988 Surgeon General's report, a common personality construct underlies both uses. Certainly, there is no evidence whatsoever that cigarette smoking causes people to start abusing hard drugs. Would the proponents have us believe that without cigarettes there would be no alcohol or hard drug abuse? The fact is that illegal drug use is on the rise when smoking is declining.

However laudable one believes the goals of those who seek a smoke-free society, we should all agree that government-sponsored messages about smoking should be founded in fact, based on truth and certainly should not have negative repercussions. The proposed addiction warning and the assumption upon which it is founded are based neither in science nor fact and will have unintended harmful results.

Thank you Mr. Chairman and members of the Committee. I would be happy to respond to any questions you may have. 
Mr. Chairman, members of the Subcommittee, my name is John slade. I am an internist specializing in addiction medicine. I am a member of the Department of Medicine at the Robert Wood Johnson Medical School of the University of Medicine and Dentistry of New Jersey and am the chairman of the Committee on Nicotine Dependence of the American Society of Addiction Medicine. My professional work largely involves the clinical and public health aspects of addictions, especially addiction to nicotine.

Cigarettes cause more illness and death in the United states than anything else (USDHHS, 1989). The nicotine in cigarettes makes cigarettes addictive. Cigarette manufacturers know their customers want nicotine, and their products are designed to deliver nicotine. The evidence presented here will show that cigarette manufacturers intend to affect the function of their customers' bodies. This, in turn, provides a basis for regulation of cigarettes as drugs under the Food, Drug and Cosmetic Act. Moreover, they intend to sustain addiction to nicotine in customers dependent on the drug.

What causes cigarette smoking? The cause of smoking is not advertising, it is not low price, it is not widespread availability of the product, it is not smoking by family members, and it is not peer pressure. These things lamong the others described as risk factors in the 1994 Surgeon General's Report (USDHHS, 1994)) facilitate the development of smoking, but they are not themselves causal. The fundamental cause of cigarette 
smoking is nicotine, and addiction to nicotine largely sustains the practice (USDHHS, 1988). Without nicotine, adolescent tobacco use would all but vanish.

\section{Nicotine Addiction}

The 1994 Surgeon General's Report tells us that it is not the first cigarette that produces addiction. It is the second, the third, and those that follow. Most adolescents who have ever smoked as few as half a carton of cigarettes have a very difficult time stopping.

What do I mean by the term "addiction"? The standard clinical definition for a drug addiction - also called a drug dependence - is loss of control over use of the substance plus its continued use despite problems. This definition is embodied in the approach taken to the addictions in the current edition of the Diagnostic and Statistical Manual (DSM) of the American Psychiatric Association, published in 1987 (American Psychiatric Association, 1987). The DSM is the standard authority for diagnosing addictions in this country. Nicotine fits this definition very well. Nicotine also fully satisfies the research-oriented criteria employed by the Public Health Service the 1988 Surgeon General's Report, The Health Consequences of Smoking: Nicotine Addiction (USDHHS, 1987). ${ }^{2}$

1 Spokesmen for cigarette makers have taken issue with whether or not nicotine is addicting. While questioning the interpretation of some of the data on which this conclusion is based, they have mostly questioned the definition of addiction. 
Nicotine, a central nervous system stimulant, produces effects in the brain that are reinforcing. The consumer becomes addicted as he or she seeks the sensations nicotine provides again and again, and the individual gradually requires an increasing dose to obtain the desired effects. Suddenly stopping nicotine use often produces a characteristic withdrawal syndrome characterized by such central nervous system effects as irritability, difficulty concentrating, headache, trouble sleeping, changes in appetite, and feelings of anxiety or depression. These symptoms can persist for weeks unless nicotine is ingested once again, either in the form of a cigarette or some other tobacco product or in the form of a nicotine replacement product such as nicotine gum or a nicotine patch.

The Public Health Service uses a different definition of adiction from that preferred by the cigarette makers. The data strongly support the conclusion that nicotine regularly causes addiction in a very high proportion of users. The government's policies towards tobacco products should be based on its best understanding of the process, as reflected in its understanding of addictive processes and the entire range of relevant data.

Spokesmen for cigarette makers frequently draw attention to the large number of people who have stopped smoking as evidence that nicotine is not addictive. While a large number of people have managed to stop smoking, the conclusion is false. It ignores the fact that more than two-thirds of those who continue to smoke want to quit but feel they cannot. It ignores the fact that a third of smokers try to stop each year. It ignores the fact that the overwhelming majority of quit attempts end in failure. It ignores the fact that spontaneous recovery is a well-known feature of $\underline{\text { all }}$ addictions. (In fact, clinicians and public health officials have long used general advice to stop using drugs to take advantage of this well-known phenomenon.) It ignores the fact that people who have addictions to more than one drug, such as heroin, cocaine, alcohol and nicotine, often regard their addiction to nicotine as the most difficult addiction to stop. Militions of people smoke and are also addicted to alcohol. 


\section{Nicotine Absorption and Basic Cigarette Design}

Nicotine from tobacco products is absorbed in the mouth in the case of moist snuff, chewing tobacco, and cigar smoke, while nicotine is absorbed from the lungs in the case of cigarettes (Gori, 1986; USDHHS, 1988). The reason for this is a major difference in the degree of acidity or alkalinity, or pH, of the nicotine found in these various products. Nicotine at an alkaline $\mathrm{pH}$ is readily absorbed in the mouth while it is not absorbed there at all if the $\mathrm{pH}$ is acidic. Cigarette smoke is acidic while most other tobacco products present nicotine in alkaline form to the oral membranes. Alkaline nicotine is harsh and irritating to the throat (Faitelowitz, 1930; USDHHS, 1988), so it is hard and unpleasant to inhale cigar smoke. The acidic smoke from a cigarette is readily inhaled, however. In fact, unless cigarette smoke is inhaled, nicotine is not absorbed (Gori, 1986).

With inhalation, acidic nicotine is absorbed and transported to the brain far more rapidly and at higher concentration than alkaline nicotine absorbed in the mouth (Henningfield et al, 1990). The difference is like the difference between crack cocaine, which is smoked by inhalation, and powdered cocaine, which is sniffed into the nose. The former is more potent mg for $\mathrm{mg}$ and gives a more intense experience. It is also more addictive.

The cigarette is the most efficient nicotine delivery device on the market today (USDHHS, 1988). Its complex balance of 
various tobacco-derived components and additives including sugars, as well as its paper, filter, and tipping paper are precisely designed to work as a unit to produce controlled doses of an acidic, nicotine-laden smoke for inhalation into the lungs. The cigarette is engineered to deliver carefully controlled doses of nicotine to the smoker's brain.

\section{The FTC Method Tert and Sales Weighted Nicotine Deliveries}

In the mid-1960s, the Federal Trade Commission began to test cigarettes offered for sale in the United States with machinebased measurements. The test parameters, codified in 1969, were derived from some first used in the 1930 s by workers at the American Tobacco Company (Slade, 1993). In the standard test, a $35 \mathrm{ml}$ puff is taken over 2 seconds once a minute until the cigarette is reduced to a certain specified butt length. The results are expressed (in milligrams) as the amounts of nicotine, particulate matter minus nicotine and water ("tar"), and (recently) carbon monoxide that appear in the mainstream smoke generated by the series of $35 \mathrm{ml}$ puffs. ${ }^{2}$

The test has been done consistently on all cigarette brands in wide distribution since 1968, initially by the FTC and recently through. the. Tobacco Institute. These results, combined with brand specific sales data for each year, have permitted the

2 The test results are not enforceable standards. That is there is no requirement that cigarettes brands actually provide the tar, nicotine and carbon monoxide deliveries measured in the samples of the products tested. 
calculation of sales weighted average nicotine deliveries, as depicted in Figure $1 .{ }^{3}$ Figure 1 shows a decline in sales weighted nicotine delivery from around $1.4 \mathrm{mg}$ per cigarette to about $0.94 \mathrm{mg}$ in the period 1968-1991. However, nearly all the decline occurred between 1972 and 1980. Since 1980, there has been no change.

Cigarette manufacturers rely on comparisons based on smoking machine tests to help sell their products. Enclosed with this statement is a recent (1993) advertising insert from the American Tobacco Company for its Carlton brand. The leaflet makes explicit comparisons of various versions of Carlton with brands made by competitors.

\section{The FTC Method Test is a Fraud}

Despite the cigarette companies' reliance on FTC method test results for cigarette brand promotions, the FTC method test does not provide consumers with a reliable index of the amount of smoke they ingest from a particular cigarette. Unlike all other test results familiar to consumers that are included in the

3 The report of sales weighted nicotine delivery prior to 1968 relied upon by Mr. Johnston in his $2 / 28 / 94$ letter to Dr. Kessler is unavailable to me. The source referenced in the 1989 Surgeon General's Report (USDHHS, 1989, page 88) was a private communication from Helmut Wakeham of Philip Morris to another investigator in 1976. Neither the 1988 Report nor the chart it references include the actual numerical values being plotted. Unless the analytic methods used are shown to be comparable to those employed for the period 1968-1991, and unless the actual values are available for replotting and analysis, the numbers taken off these charts prior to 1968 should not be used in comparisons with the later time period. 


\section{6}

March 25, 1994

Page 8

labeling for other ingested items such as foods or drugs, FTC method test results do not accurately reflect the bioavailability of the measured components. The test is, therefore, a fraud.

Neil Benowitz and his colleagues at the University of California at San Francisco have shown that nicotine yields as measured with the FTC method do not significantly correlate with blood levels of cotinine, the major metabolite of nicotine (Benowitz et al, 1983). This work has been confirmed by Gio Gori of the Franklin Institute Policy Analysis Center and his colleagues (1986) as well as by David Coultas and his colleagues at the University of New Mexico School of Medicine (Coultas et al, 1993). There is, however, a marked correlation between the number of cigarettes smoked and cotinine levels.

In two detailed studies, smokers ingested substantially more nicotine from individual cigarettes and from an alternate nicotine delivery device than predicted by the FTC test. The first study, by Dr. Benowitz's group (Benowitz et al, 1991), found that smokers who inhaled absorbed an average of $2.49 \mathrm{mg}$ of nicotine from a cigarette, when only $1.1 \mathrm{mg}$ was predicted by the machine test. This is a $127 \%$ increase over the machine-based result. The second study, by the biobehavioral research group at the R. J. Reynolds Tobacco Company (R. J. Reynolds, 1988a), found that smokers who inhaled absorbed an average of $1.0 \mathrm{mg}$ of nicotine from a cigarette rated at $0.66 \mathrm{mg}$ (51\% increase), and the same subjects absorbed an average of $0.7 \mathrm{mg}$ of nicotine from 
a prototype of Premier that was rated at $0.34 \mathrm{mg}(106 \%$ increase). ${ }^{4}$

People don't smoke like the machine. As detailed in the 1988 Surgeon General's Report (USDHHS, 1988), they generally take larger puffs than $35 \mathrm{ml}$ and do so in a shorter amount of time than 2 seconds. Robinson, Pritchard and Davis of R. J. Reynolds also found that smokers take larger puffs (mean $51 \mathrm{ml}$ ) (Robinson et al, 1992). ${ }^{5}$

Shorter, larger puffs, like those most smokers actually take, move air at a higher velocity through the cigarette. This may permit proximal parts of the cigarette to reach higher temperatures than those reached under FTC test conditions. This effect would be expected to release more volatile components such as nicotine into the smoke. This, in turn, predicts that, puff by puff, the smoke ingested by smokers who draw in air through the cigarette at higher velocities than that used by the machine will have higher concentrations of nicotine than those taken by

4 In all, three of 22 subjects in these two studies had strikingly lower nicotine leveis than the other 19 . In interpreting their data, both teams of investigators assumed that a low nicotine level meant that the subject inhaled very little smoke. The RJR team did not even include the two non-inhaling subjects in its study in their final analyses. The RJR team was only interested in the data from the ten subjects who inhaled.

5 Their paper, "Psychopharmacological effects of smoking a cigarette with typical "tar" and carbon monoxide yields but minimal nicotine," is included as an attachment to this statement. 


\section{8}

the machine with the identical cigarette. ${ }^{6}$

In actual use, the cigarettes most people smoke provide them with similar amounts of nicotine over the course of a day regardless of the FTC test-rated yield. This is a function of both the number of cigarettes smoked and the way those cigarettes are smoked. The FTC test does not provide consumers with reliable information about what they can expect to ingest when smoking cigarettes of a particular brand.

\section{The Control of Nicotine in Cigarettes}

In 1952, the Food and Drug Administration found that cigarette tobacco from the five leading brands contained an average of from 1.58 to 1.82 percent nicotine on a dry weight basis (Wright, 1952). These values may be compared to the 1.5 to $2.5 \%$ nicotine $\mathrm{Mr}$. Johnston reported for finished cigarettes in 1994 in his recent letter to Dr. Kessler. If anything, cigarettes on the market forty years ago appear to have contained less nicotine than many do now. This suggests that the losses of nicotine during manufacture from raw leaf to finished product may have been more pronounced then than now. However, the world of cigarette manufacture was vastly different four decades ago.

In 1950, the-Federal Trade Commission found,

6 Greater heating of the proximal part of the tobacco rod and of the filter by increased velocity of the draw would be expected to release even more nicotine from these potentially nicotine-enriched regions. The technology for enriching these regions with nicotine is discussed in the next section. 
Because of the large amount of tobacco leaves used in the manufacture of cigarettes and the extreme variability in nicotine content of the leaves, it is not practically possible for respondent [P. Lorillard Company], or any of the other manufacturers of leading brands of cigarettes, to maintain a constancy of nicotine in the finished cigarette. (Federal Trade Commission, 1950, page 6)

This is no longer the case. Innovations in materials processing and cigarette design since the 1950 s have made it possible for cigarette manufacturers to make products that are uniform despite the variability inherent in their chief raw material. The Appendix summarizes some patents that illustrate major ways cigarette manufacturers can use modern technology to assure a uniform product, a product that performs as intended, as a nicotine delivery device. The patents demonstrate a concern with providing predictable, controlled doses of nicotine to the consumer, engineering that makes it easier for the consumer to titrate his or her nicotine level. This overarching concern is especially clear in patent no. 3,584,630 from Philip Morris.

Reconstituted tobacco (paper sheets made from stems, fines and trash) has an inherently lower nicotine level than does tobacco leaf. Similarly, stems themselves, which are often finely cut and rolled so that they can be incorporated into cigarette blends, have a far lower nicotine content than the leafy part of the tobacco leaf (lamina). These deficiencies, as well as the variability inherent in different batches, can be compensated for with the wide variety of techniques illustrated 
in the Appendix.?

Nicotine is lost during processing, and it can be (and is) readded at multiple steps. Unlike the cigarette of 1950 , the final result is a product that is uniform and consistent. The customer is thereby assured of a predictable subjective effect from a given brand style.

The added nicotine can be recycled within the factory or it can be purchased from outside suppliers. The Bureau of Alcohol, Tobacco and Firearms licenses Special Denatured Alcohol Number 4 (SDA 4) exclusively for use in the manufacture of tobacco products. SDA 4 is prepared according to a formula found at 27 CFR 21.38. (see Appendix) Tobacco extracts, designed for specific applications and with varying nicotine content, are available from 32 different suppliers in 10 different countries (Table 1). Nineteen extract suppliers are either based in the $U$. S. or have subsidiaries here. The existence of so many suppliers suggests that there is a relatively substantial market for these materials.

7 LTR Industries, a subsidiary of Kimberly Clark, makes reconstituted sheet with nicotine content that varies from 0.7 to 3.5 percent. (Silberstein, 1985) An advertisement for LTR's sheet tobacco emphasizes this property. Another advertisement attempts to persuade cigarette manufacturers to use sheet instead of cut, rolled stems. It offers to process stems from a factory into sheet and so reduce the overhead required to operate a stem processing facility. Copies of both ads are included with the statement. 


\section{Alternative Nicotine Delivery Devices}

Table 2 lists many of the novel devices that have been patented which imitate the function of cigarettes. Figure 2 is an illustration taken from one of the patents for these devices assigned to Philip Morris. The provision of heat, from electricity, as in the device illustrated in Figure 2, or from combustion, as in Premier, (needed to volatilize pharmacologically effective doses of nicotine) is a common feature. The individual patents and the body of work taken as a whole demonstrate a core concern with delivering material to consumers that is at least relatively free of most if not all toxins other than nicotine. Some patents mention nicotine, some "tobacco flavor," and some only "flavor." The pair from B.A.T. and Brown \& Williamson are noteworthy since the British version explicitly discusses nicotine, while the very similar invention patented by its U. S. subsidiary at the same time makes no mention of nicotine or of tobacco. It only discusses "flavor."

The Imperial Group patent explicitly mentions the inhalation of nicotine as a goal sought by consumers of cigarettes.

\section{Industry Research on Nicotine}

The Council for Tobacco Research, Philip Morris, and R. J. Reynolds have each funded substantial programs of research on the pharmacology of nicotine. In addition to a program of extramural research, R. J. Reynolds has supported an intramural nicotine laboratory since at least the early 1980s. Funded research has 
encompassed the entire spectrum of subjects relevant to nicotine pharmacology. Studies have ranged from basic work on nicotine receptors and nicotine analogues to human psychopharmacology studies. The existence of these research programs means that the cigarette industry is knowledgeable about all aspects of the pharmacology of nicotine.

While there is a very large body of published research on the pharmacology of nicotine, there is remarkably little on the contribution nicotine makes to the taste and flavor of tobacco products. In fact, apart from a few patents in which experimental cigarettes were assessed for flavor, taste, harshness and the like, I cannot recall a single published study since the 1930 s in which this aspect was a central focus of the research. ${ }^{8}$

\section{Cigarette Smoke Inhalation is Intended by the Manufacturers.}

Cigarettes are designed to facilitate inhalation, and nicotine from cigarettes can only be absorbed by inhalation. This is deliberate and intentional on the part of the manufacturers.

8 The existence of Next, the denicotinized cigarette from Philip Morris, suggests that substantial quantities of nicotine are not necessary for the achievement of characteristic tobacco taste and flavor. Philip Morris offered this product in three different packagings: as Next, as Merit de-Nic and as Benson \& Hedges de-Nic. It is inconceivable that a company as careful about its products as Philip Morris would have done this unless it knew from careful premarket testing that these products provided the taste sensations of conventional cigarettes. 
- Both the R.J. Reynolds Tobacco Company and the American Tobacco Company referred to inhalation as part of the smoking process in their advertising in the 1930 s (Tye, 1986). The text of a Lucky strike ad from 1932 (American Tobacco Co., 1932) read in part,

\section{Do you inhale?}

What's there to be afraid of?

7 out of 10 inhale knowingly - the other 3 do so unknowingly. ...

Do you inhale? Of course you inhale! Every smoker breathes in some part of the smoke he or she draws out of a cigarette. ${ }^{9}$

- Until such claims were banned by the FTC in 1955. cigarette advertising often featured claims of reduced throat irritation. Table 3 provides an example of this phenomenon from each of the six major cigarette manufacturers circa 1952. Throat irritation is only an issue if the consumer inhales. If a puff of smoke is taken in and then expelled from the mouth without inhalation, there is no impact on the throat. Therefore, claims of reduced irritation are the equivalent of claims for ease of inhalation.

- If inhalation were a misuse of the product, the abundant evidence of harm from inhalation should have led the companies to take firm steps to warn its customers against inhalation and to change cigarette design to discourage the practice. Nothing of the sort this statement. 
has happened in forty years.

- Rather than discourage inhalation by product design and by consumer warnings, the industry has conducted elaborate animal studies of tobacco smoke inhalation. For instance, the Council for Tobacco Research, through its Special Projects operation, funded a $\$ 10$ million mouse study under a contract titled "Smoke inhalation studies in mice." (Henry and Kouri, 1984; Colby, 1992)

- William L. Dunn, Jr., of the Philip Morris Research Center, speaking at a CORESTA-TCRC symposium in 1972 , repeatedly referred to the fact that smokers inhale and consequently absorb nicotine. The thesis of his paper is that absorption of nicotine produces effects that the smoker has sought (Dunn, 1972).

- The R.J. Reynolds Tobacco Company treats inhalation as a major feature of intended cigarette use. When the company sought to show the scientific community how cigarette-like Premier was, it did not publish taste tests. Instead, it published a detailed study of the pharmacokinetics of nicotine, comparing nicotine absorption from a cigarette with that from prototypes of Premier. (RJ Reynolds Tobacco Company, 1988)

- An Imperial Group Limited patent for a novel nicotine delivery system notes, "Among the reasons why most people smoke conventional cigarettes is that they wish to inhale an aerosol containing nicotine." (Imperial 
Group Limited, 1982)

The inhalation of mainstream cigarette smoke, with its resultant obligatory absorption of nicotine, is an integral, foreseen, and intended part of cigarette smoking.

\section{Some Intended Pharmacologic Effects}

During the segment about cigarettes on the February 28, 1994 broadcast of Day one on $\mathrm{ABC}$, J. Donald deBethizy, Director of Research and Development for R. J. Reynolds, declared that people smoke because they are "looking for a pleasing sensory experience with mild pharmacology." What is "mild pharmacology?"

Advertising for Camel brand cigarettes in the $1930 \mathrm{~s}$ emphasized the ability of smoking to give the customer a lift and to calm the customer down (Tye, 1986). Similarly, Lucky strike advertising once included the claim,

Smoke a Lucky to feel your level best!

Luckies' fine tobacco picks you up when you're low...calms you down when you're tense. (Walsh, 1952)

In a court filing, attorneys for Lorillard have noted the benefits of smoking as follows:

Lorillard contends that smokers do derive benefits from smoking cigarettes. These benefits presumably vary from individual to individual, are personal, and cannot be put in a universal or comprehensive-list. Some of the benefits that are commonly reported by various smokers are: enjoyment; pleasure from taste; smell; relaxation; relief of anxiety and stress; reduction of boredom; increased alertness; improvement in concentration; and enhancement of social interactions. (Reply to interrogatories, Covert v Lorillard)

Similarly, attorneys for $R$. J. Reynolds have described the 
benefits of smoking for its customers in the following way:

Among the benefits of cigarette smoking which have been frequently mentioned by smokers or which have been noted in the literature are the following: pleasing taste and aroma; satisfaction; stress reduction; relaxation; stimulation; aided concentration; increased memory retention; alleviation of boredom and fatigue; avoidance of loss of vigilance in repetitive or sustained tasks; and facilitation of social interaction. (Reply to interrogatories, Gilboy v R. J. Reynolds)

The biobehavioral research laboratory at $R$. J. Reynolds has proven that several of these effects are caused by nicotine acting in the brain. A paper by Drs. Robinson, Pritchard and Davis (1992), copies of which have been provided to the Subcommittee, show that cigarettes which do not deliver nicotine (presumably Next brand cigarettes from Philip Morris) fail to change the EEG of smokers in ways characteristic of the relaxing and the stimulating effects of smoking. Conventional cigarettes do cause these EEG changes. The paper proves that it is the nicotine in cigarette smoke, and the nicotine alone, which causes these desired effects of smoking. Throughout the article, the authors emphasize that these are important pharmacologic effects of smoking and that the achievement of these effects are among the reasons people smoke cigarettes.

Cigarette companies often say they design and market their products in response to.consumer demand,.. and the explicit effects mentioned by cigarette companies and discussed in this section are among the effects smokers expect from cigarettes. Since cigarette manufacturers are market driven companies, they intend that their products provide these effects. 
Other effects many customers expect are relief from withdrawal symptoms and help with weight control.

The next two sections explore two particular industry terms in more detail. These terms, "satisfaction" and "physiologic activity," suggest relief of nicotine withdrawal and maintenance of nicotine addiction more than they suggest the relaxation and stimulation effects so emphasized by Robinson, Pritchard and Davis. ${ }^{10}$

\section{Cigarette Manufacturers Intend to Provide Tobacco Satisfaction}

Tobacco satisfaction is a technical term in the tobacco trade that denotes a quality separate and apart from taste and flavor. Its usage indicates that the term describes certain pharmacologic effects of nicotine.

Table 4 lists a few examples of the term in advertisements that clearly distinguish the concept of "satisfaction" from that of "taste."

The introduction of Premier in 1987-88 was accompanied by a variety of descriptions of the product in terms of "satisfaction" and similar sounding terms.

From a patent application:

Smoking articles of the invention....are capable of providing the user with the sensations and benefits of

10 Dr. deBethizy's term, "mild pharmacology," can readily include nicotine addiction since the $R$. J. Reynolds team has tried to make such a strong distinction between nicotine and other addicting drugs based on the fact that nicotine in usual doses does not cause intoxication (Robinson and Pritchard, 1992). 
cigarette smoking. (emphasis added) (Clearman et al, 1988)

From a company press release:

- The cigarette is based on new technology that heats rather than burns tobacco to provide smokers with tobacco taste and satisfaction. (emphasis added) (R.J. Reynolds, 1987)

From the monograph, Chemical and Biological studies...:

R.J. Reynolds' Product Development objectives for developing the NEW CIGARETTE were as follows:

- To provide the tobacco taste and smoking pleasure of other cigarettes, as demanded by smokers... . (emphasis added) (R.J. Reynolds, 1988a, page 35)

- The NEW CIGARETTE is based on a concept that allows a smoker to receive the tobacco taste, sensations and enjoyment of cigarettes without burning tobacco. (emphasis added) (R.J. Reynolds, 1988a, page 43)

From a magazine ad in a test market area:

Smoke that satisfies, yet dissipates almost the moment you exhale. (emphasis added) ${ }^{11}$ (R.J. Reynolds, 1988b)

In none of these five descriptions does "taste" or "sensation" stand alone as a sufficient description of the benefit $R$. J. Reynolds promises consumers from smoking Premier. Additional promises are made for "benefits of cigarette smoking," "tobacco satisfaction," "smoking pleasure," and "tobacco enjoyment."

Additional illumination of the meaning of the term "satisfaction" can be found in two patents, copies of which have been submitted to the subcommittee.

11 One must have first inhaled the smoke in order to be able to exhale it. 
These are patents held by $R$. J. Reynolds, number $4,830,028$ issued May 16, 1989, and number 4,836,224, issued June 6, 1989. The problem these patents set about solving is how to make cigarettes that have low "tar" delivery but which still deliver "a desirable tobacco taste, flavor and satisfaction to the smoker." The patents make repeated reference to "satisfaction" as a quality distinct from "taste." In establishing the need for the present invention, the patents note that simply adding nicotine to low "tar" cigarettes in an effort to solve the problem at hand "generally yields mainstream smoke which may be perceived as harsh or irritating to the mouth, nose and throat of the user."

The solution disclosed in the patents is the use of an organic acid salt of nicotine, especially nicotine levulinate, as an additive to cigarettes having low "tar" deliveries. The patents provide detailed instructions for the synthesis of this salt from nicotine which is 95 to 99 percent pure.

The first patent gives as examples experiments with a $99 \mathrm{~mm}$ cigarette having an FTC "tar" delivery of $4.6 \mathrm{mg}$ and with a king size cigarette having an FTC "tar" delivery of $1.8 \mathrm{mg}$. The desired smoking characteristics, increased nicotine delivery with smoother smoking, were achieved with.the addition of about $37 \mathrm{mg}$ of nicotine levulinate to the first experimental cigarette and about $36 \mathrm{mg}$ of nicotine levulinate to the second (Table 5). The patent emphasizes that the achievement of the desired effect was associated with a reduced $\mathrm{pH}$ of the smoke in the treated 
cigarettes. A cigarette spiked with nicotine alone, without the levulinic acid, had a much higher $\mathrm{pH}$ than even the control and was felt to be "extremely harsh" and "not palatable." These patents show that the addition of nicotine in a form that lowers the $\mathrm{pH}$ of the smoke increases nicotine delivery without raising "tar" delivery and does so in a way that is not harsh. The patent indicates that the use of nicotine levulinate as an additive is a solution to the problem of making a cigarette with a low "tar" delivery produce desired levels of taste, strength and satisfaction to a consumer.

R. J. Reynolds intends to provide its customers with tobacco satisfaction, and tobacco satisfaction has to do with the delivery of inhalable nicotine. Moreover, the term "satisfaction" suggests a state of comfort, of well-being, that can only be sustained by someone already addicted to nicotine by the ingestion of sufficient amounts of the drug to at least alleviate or forestall withdrawal symptoms. Since nearly all of R. J. Reynolds more than 10 million U. S. customers smoke chronically, their actual attainment of satisfaction necessarily involves the maintenance of the addiction to nicotine that most of them have. In intending to provide its customers with "tobacco satisfaction," R. J. Reynolds intends to maintain addiction to nicotine in those addicted to the drug. 


\section{Tobacco Manufacturers Intend to Provide "Desired Physiological}

\section{Activity"}

In patent no. 3,584,630 (issued June 15, 1971), Philip

Morris declares,

It has long been known in the tobacco industry that in order to provide a satisfying smoke, it is desirable to maintain the nicotine content of tobacco products at a uniform level. However, it is difficult to accomplish this result since the nicotine content of tobacco varies widely, depending on the type of tobacco and the conditions under which the tobacco is grown. ...

Maintaining the nicotine content at $a$ sufficiently high level to provide the desired physiological activity, taste, and odor which this material imparts to the smoke, without raising the nicotine content to an undesirably high level, can thus be seen to be a significant problem in the tobacco art. The addition of nicotine to tobacco in such a way that it remains inert and stable in the product and yet is released in a controlled amount into the smoke aerosol when the tobacco is pyrolyzed, is a result which is greatly desirable.

The present invention provides a solution to this longstanding problem and results in accurate control of the nicotine which is released in tobacco smoke.

For Philip Morris, providing a satisfying smoke involves controlling the nicotine delivery in a precise manner so that its customers receive the "desired physiological activity, taste and odor." The "physiological activity" of nicotine can only be understood to mean some of its pharmacologic actions on the brain .

The term "physiology," though, suggests the maintenance of homeostasis, of a state of normalcy, in the body, in contrast to the term "pharmacology," which more suggests a change in the body brought about by a drug. In individuals tolerant to the actions 
of a drug such as nicotine, though, the sudden withdrawal of that drug can produce a dis-ease, an illness, which is experienced as a disturbance of homeostasis. The ingestion of the drug, in alleviating the withdrawal syndrome, is then experienced as a restoration of normalcy. Philip Morris' choice of the term "physiolgical activity," then, implies that the particular pharmacologic actions of nicotine intended in this patent are those associated with the relief of withdrawal symptoms.

The term "satisfying smoke" also sugge.sts this, as discussed in the previous section.

Similarly, Gallahers Limited, a subsidiary of American Brands, refers to nicotine as "a physiologically active agent" in its 1980 patent, number 4,236,532.

Taken together, the two patents on tobacco satisfaction and the two on physiological activity demonstrate that major cigarette manufacturers intend to provide tobacco satisfaction and a restoration of physiological balance to their customers. This is accomplished by the delivery of nicotine to the brain, and both terms refer to the maintenance of an addiction to nicotine.

\section{Nicotine and Caffeine}

Cigarette industry spokesmen frequently compare smoking cigarettes to the drinking of coffee, tea and caffeinated beverages. They speak of smoking as a habit, like coffee drinking. In doing so, they concede that smoking is often at 
least regular, repetitive and compulsive (habitual), and that it is engaged in to achieve a range of effects, including the suppression of withdrawal symptoms (headache in the case of caffeine). However, the analogy should not be pushed too far. It by no means "proves" that nicotine is not addictive.

- An expert group reviewed the clinical and basic science literature on caffeine and concluded that, while it would be important to include the diagnosis "caffeine withdrawal" in standard classifications (DSM IV and ICD 10), the data did not support the inclusion of a rubric for "caffeine dependence," that is, for addiction to caffeine. (Hughes et al, 1992) In contrast, the DSM has had a diagnostic category for tobacco dependence or nicotine dependence since 1980.

- The potential occurrence of harmful consequences because of drug use is an important clinical criterion for addiction. Harm consequent to use is a major problem with nicotine but not with caffeine.

- There are virtually no systematic data on how difficult it is to stop caffeine use, while there are abundant data on the difficulty people encounter in becoming abstinent from nicotine. Stopping smoking is often very difficult to do. Decaf coffees and sodas are popular, but denicotinized tobacco products are not.

More than two-thirds of people who smoke cigarettes want to stop but find this a difficult thing to do. There is no evidence 
that people who use caffeine face similar difficulties. Caffeine withdrawal is a real phenomenon, as is nicotine withdrawal. Unlike caffeine ingestion, however, chronic nicotine ingestion usually produces loss of control over use and continued use despite consequences, the defining features of other drug addictions such as those produced by cocaine, heroin and alcohol. Moreover, from a regulatory perspective, to the degree that the analogy is at all valid, it only supports the conclusion that cigarettes should be regulated as drugs.

- Caffeine is already regulated as. a drug by the FDA when it is sold in tablets as a stay-awake drug or as a component of a pain relieving medication. Beverages that contain caffeine are already regulated as foods by the FDA. Since these beverages are regulated as foods, they avoid being subject to the regulations that govern drugs: The part of the definition of a drug in the Food, Drug \& Cosmetic Act that refers to affecting the structure or function of the body explicitly excludes foods. Tobacco products have never been regulated as foods, and the tobacco industry has never suggested that they should be.

To the extent that tobacco products are to be thought of as affecting the structure or function of the body in ways that are similar to caffeine, they should be regulated as drugs.

The argument that smoking cigarettes is like drinking coffee or tea and that smoking cigarettes is therefore not addictive is 
false. While there are similarities between nicotine and caffeine, there are important differences. Nicotine is highly addictive while caffeine is not. All caffeine-containing products intended for human consumption already are regulated by the Food and Drug Administration. Cigarettes are not.

\section{Nicotine Addiction is Intended}

Is nicotine addiction intended? It is.

Dr. deBethizy's reference to "mild pharmacology" is imprecise, but it evokes the often subtle and varied effects of nicotine on the central nervous system. It is compatible with the conclusion that the cigarette companies intend to create and sustain an addiction to nicotine in many of their customers. The "mildness" that Dr. deBethizy may have had in mind has been discussed in great detail by two of his colleagues at $\mathrm{R}$. J. Reynolds: at the doses usually consumed, nicotine does not produce the harsh, intoxicating changes commonly associated with many other addicting drugs (Robinson and Pritchard, 1992). This, however, is not evidence against regarding nicotine as addicting. The creation of intoxication under common conditions of use is hardly a defining feature of addicting drugs.

"Mildness" is also achieved in another sense. Unlike street drugs, the potencies of which can vary enormously from bag to bag, a given brand style of cigarette produces a very predictable puff profile of nicotine delivery because of advances in cigarette engineering. The cigarette smoker has a far more 
reliable drug delivery device than does the person who obtains drugs of widely varying potency from street dealers. This feature lets the cigarette smoker avoid unexpectedly high or low doses of nicotine, a benefit the user of cocaine or heroin does not have. The cigarette smoker will reliably receive the expected dose, a dose known to the smoker as one that will produce the desired effect. The user of heroin or cocaine does not have this assurance.

The tobacco companies are familiar with the scientific literature on nicotine and know that smoking is a hard thing for most of their customers to stop. They intend to provide their customers with "satisfaction" and to sustain in them a physiologic state of normal feeling. The industry's repeated comparison to caffeine is valid to the extent that caffeine, like nicotine, has a variety of pharmacologic effects, including stimulation, tolerance and withdrawal. However, nicotine is a more potent drug than caffeine: consumers of nicotine find it harder to stop, and experts have concluded that addiction to nicotine is a regular consequence of nicotine ingestion while addiction to caffeine seems so unusual that it has not been deemed necessary to include this diagnosis in comprehensive listings of medical conditions.

In their intention to provide customers with tobacco satisfaction, in their intention to provide customers with physiologic effects, and in their intention to provide customers with a drug that induces tolerance and withdrawal, cigarette 
manufacturers reveal their intention to sustain addiction to nicotine in their nicotine dependent customers.

\section{Discussion}

Cigarettes are intended to affect the structure or function of the body. The manufacturers have developed technologies which permit them to precisely control the dose of nicotine so it is predictable, neither too much nor too little, from cigarette to cigarette. The intended use of cigarettes involves inhaling the cigarette smoke. Inhalation has nothing to do with taste and flavor; inhalation has everything to do with the rapid delivery of nicotine to the central nervous system. The intended effects of cigarette smoking include relaxation, stimulation, the provision of satisfaction, and the promotion of physiologic equilibrium. Any one of these intended effects is sufficient to trigger application of the Food, Drug and.Cosmetic Law to cigarettes, but in fact, all four effects, as well as others, are intended.

In other words, although the cigarette makers do intend to sustain nicotine addiction among many of their customers, there are also other intended pharmacologic effects of smoking which also should result in the Food and.Drug.Administration exerting its regulatory authority over this industry.

objections from cigarette makers that sales weighted nicotine deliveries have been falling over the years are not persuasive that cigarettes are not intended to affect the 
structure or function of the body. The sales weighted average nicotine level has been level for more than a decade, and the actual nicotine taken in by smokers is substantially higher than this curve would suggest. Moreover, the decline came as a consequence of an unprecedented marketing campaign that was designed at least in large part to persuade smokers to switch to low tar cigarettes instead of to stop smoking altogether (Warner and Slade, 1992).

Objections from cigarette makers that their finished products contain less ricotine than are in the raw materials are not persuasive that cigarettes are not intended to affect the structure or function of the body. The average nicotine content of finished cigarette tobacco today appears, on average, to actually be more than it was in 1952. After processing, cigarettes still contain enough nicotine to easily sustain addiction to nicotine.

A major accomplishment of the many advances in cigarette engineering over the last 40 years has been the achievement of precise control and uniformity over nicotine delivery. This achievement was not even conceived of as possible by the federal government in 1950. This achieved consistency of nicotine delivery probably enhances the addictiveness of cigarettes since customers are able to more confidently obtain the precisely desired intake of nicotine from moment to moment.

In 1973, only a few years after his employer had been granted the patent on spiking cigarette filters with nicotine 
adsorbed onto carbon black (pat. no. $3,584,630$ ), the patent that spoke frankly of the need the industry had to carefully control nicotine delivery to achieve optimally satisfying smoke and the desired physiological activity, william Dunn described the cigarette in the following lyrical manner:

...the cigarette is in fact among the most awe-inspiring examples of the ingenuity of man. Let me explain my conviction.

The cigarette should be conceived not as a product but as a package. The product is nicotine. The cigarette is but one of many package layers. There is the carton, which contains the pack, which contains the cigarette, which contains the smoke. The smoke is the final package. The smoker must strip off all these package layers to get to that which he seeks.

But consider for a moment what 200 years of trial and error designing has brought in the way of nicotine packaging:

Think of the cigarette pack as a storage container for a day's supply of nicotine:

1) It is unobtrusively portable.

2) Its contents are instantly accessible.

Think of the cigarette as a dispenser for a dose unit of nicotine:

1) It is readily prepped for dispensing nicotine.

2) Its rate of combustion meters the dispensing rate, setting an upper safe limit for a substance that can be toxic in large doses.

3) Dispensing is unobtrusive to most ongoing behavior.

Think of a puff of smoke as the vehicle of nicotine:

1) A convenient $35 \mathrm{cc}$ mouthful contains approximately the right amount of nicotine.

2) The smoker has wide latitude in further calibration: puff volume, puff interval, depth 
and duration of inhalation. We have recorded wide variability in intake among smokers. Among a group of pack-a-day smokers, some will take in less than the average half-pack smoker, some will take in more than the average two-pack-a-day smoker.

3) Highly absorbable: $97 \%$ nicotine retention.

4) Rapid transfer: nicotine delivered to blood stream in 1 to 3 minutes. ${ }^{22}$

5) Non-noxious administration [sic].

Smoke is beyond question the most optimized vehicle of nicotine and the cigarette the most optimized dispenser of smoke. (Dunn, 1973, pages 5 and 6)

\section{Conclusions}

- Nicotine is the cause of cigarette smoking.

- Nicotine has important psychoactive effects, including addiction.

- Cigarettes are designed to promote inhalation of cigarette smoke and thereby the rapid absorption of nicotine into the body.

- Cigarettes are engineered to deliver optimal doses of nicotine. A wide range of technologies, including the addition of nicotine in various forms, can be employed to accomplish this.

- Cigarette companies intend that their customers experience a variety of pharmacologic effects from the nicotine absorbed from cigarette smoke. Among these intended effects is the sustaining of addiction to nicotine among those dependent on the drug.

- Cigarettes are articles intended by their manufacturers to affect the structure or function of the body and therefore are subject to regulation under the Food, Drug and Cosmetic Act.

12 Actually, delivery is in a matter of a few seconds. 
References

American Psychiatric Association. Diagnostic and Statistical Manual, Third Edition, Revised. Washington, D. C.: American Psychiatric Association, 1987.

American Tobacco Company. "Do you inhale?" Time, back cover, Juily 25, 1932 .

Benowitz, N. L., Hall, S. M., Herning, R. I., et al. Smokers of low-yield cigarettes do not consume less nicotine. New England Journal of Medicine 309:139-42, 1983.

Benowitz, N. L., Jacob, P., Denaro, C., Jenkins, R. Stable isotope studies of nicotine kinetics and bioavailability. Clinical Pharmacology and Therapeutics 49:270-277, 1991.

Clearman, J. F., Gentry, T. L., Shelar, G. R. Smoking article with tobacco jacket. U. S. Patent Number $4,756,318$. Assigned to the R. J. Reynolds Tobacco Company. Filed October 28, 1985, issued July 12, 1988.

Colby, F. Personal Communication, New York City, February 27, 1992 .

Coultas, D. B., Stidley, C. A., Samet, J. M. Cigarette yields of tar and nicotine and markers of exposure to tobacco smoke. American Review of Respiratory Disease 148:435-440, 1993.

Dunn, W. L., Jr. Motives and incentives in cigarette smoking. Presented at the CORESTA-TCRC Symposium, October 25, 1972, Williamsburg, Virginia.

Dunn, W. L., Jr. Motives and incentives in cigarette smoking. 
Typescript. Richmond, VA: Philip Morris Research Center, 1973.

Faitelowitz, A. Über die Bedeutung der Acidität des Tabaks für seine hygienische Beurteilung. Zeitschr. f. Untersuchung der Lebensmittel $60: 518-523,1930$.

Federal Trade Commission. In the Matter of P. Lorillard Company, a corporation. Findings as to the facts and conclusion. Docket No. 4922. May 24, 1950, page 6.

Gori, G. B., Benowitz, N. L., Lynch, C. J. Mouth versus deep airways absorption of nicotine in cigarette smokers. Pharmacology Biochemistry \& Behavior 25:1180-1184, 1986. Henningfield, J. E., London, E. D., Benowitz, N. L. Arterialvenous differences in plasma concentrations of nicotine after cigarette smoking. JAMA 263:2049-2050, 1990.

Henry, C. J. and Kouri, R. E. Final Report: The Council for Tobacco Research - U.S.A., Inc. Contract: CTR-0030: "Smoke Inhalation Studies in Mice." New York: Field, Rich \& Assocates, 1984 .

Hughes, J. R., Oliveto, A. H., Helzer, J. E., Higging, S. T., Bickel, W. K. Should cafeine abuse, dependence or withdrawal be added to $\underline{D S M-I V}$ and ICD-10? Am J Psychiatry $149: 33-40,1992$.

Imperial Group Limited. U. S. Patent 4,340,072, issued in 1982 .

R. J. Reynolds Tobacco Company. R. J. Reynolds Tobacco Co. developing new cigarette. Press release. New York: R. J. Reynolds Tobacco Company, September 14, 1987. 
R. J. Reynolds Tobacco Company. Chemical and Biological Studies on New Cigarette Prototypes that Heat Instead of Burn Tobacco. Winston-Salem, NC: R.J. Reynolds Tobacco Company, $1988 a$.

R. J. Reynolds Tobacco Company. Introducing Premier. Better Homes and Gardens (St. Louis area edition). November 1988 (1988b)

Robinson, J. H. and Pritchard, W. S. The role of nicotine in tobacco use. Psychopharmacology 108:397-407, 1992.

Robinson, J. H., Pritchard, W. S., Davis, R. A. Psychopharmacological effects of smoking a cigarette with typical "tar" and carbon monoxide yields but minimal nicotine. Psychopharmacology 108:466-172, 1992.

Silberstein, D. A. Flavouring reconstituted tobacco. Tobacco Journal International. \#1 for 1985, pages 24-29.

Slade, J. Nicotine delivery devices. In. Orleans, C. T. and Slade, J., eds. Nicotine Addiction: Principles and Management. New York: Oxford University Press, 1993. pages $3-23$.

Tye, J. Sixty Years of Deception: An Analysis and Compilation of Cigarette Ads in Time Magazine, 1925 to 1985. Palo Alto, CA: Health Advocacy Center, 1986.

U. S. Department of Health and Human Services. The Health Consequences of Smoking: Nicotine Addiction. A Report of the Surgeon General. U. S. Department of Health and Human Services, Public Health Service, Centers for Disease 
Control, Center for Health Promotion and Education, office on Smoking and Health. DHHS Publication No. (CDC) 88-8406, 1988 .

U. S. Department of Health and Human Services. Reducing the Health Consequences of Smoking: 25 Years of Progress. A Report of the Surgeon General. U. S. Department of Health and Human Services, Public Health Service, Centers for Disease Control, Center for Health Promotion and Education, Office on Smoking and Health. DHHS Publication No. (CDC) $89-8411,1989$.

U. S. Department of Health and Human Services. Preventing Tobacco Use Among Young People. A Report of the Surgeon General. Atlanta, Georgia: U. S. Department of Health and Human Services, Public Health Service, Centers for Disease Control and Prevention, National Center. for Chronic Disease Prevention and Health Promotion, Office on Smoking and Health, 1994 .

Walsh, F. H. Affadavit. FTC V Liggett \& Myers. November 19, 1952 .

Warner, K. E. and Slade, J. Low tar, high toll. American Journal of Public Health 82:17-18, 1992.

Wright, C. D. Affadavit. In the Matter of Liggett \& Myers Tobacco Company. Washington, D. C.: Federal Trade Commission, October 9, 1952. 

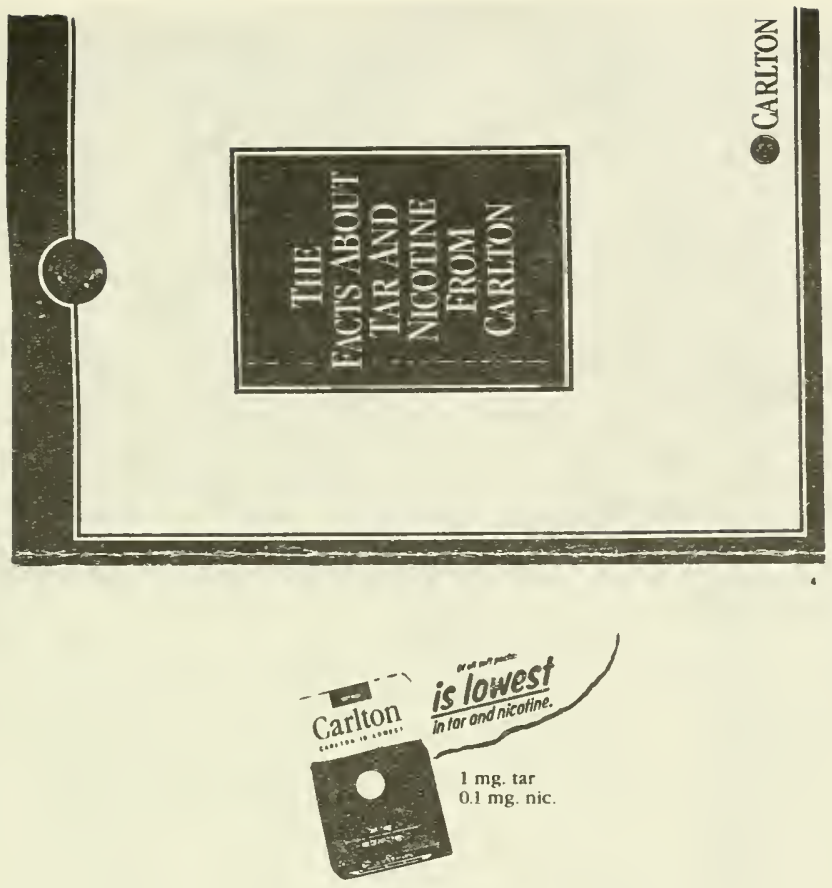

SURGEON GENERAL'S WARNING: Quitting Smoking Now Greally Reduces Serious Risks to Your Health.

Box. Soh Pack. Menthol. 100's Box and 100's Menthol Box $1 \mathrm{mg}$ "iar", $0.1 \mathrm{mg}$ nicoune; 100's Soft Pack and 100 's Menthol Sofi Pack $2 \mathrm{mg}$ "lar" $02 \mathrm{mg}$ nicoune. 120 's. $5 \mathrm{mg}$ "tar" $0.5 \mathrm{mg}$ nicotine Slims $6 \mathrm{mg}$ "lat"

$0.5 \mathrm{mg}$. nicotine, UITRA CARLION Less than $05 \mathrm{mg}$. "iar", less than $005 \mathrm{mg}$ nicolina av per cigatalle by FTC method

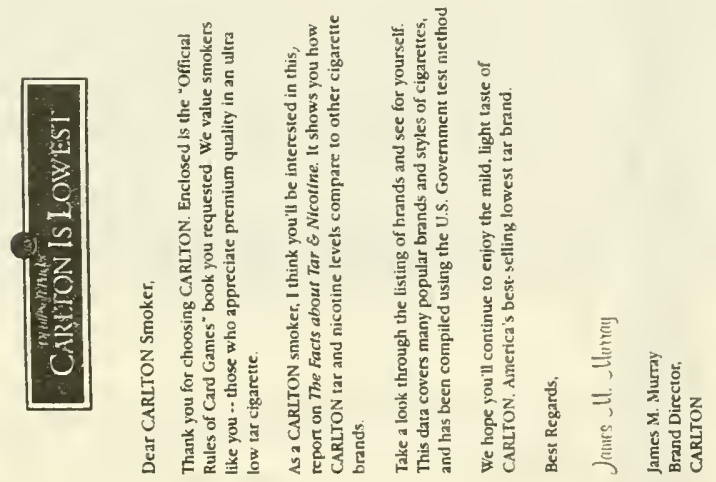




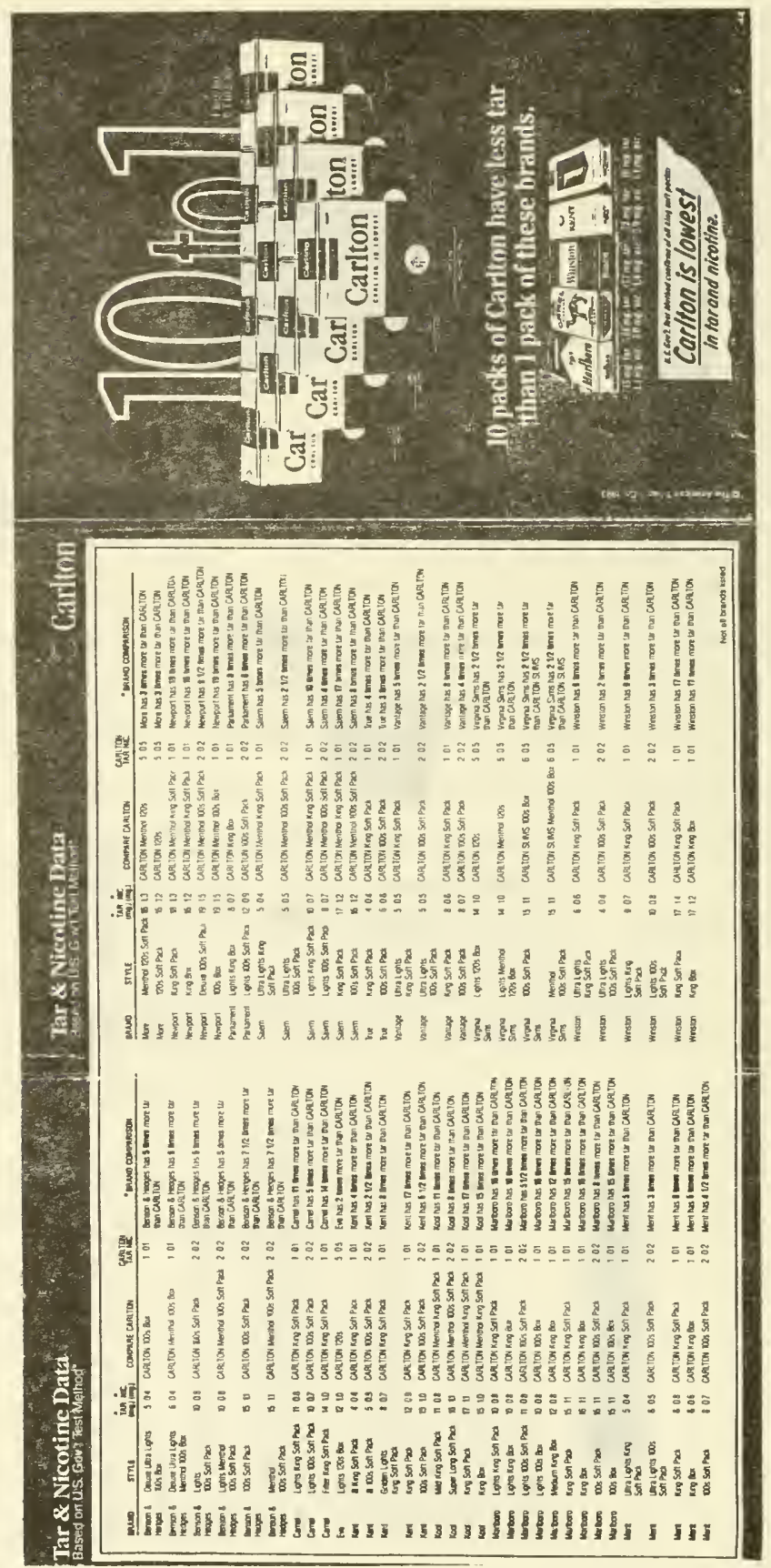




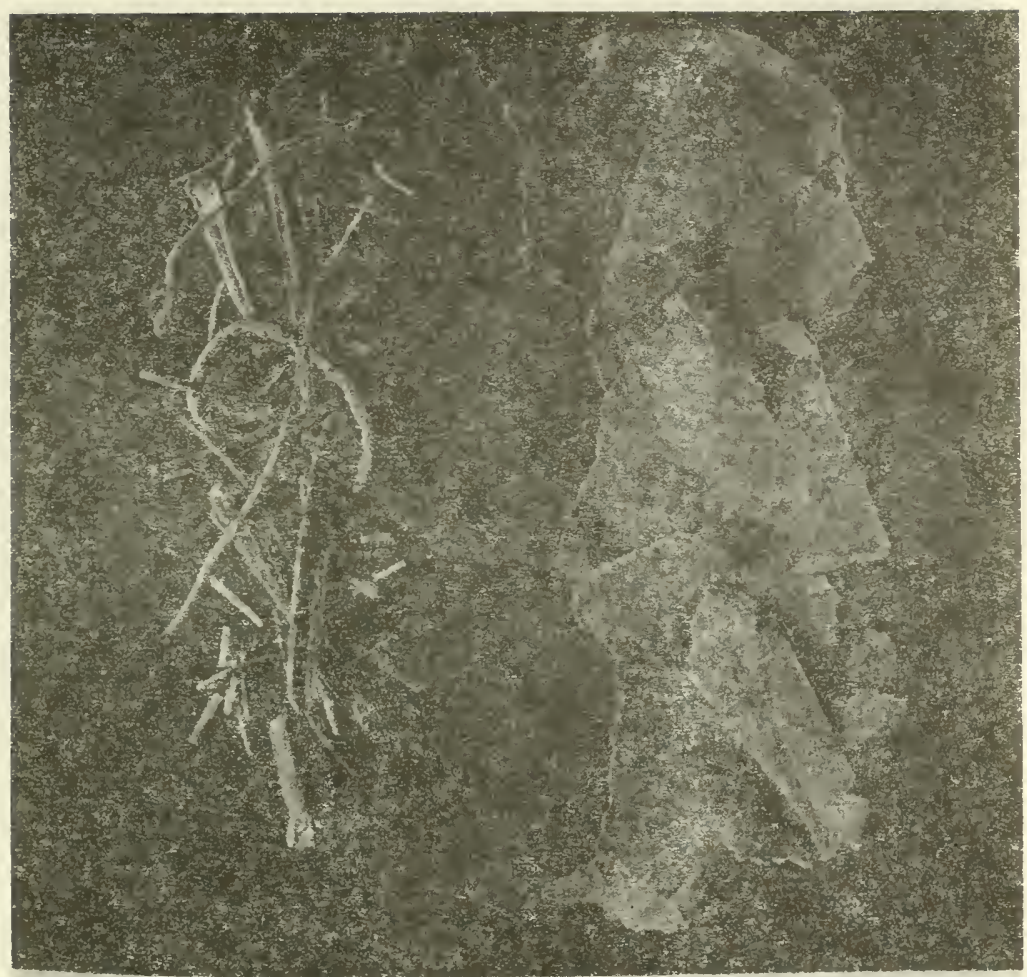

\section{$A$ better solution for your stems: Reconstitution}

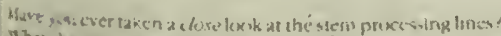

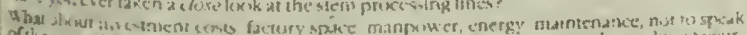
of

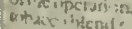

Thanis 20 istive

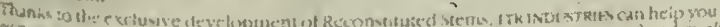

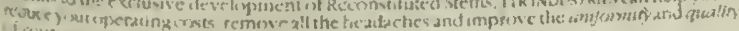

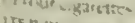

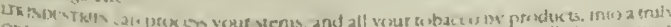

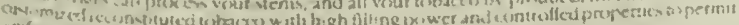

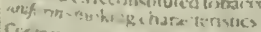

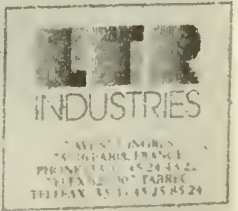

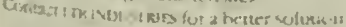

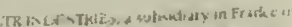

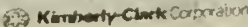




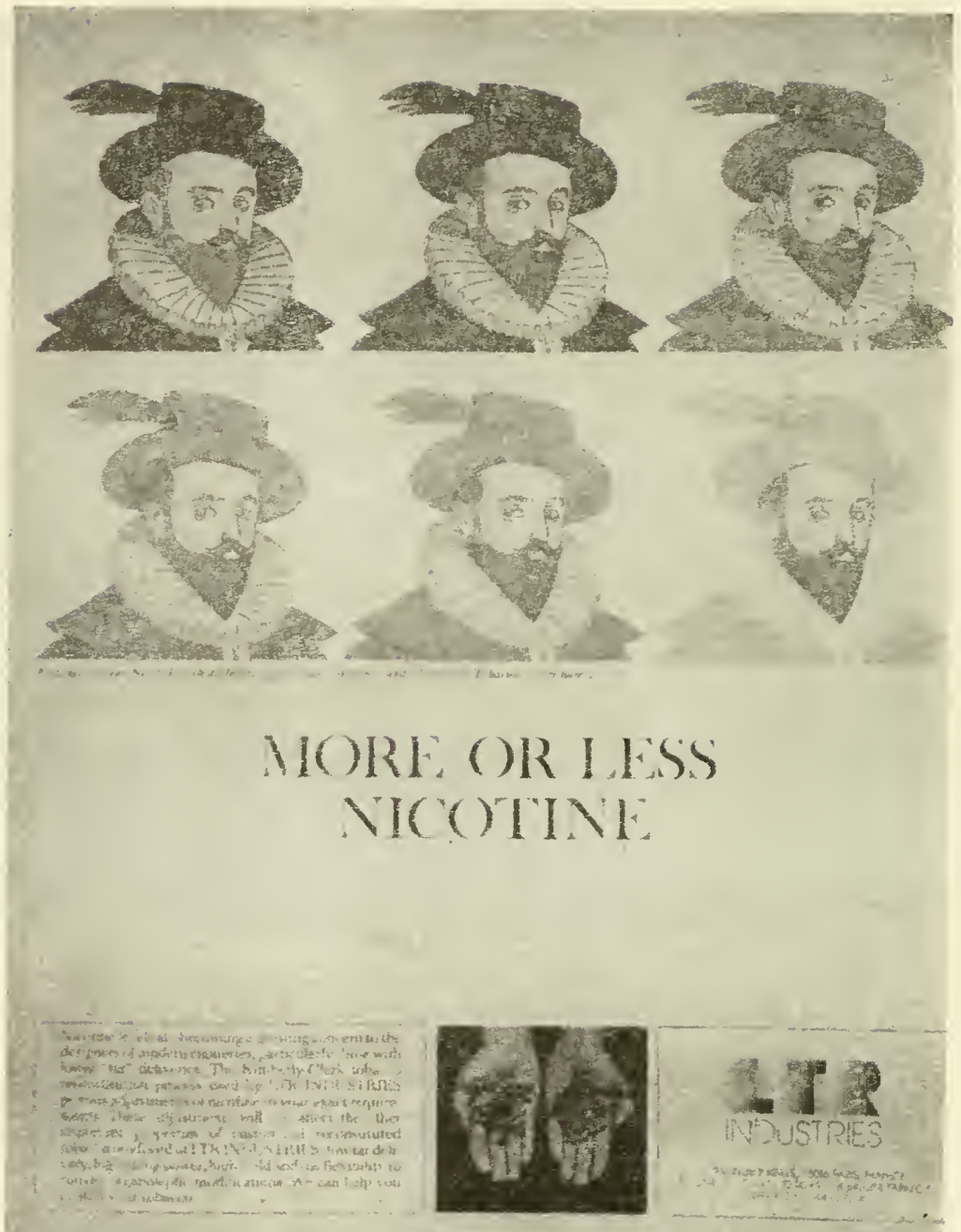

Get more tobacco from all your tobacco

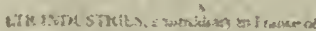

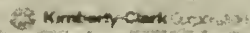




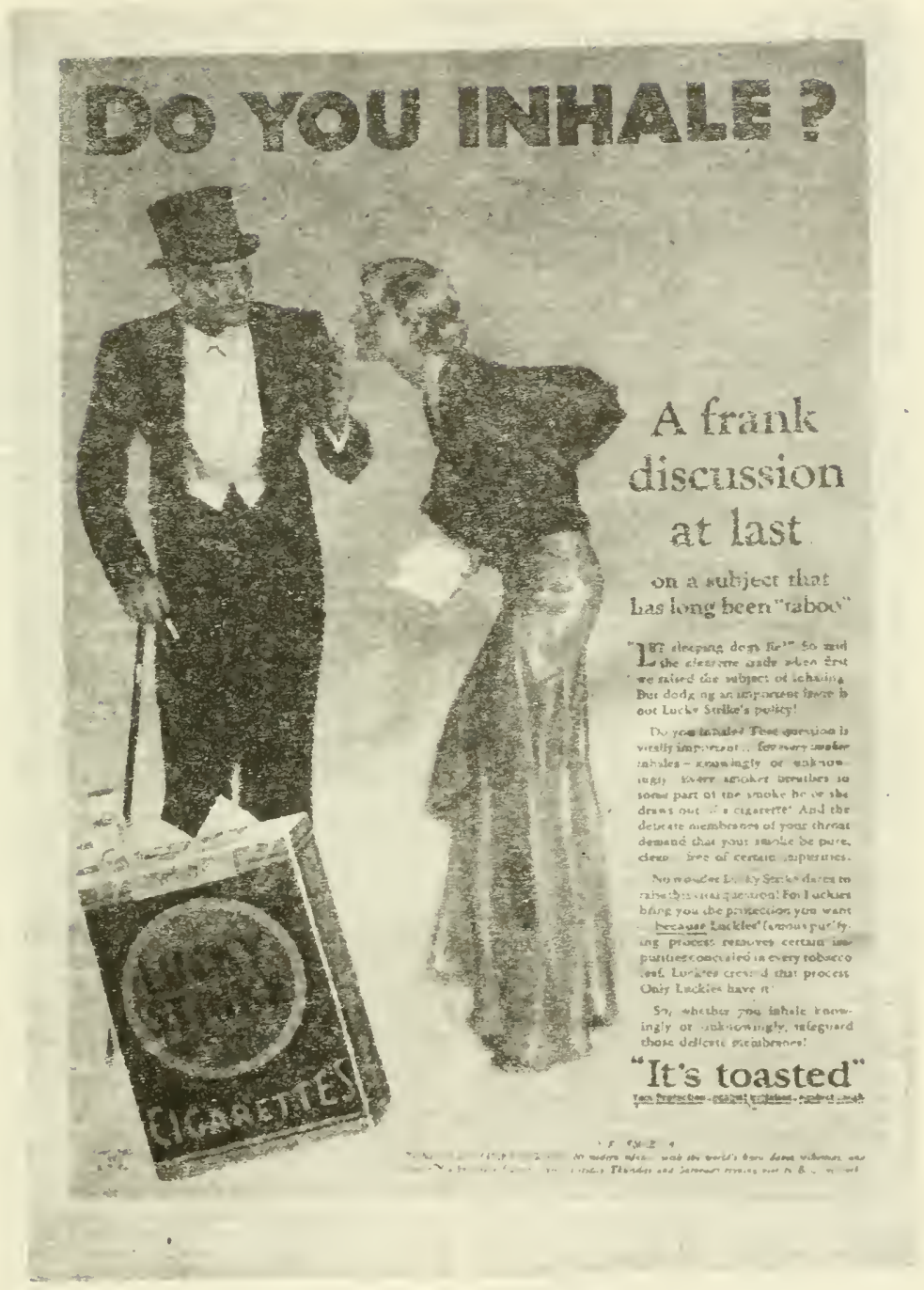




\section{United States Patent}

(III) $3,584,630$

(72) Invoreor
(21) Apd. No.
(22) Fibe
(43) Patented
(73) Atrigues

\section{Congeriter inter}

Rlbhosed, Ve.

185,50

Ane. 20,149

Ines is, 177

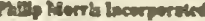

Nev Yerk, N.X.

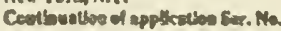

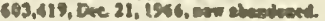

(34) TOBACCO PRODUCT RAVHG LOW MCOTWE CONTENT ASSOCUTSO \&ITI A RES CAS ACENT HAYDNG HKCOTWE WEAKLY ADSOULD THEREON

$1 \mathrm{Clak}$, No Brstates

(S2) vS.C.

(91) lot CL $131 / 267,131 / 10.8$

(s0) reth of sarst....................................... 13:18.10. $10.5,10.7,261-269.23 .10 .9$
[अ]

Eatwowen Che UNITED STATES PATENTS

$2.063 .01412 / 1936$ NHo................... 131/17X

$3,236.244$ 21186 trbyetal................. $131 / 10$

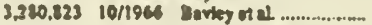
POREION PATENTS

1.135,14 Pl1\%s Oeranany.

$131 / 10$

Mimary Exeminer - Mstria D. Reie

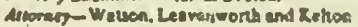

$131 / 261 \cup x$

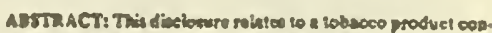

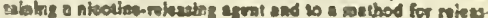

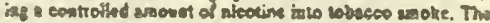
aisotin-tothesias aget coeprices a Enely disided, weak ab

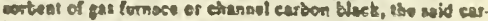

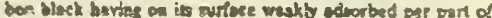

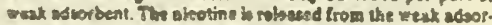

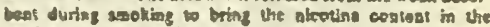

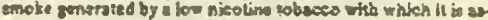
rocleted, lo a wad level od $0.1-3.0 \mathrm{ag}$. 
TOIACC FODUCT KAVMC 2 OW NTCOTIR:

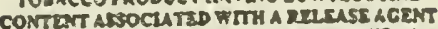

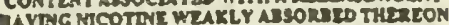

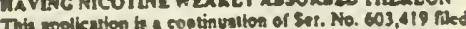
Des. 21, 1966 , now abadened.

Tht lavation reletes to a tobecs prodxct coatuibing a bothervheth agent and w a method for relessing s con. torty, the insention relstes to kobecco products containing an

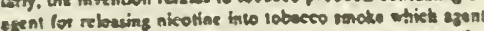

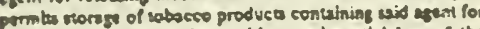

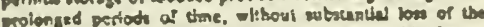

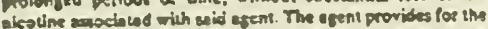

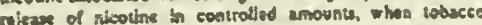

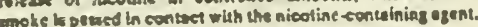

h has lon teca knowa in the robeceo induary that in order

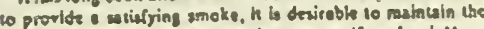
wiketine eontent of wobees product at a eatform lovel. How. met, it is dificuh to eccompliah thls mevit wnes the elcotine content of cobecso varies widely, cepending on the trpe of cobeco and the cenditions under which the robesco is grown.

tobseo and the cenditions under which the loserco is grow. winty of tobseco ate the canditions whleh eain dering the growh of the tobces, for csemple, the moisture conditions.

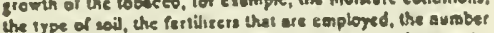
of tobnece phnts per were and the eare which in gives to the pleats dering theit growth. The nieotine sontent otso varies widely, depeading on the variety of tobeces. Meny of the aever varieties of tobseen pleate yield tobeceo which in low in icethe. Forthermore, methode of propuring lobecco produets droquently rumove come of of of the aleotine that it neturally present in the vabeco. In sodition, adem technolis to vilire porions of the sobseco plant other then the leat for asoking and rome of thene portions, sucts st the petiolet, are bo in nicotine con. tent.

tent. to prorlde the cetired phyriological activity, urte, and odor hich this mestrial imparts to the smoke, withowt towing the picotine content to an undesirebly high lawL cen chus be wen

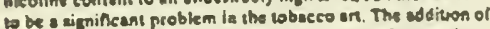
nicotine 10 tobeceo in weh s wey that it remoim inert snd sis. ble th the product and yet is released in controbed smount into the inoke serosol when the tobacco is pyrolyed, is a rouh which is greatly desitzole.

The present invention provbes a solviton to this lengatend. ine problem and rewits in eccurete coatrol of the alcollue

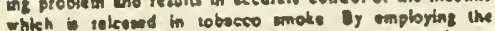
which telcesed in robecto mode of the presem bren. abotime-rebaning igents and merhods of the gresen bren-

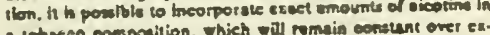

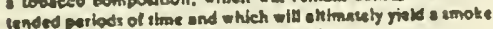
inded pariods of thase and when wiv chimer

The present innention mey sho be and to iecopporate fievorent fnto robeces gnoke.

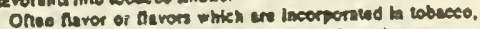

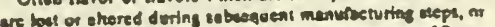
are. Il eas sho be dimkuk to contral the ymout of never

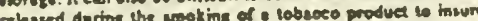

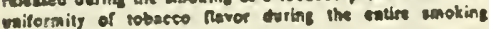

procens.

While man efforts have ber wade to hisodece fiever

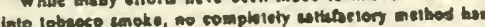

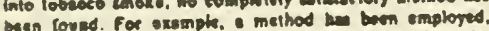

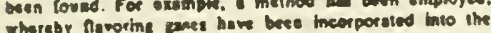

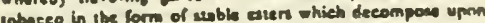
prolytis. Such s methed. however, is oahy wet for exruin

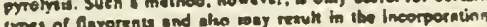
ipes of favorents and aho may reave in its incopporning exters

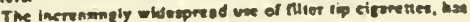

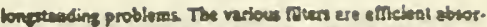

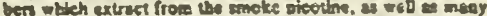

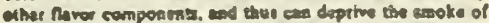
the evalities which are douled by waken.

However, while the preveal invostos can to emploged to

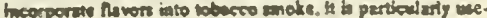
fol for the maintenance of the Froper anount of alcotine in tobeceo monoke. Thus, the disestion wich fellows and the sa.

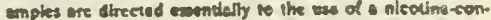
10 teinthe esent is a tobecos produst.

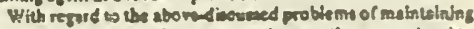
the niectinc content of robeceo preduct to the proger bovel to

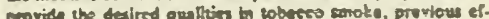
forts bave been mode lo edd akesno to tobiceo prodect

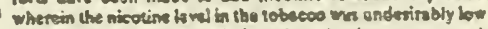

Such sforts hav inctuded ading vicotin ose the the tobneso. Kowever, is be not bees found fearible to sdd aicotine per $\approx$ wobecto produets. For one thing the

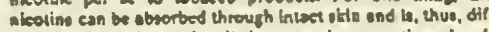
20 ncuh and hurerdous 10 handle is prockeving operatiom. In ad

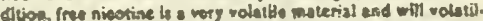
In resdity a roen conditions. Thersfort. the addition of nicotine into a tobaces product as the free material could redily reruh in cubstantial los of the nicotine during steres of the robece modict. Even though the aicajre contsnt of tobecso products could, oy the cidtion of aicsdiat content of tebesce greduct could, by the eddition of nic otias under conditen insolving condserable eftort, to made $|n|$ tially uniform, the rolatistion boset atending storage of the produst would aos problds enoke cortaising interm amount of nicotine.

in US. Pat No. 3,109,436, solution to the problem of ac dine vicotion 10 rosacce products has bom est forth. In thet pateric sicotine.ton exchange rulus ere incorporsted in the inbaces. The aleotine-bn oschenge resind decompore opos snoking of the tobecto to mult in heorporation of the aicoune in the imoke The provent iavention providas eve greter haprovemests tian thase obtained In secordance with that invention, howerer, bi thet there are no lon eschange brekcown produets introduced into the unoke.

In U.S. Pai No. 3230.823, a furtiver colution wo the problem has been provided. In that patent, the nicotise ion

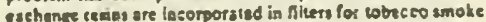

The iavention iavolved in that patent provides a tenprove. ment eret the ievetion weth fort U.S. Fac No. 3,109,436. in that the un of the wa sachenge resin in the futor abminutes the tacorportion in the cobecco mots of lon eschange mekdown products. The preant lavemion provldes eves oreter amprommenth thas thoes obuined th eceordance with

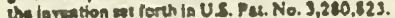

When the proseat ayents ere incorperated in robsceo, they provide en eflicient raleets of the deettae tato the robacro irroke end do not invatve incerportion tinto the rebeceo

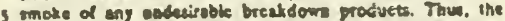
presul lavation orercomes the diadrantages of the method

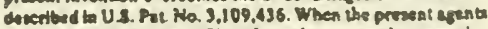
are treoportid in the fith for wbeceo smeke, nopprior

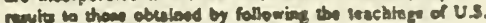
Pat. Na 3260.823 ere ebtaind, th thet tbey provtde more of.

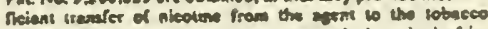

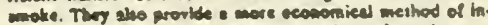

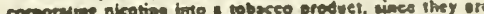

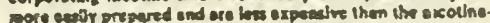
s9 ion eschence rvint.

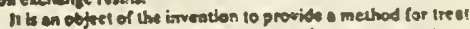
ins tobece moke thich overeomes the sove-mentions diadeanuges of the prips ant.

$n$ is anothet nhject of the iavention to pronde an ugent lor

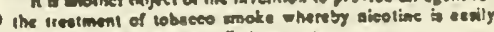
seleseed therelate in controtiod amownte.

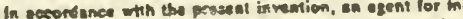

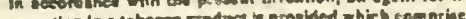

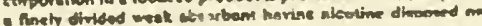




\section{3}

As ased berola the rern "veak adeortents" b inkeded to

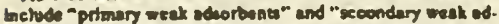

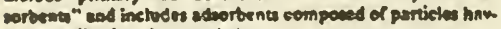
ins the follow the ehotectertstics:

1. The curthes of the particles to priacipaty formed by the exturior of the particles, in contrim to the curfoet formed by the pares asd farures, If any, of the particles of the perticies ore hydrophlite fo neture asd, thus, bold - cinurs in a manner wheroby the alcothe \& readiy dip.

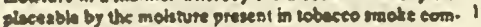
in th contset therewith;

2. The pertieles do not und to form chosieal bonde with alcethas; end

3. The porilele aborb robatantially eo nieotie.

The turm "weak deorbenta" if intended to bnelude moteri. Is

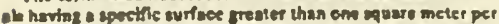
zram and the "primary week edworhente" and "eceondary weth edvortants relate, respecilvaly. to:

s. der lemts, the surface of which th vrinctpally formed by the astorios of the particles and

b. earticles which are hydrophllic in nature. as worth 4

(1) above and pousasing the olher propertien which are eiforth sbove.

The weak cdworbent, as it th employed in sccordance wth the preseat imveation, holdt the nkeotine on lu surfaec during zlorase of the tobseco product and releams the nkeotine intu the tobsceo snoke which forms when the tobecco produet to inoled.

Tebecco produces into which the present ecent may be in. corporested tnehude filier tip and nonfiter oigarmtas, eigars

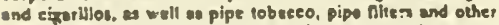
products through which tobace amoke penes on the way to the moket s mouth. The equnt can be incorporaled dirsetly in the lobaces or tan be incorportited in the fulter for sobacso mole. Prefursbly, the ogeol $k$ cmployed in a finer, eines this aned remeves any poariblity of decompostion of the alcotine durth combution of the tobsece and sines the Dithed. Rovike. Ig the moet asturats control of the smount

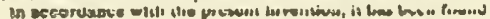
that eot all adsotbent metarisls will provide base for nicotias, wieh base will hold the nicetint duglng stornge hul frow whloh nicotipe cen watly removed imin a patung moke gtream. It has been fouad inat the adrorbent, to be of. fectw to kecordance with this hrvoation should be a fipely divided, weak adsorbent, of limiled adcorptive abilty. For ea. ample the cak edworbenl may be a primary watk adrotbenc ouch as earbon black. Ismpblock, get turnace bluck, chonnel black bontonice. ticenis, exteium or megacsium illieate. hydrated alumins, and the like. Other prtmaty weat adtor. bant whiob may be employed teclude keolin, montmnell. bnike. attapulglite, and finely divided poiyecrylonitrite.

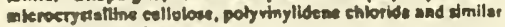
sonabeorbent palywers.

Somerbet stronger adrorbents than thoes set lorth abov way tho besd. Howevgr, when weh edvorbente are $\mathrm{em}$. plojed, they hould hove s high ominlty for water, end ean be setegorlaed a Aydrophille adeorteme. Suen hydrophilic ed.

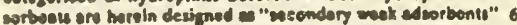

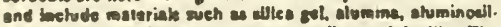

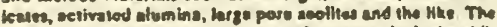
ilgh mointure coaleat of robices emols enuse the hydrophil.

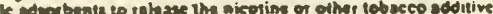
depested on their cerfoct, while they tend to adeorb, due to os deposited on theif terioct, While they tond to adsors, due to

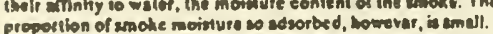

in accordanes with a preferred exabodimast of ine inven. tion, the tobaces iresting azent forms a part of a ntzep tip, or a portion of a fiter tip, for a emoking anticls owch a s cigserste 70 The nieotine th deposited on the finely divided partieles of the onlli edertiont of hydropallic deorhent serrlop which hev the eumablitv of boldiat the nicotine in readinese to to distouged

\section{4}

whth ha editive costing, is applind ooto tow or wob the? subitrate to te lens compect and aner nedliy permis the pesege of anole thorthrough. This latter cembination can form part of the ther tp.

The nicotine cas is deposted on to the rerfoce of the ad. corbent eartiof of the brention th ong nacthod wbich permh reletively untform distribution of the nloothe ow tha eurfses of ibe earier. WeHt nown wethods for thil purpese thehde $\mathrm{km}$.

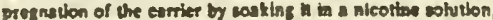

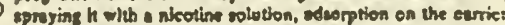
of nkotias fross a nicotim whtion, condengation of nicotipe from vapor phase on the earrier, and the Ele. For trestins the weak oceptents web earbon bleck, the ntectipe wolation ean be edded to the adoorbent end the revaltias salxture nirred of tumbled in erder to borcughly blend the samo. In the esec of weak decrbents of the thydrophlite sdeorbent trpe. preforably then moteriale are waked with a solution of dective and in relatively nonpoler solvenc, followed by altra. tion of the mixture end evaposatloa of any colvesl retabed on the nicothe-conteinin odrorbeat.

The proportion of nicotine to dry edworbem w Ill geserelly b between 1:20 and 1:1, on a welght bash, reapectivoly, and will preforably be betwee $1: 10$ and $1: 2$, reapetively.

25 The enount of aloolins (in nicotine-aderbent form) added to E filcer, on a clgaretic besls, way be from 2.0 to 35.0 anilit. grans por eigaratte and pefersbly from 4.0 to 12.0 miluigrams per sigarefte, depending on the amount of akotion in the cobseco. Osly uffiletent aleotine ahould be sdded to the o tobece product to rewh in a nicethe content is the tobaceo

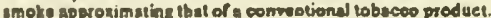
The anount of nicalne-ederbent that be eded to the cobeceo will vety depending upon the nicotine contunt originally present in the tobsece and upon ibs nleoline eos. s tent desired in the conoke. Oenerally, the akeothe concent of the tobeces in importandy to a dovel whereby there in $0.1-3.0$ me. of nicotina to the smoke per elgareuc.

One method of dewrmisins bow much of a panicular

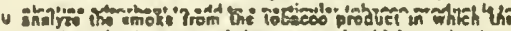
nicotine-adworbent egent la incerporated, which esn be dont by coavnitoral methods, such of to ducribed in tho "Joupnal of the Auscistion of Orfictal Aericultural Chem late" (vol. 42) (Nov. 2. (Y9y) on page iba-429. Is ectordance wits this method, in squeout solution of moke pertleulate phese in rean diatilled under appropriate condhions; this is followed by spectrophotometric examination of the revulthe distilate th the vitruvlolet epectral ragion.

Tha disections for the details of thin procedure include the following:

Collert the smoke particulate prose from 10 sucensive clgareties, wing a standerd robol waok'ng proeedure (35 mi. puff volume token over a 2 eeonod intervel, once per

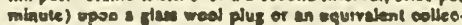
tion anediun whible for separetion of 0.1 M pertiles and larger from sa periculat phose abture. Strts the vicotine straloids tron the colluction modiom with four $10 \mathrm{mal}$. portlota of O.OS N HCI. Conbbthe the separets eht ane allote to orsetly $50 \mathrm{mt}$. with $0.05 \mathrm{~N} \mathrm{HCI}$ Trmatur $10 \mathrm{~mL}$ alfaves of this solvtion to the port of the

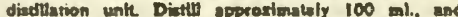
decard Make the senple in the unh alkelise by adiding a

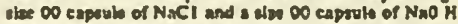
in that order. Repals the distillation and eolleet o weond

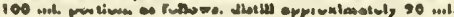
into $100 \mathrm{ml}$. volumetric hesk to which $5 \mathrm{ml}$. I $\mathrm{N} \mathrm{H,50}$ has previously been added. Dilute the distillate exactly 10 mark wh dhithed weter, wis well, and osamine vpec. trophorometrieally between 230 and $300 \mathrm{\mu}$. Correct the abeorbance of the untnown sohtion at appreximatah

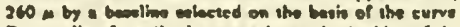
Drow : line from the lovert potit on both dden of the 


\section{$3,584,630$}

5

athe aberbance of the mank. Compare this correted

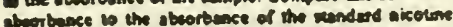
shution eerrected ba the eame esennen, and cekculate the

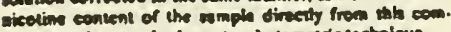
wices, vine rundard epectrophotometric wetalave.

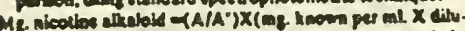

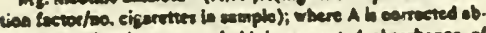

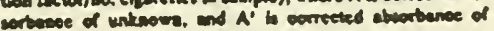
thom.

The weoth-adsorbent content for the lobereo can, by

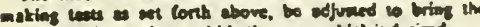

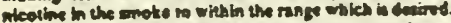

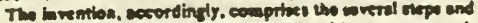
die relation of ene or more of weh wops wh thect to each of the odven, snd in articis possondes the fentures, propertiat the rolunes of etemente, which are ceomplithed in the fellowhe detaned disclesers.

\section{Exterpie}

A nirtere of 1 gram nicotino rold is the Znemes Cacmicel Conpeny, under the deoignetion "White Lobl" wes blanded

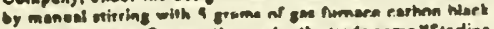
cols of the Cabot Corporation under the trede ane "sienting R." The mistore wos sei culde overaight and wa then 2 Reighed. The wight bos was found to be 0.3 parcetat. A 0.6 wation of this mbture was opread evaly orv e thin coston wab. The cosked web wes rolled trenivervily and cet hito a hollow papar tubing having an indide diameler of $7.8 \mathrm{~mm}$ ond

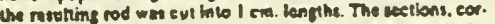
reoponsing 10 the diemeter of a conventional cterette. thed a

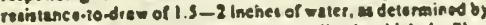
- Mernchetic ${ }^{-}$suge connected to the line in which the ther betiom wero bapned and throwgh which bir we drewn at the rete of 600 ce frimbute.

The wections were found to centein 0.054 grame of the rats.

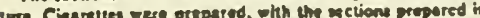
gecer lanee wh the fore going, etrue hed to the tobeces rod. followed by 5 ma. bong section of cen rentionsl callulow

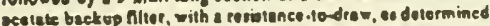
bove, of 1.2 lach of watcr. The wnoke of the eiguretres prepered in accordance with this esomple wes found by the guthod demente bove to contain 1.61 me. Nkotine per eigeretts. Comtril sugereltos mide wh conventionel filtom.

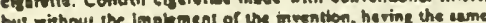

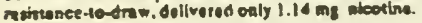

\section{Enemple 2}

A cotution of a grams nicotine of the iype used th Exumgle 1. in $20 \mathrm{~mL}$. a.hercae wac spplied 102 grams of ory allice ge! cold the Deviton Clemicel Division of $w$. R. Orace \&

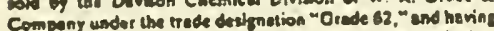
particle sise of $60 \times 200$ mech. Tat solvtion was spotled vo

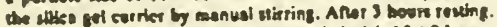

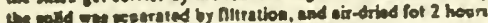
the wid wo teperated by hitration, and ab-dried fot 2 hoor

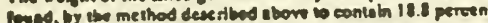

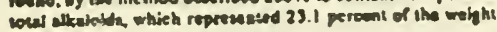
of une the get.

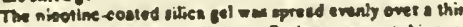
cotion web wich as miled to fil into pepos tubing of

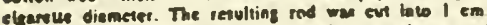
len tha, exch centaining obout 31 me. of the aicolime-conted cilice of whxh 5.1 ng. wre nic otine. The revirence-10-drew of the rever plues was found to be $2.1-2.3$ inch of wever The pere eneches to the eads of cigereus robece rods.

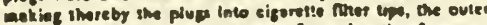
and of the tip thes res bucked up by $5 \mathrm{~mm}$. hogthe of conven.

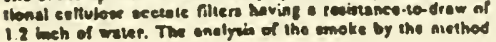

\section{6}

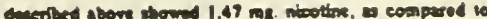

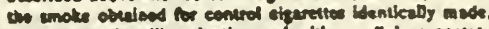

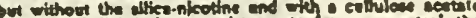

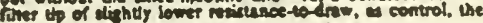

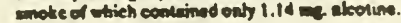

\section{Exuples}

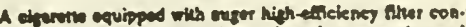

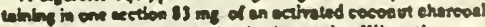

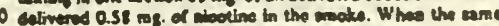
charrten hed alcotide epolled to the charced th quentities of $9.13 \mathrm{sen} 25 \mathrm{~ms}$. the berwes in ricotine dofivery was 0.16 ,

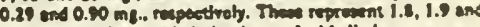
3.6 preant of the sdded aleotine, a heidedy lower propor.

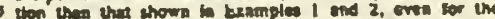

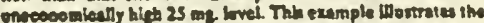

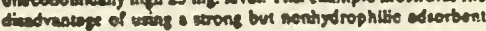
- a carrier for aicolune.

To 3.0 of "Monure" 11 chaneel eaboo Haek (Cabor Corp.) aded 1.0 \& of akotins (Eurman Chemieal $C_{0}$ wite ibel) asd toe mutwre vas biended by hand. This mix ture Wended whe tobseco nllep of handmade cigareun the reve of 30 me pas cigareth. Cigarethes vere

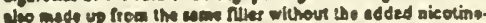

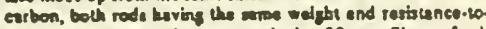
drew. The $85 \mathrm{~mm}$. rods were arrached $2020 \mathrm{~mm}$. Atun of cel lulose sceute hiving high officiescy of particulate rumoval.

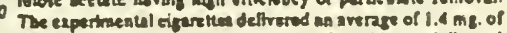
akcotion por cigentus: thos wthout the addhive defivered $0.18 \mathrm{~ms}$. In the imoke.

33

Sramples

Nucotine a a 10 percent by wigh withon in nbevene wes opplied to setiveted slumias.

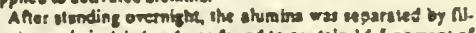
tnation and arrdeted and wes found te costain 14.5 porcent of

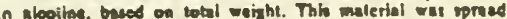
eventy on s this cotion web wakb wes than rolled and fed tato

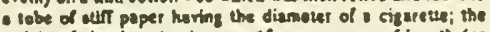
- pight of alumint-nicotixe was os me pet $\mathrm{cm}$. of kngth (or

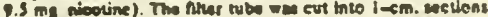

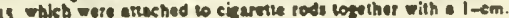

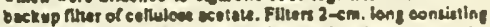
enh of cellulose cestols and heving totel moletence like the preceding were attached to the ame iype of chasetle rods to provide cemrols. Samples wh soditive detrvered $1.6 \mathrm{es}$. so nicotine to the renoks; the controls dellivered $1.1 \mathrm{mg}$

It een thus be veen that the objects wet forth, and those wede epperent from the precending decripeion, are eftectivaly ob. rataed, use aloce certain chenest may be mode in cerrylne out the sbow proces end th the aricle wi forth witheot departing sf from the seope of the tarention, It is batended thet afl mette? contatned is the abone desctprion then be thterproted a dlas.

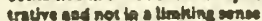

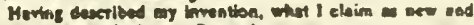
devine to erere by Leten Fuent is:

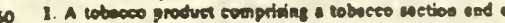

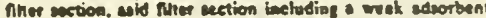

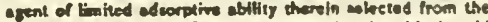
croup concieting of gas furmece of ehennal carton blect, wid

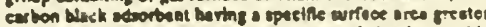
s. then I quare meter per grem. end e cherpe of picotine venkly atworbed on the surface said carbon bleck, the tobecco of the tobsees unction being of a low nicotine content, the imoke from whleh hes its aiodthe content incresesed to i tolel value of $0.1-3.0 \mathrm{mg}$ of abotios upon nisat of the nisotine from 70 sthe watk carbon black adsorbent during amokint. 


\section{UNITED STATES PATENT OFFTCE CERTIFICATE OF CORRECTION}

Patent No. 3.584 .630 Deted June. 15. 1971 Inveitor(b) G. Esler Insikeep

It 1o certifled that error appears in the dibve-1dentifled patent and that seld lettero Patent ere hereby corrected as show below:

In abstract, 12ne 4, "ab-" should be "ad-"

In.abstract, 1Ine 6, efṭer "adsorbed", "hlcotine In. an" anoune se rrnm n. Oj to one paxil by we blit" wo incteod.

Colum 2, 11ne 27 - remove "content of tobscco products could, by the addition of nicotine"

Columi 3 , IIne $15-$ "If" should be - is $\ldots$.

Colum 4, IIne 36 - "Important1y" should be -- brought --.

IIne 70 - "300 $\mu$ " should be - 300 mp -..

IIne 72 - "260 $\mu^{\prime \prime}$ should be -260 mp -.

Colum 6, 11ne 7 - "euger" should be -. -..

Slgned and sealed this 14 th day or March 1972.

(SEAL)

Attost:

BDNARD M.FTITCER, $R$. Attosting orfleer
ROBERT GOTTSCHALK

Comnisioner of Patents 
United States Patent

[19]

[II] 4,236,532

Schweizer et al.

[45] Dec. 2, 1980

[54] SMOKING ROD WRAPPER

[7S] Inventors: Alfred D. Schweizer; Williwn G. Erskine, both of Geneva; Danlel Turpin, Nyon, all of Switzerland

[73] Assignee: Gallaher Limited, Belfast, Northern Ireland

[21] Appl. No.: 940,996

[22] Filed: Sep. 11, 1978

[30] Forelgn Application Priority Data

Sep. 16, 1977 [GB] Uniled Kingdom ........ 38710/77

[s1] Int. C1. A24B 15/42; A24C S/60;

[S2] U.S. CI. A24D $1 / 02$
; $131 / 15 \mathrm{R}$. $131 / 24$

[58] Field of Search ............... 131/15 R, 15 A, I5 B, $131 / 15 \mathrm{C}, 17 \mathrm{R}, 17 \mathrm{~A}, 24,2,140 \mathrm{C}, 140 \mathrm{R}, 144$, 140 B, 8 R, 8 A, 9, 10 R; $101 / 129,114$ $427 / 282,288$
[56]

\section{References Cited}

U.S. PATENT DOCUMENTS

2,801.636 8/1957 Proh .................... 131/15 C

2.976,190 3/1961 Meyer .......................... 131/1S R

3.006,347 10/1961 Keaton .......................... 131/15 R

$3,285.253 \quad 11 / 1966$ Lebert ........................... 131/is R

$3,422.819 \quad 1 / 1969$ Jones ei al ........................ I31/1S R

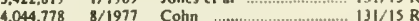

4060,091 WI/1977 Wasson et al.............. 131/9

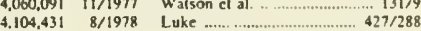

$4,340,135$ 2/1979 Godfrey, 3r....................... 131/15 C

Primary Examiner-V. Millın

Altorney, Agent, or Firm-Murray and Whisenhunt

[57]

\section{ABSTRACT}

A wrapper for a smoking rod has screen prinled on its surface a series of dols containing a volatile additive which is transferred into the main stream smoke when the smoking rod is smoked.

22 Claims, 7 Drawing Figures

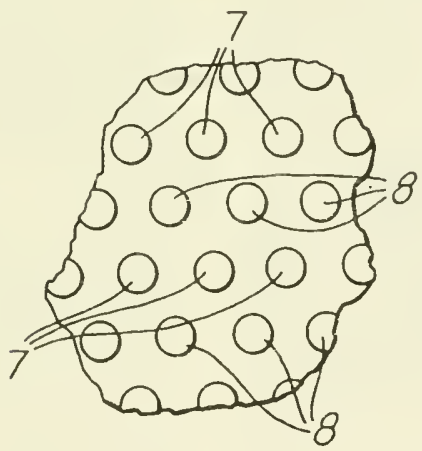




\section{6}

U.S. Patent Dec. 2, $1980 \quad$ Sheet 1 of $2 \quad 4,236,532$

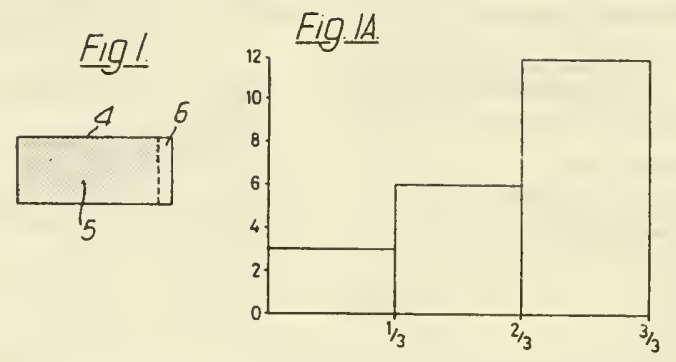

Fig.2. Fig $2 \mathrm{~A}$

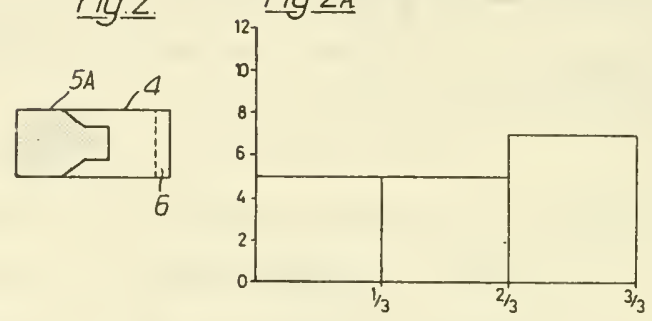

Fig. 3

Fig. $3 \mathrm{~A}$

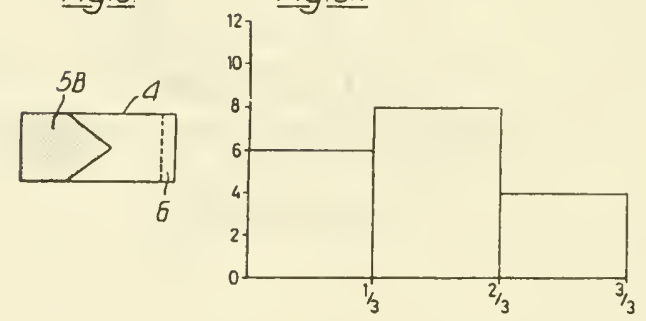

Fig는

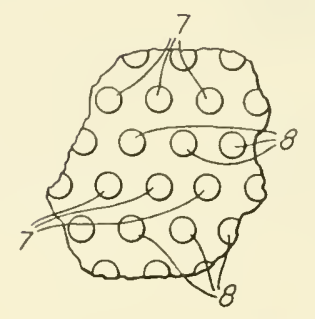




\section{SMOKING ROD WRAPPER}

The present invention relates to wrappers for smohing rods, such as cigarettes. cigars and cigarillos, comprising a combustible cubular urapper. usually made of paper or a tobacco based material, surrounding a com busuble filler of tobacco and/or tobacco substutule.

It is accepted that the smoke produced by the combustion of tobacco products contains a number of irrstatıng substaaces. Many proposals hase been nuade for reducing the amount of such substances inhaled by the smoker. These proposals fall into three groups in the first group are those which aim to reduce the amount of irritanl material which is produced durmg the combus. Iton nrocess itself, for exampic bi the ure of different iypes of tobacco or tobacce blends, by special process. ing or extraction, by the partial or icial replacemient of tobacco with so-called tobacce substitutes, or by varia. tion of the combustion temperature The second groilp relates to the dilution of the smoke before it reaches the smoker's mouth, for example b) the use of a highis permeahle paper or by the ferforation of the paper or filter The third groun reiates to the consiruction of the filter itself, to achieve high filtration efficiency or the selective semoval of particular smoke components. Whilst these proposals can lead to a significant reduc tunn in the inhalation of undesirable smoke components this reduction is accompanied by a parallel decrease in the satisfaction afforded to the smoker Thus is because It is difficult to reduce the tar yield of the product or the irritancy of the smoke without at the samc lime reduc ing the amount of desirable components made avallable to the smoter or umparing the flavour of the product.

The present invention is concerned with the application of additives. such as smokc producing agents. smoke nucleation agents, flavouring agents, and phisso logically active ageuts such as nicoune componenis to the smoking rod, in order to improve or help to improve the satisfacion provided to the smoker This is pariscu. larly useful for low tar products incorporating tohacco or tohacen substitute

II has previously been proposed to apply such add. live to the filler material and it is well know that certan materials are already added in practice to the filler However. It is almost impossible to obtain a concentration profile of the additises over the smoking length in order to controi the puff-by-puff iransfer to the smoker. and indced local concentrations of an additive such as nicotine could be undesirable. It has beell proposed 50 (Brirsh Patent Specification No. 1,342,931) to inject addituves through the ivrapper into the filier material but this is not entrely satisfactory because of paper perforation and because of the discontinuous distribu tuon of the additive. It has alsn been proposed (Brutush Patent Specification No. 1,111,007) to impregnate the wrapper with a nicotine component but this is unsatis. factory as controiled distribution of the nicotine is un factory as controiled distribution of the nicotine is unper are clianged it has been proposed (British l'utent Specification No. 1.351.560) to giavire print a bur! accelerating acent in a series of small squares in control the speed at which the wrapper burns hut tlus dves not contribute to the solution of the prohlem of the transfer of additives to the main stream smoke to enhance the smokers' satisfaction. It has aiso been proposed (Austrian Patent Specification No 277,028) to apply to a wrapper a coating in the form of a liquid dispersion of micro-capsules of flavouring or aromalic nalental hu: this involves a coating of the whole surface of the witp per uhich will effect undesirably its flexululus. Ientitition and combustion properties. The additim to .) tilut of the smoking rod of components which are to th. Iransferred to the smoke is already curremt pratitic: bi: this is limited to quite volatsie materabs, for eturupic a nasour such as menthol.

In accordance with the present uxentuon. a merhust 0 of producing a u rapper for a smohing rod cuniprives screen prinling onto the surface of the urappet s veries of discrete dots of an inh coutarn!ng an additice wisct ivill in use, upon apnroach of the hot burnuig up of the smohing rod. be transferred and contribute it the nisin 5 strcam smohe drawn thrnugh the red to srihulice the satisfaction to the smoher.

W'c have found that appreciable advaniaces arke from this method. Thus the amount and focatting is? additive deposited on the surface of the "Irapper cal be precisely controiled and therehy transferred :nto the ma!n stream smokic an a controlled manner The pilpes or other wrapper retans us nexibilis and inushustibi]. ity more or less unchanged. Furtherniose and bi cumbparison with gravure printing. the screen primlug of the dots enables dots of greater heught and more accuraic definition to be depnsired so that an acceptably iuch and accurate loading of the addilive can he applied. in prat tice up to $5 \mathrm{mg} / \mathrm{sq} \mathrm{cm}$. Whilst leaving .ul accept.this high proportion of the surface area of the wrapper tee 30 of dots.

The wrapper may he pronted with the adduscecon taining ink on the surface which will hecome enther the inner and/or outer surface of the wrapper in use but preicrably 11 is printed on the inner surface of the wrap.

per where it is least likely to be disturbed upon handiun of the smoking rod

The additive will be one or inore of a smutic provituc

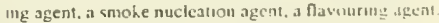
and a physinlogically active agent

The additues will generally he compounds "inch irausfer into the man stream smohe without undergenug appreciable thermal degradation. Wheli gite the re quired salusfaction to the smoker, and which are knom n in present no significant health hazards Thes mas stsw be, or anclude, compounds which undergo thermal deg. radation during the transfer process, which the prod. ucts of such degradation arc hunwn. present no heult hazards, and provide the required satusfaction to the smnker

Suitable smoke prnducing agcnts include esters such as methyl palmitatc, methyl stcarate. tinyl siearate. dimethyl sebacale. dimethyl dodecandicatc. dinethy Ictradccandioate, glyceryl isimuristale, nentacrsthritv. tctraacetate, monoethyl sebacate, trunelliyl cutrate. ms: risty! myristate, palmityl palmutate. glyceryl numustes ratc. glyceryl trilauratc, vinyl oleate. and diethyl hevy sebacate Other surtahle smoke producine agents it. clude docosene, myristic acid (tetradecunorc acid). lan. britol wax (a hlend of ceivl alcohol and steary) alcohol witli a cety//oleyl alcohol ether of polverhylene fly col), heeswax (mauly consssing of miricyl palmitatc and cerotic acid), and ceresune wax of tlicac slycers trimyristate is preferred.

A surtable smoke nucleation agent is ammonum thic ride

The invention is particularly useful fir the appiaciThe to a smoking ind of a physiolopically active nice. une compound Such a compound mav anclude a stable 
$4,236.532$

3

salt of micotine such as nicoune ascorbatc, mcolme $\mathrm{cl}$ trate, micoune lactate. nicotine succuate, nicome phos. phatc, nicotine tartrate, and nicotine liydrogen tartrate. Di-nicotine tartrate might possibly he used but this is less suitable as it tends to be unstable. The preferred nicoune compound is nicotine tartrate or nicolume liy. drogen tartrate

Two or more addituves, if mutually compauhle, mav he incorporated in the same ink for deposition sumultaneously. However, there is a practical limit to the amount of additive which can be depnsited in this way, bearing in mund ihe maximuni volume of each prinied dot and the maximum quantity of additive which can be carried in the mik, taking account of the other inh components necessary to provide the ink wib the necessary rheological properties. If two additives to be deposited are mulually incompatibic, or if a loading of the wirapper with the additives is required in ercess of that $w$ hich could be deposited in a single series of dots. different additives may be incorporated in different $10 \mathrm{ks}$ and pronted in separate series of dots If the inks are mutually menmpatible. care must he taken to ensure that the dots of the different series do not cverlap one anniher

We have found most surprisingly that the presence of certan components in the printed deposil on the " rapper nuay significantly enhance the iransler of an adjuase in the deposit into the main strcam smoke. In this context the transfer of the additive relates to the amount of the additive which is carried by the main stream snoke through the smoking rod to the mouth end and is therefore available to the smoker. The mechanics of additive transfer arc not wholly understood and are subject to many 1 artables such as the filtering effect of the smoking rod filler, the extent to which the volatsle additive condenses on the filler as 1 approaches the cooler mouth end of the smoking rod, the extent to which the additive vaporises or sublımes ins the main sircam smoke when a puff is taken as distinct from boing lost in the side stream smoke between puffs, and the tempers ture of the burning lip of the smoking rod. How ever. an iniportant factor is believed to be the particle size of the aerosol formied by the vaporising or subliming additive. the smaller the particle size, the greater the iransfer It is therefore believed that the close proximuty of certan components reduces the particle size of the additive aerosol and hence promotes the transfer of the addilive in the main stream smoke The experiments have show' n that it is not sufficient for the component merely to be present in the filler but to be present on the wrapper and thereby aclive upon the initial additive aerosol formatron. It is believed that the effect depends on mutual interaction of the component and the additive, to form either a greater proportion of aerosol or a more stable acrosol. Examples which work with nicotse contpounds are components such as docosene, stearic acid. oleic acid. which have an affinity for free base nicotine In the present context such component will be depos. ited alongside the addilive hy being incorporited with the addilive in the same series of printed dots, or deposited in a separate series of dois which may overlie those of the firsi series.

The component which promotes the Iransfer of the adduve is not nccessarily a different additue which contributes 10 the smoker's satisfacton. However. it is clearly betier if the component is another additive which contributes to the smoker's satisfaction and a smoke nucleation or smoke producing agent has been found to be effective in this way in enhancing the trans-
4

fer to the masn stream samoke of an addrusc such th nicotine. When the active component is inothet of the additives, It would be desirable if both additives mutu. ally promote the transfer of one anotiter into the matn stream smohe.

In a typical experiment a wrapper was sercen grutted with a series of dots of an wik containme nicotiric hydro. gen tartrate to provide a loading of ahout $3.5 \mathrm{mg}$ ल nicotine hydrogen turtrate per cigarctic, and will a separate sertes of dots containung n similar Inading of 1.docosene $A$ toral cumulative transfer of about $24 \%$ of nicotine was oblaned when a cigarette havme a 10 bacco surstilute filler and incorporating the urapper was smoked, compared ivith 15\% for a control cigarelte of which the wrapper was not printed with the i-docosene A similarexperiment in which the nicoline hydro. gen tartrate and 1-docosene were incorporated in a common series of dots led to a slightly lower cumula. tive sicotine transfer but sull some $50 \%$ higher than with the control cigarette

The inks used in the present invention differ from conventional printung inks mainly in the fact that the coloured component (pignient or dye) is replaced hi one or more of the above mentioned addituves, and that she other components of the ink are selected in be ac. ceptable for a smohing product

The ink will include a vehicle preferably is the form of a volatile hydroplulic liquid, for example water or an organic solvent which dries off by evaporation Exam. 0 ples of the latter are ethyl alcohol, isopropyl alcolwol or mixtures of these

The uik is also given a sultablc aluch ness and viscosity by the addition of a thickening agent, particularly a celtulosic polyner such as carboxymethyl cellulose. 5 polymethyl hydroxy cellulose, polyethyl hydroxy celjulose or hydroxy prepyl cellulose.

The inh mas also contain hydrophobic resims which will function as barriers to the diffusion of the additives from the dnis during storage.

Finally, in order to give the inh a certan "hod, " and to improve prinung characierisucs, a cliarge in the form of a filler, such as calcium carbonate, titanium dioxidc. silicon dioxide. or a silicate such as Bentonite mity be incorporated Non-dissolved additıves may also consiı. tute a charge

If the additive is applied in a uniforin distritution along the wrapper and hence aloug the smoking rod. the uniform distribution of the additives does not lead to unform transfer of the additive into the masn stream smoke drawn through the rod. This is because llic add. ive vaporases or sublimes into the main stream smohe adjacent to the hot burming tip of the rod but is partially recundensed and filtered as it passes along the cooler portion of the rod towards the mouth end. Upon subsequent approach of the burning tip. the additive is agam iransferred into th: man stream smoke together with the origual additive at that part of the rod. It follows that the relative transfer of the additive into the mati strean snohe procressively uncreases as the rod is smoked In order to compensate for this effect. The additive is preferably reduced lowards the mouth end This helps to compensate for the uneven transfer of the adduives into the man stream smoke $\mathrm{By}$ an appropriate choice of the concentrated gradient of additive alow: the rod, it is possible to approitch a substantially level transfer of the addilive inio the main strcam smokc puff-by-puff. The concentration gradient of the addituse along the wrapper can be precisely controlied when the 
5

addutive is applied by the present method and can be varied within appreciable limits by changıng ink concentration, dot size or height, or by changing the den. sity of printing. or by selecting the area of the wrapper over which the dots are printed.

\section{BRIEF DESCRIPTION OF THE DRAWINGS}

The present invention is illustrated by the attached drawings, whereun:

FIG I is a view of a paper cigarelte wrapper, showing one embodiment of arranging the additive dots.

FIG $1 \mathrm{~A}$ is a histogram showing additive transfer during the smoking of a cigarelte made from the wrapper of FIG 1 ,

FIG. 2 is a view of a paper cigarette wrapper, showing one embodiment of arranging the additive dots,

FIG. $2 \mathrm{~A}$ is a histogram showing additive transfer during the smoking of a cigarelte made from the wrapper of FIG 2.

FIG. 3 is a view of a paper cigarette wrapper, show. 20 ing one embodiment of arranging the additive dots,

FIG. 3A is a histogram showing additive transfer during the smoking of a cigarette made from the wrapper of FIG. 3, and

FIG 4 is an enlarged view of a paper cigatetle wrap. 25 per having two different additives prinied therenn

The following examples illustrate the present invention

\section{EXANPLE ।}

A composition with suttable rheological properties for batch screen printing tests was made up by adding $0.66 \mathrm{~g}$. of sslicon dioxide (Aerosil 200 obtained from Degussa AG, Zurich) and $2.56 \mathrm{~g}$. of low viscosity carbexy methyl cellulose (Hercules CMC 7L F), $30 \mathrm{ml}$. of 35 $1.0 \mathrm{M}$ solution of nicotine hydrogen tartrate. Using a nickel screen, with a mesh size of 50 , this mixture was applied to one surface of a conventional cigaretle paper, of width $27.5 \mathrm{~mm}$. and length $66 \mathrm{~mm}$ The printing occupied an area of about $24 \times 51 \mathrm{~mm}$. and took the form of distunct, well separated dots of diameter about 250 microns and height about 50 microns

About $7 \mathrm{mg}$. of meotıne hydrogen tartrate were thus deposited onto the paper at a density of $0.7 \mathrm{mg} / \mathrm{cm}^{2}$ The total cumulative transfer of nicoune, when this naper was used with a tobacco substitute filler, of the type disclosed in our British Patent Specification No. 1.431.045, amounted $1021 \%$ of the amount of nicotine present on the pnnted wrapper. Furthermore, the nufr number of the cigarette was not changed by the addi. tion of the primting to the paper

FIG 1 of the accompanying drawings shows the wrapper 4 wsth an area 5 which will surround the filler, and printed with the series of dots, and an end portion 6 which in use will surround a filter plue FIG IA is a histogram showing the total nicotine transfer during the smoking of each of the first third, second third, and the third third. of the length of the cigarette lt will be seen that the transfer increases significantly from the beginning to the end of the smoking of the cigarelte

\section{EXAMPLE 2}

The ink of composition described in the preceding example was applied to the surface of a conventional ergarette paper in the pattern shown a: 5A in FIG 2 of the accompanying dravings $W_{\text {ith }}$ the same filler material. the total cumulative transfer of nicoline was $i 8 \%$ and FIG $2 \mathrm{~A}$ is a histogram corresponding to FIG IA but in respect of the FIG. 2 example and showing how the transfer is considerably flattened although ver slightly increased at the end

\section{EXAMPLE}

The experiment was repeated as in Example 2 bu with the pattern printed as shown at $5 B$ in FIG. 3 of the accompanying drawings The total transfer of nicotine was agatn $18 \%$ and FIG. $3 \mathrm{~A}$ is a histogram also corre sponding to FIG 1 A but in respect of the FIG 3 exam. pie This shows again a slightly uneven transfer but unc which is much more level than in the first example

These examples make " clear that the puff-bv-pun profile can be modified more or less at will by uppropri ate profiling of the printed area of the wrapper

In the above examples the nicotine isansfer was determined in conventional fashion by causing the nicotine to be deposited in a Cambridge filter attached in the mouth end of the cigarette during a smoking test The results with respect to the three examples are sumna rised in the following table, in which FBN represents free base nicoune:

\begin{tabular}{|c|c|c|c|c|c|c|c|}
\hline \multirow[t]{2}{*}{ Profile } & \multirow[t]{2}{*}{$\begin{array}{l}\text { Nicolune } \\
\text { loading mg } \\
\text { FBN/cig }\end{array}$} & \multicolumn{3}{|c|}{$\begin{array}{c}\text { Cumulauve transfer } \\
\text { 10 Cambridge filier } \\
\mathrm{mg} \mathrm{FBN/SIg}\end{array}$} & \multicolumn{3}{|c|}{$\begin{array}{c}\text { Non cumulative } \\
\text { iransfer in } \\
\text { Cambindee filier }\end{array}$} \\
\hline & & 1 & 1 & $1 / 3$ & 1 & , & $1 / 1$ \\
\hline 1 & 26 & 008 & 024 & 054 & 3 & - & 17 \\
\hline 2 & 16 & 007 & 014 & 025 & s & s & 7 \\
\hline 3 & 19 & 011 & 026 & 033 & 6 & is & 4 \\
\hline
\end{tabular}

\section{EXAMPLE 4}

A further compostion with suitable rheologica properties for batch screen printing tests was made up from $20 \mathrm{~g}$ of 1 -docosene, $60 \mathrm{ml}$. of water, $4 \mathrm{~g}$ of carboxy methyl celluiose (Hercules CMC 7 LF). $05 \mathrm{~g}$ Bentonste, $14 \mathrm{~g}$. sorbitan monostearate (Span 60) and $14 \mathrm{~g}$. polyoxyethylene sorbitan monostearate (Tween $60)$. The last two of these constituents are surfactant

This mixture was sereen overprinted on the wrapper already printed with an ink containing the nicoune hydrogen tartrate as described in Example I, to give loading of about $3 \mathrm{mg}$. of 1 -docosene on the paper The paper was used in a cigarette as described in Example 1 and test smoked. The results showed good smuke production representung good transfer of the b-docosene into the main stream smokc, and an improvement of some $50 \%$ in the cumulatuve nicoune transfit

The appear ance of the printed sample of the wrapper produced in accordance with Example 4 is shown in FIG 4 of the accompanying drawings in which the dist containing the nicotine hydrogen tartrate are shown on a square matrix 7 and those containing the 1 -docosene on a square matrix 8

We claim

1 A method of producing a wrapper for a smoking 6n rod, the method comprising screen printing anto the surface of the wrapper, a series of discrete dots of an mish containing an addituve which will in use, upon approach of the hot burning tip of the smoking sod, be transferred and contribute to the main stream smoke draur through the rod to enhance the satisfaction to the smoker, wherein the addituve is one or more of is snuske prnducing agent, a smoke nucleatıon agent, a flavouring agent and a physiologically active agent 
2. A method according to claim 1, wherein the additive comprises a stable nicotine salt.

3. A method according to claim 2, in which the stable nicotine salt is nicotine tartrate or nicotine hydrogen tart rate.

4. A method according to claim 1, in which the int contains a component the presence of which promotes the transfer of the additive into the main stream smoke.

5. A method aceording to claim 4, wherein the com ponent is a different one of the additives.

6. A method according to claim 4 , in which the additive is a stable nicotine salt and the component has an affinity for free base nicotine.

7. A method according to claim 6, in which the com ponent is docosene.

8. A method according to claim 1, wherein two different additives are incorporated in the same ink.

9. A method according to claim 1 , wherein two additives are separately incorporated in different inks which are printed on the wrapper in two different series of dots.

10. A method according to claim 1, wherein the ink contains a hydrophilic vehicle.

11. A method according to claim 10, in which the hydrophilic vehicle is one, or a mixture, of water, ethyl alcohol, and isopropyl alcohol.

12. A method according to claim 1, in which the ink contains a filler.

13. A method according to claim 12 , in which the filler is calcium carbonate, titanium dioxide, silicon dioxide or a silicate such as Bentonite.

14 A method according to claim 1, wherein the ink contains a thickening agent.

15. A method according to claim 14, in which the thickening agent is carboxymethyl ccllulose, polymethyl hydroxy cellulose, polyethyl hydroxy cellulose, or hydroxy propyl cellulose.

16. A method according to claim 1, wheren the additive is concentrated at that end of the wrapper which is to be at the lit end of the smoking rod.

17. A method according to claim 16, wherein the 5 additive concentration is determined by varying the do size or dot height.

18. A method according to elaim 16, wherein the additive concentration is determined by controlling the dot density.

10 19. A method according to claim 16, wherein the additive concentration is determined by controlling the area of the wrapper surface which is printed.

20. The product produced by the process of claim 1

21. A method of producing a wrapper for a smoking

s rod the method comprising screen printing onto the surface of the wrapper, a series of discrete dots of an ink containing a hydrophilic vehicle, a thickening agent, filler, and a stable nicotine salt, the printing extending over a selected area of the wrapper to provide a greate 20 deposition of the ink adjacent to that end of the wrapper which will be the lit end in use.

22. A smoking rod of the kind comprising a filler of smoking materia) surrounded by a combustible tubular wrapper, the improvement wherein the filler is upgraded by the provision on the inner surface of the wrapper of a screen printed deposition of a series of discrete dots of an ink containing at least one additive selected from the group consisting of a smoke producing agent, a smoke nucleation agent, a flavouring agent, and a physiologically active agent, which will in use, upon approach of the hot burning tip of the smoking rod, be transferred and contribute to the main stream smoke drawn through the rod to enhance the satisfaction to the smoker, wherein the dots are printed over a selected area of the wrapper to provide a greater concentration of the additive at that end of the rod to be the lit end of the rod. 
[54] SALTS PROVIDED FROM NICOTINE AND ORGANIC ACID AS CIGARETTE ADDITIVES

[75] Invenlors: Jerry W. Lawson, Clemmons: Bruce R. Bullings; Thomas A. Perfelti, both of Winston-Salem, all of N.C.

[73] Assignee: R, J. Reynolds Tobacco Company, Winston-Salcm, N.C.

[21] Appl. No.: 12,922

[22] Filed: Feb, 10, 1987

[51] Int, C.. ..................... A24B 15/28; A24B 15/30;

A24B 15/42; CO7D 239/70 $131 / 352 ; 131 / 310$

[52] U.S. C1. ................................. $514 / 343 ; 546 / 281 ; 546 / 282$

[58] Field of Seareh .... $546 / 281,282,25$. $514 / 343,88 ; 131 / 336,352,310,3$ Reterenes Clted

\section{U.S. PATENT DOCUMENTS}

2,152,236 3/1939 Baichelder .............................. 167/

$2,1207,694$ 7/1940 Baier

$2,766,145$ 10/1956 Jones ............................................ 131/

2,914,072 11/1959 Tyrer et al.

3,095,882 7/1963 Hind et al. ................................ 131/

3,109,436 11/1963 Bavley et al. ............................. 131/

3,136,319 6/1964 Jarbece el al.

3,280,823 3/1966 Bavley el al. ........................... 131/

$3,319,630 \quad 5 / 1967$ Orrntins

$3,422,819$ 1/1969 Jones et al.

$3,584,630$ 6/1971 Inskeep

$3,861,400$ 1/1975 Perkins el al. .

3,878,850 $4 / 1975$ Gibson et al.

$3,924,64212 / 1975$ Eicher et al.

3.924,644 12/1975 Anderson et al.

4,125,118 11/1978 Rudner.

$4,236,532$ 12/1980 Schweizer et ol.

$4,256,126 \quad 3 / 1981$ Seligman et al.

4,286,604 9/1981 Ehretsmann et al.

$4,300,576$ 11/1981 van der Loo el al.

$4,481,96011 / 1984$ Bronks

4,506,682 3/1985 Muller

4.595.024 6/1986 Greene es al.

$4,676,2596 / 1987$ Ellis et al.

$4,714,082$ 12/1987 Banerjee et is.

4,715,389 12/1987 Lynm et al.

FOREIGN PATENT DOCUMENTS

$1039693 / 1984$ European Pat. OI.

$33121594 / 1983$ Fed. Rep. of Germany

\author{
988608 8/1951 France \\ 124711 2/1983 Japan \\ 446368 4/1936 United Kingdoin. \\ 1111007 4/1968 United Kingdoin. \\ $14959412 / 1974$ Unired Kingdom. \\ $\begin{array}{lll}1495941 & 2 / 1974 & \text { Unired Kingdom } \\ 2094611 & 9 / 1982 & \text { United Kingdom }\end{array}$ \\ $21851757 / 1987$ United Kingdom . \\ OTHER PUBLICATIONS
}

Perfetti, Beitrage Tabakforschung In'l', vol. 12, No. 2 , pp. 43-54 (1983).

Gabel el al., Ukr. Khim. Zbur.. 5, pp. 167-184 (1930).

Leffringwell et al., Tobacco Flavoring for Smoking Prod. ucts, pp. 11-15 (1972)

Sensabaugh et al., Tobacco Science, vol. 11, pp. 25-30 (1967).

Houseman, Beitr. Takabforsch., vol. 7, pp. 142-147 (1973).

Armitage et al., Quarterly Journal of Experimental Physiology, vol. 59, p. 55 (1974).

Jenkins et al., Ini'l Journal of Applied Radiation and Isotopes, vol. 27, pp. 323-324 (1976).

Abdallah, Sensory Testing of Cigarette Smoke, Panel Selection, Training and Use; North Carolina State Univ. Ph. D. Thesis (1974)

Wynder et al., Tabracco and Tabacco Smoke, p. 428 (1967).

Dickens, On Cancer and Hormones, pp. 107-120 (1962).

Quin and Hobbs, Anal. Chem., vol. 30, pp. 1400-1405 (1958).

Dickens and Black, Rept. Brit. Empire Cancer Carnpoign, vol. 42 (2), pp. 157-158 (1964).

Court et al., J. Chroma. Sci, vol, 16, pp. 3(4-317 (1978)

Sakuma el al., Beitr. Tabak. vol. 12, pp. 63-71 (1981). Leonard, Industrial and Engineering Chemistry. vol, 48, |331-134| (1956).

Primary Examiner-V. Millin

[57] ABSTRACT

Cigarettes having incorporated therein a salt such as nicotine levulinate exhibit low FTC "tar" 10 nicotine ratios while (i) having a smooth, palatable. navorful taste, and (ii) providing smoking satisfaction to the user. The cigarettes do not exhibit a harsh or irritating character; and do not exhibit a non-tobacco or off-taste.

44 Claims, 1 Drawing Shee

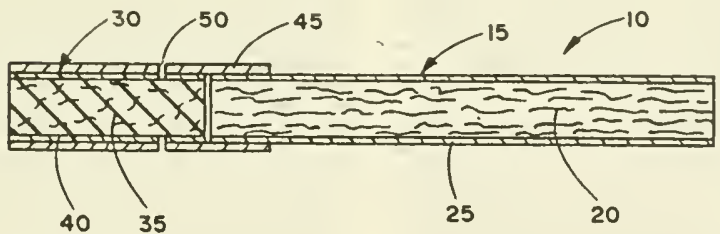


1

\section{$4,830,028$}

\section{2}

of delivering a good tobacco taste. strength and snink ing satisfaction characteristic of a "full navor" cigarctic while not being perceived as being overly harsh of irrilating.

SALTS PROVIDED IROM NICOTINE AND URGANIC ACID AS CIGARETTE ADDITIVES

\section{BACKGROUND OF THE INVENTION}

The present invention relates to smoking articles such as cigarettes, and in particular to flose snoking articles having incorporated therein an additive comprising nicotine and an organic acid.

l'opular smoking articles such as cigaretics have a substantially cylindricul rod shaped structure and include a charge of smokahle malerial such as particulates of tobacco (i.e., cut filler) surrounded by a wrapper such as paper thereby forming a tobacco rod. It has become desirable to manufacture cigarettes having cy. lindrical filters aligned in an end-to-end relationship with the tobacco red. Typically, filters are manufacturcd from fibrous ntatcrials such as cellulose acctate and are attached to the tohacco rod using a circumseribing tipping material.

The so called "full navor" cigarettes are popular smuking articles which dclivers a desirable tobacco taste, navor and satisfaction to the smoker. Typically, the "full navor" cigarettcs deliver about $14 \mathrm{mg}$ or more of FTC "tar" per cigarettc. Cigarettes also can be classified as "fult navor low tar" cigarettes. Typically, the "full flavor low tar" cigarcttes deliver from about 8 to about $14 \mathrm{mg}$ of FTC "Iar" per cigarelle, as well as lower levels of FTC nicotime as compared to "full navor" cigarettes. Yet another classification of popular cigarettes is the "ultra low tar" cigarette which delivers still lower levels of FTC "tar" and nicotine. Typically, the "ultra low tar" cigarettcs deliver less than about 7 mg of FTC "tar" per cigarette. The "full Mavor low Iar" and "ultra low tar" cigarettes conventionally have air dilution means such as laser perforations provided in the periphery of the mouth end region thereof, or lave lilter elements highly efficicnt for the removal of "tar" and nicotine from the mainstream acrosol. In general, the perceived taste or strength of the cigarettes classified as having lower levels of "tar" and nicotine are progressively less than (liat of the cigarettes which are classified as approacling the cliaracteristics of the "full Mavor" cigaretles. It has been proposed to add nicotine and other flavorants to the cut filler of lower "tar" 4 cigarettes to enhance the taste, strength and satisfaction of such cigarettes. However, the addition of nicotine to such cigarettes generally yields mainstrean smoke which may be perceived as harsh or irritaling to the mouth, nose and throat of the user.

The addition of nicotine di-(p-tolucyltartrate) salts 10 eigarettes his becn proposed in order to study the exog. enons transier of nicoline from the cigarefte during snuking. See, for example. Housenuan. Beirr. Tabokforsch, Vol. 7, p. 14 (1973); Jenkins et al, Int'l Journol of Applied Radiasion and Isinapes. Vol. 27, p. 323 (1976); Armitage et al. Quorterly Journal of Fxperimental Physiology. Vol. 59, p. 55 (1974). However, the citcd articles propose neither improved taste nor ollier enhanced smoking characteristics of the cigarettes as a result of the salt additive

It would be desirable to provide a cigarette suclı as an "ultra low tar" cigarette which is capable of delivering a good tobacco taste, strength and smoking satisfaction characteristic of a "full flavor low tar" cigarette while not being perceived as being overly larsh or irritating. In addition, it would be desirable to provide a cigarclte such as "full navor low tar" cigarette which is capable

\section{SUMMARY OF THIE INVENTION}

The present invention relates to a smoking articlc which delivers good tobacco taste while being capithl of delivering relatively low amounts of FTC "tar: 0 Preferred articles of this invention ar e cigarettes wlinch detiver a taste, strength and smoking satisfaction clur acteristic of a "full navor" cigarette, and relatively low levels of FTC "(ar" characteristic of "full finvor low tar" cigarettes. Also preferscd are cigareltes wlich deliver a taste, strength and sinoking satisfaction char acteristic of a "full flavor low tar" cigarette, and rela. tively low levels of FTC "tar" characteristic of "ultro low tar" cigarettes. In addition, the preferred cigitrettcs are cxtremely palatable and provide the perception of having a smooth smoking character (i.e. not providing a perceived larsh or irritating charatcter) relative to a comparable cigarctic delivering similar levels of FTC "tar." Or particular interest are cigarettes laving (i) relatuvely low FTC "tar" to FTC nicoture ratios (ii) relatively low FTC carbon monoxide to FTC nicotine ratios, (iii) good tobacco flavor, strength and salisfaction, and (iv) a smonth, palatable smoking character without being overly mild tasting.

A smoking article in accord with this invention has incorporated therein at least one salt provided fion nicotine and an organic acid. The salt is incorporated within the smoking article as an additive. Preferably, the salt is such that the molar ratio of nicotine to organic acid therein is $1: 3$. Most preferably, the salt addilive includes nicotine levulinate. The parlicular salt is incorporated into the smoking article in such a manner tha during use of the article, the salt is subjected to decom position conditions. The presence of the salt within the article provides improved tobacco taste, streneth and smoking satisfaction as well as improved or maintained navor characteristics to the aerosol during use of the article. Preferred smoking articles do not exhibit undesirable off-tastes.

\section{BRIEF DESCRIPTION OF THE DRAWINGS}

FIG. 1 is a longitudinal sectional view of a smoking article of this invention.

\section{DETAILED DESCRIPIION OF THE PREFERRED EMBODIMENTS}

One embodiment of a smoking article of this invention is shown in FIG. I and has the lorm of a cigarette 10 the cigarette includes a genterally cylindrical rod 15 of filler material $\mathbf{2 0}$ contained in circumscribing wrap. ping material $\mathbf{2 5}$. The rod $\mathbf{1 5}$ is hereinafter referred io as a "smokable rod" or a "tobacco rod." The ends of the tobacco rod are open to expose the filler material. The cigarette 10 also includes a filier element 30 positioned adjacent one end of the tobacco rod 15 such that the filter element and tobacco rod are axially aligned in an end-to-end relationsinip, preferably abutting one another. Filter element 30 has a generally cylindrical shape, and the diameter thereof is essentially equal in the diameter of the tobacco rod. The ends of the filter element are open to permit the passage of air and smoke thercthrough. The filter element 30 includes filtcr material 35 which is overwrapped along the longitudinally 
extending surface thereof with cırcumscribing plug wrap material 40.

The filter elenient $\mathbf{3 0}$ is attached to the tobacco rod 15 by lipping material 45 which circumscribes both the enture length of the filter element and an idjacent regiou of the tobacco rod The inucr surface of the tipping inateriat 45 is fixedly secured to the nurer surface of the plug wrap 40 and the outer surface of the wrapping matcrial 25 of the tobacco rod, using a suitable adhesive. If desired, a ventilated or air diluted smnking article is provided with an atir dilution means such as a series of perforations 50 eacl of which extend through the tip. ping material and plug wrap.

Typically, the tobacco rod las a length which ranges from ahout $50 \mathrm{mrn}$ to about $85 \mathrm{~mm}$, a circumference of about $17 \mathrm{~mm}$ to about $27 \mathrm{~mm}$; and the wrapping material thereof is a conventional cignrette wrapping paper. If desired a dual wrapper system can be employed. The tobacco rods and the resulting cigareltes can be manufactured in any known configuration using known cigarette making lechniques and equipment.

Typically, the filter element las a length which ranges from about $20 \mathrm{~mm} 10$ about $35 \mathrm{~mm}$ and a circumference of about $19 \mathrm{~mm}$ to about $27 \mathrm{~mm}$. The filter matcrial can be nny suitable material such as cellulose acetate, polypropylene, tobacco material, or the like. The plug wrap typically is a conventional paper plug wrap, and can be either air permeable or essentially aif impernieable. However, if desired, a nonwrapped cellulose acetate fitter element can bc employed. The various filter elements suitable for use in this invention can be manufactured using known cigaretle filter making teclniques and equipment.

The filler material employed in the manufacture of the smokable rod can vary. Preferably, the milority of the filler material present in thic smokable rod is a smokahle material such as tohacen material, or a blend therenf with a tobacto sulstitute material. Examples of suitable tobacco nuaterials iuclude flue-cured. Burley, Md. or Oriental tobaccos; processed tobacco materiais such as expanded tobaccos. prncessed tobaceo stems, reconstiruted tobacco materials or reconstituted tohacco materials having varying levels of endogenous and exngenous nicotine; or hlends thereof. If desired, the tolsacco materials can be blended with small amounts of carbonized and/or pyrolyzed materials. The smokable materials are enployed in the form of particu lates as is common in conventional cigarette manufac ture. For example, the smokable filler material can be employed in the form of strands cut into widths ranging from alsout $1 / 25$ incli to about $1 / 60$ inch, preferably from about $1 / 30$ inch to about $1 / 40$ inch. Gesterally such strands have lengths which range from ahout 0.25 inch to about 3 inches.

Typically, the tipping material circumscribes the filter elcment and an adjacent reginn of the tobacen rnd such that the tipping material extends about $3 \mathrm{~mm}$ to about $6 \mathrm{~mm}$ along the length of the tohacco rod. Typically, llie tipping material is a conventional paper tipping material. The tipping material can have a porosity which can vary. For example, the tipning material can be essentially air impermeahle, air perneable, or be treated (e.g., by meclianical or laser perforation techniques) so as to have a region of perforations, openings or vents thereby providing a means fnr providing air 6 dilution to the cigarette. The tntal surface aren of the perforations and the pusitinnug of the perforations along the periphery of the smoking article can he varied
4

in order to control the performance characteristics of the smoking article.

As used herein, the term "air dilution" is the ratio (generally expressed as a percentage) of the volume of air drawn through the air dilution means to the Iotal volume of air and aerosol drawn through the smoking article and exiting the extreme mouth encl portion of the smoking article. For air diluted or ventilated smoking articles of this invention. the ammint of air dilution can vary. Preferably, the amount of air dilution for a cigarctte is greater than about 20 percent, more preferably greater than about 30 percent. The upper limit of air dilution for a cigarette typically is less than about 80 percent, inore frequently less than about 60 percent.

The salt provided from nicotine and an organic acid (also referred to herein as a "nicotinc/organic acid salt") requires nicotine as a necessary component. The nicotine can be naturally occurring nicotine which is obtained as an extract from nicotineous species (e.g. (ohacco) or synthetic nicotine. The aicntine can be 1-nicotine, d-nicotine, or a inixture of d-nicotine and I-nicotine. Preferably, the nicntine is employed in rela. tively pure form (e.g., greater than about 95 percent pure, more preferably greater than about 99 percent 5 pure) and is "water clear" in appearance in order to avoid or minimize the formation nf tarry residues dur ing the subsequent salt forination steps. The nicotine can be purified by distillation or other suitable methods.

Organic acids useful herein are any organic acids or organic compounds that behave as Lewis acids when contacted with nicotine. Preferred organic acids are those acids which form salts with nicotine in a $1: 1,2: 1$ or $3: 1$ molar ratio (organic acid:nicotine). Examples of organic acids useful in practicing the present invention are aromatic acids including benzoic-type acids and substituted benzoic-type acids, hydroxyacids, heterocy. clic acids, terpenoid acids, sugar acids surth as the pectic acids. amino acids, cycloaliphatic acids, dicarboxylic acids, aliphatic acids, keto acids, and the like. Preferred 0 organic acids are the straight-chain and branched-chun aliphatic acids, more preferably the aliphatic monocarboxylic acids, and especially the keto aliphatic monocarboxylic acids. Examples of suitable organic acids inclade formic, acetic, propionic, isobutyric, butyric, 5 alpha-methylbutyric, isovaleric, beta-methylvaleric. caproic, 2-furoic, phenylacetic, heptanoic, octanoic. nonanoic, malic, citric, oxalic, malonic, glycolic, succinic, ascorbic, tartaric, fumaric and pyruvic acids, as well as the lower fatty acids (i.e., having carbon cluains less than $C_{12}$ ) and the higher falty acids (i.e. having carbon chains of $C_{12}$ to $C_{20}$ ), and other such acids. The most preferred organic acid is a gomma keto aliphatic acid known as levulinic acid $\left(\mathrm{CH}_{3} \mathrm{COCH}{ }_{2} \mathrm{CH}_{2} \mathrm{COOH}\right)$. Useful organic cnmpounds which exhibit an acid char5 acter and which form salts with nicotine include the plienolics such as guaiacol, vanillin, protocatechualde. hyde, and the like.

Preferred nicotine/organic acid salts have a molar ratio of organic acid to nicotine of $1: 1,2: 1$ or $3: 1$, nins 0 preferably $3: 1$. The most preferred salts are totally ion. ized salts of nicotine and the organic acid. For example. a particularly preferred salt is provided from 1 mole of nicotine and 3 moles of ievulinic acid and has a molar ratio theren of 1:3.

The nicotine/organic acid salts are prepared using rechniques generally known to thnse skilled in the art Many of such techniques have been catalogued by Perfetti in Beitraqe Zur Tbbakforschung Imternotional. Vol. 
5

$4,830,028$

12. No 2. 43 (1983), which is incorporated herein by reference Preferably, mcotine/organic acid salts are provided by contacting micotine with at least the stoichometric amount of the organic acid necessary to form the particular salt under conditions sufficient to form the salt.

The preferred salts provided from nicotune and the organic acid generally are essentially non-volatile at conditions under which the smoking articles are manufactured and stored, however, specific properties of the various salts can vary. For exanıple, nicotiue/organic acıd salts having strnight-chain or branched-chain aliphatic acids having less than 20 carhon atoms generally have a molar ratio of 1:3 (nicotine:acid). and generally are liquid in form at ambient conditious. Such salts typically decompose at temperatures less than $100^{\circ} \mathrm{C}$. usually in the range froin about $50^{\circ} \mathrm{C}$. 10 about $60^{\circ} \mathrm{C}$ As another exanple. mcotine/organic acid saits liaving dicarboxylic organic acids generally have a nolar ratio of $1: 2$ (nicotine:acid), and generally are solid in form at ambient conditions. Such salts typically decompose at teinperatures in the range from about $90^{\circ} \mathrm{C}$. to about $120^{\circ} \mathrm{C}$. As yet another example, nicotine/organic acid salis having acids containing phenyl groups generally have molar ratios of $1: 1 . .1: 2$ or $1: 3$ (nicotine:acid). Generally such salts are soiid iit form at ambient conditions. Such salts typically decompose at temperatures in the range from about $110^{\circ} \mathrm{C}$. 10 about $200^{\circ} \mathrm{C}$.

Numerous nicotine/organic acid salts can inprove the flavor of aroma of the nerosol, as numerous organic acids are suitable flavoranis. I lowcver, whether a narticular nicotine/organic acid salt acts as a flavoaant depends upon the amount of the particular salt einployed as an additive as well as the flavor threshold of the particular acid employed for the salt formation. See, for example, lobacen Flawning For Smoking Products, by Leffing well et al, p. 11 to 15 (1972). Examples of salts which can provide flavor and aroma to the mainstream a aerosol at certain levels include nicotine acetate, nico. tine oxalate, nicotine mllitle, nicotine isovalerate, nicotinc lactate, nicotine citrnte, nicotine phenylacetate and nicotine myristate. llowever, it may be desirable to use salts which provide flavor characteristics to the cigarette at low amounts in order to not provide undesirable off-tastes or aromas to the cigarette. For example, it may be desirable to employ certain salts at low enough levels in order tliat the cigarette does not exhibit taste or aroma characteristics which can be perceived as bcing chemical, metallic, bitter, pungent or soapy in nature, or as heing dissonant to the gencral organoleptic characteristics associaled with tohacco smoke.

The most preferred nicotine/organic acid salt is nicotine levulinate. Such a salt can provide a snootlı, palatable character to the cigarette while not providing any significant dissomant taste or aromil. If desired, certain amounts of various nicoline/organic acid salts can be blcuded with nicotine levulinate and employed as the additive of this invention.

The salts can be incorporated into the smoking article in a variety of places or sites. For example, the salt can be applied to the filler material, incorporated within some or all of the filler material, applied to the svrapper of the lobacen rod, appliesl within the glue line of the wrapper of the tobaceo rod, applied within a region (e.g., a cavity) which is suhjected to heat, or the like. Typically, the micutinc/organic acid salt additive or additive mixture is incorporated in the smoking article by admixing the additive with the smokable material.
The manner or process for applying the additive can vary depending upon whether the additive is applied II solid or liquid form, or upon the positioning of the additive within the smoking article. For exaniple. the additive can be applied using syringes or techniques such as spraying, electrostutic depositon, impregnation, gisril ture injection, spray drying, inclusion and encapsulation techriques, and the like.

When the nicotine/organic acid salts are applied using spraying techniques it is desirnble to form a liquic solution of the salt in a suitable solvent. Such solutions should exhibit a low enough viseosity to allow for spraying or injecting the solution. llowever. it is desirable that the concentration of the salt within the solution not be so dilute that the salt expericnces significant dissociation. Typically, the concentration of salt within the solution is about 20 weight percent or more.

Suitahle solvents for the salts include water, ethanol, $Q$ glycerol, propylene glyco. and the like, as well as combinations thereof. Generally, most nicotine/organic acid salts are soluble or miscible in such solvents, ane the salts do not undergo substantial dissociation when solubilized to small amounts. For example, the salt can be hydrated in water without undergoing a significan 25 amount of dissociation. However, salts diluted with substantial amounts of solvent can undergo dissociatın to some degree to provide for the application of a mix ture of nicotine/organic acid salt, nicotine and organic acid to the smoking article. Thus, it is possibie to apply an additive in the form of nicotine and levulinic acid to the smoking article.

If desired, smoking articles can have incorporated therein as an ndditive (i) at lcast one salt consisting of nicotine and an organic acid, and (ii) nicotine. Preferred additives of such type include at least one salt having a molar ratio of nicotine to organic acid of $1: 3$.

The amount of nicotine/organic acid salt or salis employed within the smoking article can vary. The amount of salt incorporated withın the smokıng article depends upon factors such as the placement of the salt within the smoking article, and the configurational as pects of the smoking article. Configurational aspect include the composition and characteristics of the filter material and initial filler blend, the degree of ventilation of the article, and other such factors. For example. for most cigarettes having fillet material comprising a nicotine content of from about I weight percent to about 2 iveight percent, it frequently is desirable to provide solt additive to provide a total nicotine content of up to about 8 weight percent, more frequently up to about 4 weight percent to the cigarette in order to provide tobacco taste, strength and satisfaction upon use. Generally, the amount of nicotine/organic acid salt applied to n cigarette provides from about 0.2 to about 15 , pref erabiy from about 1 to about 10 weight percent of sal additive, based on the total weight of the salt and the amount of filler material within the cigarette. In certain instances, it is desirable to employ about 3 weight percent of salt additive or more, based on the total weight of the salt and the amount of filler material within the cigarelle

The smoking articles of this invention preferably provide a mainstream aerosol exhbiting a pH, which is essentially equal to or less than that of a similar smoking 5 article not laving the additive (e.t. the nicutane/or. ganic acid salt additive) incorporated therein. In certain circumstances, an amount of nicotine/organic acid salt additive is incorporated into the smoking article in 
ords to reduce the $\mathrm{pH}$ of the mainstream aerosol during use of the article. Mainstream aerosol is that aerosol which is drawn through the article and into the mouth of the user. For exanuple, for a cigarette, the mainstream aerosol is the mainstream tobacco smoke which in. cludes the combustion and/or pyrolysis products of tobacco material

By the term, "pH of mainstream aetosol" is meant that averaged per-puff $\mathrm{pH}$ of the whole aesosol as measured using the techniques described by Sensahaugh et al in Tolracco Science. Vol XI, pp. 25-30 (1967), which is ineon porated herein by reference. Typical mainstream aerosol $\mathrm{pH}$ for cigarettes ranges from about 4.5 units 10 about 8.5 units on average per cigarette.

Lis referring to a reduction in the plf of mainstream nerosol, it is meant a lowering of the average $\mathrm{pH}$ of the mainstream aerosol per particular smoking article. Such reduction is provided by the addition of an effective amount of the additive (e.g., nicotine/organic acid salt additive). Typically, the reduction in $\mathrm{pH}$ is a lowering of the $\mathrm{pH}$ by more than about $0.03 \mathrm{pH}$ unit; preferably by more than about $0.08 \mathrm{pll}$ unit. Typically, reduction in the pll of the mainstream aerosol does not provide a smoking article exlyihiting mainstrean aerosol having a pll siguificantly below 4.5 units.

Tlie viecomposition of the nicotine/organic acid sal durmg use of the smoking article can introduce a reduction of the $\mathrm{pH}$ of the mainstream aerosol depending upont the quantity and type of salt additive which is ineorporated into the snoking article. Thus, a certuin balance, mellowing or marrying of the navors culmi nate in a fuller bodied tobacco flavor, strength and satisfaction which is delivered to the user. Sucl a flavor cnhancing characteristic is particularly desirable for highly air diluted or "ultra low tar" cigarettes.

The $\mathrm{pH}$ of the mainstream aerosol is influenced by a number of factors. For example, the $\mathrm{nH}$ of mainstream cigarette smoke can be influenced by factors such as the type of tobacco or blend of tobaccos employed. the type of processed robacco (e.g.. volume expanded to- 40 hacco or reconstituted tobaceo), the configuration of the cigarette (c.g., the filter low material, the degree of air dilution, the circumference of the cigarette, the type of wrapning material, etc.), the manner of drawing oll or puffung the cigarente, and olher such factors.

Cigarctles of this inveution generally deliver from about $0.05 \mathrm{mg}$ to ahout $2 \mathrm{mg}$. more frequently from ahout $0.1 \mathrm{mg}$ to about $1.7 \mathrm{mg}$ of nicotine when smoked under I.TC conditions. Generally, FTC "tar" to FTC nicotine ratios for eigareltes of this invention are less than about 10, frequently less llian aboul 7, and in certain instances less tan about 5. FTC "tar" to FTC nico. tine ratios for sigarettes of this invention often cat range from about 3 to about 6 . Typically, the FTC "tar" to F IC nicotine ratio of a cigarclle of this invention can be lowered by up to about 80 percent of that ratio of a similar cigarette not having the additrve incorporated therein.

The following examples are provided in order to further illustrate the invention bul should not be construed as limiting the scope thereof. Unless otherwise noted, all parts and percentages are by weight.

\section{EXAMPLI: 1}

A salt of nicotine and levuline acid is provided using 65 the following procedure.

Into i $1,000 \mathrm{ml}$ round hottom flask is charged about $350 \mathrm{~g}$ of 1 -nteotine provided from Kodak Laboratory
N

Chemicals, Eastman Kodak Co. (Catalugue po. 52 . P 366. Chemical No. 1124973). To the 1-nicotine is cliarged about $10 \mathrm{~g}$ of sodium hydinxide pellets The nask is fitted with a heating mantle and equipped with a magnetic stirring bar. The nicotine solution is snrred employing a magnetic stirrmg unt The nicotine is vacuum distilled using a Toud Column packed with glass helixes, and the fraction distilled between $97^{\circ} \mathrm{C}$. and $98^{\circ}$ C. at $10 \mathrm{~mm} \mathrm{Hg}$ pressure is collected at a refix ratio of about 10:1. The collected distillate is water clear. Thc nicotine so purified using the vacuun distillatuon icthnique is employed in the preparation of the 1 -n motine/. nique is employed in
levulinic acid salt.

Into a $500 \mathrm{ml}$ round bollom flask equipped with a magnetic stirring bar and heating mantle is chargeri 9.6 stripped employing a conventional magnetic stirring unit. The levulinic acid is obtaned from Aldrich Cliemical Co.. Catalogue No. 1984-85, F. 672. Compound No. L.200-9, and is employed without further purification. The levulinic acid is heated to about $50^{\circ} \mathrm{C}$. in order to provide a liquid form thereof, and the liquified component is subjected to stirring. To the liquified levulinic acid is titrated $32.4 \mathrm{~g}(0.2 \mathrm{~mole})$ of the purified 1 -nico-

25 tine over about a 20 minute time period it is preferred to introduce the nicotine 10 the organic acid in order to provide an environment of excess acid to nicotine and thus promote the formation of salt. A clear, viscous yellow colored material weighing ahout $100 \mathrm{~g}$ results

30 The product is sealed in a glass ampuole under nitrogen.

The product is 1-nicotine levulinate (as delermined using infrared spectrometry), and las a nicotinc to levulinic acid ratio of $1: 3$ (as determined by a destructive distillation in a 10 percent sodium hydroxide aqueous 35 solution, subsequent extraction using isopropanol. anc gas chromatographic analysis for nicotme). The salt is believed to have a structure substantially as generally described in FIG. 13 of the Perfelti reference, supra

\section{EXAMPLE 2}

Cigarettes incorporating varying amounts of the 1 . nicotine levulinate salt are provided using the following procedure.

Cigarettes having lengtlis of about $99 \mathrm{~nm}$ and cir45 cunferences of about $24.85 \mathrm{mni}$ have tobacco rod lengths of $68 \mathrm{~mm}$ and filter element lengths of $31 \mathrm{~mm}$ The tobacco rod includes a charge of tohaceo cut filler weigluing about $0.7420 \mathrm{~g}$ contained in a circumscribing cigarette paper wrap which is sold commercially as 754

so Cigarette Paper by Ecusta Corp. The filter elentent is manufactured using conventional cigarctte filter making teclinology from cellulose acetate fow ( 2.7 denier per (flament, 48,000 total denies) and circumscribing air permeable paper plug wrap having a COREST A porosity of $26,000 \mathrm{~cm} / \mathrm{min}$. The tobacco rod and fitter element are aligned in an abutting, end-10-end rehationslip and secured logether using tipping paper having a CORESTA porosity of $3135 \mathrm{ml} / \mathrm{min}$. The lipping pirne is adhesively secured to the filter element and the adja cent portion of the tobacco rod. The tipping matcria circumscribes the length of the filter element and alrout $3 \mathrm{~mm}$ of the length of the tobacco rod. Cigarettes so described are manufactureti using a l'ilot Cigarctlc Maker from Ilauni-Werke Kouber \& Co KG. A ring of mechanically provided perforations extends around the pcriphery of the cigarette alxout $13 \mathrm{~mm}$ from the ex. trame mouth end thereof. The perforations si) provided yield cigarettes which are 50 percent air diluted. The 


\section{9}

cigarettes so manufactured are designated Sample Nos. $1,2,3$ and $\mathrm{C}-1$, cortesponding 10 the sample of filler material from which each cigarette is manufactured.

The filler material employed in provicling the tobacco rod is in the form of strands cut at about 32 cuts per inch. The initial filler material includes a blend of about 9 percent Burley tobacco, about 41 percent flue-cured tobacco, about 32 percent reconstiluted tobacco material, and about 18 percent Oriental tobacco. The blend has an aqueous casing of glycerin and flavors applied thereto.

lour lots of the cut filler blend, each lot weighing $1.520 \mathrm{z}$, are provided. The first lot is ireated with $20 \mathrm{~g}$ of the 1 -nicotine levuhuate additive. The second lot is tranted with $60 \mathrm{~g}$ of the I-nicotine levulinate additive. Tlic third lot is treated with $100 \mathrm{~g}$ of the 1-nicotine levulinate additive. The fourth lot is not treated with the I-nicotine levulinate additive and is employed for comparison purposes.

The I-nicotinc levulimate additive is applied to cut filler as a spray using a hand sprayer to apply a $1: 1$ mixture of water and additive.

Fach of the four lots are separately placed in sealed plastic bags and stored at $70^{\circ} \mathrm{F}$. for 2 days. Then. the four lots are each mixed with about $480 \mathrm{~g}$ of a cut filler mixture of about 75 parts volume expanded Burley tobacco and about 25 parts volume expanded flue-cured totacco. The volume expanded cut filler mixture is added to each lot using a mixug dirum in order to provide a well inıxed blend having a moisture content of abuut 12 percent to about 13 percent. The resulting blend provided from the first lot of filler material has about I percent of the I-nicotine levulinate salt applied thereto and is designated as Sample No. 1. The resulting blend provided from the second lot of filler material has about 3 percent of the I-nicotine levulinate satt applied thereto and is designated as Sample No. 2. The resulting blend provided from the third lot of filler materiai has about 5 percent of the I-nicotine levulinate salt applied thicreto and is designated as Sample No. 3. The resulting blend providerl from the fourth lot of filler material is nol treated with the 1-nicotine levulinate salt additive, is employed for comparison purposes, and is designated as Sampie No. C-1

The various cigarcttes are smoked under TTC condi- 45 tions. Data concerning (i) FTC "tar," FTC nicotine and FTC carbon monoxide, (ii) the "tar"/nicotine ratio, (iii) tobacco nicotine, (iv) puft count, and (v) $\mathrm{pH}$ of the nuanstream acrosol for each sample are presented in Table 1.

TABLEI

\begin{tabular}{|c|c|c|c|c|c|c|c|c|}
\hline \multirow[b]{2}{*}{ Sample } & \multirow{2}{*}{$\begin{array}{c}\text { FTC "tar" } \\
\text { (mg/cigaretle) }\end{array}$} & \multirow{2}{*}{$\begin{array}{l}\text { FIC Nicutime } \\
\text { (mg/clugaretic)' }\end{array}$} & \multirow{2}{*}{$\begin{array}{c}\text { FrC CO } \\
\text { (mg/cigarente)' }\end{array}$} & \multirow{2}{*}{$\begin{array}{l}\text { "Ta:"' } \\
\text { Nicomimc2 }\end{array}$} & \multirow{2}{*}{$\begin{array}{c}\text { rolal } \\
\text { Nicotinel } \%)^{3}\end{array}$} & \multirow{2}{*}{$\begin{array}{c}\text { Putf } \\
\text { count }\end{array}$} & \multicolumn{2}{|c|}{ Stroke rH } \\
\hline & & & & & & & mแนที่า & maxumum \\
\hline 1 & 5.1 & $n 36$ & 94 & 01 & 205 & 87 & 575 & 601 \\
\hline 2 & to & 069 & 74 & $7 i$ & 2.51 & 8.9 & 5.65 & 6012 \\
\hline$i$ & 49 & u.ni & 67 & 6.0 & 291 & 90 & 567 & 5.98 \\
\hline C.1. & +.6 & 038 & 75 & 121 & 166 & 88 & 5.85 & 6.10 \\
\hline
\end{tabular}

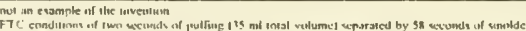

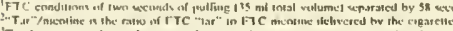

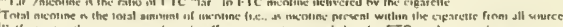

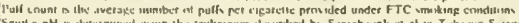

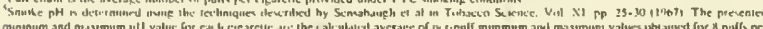
curaschle

The data in Table I indicate that the various ciga- 65 relles exhibit increased FTC nicotine values as the level of I-nicotiue levulinate is incretased In addition. the FTC "Iar" to nicotine ratius for the samples clecrense as

perforated cigarette is 75 percent air diluted The cigarettes so manufactured are designated Sample Nos. 4. 5. 
6 and C-2. corresponding to the sample of filler material from which each cigarelte is manufactured.

The filler material employed in providing the tohacco rod is in the form of strunds cut at about 32 cuts per inch. The initial filler material includes a blend of about 43 percent burley tobacco, abnut 6 percent flue-eured tobacco, about 19 percent reconstituted tobacco material, and about 32 percent Turkish tobacco. The blend has an aqueous casing of glycerin and havors applied theretrs.

Four lots of the cut filler blend, each int weighing 940 $g$, are provided. The first lol is treated with $60 \mathrm{~g}$ of the I-nicotine levulinate additive. The second lot is treated

Sample No. 7 is provided by injecting about $10 \mathrm{mg}$ of the previously described $1: 1$ mixture of ethanol:nicctine imo a cigaretie designated as Sample No. 6 using : syringe in the manner previously described. The cigarette so provided comprises a nicotune levulinate addi. tive as well as an exogenous nicotine actditive

The various cigarettes are smoked under FTC condituons. Data concerning (i) FTC "tar," FTC nicotime and FTC carbon monoxide, (i) the "tar"/nicolne ratio, (iii) 10 ubacco nicotine, and (iv) puff coumt firr Sample Nos 4-6 and C-2 are presented in Table 11 . In addition. dat: concerning the $\mathrm{pH}$ of the nuanstream aerosol for Sant ple Nos. 4-6. C-2 and C-3 are presented in Table 11

TABLE II

\begin{tabular}{|c|c|c|c|c|c|c|c|c|}
\hline \multirow[b]{2}{*}{ S.umple } & \multirow{2}{*}{$\begin{array}{c}\text { FrC "int" } \\
\text { (mig/cigaretic)! }\end{array}$} & \multirow{2}{*}{$\begin{array}{l}\text { FTC Nicolıne } \\
{\text { \{my/eigarctie }\}^{1}}^{\text {ime }}\end{array}$} & \multirow{2}{*}{$\begin{array}{c}\text { FTC CO } \\
\text { (ming/cig.urelte)' }\end{array}$} & \multirow{2}{*}{$\begin{array}{l}\text { "Tar"' } \\
\text { Nicuine? }\end{array}$} & \multirow{2}{*}{$\begin{array}{c}\text { Tntal } \\
\text { Nicotine }(\%)^{\prime}\end{array}$} & \multirow{2}{*}{$\begin{array}{c}\text { Puf } \\
\text { Coumin }\end{array}$} & \multicolumn{2}{|c|}{ Smoke olli: } \\
\hline & & & & & & & muหnium & ตวงเตับ \\
\hline 4 & 1.8 & 029 & 29 & 62 & 2.64 & 67 & 5.90 & $62 x$ \\
\hline 5 & $2 \pi$ & $0.3 n$ & 30 & 5.1 & 3.22 & 68 & 586 & 620 \\
\hline 6 & 20 & 0.51 & 11 & 39 & 392 & 68 & 501 & h!3 \\
\hline C. $-2^{*}$ & 18 & 018 & 29 & 100 & 2.ก8 & 67 & (1) & 042 \\
\hline C-3. & - & - & - & - & - & - & 678 & 711 \\
\hline
\end{tabular}

ind an cosmple or ille inveminn

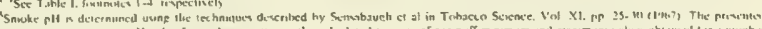

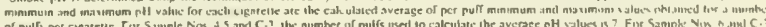

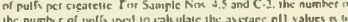

with $140 \mathrm{~g}$ of the 1 -nicotine levuliuatc additive. The third lot is treated with $200 \mathrm{~g}$ of the 1 -nicotine levulinate additive. The fourth lot is not treated with the I-nicotine levulinate additive and is employed for comparison purposes.

The 1-nicotine levulinate additive is applied to cut filler as a spray using a hand sprayer to apply a $1: 1$ mixture of water and additive.

Each of the four lots are separately placed in sealed plastic bags and stored at $70^{\circ} \mathrm{F}$. for 2 days. Then, the four lots are eacls mixed with about $1.060 \mathrm{~g}$ of a cul filler mixlure of about 35 parts volume expanded burley tobacco and about 65 parts velume expanded nue-cured tobicco. The volume cxpanded cut filler mixture is added 10 each lot using a nixing drum in order to providu a well mixed blend having a nusisture content of about 12 perceut to about 13 percent. The resulting blend provided from the first lot of filler imaterial has about 3 percent of the 1-nicotine levulinate salt applied thereto and is desimated as Saniple No. 4. The resulting blend provided froin the second lot of filler material has about 7 percell of the 1-nicntine Ivvulinate salt applied thereto and is desiguated as Saniple No. 5. The resulting blend provided frons the third lot of filler material has about 10 percent of the I-nicntine levulinate salt applied thereto and is designated as Sample No. 6. The resulting blend provided from the fourth lot of filler inaterial is not treated with the 1-nicotine levulinate salt additive, is employed for comparison purpuses and is designated as Saniple No. C-2.

For comparison purposes, Sample No. C.3 is pre= pared. Sample No. C-3 is provided by adding nicotine 10 a cigaretle designated as Sample No. C.2. In particular, about $30 \mathrm{mg}$ of a $1: 1$ mixture of ethanisl and 85 percent pure I-nicotine is injected into the cigaretle in order (t) provide a nicoune content of about 3.92 percent to the eigarette. The nicotine/ethanol mixture is incorporated into the tobacco rod by inserting a syringe into the lighting end of the rod and slowly pullung the syringe from the rod while muecting the nixture into the rod
The data in Table 11 indicate that the various cigit rettes exhibit increased FTC nicoline values as the level of I-nicotine levulinate is increased. In addition. the FTC "tar" to nicotine ratios for the samples decrease as the level of 1-nicotine levulinate is increased. The virious cigarettes eacli exhibit similaı "tar" deliveries. car bon monoxide deliveries and puff counts. Further, the 35 samples of the invention (i.e., Sample Nos. 4-6) exhıbi a $\mathrm{pH}$ of the whole smoke lower tlian that of the sample not having the exogenous addition, the $\mathrm{pH}$ of the whole smoke of Sample No. C-3 is very much ligher than that of any of the other samples.

Evaluations of the organolepuc properties of Sample Nos. 5. 6 and C-2 indicate that the cigarette having 1 percent salt additive (i.e., Sample No. 6) exhibits greater impact and smonthness as well as less harshness than the cigarette not laving the salt additive (i e.. Sample No. C-2). All cigarettes sampled provide good tobacco tast and do not exhibil a perceivable chemical off-laste or non-cigarette taste. Surprisingly, Sample No. 5 is not significuntly different organoleptically from Samplc No. C-2 in terms of impact, smonthness, harshness and overall taste even though the sample provides a higher level of FTC nicotine than the compurative sample. Saniple No. C-3 is extremely harsh and is not palasable. However, Sample No. 7 surprisingly exhibits a smooth smoking character and is palatable, even though the simple has a relatively high level of exogenous nicotine incorporated therein.

What is claimed is:

1. A cigarette having incorporated therein as an additive at least one salt consisting of nicotine and an organic acid, wherein at least one of the salts has a mola ratio of nicoline to organic acid of $1: 3$, and at least one of the salts is a salt of nicotine and a gamma keto altplatic monocarboxylic acid

2. The cigarette of claim I wherein the ratio of FTC "1ar" to FTC nicotine thereof ranges fron about 3 to about 6 .

3. A cigarette having nicotine levulinate incorporated therein is an additive. 
13

4. The cigarelte of claim 3 wherein the addituve is a blend of nicotine levulinate and at least one other salt consisting of nicotine and an organic acid.

5. The cigarette of claim $1,2,3$ or 4 wherein the $\mathrm{pH}$ of the mainstream aerosol thereof is essentially equal to or less than that of the cigarette not having the salt additive incorporated therein.

6. A cigarette laving incorporated therein as an additive at least one salt consisting of nicotine and an organic acid such that the ratio of FTC "tar" to FTC nicotine of the cigarette is less than about 7.

7. The cigarctte of claim 6 wherein the ratio of FTC "10 $r^{2}$ to FTC nicotine ranges from about 3 to about 6.

8. The cigarette of clain 6 or 7 wherein the $\mathrm{pH}$ of the mainstream aerosol is essentially equal to or less than that of the cigarctte not laving the salt additive incorporated therein

9. The cigarette of claim 6 wherein the organic acid is levulinic acid.

10. The cigarette of clain 6 wherein the additive is a blend of nicotine levulinate and at least one other salt consisting of nicotıne and an organic acid.

11. The cigarette of claim 6 wherein the organic acid is an aliphatic monocarboxylic acid.

12. A cigarette having incorporated therein as an additive at least one salt consisting of nicotine and as aliphatic monocarboxylic acid in an amount sufficient to reduce the $\mathrm{pH}$ of the mainstream aerosol provided dur. ing use of the cigarette.

13. The cigarette of claim 12 wherein the aliphatic monocarboxylic acid is a gamma keto aliphatic monocarboxylic acid

14 The cigarctte of claim 13 wherein the acid is levulinic acid

15. Tobacco cut filler mcluding a nicotine levulinate addirive.

16. The cigarette of clain 1, 2, 3, 4, 6, or 12 which is cquipped with a means for providing air dilution thereto.

17. The cigaretle of clain 1.3 or 10 including smokable filler material wherein the salt additive is incorporated in an amount ranging from about 1 percent to about 10 percent, based on weight of the salt and the filler material of the cigarette

18 A cigarelte having incorporated therein as addi$e \frac{18 \text { A cigarelte having incorporated therein as addi- }}{\text { tives (i) a least on salt consisting of nicotine and an }}$ organic acid, at least one of the salts having a molar ration of nicotine to organic acid of 1.3 , and (ii) nicotine

19 The cigarette of claim 18 wherein the organic acid is an aliphatic monocarboxylic acid

20. The cigarette of clain $\mathbf{8}$ or 19 wherein the ratio of FTC "tar" to FTC nicotine is less than ahout 7 .

21. The eigarctte of claim 18 or 19 wherein the ratio of FTC "tar" to FTC nicotine ranges from about 3 to ss about 6 .

22. The cigarette of clain 18 which is equipped with a means for providing air dilution thereto.

23. A cigarette including smokable filler material and having incorporated therein as additives (i) nicotine and (ii) levulinic acid, wheren the nicotine and levulinic acid additives are incorporated in the sigarette such that the molar ratio of nicotine additive to levulinic ncid additive is about $1: 3$, and such that the anount of nicotine and levulinic acid additives incormorated in the cigarette is greater than or equal to about 3 percent, based on the weight of the nicotine addittve, the levulinic acid additive and the fitter material of the cigarette.

\section{4}

24 The cigarette of claim 23 wherein the ratio of FTC "tar" to FTC nicotine thereof is less than about 7

25. The cigarette of claim 23 wherein the ratio of FTC "tar" to FTC nicotine ranges from about 3 to 5 about 6.

26. The cigarette of claim $\mathbf{2 3}$ which is equipped with a means for providing air dilution thereto.

27. The cigarette of clain 23 further comprising as an additive a salt consisting of niçotine and an organic acıd

28. A smoking article having nicotine levulinatc in corporated therein as an additive

29 The smoking article of claim 28 further compris ing nicotine as an additive.

30. A cigarette having incorporated therem as additives (i) at least one salt wherein one is nicotine levulinate, and (ii) nicotine.

31 The cigarette of clivim 30 wherein the ratio of FTC "tar" to FTC nicotine is less than about 7.

32. The cigarette of claim $\mathbf{3 0}$ wherein the ratio of FTC "tar" to FTC nicotine ranges from about 3 to about 6.

33. The cigarette of claim 30 which is equipped with a means for providing air dilution thereto

34. Synthetically produced substantially pure nico25 tine levulinate.

35. The cigarette of claim 28 wherein the salt is nicotine levulinate.

36. The cigarette of claim $1,3,6,9,12$ or 14 includiug smokable filler material whercin the cigarette has the additive incorporated therein as an additive to at least portion of the filler material.

37. The cigarette of claim 18, 23, 24, 27, 30, 31 or 35 including smokable filler material wherem the cigarctte has the additives incorporated thereil as additives to at 3 least a portion of the filler material.

38 The smoking article of claim 28 including smok. able filler material wherein the smoking article has the additive incorporated therein as an additive to at least a portion of the filler material.

39. The cigarette of $1,3,6,9,12,14,18,23,24$ $27,31,32$ or 36 including smokalıle filler inatleriai wherein at least a portion of the smokable filler initertal is selected from burley tabacco, flue-cured tobacon, volume expanded tobncen and reconstututed tobacco

540 The smoking article of claim 28 including smok able filler material wherein at least a portion of the smokable filler material is selected from hurley tobacco. fue-cured tobacco, volume expandel tobacco and re. constifuted tohacco.

41. The cigarette of claim 4, 18, 21 or 30 including smokable filler material wherein the salt additive is incorporated in an amount ranging from about I per cent to about 10 percent, based on the weight of the salt addituve and the filler material of the cigarette.

42. The tobacco cut filler of claim 15 wherein the amount of nicotine levulinate ranges from about 1 percent to about 10 percent, based on the weight of the nicotine levulinate and the filler.

43. The cigarette of claim 1, 3, 4, 10, 19, 21 or 30 including smokable filler material wherein the salt addi. tive is incorporated in an amount of about 3 percent or more, based on the weight of the salt additive and the filler material of the cigarette.

44. The tobacco cut filler of claim 15 wherein the amount of nicoune levulinate is about 3 percent or more, based on the weight of the nicoline levulinate and the filler. $c(a, m$ salt 


\section{UNTTED STATES PATENT AND TRADEMARK OFFICE CERTIFICATE OF CORRECTION}

PATENT NO. $4,830,028$

DATLO

May 16, 1989

INVENTOR(S). Lawson et al

It is certified that error appears in the above-tdentufied patent and that said Letters Patent is hereby corrected as shown below

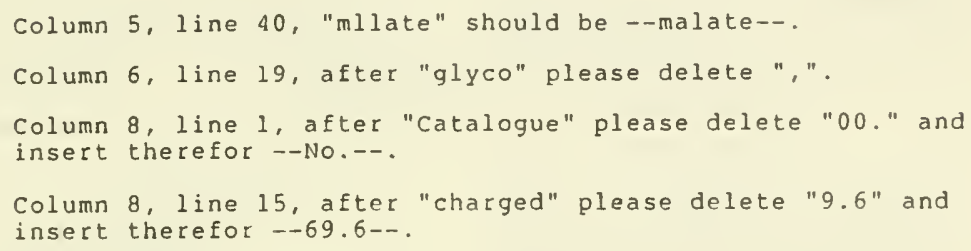




\section{UNITED STATES PATENT AND TRADEMARK OFFICE CERTIFICATE OF CORRECTION}

PATENT NO. : $4,830,028$

Page 2 of 2

DATED : May 16,1989

INVENTOR(S) : Lawson et al.

It is certified that error appears in the ahove-identified patent and that said Letters Patent is hereby corrected as shown below:

Column 14, Iine 40, Claim 39, please delete "calm" and Insert therefor -claim--.

Signed and Sealed this

Twenty-fourth Day of July, 1990

Astest:

HARRY F. MANBECK, JR. 


\section{[54] CIGARETTE}

[75] Inventors: Jerry W. Lamson, Clemmons; Bruce R. Bullings; Thomas A. Perfetti, both of Winston-Salem, all of N.C.

[73] Assignee: R. J. Reynolds Tobacco Company, Winston-Salem, N.C

[21] Appl. No.: 137,987

[22] Filed: Dee. 24, 1937

\section{- Related U.S. Applleation Data}

[63] Conlinustion-in-part of Ser. No. 12,922, Feb. 10, 1987.

[51] Int. C.4 N24D 1/C0; A24D 1/02

[S2] U.S. C1. $131 / 336 ; 131 / 333$

[58] Field of Search $131 / 352 ; 131 / 365$

\section{References Ciled}

U.S. PATENT DOCUMENTS

\begin{tabular}{|c|c|c|}
\hline$, 152,236$ & $3 / 1939$ & Batchelder \\
\hline $2,207,694$ & $7 / 1940$ & Baier. \\
\hline $2,766,145$ & $10 / 1956$ & Jones. \\
\hline $2,914,072$ & $11 / 1959$ & Tyrer et al. \\
\hline $3,099,882$ & $7 / 19$ & Hind et el. \\
\hline $3,109,436$ & $11 / 1963$ & Bavley el al. . \\
\hline $3,136,319$ & $6 / 1964$ & Jarboe et al. . \\
\hline $3,280,823$ & $10 / 1966$ & Bavley et al. . \\
\hline $3.319,630$ & $3 / 1967$ & Ortmins \\
\hline $3,422,819$ & $1 / 1969$ & Jones et al. \\
\hline $3,584,630$ & $6 / 1971$ & Inskeep. \\
\hline $3,861,400$ & $1 / 1975$ & Perkins et al. \\
\hline $3,878,850$ & 4/1975 & Gibson et al. . \\
\hline $3,924,642$ & $12 / 1975$ & Eicher et al. . \\
\hline $3,924,644$ & $12 / 1975$ & Anderson es al. \\
\hline $4,125,118$ & $11 / 1978$ & Rudner. \\
\hline $4,236,532$ & $12 / 1980$ & Schweizer et al. \\
\hline $4,256.126$ & $3 / 1981$ & Seligman et al. \\
\hline $4,286,604$ & $9 / 1981$ & Ehretsmann et al. \\
\hline $4,300,576$ & $11 / 1981$ & \\
\hline $4,481,960$ & $11 / 1984$ & Brooks . \\
\hline $4,506,682$ & $3 / 1985$ & Muller. \\
\hline $4,595,024$ & $6 / 1986$ & Greene et al. \\
\hline $4,676,259$ & $6 / 1987$ & Ellis et al. . \\
\hline $4,714,082$ & $12 / 1987$ & Banerjee et al. \\
\hline $4,715,389$ & $12 / 1981$ & Lynm el al. . \\
\hline
\end{tabular}

4,715,389 12/1987 Lynm el al.

\begin{tabular}{|c|c|c|}
\hline 103969 & $3 / 1984$ & Ersropean PaL OfT. \\
\hline $\begin{array}{l}3312159 \\
988608\end{array}$ & $\begin{array}{l}4 / 1983 \\
8 / 1951\end{array}$ & $\begin{array}{l}\text { Fed. Rep. of Germany } \\
\text { France. }\end{array}$ \\
\hline $\begin{array}{l}988603 \\
124711\end{array}$ & $6 / 1983$ & Japan \\
\hline 446368 & $4 / 1936$ & Uniled Kingdom . \\
\hline 1111007 & $4 / 1968$ & Unired Kingdom . \\
\hline 1495941 & $2 / 1974$ & United Kingdom . \\
\hline 2094611 & $9 / 1982$ & United Kingdom . \\
\hline 2185175 & $7 / 1987$ & Uniled Kingdom . \\
\hline
\end{tabular}

Abdallah, Sensory Testing of Cigarette Smoke, Pa:r: Selection, Iraining and Use; North Carolina St:ale Univ. Ph.D. Thesis (1974).

Armitage et al., Quarterly Jaurnal of Experinental Phy 1. ology, vol. 59. Pp. 55-61 (1974).

(List continued on next page.)

Primary Examiner-V. Millin

[57]

\section{ABSTRACT}

Cigarettes having high nicotine content tobacco $\iota$. filler are rendered smooth smoking and palatable by incorporating an organic acid additive therein. Fur example, cigarette having a cut filler with a ble, ii nicotine content of greater than 2 percent has at lea, one organic acid additive incorporated into the cigi. rette in an amount of greater than 1 percent. Smooll moking cigarettes yielding good tobaceo taste and minimal off-taste are provided when the majority of tli. organic acid additive is levulinic acid. The levuliuic acid can be in a dissociated and/or nondissociated form. For cigarettes having filter elements, at least a porticu of the levulinic acid can be present in the filter elemen! Altematively, .cigarettes can have at least a portion r, the levulinic acid provided in the form of nicotine lev 1 linate. Cigarettes having high nicotine content tobaccos and levulinic acid and cigarettes having a salt such as nicotine levulinate incorporated therein can exhibit low FTC "tar" to nicotine ratios while providing a smooth, palatable and havorful taste.

36 Clalms, 1 Drawlng Sheet

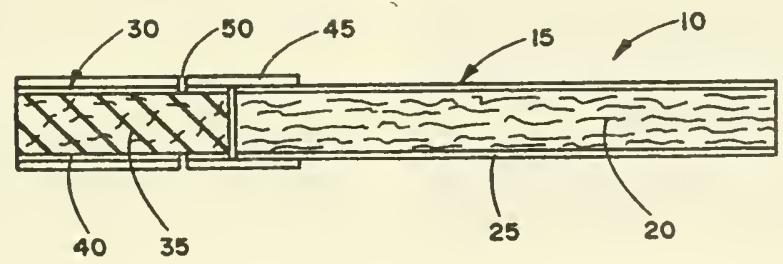


4,836,224

Page 2

\section{OTHER PUBLICATIONS}

Gabel et al., Ukr. Khim. Zbur., S, pp. 167-184 (1930). Houseman, Beitr. Tabakforsch, vol. 7, pp. 142-147 (1973).

Jenkins et al., Int'l Journal of Applied Radiation and Isotopes, vol. 27, pp. 323-324 (1976).

Leffringwell et al., Tobacco Flavoring for Smoking Products, pp. 11-15 (1972).

Lconard, Industrial and Engineering Chemistry, vol. 48, $133 i-1341$ (1950).
Perietti, Beitroge Tabakforschung Int'l, vol. 12, No. 2 , pp. 43-54 (1983)

Sensabaugh et al., Tobacco Science vol. 11, pp. 25-30 (1967).

Wynder et al., Tobocco and Tobocco Smoke, p. 428 (1967).

Dickens, On Cancer and Hormones, pp. 107-120 (1962). Quin and Hobbs, Anal. Chem., vol. 30, pp. 1400-1405 (1958).

Dickens and Black, Rept. Brit. Empire Cancer Ca.npaign, vol. 42 (2) pp. 157-is8 (1964).

Court et ai., J. Chroma Sci., vol. 16, pp. 314-317 (1978). Sakuma et al., Beitr. Tabak, vol. 12, pp. 63-71 (1983). 


\title{
Psychopharmacological effects of smoking a cigarette with typical "tar" and carbon monoxide yields but minimal nicotine*
}

\author{
Joho H. Robinson, Walter S. Pritchard, and Riley A. Davis \\ Biobehavioral R \& D, R.J. Reynolds Tobacco Company, Reynolds Boulevard, Winston-Salem, NC 27102, USA \\ Received February 28, 1992 / Final version March 18. 1992
}

\begin{abstract}
Five male smokers were tested, after 48 -h abstention from tobacco-product use, smoking a leading "lights" category cigarette (Control - FTC nicotine yield $0.6 \mathrm{mg}$ ) and another cigarette yielding similar amounts of "tar" and carbon monoxide (CO), but only $0.06 \mathrm{mg}$ ricotine (Test). Heart rate (HR) and the electroencephalogram (EEG) were monitored before, during and after the smoking of eacb cigarette. Other measures obtained included the subjects' puffing and breathing behaviors during smoking, plasma nicotine concentrations, blood carboxyhemoglobin concentrations and expired-air $\mathrm{CO}$. The results indicated no significant differences in the way the subjects puffed and inhaled the two cigarettes and they were therefore assumed to bave inhaled similar amounts of particulate matter and gasphase components. Plasma nicotine concentrations were significantly higher following smoking of the Control cigarette. HR (percent relative change) increased following smoking of either cigarette; however, $H R$ increase was significantly greater following smoking of the Control cigarette. Smoking the Test cigarette had no effect on the EEG. Smoking the Control cigarette produced a significant increase in beta 2 magnitude and a significant decrease in delta magnitude. This indicates that the effects of smoking on the EEG are a function of nicotine absorbed from cigarette smoke upon inhalation and not a function of inhaled particulate matter, $\mathrm{CO}$, or other gas-phase components.
\end{abstract}

Key words: Tar - Carbon monoxide - Nicotine - Psychopharmacological effects

\footnotetext{
- A nonlinear dynamical analysis of the EEG data presented in this paper appeared previously in Pritchard et al. (1992). An abstracl of this work was presented al the annual meeting of the Society for Psychophysiological Research, October 1990 in Boston, MA.

Correspondence 10: J.H. Robinson
}

The particulate and gas phases of mainstream cigarette smoke contain several thousand compounds (Dube and Green 198:; US DHHS 1983), including such pharmacologically active compounds as carbon monoxide $(\mathrm{CO})$, acetaldehyde (US DHHS 1988), and alkaloids, including nicotine. Yet, investigations of the psychopharmacological effects of cigarette smoking have generally concluded that nicotine is the chemical in cigarette smoke responsible for such effects (US DHHS 1988). Evidence supporting this conclusion has been derived from studies demonstrating that similar blood concentrations of nicotine resulting from different methods of administration [cigarette smoking, chewing nicotine gum, intravenous (IV) injection of nicotine] produce similar physiologic responses [e.g., changes in heart rate, blood pressure, electroencephalographic (EEG) activity]. Conversely, different blood concentrations of nicotine result in different physiologic responses. Similarly, variations in the nicotine yield of cigarettes as well as differences in the puffing and inbalation behaviors of smokers (which all presumably affect biood nicotine concentrations) also have been reported to result in differing physiologic responses (see Martin et al. 1987; Adlkofer and Thurau 1991).

Benowitz (1986) reviewed studies indicating a $10 \mathrm{ng} /$ $\mathrm{ml}$ rise in plasma nicotine (slow IV infusion) produces a 15 beat per $\min (B P M)$ rise in heart rate (HR) in nicotine-deprived subjects, similar to changes in HR seen following smoking the first cigarette of the day. Nicotine-gum administration results in cardiovascular changes (heart rate and blood pressure) similar to those observed following cigarette smoking (Benowitz 1988). Stalke et al. (1991) showed changes in neurohumoral re lease following an IV infusion of nicotine that resulted in plasma nicotine concentrations equal to those seen following smoking. Finally, several studies have reported that nicotine gum facilitates cognitive performance in a manner similar to smoking (Parrott and Winder 1989; Hindmarch et al. 1990; Hindmarch et al. 1991; Sherwood et al. 1990; Kerr et al. 1991; Provost and Wood ward 1991: Sherwood et al. 1991) as does chewing buffered nicotine tablets (Wesnes and Warburton 1978; 
Wesnes et al. 1983). However, the pharmacokinetics of nicotine (and other cigarette smoke constituents) following inhalation are quite different from those seen following slow IV infusion or buccal absorption of nicotine from chewing gum (Benowitz 1988). Conclusive evidence for the "nicotine primacy" hypotbesis can only come from inhalation-route studies.

Knott (1991) has shown that the EEG is affected differently by smoking "familiar" and "novel" cigarettes, presumably reflecting differential nicotine absorption by the subjects. Pritchard (1991) reported that subjects who had a small pre- to post-smoking rise in expired air $\mathrm{CO}$ (and were assumed to have absorbed small amounts of nicotine) exhibited a decrease in magnitude in lowerfrequency EEG bands (EEG activation). In contrast, subjects who had a large change in pre- to post-smoking expired air $\mathrm{CO}$ (and were assumed to bave absorbed larger amounts of nicotine) exhibiteo an increase in magnitude in the fast-frequency beta2 EEG band; a change associated with anxiety relief. Some studies of smoking and cognitive performance have reported differential effects of varying cigarette nicotine yield. Wesnes and Warburton (1983) reported that smoking cigarettes that yielded $1.65 \mathrm{mg}$ but not 0.28 or $0.71 \mathrm{mg}$ nicotine facilitated performance of a sustained reaction time (RT) task. Similar results were obtained by Wesnes and Warburton (1984; effects for 1.3, 1.5, and $1.7 \mathrm{mg}$ but not $0.9 \mathrm{mg}$ nicotine-yield cigarettes). However, other studies of smoking and cognitive performance have varied cigarette nicotine yield and found no differential effects (Williams 1980; Suter et al. 1983; Edwards et al. 1985; Revell 1988). Finally, two investigations employed nicotine-free control cigarettes, e.g., commercially-available "herbal" cigarettes (Wesnes and Warburton 1983; West and Hack 1991). However, the taste, and the "tar" and CO yields of such cigarettes are unknown, and it is extremely doubtful that subjects would smoke them in a manner similar to tobacco cıgarettes in terms of puff volume, puff intensity, number of puffs, etc.

Although the results of these studies are consistent with the hypothesis that nicotine is responsible for the psychopharmacological effects of smoking, they are also not conclusive. This is because the manipulations employed in these studies that presumably affected nicotine absorption (cigarette design/nicotine yields, subjects' puffing and inhalation patterns; see Nil and Bättig 1989) would also have affected the absorption of other mainstream smoke components (again, $\mathrm{CO}$ or one of the other compounds contained in the particulate fraction or gas phase of smoke).

To dissociate the psychopharmacological effects due to nicotine absorbed from cigarette smoke versus other compounds absorbed from the particulate or gas phase, one would require a cigarette that yielded little or no nicotine in the mainstream smoke, but did yield similar levels of "tar" and gas-phase components. A commercial cigarette that fulfilled these criteria was recently sold for a short period of time in limited test markets. The cigarette was manufactured with tobaccos which had been processed such that nearly all the nicotine had been extracted and therefore yielded extremely small quanti- ties of nicotine in the mainstream smoke. The cigarette did, however, yield levels of "tar" and CO typical of leading "lights" category cigarettes. We tested this cigarette in an attempt to dissociate psychopharmacological responses related to nicotine absorbed from tobacco smoke from those related to components absorbed from the particulate or gas phase.

The specific goals of the present study were to determine the behavioral and psychophysiological impact of smoking two cigarettes, one yielding typical levels of "tar", nicotine, and CO (Control cigarette), and the other yielding similar levels of "tar" and $\mathrm{CO}$, but minimal nicotine (Test cigarette). The two psychophysiologica) variables measured were HR and EEG. Subjects' puffing patterns ("puft-profile"), breathing patterns. and plasma nicotine, blood carboxyhemoglobin $(\% \mathrm{COHb})$, and expired-air $\mathrm{CO}$ concentrations were also monitored to determine the impact of smoking the Control and Test cigarettes on these variables.

\section{Materials and methods}

Subjects and cigarettes. Subjects were five male employees of the R J. Reyoolds Tobacco Company who volunieered to participate io the study. Employee voluoteers were used because they were known to the experimenters to be inhaling smokers who could be relied on to comply with pre-experimental smoking restrictions. Subjocts gave theit informed consent prior 10 participaling in the study and all procedures used were approved by the human re search review board. The consent form described the procedures to be used and the measurements to be made, but did not disclose the purpose of the test or the charactenstics of the ctgareltes to be used (other than that the cigarelles to be lested were commercially available brands). Subjects were lested individually beginning at 0830 hours following 48 -h abstention from tobacco-product use. Subsequent analysis of plasma samples for nicoline and cotinine iodicated that all subjects had complied with the tobacco-use re strictions.

Mainsiream smoke yields for the two cigaretles used in this test as determined by the US Federal Trade Commission Method (Pillsbury el al. 1969) are reported in Table 1.

Blood sampling (plesma nicotine ond \% $\mathrm{COHb}$ ). A sterile indwelling Teflon ${ }^{\mathrm{TM}}$ catheler (Becton-Dickinson. $21 \mathrm{ga}$ ) was inserted into the anlocubital vein in one arm and capped with a rubber stopper This technique allows multiple blood samples to be drawn with only one vein puncture and no discomfort to the subject following the initial needle stick. Individual blood samples were drawn into $7 \mathrm{ml}$ Vacutainer ${ }^{\mathrm{TM}}$ tubes containing EDTA as the antuccagulan ("purple-1op"). Samples were slored in the dark in an ice water slurry until centrifuged (usually within ith of the start of the lest). Plasma samples were aliquoled and stored at $-70^{\circ} \mathrm{C}$ for subsequent analysis of oicoune and counune (Davis 1986).

Percenl carboxyhemoglobin was determined for selecled (see bclow) pre- and post-smoking whole blood samples using a Model IL482 Co-Oximeter. These determinalions were made within 5 min of drawing the sample. Expired air $\mathrm{CO}$ concentrations were determined using an Ecolyzer ${ }^{\mathrm{rm}} \mathrm{CO}$ Analyzer and were made whin I min of taking the breath sample.

Table 1. Mainstream-smoke yields (FTC method)

\begin{tabular}{lcl}
\hline & Control & Tesi \\
\hline "Tar" (mg/cig) & 7.5 & 7.4 \\
Nicotine (mg/cig) & 0.6 & 0.06 \\
CO (mg/crg) & 10 & 7.6 \\
\hline
\end{tabular}


Smoking behaviors (puffing and breathing patterns). Subjects' puft ing and breathing patterns were monitored for all cigarettes smoked during the study. Puffing patterns were measured usiog a system developed at the R.J. Reynolds Tobacco Company, simila to the system of Rawbone et al. (1978; see also Creighton et al. 1978). Breathing patterns were monitored using an inductive pleth ysmography system (Non-Invasive Monitoring Systems, Miami, FL, USA; see Tobin and Sackner 1982).

$E E G$ and heart rafe. During EEG and HR recording, subjects sat in a comfortable chair in a dimly-lit, electronically shielded, and soundproof room. EEG was recorded from Sn electrodes placed at 18 scaip loci referred to the nose (forehead ground). These loci corresponded to the 19 standard scalp loci of the international 10-20 system, with Fpz substituted for Fpl/Fp2. Heart rate wa recorded from an electrode placed on the left shoulder also referred to the nose. High- and low-pass filter settiogs of 1 and $30 \mathrm{~Hz}$ (12 dB/octave rolloff) were employed with a digtization rate of $128 \mathrm{~Hz}$ and 8 bits A/D precision. EEG and HR data were stored on computer disk for later off-line analysis.

Design. Subjects reported for testing at 0830 hours following 48-h abstention from tobacco-product use. The EEG and HR electrodes were attached, followed by two elastuc bands for recording the breathing patterns. The catheter was then inserted. Two recordin conditions were employed. Io the first, subjects rested comfortably with their eyes closed for $30 \mathrm{~s}$. In the second. they stared at a fixation point on the wall and tred not to blink for $30 \mathrm{~s}$. The two conditions together will be referred to as one "recordio block". Across the study, the order of the two recording conditions was counterbalanced across recording blocks.

After subjects were seated in the testing chamber and all recording equipment calibrated, the following expenmental schedule was employed (Fig. 1): an initial blood sample was drawn. Subject then experienced two baseline recording blocks, followed by a second blood sample. The subjects then "sham-smoked" (puffed an

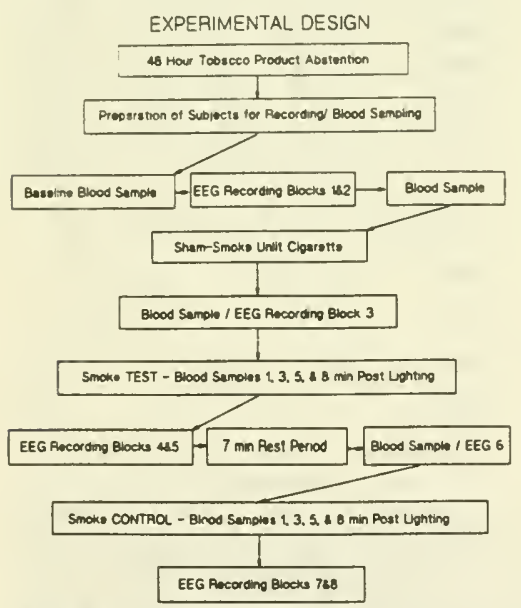

Fig. 1. Schematic of tesung procedures used. Each recording "block" consisted of one 30-s "eyes-closed" and one 30-s "eyesopen" recording un-lit Test cigarette) by taking eight cued puffs, each puft spaced $30 \mathrm{~s}$ apart. This was followed by a thurd blood sample and recordug block. Subjects next smoked the Test cigarette ad libitum. Blood samples were drawn at $1,3,5$, and 8 mo post-lighung of the cigarette. Smoking was followed by a 4 th and Stb recording block. which were followed by a 7 -min rest period. Another blood sample and a 6th recording block followed the end of the rest penod (approxumately $18 \mathrm{~min}$ after first lightung the Test cigarette). The "18 min" sample for the Test cigarette served as the "baselıne" sample for the Control cigarette.

Subjects next smoked the Control cigarette ad libitum. Blood samples were again drawn at $3,3,5$, and $8 \mathrm{~mm}$ post-lightung of the cigarette. This was followed by a 7 th and 8 th recording block to finish the experimental session. Plasma nicotine and cotinine conceotrations were subsequently determined for all the blood sampies drawn. Expired breatb samples for $\mathrm{CO}$ analysis were obtained immediately before lighung and 5 min post-lighting each cigarette. $\% \mathrm{COHb}$ determinations were made for whole-blood samples drawn at the same time the expired-air samples were collected.

\section{Results}

The level of significance chosen was 0.05 . Effects with $P$ values unde: 0.10 are reported as "marginally significant". The primary method of hypothesis testing was analysis of variance (ANOVA). Significance levels were Greenhouse-Geisser corrected where appropriate. Where necessary. ANOVA was followed by post-hoc tests according to the method of Scheffe (Bruning and Kintz 1987)

\section{Plasma nicotine}

Average plasma nicotine rise (increase from baseline) data are presented in Fig. 2. At the $5 \mathrm{~min}$ post-lighting sample, statistically significant increases in plasma nicotine concentration were seen for both cigarettes tested. Smoking the Test cigarette resulted in an average rise in nicotiste concentration of $3.63 \mathrm{ng} / \mathrm{ml}[t(4)=3.43, P<$

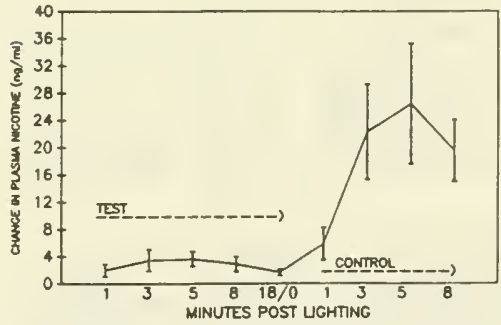

Fig. 2. Average plasma nicotine rise dunng the smoking of the Test and Control cigarettes. Peak plasma nicotine rise occurred 5 min post-lighting for both cigarettes. Plasma nicotine concentrations were significantly elevated over baseline at $S$ min post lighting for the Test cigarette and at 3, 5, and $8 \mathrm{~min}$ post lighting for the Control. Smoking the Control cigarette resulted in a significantly larger increase in plasma nicotine concentration compared to smoking the Test 
0.03 ] at the 5-min sample point (the only time point for the Test cigarette where the change in plasma-nicotine concentration was significantly different from zero). Smcking the Control cigarette resulted in an average increase in plasma nicotine concentration at the 5 - $\mathrm{min}$ sample point of $26.42 \mathrm{ng} / \mathrm{ml}[\iota(4)=2.94, P<0.05]$. When subjects smoked the Control cigarette, the rise in their plasma nicotine concentrations was significantly different from zero at the 3-,5- and 8-min sample points. As expected, sham-smoking the unlit Test cigarette had no effect on plasma nicotine concentrations.

No significant change from baseline in plasma cotinine concentration was seen at any sampling point for either cigarette tested. Average baseline cotinine concentration $(42.3+1-30.9 \mathrm{ng} / \mathrm{ml})$ confirmed that the five subjects had complied with the 48 -h tobacco-use restrictions prior to the test.

\section{Puffing and breathing patterns}

The puff-profile data are summarized in Table 2. No statistically significant differences were seen in the puffing patterns of these five subjects between the Test and Control cigarettes. In fact, the number of puffs taken, along with the average puff volume, average "frequency" (time from the stast of one puff to the start of the next puff), and puff duration were remarkably similar for the two cigarettes. In addition, the total puff volumes drawn through the cigarettes and the time alight (total smoking time from lighting to the end of the last puff) did not differ between the two cigarettes.

Table 3 summarizes the breathing data collected during smoking. Only breaths immediately following a puff on the cigarette, and therefore categorized as "smokecontainng" breaths, were included for analysis. The only statistically significant difference seen in any of the

Table 2. Puff-profile data: mean (standard error)

\begin{tabular}{lcc}
\hline Parameter & Test & Control \\
\hline Number of puffs & $12.8(1.5)$ & $13.6(1.5)$ \\
Volume (ml) & $51.0(3.7)$ & $52.0(5.2)$ \\
"Frequency" (s) & $21.4(3.6)$ & $23.1(3.3)$ \\
Duration (s) & $2.33(0.17)$ & $2.21(0.19)$ \\
Total volume (ml) & $633.5(43.8)$ & $677.9(22.7)$ \\
Time alight (s) & $255.5(22.4)$ & $298.6(21.6)$ \\
\hline
\end{tabular}

Table 3. Breathıng data. mean (standard error)

\begin{tabular}{lcc}
\hline Parameter & Test & Control \\
\hline Number breaths & $12.4(1.4)$ & $12.8(14)$ \\
Frequency (breaths/min) & $12.1(2.6)$ & $12.5(1.7)$ \\
Inspiratory vol $(\mathrm{ml})$ & $828(126)$ & $845(105)$ \\
Inspiratory tume $(\mathrm{s})$ & $2.17(0.4)$ & $2.13(0.3)$ \\
Expiratory vol $(\mathrm{ml})$ & $1026(159)$ & $891(101)$ \\
Expiratory time $(\mathrm{s})$ & $3.95(0.5)$ & $3.39(0.4)^{\bullet}$ \\
\hline
\end{tabular}

- $P<0.05$

Data are for "smoke-containing " breaths only breathing parameters measured was for expiratory time Subjects took significantly longer to expire the smoke inhaled from the Test cigarette than from the Control cigarette. The practical significance of this finding is not immediately known.

Despite the differences in tobacco and smoke nicotine for these two cigarettes, the puffing and breathing patterns of the subjects did not differentiate the Test and Control cigarettes. These puffing and breathing patterns. coupled with the $\mathrm{CO}$ exposure measures (see below) indicate that the subjects (as a group) were exposed to similar amounts of smoke and therefore similar amounts of particulate matter when smoking either cigarette.

\section{EEG}

For each 30-s EEG recording, as many artifact-free 2-s segments as were available were submitted to a Fast Fourier Transform (Hanning window) to generate a magnitude spectrum (EEG activity in microvolts as a function of frequency). Average magnitude (microvolts) in each of the traditional EEG frequency bands of delta $(1-4 \mathrm{~Hz})$, theta $(5-7 \mathrm{~Hz})$, alpha $(8-12 \mathrm{~Hz})$, betal $(13-$
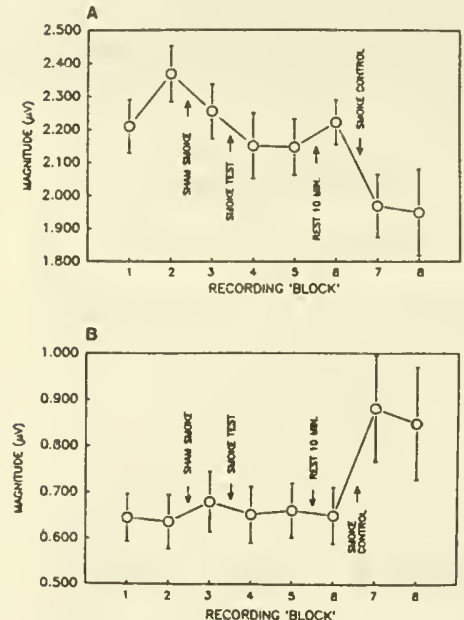

Fig. 3. A Average delta magnitude as a function of test condition Neither sham-smoking or smokıng the Test cigarette affecied delta magnıtude. Smokıng the Control cigarette resulted in a significant decrease in delta magnilude, an effecl associated with corlical arousal. B Average beta2 magnilude as a function of lest condilions. Again, neither sham smokıng or smokıng the Test cigarelie affected beta 2 magnitude Smoking the Control cigarelle resulted in a significant increase in beta2 magnitude, an effecl associated with anxisty relief 
$18 \mathrm{~Hz}$ ), and beta2 $(19-28 \mathrm{~Hz})$ was computed and ANOVA performed for each band. Results indicated significant effects on EEG magnitude in the low-frequency delta and high-frequency beta 2 bands. [For delta, main effect of blocks $F(7,28)=4.76, P<0.025$; for beta2, main effect of blocks $F(7,28)=6.85, P<0.0034]$. Post-hoc test ing indicated that smoking the Control cigarette significantly increased beta 2 magnitude (an effect associated with anxiety relief: Pritchard 1991), and attenuated delta magnitude (an effect indicative of arousal of the brain; Pritchard 1991). Sham-smoking the unlit cigarette or smoking the Test cigarette did not significantly affect the EEG. These data are presented in Fig. 3.

\section{Heart rate}

Average HR in absolute BPM across the experiment is displayed in Fig. 4A (in the figure, sessions 1 and 2 , 4 and 5 , and 7 and 8 have been averaged together) ANOVA indicated that HR changed significantly across the experiment $[F(4,16)=40.32, P<0.0001]$. Post-hoc testing showed a significant increase in HR followng smoking of the Control cigarette. The apparent slight increase in $\mathrm{HR}$ seen following smoking the Test cigarette was marginally significant $(P=0.08)$. Since $H R$ varies quite a bit among individuals, it is common to report $\mathrm{HR}$ effects in terms of percent change. Average percent
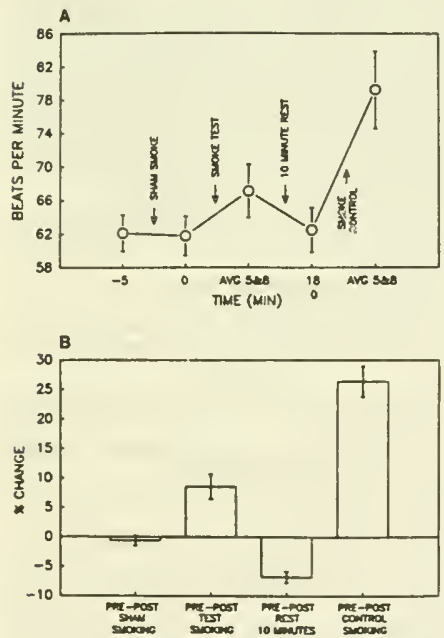

Fig. 4. A Average HR in beats per minute as function of iest conditons. Sham-smoking did not affect HR B Average percent change in $\mathrm{HR}$ as a funcuon of lest conditions (percent change in $\mathrm{HR}$ controls for inter-subject differences in baseline HR) change in HR across the experiment is illustrated in Fig. 4B. ANOVA indicated that percent change in HR varied significantly across the expenment $[F(3.12)=$ 64.57. $P<0.0001]$. Post-hoc testing indicated that smoking both the Test and Control cigarettes produced significant percent changes in HR, with the Control producing a significantly greater change than the Test cigarette.

\section{Carbon monoxide}

Smoking either the Test cigarette or the Control cigarette resulted in similar increases over baseline in expired-air $\mathrm{CO}$ and whole-blood levels of $\% \mathrm{COHb}$. These data are presented graphically in Fig. $S$ and indicate, along with the puffing and breathing data (see above) that the subjects were exposed to similar amounts of mainstream smoke and therefore may be assumed to have absorbed similar amounts of particulate components when smok-
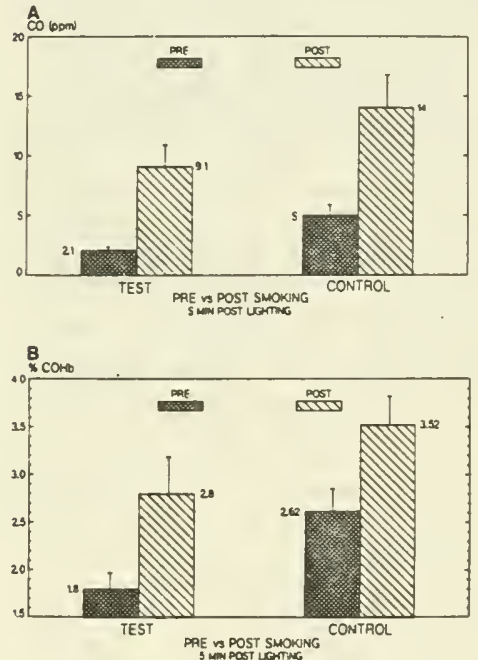

Fig. 5. A Average expired-air CO, pre-and posi-smokıng. Smokıng eilher cigarelte resulted in a significant increase over baseline in expired-air CO levels. These increases were of similar magnitude for the Iwo cigarelles and were not stausucally diftereni. B Average $\% \mathrm{COHb}$ blood levels, pre- and post-smoking. Smoking the Test cigarelte resulied in ao average increase in $\%$ COHb of $1.0 \%$ Smoking the Control cigaretle resulted in an average increase of $0.9 \%$. The baseline value of $1.8 \%$ for the Test is lower than the $2.6 \%$ baseline for the Conurol because the subjects were $48 \mathrm{~h}$ smoking depnived at the stan of the session. The baseline value for the Control cigarette was obtained 10-12 min after smoking the Test cigarette. accounling for the higher pre-smoking baseline for Ihe Control 
ing either the Test or Control cigarette. It should be noted that the baseline level for the Control cigarette is higher than the baseline level for the Test cigarette for both the expired-air $\mathrm{CO}$ and $\% \mathrm{COHb}$ measures. This can be accounted for by the fact that the subjects abstained from smoking for $48 \mathrm{~h}$ prior to smoking the Tes cigarette and smoked the Control cigarette 10-12 min after finishing the Test cigarette. For this reason, changes from baseline for the expired-air $\mathrm{CO}$ and \% $\mathrm{COHb}$ measures were used to compare the two cigarettes.

\section{Discussion}

Smoking both the Test and Control cigarettes resulted in significant increases in plasma nicotine concentration within $5 \mathrm{~min}$ of lighting. The maximum rise in plasma nicotine concentration following smoking of the Control cigarette was significantly greater than the maximum change seen following smoking of the Test cigarette $(30.96 \mathrm{ng} / \mathrm{ml}$ versus $4.34 \mathrm{ng} / \mathrm{ml} ; P<0.03)$. The difference seen in this average maximum plasma ricotine rise was proportional to the difference in FTC nicotine yields for the two cigarettes $(0.06 \mathrm{mg}$ Test, $0.60 \mathrm{mg}$ Control) It should be pointed out, bowever, that increases in plasma nicotine concentration were seen in all five subjects following the smoking of the Test cigarette, indicating that it was possible for a smoker to absorb some nicotine from the smoke of this cigarette. The small amount absorbed was sufficient to produce a small percentage rise in $\mathrm{HR}$ in all five subjects, but was not sufficient to produce significant changes in EEG magnitude. No changes were observed in any of the physiological measures following sham-smoking an unlit cigarette.

The similar manner in which the two cigarettes were smoked was somewhat surprising given the extremely low levels of nicotine in the smoke of the Test cigarette and the theory that mainstream smoke nicotine may provide an important cue for the puffing behaviors of smokers (Rose et al. 1984). The smoking behaviors of the subjects were essentially identical for both cigarettes. The only significant difference in smoking behavior was an increase in expiratory time for the Test cigarette. Since the majority of the smoking behaviors were not different for the two cigarettes, it is not known if the difference in average expiratory time represents a physiologically significant finding that could be replicated. Although the smoking behaviors were nearly identical for the two cigarettes used in the study, we would note (anecdotally; no formal questionnaire ratings were obtained) that after the sessions nearly all the subjects made a comment indicating that they could distinguish a difference in the "strength" of the cigarettes they had just smoked, with the first (Test) cigarette being noticeably "weaker".

Finally, the changes seen in the EEG power spectrum following the smoking of the Control cigarette were similar to those reported previously (Pritchard 1991; Pritchard et al. 1991). These changes included an increase in power in the beta2 band. an effect associated with anxiety relief, and a decrease in power in the delta band, an effect associated with cortical activation. Anxiety relief and improved mental alertness are two of the benefits of smoking commonly reported by smokers as their teason for smoking (see Gilbert 1979; Warburton 1988a, b; Warburton et al. 1988). Since the "tar" fractions of these two cigarettes were apparently quite similar and since the subjects apparently absorbed similar amounts of particulate- and gas-phase components from both cigarettes (evidenced by the similar puffing and breathing patterns and the similar changes in absorbed $\mathrm{CO}$ ) we conclude that the particulate fraction and gas phase of cigarette smoke have little effect on the psychophysiological responses seen following smoking. This indicates that the beneficial effects of smoking on cognitive performance (see Introduction) are a function of nicotine absorbed from cigarette smoke upon inhalation.

Acknowledgement. Figure I was reprinted with permission frnm: Pritchard WS, Duke DW, Coburn CL, Robinson JH (1992) Nonlinear dynamical electroencephalographic analysis applied to neotine psychopharmacology aod Alzheimer's disease. In: Lippiello PM, Collins AC, Gray JA, Robinson JH (eds) The biology of nicotıpe: curreni rescarch issues. Raven Press, New York, p 204

\section{References}

Adlkofer F, Thurau K (eds) (1991) EfTects of nicolıne on biological sysiems. Birkhäuser, Berlio

Benowitz NL (1986) The human pharmacology of nicotine. In: Chappell $\mathrm{HD}$ et al (eds) Research advances in atcohol and dris problems, vol 9. Plenum Press, New York. pp 1-52

Benowitz NL (1988) Toxicity of nicoline: Implications with regard to nicotine replacement therapy. In: Pomericau OF, Pomerleau CS (eds) Nicoline replacement: a critical cvaluation Progress in clinical and biological research, vol 261. Liss, New York. pp 187-218

Bruning JL, Kintz BL (1987) Computational handbook of staustics. Scoil Foresman and Company. Glenvew, IL

Creighton DE, Noble MJ, Whewell RT (1978) Instruments to measure, record and duplicate human smoking patterns. In: Thernton RE (ed) Smoking behavior. Churchill Livingstone, New York, pp 277-288

Davs RA (1986) The delermination of nicotine and cotinine is plasma. J Chromatogr Sci 24:134-141

Dube MF, Green CR (1982) Methods of collection of smoke for analytical purposes. Recen1 Advances in Tobacco Science 8:42102

Edwards JA, Wesnes K, Warburton DM, Gale A (1985) Evidence of more rapid sumulus evaluation following cigaretie smoking. Addicl Behav 10:113-126

Gilbert DG (1979) Paradoxical 1ranquilizng and emouion-reducing effects of nicotine. Psychol Bull 86:643-66

Hindmarch I, Kerr JS. Sherwood N (1990) Effects of nicotine gum on psychomolor performance in smokers and non-smokers. Psychopharmacology 104: 113-119

Hindmarch 1, Kerr JS, Sherwood N (9991) The comparative psychopharmacology of nicotive. In: Adlkofer F. Thurau $K$ (eds) Effects of ncoune oo biologacal systems. Birkhäuser, Basel, pp $509-519$

Kern JS, Sherwood N, Hindmarch I (1991) Separale and combined effects of the social drugs on psychomotor performance. Psychopharmacology 104:113-119

Knolt V (1991) Neuroelectnc correlates of smoking behavior. In: Adlkofer F, Thurau K (eds) Effects of nicolne on biological systems. Birkhāuser, Basel, pp 509-5i9 
Martun WR. van Loon GR, I wamoto ET, Davs DL (eds) (1987 Tobacco smoking and ncoune: a aeurobiologe approacb. Plenum Press, New York

Nil R. Bāıtug K (1989) Smokıng behavor: a multivariate process. In: Ney T, Gale A (eds) Smokung and human behavior. Wiley. Chichester, pp 199-222

Parrott AC. Winder G (1989) Nicotioe chewing gum ( $2 \mathrm{mg}, 4 \mathrm{mg}$ ) and cigarette smoking: comparative eftects upon vigilance and heart rate. Psychopharmacology $99: 257-261$

Pillsbury HC, Bright CC, O'Connor KJ, Irish FW (1969) Tar and nicotine in cigaretle smoke. J Assoc Of Anal Chem 36:458-462

Pnichard WS (199!) Electroencephalographic eftects of cogarette smokung Psychopharmacology 104:485-490

Pritchard WS, Robioson JH, de Bethizy JD, Dans RA (1991) Ef fect of smoking and cafteine on EEG, heart rate. performance. and anxiety/mental alertness/muscular teasion Psychophysiology $28: \mathrm{S} 44$

Pnichard WS, Duke DW, Cobum CL, Robinson JH (1992) Nonlinear dynamical electroencephalographic analysis applied to nicotıne psychopharmacology and Alzheimer's disease. In: Lippiello PM, Collıns AC, Gray JA, Robinson JH (eds) The biology of nicotine : current research issues. Raven Press, New York. pp 195-214

Provost SC, Woodward R (1991) Effects of nucotıne gum on repeat ed administration of the Stroop test. Psychopharmacology $104536-540$

Rawbone RG. Murphy K. Tate ME, Kane SJ (1978) The analysis of smoking parameters. inhalation and absorption of tobacco smoke in studies of human smoking behavior. In: Thornton RE (ed) Smoking behavor. Churchill Livingstone, New York. pp 171-194

Revell AD (1988) Smoking and performance - a puft-by-puft anal ysis. Psychopharmacology 96:563-565

Rose JE, Zinser MC. Tashkın DP, Newcomb R, Ertle A (1984) Subjectuve response to cagarette smoking following airway anesthetization. Addict Behav 9.211-215

Sherwood N. Kerr JS. Hindmarch ! (1990) No differences in the psychomotor response of heavy, light and non-smokers to the acute administration of nicotine. Med Sci Res 18:839-840

Sherwood N, Kerr JS. Hindmarch 1 (1991) Effects of nicoune on short-term memory In: Adlkofer F. Thurau K (eds) Eftects of nicotıne on biological systems. Birkháuser. Basel. pp 53!-535 Stalke J. Hader O, Hensen J. Bāhr V, Scherer G. Oelkers W (1991) Nicotine infusion in man stimulates plasma-vasopressin.
-ACTH, and -costisol in a dose dependent manner. In: Adlkofer F. Thurau $\mathrm{K}$ (eds) Effects of nicotune on biological systems. Birkhäuser, Basel, pp 339-344

Suter T, Buzz R, Woodscn PP, Bāttig K (1983) Psychophysiolog cal correlates of confict solving and cigarette smoking Actuvi Nerv Super (Praha) 25:26!-27!

Tobın MJ, Sackner MA (1982) Monitoring smoking patterns of low and high tar cigarettes with inductuve plethysmography Am Rev Resp Dis 126:258-264

US Department of Health and Human Services (1983) The health consequences of smoking: cardiovascular disease. A report of the Surgeon General. DHHS Publication No. (PHS) 84-50204. US Government Printing Office. Washington DC

US Department of Health and Human Services (1988) The health consequences of smoking: nicoune addiction. A report of the Surgeon General. US Government Prntıng Office, Washingtoo DC

Warburion DM (\$988a) The functional use of mcotine In. Wald NJ, Froggatt P (eds) Nicotine, smoking, and the low tar programme. Oxford University Press, Oxford, pp 182-199

Warburton DM (1988b) The puzzle of nicotine use. In: Lader $M(e d)$ The psychopharmacolocy of addiction. Oxford University Press. Oxford. pp 27-49

Warburton DM, Revell A, Walters AC (1988) Nicoune as a resource. la: Rand M. Thurat $K$ (eds) The pharmacology of nucoune. IRL Press, London, pp 359-373

Wesnes K. Warbuton DM (1978) The effects of cigarette smokin 8 and micotine tablets upon human attention. In: Thomton RE (ed) Smoking behaviour. Physiological and psychological influences. Churchill Livingstone, New York, pp 359-373

Wesnes K. Warburton DM (1983) Eftects of smoking on rapid information processing performance. Neuropsychobiology 9:223-229

Wesnes K, Warburton DM (1984) The effects of cigarettes of vary. ing yeld on rapid information processing performance. Psychophamacology $82: 338-342$

Wesnes K, Warburton DM, Matz 8 (1983) Effects of nucotine on stımulus sensitınty and response bias in a visual vigilance task Neuropsychology $9 \cdot 41-44$

West RJ, Hack S (1991) Effects of crgarettes on memory search and subjecuve ratings. Pharmacol Biochem Behav 25:727-731

Williams DG (1980) EfTects of cigarette smoking on immediate memory and periormance in different kinds of smokers. Br J Psychol 71.83-9 
Table 1

Suppliers of Tobacco Extracts

Bell Flavors \& Fragrances, Inc. Heinr. Borgwaldt $\mathrm{GmbH}$

M. Brown \& Sons Inc.

Bush Boake Allen Inc

Bush Boake Allen Singapore Pte Ltd.

Curt Georgi $\mathrm{GmbH} \& \mathrm{Co}$.

Döhler-Szilas $\mathrm{GmbH}$

Dragoco Gerberding \& Co. AG.

F\&C Licorice

Flavor Technology Corp.

Fuji Flavor Co. Ltd.

Givaudan-Roure Corp.

Givaudan-Roure Flavors Ltd.

Givauden-Roure Ltd.

Haarmann \& Reimer Corp.

Haarmann \& Reimer GmbH

T. Hasegawa Col. Ltd.

Hertz \& Selck European Frutarom Corp.

Alfred N. Hertz Flavors GmbH

International Flavors and

Fragrances Inc.

\section{MAFCO}

Dr. Madis Laboratories Inc.

Inds. Alimenticias Maguary

Meer Corp

M.F. Neal and Co.

ottens Flavors

Pfizer Flavor \& Fragrance Product

Group (C.A.L.)

Quest International

Schimmel \& Co. GmbH

Soda Aromatic Co. Ltd.

Takasago International Corp.

Technology Flavors \& Fragrances Inc.

Union Camp Corp.

Universal Flavor Corp.

Universal Flavors

Virginia Dare Inc.

The Whole Herb Co.

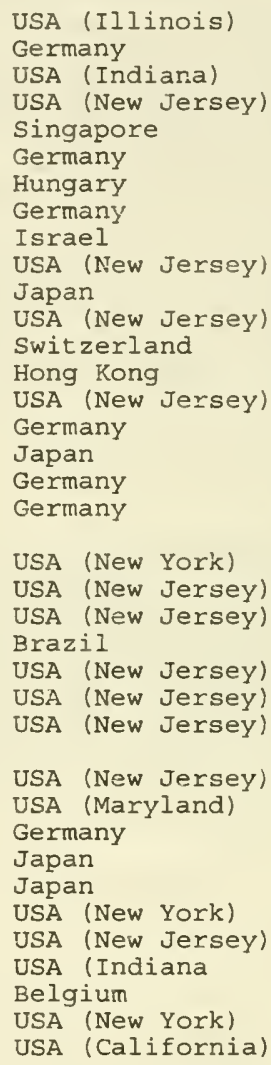

Source: Tobacco International 1994 Buyers' Guide and Directory. 60 th Edition. November 15, 1993. pages 54 and 56.

Note: These companies are listed under "Flavors (Extracts)". other subheadings under "Flavors" are Additives, Aromatics, Casings \& Casing Materials, Essential Oils, Fixatives, Menthol, Top Casing and Top Dressing 


\section{CIGARETTE}

\section{REFERENCE TO RELATED APPLICATION}

This is a continustion-in-part of U.S. patent application Ser. No. 012,922, filed Feb. 10, 1987, the disclosure of which is incorporated by reference.

\section{BACKGROUND OF THE INVENTION}

The present invention relates to cigarettes and other to such type of smoking erticles, and in particular to those smoking articles having an organic acid additive incor. porated therein.

Cigarettes are popular smoking articles which have a substantially cylindrical rod shsped structure and include charge of tobacco (i.e., in cut filler form) surrounded by a wrapper such as paper thereby iorming a tobacco rod. Currently, popular cigarettes include hlends of tobacco materials, the majority of the biends having nicotine contents in the range from about 1.220 percent to about 2.25 percent, more frequently from about 1.4 percent to about 2 percent, and most fre. quently from about 1.6 percent to about 1.8 percent, bssed on the dry weight of the tobacco materials. It has become desirable to manufacture cigarettes having cy. lindrical gilters eligned in an end-to-end relationship with the tobacco rod. Typically, filters are manufactured from fibrous materials such as cellulose scetate and are attached to the tobacco rod using a circumscribing tipping material.

Popular cigarettes classified as "full favor" cigarettes deliver a desirable tobacco taste, favor and satisfaction to the smoker. Typically, tbe "full flavor" cigarettes deliver about $14 \mathrm{mg}$ or more of FTC "tar" per cigarette. A second clascification of popular cigarettes is the "full flavor low tar" classification. Typically, the "full flavor low tar" cigsrettes deliver from about 8 to about $14 \mathrm{mg}$ of FTC "tar" per cigarette, as well as lower levels of FTC vicotine as compared to "full flavor" cigarettes. A third classification of popular cigarettes in the "ultra low ur" classification. Surch "ultra low tar" cigarettes deliver still lower levels of FTC "tar" and nicotine. Typically, the "ultra low tar" cigarettes deliver less than about $7 \mathrm{mg}$ of FIC "tar" per cigarette. The "full flavor low tar" and "ultre low ter" cigarettes conventionally heve air dilution means such as laser perforstions provided in the periphery of the mouthend region thereof, or have filter elements highly efficient for the removal of "tar" and nicotine from the mainstream aerosol.

in general, the perceived taste or strength of the cigarettes clestified as having lower levels of "tar" and nicotine are progressively less than that of the cigarettes which are classified as approsching the characteristics of the "full flavor" cigarettes. It has been proposed to add numerous flavorants to the cut filler of lower "ar" cigarettes to enhance the taste, strength and satisfaction of such cigarettes. However, such addition generally yields mainstream amoke which may be perceived as harsh or irritating to the mouth, nose and throat of the 60 user.

Additionally, it is possible to employ tobeccos having a aturally high nicotine content as cut filler to enhance the tobacco taste, strength and satiafection of such cigarettes. However, cigarettes baving high aicotine contents ( $\mathrm{eg}$, which include tobseco blends having natural nicotine contents bove bout 2.25 weight percent) generally have the propensity to yeild unpalatable main.

\section{2}

stream smoke which may be perceived as harsh or irritating to the mouth, nose and throat of the user.

It would be desirable to provide a cigarette such as an "ultra low tor" cigarette which is capable of delivering - good tobacco taste, strength and sinoking satisfaction characteristic of a "full flavor low tor" cigarette while being perceived as palatable but not as overly harsh or irritating. In addition, it would be desirable to provide a cigarette such as a "full navor low tar" cigarette which

is capsole of delivering a good'tobacco taste, strength and smoking satisfaction characteristic of a "full flavor" cigarette while being perceived as palatable but not as overly harsh or irritating. Furnhermore, it would be desireble to improve the smoking character of cigarettes which employ tobsccos or other tobacco materi. als having a wide range of nicotine contents.

\section{SUMMARY OF THE INVENTION}

The present invention relates to a smoking article which delivers good tobacco taste while being capable of delivering relatively low anounts of FTC "tar." Preferred articles of this invention are cigarettes which deliver taste, strength and smoking satisfaction characteristic of "full flavor" cigarettes, and relatively low leveis of FTC "tar" characteristic of "full flavor low tar" cigarettes. Also preferred are cigarettes which deliver taste, strength and smoking satisfaction charac. teristic of "full flavor iow tar" cigarettes, and relatively 30 low levels of FTC "tar" charscteristic of "ultra low ur" cigarettes. In addition, the preferred cigarettes are extremely palatabie and provide the perception of having a smooth smoking character (i.e., not providing a perceived harsh or irritating charscter) relative to a comparable cigarette delivering similar ievels of FTC "tar." Of particular interest are cigarettes having (i) relatively low FTC "tar" to FTC nicotine ratios, (ii) relatively low FTC carbon monoxide to FTC nicotine ratios, (iii) good tobacco flavor, strength and satisfaction, and (iv) a smooth, palatable smoking cheracter without being overly mild tasting.

A cigarette in accord with this invention includes smokable (eg., tobacco) material end at least one organic acid additive. For example, a cigarette of this invention can have (i) nicotine content above about 2 percent, besed on the dry weight of the smokable material thereof; and (ii) at least one organic acid which is an additive to the cigarette in an amount of grester than about 1 pecent, based on the dry weight of the smokable material. Generaily, the organic acid is an additive to at least portion of the smokable material. The acid can be present within the cigarette in a dissceiated and/or nondissociated form. A preferred organic acid additive is levulinic acid, and can be present within the cigarette as levulinic ecid and/or levulinete ion.

As used herein, the term "dry weight" in referring to the smokable material of the smoking sticle is mesnt the mass of the smokable material after being dried to constant weight at $214^{\circ} \mathrm{F} .\left(101^{\circ} \mathrm{C}\right.$ ) for 3 hours in a force-drant oven. See, Moseley et al, Ind. Eng. Chem. Vol. 43, p. 2342 (1951).

As used herein, the term "nicotine content" in referring to the smokable material is meant the mass alkaloid nicotine as analyzed and quantitated by spectroscopic techniques divided by the dry weight of the smokable material analyzed. See, Harvey et a, Tob. Sci, Vol. 25, p. 131 (1981). 
The smokable material from which eigarettes of this invention are manufactured conveniently can be a cut filer material composed of one or more tobacco materials having a naturally high nicotine content. The naturally high nicotine content tobacco material(s) can be employed alone or as blends with (i) one or more tobacco materials having low nicotine contents, and/or (ii) one or more tobacco aubstitutes. As such, cigarettes of this invention include those cigarettes wherein the smokable material thereof exhibits a total nicotine content or blend nicotine content above about 2 percent.

A cigarette in accord with this invention convenienily can have incorporated therein at least one sait provided from nicotine and an organic acid. The salt is incorporated within the cigarette as an additive. Preferably, the salt is such that the molar ratio of nicotine to organic acid therein is 1:3. Most preferably, the salt additive includes nicotine levulinate. The particular salt is incorporated into the cigarette in such a manner that during use of the cigarette, the salt is subjected to decomposition conditions. For example, a cigarette of this invention can include a smokable material as well as a least one salt of nicotine and an organic acid as an additive, wherein (i) the nicotine content of the cigarette is above about 2 percent, based on the dry weight of the smokable material, and (i) one of the aforementioned salts is nicotine levulinate

The presence of the nicotine/organic acid salt within the cigarette provides improved tobacco taste, strength and smoking satisfaction as well as improved or maintained favor characteristics to the acrosol during use of the article.

Preferred cigarettes of this invention do not exhibit undesirable off-tastes during use.

\section{BRIEF DESCRIPTION OF THE DRAWINGS}

FIG. $l$ is a longitudinal section view of a cigarette of this invention.

\section{DETAILED DESCRIPTION OF THE} PREFERRED EMBODIMENTS

One embodiment of this invention is shown in FIG. I and has the form of a cigarette 10. The cigarette includes a generally cylndrical rod $\mathbf{1 5}$ of smokable material 20, such as tobacco cut filler, contained in circum. scribing outer wrapping traterial 25 . The rod 15 is here. inafter referred to as "tobacco rod." The ends of the tobacco rod are open to expose the smokable material. The cigarette $\mathbf{1 0}$ also includes a filter element 30 posi tioned adjacent one end of the tobacco rod 15 such that the filter element and tobacco rod are axially aligned in an end-to-end relationship, preferably abutting one an other. Filter element 30 has a generally cylindrical ahape, and the diameter thereof is essentially equal to the diameter of the tobacco rod. The ends of the fitter element are open to permit the passage of air and smoke therethrough. The fiter element $\mathbf{3 0}$ includes filter mate rial 35 which is overwrapped along the longitudinal extending surface thereof with circumscribing plug wrop material 40 .

The filter element 30 is attached to the tobacco rod 15 by tipping material 45 which circumscribes both the entire length of the filter element and an adjacent region of the tobacco rod. The inner surface of the tippng material $\mathbf{4 5}$ is fixedly secured to the outer surface of the plug wrap 40 and the outer surface of the wrapping material 25 of the tobacco rod, uaing a auitable adhesive. If desired, ventilated or air diluted cigarette is pro- vided with an air dilution means such as a series of perforations 50 each of which extend through the tipping material and plug wrap.

Typically, the tobacco rod has a length which ranges from about $50 \mathrm{~mm}$ to about $85 \mathrm{~mm}$ a circumference of about $17 \mathrm{~mm}$ to about $27 \mathrm{~mm}$; and the wrapping materiaj thereol is a conventional cigarette wrapping paper. Suitable cigarette wrapping papers are commercially svailable as Reference Nos. 719 and 856 from Kimber. ly-Clark Corp. or as Ecusta Experimentai Nos. TOD 01788 and TOD 03363 from Ecusta Corp. If desired a dual wrapper system can be employed. The tobacco rods and the resulting cigarettes can be manufactured in any known configuration using known cigarette making s techniques and equipment.

Typically, the filter element has a length which ranges from about $20 \mathrm{~mm}$ to about $35 \mathrm{~mm}$ and a circumference of about $17 \mathrm{~mm}$ to about $27 \mathrm{~mm}$. The filter material can be any suitable material such as cellulose 20 acctate, polypropylene, tobacco material, or the like. Filter materials having compositions or characteristics so as to exhibit low nicotine filtration efficiencies can be employed. The plug wrap typically is a conventional paper plug wrap, and can be either air permeable or essentially air impermeable. However, if desired, a nonwrapped cellulose acetate filter element can be employed. The various filter elements suitable for use in this invention can be manufactured using known cigarette filter making techniques and equipment.

Typically, the tipping material circumscribes the filter element and an adjacent region of the tobacco rod such that the tipping material extends sbout $3 \mathrm{~mm}$ to about $6 \mathrm{~mm}$ along the length of the lobacco rod. Typically, the tipping material is a conventional paper tip35 ping material. The tipping material can have a porosity which can vary. For ezample, the tipping material can be essentially air impermeable, air permeable, or be treated (cg., by mechanical or laser perforation techniques) so as to have a region of perforations, openings

40 or vents thereby providing a means for providing air dilution to the cigsette. The total surface area of the perforations and the positioning of the perforations along the periphery of the cigarette can be varied in order to control the performance characteristics of the cigarette.

As used herein, the term "air dilution" is the ratio (generally expressed as a percentage) of the volume of air drawn through the air dilution means to the tolal volume of air and aecosol drawn through the cigarette so and exiting the extreme mouthend portion of the cigarette. For air diluted or ventilated cigaretes of this invention, the amount of air dilution can vary. Prefera. bly, the amount of air dilution for a cigarette is greater than bout 20 percent, more preferably greater then 5 about 30 percent. The upper limit of air dilution for a cigarette typically is less than about 80 percent, more frequently less than about 60 percent.

The smokable material employed in the manufacture of the tobacco rod can vary. For example, the tobacco 60 material can be engineered in a processed form such as an extruded form (eg., as a foemed exiruded rod or extruded into a tubular ahape), have the form of filler such as tobacco cut filler, or the like. Generally, the tobaceo material of cigarettes has the form of cui filler. os As used herein, the terms "filler" or "cut filler" are meant to include tobacco materials which have a form suitable for use in the manufacture of cigarette tobacco rods. As such, filler can include tobacco materials 


\section{5}

which are blended and are in a form ready for cigarette manufacture. The tobacco filler materials conventiently are employed in the form of strands or shreds as is com. mon in conventional cigarette manufacture. For example, the tobacco cut filler material can be employed in the form of strands cut into widths ranging from about $1 / 25$ inch to about $1 / 60$ inch, preferably from about $1 / 30$ inch to about $1 / 40$ inch. Generally, such strands have lengths which range from sbout 0.25 inch to sbout 3 inches.

Tobacco materials can be cased and cop dressed as is conventional performed during various stages of cigarette manufacture. For example, additives such as fiavorants and humectants can be applied to the tobacco material as is commonly done when cigarettes are man- is ufactured. Suitable additives include flavorants such as vanillin, cocoa, licorice, methaol, tobacco aroma oils. tobacco extracts, and the like. Such additives conventiently are applied to the smokable material as top dressing components.

The majority of the filler material present in the smokable rod is a tobacco material. However, the tobacco material can be blended with another smokable material such as a tobacco substitute material. Examples of suitable tobacco materials include flue-cured, Burley, Maryland or Oriental tobaccos; processed tobacco materials such as expsnded tobaccos, processed tobacco stems, reconstituted tobacco materials or reconstituted tobacco materials having varying levels of endogenous and exogenous nicotine; or blends thereof. If desired, the lobacco materials can be blended with small amounts of carbonized and/or pyrolyzed materials.

Tobacco material(s) having a naturally high nicotine content conveniently constitute at least a portion of the smokable filler material useful in manufacturing smok- 3 ing articles of this invention. Typically, such useful high nicotine content tobaceos or high nicotine content processed tobaccos have nicotine contents of above about 2.5 percent. The nicotine contents of high nicotine tobrceo materials oftentimes are above about 3 percent, frequenity above about 4 percent, and in certain circumstances above about 5 percent. Generally, the nicotine content of tobacco materials useful in this invention does not exceed about 10 percent.

The high nicotine content filler material can vary. For example tobaccos designated by the U.S.D.A. as Type 35 (One Sucker), Type 36 (Green River) or Type 37 (Virginia Sun Cured) are common tobaccos having a naturally high nicotine content. A cultivar such as Nicoliama rustica often has a natural nicotine content in the so range of about 6 percent to about 10 percent. Addition ally, also useful are upper stalk leaves of commercial lines of nue-cured tobacco (designsted by the U.S.D.A. as Types 11-14) and Burley tobacco (designated by the U.S.D.A. s Type 31). The natural nicotine content of many tobaccos can depend upon the agronomic conditions under which the tobaccos are grown as well as the particular genetic line of the tobsoco.

Processed tobacco materials can be employed. Such processed lobaccos can be provided using tobacco reconstltution-type processes. For exsmple, materials can be manufactured using extrusion, cast sheet, fourdrinier or paper making processes. Raw materials used in manufacturing processed tobaccos can include those high nicotine tobaccos described hereinbefore; or various types of tobacco extracts can be employed in the manufacturing steps of the processed tobaccos. Alternatively. processed tobaccos can be manufactured under

\section{6}

conditions suitable to provide products having various nicotine levels. If desired, nicotine csn be incorporated into the expansion solvents used to provide a volume expanded processed tobacco material having a high nicotine content. A typical expansion process is de. scribed in U.S. Pat. No. 3.524,451 to Fredrickson. Also. processed tobacco materials include tobaccos or tobacco materials mixed, blended or otherwise treated with tobacco extracts, spray dried tobacco materials or

10 tobacco sroma oils. As such, the processed tobacco materials have high nicotine contents upon completion of the processing steps involved in their preparation or manufacture, and prior to their use in the manufacture of cigarettes.

High nicotine tobacco(s) and/or high nicotine processed tobacco(s) can be employed as the tobacco material of the cigarette, as the component(s) of cigaretts blends or as portions of the components of cigarette blends. For example, the high nicotine tobacco(s) anc'-

20 /or high nicotine processed tobacco material(s) can te blended with tobacco substitute(s) and/or Icbaccu materisl(s) having nicotine contents of less than about 2 percent. Typically, the so-called "American blends having high nicotine contents (i.e., total blend nicotire contents above about 2 percent) are desirable for ciga. rette manufacture. Typical total nicotine contents of the tobacco material or blends of materials from which tobacco rods for cigarettes of this invention are manufactured are greater than about 2.25 percent, generally greater than 2.5 percent, often greater than about 3 percent, frequently greater than about 3.5 percent, and in certain circumstances greater than about 4 percent.

Organic acids useful herein are any organic acids or organic compounds that behave as Lewis acids when 35 contacted with nicotine. Examples of organic acids useful in practicing the present invention are arcmatic acids including benzoic-type acids and substituted benzoic-type acids, hydroxyacids, heterocyclic acids, terpenoid acids, sugar acids such as the pectic acids, amino to acids, cycloaliphatic acids, dicarboxylic acids, aliphatic acids, keto acids, and the like. Preferred organic acids sre the strasght-chain and branched-chain aliphatic acids, more preferably the aliphatic inonocarboxylic acids, and especially the keto aliphatic monocarboxylic acids. Examples of suitable organic acids include formic, acetic, propionic, isobutyric, butyric, alpha. methylbutyric, isovaleric, beta-methylvaieric, caproic, 2-furoic, phenylacetic heptanoic, octanoic, nonanoic. malic, citric, oxalic, malonic, glycolic, succinic, ascor-

$30 \mathrm{bic}$, tartaric, fumaric and pyruvic acid, as well as the lower fatty acids (i.e., having carbon chains less than $\mathrm{C}_{12}$ ) and the higher fatty acids (i.e., having carbon chains of $C_{12}$ to $C_{20}$ ), and other such acids. The most preferred organic acid is a gamma keto aliphatic acid known as levulianc acid $\left(\mathrm{CH}_{3} \mathrm{COCH}_{2} \mathrm{CH}_{2} \mathrm{COOH}\right)$. Levulinic acid also is known as scetylpropionic acid alpha-ketovaleric acid and 4 -oxypentaoic acid. Useful organic compounds which exhibit an acid character include the phenolics such as guaiacol, vanillin, protocatechualdehyde, and the like.

Numerous organic acids can improve the flavor or aroma of the aerosol, as numerous or ganic acids are suitable flavorsnts. However, whether a particular or ganic acid acts as a navorant depends upon the smount of the particular organic acid employed as an additive as well as the flavor threshold of the particular acid employed. See, for example, Tobacio Flovoring For Smok ing Products, by Leflingwell et al, p. II to is (1972). 
7

However, it may be desirable to use organic acids which provide specific flavor characteristics to the cigarette at low amounts in order to not provide undesirable off-tastes or aromas to the cigarette. For example, it may be desirable to employ certain organic acids at low enough levels in order that the cigarette does not exhibit taste or aroma characteristics which can be perceived as being chemical, metallic, bitter, pungent or soapy in nature, or as being dissonant to the general organoleptic characteristics associated with tobacco to smoke.

The most preferred organic acid is levulinic acid. Such an organic acid can provide a smooth, palatable character to the cigarette while not providing any significant dissonant taste or aroma. If desired, certain amounts of various other organic acids can be blended with levulinic acid and employed as the additive of this invention. For example, it is desirable that a majority of the organic acid additive be levulinic acid.

The organic acid additive can be incorporated into the cigarette in a variety of places or sites. For example, the organic acid or organic acid mixture can be applied to the filler material, incorporated within some or all of the filler material, applied to the wrapper of the tobacco rod, applied within the glue line of the wrapper of the 2 tobacco rod, provided within the filter element of the cigarette, or the like. If desired, the organic acid additive can be incorporated into processed tobaccos during the manufacture of such materials. For example, the organic acids can be mixed with tobacco extracts or tobacco aroma oils, and the resulting tobacco material. /organic acid mixture can be blended with, mixed with, or otherwise used to treat other tobacco(s) or tobacco material(s). The organic acid can be applied to the cigarette or be present within the cigarette in nondissociated form and/or in a dissociated (eg., carboxylate) form.

Typically, the organic acid additive is incorporated in the cigarette by admixing the additive with the tobacco material. The manner or process for applying the additive can vary depending upon whetter the additive is applied diluted in liquid form, or upon the positioning of the additive within the cigarette. For example, the additive can be applied using syringes or techniques such as spraying, casing, electrostatic deposition, impregnation, garniture injection, spray drying, inclusion and encapsulation techniques, and the like.

Suitable solvents for the organic acids include water, ethanol, glycerol, propylene glycol, and the like, as well as combinations thereof.

One or more salts provided from nicotine and an 50 organic acid can be incorporated into the cigarette. The use of such salts can provide for a cigarette having a relatively high nicotine content as well as provide the organic acid additive. Such salts can be incorporated into cigerettes which include tobacco materials having a wide range of nicotine contents.

Preferred nicotine/organic acid salts have a molar ratio of organic acid to nicotine of $1: 1,2: 1$ or $3: 1$, most preferably $3: 1$. The most preferred salts are totally ionized salts of nicotine and the organic acid. Such preferred ionized salts are those salts wherein both of the nicotine nitrogen atoms are ionized by the acid hydrogens of the organic acids. For example, a particularly preferred salt is provided from 1 mole of nicotine and 3 moles of levulinic acid and has a molar ratio thereof of 65 $1: 3$.

The nicotine/organic acid salts conveniently are prepared using techniques generally known to those skilled

\section{8}

in the art. Many of such techniques have been catalogued by Perfetti in Beitrage Zur Tabakforschung Inter. national, Vol. 12, No. 2, p. 43 (1983), which is incorporated herein by reference. Preferably, nicotine/organic acid salts are provided by contacting nicotine with at least the stoichiometric amount of the organic acid necessary to form the particular salt under conditions sulficient to form the salt.

The preferred salts provided from nicotine and the organic acid generally are essentially non-volatile at conditions under which the smoking articles are manufactured and stored, however, specific properties of the various salts can vary. For example, nicotine/organic acid salts having straight-chain or branched-chain aliphatic acids having less than 20 carbon atoms generally have a molar ratio of 1:3 (nicotine:acid), and generally are liquid in form at ambient conditions. Such salts typically decompose at temperatures less than $100^{\circ} \mathrm{C}$. usually in the range from about $50^{\circ} \mathrm{C}$. to about $60^{\circ} \mathrm{C}$ As another example, nicotine/organic acid salts having dicarboxylic organic acids generally have a molar ratio of $1: 2$ (nicotine:acid), and generally are solid in form at ambient conditions. Such salts typically decompose a temperatures in the range from about $90^{\circ} \mathrm{C}$. to about $25120^{\circ} \mathrm{C}$. As yet another example, nicotine/organic acid salts having acids containing phenyl groups generally have molar ratios of 1:1, 1:2 or 1:3 (nicotine:acid). Generally such salts are solid in form at ambient conditions Such saits typically decompose at temperature in the 30 range from about $110^{\circ} \mathrm{C}$. to about $200^{\circ} \mathrm{C}$.

Numerous nicotine/organic acid salts can improve the flavor or aroma of the acrosol, as numerous organic acids are suitable flavorants. Examples of salts which can provide flavor and aroms to the mainstream aerosol at certain levels include nicotine acetate, nicotine oxalate, nicotine malate, nicotine isovalerate, nicotine lactate, nicotine citrate, nicotine phenylacetate and nicotine myristate. However, it may be desirable to use salt which provide flavor characteristics to the cigarette at low amounts in order to not provide undesirable offtastes or aromas to the cigarette.

The most preferred nicotine/organic acid salt is nicotine levulinate. Such a salt can provide a smooth, palat able character to the cigarette while not providing any significant dissonant taste or aroma. If desired, certain amounts of various nicotine/organic acid salts can be blended with nicotine levulinate and employed as the additive to provide cigarettes of this invertion.

The salts can be incorporated into the cigarette in a variety of places or sites. For example, the salt can be applied to the filler material, incorporated within some or all of the filler material, applied to the wrapper of the tobacco rod, applied within the glue line of the wrapper of the tobacco rod, applied within a region (eg., a cavity) which is subjected to heat, or the like.

Typically, the nicotine/organic acid salt additive or additive mixture is incorporated in the cigarette by admixing the additive with the tobacco material. the manner or process for applying the additive can vary 0 depending upon whether the additive is applied in solid or liquid form, or upon the positioning of the additive within the cigarette. For example, the additive can be applied using syringes or techniques such as spraying. electrostatic deposition, impregnation, garniture injection, spray drying, inclusion and encapsulation techniques, and the like.

When the nicotine/organic acid salts are applied using spraying techriques it is desirable to form a liquid 
$4,836,224$

solution of the salt in suitable solvent. Such solutions should exhibit a low eoongh viscosity to allow for spraying or injecting the solution. However, it is desitable that the concentration of the salt within the soiution not be so dilute that the salt experiences significant dissociation. Typically, the concentration of salt within the solution is about 20 weight percent or more.

Suitable solvents for the salts include water, ethanol, glycerol, propylene glycol, and the like, as well as combinations thereof. Generally, most nicotine/organic acid salts are soluble or miscible in such solvents, and the salts do not undergo substantial dissociation when solubilized to small amounts. For example, the salt can be hydrated in water without undergoing a significant amount of dissociation. However, salts diluted with substantial amounts of solvent can undergo dissociation to some degree to provide for the application of a mix. ture of nicotine/organic acid salt, nicotine and organic acid to the cigarette. Thus, it is possible to apply an additive in the form of nicotine and levulinic acid to the cigarette.

If desired, cigarettes can heve incorporated therein as an additive (i) a lest one salt consisting of nicotine and an organic acid, and (ii) nicotine. Preferred additives of such type include at least one salt having molar ratio of nicotine to organic acid of 1:3.

The amount of organic acid employed within the cigarette can vary. The amount of organic acid incorporated within the cigarette depends upon factors such as the placement of the organic acid within the cigarette, and the configurational aspects of the cizarette. Config urational aspects include the composition and characteristics of the filter material and initial filler blend, the degree of ventilation of the cigarette, and other such factors. For example, for most cigarettes of this inventlon comprising tobacco material having a total or blend nicotine content of from ebout 2 percent to about 10 percent, it frequently is desirable to provide organic acid additive to the cigarette in an amount from about I percent to about 10 percent, based on the dry weight of the tobscco fillet material in order to provide acceptable tobacco taste, strength and satisfaction upon use. Generally, the amount of organic acid applied to such a cigarette is greater than about 2 percevt, and oftentimes greater than about 3 perceot, based on the dry weight of the tobacco filler materal within the cigarette.

The amount of aicotine/organic acid salt or salts employed within the cigarette can vary. The amount of salt incorporated within the cigarette depends upon factors such es the placement of the salt within the cigarette, and the configurational aspects of the cigarette. For most cigarettes having tobacco filler material comprising a nicotine content of from about 1 percent to sbout 2 percent, if frequently is desirable to provide salt additive to provide a total nicotine content of up to bout 8 percent, more frequently up to about 4 percent to the cigarette. Such an amount of additive can provide for good tobacco taste, strength and satisfaction upon use. Generally, the amount of nicotin/organic acid salt applied to a typical cigarette provides from about 0.25 percent to about 20 percent, preferably from about 1.2 to about 13 percent of salt additive, based on the dry weight of the tobaceo filler material within that cigarette. In certain instances, it is desirable to employ about 6 3.5 percent of salt additive or more, based on the dry weight of the tobacco filler material within the cigarette.
10

The cigarettes of this invention preferably provide a mainstream aerosol exhibiting a pH which is essentiaily cqual to or less than that of a similar cigarette having a low amount (e.g., less than about 0.2 weight percent) of the organic acid additive incorporated therein. In certain circumstances, an amount of organic acid additive is incorporated into a cigarette in order to reduce the $\mathrm{pH}$ of the mainstream aerosol during use thereof. Mainstrean aerosol is that serosol which is drawn through the article and into the mouth of the user. For example, for a cigarette having smokable tobacco material contained in a circumscribing outer wrapping material, the mainstream aerosol is the mainstream tobacco smoke which includes the combustion and/or pyrolysis prodis acts of tobacco material.

By the term, "pH of mainstream aerosol" is meant that averaged per-puff $\mathrm{pH}$ of the whole aerosol es measured using the techniques described by Sensabaugh et al in Tobacco Science. Vol. XI, pp. 25-30 (1967), whicl 20 is incorporated herein by reference. Typical mainstrean aerosol pH for a cigarette ranges from about 4.5 units to about 8.5 units on average per cigarette.

In referring to a reduction in the $\mathrm{pH}$ of mainstrean serosol, it is meani a lowering of the sverage pH of the 25 mainstream aerosol per particular cigarette. Such re. duction is provided by the addition of an effective amount of the additive (eg., organic acid additive and/or nicotine/organic acid salt). Typically, the reduction in $\mathrm{pH}$ is a lowering of the $\mathrm{pH}$ by more than about 0.03 $30 \mathrm{pH}$ unit; preferably by more than about $0.08 \mathrm{pH}$ unit. Typically, reduction in the $\mathrm{pH}$ of the mainsiream aero. sol does not provide a cigarette which yields mainstream acrosol having a $\mathrm{pH}$ significantly below 4.5 units.

The presence of the organic acid (which can be provided by the decomposition of the nicotine/organic acid salt during use of the cigarette can introduce a reduction of the $\mathrm{pH}$ of the mainstream aerosol depending upon the quantity and type of organic acid which is 0 incorporated therein. Thus, a certain balance, mellowing or marrying of the flavors culminate in a fully bodied tobacco flavor. strength and satisfaction which is delivered to the user. Such a Davor enhancing characteristic is particularly desirable for highly air diluted or "ultra low tar" cigarevtea.

The $\mathrm{pH}$ of the mainstream aerosol is influenced by a number of factors. For example, the $\mathrm{pH}$ of mainstream cigarette smoke can be influenced by factors such as the type of tobacco material or b!end of tobacco materials employed, the type of processed tobacco (e.g., volume expanded tobacco or reconstituted tobacco), the configuration of the cigarette (eg., the filter tow material, the degree of air dilution. the circumference of the cigarette, the type of wrapping material, etc.), the manner of drawing on or pufting the cigarette, and other such factors.

Cigarettes of this invention generally deliver from about $0.2 \mathrm{mg}$ to about $3.5 \mathrm{mg}$. frequently from about 0.3 $\mathrm{mg}$ to about $2.5 \mathrm{mg}$, more frequently from about $0.4 \mathrm{mg}$ 0 to about $1.5 \mathrm{mg}$ of nicotine when smoked under FTC conditions. Typically, FTC "tar" to FTC nicotine ratios for cigarettes of this invention are less than about 12, generally less than about 9 , frequently less than bout 7, and in certain instances less than about 5. FTC os "tar" to FTC nicotine ratios for cigarettes of this invention often can range from about 3 to about 6 . Typically, the FTC "tar" to FTC nicotine ratios of a cigarette having a nicotine/organic acid salt incorporated therein 


\section{1}

can be lowered by up to about 80 percent of that ratio of similar cigarette not having the salt additive incorporated therein.

The following examples are provided in order to further illustrate the invention but should not be con. strued as limiting the scope thereof. Unless otherwise noted, all parts and percentages are by weight.

\section{EXAMPLE :}

A salt of nicotine and levulinic acid is provided using the following procedure.

Into a $1,000 \mathrm{ml}$ round bottom flask is charged about $350 \mathrm{~g}$ of $\mathrm{l}$-nicotine provided from Kodak Laboratory Chemicals, Eastman Kodak Co. (Catalogue No. S2, p. 366. Chemical No. 1124973). To the 1-nicotine is charged about $10 \mathrm{~g}$ of sodium hydroxide pellets. The flask is fitted with a heating mantle and equipped with a magnetic stirring bar. The nicotine solution is stirred employing a magnetic stirring unit. The nicotine is vacuum distilled using a Todd Column packed with glass helixes, and the fraction distilled between $97^{\circ} \mathrm{C}$. and $98^{\circ}$ C. at $10 \mathrm{~mm} \mathrm{Hg}$ pressure is collected at a reflux ratio of about 10:1. The collected distillate is water clear. The nicotine so purified using the vacuum distillation technique is employed in the preparation of the 1-nicotine/. levulinic acid salt.

Into a $500 \mathrm{ml}$ round bottom flask equipped with a magnetic stirring bar and heating mantle is charged 69.6 $g$ ( 0.6 mole) of levulinic acid. The levulinic acid is 3 stripped employing a conventional magnetic stirring unit. The levulinic acid is obtained from Aldrich Chemical Co., Catalogue No. 1984-85, p. 672, Compound No. $\mathrm{L}-200-9$, and is employed without further purification. The levulinic acid is heated to about $50^{\circ} \mathrm{C}$. in order to 35 provide a liquid form thereof, and the liquified component is subjected to stirring. To the liquified levulinic acid is titrated $32.4 \mathrm{~g}(0.2$ mole $)$ of the purified l-nicotine over about a 20 minute time period. It is preferred to introduce the nicotine to the organic acid in order to provide an environment of excess acid to nicotine and thus promote the formation of salt. A clear, viscous yellow colored material weighing about $100 \mathrm{~B}$ results. The product is sealed in a glass ampuole under nitrogen.

The product is I-nicotine levulinate (as determined using infrared spectrometry), and has a nicotine to levulinic acid ratio of 1:3 (as determined by a destructive distillation in a 10 percent sodium bydroxide aqueous solution, subsequent extraction using iscpropanol, and gas chromatographic analysis for nicotine). The salt is believed to have a structure substantially as generally described in FIG. 13 of the Perfetti reference, supra.

Cigarettes incorporating varying amounts of the 1 . nicotine levulinate salt are provided using the following procedure.

Cigarettes having lengths of about $99 \mathrm{~mm}$ and circumferences of about $24.85 \mathrm{~mm}$ have tobacco rod lengths of $68 \mathrm{~mm}$ and filter element lengths of $31 \mathrm{~mm}$. The tobacco rod includes a charge of tobacco cut filler weighing about $0.74 \mathrm{~g}$ contained in circumscribing cigarette paper wrap which is sold commercially as 754 Cigarette Paper by Ecusta Corp. The filter element is manufactured using conventional cigarette filter making technology from cellulose acetate tow (2.7 denier per filament, 48,000 total denier) and circumscribing air permeable paper plug wrap having a CORESTA poros. ity of $26,000 \mathrm{~cm} / \mathrm{min}$. The tobscco rod and filter ele-

\section{2}

ment are aligned in an abutting, end-to-end relationship and secured together using tipping paper having a CORESTA porosity of $3135 \mathrm{ml} / \mathrm{min}$. The tipping paper is adhesively secured to the filter element and the adjacent portion of the tobacco rod. The tipping material circumscribes the length of the filter element and about $3 \mathrm{~mm}$ of the length of the tobacco rod. Cigarettes so described are manufactured using a Pilot Cigarette Maker from Hauni-Werke Korber \& Co. KG. A ring of mechanically provided perforations extends around the periphery of the cigarette about $13 \mathrm{~mm}$ from the extreme mouthend thereof. The perforations so provided yield cigarettes which sre 50 percent air diluted. The cigatettes so manufactured are designated Sample Nos. $1,2,3$ and $C \cdot 1$, corresponding to the sample of filler material from which each cigarette is manufactured.

The filler material employed in providing the tobacco rod is in the form of strands cut at about 32 cuts per 20 inch. The initial filier material includes a blend of about 9 percent Burley tobacco, about $\$ 1$ percent flue-cured tobacco, about 32 percent reconstituted tobacco material, and about 18 percent Oriental tobaccos. The blend has an aqueous casing o! glycerin and flavors applied 25 thereto.

Four lots of the cut filler blend, each lot weighing $1,520 \mathrm{~g}$, are provided. The first lot is treated with $20 \mathrm{~g}$ of the 1 -nicotine levulinate additive. The second lot is treated with $60 \mathrm{~g}$ of the 1 -nicotine levulinate additive. The third lot is treated with $100 \mathrm{~g}$ of the 1-nicotine levulinate additive. The fourth lot is not treated with the I-nicotine levulinate additive and is employed for comparison purposes.

The 1-nicotine levulinate additive is applied to cut filler as a spray using a hand sprayer to apply a $1: 1$ mixture of water and additive.

Each of the four lots are separately placed in sealed plastic bags and stored at $70^{\circ} \mathrm{F}$. for 2 days. Then, the 40 four lots are each mixed with about $480 \mathrm{~g}$ of a cut filler mixture of about 75 parts volume expanded Burley tobacco and about 25 parts volume expanded flue-cured tobacco. The volume expanded cut filler mixture is added to each lot using a mixing drum in order to pro-

45 vide a well mixed blend having a moisture content of about 12 percent to about 13 percent. The resulting blend provided from the first lot of filler material has about I percent of the I-nicotine levulinate salt applied thereto (based on the filler conditioned weight) and is so designated as Sample No. 1. The resulting blend provided from the second lot of filler material has about 3 percent of the 1-nicotine levulinate salt applied thereto (based on the filler conditioned weight) and is designated as Sample No. 2. The resulting blend provided from the third lot of filler material has about 5 percent of the 1-nicotine levulinate salt applied thereto (based on the filler conditioned weight) and is designated as Sample No. 3. The resulting blend provided from the fourth lot of filler material is not treated with the 1-nicotine levulinate salt additive, is employed for comparison purposes, and is designated as Sample No. C-1.

The various cigarettes are smoked under FTC conditions. Data concerning (i) FTC "tar," FTC nicotine and FTC carbon monoxide, (ii) the "tar"/nicotine ratio, (iii) cigarette nicotine content, (iv) puff count, and (v) $\mathrm{pH}$ of the mainstream aerosol for each sample are presented in Table 1. 
13

$4,836,224$

14

\begin{tabular}{|c|c|c|c|c|c|c|c|c|}
\hline \multirow[b]{2}{*}{ Sample } & \multirow{2}{*}{ 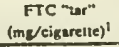 } & \multirow{2}{*}{$\begin{array}{l}\text { FTC Nicotine } \\
\text { (mg/ćigarette) }\end{array}$} & \multirow{2}{*}{$\begin{array}{c}\text { FTC CO } \\
\text { (mg/cigarelte) }\end{array}$} & \multirow{2}{*}{$\begin{array}{c}\text { Tar"' } \\
\text { Nicoune? }\end{array}$} & \multirow{2}{*}{$\begin{array}{c}\text { Tolal } \\
\text { Nicotine (\%) }\end{array}$} & \multirow{2}{*}{$\begin{array}{c}\text { Purt } \\
\text { Count }\end{array}$} & \multicolumn{2}{|c|}{ Sinoke ph ${ }^{3}$} \\
\hline & & & & & & & mınımum & maximum \\
\hline 1 & 5.1 & 0.56 & 74 & 9.1 & 2.05 & 8.7 & 5.73 & 601 \\
\hline 2 & 4.9 & 69 & 74 & 71 & 2.51 & 19 & 5.65 & 602 \\
\hline$c_{-1}^{3}$ & 49 & 0.81 & 6.7 & 6.0 & 2.91 & 90 & 567 & 5.98 \\
\hline $\mathrm{C}_{1}{ }^{\circ}$ & 4.6 & 0.38 & 7.3 & 12.1 & 1.66 & 81 & 589 & 610 \\
\hline
\end{tabular}

The data in Table I indicate that the various ciga. Is rettes have increased nicotine contents and exhibit increased FTC nicotine values as the level of l-nicotine levulinate is increased. In addition, the FTC "tar" to nicotine ratios for the samples decrease as the level of 1 -nicotine levulinate is increased. The various cigarettes 20 each exhibit similar "tar" deliveries, carbon monoxide deliveries and puff counts. Further, the samples of the invention (i.e., Sample Nos. 1-3) exhibit a pH of the whole smoke lower than that of the sample not having the exogenous nicotine/organic acid salt (i.e., Sample 25 No. C-1).

Evaluations of the organoleptic properties of the Sample Nos. 2, 3 and C-1 indicate that the cigarette having about 5 percent salt additive (i.e., Sample No. 3) exhibits greater impact and smoothness as well as less harshness than the cigarette not having salt additive (i.e., Sample No. C-1). Sample No. 2 is not significantly different organoleptically from Semple No. C-1 in terms of harshness and overall taste, even through there is substantial increase in FTC nicotine of the sample relative to the comparative sample. Thus, the nicotine levulinate additive provides for a cigarette having a relatively low FTC "tar" to FTC nicotine ratio while having a smooth (i.e., not overly harsh) taste.

\section{EXAMPLE 2}

Cigarettes incorporating varying amounts of the 1nicotine levulinste salt are provided using the following procedure.

Cigarettes having lengths of bout $84 \mathrm{~mm}$ and cir* cumferences of about $24.85 \mathrm{~mm}$ have tobacco rod lengths of $57 \mathrm{~mm}$ and filter element lengths of $27 \mathrm{~mm}$. The tobacco rod includes a charge of tobacco cut filler weighing about $0.49 \mathrm{~g}$ contained in circumscribing cigerette paper wrap which is sold commercially as 854 Cigarette Paper by Ecusta Corp. The filter element is manufactured using conventional cigarette filter making technology from cellulose acetate tow (2.1 denier per filament, 48,000 total denier) and circumscribing non-air permeable paper plug wrapp. The tobacco rod and fitter element are aligned in an abutting, end-to-end relationship and secured together using non-sir permeable tipping paper. The tipping paper is adhesively secured to the filter element and the adjacent portion of the tobacco rod. The tipping material circumecribes the length of tha filter element and about $3 \mathrm{~mm}$ of the length of the tobacco rod. Cigarettes so described are manufactured using Pilot Cigarette Maker from HauniWerke Korber \& Co. KG. A ring of laser perforations are provided amound the periphery of the cigarette bout $13 \mathrm{~mm}$ from the extreme mouthend thereof. The perforations penetrate through the tipping paper and plug wrap, and are provided using a Laboratory Leser

Perforator from Hauni-Werke Korber \& Co. KG. Tlic perforated cigarette is 75 percent air diluted. The cigarettes so manufactured are designated Sample Nos. 4, 5, 6 and $C-2$, corresponding to the sample of filler material from which each cigarette is manufactured.

The filler material employed in providing the tobacco rod is in the form of strands cut at about 32 cuts per inch. The initial fillet material includes a blend of about 43 percent burley tobacco, about 6 percent flue-cured tobacco, about 19 percent reconstituted sobacco material, and about 32 percent Turkish tobacco. The blend has an aqueous casing of glycerin and havors applied thereto.

Four lots of the cut filler blend, each lot weighing 940 $\mathrm{g}$, are provided. The first lot is treated with $60 \mathrm{~g}$ of the 1-nicotine levulinate additive. The second lot is treated with $140 \mathrm{~g}$ of the 1 -nicotine levulinatc additive. The third lot is treated with $200 \mathrm{~g}$ of the $\mathrm{i}$-nicotine levulinate additive. The fourth lot is not treated with the 1-nicotine levulinate additive and is employed for compariso:ı purposes.

The 1 -nicotine levulinate additive is applied to cur filler as a spray using a hand sprayer to apply a $1: 1$ mixture of water and additive.

40 Each of the four lots are separately placed in sealed plastic bags and stored at $70^{\circ} \mathrm{F}$. for 2 days. Then, the four lots are esch mixed with about $1,060 \mathrm{~g}$ oi a cut filler mixture of about 35 parts volume expanded burley tobacco and about 65 parts volume expanded flue-cured tobacco. The volume expanded cut filler mixture is added to each lot using a mixing drum in order to pro. vide a well mixed blend having a moisture content of about 12 percent to about 13 percent. The resulting blend provided from the first lot of filler material has about 3 percent of the 1 -nicotine levulinate salt applied thereto (based on the filler conditioned weight) and is designated as Sample No. 4. The resulting blend pruvided from the second lot of filler material has about 7

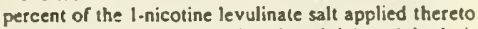
(based on the filler conditioned weight) and is desiganted as Sample No. 5 . The resulting blend provided from the third lot of filler maternal has about 10 percent of the 1-nicotine levulinate salt applied thereto (based on the filler conditioned weight) and is designated as Sample No. 6 . The resulting blend provided from the fourth lot of filler materisl is not treated with the 1 -nicoine levulinate salt edditive, is employed for comparison purposes, and is designated as Sample No. C-2.

For comparison purposes, Sample No. C-3 is prepared. Sample No. $\mathrm{C}-3$ is provided by adding nicotine to a cigarette designated as Sample No. C-2. In particuIar, about $30 \mathrm{mg}$ of 1:1 mixture of ethanol and 85 percent pure 1-nicotine is injected into the cigarette in 
order to provide nicotine content of about 3.92 percent to the cigarette. The nicotine/ethanol mixture is incorporated into the tobacco rod by inserting a syringe into the lighting end of the rod and slowly pulling the syringe from the rod while injecting the mixture into the rod.

Sample No. 7 is provided by injecting about $10 \mathrm{mg}$ of the previously described $1: 1$ mixture of ethanol nicotine into a cigarette designated as Sample No. 6 using a syringe in the manner previously described. The cigarette so provided comprises a nicotine levulinate additive as well as an exogenous nicotine additive.

The various cigarettes are smoked under FTC conditions. Data concerning (i) FTC "tar," FTC nicotine and FTC carbon monoxide, (ii) the "tar"/nicotine ratio, (iii) cigarette nicotine content, and (iv) puff count for Sample Nos. 4-6 and C-2 are presented in Table II. In addition, data concerning the $\mathrm{pH}$ of the mainstream aerosol for Sample Nos. 4-6, C-1 and C-3 are presented in Table II.

TABLE II

\begin{tabular}{|c|c|c|c|c|c|c|c|c|}
\hline \multirow[b]{2}{*}{ Sample } & \multirow{2}{*}{$\begin{array}{c}\text { FTC "Tar" } \\
\text { (mg/cigerette) }\end{array}$} & \multirow{2}{*}{$\begin{array}{l}\text { FTC Nicotine } \\
\text { (mg/cigarette) }\end{array}$} & \multirow{2}{*}{$\begin{array}{c}\text { FTC CO } \\
\text { (mg/cigarente) }\end{array}$} & \multirow{2}{*}{$\begin{array}{l}\text { "Tar"/ } \\
\text { Nicoline? }\end{array}$} & \multirow{2}{*}{$\begin{array}{c}\text { Told } \\
\text { Nicoline }(\%)^{3}\end{array}$} & \multirow{2}{*}{$\begin{array}{c}\text { Puff } \\
\text { Count }\end{array}$} & \multicolumn{2}{|c|}{ Smoke $\mathrm{pH}^{3}$} \\
\hline & & & & & & & minumum & meximum \\
\hline 4 & t.8 & 0.29 & 2.9 & 6.2 & 2.64 & 67 & 390 & 628 \\
\hline 5 & 2.0 & 0.39 & 3.0 & 3.1 & 322 & 68 & 386 & 6.20 \\
\hline 6 & 20 & 0.51 & 3.1 & 3.9 & 392 & 68 & 3.91 & 6.32 \\
\hline $\mathrm{C}_{-2}{ }^{\circ}$ & 1.8 & 0.18 & 29 & 10.0 & 2.08 & 67 & 613 & 642 \\
\hline C.3० & - & - & - & - & - & - & 6.78 & 711 \\
\hline
\end{tabular}

- Not an exaraple of the invention.

treo Toble L. lootnoles 1-4, repectively.

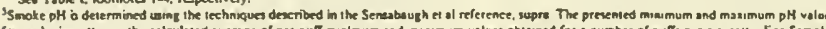

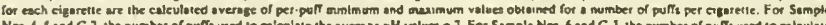

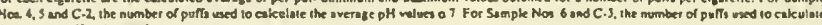
the avenge oH values a 6.

The data in Table 11 indicate that the various cigarettes have incresed nicotine contents and exhibit increased FTC nicotine values as the level of l-nicotine levulinate is increased. In addition, the FTC "tar" to nicotine ratios for the samples decrease as the level of 1-nicotine levulinate is increased. The various cigarettes each exhibit similar "tar" deliveries, carbon monoxide deliveries and pult counts. Further, the samples of the invention (i.e., Sample Nos. 4-6) exhibit a $\mathrm{pH}$ of the whole smoke lower than that of the sample not having the exogenous nicotine/organic acid salt (i.e., Sample No. C-2). In addition, the $\mathrm{pH}$ of the whole smoke of Sample No. C-3 is very much higher than that of any of so the other samples.

Evaluations of the organoleptic properties of Sample Nos. 5, 6 and $C-2$ indicate that the cigarette having about 10 percent salt additive (i.e., Sample No. 6) exhib. its greater impact and smoothness as well as less harshness than the cigarette not having the salt additive (i.e. Sample No. C-2). All cigarettes sampled provide good tobacco taste and do not exhibit a perceivable chemical off-taste or non-cigarette taste. Surprisingly. Sample No. 5 is not significantly different organoleptically from Sample No. C-2 in terms of impact, smoothness, harshness and overall taste even though the sample provides a higher level of FTC nicotine than the comparative sample. Sample No. C-3 is extremely harsh and is not palatable. However, Sample No. 7 surprisingly exhibits a smooth smoking character and is palatable, even though the sample has a relatively high level of exoge nous nicotine incorporated therein.
35 the filter element and the adjacent portion of the tobacco rod. The tipping material circumseribes the length of the fitter element and about $4 \mathrm{~mm}$ of the length of the tobacco rod. Cigarettes so described are manu. factured using a Pilot Cigarette Maker from HauniWerke Korber \& Co. KG. A ring of mechanically pro. vided perforations extends around the periphery of the cigarelte about $13 \mathrm{~mm}$ from the extreme mouthend thereof. The perforations so provided yield cigarettes which are 75 percent air diluted. The cigarettes so manufactured are designated Sample Nos. 8, 9, 10 and C-4. corresponding to the sample of filler material from which each cigare!te is manufactured.

The filler material employed in providing the tobacco rod is in the form of strands cut at about 32 cuts per 0 inch. The initial filler material includes a blend of about 40 percent Burley tobacco having a nicotine content of about 5 percent, about 18 percent flue-cured tobacco having a nicotine content of about 3.5 percent, about 30 percent reconstituted tobacco material having anicotine content of about 0.5 percent, and 12 pereent of an Oriental tobacco blend having a nicotine content of about 0.9 pereent. The blend has an aqueous casing of glyeerin and flavors applied thereto.

Four lots of the cut filler blend, each loc weighing $2,000 \mathrm{~g}$ on a dry weight basis, are provided. The first lot is treated with $120 \mathrm{~g}$ of the levulinic acid additive. The second lot is treated with $280 \mathrm{~g}$ of the levulinic acid additive. The third lot is treated with $400 \mathrm{~g}$ of the levulinie acid additive. The fourth lot is not treated with the levulinie acid additive and is employed for comparison purposes.

The levulinic acid additive is applied to cut filler as a spray using a hand sprayer as a mixture of water and 
17

$4,836,224$

sdditive. The quantity of water of the water/additive mixture is adjusted to attain a final cut filler moisture content of about is percent.

Each of the four lois are separately placed in sealed piastic bags and stored at $70^{\circ} \mathrm{F}$. for 2 days. Then, the four lots are each mixed with about $2,000 \mathrm{~g}$ on a dry weight basis, of a cut filler mixture of about 35 parts volume expanded Burley tobacco baving a nicotine content of about 4 percent, and about 65 parts volume expanded nue-cured tobscco having a nicotine content of about 4 percent. The volume expanded cut filler mixture is added to each lot using a mixing drum in order to provide a well mixed blend having moisture content of berween about 12 percent and about 13 percnet.

The resulting blend provided from the first lot of filler materiel has sbout 3 percent of the levulinic acid applied thereto (based on the filler dry weigbt) and is designated as Sample No. $\mathbf{8}$. The resulting blend provided from the second lot of filler material has about 7 percent of the levulinic acid applied thereto (based on the filler dry weight) and is designated as Sample No. 9. The resulting blend provided from the third lot of filler material has about 10 percent of the levulinic acid ap. plied thereto (based on the filler dry weight) and is 25 designated as Sumple No. 10. The resulting blend provided from the fonrth lot of flller material is not treated with the levulinic acid additive, is employed for comparison purposes, and is designated as Sample No. C-4.

The various cigarettes are smoked under FTC conditions. Data concerning (i) the nicotine content of each blend, (ii) FTC "tar," FTC nicotine and FTC carbon monoxide, (iii) the "tar"/nicotine ratio, (iv) puff count and $(v) \mathrm{pH}$ of the mainstream aerosol for each sample, are presented in Table III.

TABLE II!

18
while the control sample is very harsh. The mildness of Sample Nos. 8 and 9 is considered comparable. The cigarettes of the invention yield good tobacco teste, strength and smoking satisfaction. The control sample is very strong, and the overpowering sensation provided thereby is not satisfying.

\section{EXAMPLE 4}

Cigarettes incorporating varying amounts of the levolinic acid are provided using the following procedure.

Cigarettes having lengths of about $84 \mathrm{~mm}$ and circumferences of about $24.85 \mathrm{~mm}$ have tobacco rod lengths of $57 \mathrm{~mm}$ and iilter element lengths of $27 \mathrm{~mm}$. The tobacco rod includes a charge of tobacco cut filles is weighing about $0.82 \mathrm{~g}$ contained in circumscribing cigarette paper wrap which is sold commercially as 856 Cigarette Paper by Ecusta Corp. The filter element is manufactured using conventional cigarette filter making technology from cellulose acetate tow (2.7 denier 20 per filament, 48,000 total denier) and circumscribing air permeable paper plug wrap having a CORESTA poros ity of about $26,000 \mathrm{~cm} / \mathrm{min}$. The tobacco rod and filter element are aligned in an abutting, end-to-end relationship and secured together using essentially air impermeable tipping paper. The tipping paper is adhesively secured to the filter element and the adjacent portion of the tobacco rod. The tipping material circumscribes the length of the filter element and about $4 \mathrm{~mm}$ of the length of the tobacco rod. Cigarettes so described are manuo factured using a Pilot Cigarette Maker from HauniWerke Korber \& Co. KG. A ring of laser perforations estends around the periphery of the cigarette about 13 $\mathrm{mm}$ from the extreme mouthend thereof. The perforations so provided yield cigarettes which are 50 percent 5 air diluted. The cigarettes so manufactured are desig-

\begin{tabular}{|c|c|c|c|c|c|c|c|c|c|}
\hline \multirow[b]{2}{*}{ Sample } & \multirow{2}{*}{$\begin{array}{l}\text { FTC "To" } \\
\text { (ing/cigarette) }\end{array}$} & \multirow{2}{*}{$\begin{array}{l}\text { FTC Nicokine } \\
\text { (m//cigarette) }\end{array}$} & \multirow{2}{*}{$\begin{array}{c}\text { FTC CO' } \\
\text { (any/cigerente) }\end{array}$} & \multirow{2}{*}{$\begin{array}{l}\text { "Tar }{ }^{n+12} \\
\text { Nicotine }\end{array}$} & \multirow{2}{*}{$\begin{array}{c}\text { Total }^{J} \\
\text { Nicotine }\left({ }_{0}\right)\end{array}$} & \multirow{2}{*}{$\begin{array}{l}\text { Pam } \\
\text { Count }\end{array}$} & \multicolumn{2}{|c|}{ Smoke $\mathrm{pH}^{5}$} & \multirow{2}{*}{$\begin{array}{l}\text { Average } \\
\text { Smoke pH }\end{array}$} \\
\hline & & & & & & & muminum & masimum & \\
\hline 8 & 1.2 & 0.27 & 208 & 3.22 & 3.12 & 67 & 6.12 & 6.41 & 6.57 \\
\hline 9 & 1.4 & 0.23 & 210 & 6.09 & 3.00 & 67 & 616 & 630 & 6.16 \\
\hline 10 & is & 0.23 & 2.18 & 5.56 & 294 & 6.8 & 9.48 & 5.82 & 520 \\
\hline $\mathrm{CA}^{\circ}$ & 1.2 & 0.21 & 204 & 5.71 & 3.08 & 6.7 & 6.47 & 6.82 & 6.79 \\
\hline
\end{tabular}

Hot to exsepple of the kreation

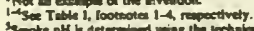

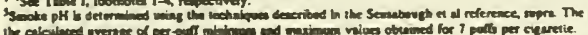

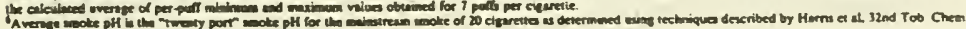
Alas cons (1978).

The data in Table III indicate that the various cigarettes having high nicotine conteot cut filler (i.e., approximstely 3 percent total blend nicotine) exhibit com- 50 nated Samples Nos. 11, 12, 13 and C-5, corresponding to parable FTC "tar," nicotine and carbon monoxide deliveries, as well as comparable FTC "tar" to FTC nicotine ratios and puft counts. However, cigarettes of the invention (i.e., Semple Nos 8-10 which contain the levulinic acid additive) exbibit reduced mainstream by puff and average smoke $\mathrm{pH}$ when compared to a control (i.e., Sample No. C 4 which does not have the levu. linic acid additive). la addition, the data indicate that the smoke $\mathrm{pH}$ of cigarettes of the invention is reduced significantly the level of levulinic acid additive incresses. The reduction in the smoke $\mathrm{pH}$ of the sumples of the invention is indicative of a substantial increase in the hydronium ion concentration of the tobacco smoke. Sucb an increase in the hydronlum ion concentration of the mainstream smoke is anficient to provide a change os in the orgenoleptic quality of the moke. .

Organoleptic evaluation of the samples indicates that the cigarettes of the invention are smooth moking the sample of filler material from which each cigarette is manufactured.

The filler material employed in providing the tobacco rod is in the form of strands cut at about 32 cuts per s inch. The initial filler material includes a blend of about 31 percent Burley tobacco having a nicotine content of about 5 percent, about 20 percent nue-cured tobacco having a nicotine content of about 3.5 percent, about 31 percent reconstituted tobacco material having a nico0 tine content of about 0.5 percent, and 18 percent of an Qriental tobaceo blend having a nicotine content of about 0.9 percent. The blend has an aqueous casing of glycerin and flavors applied thereto.

Four lots of the cut filler blend, each lot weighing $3,120 \mathrm{~g}$ on a dry weight basis, are provided. The first lot is treated with $\mathbf{4 0} 8$ of the levulinic acid additive. The second lot is treated with $120 \mathrm{~g}$ of the levulinic acid additive. The third lot is treated with $200 \mathrm{~g}$ of the levu- 
19

linic acid additive. The fourth lot is not treated with the levulinic acid additive and is employed for comparison purposes.

The levulinic acid additive is applied to cut filler as a spray using hand sprayer as a mixture of water and additive. The quantity of water of the water/additive mixture is adjusted to attain a final cut filler moisture content of about is percent.

Eacb of the four lots are separately placed in sealed plastic bags and stored at $70^{\circ} \mathrm{F}$. for 2 days. Then, the four lots are each mixed with about $880 \mathrm{~g}$ on a dry weight basis, of a cut filler mixture of about 35 parts volume expanded Burley tobacco hoving a nicotine content of about 4 percent, and about 65 parts volume expanded fue-cured tobacco having a nicotine content of about 4 percent. The volume expanded cut filler mixture is added to each lot using a mixture drum in order to provide a well mixed blend having a moisture content of between about 12 percent and about 13 percent.

The resulting blend provided from the first lot of filler material has about 1 percent of the levulinic acid applied thereto (based on the filler dry weight) and is designated as Sample No. 11. The resulting blend provided from the second lot of filler material has about 3 percent of the levulinic acid applied thereto (based on the filler dry weight) and is designated as Sample No. 12. The resulting blend provided from the third lot of fuler material has about 5 percent of the levulinic acid applied thereto (based on the filler dry weight) and is designated as Sample No. 13. The resulting blend provided from the fourth lot of filler material is not treated with the levulinic acid additive, is employed for com parison purposes, and is designated as Sample No. C.5

The various cigarettes are smoked under FTC condi. tions. Data concerning (i) the nicotine content of each blend, (ii) FTC "tar," FTC nicotine and FTC carbon monoxide, (iii) the "tar"/nicotine ratio, (iv) puff count, and $(v) \mathrm{pH}$ of the mainstream aerosol for each ssmple are presented in Table IV.
20

and average smoke $\mathrm{pH}$ when compared to a control (i.e., Sample No. C-5 which does not have the levulinic acid additive).

Organolepic evaluation of the samples indicates that the cigarettes of the invention are smooth smoking while the control sample is very harsh. The mildness of Sample Nos. 12 and 13 is considered comparable. The cigarettes of the invention yield good tobacco taste, strength and smoking satisfastion. The control sample is 0 very strong, and the overpowering sensation provided thereby is not satisfying.

\section{EXAMPLE 5}

Cigarettes incorporating varying amounts of the lev. ulinic acid are provided using the following procedure.

Cigarettes having lengths of about $84 \mathrm{~mm}$ and cir. cumferences of about $24.85 \mathrm{~mm}$ have tobacco rod lengths of $57 \mathrm{~mm}$ and filter element lengths of $27 \mathrm{~mm}$. The tobscco rod includes a charge of tobacco cut filler 20 weighing about $0.82 \mathrm{~g}$ contained in a circumscribing cigarette paper wrap which is sold commercially as 856 Cigarette Paper by Ecusta Corp. The nilter element is manufactured using conventional cigarette filter mak. ing technology from cellulose acetate tow (2.7 denier per filament, 48,000 total denier) and circumscribing sir permeable paper plug wrap having a CORESTA porosity of about $26,000 \mathrm{~cm} / \mathrm{min}$. The tobacco rod and filter element are aligned in an abutting, end-to-end relatioship and secured tagether using essentially air impermeable tipping paper. The tipping paper is adhesively secured to the filter element and the adjacent portion of the tobacco rod. The tipping material circumscribes the length of the filter element and about $4 \mathrm{~mm}$ of the length of the tobacco rod. Cigarettes so described are manufactured using Pilot Cigarette Maker from HauniWerke Korber \& Co. KG. The cigarettes so manufac tured are designated Sample Nos. 14, 15, 16 and C.6, corresponding to the sample of filler material from which each cigarette is manufactured.

40 The filler materials employed in providing the 10 -

TABLE IV

\begin{tabular}{|c|c|c|c|c|c|c|c|c|c|}
\hline \multirow[b]{2}{*}{ Semple } & \multirow{2}{*}{$\begin{array}{c}\text { FTC Ter"1 } \\
\text { (me/cigerelte) }\end{array}$} & \multirow{2}{*}{$\begin{array}{l}\text { FTC Nicotine' } \\
\text { (me/cigarette) }\end{array}$} & \multirow{2}{*}{$\begin{array}{c}\text { FTC CO' } \\
\text { (mg/cigerelte) }\end{array}$} & \multirow{2}{*}{$\begin{array}{l}\text { Tur" /2 } \\
\text { Nicoline }\end{array}$} & \multirow{2}{*}{$\begin{array}{c}\text { Tolal }^{3} \\
\text { Nicoline (\%) }\end{array}$} & \multirow{2}{*}{$\begin{array}{l}\text { Purr } \\
\text { Couni }\end{array}$} & \multicolumn{2}{|c|}{ Smoke $\mathrm{fH}^{3}$} & \multirow{2}{*}{$\begin{array}{l}\text { Average } 6 \\
\text { Smoke pH }\end{array}$} \\
\hline & & & & & & & minımum & masimum & \\
\hline 11 & 9.2 & 0.54 & 6.95 & 9.63 & 2.53 & 6.0 & 6.25 & 6.57 & 6.43 \\
\hline 12 & 4.9 & 0.36 & 6.53 & 8.75 & 2.64 & 9.9 & 6.33 & 6.75 & 6.28 \\
\hline 13 & 5.1 & 0.60 & 6.53 & 850 & 2.58 & 60 & 5.69 & 5.97 & 3.56 \\
\hline C.5 & 9.0 & 0.58 & 6.87 & 82 & 244 & 6.0 & 647 & 6.80 & 6.61 \\
\hline
\end{tabular}

Not an exumple of the lavesilon.

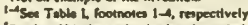

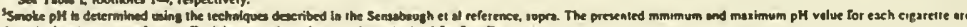

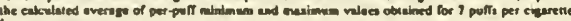

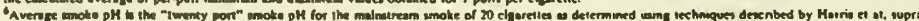

The data in Table IV indicate that the various cigarettes of this inention having high nicotine content cut fuler (i.e., more than 2.5 percent total blend nicotine) exhibit FTC "tar," nicotine and carbon monoxide deliv eries comparable to the control cigarette. The various cigarettes also exhibit comparable FTC "tar" to nicotine ratios and puff counts. However, cigarettes of the invention (i.e., Sample Nos. 11-13 which contain levu. linic cid additive) exhibit reduced mainstream by puff bacco rods for Sample Nos. 14, 15, 16 and C-6 are the filler materials described for Sample Nos. 11, 12, 13 and C-5, respectively.

The various cigarettes are smoked under FTC conditions. Dats concerning (i) the nicotine content of esch blend, (ii) FTC "Lar" and FTC nicotine, (iii) the "tar" /nicotine ratio, (iv) puff count, and (v) pH of the mainstream aerosol for each sample, are presented in Table V.

TABLE V

\begin{tabular}{|c|c|c|c|c|c|c|}
\hline Sample & $\begin{array}{l}\text { FTC "Tsr"1 } \\
\text { (mg/cigarelte) }\end{array}$ & $\begin{array}{l}\text { FTC Nicotinel } \\
\text { (me/cigarelle) }\end{array}$ & $\begin{array}{l}\text { "Tar" } / 2 \\
\text { Nicotine }\end{array}$ & $\begin{array}{c}\text { Total }^{3} \\
\text { Nicotine }(\%)\end{array}$ & $\begin{array}{l}\text { Puift } \\
\text { Count }\end{array}$ & $\begin{array}{l}\text { Averages } \\
\text { Smoke pH }\end{array}$ \\
\hline 14 & 9.3 & 0.87 & 10.7 & 2.55 & 7.1 & 6.36 \\
\hline is & 94 & 0.91 & 10.3 & 264 & 7.0 & 5.56 \\
\hline 16 & 11.0 & 1.06 & 10.4 & 2.58 & 7.0 & 5.56 \\
\hline
\end{tabular}


TABLE V-continued

\begin{tabular}{|c|c|c|c|c|c|c|}
\hline Somple & $\begin{array}{c}\text { FTC "Ter }{ }^{-1} \\
\text { (my agarette) }\end{array}$ & $\begin{array}{l}\text { FTC Nicotine }{ }^{1} \\
\text { (mig/cigaretle) }\end{array}$ & $\begin{array}{l}\text { Tur" } \\
\text { Nicotise }\end{array}$ & $\begin{array}{c}\text { Tolal' } \\
\text { Nicotine (\%) }\end{array}$ & $\begin{array}{l}\text { Purt } \\
\text { Count }\end{array}$ & $\begin{array}{l}\text { Avernge }{ }^{3} \\
\text { Smoke } \mathrm{pH}\end{array}$ \\
\hline$C-6^{\circ}$ & 96 & 0.86 & 18.2 & 2.4 & 7.1 & 6.34 \\
\hline
\end{tabular}

10 11. The cigarette of claim 10 wherein the smokable

The data in Table $\mathrm{V}$ indicate that the various cigs. rettes of this invention having high nicotine content cut filler (i.e., more than 2.5 percent total blend nicotine) exhibit FTC "tar" and nicotine deliveries comparable to the control cigarette. The verious cigarettes also exhibit comparable FTC "tar" to nicotine ratios and puff counts. However, cigarettes of the invention (i.e., Sample Nos. 14-16 which contain levulinic acid additive) exhibit reduced average smoke $\mathrm{pH}$ when compared to a control (i.e. Sample No. C.6 which does not have the levulinic acid additive)

Organolepic evaluation of the samples indicates that the cigarettes of the invention are smooth smoking while the control sample is very harsh. the mildness of Sample Nos. 15 and 16 is considered comparable. The 25 cigarettes of the invention yield good tobacco laste, strength and smoking satisfaction. The control sample is very strong, and the overpowering sensation provided thereby is not satisfying.

What is clained is:

1. A cigarette having smokable material contaned in circumscribing outer wrapping material, the cigarette having (i) a nicotine content greater than about 2 per. cent, based on the dry weight of the smokable material, and (ii) levulinic acid in dissociated and/or nondis. sociated form incorporated therein in an amount greater than about 1 percent, based on the dry weight of the smokable material.

2. The cigarette of claim 1 wherein the smokable material is smokable cut filler material.

3. The cigarette of claim 1 wherein essentially all of the levulinic acid is in nondissociated form.

4. The cigarette of claim 1 wherein at least a portion of the levulinic acid is provided to the cigarette in the form of nicotine levulinate.

5. The cigaretle of claim 1, 2,3 or 4 having a ratio of FTC "tar" to FTC nicotine of less than 7.

6. The cigarette of claim 1, 2,3 or 4 having a ratio of FTC "tar" to FTC nicotine within the range of 3 to 6 .

7. The cigarette of claim 1, 2, 3 or 4 wherein the levulinic acid additive is incorporated therein in an amount greater than about 2 percent, based on the dry weight of the smokable material.

8. The cigarette of claim 1, 2, 3 or 4 wherein the levulinic acid additive is incorporated therein in an amount greater than about 3 percent, based on the dry weight of the smokable material.

9. The cigarette of claim 1 or 3 including a filter element, at least portion of the levulinic acid being present within the filter element.

10. A cigarette having smokable material contsined in arcumscribing outer wrapping material, the cigarette baving (i) nicotine content greater than about 2.25 percent, based on the dry weight of the smoksble mate rial, and (ii) levulinic acid in dissociated and/or nondissociated form incorporated therein in an amount greate than about 1 percent, based on the dry weight of the smokable material. material is smokable cui filler material.

12. The cigaretle of claim 10 wherein essentially all of the levulinic acid is in nondissociated form.

13. The cigaretle of claim $\mathbf{1 0}$ wherein at least a pors tion of the levulinic acid is provided to the cigarette in the form of nicotine levulinate.

14. The cigarette of claim 10,11, 12, or 13 having a ratio of FTC "tar" to FTC nicotine of less than 7 .

15. The cigarette of claim $10,11,12$ or 13 having d ratio of FTC "tar" to FTC nicotine within the range of 3 to 6 .

16. The cigarette of claim $10,11,12$ or 13 wherein thic organic acid additive is incorposted therein in an smount greater than about 2 percent, based on the diy weight of the smokable material.

17. The cigarette of claim 10,11, 12 or 13 wherein the organic acid additive is incorporated therein in an amount greater than about 3 percent, based on the dry weight of the smokable material.

30 18. A cigarette of claim 10 or 12 including a filte element, at least a portion of the levulinic acid being present within the fileer element.

19. A cigarette having smokable material contained in a circumseribing outer wrapping material, the cigarette having (i) a nicotine content greater than about 2.5 percent, based on the dry weight of the smokable mate rial, and (ii) levulinic acid in dissociated and/or nondis sociated form incorporated therein in an amount greater than about 1 percent, based on the dry weight of llie 40 smokable material.

20 The cigarette of claim 19 wherein the smokable material is smokable cut filler material.

21. The cigarette of claim 19 wherein essentially all of the levulinic acid is in nondissociated form.

45 22. The cagarette of claim 19 wherein a portion of the levulinic acid is provided to the cigarette in the form of nicotine levulinate.

23. The cigarette of claim 19, 20, 21 or $\mathbf{2 2}$ having a ratio of FTC "tar" to FTC nicotine of less than 7.

24. The cigarette of claim 19, 20, 21 or 22 having a ratio of FTC "tar" to FTC nicotine within the range of 3 to 6 .

25. The cigarette of claim 19, 20, 21 or 22 wherein the organic acid additive is incorporated therein in an amoun' greater than about 2 percent, based on the dry weight of the smokable material.

26. The cigarette of claim 19, 20, 21 or $\mathbf{2 2}$ wherein the organic acid additive is incorporated therein in an amount greater than about 3 percent, based on the dry 60 weight of the smokable material.

27. The cigarette of claim $\mathbf{1 9}$ or $\mathbf{2 1}$ including a filte element, at least a portion of the levulinic acid being piesent within the filter element.

28. A cigarette having smokable material contained in a circumscribing outer wrapping matetial, the cigarette having (i) a nicotine content greater than about 3 percent, based on the dry weight of the smokable material, and (ii) levulinic acid in dissociated and/or nondis- 


\section{3}

$4,836,224$

sociated form incorporated therein in an amount greater than about 1 percent, based on the dry weight of the smoksble material.

29. The cigarette of claim 28 wherein the smokable material is smokable cut filler material.

30. The cigarerte of claim 28 wherein essentially all of the levulinic acid is in nondissociated form.

31. The cigarette of claim 28 wherein a portion of the levulinic acid is provided to the cigarette in the form of nicotine levulinate.

32. The cigarette of claim 28, 29, 30 or 31 having a ratio of FTC "tar" to FTC nicotine of less than 7.
33. The cigarette of claim $28,29,30$ or 31 having a ratio of FTC "tat" to FTC nicotine within the range of 3 to 6 .

34. The cigarette of claim $28,29,30$ or 31 wherein the organic acid additive is incorporated therein in an amount greater than about 2 percent, based on the dry weight of the smokable material.

35. The cigarette of elaim 28, 29, 30 or 31 wherein the organic acid additive is incorporated therein in an 0 amount greater than about 3 percent, based on the dry weight of the smokable material.

36. The cigarette of claim 28 or $\mathbf{3 0}$ including a filter element, at lesst portion of the levulinic acid being present within the filter element. 
Table 2

A Sampler of Alternative Nicotine Delivery Devices

Company Patent comment

$\begin{array}{ll}\text { BAT } & 4,945,929 \\ \text { (1990) } & 4,945,931 \\ \text { Brown \& } & \\ \text { Williamson } & \\ \text { (1990) } & \\ \text { Imperial Group } 4,340,072 \\ \text { Limited (1982) }\end{array}$

Philip Morris 5,144,962 (1992)

Philip Morris $5,240,012$ (1993)

\section{Procter \&}

Gamble (1988)
Aerosol device simulating a smoking article, explicitly designed for dispensing nicotine

Aerosol simulated smoking device, mentions delivery of flavor only; no mention of nicotine

Cigarette-like device with a fuel rod core surrounded by inhalant material. "Among the reasons why most people smoke conventional cigarettes is that they wish to inhale an aerosol containing nicotine." "The aerosol material may, as an alternative to a flavourant solution, comprise a solution of a flavourant and/or nicotine in triacetin or benzyl benzoate. Any psycho-active or physiologically active compound such as ephedrine or a nicotine/ ephedrine mixture may be used... ."

Electrically powered flavordelivery article for the delivery of "tobacco flavor components" to "produce the taste and sensation of smoking without burning tobacco."

Disposable carbon heat source and "tobacco flavor producing element" ejectable after use from a reusable holder. While similar devices are described as producing a "nicotinecontaining aerosol," the word "nicotine" is not used at all in reference to this article.

Dosing device to provide vaporized medicament to the lungs as a fine aerosol. Battery operated heater designed to deliver nicotine or a nicotine salt "to satisfy the smoker's craving for nicotine... ." 
Table 2, Sampler of Novel Devices, continued...

$\begin{array}{lll}\begin{array}{l}\text { RJ Reynolds } \\ \text { (1987) }\end{array} & 4,714,082 & \begin{array}{l}\text { Premier. Multiple other patents } \\ \text { describe various aspects of this } \\ \text { and related devices. }\end{array} \\ \begin{array}{ll}\text { RJ Reynolds } \\ \text { (1990) }\end{array} & \begin{array}{l}\text { Three separate patents for articles } \\ 4,947,874,875\end{array} & \begin{array}{l}\text { using electricity to heat tobacco, } \\ \text { a flavor generating aerosol, or a } \\ \text { drug-delivering aerosol }\end{array}\end{array}$

Comment: The BAT patent is for a device similar to the one patented by Brown \& Williamson, but the US subsidiary of BAT does not use the word "nicotine" at all, while the delivery of nicotine is clearly the whole point of the British device.

The Imperial Group patent makes no pretense, either, about what customers want: "they wish to inhale an aerosol containing nicotine."

Philip Morris avoids talking about nicotine in relation to its inventions.

Procter \& Gamble see the main point of another batteryoperated, cigarette-like device as being the delivery of nicotine to the customer without combustion to satisfy a "craving".

RJ Reynolds' Premier has been discussed elsewhere, in the FDA's docket on the two petitions about Premier from 1988. The Company's battery-powered device can be used like a cigarette, as a flavor dispenser, and as a medication dispenser. 
Table 3

Examples of Cigarette Advertising claiming

Reduced Throat Irritation

\begin{tabular}{|c|c|c|}
\hline Company & Brand & Text \\
\hline American Tobacco & Pall Mall & Guard against throat-scratch \\
\hline Brown \& Williamson & Kool & $\begin{array}{l}\text { Your mouth and throat will } \\
\text { feel soothed, more relaxed, } \\
\text { than with 'hot' cigarettes. }\end{array}$ \\
\hline Liggett \& Myers & Chesterfield & $\begin{array}{l}\text { Nose, Throat and Accessory } \\
\text { Organs not Adversely Affected } \\
\text { by Smoking Chesterfields. }\end{array}$ \\
\hline Lorillard & old Gold & $\begin{array}{l}\text { Lowest in throat-irritating } \\
\text { tars and resins. }\end{array}$ \\
\hline Philip Morris & Philip Morris & $\begin{array}{l}\text { Something wonderful happens } \\
\text { when you change to philip } \\
\text { Morris! Here's why: } \\
\text { 1. You'll feel better } \\
\text { because, in case after case, } \\
\text { coughs due to smoking } \\
\text { disappear... parched throat } \\
\text { clears up... that stale smoked- } \\
\text { out feeling vanishes. }\end{array}$ \\
\hline RJ Reynolds & Came1 & $\begin{array}{l}\text { The "T-Zone" - - Taste and } \\
\text { Throat - the proving ground } \\
\text { for cigarettes. }\end{array}$ \\
\hline & & $\begin{array}{l}\text { Not one single case of throat } \\
\text { irritation due to smoking } \\
\text { Camels. }\end{array}$ \\
\hline
\end{tabular}

Sources: New York Daily News, $9 / 22 / 52$ (Chesterfield ad). All others: Affidavit of Frederick H. Walsh, FTC V Liggett \& Myers, $11 / 19 / 52$. 


\section{6}

Table 4

Examples of Usages of the Term "Satisfaction"

Distinct from References to "Satisfying Taste"

Company (year) Brand Text

Brown \& Williamson Kool (1977)

Lorillard (1977) Kent

RJ Reynolds

(1976)

Now

RJ Reynolds

(1978)

Salem

RJ Reynolds (1980)
Never before has there been a low "tar" menthol like this one. So refreshing. So satisfying. Yet so low in "tar".

Kent Golden Lights. As low as you can go and still get good taste and smoking satisfaction.

Now also gives you real smoking satisfaction.

More and more smokers prefer the mellow flavor, cooling menthol and total satisfaction.

Discover satisfaction. Camel Lights.

Sources: Time, $8 / 8 / 77$; Time, $11 / 7 / 77$; Time, 9/27/76; Time, $7 / 10 / 78 ;$ Time, $2 / 11 / 80$. 


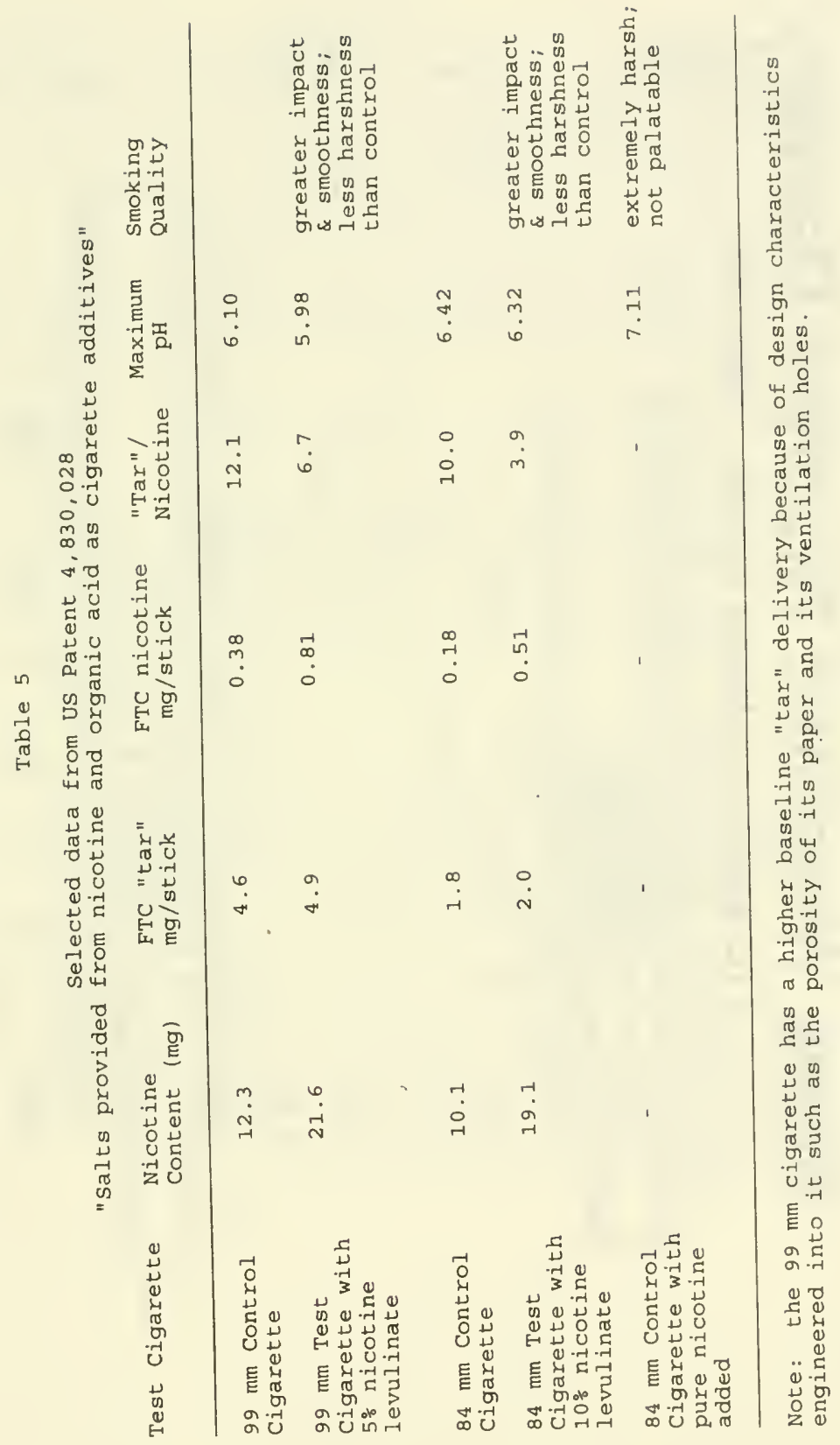




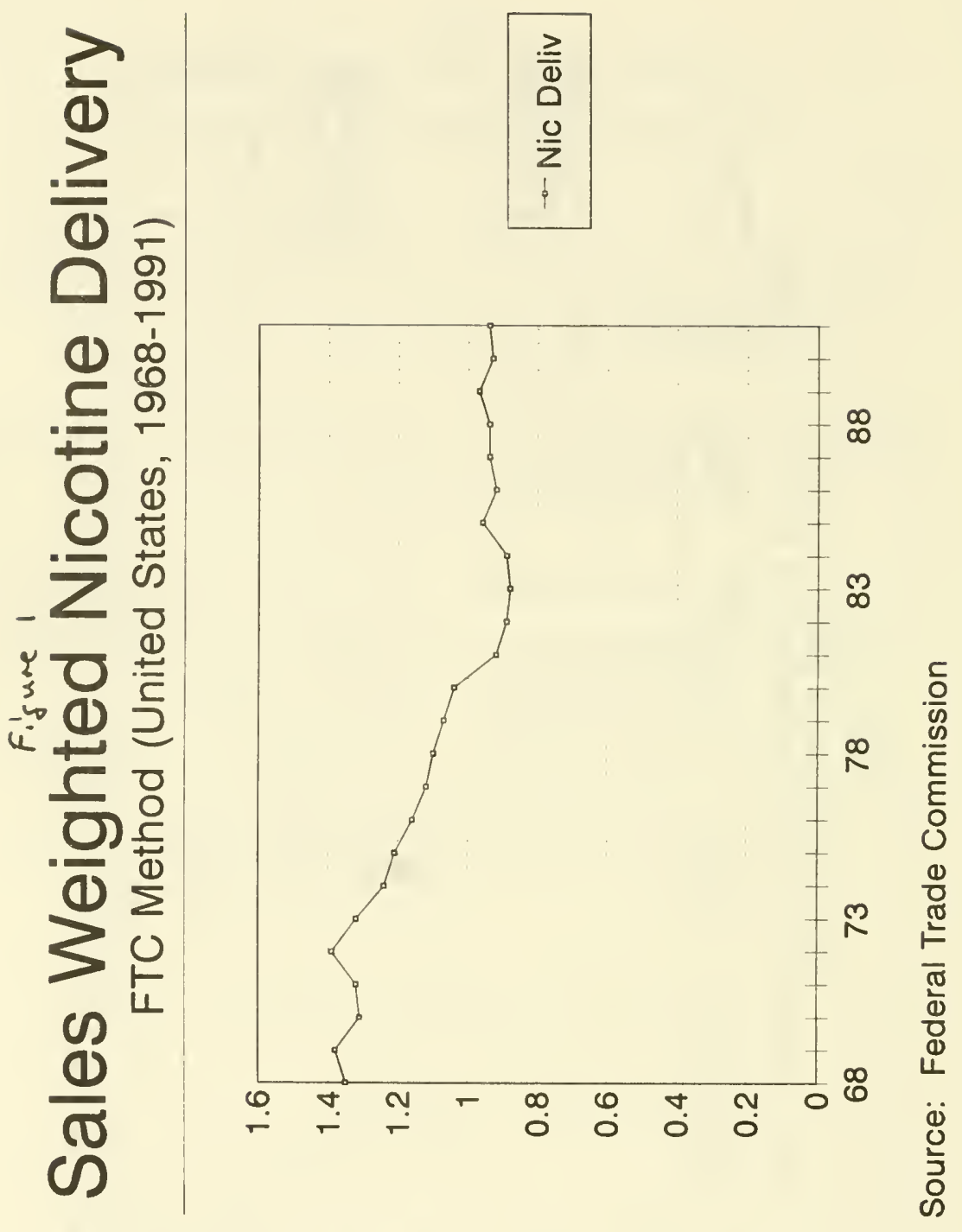


Fisure 2

U.S. Patent

Sep. 8, 1992

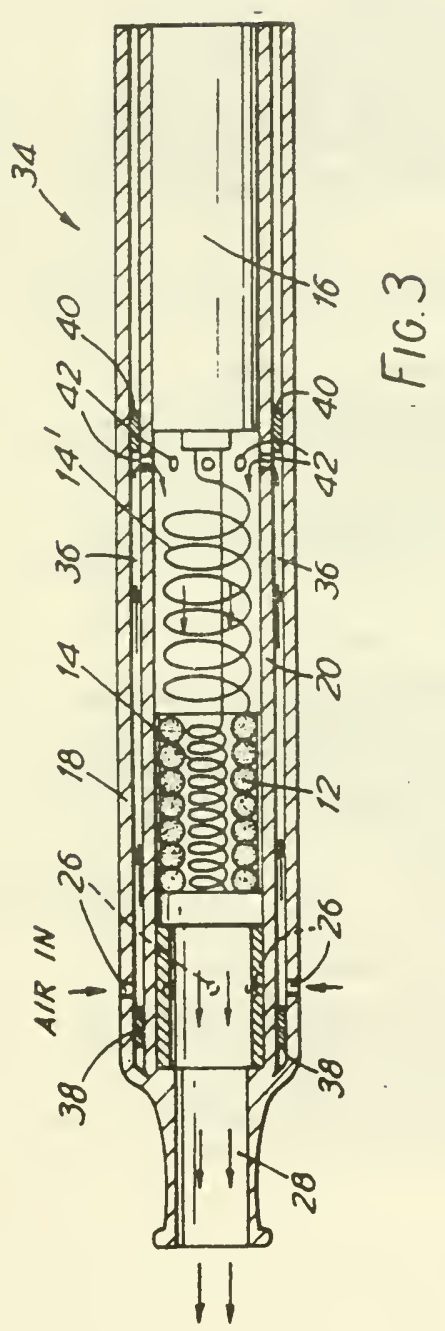

$5,144,962$

Assigned to Phil.p Morni, Inas Flevor - Delivery Article 
Appendix

Some Patents on Nicotine and Tobacco Extract in Cigarettes

The following patents illustrate many of the ways cigarette manufacturers can manipulate and control the nicotine contents and deliveries of their products.

The compilation is illustrative, not exhaustive.

In addition to demonstrating the options for nicotine manipulation available to cigarette design engineers, four of the patents are especially informative in revealing the way the companies regard nicotine. These four are identified by $a$ * and have been included in full with the materials provided to the subcommittee.

Desirable chemical alterations of nicotine

Imperial Tobacco Group, Ltd. Pat. 3,861,400, 1975.

Salts of nicotine are added to tobacco blends to boost nicotine delivery without increasing "tar". The particular salts used are nicotine pectinate and nicotine alginate.

The patent notes, "Nicotine in the smoke is thought to contribute substantially to the satisfaction traditionally associated with smoking and it is undesirable to remove it."

B.A.T. Cigarettenfabriken GmbH. Pat. 4,641,667, 1987.

The patent describes the preparation of the trans isomer of nicotine $\mathbb{N}^{\prime}$-oxide and the use of this material as an additive to tobacco blends, to cigarette paper, and to tobacco prior to a puffing process. Nicotine $\mathbf{N}^{\prime}$-oxide is converted to nicotine during the smoking of a cigarette, and the patent makes clear that this additive is intended to function as a precursor for nicotine.

The patent describes the separation of the trans isomer from the cis isomer of nicotine $N^{\prime}$-oxide, a separation that makes it practical to use this additive since the cis isomer contributes an off taste to the finished product.

The trans-nicotine $\mathrm{N}^{\prime}$-oxide additive boosts the nicotine delivery of cigarettes made with this additive without increasing the "tar" component of the smoke.

The company is a subsidiary of the company that also owns Brown \& Williamson in the U. S. 
* R.J. Reynolds Tobacco Co. Pats. 4,830,028\&4,836,224, 1989.

These two patents describe the addition of the levulinic acid salt of nicotine to tobacco mixtures. The goal is the achievement of enhanced tobacco taste and satisfaction without the smoke being perceived as harsh or irritating. This is accomplished by the addition of a salt of nicotine which boosts the nicotine delivery of the smoke while keeping the $\mathrm{pH}$ low (acidity high). The practical result is the maintenance of a low $\mathrm{pH}$ and the production of a cigarette that delivers the desired dose of nicotine in a form that is not harsh, that is, that can be easily inhaled.

Adding nicotine to cigarette paper

Imperial Tobacco Company (of Great Britain and Ireland), Limited. Pat. 3,422,819, 1969 .

The patent describes the impregnation of a nicotine salt into cigarette paper. Nicotine alone does not work well because of losses during storage. This problem is overcome by using a salt of nicotine, preferably a citric acid salt.

The patent also describes various ways to keep the consumer from taking the treated paper directly into the mouth using either an overwrap or a tipping paper.

* Gallaher Limited. Pat. 4,236,532, 1980.

The patent describes the printing of a series of dots on the inside surface of cigarette paper using a screen printing process. There may be more than one additive in the inks used in the process, and it is clear that the process is designed to boost the delivery of nicotine in mainstream smoke. The pigment of an ordinary ink is replaced in this invention by the additive(s).

The first two claims read as follows:

We claim:

1. A method of producing a wrapper for a smoking rod, the method comprising screen printing onto the surface of the wrapper, a series of discrete dots of an ink containing an additive which will in use, upon approach of the hot burning tip of the smoking rod, be transferred and contribute to the main stream smoke drawn through the rod to enhance the satisfaction to the smoker, wherein the additive is one or more of a 
smoke producing agent, a smoke nucleation agent, a flavouring agent and a physiologically active agent.

2. A method according to claim 1, wherein the additive comprises a stable nicotine salt.

Gallaher has been controlled by American Brands (which also owns the American Tobacco Companyl since 1975.

\section{Adding nicotine to filters}

* Philip Morris Incorporated. Pat. 3,584,630, 1971.

The patent describes the addition of a "nicotine releasing agent" to a filter. The "nicotine releasing agent" is nicotine adsorbed onto carbon black. The idea is to add nicotine to the mainstream smoke without adding to the "tar" fraction. The patent reads in part:

Maintaining the nicotine content at a sufficiently high level to provide the desired physiological activity, taste, and odor which this material imparts to the smoke, without raising the nicotine content to an undesirably high level, can thus be seen to be a significant problem in the tobacco art. The addition of nicotine to tobacco in such a way that it remains inert and stable in the product and yet is released in a controlled amount into the smoke aerosol when the tobacco is pyrolyzed, is a result which is greatly degirable.

The present invention provides a solution to this longstanding problem and results in accurate control of the nicotine which is released in tobacco smoke. By employing the nicotine-releasing agents and methods of the present invention, it is possible to incorporate exact amounts of nicotine in a tobacco composition, which will remain constant over extended periods of time and which will ultimately yield a smoke containing a controlled amount of nicotine.

The present invention may also be used to incorporate flavorants into tobacco smoke.

Nicotine is treated as something quite separate and apart from flavorants, and the patent states that nicotine is needed "to provide the desired physiological activity, taste, and odor." Philip Morris does not presently sell cigarettes with charcoal filters in the U. S., but in Japan, its Lark brand features a charcoal filter. 
Appendix

Page 4

\section{Extraction processes}

Loews Theatres, Inc. Pat. 4,215,706, 1980.

The patent, titled "Nicotine transfer process," describes a process for extraction of soluble material from tobacco and its transfer to another material. The receiving material can be a different grade of tobacco or some other filler material. Nicotine transfer is specifically discussed as part of the process. The patent indicates that both the donor tobacco and the receiving material can be employed in smoking products.

Lorillard is a wholly owned subsidiary of Loews Theatres.

R. J. Reynolds Tobacco Co. Pat. 5,197,494, 1993.

The patent illustrates an extraction process for tobacco. It refers to the previous literature on the subject and discusses the uses of tobacco extracts as additives in multiple stages of the manufacturing process, including use as casing or as top dressing for "tobacco strip," "cut filler," or "other smokable materials." The extracts are also potentially useful as filter additives. Specifically mentioned filter substrates are polypropylene, polyester, and low density polyethylene. The extracts can also be placed inside cigarette pack wrappers to create "a desirable cigarette aroma and 'pack aroma."

Some of the extraction procedures described are specifically designed to increase or decrease the extraction of nicotine. That is, the solvent used in the process determines in large measure the nicotine content of the final extract.

Adding tobacco extracts to tobacco

R. J. Reynolds Tobacco Co. Pat. 4,898,188, 1990.

Describes the addition of an extract of burley tobacco to flue-cured tobacco.

R. J. Reynolds Tobacco Co. Pat. 5,234.008, 1993.

Describes a process for "altering, in a controlled manner, the character of a tobacco material. In particular, the process involves removing and then redistributing certain components of a tobacco material within that tobacco material." The stated purpose of the invention is "to 
provide a process for efficiently and effectively altering the chemical nature or composition of tobacco, and in particular to provide a process for controlling the composition of a tobacco material." The extract can be manipulated with the addition or removal of certain elements before being reintroduced to the tobacco.

The $\mathrm{pH}$ of the extraction solvent is controlled. The use of ammonia, which raises the $\mathrm{pH}$ and increases nicotine extraction, is specifically mentioned.

The patent gives an indication of the degree to which tobacco extracts can be manipulated and fine tuned to control the final composition of a tobacco product.

Adding tobacco extract to "reconstituted tobacco"

Brown \& Williamson Tobacco Corporation. Pat. 3,840,024, 1974.

The patent describes a process for increasing the absorbency of reconstituted tobacco sheet by incorporating bibulous fibers. The resulting product, which is composed of from $5 \%$ to $25 \%$ of these bibulous fibers, is capable of absorbing a larger amount of additive than tobacco sheet made without these fibers. This increased absorbency permits "the impregnation of the base sheet, after drying, with a sufficiently concentrated extract of tobacco."

Adding tobacco extract to filters

American Tobacco Company. Pat. 3,428,049, 1969.

The patent discloses the insertion of breakable hollow capsules into cigarette filters which the customer presses on to release the contents into the filter prior to smoking. The possible contents of capsules include tobacco extract. A medication such as a decongestant is also suggested as a possible additive in this system.

Philip Morris Incorporated. Pat. 4,756,316, 1988.

A method for applying additives to cigarette filter tow is described. Tobacco extract is one of the additives that can be used in this process. 
R. J. Reynolds Tobacco Company. Pat. 4,862,905, 1989.

The patent describes a system for adding pellets to cigarette filters. The pellets may contain or carry on their surfaces a variety of additives including "menthol, cinnamon, citrus, cocoa, licorice, tobacco extract, nicotine, and the like." The object of the invention is to permit the production of "cigarette filter elements having well controlled amounts of flavorant contained therein."

Philip Morris Incorporated. Pat. 5,115,823, 1992.

The patent describes a "flavor-enhancing smoking filter" involving a "flavor-enhancing zone" and a "filtering zone." The former is charged with additives which may include "reconstituted tobacco, tobacco paste, tobacco solubles and ground or particulated tobacco." The term "tobacco solubles" is a synonym for tobacco extract.

Eastman Kodak Company. International Pat. Application WO $92 / 05713,1992$.

The patent application describes cigarette filter fibers with complex geometries making them capable of holding additives. The fibers" designs "result in improved delivery of the tobacco modifying agent to the user." Tobacco extract, nicotine and nicotine salts are listed as possible additives that can be used.

Kimberly-Clark Corporation. Pat. 5,269,329, 1993.

The patent describes a process for adding tobacco extract to cigarette filters. The process can be used to add tobacco extract of from $10 \%$ to $110 \%$ of the filter fiber weight.

\section{Cigarettes incorporating two different smoking mixtures}

R. J. Reynolds Tobacco Company. Pat: 4,759,380, 1988.

Mollins PLC. Pat. 4,793,364, 1988.

Rothmans, Benson \& Hedges Inc. and Rothmans International Services Limited. Pat 4,896,681, 1990.

These three patents describe the concept and some machinery 
capable of producing cigarettes with two different charges of smokable material, with one positioned distally, near the lit end, and the other proximally, near the filter.

In each case, the patent describes using a more expensive, more flavorful blend distally and a relatively bland, filler mixture proximally. This design permits the initial draws on the lit cigarette to be more flavorful while perhaps enabling the later draws, flavored more by smoke material distilled from the richer mixture, to not be overpowering. These designs seem to accomplish two things: they permit the use of less expensive filler for part of the rod and they may provide for a more even delivery of nicotine and other smoke components throughout the smoking of the cigarette. In conventional cigarettes, nicotine delivery increases with each succeeding puff. That would not necessarily be the case with this design, depending on the composition of the two smoking mixtures and how their respective zones overlapped.

An effect similar to that achieved by adding tobacco extract to the filter could be achieved by reversing the strategy described in the patents. These inventions would permit placing a charge of more potent tobacco, such as pure burley, at the proximal position, next to the filter. Smoke drawn through this charge of burley would pick up volatiles, including nicotine, from the burley. If the burley charge were sufficiently short, or if the tipping paper overwrap sufficiently long, it would not be burned.

Lowering "tar" and nicotine delivery by reducing the puff count

\section{R. J. Reynolds Tobacco Company. Pat. 4,776,354, 1988.}

This patent discloses a cigarette design which, by using an unusually long filter, reduces the number of puffs the consumer can take. In doing so, the resulting overall "tar" and nicotine numbers resemble those of a low tar brand, but on a puff by puff basis, the smoke delivery from the cigarette can exactly match the initial puffs from a "full flavor" brand. This design takes advantage of the fact that smoke delivery increases with succeeding puffs. Eliminating the later puffs can reduce overall deliveries substantially.

Denicotinized tobacco

R. J. Reynolds Tobacco Company. Pat. 5,025,812, 1991.

This is one of many patents for the denicotinizing of tobacco. The process described here involves an aqueous extraction of tobacco using an alkaline solvent. The resulting extract is then processed by mixing it with an immiscible liquid in which the nicotine becomes dissolved. The two liquids are then separated. The processed, denicotinized extract can then be returned to the tobacco. Extraction efficiencies of $90 \%$ to $95 \%$ are claimed. 


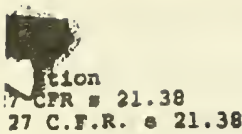

PAGE 8

\section{FOUND DOCUMENT}

Database

CYR

CODE OF ERDERAL REGULATIONS

TITLE 27--ALCOHOL, TOBACCO PRODUCTS AND FIRENRYS

CHAPTSR I--BUREAU OF ALCOROI, TOBACCO AND BIRBARY, DEPARTIEENT OF THE TREASDRY SUBCHNPTER A--LIOUORS

PART 21--FORMULAS FCR DENATURED ALCOKOL AND RUM SUBPART D-SPECINILY DEMATURED SPIRITS PORMULAS AND AUTHORIZED USES

- 21.38 Formula No. 4 .

(a) Pormula. To overy 100 gallons of elcohol, or to every 100 gallons of rum of not less than 150 proof, add:

one gallon of the following solutions Flve gallone of an aqueous solution

containing 40 percent nicotine; 3.6 avolxdupols ounces of methylene blue, U.S.P.; and water sufflcient to make 100 galions.

(b) Authordzed uses. (1) Ae a solvent:

460 . Tobacco apray and flavor.

(2) Micellareou uses:

012. Product development and pllot plant uses (own use only).

PART 21--FORMULAS FOR DBNATURED ALCOHOL AND RUM

Authority: 5 U.S.C. $552($ a): 26 U.S.C. 5242, 7805.

Bources $48 \mathrm{FR}$ 24673, June 2, 1983, 52 FR 5961, Feb. 27, 1987, unles8 otherwlee noted.

27 C. F. R. $=21.38$

$27 \operatorname{crs} \cdot 21.38$

BND OF DOCURENT 
Statement of

Sherwin Gardner, Consultant

before the

House Subcommittee on Health and the Environment March 25, 1994

Members of the Subcommittee, my name is Sherwin Gardner. I am an independent consultant to industry specializing in issues arising from regulation of food and other products by the Food and Drug Administration. My experience includes 13 years as Senior Vice President for Science and Technology with the Grocery Manufacturers of America, and seven years as Deputy Commissioner of the Food and Drug Administration. I am here at the request of Philip Morris U.S.A., which retained me to review its tobacco processing and cigarette manufacturing practices in light of recent allegations regarding manipulation of the nicotine content of cigarettes.

To do this, I visited several Philip Morris manufacturing facilities in the Richmond, Virginia area. I was accompanied by two consultants from the Weinberg Group, an independent technical consulting organization, who are experienced in auditing food and drug manufacturing facilities in the United States. The assistance of these consultants was requested by me, and they served under my supervision. Biographical statements about myself and the two consultants are included in the accompanying report that I am submitting for the record. The information presented to the Subcommittee is based on the observations made and the interviews conducted with Philip Morris personnel during these visits. We sent 
an agenda to Philip Morris outlining our information interests prior to our risits: the personnel we saw during our inspections responded cooperatively in helping to gather the information for this review.

We did not find any basis for concluding that Philip Morris manipulates, or intentionally adds measurably to, the nicotine content of cigarettes through its processing and manufacturing.

Two of the facilities manufacture reconstituted tobacco products known as blended leaf and reconstituted leaf, respectively. These are produced by utilizing tobacco leaf stems and other tobacco leaf particles, which are ground up and made into a thin tobacco sheet. Indeed, the reconstituted tobacco production process is comparable to many food processing operations in which natural agricultural products are separated and recombined.

During the manufacture of these blended and reconstituted tobacco leaf products, certain non-tobacco materials are used for flavoring and as processing aids. None of these materials contain nicotine; the nicotine content of the resulting reconstituted tobacco products is a function of that which naturally occurs, less processing losses. In the blended leaf process $30-40 \%$ of the nicotine is lost: and $20-25 \%$ is lost in the reconstituted leaf process. Flavorings containing tobacco extracts are not used in the manufacture of reconstituted tobacco products for domestic use. These reconstituted products are used as 
part of the tobacco filler in a cigarette, and comprise approximately $25 \%$ of the blend in a cigarette, the actual percentage varying by brand and type.

During our inspections of these facilities. we were able to see manufacturing records of the controls used in producing these reconstituted tobacco products. These were used to track moisture content (a critical factor in the production process), and the use of the identifiable non-tobacco materials. We did not observe any manufacturing controls in reconstituted tobacco production for nicotine content.

Another of the facilities, the Flavor Center prepared the flavor concentrates for application to tobacco just prior to cigarette making. I understand that there are as many as 100 substances that are blended to formulate flavors for different brands and types of cigarettes. We did not see the specific names or specifications for these flavoring substances, but were informed that none contained nlcotine, except for the flavor carrier, which is denatured alcohol. The alcohol is denatured with nicotine sulfate, which is the only denaturing agent approved by BATF for sprays used in the processing of tobacco.(see 27CFR21.38) The amount of nicotine added to a cigarette by this use in spraying flavors on tobacco is calculated to be .0011 milligrams per cigarette, or approximately one part per ten thousand of the nominal 15 milligrams of nicotine in one cigarette. 
This can also be compared with the nicotine variation in one cigarette of plus or minus 1 milligram, caused by random weight variations of the manufacturing process. The amount of nicotine contributed by denatured alcohol to a finished cigarette is not measureable by standard analytical methods.

To further evaluate the significance of flavoring at the final stage of tobacco preparation for cigarettes, we computed the hypothetical addition of nicotine assuming all the added flavor was nicotine. The Philip Morris flavor department advised us that up to 0.201 milligrams of flavoring agent is used per cigarette. This amounts to approximately one and one third per cent (.013) of the 15 milligrams nominal nicotine content of a single cigarette.

Finally, we visited the Cigarette Manufacturing facility, where the two reconstituted tobacco products are blended with the natural tobacco leaf to formulate the filler for cigarettes. Here, the natural (unprocessed) leaf receives non-tobacco flavoring agents, and is blended with the reconstituted tobacco products according to the brand and type of cigarette. The blended tobaccos are cut and in a final step prior to cigarette making. flavored as discussed previously. The final steps in cigarette making comprise filling a continously formed tube of cigarette paper, and adding a filter and band that secures it to the filled tobacco tube. Nicotine is not added to the filter. 
In conclusion, the interviews and inspections of these four Philip Morris manufacturing facilties provided us with the information to find that the nicotine content of cigarettes is not intentionally controlled by the manufacturing processes, nor is nicotine added during the process of preparing reconstituted tobacco nor as part of a flavoring agent. The nicotine content of cigarettes results from the natural content of tobacco leaves and stems, with the exception of an insignificant amount contributed by the denatured alcohol used as a flavor carrier.

The question of FDA's authority to regulate tobacco products is clearly a legal matter. This question has arisen previously, including during my tenure as Deputy Commissioner at the agency. It hinges on a marketer's intent and representation to consumers. The agency and the courts have held that, in the absence of representations that the tobacco product is intended to affect any function of the body, the product does not fall within the statutory definition of a drug 121 USC $\S 321(\mathrm{~g})(1)(\mathrm{C})]$. The definitive court holding on this issue was in the case of Action on Smoking and Health v. Harris in 1980 [655 F. 2d 236. D.C. Cir. 1980j. Considering this and other provisions of the FD\&CAct, nothing I have learned during my service at FDA or since changes my understanding of the Act and its applications in this area. including the recent FDA consideration of cigarette regulation. My recent inspections of the Philip Morris facllities did not disclose any 
facts that would support regulation of cigarettes as drugs under current law.

Certainly the Congress in its wisdom may decide to change the legal standards under which cigarettes are regulated. I have serious reservations, however. about burdening the FDA with the implementation of another major regulatory program. The agency already is responsible for the regulation of about $25 \%$ of the consumer's purchases, and Congress has added important new regulatory responsibilities over the past 15 years without significant additional resources to carry these out. Indeed, when I served on Secretary Sullivan's advisory committee on the FDA only three years ago, agency officials stressed their needs for additional resources to perform effectively. Adding the regulation of cigarettes to the agency's responsibilities will only jeopardize its ability to serve the public through the approval of new drugs, biologicals and devices, and to monitor the safety of the food supply.

I thank you for your attention, and will be pieased to respond to the Subcommittee's questions.

SHER WIN GARDNER is a consultant in regulatory policy and strategy. He was formerly Senior Vice President. Science and Technology at the Grocery Manufacturers of America. Inc. In that role. he "I as responsible for GMA activities with respect to the scientific and technological issues affecting the grocery Industry. Mr. Gardner provided staff support for the GMA Technical Regulatory Affairs Committee. and clirected the GMA international affairs program. Prior to joining the GMA. Mr. Gardner held the position of Deputy Conimissioner of the FDA for over seven years, having been appointed to that position on June I, 1972. As Deputy Commissioner. Mr. Gardner shared with the Commissioner the responsibility for managing agency programs, and served as Acting Commissioner during three evtended periods when the position of Commissioner was vacant. Mr. Gardner has also served as an engineering rescarch and development expert specializing in areas of instrumentation and control. Mr Gardner has authored several papers on food safety and related subjects. He received awvards from the FDA and the Public Health Service for his work, and was honored by FDLI in 1980. Mr Gardner received his Bachelors degree in mechanical engineering. cum laude, from City College of New York and completed his graduate studies in industrial amnagement at Polytechnic Institute. Brooklyn, New York. He is a licensed Professional Engineer in the State of New York and a member of the institute of Food Technologists. 


\section{REPORT OF THE REVIEW OF THE PHILIP MORRIS, U.S.A. MANUFACTURING FACILITIES AS SUBMITTED TO SHERWIN GARDNER}

\section{FACILITIES}

\section{A. Introduction}

Based on prospective observation by the reviewing team, it is evident Philip Morris. U.S.A has developed several processes that utilize all of the parts of the purchased leaf tobacco used in the manufacture of cigarettes. Reconstituted tobaccos, described later, have become significant components, along with leaf tobacco, in the filling of cigarettes. The in-process and finished product testing controlled for flavor levels, texture. and moisture content: the nicotine level of the tobacco is neither monitored nor controlled via additives.

Cigarettes are made by blending various grades and types of both domestic and foreign tobaccos and reconstituted tobacco products of natura! origin. Three types of natural tobaccos are purchased for cigarette production: Bright tobacco, which has been flu-cured; Burley tobacco, tobacco thai has been air-cured; and sun-cured tobacco, or Oriental tobacco. The blends are accented with an assortment of flavors and humectants at several stages of production before the tobaccos are formed into the commercial product, cigarettes.

The raw tobacco leaves chosen for production undergo a procedure which removes the stem and veins from the body of the leaf (ihreshing). Bales of Oriental tobacco are not threshed. but are aged until production. The remaining portion of the leaf (lamina) is stored in round barrels (hogsheads) until direct transfer to the cigarette manufacturing facility after aging. The stems, dust, and small leaf parts (below $1 / 4$ inch) are transferred to facilities responsible for manufacturing the two types of reconstituted tobacco used by Philip Morris, U.S.A., blended leaf and reconstituted leaf tobacco. The products from each of these facilities are blended with leaf tobacco for the production of cigarettes.

Flavoring is a key element of the cigarette process. Philip Morris, U.S.A. adds numerous flavors during the reconstituted leaf process, blended leaf process, and final blending process. Many of the flavors are mixed at the facility of use, while other formulations are blended by the Philip Morris Flavor Center. Flavors are added as aqueous mixtures during the manufacture of the blended leaf and reconstituted leaf tobaccos, during the preparation of the leaf tobaccos, or "casing" process, and in a denatured alcohol spray on the final blend.

As shown in a flow diagram on the following page, all of these procedures are key elements of the final manufacture of cigarettes. Threshing, which is performed by a contractor, was not reviewed or inspected. Threshing is a purely physical process in which no additives are used. The findings during the review of the facilities responsible for blended leaf, reconstituted leaf, flavoring, and cigarette manufacturing are discussed further. 
DIAGRAM 1

MANUFACTURING FLOW OF TOBACCO

COMPONENTS

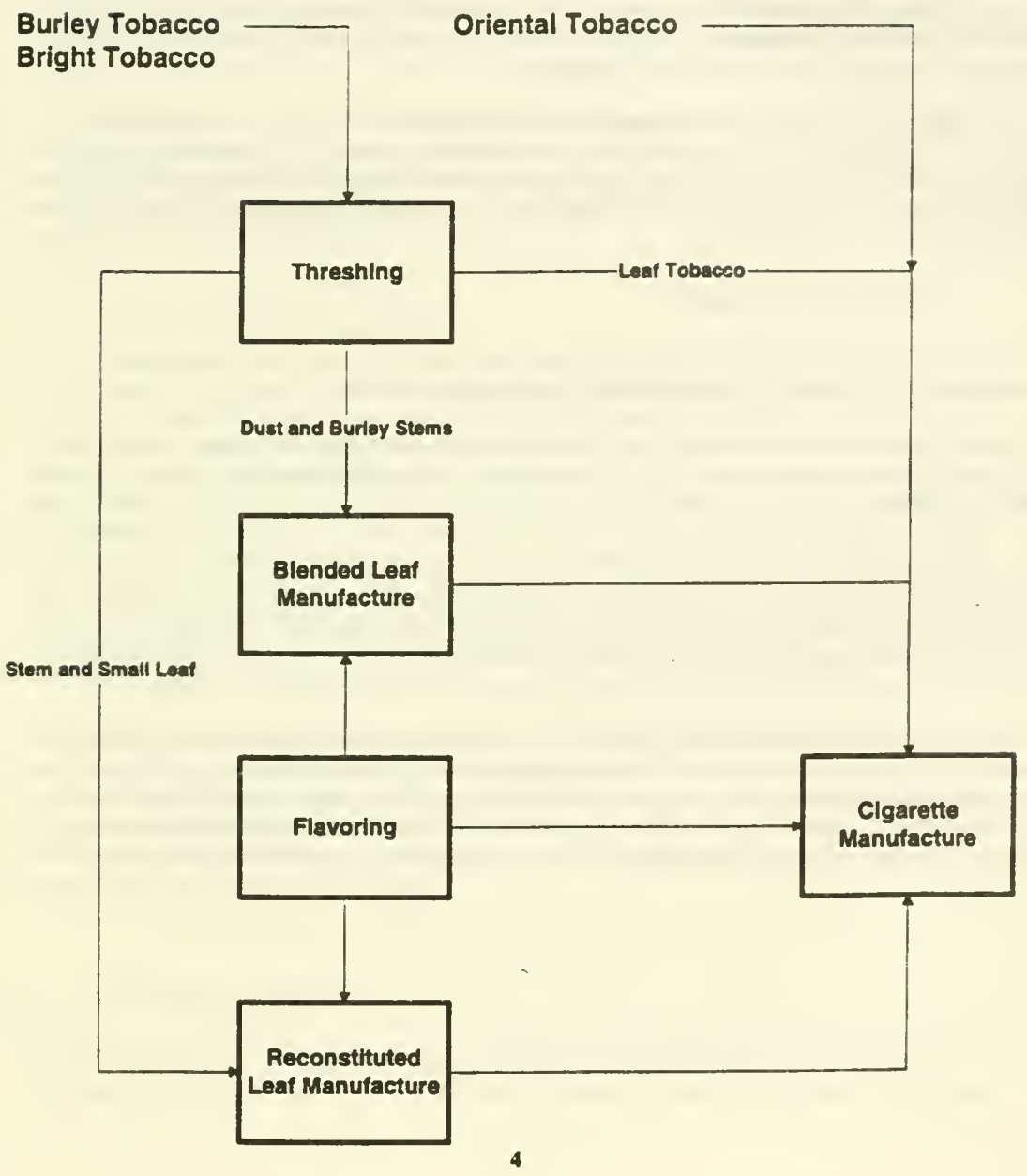




\section{B. Blended Leaf Facility}

Stems, dust, and leaf parts of less than 1/16 inch primarily from Burley tobacco, are used in this process. The two components are first treated separately, the stems being ground and the dusts being wetted and screened. The crushed stems and dust paste are then combined with flavors in de-ionized water. The mixture is aged and then fed onto a stainless-steel sheet conveyor belt. The paste solution is cast onto a conveyor belt that passes through dryers which dry the paste into a sheet. The sheet is cut into 4 -inch chevrons and packed in large wooden containers for use in cigarette production.

The facility does not control for nicotine levels in the incoming raw material or the finished product. The primary in-process production control is the moisture level. The facility does not account for nicotine levels in the incoming raw material or the finished product.

Approximately 40 percent of the nicotine contained in the tobacco entering the process is lost and not returned or replaced.

\section{Reconstituted Leaf Facility}

Reconstituted leaf is manufactured from the stems and small leaf parts from threshing and processed in an separation and recombination paper-making process.

The stems and small leaf parts are first crushed and mixed in a large solution tank. The mixture of fiber is pressed and divided into two parts: the semi-solid cellulose fibers and tobacco solubles.

The cellulose fibers are transferred to a wire screen where water is removed, the remaining fibers form a tobacco sheet, and the sheet is partially dried. Potassium nitrate is removed from the liquor containing tobacco solubles. The tobacco solubles are flavored with ingredients, and recombined with the tobacco sheet. The tobacco sheet is then dried, cut into chevrons, and packed in wooden hogsheads for storage until used in cigarette production.

There are process controls for the quality of the product; in-process and final process samples are tested for water soluble content. Equipment settings are adjusted to ensure target soluble content is achieved in the final product. The raw materials, liquor, and finished product are not controlled for nicotine levels. There is a 20 to 25 percent loss of nicotine contained in the tobacco entering the process and the lost nicotine is not replaced or returned to the tobacco. 


\section{Flavor Center}

The Philip Morris Flavor Center produces over 100 flavors for use in cigarette manufacturing. All raw materials received and flavors produced in the Flavor Center are tracked by a comprehensive quality assurance system which includes a computerized management system. The facility mixes the solutions during the day, and performs full analytical testing in the evening. Laboratories, equipment, and a sample of records were reviewed. Personnel at the Flavor Center indicated that 95 to 98 percent of all of the flavor ingredients used are foodgrade.

None of the materials used in the production of the flavorings contains nicotine except denatured alcohol and the flavor packages containing tobacco extract. Flavor packages containing tobacco extract have not been used in domestic product since 1993. Prior to 1993. flavor packages containing tobacco extract contributed negligible quantities of nicotine to the total nicotine content per cigarette.

\section{E. Cigarette Manufacturing Center}

The components produced in the Blended Leaf Facility, Reconstituted Leaf Facility, Flavor Center, and Threshing Facility come together in the Cigarette Manufacturing Center. Before the Burley leaf tobacco is mixed with the other tobacco components, it is sprayed with a mixture of flavors and humectants. The treated Burley is then blended with a mixture of cased Oriental and Bright leaf tobacco. To this blend is added the reconstituted leaf tobacco and blended leaf tobacco. This blend of tobaccos is cut, dried, and mixed with tobacco that has been expanded. Bright lamina and stem are expanded after impregnation. Improved and Expanded stem are also added. This expanded tobacco is added to the mixture to increase the bulk. The complete blend is sprayed with an alcohol mist containing final flavors. The tobacco is dried to a final moisture specification, formed into cigarettes, and packaged for retail sale.

There is no indication that nicotine is added in any of these processes. The denatured alcohol used in the final spray is the only ingredient currently used with a measurable nicotine content. The alcohol is denatured with nicotine sulfate as required by the Bureau of Alcohol, Tobacco, and Firearms (BATF). There is no analysis for nicotine in the various tobaccos used in production. Nicotine and tar yields are tested in the smoke of cigarettes pursuant to Federal Trade Commission regulations.

\section{NICOTINE CONTENT}

The nicotine content of tobacco varies and is affected by several environmental factors including rain fall, growing location, and length of growing season. Also, there is significant 
variability among the three types of tobacco. In 1993, Burley tobacco contained approximately 3.4 percent nicotine, Bright contained 2.9 percent, and Oriental contained 1.3 percent nicotine. The nicotine content of tobacco is tracked through recording yearly nicotine trends of the various tobacco types. Also, nicotine is lost during manufacture due to nicotine's volatility and water solubility. During the over-all process, approximately 25 percent of the nicotine content contained in the raw tobacco is lost.

The typical cigarette contains 750 to $760 \mathrm{mg}$ of tobacco. The average concentration of nicotine per cigarette is $15 \mathrm{mg}$. There were two potential sources of added nicotine in the manufacture of cigarettes, flavorings containing tobacco extract and alcohol denatured with nicotine sulfate. Philip Morris stopped using flavors containing tobacco extract in domestic product in 1993. When flavors containing tobacco extract were used, Merit Ultra Lights Menthol was the Philip Morris product which had the highest combined use of flavors containing tobacco extract and nicotine sulfate denatured alcohol. The total contribution of nicotine from the flavor containing tobacco extract and the denatured alcohol was calculated as $0.00544 \mathrm{mg}$ per cigarette. This amiount falls below standard analytical detection limits and represents less than 0.04 percent of the total nicotine in a single cigarette.

\section{FINDINGS}

Based on the procedures and processes observed in the four different facilities, there is no basis for the claim that Philip Morris controls or manipulates the levels of nicotine in the processing of its tobacco for cigarettes.

Processing of blended leaf and reconstituted leaf tobaccos were developed to utilize all of the purchased leaf tobacco, much like any other agriculture-based industry. These processes do not increase the amount of nicotine in the resultant tobaccos, rather they reduce it with no processes to re-introduce or replace the lost nicotine. The frequent addition and removal of water lowers the concentration of a water-soluble compound such as nicotine. Utilizing components such as stems in cigarette manufacturing also lowers the nicotine level because these elements have much lower concentrations of nicotine than leaf.

The addition of flavors to tobacco does not contribute measurable nicotine to the tobacco. The only exceptions in this case are for the addition of flavors containing tobacco extract and the nicotine contained in the alcohol used as a vehicle for the flavors. Tobacco extract has not been used by Philip Morris in cigarettes sold domestically since 1993 and is presently not used in foreign exports. When flavors containing tobacco extract were used, the additional nicotine content per cigarette was not detectable by standard analytical methods. 
STATEMENT OF GREGORY N. CONNOLLY

$-1-$

My name is Dr. Gregory Connolly and 1 am pleased to testify before the Subcommittee on Health and the Environment on behalf of the American Public Health Association in support of the Federal Food and Drug Administration's regulation of tobacco products as drugs. I will focus my remarks on regulation of moist oral snuff as a drug. I am the director of the Massachusetts Tobacco Control Program which is a $\$ 52$ million state agency charged with curbing tobacco use in Massachusetts. I have conducted research on the health effects of oral tobacco and have published a number of articles in the scientific literaturc on this topic. I am chairman of the World Health Organization's Study Group un Smokeless Tobacco and a consultant to Major League Baseball. In that capacity I have researched dependence anong baseball players on oral snuff and developed a cessation program for those who are interested in quitting.

\section{Summary of Testimony}

1) Nicotine is an addictive druy and the larger manufacturer of muist oral snuff, U.S. Tobacco Company (UST) which has $88 \%$ of U.S. sales has conducted research on the phamnacological properties of nicotine and has knowledge of its dependence producing properties.

2) The manufacturer has used this knowledge to develop low nicotine starter snuff brands with the intent having new users experiment with the products and gradually develop dependence.

3) The manufacturer employs a "graduation" strategy with the intent of moving new users from the low nicotine brands up to higher nicotine brands as dependence occurs. The manufacturer intentionally adjusts the ricotine dose in each brand to cause and maintain dependence.

4) The manufacturing strategy has contributed an 83 percent increase in sales of moist oral snuff from 1981 to 1991 and a 20 fold increase in use among males $18-19$ from 1976 to $1991(.3$ to $7.6 \%)$.

5) Based on the manufacturer's knowledge of nicotine and intent to causc and satisfy dependence among consumers, noist oral snuff should be classified as a drug under the Federal Food, Drug and Cosmetic Act. 


\section{Description of Smokeless Tobacco Products}

There arc two forms of smokeless tobacco; oral snuff and chewing tobacco. Snuff is a finely gruund tobacco that is held in the mouth next to the cheek and grm. Chewing tobacen is cut-leaf tobacco that is chewed. Oral snuff is called "dip" and is sold under brand names as Skoal, Copcrhagen, and Hawken in $1.2 \mathrm{oz}$ tins. Chewing tubacco is called "chew" and common brands include Red Man and Levi Garrett that come generally in 3 oz pouches.

II. Use of Smokeless Tobacco Products Cause Cancer and Other Life Threatening Diseases

Oral snuff, the most popular form of smokeless tobacco, causes mouth cancer, gum recession, and other oral health problems. A North Carulina study found that longterm users of oral snuff were 50 times more likely to devclop mouth cancer than nonusers. Mouth cancer is a dcvastating disease resulting in the loss of portions of the face and jaw. More than 40 percent of patients are dead within five years of diagnosis. Cancer-causing chemicals contained in oral tobacco include polonium 210 (a radioactive particle), benzopyrene, and nitrosamines. Nitrosamines are potent carcinogens and are found in ural tubacco at levels 20,000 times greater than ailowed in food and beverages. Cancers are often preceded by oral leukoplakia, white patches caused by the irritation of the tobacco. Approximately 3 to 6 percent of oral leukoplakia exhibit precancerous cell changes. Use of oral snuff also causes breakdown of the gum tissuc next to where the tobacco is held, a condition called gingival recession. Treatment of this problem can be painful and expensive.

III. Use of Oral Snuff Can Cause Dependence and Nicotine's the Active Chemical In Oral Snuff that Produces the Dependence

There have been a number of reviews of the literature on the addictiveness of oral snuff. The U.S. Surgeon General and World Health Organization have concluded that smokeless tobacco can cause addiction. Thesc reviews show that oral snuff delivers nicotine to users at levels equal to that for cigarette smoking (see appendix $A$ ), and that users demonstrate the same addictive behaviors as cigarette smokers. 
$-3-$

"There is ample cvidence that the blood nicotine levels of smokeless tobacco users were as high as or even higher than those found in many cigarette smokers. Its continued use therefore, does cause addiction and dependence in humans."

World Health Organization Smukeless Tobacen Control. Repor uf a WHO Swdy Group, World Health Organizatiun Technical Report Series 777.

Geneva 1988

" Since nicotine levels in the body resulting from smokeless tobacco use are similar in maynitude to nicotine levels from cigarette smoking it is concluded that smokeless tobacco can be addictive."

U.S. Department of Health and Human Services, The Health Consequences of Using Smokeless Tobseco, $\wedge$ Report of the Advisory Committee to the Surgeun General, U.S. Department of Health and Human Services. Public llealth Servicc, NTH Publication No.86-2874, April 1986C.

IV. Oral Snuff Manufacturers Have Conducted Research un the Pharmacological Effects of Nicotine on Humans and Have Knowledge That Nicotine Can Produce Dependence

Evidence submitted in the Marsee vs. U.S. Tobacco Company (UST) Court Case show that UST conducted extensive research on the bioavailability and pharmacokinetics of nicotine delivered from cigarettes and oral snufl among naive and habitual tobaccu users. The study entitled "Pharmacokinctics of Nicotine in Major Metabolites in Naive and Habitual Snuff Takers" measured nicotine bioavailability from snuff and compared it to that from cigarettes. The summary of that study is appended (see appendix B). There is only one reason that this type of research would be conducted and that is to understand how the drug nicotine delivered from ora! snuff effects the structure and function of the human user as compared to cigarette smokers and in tum assist UST in creating and maintaining dependence on their products among consumers.

Other evidence submilled to the Court included a statement of Mr. P.E. Lindquist. UST Sr. Vice President, from document (No. 1027818-24) read by Plaintiff's attorney George Braly.

" Taste and strength (nicotine) should be medium, recognizing the fact that routinely all tobacco usage is based upon the nicotinc ("the kick') satisfaction"

Marsee vs. UST. Vol. 4, p\& 113

P.E.Lindquist, Sr.V P.. U.S.Tobacco June 5, 1981

Cour Document No. 1027818-24

Statemeat by Mr. Braly 
In another statement read into the court case, a UST scientist Dr. Bennell recommended,

" Develop new products. For example, artificial snuff, a consumable confectioncry which would satisfy the snuff user."

V. Oral Snuff Manufacturers Show Intent to Cause Nicotine Dependence Among Consumers through a Strategy that First Involves Promoting Use of Lower Nicotine Brands with the Intent of Muvinu Users Up to Higher, More Addictive Brands Over Time

Other court exhibits submitted in the Marsee vs. UST Case. describe the use of low nicotine starter products and a graduation strategy. These strategies are described on the "Lutus Project"and the documents arc appended (see appendix C).

The Lonus Project called for a development of a new product that later was markeled as the SKOAL Bandit. The SKOAL Bandit was introduced in 1983 and is still sold today. The target group for the new brand was described as "new users, mainly cigarettes smokers, age, 15 35"; product strength was described as "nicotine salisfaction." A second nemo on the T.ntus Project called for three different brands with high, medium and low nicotine content. The graduation process was read inlu evidence by Attorney George Braly. According to the Cour Transcript:

"Graduation theory. New users of smokeless tobacco..atributed to the catcgory for a varicty of rcasons...are most likely to begin with products that are milder tasting, more flavored and/or easier to control in the muuth. After a period of timc, there is a natural progression to products switching to brands that are more full-hodied less flavored, has more concentrated tobacco taste that the entry brand."

Statement of Mr. Braly, Vol.4.pg.112. May 21. 1986

Documeut No. 247-3950

The graduation strategy was further described in court Exhibit No.100 in the case (see appendix D). The chart shows that the graduation process was dependent un varying nicutinc content and began with use of the lowest aicotine brand, SKOAL Bandits, then Happy Days, Sknal Long Cut, and finally, Copenhagen. Evidence demonstrating this process comes alsu from published industry documents. According to Mr. Jack Africk, Executive Vice President, U.S. Tobacco, 
-5 -

"As far as strategy for entering a new market is concerned - for each market thcre is a set of criterid, which have been established and must be met. SKOAL Bandits is the intrnductory product; and then we look rowards establishing a normal graduation process. The bottom line is that Bandits is a vehicle that is going to expand the use of smokeless tobacco."

(Up to Snuff-Autumn 1984.pg 2 UST, Greenwich, CT)

Independent analysis of nicotine levels of these brands show graduated levels of aicotine.

Table I - Nicotine Dose per Unit of Selected Moist and Snuff Brands

\begin{tabular}{llcccc} 
Brand & $\begin{array}{c}\text { Sumples } \\
\text { Tested }\end{array}$ & $\begin{array}{c}\text { Average } \\
\text { Nicotine } \\
\text { Mg/erams }\end{array}$ & $\begin{array}{c}\text { (1) } \\
\text { Dose of Tobaceo } \\
\text { grams }\end{array}$ & $\begin{array}{c}\text { Nicotine/Unit } \\
\text { Dose (mg) }\end{array}$ & $\begin{array}{c}\text { Nicotine/Dose/ } \\
\text { Tin }\end{array}$ \\
\hline SKOAL Bandits & 1 & 16.9 & .5 & 8.5 & $17 \mathrm{mg} / \mathrm{tin}$ \\
Skoal & 3 & 21.3 & 1.2 & 25.9 & $68.2 / \mathrm{tin}$ \\
Copenhagen & 2 & 28.4 & 1.2 & 34.1 & $81.0 / \mathrm{in}$
\end{tabular}

(1) Dose $=$ Bandits Sachet $\$ 16$ grams tobacico

SKOAL /Copenhagen(pineh) 1.2 grams tobacio

Source: American Health Foundation: Vathalla, NY, 1994 
VI. Advertising and Promntional Practices Demonstrate Manufacturer Intent to Have Consumers Experiment with Low Nicotine Brands and Graduate to Higher Nicotine Brands Over Time

According to National Leading Advertisers (NLA), advertising expenditurcs for the low nicotine brands far outweigh those for the higher nicotine brands. In 1983, total US lobacco advertising dollars for SKOAL Bandits was $47 \%$ while the brand made up only $2 \%$ of ruarkct share by weight. Copenhagen, the highest nicotine brand, had only $1 \%$ of advertisement expenditures bur $50 \%$ of market sbare. UST spent $\$ 5.8$ million in 1990-91 for print advertising for Skoal or SKOAL Bandits. No advertising was reported for Copenhagen.

A secund source of evidence that shows intent is the advertising messages. The content is exemplified by two ads (see appendix E). The first is a Skoal Brands thill uses terms such as "Introducing" "Easy to Use". Coupons for a frec sample generally accompany these advertisements and US Tubacco reported 400,000 solicitations through magazines in the last six months of 1984. Free sampling is routinely done for SKOAL Bandits and Skoal but not for Copenhagen. In the 1980's, UST operated a "College Marketing Program". According to College Marketing Manual,

"Your first and foremost responsibility is consumer sampling. All activities on and off campus will focus on sampling."

A brochure for SKOAL Bandit offers new users instructions how to use the product. According to the brochure:
How long should I keep the pouch in my mouth?
If you haven't tried SKOAL Bandit before, we recommend that you keep your
first one in for about a minute - then remove. The next time you try
another one, leave it in a bit longer. Like your first beer, SKOAL Bandit
can be a taste that takes time to acquire and get the most out of. After four
or five Skoal Bandits you'll find you've developed quite a taste for them and you'll want to keep a pouch in as long as the flavor lasts-this varies from person to person.

In contrast to advertisement for the introductory product, the sccond ad for Copenhagen use one simple message, "Sooner or Later It's Copenhagen". 
$-7$.

VII. The Use of Low Nicotine Brands Alnng with Gruduation Strategy Has Resulted in a Sharp Increase of Oral Snuff Sales and Widespread Nicotine Dependence Among Young Males

From 1981 to 1991 UST sales of moist oral snuff rose $50 \%$ from 27.3 million pounds to 41 million pounds. Interestingly, there was no increase in sales for starter producls such as Happy Days and SKOAL Bandits but a $83 \%$ increase for the highest nicotine brand, Copenhagen, 12 million to 22 million pounds. The fajlure in sales growth of the low nicotinc brands demonstrate that the brands serve as iransition products to the higher nicotine brands.

From 1970 to 1991 , the prevalence of use of snuff by men age $18+$ rose from $1.4 \%$ to $3.1 \%$ and among males $18-19$ from $.3 \%$ in 1970 to $7.6 \%$ making that age group the heaviest users of the product. The 1990 Youth Risk Behavior Survey found that 24 percent of all white male high school students use smokeless tohacco at least once during the past month. A 1989 National Collegiate Athletic Association (NCAA) survey of college athletes found a 40 percent increase (from 20 percent to 28 percent) in the use of smokeless tobacco from 1985 to 1989. Among NC.AA baseball players an allarming 57 percent use.

\section{CONCLUSION}

Based on the information supplied abnve oral snuff should be declared a drug under federal law

Commissioner Kessler of the FDA has stated that if tobacco products are declared drugs, then Congressional action may be necded to prevent prohibition of tohacco products. If Congress does intervene we strongly recommend that the marketing of cigarettes be restricted to standards that currently apply to other drugs including no direct advertising or promotions to consumers, full disclosure of all additives and full disclosure of all bealth risks and generic packaging. Also, new products such as SKOAL Bandits be treated in the same manner as any other drug and be prohibilcd from sale if deemed harmful to human health. 
Figure 1

Nicotine absorption pates frum tubacco smoke and smokeless tubacen

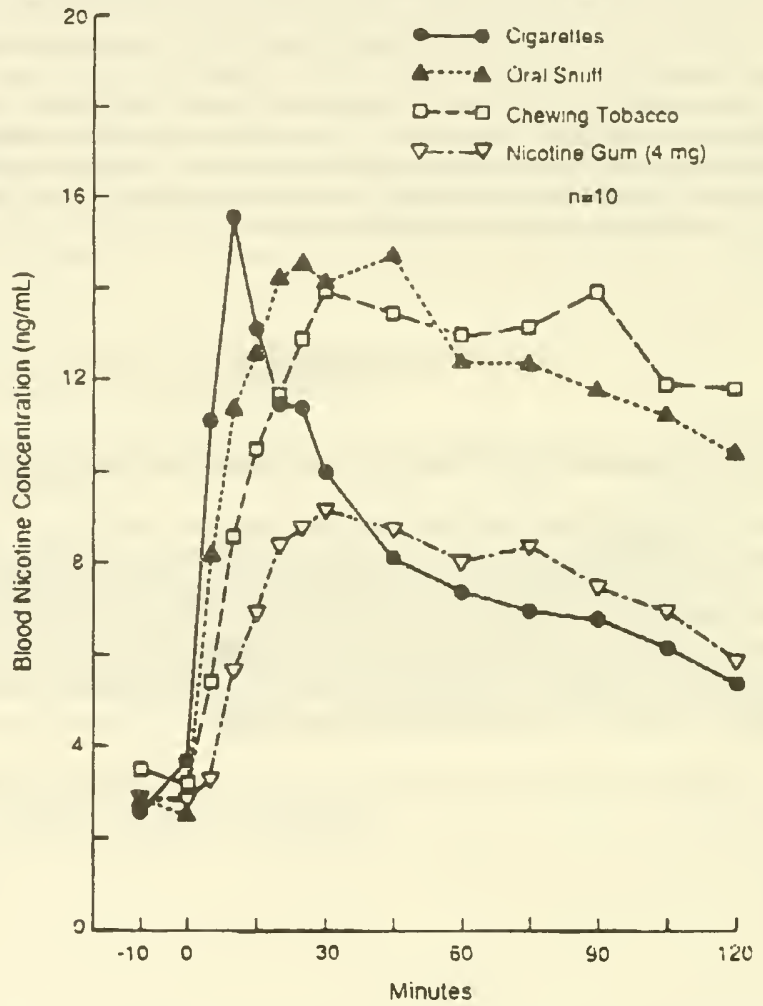

Averago blood nicotino levels in 10 men who smoked inr 9 min ! 1.3 cigaretres', flazcs $2.5 \mathrm{~g}$ molst oral snutf in the mouth for $30 \mathrm{~min}$, shewed an average of $7.9 \mathrm{~g}$ !rance ot $0.9 \mathrm{~s}$ $1017 \mathrm{8} \mathrm{g}$ ) chewing tobacco for $30 \mathrm{mio}$, and cheved $4 \mathrm{mg}$ nicoline gum (iwo $2 \cdot \mathrm{mg}$ pieccs of Nicorene) for $30 \mathrm{~min}$. Studias were pertormed in the Torn!ng atter oversight Jbstinence from tovacco.

\section{Source. Adypted from Benowiz el al. 1988}

ivitin regular daly sigareite smoking. bloul of plasma levels of masotin: sampled in the aftcrnoum when those levels are at or reat steady state generally range from 10 to 50 ngimL. In a resedrch ward study of eight 
APPENDIX B

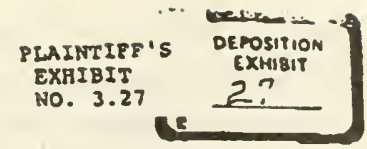

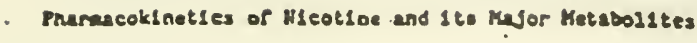

\section{Malve and Rabstured Snusf Fakers}

\section{In: avpunosun}

The polynuelear aroeatsc ordrocarbon (PAK) Sraction or lobscto anoke 1e sonerated fron pyrolysia of adiphate parafelns In tobacto deef (Stcdean,

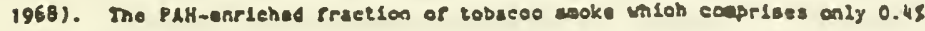
of ste orude condensete velgbt (Azin et a1.. 1976) io Lovolved in codseting

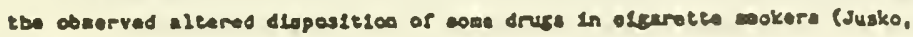
1978).

Consubers of cokeless tobacoco - anufs cakero end tobacoo obevers - eppar to a usenl population for atudying alcoths pharacokiseties, ropresenting - sood experimental codel for delineatiag the erfocts of ohronic ndeotlne ingestion uthout being exposed to the signirseant Induetive atsuls of the pels eret are'produced fros anoked tobaceo.

Caede (1941), atudying alootine absorpt10s trow chewles tobsoso, obatred less raple oleotloe absorptloo after cheulng the after soking usth inhelatson. Loles and Giles (1950) quatitatively estlated the asounte of alcotine absorbed frope eheirine tobacco and observed that peak plasal nlootso coneentratlons echloved after tobaooo theulne were sightly lege than those echlevod after woklins oomparable amounts or oleotlne. Jexple (1976) provided evldence tbet nleotine 13 sbsorbed frod tobecco snurf through the nasal wucous wetbrane and that the urinary elialnatlon of nleotine and gls fajor wetabolites was olaldar to that following absorption of nicotine froo tabacco omoke.

14 yet, no report or en extensive pharacokinotse-aetabolse Investigation, lnvolving serlal saplins of both blood and uplne after use of enokeless tobseco, has appeared. Therefore, we undertiok to Investleate the disposition prorsle or ndeotine, cotinine ind nseotine-1--M-oxide in both plased and urlne of nalve and mabltuated users of tobaceo snurf after a siandaraized "asp" of snutr. Comparatsve Investagations arter tobacco cheuling and eigarelle . $i: \ldots . . . . .$.

..

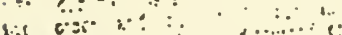

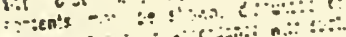
Qis:-a:s: $-2-$ USTEOSO00:305 order:" 


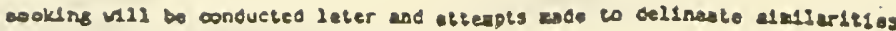
and astrerenove in nlootine pharaseldaetles orer soute and ohronle use of woked and soleless robecos produets.

\section{YATERIMS MP HOTHODS}

\section{Besrenta}

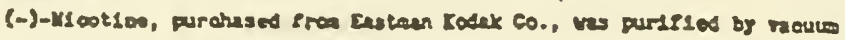

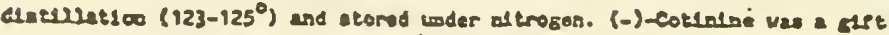

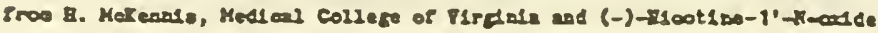

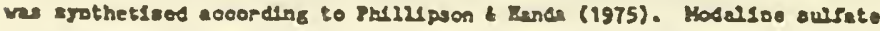

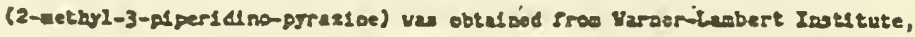

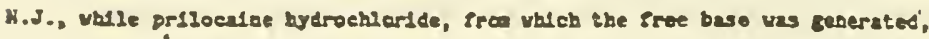

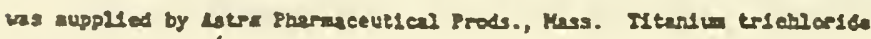

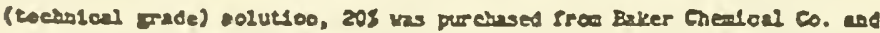
duvted to 0.28 by coblning 1.5 parts of 14 web 1 pert coseatrated BCI and 7.5 parts aet121ed vater. Other reagents and solveats used and ebel $r$ sources are 12eted belou:

Fther, abolute reageat - Hebesoa, Colean \& Bell, Narrood, Ohso Hethylene chlor14e, spectranalyzed - F13ber Selent1ric Co., Fas Lavn, K.J. Butyl acetate. Photrex reagent - Bgker Chee. Co., Phll21psburg. M.J. Acetone, glas alstilled - burd1ck \& Jíkson Lo Ine., Muskegon, hI Sodsu hydrodde, IOH - Flaher Seleolifle Co., Fal Laun, H.J.

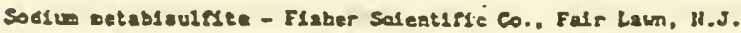
Hydrochlorle neld, concentrated (12.2N); - aker Chemial Co.. Ph1121psourg. N, Subjects_and Sageles

S1x nelve and alx mbltunted male tobacco snuts takers took part in

the siudy. The habluted subjects consubed lobaceo snuff on a regular basis, "CONFIDEINTIAL"

"This dosumen! is sabiect 10 protec. tive orecl snd neilaet it nor its contents may te shoxn. discussed of disclosed escept in accordance with euch ordef." 


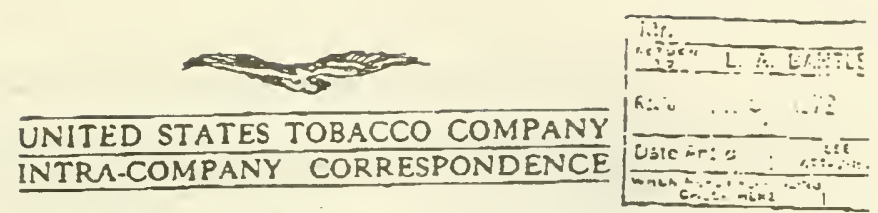

ro: FaOM:

Mr. L. A. Bantle, President

W. W. Wacson, President - United Scandia Incematonal

June 2, 1972

\section{LOTUS}

The moist snuff user and manufacturer has, for a long period of cime, deslred and scarched for a method of placing moist snuff into a single unit or portion for convenience of use.

Market research and our consumer suggestion file shows strong support for such a packaging concept.

To sailsfy this consumer want there are several forms molst could lakr, such as - capsule, lablet, candy coated chiclet, or tea bag concept (Lows). All of these concepes should be explored. However, as of today, much work has gone into the Loous project.

1. A prototype machine is avallable with initial success.

2. Market resis (Sweden) of the packaging idea show strong acceptance from the consumer.

3. Lotus satisfies all but one of the product needs (product laste) and there is a strong betkef that with hand work on the part of STA and UST a . satisfactory produet will be produced.

Therefore, for the immediate Nurune, we must concentrate all cfforts on Lotus.

There are and will be many problems to be solved before Lotus can be marketed. How important is it that UST and STA be finst in the market with an occeptable oroduct? if not first, should we not ot leasi be second. My personal vote is to be first with the best damn product possible and sopn.

\section{"CONFIDENTIAL"}

"This coctinent is s:" jiect to a protec. tre $6:-21$ ans nithet il nor its conisats $\mathrm{n}=\mathrm{y}$ te stom. o.secssed of disciosed excepl in ascordance with such order."

$$
\text { Vol } 25 \text { pq } 2225
$$

po 2232 2in 12 ats

01. Depo Exh 14 TRIPLEXh.158
UST 5000001471 
$-2-$

To narrow the problem down. may we calk abour what is the product to be.

Results of meetings held wh the project group in Sweden and one meeting with the group in UST plus beveral smaller meetings, conclude the following:

1. There should be three products of thrce different tastes and strengths of nicotine.

a. High nicotine, strong tobacoo flavor for consumer who presently uses tobacco in the mouth.

Can this be accomplished by using present product of Copenhagen or Etona?

Can it be accompllshed by larger portion than present sample?

Can this be done by using stronger tobacco colors in packaging?

b. Medlum strength of nicotine.

Can this be accornplished by using a Happy Days product?

Can this be accomplished by using medium slze package?

Can we use spirles zuch as rum, cognac, bourbon; wines - sherry: coffee, tea, for this product?

Will the color of the package be medium in strength?

c. Low nicotine, sweet product.

Can this be done by using present size Lotus?

is there a milder smuff moist avaitable than we are presently using (sweet dry snufi)?

Do we flavor this product with honey. chocolate or vanilla?

Above are three objectlves as to guidelines for product development. They are the best offerings thus far. What has been done to develop these products? Is it possible to develop any of these suggestions?

\section{"CONFIDENTIAL"}

"This docunted is sitiasl lo a protec live oreer and ne:ict it nor its conterts may be sitom. discussed or disclosed excepl in accordance with such oroer." 
Word Bemett was the first to suggest that the paper being used for the inside sack was not allowing sufficlent havor to pass through. He is working on other papers. What is his progress?

A machine could be ready for use in Chicago by the end of 1972. Do we wane this machine?

What do we do while we are waiting for the machine? I suggest we work like hell on the product. With no other suggestions coming forth, I advise that we go with the above autline as to procuct.

However, may I offer that to gain the advantage of many walents in U.S.T. that a small group be appointed by you, Mr. Bantle, to bring together what may be thoughes of maxuracuring. product research, and marketing to agree on the steps to be raken.

You, Mr. Bantle, would be head of the grap or group committee could neport to yau directiy. May 1 not appear too bold to suggest - Coondinator be appointed and if ir shaulo please yau, 1 would be hononed and happy to act in this enpacity. The reason for the suggestion of myself is that it would bring to the group the progress and work already done by S.T.A. Secondly. U.S.I. is very inter ested in obiaining the righe Lotus package for intemational marketing and soon.

To my sorrow, this report is not the full answer to the problem. out it is my belief that it is a big step forwand.

Please, Mr. Bantie, chould you need any further disoussion on this matter. the writer is most anxious to be of service to you.

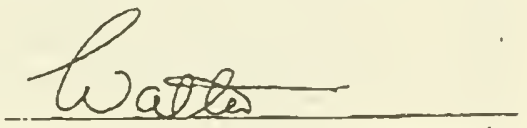

Whinim

\section{"CONFIOENTIAL"}

"This docuneal is s.:! ect to o protes.

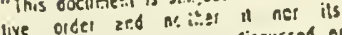
live oldet zr.d be s:o:-n. discussed of eonients may be s.o..n. discessed such discloses esecpl in accordance with suen orset." 


\section{Minules from a Meeting in}

Greenwich 7-1B-72 at

Mr. L. A. Bantle's Office

Subject:

The Lotus Project

$\begin{array}{lll}\text { Present: } & \text { L. A. Bantle } & \text { S. B. Erlandson } \\ & \text { O.. D. Roeder } & \text { W. W. Watson } \\ \text { P. E. Lindevist } & \text { T. B. O.Grady } \\ & \text { J. W. Haury } & \text { W. J. Leinen } \\ & \text { R. T. Gaddis } & \text { W. R. Quail }\end{array}$

Mr. L. A, Bantle opened the meeting by explaining that "Lotus" is the code name for smokeless tebacco in a portion pack form. This projec: is being launched this fall in Sweden by Swedish Tobacco Company. it is an understanding between the Swedish Tobacco Company and United States Tobacco to keep one another informed and to cooperate on this frojec:

Mr. Bantle Nurther declared that he wanted a Lotus produc: for the U.S. marke: as soon as possible and that this product should not be a Cssenhagen or Skoal" in the portion pack form, Dui an entirely new oceducl aumed o: new consurriecs, meinly cigarette smokers.

Asked what information research could cchtribute towards the possible accepiance of the Lolus idea by the consumer, Mr. O'Grady stated that

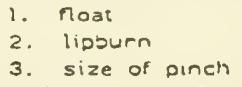

3. size of pinch

were dominating factors in creating problems for new users to oet accusiomed to smokeless. The Lotus idca could to a grea: extent overcome these probiems, thereby making it easier to open up a larger marke:.

Mr. Bentle explained that in egreemen: with Swecish Tobacco Company, Unites Scandia International is going to offer Lotus to the international marke:. The product USI will offer may be choosen from either of the two mother compenies, whichever company USI thinks is making the right product for $\times$ market. Thus could mean that several products might have to be developed although the ideai situation would be if the U.S.-Lotus could be used norlewide.

To accomplish a sound an rapid development of. the Lotus projec:, Mr. Bantle declared that he wanted to set up a special lask force with the following participan:?

$$
\begin{aligned}
& \text { P. } \frac{\text { E.S.1. Lindquist }}{\text { W. W. Waison }} \\
& \text { W. W. }
\end{aligned}
$$

\section{- CONFIDENTIAL"}

"This document is subject 10 s protec. live order and nether it nor its contents may be shorn. discussed of disciosed extept in actordance with and oider."

\author{
United States Tobzeco Co. \\ W. B. Eennert W. J. Leinen \\ E. J. Boyd C. A. Nickolaus \\ R. T. Gaddis T. B. O.Grzdy (C: \\ J. W. Haury R. 1.. Rossi m.
}


This task force should report directly to Mr. Bantle and always bcar in mind the secrecy of the project.

Before the meeting was ended several technical aspcets of the project were discussed (navored paper, size of pinch ond homogenized leaf). Mr. Bantle In summing up this discussion declared that all possibilities to make the right Lotus product for the new consumer must be explored with every effort put into the project.

Mr. Thomas B. O'Grady has been appointed Chairman of this task force committee.

The next meeting of the Lotus Committee will De the middle of August. Members will be given sufficient notice as to the place, time and date.

"This document is subject to a prolec. the order and nether it nor its tive order and be shoin. discussed of contents may be shoin. discusse with such disclosed except in accordance with such ordet." 
APPENDIX C

THE LOTUS PRQECT

AlM:

TARGET GROUP:

PROOUCT:

To make ti easier for a new user to use tobacco in the mouth.

New users, mainly cigarette smokers, age group $15-35$.

A. Strenoth

1. Nicotine satisfaction.

Mlld like Happy Days

instane but not shoeking.

2. Feeling in the mouth.

As little harshness as possible on the gum and in the thiroet.

B. Taste

A navored taste like mint, cherry or rum; not too strong to give harshncss but strong enough to cover

any salty bitierness or other unpleasanuness for a new user in having tobasco in the mouth.

PACK:

A. Size of Pinch

Small enough for a new user to manape.

The present Lotus size is perhaps okay.

This point has to be elosely worked out, lakes into consideration the desired eifects mentioned under "Strength."

B. Paper

The paper is only there to keep the tobacco in $p$ ! ace and to make ehewing look cleaner. The paper should be felt as little as possible and should allow navor and tas:e to do its joo as if no paper was there.

"This document is subject 10 o protet live order and ne thet it nor contents may be shorn. discussed wuch disclosed

U.S.I. $\quad 0^{7-18-72}$ order:" 
APPENDIX I

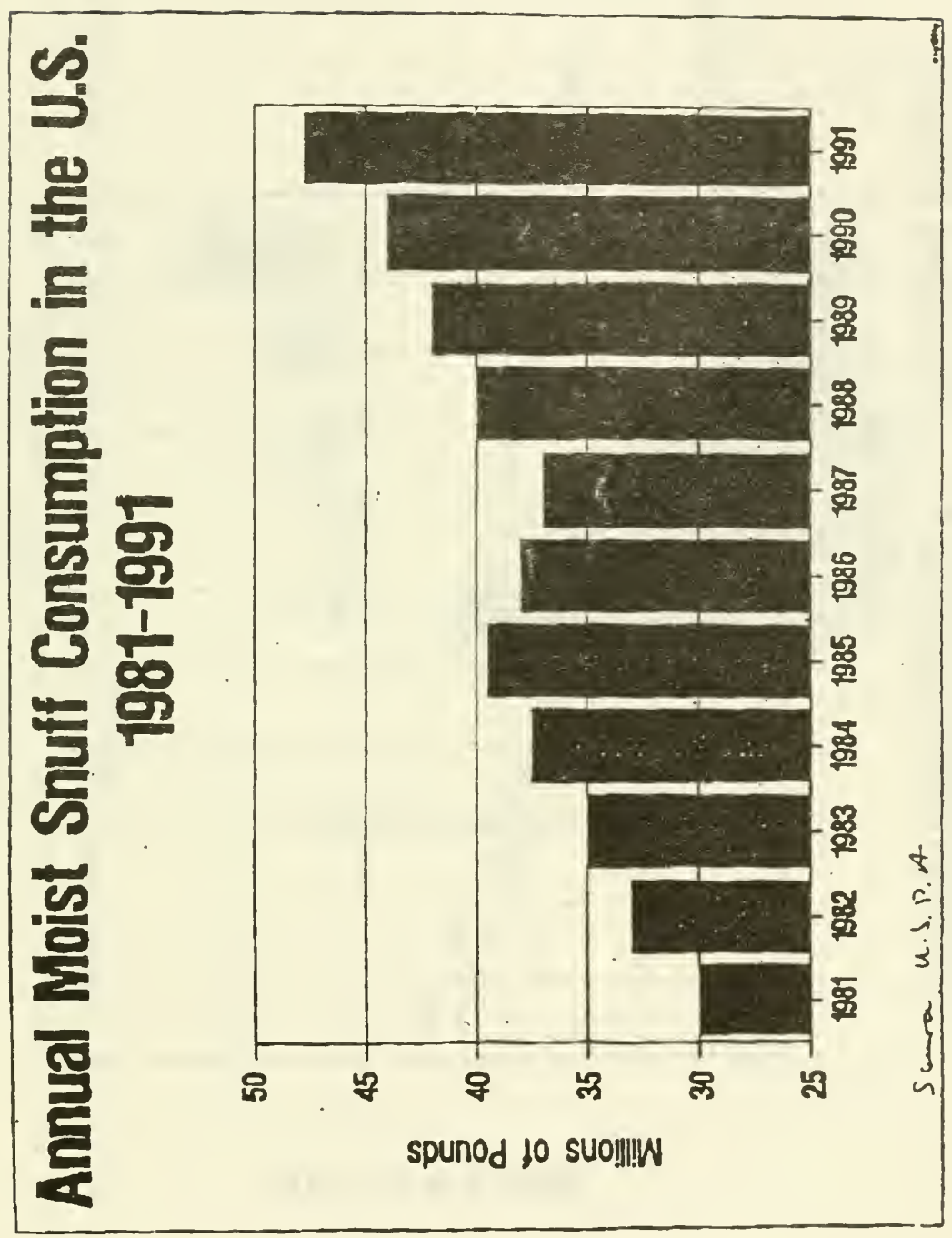


516
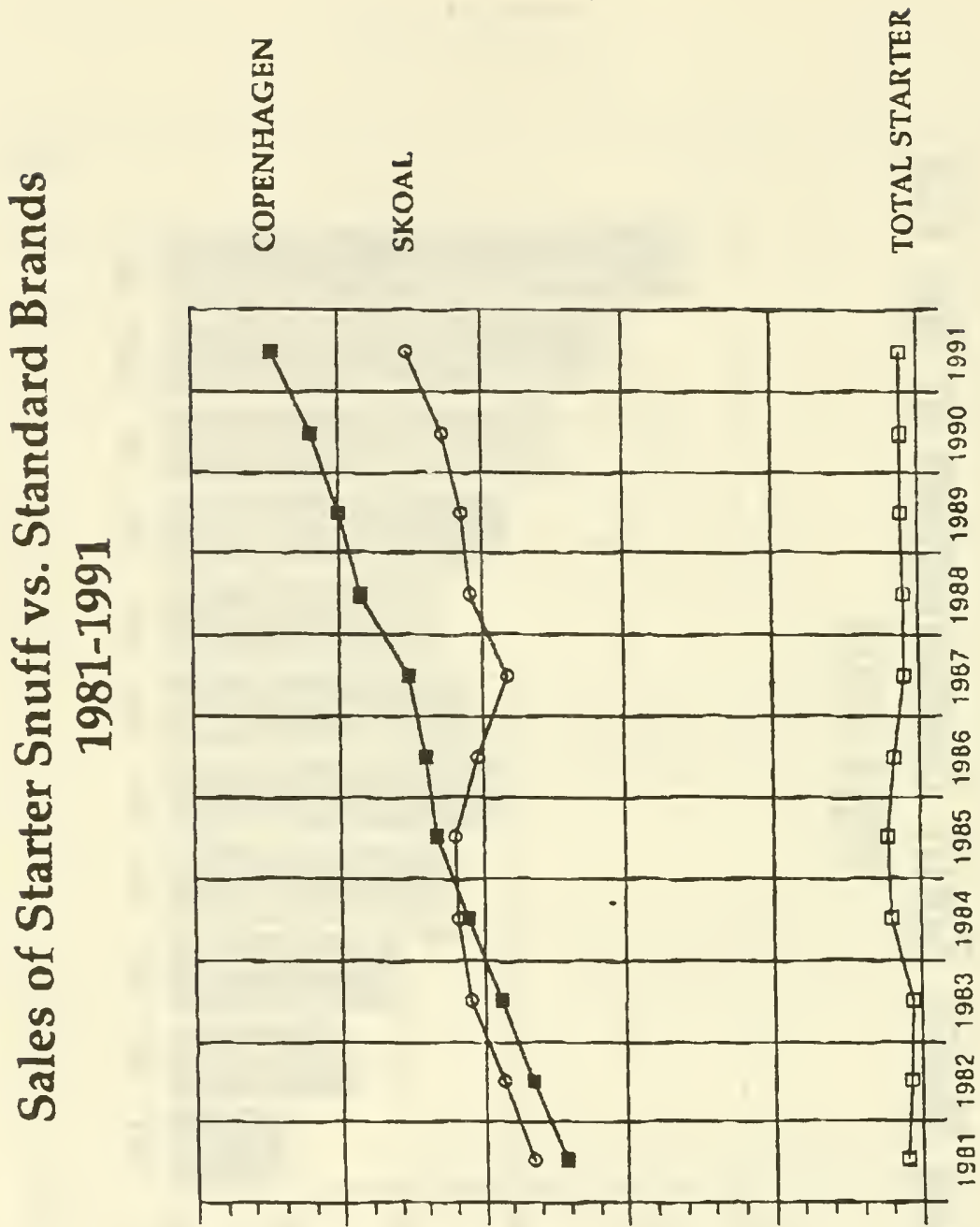

spunod fo suo!II!W 

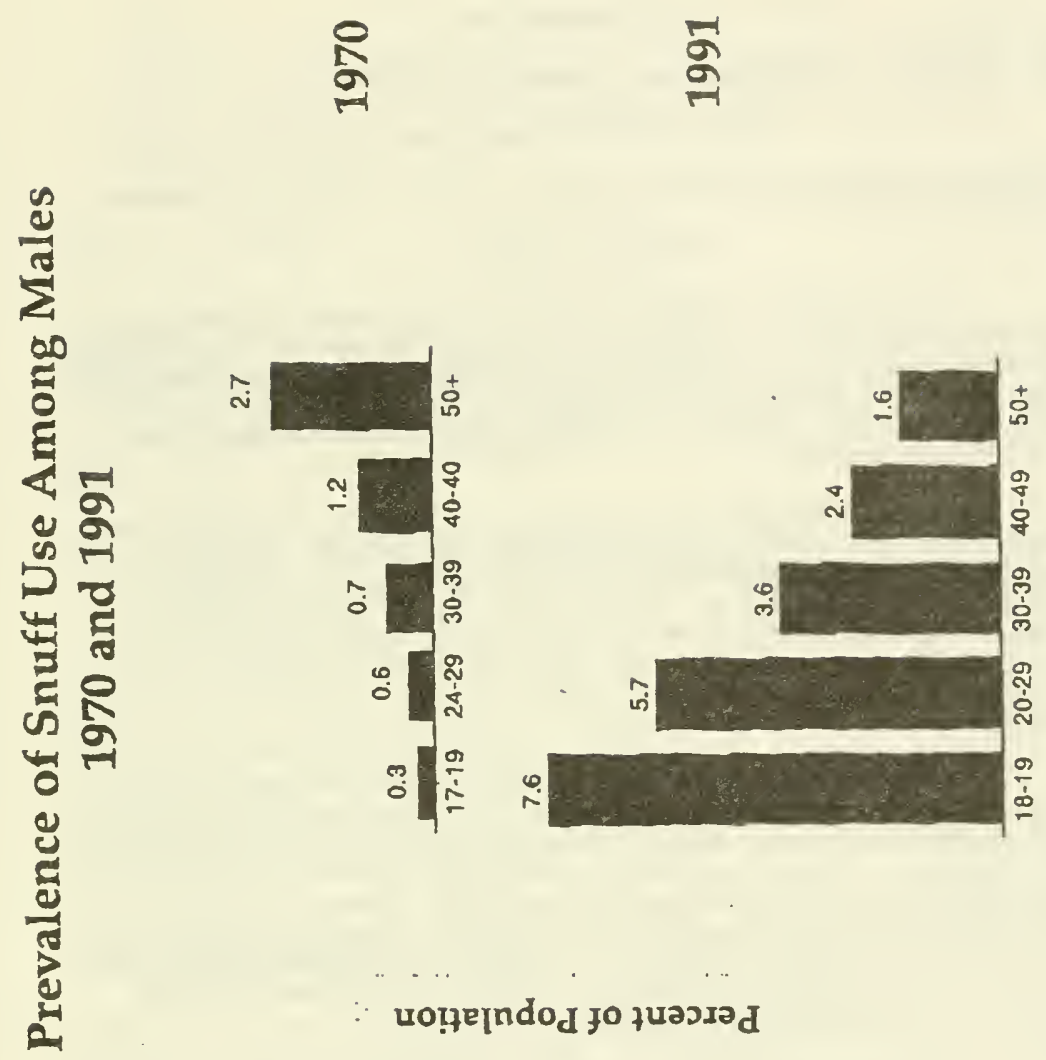

uo!̣ejndod fo quasม⿰丿 
STATEMENT OF

CONGRESSMAN JAMES V. HANSEN

FIRST DISTRICT OF UTAH

\title{
BEFORE THE SUBCOMMITTEE ON HEALTH AND THE ENVIRONMENT
}

\author{
MARCH 25, 1994
}

Mr. Chairman I appreciate the opportunity to submit testimony today before this Subcommittee. I wish to stostantiate that Congress has a responsibility to provide guidelines for the Food and Drug Administration's (FDA) regulation of tobacco and tobacco products. As Co-Chairman of the Congressional Task Force on Tobacco and Health, I endorse your attempt to address this complicated and highly controversial issue.

As we all know, the consequences of tobacco use are widespread and life threatening. Not only do tobacco users suffer, but everyone around them is in danger as well. Tobacco products are directly linked to hundreds of thousands of deaths each year, but the industry is unlike every other industry in America - it is virtually unregulated. Although further regulation goes against the grain of my philosophy, I have no problem endorsing FDA intervention and regulation of this industry when tobacco use is clearly the cause of so much death and disease in the United States.

My own home state of Utah recently became the second state in the nation to pass a law banning smoking in public places. Utah's law is the most comprehensive in the country, and the first to eliminate smoking in all private and public workplaces. Utah was also the first state to ban cigarette vending machines, prohibit distribution of free tobacco samples, and to ban billboard advertising. I'm thrilled that local lawmakers, businesses, and the military have seen the need to provide a safe and healthy environment for everyone. With the momentum behind this national wave of health consciousness, I think it would be irresponsible of Congress to not act quickly on this matter.

I am a cosponsor of H.R. 2147, introduced by Mr. Synar. It's a good bill and I believe its provisions should be seriously considered as you begin drafting guidelines for the FDA. The tobacco industry has gotten away with too much for too long. The fact these companies operate without government intervention is unreal; you can't look anywhere in our market and see a company operating this way. The manufacture, labeling, distribution and marketing of this business needs government regulation, and it needs it now. I believe we have a responsibility to keep the public fully informed and protect people's health. It is important for people to know exactly what ingredients they are inhaling, snuffing or chewing -- the reality may have a positive impact and save a few lives. So what if it costs the tobacco companies a few dollars, I think they can afford it.

Mr. Chairman, I encourage you to continue this discussion and design a solution which protects the health of our children and their parents. I thank you for your time. 
OHice of the Executive Director

21! Easi C- :ag? Aven:e

Cr cac. - - $5006 \%, 2679$

3.21 i. 2.2530

$F_{3} \cdot 13=4 \div 0.748$

March 31, 1994

Honorable Henry A. Waxman

Chairman

Subcommittee on Health and the Environment

Committee on Energy and Commerce

2415 Rayburn House office Building

U.S. House of Representatives

Washington, D.C. 20515

RE: Statement for the Record for March 25, 1994 Hearing Concerning Regulation of Tobacco Products under the Federal Food, Drug and cosmetic Act

Dear Chairman Waxman:

The American Dental Association (ADA or Association) appreciates the opportunity to submit a statement for the record concerning the regulation of tobacco products. As the representative of over 140,000 dentists nationwide, the Association has, as a core responsibility, a mandate to support activities to enhance the oral health of the American public.

To that end, the ADA agrees with those who call for legislation that defines tobacco as a drug and transfers its regulation to the Food and Drug Administration.

A March 25, 1994 Morbidity and Mortality Weekly Report (Vol. 43, No. 11 , at p. 198) published by the centers for Disease Control (CDC), U.S. Public Health Service confirms that the use of tobacco products continues to be a significant oral health problem, as the 5-year survival rate for people with oral cancer remains a very low 53 percent. According to CDC, oral cancer was diagnosed in about 30,000 people in the United states in 1992, causing nearly 8,000 deaths. Furthermore, CDC states that approximately 70 percent of those deaths are associated with'smoking and other forms of tobacco use.

It is important to keep in mind that oral cancer is truly a devastating disease, often resulting in the loss of portions of the face and jaw. While oral examinations are effective at reducing morbidity and mortality caused by oral cancers, prevention always remains the best first-line defense. In this instance, the best preventive measure is simply not using tobacco products.

The Assosiation has strived for years to eliminate the use of smokeless tobacco, especially among adolescents. To accomplish this goal, the ADA continues to work with professional baseball to 
discourage its use among players. We believe that if role models kick the habit, adolescents are less likely to take up smokeless tobacco.

Unfortunately, the use of smokeless tobacco products among college athletes and adolescents has increased significantly over the past twenty years. Gregory N. Connolly, D.M.D., Director of the Massachusetts Tobacco control Program, testified before this subcomittee that the use of snuff among males 18-19 years of age increased from .3 percent in 1970 to 7.6 percent in 1991 . Twentyfour percent of all white male high school students used smokeless tobacco at least once during the past month, according to a 1990 Youth Risk Behavior Survey. Finally, there was a forty percent increase (from twenty percent to twenty-eight percent) in the use of smokeless tobacco among college athletes from 1985 to 1989 , with a fifty-seven percent usage rate among NCAA baseball players.

The U.S. Surgeon General has warned that the use of smokeless tobacco among adolescent boys could lead to higher oral cancer rates several decades from now, according to a 1992 study by the National Institutes of Health and the National Cancer Institute.

You and the entire Subcommittee on Health and the Environment are to be commended for your efforts to draw attention to the very significant public health problems caused by tobacco products. The Association also supports your efforts, Mr. Chairman, to create a smoke-free work environment through the enactment and enforcement of legislation and regulations to reduce the exposure of nonsmoking adults and children to environmental tobacco smoke, pursuant to H.R. 3434 .

The need for strict regulation of tobacco products and environmental tobacco smoke (ETS) is obvious. A report recently published by the Environmental Protection Agency (EPA) concluded that ETS is a grave threat to nonsmokers. ETS is a human lung carcinogen, responsible for about 3000 lung cancer deaths annually in nonsmokers. The EPA also estimated that ETS increases the risk of respiratory disease in children, 7,500 to 15,000 of such illnesses result in hospitalization each year. In those who smoke, inhalation of tobacco products is now responsible for about 434,000 deaths per year. It has also been documented for about 40 years that tobacco use causes lung cancer in humans, is a major risk factor for heart disease and causes many chronic respiratory diseases.

The ADA will be pleased to work with you in the future as you determine the best course to follow in determining FDA jurisdiction and other appropriate legislative and regulatory actions.

Sincerely,

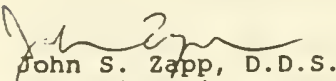

Executive Director 


\section{STATEMENT OF TAYLOR M. GULNN SUBMITTED TO THE \\ SUBCOMMITTEE ON HEALTH AND THE ENVIRONMENT HOUSE ENERGY AND COMMERCE COMMITTEE MARCH 25, 1994}

Mr. Chairman, members of the Subcommittee, thank you for the opportunity to submit this statement addressing the issue of nicotine in the processing and manufacturing of cigarettes - an issue which has recently been the subject of considerable attention.

1 retired from the U.S. Food and Drug Administration in 1985 after 34 years of service. My FDA experience includes 10 years as an investigator conducting comprehensive field investigations of food, drug and cosmetic manufacturing facilities. These inspections included the review of ingredients and additives as well as material balance evaluations. I held the position of Director. Division of Regulatory Guldance, Bureau of Foods, from January, 1970 through September. 1976, and served as Associate Director for Compliance. Bureau of Foods from September, 1976 until my retirement on February 1. 1985. Since 1985. I have been President of Taylor Guinn Consulting Inc., conducting inspections and audits of marufacturing facilities in the food industry for quality control procedures, good manufacturing practices, contamination problems and material balance evaluations.

Phillp Morris U.S.A. recently engaged me to conduct an independent investigation concerning nicotine in their tobacco processing and manufacturing practices, and $I$ am appearing today at their request. 
In the course of conducting my independent investigation I inspected Philip Morris facilities in the Richmond, Virginia area including the two plants where reconstituted tobacco sheets are prepared, the Flavor Center responsible for the ingredients added to cigarettes and the Cigarette Manufacturing Center.

I wish to emphasize that I had complete autonomy in conducting the investigation and directed that I be given access to comprehensive information and data regarding Philip Morris tobacco processing and manufacturing. My investigation focused on several key questions:

(1) nicotine in tobacco processing:

(2) what processing aids and ingredients were being added during the various stages of tobacco processing and manufacturing;

(3) determining which processing aids or ingredients contained nicotine and, if so, how much;

(4) the nicotine content in various finished products; and

(5) how much of the nicotine in the finished product came from the raw tobacco and how much nicotine, if any was added. 
During the course of my investigation I randomly requested data with respect to brands and time periods, and all of the information requested was provided. For example, while I reviewed all of the ingredients used in the manufacture of Philip Morris cigarettes I randomly chose thrce brands - Marlboro, Merit Regular and Merit Menthol - and was provided with a list of flavors and processing aids for each brand. I also requested this information for randomly selected time periods and was provided with this information for all three brands currently as well as six months and one year ago. Similarly, data regarding nicotine content for all three brands for all three time periods was produced at my instruction.

I was permitted to ask any question of any Philip Morris employee I chose, and all inquiries were readily answered. Also, all records that I requested were readily provided.

The conclusions of my investigation can be summarized as follows:

1. There is nothing I observed in the processing of tobacco or the manufacture of cigarettes at Philip Morris that would materially increase the nicotine in their products above what naturally occurs in the tobacco.

2. The denatured alcohol used as a processing aid by Philip Morris contains nicotine in the form of nicotine sulfate (SDA4) as approved by the Bureau of Alcohol, Tobacco and Firearms and 27 C.F.R. $\$ 21.38$. Denatureć alcohol contains 
nicotine in amounts so small that it would be undetectable in the tobacco in the finished cigarette considering the much larger amount of nicotine from the tobacco. This is confirmed by my calculations demonstrating that the nicotine contribution from SDA-4 denatured alcohol is 0.0006 to 0.0008 milligrams of nicotine per Marlboro Regular cigarette, 0.0011 to 0.0015 milligrams of nicotine per Merit Regular cigarette and 0.0012 to 0.0023 milligrams of nicotine per Merit Menthol cigarette. The level of total nicotine in these cigarettes ranges from approximately 16 milligrams to approximately 13 milligrams. So the amount contributed by the SDA-4 could not be measured against this naturally occurring background.

3. The commercial tobacco flavoring commonly referred to as "tobacco extract" was used by Philip Morris in 1993 in its Merit Menthol cigarette. This extract contains naturally occurring nicotine in small amounts. No other flavor used by Philip Morris contains nicotine and this flavor was used only in Merit Menthol. The nicotine contribution from tobacco extract to the finished cigarette in which it was used is so small that it does not measurably change the level of nicotine in the cigarette. For example, the maximum possible contribution of nicotine from tobacco extract in Merit Menthol is about 0.0029 milligrams of nicotine per cigarette by my calculations. When this is combined with the nicotine contributed by SDA-4, it would result in a 
maximum of approximately 0.0052 milligrams of nicotine per cigarette. Again, considering the total nicotine in the cigarettes, the nicotine contributed by these two sources could not be measured against the naturally occurring nicotine.

4. My extensive investigation into the Philip Morris processes of preparing reconstituted tobacco resulted in the conclusion that no measurable nicotine is being added.

As an experienced investigator. I was satisfied with the cooperation and candor of all Philip Morris personnel during my inspection of their facilities. I observed no evidence that would support any allegation that Philip Morris adds any measurable level of nicotine to cigarettes over and above the amount of nicotine naturally found in tobacco.

Thank you. 



\title{
REGULATION OF TOBACCO PRODUCTS
}

\author{
THURSDAY, APRIL 14, 1994
}

HoUSE OF REPRESENTATIVES, COMMITTEE ON ENERGY AND COMMERCE, SubCOMMITTEE ON HEALTH AND THE ENVIRONMENT, Washington $D C$.

The subcommittee met, pursuant to notice, at 9:05 a.m., 2123 Rayburn House Office Building, Hon. Henry A. Waxman (chairman) presiding.

Mr. WAXMAN. The meeting of the subcommittee will come to order. I'd like to ask our guests to please take your seats.

This is an historic hearing. For the first time ever, the chief executive officers of our Nation's tobacco companies are testifying together before the U.S. Congress. They are here because this subcommittee has legislative jurisdiction over those issues that affect our health. And no health issue is as important as cigarette smoking.

It is sometimes easier to invent fiction than to face the truth. The truth is that cigarettes are the single most dangerous consumer product ever sold. Nearly a half million Americans die every year as a result of tobacco. This is an astounding, almost incomprehensible statistic. Imagine our Nation's outrage if two fully loaded jumbo jets crashed each day, killing all aboard. Yet that is the same number of Americans that cigarettes kill every 24 hours.

Sadly, this deadly habit begins with our kids. Each day 3,000 children will begin smoking. In many cases they become hooked quickly and develop a life long addiction that is nearly impossible to break. For the past 30 years a series of surgeons general have issued comprehensive reports outlining the dangers these children will eventually face.

Lung cancer, heart disease, emphysema, bladder cancer, and stroke are only some of the diseases caused by tobacco causes. And now we know that kids will face a serious health threat even if they don't smoke. Environmental tobacco smoke is a Class A carcinogen, and it sickens more than 1 million kids every year.

In fact, five former surgeons general of the United States testified before this subcommittee this year, that the most important legislation in disease prevention that we could enact would be restrictions on smoking in public places. This subcommittee will soon act on that legislation, and it will consider other measures as well. This hearing will aid our efforts by presenting an important perspective. But these hearings are important for another reason as well. 
For decades the tobacco companies have been exempt from the standards of responsibility and accountability that apply to all other American corporations. Companies that sell aspirin, cars, and soda are all held to strict standards when they cause harm.

We don't allow those companies to sell goods that recklessly endanger consumers. We don't allow them to suppress evidence of dangers when harm occurs. We don't allow them to ignore science and good sense. And we demand that when problems occur, corporations and their senior executives be accountable to Congress and the public.

This hearing marks the beginning of a new relationship between Congress and the tobacco companies. The old rules are out, the standards that apply to every other company are in. We look forward to hearing the testimony this morning, and to working with these companies to begin to reduce the extraordinary public health threat that tobacco poses.

An old proverb says that a journey of a thousand miles must begin with a single step. Today is the first step. Many more are to come as we deal with the most serious health problem facing our Nation.

Before calling on our witnesses, I want to recognize members of the subcommittee for opening statements, and to call on Mr. Bliley first.

Mr. Bliley. Thank you, Mr. Chairman. Ladies and gentlemen, I certainly would like to know, who is the anti-smoking groups' P.R. agent because this person has done more for the name I.D. of this small town Virginia mayor over the past few weeks than all of my the press secretaries combined for the past 14 years.

Seriously, ladies and gentlemen, over the past several weeks, we have witnessed an unprecedented assault on tobacco that has unfortunately been driven not by science but by press release. Now I've come to expect such behavior from the zealots in the antismoking community, but it seems that when it comes to tobacco that these tactics have acquired mainstream credibility. It is clear that tobacco is not politically correct.

I must say that I was saddened by what took place in this room a couple of weeks ago. I witnessed the Commissioner of the FDA, who is both a trained scientist and a lawyer, take threads of truth and weave them into whole cloth of rumor and innuendo. The members of this subcommittee were rude and hostile to any witness who dared to attempt to offer a different explanation. I hope today is different.

I welcome the leaders of the American tobacco manufacturers before our subcommittee to set the record straight. I pledge to you that I will do what I can to ensure that this proceeding is fair, and that your voice is heard. I am proud to represent thousands of honest, hard working men and women who earn their livelihood producing this legal product.

I am proud of all their positive contributions to my community, and I'll be damned if they are to be sacrificed on the alter of political correctness. This Congress must not turn its back on science and rəason just because of the bubble of popularity. Though it may be only tobacco today, what lies next. Thank you, Mr. Chairman.

Mr. WAXMAN. Thank you Mr. Bliley. Mr. Synar? 
Mr. SYNAR. Thank you, Mr. Chairman. Let me commend you and $\mathrm{Mr}$. Wyden both for this very historic day on which we begin this journey.

Fifty million Americans are addicted to smoking. Four hundred and twenty thousand of our fellow citizens die each year because of tobacco and tobacco-related illnesses. Americans want to know why. Americans also want to know why American CEO's and executive continue to deny basic responsibility that they are not accountable for 1,000 deaths every day of the year in this country.

Americans want to know why corporate executives in America deny that their companies prey upon children as they spend $\$ 4$ billion advertising and promoting a product to the most vulnerable in our society. And Americans want to know, very simply, why corporate executives in this great country of ours continue to deny consumers basic information so that they can make informed decisions.

Today, at long last, we're going to get some of those answers. I look forward to today's hearing, and as the chairman said, this is the first step in a long journey.

[The prepared statement of Mr. Synar follows:]

\section{Opening Statement of Hon. Mike Synar}

Ladies and Gentlemen, I am thrilled to be here, face to face, with the Chief Executive Officers and Chief Researchers from the seven largest cigarette and oral tobacco companies in the United States.

From their written testimony, I see that they are issuing the same blanket denials that they have clung to for the past 30 years.

These denials are simply no longer acceptable to this subcommittee or to the American people.

Fifty million Americans are addicted to smoking. They want to know why. They want to know all 700 ingredients, not just the 599 released yesterday in cigarettes and oral tobacco and how these ingredients affect their bodies. They want to make sure that tobacco companies are not preying on children.

Today, the tobacco industry, instead of continuing its attack on my bill, H.R. 2147 (which would give the FDA broad regulatory authority over tobacco while prohibiting the Agency from banning it) has instead tried to cast shadows on the credibility of two of the most respected health officials in our country: Dr. David Kessler, the Commissioner of the FDA, and Dr. Greg Connolly, a representative of the American Public Health Association.

Why is this necessary? Why not just provide this subcommittee with solid, honest answers?

This is a simply case of corporate responsibility. We require that Kraft cheese, owned by Philip Morris, list its ingredients on the back of the package. Marlboros, although exempted from every other regulation, cannot be allowed to cast its smoke screen over the health of Americans. Any other company that even attempted what the tobacco companies have done to the health of America's youth would have been sued out of existence years ago.

I hope that this hearing reveals some real answers about this deadly product, and gives some desperately needed information to the 50 million Americans addicted to cigarettes and oral tobacco.

Mr. Waxman. I thank you, Mr. Synar. Mr. McMillan?

Mr. MCMillaN. I thank the chairman. And thank you for taking the time to investigate further this most important issue. Especially, I would like to thank you for giving the tobacco industry an opportunity to come in and directly explain some of the complexities of the issues which have been raised in recent weeks and years, confusing so many in this chamber.

It is extremely important that we pause long enough to listen and to get a clear understanding of what is at stake. I should point 
out, unfortunately, that several Members of this Congress in the North Carolina delegation who's districts are impacted by this issue were not allowed to testify today.

These Representatives probably represent some 70,000 people who work directly in the tobacco industry either as growers or processors. And I think their interest and insight into this matter would be useful. And I hope that at a future date they can be included in the process and that their written testimony could be included in the record today.

I know that we will address a number of issues concerning tobacco processing and smoking in this hearing. I am particularly interested in hearing from the principal executives of the seven major tobacco companies about some of the issues previously raised before this subcommittee, particularly those that were raised, and possibly distorted, by Commissioner Kessler several weeks ago.

It is extremely important that we get factual information at this hearing. I believe that the gentlemen here today are in a position to provide that. Dr. Kessler spent a great deal of time explaining how he perceived the position and actions of the tobacco industry. Several of the issues discussed appeared to be in direct contradiction to my understanding as to how tobacco is processed, and certainly, I think, to the understanding of the gentlemen who are here today.

I expect that this hearing can shed considerable light on these for the benefit of the members of the committee and the American public who are watching. It is important that this subcommittee deal with factual information, as it should on matters of this import, and that it should take whatever actions are necessary, based on fact and not on public perception. However, I am extremely concerned that there are too many members here, and too many others outside, who are too eager to jump to conclusions before they look at the facts.

And I think we need to back up and, as the chairman said in his opening statement, apply equivalent standards to this product as we do to other products, applying the same rational thought to each. If we do this we will serve the American public well. I yield back the balance of my time.

Mr. WAXMAN. Thank you, Mr. McMillan. I do want to note that our colleagues from North Carolina were here to testify at our March 25th hearing. We'll have their statements in the record. Mr. Wyden?

Mr. Wyden. Thank you very much, Mr. Chairman. I want to commend you for all of your years of leadership in this effort, and also our colleague, Mike Synar, who has done a tremendous job in advocating for the health rights of children who are so directly affected by tobacco products.

And I think I'd like to start by saying that I come to this hearing as a parent of a 4 year old and a 10 year old, and in a few years all of you, the executives who are sitting at the witness table, are going to be using advertising by Joe Camel to try to hook my kids and addict them to tobacco products.

Now, some of you are parents and grandparents as well, and I think you'd agree with me that all our children are our most valuable possession. And I just can't understand how each of you is en- 
gaged in an enterprise that is sure to kill some of our children. I hope today that you will tell us how you all can live with such a killing record on your conscience.

Now, this issue, in my view, is no longer a matter of free choice. It's clear that nicotine is addictive, and it's clear that people get hooked and they can't get off. The same is true of second-hand smoke. We have innocent bystanders that are hurt as the result of second-hand smoke, so this is no longer a matter of free choice. And I hope you will answer to us exactly how you all think that it is a matter of people just exercising an individual preference.

Finally, let me wrap up by saying that yesterday you all treated the American people to a chemical smorgasbord, and you put out a list of all these additives and, in effect, said that they are all safe. Well, I have a letter here from the Centers for Disease Control that disagrees with you. And let me read it to you.

"We cannot categorically state that any of the ingredients are either safe or hazardous without a reference to a specific dosage, and we are unable to determine hazardous risk for any of the substances."

You all didn't put out the quantities of chemicals that are used in cigarette products. You didn't put it out in terms of each brand of cigarettes. I'm going to make this letter from the Centers for Disease Control available to each of you, because it makes it very clear that until you put out that quantity of chemical that is used, it cannot be declared that these additives are safe.

Mr. Chairman, again, I commend you and our colleague, Mike Synar, for many years of work, and I look forward to our witnesses.

Mr. WAXMAN. I thank you, Mr. Wyden. Mr. Greenwood?

Mr. GREENWOOD. Mr. Chairman, in the interest of time, I'd like to forgo an opening statement. I look forward to hearing from the witnesses.

Mr. WaXMan. Thank you. And Mr. Bryant?

Mr. BRYANT. Thank you, Mr. Chairman. I commend you for putting this together and I am glad that we have the executives here today. I would just like to say that while I do not think I have ever voted with your industry, I have not been an anti-smoking zealot by any definition.

I got into my teenager's car à couple of weeks ago and flipped open the glove compartment. There was a pack of Camel cigarettes which, ironically, is the same brand of cigarettes which my grandfather smoked, who died of lung cancer, after smoking your products for his entire life, when I was in the sixth grade.

I have always believed that the best way to raise kids is to let them have experience in life and make their own rational choices. But the problem with this is that I am not arguing with reason here, I am arguing with the fact that your product is addictive, depriving him and millions of other Americans of the ability to make a rational choice. And I think we are going to have to talk about that today.

In my view, the question raised by Mr. Wyden, about your moral responsibility to your fellow human beings is right at the center of this discussion. And I am one of millions of parents who is trying to figure out how to deal with this without forgoing the right of your child to have experiences and make reasonable decisions? 
They cannot do that if they are going to be addicted to your product. And that is what your product does, it addicts people to something they cannot get rid of later in life. It deprives them of the reason that otherwise would come to bear on a decision to make a consumer choice.

So we are really not talking about consumer choices, a phrase which seems to weave itself through all of your written testimony. We are really talking about the inability of consumers to make a choice after they try your product for very long because they are hooked. I yield back my time.

Mr. WAXMAN. Thank you, Mr. Bryant. Mr. Kreidler?

Mr. KREIDLER. Thank you, Mr. Chairman. I want to thank you for holding these hearings so that we can hear from the tobacco industry. Tobacco kills the equivalent of the population of an entire congressional district every year. As a health care professional, I take a considerable interest in this heavy toll that we're taking right now that affects our public health, our medical system, and families.

We've seen enough of what has to be labeled as dodging, denial, and dissembling by the industry. And it's clear that it is time to learn the truth, to learn what toxins from cigarettes do to people, how much nicotine is in cigarettes, and what other chemicals do to people. It's time for full disclosure.

And, Mr. Chairman, I commend you for holding these hearings so that we can get to the bottom of this and find out what's really happening to the American people. Thank you, Mr. Chairman.

Mr. WAXMAN. Thank you very much, Mr. Kreidler.

[The prepared statement of Hon. Gary Franks follows:]

\section{Opening Statement of Hon. Gary A. Franks}

Thank you, Mr. Chairman. Today's hearings are an important part of moving the whole tobacco issue out in the public's eye for review. Tobacco use is an important subject, and when the public interest is concerned it should be reviewed.

We all know there is a great deal of interest on this topic. However, there is also a great deal of conflicting data available for public consumption. But charges and counter-charges will not get us to the facts, that is why these hearings play such an important role in the tobacco debate.

I believe the tobacco industry should be scrutinized for their actions, if they are not in the public's best interest. But by the same token, the arguments against the tobacco industry should be put to the same test. I would like to see all of the studies thoroughly reviewed and see if the conclusions all hold up to the same scrutinization.

As I understand it, the primary issues here are nicotine and its alleged manipulation and addiction, tobacco ingredients, tobacco's appeal to youth, and tobacco's impact on health.

Mr. Chairman, we need more facts on these issues before we start voting on any legislation regarding these issues.

Routinely, I request my staff to look into the various claims that cross my desk in the form of "Dear Colleague" letters. Many of these letters claim that tobacco use causes all sorts of problems. Many times, my staff learns that the information in these "Dear Colleague" letters lead you to conclusions that are exaggerations, or perhaps, distortions of the facts. Mr. Chairman, these distortions should only compel you to insure a fair and impartial hearing today.

A recent study from the Department of Health and Human Services confirms that the youth usage of smokeless tobacco products is currently declining and continues to go down. I would not of reached that conclusion from the information that has passed over my desk recently sent out by my colleagues here in the House of Representatives. 
I understand that recent epidemiological studies that demonstrate statistical association are insufficient alone to propel a ban on consumer products or to move their classification as an addictive substance.

Certainly, before we start to criticize the industry's manufacturing process we should be very certain of the facts.

Let's leave the decision to use or not to use a tobacco product to the public after we provide them with complete and honest information about the product and it's production.

I am very concerned about the health of the American people, but my concern also extends to the millions of workers in one of the largest industries in America. We need to be sure of the facts of the tobacco issue before we denigrate an entire industry by loose interpretations of biased reports and slanderous remarks made by U.S. Government officials.

I look forward to hearing what these panels have to say. I have a healthy cynicism for all the claims made by the parties on both sides of this matter, and I look forward to getting to the honest facts about these issues.

I yield back the balance of my time.

Mr. WAXMAN. Gentlemen, we welcome you to our hearing today. There is a blue pamphlet at the witness table, that will inform you of the limits on the power of this subcommittee and the extent of your rights during your appearance today. You, I'm sure, are all aware that you are entitled to be represented by counsel, or advised by counsel during your appearance here today. Do you or those of who you have asked to accompany you object to appearing before this subcommittee under oath?

[No response.]

Mr. WAXMAN. If not, I'd like you to rise, and those who will be testifying, as well, with you to rise. Will you raise your right hands?

[Witnesses sworn.]

Mr. WAXMAN. Please consider yourself to be under oath. And we'd like to ask each of you to identify yourself, including those who are accompanying the witnesses, so that we can have that for the record.

Mr. Campbell. William Campbell, President of Philip Morris U.S.A. I'm accompanied by Harold Burnley, our director of processing, and Dr. Kathy Ellis, our director of research.

Mr. JAMES JohnstoN. I am Jim Johnston. I'm chairman and CEO of RJ Reynolds Tobacco Company. I am accompanied by Andy Schindler, our head of manufactûring and operations; Carl Lehman, our head of $\mathrm{R}$ and $\mathrm{D}$; and Richard Cooper, our outside counsel and former general counsel of the FDA.

Mr. TADDEO. My name is Joe Taddeo. I am president of U.S. Tobacco. I'm accompanied by Robert Lawrence, he is our executive vice president of manufacturing and $R$ and $D$.

Mr. TISCH. Mr. Chairman, I'm Andrew H. Tisch, chairman and chief executive officer of Lorillard Tobacco Company. With me is Dr. Alexander W. Spears, Lorillard's vice chairman and chief operating office. Dr. Spears has senior responsibility for Lorillard's research and production operations.

Mr. HorRIgaN. Mr. Chairman, I'm Ed Horrigan, chairman and chief executive officer of Liggett Group. Accompanying me this morning is Greg Sulin, our vice president of operations.

Mr. SANDEFUR. Mr. Chairman, I'm Tommy Sandefur, chairman and chief executive officer of Brown and Williamson Tobacco Company. I'm accompanied by Dr. John Jewell, who is in charge of our 
manufacturing production operations, as well as Tilford Riehl, who is vice president of $R$ and $D$.

Mr. DONALD JoHnston. Mr. Chairman, my name is Donald Johnston. I'm president and chief executive officer of the American Tobacco Company. And with me today is Robert F. Sprinkle, executive vice president of research and quality assurance.

Mr. WAXMAN. I thank you all very much. Without objection, your prepared statements will be a part of the record in full. We would ask that you summarize your prepared statement in approximately 10 minutes or less. I want to note, at the request of Mr. Bliley, we've agreed to allow Mr. Campbell of Philip Morris and Mr. Johnston of RJ Reynolds, an additional 5 minutes to complete their presentations.

I would also note before we begin that the subcommittee received a number of requests from Members of the House of Representatives who desire to present oral testimony. Although the hearing schedule precluded expanding the witness list today, without objection, the record will be held open to receive iestimony from those of our colleagues who requested to testify.

[The prepared statements of Hon. Howard Coble, Hon. H. Martin Lancaster, and Hon. Karen Shepherd follow:] 


\section{STATEMENT OF THE HONORABLE HOWARD COBLE}

Subcomittee on Health and the Erviroment

House Energy and Camerce Committee

April 14, 1994

Thank you, Mr. Chairman. I appreciate the opportunity to share my views with the menbers of the Subcamittee today.

My congressional district is one in which tabacco faming has been and still remains a vital part of the state and local economy. The Sixth District mirrors many regions in North Carolina in this regard, particularly those areas which are nural and less affluent.

I am somewhat surprised by the tome and content of this debate, as if the issue were novel. Cigarette companies have not suddenly altered their mamufacturing processes or just started to use these ingredients. Similarly, there has been no change to federal food and drug law that would require the FDA to rethink its langstanding and well-reasoned position on cigarettes. In addition, nothing is new about the anti-smoking groups petitioning the FDA to regulate tabacco as a dnug. These groups have done this for decades, and the FDA, with the approval of the courts, has denied these petitions for decades as well.

Dr. Kessler has suggested that he believes there may be a middle ground. As I understand his position, it might be possible for cigarettes containing low levels of nicotine or no nicotine at all to remain on the market while all other tobacco products are banned. This is the same tact the Anti-Saloon League used in the $1920^{\prime} \mathrm{s}$. First, it persuaded Congress to prohibit interstate shipments of liquor to "dry" states and territories. It then 
secured a congressional prohibition of liquor advertisements through interstate mail to "dry" states. Also at the behest of the League, Congress amended wartime food-control statutes by prohibiting the mamuacture of "spirituous liquors," and authorized the President to ban or otherwise regulate the sale and procuction of all beer and wine.

Originally, prohibitionists said they were only after the traffic in liquor, not individuals or consumers. It soon became apparent, however, that the point of the Temperance Movement was to regulate the drinking habits of each and every American. Does all this sound familiar? It should. And, it should also alam the American public.

If the members of this subcomittee think that Dr. Kessler and antitobacco groups really will be satisfied with anything short of an outright ban on cigarettes, they are not, in my view, being realistic. Dr. Kessler's February 25 letter speculates that only those brands containing nicotine at nonaddictive levels could remain on the marketplace. I simply find it hard to believe that the FDA, pressured by the anti-tabacco groups, will ever arrive at an 'acceptable" clinical definition of nonaddictive nicotine.

Moreover, why is this agency spending so much of its time and resources reviewing an old subject? Are not these resources better directed toward reducing the chronic backlog of pending medical device applications and new drug approvals before the FDA. Based on recent figures, the agency will visit each of the dnug and device establishments it is required to inspect -- 90,000 in all -. once every six years instead of once every two years, as the statute requires. The infrequent rate at which the agency inspects imported products and foreign plants is alaming as well. Fram 1985 to September 1989, for example, anly 31 of the 3,400 registered foreign canneries were inspected.

My constituents would rather the FDA use their tax dollars to protect the safety of their food, drugs, and medical devices. They do not want the agency to launch a paternalistic crusade that will ultimately cost them their livelinoods. 


\author{
Statement \\ of the \\ Honorable H. Martin Lancaster \\ before the \\ Subcommittee on Health and the Environment
}

April 14, 1994

Mr. Chairman, this Subcommittee is currently is currently considering issues that are extremely important to me and the livelihood of many of my constituents. I remain deeply troubled about the ill-conceived attack this Subcommittee and Commissioner Kessler launched regarding nicotine in cigarettes.

Commissioner Kessler has acknowledged that, if his agency regulated tobacco as a drug. the overwhelming majority of tobacco products, if not all of them, would have to be banned. But because Commissioner Kessler recognizes the disastrous ramifications of Prohibition, he has asked Congress to give him "clear direction".

I am happy to provide the Commissioner with the direction he has requested. My direction is simple. LEAVE TOBACCO ALONE!

In reviewing the testimony offered to this Subcommittee on March 25. I find no convincing justification for giving the FDA additional authority to regulate tobacco. Much of Commissioner Kessler's testimony was focused on 33 of the more than 26.000 patents held by the cigarette manufacturers. Of those 33 patents Dr. Kessler focused his attention, he had no indication whatsoever that any of the patents were being used. I believe will today's testimony will substantiate the industry's assertion that none of these 33 patents are used to increase the level of nicotine in cigarettes.

The FDA's other "evidence" included charts which insinuate that nicotine levels are increasing in cigarettes while tar levels are decreasing. Such a suggestion flies in the face of several reports by the Surgeon General which clearly point out that nicotine and tar levels in cigarettes have fallen dramatically over the past 40 years and continue to do so at a ratio which approaches one-to-one.

The FDA has traditionally asserted no jurisdiction over tobacco under the Federal Food, Drug and Cosmetic Act because manufacturers make no health claims for the product. Commissioner Kessler now suggests that cigarettes should be treated as a "drug". regardless of how they are promoted to the consumer. He bases this proposal on the supposed "new" information that cigarette companies are apparently able to control nicotine levels in cigarettes. This reminds me of the Claude Rains character in "Casablanca" who declared he was "shocked, shocked" to discover that gambling was going on in Rick's cafe. For the past twenty or thirty years cigarette manufacturers have offered consumers cigarettes whose smoke contains substantially reduced amounts of both nicotine and tar. Clearly the fact that low-tar and nicotine brands have been in the marketplace for many years suggests that nicotine in finished cigarettes is not at the same level as that which occurs naturally in the cured tobacco leaf. However, in no case is the level of nicotine increased as Dr. Kessler asserted in his testimony last month.

Dr. Kessler appears to have joined forces with the neo-Prohibitionists. But their version of America is not one which my constituents or I share. We are also insulted at the comparisons made between cigarettes and illicit hard drugs, such as heroin and cocaine. 
Though I am not a chemist, it is brutally obvious to me that a tremendous difference exists between those who use legal tobacco products and those whose only concern is how to obtain their next fix of an illegal drug. Our prisons are not currently overflowing because of so-called cigarette addicts who steal, rob, injury and kill in order to obtain their next fix.

Tobacco growers are law abiding citizens who take umbrage at being associated with the likes of the Columbian drug cartel. And Dr. Kessler would now turn tobacco growers and smokers into criminals just because they choose to live their lives in a manner other than Dr. Kessler thinks they should. The FDA is directing us down a very serious and treacherous path. Let us not forget that this is an agency that cannot now fulfill its many other responsibilitles.

On behalf of the many small family farmers who proudly grow tobacco in North Carolina's Third Congressional District and support themselves and their families by laboring during the hot and humid eastern North Carolina summers, I urge this Subcommittee to join me in providing Commissioner Kessler with the direction he seeks, based on the facts we will hear today. I have no doubt that only conclusion will be to LEAVE TOBACCO ALONEI

I welcome today's panel of witnesses and am pleased that top executives of the major cigarette manufacturers have voluntarily agreed to testify, under oath, on the issue of nicotine in cigarettes. I look forward to hearing their testimony as I know they will provide this Subcommittee and Dr. Kessler with a complete picture of the issue instead of the mere conjecture we heard from the FDA a few weeks ago.

Mr. Chairman, thank you for convening this hearing so that every side of this issue can be properly and fairly aired.

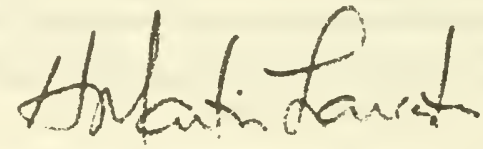


April 28, 1994

\section{TESTIMONY OF CONGRESSWOMEN KAREN SHEPHERD SUBMITTED TO THE HEALTH AND ENVIRONMENT SUBCOMMITTEE}

Thank you Mr. Chairman, for the opportunity to appear before your Subcommittee regarding the need to regulate tobacco products.

Most of us would never think of eating or drinking something filled with mystery ingredients, and we don't have to. Everything from chewing gum to shampoo clearly lists its ingredients on the side of the package. Except for cigarettes.

Unlike cosmetics and food, the law permits cigarettes to contain secret ingredients, which until now, have been guarded by the tobacco industry as trade secrets. The time has come to treat cigarettes like the dangerous consumer product that they are.

States and cities have long been cracking down on smoking in public. Utah Governor Mike Leavitt recently signed legislation which prohibits smoking in all public places, government buildings, schools and workplaces. I am co-sponsoring your bill, which would extend the ban nationwide. The Environmental Protection Agency has rated cigarette smoke a class-A carcinogen. The Occupational Safety and Health Administration has proposed banning smoking in the work place and the Food and Drug Administration is examining whether to regulate nicotine as a drug. In addition, tobacco companies have recently been accused of manipulating the nicotine levels in their cigarettes and conspiring to keep fire-safe cigarettes off the market.

Now questions have been raised over whether tobacco companies add dangerous chemicals to an already deadly product. Mr. Chairman, I watched in horror as the chief executive officers of the country's tobacco companies came before your 
Subcommittee and denied thet smoking poses a health risk. Smoking, one unenlightened CEO contended, is no more dangerous than eating twinkies.

The reality is smoking, unlike eating twinkies, kills a half a million smokers annually and drags 3,000 non-smokers to their graves through second-hand smoke. Smoking is the leading cause of preventable death in the United States. Smokers annually add $\$ 100$ billion to the national price tag for health care. An individual smoker will pay about $\$ 6,000$ in extra medical costs over a lifetime. Smoking costs businesses $\$ 47$ billion in 1990 in lost productivity, and all those statistics combined do not even begin to address the other health hazards of smoking, including fires caused by smokers, and increases in breast cancer rates for women.

Now we are confronted with the knowledge that tobacco companies have been adding chemicals to their cigarettes. Recently, National Public Radio reported that it had obtained a list-heretofore top secret-- of 700 chemicals added to cigarettes. At least two of the chemicals have been shown to cause liver damage and convulsions when tested on animals; and two of the chemicals are considered too dangerous to be allowed in municipal waste dumps. The list is considered a trade secret and is provided only to the Centers For Disease Control and, on a restricted basis, to a few Members of Congress.

Most of the chemicals on the list are well-known food additives. But there are six chemicals that are not food additives, but deadly chemicals that we know nothing about. Just how much Methoprene, "an active ingredient of a registered pesticide," does a human need to inhale before causing critical damage to their body? What are the cancer rates for long-term exposure to Dimethyltetrahydrobenzofuranone "a 
solvent that is flammable and has 'moderate' toxicity"? These chemicals must be researched. There has been an increase in breast cancer in women from 1 in 20 to 1 in 8 . True, this increase coincides with the increase in smoking among women, but are these chemicals also contributing to the higher cancer rates? In order to know we need research and full disclosure of the chemicals added to cigarettes.

We have trusted the tobacco companies long enough. They have withheld information and denied science. Profits are clearly more important to them than human health.

I have introduced legislation that would force cigarette companies to label their products. The goal of the legislation is to provide consumers with the same information they get before buying other products they take into or use on their bodies.

The fact is, you can walk into any grocery store and find extensive labeling on products. A simple can of soda pop has a label listing its fat, sugar and protein levels; how many calories it has and what ingredients it contains. The labels were mandated to help consumers make educated choices about what they put into their bodies. The labels were mandated to make sure companies are truthful in their advertising. And yet cigarettes--a product we know to be deadly, has only one thing printed on the side of the box: a warning label that smoking tobacco will cause, among other things, cancer. Warning people is a good start, but now we have reason to believe that consumers are smoking more than just tobacco. Until we push for strict regulations and force cigarette companies to make their ingredients known, consumers will continue to suffer the consequences. 
Mr. Waxman. Mr. Campbell, we'd like to start with you. And I guess the best thing to do is to pass the microphone right in front of you.

TESTIMONY OF WILLIAM I. CAMPBELL, PRESIDENT, PHILIP MORRIS U.S.A., ACCOMPANIED BY KATHY ELLIS, DIRECTOR OF RESEARCH; JAMES W. JOHNSTON, CHAIRMAN, RJ REYNOLDS TOBACCO CO., ACCOMPANIED BY ANDY SCHINDLER, HEAD OF MANUFACTURING, AND RICHARD COOPER, COUNSEL; THOMAS E. SANDEFUR, JR., CHAIRMAN, BROWN \& WILLIAMSON TOBACCO CORP., ACCOMPANIED BY TILFORD F. RIEHL, VICE PRESIDENT; ANDREW H. TISCH, CHAIRMAN, LORILLARD TOBACCO CO., ACCOMPANIED BY ALEXANDER SPEARS III, VICE CHAIRMAN; DONALD S. JOHNSTON, PRESIDENT, AMERICAN TOBACCO CO.; EDWARD A. HORRIGAN, JR., CHAIRMAN, LIGGETT GROUP, INC.; AND JOSEPH TADDEO, PRESIDENT, U.S. TOBACCO CO.

Mr. CAMPBEll. Thank you, Mr. Chairman, distinguished members of the subcommittee. In recent weeks a number of charges have been leveled against the tobacco industry generally, and Philip Morris specifically. I sincerely hope that you and other members of the subcommittee are today interested in separating the facts from the rhetoric regarding issues raised a few weeks ago in Commissioner Kessler's presentation.

$\mathrm{Be}$ that as it may, our consumers are being misled and when that happens Philip Morris has and will continue to speak out loudly and clearly. Our consumers deserve to know the truth, and I thank you for creating a forum that allows me the opportunity to set the record straight. I have a few charts to supplement my testimony. We have copies of them available here.

Philip Morris does not add nicotine to our cigarettes. Philip Morris does not manipulate nor independently control the level of nicotine in our products. There were a number of incorrect statements or assumptions in Commissioner Kessler's presentation. These issues are not new and many require a detailed rebuttal.

The claim that cigarette smoking is addictive has been made for many years. The fact that tar and nicotine levels vary among our many products has been publicized for over 20 years. The process by which cigarettes are manufactured, and which at our invitation FDA representatives saw first hand several weeks ago, has been publicly known for over 50 years. And the call for FDA to assert or be given jurisdiction over cigarettes has been made and rejected by the FDA and the courts on several occasions in the past.

To the extent possible in the time available today, my colleagues and I will try to answer the subcommittees questions, and we will be happy to supplement the points we make in a detailed written submission.

Point one, Philip Morris does not add nicotine to our cigarettes. The claim that Philip Morris secretly adds nicotine during the manufacturing process to keep smokers addicted is false. The processes used to manufacture cigarettes have been a matter of public record for years in patent filings and in the published literature.

The result of that processing, cigarettes with varying levels of tar and nicotine reflecting a wide variety of consumer preferences, has 
been closely monitored and reported by the Federal Trade Commission. The manufacturers have published the deliveries in every advertisement for the past 25 years.

The fact is that tar and nicotine levels have decreased dramatically over the past 40 years. Today the market is populated with a number of ultra low brands which deliver less than 5 percent of the tar and nicotine levels of popular brands just 20 years ago.

Philip Morris and other manufacturers have reduced nicotine deliveries in a number of ways. The most important is through the use of increasingly efficient filters which substantially reduced main smoke components, including both tar and nicotine. Filtration alone reduces nicotine delivery by 35 to 45 percent as compared to cigarettes made of simply tobacco and paper.

Through a process called ventilation, which allows fresh air to be drawn through the cigarette, nicotine levels are reduced by a further 10 to 50 percent. Through the use of expanded tobacco, a process developed by which Philip Morris puffs tobacco much like puffed rice cereal, tar and nicotine levels are reduced still further.

A fourth manufacturing technique, the reconstituted tobacco process, also reduces the nicotine in cigarettes. This process which has been thoroughly described in the literature for years does not increase nicotine levels in tobacco or in cigarettes. Through this process 20 to 25 percent of the nicotine in the tobacco used to make reconstituted leaf is lost and is not replaced.

These processes, when combined in cigarettes Philip Morris sells today, reduce nicotine deliveries, for example, by 50 percent in the case of Marlboro, and 90 percent in the case of Merit Ultima; again, compared to cigarettes made simply of tobacco and paper.

Ignoring these reductions, some critics have focused on the minute amounts of nicotine which are found in tobacco extracts and denatured alcohol. Even when used together, they have no measurable effect on the nicotine levels of our cigarettes. Philip Morris uses small amounts of denatured alcohol to apply flavors to the tobacco.

The alcohol is denatured, in fact, in order to make it drinkablenon-drinkable under a formula required by the Bureau of Alcohol, Tobacco, and Firearms, and found in the Federal Register. In other words, the outside vendors who supply us with the denatured alcohol use that tiny amount of nicotine solely to comply with the Federal law. All use by Philip Morris is reported annually to the B.A.T.F.

Philip Morris has spent hundreds of millions of dollars to reduce tar and nicotine levels to provide the products that the marketplace demands. Why, if we were supposedly intent on adding nicotine to cigarettes, why would Philip Morris have spent over $\$ 300$ million to develop a process to denicotinize tobacco and launch next a near zero nicotine brand?

I'll tell you why. Our public opinion research indicated smokers were interested in a no-nicotine cigarette. Our Maxwell House Coffee Company had pioneered processes for decaffeination of coffee, and we used that technology as a spring board for denicotinization of tobacco. The process worked the resulting product did not. 
We gambled $\$ 300$ million and lost. That's business. If Philip Morris does not strive constantly to meet consumer demand, we will fail in the American marketplace.

Point two. Philip Morris does not manipulate nor independently control the level of nicotine in our products. We voluntarily opened our manufacturing operations to the FDA in a good faith effort to resolve the allegation that we add nicotine or control its level in our cigarettes. As representatives of the FDA learned, nicotine levels in tobacco are measured at only two points in our manufacturing process, prior to the tobaccos being blended, and then 18 months later when those leaves have been manufactured into finished cigarettes.

Although Philip Morris maintains over 400 quality control checkpoints in the manufacturing process that measure things like moisture, weight, et cetera, none, not one, measure, report, or analyze nicotine levels in tobacco.

Commissioner Kessler indicated in his testimony that the nicotine to tar ratio increased as tar delivery decreased. The reason for the slight increase in the nicotine to tar ratio in lower tar and nicotine cigarettes is not the result of intentional manipulation but the result of the difference between filtering tar and filtering nicotine.

Simply put, filters are more efficient in removing tar than nicotine. As tar and nicotine levels fall, proportionally more tar is filtered out than nicotine. This does not mean that consumers of low tar cigarettes get more nicotine. Quite the contrary. On an absolute basis, far less nicotine is delivered per cigarette in lower tar and nicotine deliveries.

Commissioner Kessler suggested that during the period 1982 to 1991 tar delivery levels have remained flat while nicotine delivery levels have increased. The fact is, after substantial decreases since the 1950's, tar and nicotine levels both have remained relatively flat during the past decade.

Fact three. Philip Morris has not used patented processes to increase or maintain nicotine levels. Commissioner Kessler spent a great deal of his testimony attempting to support the proposition that Philip Morris may be using secret patented processes to increase or maintain nicotine delivery in our cigarettes. We have not. We are not.

Philip Morris, like every other corporation, applies for and obtains patents on virtually every innovation that we pioneer. That is critical to ongoing research efforts. Philip Morris currently holds over 600 patents, only about a quarter describe processes ever used. The processes described in the patents are no more secret than the regulations of the FDA. They are publicly disclosed upon issuance through the U.S. Patent Office.

In his testimony, Commissioner Kessler said he had no evidence that Philip Morris or any of the other companies ever actually used any of these patents to increase or maintain nicotine levels. As he correctly said, patents do not necessarily tell us what processes are currently being used in manufacturing cigarettes. To make myself perfectly clear, Philip Morris has never used any of the patents Commissioner Kessler cited except those to reduce nicotine levels.

Fact four-point four. Cigarette smoking is not addictive. During the March 25th hearing, Commissioner Kessler and members of 
the subcommittee contended that nicotine is an addictive drug, and, therefore, smokers are drug addicts. I strenuously object to that premise. I strenuously object to that conclusion.

Cigarettes contain nicotine because it occurs naturally in tobacco. Nicotine contributes to the taste of cigarettes and the pleasures of smoking. The presence of nicotine, however, does not make cigarettes a drug or smoking an addiction.

Coffee, Mr. Chairman, contains caffeine, and few people seem to enjoy coffee that does not. Does that make coffee a drug? Are coffee drinkers drug addicts? I think not.

People can and do quit smoking. According to the 1988 Surgeon General's Report, there are more than 40 million former smokers in the United States, and 90 percent of those who quit did so on their own, without any outside help. Smoking is not intoxicating, no one gets drunk from cigarettes, and no one has said that smokers do not function normally. Smoking does not impair judgment. In short, no one is likely to be arrested for driving under the influence of cigarettes.

Our consumers smoke for many reasons. Smokers are not drug users or drug addicts, and we do not appreciate or accept being characterized as such because, yes, Mr. Chairman, I am one of the 50 million smokers in this country.

Point five. Philip Morris research does not establish that smoking is addictive. At the March 25th hearing, Commissioner Kessler made the statement, supported by Dr. Heningfield, that in 1983 a company, later identified as Philip Morris, suppressed research by one of its own scientists who, allegedly, concluded that nicotine was an addictive substance.

That is false. In fact, that scientist published two full papers and five abstracts related to the work in question, including one published in 1982, a year prior to the creation of the manuscript in question. The manuscript subsequently provided to the committee by Commissioner Kessler, presented some evidence that rats will self-administer nicotine, and that nicotine, therefore, is a weak reinforcing agent.

The researcher later concluded that nicotine is a reinforcer in the class of non-addictive chemical compounds such as saccharin and water. In addition, and Commissioner Kessler failed to note this, the manuscript itself states, and I quote, "Termination of prolonged access to nicotine under conditions in which it functions as a positive reinforcer does not result in physiological dependence."

Thus the manuscript did not conclude that nicotine is addictive. And both Dr. Kessler and Dr. Heningfield know that. More importantly, the committee should know that by the time the Philip Morris researcher was ready to publish his study in 1983, the positive reinforcing nature of nicotine had already been reported in other published literature.

Indeed, the 1988 Surgeon General's Report, to which Dr. Heningfield was a contributor, stated that such nicotine reinforcement was shown conclusively, as early as 1981, based on Government-supported research. Last month Dr. Heningfield testified before this committee that because the manuscript was unpublished, he could not cite it in his literature reviews. In fact, Dr. 
Heningfield did cite the manuscript in a 1984 literature review he wrote.

Finally, in that same review, Dr. Heningfield acknowledged that another abstract by the same researcher actually showed that even, and I quote, "At high levels of tobacco smoke or nicotine intake, maintained for extended periods, abrupt abstinence is not followed by the onset of withdrawal syndrome." I'm sure Dr. Heningfield simply forgot that publication.

Point six. Consumers are not misled by the published nicotine deliveries as measured by the FTC method. Contrary to the impression given by Commissioner Kessler that the FTC has somehow adopted a test procedure that can mislead the public as to the true levels of tar and nicotine they are inhaling.

The routine analytical smoking methods derived from the FTC method are nearly identical to those used throughout the world to measure tar and nicotine levels and accurately compare brand deliveries. All of the tests are conducted on cigarettes obtained from the marketplace. They are therefore the same cigarettes smoked by consumers.

Commissioner Kessler suggested that the FTC figures were misleading because smokers might compensate for a lower tar and lower nicotine brand by smoking those cigarettes differently. If Commissioner Kessler is also claiming that lower yield cigarette smokers smoke more cigarettes, he is simply wrong. The data show smokers of low yield brands smoke fewer cigarettes than smokers of high yield brands.

Mr. Chairman, we at Philip Morris appreciate the opportunity to respond to some of the claims made against us. We will be pleased to answer any questions you may have about these matters, and to provide a more detailed written submission, should that be appropriate.

Further, I extend to you and the other members of your subcommittee an invitation to come see our manufacturing process first hand, as the FDA has already done. We're proud of our company, our products, and the people at Philip Morris. Thank you, Sir.

[Testimony resumes on p. 558.]

[The prepared testimony of Mr. Campbell follows:] 
Statement of William I. Campbell President and Chief Executive officer of Philip Morris U.S.A.

\section{before the}

Subcommittee on Health and the Environment House Energy and Commerce Committee

$$
\text { April 14, } 1994
$$

Mr. Chairman and distinguished Members of the subcomittee. I am here today at your request, and I would like to take this opportunity to set the record straight on charges that have recently been made against the industry and Philip Morris. First, Philip Morris does not add nicotine to our cigarettes. Second, Philip Morris does not "manipulate" or independently "control" the level of nicotine in our products. Third, Philip Morris has not used patented processes to increase or maintain nicotine levels. Fourth, cigarette smoking is not addictive. Fifth, Philip Morris has not hidden research which says that it is. And, finally, consumers are not misled by the published nicotine deliveries as measured by the FTC method.

Mr. Chairman, I trust that you and the other Members of the subcommittee are sincerely interested in learning the facts about the various issues raised a few weeks ago in Commissioner Kessler's presentation -issues which, I might add, are not new. The claim that 
cigarette smoking is addictive has been made for many years. The fact that tar and nicotine levels vary among our many products has been publicized for over 20 years. The process by which cigarettes are manufactured, and which, at our invitation, FDA representatives saw firsthand several weeks ago, has been publicly known for over 50 years. And the call for the FDA to assert, or be given, jurisdiction over cigarettes has been made and rejected by the FDA and the courts on several occasions in the past.

There were a number of incorrect statements or assumptions in Dr. Kessler's presentation. Many require a detailed rebuttal. To the extent possible in the time available today, I will try to respond to them and to the subcommittee's questions.

\section{PHILIP MORRIS DOES NOT ADD NICOTINE TO OUR CIGARETTES}

The claim that Philip Morris secretly adds nicotine during the manufacturing process to "keep smokers addicted" is a false and irresponsible charge. The processes used to manufacture cigarettes have been publicly disclosed for years in patents and the published literature. And the results of that 


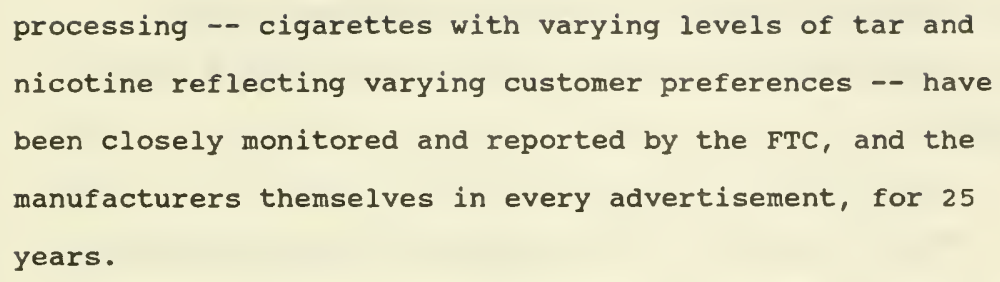

Philip Morris and other manufacturers have reduced delivery in a number of ways. The most important is the use of increasingly efficient filters which substantially reduce many smoke components, including both tar and nicotine. Filtration reduces nicotine delivery $35 \%$ to $45 \%$ in.today's brands, as compared to a "standard" cigarette made simply of tobacco and paper.

Through a process called ventilation, nicotine levels are reduced by $10 \%$ to $50 \%$. Through the use of expanded tobacco -- a process developed by Philip 
Morris, in which tobacco is "puffed" much like puffed rice cereal -- tar and nicotine levels are reduced still further.

There has been a fair amount of recent discussion of the reconstituted tobacco process. Again, that process has been thoroughly described for years in the published literature. In that process, stems and small leaf parts are re-formed into a paper-like sheet. The reconstituted leaf process does not increase nicotine levels in tobacco or cigarettes. To the contrary, $20 \%$ to $25 \%$ of the nicotine in the tobacco used to make reconstituted leaf is lost and not replaced.

These processes, when combined in the cigarettes Philip Morris sells today, reduce nicotine delivery levels by more than $50 \%$ in the case of Marlboro, to $96 \%$ in the case of Merit Ultima, as compared to a "standard" cigarette made of nothing but tobacco and paper.

Ignoring these reductions, some critics have focused on minute amounts of nicotine that are found in tobacco extracts and denatured alcohol -- which together have no measurable effect on nicotine delivery of our cigarettes. 
Philip Morris uses denatured alcohol to spray flavors on the tobacco. The alcohol is denatured -that is, it is made to taste bitter so that no one will drink it -- under a formula required by the BATF and found in the Federal Register.

Again, the small amount of nicotine found in denatured alcohol and tobacco extracts cannot be measured in cigarette smoke.

The expenditure of millions of dollars to reduce tar and nicotine in these various ways undercuts any suggestion that Philip Morris is "intent" on adding nicotine to its cigarettes in an effort to "maintain" nicotine levels or to "addict" smokers.

II. PHILIP MORRIS DOES NOT "MANIPULATE" OR INDEPENDENTLY "CONTROL" THE LEVEL OF NICOTINE IN OUR PRODUCTS

The cigarette industry, markets and advertises products by tar category to satisfy a variety of consumer preferences. Within tar categories, we attempt to provide a competitive advantage by providing the best possible taste. 
When creating a cigarette for a tar category, we select a particular tobacco blend and flavors to provide "uniqueness" for the product. The most significant parameters for determining tar delivery are the amount of expanded tobacco used, filtration efficiency, and ventilation.

So, how do we "manipulate" or independently "control" nicotine as our critics charge? The answer is we don't. We accept the nicotine levels that result from this process.

As representatives of the FDA learned when, at our invitation, they recently visited our manufacturing center in Richmond, nicotine levels in tobacco are measured at only two points in the manufacturing process -- at the stemmery, where tobacco leaves are prepared for processing, and then 18 months later after those leaves have been manufactured into finished cigarettes. Although Philip Morris maintains over 400 quality control checkpoints in the manufacturing process -- for example, moisture levels, weight, etc. -- none measures, reports or analyzes nicotine levels in tobacco. 
III. PHILIP MORRIS HAS NOT USED PATENTED PROCESSES TO INCREASE OR MAINTAIN NICOTINE LEVELS

Commissioner Kessler spent a great deal of his recent testimony attempting to support the proposition that Philip Morris may be using secret patented processes to increase or maintain nicotine delivery in our cigarettes. We are not.

The processes described in the patents referred to by Commissioner Kessler are not at all secret but, rather, were publicly disclosed years ago, first to the U.S. government and then to the world.

Philip Morris in fact has never used any of the processes described in these patents to increase, or even maintain, nicotine levels in any of its products. To the contrary, the only patents cited by commissioner Kessler which Philip Morris has ever used were for the reduction and in some cases the virtual elimination of nicotine.

IV. CIGARETTE SMOKING IS NOT ADDICTIVE

During the March 25 hearing, Dr. Kessler and some Members of the subcommittee contended that nicotine is 
an addictive drug and that, therefore, smokers are drug addicts. I object to the premise and to the conclusion.

Many people like to smoke. Some people like the look and feel of the pack or the smell of tobacco. Some like to hold and fiddle with a cigarette. And, of course, there is the taste and aroma of the tobacco, and the sight of the smoke.

Cigarettes contain nicotine because it occurs naturally in tobacco. Nicotine contributes to the taste of cigarettes and the pleasure of smoking. The presence of nicotine, however, does not make cigarettes a drug or smoking an addiction.

People can and do quit smoking. According to the 1988 Surgeon General's Report, there are over 40 million former smokers in the United States, and $90 \%$ of smokers quit on their own, without any outside help.

Further, smoking is not intoxicating. No one gets drunk from cigarettes, and no one has said that smokers cannot function normally. Smoking does not impair judgment. No one is likely to be arrested for driving under the influence of cigarettes. 
In short, our customers enjoy smoking for many reasons. Smokers are not drug addicts.

V. PHILIP MORRIS RESEARCH DOES NOT ESTABLISH THAT SMOKING IS ADDICTIVE

At the March 25 hearing, Commissioner Kessler repeated the charges of Dr. Jack Henningfield, that in 1983, a company, later publicly identified as Philip Morris, suppressed research by one of its scientists which allegedly concluded that nicotine was an addictive substance. That claim is false.

In fact, that scientist published two full papers and five abstracts concerning the work in question prior to the creation of the manuscript in question. That manuscript, which was subsequently provided to the Subcommittee by Commissioner Kessler, did present some evidence that nicotine will be self-administered by rats and is, therefore, a "weak" reinforcing agent. But the manuscript itself states:

"that termination of prolonged access to nicotine under conditions in which it functions as a positive reinforcer does not result in physiological dependence." 
The manuscript thus did not conclude that nicotine is "addictive."

Moreover, by the time the Philip Morris researcher was ready to publish this information (1983), the "positive reinforcing" nature of nicotine had already been reported in other published literature. Indeed, the 1988 surgeon General's Report states that such nicotine reinforcement was "shown conclusively" as early as 1981, based on government-supported research.

VI. CONSUMERS ARE NOT MISLED BY THE PUBLISHED NICOTINE DELIVERIES AS MEASURED BY THE FTC METHOD

Contrary to the impression given by Commissioner Kessler that the FTC has somehow adopted a test procedure that misleads the public as to the true levels of $\operatorname{tar}$ and nicotine they are inhaling, the routine Analytical Smoking Methods derived from the FTC method are nearly identical to those used throughout the world to measure tar and nicotine deliveries and accurately compare brand deliveries.

All of the tests are conducted on cigarettes obtained from the marketplace. They are, therefore, the 
same cigarettes smoked by the consumer after all cigarette manufacturing processes have been completed.

As a result of this testing, the nicotine delivery of all commercial cigarettes is measured and disclosed to the tenth of a milligram, both in public releases by the FTC and, perhaps more importantly, in every cigarette advertisement.

Commissioner Kessler suggested that the FTC figures were misleading because smokers might "compensate" for lower tar and lower nicotine brands by smoking those cigarettes differently. In fact, the data indicates that, despite the dramatic reductions in tar and nicotine levels over the past decades, the number of cigarettes smoked by an individual has remained constant, and even declined slightly. More importantly, the data shows no difference in the number of cigarettes smoked by those who favor higher and lower yield brands.

Mr. Chairman, we at Philip Morris appreciate having the opportunity to respond to some of the claims made against us. We will be pleased to answer any questions you may have about these matters and to provide a more detailed written submission should that be appropriate. 
Mr. WaXMan. Thank you very much, Mr. Campbell. We do have questions, but we're going to hear from all of the witnesses before members on the panel ask their questions. Mr. James Johnston? Please pull the microphone in front of you?

\section{TESTIMONY OF JAMES W. JOHNSTON}

Mr. JAMES Johnston. Good morning, Mr. Chairman, members of the subcommittee. Again, I am Jim Johnston, chairman and chief executive officer of RJ Reynolds Tobacco Company. I appreciate this opportunity to discuss a number of important issues concerning the tobacco industry.

I am proud to be here to day to speak for the 45 million adults who choose to smoke, and the growers, retailers, and the other 2.3 million Americans who are part of the tobacco industry. I am proud to represent the more than 10,000 people at Reynolds Tobacco, who are dedicated to making the best cigarettes that we can make.

My company and I take very seriously the allegations that have leveled against us. And I would like the record to clearly show that Reynolds Tobacco does not spike its products with nicotine. In fact, our process results in the loss of nicotine. We do not add, or otherwise manipulate nicotine to addict smokers. Finally, there is no justification for the FDA to regulate cigarettes as a drug.

I also want to talk to you about the real issue before the American people and this subcommittee. The real issue is, should cigarettes be outlawed? Let's make no mistake about it, the goal of the anti-smoking industry is to bring back prohibition. This morning I intend to show you how they hope to achieve that goal.

But, first, I want to address the charge that Reynolds Tobacco manipulates the level of nicotine in its products, the implication is that we are somehow doing something sinister to addict smokers or to keep them addicted. We do not.

We do reduce the amount of nicotine in our products. We do monitor and measure tar and nicotine yields because we are required to publish those figures in our advertising. And we do maintain the consistent taste and quality of our brands which our customers expect. But we do not do anything to hook smokers or to keep them hooked.

Let me repeat, we do not manipulate nicotine to addict smokers. We no more manipulate nicotine in cigarette than coffee manufacturers manipulate caffeine in their products. There is nothing sinister about it.

I think the subcommittee should also be aware that Dr. Kessler's definition of addiction would classify most coffee, cola, and tea drinkers as addicts, caffeine addicts. Many people experience a strong urge for a cup of coffee each morning, and there is a welldocumented physical withdrawal syndrome associated with the consumption of coffee and caffeinated soft drinks.

Nonetheless, I seriously doubt that the American public would say that these characteristics put caffeine in the same class as addictive drugs such as cocaine and heroin. And I don't think anyone would seriously suggest that the FDA consider regulating coffee, tea, or soda as drugs, even though soft drink manufacturers routinely add caffeine to their products. 
In the same vein, the manufacturers of alcoholic beverages constantly monitor the alcohol content of their products through the fermentation process to precisely control the level of alcohol. In addition, some wines are fortified with added alcohol. Nonetheless, Reynolds Tobacco is not aware of any efforts to regulate wine, beer, or spirits as a drug. And we certainly don't believe that efforts of that type are necessary or desirable.

Much of the recent controversy surrounding our products is focused on our use of various techniques that help us reduce the tar and nicotine yields of our products. Let me be clear. We could stop using those techniques. We could chop up the tobacco and roll it in paper, but the consequence of doing that would be a return to the 1940 's, when the average cigarette yielded 40 milligrams, 2.8 milligrams of nicotine. That would increase the tar and nicotine in our cigarettes by 300 to 400 percent. I trust this committee would not endorse such an effort as a matter of public policy, regardless of your personal views about smoking.

At the last hearing on this subject, some people asked why we don't simply eliminate from our products. Nicotine plays an essential role in the overall smoking experience. It enhances the taste of the smoke and the way it feels on the smoker's palate, and it contributes to the overall smoking enjoyment. During the past several years there have been a wide variety of attempts to convince the American public that cigarettes are addictive, and some public officials have even gone so far as to put cigarettes in the same class as cocaine and heroin.

You don't need to be a trained scientist to see this isn't true. All you need to do is ask and honestly answer two simple questions. First, would you rather board a plane with a pilot who just smoked a cigarette, one with a pilot who just had a couple of beers, or snorted cocaine, or shot heroin, or popped some pills?

Second, if cigarettes were addictive, could almost 43 million Americans have quit smoking, almost all of them on their own without any outside help? The answers are obvious, and that is precisely my point. Cigarettes are clearly not in the same class as addictive, mind-altering like heroin and cocaine.

I agree that for some people cigarette smoking is habit forming in the same way that other pleasurable activities such as watching TV, eating your favorite foods, sometimes overeating your favorite foods, and drinking coffee can be habit forming. And, yes, some smokers find it difficult to quit.

But there is nothing about cigarette smoking that prevents a person from clearly thinking and making reasoned decisions, including the decision to quit. The allegation that smoking cigarettes is addictive is part of a growing and disturbing trend that has destroyed the meaning of the term by characterizing virtually any enjoyable activity whether it is eating sweets, drinking coffee, playing video games, or watching TV. This defies common sense.

Now, let's go to the real issue, prohibition. The anti-smoking industry is committed to achieving what essentially amounts to prohibition. When confronted, they will tell you they don't want prohibition, but their actions belie those claims. Regardless of what we in the tobacco industry do, our opponents in the anti-smoking industry cry "Foul." We produce high tar cigarettes and they say, 
"Reduce tar and nicotine." We lower those levels and they say, "It doesn't matter, regulate those products as drugs."

Let me cite just two examples. When Philip Morris introduced a cigarette that was essentially nicotine-free, the Coalition on Smoking OR Health called it, quote, "The most dangerous product put on the market in the last 10 years." And they petitioned the FDA to ban it.

Several years ago our company test marketed a cigarette that had virtually no tar and less nicotine than 97 percent of the cigarettes on the market. It virtually eliminated second-hand smoke, and was essentially fire safe. The response? The product and our company were viciously attacked, and petitions were filed with the FDA to ban the product. The bottom line is, in the eyes of the antismoking industry, we can do nothing right short of firing our employees and going out of business.

A good example is the recent use of scare tactics concerning the ingredients used by the tobacco industry. Ingredients are added to our product to enhance the flavor and aroma of our products. And despite all the claims that have been made about our ingredients, the fact is more than 99.99 percent of this Winston cigarette, and all the cigarettes we make, 99.99 percent is tobacco and ingredients that can be lawfully used in foods. The other $1 / 100$ th of 1 percent are ingredients that have been approved by other governments for use in tobacco products.

In addition, all the ingredients used by the industry have been thoroughly reviewed by a blue ribbon panel of experts, scientific experts, toxicologists, who have concluded that those ingredients are, and I quote, "Not hazardous under the conditions of use." So let's be clear about the fact that the anti-smoking industry's call for a smoke-free society by the year 2000 is little more than a thinly veiled attempt to achieve back door prohibition.

If you don't believe that is the case, just look at how extreme some of these efforts are, like trying to prohibit people from smoking outdoors, in public parks, in their cars, or even their own homes. And consider this, alcohol prohibition started with the antialcohol movement, claiming that their goal was simply temperance.

The American public overwhelmingly opposes prohibition whether it comes in through the front door or sneaks in through the back door. So let's be clear about the fact that back door prohibition is prohibition nonetheless. Raising taxes to force smokers to quit is back door prohibition. Banning smoking in all public places, indoors and outdoors, including parks, work places, and outdoor stadiums to further stigmatize smokers is back door prohibition.

Banning advertising so that new or better products can't be effectively communicated and introduces is censorship and it is back door prohibition. Forcing manufacturers to produce products that smokers find unsatisfying or unacceptable is back door prohibition. Attacking every attempt by the industry to respond to public and smoker concerns is back door prohibition.

And advocating that the FDA regulates cigarettes as a drug, which would effectively ban cigarettes from the market, is clearly back door prohibition.

If any member of this subcommittee truly believed that cigarettes are too dangerous to be sold, then stand up, vote for prohibi- 
tion and be prepared for the consequences. But no one should try to use the back door and force prohibition by saying cigarettes are a drug because they contain tobacco which contains nicotine. My company and I must speak up for smokers and for the 85 percent of all Americans who oppose prohibition.

So I submit the real question before the American public and this subcommittee is this, should cigarettes be outlawed? Will adults be allowed to choose to smoke, to afford to smoke, to smoke outside their homes, or is it time to say, "No, the Government knows better." Thank you.

[Testimony resumes on p. 590.]

[The prepared statement of James W. Johnston follows:] 


\section{Statement of R. J. Reynolds Tobacco Company}

R.J. Reynolds Tobacco Company ("Reynolds Tobacco") welcomes this opportunity to respond to the inaccurate and misleading attacks that have precipitated these hearings. For the past several weeks, Reynolds Tobacco and the rest of the tobacco industry have been bombarded with spurious and inflammatory claims. Our responses to these charges are simple and straightforward:

- Does Reynolds Tobacco add nicotine to its products? No.

- Does Reynolds Tobacco manipulate nicotine yields to create, maintain, or satisfy "addiction"? Again, the answer is no.

- Does Reynolds Tobacco hold patents for technology that relates to modification of nicotine yields independent of "tar" yields? Yes. In fact, for years some governments, smoking and health critics, and international public health scientists have encouraged such developments in cigarette design.

- Is Reynolds Tobacco using such technology commercially? No.

- Is cigarette smoking an "addiction"? No, cigarette smoking is not an "addiction" under any meaningful definition of the term, including the new definition presented by Dr. Kessler before this Subcommittee.

There is no factual or policy basis to regulate or ban cigarettes as drugs simply because they contain nicotine or simply because cigarette manufacturers have the ability to reduce the nicotine yields of their products. This company is not engaged in some sinister plot to deceive the American smoker.

\section{Progress or Prohibition}

If this Subcommittee fairly and objectively evaluates the true facts about cigarette design, it must find that the efforts of Reynolds Tobacco and others in the industry demonstrate a remarkable record of achievement and progress. This company is justifiably proud of those accomplishments and of the dedicated and talented employees who have 
contributed and now contribute to them. We regret that others seek to advance an agenda of prohibition over progress.

Today, we are here to discuss whether there is a basis for FDA regulation of cigarettes as drugs. Contrary to many reports, this issue is not novel. In fact, the question has been advanced and rejected many times before. For example, twenty-two years ago, the Commissioner of the Food and Drug Administration (FDA), Dr. Charles C. Edwards, testified at a hearing similar to this one before the Consumer Subcommittee of the Senate Committee on Commerce. Dr. Edwards stated, "Cigarettes and other tobacco products would be drugs subject to the Federal Food, Drug and Cosmetic Act if medical claims are made for the product .... However, cigarettes recommended for smoking pleasure are beyond the Federal Food, Drug, and Cosmetic Act."1 Dr. Edwards was echoing a conclusion that has been consistently reached - both by FDA and the courts prior to and after his statement. $^{2}$

Three weeks ago, FDA Commissioner Dr. David Kessler appeared before this Subcommittee and testified extensively concerning the "task facing the FDA," which he characterized as "to determine whether nicotine-containing cigarettes are 'drugs' within the

1 To Amend the Federal Cigarette Labeling and Advertising Act to Require The Federal Trade Commission to Establish Acceptable Levels of Tar and Nicotine Content of Cigarettes, 1972: Hearings on S.1454 Before the Consumer Subcomm. of the Senate Comm. on Commerce, 92nd Cong., 2d Sess. 239 (1972) (statement of Charles C. Edwards, Comm., FDA).

2 See, e.g., FTC v. Liggett and Myers Tobacco Co., 108 F.Supp. 573 (S.D.N.Y. 1952), aff'd on op. below, 203 F.2d 955 (2d Cir. 1953); Letter from Donald Kennedy, Commissioner of Food and Drugs, to John F. Banzhaf, III, Dkt. No. 77P-0185 (December 5, 1977); Action on Smoking \& Health v. Harris, 655 F.2d 236 (D.C. Cir. 1980). 
meaning of the Federal Food, Drug, and Cosmetic Act." All cigarettes sold are "nicotinecontaining cigarettes," and indeed the tobacco plant is known as nicotiana tabacum in recognition of the fact that it naturally contains nicotine. Moreover, the facts relevant to whether FDA has jurisdiction over cigarettes today are substantially the same as when Dr. Edwards testified in 1972 and when the FDA rejected petitions to regulate cigarettes in 1977 and on other occasions. At those times, as is the case today, a variety of cigarette brands was available to consumers which yielded a variety of "tar" and nicotine levels. Through advances in cigarette design and in response to consumer preferences, however, the average cigarette sold today yields one-third less "tar" and nicotine than when Dr. Edwards testified.

\section{Cigarette Design}

How and why have these reductions in "tar" and nicotine yields come about? To evaluate these questions completely, it is imperative to consider the evolution in the design of cigarettes over the last forty years -- an evolution that, in its purpose and effect, differs significantly from the grossly inaccurate allegations and misrepresentations by our critics in these proceedings and recently in the press. In short, Reynolds Tobacco designs cigarettes to respond to consumer demand and to attempt to address the many scientific and other criticisms that have been leveled at our products for more than forty years. Today's cigarettes reflect the enormous efforts to respond directly to consumer demand and those criticisms and suggestions. A very brief discussion of the history of cigarette design will illustrate why these recent claims are misguided.

Early cigarettes were primarily cut tobacco (much like pipe tobacco) wrapped in paper, with flavorings such as the oil of citrus peels. The quality of a cigarette depended 
primarily on the single type of tobacco it contained -- Turkish tobacco was used in premium cigarettes and domestic air-cured or flue-cured tobacco was used in less expensive cigarettes. The first American blend cigarette, which combined both Turkish and domestic tobacco, was Reynolds Tobacco's Camel brand, introduced in 1913. Although slightly different blends and different materials were used in cigarette manufacturing, cigarettes remained largely unchanged until the early 1950 s.

At that time, most cigarettes produced in the United States were made from fluecured, burley and Turkish tobaccos. They were $70 \mathrm{~mm}$ long and unfiltered. When smoked, these cigarettes yielded an average of $40 \mathrm{mg}$ of "tar" and $2.8 \mathrm{mg}$ of nicotine by methods comparable to those used by the United States Federal Trade Commission (FTC). (The FTC methods became official in 1969).

A number of watershed developments in the early 1950 s led to another evolution in cigarette design. Several epidemiologic studies published during the early 1950 s reported that there was a statistical association between cigarette smoking and lung cancer. Also, in 1953, Dr. Ernst Wynder and others published the results of a mouse skin painting experiment in which the researchers observed skin tumors on the backs of mice exposed to cigarette smoke condensate. All these studies were widely publicized in the general media and the media coverage affected consumer demand. Reynolds Tobacco in turn has made extensive efforts to respond to these scientific theories and demands and the tastes of its consumers to produce a broad array of products.

Since the 1950s, Reynolds Tobacco, among many other lines of research, has pursued two basic lines of research and development in this area: (i) identification of individual 
constituents in tobacco smoke and development of technology to attempt to reduce or remove those of potential concern, and (ii) development of new technologies to reduce yields of "tar" and nicotine generally. The first line of research has had limited success; the second line of research has been remarkably successful.

\section{Selective Reduction}

During the 1950 s and early 1960s, many researchers focused on one chemical constituent of smoke (or a family of constituents) in the search for a "cancer-causing" agent that would explain the epidemiologic and skin painting results. This focus turned to disappointment, as reflected in the 1964 Report of the Advisory Committee to the Surgeon General ("Surgeon General's Report"). From the mid-1950s until today, a succession of constituents has been targeted by the biomedical community. Even today, however, the biomedical community has been unable to agree on which, if any, of those constituents is responsible for the reported association between cigarette smoking and lung cancer.

Cigarette manufacturers and others explored and published numerous methods to reduce or eliminate individual constituents (or a family of constituents) in cigarette smoke, e.g., reducing the temperature at which the cigarettes burned, breeding tobacco plants to change the chemical composition of the tobacco, and adding different types of filters or other filtration mechanisms to the cigarette. Unfortunately, manufacturers faced a moving target as the focus changed from constituent to constituent. Constituents of concern at one point in time were later determined by the scientific community to be of no significance. Moreover, techniques that might have selectively reduced a constituent in the laboratory 
commonly increased another constituent. In general, efforts to reduce individual constituents have not been successful.

\section{General Reduction}

During the same period, Reynolds Tobacco and other cigarette manufacturers also directed their research to attempt to reduce levels of all constituents. This approach, also advocated by researchers such as Dr. Ernst Wynder, offered advantages over selective reduction because it led to the reduction of total smoke yields and the levels of individual compounds more or less proportionately.

To understand the concept of general reduction, it is essential to understand what smoke is. Smoke is a complex mixture -- it consists of a particulate or "tar" phase as well as a vapor or gas phase. Since the mid-1950s, cigarette manufacturers have devoted extensive resources to achieve a general reduction in "tar" and the vapor phase components of cigarette smoke. Techniques incorporated in cigarettes over the last 40 years which reduce "tar" include:

- Filtration

- Reconstituted tobacco

- Paper porosity

- $\quad$ Reduced tobacco

- Expanded tobacco

- Filter ventilation

Design changes such as the development of more porous cigarette paper, improved filtration, and the use of expanded (or "puffed") tobacco and reconstituted tobacco made 
general reduction possible. By utilizing one or more of these techniques, cigarette manufacturers can offer smokers a variety of cigarettes with a range of "tar" and nicotine levels. Cigarette designers have been so successful in their efforts to respond to the demand for these reductions that today there are commercially available cigarettes that yield "tar" and nicotine at levels so low they cannot be measured reliably by the FTC's standard procedure. ${ }^{3}$ In 1979 , the Surgeon General listed more than 25 different design techniques that reduce yields of "tar" and nicotine. ${ }^{4}$ Each of these techniques has been well-publicized and known to the government, public health, scientific and even lay communities. A brief analysis of these design achievements demonstrates the effectiveness of general reduction methods to achieve lower yields of "tar" and other smoke constituents.

The earliest developments included the cellulose acetate filter, use of porous paper, and use of reconstituted tobacco. Each of these developments was in place by 1965 , and "tar" and nicotine yields had been reduced dramatically. After 1965, the principal design

3 See, e.g., Federal Trade Commission, "Tar," Nicotine and Carbon Monoxide in the Smoke of 207 Varieties of Domestic Cigarettes 2-3 (1985).

4 Public Health Service, U.S. Department of Health, Education, and Welfare, Smoking and Health: A Report of the Surgeon General 14:110 (1979) ("1979 Surgeon General's Report"). The techniques identified in the 1979 Surgeon General's Report were genetics and breeding of tobacco plants, planting density, nitrate fertilization, applying agricultural chemicals, topping the tobacco plant at different stages, altering the type of tobacco, altering the position of the stalk, changing the nitrate content, selecting tobacco with specific constituents (e.g., proteins, carbohydrates, resins), curing, homogenized leaf curing, grading, fermentation, solvent extraction, tobacco expansion (freeze-drying), additives, blending, changing the amount of tobacco, changing the amount of tobacco stems, utilizing varying amounts of reconstituted tobacco, using expanded tobacco, varying the tobacco cut, using porous cigarette paper, perforating the cigarette paper, smoke filtration, and perforating the filter tips. Id. at 14:108-14. 
breakthroughs were expanded tobacco and air dilution through perforation of cigarette filters. Expanded tobacco resulted from the search for ways to reduce the volume of tobacco in each cigarette in order to reduce "tar" and nicotine yields. The tobacco is "puffed" or expanded in order to allow the same amount of tobacco to occupy more space, much like popping popcorn. As a result, each cigarette is filled with less tobacco, there is less tobacco available to be burned, and the yields of "tar" and nicotine are therefore reduced. Reynolds Tobacco developed expanded tobacco and was the first to introduce it commercially, in 1968. In fact, Reynolds Tobacco licensed this process to others in the industry for commercial use throughout the world.

In the late 1960 s, scientists discovered that perforating the cigarette filter allows air to mix with the mainstream smoke, thereby diluting the smoke and reducing the total yields of "tar," and nicotine. Air dilution also reduces the burning temperature of tobacco and causes less tobacco to be burned per puff, thereby further reducing the "tar" and nicotine yields. Perforated filters were first sold commercially in about 1972. By 1981, approximately $50 \%$ of all cigarette brands sold had perforated filters. ${ }^{5}$

By 1981 , the tobacco content by weight of the average cigarette had declined by $23.8 \%$ through the use of expanded tobacco. ${ }^{6}$ In some ultra low-"tar" brands, expanded

$s$ Public Health Service, U.S. Department of Health and Human Services, The Health Consequences of Smoking: The Changing Cigarette. A Report of the Surgeon General 209-10 (1981) ("1981 Surgeon General's Report").

6 Id. at 209-10. 
tobacco was used to a much greater extent to reduce the weight even more dramatically. Thus, as part of the design techniques to achieve lower yields of "tar" and other smoke constituents, the amount of tobacco in cigarettes has been reduced, with the corresponding result that the smoke nicotine has also been reduced dramatically.

The cigarette design efforts discussed above have been reviewed and commended by government and other scientists. For example, from 1966 through 1978, the National Cancer Institute supported a program to develop a "less hazardous cigarette". This effort involved government, tobacco industry, public health groups, and universities. Reynolds Tobacco and other cigarette manufacturers participated in this program. The NCI program evaluated over 100 different cigarette designs -- many of which had already been incorporated in commercial cigarettes by the major manufacturers. The results of this program indicated that the general reduction approach as described above was the best approach to respond to the scientific criticisms of cigarettes. Importantly, virtually every design variable that was evaluated by the NCI group had been developed by the United States tobacco industry and utilized in a commercial brand.

In 1979, scientists involved in the field of smoking and health came together at the Banbury conference. This conference reviewed virtually all work that had been done to modify cigarettes during the previous twenty-five years in response to the smoking and health controversy. All of the papers presented at the Banbury conference were published,

7 This point is especially significant because it addresses Dr. Kessler's "surprise" at finding that, for some brands in the ultra low-"tar" category, the percent nicotine in the tobacco itself might be the same or slightly higher than the percent nicotine in the tobacco used in higher-yield cigarettes. Reducing the amount of tobacco has a major influence on the nicotine yield to the smoker. 
together with all the debate and discussions. The consensus among scientists participating in that program was that overall "tar" and nicotine reduction was the most effective and most appropriate approach. Several scientists, including Dr. Dietrich Hoffmann, acknowledged the responsiveness of the tobacco industry:

I do think the tobacco industry, voluntary or not, adjusts very well to the demands of the logical reasoning of the scientific community and that we should continue on this path. ${ }^{8}$

In Dr. Kessler's March 25, 1994 statement, he asked the cigarette companies to address the intent of cigarette design developments. The clear intent behind cigarette design developments has been and remains to manufacture and market a broad range of cigarette products in response to the demands and tastes of today's adult smokers and to ensure cigarette to cigarette and pack to pack consistency within a brand. Within the universe of cigarette products, there is a range of "tar" and nicotine levels. As noted earlier, reducing "tar" yields automatically results in roughly proportional reductions in nicotine yields. That is seen by the dramatic reduction in both "tar" and nicotine achieved by Reynolds Tobacco and other cigarette manufacturers since. 1955.

In 1957, Dr. Ernst Wynder and others called for efforts to reduce "tar":

[F]or practical purposes, a filter-tip capable of filtering out 40 percent of the tar would be a step in the right direction .... "Such a filter-tip ... placed on a regular-size cigarette which normally yields 30 milligrams of tar in its smoke, would reduce the smoker's tar exposure to about 18 milligrams. A reduction to that level, as shown both by animal experiments and human

8 Dietrich Hoffmann, Discussion in "Risk Reduction Achievements", Banbury Report 3 - A Safe Cigarette?, pp. 155-178 at 174 (1980). 
statistical studies would be a significant reduction in cancer risk."

The tobacco industry has accomplished this objective -- and has gone much further. The vast majority of today's cigarettes are $85-100 \mathrm{~mm}$ long, have filters and yield an average of $11.5 \mathrm{mg}$ of "tar" and $0.8 \mathrm{mg}$ of nicotine. Some cigarettes now available yield less than 1.0 mg of "tar" as measured by the FTC method.

These "tar" and nicotine reductions have largely been achieved through innovations in cigarette design -- innovations pioneered by Reynolds Tobacco and other members of the tobacco industry. Since the complexity of smoke provides a cigarette with its taste and other sensory properties, many of these reductions in "tar" and nicotine have come at the expense of flavor. Some smokers are unwilling to sacrifice flavor for reduced "tar." This has prompted a continuing effort to develop new cigarette designs.

It is ironic that in the face of the overwhelming recommendations of just such an approach, certain public and private critics of cigarettes have decided once again to attack the industry -- and to seek to stop, if not to reverse, the extensive design innovations that other public and private critics have encouraged over the years.

\section{"Tar"/Nicotine Ratios}

Reynolds Tobacco does not manipulate the nicotine in its products to create, maintain, or satisfy "addiction". Claims to that effect are false. As "tar" yields have been reduced over the years, nicotine yields have also been reduced, roughly in proportion to the "tar." The fact that "tar" to nicotine ratios are not exactly the same for all cigarettes is not

9 Mattox, L. and Monahan, S., "Wanted - And Available -- Filter-Tips That Really Filter", Readers Digest, pp. 43-49, 44 (August 1957) (quoting Dr. E.L. Wynder). 
news to anyone familiar with tobacco products or to anyone who has reviewed the extensive "tar" and nicotine reports published by the FTC.

Reynolds Tobacco's cigarettes contain approximately one and one-half to two and one-half percent nicotine, depending upon the tobacco blend. When burned, these cigarettes yield varying amounts of "tar" and nicotine. "Tar" to nicotine ratios, while not constant, are very closely linked because both are found in the particulate phase of smoke. As "tar" yield is reduced, through filtration, paper porosity, expansion, and other design parameters, nicotine yield is also reduced. Filters, however, are slightly more efficient at reducing "tar" yield than nicotine yield. This is due to the fact that cellulose acetate, the primary filter material used by Reynolds Tobacco and others, was developed to reduce "tar" yield. The ability of these filters to reduce the gas phase constituents is somewhat limited. Since a small amount of nicotine (unlike "tar") is found in the gas phase of cigarette smoke, as well as in the particulate phase, slightly more "tar" is filtered out of the smoke, proportionately, than nicotine. Thus, as yields are reduced, the ratio of "tar" yield to nicotine yield is reduced slightly.

In response to the fact that "tar" and nicotine yields are so closely and naturally linked in cigarette smoke, many public health officials and others have suggested that the tobacco companies should attempt to develop cigarettes which break that link. In other words, we have been encouraged to develop cigarettes with reduced "tar" while maintaining nicotine yields. Notable among officials who have encouraged such development is the Independent Committee on Smoking and Health of the United Kingdom, which recommended in 1983 that "... there should be available to the public some brands with 
low levels of tar and a proportionately higher nicotine yield." ${ }^{\text {10 }}$ According to one recent publication cited by Dr. Kessler in his testimony:

One proposal has been to develop tobacco that is high in nicotine but low in tar. This is not easy to do naturally; nicotine and tar are highly correlated in the tobacco leaf. One method would be to add nicotine to a low tar, low nicotine cigarette. ${ }^{11}$

The fact is many scientists, government and/or public health officials have suggested reducing "tar" to nicotine ratios as a way toward potential progress in cigarette design. ${ }^{12}$

Much as the industry responded to calls to reduce "tar" and nicotine yields in the 1950s and 1960s, Reynolds Tobacco has devoted research to responding to these calls to reduce the "tar" to nicotine ratios. Out of the hundreds of patents issued to Reynolds Tobacco personnel over the years, Dr. Kessler referred to nine Reynolds Tobacco patents during his recent testimony to this Subcommittee. These patents reflect work that Reynolds has done in this area. As Dr. Kessler recognized, however, patents do not necessarily reflect what is being used in practice. While Reynolds Tobacco has been able to develop a cigarette which disassociates "tar" and nicotine in the laboratory, it has not been able to achieve an acceptable commercial product. As stated above, this is not easy to do because

10 Third Report of the Independent Scientific Committee on Smoking and Health of the United Kingdom (1983).

11 Scheliing, T.C., "Addictive Drugs: The Cigarette Experience." Science Vol. 255:430433 (1992).

12 See, e.g., "UICC Tobacco Control Fact Sheet 3," Tobacco and Cancer Programme, International Union Against Cancer (March 1993); Editorial, "Monsieur Nicot's Legacy," Lancet II (8249): 763 (1981); Russell, M.A.H., "Smoking and Society (There Is No Question)", Rehabilitation, 32 (1-4): $41-42$ (1979). 
"tar" and nicotine are so highly correlated. If we could develop such a cigarette acceptable to the consumer, it would apparently be welcomed and encouraged by European governments and public health officials, rather than being characterized as some sinister plot by tobacco companies, as Dr. Kessler appears to characterize it. ${ }^{13}$ In fact, none of the nine Reynolds Tobacce patents cited by Dr. Kessler has been used commercially.

\section{Published FTC "Tar" and Nicotine Yields}

The amount of nicotine present in a cigarette is in large part a result of the choice of tobaccos used in the cigarette blend, which are chosen because of their taste and other properties. ${ }^{14}$ It is not present as a result of a decision to "manipulate" nicotine levels to some carefully controlled "addictive level." The concept of an "addictive level", raised but not defined by Dr. Kessler, is not a concept known to or understood by Reynolds Tobacco. Neither that concept nor any similar concept is used by Reynolds Tobacco in the design of its cigarettes. We do not know what the concept means, and we are unaware of any data

13 In 1988, Reynolds Tobacco introduced Premier, a cigarette that heated rather than burned tobacco. That cigarette addressed many of the scientific criticisms that had been made against cigarettes for many years. It virtually eliminated "tar"; it vastly reduced environmental tobacco smoke; and it reduced cigarette ignition propensity. Despite these attributes, certain U.S. government officials, public health officials and, of course, anti-smoking activists launched a vigorous attack on the cigarette -- in terms that sound strikingly similar to the anti-smoking rhetoric surrounding this current debate. European health officials, on the other hand, and some United States scientists recognized the attributes of Premier and, indeed, encouraged the development of similar cigarette technologies. See, e.g., "Smoking Pleasure Without the Danger of Fire and Risks To Health," Die Neu Aerztliche (December 19, 1988); Hoffmann, D., et al., "Cancer of the Upper Aerodigestive Tract: Environmental Factors and Prevention," Journal of Smoking-Related Diseases 3(2): 109-129 (1992).

14 A variety of agricultural factors and practices influence these properties, including, for example, tobacco type, stalk position of the leaf, curing practices, and crop year. 
that give it meaning. Further, what is relevant is not what is present in the cigarette, but what is present in the smoke.

Dr. Kessler has made much of the fact that the FTC numbers do not necessarily reflect the precise "tar" and nicotine yields for every smoker. This is certainly true, just as EPA mileage estimates do not reflect the precise fuel economy that will be achieved by every automobile driver. The important point is that in spite of broad variations in how individual smokers may smoke any given cigarette, the fact remains that the lower the yield by FTC numbers, the lower the yield will be to any given smoker. The yield for any given smoker will probably be different from the FTC yield; for some smokers it will be higher, for some it will be lower, but overall, the FTC yields are generally predictive of the yield to smokers as a group. The statement, however, that "in reality" low yield cigarettes do not yield low "tar" and nicotine, is not true. In work published by members of the Swiss Federal Institute of Technology, lower yield cigarettes were associated with reduced smoke absorption. ${ }^{15}$

Another indication of Dr. Kessler's misunderstanding of cigarettes relates to his statements concerning low "tar" cigarettes. He stated that from 1967 to 1978 eighteen brands of filter cigarettes underwent increases in overwrap width, resulting in less tobacco being smoked by machine smoking in accordance with the FTC method. Since the FTC method specifies that the cigarette is smoked to within 3 millimeters of the tipping overwrap, and Dr. Kessler stated that the tobacco within the overwrap was still smokeable

1s Hofer, et al., "Nicotine Yield as Determinant of Smoke Exposure Indicators and Puffing Behavior." Pharmacology Biochemistry and Behavior, Vol. 40, 139-149 (1991). 
(and would be smoked by the consumer), he concluded that these brands deviously "cheat" the FTC method. That is not true. First, Reynolds Tobacco uses standard tipping overwrap and has not increased the width because that would reduce puff count and the value to our consumers. But, more importantly, the tipping overwrap simply is not smokeable. No smoker would consciously smoke the overwrap more than once. The tipping paper, because it is not intended to be smoked, imparts a significant off-taste to the cigarette smoke.

Finally, in his testimony before this Subcommittee, Dr. Kessler used several charts (which have since been widely publicized) to support his contention that the nicotine/tar ratio for the lowest "tar" cigarettes has increased since 1982 on a sales weighted basis. This allegation surprised Reynolds Tobacco as much as it surprised Dr. Kessler. Company scientists immediately tried to duplicate Dr. Kessler's charts, using the identical FTC data and the only publicly-available brand sales data of which this company is aware. Despite applying the same data allegedly employed by Dr. Kessler's staff, our scientists cannot duplicate these findings. In fact, our results show exactly the opposite -- nicotine yields and nicotine/"tar" ratios in the lowest "tar" category decreased slightly between 1982 and 1991 . - the time period covered by Dr. Kessler's charts. We have, in fact, asked FDA staff members to provide its data and complete methodology. We would welcome the opportunity to review the data and methodology used by FDA staff to prepare these charts, so that we would have a full opportunity to understand and review the procedures used and evaluate the conclusions reached. 


\section{The "Addiction" Hypothesis}

A major premise of the charges against the cigarette industry today is the claim that cigarettes are "addictive". Dr. Kessler and our other critics rely on selective and incomplete evidence to support this claim. They ignore significant and meaningful differences between cigarettes and truly "addictive" drugs. When long-established criteria for labeling a substance or activity as "addictive" do not permit our critics to fit cigarette smoking nicely within the existing criteria, these critics resort to a simple tactic to further their agenda -they attempt to lower the standards and change the definition of "addiction" and its alleged components.

In 1964, the Advisory Committee to the Surgeon General recognized that cigarette smoking did not meet well-established criteria for "addiction." ${ }^{16}$ In 1988, the Surgeon General altered the definition to fit the existing data on smoking. In essence, the Surgeon

16 The 1964 Advisory Committee Report to the Surgeon General defined "addiction" as follows:

"a state of periodic or chronic intoxication produced by the repeated consumption of drug (natural or synthetic) whose characteristics include:

"(1) An overpowering desire or need (compulsion) to continue taking the drug and to obtain it by any means;

"(2) A tendency to increase the dose;

"(3) A psychic (psychological) and generally a physical dependence on the effects of the drug;

"(4) Detrimental effect on the individual and on society"

The Report concluded that tobacco smoking was properly classified as a habituation. 1964 Surgeon General's Report, 351, 354. 
General moved the goalposts after he located the ball on the field. We categorically reject the claim that cigarettes are "addictive", and we know that an objective review of the facts and science supports our position.

Dr. Kessler defined "addiction" in terms of four elements:

- compulsive use

- psychoactive effect

- reinforcing behavior

- withdrawal symptoms

When each of these elements is carefully analyzed in an unbiased manner, it becomes clear that cigarette smoking is no more "addictive" than coffee, tea or Twinkies. ${ }^{17}$ Further, in spite of the efforts to expand the definition, it still does not properly encompass cigarette smoking.

1. Compulsive use. This concept of compulsive use, like the definition of "addiction" itself, has undergone a redefinition in an attempt to encompass cigarette smoking. The classic definition of "addiction", as used in the 1964 Surgeon General's Report, properly defines compulsive use seen with hard drug addiction as "an overpowering desire or need (compulsion) to continue taking the drug and obtain it by any means." This is precisely what is seen with truly "addicting" substances like cocaine and heroin. The

17 Using similarly vague definitions, researchers claim to have discovered addiction to love, jogging, television, credit cards and even eating carrots. See, e.g., Peele, S., Love and Addiction, 1976; Hailey and Bailey, "Negative Addiction in Runners," (1979); Winn, M., The Plug In Drug (1977); Parade Magazine, April 5, 1987, p. 28; Wright, M.R., "Surgical Addiction: A Complication of Modern Surgery?" Archives of Otolaryngology: Head and Neck Surgery, 112: 870-872 (1986); Cerny and Cerny, "Can Carrots Be Addictive? An Extraordinary Form of Drug Dependence," Br. J. Add. 87:1195 (1992). 
desire is overpowering and leads to criminality and violence, if necessary, to satisfy the need for the drug.

In the 1988 Surgeon General's Report, the term "compulsive use" was expanded to include behaviors driven by "strong urges". ${ }^{18}$ There is a world of difference between the irresistible need of the hard drug addict and a "strong urge" to engage in a pleasurable behavior or activity. People have strong urges to eat sweets, drink coffee and watch their favorite soap operas. It is misleading to label these types of "urges" as compulsions. Smokers are frequently in situations where they resist the urge to smoke. They are not in the throes of an overpowering desire to use and obtain cigarettes by any means. They do not remotely resemble cocaine addicts whose very real compulsion to take this highly intoxicating drug totally disrupts their lives, their families and their occupations.

Smokers are now constantly characterized as addicted and thus unable to quit. Common sense belies that conclusion. Since 1974, more than 40 million people have stopped smoking permanently without any outside intervention or assistance. As one exsmoker has candidly acknowledged: "To quit, you have to decide you want to quit. Then you quit."19

18 The full definition states: "Highly controlled or compulsive drug use indicates that drug seeking and drug-taking behavior is driven by strong, often irresistible urges". It provides no criteria for determining when a strong urge becomes "irresistible". In fact, no such criteria exist, as admitted by the American Psychiatric Association. "The line between an irresistible impulse and an impulse not resisted is no sharper than that between twilight and dusk. ..." See "American Psychiatric Association Statement on The Insanity Defense", Am. J. Psychiatry, 140(6), 681-688, 1983.

19 Leonard Larson, Scripp Howard News Service. 


\section{1}

This is not to say that stopping smoking, or changing any weli-liked, habitual behaviol is easy. It takes effort and commitment. But, the process is not different from successfully losing several pounds and maintaining the weight loss or developing a regular exercise program. It is completely different from successfully recovering from hard drug addiction or alcoholism. The true addict must overcome severe physical withdrawal, rebuild every aspect of his life, learn new value systems, and approach life without being constantly intoxicated. None of these impediments is present in stopping smoking.

2. Psychoactive effect. Originally, the scientific community described the term "psychoactive" to include, as a necessary component, distortions or disruptions in cognitive and motor performance, i.e., intoxication. Those concepts were in effect for decades and were included in the 1964 Surgeon General's Report. ${ }^{20}$ Smoking/nicotine, however, does not produce intoxication. To eliminate this inconvenient truth, the 1988 Surgeon General's Report redefined "psychoactive" to mean anything that gets to and produces effects in the brain. Based on this imprecise and revised definition, nicotine is psychoactive. So too is the caffeine in chocolate, coffee and soft drinks. Sugar, warm milk, cheeses, and many other everyday substances and common pleasant experiences (such as watching sporting events or listening to music) also produce psychoactive effects similar to those from smoking. They are quite unlike the profound effects caused by hard drugs and alcohol. It is the intoxication of hard drugs and alcohol that sets them apart and causes muddled thinking and loss of self control.

20 Robinson, J.H. and Pritchard, W.S., "The Role of Nicotine in Tobacco Use." Psychopharmacology, 108, (4): 397-407, 1992. 
Dr. Kessler testified that nicotine contained in cigarette smoke releases a certain chemical (dopamine) in the "pleasure centers" of the brain, resulting in similar effects as addicting drugs such as heroin and cocaine. Dr. Kessler failed to acknowledge that many different pleasurable and not so pleasurable experiences and activities also result in the release of dopamine in these "pleasure centers". Once again, the attempted analogy becomes meaningless when viewed objectively and without blinders. Dopamine release is ore part of the neurochemical response to both pain and pleasure. It will occur if one receives an electric shock or slap in the face and also occurs in response to pleasant experiences of all kinds. Attempting to mystify a basic physical reaction and implying that it only occurs with addicting drugs is misleading at best.

3. Reinforcing behavior. Dr. Kessler's third criterion, reinforcing behavior, provides yet another example of the attempt to invest commonplace concepts with scientific mystique, combined with an erroneous implication that the condition only occurs with addicting drugs. Such is not the case. As presented in the 1988 Surgeon General's Report, reinforcing behavior merely refers to the fact that a pleasant experience will likely be repeated, whether it involves a chemical or activity. ${ }^{21}$ Dr. Kessler cites two lines of evidence as support for his claims regarding reinforcement from nicotine:

1. That animals can be trained to self-administer nicotine; and

2. The experiments which claim that nicotine causes activation of "pleasure centers" in the brain involving dopamine.

21 The report artificially attempts to separate reinforcement involving chemicals from those involving activities. In reality, it is the magnitude of the effect that is most important, not the source. Further, we reject the notion that the reinforcement, or pleasure, derived from cigarette smoking is solely the result of ingestion of nicotine. 
Although it is true that animals will self-administer nicotine under certain very limited circumstances, this does not imply that the effects produced by or the motivation for ingesting nicotine are in any way similar to those of truly "addicting" drugs. Scientists at the Bowman Gray School of Medicine, in association with a Reynolds Tobacco scientist, recently published a peer-reviewed study demonstrating that nicotine and caffeine are very weak reinforcers when compared to cocaine and methylphenidate (Ritalin $\left.{ }^{m}\right){ }^{22}$ Their findings were in line with the overall weight of the scientific evidence, which has consistently found caffeine and nicotine are both weak reinforcers. ${ }^{23}$ Animals can be trained to selfadminister a wide variety of substances. Animals have been trained to self-administer very painful electric shocks, and morphine addicted monkeys have been trained to self-administer opiate antagonists, precipitating very painful withdrawal symptoms. However, none of these self-administration behaviors proves the existence of an "addiction". Moreover, animals do not have to be extensively trained to self-administer cocaine or heroin. Once they start receiving either drug, they quickly become hooked and self-administer it to the exclusion of food and water and until death if not stopped.

4. Withdrawal symptoms. Although nicotine withdrawal was defined in 1987 by the American Psychiatric Association (DSM-IIl-R) as an element of tobacco dependence,

22 Dworkin, et al., "Comparing the Reinforcing Effects of Nicotine, Caffeine, Methylphenidate and Cocaine." Medical Chemistry Research, Vol. 2:593-602 (1993).

${ }^{23}$ Griffiths, R.R., Brady, J.V., and Bigelow, G.E., "Predicting The Dependence Liability of Stimulant Drugs" in Thompson and Johansen Behavioral Pharmacology of Human Drug Dependence, NIDA Monograph 37, 1981, p. 92. This position has not changed. Griffiths, R., American Psychiatric Association Annual Meeting, San Francisco, CA, (1991). 
the associated symptoms were identified in the 1964 Surgeon General's Report: restlessness, anxiety, trouble concentrating, and other "mild and variable symptoms". 24 That report stated that these symptoms were the same as those seen when any well-liked behavior was suddenly stopped. Nothing new has been established in this area. Caffeine withdrawal is much more well-established and well-defined, including the physical symptom of the "caffeine headache." Under Dr. Kessler's definition, caffeine and heroin should be treated equally.

Smoking cessation never involves any of the severe physical and behavioral disruptions involved in withdrawal from truly addicting drugs such as heroin, cocaine, and amphetamines. In fact, the symptoms of hard drug withdrawal normally require medical treatment. With many drugs (e.g., barbiturates and alcohol), the addict can die from withdrawal if not medically treated. An addict undergoing withdrawal from hard drugs is unable to think clearly or control his actions while in the throes of withdrawal. This is never the case with cigarette smokers who quit. They continue to attend to their responsibilities and lead normal lives. The symptoms reported by cigarette smokers when they stop are of the same kind and magnitude reported by dieters and people changing sleep patterns (e.g., changing from the first to third shift at work $).^{25}$

241964 Surgeon General's Report, supra, at 352.

${ }^{25}$ It should be noted that DSM-III-R states that there is no evidence that, even at its most severe level, tobacco withdrawal prevents a person from successfully stopping. The same can not be said for barbiturates, alcohol or crack cocaine. Diagnostic and Statistical Manual of Mental Disorders (Third Edition - Revised) American Psychiatric Association, (1987), 151. 
Cigarette smoking is more like drinking coffee and eating chocolate than like using cocaine, heroin, or any truly addicting hard drug. Cigarettes, however, are unpopular, which is why our critics strain so mightily to demonstrate that smoking is "addictive". The plain truth is that, under any objective scientific (or common sense) measure, cigarette smoking should not be considered "addictive".

Dr. Kessler and others support their assertions by repeating a deluge of facts that, in their judgment, prove their conclusions. Let us examine just a few of these "facts":

- First, Dr. Kessler quotes a 1993 Gallup Survey reporting that $75 \%$ of smokers say they are addicted. What Dr. Kessler does not report is that the same survey found that $69 \%$ of the same smokers said they "could quit if I wanted to." Moreover, this survey was conducted after the well-publicized 1988 Surgeon General's Report, which equated cigarette smoking with cocaine and heroin addiction. Does Dr. Kessler not believe that such publicity could affect responses to this survey?

- Dr. Kessler states that "By some estimates, as many as 74 to 90 percent are addicted." He relies on a paper by Hughes, et al. This paper also included the comment, "In addition, the fact that this definition [referring to DSM-III-R] classified $90 \%$ of the tobacco users in this study as dependent suggests that it is over inclusive and thus may lack diagnostic discriminability".

- Dr. Kessler makes repeated references to how certain percentages of people "may" or "might" possibly behave in certain circumstances. In one example, he discusses patients who continue to smoke after surgery or a coronary event. Some continue to smoke; most quit. Some also follow their doctor's advice and eat less fat, exercise regularly and lose weight. Some don't. The fact that human behaviors run a wide gamut when faced with similar situations tells us something about human behavior and little about smoking or nicotine.

- Dr. Kessler's "experts" tell him that most smokers reach for their first cigarette within 30 minutes of waking. He concludes that this fact is "a meaningful measure of addiction". By this measure most coffee drinkers should be considered addicts. 
Manufacturers of coffee makers have even developed machines which have coffee prepared by exact times to ensure that the coffee "addiction" can be satisfied immediately upon awakening.

It should be pointed out that Dr. Kessler's "definition" of addiction would classify most coffee, cola, and tea drinkers as caffeine addicts. Caffeine is psychoactive and the effects last longer than those of nicotine. ${ }^{26}$ Many people experience a "strong urge" for a cup of coffee each morning. There is a well-established physical withdrawal syndrome for 2-3 cups a day coffee drinkers who suddenly stop drinking coffee. Is caffeine similar to cocaine and heroin because of this? Neil Benowitz, one of the editors of the 1988 Surgeon General's Report, admitted that caffeine meets their new definition of addiction:

Many physicians have treated patients who continue to drink large quantities of caffeinated beverages in the face of information that caffeine is harmful to their health and advice to quit. Such behavior suggests that these people are addicted to caffeine. Addiction liability can be analyzed according to criteria recently presented by the United States Surgeon General. The three major criteria for addiction liability are psychoactivity, drug-reinforced behavior, and compulsive use. That caffeine is psychoactive and that some people consume caffeine compulsively is clear. That caffeine reinforces its consumption has recently been demonstrated in people, although reinforcement is highly dependent on the dose, with excess doses producing dysphoria. Minor criteria for addiction liability include the development of tolerance, physical dependence, and recurrent intense desire for the drug, all of which are characteristic of regular caffeine consumers. Thus, there is a group of coffee drinkers who appear to be addicted

${ }^{26}$ See Jaffe, J. and Kantzer, M., "Nicotine: Tobacco Use, Abuse and Dependence, Subst, Abuse, 0(0): 256, 1981. See also Sawyer et al., "Caffeine and Human Behavior: Arousal, Anxiety and Performance Effects, J. of Behav. Med., 5(4): 415, 1982. "Caffeine is, without question, the most commonly used psychoactive drug in the World." Jaffe, J.H., Comprehensive Textbook of Psychiatry, Chapter 13, Psychoactive Substance Use Disorders, 1(0), page 683, 1989. 
to caffeine, although the extent of caffeine addiction in the population is unknown. ${ }^{27}$

If the same "standards" are applied to caffeine, should the FDA also be considering (or should you suggest that it begin) regulating coffee and soft drinks as drugs?

One final point is important. Essentially every claim made about manipulating nicotine in cigarettes by Dr. Kessler can be made about alcohol in beer, wine and spirits. Spirits manufacturers constantly monitor the alcohol content of their products throughout the fermentation process to precisely control the level of alcohol. Beers and wines are offered to the public with a wide range of alcohol content. Alcohol is added to fortified wines. High alcohol malt liquors are also available to the public. While no one will dispute that alcohol can be a truly "addicting" substance under any definition, there is no move to regulate alcohol as a drug, and we do not believe there should be.

\section{Why People Choose to Smoke}

Dr. Kessler dismisses the issue of why people smoke by concluding, as the antismoking supporters he relies upon conclude, that smoking is an "addiction" and smokers would quit if they could break this "addiction". In the current climate of social disapproval and "political correctness", it is unpopular for smokers to honestly state that they smoke for pleasure and enjoyment. Yet for hundreds of years smoking has been accepted as a social custom, providing a pleasurable, enjoyable break from normal activities. Smokers enjoy the taste and other sensory aspects of smoking. A few moments with a cigarette can be a break

27 Benowitz, N.L., "Clinical Pharmacology of Caffeine." Ann. Rev. Med., 41(0) 277-288, 1990. 
during boring or intensive tasks, or a nice complement to a meal. All of these highly subjective reasons for smoking have found support in scientific publications.

Dr. Kessler pejoratively refers to "top tobacco industry officials" when referencing internationally respected Reynolds Tobacco scientists who have published widely in peerreviewed scientific journals because they do not believe that tobacco is addictive. He then goes on to mischaracterize their data. In the journal article referenced by Dr. Kessler, Drs.

Robinson and Pritchard summed up the evidence concerning addiction and tobacco use:

We believe that Warburton (1990) has developed a balanced, functional theory of nicotine use that recognizes the beneficial psychological effects of nicotine. This "resource" or "psychological tool" hypothesis holds that people smoke cigarettes primarily for purposes of enjoyment, performance enhancement and/or anxiety reduction. This theory also passes the common sense test of why people smoke. They smoke, not because they are addicted to nicotine, but because they achieve some benefits from smoking, enjoy these benefits which are totally compatible with everyday tasks and stresses, and choose to continue to enjoy these benefits ....

We believe the distinctions are clear and cannot be stated more clearly than what was said in the 1964 SGR [Surgeon General's Report]: "the practice [smoking] should be labeled habituation to distinguish it clearly from addiction, since the biological effects of tobacco, like coffee and other caffeine-containing beverages, ... a are not comparable to those produced by morphine, alcohol, barbiturates, and many other potent addicting drugs" (p. 350, emphasis in original). If we lose this common-sense perspective of the role of nicotine in tobacco use, those of us who enjoy the "lift" we receive from that first cup of coffee in the morning or that cola drink in the late afternoon may find that a few years from now a small group of researchers have equated our coffee/cola-drinking behavior to that of a hard-core crack or heroin addict. ${ }^{28}$

28 Robinson and Pritchard, supra, at 405-6. 
No scientific breakthrough has occurred since the 1964 Surgeon General's Report to warrant classifying cigarette smoking as "addictive". All of the essential facts describing the behavior have been well known for years. The only thing that has changed is the political climate surrounding cigarette smoking, and with it the ability of anti-smoking critics to develop a new definition of "addiction" solely to include cigarette smoking within it.

\section{Conclusion}

The facts are clear:

- Reynolds Tobacco does not add nicotine to its cigarettes.

- Reynolds Tobacco does not manipulate nicotine yields in its cigarettes in order to create, maintain, or satisfy "addiction".

- Cigarette smoking is not an "addiction" under common sense and honest comparison with truly "addicting" drugs.

Simply put, there is no factual basis or policy reason for the FDA to regulate cigarettes as drugs. The result of FDA regulation, moreover, would be a ban, or prohibition, of cigarettes. Dr. Kessler made this point clear in his recent statement before the Subcommittee. Members of this Subcommittee have stated that a ban or prohibition is not their intent; the American public resoundingly rejects the prohibition of cigarettes as well. We encourage a dialogue that will lead to progress rather than prohibition. 
Mr. WAXMAN. Thank you, Mr. Johnston. At the request, I gather, of the witnesses, we're going to call on our next speaker, Thomas E. Sandefur, chairman and CEO of Brown and Williamson Tobacco Company, rather than go down the list. Mr. Sandefur?

\section{TESTIMONY OF THOMAS E. SANDEFUR, JR.}

Mr. SANDEFUR. Mr. Chairman, I have a short statement to make. It's been given to the subcommittee and to save time, I'll be more than happy to forgo reading that. It's your pleasure. If you want me to read my statement to you, I'll be happy to.

Mr. WAXMAN. If you want. It's going to be in the record, so-

Mr. SANDEFUR. It's in the record.

Mr. WAXMAN [continuing]. So if you want to say something orally, do so. If you don't we'll move on to the next witness. We've got a lot scheduled.

Mr. SANDEFUR. Fine. Thank you.

[The prepared statement of Mr. Sandefur follows:]

\section{Statement of Thomas E. Sandefur, Jr., Chairman and Chief Executive} OFFICER, BROWN \& WILLIAMSON TOBACCO CORPORATION

Mr. Chairman and members of the subcommittee, I appear today on behalf of Brown \& Williamson Tobacco Corporation in response to the chairman's letter of March 31, 1994, to address questions concerning nicotine in cigarettes that have been raised in recent weeks by FDA Commissioner David A. Kessler and others. This statement supplements the statement submitted by Brown \& Williamson in connection with the subcommittee's hearing on March 25, which is part of the record of that hearing.

The premise of the questions raised by Commissioner Kessler is that nicotine is "addictive." The term "addiction" has been used to describe everything from an enslavement to hard drugs to an inability to lose weight or watch less television, and Surgeon General Koop himself proclaimed in 1982 that children were "addicted" to video games. In view of the racical differences between tobacco and hard drugs in their effects on behavior and the symptoms associated with quitting, and in view of the fact that more than half of all Americans alive who have ever smoked have quit-over 90 percent without professional help-equating cigarettes and hard drugs is nothing more than rhetoric.

Initially, in his letter of February 25, 1994, Dr. Kessler suggested that cigarette manufacturers "commonly add nicotine to cigarettes to deliver specific amounts of nicotine." Brown \& Williamson has never done that, as we demonstrated in our submission to this subcommittee in connection with its March 25 hearing. Dr. Kessler mentioned a number of patents in his testimony on March 25, including some that have been secured by Brown \& Williamson. I can state categorically that Brown \& Williamson does not utilize, and has never utilized, any of these patents to control the amount of nicotine in cigarettes. As Brown \& Williamson explained, moreover, "the nicotine content of $B \& W$ cigarettes is lower than the nicotine content of the tobacco used to produce them." According to the New England Journal of Medicine, the average nicotine delivery dropped from 2 milligrams to 0.9 milligrams between 1955 and 1987.

After the submissions by Brown \& Williamson and the other manufacturers, Dr. Kessler, in his testimony on March 25, retreated to the suggestion that the cigarette manufacturers' failure to use the technology supposedly at their disposal to eliminate nicotine from cigarettes suggests that they may intend it to satisfy an addiction. This, too, is incorrect.

Without nicotine, you don't have tobacco. Without nicotine, cigarettes simply would not taste like cigarettes. The experience of another manufacturer indicates that consumers will not accept a cigarette without nicotine. Calls for legislation to eliminate nicotine amount to a call to ban cigarettes-not because the substance that allegedly satisfies an "addiction" would be removed, but because the resulting product would taste nothing like a cigarette. We offer a range of products with a range of nicotine deliveries and the consumer makes the choice.

We also vigorously dispute the suggestion of Dr. Kessler and Dr. Slade that the "tar" and nicotine ratings produced using the FTC test method are meaningless or misleading. The cigarette manufacturers have never suggested that these ratings re- 
flect the precise amount of "tar" and nicotine that each individual smoker actually receives. But we do believe that smokers can expect to receive lower amounts of those constituents from lower-rated brands than from higher-rated brands, and that the FTC test method therefore reliably ranks cigarettes in terms of "tar" and nicotine deliveries. EPA's mileage figures may not reflect the actual experience of individual drivers, but EPA is correct that a Cadillac delivers fewer miles per gallon than a Honda.

Hopefully our testimony today will help to clear up some of the misconceptions that currently exist about nicotine in cigarettes.

On April 5, Dr. Kessler wrote me a letter asking to arrange a meeting between FDA representatives and members of our research, scientific, technical, and production staffs to review relevant information. I have responded to Dr. Kessler's request and anticipate that such a meeting will take place shortly.

Mr. WAXMAN. Next we'll hear from Andrew Tisch, chairman and CEO of Lorillard Tobacco Company.

OK. Thank you.

\section{TESTIMONY OF ANDREW H. TISCH}

Mr. Tisch. Thank you, Mr. Chairman. At the committee's request, I have submitted for the record at this hearing a written statement in response to each of the questions set forth in your invitation letter. In normal circumstances I would be happy to summarize that statement orally and then respond to any questions you or the members of the committee might have.

But these are not normal circumstances, Mr. Chairman, you have made a number of very serious claims and assertions during the press conference that you called yesterday. Claims and assertions that question the integrity of our company and of Dr. Alexander Spears, who is with me today and testified before this committee on March 25th.

When a representative of our company called your staff yesterday following a press conference to ask that Dr. Spears be given a separate opportunity to respond to the claims and assertions from your press conference that related to him, we were told that this would not be possible.

More specifically, we were told that Dr. Spears opportunity to respond would be limited to any time that might be left from the time that has been allotted to my testimony or to the question and answer period that is to follow.

Mr. Chairman, I frankly cannot understand the attitude conveyed by your staff. Indeed, I am left with no choice but to cede the balance of my time to Dr. Spears to ensure that he will have the adequate opportunity to correct the very serious misstatements and misconceptions that were conveyed in yesterday's press conference.

Mr. Chairman, with your permission, I'd like to ask if Dr. Spears may respond during the rest of my time period?

Mr. WAXMAN. Mr. Tisch, we're going to have plenty of opportunity for Dr. Spears to respond. I do have a number of questions to ask of him, he will have his chance. But this is our chance to hear to from you. And we want to hear from you at this point.

Mr. TISCH. OK, fine. I must respectfully disagree with that, but you are the boss.

On behalf of the more than 3,700 employees at Lorillard Tobacco Company, I am pleased to have this opportunity to address you about the issues you identified in your letter to Lorillard of March 
31st, 1994, announcing this hearing. You will recall that Dr. Spears testified before this subcommittee on March 25, 1994, with respect to the same subjects proposed for discussion here today.

In as much as Dr. Spears and Lorillard's position on the questions raised has not changed in the past 2 weeks, for the sake of brevity, I have attached to my statement a copy of Dr. Spears' written submission of March 25th, and ask your permission that it and his March 25th oral testimony also be entered into the record.

Mr. WAXMAN. Without objection. [See p. 377.]

Mr. TISCH. At the outset, I want to reaffirm and emphasize what Dr. Spears said during his appearance on March 25th, and to make absolutely clear to the Congress and to the public that the level of nicotine in the products manufactured and sold by Lorillard is solely determined by the tobacco that we buy and the blending of the different tobaccos used in our manufacturing.

The tar and nicotine yields of our products are determined by a combination of the tobacco blends and the physical characteristics which constitute the construction of the cigarette, namely, length, circumference, paper porosity, filter, tip ventilation, and tobacco density. Nicotine levels follow tar levels and are not raised or reduced for particular brands.

Dr. Spears previously advised you that in the course of manufacturing we use denatured alcohol which the Bureau of Alcohol, Tobacco, and Firearms requires be made unpotable by the manufacturer of the alcohol to the addition of a miniscule amount of nicotine. We also use a number of flavors which incorporate a tobacco extract that contains some nicotine. But it is important to understand that the combined amount of nicotine from these sources is too small to be measured in the final products.

The manufacture of our brands of cigarettes also involves the use of reconstituted tobacco, or tobacco sheet. One of the processes Lorillard uses in the production of reconstituted tobacco involves a temporary separation and subsequent reapplication of water soluble components of tobacco, including nicotine. However-and I invite your specific attention to this important fact-this process and all others, all of which are well known in published literature, results in a reduction of nicotine in the finished product.

Dr. Kessler's March 25th testimony referred to a 1980 Lorillard patent dealing with nicotine and reconstituted tobacco. I am advised that an earlier laboratory observation indicated a possible use for this process. Following our usual business practice, and that of virtually every other company in American, we applied for and obtained the patent.

However, so there is no misunderstanding, the record should reflect that Lorillard has never practiced the patented process in any commercial manner. Moreover, even if it was to be used, the process would not result in any increase or decrease in the nicotine level.

In your March 31st letter, we are asked to address any studies of the physiological or psychological effects of nicotine and related compounds which have been undertaken by Lorillard. I can respond succinctly. Lorillard has not undertaken any such research.

As regards cigarette ingredients, please note the following. The cigarette manufacturers have provided to the Department of 
Health and Human Services, each year since 1984, a comprehensive listing of cigarette ingredients. HHS has never indicated to Lorillard at any time, in response to those submissions, that it had a problem with respect to any individual ingredient or groups of ingredients.

Indeed, when HHS asked the manufacturers for the quantity of each ingredient being used, the manufacturers promptly provided that information to HHS on a confidential basis. To my knowledge, HHS has no outstanding requests to this manufacturer or any others for additional information.

The manufacturers, including Lorillard, have assured HHS repeatedly that we would be happy to meet with HHS officials, and/ or HHS scientific consultants to answer any questions about ingredients which the HHS or its consultants might have. I reaffirm that commitment now.

Finally, Mr. Chairman, allow me to sum up and to state Lorillard's position on the principal issues raised in the statement released by you when you scheduled today's hearings. In doing so, it is also my purpose to respond to Dr. Kessler's erroneous assertions first made on February 25th, and then expanded upon at your March 25th hearing.

Lorillard does not take any steps to assure a minimum level of nicotine in our products. Lorillard does not add nicotine to cigarette tobacco for the purpose of manipulating or spiking the amount of nicotine received by the smoker. Lorillard makes no effort to keep secret any information about the nicotine content of our products.

And, as you know, since 1971, every cigarette advertisement has carried a complete disclosure of the tar and nicotine content. Mr. Chairman, I respectfully suggest to you that Lorillard has acted and will continue to act in a completely responsible manner in this as well all our business practices.

Furthermore, I state unequivocally that our manufacturing processes neither violate the Federal Food, Drug, and Cosmetic Act, nor do they justify placing the manufacture of cigarettes under the jurisdiction of the FDA.

I thank you for your attention and for this opportunity to state Lorillard's position. At the appropriate time, Dr. Spears and I will take any questions you or your colleagues might have. Thank you.

Mr. WAXMAN. Thank you, Mr. Tisch.

Donald Johnston, president of American Tobacco Company.

\section{TESTIMONY OF DONALD S. JOHNSTON}

Mr. DONALD Johnston. Thank you, Mr. Chairman. What I have to say is repetitive from the statements already read, but I believe these points do bear repetition as they focus on the facts concerning the issues you raised in your letter inviting us to this hearing.

Aside from tobacco itself, and federally authorized use of alcohol denatured with minute amounts of nicotine, the American Tobacco Company does not use nicotine in the manufacture of its cigarettes. Contrary to the implications that have aired before this subcommittee and elsewhere, the American Tobacco Company does not spike its cigarettes with nicotine, or it does not use any of the patents that have been placed before this subcommittee on any other like processes or devices. 
The only source of nicotine, other than that naturally occurring in tobacco is introduced from Specially Denatured Alcohol Number 4 , which is used as a solvent for flavorings. SDA No. 4 is authorized for tobacco use in accordance with the 27 Code of the Federal Regulations of Alcohol, Tobacco Products, and Firearms which were revised as of April 1, 1993. I believe it is section 21.118 and 21.38. And it is denatured by the alcohol manufacturer in accordance with the prescribed formula outlined in the regulations.

Now, the quantity of nicotine indirectly added to tobacco from the use of SDA No. 4 is on the order of 3 parts per million to 5 parts per million, or 3 ten thousands of a percent to 5 ten thousands of a percent by weight, which is infinitesimal in comparison to the naturally occurring nicotine of tobacco blends that generally contain 2 to 2.5 percent by weight.

Further, the American Tobacco Company does manufacture reconstituted tobacco by the Fourdrinier papermaking process that involves separation of water soluble components from tobacco, formation of the tobacco cellulosic sheet, and reapplication of the water soluble components to the sheet that's in a continuous process. American does add nicotine to this process.

The end product is tobacco material that contains only the quantity of water soluble components, including nicotine originally removed from the tobacco. In practice, as I believe has already been mentioned, the nicotine content of the reconstituted tobacco material is approximately 4 percent less, which is owing to the processing losses, than the nicotine content of the tobacco utilized in the reconstitution process.

The American Tobacco Company uses various types of natural tobaccos, including reconstituted tobacco in the manufacture of its cigarettes. The percentages of natural tobacco types and reconstituted tobacco vary by brand. However, after processing of tobacco for cigarette manufacture, the nicotine content is on the order of 5 percent less than that of the various tobaccos entering into the process.

On the matter of patents, the American Tobacco Company has been issued two patents, U.S. Patent Number 3428049, and Number 4505282 which reference the addition of materials which could include tobacco extract and/or nicotine to cigarettes and an innerliner wrap for a tobacco smoking article. As with any patent, the language is purposely broad in scope with an objective of covering a wide variety of conceptual applications which may or may not be reduced to practice.

While the American Tobacco Company has been issued such patents, addition of tobacco extract or nicotine to cigarette filters and wrapper have never been employed in a commercial cigarette product by American Tobacco.

In summary, nicotine involved in the federally regulated and authorized use of SDA No. 4 denatured alcohol is negligible. Nothing is done in the tobacco processing or manufacture of cigarettes or filters by the American Tobacco Company to increase nicotine beyond that which is naturally occurring in the tobacco.

I would now like to address questions that have also been raised with respect to the intent of the design of our cigarettes in relation to nicotine. In 1966, the Federal Trade Commission amended its 
cigarette advertising guides to encourage cigarette manufacturers to publish the tar and nicotine content expressed in milligrams of the mainstream smoke from a cigarette, declaring that to be information concerning cigarettes which may be material and desired by the consuming public. Time has proven the FTC to have been right and that consumers have shown an interest in and differing preferences for different levels of tar and nicotine.

Moreover, since 1971, American has been governed by and has adhered to an FTC Consent Order requiring American to publish in its advertisements for low tar cigarettes tar and nicotine data as determined by the testing method employed by the FTC in the testing of the smoke of its domestic cigarettes.

Through tobacco blends, filtration, ventilation, American Tobacco has, on a sales-weighted average, reduced tar and, consequently, nicotine levels as determined by the FTC method. The tar and nicotine data for each of American's products are published. American carefully monitors its finished cigarettes, and the published data to assure that the tar and nicotine figures are accurate.

Thus American Tobacco manufactures and sells cigarettes with tar and nicotine content in response to the consumer demand for different types of cigarettes, and provides correct information to consumers about those amounts. American has no desire or intent to manipulate nicotine.

At no time has the American Tobacco Company attempted to market a cigarette based upon nicotine content. Or more generally, has it ever designed or marketed a cigarette with the purpose or intent of selling nicotine. Rather, American has always considered that it sells cigarettes and that nicotine is one of the several intrinsic properties characteristic of the tobacco itself.

Thank you for your attention, Mr. Chairman.

Mr. WAXMAN. Thank you very much, Mr. Johnston.

Next I want to hear from Mr. Horrigan.

\section{TESTIMONY OF EDWARD A. HORRIGAN, JR.}

Mr. HORRIGAN. Thank you Mr. Chairman and fellow members of the committee. My name is Ed Horrigan, Jr., and I am chairman and chief executive officer of the 'Liggett Group. Although I've only somewhat recently joined the Liggett, I have had the pleasure of addressing this subcommittee on a prior occasion.

After having served in the military and then in companies in other industries in this country for over 20 years, I joined the tobacco industry 16 years ago. And then in 1989 I retired as chairman and CEO of Reynolds Tobacco, as well as vice-chair of RJR Nabisco. I came out of retirement to rejoin the tobacco industry mindful of the challenges presented to it at this time.

And also with the knowledge, born of my experience, that the tobacco industry is one of the respectable American industries that make up American commerce. It acts responsibly in its business practices, and it produces a product recognized world-wide for its quality.

And, therefore, I am pleased to have this opportunity to address the subcommittee on behalf of Liggett on the matters that were discussed during your meeting earlier on March 25th. 
While my remarks will be somewhat redundant, repetitive from the other companies, I will highlight them to show the uniform sense of responsibility and accountability that exists in this industry, and to add our sense to the absurdity of the allegations that people continue to place against this industry.

At the outset, I would like to make it clear that Liggett does not increase the nicotine level of our cigarettes beyond the level of nicotine found naturally in the unprocessed tobacco that we use to make our cigarettes. Second, Liggett does not manipulate the level of nicotine in our cigarettes to hook or addict smokers. Third, Liggett does not use any of the patented technology that was referred to by Dr. Kessler in his testimony before this committee last month.

And, finally, I want to emphasize that we at Liggett are proud of the quality of the cigarettes that we produce, we're proud of the people who grow our tobacco that goes into our product, we're proud of the people who manufacture them for us, as well as those people who distribute and sell our product legitimately around this country.

Now, with regard to the manufacture of cigarettes, I would like to emphasize that the manufacturing process results in a reduction in the amount of nicotine in cigarettes when compared to the nicotine in the unprocessed tobacco.

Second, the essential components of cigarette manufacturing, and specifically, the use of reconstituted tobacco has been publicly documented for decades, so none of this is new. Reconstituted tobacco is used to reduce waste and to achieve the most efficient use of the natural tobacco that we purchase for our product.

Tobacco is the most expensive component of the cigarette and, therefore, any loss of that tobacco would make the production of cigarettes more costly. In brief, the reconstitution process involves the addition of water to the tobacco to separate water soluble substances, including some nicotine, from the tobacco.

The remaining tobacco cellulose can then be formed into sheets. Water soluble substances originally removed from the tobacco are then once again returned to that tobacco sheet. No nicotine not found naturally in the tobacco is added in the production of the reconstituted tobacco. In fact, the reconstituted tobacco contains less nicotine than raw tobacco, from which it was made, because a certain amount of the natural nicotine is inevitably lost in that process.

Denatured alcohol and tobacco flavorants are the only other sources of nicotine in our cigarettes. Nicotine occurs naturally in the water soluble extracts of tobacco used in miniscule amounts as flavorants. The use of tobacco flavorants has been a matter of public record, again, for decades.

The Specially Denatured Alcohol No. 4, which is used as a carrier for flavors, is the only denatured alcohol that is approved by B.A.T.F. for the manufacturing process in cigarettes. The B.A.T.F. requires that that alcohol be denatured by the addition of a miniscule amount of nicotine to make it undrinkable. And it is denatured in accordance with the prescribed formulas outlined by B.A.T.F. 
The amount of nicotine contributed to tobacco smoke by way of tobacco flavorants and denatured alcohol, is so miniscule that it cannot be measured in tobacco smoke, using the FTC's standard methods. Moreover, as I noted, the nicotine content of cigarettes, manufactured by Liggett, is lower than the nicotine in the unprocessed tobacco that we use to make our product.

Therefore, Liggett, like the rest of us, does not manipulate or spike the amount of nicotine during the manufacture of its cigarettes to achieve an alleged addicting level of nicotine. Specifically, Liggett does not and has not used any of the patented processes described in those patents referred to in Dr. Kessler's earlier testimony.

Liggett does not believe that there is any such thing as an addicting level of nicotine in cigarettes, or that cigarettes are addictive like heroine or cocaine, as has been alleged. In fact, to equate cigarette smoking with actual hard drug addiction ignores the significant differences between them. It also blinks at reality.

As has been mentioned, there have been over 40 million Americans who have chosen to quit smoking. And more than half of all adult smokers have quit, 90 percent of them quitting without the aid of the Betty Ford Clinic, or the Hazelton Clinic, or any other such clinic. It's thus apparent that irrespective of the nicotine in cigarettes, consumers can and do choose to quit.

Consumers also express their personal preference by choosing from a wide variety of cigarette brands and styles on the market that have different "tar" and nicotine yields. To meet the demands of the marketplace, Liggett produces a variety of cigarette brands with a variety of "tar" and nicotine yields. For more than 20 years, cigarette advertising has carried the nicotine yield of each cigarette brand and style as measured in accordance with FTC standard test methods. Over the years, consumers have expressed a growing preference for cigarettes with lower "tar" and nicotine yields. This has resulted, on an industry-wide basis, in more than a 50 percent reduction in average nicotine yields over the past 40 years.

In conclusion, let me say that nicotine is a naturally occurring substance in tobacco, which is obviously an intrinsic characteristic of our product. Liggett does not design or manufacture its cigarettes with the intent to spike the amount of nicotine in cigarettes. There is no secret about the yields of Liggett's cigarettes, which I reiterate has been publicly disclosed for years.

In closing, I'd like to add a personal observation. Some anti-tobacco zealots would have the American people believe that in our manufacturing process there is a gentleman at the end of each line with a pot of nicotine making sure that we sprinkle the product as it goes out the door to be sure that there is enough nicotine to hook or addict smokers. We don't do that, and I've never heard of it being done.

In all of my years in this business world-wide, I have never known of a product-designed objective or goal that included even the notion of spiking the amount of nicotine in a cigarette to achieve a level that would hook or addict smokers.

I am pleased to be back before your committee, Mr. Chairman. We look forward to answering your questions.

Mr. WAXMAN. Thank you very much, Mr. Horrigan. 
And, last, is it Mr. Taddeo?

\section{TESTIMONY OF JOSEPH TADDEO}

Mr. TADDEO. Taddeo. Thank you, Mr. Chairman. U.S. Tobacco is a leading manufacturer and producer of smokeless tobacco products, including moist snuff. U.S. Tobacco does not manufacture cigarettes. U.S. Tobacco's smokeless tobacco brands include Copenhagen, which is one of America's oldest registered brand names. It was introduced in 1822 . Skol, our second largest selling brand was introduced in 1934.

Clearly, smokeless tobacco is not a new product. The use of smokeless tobacco has been a tradition in the United States since the 18th Century, predating branded cigarettes by over 100 years. In fact, smokeless tobacco products dominated the American tobacco market until the early 20th Century when cigarettes began to win wide public acceptance.

While today smokeless tobacco products are consumed throughout the United States, per capita consumption of smokeless tobacco in the 1990's is less than 25 percent of what it was at the turn of the century. As for U.S. Tobacco's products specifically, the makeup and manufacturing process for its smokeless tobacco brands is very similar to what it was at the turn of the century, regardless of the flavor, cut of the tobacco, form, or packaging.

I welcome, Mr. Chairman, this opportunity to set the record straight, with regard to the baseless claims made before this subcommittee on March 25th, concerning U.S. Tobacco's marketing practices.

Before tuming to those matters, however, I will comment on allegations of manipulation or control of nicotine in tobacco products. U.S. Tobacco does not in any way manipulate the nicotine level in its tobacco products, nor does U.S. Tobacco take any action to control the nicotine content of its tobacco products before, during, or after the manufacturing process. In fact, an incidental effect of our manufacturing process is that the nicotine content of our smokeless tobacco products is less than that which occurs naturally in the tobacco.

Other than tobacco itself, the only material used in the manufacture of U.S. Tobacco's smokeless tobacco products which contains nicotine is denatured alcohol, which is purchased from a supplier as a carrying agent for the application of certain flavorings that do not dissolve in water.

The denatured alcohol that is used by U.S. Tobacco has been denatured by its manufacturer with small amounts of nicotine. The use of nicotine as a denaturant for alcohol which is to be used in the processing and manufacturing of tobacco products is specifically approved by the Bureau of Alcohol, Tobacco, and Firearms.

The amount of nicotine that might be contributed to our smokeless tobacco products through the use of this denatured alcohol in the manufacturing process is so miniscule as to be unmeasurable by standard laboratory methodologies.

Mr. Chairman, there were three serious allegations, made before this subcommittee on March 25th, regarding U.S. Tobacco's marketing practices. First, the allegation that U.S. Tobacco markets its smokeless tobacco products to persons under the age of 18 . 
The second allegations was that U.S. Tobacco has conducted scientific research for the purpose of, quote, "Creating and maintaining dependence among smokeless tobacco consumers." And, third, the allegation that U.S. Tobacco products are developed in the basis of some sort of graduating levels of nicotine.

As to the allegation that U.S. Tobacco markets these products to persons under the age of 18 , that allegation is absolutely false. We strongly believe at U.S. Tobacco that those who enjoy our products should be adults. That is why U.S. Tobacco and other smokeless tobacco manufacturers have devoted substantial efforts and resources to discourage the sale of their products to minors.

Those efforts include support of State laws mandating 18 as a minimum purchase age for smokeless tobacco products. Programs to remind parents, retailers, and other adults that smokeless tobacco is an adult custom not intended for youth, a national campaign in publications such as U.S.A. Today, U.S. News and World Report to communicate our adults only policy.

$\mathrm{I}$, too, am concerned reports indicating that some individuals have tried tobacco products including smokeless tobacco before they are adults. Research, conducted by others, indicates that advertising plays little, if any, role in the decision to begin using smokeless tobacco. That research indicates that a variety of factors, including family and friends appear to influence the decision to begin using various products, including smokeless tobacco.

It's noteworthy that according to a recent Department of Health and Human Services Report, use of smokeless tobacco by males under 18 years of age is low, decreasing, and very close to HHS's target or goal for the year 2000.

In 1992, Healthy People Review states that the reported use of smokeless tobacco, which is defined as use on at least one occasion in the last 30 days by 12 to 17 year old males decreased by 20 percent from 6.6 percent in 1988 to 5.3 percent in 1991.

Moreover, a survey published in October 1993, by the Substance Abuse and Mental Health Services Administration, reported that the use of smokeless tobacco by 12 to 17 year old males had further declined in 1992 to 4.8 percent, which is very close to the 4 percent target for the year 2000 in Healthy People 2000 Review.

Even though these trends are encouraging, they're not good enough. We're not going to rest until that figure is zero. U.S. Tobacco will continue its efforts, with other members of the industry, to discourage the sale of smokeless tobacco products to minors.

As for the allegation that U.S. Tobacco has conducted scientific research for the purpose of, and I quote, "Creating and maintaining dependence among consumers," that allegation is also false. The research in question was funded by U.S. Tobacco and other tobacco manufacturers.

However, it was neither intended or used by U.S. Tobacco to develop or manufacture smokeless tobacco products. The research was conducted 15 years ago by a group of independent researchers in the Department of Pharmacology at Pennsylvania State University College of Medicine.

For a number of years, the Pennsylvania State researchers had been interested in measuring extremely low levels of blood nicotine in tobacco consumers. And later they became interested in studying 
the absorption by humans of nicotine from snuff and chewing tobacco. The Pennsylvania State researchers submitted a proposal for a 3 year study to pursue this matter.

Several tobacco companies, including U.S. Tobacco, funded this research during the period 1978 to 1981 . The document relied upon to support this allegation and testimony relates to the research conducted at Pennsylvania State and was prepared by those researchers. The results of that research are reflected in a 1983 publication by the Pennsylvania State researchers in the journal Pharmacology, therefore, available in the public domain.

And this project, the funding of this research, was part of the smokeless tobacco industry's ongoing funding of research by independent investigators into questions relating to smokeless tobacco and health. Over the years, such funding has totalled more than $\$ 25$ million and has been acknowledged in nearly 800 scholarly articles and abstracts in a wide spectrum of scientific publications.

As to the allegation that U.S. Tobacco products are developed based on a graduating levels of nicotine, that allegation is false. As indicated in my written statement, the assertion that U.S. Tobacco manipulates its consumers and dictates which of its smokeless tobacco products those consumers ultimately choose to use are totally false.

The key to our product development process is developing products which appeal to the taste preferences of our consumers. The taste characteristics of our smokeless tobacco products, as with all tobacco products, are inherently complex. A number of factors interacting with each other affect the ultimate taste, including leaf blend, cut of tobacco, moisture, $\mathrm{PH}$, flavors, and undoubtably nicotine in the tobacco leaf.

U.S. Tobacco's success is based upon its unique ability to develop a wide selection of flavored products incorporating blends of tobacco that have been developed over hundreds of years ago.

What would I tell someone who said, you are using the graduation strategy to entice consumers to begin using low nicotine starters products, either through advertising or through nicotine dependence to graduate down to products of higher levels of nicotine? I'd tell them that our consumers do not conform to any so-called graduation theory.

The oral tobacco market does not work that way. There is no set pattern of brand switching among smokeless tobacco consumers. Smokeless tobacco consumers remain loyal to a single brand, or switch among a variety of brands according to their taste preferences, cut of tobacco, form, and packaging.

U.S. Tobacco's line of smokeless tobacco is based on the appreciation that we can not make any part of the public like and use any one of our products, if it does not appeal to their taste preferences.

Finally, Mr. Chairman let me address the general concerns which have been raised about the ingredients added to tobacco products. The identity of the ingredients in U.S. Tobacco's smokeless tobacco products is proprietary information. I can assure you, however, that U.S. Tobacco has a procedure in place for the evaluation of all available scientific information regarding the ingredients added to the tobacco in the manufacture of our products. 
As a result of these evaluations, U.S. Tobacco believes that no ingredient, which it adds to tobacco in the manufacture of its products, would result in adverse health consequences to a consumer of our products.

Without revealing proprietary information, I can tell you that every ingredient which U.S. Tobacco adds to tobacco in the manufacture of our products is a common food item, or approved for use in food, with the one single exception of denatured alcohol which you've heard a lot about today, which is the only substance approved by the B.A.T.F. for use in the manufacture of tobacco products.

[Testimony resumes on p. 619.]

[The prepared statement of Mr. Taddeo follows:] 


\section{Statement of United States Tobacco Company Before the \\ House Energy and commerce committee \\ Subcommittee on Health and the Environment April 14, 1994}

United States Tobacco Company welcomes this opportunity to address a number of issues, as they relate to smokeless tobacco products, raised at the March 25, 1994 hearing before this Subcomittee concerning the possible jurisdiction of the Food and Drug Administration over the manufacture of tobacco products, and in Chairman Henry Waxman's March 31, 1994 letter inviting United States Tobacco company to participate in today's hearing.

Further, United States Tobacco Company will set the record straight with regard to the baseless claims made by Dr. Gregory Connolly on March 25th concerning United States Tobacco Company's marketing practices.

To provide a context for this discussion, this statement will briefly adaress the history of smokeless tobacco, and the background of United States Tobacco Company, its products, and the process by which they are manufactured. 


\section{Smokeless Tobacco}

Smokeless tobacco products -- snuff and chewing tobacco -are a variety of consumer products which, unlike cigarettes, cigars, pipe tobacco or other smoking tobacco, are not manufactured to be smoked but instead are placed in the mouth and chewed or passively enjoyed. Consumers choose to use smokeless tobacco products for a variety of reasons, particularly where smoking is inconvenient.

Smokeless tobacco was introduced in Europe early in the 16th century by explorers who found the natives in the western Hemisphere using tobacco in several ways. Its use quickly grew in popularity throughout Europe and the British Isles. The use of smokeless tobacco has been a tradition in the United States since the 18 th century, predating branded cigarettes by over a hundred years. Smokeless tobacco dominated the American tobacco market until the early 20 th century when cigarettes and other lighted forms of the leaf began to win wide public acceptance. Today, smokeless tobacco products are consumed throughout the United States, although per capita consumption of smokeless tobacco in the $1990 \mathrm{~s}$ is less than 25 percent of what it was at the turn of the century. 


\section{4}

\section{United States Tobacco Company}

United States Tobacco Company (U.S. Tobacco), founded as the Weyman-Bruton Company in 1911, is a leading producer and marketer of smokeless tobacco products, including moist snuff.

U.S. Tobacco's leading moist snuff brands include Copenhagen, one of America's oldest registered brand names, introduced in 1822; Skoal, another fine-cut smokeless tobacco product introduced in 1934; Skoal Long cut, consisting of slightly larger particles of fine-cut tobacco, introduced in 1984; and Skoal Bandits, a portion-pack product developed for ease of use introduced nationally in 1983.

\section{U.S. Tobacco's Smokeless Tobacco Manufacturing Process}

U.S. Tobacco's smokeless tobacco products are made up of a combination of aged tobaccos and flavorings. The tobaccos used in U.S. Tobacco's smokeless tobacco products are a historical blend which includes whole or threshed dark fired, dark air cured and burley tobaccos. The hallmark of U.S. Tobacco's basic manufacturing process is tradition. Thus, for example, the makeup of and manufacturing process for copenhagen brand smokeless tobacco today is very similar to what it was in 1906, the earliest date for which records are available. 
The process by which U.S. Tobacco's smokeless tobacco products are manufactured is illustrative. The process begins at U.S. Tobacco's facility with the arrival of the tobacco from farmers. It is then processed for aging in large containers known as hogsheads. After aging, the tobacco is removed from the hogshead and put into bulking bins where it is blended. Blended tobacco from the bulking bins is then cut to the final particle size. Once cut, the tobacco is then dried and sifted.

As the process continues, water and other ingredients are added. The product next goes into stainless steel cure bins where it is subjected to curing and mixing.

Once cured, the tobacco is sifted. Flavoring and other ingredients are added during the process. The product is then brought into the packing room where it is packed, labeled and wrapped. Finished rolls are packed into cartons for shipment.

Over the years, this process has remained substantially the same. Of course, as technology progressed with the times, the machinery used to perform the functions described has become more automated. 
Throughout the entire manufacturing process, the product and process are carefully monitored to ensure adherence to U.S. Tobacco's high standards of manufacturing practices and product quality.

\section{General Claims Regarding Addiction and Nicotine Manipulation}

At the March 25th hearing, Dr. David Kessler and others charged that tobacco products are highly addictive, and that tobacco manufacturers may intentionally manipulate or control the amount of nicotine in their products for the purpose of creating and maintaining dependence on tobacco products among their consumers.

\section{The Addiction Claim}

The assertion that smokeless tobacco use can be addictive is without merit. In this day and age, people claim to be addicted to a wide variety of things -- to work, to sweets, to video games -- when in fact they are describing settled practices or habits. The fact of the matter is that tobacco use, like many other routinely repeated activities in life, involves a wide array of diverse psychological and physical factors that elude scientific explanation. When confronted with such a lack of understanding, 
some have resorted to the charge that tobacco use is "addictive". Such charges ignore the scientific facts, including the fact that more than 50 million Americans have given up tobacco, including 8 million who have given up smokeless tobacco. While the use of smokeless tobacco may become a settled practice or habit, it is not addictive.

U.S. Tobacco is, of course, aware that the 1988 surgeon General's Report on nicotine claims that tobacco is "addicting" and that "nicotine is the drug in tobacco that causes addiction."

Professor David M. Warburton, a British researcher who prepared a portion of the 1988 Surgeon General's Report, has published a critique of that Report. ${ }^{1}$ It is Professor Warburton's judgment that the Report's conclusions are "political pronouncements" rather than experimentally verified scientific claims.

Furthermore, Professor warburton believes that the surgeon General's "misleading comparisons" of tobacco and drugs may

${ }^{1}$ Warburton, D.M., "Is Nicotine Use an Addiction?", The Psychologist, 4, 166-170, April 1989. 


\title{
608
}

unintentionally encourage teenagers to experiment with heroin and cocaine:

\author{
"The problem is that putting tobacco, a legal \\ product, in the same category with heroin and \\ cocaine trivialises the illicit drug problem. \\ Thus, statements that equate [tobacco use] with \\ heroin use and cocaine use could promote hard drug \\ experimentation with all its risks. Teenagers see \\ the normality of friends and relatives who [use \\ tobacco] and think that, if heroin and cocaine use \\ are only like [tobacco], then there is no harm in \\ trying these drugs. Nothing could be further from \\ the truth. Heroin use in our society leads to \\ gross physical, social and moral deterioration in \\ the frequent user. Misleading comparisons of \\ [tobacco] with other substances may \\ unintentionally encourage hard drug use and its \\ horrifying evils."
}

The concept of "addiction" cannot and should not be applied to a consumer product such as smokeless tobacco which has been widely used and accepted worldwide for hundreds of years. 


\section{The Nicotine Manipulation Claim}

U.S. Tobacco offers smokeless tobacco products suited to the taste of those consumers who choose to make tobacco a part of their lifestyle. U.S. Tobacco actively competes against more than 600 brands of other tobacco products and the variety of its products reflect the wide range of consumer preferences in flavor, cut of the tobacco, form and packaging.

U.S. Tobacco does not in any way manipulate or "spike" the nicotine levels in its tobacco products. Nor does U.S. Tobacco take any action to control the nicotine content of its tobacco products before, during or after the manufacturing process. In fact, an incidental effect of U.S. Tobacco's manufacturing process is that the nicotine content of U.S. Tobacco's smokeless tobacco products is less than that which occurs naturally in tobacco.

The only material used in the manufacture of U.S. Tobacco's smokeless tobacco products, other than the tobacco itself, which contains nicotine, is denatured alcohol which is purchased from a supplier as a carrying agent for the application of certain flavorings that do not dissolve in water. The denatured alcohol (SDA-4) used by U.S. Tobacco has been denatured by its 
manufacturer with small amounts of nicotine. The use of nicotine as a denaturant for alcohol which is to be used in the processing and manufacturing of tobacco products is specifically approved by the Bureau of Alcohol, Tobacco and Firearms (see 27 CFR 21.38). The amount of nicotine that might be contributed to a U.S. Tobacco smokeless tobacco product through the use of denatured alcohol in the manufacturing process is so minuscule as to be unmeasurable by standard laboratory methodologies.

\section{Claims Regarding U.S. Tobacco}

At the hearing held by this Subcommittee on March 25, 1994, Dr. Connolly made a series of claims regarding U.S. Tobacco that may be summarized as follows:

1. Allegation that U.S. Tobacco has conducted proprietary "in-house" scientific research on the pharmacological properties of nicotine, and has used that knowledge to create and maintain dependence on its smokeless tobacco products among consumers;

2. Allegation that U.S. Tobacco developed Skoal Bandits to target cigarette smokers aged 15 to 35 years of age; and 
3. Allegation that U.S. Tobacco employs a "graduatior strategy" with the intent of moving new users from low nicotine brands up to higher nicotine brands as dependence occurs, and intentionally adjusts the nicotine dose in each brand to cause and maintain dependence.

\section{Dr. Connolly's Agenda}

Before addressing the substance of these allegations, it is important to understand the demonstrable bias of the individual who is making them. Although Dr. Connolly stated on March 25th that he was appearing on behalf of the American Public Health Association, his public statements on matters relating to U.S. Tobacco and the smokeless tobacco incustry are not those of an objective public health official. Rather, they depict a vindictive individual whose personal crusade against U.S. Tobacco and the smokeless tobacco industry extends far beyond any responsible public health stand.

Two examples of Dr. Connolly's personal agenda will suffice. He was quoted in a 1986 Business Week article as stating, "I'm going to kill [U.S. Tobacco]." Dr. Connolly recently admitted the accuracy of this statement before the House Ways and Means Committee. And in $1985 \mathrm{Dr}$. Connolly was quoted as having the 
self-proclaimed goal of "crippling the smokeless tobacco industry nationwide."

It should also be noted that the claims which Dr. Connolly made on March 25, 1994 were first put forth during the 1986 trial of a product liability lawsuit, Marsee V. U.S. Tobacco, in which Dr. Connolly attempted to testify on behalf of the plaintiff.

In the Marsee case, an oklahoma jury rendered a unanimous verdict in favor of U.S. Tobacco, indicating that the jury did not believe U.S. Tobacco was responsible for a 19-year old's tongue cancer and subsequent death. The jury announced its verdict after approximately six hours of deliberation following a five-week trial during which the plaintiff called thirty-one witnesses and introduced 140 exhibits. The suit was brought by the mother of sean Marsee after his death. She claimed his cancer was caused by his use of snuff and sought approximately $\$ 147$ million in damages, including punitive damages. The Tenth Circuit Court of Appeals in Denver, Colorado upheld the jury verdict in favor of U.S. Tobacco.

\section{The Nicotine Research Allegations by Dr. Connolly}

In support of his assertion that U.S. Tobacco "has conducted research on the pharmacological properties of nicotine 
and has knowledge of its dependence producing properties," Dr. Connolly points to a single document which was made available by U.S. Tobacco to plaintiff's counsel prior to the Marsee trial. That document is entitled "Pharmacokinetics of Nicotine and its Major Metabolites in Naive and Habituated Snuff Takers." Dr. Connolly further asserts that "there is only one reason that this type of research would be conducted and that is to understand how the drug nicotine delivered from oral snuff effects the structure and function of the human user as compared to cigarette smokers and in turn assist [U.S. Tobacco] in creating and maintaining dependence on their products among consumers."

Dr. Connolly misstates the facts both as to who conducted the research, and the purpose for which it was conducted. Both Dr. Connolly's assertion that this research was conducted by U.S. Tobacco and his assertion that its purpose was to "assist [U.S. Tobacco] in creating and maintaining dependence on their products among consumers", are false.

The research in question was not conducted by U.S. Tobacco, and was neither intended nor used by U.S. Tobacco to develop or manufacture smokeless tobacco products. The research was conducted 15 years ago by a group of independent researchers in the Department of Pharmacology at Pennsylvania State University college of Medicine. For a number of years, the Pennsylvania 
State ressearchers had been interested in measuring extremely low levels of blood nicotine in tobacco users, and later became interested in studying the absorption by humans of nicotine from snuff and chewing tobacco. The Pennsylvania state researchers submitted a research proposal for a three-year study to pursue this matter. Several tobacco companies, including U.S. Tobacco, funded this research during the period 1978 to 1981 . The document relied upon by Dr. Connolly relates to the research conducted at Pennsylvania state and was prepared by those researchers. The results of that research are reflected in a 1983 publication by the Pennsylvania state researchers in the journal pharmacology.

This project was part of the smokeless tobacco industry's ongoing funding of research by independent investigators into questions relating to smokeless tobacco and health which over the years has totaled more than twenty-five million dollars and has been acknowledged in nearly eight hundred scholarly articles and abstracts in a wide spectrum of scientific publications.

\section{The Youth Allegations By Dr. Connolly}

Again relying on allegations made in the Marsee case, Dr. Connolly asserts that U.S. Tobacco's Skoal Bandit product was targeted at "new users, mainly cigarette smokers, age 15-35." That allegation is also false. The document relied upon by 
Dr. Connolly to support his assertion was written over 20 years ago, does not mention skoal Bandits, was not created by U.S. Tobacco and does not reflect U.S. Tobacco policy.

\section{U.S. Tobacco strongly believes that those who enjoy its} products should be adults. That is why U.S. Tobacco and other smokeless tobacco manufacturers have devoted substantial efforts and resources to discourage the sale of their products to minors. Those efforts include support of state laws mandating 18 as the minimum age for purchase of smokeless tobacco; programs to remind parents, retailers and other adults that smokeless tobacco is an adult custom not intended for youth; and a national campaign in publications such as USA Today and U.S.News and World Report to communicate our "adults only" policy.

In this regard, it is noteworthy that according to a recent HHS report, use of smokeless tobacco by males under 18 years of age is low, decreasing and very close to HHS's "target" or goal for the year 2000. The 1992 Healthy People 2000 Review $^{2}$ states

${ }^{2}$ The 1992 Healthy People 2000 Review was compiled by the National Center for Health Statistics (Centers for Disease control and Prevention) and submitted by HHS Secretary Shalala to the President and Congress in compliance with the Health Services and Centers Amendments of 1978. 
that the reported use of smokeless tobacco (defined as use on at least one occasion in the last 30 days) by 12-17 year old males decreased from $6.6 \%$ in 1988 to $5.3 \%$ in 1991 .

Moreover, a survey published in October 1993 by the Substance Abuse and Mental Health Services Administration (SAMSHA) $^{3}$ reported that use of smokeless tobacco by 12-17 year old males had further declined in 1992 to $4.8 \%$, which is very close to the $4.0 \%$ "target" for the year 2000 in Healthy People 2000 Review.

Furthermore, the reported use of smokeless tobacco by the total 12-17 year old population (males and females) was only $2.6 \%$ in 1992 according to the SAMHSA survey.

\section{Allegations Regarding A "Graduation Strategy"}

Dr. Connolly has alleged that U.S. Tobacco "employs a 'graduation' strategy with the intent of moving new users from the low nicotine brands up to higher nicotine brands as dependence occurs." And Dr. Kessler has asserted that "there is evidence that smokeless tobacco products with lower amounts of nicotine are marketed as 'starter' products for new users, and

${ }^{3}$ National Household Survey on Drug Abuse: Population Estimates 1992 DHHS Pub. No. (SMA) 93-2053, Oct. 1993, p. 97. 
that advertising is used to encourage users to 'graduate' to products with higher levels of nicotine."

The assertions of Drs. Connolly and Kessler suggest that U.S. Tobacco manipulates its consumers and dictates which of its smokeless tobacco products those consumers ultimately choose to use. Those assertions are totally false. U.S. Tobacco does not employ any marketing strategy based upon a theory that consumers can be enticed to begin using low-nicotine "starter" smokeless tobacco products, and subsequently caused to "graduate" through advertising (according to Dr. Kessler) or through nicotine dependence (according to Dr. Connolly) to products with higher levels of nicotine.

This fanciful concept was created by plaintiff's counsel in the 1986 Marsee litigation in an unsuccessful attempt to sway the jury against U.S. Tobacco. This fiction has been perpetuated by Dr. Connolly.

Furthermore, the inflammatory allegations of Drs. Connolly and Kessler regarding a so-called "graduation strategy" are not supported by the facts. Smokeless tobacco products, like all tobacco products, vary in nicotine content. Any suggestion that U.S. Tobacco's line of products is developed based on "graduating" levels of nicotine is not true. 
Moreover, there is no set pattern of brand switching among smokeless tobacco consumers. In short, smokeless tobacco consumers remain loyal to a single brand or switch among a variety of brands according to their preference for flavor, cut of tobacco, form and packaging. They do not conform to any socalled "graduation strategy".

U.S. Tobacco offers smokeless tobacco products suited to the tastes of those consumers who choose to make tobacco a part of their lifestyle. The variety of different U.S. Tobacco products reflects the wide range of consumer preferences in flavor, cut of the tobacco, form and packaging.

\section{Conclusion}

U.S. Tobacco does not in any way manipulate the nicotine levels in its smokeless tobacco products, nor does it control the nicotine content of its tobacco products before, during or after the manufacturing process.

Furthermore, U.S. Tobacco does not employ any marketing strategy based upon a theory that consumers can be enticed to begin using low-nicotine "starter" smokeless tobacco products, and subsequently caused to "graduate" to products with higher levels of nicotine. 
Mr. WAXMaN. Thank you very much, Mr. Taddeo.

Mr. TADDEO. Thank you, Mr. Chairman.

Mr. WAXMAN. I and all my colleagues on the subcommittee appreciate your being here. Your participation in the subcommittee's ongoing investigation into tobacco is essential. This is, however, not going to be an easy day. We have a lot of substantive issues that we want to go into.

When we hear about scientific disputes, we have to listen to one expert versus another. But let me tell you there are some things that we know about from our own personal experience. I was a smoker and I know how addicted I was to smoking. I know how hard it was to quit. Each and every time I did try to quit, I had to do it a number of times before I was successful. So from my own personal experience, and from people I've known and talked to, your universal comment that cigarette smoking is not addictive just doesn't ring true.

Now, Mr. Johnston, I want to start with your testimony. You and your colleagues seem to have almost a fanatical insistence your products are the same as all these other products. This morning, in your written statement and in your oral statement, you have compared cigarettes to coffee, tea, sweets, sugar, warm milk, cheese, chocolate, and Twinkies. That's quite a list.

I'm struck by what I think is a calculated attempt to trivialize the devastating health impacts of your product. You and I both know that Twinkies don't kill a single American a year. They may not add to a healthy diet, but they don't kill. The difference between cigarettes and Twinkies, and the other products you mentioned is death. I'm sure you are aware that the Surgeon General and the American Medical Association estimate that cigarettes kill over 400,000 smokers every year. Putting aside your assertion that people accept this risk willingly, do you agree with this estimate?

Mr. JAMES JOHNSTON. Do I agree with the estimate of why the 35,000 people? I've heard from this subcommittee this morning three or four different numbers. My understanding of how that number is-

Mr. WAXMAN. If you don't agree with that number, then give us your number. How many smokers die each year from smoking cigarettes?

Mr. JAMES JOHNSTON. I will explain.

Mr. WAXMAN. No. I want you to answer. We have limited time.

Mr. JAMES JOHNSTON. I do not know how many.

Mr. WAXMaN. Do you disagree with the Surgeon General's estimate?

Mr. JAMES JOHNSTON. It is a computer generated number that makes-

Mr. WAXMAN. Mr. Johnston, I'm going to have to ask you to respond to my questions. Do you or do you not agree with the Surgeon General's estimate that over 400,000 smokers die-

Mr. JAMES JOHNSTON. I do not agree.

Mr. WAXMAN. OK. Do you know how many smokers die each year?

Mr. JAMES JOHNSTON. I do not know. 
Mr. WAXMAN. How can you as a chief executive of a company manufacturing a product that has been accused of killing so many people, not know this information? How is it?

Mr. JAMES JOHNSTON. I'm telling you that number is generated by a computer and it makes two important assumptions. The first is that virtually everyone that smokes and dies, dies because they smoke unless they got run over by a bus. And, second, that mode! allows people to die one, two, three, four times. I don't know how that can happen. But that is what that model does.

Mr. WAXMAN. Well, I'm struck by the overwhelming scientific agreement on the dangers of smoking. The U.S. Public Health Service, the Surgeon General, the Food and Drug Administration, the World Health Organization, The National Cancer Institute, the American Medical Association. I guess, all of these groups you would call the anti-tobacco industry. They all say it's hazardous. The experts also agree that smoking causes heart disease. Do you agree that smoking causes heart disease?

Mr. JAMES JOHNSTON. It may.

Mr. WAXMAN. OK. They agree that smoking causes lung cancer, do you agree?

Mr. JAMES JOHNSTON. It may.

Mr. WAXMaN. Do you know whether it does?

Mr. JAMES JOHNSTON. I do not know.

Mr. WAXMAN. Why not?

Mr. JAMES JOHNSTON. Because all of that is-

Mr. WAXMAN. Proprietary?

Mr. JAMES JOHNSTON [continuing]. Statistically generated data. It is epidemiological as opposed to empirical. There have been no laboratory studies which have been able to confirm any statistic-

Mr. Waxman. My colleague, John Bryant, said in his opening statement, his grandfather smoked all of his life and died of lung cancer. Do you think that lung cancer was caused by smoking?

Mr. JAMES JOHNSTON. I don't know, Mr. Chairman.

Mr. WAXMAN. OK. The medical experts agree that smoking causes emphysema. Do you agree?

Mr. JAMES JOHNSTON. It may.

Mr. WAXMAN. They agree that smoking causes bladder cancer, stroke, and low birth weight. Do you agree?

Mr. JAMES JOHNSTON. It may.

Mr. WAXMAN. Mr. Tisch, I want to move to you for a moment. In a deposition last year, you were asked whether cigarette smoking causes cancer. Your answer was, quote, "I don't believe so." Do you stand by that answer today?

Mr. TISCH. Yes, Sir.

Mr. WAXMAN. Do you understand how isolated you are in that belief from the entire scientific community?

Mr. TISCH. I do, Sir.

Mr. WAXMAN. You are the head of a manufacturer of a product that's been accused by the overwhelming scientific community to cause cancer, and you don't know? Do you have an interest in finding out?

Mr. Tisch. I do, Sir. Yes.

Mr. WAXMAN. And what have you done to pursue that interest? 
Mr. Tisch. We have looked at the data, and the data that we have been able to see has all been statistical data that has not convinced me that smoking causes death.

Mr. WAXMAN. Mr. Campbell, you were also deposed. And you said, quote, "To my knowledge it has not been proven that cigarette smoking causes cancer." This is a rather passive and puzzling approach, especially in light of the consensus not by some but all of the scientific community. Will you ever be convinced? What evidence are you waiting for? And let's have the microphone passed over.

Mr. CAMPBell. Yes, I may be convinced. We don't know what causes cancer, in general, right now, so I think that we may find out what causes cancer, and we may find out some relationship, which has yet to be proven.

Mr. WAXMaN. I must say, this is rather a passive approach. Don't you feel you have an obligation, the same obligation that every other consumer company has to determine whether you are causing harm, and to take steps to minimize that harm? You are not meeting that responsibility.

And it's clear your views on the health impact of cigarettes are out of step with the overwhelming scientific evidence. If all the medical people, who don't work for you, say it causes cancer, what more do you need to understand that that is the case, and accept it, and then try to work constructively to try to see if we can avoid that terrible tragedy to so many people?

Mr. CAMPBELL. Is there a question, Sir?

Mr. WAXMAN. That's the question.

Mr. CAMPBELL. I'm sorry, it was too long for me to

Mr. WAXMAN. Well, I think the point I'm making is that all of you have some responsibility not simply to say you don't know, even when the overwhelming weight of scientific evidence is against you. I think you have an obligation to know. In my view, at the center of the entire debate over tobacco is nicotine. This ingredient in tobacco has an enormous impact on humans.

At our last hearing, Mr. Spears told the subcommittee that nicotine is an important flavor. In contrast, Dr. Kessler said the taste of nicotine is actually bitter, and can be replicated through the addition of pepper. Dr. Kessler also told the subcommittee that he was unaware of any purpose for the inclusion of nicotine in a tobacco product except for it's addictive effect. Yet Mr. Spears insisted to the subcommittee that nicotine was a flavor.

I want to cite, at this point, a document entitled, "Tobacco Flavoring for Smoking Products." The document was published by the RJ Reynolds Tobacco Company in 1972. The document lists hundreds of potential flavorings for tobacco, and rates them for smoke taste and smoke aroma. But neither nicotine nor nicotine sulphate is listed as an additive. Am I missing something, Mr. Johnston? This is RJ Reynolds. Why wasn't nicotine listed as a tobacco flavoring? Or do you disagree with Mr. Spears?

Mr. JAMES JOHNSTON. I would want to see the document, but I think I can give you the general answer to that. Nicotine is the natural component of tobacco leaf, and therefore would not be an added ingredient. Nicotine sulphate, as everyone here has testified, 
is required by the Bureau of Alcohol, Tobacco, and Firearms in miniscule quantities.

Mr. WAXMAN. So you say it's not a flavor because it wasn't added?

Mr. JAMES JohnSTON. That was a document, as I recall, that addresses flavors and aromas.

Mr. WAXMaN. So you submit then that it is not listed as a flavor in your company's document, because it's a natural ingredient in the tobacco?

Mr. JAMES JOHNSTON. I would have to look at that document, understand what it's purpose and intent is. I'm trying to give you a generalized answer to a publication 22 years old.

Mr. WAXMan. Well, we're going to move on. We'll get back to some of these issues. Mr. Bliley?

Mr. Bliley. Mr. Campbell, allegations have been made that the cigarette industry adds or controls nicotine to hook smokers. But it seems inconsistent with a number of facts, including Philip Morris' development of a virtually nicotine-free cigarette. Did Philip Morris spend about $\$ 200$ million in the late 1980 's building a plant capable of producing denicotinized tobacco in commercial quantities?

Mr. CAMPBEll. On expenses and in promoting and trying to sell the product, yes, sir.

Mr. BlILEY. It Philip Morris a long time to develop a denicotinized cigarette, isn't that because the technology for selectively removing nicotine from tobacco was unavailable until recently?

Mr. CAMPBELL. It was very unusual technology. When we acquired the Maxwell House Company, we saw their decaffeination process over in Europe. And it's a very selective type of process, and we were able to take out the nicotine without taking out a lot of other things, so we applied that technology, yes, sir.

Mr. Bliley. Am I correct that between 1986 and 1989 Philip Morris research and development team, working with a marketing team, tested different blends using denicotinized tobacco in an attempt to produce a cigarette with all the other desirable properties of cigarettes, but no nicotine?

Mr. CAMPBELL. Innumerable man hours, sir. That work actually still continues today.

Mr. BLILEY. My understanding is that Philip Morris denicotized cigarettes failed in marketplace because consumers didn't like the way they tasted, is that correct?

Mr. CAMPBELL. That's exactly correct. People found them a little bit lacking in taste and flavor. And the other word they used was "flat," which relates to, I guess, mouth impact. Nicotine seems to have an impact that's like carbonation in a soda.

Mr. Bliley. Mr. Johnston, didn't you have a similar experience with your so-called, well, your tobacco-free cigarette, Premier?

Mr. JAMES JOHNSTON. We were not able to provide the level of taste that smokers expected. We continue to do a lot of

Mr. Bliley. I know my wife is a smoker. I took a pack of your cigarettes, those, home and she took three puffs, put it down never to pick it up again. She said it tasted terrible. 
Mr. JAMES JOHNSTON. Sometimes the greatest attempts at technology fail to provide consumers with what they want, despite whatever advantages that product might bring.

Mr. BLILEY. Mr. Campbell, aside from taste, wasn't the initial failure of Next also attributable to the fact that there were already a number of brands on the market with virtually no nicotine, and consumers therefore did not perceive the even greater reduction of nicotine in Next as a selling point?

Mr. CAMPBELL. That's correct. There is some major brands that have under one milligram of tar and under 0.1 milligrams of nicotine, so that made the competitive marketplace difficult.

Mr. BLILEY. Do you think the marketing of Next was hindered by petitions from the Coalition on Smoking OR Health which argued that the elimination of nicotine from the product made it a drug under the food and drug laws?

Mr. CAMPBELL. Yes. And I think Mr. Johnston pointed out the irony of that in his prepared remarks.

Mr. BLILEY. Did members of the Coalition on Smoking OR Health ironically argue to the FDA that Philip Morris' denicotized Next cigarettes posed a greater health hazard to smokers than ordinary cigarettes?

Mr. CAMPBELL. That's exactly correct, sir.

Mr. BLILEY. Isn't that petition position totally contrary to what they and Dr. Kessler are now saying, which is that products without nicotine should be the only ones allowed in the marketplace?

Mr. CAMPBELL. Yes. I think, as many of my colleagues said, there is great ironies here. We do something and we get-for it, and we do something and we do something else and we get-for that as well. So, it's difficult for us, sir.

Mr. BLILEY. What was Philip Morris' objective in marketing it's denicotized Next cigarettes?

Mr. CAMPBELL. Our objective was to try to get a piece of the marketplace, because we try to provide what the public wants.

Mr. BLILEY. When you say, "a piece of the marketplace," you know, I've heard different figures, but 1 percent in the marketplace, of all sales of cigarettes, what does that mean in dollars?

Mr. CAMPBELL. Oh, I guess, about $\$ 150$ million, sir.

Mr. BliLEY. So that's a reason'to be very competitive, I would think.

Mr. CAMPBell. I think it is, yes, sir.

Mr. BLILEY. Mr. Johnston, at last week's hearing, data was presented from the Surgeon General's Report which showed a dramatic reduction in tar and nicotine levels over 30 years. Dr. Kessler, during his testimony, showed us several graphs which showed us dramatically different results. His graphs showed nicotine increasing, and tar decreasing over the period 1982-1991.

First, let's examine the first graph, which is taken from the 1989 Surgeon General's Report. This graph documents the decline of tar and nicotine from the 1950's to the 1990's. For both tar and nicotine there has been a 69 percent reduction.

[The graphs referred to follow:] 


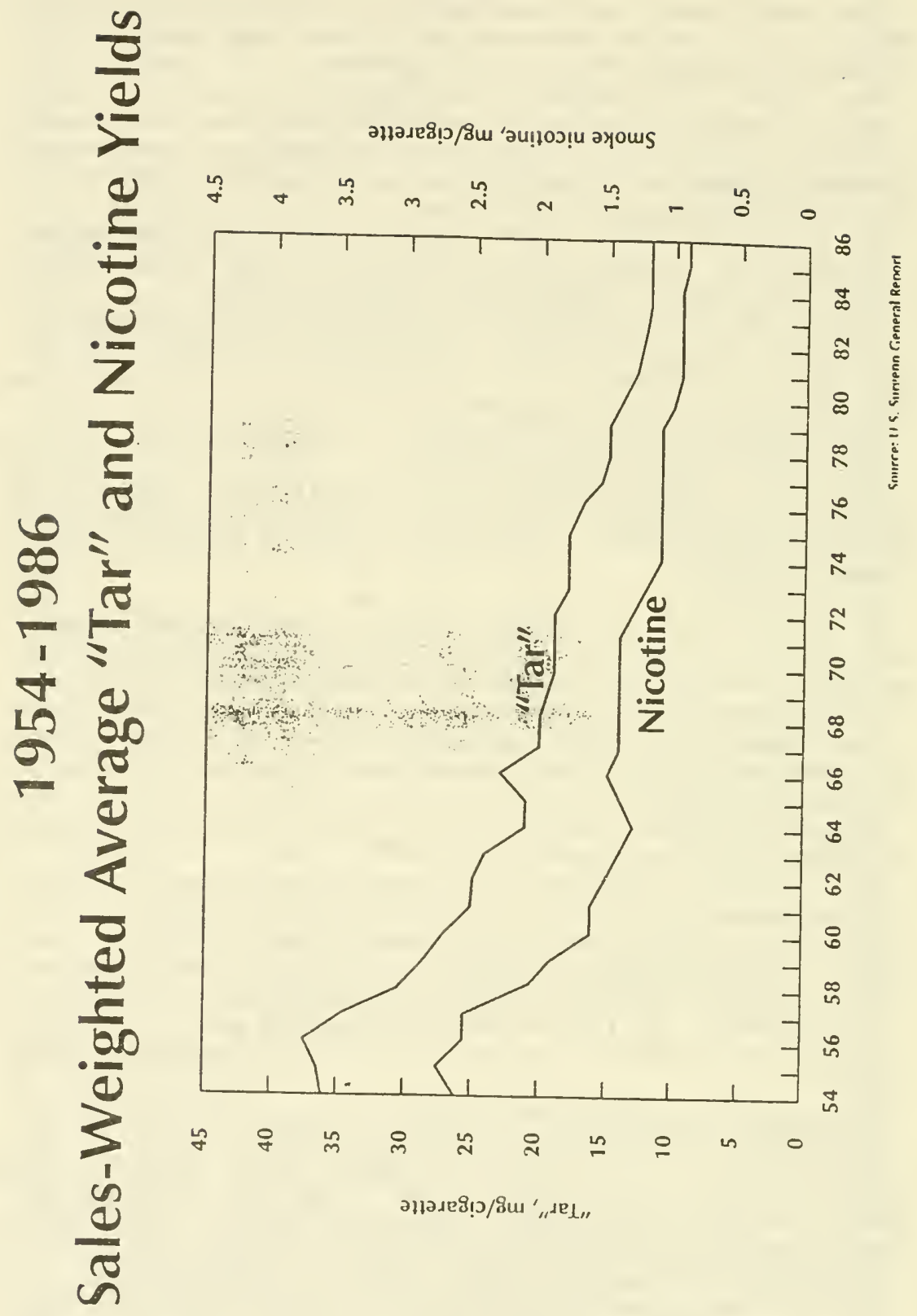




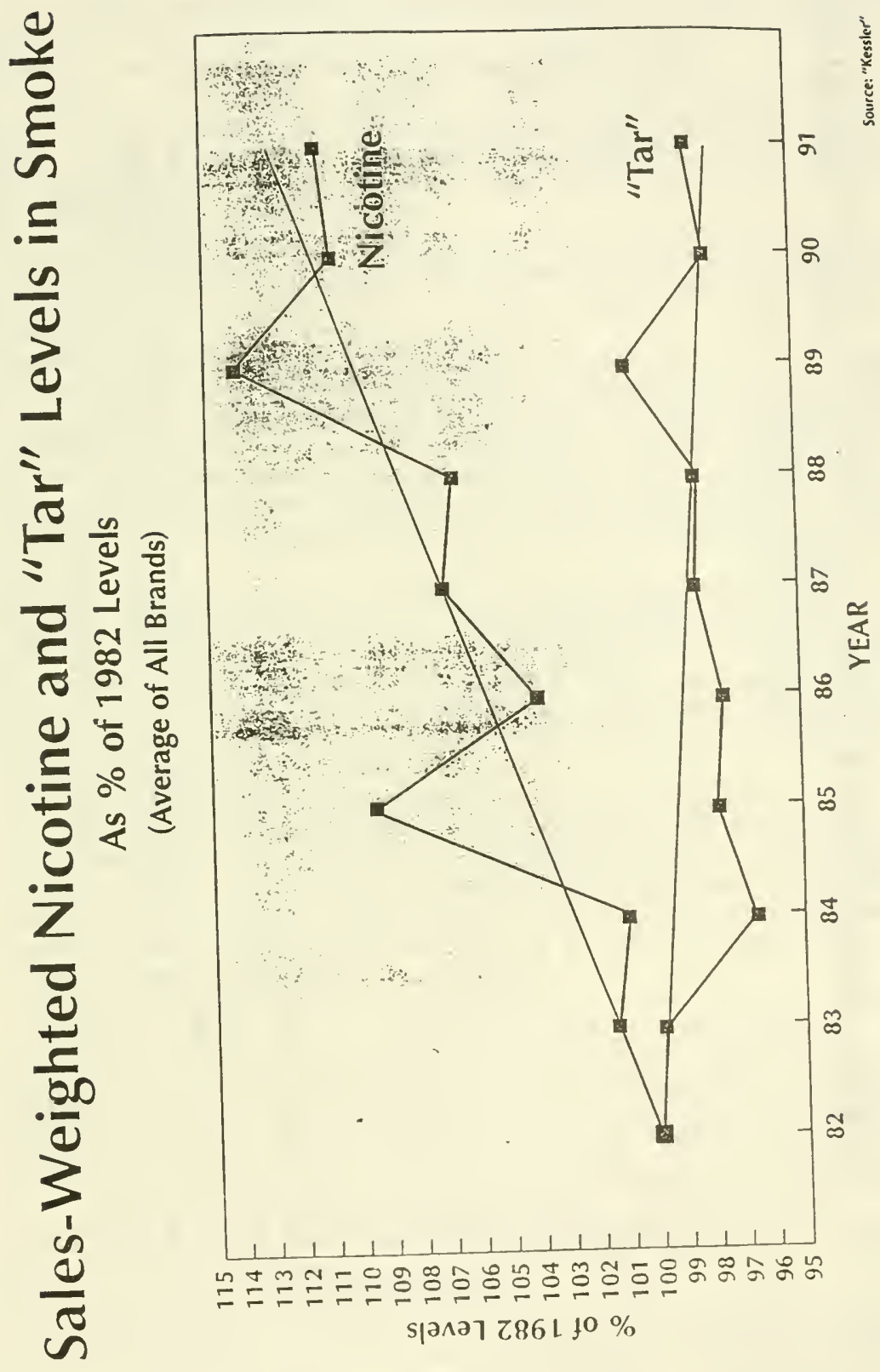




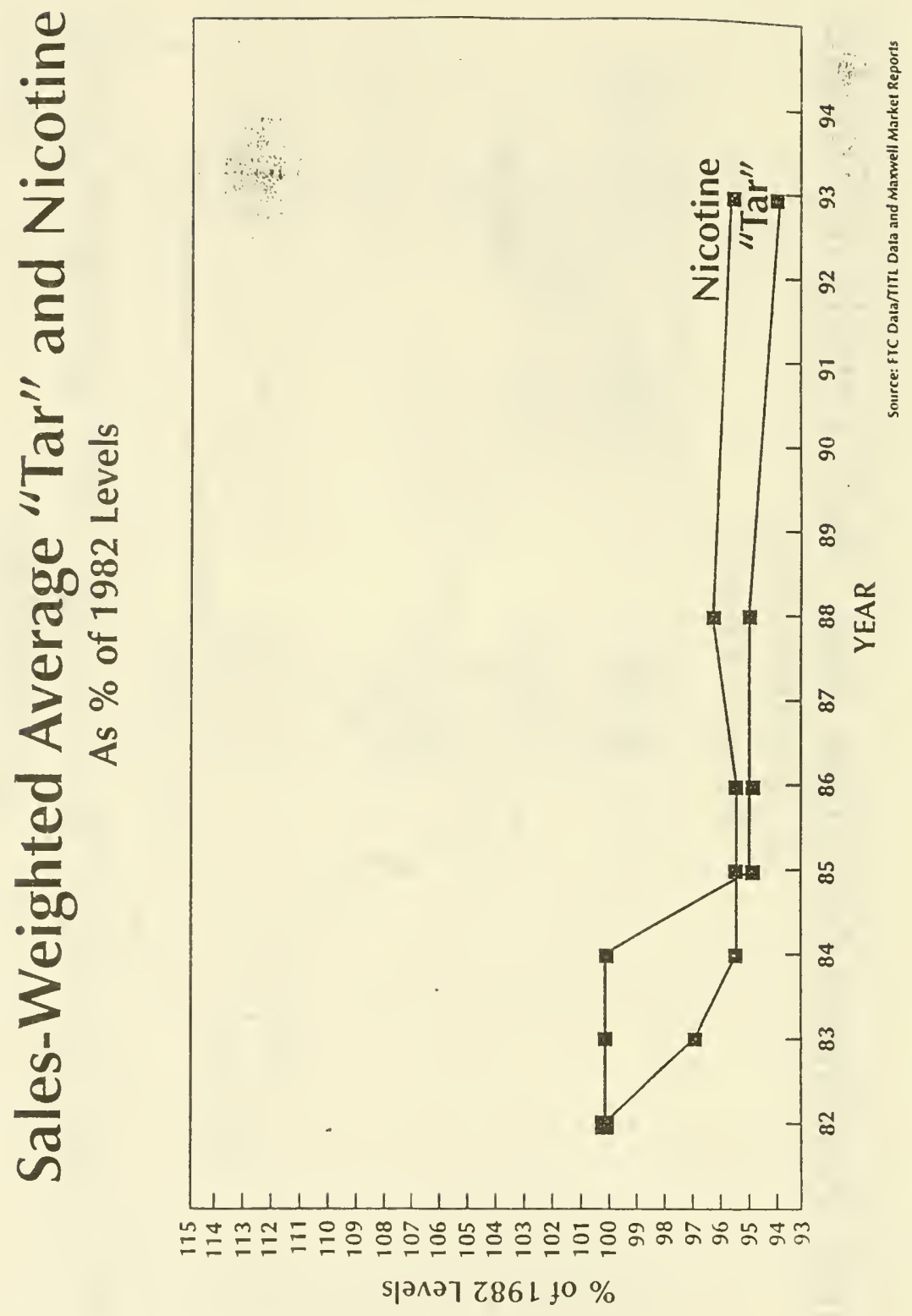


Mr. BliLEY. This graph shows that nicotine levels are a function of tar levels in tobacco. When tar levels are set, nicotine levels follow. And as the manufacturers have reduced their tar levels over the years, nicotine levels have correspondingly fallen.

Now, the second chart, which is taken from Dr. Kessler's testimony shows the opposite. His chart shows that as tar levels have fallen, nicotine has actually risen. I understand that your company has run a further analysis of this data. Could you please explain the differences in these graphs?

Mr. JAMES JOHNSTON. Yes, Congressman, I can. First, going back to the Surgeon General's data, which were presented at the previous hearing, we went back-the Surgeon General's data, David, please?

Just to make sure that those data were correct, we went back and selectively recalculated data. Our data were exactly in line with the Surgeon General's data which show a steady and quite remarkable decline in tar and nicotine deliveries. Certainly not an indication of increasing nicotine or addiction, or any of that sort of thing, with a 65 percent reduction in nicotine, a 67 percent reduction in tar, based on what people are actually smoking in the United States.

The FDA chart was quite startling and amazing to us, and so we set about immediately to try to reconstruct those data. We contacted the FDA and asked them to share their data with us. We believe the FDA calculations are incorrect. They used several simplifying assumptions, and took just the three basic categories, made three multiplications, full flavor times average tar and nicotine, low tar, and ultra low tar.

We went back and calculated for that 10 year period every single one of the 500 brand styles times their exact tar and nicotine number, times their exact sales in the marketplace. So, if you'll show chart three? This is precisely what Americans smoked on average for that 10 year period. And what you see, and what we expected to see, and what we have now confirmed, is that both tar and nicotine levels did decline during that period.

You do get changes year to year because we are dealing with an agricultural crop, based on sunlight, and rain, and wind, and all those sorts of things. Nicotine naturally varies year to year, so you get little changes. I want to be very clear Congressman. I am not accusing Dr. Kessler of manipulating data. I know how it is to be falsely accused. We have contacted the FDA. We are providing them with our calculations, and we have offered to be any help we can.

But it was Dr. Kessler's chart that was picked up by every newspaper in this country, and on television, as the proof that we were manipulating nicotine, and it was wrong.

Mr. BLILEY. When you say, Mr. Johnston, that sunlight, moisture vary the amount of nicotine in a stalk of tobacco, what kind of variance do you get from, say, a very dry summer, a hot summer, to a relatively cool summer, and a wet summer?

Mr. JAMES JOHNSTON. Mr. Congressman. You have just gone beyond my technical ability to answer that question. Mr. Schindler?

Mr. SCHINDLER. I don't know the exact numbers, but my understanding is that the ratio of nicotine to weight in the leaf varies 
according to the rainfall in the growing season. The amount of nicotine in a leaf is essentially the same regardless of the size and weight of the leaf. In a dry season, the leaf is smaller so it has more nicotine relative to the smaller size and weight of the leaf. In a wet season, the leaf is larger so it has less nicotine relative to the larger size and weight of the leaf.

Mr. WAXMAN. Thank you, Mr. Bliley, we'll have to get that statement reiterated for the record. I don't know if it was picked up. You'll see later if it was on the record.

Mr. Wyden?

Mr. WYDEN. Thank you, Mr. Chairman. Just before we go to the subject of my questioning, I know that the witnesses want to turn this to the battle of the charts, I guess, with respect to Dr. Kessler and the FDA. We're going to get into it later, but we believe that the chart in question, with respect to the FDA, is an accurate one, and we'll get into it a little bit later.

Let me begin my questioning on the matter of whether or not nicotine is addictive. Let me ask you first, and I'd like to just go down the row, whether each of you believes that nicotine is not addictive. I heard virtually all of you touch on it. Yes or no, do you believe nicotine is not addictive?

Mr. CAMPBELL. I believe nicotine is not addictive, yes.

Mr. WYDEN. Mr. Johnston?

Mr. JAMES JOHNSTON. Mr. Congressman, cigarettes and nicotine clearly do not meet the classic definition of addiction. There is no intoxication.

Mr. Wyden. We'll take that as a "no." Again, time is short. I think each of you believe that nicotine is not addictive. We would just like to have this for the record.

Mr. TADDEO. I don't believe that nicotine or our products are addictive.

Mr. TISCH. I believe that nicotine is not addictive.

Mr. HORRIGAN. I believe that nicotine is not addictive.

Mr. SANDEFUR. I believe that nicotine is not addictive.

Mr. DONALD JOHNSTON. And I, too, believe that nicotine is not addictive.

Mr. Wyden. Dr. Campbell, I assume that you are aware that your testimony, and you said in your testimony that nicotine is not addictive is contradicted by an overwhelming number of authorities and associations. For example, in 1988, the Surgeon General of the United States wrote an entire report on this topic. The Surgeon General, of course, is the chief health advisor to our government. I assume that you have reviewed that report?

Mr. CAMPBEll. Yes, I have, Sir.

Mr. Wyden. All right. Exhibit 1 excerpts from the report. And I'm going to ask the clerk from our committee to give you an exhibit. And I would ask unanimous consent, Mr. Chairman, to put this exhibit into the record as well?

Mr. WAXMAN. Without objection, that will be the order.

[Testimony resumes on p. 640.]

[Exhibit No. 1 follows:] 
THE HEALTH CONSEQUENCES OF SMOKING: NICOTINE ADDICTION

(A Report of the Surgeon General)

FOREWORD

This 20th Report of the Surgeon General on the health consequences of tobacco use provides an additional important piece of evidence concerning the serious health risks associated with using tobacco.

The subject of this Report, nicotine addiction, was first mentioned in the 1964 Report of the Advisory Committee to the Surgeon General, which referred to tobacco use as "habituating." In the landmark 1979 Report of the Surgeon General, by which time considerably more research had been conducted, smoking was called "the prototypical substance-abuse dependency." Scientists in the field of drug addiction now agree that nicotine, the principal pharmacologic agent that is common to all forms of tobacco, is a powerfully addicting drug.

Recognizing tobacco use as an addiction is critical both for treating the tobacco user and for understanding why people continue to use tobacco despite the known health risks. Nicotine is a psychoactive drug with actions that reinforce the use of tobacco. Efforts to reduce tobacco use in our society must address all the major influences that encourage continued use, including social, psychological, and phar. macologic factors.

After carefully examining the available evidence, this Report concludes that:

- Cigarettes and other forms of tobacco are addicting.

- Nicotine is the drug in tobacco that causes addiction.

- The pharmacologic and behavioral processes that determine tobacco addiction are similar to those that determine addiction to drugs such as heroin and cocaine.

We must recognize both the potential for behavioral and pharmacologic treatment of the addicted tobacco user and the problems of withdrawal. Tobacco use is a disorder which can be remedied through medical attention; therefore, it should be approached by health care providers just as other substance-use disorders are approached: with knowledge, understanding, and persistence. Each health care provider should use every available clinical opportunity to encourage or assist smokers to quit and to help former smokers to maintain abstinence. 
To maintain momentum toward a smoke-free society, we also must take steps to prevent young people from beginning to smoke. First, we must insure that every child in every school in this country is educated as to the health risks and the addictive nature of tobacco use. Most jurisdictions require that school curricula include prevention of drug use; therefore, education on the prevention of tobacco use should be included in this effort. Second, warning labels regarding the addictive nature of tobacco use should be required for all tobacco packages and advertisements. Young people in particular may not be aware of the risk of tobacco addiction. Finally, parents and other role models should discourage smoking and other forms of tobacco use among young people. Parents who quit set an example for their children.

Smoking continues to be the chief preventable cause of premature death in this country. Nicotine has addictive , Jperties which help to sustain widespread tobacco use. It is gratifying to see the decline in reported smoking prevalence and cigarette consumption in the United States during the past 25 years. However, we cannot expect to see a sustained decline in rates of smoking-related cancers, cardiovascular disease, and pulmonary disease without sustained public heaith efforts against tobacco use.

The Public Health Service is committed to preventing tobacco use among youth and to promoting cessation among existing smokers. We hope that this Report will assist the health care community, voluntary health agencies, and our Nation's schools in working with us to reduce tobacco use in our society.

Robert E. Windom, M.D. Assistant Secretary for Health 


\section{PREFACE}

This Report of the Surgeon General is the U.S. Public Health Service's 20th Report on the health consequences of tobacco use and the 7th issued during my tenure as Surgeon General. Eighteen Reports have been released previously as part of the health consequences of smoking series; a report on the health consequences of using smokeless tobacco was released in 1986.

Previous Reports have reviewed the medical and scientific evidence establishing the health effects of cigarette smoking and other forms of tobacco use. Tens of thousands of studies have documented that smoking causes lung cancer, other cancers, chronic obstructive lung disease, heart disease, complications of pregnancy, and several other adverse health effects.

Epidemiologic studies have shown that cigarette smoking is responsible for more than 300,000 deaths each year in the United States. As I stated in the Preface to the 1982 Surgeon General's Report, smoking is the chief avoidable cause of death in our society.

From 1964 through 1979, each Surgeon General's Report addressed the major health effects of smoking. The 1979 Report provided the most comprehensive review of these effects. Following the 1979 Report, each subsequent Report has focused on specific populations (women in 1980, workers in 1985), specific diseases (cancer in 1982, cardiovascular disease in 1983, chronic obstructive lung disease in 1984), and specific topics (low-tar, low-nicotine cigarettes in 1981, involuntary smoking in 1986).

This Report explores in great detail another specific topic: nicotine addiction. Careful examination of the data makes it clear that cigarettes and other forms of tobacco are addicting. An extensive body of research has shown that nicotine is the drug in tobacco that causes addiction. Moreover, the processes that determine tobacco addiction are similar to those that determine addiction to drugs such as heroin and cocaine.

\section{Actions of Nicotine}

All tobacco products contain substantial amounts of nicotine. Nicotine is absorbed readily from tobacco smoke in the lungs and from smokeless tobacco in the mouth or nose. Levels of nicotine in 
the blood are similar in magnitude in people using different forms of tobacco. Once in the blood stream, nicotine is rapidly distributed throughout the body.

Nicotine is a powerful pharmacologic agent that acts in a variety of ways at different sites in the body. After reaching the blood stream, nicotine enters the brain, interacts with specific receptors in brain tissue, and initiates metabolic and electrical activity in the brain. In addition, nicotine causes skeletal muscle relaxation and has cardiovascular and endocrine (i.e., hormonal) effects.

Human and animal studies have shown that nicotine is the agent in tobacco that leads to addiction. The diversity and strength of its actions on the body are consistent with its role in causing addiction.

\section{Tobacco Use as an Addiction}

Standard definitions of drug addiction have been adopted by various organizations including the World Health Organization and the American Psychiatric Association. Although these definitions are not identical, they have in common several criteria for establishing a drug as addicting.

The central element among all forms of drug addiction is that the user's behavior is largely controlled by a psychoactive substance (i.e., a substance that produces transient alterations in mood that are primarily mediated by effects in the brain). There is often compulsive use of the drug despite damage to the individual or to society, and drug-seeking behavior can take precedence over other important priorities. The drug is "reinforcing"- that is, the pharmacologic activity of the drug is sufficiently rewarding to maintain selfadministration. "Tolerance" is another aspect of drug addiction whereby a given dose of a drug produces less effect or increasing doses are required to achieve a specified intensity of response. Physical dependence on the drug can also occur, and is characterized by a withdrawal syndrome that usually accompanies drug abstinence. After cessation of drug use, there is a strong tendency to relapse.

This Report demonstrates in detail that tobacco use and nicotine in particular meet all these criteria. The evidence for these findings is derived from animal studies as well as human observations. Leading national and international organizations, including the World Health Organization and the American Psychiatric Association, have recognized chronic tobacco use as a drug addiction.

Some people may have difficulty in accepting the notion that tobacco is addicting because it is a legal product. The word "addiction" is strongly associated with illegal drugs such as cocaine and heroin. However, as this Report shows, the processes that 
determine tobacco addiction are similar to those that determine addiction to other drugs, including illegal drugs.

In addition, some smokers may not believe that tobacco is addicting because of a reluctance to admit that one's behavior is largely controlled by a drug. On the other hand, most smokers admit that they would like to quit but have been unable to do so. Smokers who have repeatedly failed in their attempts to quit probably realize that smoking is more than just a simple habit.

Many smokers have quit on their own ("spontaneous remission") and some smokers smoke only occasionally. However, spontaneous remission and occasional use also occur with the illicit drugs of addiction, and in no way disqualify a drug from being classified as addicting. Most narcotics users, for example, never progress beyond occasional use, and of those who do, approximately 30 percent spontaneously remit. Moreover, it seems plausible that spontaneous remitters are largely those who have either learned to deliver effective treatments to themselves or for whom environmental circumstances have fortuitously changed in such a way as to support drug cessation and abstinence.

\section{Treatment}

Like other addictions, tobacco use can be effectively treated. A wide variety of behavioral interventions have been used for many years, including aversion procedures (e.g., satiation, rapid smoking), relaxation training, coping skills training, stimulus control, and nicotine fading. In recognition of the important role that nicotine plays in maintaining tobacco use, nicotine replacement therapy is now available. Nicotine polacrilex gum has been shown in controlled trials to relieve withdrawal symptoms. In addition, some (but not all) studies have shown that nicotine gum, as an adjunct to behavioral interventions, increases smoking abstinence rates. In recent years, multicomponent interventions have been applied successfully to the treatment of tobacco addiction.

\section{Public Health Strategles}

The conclusion that cigarettes and other forms of tobacco are addicting has important implications for health professionals, educators, and policy-makers. In treating the tobacco user, health professionals must address the tenacious hold that nicotine has on the body. More effective interventions must be developed to counteract both the peychological and pharmacologic addictions that accompany tobacco use. More research is needed to evaluate how best to treat those with the strongest dependence on the drug. Treatment of tobacco addiction should be more widely available and should be 
considered at least as favorably by third-party payors as treatment of alcoholism and illicit drug addiction.

The challenge to health professionals is complicated by the array of new nicotine delivery systems that are being developed and introduced in the marketplace. Some of these products are produced by tobacco manufacturers; others may be marketed as devices to aid in smoking cessation. These new products may be more toxic and more addicting than the products currently on the market. New nicotine delivery systems should be evaluated for their toxic and addictive effects; products intended for use in smoking cessation also should be evaluated for efficacy.

Public information ampaigns should be developed to increase community awareness of the addictive nature of tobacco use. A health warning on addiction should be rotated with the other warnings now required on cigarette and smokeless tobacco packages and advertisements. Prevention of tobacco use should be included along with prevention of illicit drug use in comprehensive school health education curricula. Many children and adolescents who are experimenting with cigarettes and othe ${ }_{1}$ iorms of tobacco state that they do not intend to use tobacco in later years. They are unaware of; or underestimate, the strength of tobacco addiction. Because this addiction almost always begins during childhood or adolescence, children need to be warned as early as possible, and repeatedly warned through their teenage years, about the dangers of exposing themselves to nicotine.

This Report shows conclusively that cigarettes and other forms of tobacco are addicting in the same sense as are drugs such as heroin and cocaine. Most adults view illegal drugs with scom and express disapproval (if not outrage) at their sale and use. This Nation has mobilized enormous resources to wage a war on drugs - illicit drugs. We should also give priority to the one addiction that is killing more than 300,000 Americans each year.

We as citizens, in concert with our elected officials, civic leaders, and public health officers, should establish appropriate public policies for how tobacco products are sold and distributed in our society. With the evidence that tobacco is addicting, is it appropriate for tobacco products to be sold through vending machines, which are easily accessible to children? Is it appropriate for free samples of tobacco products to be sent through the mail or distributed on public property, where verification of age is difficult if not impossible? Should the sale of tobacco be treated less seriously than the sale of alcoholic teverages, for which a specific license is required (and revoked for repeated sales to minors)?

In the face of overwhelming evidence that tobacco is addicting, policy-makers should address these questions without delay. To achieve our goal of a smoke-ree society, we must give this problem the serious attention it deserves. 
Chapter II: Nicotine: Pharmacokinetics, Metabolism, and Pharmacodynamics

1. All tobacco products contain substantial amounts of nicotine and other alkaloids. Tobaccos from low-yield and high-yield cigarettes contain similar amounts of nicotine.

2. Nicotine is absorbed readily from tobacco smoke in the lungs and from smokeless tobacco in the mouth or nose. Levels of nicotine in the blood are similar in magnitude in people using different forms of tobacco. With regular use, levels of nicotine accumulate in the body during the day and persist overnight. Thus, daily tobacco users are exposed to the effects of nicotine for $24 \mathrm{hr}$ each day.

3. Nicotine that enters the blood is rapidly distributed to the brain. As a result, effects of nicotine on the central nervous system occur rapidly after a puff of cigarette smoke or after absorption of nicotine from other routes of administration.

4. Acute and chronic tolerance develops to many effects of nicotine. Such tolerance is consistent with reports that initial 
use of tobacco products, such as in adolescents first beginning to smoke, is usually accompanied by a number of unpleasant symptoms which disappear following chronic tobacco use.

\section{Chapter III: Nicotine: Sites and Mechanisms of Actions}

1. Nicotine is a powerful pharmacologic agent that acts in the brain and throughout the body. Actions include electrocortical activation, skeletal muscle relaxation, and cardiovascular and endocrine effects. The many biochemical and electrocortical effects of nicotine may act in concert to reinforce tobacco use.

2. Nicotine acts on specific binding sites or receptors throughout the nervous system. Nicotine readily crosses the blood-brain barrier and accumulates in the brain shortly after it enters the body. Once in the brain, it interacts with specific receptors and alters brain energy metabolism in a pattern consistent with the distribution of specific binding sites for the drug.

3. Nicotine and smoking exert effects on nearly all components of the endocrine and neuroendocrine systems (including catecholamines, serotonin, corticosteroids, pituitary hormones). Some of these endocrine effects are mediated by actions of nicotine on brain neurotransmitter systems (e.g., hypothalamic-pituitary axis). In addition, nicotine has direct peripherally mediated effects (e.g.. on the adrenal medulla and the adrenal cortex).

\section{Chapter IV: Tobacco Use as Drug Dependence}

1. Cigarettes and other forms of tobacco are addicting. Patterns of tobacco use are regular and compulsive, and a withdrawal syndrome usually accompanies tobacco abstinence.

2. Nicotine is the drug in tobacco that causes addiction. Specifically, nicotine is psychoactive ("mood altering") and can provide pleasurable effects. Nicotine can serve as a reinforcer to motivate tobacco-seeking and tobacco-using behavior. Tolerance develops to actions of nicotine such that repeated use results in diminished effects and can be accompanied by increased intake. Nicotine also causes physical dependence characterizec jy a withdrawal syndrome that usually accompa. nies nicotine abstinence.

3. The physical characteristics of nicotine delivery systems can affect their toxicity and addictiveness. Therefore, new nicotine delivery systems should be evaluated for their toxic and addictive effects. 
Tobacco Use Compared to Other Drug Dependen3.5
3

stivil.

pharmacologic and behavioral processes that determine Sacio addiction are similar to those that determine addiction drugs such as heroin and cocaine.

forvironmental factors including drug-associated stimuli and Wocial pressure are important influences of initiation, patterns T. 1 use, quitting, and relapse to use of opioids, alcohol, nicotine, and other addicting drugs.

3. Many persons dependent upon opioids, alcohol, nicotine, or other drugs are able to give up their drug use outside the context of treatment programs; other persons, however, require the assistance of formal cessation programs to achieve lasting drug abstinence.

4. Relapse to drug use often occurs among persons who have achieved abstinence from opioids, alcohol, nicotine, or other

drugs.

Fr 5. Behavioral and pharmacologic intervention techniques with demonstrated efficacy are available for the treatment of addiction to opioids, alcohol, nicotine, and other drugs.

\section{Chapter VI: Effects of Nicotine That May Promote Tobacco Dependence}

1. After smoking cigarettes or receiving nicotine, smokers perform better on some cognitive tasks (including sustained attention and selective attention) than they do when deprived of cigarettes or nicotine. However, smoking and nicotine do not improve general learning.

2. Stress increases cigarette consumption among smokers. Further, stress has been identified as a risk factor for initiation of smoking in adolescence.

3. In general, cigarette smokers weigh less (approximately $7 \mathrm{lb}$ less on average) than nonsmokers. Many smokers who quit smoking gain weight.

4. Food intake and probably metabolic factors are involved in the inverse relationship between smoking and body weight. There is evidence that nicotine plays an important role in the relationship between smoking and body weight.

\section{Chapter VII: Treatment of Tobacco Dependence}

1. Tobacco dependence can be treated successfully.

2. Effective interventions include behavioral approaches alone and behavioral approaches with adjunctive pharmacologic treatment. 
3. Behavioral interventions are most effective when they include multiple components (procedures such as aversive smoking. skills training, group support, and self-reward). Inclusion of too many treatment procedures can lead to less successful outcome.

4. Nicotine replacement can reduce tobacco withdrawal symptoms and may enhance the efficacy of behavioral treatment.

\section{Appendix A: Trends in Tobacco Use in the United States}

1. An estimated 32.7 percent of men and 28.3 percent of women smoked cigarettes regularly in 1985 . The overall prevalence of smoking in the United States decreased from 36.7 percent in 1976 (52.4 million adults) to 30.4 percent in 1985 (51.1 million adults).

2. In 1985, the mean reported number of cigarettes smoked per day was 21.8 for male smokers and 18.1 for female smokers.

3. Smoking is more common in lower socioeconomic categories (blue-collar workers or unemployed persons, less educated persons, and lower income groups) than in higher socioeconomic categories. For example, the prevalence of smoking in 1985 among persons without a high school diploma was 35.4 percent, compared with 16.5 percent among persons with postgraduate college education.

4. An estimated 18.7 percent of high school seniors reported daily use of cigarettes in 1986. The prevalence of daily use of one or more cigarettes among high school seniors declined between 1975 and 1986 by approximately 35 percent. Most of the decline occurred between 1977 and 1981. Since 1976, the smoking prevalence among females has consistently been slightly higher than among males.

5. The use of cigars and pipes has declined 80 percent since 1964 .

6. Smokeless tobacco use has increased substantially among young men and has declined among older men since 1975. An estimated 8.2 percent of 17 - to 19 -year-old men were users of smokeless tobacco products in 1986.

\section{Appendix B: Toxicity of Nicotine}

1. At high exposure levels, nicotine is a potent and potentially lethal poison. Human poisonings occur primarily as a result of accidental ingestion or skin contact with nicotine-containing insecticides or, in children, after ingestion of tobacco or tobacco juices.

2. Mild nicotine intoxication occurs in first-time smokers, nonsmoking workers who harvest tobacco leaves, and people who 
arcessive amounts of nicotine polacrilex gum. Tolerance effects develops rapidly.

soitine exposure in long-term tobacco users is substantial, cting many organ systems (Chapters II and III). PharmacoWitc actions of nicotine may contribute to the pathogenesis of moking-related diseases, although direct causation has not yet wen determined. Of particular concern are cardiovascular divease, complications of hypertension, reproductive disorders, enncer, and gastrointestinal disorders, including peptic ulcer disease and gastroesophageal reflux.

4. The risks of short-term nicotine replacement therapy as an zid to smoking cessation in healthy people are acceptable and substantially outweighed by the risks of cigarette smoking. 
Mr. Wyden. We'll wait just a moment, Dr. Campbell, so that you can have the exhibit.

All right. At page 4, you'll note that the Surgeon General lays out the standard definition of drug addiction that's been adopted by various organizations, including the World Health Organization and the American Psychiatric Association.

Here is what the Surgeon General said, with respect to the elements, on drug addiction. First, the central element among all forms of drug addiction is that the behavior of the user is largely controlled by a psychoactive substance. Second, there is often compulsive use of the drug despite damage to the individual or to society. And drug-seeking behavior can take precedence over other important priorities.

Third, the drug is reinforcing. That is, it is the pharmacologic of the drug is sufficiently rewarding to maintain self-administration. Fourth, tolerance is another aspect of drug addiction, whereby a given dose of the drug produces less effect, or increasing doses are required to achieve a specified intensity of response.

Fifth, the physical dependence on the drug can also occur, and is characterized by withdrawal syndrome that usually accompanies drug abstinence. Six, after cessation of drug use, there is a strong tendency to relapse.

Now, the Surgeon General goes on to state, and I quote, "This report demonstrates in detail that tobacco use and nicotine, in particular, meet all these criteria."

Do you still disagree with the conclusion of the Surgeon General?

Mr. CAMPBELL. I have a common sense definition of addiction which tells me that, first of all, I'm a smoker and I'm not a drug addict. And, basically, I can function in quite a normal way, my judgment is not impaired, I like most smokers don't have an indication of-there is no indication that there is tolerance at play here. People smoke the same amount-

Mr. WYDEN. We'll say you disagree because time is short.

Mr. CAMPBELl. OK, fine. Thank you.

Mr. WydEN. In Chapter 4, the Surgeon General reaches the following conclusions. They appear on page 14 of this same exhibit. First, cigarettes and other forms of tobacco are addicting, patterns of tobacco use are regular and compulsive, and a withdrawal syndrome usually accompanies tobacco abstinence. Are you familiar with this statement by the Surgeon General?

Mr. CAMPBELL. I'm just catching up to you, sir. I'm sorry Congressman Wyden. Would you-

Mr. WYDEN. Do you disagree with that statement from the Surgeon General?

Mr. CAMPBELL. I think that it is rather ironic that the Surgeon General in 1964 did not conclude that cigarettes were addictive, and then in 1988 he seems to have changed his mind. I stick by my common sense definition. I really, you know, I think that these kind of comparisons with heroine, and cocaine, and hard drugs, are really not applicable.

Mr. WYDEN. Hopefully, we'll get a yes or no answer to some of these questions.

Mr. CAMPBELL. OK. 
Mr. Wyden. And I'd like to stick to that. Now, the Surgeon General goes on to state that nicotine is the drug in tobacco that causes addiction. Specifically, nicotine is psychoactive, mood altering, and can provide pleasurable effects. Nicotine can serve as a reinforcer to motivate tobacco-seeking and tobacco-using behavior. Tolerance develops such that repeat use results in diminished effect and be accompanied by increased intake. Nicotine also causes physical dependence, characterized by withdrawal syndrome that usually accompanies nicotine abstinence. Do you disagree with this statement?

Mr. Campbeli. Yes, I do.

Mr. WYDEN. In Chapter 5, the Surgeon General concludes, and I quote, "The pharmacologic and behavioral processes that determine tobacco addiction are similar to those that determine addiction to drugs such as heroine and cocaine." Am I correct that you disagree with this statement as well?

Mr. CAMPBEll. Yes, I do. And I particularly-I think there is some people, including some anti-tobacco people that disagree with that, the characterization like heroine and cocaine.

Mr. WydEN. Now, Dr. Campbell, the Surgeon General-

Mr. CAMPBELl. I'm not a doctor, sir, I'm sorry.

Mr. WyDEN. All right. Mr. Campbell, the Surgeon General is not exactly out there by himself with respect to the scientific community. Let me now give you Exhibit 2 .

[Exhibits 2 and 3 follow:] 
STATEMENT OF

THE AMERICAN PSYCHOLOGICAL ASSOCIATION

before the

U.S. HOUSE OF REPRESENTATIVES

COMITTEE ON ENERGY AND CONERCE

SUBCOMITTEE ON HEALTH NND THE ENYIROMENT

on the sublect of

The Surgeon Goneral's ReDort.

"The Health consequences of Senoking: NIcotine Addletion"

July 29,1988

The Honorable Henry Waxman, Chale

2123 Rayburn House Opplco Bullaing

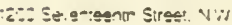

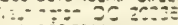


The Amerlean Psychologleal Assoclation Is the national scientiple and Drofessional organlzation of Dsyenologisis In ine Unlted states. Our membership of over 90,000 psychologisis inc'uces selentisis and Dractitloners who are engaged in the stusy of numan behavior and the ireatment oi abnormal and healin-damaglng tenavlors. WIinir ine scoce o: our expertise is the siucy and treatment of azcleive cenaviors. in fas: several divisions of cur organization (e.g.. Psychcoharmacology. Heal:h Psychology) include menbers who are world-renowned experis on addle:lon anc whose researeh and treatment activitles are concentrated on the toglc $0^{\circ}$ zediction.

The Anerlean Psychologleal Assoclation concurs with the conclusions of the Surgeon General's Report. "The Hoalth Consequences of SmokIng: NIcotine Addetion," that :

1. Clgarette and other forms of tobaces are addleting.

2. Nicotine is the drug in tsoacso that causes addiction.

3. The pharmacologle and behavloral processes that determine tobacec addletion are similar to those that cetermino addiction to drugs such as neroln and cocalne.

In our opInlon, this surgeon General's Report thoroughly and accurately presents and rovlews the selentlfle evldencs necsessary to reach these conclusions. 
The cilierla for addiction used in this Resort are comoletely consistent 1 in the crlterla and definltions of addle: Ion used by the worle Hea Ith Organization, the National Institute on Drug abuso, and the Amerlcan Psychiatrle Association. Wo comollment the Surgoon Goneral for clearly oresenting these criterla agains: which to csmoaro the data tiat are reviewed througncut the Rezor:. The Surgeon Gereral's keport has zortorned a valuasle cublic servico in srovialng a clear explanation of the criterla for drug addicion that navo ceen ostablished by the communi:y of drug adaletien exzerts over the cast 20 years. Many Individuals are unaware of those cel terla.

The Report acsurately reviews the overwhelming scientifle ovidence to supoort ine cenclusiens summarlzod in Chapter I. The roview is comprehenslve and falr. In ace. the Roport is writion as a scholarly reviow in that weaknesses as well as sirengths of varlous studles aro DoInied out. The Report presents state-of-the-art knowledge on nlest Ine addiction, Including relevant behavloral. osychological, and olologleal data that are necessary to understand the addictlvo behavior of tobacco use.

Top experts irom the U.S. and abroad who stuey overy aspect of nlcotine's oftects contributed to inls Report. Each chapter was rovlowed and erltiqued by up to il other Internationally known oxperts and thelr comments wore used to procuco the ilnal verslen of the Repor:. Many, memeers of the Amerlcan Psychologleal Assoclation, as well as oxperts from othor disclobines including onarmacology and the neurosclences, contributed to overy phase of thls prscess, Including authorships, rovlews, and sclentifle od I ing. 
Jü Y 29,1988

$-3-$

in addition to presenting evidence that tobacco use is addicing and that nicotine is the drug in tobacco that causes addiction, the feport compares iobaceo use to other drug add... ons. The inclusion of these comparlsons is erlelcally Imcortant, especlally at a time when our country Is deeply cencernec abeut drug abuse. It is necessary that the public and

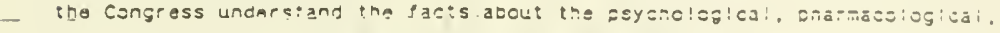
and soclologleal processes that are involved in drug abuse. The Recor: provldes a valuable perspective that should be roflected in the covelocmen: of public pollelos to deal with varlous drugs of adciction.

FInally, the Repor: reviews ireatment acproaches and outcomes and concluces that benavioral and onarmacologle Intervention technlaues with demonstrated efflcacy are avallable, offering hode for thcse who seex ass|stance in qul:ting.

Thank you for thls opporiunlity to comment. 


\section{DIAGNOSTIC AND STATISTICAL MaNual OF Mental DisORDers}

(THIRD EDITION - REVISED)

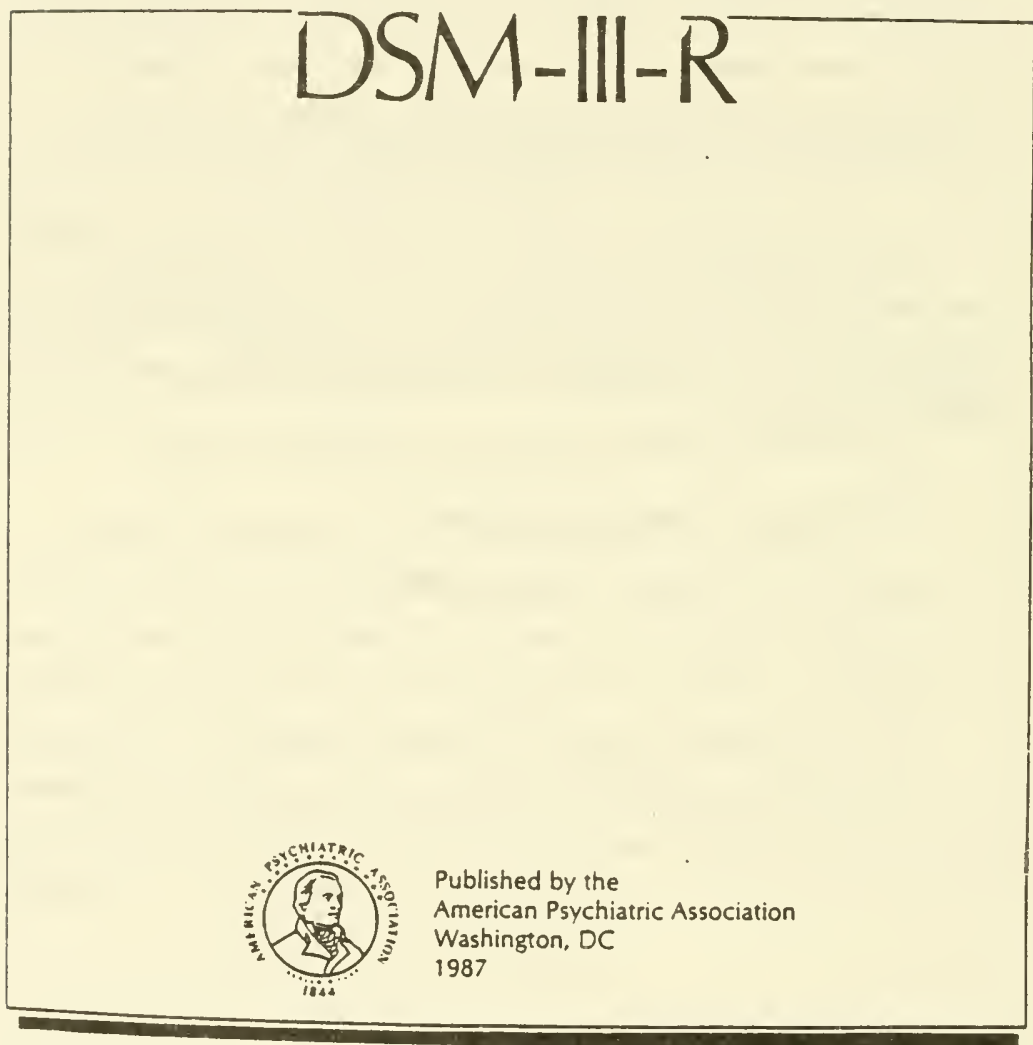




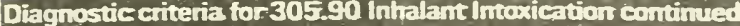

4) slurred speech

(5) unsteadv gait

(6) iethargy

(7) depressed rellexes

(8) psvchomotor retardation

(9) tremor

10) generalized muscle weakness

(11) blurred vision or diplopia

(iz) siup̃ür ùr curria

(13) euphorla

D. Vor due to anv phisical or other mental disorder

Note: When the dirferentral diagnosis must be made without a clear-cut history or toxicologic analvsis of bodv iluids, "t mav be qualified as "Provisional."

\section{NICOTINE-INDUCED ORGANIC MENTAL DISORDER}

\subsection{Nicotine Withdrawal}

See p. 181 for a description of the different iorms of nicotine and vicotıne Dezendence.

The essential ieature of this disorder is a characteristic withdrawal svndrome due to the abrupt cessation of or :ecuction in the use of nicotıne-containing substances e.g.. cigarertes, cigars, and pipes, chewing tobacco, or nicoiıne guml that has been at least moderate in duration and amount. The sundrome includes craving ior nicotine; irritaollIt , frustration, or anger; anxiety; difficulty concentrating; restlessness; decreased heart rate: and increased appetıte or weight gain.

In manv heaw cigarette-smokers. changes in mood and periormance that are related to withdrawal can be detected within two hours arter the last tobacco use. ine sense of craving appears to reach a peak within the first 24 hours arter cessation or tobacco use. and gradually declines therearter over a rew days to several weeks. in anv given case it is diriicult to distinguish a withdrawal effect from the emergence of psvchological traits that were suppressed, controlled, or altered bv the eriects or nicotine or irom a behavioral reaction (e.g., frustration) to the loss oi a reiniorcer.

Mild symptoms of withdrawal mav occur arter switching to low tar/nicotıne c:zarettes and atter stopping the use of smokeless (chewing) tobacco or nicorine gum.

Associated features. Increased slow rhythms on an EEG, decreased catecnolamines, decreased metabolic rate, tremor, increased coughing, REM change, gastroIntestinal disturbance, headaches, insomnia, and impairment of periormance on tasks requiring vigilance are commonly assoclated ieatures or vicotine Withdrawal.

Course. The svmptoms begin within 24 hours of cessation of or reduction in nicotine use and usually decrease in intensity over a period of a few days to severa! weeks. Some iormer nicotine users report that craving for the substance continues ior longer perrods. 
Complications. Whether severe Vicotıne Withdrawal decreases the abrittv to stop smoking or :emain abstinent from smokıng is unknown.

Ditierential diagnosis. The diagnosis of Vicotıne Withdrawal is usuallv seif-evident from the person's hisiorv, and disappearance or the symptoms if smoking is resumed is contirmator. However, withdrawal from other psychoactive substances mav take place simulianeously, and produce similar svmptoms.

\section{Diagnosticciteria for-29200 Nicotine Withdrawal:}

A. Dari: sse or nicotine for at least several weeks.

B. Abrust cessatton of nicotine use, or reduction in the amount oi nicotine used. followed within 24 hours by at least four of the following signs:

(1) craving for nicotine

(2) iratabılitv, irustration, or anger

(3) arxiety

(4) ciricultr concentrating

(5) estlessness

(6) cecreased heart rate

(i) :ncreased appetite or weight gain

\section{OPIOID-INDUCED ORGANIC MENTAL DISORDERS}

See p. 18: : or a description of substances in this class and Opioid Depencence and Abuse.

\subsection{Opioid Intoxication}

The essential features or this disorder are maladaptive behavioral changes and specific neurologic signs due to the recent use of an opioid.

The initial maladaptive behavioral changes from intravenous opioids occur within 2 to 5 minutes arter use and orien include euphoria that mav last 10 to 30 minutes. This is iollowed by a longer period (two to six hours, depending upon the type of opiold, the dose, and the previous history of drug-taking) of lethargy, somnolence, and apathv or dysphoria. Other maladaptive behavioral errects during the period of intoxication include imsarred judgment and Impai: in Alcohol Intoxication, aggression and violence are rare.

Puptliary constriction is always present (or dilation due to anoxia irom a severe overdose:. Other neurologic signs commonly observed are drowsiness, slurred speech, and imparment in attention and memory.

Associated features. Pupillary constriction mav lead to reduced visual acuity. The inhibitor efrect or the psvchoactive substance on gastrointestinal motility mav cause constipation. There mav be analgesia.

For many people, the eifect or taking an opioid for the irist time is dysphoric rather than euphoric, and nausea and vomiting may result. 
Associated features. L'sers or inhalanis nearly alwais use other psvchoactue substances as we!l. When inhaiant Dependence exists. however. It is usualv clear ihat innalants are the prererreo subsiance, and inhalants are used egulariv snereas otrer substances are used oniv sporadicallv. Even occasıonal users or innalants are !ikeiv to have sıg-iacant phisical and mental prociems.

Course. Younger childien diagnosed as having Innaiant Depencence mav use innalants several times a week. orten on weekends and arter school. Severe dependence in :oung adults mav involve varving periods or intoxication throughout each dav and occisional periods of heavier use that mav last several davs. This pattern mav persist ior manv vears. with recurrent need ior treatment. Lsers of inhalants mav have a preterres 'evei or degree or intoxication. and the method of adminisiration allows a user to maintain that specinc level ior severai hours. Cinronic heav users or innaiants mav deve'op renal and hepatic complicai:ons.

Tolerance to innalants has been reporied. but mav be mereiv nc:eased use over tim.e. with more perods oi intoxication and increased preterence for higner leveis of intoxication. Withcrawal has aiso been reported, but there is inadequate exicence to suostantiaie tts exisience.

Prevalence. Vo iniormation

\subsection{Nicotine Dependence}

See Vicc:ine-incuced Organic Vental Disorders p. 150$)$ ior a description or vicotine Withdrawal.

Patterns of use. At present, the most common form of Vicotine Dependence is associated with the inhalation of cigarette smoke. Pipe-and cigar-smokırig, the use of snuri, anc the chewing oi tobacco are less likelv to lead to Vicotire Depencence. The more ravic onset of nicotıne eriects with cigarette-smoking leads to a more intensive hablt patiern that is more diricult to give uo because of the riequencv of renniorcement and the greater phisical dependence on nicotine.

Associated features. People with this disorder are orten distressed because or their inability : o stop nicotine use. particularlv when they have sertous pinvical svmptoms that are aggravated by nucotine. Some peoole who have vicotıne Dependence mav have diricultv remainıng in social or occupational sıtuations in which smoking is prohibited.

Course. The course of Vicotıne Dependence is varıble. Most people repeatedlv attempt :o give up n!cotıre use w!thou: success. In some the depcndance is bitici, in that when they expertence concern about nicotine use. they promptly make an erion to siop smoking and are successiul, though in many cases they mav experrence a perıod of vicotıne Withdrawal lasting trom days to weeks. Studies oi treatment outcome suggest that the relapse rate is greater than $50 \%$ in the first 6 months, and at least $70 \%$ within the iirst 12 months. After a vear's abstinence, subsequent relapse is unlikely.

The cirticultv in giving up nicotıne use definitıvelv, particularlv cigarettes, mav be due to the unpleasant nature or the withdrawal syndrome. the deeply engranned nature oi the haoit. the repeated eriec:s of nicotine, which rapidy follow the inhalation ot cigarette smoke ( $/ 5,000$ puris per vear for a pack-a-dav smoker), and the likelihood that a desire to use nicotine is elicited by environmental cues, such as the ubiquitous 
presence oi other smokers and the widespread availability of cigarettes. When efforts to give up smokıng are made, Nicotine Withdrawal may develop.

Impairment. Since nicotine, unlike alcohol, rarely causes any clinically significant state of intoxication, there is no impairment in social or occupational functioning as an immediate and direct consequence of its use.

Complications. The most common complications are bronchitis, emphysema, coronary artery disease, peripheral vascular disease, and a variety of cancers.

Prevalence and sex ratio. A large proportion of the adult population of the United Stares has Nicotine Dependence, the prevalence among males being greater than that among remales. Among teen-age smokers, males are affected approximately as often as fernales.

Familial pattern. Cigarette smoking among first-degree biologic relatives of people with Nicotune Dependence is more common than among the general population. Evidence for a genetic iactor has been documented, but the effect is modest.

\subsection{Opioid Dependence}

305.50 Opioid Abuse

See Opioid-induced Organic Mental Disorders (p. 151) for a description of Opioid Intoxication and Withdrawal.

This group includes natural opioids, such as heroin and morphine, and synthetics with morphinelike action, which act on opiate receptors. These compounds are prescribed as analgesics, anesthetics, or cough-suppressants. They include codeine, hydromorphone, meperidine, methadone, oxycodone, and others. Several other compounds that have both direct opiatelike agonist effects and antagonist effects are included in this class of substances because they often produce the same physiologic and behavioral eriects as pure opioids, e.g., pentazocine and buprenorphine. Prescription opiates are typically taken orally in pill form, but can also be taken intravenously; heroin is typically taken intravenously, but can also be taken by nasal inhalation or smoking. Regular use of these substances leads to remarkably high levels of tolerance.

Although methadone is included in this class, people properly supervised in a methadone maintenance program should not develop any of the Opioid-induced Organic Mental Disorders. When the criteria for one of these diagnoses are met, this indicates that there has been nonmedical use of methadone, in which case the appropiriāie úlayruusis snuuió be made.

Patterns of use. There are two patterns of development of dependence and abuse. in one, which is relatively infrequent, the person originally obtained an opioid by prescription, from a physician, for the treatment of pain or cough-suppression, but has gradually increased the dose and frequency of use on his or her own. The person continues to justify the substance use on the basis of treatment of symptoms, but substance-seeking behavior becomes prominent, and the person may go to several physicians in order to obtain sufficient supplies of the substance.

A second pattern that leads to dependence or abuse involves young people in their teens or early 20 s who, with a group of peers, use opioids obtained from illegal sources. Some use an opıoid alone to obtain a "high," or euphoria. Others use these substances in combination with amphetamines, cannabis, hallucinogens, or sedatives to enhance the euphoria or to counteract the depressant effect of the opioid. In this 
Mr. Wyden. It is a statement from the American Psychological Association presented to this subcommittee in 1988. Now, the American Psychological Association is, of course, a professional association of psychologist, and it's got 70,000 members. And they agree with the Surgeon General's conclusion, one, that cigarette and other forms of tobacco are addicting, nicotine is the drug in tobacco that causes addiction, and it is the pharmacologic and behavioral processes that determine tobacco addiction are similar to those that determine addiction to drugs, again, such as heroine and cocaine.

Are we correct in assuming that you disagree also with the American Psychological Association?

Mr. CAMpBell. Yes, I do. And a lot of other people do as well.

Mr. WrDEN. Now, we have a third group, the American Psychiatric Association. And they have described, also, the addictive properties of nicotine. The American Psychiatric Association has 39,000 members. I'd like to give you now Exhibit 3, it's called the Diagnostic and Statistic Manual of Mental Disorders.

They recognize dependence as a psychoactive substance abuse disorder. I'll let the staff give you this.

I quote here. "People with this disorder are often distressed because of their inability to stop nicotine use, particularly when they have serious physical symptoms. In many cases they may experience a period of nicotine withdrawal lasting from days to weeks. The relapse rate is greater than 50 percent in the first 6 months, and at least 70 percent in the first 12 months."

The American Psychiatric Association goes on to state, nicotine withdrawal is, quote, "an organic mental syndrome and disorder." This disorder includes craving for nicotine, irritability, frustration or anger, difficulty concentrating, restlessness, decreased heart rate, increased appetite or weight gain.

Are we, again, correct in saying that you disagree with the American Psychiatric Association?

Mr. CAMPBELL. I do. And, again, many of these symptoms that are being described here are not accurate. And, you know, I stand beside the fact that 90 percent of the 40 million smokers who have quit have quit without any assistance.

Mr. WYDEN. Let's just keep building this mountain of evidence, if we could, from these medical experts because I'd like to refer you to Exhibit 4 where the American Medical Association, has also taken a position on the issue. They have 270,000 members who are doctors. I assume that you are aware that the AMA has identified nicotine as a drug of addiction. Do you disagree with the American Medical Association as well?

Mr. CAMPBElL. I don't have the documents, but I do not believe inat cigarette smoking is addictive.

Mr. WYDEN. All right. The World Health Organization, a fifth organization, has taken the position that nicotine is addictive. Just so we get you this exhibit, they are, of course, the premier international public health organization.

[Exhibits 4 and 5 follow:] 


\section{Fmerion meled Associatioy}

1993 AMA POLICY COMPENOIUNA

Exhibit 4

30.000 Alcohol and Alcoholism ISze also: Aecident Prevention: Moror Vehicles: Orvo Abuse: Pregnanchl

30.954 Prehibiting Bear AJs on Talavision: The AMA requests Congress io ban ail beep sdvertising on ielevisien. (Res. $410,1 \cdot 32$ )

30.955 Sequelas of Alconol Inrake: The AMA III will initiate and main:ain an intensive camoaign to encourage all onysic:ans : a :ake an alconol history trem all their teenage and adult patients and io warn them of the seflous sequeiae of alcenol csnsumperon: and $(2)$ will agonse all pnysicians of :re many reasens trat coctcis otten ioathe to intervene with parients suse alcehol as ourlined in the jeurnal of pre Ameriean Mescal Associarion, Volume 257, Nc .. 2avianis Who apink Toc vuch. (Res. 4.28, A.SZ)

30.956 Inclusion of Dascxilicatlon Coversge in Minirrum genafits Pseksge fcr tha Uninsurgd: The ABAA enccises the essiticn grat esve:age for ce:oxification shouid te included in any minimum heatth insurance benefitg ackags (A-ended Res. 806. 1.91)

30.957 Age Rsqulrement for Purchase of Nonalceholic Beer: The AMA (1) suspors accurate and acopopriate lateling oisclesing tre alcohol comeat of all teverages, inciuding so-called "ncnalccholic" teer and strer sustances as weil, includino over-the coumer and preszicsica medications, wi:n remaval ct "nonalesnolic" ifsm the label of any subsiance centaining any alcohol: (2) suocers ate-s is etueas the putic and consuners palating to the alconol content of so-cailed "nonalcuhclic" ceverszes and othep suostances, inclucino medicailons, especally as ialated to consumpticn sy miners: and (3) expresses its stong disaporoval of any consumpton at "nonalcchdic tee" by zersons under 21 years of age. wheh creares an image of drinking iconolic boverages and thefeby may encourage the illegal underaged use of alcohol. (Sub. Res. $217,1.911$

30.958 Ethyl Alcohol and Nicozins as Addletive Orugs: The AMA III identifies alconcl and ricotine as drugs of addisten which ate jateways to the use of other drugs by young people: (2) urces all ohysicians io intervere as eary ss possible with their patients who use robacco products and have prcblems related to alcshol ust. so as to prevent adverse health effects and reduce the probability of long-tam adcitian; $|3|$ encaurases physicians who great patients with alcohol problems to pe alen to the hign spotability of ea-existing nicotine problems; and (4) reatfitms inat individuais whe suffes from drug abdicoon in ary of iss manifestations ate persons with a treatable disease. (Amended Res. 28, A-91)

30.959 Mendxtory Lese of Drivar's License for Orivers Under Age 21 with Any Blood Alcohol Levsl: The AMA (1) suppors the sevelopment of meoel iegislation which would provide for schod educavon progtams to teach adclescents soout the dangers of drinking and driving and which would mandate the following conalties when s trive: under age $2 i$ drivas with any bioos alcend level texceor for minimal bleod alconol levels, such as less than .02 percent, oniy from medicatons or retigious practices): (a) for the first offenge - mandatory revocation of the driver's license for one yesp and $|b|$ for the second offense - mandatory pevocation of the drivef's lleanse for two years of until sge 21, whichever it greater; (2) urges state medieal associarions to seek enactnent of the legisiation in theit legislatures; and (3) encourages rete medieal associations to pardelonte in educational activities selated to eliminating atcohol use by adolescemts. (Amended sOT Rep. T. A.911

30.950 Physiden Ingssilon of Alcohol and Potient Cars: The AMA, betieving that the possibultry, or even the perception, of any alcohol-incueed impairmem of oriem eare activmes is inconsistem with the prolessional image of the physictan. (1) urges that anysicians engaging in patiem eare have no signifiesnt body content af alsohal and (2) urges thet ail physicians, prior to being availatie for atient care, teffan trom Ingesting an amount of alcehal that has the potendal to cause impairment of pertormance or create "hangover" attect. (Ar.enced BOT Rep. Y, A.9 I) 
$43 \varepsilon$

495.000 Tobocco: Laboling and Wanning iSee alss: Deam. Peventive Medicine; Public Healen, Tobacco: Tebacco: Mackesing and Pometion; Tooacco: Promibivens an Sole and Usai

495.991 Spectic Size and Location of Warning Labals on Cigareno Packs and in Advarisaments: The AMA urges the Concress :o require that: ( 1 ) warping labels on Cgarerre packs should aopear on the from and the basx and ocevpy iwemy-five dereen of the potal surface area on each sict: $(2)$ in the ase of sigarerte asvertisement3. 'abals of eigarette gacks shculd be moved to the ice of the ad ane shesld be eniarged to twentr-five percent of total ad spaco; and (3) warning lava:s following inese specifications showld be incfuded on ejgarerte packs of U.S. compsnies being distrieured eor sais in 'oreign markets. \{Ras. 523, A.92?

495.992 Hazith Warnings on Cigarera Packages: The A.MA li! fealtirms existing palicy salling "or a :ra seavion pervibition of promotion of robacco and tooacco prosucts, and 121 suppors aetvely engaging in lecoving for legislation that would reguire an increase in the size of waming labels :0 incives the saremem that Smoking is ADOICTiVE and may result in OEATH. (Sub. R.e3. 99. A.91)

495.993 Warnings Atout Tobaces Dangers: The AMA III encoveages physicisns to take ucen themselves

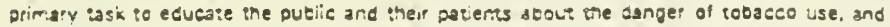
especally iogrere smeking, and urges thiese seople to elimins:e the use of cooaces in all corms:

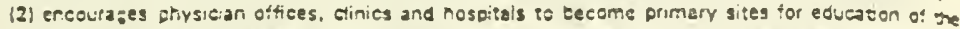

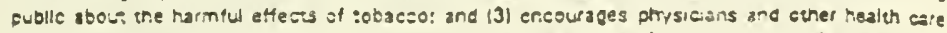
workers ic introduce ane suppor orther heaithy lifestyle pracices in their optices, dincs and hospieals. (R०s. $40,1.89$ !

495.994 Strengthaning Tobaces and Alcohol Mroduct Warnings: The AMA suppors workung toward more effecejva wamings regarfing the use of tedaceo and alcehol products. (Ries. 16, 1-891

455.995 Tobsceo Produet Packsge Labeiling: The AMA ruppors tederal legislation that wowld require rovaceo product manufacturers so print in a eleap and conspicuous rianner the Surceon General's watsing on all robaces producs, widh all waming late's to be entarged to covep as ieart 25 cercer of the package trone, print aevernsemsmt of billboard, and to be ser out in a black-and-white block (Res. 72. A.89; Amended Sub. Ree. 221, 1.91)

495.996 Cigarere Additives: The AMA supports exension of labeling requirements of ingredients to iobaceo producs sold in une Unied Sta:es. (Res. 19. A-b4)

495.997 Cigarote Advariaing and Paekage Labeling: The AMA supports legislation to pequre als atyere!sements for egareses and each pack of dgareses to earry a legible. boxod warrirg such

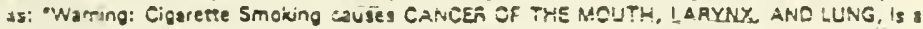
ma;or Euse of WEART OISEASE ANO EMPHYSEMA, is AOOICTIVE, end may tesult in DEATH. Intanes and enlleren living with smokers mave an increased risk of respiratory intereens and esncer." (Res. 94, A.84; Amended Sub. Res. 221, 1.91)

495.998 Smokoless Tobaceo (Snuff and Chewing Tobecco): The AMA (II) believes that snutf dipping and robacss chewing are hazardous io health and are cerainly not safe altemadves ro smoking: 12) encourages tre U.S. Surzeor jeneral to require a healts hazard warning on smokeless :coas similat to the warnings currentl, a eigarertes: and (3) urges physieians to make every etfer: : discourage the use of smekeisss iobacso. (Res. 122, A.84)

495.999 Cigarerte Peckege Werninga: The AMA reatfirms its support for the concept of rcarchal warri on eigarutte eacuages. (Sub. Res. 43. 2.82; Reaffirmed: CLRPO Rep. A, 1-921 


\section{Exhibit 5 \\ Women and tobacco}

\section{Nicotine dependence'}

Vicotine, an alkaloid, is a constituent of all cobacco products and is fundamentally the reason why people use tobacco: nicotinefree tobacco does noi satisfy the needs of those who are dependent on tobacco.

Alkaloids are a group of chemical compounds of plant origin. many of which have long been used by people for their medicinal properties, their psychoacrive effects and as poisons. Mlosi alkaloids are poisonous at high concentrations and nicotine is no exception: at high exposure levels it is a potent and lethal poison.

Alkaloids are by definition alkali-like and nicotine can exist as the free base or as 3 salt. lihen tobacio is combined with lime for thewing, as in south-east Asia. the nicotine is released from the tobacco as the free base, and absorbed in the mouth. Smoke from pipes and sigars also contains nicotine as the free base which is absorbed in the mouth and nose. The smoke from other nicotine-delivery devices, particularly cigarettes, is acidic; in this case, the nicotine is absorbed in the lungs.

The absorption of nicotine by the blood is very rapid; nico. tine is quickly distributed to the brain and its effects on the central nerous system are manifested almost instantaneously.

Studies in both humans and animals have shown that nicotine is a potent psychoactive drug. High doses can lead to intoxication and death; at doses typically obtained from tobacco products, nicotine is responsible for much of the pleasure and satisfaction obtained by tobacco users. Through activation of nicotine receptors in the central nervous system, nicotine can produce dependence. It also appears that nicotine can alleviate various dysphoric states associated with boredom, stress, and the nicotine withdrawal sundrome.

Nicotine administration can lead to tolerance and physiological dependence. Tolerance is indicated by the diminished response to repeated doses of nicotine. Vicotine-induced physiological dependence and withdrawal are specific to the administration or removal of nicotine itself. The withdrawal syndrome includes a craving for nicotine, impaired ability to concentrate, disrupted cognitive performance, mood changes, and impaired brain function. The severity of the symptoms may be such that heavy smokers are unable to abstain permanently fiom tobacco without treatment; however, the symptoms usually disappear within a few weeks. 
Nicotine dependence, like other forms of drug dependence, is a progressive, chronic, relapsing disorder. The severity of the disorde: varies from low levels to levels at which the behaviour is highly resistant to change.

\section{Mortality and morbidity}

In 1980 the report of the US Surgeon-General on The ireaith consequences of smoking for women $(j h)$ exposed clearly the fallacy of the beliei inat women were immune to tobacco-related diseases. This impression was gained from studies conducted between 1950 and 1980, which compared the death rates from tobaccorelated diseases among men with those among women. More recent research has shown that whenever the cigarette smoking characteristics - in particular duration and intensity - of women emulate those o: men. their relative risks of smoking-related illness are likely to be similar.

Currently, robacco use is estimated to accoune for $3 r^{\circ}$ in deachs per year. Wore than half of these occur in developed . ntries, and more than 300000 of them are among women in these countries. The cumulative exposure of women to tobacco (primarily from smoking) has been much higher in these countries than in the developing countries and as a consequence the death rates from smoking-related diseases among women in developing countries are likely still to be relatively low. However, the mortality rates from other forms of tobacco use among women (primarily chetving) is substantially higher in developing countries, with annual estimates of at least 100000 deaths in India alone. Current trends suggest that among women who smoke, at least $25 \%$ will die from smoking-related diseases.

In Chapter 2, it was pointed out that the uptake and increase in tobacco consumption by women is mainly in the form of smoking, particularly cigarette smoking; consequently this chapter will concentrate on this issue. However, in some developing countries such as India, cigarette smoking represents only a small fraction of the total tobacco consumption, in particular among women in rural areas. In these countries, smokeless tobacco is also imposing its burden of robacco-related diseases and deaths. The risks of oral cancer, as well as of numerous odontological disorders and diseases of the mouth and gums, are greatly increased by the use of smokeless robacso. Smokeless tobacco use has also been shown to be related to hypertension and an increased heart rate. In addition, tobacco chewing poses specific risks for women, e.g. for potential adverse effects on the fetus during pregnancy. 
Mr. WYDEN. They have stated that nicotine administration can lead to tolerance and physiological dependence. The withdrawal syndrome includes a craving for nicotine, impaired ability to concentrate, disruptive cognitive performance, mood changes, impaired brain function. Am I correct in saying that you disagree with this organization as well?

Mr. CAMPBEll. Yes, that's correct. And would you like to hear some scientific opinion on this from my standpoint as well, or not?

Mr. WYDEN. Why don't-if you could state it briefly, that'd be fine. You know, to me, the evidence, from the medical experts is overwhelming. It is unanimous. And what we will have seen in the course of the hearing that we even see the results of suppressed industry research that demonstrates addiction.

And I'm really struck by the fact that if you just go ask your customers, you'll find that this is addictive. Again, and again, I hear from smokers at home saying that they just cannot stop.

And yet in spite of this enormous amount of evidence that nicotine is addictive, in spite of the fact that all of these recognized medical leaders in a unanimous fashion say that nicotine is addictive, you all come before us and say, no.

So I would be happy to hear any arguments you have that support your point of view?

Mr. CAMPBELL. Would you like to hear from my scientist, sir?

Mr. WydEN. Mr. Chairman? That would be fine by me?

Mr. CAMPBELl. Dr. Ellis, would you comment on the definitions of addiction?

Ms. ElLIS. Yes, Mr. Wyden. I think at issue here is a scientific definition of addiction. I do not believe that there is a consensus in the scientific community on the criteria necessary to classify a substance as additive. And, in fact, the lay community freely associates the word "addictive" to food substances such as chocolate and exercise. Therefore, it is a very complicated question which requires an extremely complicated answer.

The psychologists are not pharmacologists, nor are the medical community pharmacologists. The strict pharmacological definition of addiction involves three different criteria. They are, intoxication, physical dependence, and tolerance. And to my knowledge there is no evidence that nicotine or cigarette smoking plays in any of these definitions.

Mr. WYDEN. Tell me, if you would, because we have thousands of medical experts coming to us and saying nicotine is addicting. Certainly the Surgeon General, with a full report on the subject has spoken to it. What are your qualifications, and who pays your salary?

Dr. Ellis. Mr. Wyden, I have a Ph.D. in pharmacology, and I'm the director of research for Philip Morris U.S.A.

Mr. WAXMAN. Would the gentleman yield to me?

Mr. WYDEN. I'd be happy to yield.

Mr. WAXMAN. I find it amazing when you have the scientific community, and we're not talking about just some people involved in this issue, we have the Surgeon General of the United States, the American Medical Association, the American Psychological Association, the American Psychiatric Association, the World Health Organization, all coming to the conclusion as they look at the issue of 


\section{7}

addiction, that cigarette smoking is addictive. That is all on one side and on the other side are the tobacco companies. I say this because it really raises a question of credibility. Who else is on your side?

Mr. SANDEFUR. Mr. Chairman

Mr. WAXMAN. I asked the question of this lady here.

Ms. ELLIS. Mr. Waxman, I think there is technical, scientific literature available. And some of that I know you are aware of, because it was submitted to you, that indicates that nicotine cigarette smoking does not meet these criteria.

Mr. WAXMAN. Are there any major health organizations that would agree with you?

Ms. ELLIS. We would be happy to supply that information to you, and other information that is in the scientific literature.

Mr. WAXMAN. We'll hold the record open. I thank the gentleman for yielding to me.

[The following letters were submitted:] 
NEW YORK, NEW YORK 10022.3519 (212) $750-5050$

PETERT. GROSSI. JR OIRECT LINE: (2O2) 872.5670
ARNOLD \& PORTER

1200 NEW HAMPSHIRE AVENUE. N. W. WASHINGTON, D C. 20036.6885

(202) 872.6700

CABLE ARFOPO

FAX $120218>2.6750$

TELEX 19.2733

September 28,1994

\section{BY HAND}

The Honorable Henry A. Waxman, Chairman The Honorable Thomas J. Bliley, Jr. Ranking Minority Member

Subcommittee on Health and the Environment House Comnittee on Energy and Commerce

2415 Rayburn H.O.B.

Washington, D.C. 20515

Dear Mr. Chairman and Rep. Bliley:

I am writing to submit, on behalf of Philip Morris U.S.A., information that you requested from Dr. Cathy Ellis at the Subcomittee's April 14, 1994 hearing. Specifically, we are providing statements from scientific experts as well as relevant literature in support of her view that neither smoking nor the nicotine delivered in cigarettes is properly classified as "addictive."

First, we enclose the summary statements of the following eight eminent scientists: Rubin Bressler, M.D., Professor of Medicine and Pharmacology, University of Arizona College of Medicine; Robert Cancro, M.D. Lucius N. Littauer Professor of Psychiatry, and Chairman of the Department of Psychiatry, New York University Medical Center; Harold H. Kassarjian, Ph.D., Professor Emeritus of Marketing and Consumer Behavior, Graduate School of Management, University of California at Los Angeles; Stuart A. Kirk, D.S.W., Ralph and Marjorie Crump Professor of Social Welfare, Department of Social Welfare, School of Public Policy and Social Research, University of California at Los Angeles; P. Caren Phelan, Ph.D., clinical psychologist, Austin, Texas; c. Robert cloninger, M.D., Wallace Renard Professor of Psychiatry, Washington University Medical School, and Psychiatrist-in-Chief, Barnes and Allied Hospitals, st. Louis, Missouri; Michael A. Bozarth, Ph.D., Associate Professor, Department of Psychology, State University of New York at Buffalo; Domenic A. Ciraulo, M.D., Professor 
The Honorable Henry A. Waxman, Chalrman

The Honorable Thomas J. Billey, Jr.

September 28, 1994

Page 2

of Psychiatry, Tufts University School of Medicine.

These statements are contained in Volume 2.0 of the sixvolume submission that Philip Morris made to the FDA's Drug Abuse Advisory Committee in connection with that Committee's meeting on August 2, 1994. As you know, the Advisory Committee addressed "issues related to nicotine and smoking, including the relationship between nicotine dose and addiction in smokers." 59 Fed. Reg. 35738 (July 13, 1994).

Second, also enclosed in response to your request, are the remaining volumes of the six-volume set submitted to the Advisory Committee. As you will note, Volume 1.0 is the statement submitted by Philip Morris and American Tobacco regarding the issues considered at the Advisory Committee's August 2 meeting. It includes numerous citations, the texts of which can be found in Volumes $3.1,3.2,3.3$ and 3.4 . Because the volume 3 set constitutes about 1,500 pages in length, we have provided copies only to you, and not to all subcommittee Members. However, we would be happy, upon request, to provide copies to any subcommittee Member.

Finally, we refer you to the enclosed excerpts from the transcript of the August 2 Advisory Committee meeting, which are statements of three witnesses who testified in general agreement with the views expressed by Dr. Ellis. Two of these are Doctors Bozarth and Ciraulo, whose credentials are described above, and the other is Dr. John Robinson of the R. J. Reynolds tobacco company.

We trust that the enclosed materials respond to your inquiry.

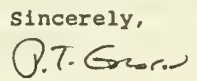

Peter T. Grossi, Jr.

\section{Enclosures}

cc: Members of the Subcommittee on Health and the Environment 


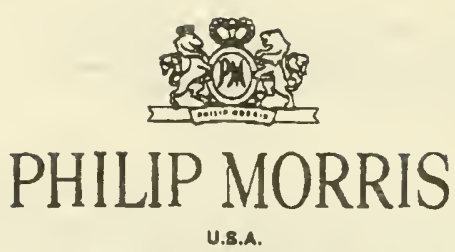

AESEARCH CENTER: P.O. BOX 26583, AICHMONO. VIRGINIA 23201 B580 TELEPMONE (804) 274.2000

May 9, 1994

\section{VIA TELEFAX}

The Honorable Henry A. Waxman

Chairman

Subcommittee on Health and the Environment

Committee on Energy and Commerce

2415 Raybum House Office Buslding

Washington, DC 20515-6118

Dear Mr. Waxman:

During the April 28, 1994, hearing before the House Energy \& Commerce Subcommittee on Health and the Environment, you and Representative Wyden referred to portions of the testimony that I presented to the Subcommittee on April 14, 1994. In particular, you referred to the following statement, found in the unofficial transcript that I have reviewed: "The strict pharmacological definition of addiction involves three different criteria: they are intoxication, physical dependence and tolerance. And to my knowledge, there is no evidence that nicotine or cigarette smoking plays in any of these definitions."

The subject of addiction is scientifically complex and is further complicated by a great deal of semantic confusion. During the hearing the rapid pace of questioning and the Subcommittee's frequent insistence on "yes or no" answers inhibited a full discussion of the topic. Accordingly, I am writing this letter to clear up any misunderstandings that may have led you and Representative Wyden to challenge my views.

As I tried to explain during the hearing, there is much debate within the sclentfic community regarding the meaning of "addiction" and the scientiflc criteria that must be met before classifying a substance as addictive. Given the terminological confusion in this area, I believe that an inquiry into a substance's so-called addictive properties should focus on the extent to which the substance is associated with the pharmacological phenomena of intoxication, tolerance, and physical dependence (as characterized by withdrawal). 
Chairman Woxman

May 9, 1994

Page 2

There is a great deal of literature regarding the pharmacological aspects of nocoine and smoking, and I wouid like to make clear that I did not intend my testimony to be read as denying the existence of such literature or as denying that certain research findings reposted in the literature have led others to conclude that nicotine is "addictive." In my view, however, the information with which I an familiar does not support the conclusion that the nicotine in clgarettes causes smokers to experience intoxication, pharmacological tolerance, and physical dependence in a gnanner that would impair the smoker's abillty to exercise a free cholce to continue or to quit smoking. Thus, I do not believe that pharmacological evidence, viewed in light of what I consider an appropriate definition of "addiction," supports the conclusion that dgarette smoking is an "addiction." That was the thrust of my statement that "there is no eyidence that nicotine or dgarette smoking plays in any of these definitions." As promised during the hearing on April 14, 1994, Philip Morris will be submitting references in support of the points that I have expressed.

Finally, I am not aware of research results obtained by Drs. DeNoble and Mele while at Phillp Morris, or any statements they made to management during their tenure at Philip Morris, that would lead me to a different conclusion regarding the weight and significance of the pharmacological evidence to which I have referred.

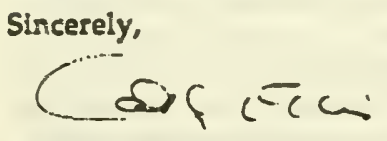

Cathy Ellis, Ph.D.

Director, Research

PC: The Honorable Thomas J. Bllley 
Mr. WYDEN. Well, Mr. Chairman, I think what is really striking is that the people who have no vested financial interest in this particular subject say that nicotine is addictive. And the people who have a vested financial interest in saying otherwise argue that it's not. Now, I could keep going on.

I note that the National Institute on Drug Abuse has said that nicotine is as addictive as heroine. They have indicated that it is like 5 to 10 times more potent than cocaine or morphine, in terms of producing effects on mood and behavior.

I have found it very interesting in listening to the testimony that we have heard already today, all of you are comparing cigarettes to traffic accidents, and television, and coffee, and soft drinks.

I don't know anybody who charged that cigarette are causing traffic accidents. I don't know anybody that's proved that coffee has caused cancer. But what we do know is that the preponderance of medical experts in our country say that nicotine is addicting, and that there is solid indisputable proof that smoking causes lung cancer.

I'm just struck by how, when the chairman and other experts pile up this mountain of evidence, report after report, the Surgeon General, the American Medical Association, the World Health Organization, report after report, after report, after report, your companies, who have a vested financial interest in saying otherwise, are the only folks who make the contention, that is contradicted even by your customers, that smoking is not addictive.

Mr. WAXMaN. Mr. Wyden, if you will yield to me. I just also want to remark on the fact that this woman is the director of research for Philip Morris, and this is a fundamental question, I would think, for the tobacco industry, whether their product is addictive, but you have reached the conclusion it isn't.

You will have to do research to find out if there is any other reputable organization, but you would think that if there were, you would know it. But we will keep the record open. And we specifically want you to submit to us your research data that indicates that this is not addicting.

Mr. CAMPBEll. Could I enter a quote, sir, on the topic of addiction?

Mr. WaXMan. Yes, Mr. Campbell?

Mr. CAMPBEll. Could I enter a quote, Mr. Chairman, from an eminent person, with respect to addiction?

Mr. WAXMAN. Before we do that, I would like for you to submit your research data to us on this addiction question.

Mr. CAMPBELL. We said that we would submit data on addiction experts that agree with Dr. Ellis' position.

Mr. WAXMAN. But I think we should have for the record your research data showing it's not addictive.

Mr. CAMPBELL. I'm-we have-

Mr. WAXMAN. Let me ask it this way. I want from you any research that you have showing it's not addictive, and I also want any research data from you that shows it is addictive. Will you agree to submit that to us?

Mr. CAMPBELl. I see no problem supplying material. We'll get the appropriate people together from our side with the appropriate people from your side, and see how it can be handed over. 
Mr. WAXMAN. Thank you.

Mr. Synar, I promised Mr. McMillan that he would be next, and that we'd let Mr. Wyden go on a little longer. So if you would permit, I'm going to go vote. We'll assume he's on his way, we'll give him another 5 minutes.

[Brief recess.]

Mr. SYNAR [presiding]. The subcommittee will come back to order. Mr. McMillan is recognized for 10 minutes.

Mr. MCMillan. I thank the Chair. I think that Mr. Jim Johnston in his opening statement characterized the nature of what we're here for. The real motive behind most of this is a ban on the use of tobacco and not a whole host of other things that are being asserted. On CNN last night, the gentleman from Oregon, on CNN last night, said that he was not interested in banning tobacco, but my perception is that the contrary is true and I do not think we should approach it that way.

If we're going to abide by the chairman's opening statement, then the same standards that we apply to tobacco should be applied to other products. I think that's been suggested here today in a number of ways, including a wide range of products-alcohol, caffeine content products, sugar content products, fat content products-we could go on down that list.

I think it's important to be candid in what we are talking about. I've smoked in the past. I've used alcohol in the past. Nicotine, I think, is essential to the use of tobacco. Alcohol is essential to the use of alcoholic products. I drink coffee. I don't like it if it doesn't have caffeine in it. I like candy. I don't think I'd like it if it didn't have chocolate or sugar.

The question is how do we deal with the fact that use to excess or misuse of certain products may be harmful in one way or another. They can be harmful physically. They can be harmful psychologically. They can modify behavior.

Somehow or another, in all this, we don't seem to be applying any commonly accepted standards with respect to similar products and I don't know how to deal with this issue rationally unless we do.

My first question has to do with the much ballyhooed list, the socalled secret list that became public. Why was nicotine not included on the list of 600 items that were disclosed? Anyone can answer.

Mr. JAMES JOHNSTON. Congressman, it's because nicotine is the natural component of the tobacco leaf. Nicotine sulfate was on the list. It's present because it is required to be there by the BATF. It's in minuscule quantities.

This cup, if poured into a 3,000 gallon swimming pool, would represent how much nicotine is present in that nicotine sulfate. It can't even be measured. And it's required to be there by the BATF.

Mr. MCMillan. We don't require a secret list of the 30 to 40-plus additives that go into a bottle of gin in excess of alcohol, do we? Over and beyond alcohol. Most of us don't even know what they are.

Mr. JAMES JOHNSTON. The ingredients released by these manufacturers yesterday goes far beyond what has ever been provided by any manufacturer of food products. They're not required to disclose processing agents. We have supplied those data to the U.S. 
Government for over 10 years. We have fully cooperated with the Department of Health and Human Services.

A prior chairman of this company testified before Congress in 1964 and offered our ingredient list to Congress 30 years ago this year. We've not been trying to hide anything. We've been fully cooperative on this. We've been highly responsible in having not only each of those ingredients analyzed, but analyzed in totality, analyzed in totality by independent toxicologists.

Mr. McMillan. On the subject of the chart, Mr. Campbell, that was subsequently discussed with respect to the testimony of Dr. Kessler and relative content of tar and nicotine, isn't it true over that period of time that we also went through a transition in production of cigarettes, trying to conform to consumer preference, and that probably embraces the introduction and growth of filter-tipped cigarettes and the decline of non-filter-tipped cigarettes?

How does that enter into the equation?

Mr. CAMPBELL. There's been a number of things put up to show that the overall levels of tar and nicotine over the last 40 years have dropped in the neighborhood of 60 percent. Dr. Kessler maintained that that had stopped after 1982 and that somehow the nicotine level was going up.

Well, Mr. Johnston's charts actually, once Dr. Kessler's data was available to us and they could break it down, shows that the tar and nicotine has admittedly slowed down in terms of its average consumption, but it's still going down and nicotine and tar are going down together, as they always have.

Mr. MCMILLAN. The introduction of filter-tipped cigarettes came about for what reason?

Mr. CAMPBELL. I think that the introduction of filter-tipped cigarettes was in about 1953 or 1954 and I think that what happened was that the consumers expressed that they wanted a better way to smoke and consumers were expressing an interest in, at that time, more mildness. But it has since become an interest in tar and nicotine and we've responded.

Mr. JAMES JOHNSTON. And, Mr. Congressman, there were public health concerns about tar. There were requests by the public health and scientific communities to reduce tar in cigarettes. It is quite a remarkable result that has been achieved.

Mr. McMillaN. The filter tip, did it not only reduce tar, but also reduce nicotine?

Mr. JAMES JOHNSTON. Yes.

Mr. MCMillaN. Proportionately?

Mr. JAMES JOHNSTON. Its intent was to reduce tar. By reducing tar, it roughly proportionately brought nicotine down, as well. That wasn't the intent by the manufacturers. In the context of this hearing today, however, it is important because of all the allegations that have been made about nicotine.

I point to one simple thing, which is if we had this Nation of addicts-now, addicts demand increasing dosages of products, of that substance. Heroin users go from 1 shot a day to 2 to 3 to 4 . Here is a Nation that has decreased its consumption of nicotine by twothirds. Common sense says this is not some overwhelming

Mr. McMillan. But in the filter tip, there is a presumption of removing something that was perceived to be potentially damaging 
and the industry responded to it and the consumer demonstrated a preference for it. Isn't that the truth or not?

Mr. JAMES JOHNSTON. Tar. Yes, sir. Tar.

Mr. McMillan. Yes. And tar was the one that was identified as a problem, not nicotine.

Mr. JAMES JOHNSTON. That's correct.

Mr. MCMillaN. Although there may be some problems with nicotine taken to excess. Has the government ever attempted to regulate the amount of nicotine that goes into a cigarette? It requires disclosure, I understand that, but has there ever been an attempt to limit it?

Mr. JAMES Johnston. Not until recently, there hasn't. Smokers know, have always known that nicotine is part of the natural product. It's been in the common vernacular for a long time. What has scared smokers out of what are truly hysterical charges being made is that we are somehow adding nicotine to hook them or addict them.

One simple chart, the Surgeon General's chart shows it's been just the opposite. A two-thirds reduction. We owe it to the American people for this subcommittee, after they've done whatever work they need to do, to go on record to say it is not true. We've checked this out, we agree with the tobacco manufacturers, we agree with the Surgeon General of the United States that nicotine has been reduced, not increased.

Mr. MCMillan. Has it ever been the intent of the law to require that tobacco products be sold with a nicotine content less than that naturally occurring in a typical blend of tobacco products or tobacco leaf?

Mr. CAMPBELL. No, absolutely not. The nicotine has just gone down on its own in response to consumers' interest in these areas.

Mr. McMillan. Has my time expired or can I continue?

Mr. WAXMAN You can take another minute.

Mr. MCMillan. Let me just conclude this round of questioning. I think it's been said, but it's worth repeating. Anyone answer this question. Does anyone produce a tobacco product in which you deliberately try to engineer a nicotine content in excess of the natural content of the tobacco leaf used in the product?

Mr. CAMPBELl. Absolutely not.

Mr. MCMillan. In fact, the opposite is true, right? You do engineer a product, the filter tip is a case in point, of product that is below the norm that would be contained in the leaf itself.

Mr. CAMPBEll. Dramatically.

Mr. MCMILLAN. That's a true statement.

Mr. JAMES JOHNSTON. Dramatically.

Mr. MCMillaN. Thank the Chair.

Mr. WAXMAN. Thank you, Mr. McMillan. Before I recognize Mr. Synar, just for housekeeping purposes, Mr. Campbell, my staff wanted me to make this very clear for the record. What we're requesting of you is any report, memorandum or other document describing research conducted by Philip Morris on nicotine and addiction, regardless of whether the document shows nicotine is addictive or that it is not addictive. 
If you need to have our staffs meet about that, we will certainly make our staff available. But we would like a commitment from you to get that.

Mr. CAMPBELL. I hear your request. I'll have to take it-I'll make the commitment to look into it and to put the two staffs together. I don't know if there are any privileged documents involved. I'm not sure.

Mr. WAXMAN. You're the Chief Executive Officer. For what reason could you not give us this research if it's been conducted?

Mr. CAMPBELL. I have no problem giving you any material we have if it's not in some way involved in active litigation at this time.

Mr. WAXMAN. Let me tell you that litigation is not a reason not to give the Congress of the United States information. We expect to get it. Mr. Synar?

Mr. SYNAR. Let me reiterate that there is absolutely no legal reason why you should not be required to provide that information. Your lawyers know that proprietary information provided to Congress does not make it public. It would be handled in a confidential manner.

Gentlemen, I'm a little bit distressed as I hear some of your answers with respect to your flippant attitude on the impact of nicotine and its addictiveness and the impact of cigarettes in general.

I call to your attention to your left, that stack of books, overwhelming medical evidence, over the last 25 years of the addictiveness, as well as the hazard of the product that you produce.

Mr. Campbell, 2 weeks ago, Congressman Waxman released a study written by Dr. Victor DeNoble. I'd ask unanimous consent to enter in the record at this time Exhibit 5-A.

Mr. WAXMAN. Without objection, that will be the order.

Mr. SYNAR. As you know, Dr. DeNoble was a research scientist at Philip Morris during the early 1980's. You have in front of you the DeNoble study. Dr. DeNoble was studying the nicotine of rats. In 1983, he found that rats will self-administer nicotine when hooked up to an intravenous nicotine solution. In other words, they will work to get nicotine. And as Dr. Kessler told us in the hearing in which he testified, self-administration of this type is hallmark addiction.

I'd ask unanimous consent to enter in the record Exhibit 6.

Mr. WAXMAN. Without objection, that will be the order.

Mr. SYNAR. Mr. Campbell, before you is a press release, your press release that said that Dr. DeNoble's study showed exactly the opposite. I have a copy here, which is marked, and it says that the DeNoble study showed that nicotine is "in a class of non-addictive chemical compounds, such as saccharine or water."

I don't think any of us are ever going to find, Mr. Campbell, a study that shows rats or any other animals will self-administer saccharine or water intravenously the way they do nicotine.

I ask unanimous consent to enter in the record Exhibit 7.

Mr. WAXMAN. Without objection, that will be the order.

Mr. SYNAR. Mr. Campbell, this is a letter from the Director of the National Institute of Drug Abuse regarding the DeNoble study which is in question here. This letter directly contradicts your as- 
sertions. According to the expert Federal agency on drug abuse, and let me quote from it, "These findings from the DeNoble study indicate that nicotine has reenforcing properties, one of the hallmarks of addictive substances."

Yet, with this overwhelming evidence by medical experts, you continue to contend that your study shows the opposite. Would you have this subcommittee believe that the National Institute doesn't know how this study was conducted or understand it at all?

Mr. CAMPBELl. I can't comment. I obviously just received the document for the first time.

Mr. SYNAR. Mr. Campbell, was Dr. DeNoble's work part of your company's effort to develop a nicotine analog, which are chemicals which would have addicting or reenforcing features without any of some of the nicotine side effects? Yes or no?

Mr. CAMPBELL. Yes.

Mr. SYNAR. OK. I have here and I ask unanimous consent to enter in the record Exhibit 8.

Mr. WAXMAN. Without objection, that will be the order.

Mr. SYNAR. It is a 1980 internal memorandum written by one of your scientists, J.L. Charles. This memorandum describes nicotine receptor research that your company was funding at the University of Rochester.

Was this related to Dr. DeNoble's work?

Mr. CAMPBELL. I studied this matter in general, but you've now entered into a depth of study that I-can I ask Dr. Ellis to help me?

Mr. SYNAR. Mr. Campbell, was this part not-turn around and ask them. Was this part of Mr. DeNoble's work?

Mr. CAMPBEll. Yes.

Mr. SYNAR. I ask unanimous consent to enter in the record Exhibit 9.

Mr. WAXMAN. Without objection, that will be the order.

Mr. SYNAR. There's something that bothers me, Mr. Campbell, even more than your complete misrepresentation and characterization of the DeNoble work. It's the apparent attempt by your company to suppress the findings in the DeNoble study and to keep the important study secret because it might hurt the industry.

Now, let me go through the chronology with you. Dr. DeNoble submitted his study to a leading scientific journal, Psychopharmacology, in 1983. It was peer reviewed. It was accepted for publication. It was edited. Then, at the last minute, Dr. DeNoble withdrew the study.

In a letter written to Philip Morris on Philip Morris stationery, which you have before you, Dr. DeNoble explained that he was withdrawing that study "for reasons beyond my control."

Dr. DeNoble resubmitted that study in $1985, \mathrm{Mr}$. Campbell. It went through the same peer process. I'd ask for Exhibit 10 to be made part of the record.

Mr. WAXMAN. Without objection, that will be the order.

[Testimony resumes on p. 685.]

[Exhibits 5-A through 10 follow:] 


NICOTINE AS A POSITIVE REINFORCER FOR RATS
EFFECTS OF INFUSION DOSE AND FIXED RATIO SIZE

Victor J. DeNoble, Paul C. Mele and Francis J. Ryan Philip Morris Research Center

ABSTRACT

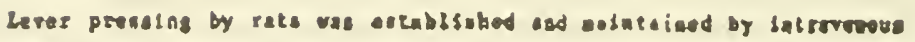

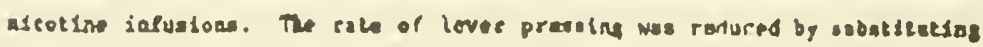

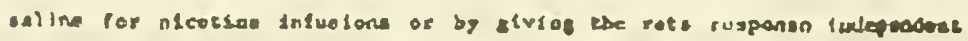
ascotion salvaloas. The rete of lover prosxing wa ernaltive co both dosed and

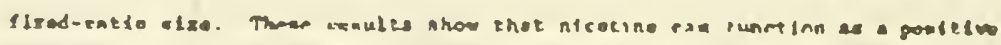

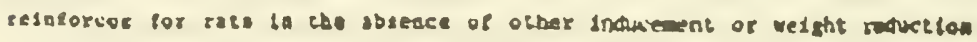

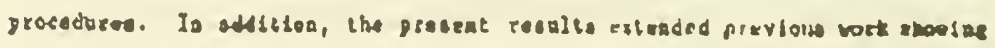

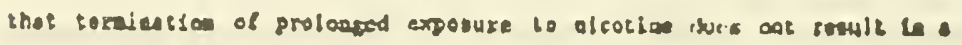
phyeloloticel dependecer. 


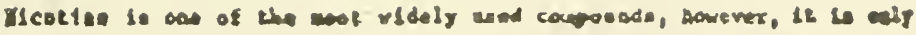

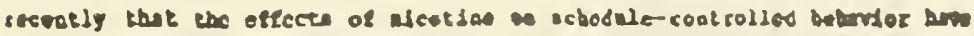

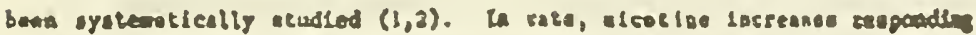

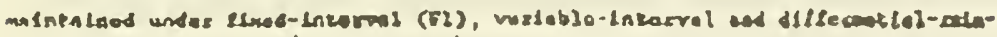

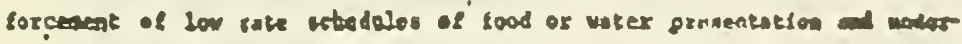

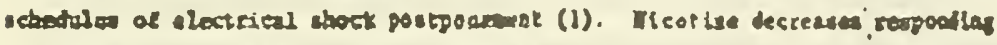

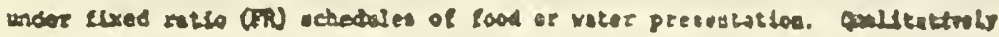

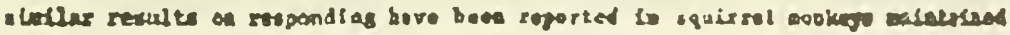

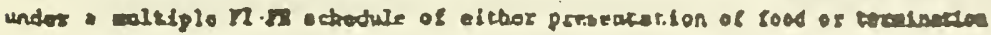

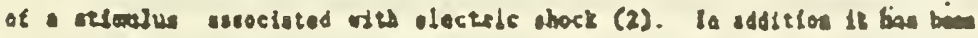

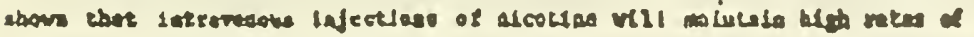

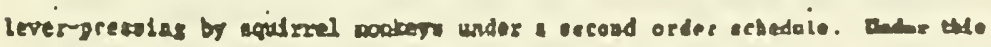

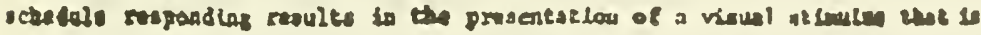

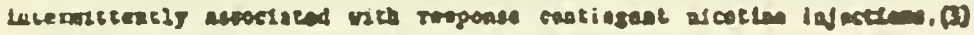

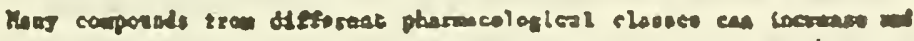

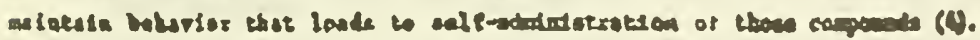

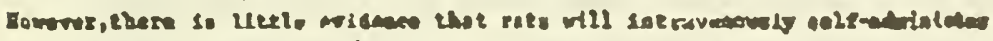

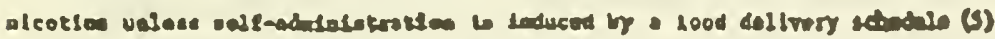

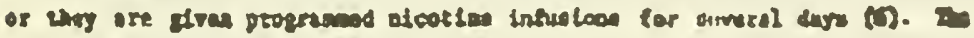

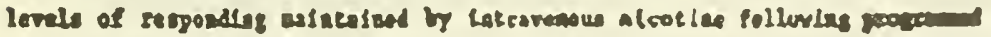

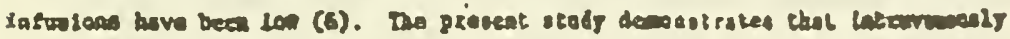

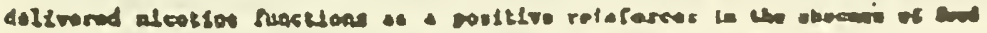

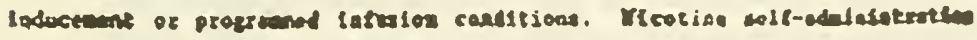

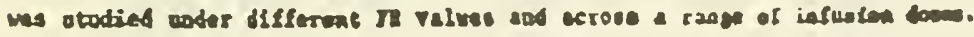

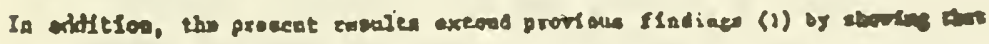

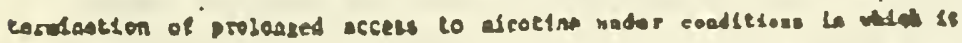

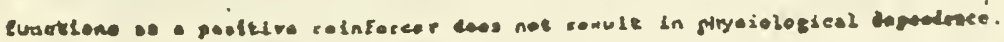




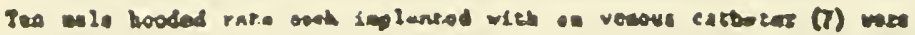

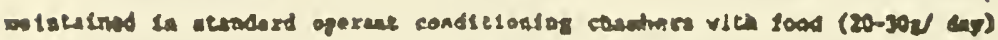

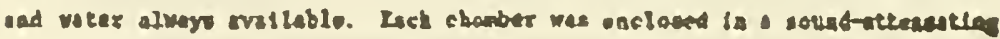

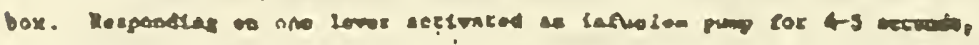

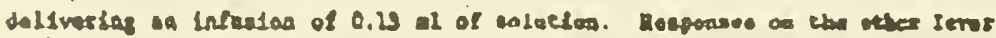

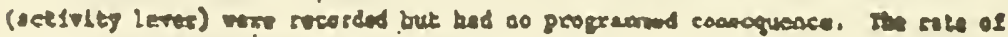

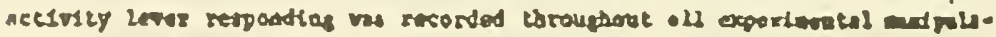

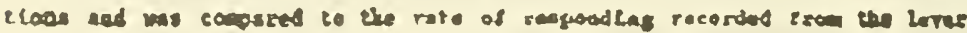

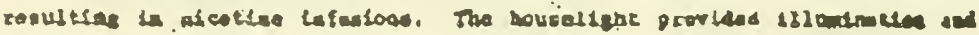

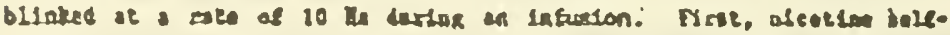

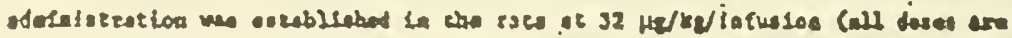

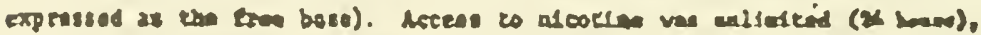

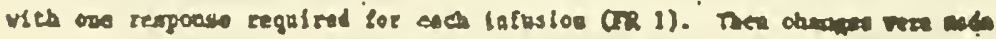

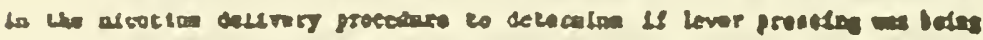

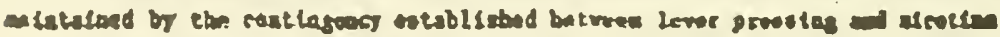

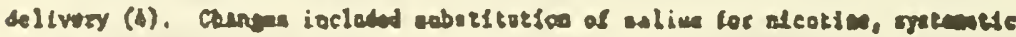

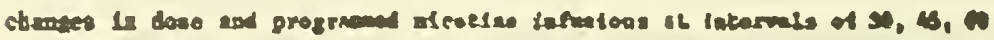

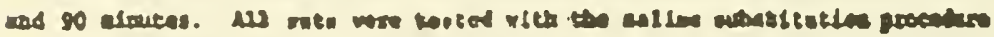

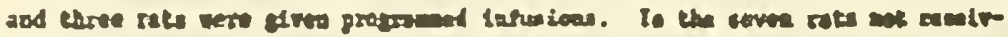

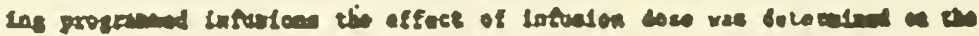

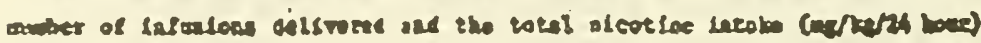

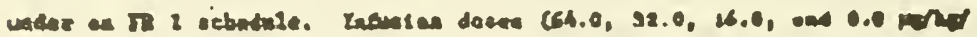

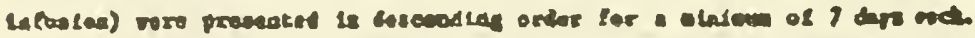

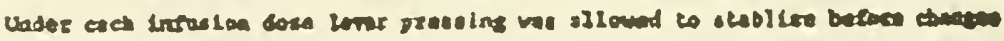

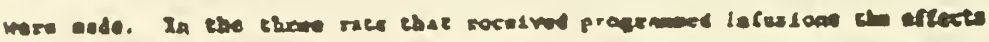

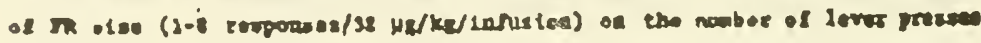

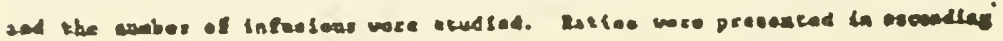




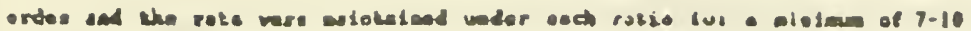
acesten.

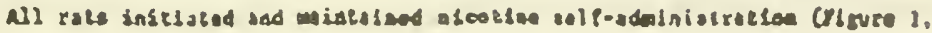

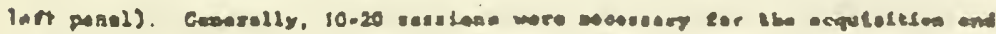

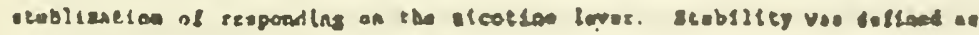

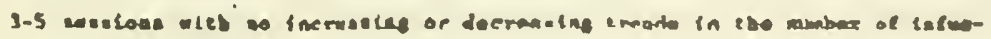

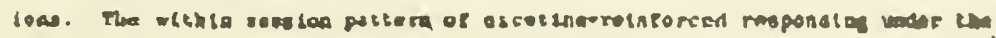

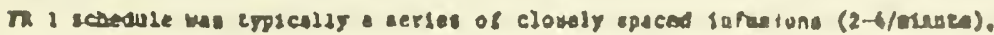

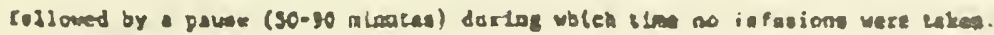

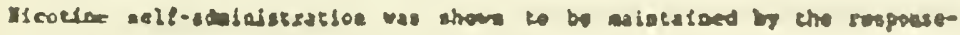

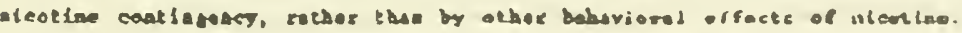

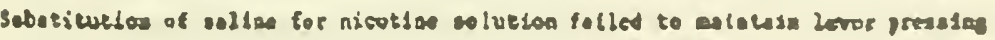

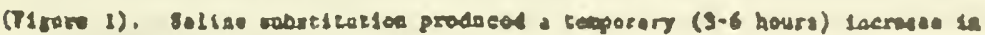

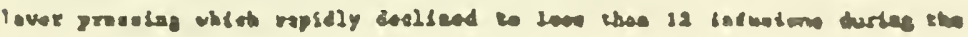

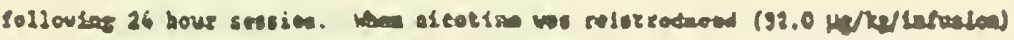

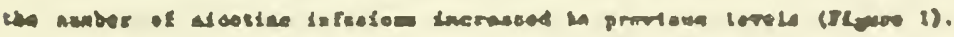

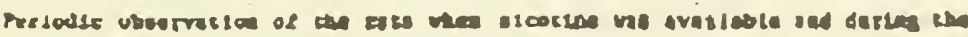

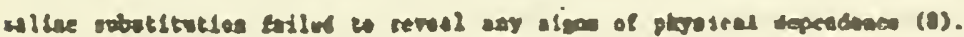

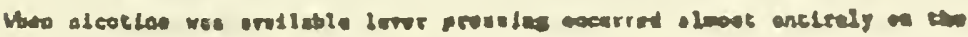

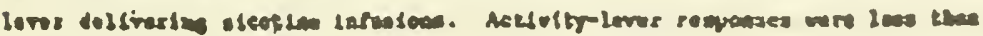

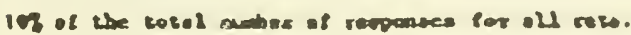

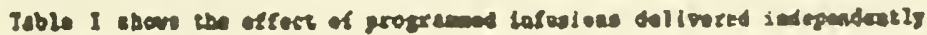

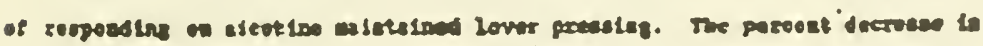

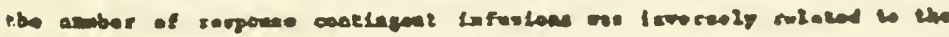

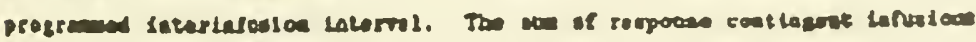

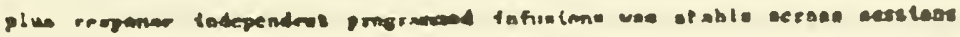

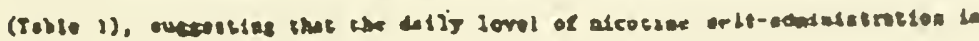

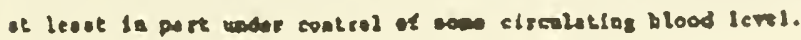




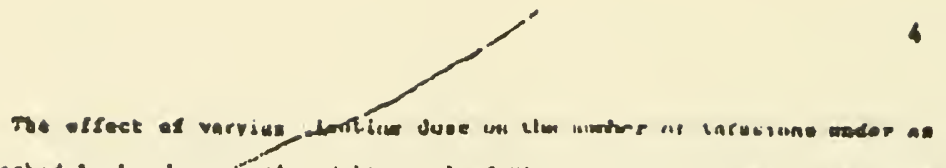

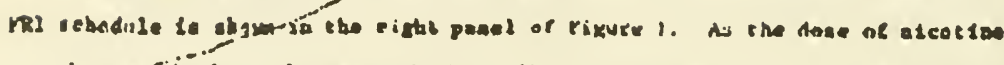

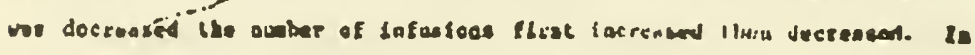

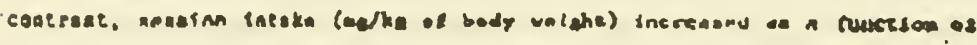

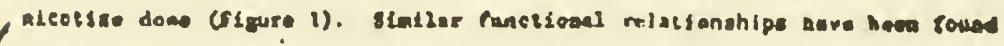

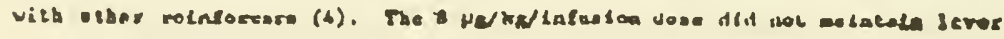
preaslag abere onlue levels.

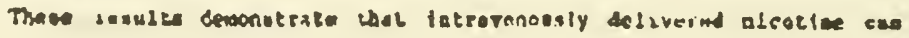

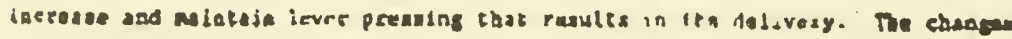
sa tae afcotice dellvery procedure stowed that lever presaiog wal materainad

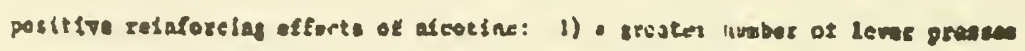

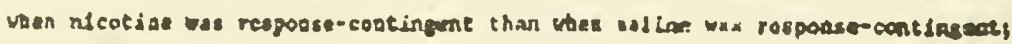

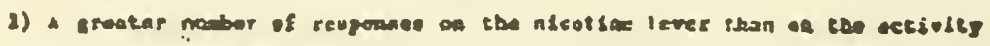

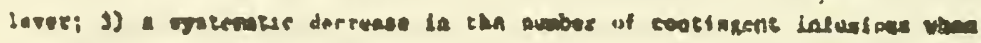

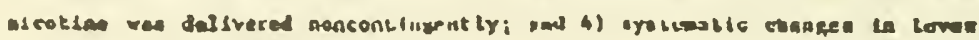

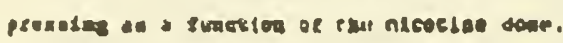

The offect of fecreatog the ratio steo on the number it lever preanea

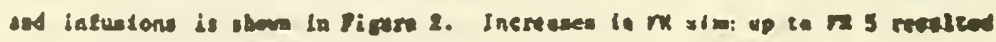

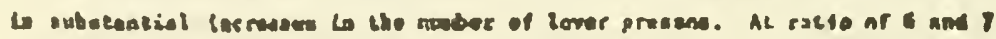

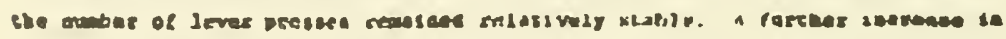

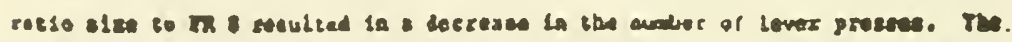

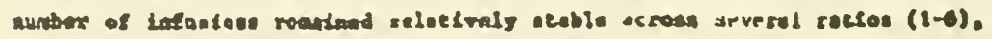

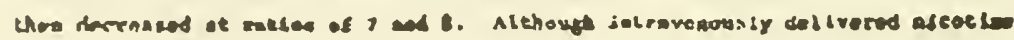
ainesiand ratle performece, these overall ratos of mnpondlas conpard to

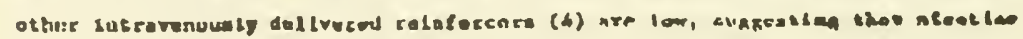
ny be a realaborclan ejeal. 


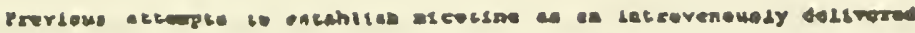

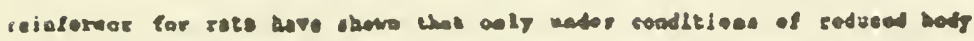

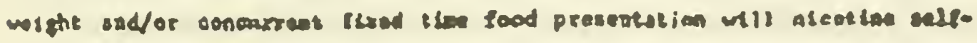

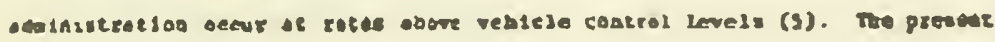

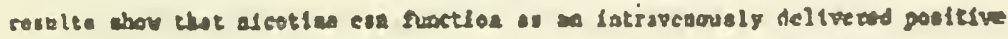

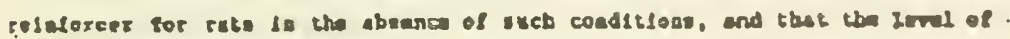

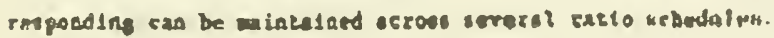

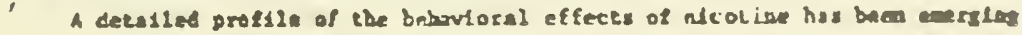

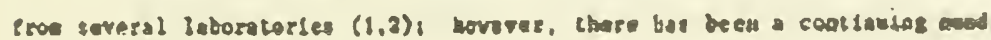

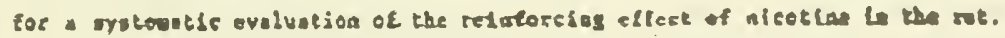

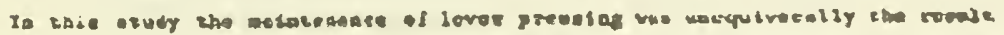

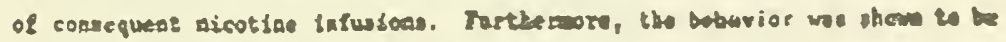

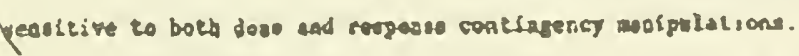




\section{Ralerensea}

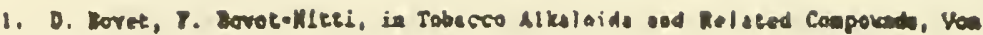

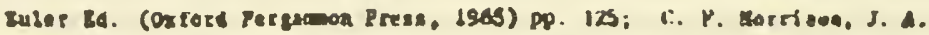

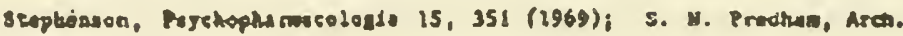

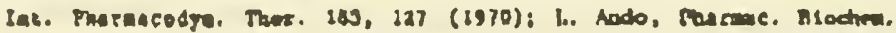

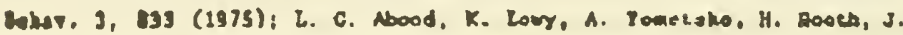
Ievro. 8ct. Wes. 3, 327 (1979), P. J. Detoble, Y. Dragan, I. Cazrea, Perebophanacology (is peree 19ex), T. J. Defoble, P. J. Ryeul, Y. P.

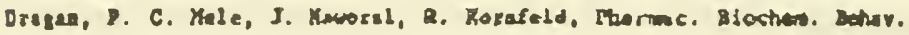

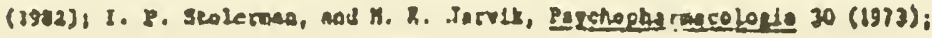

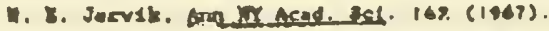

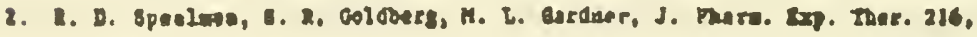
44 (1981), T. 2. A. Daris, C. J. Tonoler, P. M. Dew, Parctoplabscologe 32,51 (1973).

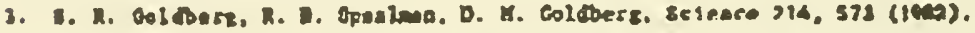

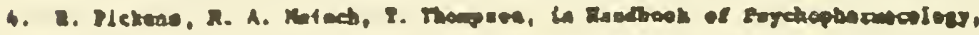

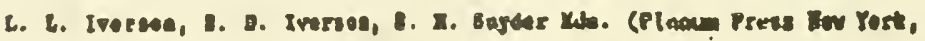
เอก). 12, 2. 2 .

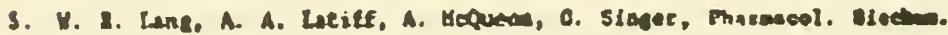
Rehav. 7, 65 (1977), B. A. Seled, W. J. Lang, 1614, 19, 215 (1920).

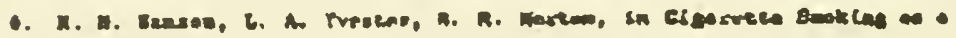

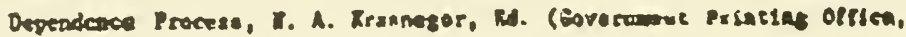
Washincess, D.C. 3979 ), 70.

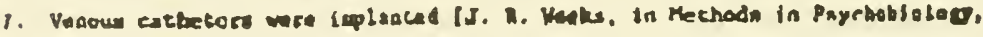

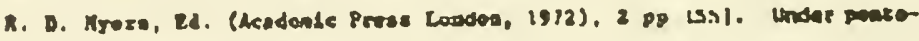

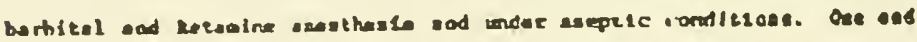

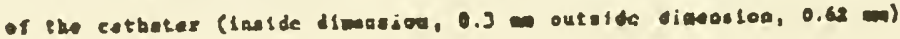


wa pased of viy of the exlemal jogular vesa inte the supartor vene

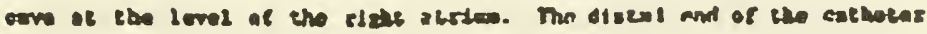

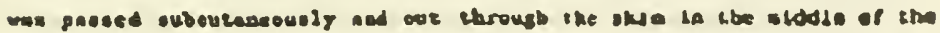

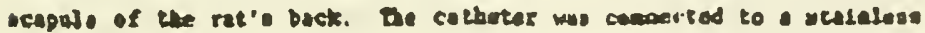

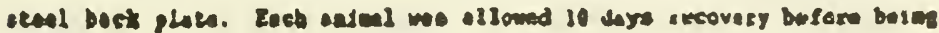
placed te a cent chaber.

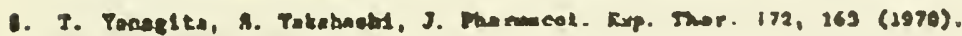

\section{Teste 1}

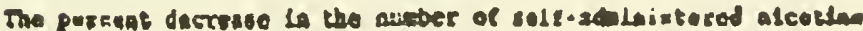

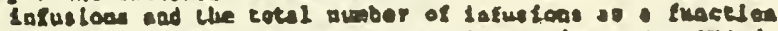

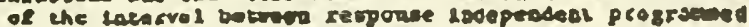
aleothe infupton.

Iatoriefoslon Incerval (cinare) Control

30

45

60

9
Year (t rencente erve) 8 dacrence la tha naber of - Alf-odelatcered is lasion

s) (14.3)

$45(25.0)$

$90( \pm 3.4)$

$23(21.5)$ rem totel infester (t)

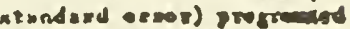

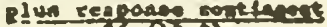
$16( \pm .0)$

$8 i^{\circ}(23.6)$

15 (24.3)

$79(18.1)$

$78.6)$ 


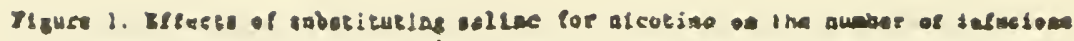

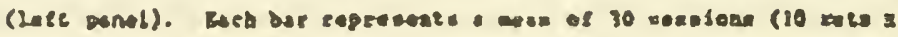

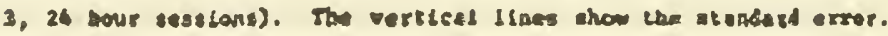

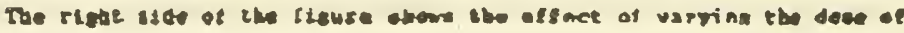

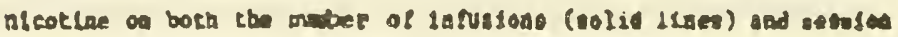

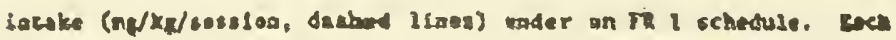

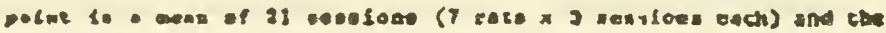

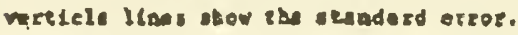

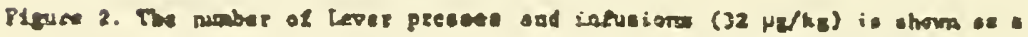

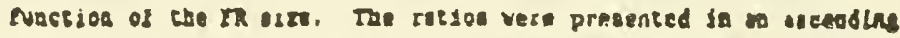

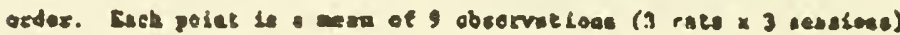

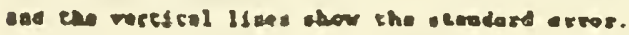

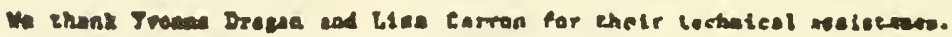




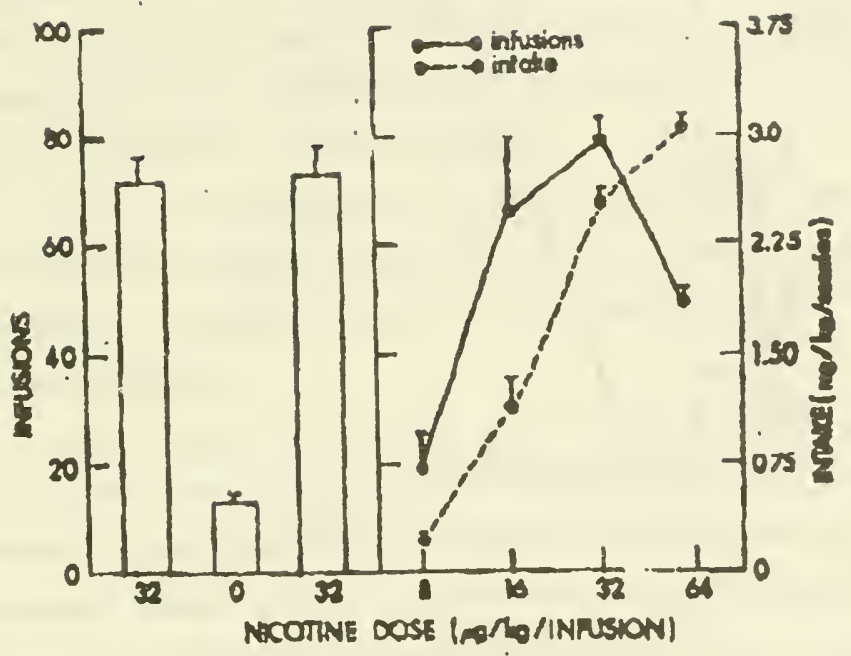

Iruse 1 


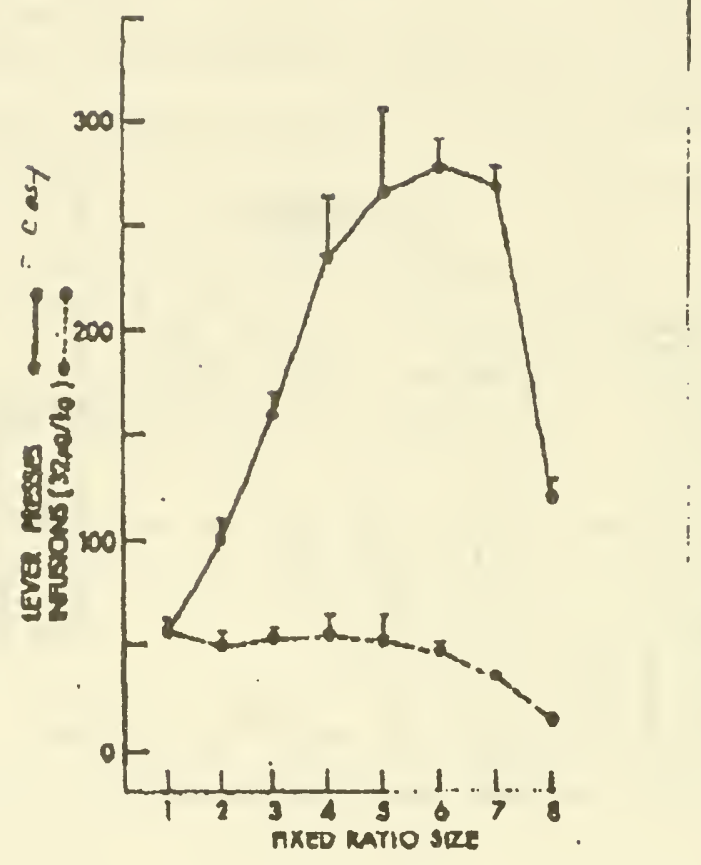

live. 


\section{Exhibit 6 \\ PHLW MORALSUSA STATIMRENT RESPONDNO TO CONGRSS8MUN WAXMNN'S PIESS CONIRRTNCT MARCH 31, 1996}

Dr. Victor De Noble was employed by Phllip Morris from April 1980 to March 1946 as a rosearch sciantast in tho Research and Development Dopertment. Ds. Do Noble conducted sleotinorelated resourch and concluded that nlootine is a

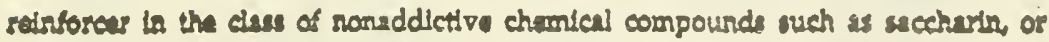

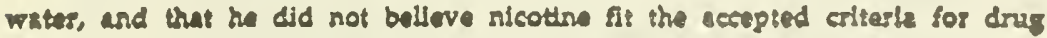

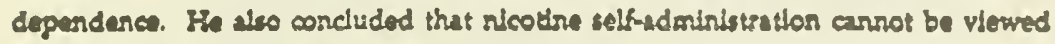
us a form of drug "abuse" or as an "addiction."

Contrary to the ruggestions that $D$ r. De Noble' sesearch has been somehow whthreld from the scientific community and public, we find darens of publientions authored by him including five based on his nleothnerelated resuarch conductod while at Phillo Morre.

At no time did Fallig Mosrls soek an injunetion, irgal ar othorwtea, against the publieation of ang of Dr. De Noble's sesearch. As with vistually all industrios.

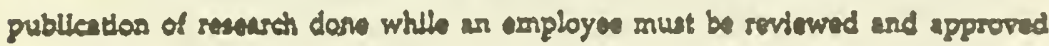
prox to such publication. Wo are aware of one inatanee when Dr. Da Noble fallod to to through the Phillp Morris manuseript soviow process and thus was told not to

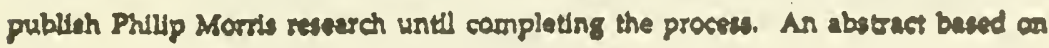
thent researeh wes published.

\section{Contect: Victor Hen}

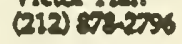


The Honorable Henry A. Waxman

Chairman, Subcommittoe on

Health and the Environment

Committee on Energy and Commerce

House of Representatives

Washington, D.C. $20515-6118$

Dear Mr. Warman:

I am writing in response to your request of April 11 for the evaluation by the National Institute on Drug Abuse (NIDA) of the significance of the findings presented in Dr. Victor DeNoble's 1983 research paper, "Nicotine as a Positive Reinforcer in Rats: Effects of Infusion Dose and Fixed Ratio Size." The findings from Dr. DeNoble's study demonstrate that nicotine does act in a reinforcing manner when tested in an animal model.

It is also important to note that the rate of nicotine self-administration vaned with the dose of the drug. Furthermore, when the subject's baseline nicotine level was increased by the researcher, the rate of self-administration of nicotine by the subject in the study was decreased. These two findings support the contention that nicotine reinforcement was due to the pharmacologic effects of this substance. These findings from the DeNoble study indicate that nicotine has reinforcing properties, one of the hallmark characteristics of an addictive drug, and are consistent with thosc of NIDA-supported researchers who have studied the reinforcing effects of nicotine.

You also requested my comments on the statement by the Phillip Morris Company that the DeNoble study shows that "nicotine is a reinforcer in the class of nonaddictive chemical cumpounds such as saccharin or water." It is toue that saccharin and watcr can also serve as reinforcers: however, the reinforcing properties of water depend upon the animals bcing deprived of water and the reinforcing properties of saccharin are due to its caste. In the DeNoble study, the animals were neither food nor water deprived, and nicotine was administered intravenously, which avoids taste effects. Therefore, nicotine docs not have the same characteristics as water and saccharin.

I hope you will find this information helpful.

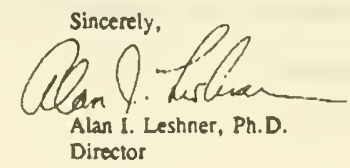


II PHILIP MCRRIS U. S. A.
$\therefore$ INTER-OFFICE CORRESPONOEHEE

xnibit 8

aboe.

(1)

.CONFIDENT

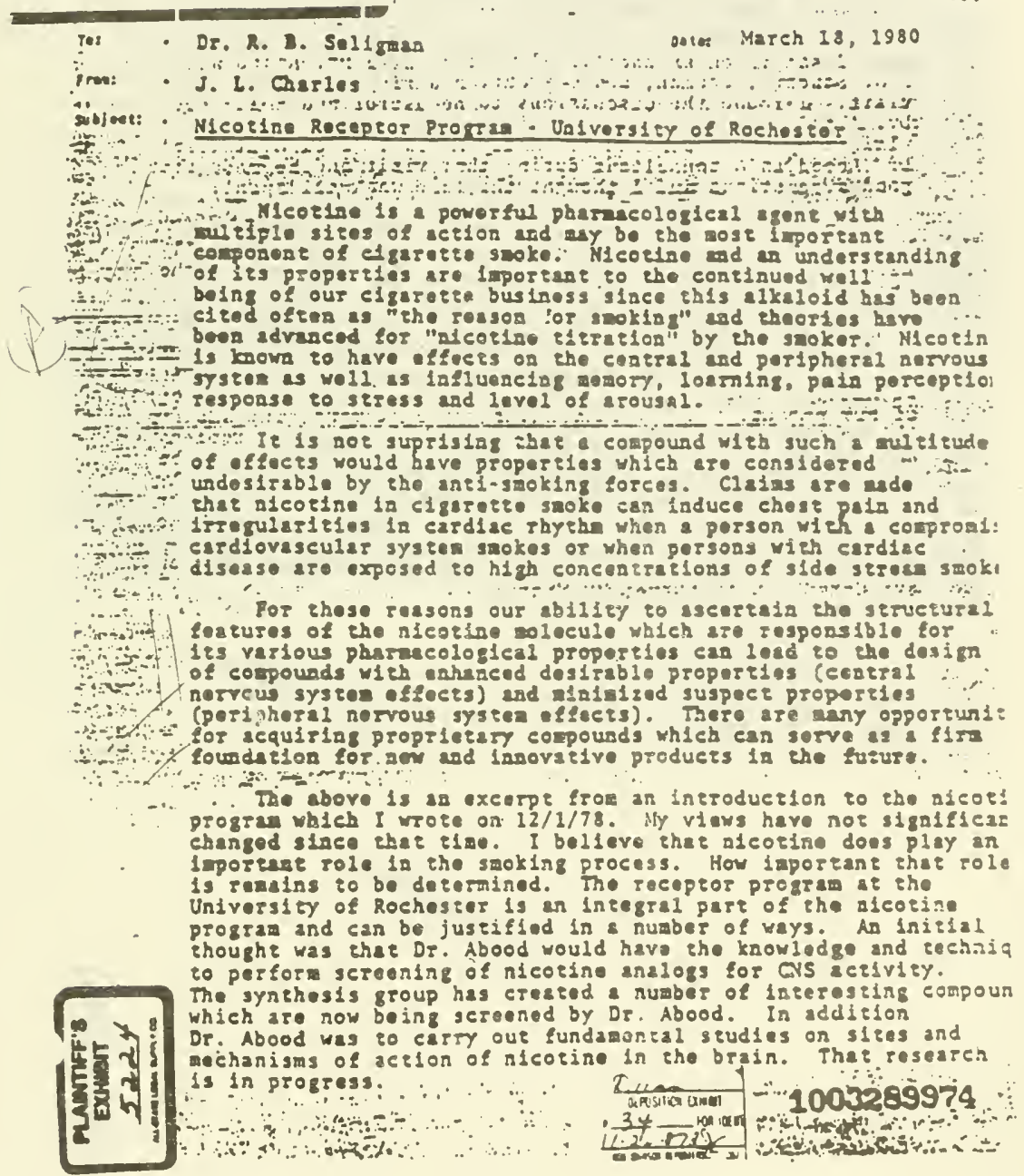


I se ia on an addlitional meesing with Dr. Abood and Drs. Sanders. Seeman, and Chavdarian during Dr. Abood's lase risit. I found the discusstons $\mathrm{CC}$ be useful and folt that Dr. Nbood was dolng sone very inceresting work which ean Ulelarely be of benefle to Philip Mortis. I also ueilizod Dr. Abood s a consultant during that visit and he macie some good suggestions and I thought the tine was well spert.

In surs, the alcotine receptor progrea se the Universisy of Rocheseer is an lneegral pare of our overal alcotide profrem. The combination of basle reserch on the phermecology of the ntcotine receptor combined with the capablifty to screan alcotine analogs lor CVS activity couplenents ous lacernal syntheric and behavioral efforts in the nleorla progra. The prograa is justified ta ay view as defenstre response to the anti-snoking forces criticisas of nlcorino and 150 as fundamental research lato the nature of out produce and how le affects our custonors, the saokes. Thls entre progrem involves coaplex technologleal probless and the beneslts to be derived from the progran will not be reallzed lmodiarely. Indeed the beneflis will necessarily be of long-tera nature and ay have dfrect bearing on our

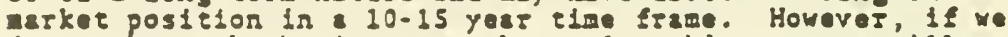
do not have the basic resestch resules this progran will provide we will not be in a position to respond if and when the pressures to change do occur.

\section{Лc/mro}

ce: Dr. T. S. Osdene
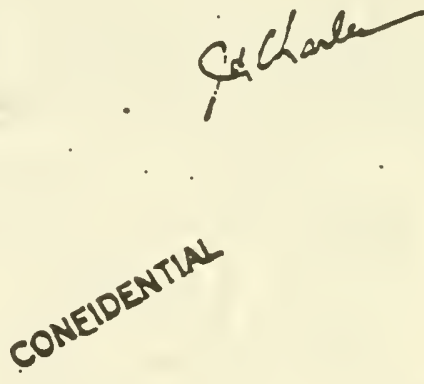
4 trat

Docerrors 2
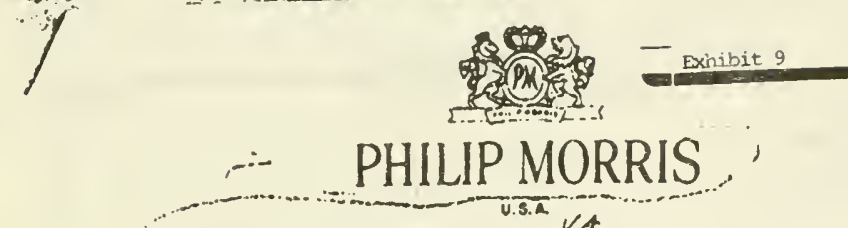

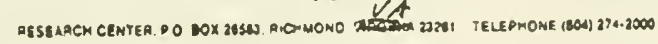

August $30,: 983$

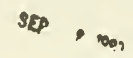

Herbert Barry, 111, th. 0.

University of Pittsburgh

School of Pharmacy

Pitesburgh, Pennsyivania 15261

Dear Dr. Barry:

I regret to inform you that due to factors beyond my control I must withdraw our manuscriot 18304400 from consideration as a publication in Dsychopharmacology.

Please accept ny sincerest apology.

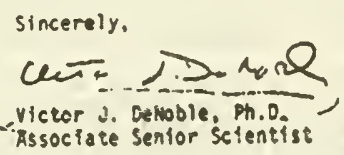

VJo/mps 
Tleter J. Drllobde, F.D.

22 septeoder $19 \% 6$

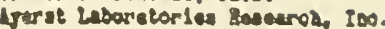

CII 000

irinotos, in ossas-9990

Dar Viotar!

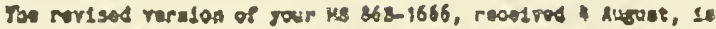

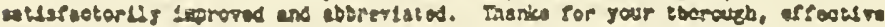
abange.

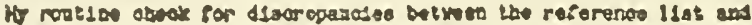

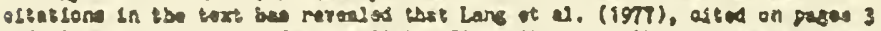

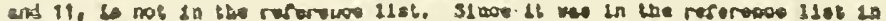
the orlor reralea, this on of the 16 refarance liot lteas deleted apparanty obould in teen rotalind.

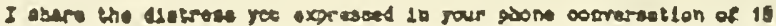

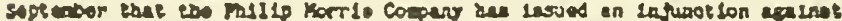

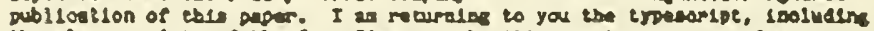

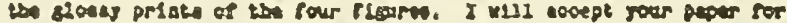

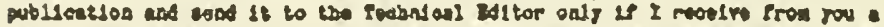

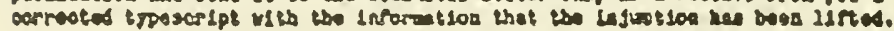

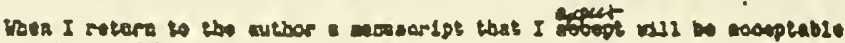

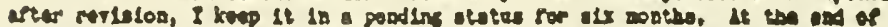

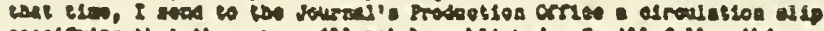

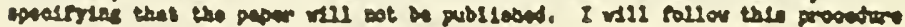

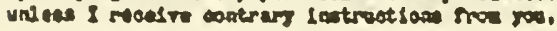

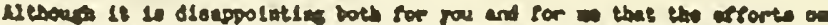

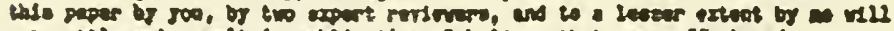

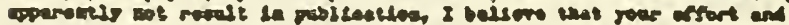

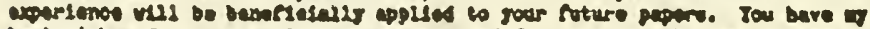

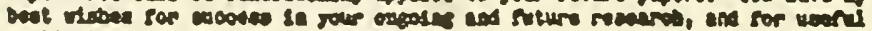

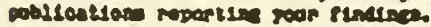

\title{
stowes rowr,
}

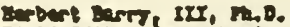

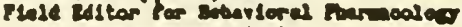 \\ in deboraters anders
}

tros. 
Mr. SYNAR. It then had to be withdrawn again. According to this letter written to the journal editor, the reason was that Philip Morris had "issued an injunction against publication of this paper." The letter was from the editor, as you can see.

Mr. Campbell, do you deny that Philip Morris kept the DeNoble study from being published?

Mr. CAMPBELL. I will not deny that.

Mr. SYNAR. You did keep it from being published.

Mr. CAMPBEll. Yes. We did not in any way employ legal techniques, such as injunctions, but we did not choose to publish that.

Mr. SYNAR. Isn't it true, Mr. Campbell, that prior to the time that Dr. DeNoble submitted his study to the journal in 1983, his study had been reviewed by Philip Morris for publication?

Mr. CAMPBELL. I believe that to be the case, yes.

Mr. SYNAR. All right. In its press release, Mr. Campbell, Philip Morris states that it did not obtain an injunction against the publication. My question to you is did Philip Morris, its attorneys or any of its employees threaten a court injunction that would be sought against Dr. DeNoble if the article was published?

Mr. CAMPBELL. Not to my knowledge, sir, and I have investigated to some extent.

Mr. SYNAR. Do you have a written memo on that investigation from your staff?

Mr. CAMPBELL. I don't think so.

Mr. SYNAR. If you do, would you leave that memo available for the record and submit it?

Mr. CAMPBELL. Thank you.

[The following letter was received:] 


\section{PHILIP MORRIS}

120 PARK AVENUE, NEW YORK, NY 1009

WILLIAM I. CAMPBELL

PRESIDENT AND

CHIEF EXCCUTIVE OTICER

April 26, 1994

Henry A. Waxman

Chairman, Subcommittee on Health

and the Environment

2415 Rayburn House Office Building

Washington, DC 20515-6118

Dear Mr. Chairman:

I have had an opportunity to review an unofficial transcript of the April 14 Hearing. While I may have additional clarifications for the Record after further review, there are a few clarifications I would like to make now.

Congressman Synar, in referring to Dr. DeNoble's unpublished 1983 manuscript, said that the research described in the manuscript "found that rats will self-administer nicotine when hooked up to an intravenous nicotine solution." Congressman Synar went on to say that Philip Morris's March 31 press release "said the DeNoble study showed exactly the opposite." I don't believe Congressman Synar is correct. The Philip Morris press release said that Dr. De Noble "conducted nicotine-related research and concluded that nicotine is a reinforcer in the class of non-addictive chemical compounds such as saccharin, or water ...." And that is indeed what he concluded. The press release went on to say that Dr. DeNoble "did not believe nicotine fit the accepted criteria for drug dependence." And again, that is indeed what he concluded. Our press release did not say that Dr. DeNoble's 1983 unpublished manuscript showed anything other than what it did.

Congressman Synar asked me whether Dr. DeNoble's work was part of the Company's "effort to develop a nicotine analog, which are chemicals which would have addicting or reinforcing features without any [of some] sic of the nicotine side effects? Yes or no?" In answering "yes," I was not agreeing that either nicotine or the analogs had addicting features, but simply that the analogs might be reinforcing. 
Congressman Synar also asked whether "Philip Morrss, its attorneys or any of its employees, threaten[ed] a court injunction that would be sought against Dr. DeNoble if the Joumal or the article was published?" I answered: "Not to my knowledge, sir, and I have investigated to some extent." I am unaware of any threat of a court injunction against Dr. DeNoble. As a result of the publication, on several different occasions, of the results of research conducted while with the Company, wlthout Company approval as was required by his employment agreement, an attorney with the Company wrote to Dr. DeNoble, two years after he left the Company, saying:

"The Company cannot tolerate this type of conduct. As I stated in my earlier letter, if you wish to publish or otherwise utilize research from Philip Morris, you must request and receive permission from the Company. Any further breach of your agreement will result in action belng taken."

The Company acted appropriately. No legal action, however, was ever taken against Dr. DeNoble by the Company.

Finally, Mr. Wyden asked me whether the Company is currently the subject of a potential antitrust action by the Department of Justice over our refusal to develop a fire-safe cigarette. I answered, "I don't know that, sir." I was confused by the question and, as a result, my answer was incorrect. On January 11, 1994, the Department of Justice, Antitrust Division, issued a Civil Investigative Demand (CID) directed to Philip Morris Incorporated, as part of "an antitrust investigation to determine whether there is, has been, or may be a violation of Section 1 of the Sherman Act." The investigation is into "joint activity to restrain competition in the manufacture and sale of cigarettes, inciuding joint activity, to limit or restrict research and development or product innovation." We are informed that the focus of the investigation is into allegations of joint industry activity to restrict the development of a "fire-safe" cigarette. Therefore, we are the subject of a Department of Justice antitrust investigation related to the development of a "fire-safe" cigarette.

I appreciate having this opportunity to clarify the Record. Should a further review require additional clarification, I will advise you promptly.

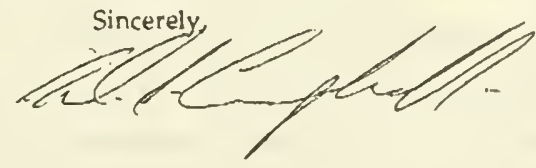

cc: The Honorable Thomas J. Bliley

Ranking Minority Member 
Mr. SYNAR. The subcommittee was informed, Mr. Campbell, that in early 1984, Philip Morris or Berkeley closed down the research laboratory of Dr. DeNoble and his colleagues and the employees were told to find other jobs. Is that true?

Mr. CAMPBELL. That's correct.

Mr. SYNAR. Is it true that Philip Morris took that action because of the adverse research findings that were being found by the laboratory?

Mr. CAMPBEll. No.

Mr. SYNAR. Does Philip Morris have copies of any of Dr. DeNoble's studies, reports, notes or any other documents pertaining to work he performed or any other documents pertaining to his animal research?

Mr. CAMPBELL. I would think that we do, sir.

Mr. SYNAR. Will you provide those documents to the subcommittee and for the record?

Mr. CAMPBELL. I see no problem.

Mr. SynaR. The subcommittee contacted Dr. DeNoble, Mr. Campbell, to ask his version of the events and Dr. DeNoble informed this subcommittee that he would be unable to talk to us because it may be subject to a confidentiality agreement that he has with your company, Philip Morris. Therefore, it would bar the testimony of Dr. DeNoble because of that agreement.

Mr. Campbell, will you release Dr. DeNoble from his confidentiality agreement so that he can appear voluntarily before this subcommittee to tell us what really happened?

Mr. CAMPBELL. I don't know of the confidentiality agreement. So I'd have to have an investigation, but then I will answer.

Mr. SYNAR. Will you release Dr. DeNoble from any contractual arrangements that would allow him to voluntarily testify before this subcommittee?

Mr. CAMPBELl. Dr. DeNoble is quite on record in a-

Mr. SYNAR. Yes or no? Will you allow Dr. DeNoble to come forward?

Mr. CAMPBEll. I see no problem and our people will discuss it with you.

Mr. SYNAR. No. That's not the question. Mr. Campbell, Dr. DeNoble will voluntarily appear if he can get through the agreement that he has with your company. Will you release him from that agreement?

Mr. CAMPBELl. Can I check with my counsel at this time?

Mr. SYNAR. I just want to know. You're the chairman of the board.

Mr. Campbell. No, I'm not, sir. I'm just the president, but-

Mr. WAXMAN. Mr. Synar, let's give him a minute.

Mr. SYNAR. All right.

Mr. CAMPBEL. We'll do it, sure.

Mr. SYNAR. Thank you. Mr. Johnston, do you currently have animal research going on in your laboratory?

Mr. JAMES JOHNSTON. I believe we do, yes.

Mr. SYNAR. Will you make available to the subcommittee all documents pertaining to that animal research that you are presently and have in the past conducted? 
Mr. JAMES JOHnston. Those which do not involve proprietary product development-

Mr. SYNAR. Mr. Johnston, that is an unacceptable answer. Proprietary information is available to Congress in confidential form. That is not a legitimate excuse for not providing it to the subcommittee.

Mr. JAMES JOHNSTON. Congressman, may I finish my response?

Mr. SYNAR. You may finish.

Mr. JAMES JOHNSTON. Those documents which relate to specific product development, it is my clear understanding that without being very careful with those documents, we could then have the Justice Department come after us for anti-competitive behavior. So this requires specific documents.

I have no problems with cooperating with this committee in any way.

Mr. SYNAR. Mr. Johnston, I take that as a yes that you will provide all the animal research and laboratory information that you are presently-

Mr. JAMES JOHNSTON. We will provide any reasonable data.

Mr. SYNAR. No. That's not what I'm suggesting, Mr. Johnston. That's not up to your determination what is reasonable. I'm asking you, will you and will every one of the gentlemen to your right provide all present and previously conducted animal research data to this committee that has been done, and reports, notes, et cetera. Mr. Johnston?

Mr. JAMES JOHNSTON. I will repeat if

Mr. SYNAR. Yes or no, Mr. Johnston?

Mr. JAMES JOHNSTON. If there is a possible violation of anti-competitive law-

Mr. SYNAR. Mr. Johnston, let me give you the rules. Maybe you don't understand-

Mr. JAMES JOHNSTON. I will not knowingly

Mr. SYNAR. Mr. Johnston.

Mr. JAMES JOHNSTON [continuing]. Violate the law.

Mr. SYNAR. Mr. Johnsion, you cannot withhold information from the U.S. Congress. Now, we can either ask you to provide that information or we can use our subpoena power to do that. There is no bar from that information on the basis that it is proprietary or that there is pending litigation.

We will have our lawyers explain to your lawyers, if that's necessary and I don't think it is, that the providing of proprietary information does not constitute making that information public, therefore violating any formulas or particular private information that you have.

Now, the question I ask you one more time and to each gentlemen to your right. Will you provide us all the test reports and notes from all animal laboratory testing that you are presently or formerly been involved in? Yes or no?

Mr. JAMES JOHNSTON. I will provide those documents which do not threaten a Justice Department charge of anti-competitive behavior and I will require, Mr. Congressman, some kind of assurance from the subcommittee staff that those proprietary, competitive information be held in confidence. We've had some issues late- 
ly of data being released in an inflammatory sense, in possible violation of a Federal-

Mr. WAXMAN. Just a minute. The question is whether you're going to submit this data. You're not suggesting that this subcommittee has released any data you've submitted to us in confidence in any improper way, are you?

Mr. JAMES JOHNSTON. No, Mr. Chairman.

Mr. WaXMan. You will submit the data. May I have the answers from the others? We'll have to move on.

Mr. TADDEO. I'm unaware that we have any in-house animal research.

Mr. WAXMAN. Speak into the microphone.

Mr. TADDEO. I'm unaware that we have any in-house animal research.

Mr. WAXMAN. Whatever you have, we want you to submit it to us. Will you agree to that, Mr. Tisch?

Mr. Tisch. Yes, sir. We will provide to Congress whatever is appropriate and required by law, sir.

Mr. SYNAR. Gentlemen, let me explain to you something. If we have to subpoena this information, you will not be able to determine the appropriateness of the information. So you can either voluntarily agree to submit all information, including notes, records, et cetera, or the subcommittee may be forced to consider a subpoena, through which we will get all the information.

Mr. TISCH. I understand that, sir.

Mr. WAXMAN. Are you committing to cooperate with the subcommittee and get us the data?

Mr. TISCH. I have not, not cooperated, with the committee. Like I said, I will be glad to provide whatever is appropriate and whatever you require of us and whatever you ask of us.

Mr. WAXMAN. Mr. Horrigan?

Mr. HoRRIGAN. We will cooperate. And if I may, at this juncture, I am somewhat appalled by the conduct of this hearing. You invited responsible executives here to devote their time and their honesty to the answers. You overwhelm people with questions. You ask yes and no. And I would like to think if we were going to have an exchange here, a true exchange, for you to be informed rather than have your minds made up, we should be given chances in future questioning to expand, if necessary.

Mr. WAXMAN. Mr. Horrigan-

Mr. HORRIGAN. We will cooperate fully with the question represented by Mr. Synar.

Mr. WAXMAN. So your answer is yes. Mr. Sandefur?

Mr. SANDEFUR. Yes. We will cooperate. We have not done any animal research.

Mr. WAXMAN. Mr. Johnston?

Mr. DONALD JOHNSTON. Yes. We will cooperate. We have not done any such studies in our own facilities. However, I would point out that in the period of the 1930's through the 1960's, we did participate in a program of grants with the Medical College of Virginia, and that information may be something we can provide.

Mr. WAXMAN. Thank you very much. Mr. Bryant?

Mr. BRYANT. Thank you very much. I would like to ask each of you sort of a rhetorical question I think I know the answer to al- 
ready. But it is true, is it not, that in product liability cases that have been filed against the tobacco companies that seek to hold your companies responsible for the illness or death of a smoker, one of the defenses which the tobacco companies always assert is that the sick or dead individual who smoked did so as a matter of his or her own free choice and that he or she, therefore, assumed the risk of diseases which are publicly associated with smoking.

Isn't that the case, Mr. Johnston?

Mr. JAMES JOHNSTON. There is virtually universal awareness by the American public of the health risks involved in smoking. That is part of litigating these issues.

Mr. BRYANT. I just asked a question. I do not want to cut you off, because I want you to be able to give a full answer. But you have got to answer the questions pretty quickly. It is the case, is it not, that your usual defense is the smoker smoked voluntarily as a matter of free choice and, therefore, assumed the risk and you are not responsible? Is that not the case?

Mr. JAMES JOHNSTON. That's correct, sir.

Mr. BRYANT. Is it also true that your argument that smokers continue to smoke as a matter of their own free choice is a key part of the defense? It is the essential part of your defense. Is that not right?

Mr. JAMES JOHNSTON. I wouldn't characterize it as essential. It is part of the defense, yes, and part of the American record.

Mr. BRYANT. Is it not the case that that defense would be wiped out if you conceded here today or any forum that nicotine and your products are addictive?

Mr. JAMES JOHNSTON. Mr. Congressman, I don't know. Addiction is a term that is-

Mr. BRYANT. We all know what it means. Would it not be the case if you conceded here today that nicotine was addictive and your products were addictive, that you would no longer be able to claim that the sick or dead individual smoked as a matter of free choice? Is that not the case?

Mr. JAMES JOHNSTON. I can tell you what juries believe. Juries usually believe, because of the common definition of addiction, that the person was addicted, but the person can quit.

Mr. BRYANT. The fact of the matter is that you can not sit here today and say to us that people made a free choice to smoke if you also concede that once a person starts, they are addicted. Now, you cannot do that.

So it is very clear that you all have a very clear economic interest in telling the American people and in sustaining the idea and saying and not deviating from the assertion that your products are not addictive. I think that is just a matter of logic.

Mr. JAMES JOHNSTON. I respectfully disagree with you. The truth, Mr. Congressman-

Mr. BRYANT. So you think a person could be addicted to cigarettes and you could still assert that they smoked as a matter of free choice.

Mr. JAMES JOHNSTON. I'm telling you that the truth is the truth. I will speak the truth as I know it, disregarding litigation consequences. If we- 
Mr. BRYANT. Fine. All I am saying-I think it is clear what I am saying. You cannot claim somebody smoked as a matter of free choice and, at the same time, admit that they are addicted to your product, now can you?

Mr. JAMES JOHNSTON. Mr. Congressman, I'm not a litigation lawyer or expert.

Mr. BRYANT. But I would hope you are a logical thinker.

Mr. JAMES JOHNSTON. I am, I hope.

Mr. BRYANT. I think the logic leads us to that conclusion. When everybody on the panel says the same thing and, Mr. Horrigan, you took offense at our questioning a moment ago, but when everybody on the panel says the same thing and, astonishingly, says it in the same way, as you did a moment ago when you affirmed that you did not believe nicotine is addictive, it raises the question about whether or not the response was rehearsed.

Mr. Horrigan, did your lawyer tell you that you needed to affirm today without equivocation that nicotine is not addictive?

Mr. HORRIGAN. No one had to tell me anything about my opinions about addiction, sir.

Mr. BRYANT. Did this group discuss the need to state clearly in the same words as you all did, in the same words that nicotine is not addictive?

Mr. CAMPBELL. Absolutely not.

Mr. HorRigaN. You may think that we get together and meet. That's absolutely outrageous.

Mr. BRYANT. What is outrageous?

Mr. HorRIGAN. That is outrageous for you to assume that we meet and talk about these issues. We are competitors. We're independent. We're fighting for survival in a legitimate marketplace.

Mr. BRYANT. You mean you have never collaborated-

Mr. HORRIGAN. And we all have our own opinions.

Mr. BRYANT. You have never collaborated in defending against a product liability case brought against you for making people dead and sick?

Mr. HoRRIGaN. If lawsuits are brought against companies together, then the companies obviously, as a group, would protect themselves if they are brought together.

Mr. BRYANT. That is all I'm talking about, Mr. Horrigan. I would also observe, Mr. Horrigan, it is very difficult for me to find you at this table characterizing anything as outrageous after 7 apparently intelligent people have stood here and told the American people, 250 million of whom know better, that cigarettes are not addictive. What could be more ridiculous?

So if we sit up here a little skeptical of your answers in other areas, you will understand why.

Now, Mr. Johnston, the Mr. Johnston who is with R.J. Reynolds, we have spent a long time on the medical and scientific aspects of nicotine addiction today. Behind the medical and scientific jargon about self-administration and reenforcing effects are, of course, real people who are suffering real pain and serious diseases and ultimately loss of life because of their addiction to cigarettes.

I have a letter from one of these people, Mr. Pat McLaughlin from Florida. It is marked as Exhibit No. 11. I think Ms. McLaughlin's letter should be read. She writes, "I must comment 
on the statement that cigarettes are not addictive. Let me tell you about my father's death from emphysema. His death was not the bad part. His life was the real horror story. My earliest childhood memories include hearing my dad's persistent and constant hacking cough, watching him continually spit up phlegm into a coffee can which he had by his side 24 hours a day."

She writes, "I also remember my dad being in the hospital once or twice each year for a lengthy stay while his lungs were being pumped of the poisons from nicotine. My most vivid memories were my dad's unforgettable words of despair. Not one day went by when he didn't say 'I know these damned cigarettes are killing me, but I can't quit.' I remember his being under the oxygen tent and begging for a cigarette."

She concludes by saying "My dad never got the chance to meet his three grandchildren and he died with a cigarette in his hand."

Were you aware, Mr. Johnston, that your cigarette caused this kind of misery for the McLaughlin family and for hundreds of thousands of families like them each year?

Mr. JAMES JOHNSTON. Mr. Congressman, I am sorry to hear about the McLaughlin family's situation. I do not believe that Mr. McLaughlin was addicted to cigarettes. My mother has diabetes. When we talked about all those other substances that aren't harmful, sugar is perhaps killing my mother. I have talked to her. I have begged her. I have pleaded with her to stay away from sugar.

In the end, she makes that choice, knowing everything she knows about the risks of diabetes, having all the encouragement from her son and her daughters. She makes that choice.

[Exhibit 11 follows:] 


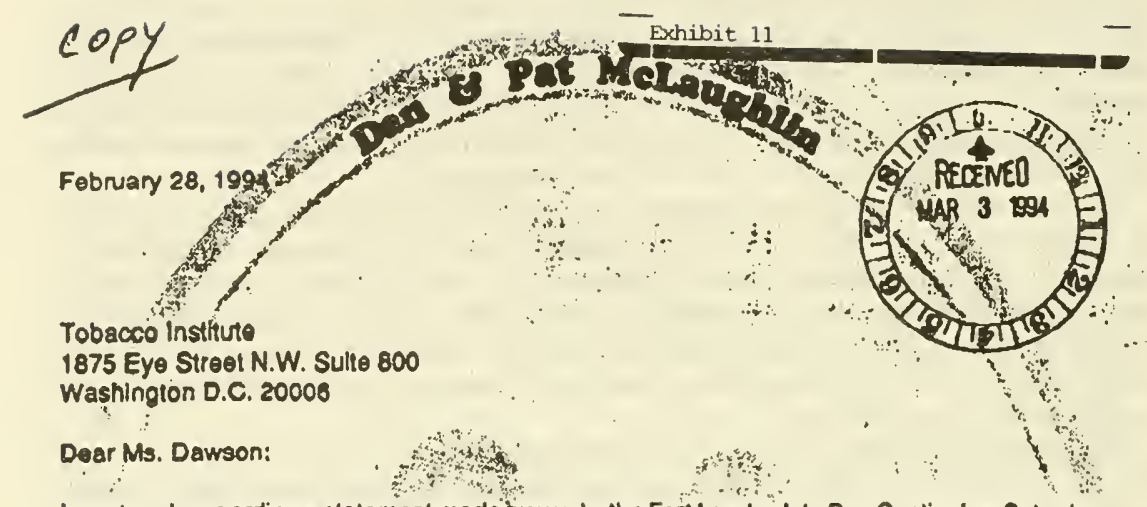

I must reply regarding a statement made by you in the Fort Lauderdale Sun Sentinel on Saturd: : February 26 about the FDA's authority to ban clgarettes.

I am not concerned with the FDA's deciston, but I must comment on your statement that "CIGARETTES ARE NOT ADDICTIVE".

Lei me tell you, Ms. Dawson, about my lather's death from emphysema. His DEATH was nol the bad part. His LIFE was the real horror story. My earliest childhood memories include hearing my Dad's persistent constant hacking cough, walching him continually spit up phlegm into a cotfee oan (which ho had by his side 24 hours a dayl).

I aiso remember my Dad belng in the hospital once or twice each year for a lengthy stay while his lungs were being pumped of the poisons from nicoline.

My most vivid memories were my Dad's unforgettable words of despair. Nol one day went by when he didn't say "I know these damned cigarettes are killing me, but I can't quit". I remember him being under the oxygen tent begging for a cigarelle.

Does this sound like a pleasurable, non-eddicting hobby or a disgusting addicting disease? Do you think a person would choose this llfestyle? My Dad never got the chance to meet his three grandchildren and he dled with a cigarette in his hand.

It's too late for my Dad, but please be honest, Ms. Dawson, for the sake of our young people today who still have a chance to "JUST SAY NO" to this harmiul drug called nicotine, which is known to be more addictive than heroln.

Very inuly yours,

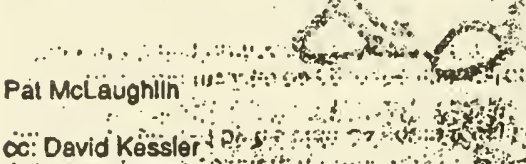

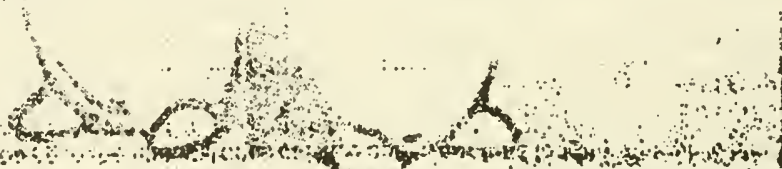

o for

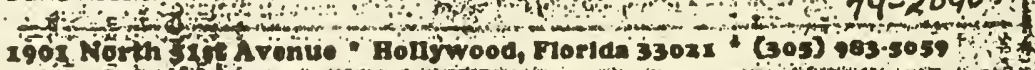

1901 North sif Avonte Foligwood, Forlda 33021

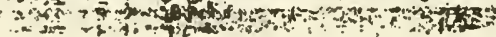


Mr. BRYANT. I will just have to say no medical experts agree with your assessment or comparison of sugar and nicotine. None, none whatsoever. There is a stack of books that say you are wrong or that you are stating something you do not believe, one way or the other.

Do you think the Schick Clinics and the people who sell patches and all who are trying to help people escape from this addiction are operating a fraudulent enterprise?

Mr. JAMES JOHNSTON. No, Congressman, I do not. But for you to sit here and tell me that my mother's life is not at stake is wrong, as well.

Mr. BRYANT. No one in this room heard me say that. You did not hear me say that either. You are evading my question. Do you think that Schick and these people who are trying to provide people with medically-approved means of getting away from your product are running a fraudulent operation?

Mr. JAMES JOHNSTON. For some smokers, it may make a difference. The success rates, as I understand them, with stop smoking clinics and with patches and the nicotine gum and so forth is somewhere, I believe, and this is speculation, not a fact, but my understanding is around 25 percent. So for some people, it is an aid to support their decision.

Mr. BRYANT. So for some people, perhaps it is addicting. Would you agree?

Mr. JAMES Johnston. Any one of those clinics will tell you when you walk in the door if you aren't committed, if you haven't really made the decision to quit, you will not quit.

Mr. BRYANT. But would you agree that for those 25 percent of the people, they are addicted to nicotine?

Mr. JAMES JOHNSTON. I'm sorry, Congressman.

Mr. BRYANT. You acknowledge 25 percent of the people are aided in quitting by those clinics. Would you agree that those people are addicted to nicotine?

Mr. JAMES JOHNSTON. No, sir. No, Congressman.

Mr. BRYANT. Then what good does a patch that puts nicotine into their body do them?

Mr. JAMES JOHNSTON. Pardon me?

Mr. BRYANT. What is the effect of the patch that gives them nicotine?

Mr. JAMES JOHnSTON. What is the

Mr. BRYANT. What is the effect of the treatment if they are not addicted?

Mr. JAMES JOHNSTON. What is the-I'm sorry, Congressman.

Mr. BRYANT. If they are weaned from their habit with a nicotine delivery system, then how can you say that nicotine was not involved in their inability to stop smoking?

Mr. JAMES JOHNSTON. Nicotine provides pleasure. It provides enjoyment.

Mr. BRYANT. Let us move on to something else.

Mr. WAXMAN. Before you do move on, do you believe that nicotine administered through a patch is pleasurable?

Mr. JAMES JOHNSTON. I don't know. It has a mild pharmacological effect. Those products are marketed as a drug. And the reason-this is very important, Mr. Chairman. The reason that 
many people do not stay with nicotine patches, which provide nicotine just like a cigarette does, is that there's something more to smoking than just nicotine. It's the ritual. It's the way we associate it after a meal or with a cup of coffee.

So to say that people taking nicotine through gum or patchesif it was only nicotine, they'd stay with it. But there is something more to smoking. There is pleasure and enjoyment out of smoking.

Mr. WAXMAN. And 400,000 people die each year. Thank you, Mr. Bryant. Mr. Kreidler?

Mr. KREIDLER. Thank you, Mr. Chairman.

Mr. WAXMAN. Mr. Hastert has arrived. Do you want to take your time now? Mr. Kreidler.

Mr. KREIDLER. Thank you, Mr. Chairman. My father said to me, he said "I just wish I had known" what he had known 10 years ago. He wished he had known at the age of 14 what he knew 10 years ago. The sad part of that was that he was telling me this as he was in a nursing home bed dying of emphysema.

I was in the State legislature at the time and after the end of the day, I'd go up and I'd spend my evenings with my father over those last few months and it was a prized time to have that kind of exchange of information with your father as he's dying.

But it was really hard because it was interrupted so frequently with his laboring coughs and his attempts to get breath. It would be hard for me to imagine that there's one of you gentlemen sitting here that have ever witnessed something like that. My father started smoking when he was 14 years of age. He quit 10 years before he died because of the diagnosis of emphysema, took every medication he possibly could on a very regimented schedule, but it's progressive. It just goes until you die. You can't get any breath.

I can't imagine there's one of you gentlemen here that could actually advocate to a loved one please take up cigarette smoking, particularly if you've ever witnessed on a very personal level somebody very close to you dying under those circumstances, which I had, unfortunately, the opportunity to do.

My dad died that way and it was very sad. A very proud man under a very sad situation.

Mr. Campbell, you said it's not addictive. It's very hard for me to sit here and hear anybody say that it's not addictive when I witnessed what it did to my father over those years and the statements that he made, which clearly indicate that it is not just addictive, it's very addictive.

How do you respond? Would you ever want a loved one to take up cigarette smoking, knowing that the outcome, particularly if it were to lead to something like emphysema, would be something that could lead to the kind of death that I had to witness with my father?

Mr. Campbell. As I said, I really don't accept, from a common sense standpoint, that smoking is addictive. In terms of your own family situation, I can only feel the same kind of remorse that you reflect. But I guess what I would say is that when it comes to family members, I think of my own daughters and I would like them to take no risks.

But I accept that at some point that they're going to be taking some risks and I want them to be informed about those risks. I 
think that in a lot of ways, this product and a lot of other products that Congress, Health and Human Services-

Mr. KREIDLER. Would you want them to take up cigarette smoking?

Mr. CAMPBELL. I want them to be completely informed about all the kinds of pursuits that are associated with current-

Mr. KREIDLER. As a parent, if you had the choice.

Mr. CAMPBELl. In the end, I'm going to have to accept that they will be taking risks and I won't second guess them.

Mr. KREIDLER. I've scuba dived. I was a smoke jumper for the Forest Service. I did some things that were risky behavior. If you had a choice, as a parent, would you have your daughters start cigarette smoking?

Mr. CAMPBELL. I can't make the choice for my daughter and that's all I can tell you.

Mr. KREIDLER. If you, as a parent, could make a recommendation to your daughters.

Mr. CAMPBELL. My daughter is getting recommendations all the time about a lot of things. But in the end, they'll be as informed as they can be and make their own decision.

Mr. KREIDLER. So you wouldn't give them a recommendation on cigarette smoking.

Mr. CAMPBELL. It wouldn't matter if I gave them a recommendation with the amount of information that they'll have about this and a lot of other things. I think the important thing is that our children and everyone gets as much information as possible.

Mr. KREIDLER. I think we know the answer. In all honesty, you would tell your daughters don't do it because you know enough about it and it is very risky behavior and it's something that you wouldn't want to see them do.

I, too, apprise my kids of that same concern and I can always point to my father and I said do you remember how grand-dad died, that's why you don't want to smoke.

Let's turn to another issue that has to do with some of the myths that surround nicotine. This is the claim that nicotine levels in cigarettes have gone down dramatically. The industry position is simple. It says that nicotine yields calculated by the FTC test has dropped over 60 percent in the last 10 years, demonstrating a massive reduction in nicotine.

There's just two problems with that claim. First, it's not true that the FTC nicotine yields have been dropping for the last 10 years. In fact, for the last 10 years, they've been increasing. Second and even more important, the FTC's nicotine yields are an unreliable measure of how much nicotine is consumed in smoke in a particular cigarette.

The FDA, the Surgeon General, independent experts, and even the industry's own consultant have concluded that there is virtually no relationship between the measured FTC yield and the amount of nicotine actually inhaled by smokers.

My question is this. Dr. Spears, for Lorillard, 3 weeks ago, you presented a chart to the subcommittee that, Dr. Spears, you claimed showed that nicotine levels have consistently fallen for the past 10 years. A copy of your chart, marked to emphasize the most recent decade, is Exhibit No. 16. 
I believe that except for the markings that have been added, this is the same graph that you submitted to the subcommittee on March 25. Dr. Spears, is that correct?

Mr. SPEARS. Yes. This is a graph that I submitted to the hearing on March 25.

Mr. KREIDLER. According to the notation at the bottom of the graph, the bulk of this graph, including the years from 1956 to 1987 , is drawn from the Surgeon General's 1989 report on smoking, which charts nicotine levels based on the FTC data. Is that correct?

Mr. SPEARS. This chart is basically a replication of a chart in the Surgeon General's report extrapolated to 1990. I don't remember exactly where the chart stopped in the Surgeon General's report.

Mr. KREIDLER. The Surgeon General's 1989 chart is Exhibit No. 17. I believe this is essentially the same as the Philip Morris chart number two. I'd like to put both charts in the record at this point, if I might, Mr. Chairman.

Mr. WAXMAN. Without objection, they will be received for the record.

Mr. KREIDLER. Dr. Spears, in our last hearing, you used this chart to contradict FDA Commissioner David Kessler who had suggested that in recent years nicotine levels in cigarettes are going up.

Now that we have had time to look more closely at your chart and the data upon which it is based, however, we see some problems. At least over the most recent decade, the chart does not appear to reflect either the FTC data or the 1989 Surgeon General's chart upon which it is supposedly based.

I have an exhibit and poster that are taken directly from the 1989 Surgeon General's report and from the chart you submitted to the committee. The exhibit is Exhibit Number 18. It shows the major difference between your chart and that of the Surgeon General after 1982.

[Exhibits 16, 17, and 18 follow:] 


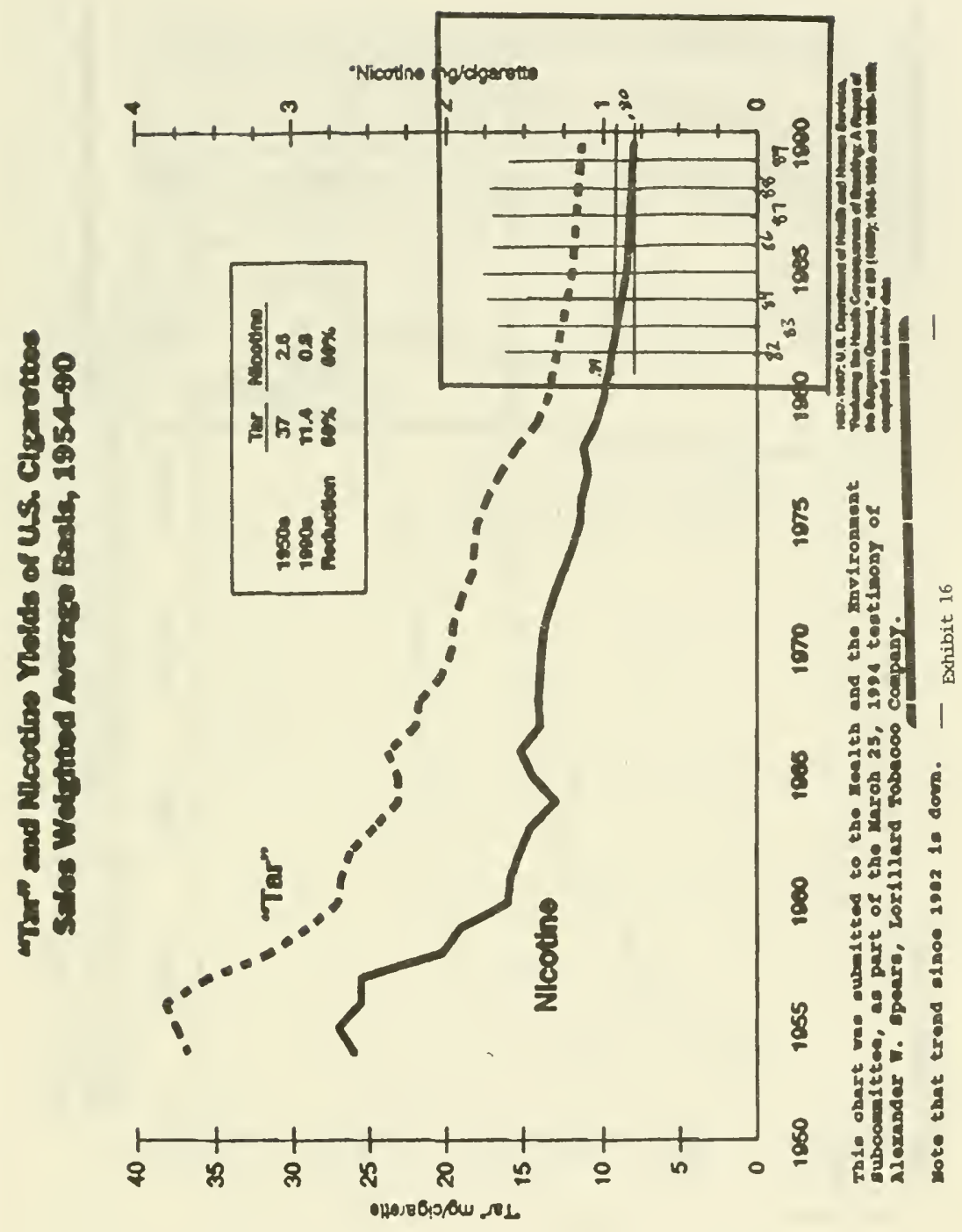


700

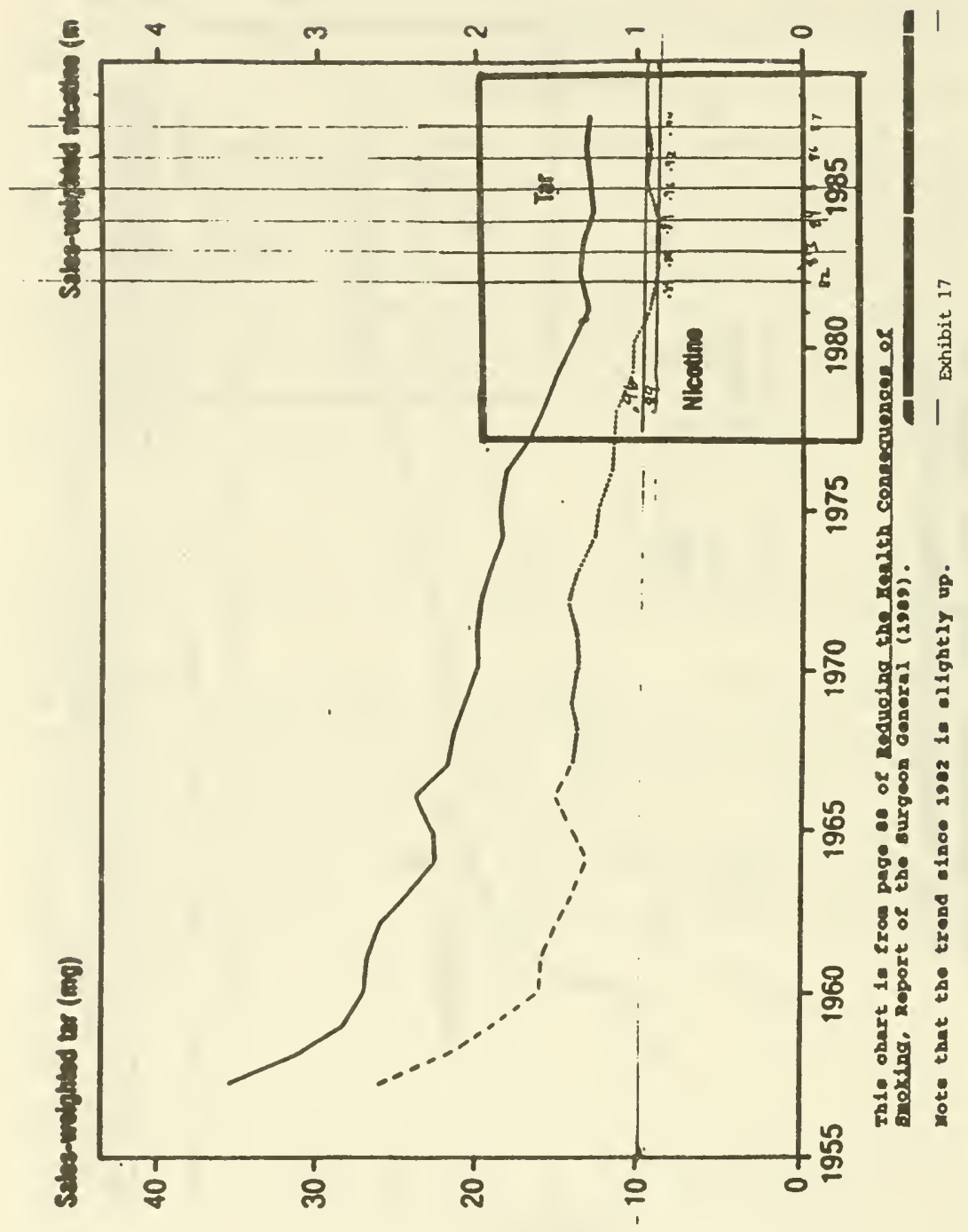




\section{Average Nicotine Yields of U.S. Cigarette Sales Weighted Average Basis}

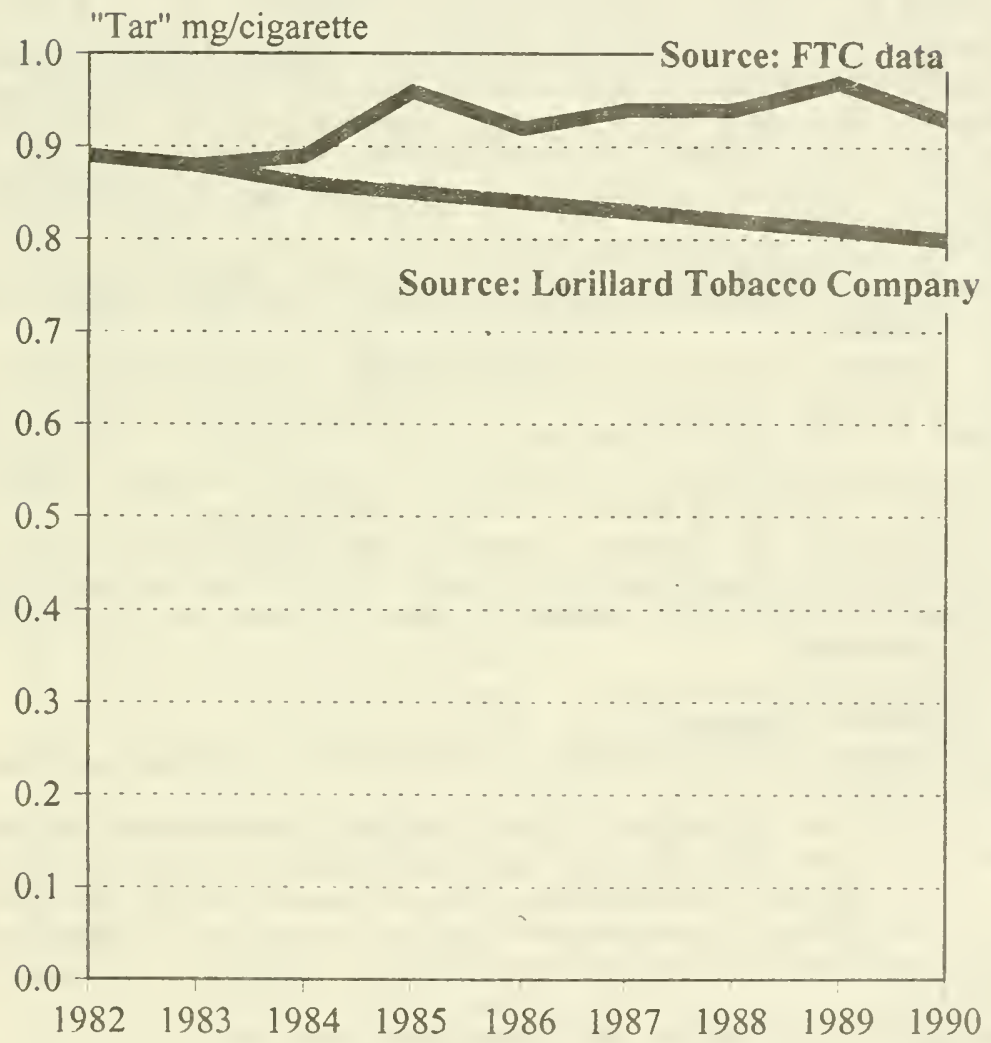

* Based on data furnished to the FDA by the FTC

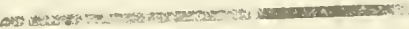


Mr. KREIDLER. Your chart shows a continuing decrease in nicotine levels after 1982, but the Surgeon General's chart shows-if we could bring up Philip Morris Chart Number 2 in lieu of that Surgeon General's chart. We have the exhibit. We didn't have a poster. So the public can see the exhibits being passed out.

But the Surgeon General's chart shows-or, I should say, Philip Morris here-shows an increase in nicotine levels. For instance, the Surgeon General's chart shows a significant increase in nicotine yields in 1985. This is not reflected in your chart at all. In fact, your chart shows a decrease from 1984 to 1985.

A look at the FTC data upon which the Surgeon General's chart is based is very revealing. If you could, pull out the chart and poster showing this data for a moment. According to the FTC data, there is a clear increase in nicotine levels in 1985 and again in 1987. The increase is reflected in the Surgeon General's chart, but not in your chart.

Mr. Spears, is it possible for you to make a mistake in representing the Surgeon General's chart as a basis of your chart before this subcommittee?

Mr. SPEARS. I'd like to say a few things about this. Obviously, there is a lot of confusion. Let me say, number one, what I represented to you was not the very minute detail that you're now talking about, but the fact that tar and nicotine decreased through the period 1950's to the present in a parallel fashion.

Mr. KREIDLER. Dr. Spears, these are the numbers from 1982 to 1990. These are the raw data numbers. Did you look from 1982 going down through 1990 - does that show a decrease or does that show an increase?

Mr. SPEARS. May I finish?

Mr. KREIDLER. Proceed.

Mr. WAXMaN. Just a minute. You're entitled to have an answer to your question.

Mr. KREIDLER. I'm curious. This is the hard data for that 10-year period right now. It's the raw data. Does that show a decrease? Your chart showed it decreasing. This is the raw data. Are those numbers showing a decrease or actually an increase? I think it's hard to say that those represent a decrease. They are, in fact, an increase.

Mr. SPEARS. It's hard to say it represents an increase.

Mr. KREIDLER. But your chart-

Mr. SPEARS. Just a minute. I am not prepared to say that these are the correct data that you're showing me. We have gone back and I have recalculated a lot of this data in view of seeing Dr. Kessler's charts, which alleged significant increases in nicotine and flat levels of tar.

Mr. KREIDLER. I would argue and put forward to you that-

Mr. SPEARS. No. What he showed-

Mr. KREIDLER. We're talking about FTC data that-this isn't something that's been manipulated by somebody else. This is FTC data. If you want to take a look at it and get confirmation, I presume that when you submitted the data that you had had a chance to review it when you presented it to the committee the first time. But this is the hard data from FTC. 
Mr. SPEARS. It's not the hard data from FTC. What it is is FTC data, sales weighted by reports on the sale of the cigarettes.

Mr. KREIDLER. Which is the same data that you were using, correct?

Mr. SPEARS. And you have to do it correctly. I do not believe that Dr. Kessler's work was correct and I said this caused us to go back and look at recalculation of these figures. I cannot confirm Dr. Kessler's graphs.

Mr. KREIDLER. But you still argue at this point and you'd still submit to the committee that the nicotine levels are decreasing, specifically over this last 10 to 15 -year period.

Mr. SPEARS. I did not make that as a profound statement. I made a-

Mr. KREIDLER. You submitted data that would lead us to that conclusion.

Mr. SPEARS. The statement was that nicotine follows tar from the period 1950's to 1990. I stick with that statement and I believe it is accurate. We've gone back and rechecked the calculations.

Mr. KREIDLER. You submitted it as the Surgeon General's chart.

Mr. SPEARS. Now, if you wanted to-

Mr. KREIDLER. Excuse me, Dr. Spears, but you submitted this as a Surgeon General's chart. Is it or is it not the Surgeon General's chart?

Mr. SPEARS. This chart came from the Surgeon General's report that was identified, yes.

Mr. KREIDLER. Was it presented accurately? Why does it-for the last 10-year period, why does your chart show that the levels are decreasing when, in fact, the data shows us they're increasing?

Mr. SPEARS. It looks to me like-

Mr. KREIDLER. And the Surgeon General's chart also shows that.

Mr. SPEARS. It looks to me like my chart might show a 10 percent decrease. But the data you put up there might show a zero or certainly much less than a 10 percent increase and the Reynolds picture shows that it's slightly decreasing or flat.

Mr. WAXMAN. Mr. Kreidler, your time has expired.

Mr. KREIDLER. Thank you very much, Mr. Chairman.

Mr. WAXMAN. You may want to catch that vote. The Chair will recognize himself for the next round of questioning. I have in front of me a copy of-Mr. Spears, you might want to stay there. I have a copy of a 1981 report written by Mr. Alexander W. Spears, the vice chairman of Lorillard. Without objection, it will be entered in the record as Exhibit 12.

[Testimony resumes on p. 715.]

[Exhibit 12 follows:] 

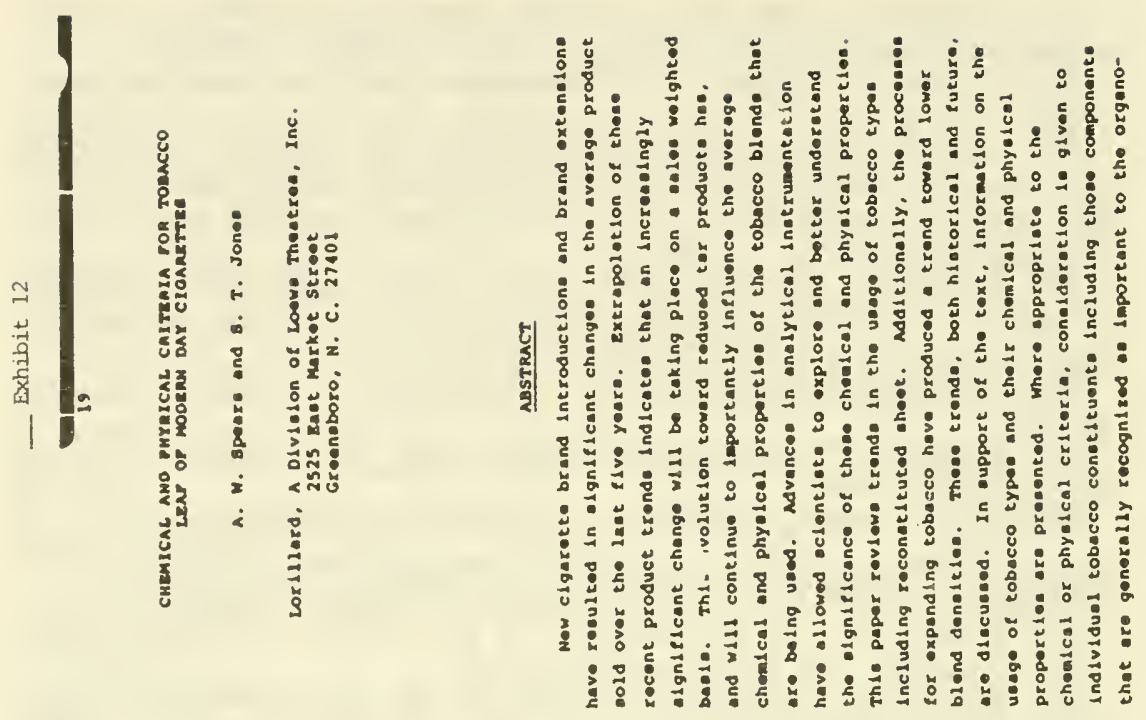


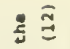

送

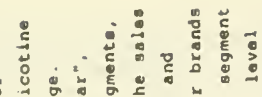

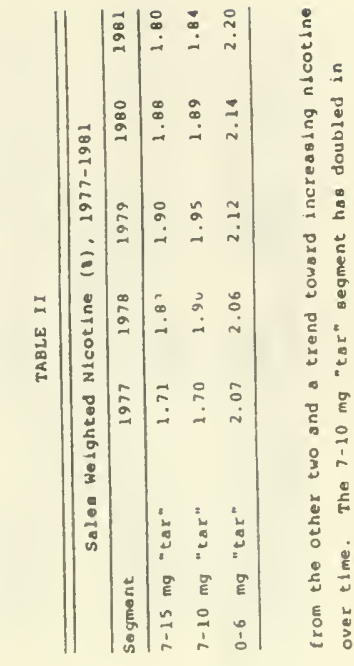

$\approx \quad 0.0$

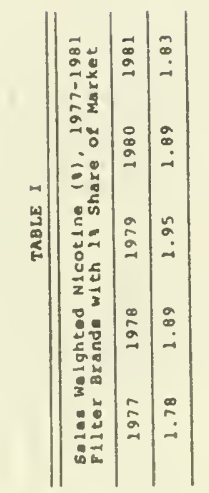

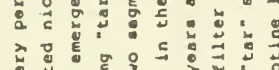

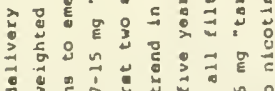

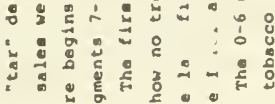

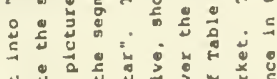

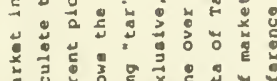

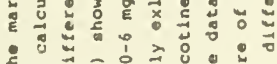

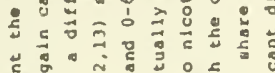

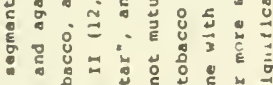

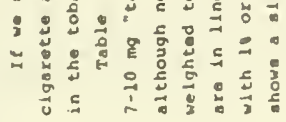

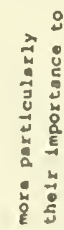

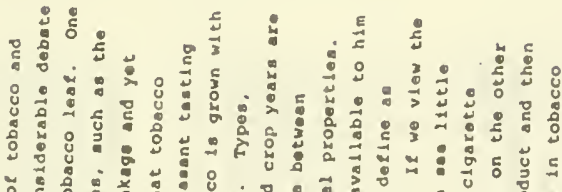

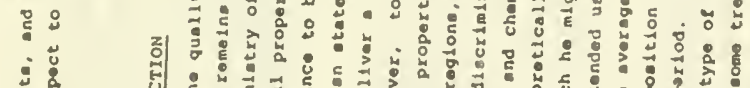
ว

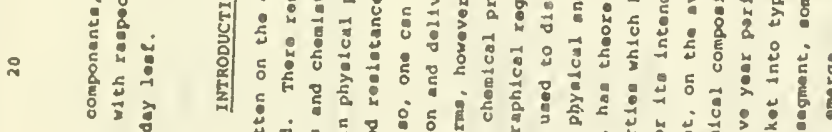
ชิ

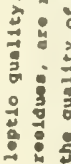
II

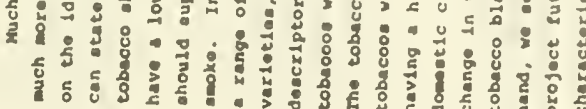

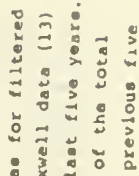

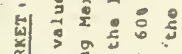

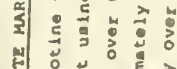

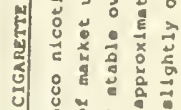
쑹 ๖ำ 㟢示

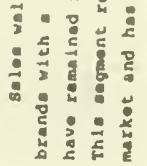


5

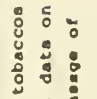

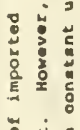

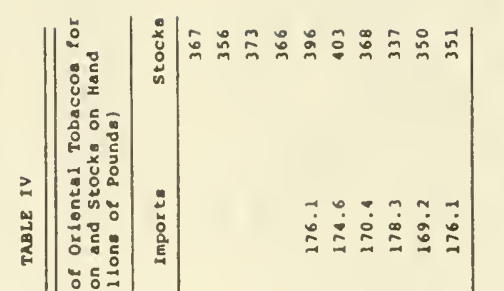

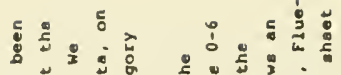

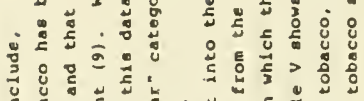

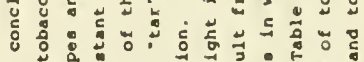
× 马

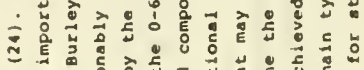

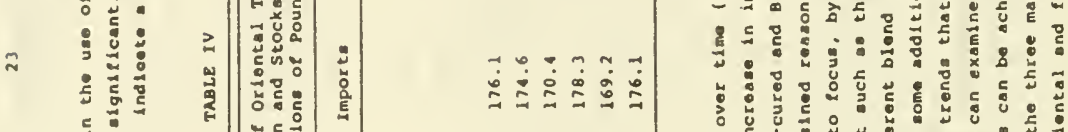

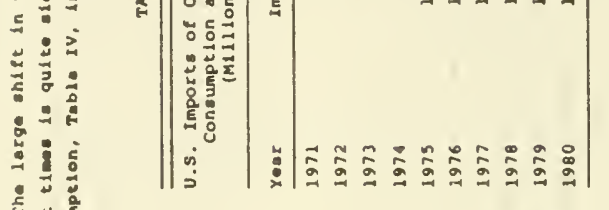
ำ

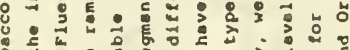

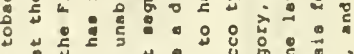

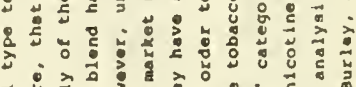

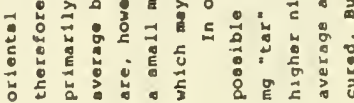

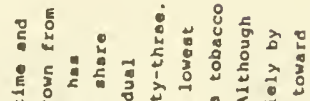
ว

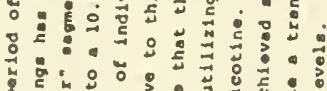

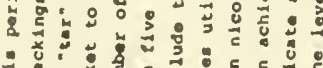

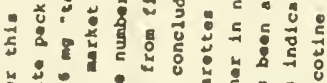

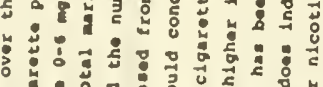
N تี

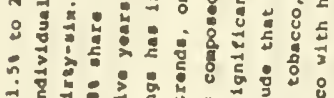
二

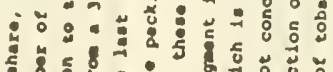
ช

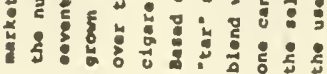

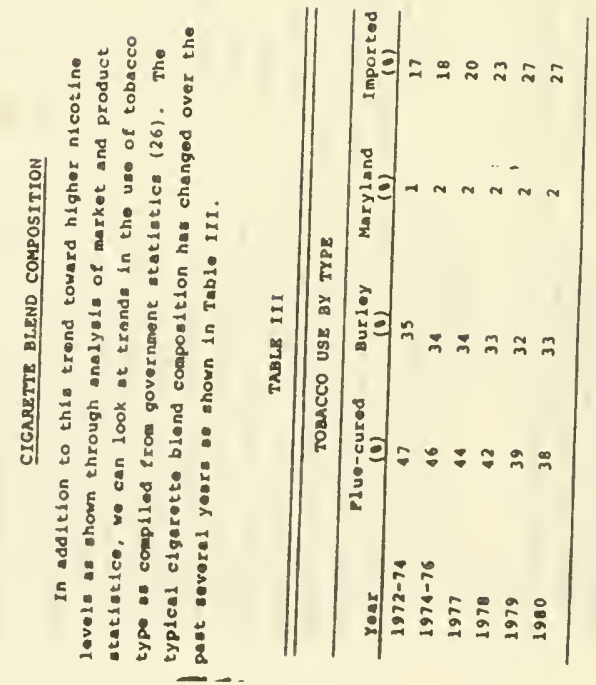



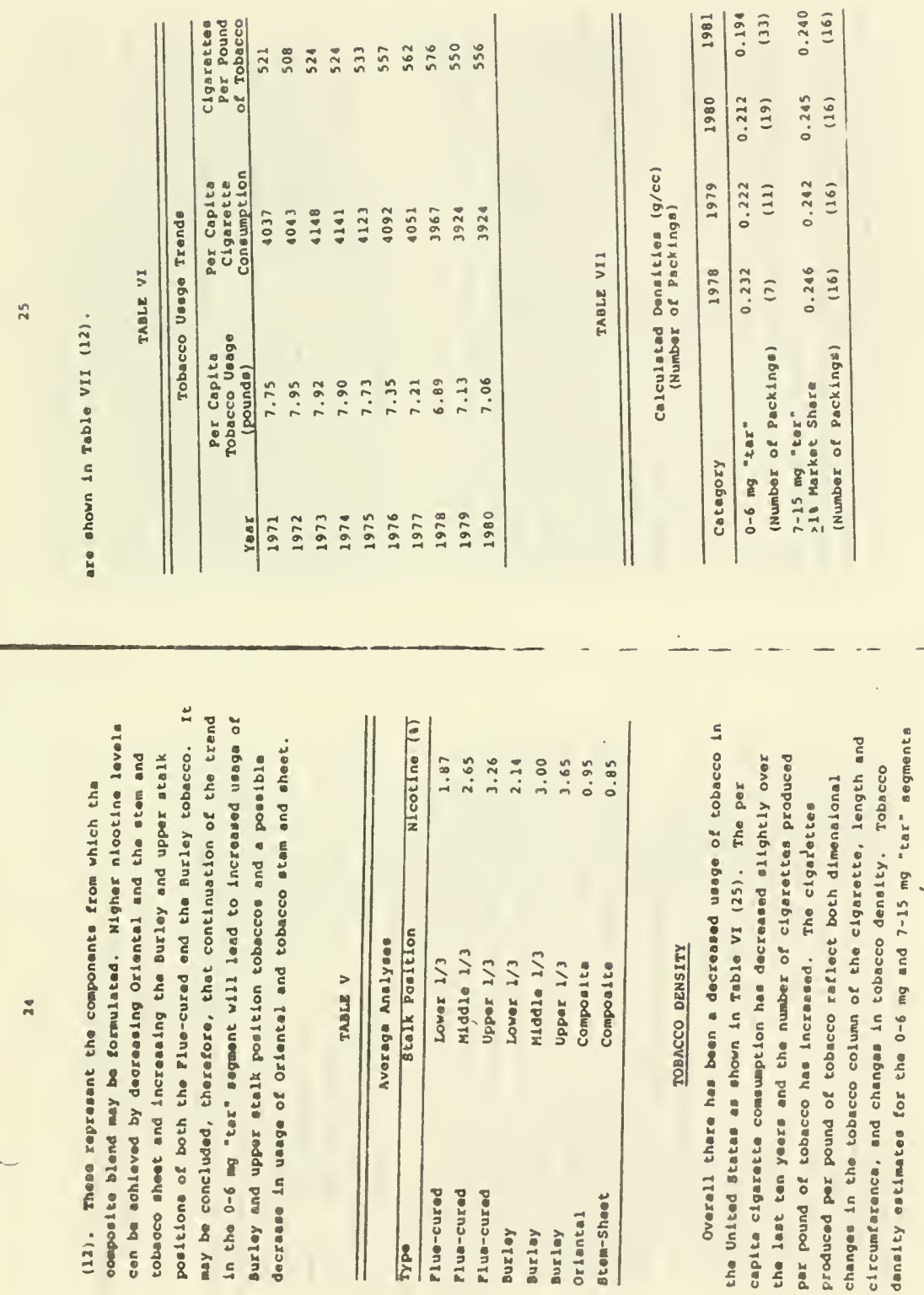


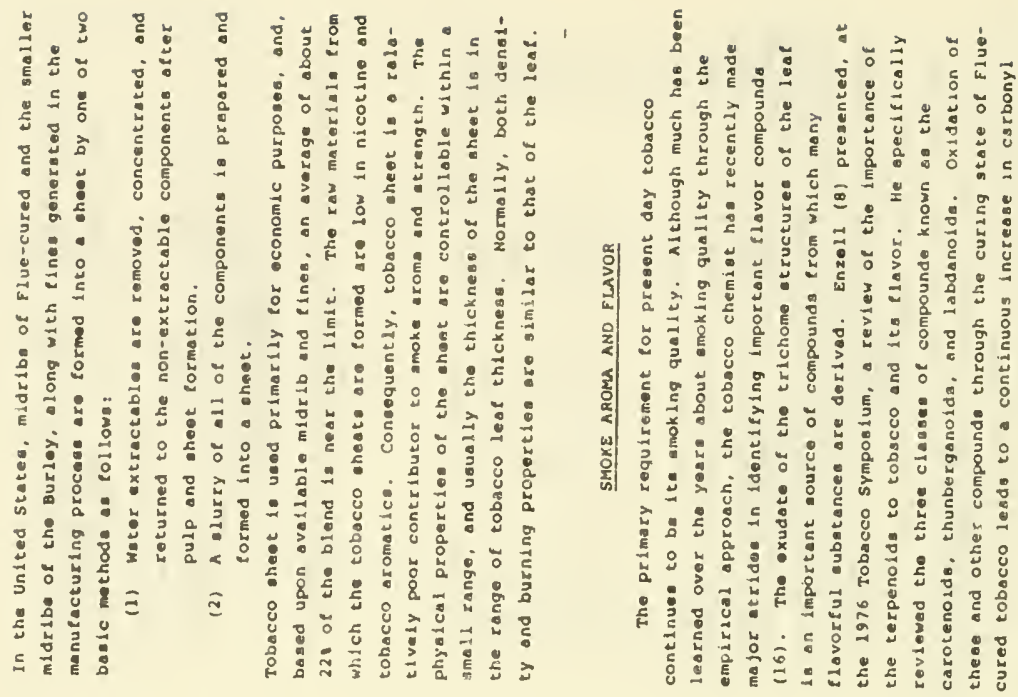

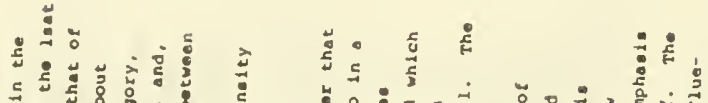

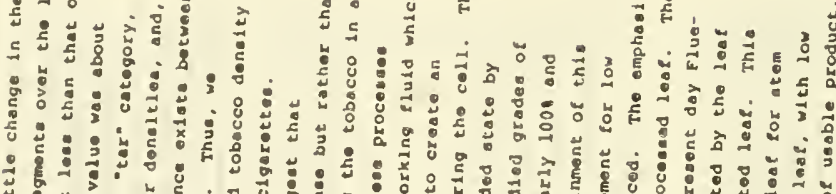

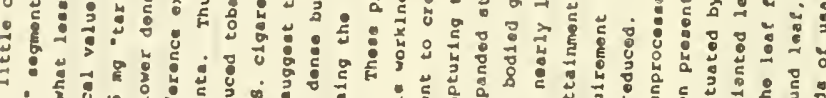

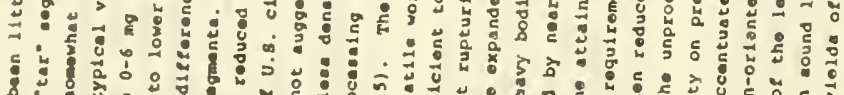
(n)

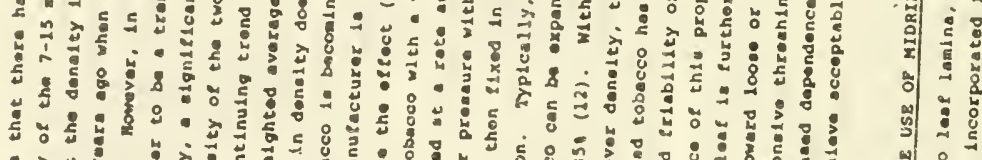
In)

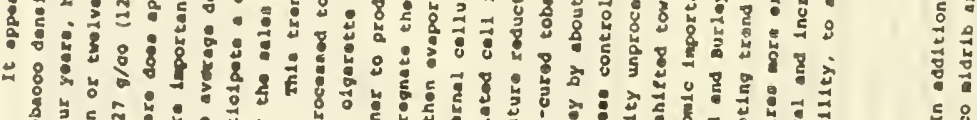

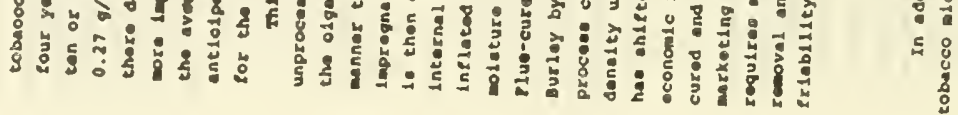



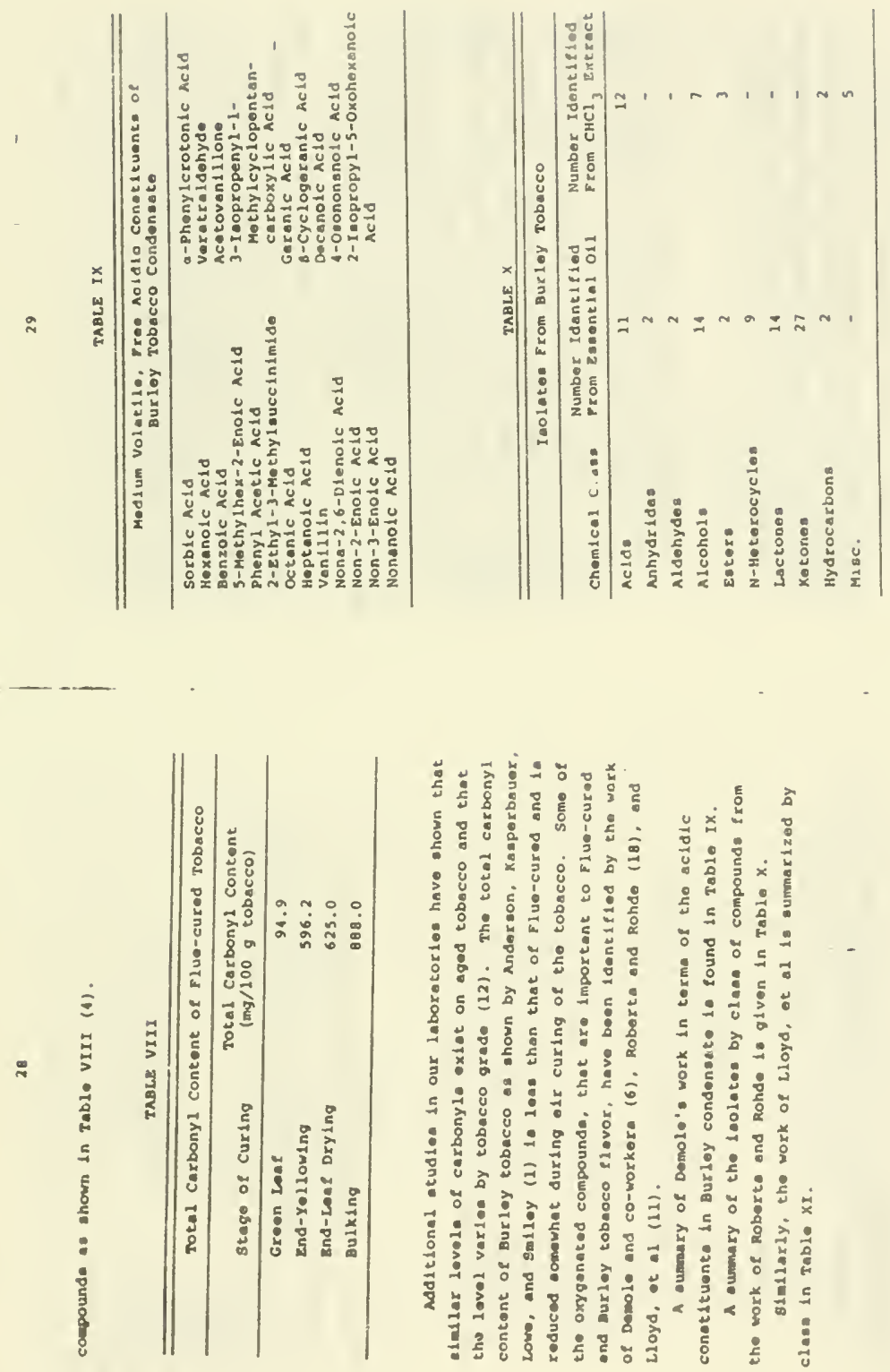


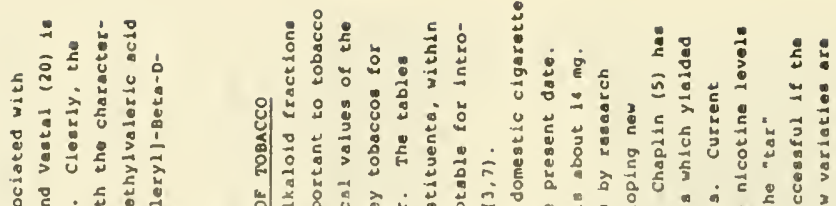

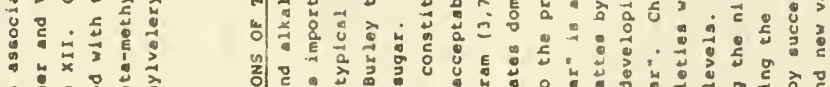

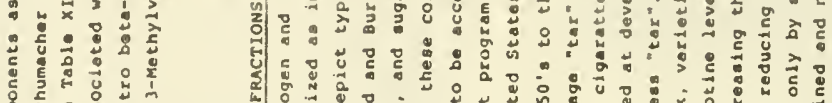

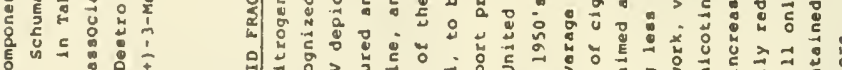
施:

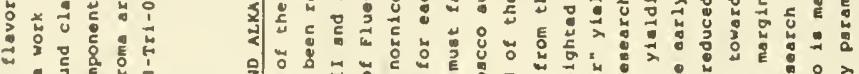

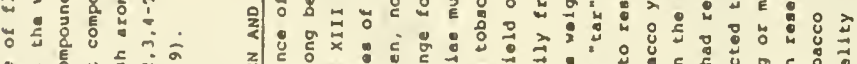

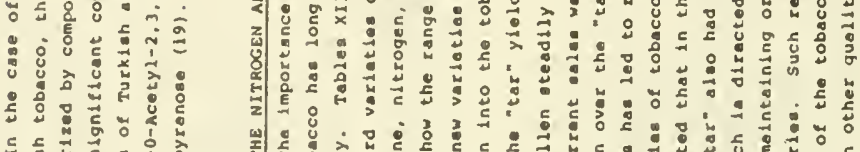

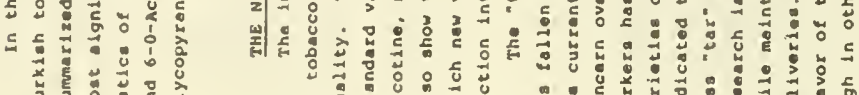

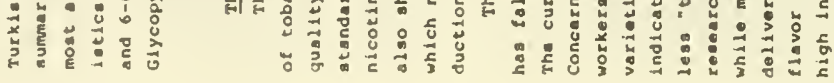
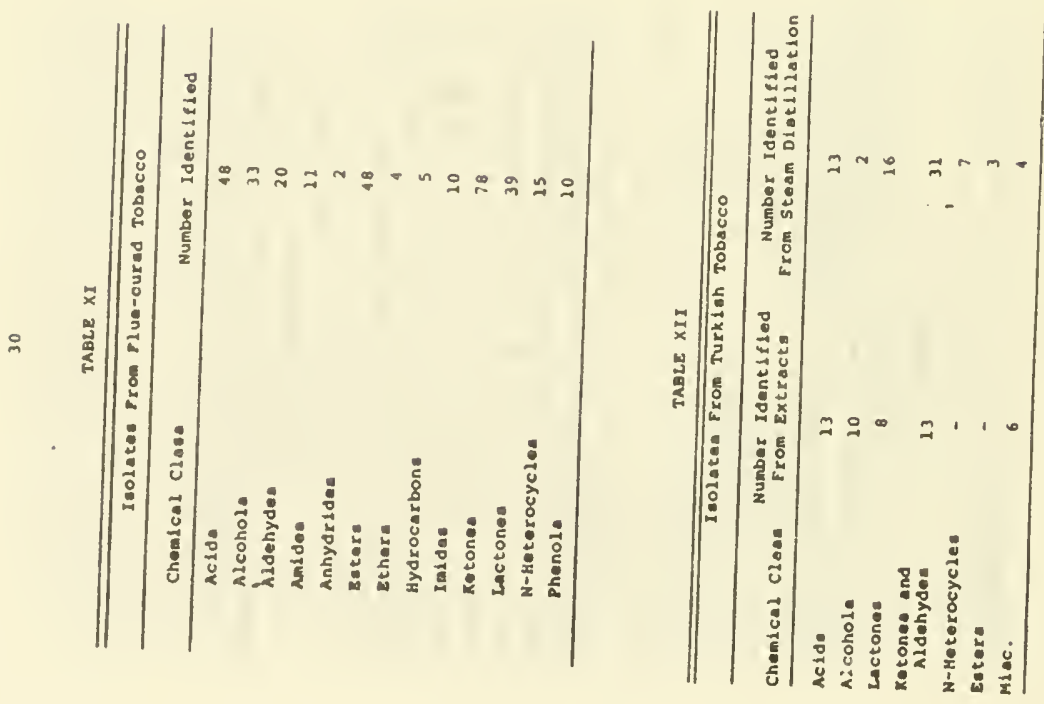

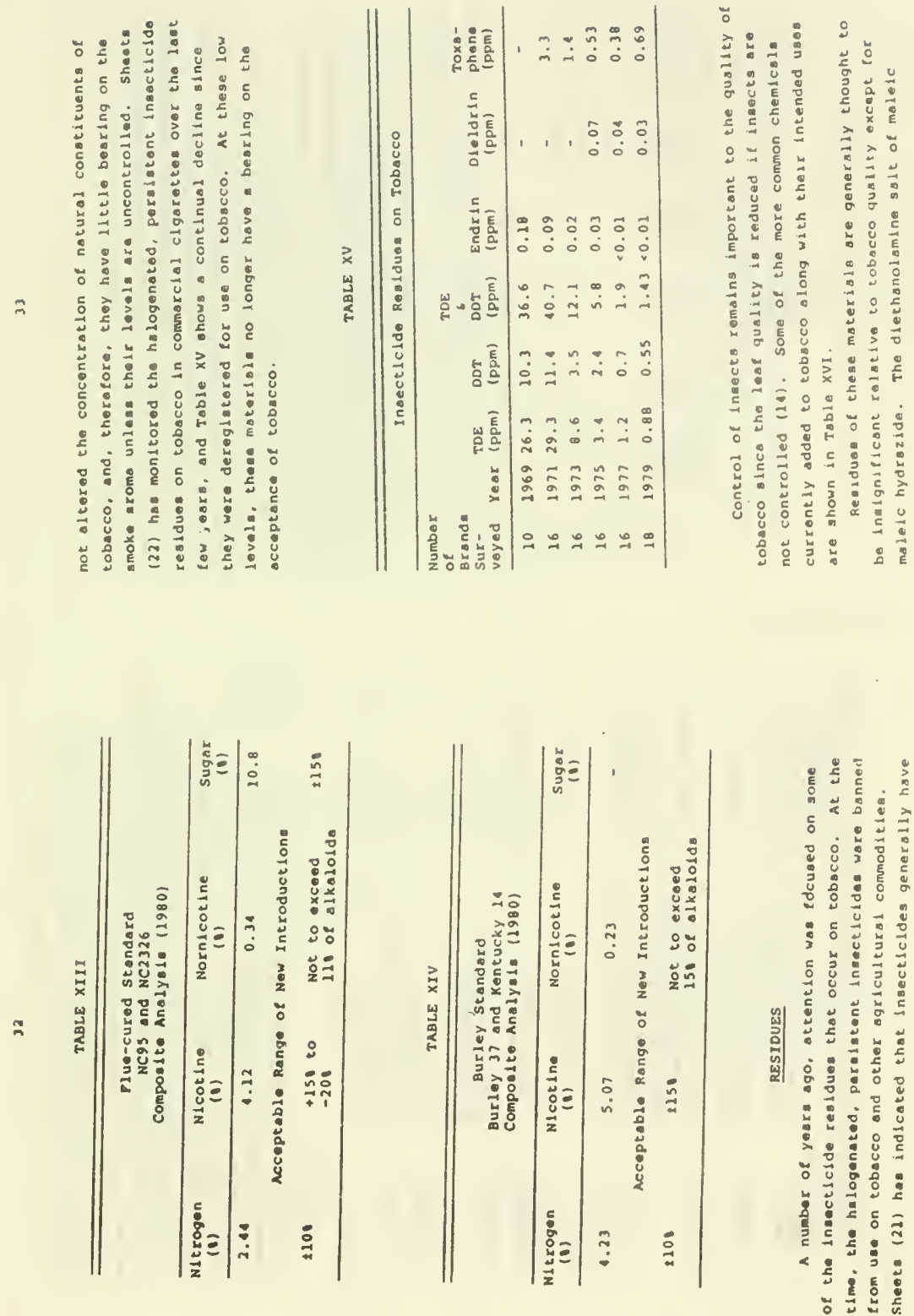

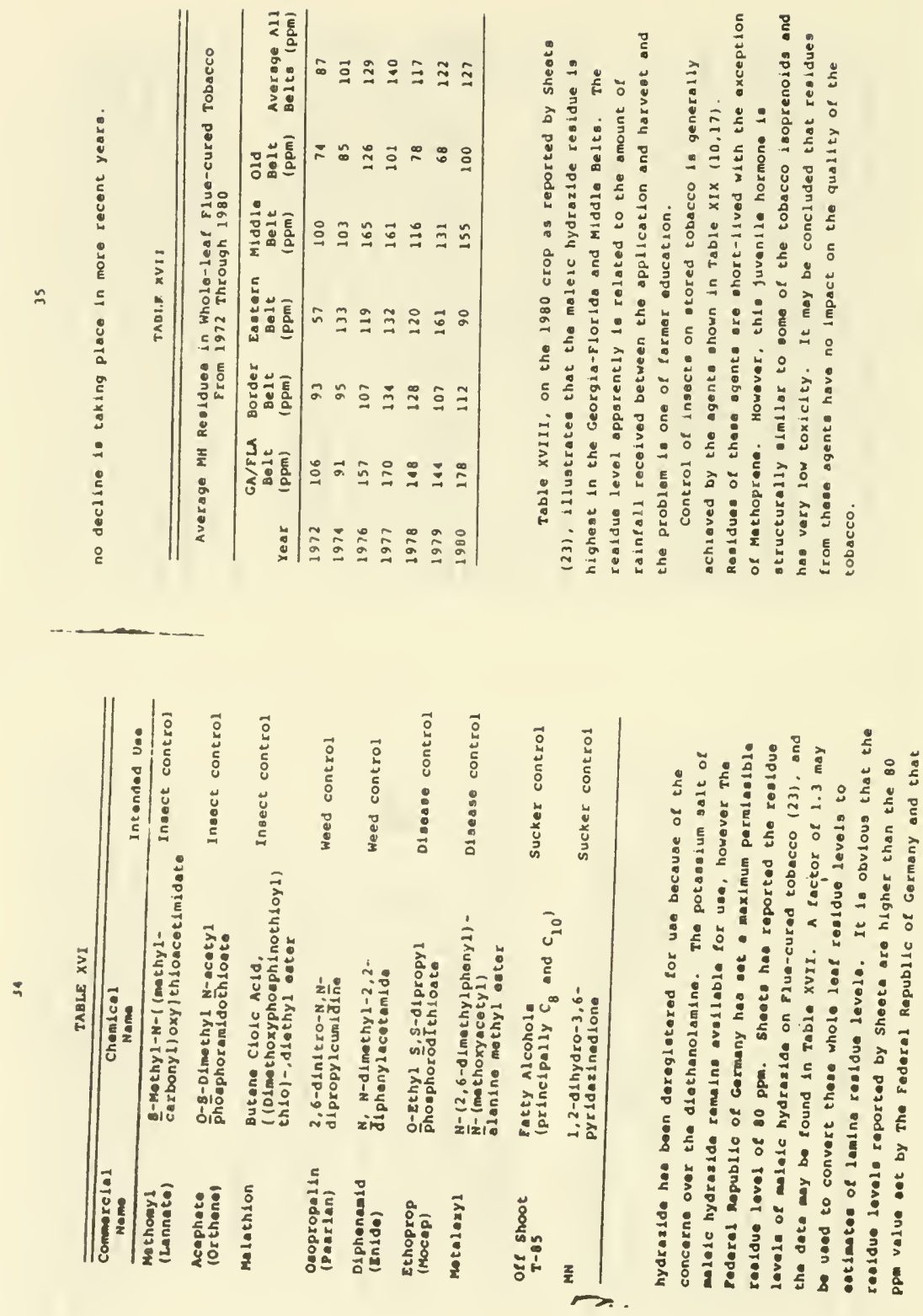


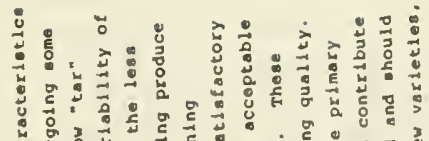

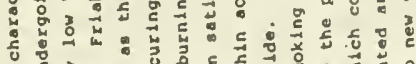

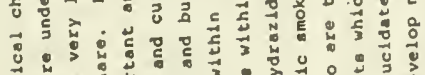

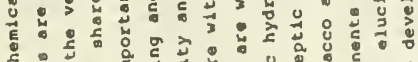

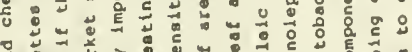

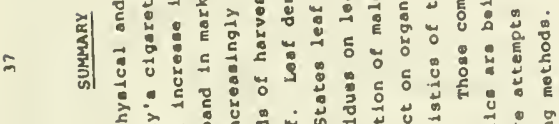

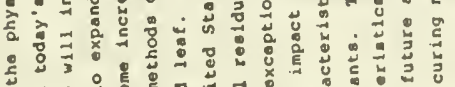

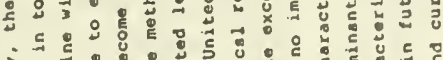

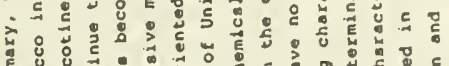

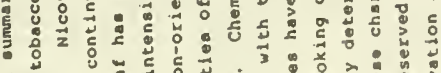

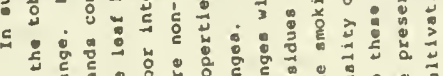

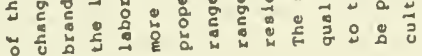

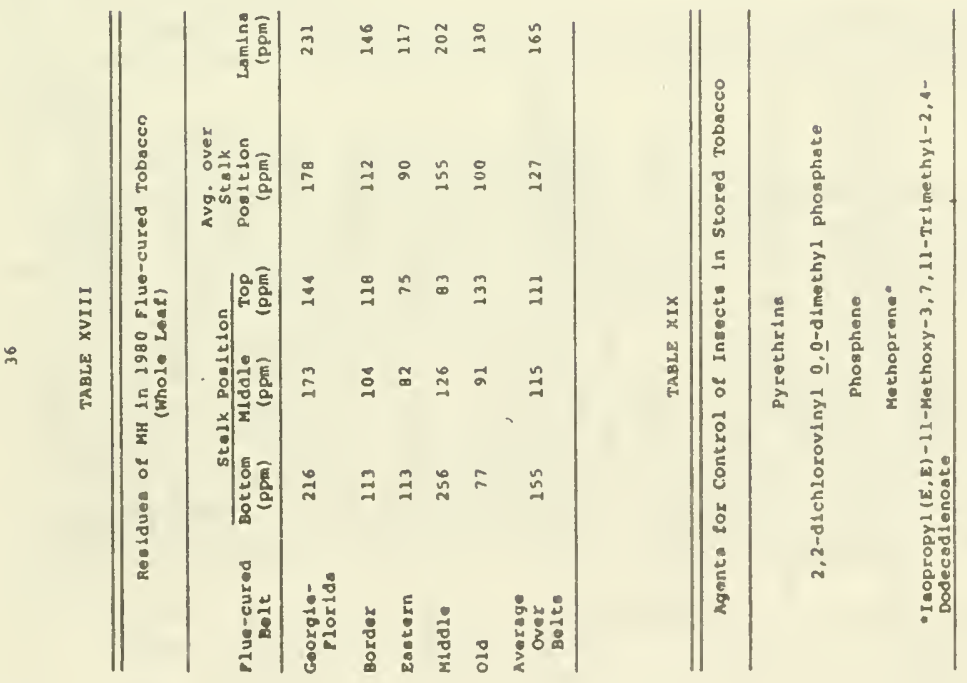



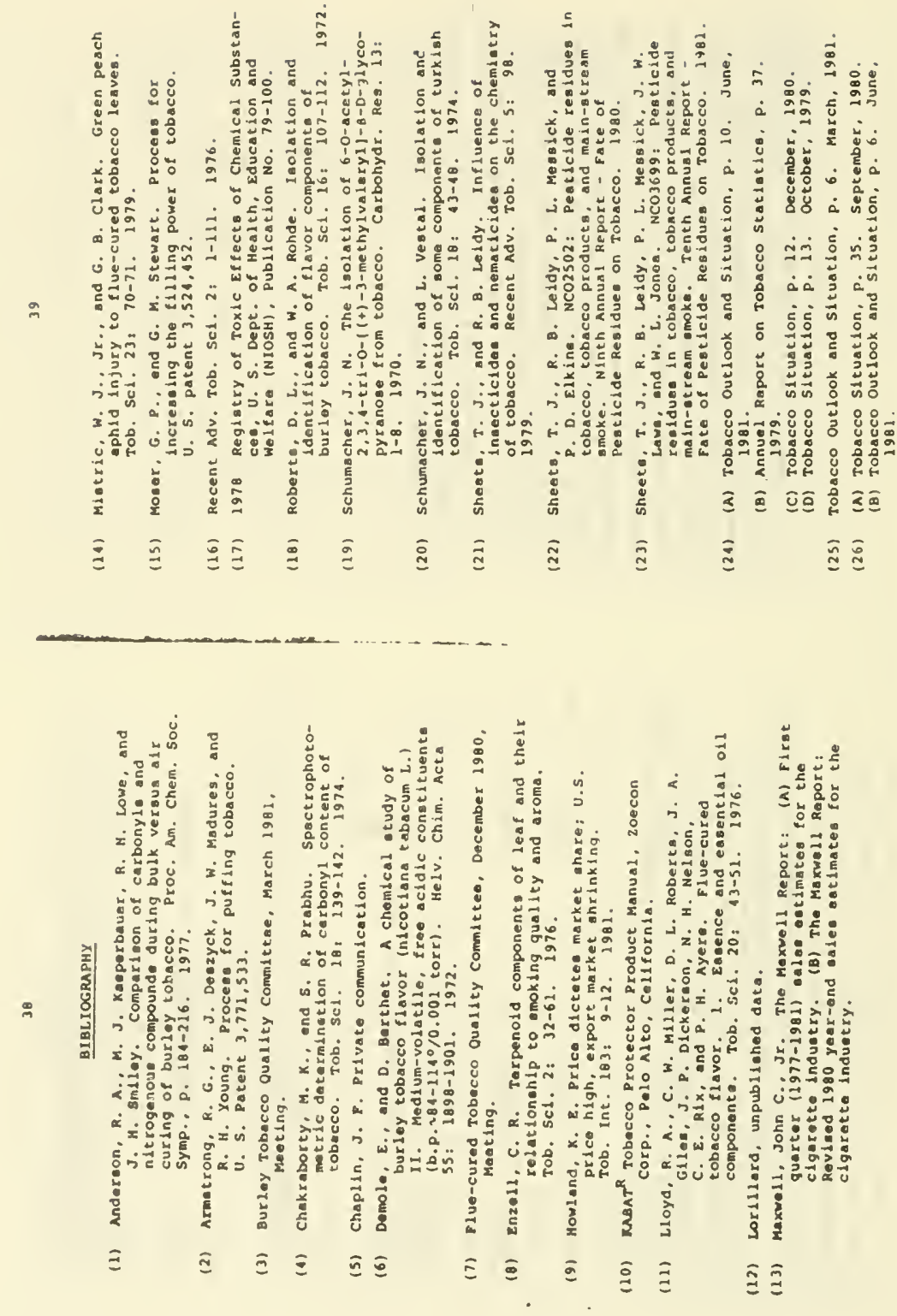
Mr. WAXMAN. This article says that nicotine levels can be increased through the blending process. Specifically, the article concludes, and I quote, "Higher nicotine levels can be achieved by decreasing oriental and the stem and tobacco sheet and increasing the burley and upper stock positions of both the flue-cured and the burley tobacco."

Mr. Spears, did you write this article?

Mr. SPEARS. I believe you're referring to the article that I wrote in 1981 , yes.

Mr. WAXMAN. That's correct.

Mr. SPEARS. Which appeared in the Advances in Tobacco Science symposium of the 35th Tobacco Chemist Conference. Is that correct?

Mr. WAXMAN. That's the one I'm referring to.

Mr. SPEARS. I wrote that.

Mr. WAXMAN. Do you agree that cigarette makers can adjust the level of nicotine in cigarettes through the process of blending different types of tobacco?

Mr. SPEARS. Mr. Waxman, I have prepared a statement in view of your press conference yesterday and if you'll permit me, I'd like to present that statement.

Mr. WAXMAN. We'll be pleased to-

Mr. SPEARS. It deals with this subject and a couple of others. It deals with this subject.

Mr. WAXMAN. I understand it deals with this subject. We'll be pleased to receive the statement for the record. Is it a lengthy presentation?

Mr. SPEARS. No, it's not.

Mr. WAXMAN. Then, please, go ahead.

Mr. SPEARS. Thank you, Mr. Chairman and members of the subcommittee, for the opportunity to speak. I will try to be brief, but I must take this opportunity to clarify some issues that Dr. Kessler introduced at the March 25 hearing and that you, Mr. Chairman, raised at a press conference yesterday.

I have four specific points that I'd like to address. I stated in my earlier testimony that nicotine follows tar and used the latest FTC tar and nicotine yields to prove this point. The correlation coefficient between tar and smoke nicotine data for all commercial brands measured was 0.975 . That has not changed and I have not heard any challenge to it. This, of course, includes ultra-low tar brands.

I also showed the changes in the sales weighted tar and nicotine values of the commercial brands from the 1950's to 1990 . Reductions in tar were followed by reductions in nicotine of similar percentages. Dr. Kessler showed charts at the Miarch 25 hearing indicating that sales weighted smoke nicotine has been increasing since 1982 and that tar has undergone little or no change.

My staff cannot duplicate the data used to construct Dr. Kessler's charts and I stand by my prior charts and testimony on this subject. Smoke nicotine follows tar to a very high degree among the commercial brands.

Second point, nicotine concentration in tobacco should not be confused with nicotine smoke yields as measured by the FTC method. Ultra-low tar cigarettes are also ultra-low smoke nicotine ciga- 
rettes. The nicotine concentration in the tobacco is not correlated to FTC tar and smoke nicotine yields. That is differences in tobacco nicotine concentrations are not correlated to smoke nicotine yields in the cigarette.

The filter, the filter-tipped ventilation, density of the tobacco are the principal factors that control the nicotine smoke yield.

Mr. Chairman, you told the press and the public yesterday that a 1981 publication of mine, which was just referred to, reported higher concentrations of nicotine in the tobacco of very low tar cigarettes, meant that smokers of these cigarettes receive high yields of nicotine. This is not true.

The ultra-low brand cigarette was defined in my paper as a 0 to 6 milligram tar segment. The Federal Trade Commission nicotine yield of this segment are also the lowest among commercial brands. Smoke nicotine follows tar.

Third, the cigarette tobacco blends are formulated to try to achieve taste acceptance, brand distinction and preference within the smoker franchise. The fact that nicotine concentrations vary among the compounds or components used to formulate the blend has been discussed in the Surgeon General's report and many other publication besides my 1981 paper.

The fact that commercial cigarette blends vary in nicotine concentration should not be treated as a revelation by this committee. The practice of using tobacco blend differences to establish unique taste characteristics have given rise to all Turkish cigarettes, the American blended cigarette, the black tobacco cigarette of France and so forth.

This centuries old practice is well known and cannot be construed as manipulation of nicotine.

For the purpose of this committee or those of Dr. Kessler, the suggestion that my 1381 article provides evidence of nicotine manipulation, as stated in your press conference, Mr. Chairman, appears to result from a total misunderstanding of the data, design and manufacture of cigarettes from an agricultural commodity in varying compositions.

I've also looked at your staff report on that 1981 article and I would like to address two specific things there. One, they indicated that this article suggested that there was ongoing research in the industry to raise the nicotine level of tobacco so that nicotine would be higher than tar.

That was work that came out of, I think, the Tobacco Working Group of the National Cancer Institute, was being conducted by the USDA and the land grant universities in the tobacco growing States. It had nothing to do with the manufacturers or this industry. Inference that it was the manufacturers by the staff report is totally incorrect.

I'll stop there, if you have other questions.

[The prepared statement of Mr. Spears follows:]

\section{Statement of Alexander W. Spears, Vice Chairman and Chief Operating OFFICER, LORILLARD TOBACCO COMPANY}

Mr. Waxman and members of the subcommittee, thank you for the opportunity to speak. I will try to be brief, but I must take this opportunity to clarify some issues that Dr. Kessler introduced at the March 25 hearing and that you, Mr. Chair- 
man, raised at a press conference yesterday. I have four specific points that will be addressed.

No. 1, I stated in my earlier testimony that nicotine follows tar, and used the latest FTC tar and nicotine yields to prove this point. The correlation coefficient between the tar and smoke nicotine data for all commercial brands measured was 0.975 . This, of course, includes ultra low tar brands. I aiso showed the changes in sales-weighted tar and smoke nicotine values of commercial brands from the 1950's to 1990. Reductions in tar were followed by reductions in nicotine of similar percentages. Dr. Kessler showed charts at the March 25 hearing indicating that salesweighted smoke nicotine has been increasing since 1982, and that tar has undergone little or no change. My staff cannot duplicate the data used to construct Dr. Kessler's charts, and I stand by my prior charts and testimony on this subject. Smoke nicotine follows tar to a very high degree among the commercial brands.

No. 2, Nicotine concentration in tobacco should not be confused with nicotine smoke yields as measured by the FTC method. Ultra low tar cigarettes are also ultra low smoke nicotine cigarettes. The nicotine concentration in the tobacco is not correlated to FTC tar and smoke nicotine yields because the amount of tobacco in the cigarette, the filter and filter tip ventilation are the principle factors that control nicotine smoke yield. Mr. Chairman, you told the press and the public yesterday that a 1981 publication of mine which reported higher concentrations of nicotine in the tobacco of very low tar cigarettes meant that smokers of these cigarettes received high yields of nicotine. This is not true. The ultra low tar cigarette brand segment of market was defined by my paper as the 0.6 tar segment. The FTC nicotine yields of this segment are also the lowest among commercial brands. Smoke nicotine follows tar.

No. 3, Cigarette tobacco blenàs are formulated to try to achieve taste acceptance, brand distinction, and preference within the smoker franchise. The fact that nicotine concentrations vary among the components used to formulate the blend has been discussed in a Surgeon General report and many other publications besides my 1981 paper. The fact that commercial cigarette blends vary in nicotine concentration should not be treated as a revelation by this committee. The practice of using tobacco blend differences to establish unique taste characteristics have given rise to the all Turkish cigarette, the American blended cigarettes, the black tobacco cigarette of France, etc. This centuries-old practice is well-known and cannot be construed as manipulation of nicotine for the purposes of this committee of those of Dr. Kessler. The suggestion that my 1981 article provides evidence of nicotine manipulation as stated in your press conference, Mr. Chairman, appears to result from a total misunderstanding of the data, design, and manufacture of cigarettes from an agricultural commodity with varying composition.

No. 4, The last point relates to your staff s analysis of $\mathrm{my} 1981$ paper. They indicated that this paper reported that the industry was doing research to increase the nicotire level, while keeping the tar level constant. The reference to this in the perer relates to an idea that came from the Tobacco Working Group of the NCI and others. It pertains to research toward the development of new varieties of tobacco at the USDA experiment stations and the universities in the tobacco growing States. it was not research being conducted by the manufacturers and cannot be related to manipulation of nicotine by the manufacturers.

Mr. WAXMAN. Thank you. Without objection, I'm going to start my time from the period at which you've ended. Dr. Spears, your article said that increased nicotine is in the lowest yield cigarette. It's indisputable that there is more nicotine in the cigarette. There's more nicotine in the smoke, as well. Furthermore, you're relying on FTC numbers which, I would submit, are not meaningful because they don't relate to what the smoker actually takes in.

I have a line of questions on that point and I want to get to that in a minute.

Mr. SPEARS. May I say something? I disagree with what you just said, that it's indisputable that the concentration of nicotine in tobacco relates to what's in the smoke. The question is does the concentration of nicotine in tobacco relate-differences in that concentration relate to what's in the smoke. 
Mr. WAXMAN. If you raise the level of nicotine in the cigarette, all other things being equal, it would raise the level of nicotine in the smoke. Do you disagree with that statement?

Mr. SPEARS. If all other things were equal, but they are not.

Mr. WAXMAN. We'll get into that in a minute. You wrote in this article that higher nicotine levels can be achieved by decreasing oriental and the stem and tobacco sheet and increasing the burley and upper stock positions of both the flue-cured and the burley tobacco.

Do you agree that cigarette makers can adjust the level of nicotine in cigarettes through the process of blending different types of tobacco?

Mr. SPEARS. People will get different nicotine concentrations in the tobacco depending upon the specific blend, yes.

Mr. WAXMAN. Now, I want to ask if everyone on this panel agrees. Do each of you agree that you can adjust the level of nicotine in your cigarettes through the blending process? Mr. Johnston?

Mr. DONALD JOHNSTON. Yes, Mr. Chairman.

Mr. WAXMaN. Mr. Sandefur?

Mr. SANDEFuR. Depending on the availability of the blend constituents, yes, you can.

Mr. WAXMAN. Mr. Horrigan?

Mr. HORRIGAN. The same response as Mr. Sandefur.

Mr. WAXMAN. Mr. Taddeo, do you agree?

Mr. TADDEO. In smokeless tobacco products, you can vary it.

Mr. WAXMAN. Mr. Johnston?

Mr. JAMES JOHNSTON. Yes, Mr. Chairman.

Mr. WaXman. You agree. And Mr. Campbell?

Mr. CAMPBEll. Just a moment, please. No. It's important to remember that the concentration can be changed, but it is the absolute level in low delivery cigarettes that is all important. We're talking about-

Mr. WAXMAN. Do you agree that you can adjust the level of nicotine in your cigarettes through the blending process?

Mr. CAMPBELl. Yes.

Mr. SPEARS. Mr. Chairman, would you say concentration and not nicotine level? Then I can agree with you.

Mr. WAXMAN. You have each told us that you can have the potential to adjust the nicotine levels

Mr. SPEARS. Concentration.

Mr. WAXMaN. Concentration or levels-through blending. What I'd like to know is whether you have actually exercised this control. Mr. Johnston, let me begin with you, whether you've actually exercised this control.

Mr. JAMES JOHNSTON. Mr. Chairman, we do not design our cigarettes with any nicotine levels in the specifications. We design our cigarettes, this is very important, for tar levels, usually within a band. It might be a light cigarette within that band or sometimes a specific tar level objective and the nicotine flows from there, because filtration takes-

Mr. WaXMan. You have the ability to control it. Your answer is you have controlled it, but for other reasons. Is that a fair statement of your answer? 
Mr. JAMES JOHNSTON. We design our products and we control for tar, as we are required to do.

Mr. WAXMAN. Last night, one of your officials, Mr. Suber, appeared on CNN. Mr. Suber was asked whether your company manipulates the level of nicotine, and this is what he said. "In order to deliver to the consumer a product that he wants, a consistent level of nicotine, we have to blend the tobacco's accordingly. So we do control it."

Mr. Johnston, do you agree with Mr. Suber? He says that in order to deliver the consumer a consistent level of nicotine, which is what the consumers want, you do control nicotine levels. What is your answer? Do you agree or not?

Mr. JAMES JOHNSTON. As I said both in the written statement and in my oral statement-

Mr. WAXMAN. No. I want to know whether you are disagreeing or agreeing with Mr. Suber's statement as I just read it to you.

Mr. JAMES JOHNSTON. I'm telling you what I agree with.

Mr. WAXMAN. No. I want a yes or no. Do you agree or do you disagree?

Mr. JAMES JOHNSTON. Please restate the question.

Mr. WAXMAN. I'm sorry. What did you answer?

Mr. JAMES JOHNSTON. Please restate the question.

Mr. WaXman. Do you agree or disagree with Mr. Suber's statement that I quoted for you from his interview on CNN, where he said "In order to deliver to the consumer a product that he wants, a consistent level of nicotine, we have to blend the tobaccos accordingly. So we do control it."

Mr. JAMES JOHNSTON. I disagree with that wording of the statement, yes.

Mr. WAXMAN. You disagree with him.

Mr. JAMES JOHNSTON. Yes.

Mr. WAXMAN. I'd like to ask the other members of the panel. Well, staff is raising a good point. Mr. Suber works for you, doesn't he?

Mr. JAMES JOHNSTON. Yes, he does.

Mr. WAXMAN. And he was representing your company on television last night as a spokesman.

Mr. JAMES JOHNSTON. Yes, sir, he was.

Mr. WAXMAN. How could he make a statement with which you disagree on such a fundamental point?

Mr. JAMES JOHNSTON. It's not a fundamental point. It's a choice of how he phrased it. What I've tried to communicate, Mr. Chairman, is what we do design and manufacture our cigarettes for is to tar specifications. As I said in my statement, we monitor and measure both tar and nicotine and they come right in line, and we are required-

Mr. WAXMaN. Well, Mr. Suber says that the smoker wants a consistent level of nicotine. Nicotine, not tar. You can't assure a consistent level of nicotine without controlling the level of nicotine, can you?

Mr. JAmes Johnston. That's what I disagree with, Mr. Chairman. Our smokers want a consistent product. They want the Winston that they smoke today to be like the Winston they smoke tomorrow, like the Winston they smoke in California or the Winston 
they smoke in Oklahoma or the Winston they smoke in North Carolina.

Further, our tar and nicotine numbers are in every advertisement and we have tried to-

Mr. WAXMAN. You're going through all your protestations, but you have a spokesman from your company who made a statement. You're saying he was incorrect in his statement. Now, we know that-we know from Dr. Spears that if you adjust the level of tar, it might not change-it generally changes the level of nicotine, but that can be changed through blending. You don't disagree with that, do you?

Mr. JAMES JOHNSTON. I don't disagree with that whatsoever.

Mr. WAXMAN. You do disagree, however, with your own spokesman from your company that says that the consumer wants this level consistent and, therefore, they blend to reach that consistent level.

Mr. JAMES Johnston. Mr. Chairman, I don't even know the context of his remarks. I might look at them in context and come back and tell you I precisely agree with him. It can be one sentence that I wasn't there to hear. I'm telling you that as you read it to me, Mr. Chairman, I do disagree with it.

Our customers, our smokers want Winston to taste like Winston yesterday, today and tomorrow, as any consumer products manufacturer would do, and we want to comply with the law. Our advertisement has our tar and nicotine level in it. We file it with the FTC and we are obligated to do our best to deliver precisely that.

Mr. WAXMAN. Let me read to you precisely what Mr. Suber, the representative from RJR Tobacco Company, said. "In order to deliver to the consumer a product that he wants, a consistent level of nicotine, we have to blend the tobaccos accordingly. So we do control it. We have advertising that states what the level of nicotine is and the level of tar. Therefore, we have to control this. Otherwise, we're in violation of advertising regulations."

Do you agree with that statement now that you've

Mr. JAMES JOHNSTON. I agree with everything that is in that quote with the exception that the consumer wants a consistent level of nicotine. In fact, what happens in a natural agricultural product is that there are crop-to-crop variations. There are rounding. We're dealing with such small numbers here that in our lowest tar products, a one-tenth milligram rounding, and we are required by the FTC to round, can change the number by 50 percent and actually you've only changed the number by 1 percent.

Mr. WAXMAN. When you control the level for tar, does nicotine go along with it?

Mr. JAMES JOHNSTON. In a rough proportion. It is not a direct proportion because filters are slightly more effective at reducing particulate matter than they are vapor matter. Nicotine comes through in both forms. More of it is filtered out in the particulate form, but less in the vapor form. So it's not-

Mr. WAXMAN. So if you're trying to get a consistent level of nicotine and they don't go precisely together, you have to adjust nicotine levels separately, don't you?

Mr. JAMES JOHNSTON. No. No.

Mr. WAXMAN. You haven't told Mr. Suber that. 
Mr. JAMES Johnston. Mr. Suber-

Mr. WAXMAN. Dr. Spears indicated in his statement-his article, rather, that I released yesterday, that through a blending process, the nicotine levels can be changed. You've indicated that you agree with that.

Mr. JAMES JOHNSTON. I know of no such article.

Mr. WAXMAN. Let's start again. You know Mr. Suber, don't you? Mr. JAMES JOHNSTON. I do, indeed.

Mr. WAXMAN. Yesterday, there was a discussion of an article issued by Dr. Spears. You have not been made aware of that article.

Mr. JAMES JOHNSTON. You said Dr. Suber's article.

Mr. WaXMan. Dr. Spears.

Mr. JAMES JOHNSTON. I said there is no such -

Mr. WAXMAN. You're aware that Dr. Spears wrote an article in 1981.

Mr. JAMES JOHNSTON. Now that we have the correct person, yes, Mr. Chairman, I am aware of that.

Mr. WAXMAN. Now, he indicated that through a blending process of tobaccos, the nicotine concentrations or levels can be changed and often are separately adjusted from the tar levels. Do you do that?

Mr. JAMES JOHNSTON. Repeat the question.

Mr. SPEARS. That statement is not found in my article that you can separately adjust tar and nicotine.

Mr. WAXMAN. Let me read to you your article. "Based on these trends, one would conclude that the lowest tar segment is composed of cigarettes utilizing a tobacco blend which is significantly higher in nicotine. Although one cannot conclude that this has been achieved solely by the selection of tobacco, it does indicate a trend toward the use of tobacco with higher nicotine levels." That's page 22.

Mr. SpeARS. Yes, sir. But you said that this indicates you could separate tar from nicotine. tine.

Mr. WAXMAN. That you can adjust separately the tar and nico-

Mr. SPEARS. It does not indicate that.

Mr. WAXMAN. We're talking about the lowest tar cigarettes.

Mr. SPEARS. I understand.

Mr. WAXMAN. Does your article say or not say that those can also be the highest nicotine concentrations?

Mr. SPEARS. In concentration in the tobacco, but not in the nicotine yield of the cigarette smoke.

Mr. WAXMAN. And the

Mr. SPEARS. Let's not confuse it any further, if I may.

Mr. WAXMAN. When you say the nicotine content in the smoke is separate from the cigarette, that seems to me a very strange notion.

Mr. SPEARS. I'm trying.

Mr. WAXMAN. If you're going by the FTC -

Mr. SPEARS. Let me explain it to you.

Mr. WAXMAN. No. I'm going to get into that whole question, but I want to do it in an orderly way. We're going to get to that. Let me just say that's a very strange notion and we're going to examine that more carefully. 
It defies anybody's understanding of a concentration of a higher level of nicotine in a cigarette. It may or may not be reflected in the smoke. It could be different in the FTC numbers as opposed to the concentration in the cigarette. And both of those can be different than what the smoker, in fact, inhales. Is that correct?

Mr. SPEARS. Let's start fundamentally. Understand that if you have the concentration, you must also know the amount of tobacco in the cigarette in order to determine how much nicotine is in the tobacco column of the cigarette. The paper does not discuss the tobacco weight levels in these very low tar cigarettes, low nicotine cigarettes, versus the others that I talk about.

So the starting premise that you can relate directly concentration to what is in the smoke is incorrect. Further, what is in the smoke is modified by the construction of the cigarette, the filter, the air tip ventilation and so forth. These are the important determinants of what the nicotine and tar will be.

The differences between the blend concentrations in that paper are totally insignificant in terms of what ends up in the smoke.

Mr. WAXMAN. I have an article that I'm going to have distributed to you. It's Exhibit 21. It's an article by Dr. Neal Benowitz, M.D., and others, "Smokers of Low Yield Cigarettes Do Not Consume Less Nicotine" is the title. He shows in his graph-wait a minute.

This article is from the New England Journal of Medicine and without objection, it will be made part of the record as Exhibit No. 21.

[Exhibit 21 follows:] 
Benowttz, M.D., Sharon M. Hall, Ph.D., Ronalo I. Hennino, Ph.D., Perton Jacoa III, Ph.D., Reese T. Jones, M.D., and Asdel-Lutus Osman, M.D.

B. Advertsements suggest that smokers of cina7. bw in rucotine are exposed to less nicotine and ter. 4or. nots are measured with smoking machines, bu tines do not smoke agareltes as peoplo do. We ir mere measured the actual niboune content of com b.dy cogarentes with different nicotine and tar vields as itmned with smoking machinos, and also measured 3.) ncotine intake as indicaled by blood concentrations i molbolle, cotinine, in 272 subjects smoking various in of cigarotites.

4. lound that bw-yield cigarette tobacco ofd not con-

NOB.4CCO advertisements claim that low-yiek 3 cogarettes "bave" and deliver less tar and nicotine higher-yield brands. Many physicians advise pato who cannot stop smoking to switch to low-tar, -aicotine cigaretles, believing that they are safer. - wever, the figures for nicotine aod tar determined F the unoting machines used by U.S. Federal it' Commission (FTC) and cied by cigarette manctares in adverisements are misleading. The FTC tos do not refece what is actually caten into the in of the cigarette smoker.

Wen measurements of cigurette nicotine and ur - are determined by a smoking machine, a syringe in 35-ml pufis each minute und a sel kngth of - iretre is burned.' Cigareites can have low viclds in ing-machine assays for several reasons. The wo to may be lower in nicotine and may generate less - The use of vegtilated fliers or porous cigarette - Jen may result in dilution of the tobacos smote. "fers that burn faster may reduce the time in which cigarette burns; faster burning means that fewer are caken by the machine to burn a given amount becoc. Korlowski et al. have pointed out that the

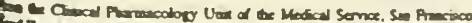

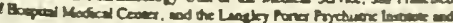

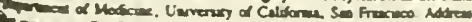

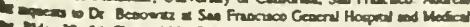

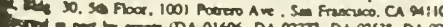

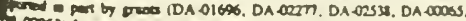

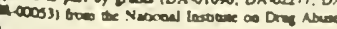

tain less ricotine; in fect, the ricotine concantration in to becoo invisisely correlated $(r=-0.53, p<0.05$ ) with the concentration measured by sinolong machines. Blood co tinine concentrations corrolated with the numiter of cigareltes smoked per day but not with the nicotine yietd meesured by smoking machines. Onty 3.8 to 5.0 per cent of bota variance in blood cotinine was contributed by nicotine neld

We conclude that smokers of low-ricotine cioaretles do nol consume less nicotine. (N Engl J Med 1983; 309:139 42.)

use of ventilated flers and more rapid buming time can explain much of the reduced yield of currently manufactured cigarettes. ${ }^{23}$ The ventilation characteriscics of the filter as well as the number of puffs taten before a cigarette is discarded can be controlled to a substantial degree by the way in which the cigarette is held and smoked. Many smoter will aleer their smot. ins behavior, changing the number of cigareties smaked, the method of puffins, and the depth of inhal. ing the smote, to mainuin a desired level of nicotine incle. * For all these reasons, we questioned whecher or not smokers of low-vield cigarettes truly consume less nicotine.

We addressed two questions: What is in the ciga. rette tobacos - that is, does the tobacoo of low-yield cigarettes contain less nicocine? And do the FTC fg $_{8}$ ures predict the actual nicotine incake of smokers? We measured blood concentrations of ootinine as an index of nicotine consumption. Cotinine is the major metabolite of nicotine and persises in the body for a much longer period than nicotine,' with a haif-life averaging 20 bours (unpublished data). Because of the long half. life, cotinine blood concentrations vary relatively litele throughout a day of smoking and thus are a reasonably consistent measure of nicotine exposure.

\section{Merrodos}

The nicotine content of robacos froen is popular brands of cira. rettes was measured Esumates of akotine delivered bn ouchine ranged from 005 to $t .5 \mathrm{mg}$ Cyparenco were cut to the buit length 
specified in the FTC report of December 1981." The puper wa removed and the iobscos weigbed. Nicovine was eatracied by was. ing the tobacos is $20 \mathrm{mi}$ of I $N$ hydrochloric acid for one bour ie a boiling water bath. Aher the eubes stood overnighth they were mixed, and $100-\mu l$ aliquois were removed and dilured with $900 \mu \mathrm{H}$ of $0.14 \mathrm{~N}$ aqueous ammonis. Nicotioe concentrations were measured by bigh-performance liguid chromalography (Bectman Moded $112 A$ pump with a Pertio-Elmer Madet LC.15 fixed waveleagl detector sel at 254 ams). A revense-phase column was used (Allioch $10 \mu \mathrm{C}-8$ ), with a mabik phase of 65 per cent methand and 35 per cent of an aqueous solution containing I per cent (rol/rol) 2 methoxyethylamine adjusted to a pH of a mith acetic acid, at a bon rate of $0.5 \mathrm{ml}$ per minute. The retencion time for nicorine was 14.2 minutes. An external aqueous sundard of nicotise was used, which gave a line as gtanda a d curve over the enire range ( \& $10100 \mathrm{Mg}$ per milliliter) of oboerved concentrations.

Two cigaretles were measured from each pact. The nicotine centrations of cigarettes from the same pact differed on average by 5.0 per cenc.

To estimate nicosine intake, blood samples were taken from 272 subjecas -122 men and 150 women, wich an average age of $37=8$ veara (S.D.; range, 20 to S6). All subjecss were about to begio a anoting-treatment program. Each subject was asked the brand and number of cigareties he or the had amoked in the previous 24 hours Blood samples for cocinine analysis were drawo at roo differeat imes in two subgroups of pacients. In Group I (n $=149$ ), the sass ote was drawn late in the afternoon, usually around 5 p.m. (range. 100 to $6: 30 \mathrm{pm}$.$) . In Group 2(\mathrm{a}=123)$, the btood sample wes drewn at 8 a.m., after 8 to 12 hours of abstinence. Counise was measured by gas chromatography with ritrogen-phosphorus detex. won and a structural anaboge of cotinine as the internal seandard."

Vicotine content was exprased as a percentage of tobaccos werght and also as the tocal amount of nicotine in the amount of robucoso usually bursed in the FTC smoking-machine assay. The relation

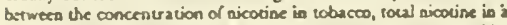
ciaretse, and the aicotine delivered by machine were measured by incar regression.

Dau on blood covinise concentrations in Groups 1 and 2 were analyzed separately U'nivariate linear regression was used to meas ure the relation between blood coumine concentration and age. oumber of cigareties imoked per day, machine-determined nucotine vietd, and "dzily dose" of ajocune (as cavinated by the product of oumber of cigaretlas and the riets). Hierarchical nutiple tinear regreasion to was ured to examine the effect of mschise nicotine vidd oo btood cokinine concentration, with cotutrol for the exters of ace. ser, and aumber of cigareties smoked per day.

\section{Resurts}

Cigaretle robacco contained an average of $1.57 \pm 0.33$ (S.D.) per cent of nicotine. Neither the concentration of nicotine in the tobacco nor the total amount of nicotine in the cigaretic correlated positive. ly with the FTC machine-delivery estimate (Fig. 1). In fact, among the cigarette brands sampled, there was a significant inverse correlation beiween the nicotine concentrations in the tobacco and the nicotine deliversd.

Bload cotinine concentrations were significanty correlated with the number of cigarettes smoked by both groups (Fig. 2A). The correlation between ma. chine-determined nicotine vield and blood cotinine concentration was not significant in either group (Fig. $2 B$ ). The daily intake of nicotine (number of cigarelles smoked per day multiplied bj the nicotine yield of each cigarette) correlated no better with cotinine concentration ( $r=0.42$ and $r=0.39$ for Groups 1 and 2, respectively) than with number of cigarettes alone. Multiple regression analysis showed that combination of the variables age, sex, and number of cigarettes per
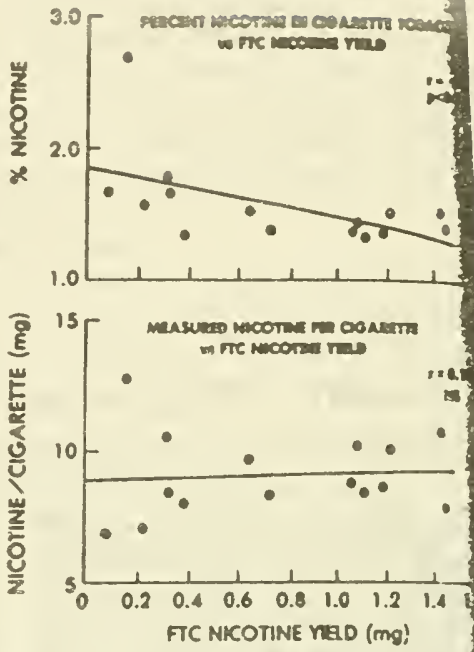

Foure 1. Nicotine Contert of Cigereata as Compered w 7 Detarminod Vatuss (Rogresion Analyid)

Lassured nicotine per clarotio" denctis loted emane of

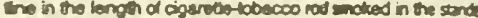
FTC smalding-mactine eavey. Fiteen paples commercel of rotho brands wore eseted.

day accounted for 21.2 per cent and 23.3 per crea the variance in blood cotinine concentravion Groups I and 2, respectivety. The addition of chine-delivered nicotine vield added only 2.8 per con and 5.0 per cent to the explained variance in Groops ts and 2 , respectively.

\section{Descussion}

Tobacco from low-yiedd cigarena does not wait less nicotine than tobacos from higher-yield cigarenea This is probably well known to de wacoo indestr but to our knowledge, it has not beca discussed in the medical literature. The main detericinants of wbrile a cigarette has a low or a high yield in machine tesing are the characieristics of its ventilation and burnun 2 Boch these variables are under the control of the ofzrette smoker and allow considerable variation in motine intake. ${ }^{2}$ We also found that people who wanted to stop smoking and who were smotieg low-yield ciso rettes did not consume less nicocioe, as judged by blood cotinine concentration, than smoters of higter. vield cigarettes.

Blood cotinine concentration is not a perfect marte of nicotine consumption, because of individual izm ability in both the conversion of nicotine to counus and the elimination rate of cotinine isself. But we bave no reason to think that there is ans relation betwere the rate or pattern of nicotine or cotinine metabolsa 

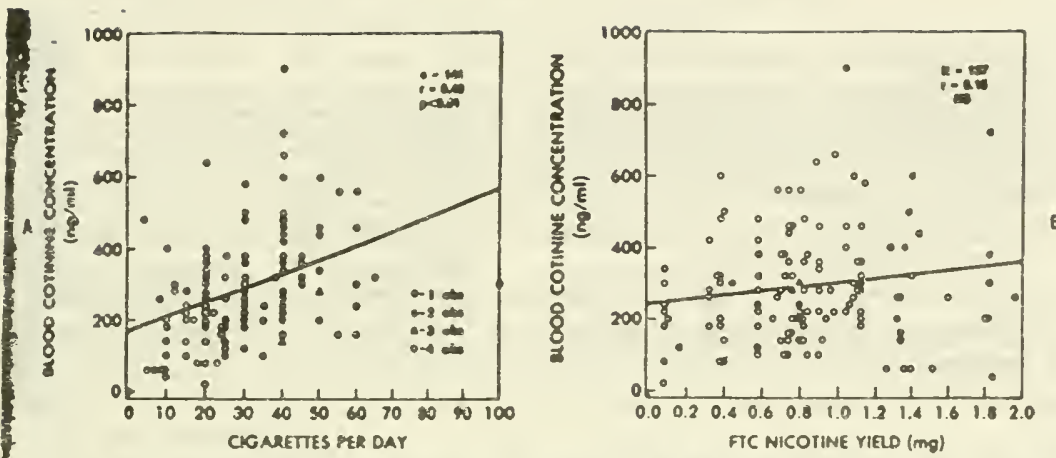

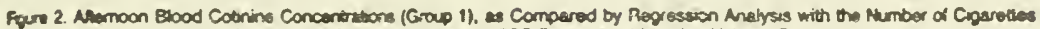
Smoked per Dery (N and with the FTC-Dotermined Nicotine Values $(\mathrm{E})$.

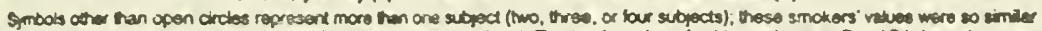
in plots of indindual values overlapped (obs denctes otservations). The lotal rumber of subjects shown n Pand 8 is lower because

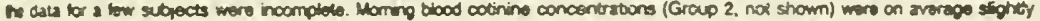
lower but had sirniler correlstions wh the number of cigarettes $(i=0.45)$ and the FTC yeld $(r=0.06)$.

an the brand of cigarette smoked that would cause wir data to be biased.

Our findings are consistent with other reports that aly a small percentage of the variance in blood nico ine concentzetions is accounted for by machine-deter mined nicotine yield. "1: Rickert and Rabinson also reported no correlation between machine-determined icotine yield and plasma cotinine concentrations. ${ }^{12}$

Lot theis subjects included few smoters of tow-nico ine cigarettes ( $<0.7 \mathrm{mg}$ ). In contrast, in our study population the full range of cigarelte brands was encompassed.

We focused on nicotine intake from smoking diffes at ngarelie brands. Niootine is suspected of having a wet in mortidity and mortality from corcoary beas Coease, but its quantilative importance has pot been 'otablished For example, a recent study showed that L rist of myocardial infarction increased with the menber of cigarettes imoked but did oor differ be meen smokers of low-yield cigaretter and thase of ligtrield cigarettes. ${ }^{13}$ Our data parlly explain this decrvacioe.

fif Is contrast, there is evidence impliating exposure - arbon monoxide and ur as a cause of disease. - Otha invescigalors have reported that carton monos. 2 levels are no different in smoken of low-yield Ptometle and smokers of higher-yield cigarentes." This was also true in our subjects. There are no mart- Es of ur consumpcion in people. In smoking-machine isan, bow-yield cigarettes deliver a fower racio of tar E. moocine the do higher-yield cigarettes"; bowever, If not esublisbed that this observation botds when Tereties are smoked by people. It may be that the is of ur incake to nicotine intaire is lower when low. id cigarertes ase smoked. However, since the intake terms of reduced tar intake is obviously far less than suggested by cigarette advertisements.

Perhaps the smokers who participated in our study and were secking treatment consumed more nicoline or were more dependent on it than other smokers. If so, they were more likely to regulate their nicotine. intake independendy of the type of cigaretie they smoked. Ia contrast, lighter smoken who switch to low-yield cigarettes may, in fact, consume less nicoine. Although this possibility cannor be discounted, our subjects were representative of smokers who for whatever reasons cannot stop smoting without professional help. We think that in the case of the habitual smoker for whom cutting down on nicotixe and war intake is considered to be medically important, it is unlitely that changing the brand of ograrette will accompliab this gos!.

In summary, we found that the tobacco in low-yield cigaretles does not "contain" less nicotine than high. er-yield cigarettes and that smakers of tbese cigareltes do not consurbe less nicotine. The FTC ciga. retu-teating data do not predict nicotine intake by the cigarette smoker. Advertisement from cigarette manufacturers suggesting that smoters of low-yield eigarettes will be exposed 10 less tar and nicotine are misleading. Patients who smoke cigarettes should be so advised

\section{Rereances}

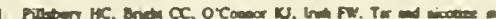

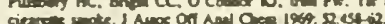

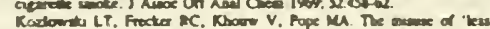

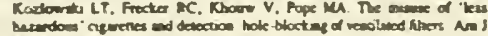
Restic Heals 1900, xo I 200-3

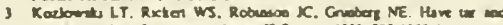

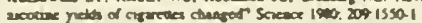




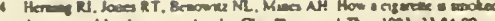

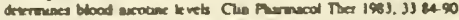

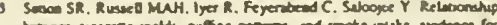

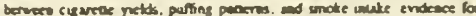
- compensumios' B Med I I9t2. I8s too.

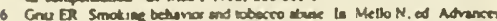

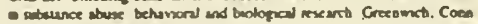
JA] Mess, 1980-91.158

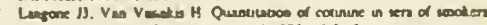
Res Comme Cace ratiol Pharmucal 1975. 1021.8

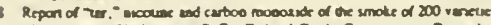

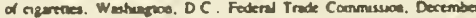
191.

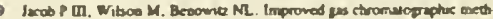

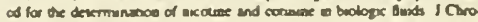
and 1951.22261 .70

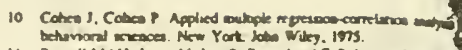

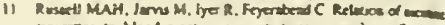

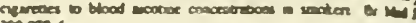
200926

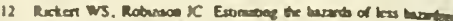

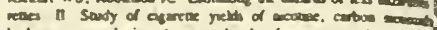

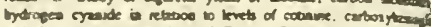

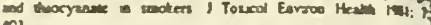

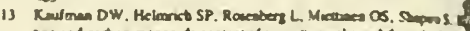

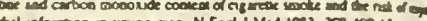

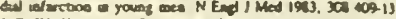

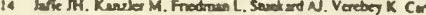

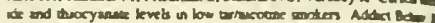
63974 
Mr. WAXMAN. Are you familiar with this article?

Mr. SPEARS. Yes, I am.

Mr. WAXMAN. He says that measured nicotine per cigarette denotes total amount of nicotine and the length of cigarette tobacco rod smoked in the standard FTC smoking machine assay, and he went through 15 popular commercial cigarette brands were assayed. What he shows in this graph is that the nicotine content of cigarettes, even if it were a low tar cigarette, can be the same level as in a non-low tar cigarette.

Mr. SPEARS. You have introduced another subject, which is how do people smoke cigarettes. I haven't read this article very recently, but, please, it should be obvious that if people smoke more or less cigarettes number-wise, this will change the amount of nicotine that they receive.

So the first question is are we standardizing the number of cigarettes that this consumer takes in. Number two, people smoke cigarettes in different ways. There's no question about that. Puff it more frequently, you will get more than if you puff it less frequently. But if you standardize all of these things, I believe that the FTC numbers represent, as fairly as they can be represented, the yield of cigarettes.

Mr. WAXMaN. Dr. Spears, I'm going to move on. I'm going to let you have this article to look at and we'll get back to it later. Let me just submit to you that Dr. Benowitz is indicating that the nicotine levels of low tar cigarettes are as high in others and we'll examine what it means. I think we need to go into that in some detail, what the smoker ingests as opposed to the concentration in the tobacco and whether that's a meaningful distinction or not.

Mr. Bliley.

Mr. BlILEY. Thank you, Mr. Chairman. The first thing, I might, in this series, run a little long, but since you went considerably beyond the 10 minutes, I hope you'll be considerate.

First, I'd like to demand that any documents that this subcommittee has requested be subject to strict confidentiality procedures by the subcommittee and its staff in the receipt, review and use of the materials which have been requested by all subcommittee members.

There are obvious proprietary concerns and others that we request that these procedures be strictly followed.

Mr. WAXMAN. Mr. Bliley, when we get these documents and there's a request for confidentiality, we will review that with the members of the subcommittee. But I'm certainly not going to agree that everything is going to be kept confidential because the tobacco industry wants to keep it confidential.

We have had too many things that have been kept out of the public view and I'm not going to agree that everything they submit to Congress can never be in the public view again. So I will not agree to that proposition, but we can discuss it when the time arises.

Mr. Bliley. Thank you, Mr. Chairman. Mr. Johnston, as I understand it, the question of the manufacturers' intent is very important in order to determine whether or not the nicotine in cigarettes, the caffeine in coffee or the alcohol in wine is a drug under Federal law. This is confusing to me because I know caffeine helps me stay 
awake, but when it's added to soda, it's not a drug. But when it's added to No-Doz, it is a drug.

Can you explain this to me?

Mr. JAMES JOHNSTON. Mr. Congressman, our-

Mr. BLILEY. Turn your mike on.

Mr. JAMES JOHNSTON. Yes, sir. My common sense understanding is the same as yours, that No-Doz is a drug because of the manufacturer's intent. But this is really a technical and legal question and I would like Mr. Cooper, our outside counsel, to respond to that question, sir.

Mr. COOPER. Mr. Bliley, the law here doesn't necessarily follow common sense, but it does have its own logic. In the definition of the term "drug" in the Food, Drug and Cosmetic Act, there are two branches of the definition that employ the concept of intended use.

One is intended use in the diagnosis, cure, mitigation, treatment or prevention of disease. That's not the definition that Dr. Kessler invoked and I don't think it's the one that's particularly relevant here.

The other branch is intended to effect the structure or function of the body, and that branch of the definition has an explicit exemption for foods. Now, the intended use of a product, in almost all cases, is determined by the claims and representations made by the manufacturer of the product in connection with its distribution.

Thus, if I put out a product and claim that it will keep you awake, that brings the product within the second branch that I referred to because I am claiming that the product will, indeed, have an effect on the function of the body. It will keep you awake when otherwise you might be drowsy or fall asleep.

So if I put caffeine in such a product and I make that claim and caffeine is the active ingredient that makes the claim true, then the caffeine is what is making that product a drug, along with the claim.

If, however, I put caffeine in a cola beverage and I don't make such a claim, even though the caffeine may be having the same effect, it doesn't make the product a drug, at least as the law has been currently understood.

Mr. BLILEY. Thank you. Mr. Johnston, I heard the industry say that it doesn't want kids to smoke. Is that true?

Mr. JAMES JOHNSTON. Yes, Mr. Congressman. That is correct.

Mr. BLILEY. What is your company doing about the serious problem of under-age smoking?

Mr. JAMES JOHNSTON. It is a serious issue for parents and for the society. I would like to put it in brief perspective, if I may. David, the chart, the government chart on under-age smoking, please.

Great progress has been made in this society of reducing underage smoking. We'll have a chart up in a moment. It is important that we as a company do something about it. I want to mention just two of the programs we have.

What the science, social science, and what parents know and what children know is the driving force in an under-age person starting to smoke is peer pressure. The next most important issue is whether an older brother or sister smoke. Those are the most powerful driving forces. We have a program that deals with the 
peer pressure issue. It was developed by Lifetime Learning Systems, an educational development company.

We have that program in 10,000 schools in the United States, helping 3 million children a year avoid falling into peer pressure. We use folks like Will Smith, the Fresh Prince who does public service announcements on this issue. We have a program to enforce restrictions on sales to minors. Our company and our industry helped bring the legal age for smoking up to age 18 in something like 18 States.

We've gone out to retailers. We have 25,000 retailers today cooperating with our Support the Law program, asking for ID's, training clerks to check for ID's. Getting access out of kids' hands is the way to go about it. Most kids don't get their cigarettes in a store. They swipe them from their older brother or sister or parents. I would strongly urge parents to keep their cigarettes away from kids.

We also use actor Danny Glover in that program and as of this year, it is a cooperative effort with the National Jaycees, who have taken this on to help.

Mr. BLILEY. How much, as a company, do you spend on that program?

Mr. James Johnston. Mr. Congressman, I don't recall the price, the exact-

Mr. BLILEY. Will you submit it for the record?

Mr. JAMES JOHNSTON. It's millions of dollars per year. Is it enough? I don't know if it's enough. As we find these programs work, we try to extend them. The more they work, the more we're willing to spend.

Mr. Bliley. Mr. Campbell, do you have any idea how much Philip Morris spends on it?

Mr. CAMPBElL. I don't know, as well. But it is, again, millions of dollars. Our combined efforts are combined through the Tobacco Institute. You're talking about a substantial amount. As Jim said, we're never quite sure that we're doing enough because we do not want young people to smoke. We're working very closely with our customers, the National Association of Convenience Stores, and the instrumental, which is a logical place for kids to go to get cigarettes.

They are very, very strict about their It's the Law and we're working very closely with them, as well.

Mr. JAMES Johnston. Mr. Congressman, if I might add, the charge that's always hurled at the industry is you have to go out and recruit these new smokers, you just have to. And the answer is that would be the stupidest thing we can do. I have a huge opportunity. The opportunity to grow my company is by taking Mr. Campbell's smokers away from him and switching them to my brands and Mr. Tisch's and so forth. There are 30 million smokers who don't smoke R.J. Reynolds brands.

That's my opportunity. They're already smoking. If I can provide better products and I can communicate that to them through advertising, that's my business. So every time a kid lights up a cigarette, we get blamed and we know we get blamed for it, but it would be stupid because the objective of this is to ban advertising. 
Without advertising, I can't go take Mr. Campbell's smokers away from him and bring them over to my brands.

Mr. Bliley. Mr. Johnston, clear up another question for me. Thirty patents held by the tobacco industry were presented here by Dr. Kessler. Many of the companies have stated publicly that they are not using these patents. In its written comments, your company stated that it doesn't use such technology commercially.

Why do you patent all these things if you don't use them?

Mr. JAMES JoHnSTON. Mr. Congressman, that's a good question. I've been asking that myself. Of our 600 -plus patents, about 20 percent or less are actually in use. As I understand it, we can patent a technology or an idea, but having created an original idea doesn't mean it's commercially feasible.

In many of the patents we have today, there is a technology which, according to U.S. patent law, can be patented and the researcher can feel good about it, but it doesn't have commercial application.

Mr. Bliley. I would like to ask each of you are you using any of the patents that Dr. Kessler mentioned in his testimony?

Mr. CAMPBELl. Yes, Mr. Bliley, I am. I'm using the patents that relate to the reduction of nicotine through my de-nicotization process. I am using no other patents.

Mr. BliLEY. Mr. Johnston?

Mr. JAMES JOHNSTON. No, we are not. But this raises a very important issue, Mr. Congressman. There wouldn't be anything wrong if we did use those patents. There have been calls from governments, from scientists all over the world, including the United States, for the industry to provide lower tar cigarettes while maintaining nicotine yields, the theory behind that being that people will-that tar is the risk factor here, that people will smoke fewer cigarettes.

Our company is being actively encouraged outside the United States to produce those products, and look what's happening in this room today.

Mr. BLILEY. Mr. Taddeo?

Mr. TADDEO. What is the question, Mr. Bliley?

Mr. BLILEY. Does your company use any of the patents described by Dr. Kessler in his testimony, to your knowledge?

Mr. TADDEO. No. We didn't have any of those patents.

Mr. TISCH. No, sir. We do not use any of those patents.

Mr. Bliley. Mr. Horrigan?

Mr. HORRIGAN. Nor does Liggett.

Mr. Bliley. Mr. Sandefur?

Mr. SANDEFUR. No, sir, we don't.

Mr. BLILEY. Mr. Johnston?

Mr. DONALD JOHNSTON. No, sir.

Mr. Bliley. Thank you. Mr. Johnston, what do you think the consequences would be if Congress or the FDA simply said cigarettes may no longer be sold?

Mr. JAMES JOHNSTON. Congressman Bliley, that is the question we've been avoiding all morning. We hear these strong feelings about the dangerousness of this product. We hear strong feelings about the character and motives of the people at this table and the 
2.3 million people engaged in this industry. We hear about addiction and the threats.

If cigarettes are too dangerous to be sold and they are addictive, then ban them. But let me tell you what the consequence of banning them is. Some people will quit. Some people, no matter what, will obey the law. Many will not. Many will not.

And people will get their cigarettes from people selling them out of the trunks of cars, made who knows where, of who knows what, and sold to my kids and yours and everybody else's, because criminals don't care who they sell to.

My colleagues and I, the 10,000 people in Reynolds Tobacco, we will go find other jobs somewhere where we cannot be accused of all these things.

Mr. BLILEY. Mr. Johnston, I want to be absolutely certain of this, because there has been a lot of interest in this subject and at least one of your competitors has sued $A B C$ over it. Once and for all, does your company spike its cigarettes with nicotine?

Mr. James Johnston. No, Mr. Congressman. We do not spike our products with nicotine.

Mr. BlileY. Mr. Campbell?

Mr. CAMPBELl. Mr. Bliley, we do not spike our cigarettes and we have sued the $A B C$ Company for its accusing us of doing so.

Mr. Bliley. Mr. Tisch? Mr. Taddeo, you don't have cigarettes.

Mr. TISCH. No, sir. We do not spike our cigarettes with nicotine.

Mr. BLILEY. Mr. Horrigan?

Mr. HORRIGAN. At Liggett, we do not spike our cigarettes with nicotine.

Mr. BliLey. Mr. Sandefur?

Mr. SANDEFUR. We do not add nicotine to our cigarettes, no, sir.

Mr. BLILEY. Mr. Johnston?

Mr. DONALD JOHNSTON. We do not spike our cigarettes at all.

Mr. Bliley. Thank you. Thank you, Mr. Chairman, for your indulgence.

Mr. WaXman. Thank you, Mr. Bliley. Mr. Synar.

Mr. SYNAR. Thank you, Mr. Chairman. Mr. Johnston, 1,147 people die each day because of cigarettes. And with those deaths, there is need to replenish the customer base. It is your claim that you do not target children to replenish that base. Is that correct?

Mr. JAMES JOHNSTON. There is no need to-

Mr. SYNAR. Is that correct?

Mr. JAMES JOHNSTON [continuing]. Approach that base and, no, we do not market to children and will not.

Mr. SYNAR. Thank you, Mr. Johnston. In deciding to launch your Joe Camel campaign, and I'd ask the staff to put the advertisement up, according to FTC documents, your company sponsored focus groups studies to determine the preferences of your likely customers. By 1987, your sales of our product among young people had been declining because your product's image was an older person's cigarette.

In fact, at the time, your market share among 18 to 34-year-olds was on the decline. When your campaign began in 1988, Mr. Johnston, the focus group data confirmed that "Smooth Moves" campaign and its later revisions had greater appeal among younger age segment, 18 to 20 , than the older segment of 18 to 34 . 
Now, the American Medical Association found that since 1987, Mr. Johnston, the Joe Camel campaign has, for under 18 year old smokers, increased from 0.5 percent share to 32.8 percent. The study concluded that the 32 percent market increase was worth $\$ 476$ million to R.J. Reynolds. That's a remarkable coincidence, isn't it?

Mr. JAMES JOHNSTON. Mr. Congressman, those numbers are false. Now, I want to be very clear. We do not survey anyone under the age of 18. So I cannot provide you with R.J. Reynolds' data-

Mr. SYNAR. It is your position that the American Medical Association study is false.

Mr. JAMES JOHNSTON. Absolutely.

Mr. SYNAR. Thank you.

Mr. JAMES JOHNSTON. No question about it.

Mr. SYNAR. Thank you, Mr. Johnston.

Mr. JAMES JOHNSTON. I rely on the U.S. Government for those numbers and-

Mr. SYNAR. Mr. Johnston, thank you.

Mr. JAMES JOHNSTON [continuing]. The U.S. Government disagrees with the

Mr. SYNAR. R.J. Reynolds spokeswoman Mora Payne Ellison told the Washington Post Magazine, Mr. Johnston, the following. "We don't do research among young smokers because we don't think young people should smoke." Yet, in December of 1991, again, the American Medical Association found that 91 percent of the children age 3 through 6 could match Joe with a Camel cigarette, which means, Mr. Johnston, that Joe Camel was as well known as Mickey Mouse.

Do you still maintain that Joe Camel cartoons are not targeted toward children?

Mr. JAMES JOHNSTON. Congressman Synar, when

Mr. SYNAR. It's a simple question, Mr. Johnston. Do you contend-you do contend that Joe Camel is not targeted toward children.

Mr. JAMES JOHNSTON. Clearly and absolutely.

Mr. SYNAR. All right.

Mr. JAMES JOHNSTON. But I can explain

Mr. SYNAR. Mr. Johnston, I would ask you to submit to this subcommittee all the documents and other materials produced in connection with the Joe Camel advertising campaign from your company and your advertising firms since its inception, including internal memos, reports, presentations of any kind, story boards, results of focus groups and marketing surveys, and any material within that description. Will you provide that for the subcommittee?

Mr. JAMES JOHNSTON. Absolutely. We have provided 60,000 pages of documents already to the U.S. Government. To help minimize any environmental impact, I can direct you to where those documents are already supplied.

Mr. SYNAR. Mr. Campbell, has Philip Morris done any research of any kind on the Joe Camel advertising campaign and its effectiveness?

Mr. CAMPBELL. I'm not acquainted with anything specifically. 
Mr. SYNAR. Have any of the other companies seated at the table done any research with respect to the impact of the Joe Camel campaign? Mr. Horrigan?

Mr. HORRIGAN. No, sir.

Mr. SYNAR. Thank you. Now, Mr. Johnston, in answer to a previous question, you stated that one of the goals of advertising and promotion was to get the smokers from your competitors that are sitting at the table; in other words, to get people to switch brands.

Mr. JAMES JOHNSTON. That's the only goal and-

Mr. SYNAR. And I find that fascinating since we know from the records that, combined, you all spend about $\$ 4.6$ billion a year advertising and promoting your product. There are 50 million smokers. We know that only 5 percent of all smokers switch, which means that's 2.5 million people per year. So you're spending, by our calculations, roughly $\$ 1,840$ per person to get them to switch.

Now, can you explain to me a 1989 advertisement, which I have right here, that you later withdrew, if switching is the only reason you have? You have here "fool-proof dating advice" that starts with "Number one, never date a woman named Dave." And it continues. How to impress someone on the beach. "One, run to the water, grab someone, drag her back to the shore and act as if you're saving her from drowning. The more she kicks and screams, the better."

Is that an advertisement to get people to switch or to rape? Mr. Johnston, you withdrew this. Is that not correct?

[The advertisement follows:] 


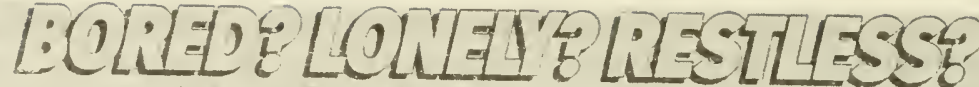

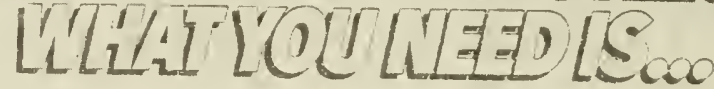

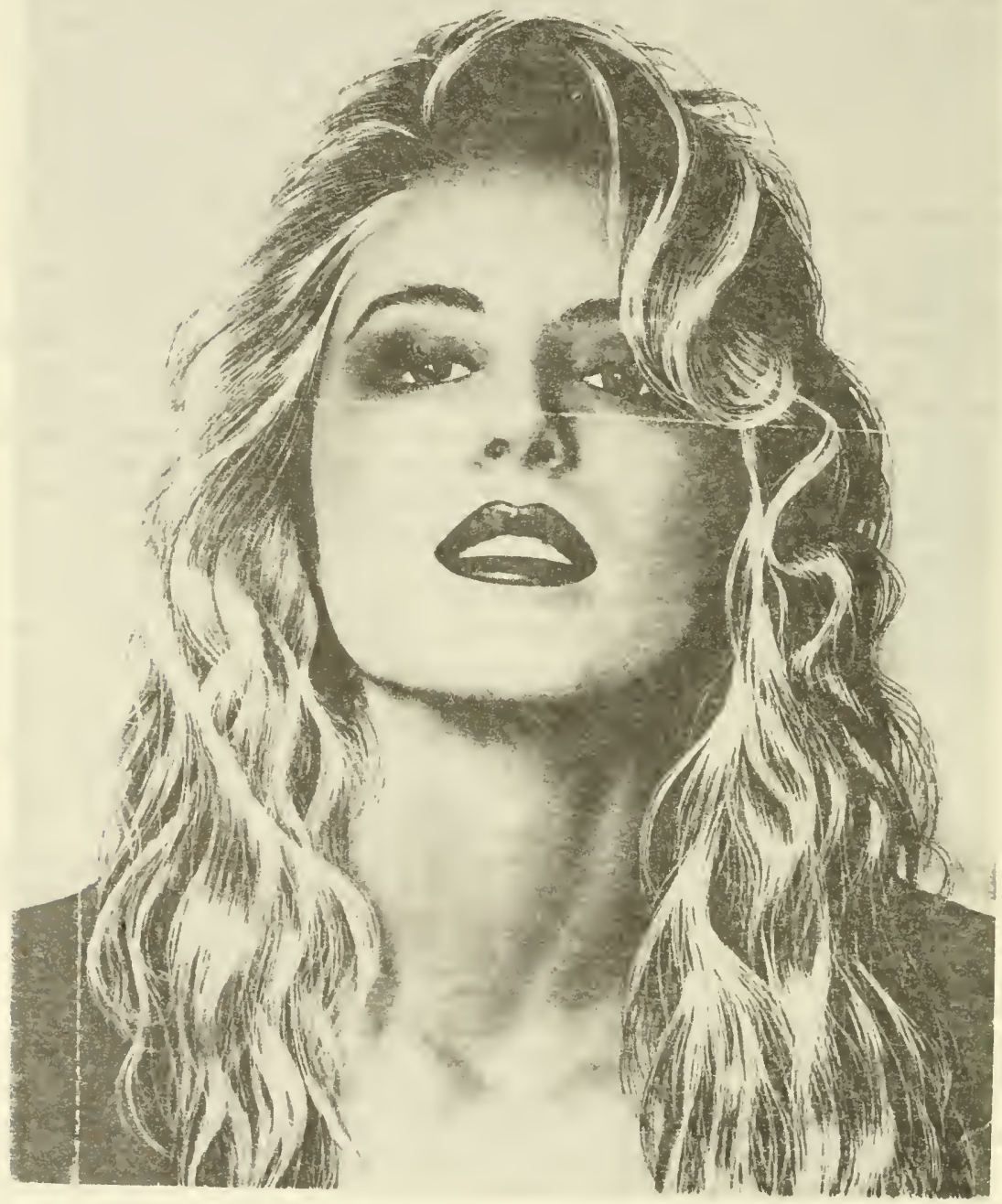




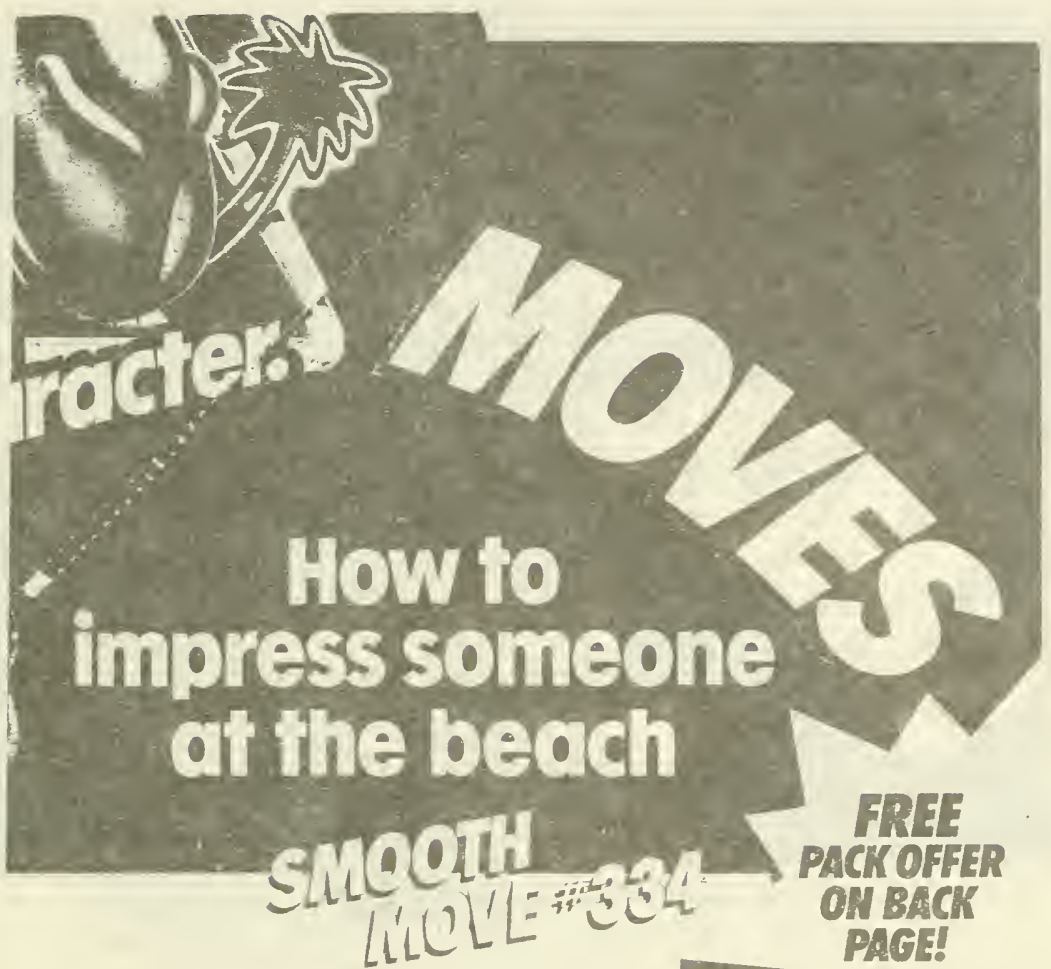

1. Run into the water, grab someone and drag her back to the shore, as if you've saved her from drowning. The more she kicks and screams, the better.

2. If you're overweight, lie on a towel with vertical stripes.

3. If you're underweight, lie on a towel with harizontal stripes...

4. Always have plenty of Camels ready when the beach party begins.

LOOK FOR MORE SMOOTH MOVES COMING YOUR WAY SOON.

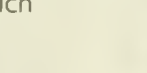




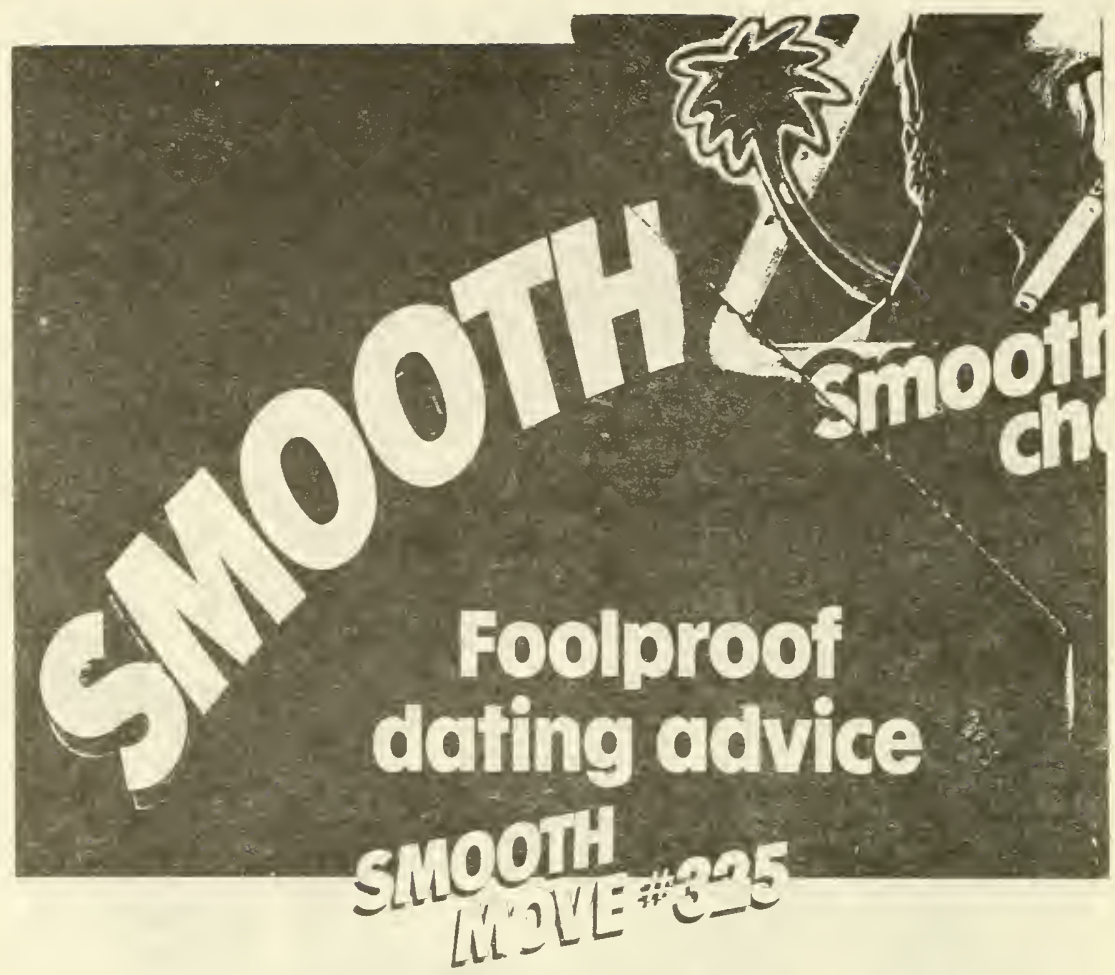

1. Never date a woman named Dave.

2. Never date a woman wha has 12 older brothers.

3. Never date a waman whose father is called "Captain."

4. Always break the ice by offering her a Camel.

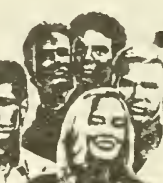

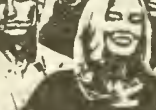
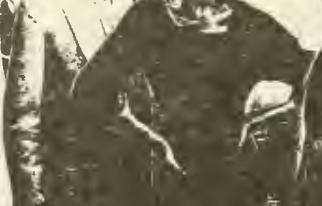

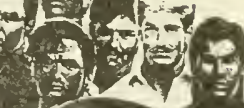
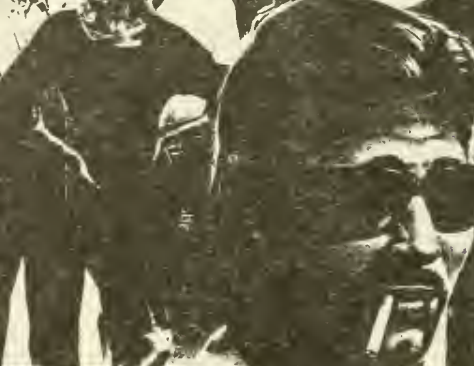
s. A क्ष. 21

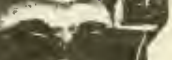
\&1)

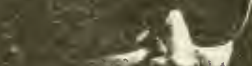

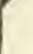

SURGEON GENERAL'S WARNING: Cigarette Smoke Contains Carbon Monoxide. 


\section{How to get a FRF E pack even if you don't like to redeem coupons.}

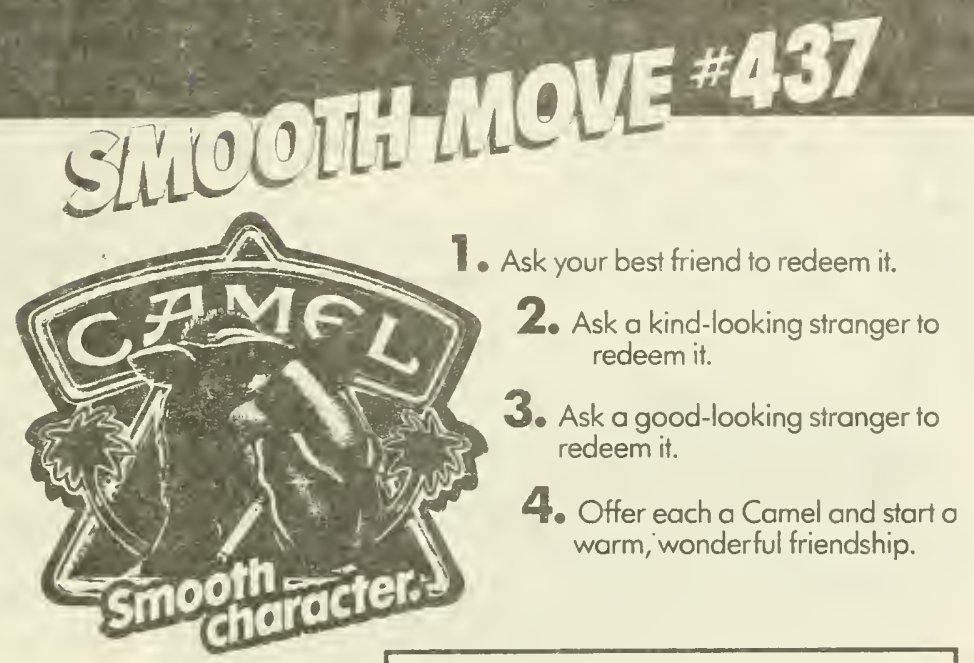

SURGEON GENERAL'S WARNING: Cigarette

Smoke Contains Carbon Monoxide.

LIGHTS: 9 mg. "iar", 0.7 mg. nicotine. LIGHTS HARO PACK. 10 mg. "tar", 0.7 mg. nucotsne, LIGHTS 100's: 12 mg. "tar", $0.9 \mathrm{mg}$. nicotine, FlLTERS: $16 \mathrm{mg}$. "tar", $1.0 \mathrm{mg}$. nicoune, FlL IERS HARD PACK: $17 \mathrm{mg}$. "lar", $1.1 \mathrm{mg}$. nicoune, FliteRS 100 's. $18 \mathrm{mg}$. "tar", $1.2 \mathrm{mg}$. nicotine, REGULAR. $21 \mathrm{mg}$. "tar", $1.4 \mathrm{mg}$. nicotine, av. per cigarette by FTC method

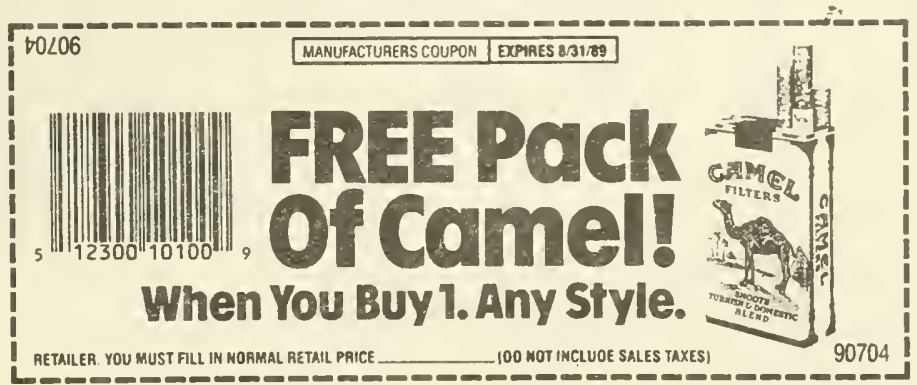


Mr. JAMES Johnston. That ad ran once. That is not an ad that represents what I want our company or any of our brands to represent. I wrote a letter to Congress at that time, and I quote, "I have carefully reviewed the situation and have concluded that this ad should never have run."

I can also say that it would not have run had I been running the company at that time. I had come to the company after it ran. I apologize. It was offensive. It was stupid. We do make mistakes and, Mr. Congressman, we

Mr. SYNAR. I take that as a sincere apology.

Mr. JAMES JOHNSTON. Absolutely.

Mr. SYNAR. Because, Mr. Johnston, of that sincerity, I have to tell you that your advertisement campaign, which is demonstrated here and across this country in many mediums, is some of the most cynical, explosive, perversive advertising we have ever seen in this country. It has one purpose, whether you will agree to that or not, and that is to attract children.

Now, I'm not satisfied with your answers, but I do know because you have the opportunity as the chief of your company to make the decision to pull that ad so that there will be no doubt that you're trying to attract children, will you pull that ad and that advertising campaign so that we can eliminate the attraction that this ad clearly does to children? Will you do that?

Mr. JAMES JOHNSTON. I will repeat for the record if I thought that campaign caused any young people to begin smoking, I would pull it in a heartbeat. We have taken this issue very seriously, very responsibly. We have gone out and replicated that research through the Roper Organization, much larger sample bases. The sample bases that were used in that, generally, the American Medical Association work you wouldn't accept for political polling purposes. They were too small.

Here is what we found. Teenagers who associate Joe Camel with cigarettes and who may like Joe Camel have uniformly negative views of smoking. I might like Snoopy the dog, but I don't like Met Life insurance. They might like Joe Camel, but here are the results and I'd like them submitted for the record.

Mr. WAXMan. They will be.

[The following information was furnished:] 


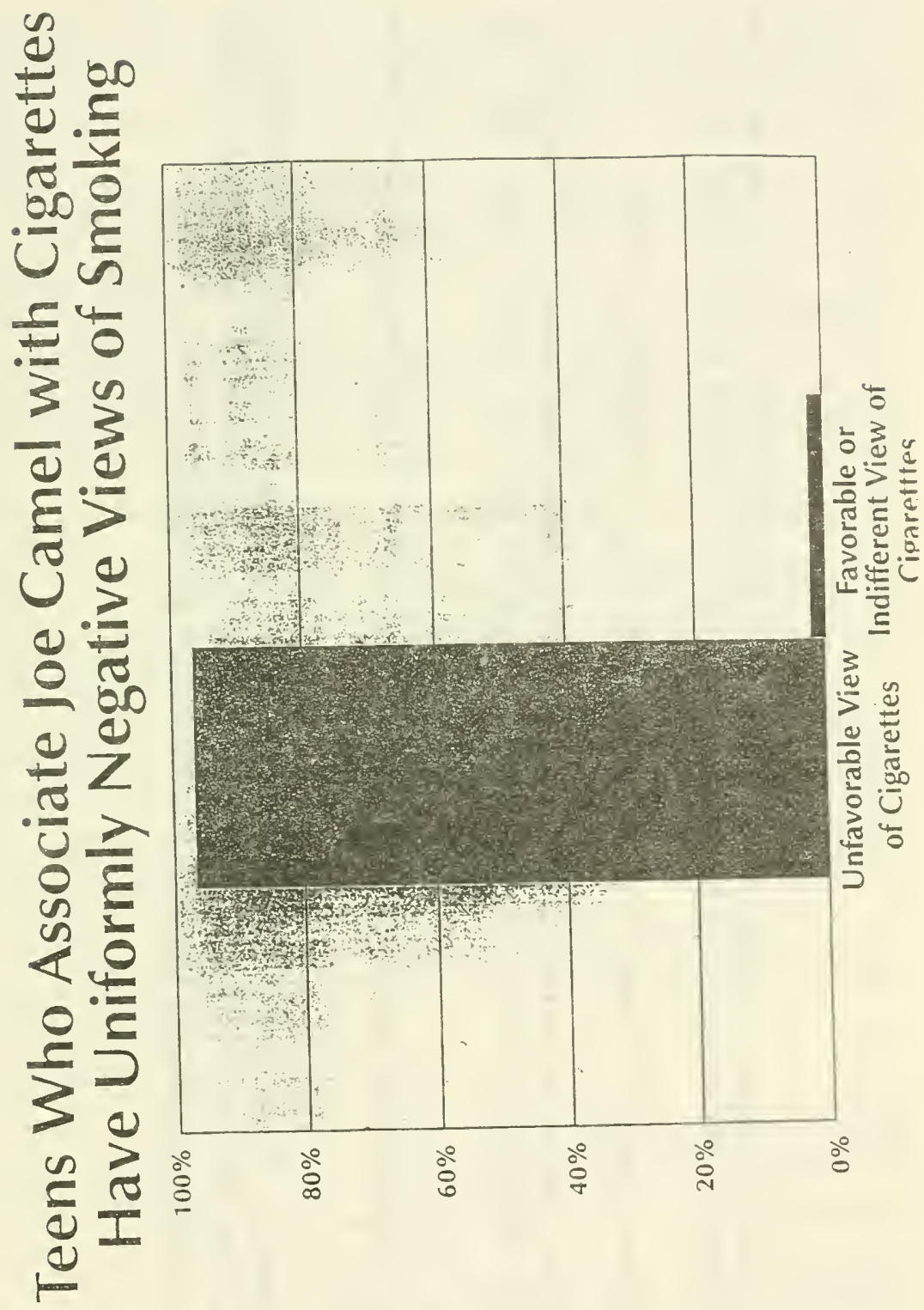




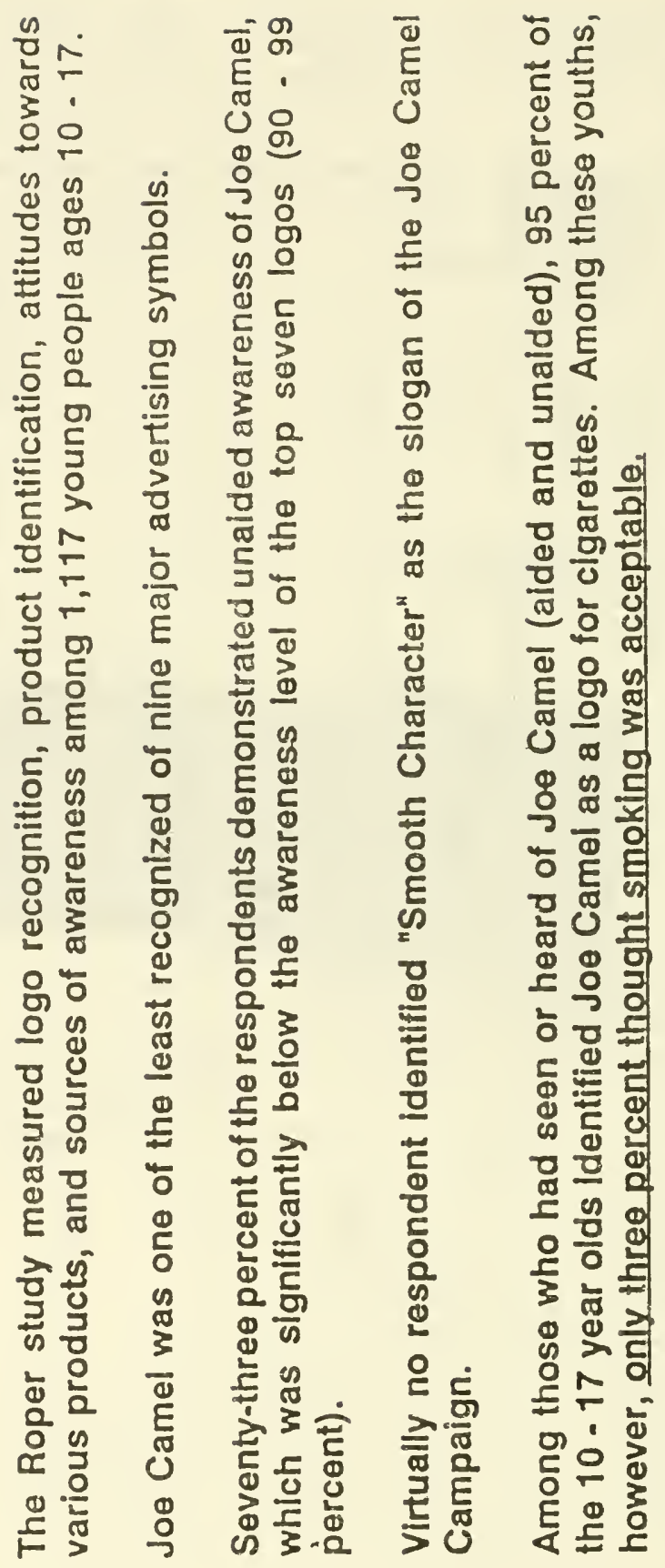


Mr. SYNAR. Mr. Campbell-I'm sorry, Mr. Johnston. I have limited time. I'd like to go to Mr. Campbell. The American Medical Association has found that the initiation rates increased rapidly in girls under 17 as a result of the Virginia Slims ads. In 1973, the initiation rate for girls under 17 increased 110 percent over 1967's rates.

I have behind me a poster. In that poster, it says, right here, "Hey, if you think female bonding is all about hair spray and nail glue, you're obviously stuck in the past." Can you tell me who this ad was pointed to?

Mr. CAMPBELL. That's to attract women smokers over the age of 20,25 , something like that. Those women are all over 25 in that ad. It's to attract some of my competitors' business.

Mr. SYNAR. So you don't think any little girls looking at that thinking that they can be successful and attractive, sexually attractive, would never think that that ad might be pointed towards them.

Mr. CAMPBELL. We have no evidence of that, Congressman Synar.

Mr. SYNAR. All right. Mr. Taddeo, I haven't been talking to you today, but I want to. You've testified that U.S. Tobacco does not employ a graduation schedule to move oral tobacco users from a lower to a higher nicotine level.

Mr. TADDEO. Right.

Mr. SYNAR. In the spring 1985 edition of Up to Snuff-this is what you send to college student sales representatives. Your Executive Vice President, Jack Africk, said "Skoal Bandits is an introductory product and then we look toward establishing a normal graduation product," as you can see. We then have the ad in front of us to your left with respect to Copenhagen, where it says "Sooner or later, it's Copenhagen."

What does that mean, "Sooner or later, it's Copenhagen?"

Mr. TADDEO. That was a competitive ad; that out of all the tobacco products we compete against, that finally you'll try Copenhagen and hopefully prefer that.

Mr. SYNAR. So it is your contention that you do not use the graduation system that I just described.

Mr. TADDEO. We absolutely have never used the graduation system as you described and there's a couple reasons why it's impossible to do. But one reason is that each of our cans contains loose tobacco. There is not a uniform portion of tobacco in each can.

A dip of tobacco would consist of different weights and different measures for each person consuming it.

Mr. SyNAR. All right. You have stated that U.S. Tobacco does not conduct its own research, but you have admitted that you funded a Penn State study on the effect of different levels of nicotine. For the record, what other studies have you funded?

Mr. TADDEO. There is a list of studies that we fund through the Smokeless Tobacco Research Council. I don't know the number of them.

Mr. SYNAR. Will you provide that for the record?

Mr. TADDEO. Yes, we will.

Mr. SYNAR. And make them, also, public?

Mr. TADDEO. Yes, we will. 
Mr. SYNAR. Thank you very much. Now, you, on page 10 of your testimony, attack Dr. Connolly, a Massachusetts public health official who has testified before this committee. You say he has an alternative motive.

Mr. Taddeo, how much do you get paid by U.S. Tobacco every year?

Mr. TADDEO. I have a salary of $\$ 400,000$.

Mr. SyNAR. Your salary as Executive Vice President of the tobacco parent company is $\$ 400,000$.

Mr. TADDEO. That's my salary, yes.

Mr. SYNAR. We're not able to find out what else you're paid. Would you like to volunteer what other things are in your incentive package?

Mr. TADDEO. My bonus last year was a little over $\$$ million.

Mr. SYNAR. So your salary last year was $\$ 1.4$ million approximately, correct?

Mr. TADDEO. No. The salary was $\$ 400,000$. The total compensation was a little over $\$ 1.4$ million.

Mr. SYNAR. Also, we have learned that you hold 167,200 shares of U.S. Tobacco Corporation stock, which closed yesterday worth about $\$ 4$ million. Is that correct?

Mr. TADDEO. I still owe some money on those shares, yes.

Mr. SYNAR. Would you say your annual salary of $\$ 6$ million alternative motive may be just as strong of an ulterior motive as Dr. Connolly's?

Mr. TADDEO. I don't know what the question is.

Mr. SYNAR. All right. Mr. Taddeo, a North Carolina study found that long-term users of oral snuff were 50 times more likely to develop mouth cancer than non-users. More than 40 percent of the patients are dead within 5 years of diagnosis. I have behind rieI'm going to put it on the chart-a photograph of mouth cancer resulting from moist snuff and chewing tobacco.

Do you still deny that oral tobacco causes mouth cancer?

Mr. TADDEO. Oral tobacco has not been established as a cause of oral cancer.

Mr. SYNAR. Thank you. All right. Ms. Brenda Dawson, the Vice President of the Tobacco Institute, has stated on many public occasions that the tobacco companies have never tried to stop any offorts to keep cigarettes from minors.

Mr. Campbell, you have maintained that the tobacco industry wants to enact strict measures banning cigarette sales to minors. I think you went through a number of questions with Mr. Bliley concerning this.

First of all, we have with us here today a petition for a ballot initiative paid for Philip Morris in California, to try to counteract some of the stricter local smoking restrictions in Califormia.

I also have with me a State-to-State analysis of current State legislative trends, where it says that in 1994, the Tobacco Institute has initiated a major push to seek enactment of its own model bill on cigarette sales, and they list a number of States.

My question is how can you contend that you have done nothing to try to keep laws from being enacted to enforce against minors when you issue these types of petitions that would override and preempt stricter city and county smoking restrictions? 
Mr. CAMpbell. Congressman Synar, I think if you investigate more closely, you'll find that the tobacco industry and our company has very actively supported in States that don't have 18-year age limits, that we very aggressively supported that.

Mr. SYNAR. All right. Let's talk about how aggressively you have enforced it. It is your official company position, is it not or is it, regarding withholding a product from retailers who sell cigarettes to minors? Do you or do you not withhold cigarette sales to retailers that have been found in violation of selling to minors?

Mr. CAMPBELl. I don't know of cases in that regard, but I don't know that we have the right to do-

Mr. SYNAR. Is it your policy that where you find-you stated earlier that you work with a thousand retailers nationwide in order to enforce against sales to minors. Is it your official or unofficial policy to-

Mr. CAMPBELl. If we have proven egregious abuse of these cigarette minors laws, we would not supply those stores.

Mr. SYNAR. In the past year, how many retailers has your company stopped selling the product to because you've learned a retailer was selling to kids under 18 ?

Mr. CAMPBELL. We have learned of no one doing so. There's very few prosecutions brought in that regard, but that doesn't mean that we wouldn't be responsive to any suggestions you have in that regard, Congressman Synar.

Mr. SYNAR. So you're telling me that you have not found a violation anywhere in the country, is that correct?

Mr. CAMPBELL. They have not been brought to my attention, I can say that.

Mr. SYNAR. I'd like to conclude my round by infusing a little bit of reality from my own State of Oklahoma. I received on the 15th of March of this year a letter from a young lady named Laura Sandefur. I don't think she's related to you, Mr. Sandefur. She may be. "Dear Congressman, my civics class just saw a movie about your days, what it consists of. I enjoyed watching it. I think of you working hard." I had to give my self some advertising here.

"The purpose of this letter is to try and help me know what I can do with this problem we have. Of about 25 people that ride my bus, about 15 of them smoke. I'm in the eighth grade and I think it's totally wrong. To make matters worse, just recently my mom and I walked into Quick Trip and saw a bunch of cigarettes sitting on the shelf and a sign that said 'Free, take one.' By advertising those cigarettes as free they tell kids of all ages that it's OK to smoke. I think that's totally wrong. Would you help me solve this problem and let me know what I can do."

Does that offend you that free samples are available at Quick Trips across this country where children can walk in as they're purchasing candy and grab one?

Mr. JAMES JOHNSTON. I don't believe that to be true. We do not do that. We do not support that.

[The following letters were submitted:] 


\section{4}

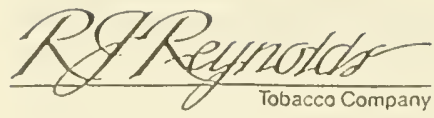

April IS. 1994

JAMES W. JOHNSTON

Chairman and

Chiel Executive Olficer

Winston-Salem, N.C. 27102 919.741 .7925

Mr. Chester E. Cadieux

Chairman, President

QuikTrip Corporation

Post Office Box 3475

Tulsa, Oklahoma 74101

Dear Mr. Cadieux:

As you may know, I and the CEO's of the other six major U.S. tobacco companies had the opportunity to testify before Congressman Waxman's subcommittee yesterday.

During our testimony, we were asked a series of questions by Congressman Synar relating to a letter he had received from one of his constituents. Apparently, this constitueat wrote that she was in a QuikTrip outlet recently and saw individual cigarettes on display with a sign that said something to the following effoct. "Take one, they're free." Mr. Synar was quite adamant and said that he also had personally seen this "offer." The suggestion from all this by Mr. Synar was that these cigarettes were accessible to children and could encourage them to experiment with smoking.

I wanted to call this matter to your attention because I understand from the folks in our regional sales office in Oklahoma City that you are as firmly committed to keeping cigarettes out of the hands of minors as we are.

I would greatly approciate your looking into this and letting me know whether there is any basis for the allegations and conclusions drawn by Mr. Synar.

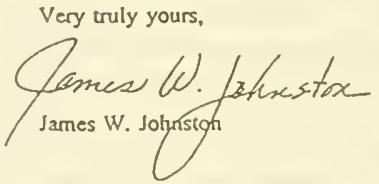


We reccived your letter about Mr. Synar's statements conceming our company. QuikTrip works diligently to be a respoosible tobacco retailer and are very sorry a program we ran was so misunderstood.

On March 14, 1994, sample cigarette products were placed on checkstands in our stores. The sole intent was to allow adult customers who choose to swoke to try another brand. We would never condone the selting or sampling of cigarettes to minors in our store. It's morally wrong and also illegal.

The sample products were placed aear the employee on duty for continual supervision. Signs from the corporate office clearly Labeled the display, "For our adult customers who choose to smoke" The sign also promineatly carried the Surgeos General's waraing. If any stores lacked signage or had incorrect signage it was corrected in a very short time. We feel we conducted this program in a fully professioaal manner completely within the law.

Being a responsible retailer, we discontinued the program when some of our customers complained. The program was discontinued in Oblahoma on March 31st and in our other market areas on April Sth (the program was oever conducted in our lowa stores). It's noceworthy that QuikTrip volustarily discontinued the program roughly two wreeks prior to Mr. Synar's comments, and Mr. Synar aever contacted our offices for information or facts about the program.

We do not intend to provide nor sell cigarettes to minors, and bave steps in place to easure this and to coforce the law. We thoroughly train responsible tobacoo retailing procedures to all employees and bave promineat signs displayed in the stores which indicate the legal age to purchase tobacco products.

There are ao current cigarette sampling programs at QuikTrip nor do we presendly anticipate future cigarette sampling programs.

We are enclosing a copy of the Tulsa World newspaper article dated Saturday, April 16th, about Mr. Synar's comments The article quotes a spokesperson for the American Lung Association in Tulsa as saying they were pleased with QuikT rip's actions in halting the program. Obviously our timing was bad oo this program but to say our inteot was to get cigarettes 10 minors is totally false.

I an sorry we put you in an embarrassing situation during the bearings and appreciale your thelp in setting the record straight.

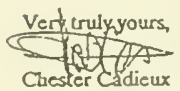

President and Chief Executive Officer

Enclosure 
Mr. SynaR. So Ms. Laura Sandefur from Tulsa, Okla. is lying.

Mr. JAMES JOHNSTON. No. I'm not going to go around making unsubstantiated allegations. She could be wrong. That doesn't make her a liar. She could be wrong. She may have seen a sign that said "Buy one, get one free." That's probably what she saw.

Mr. SYNAR. Mr. Johnston, I can tell you I've been in a Quick Trip or two over the last 2 weeks as I've travelled through my district and she's telling the truth, because I saw those cigarettes laying out.

Mr. JAMES Johnston. Congressman, I will investigate this immediately and I will submit for the record what we found and what action we have taken, if our company is involved in any way. That is unacceptable to us, if that's true.

Mr. CAMPBELL. You have the same commitment from me, Congressman Synar. That is unacceptable to us and if our sales force is involved in any way, they will be suitably reprimanded.

Mr. WAXMan. Mr. Synar, your time has expired. Mr. McMillan.

Mr. MCMillaN. I would just comment. If the ad with Joe Camel in Joe's Place was designed to appeal to young, then both the bar and the advertising were poorly targeted because people under 18 aren't allowed in the bar nor are they allowed to purchase cigarettes. It doesn't seem to make much sense.

Mr. JAMES JOHNSTON. That's correct.

Mr. MCMillan. Is nicotine produced and put into product in amounts in excess of that found in tobacco for any other reason or in any other product that you're aware of?

Mr. CAMPBEll. Any one of us?

Mr. MCMillan. Yes.

Mr. CAMPBELL. Absolutely not.

Mr. MCMILLAN. I don't mean the tobacco companies doing it. I mean is it out there in the marketplace for any other purpose.

Mr. CAMPBELL. It's available in nicotine gums and in the patch, which is a pharmaceutical application.

Mr. MCMILLAN. That's the prescription use of nicotine.

Mr. JAMES Johnston. And it's found, Mr. Congressman, nicotine is found naturally in tomatoes and eggplant and a number of other vegetables in very low amounts.

Mr. MCMillaN. I think some of the parallels here when we talk about common standards are interesting when we start looking into the area of caffeine or alcohol, especially. We have alcohol sold in this country with widely varying amounts, which I presume are deliberately determined and formulated into the product, to the point where in the labeling of the product, it's rather precisely stated, either in terms of percentages of proof and, yet, we don't consider alcohol to be an addictive drug and it's not treated as such.

It strikes me as somewhat unusual that we're trying to apply standards to tobacco, with a product that perhaps is potentially far less threatening physically, psychologically and behaviorally than, say, alcohol.

I've missed some of the testimony here having to do with attempts to define what is addictiveness and so forth. Is there a precise science, in your view, in which this committee could address the question of addictiveness or call it something less that can be 
evaluated in terms of the potential adverse effects on an individual, whether they be physical or psychological or behavioral?

Mr. JAMES JOHNSTON. The definitions of addiction have changed over time; not based on new learning, but based on looser and looser definitions of what addiction really is. You'll recall earlier today it was mentioned the 1964 Surgeon General's report said cigarettes are not addictive. They're habit-forming, they're not addictive. There was no new learning between 1964 and 1988.

The goalpost was moved. The definition was changed. But we come back to what's a common sense definition of addiction. As we've tried to look through some of the literature-this is sworn testimony. I'm obviously telling the truth. I will submit this for the record. I came across an article in the British Journal of Addiction, peer reviewed journal, saying that carrots can be addictive and even more so than cigarettes.

[The article referred to follows:] 
-

\title{
RESEARCH REPORT
}

\section{Can carrots be addictive? An extraordinary form of drug dependence}

\section{LUDĔK ČERNÝ' \& KAREL ČERNÝ?}

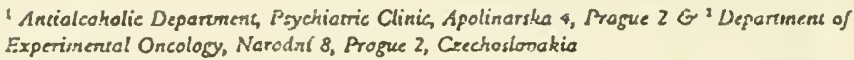

\begin{abstract}
Abacrace
The paper describes etree easet of dependence on carotenoids with typieal symptoms of irrilability and nervousress accompanying their abstinence, with a long-lerm dependence, and an inability to stmply disconsinue. Threc pesionis (a man and 5000 women) alt being smokers, enaluated this dependence as very simller to that on tobaceo. The limitotion of further wse had the same effea in hoch cares. The women evalucte the dependence as stronger then that on cifarcues, the man as somerathat weaker. The former partent-o womsn-coer relopsed, and reesntly found herself in danger of funther zelapse. This, howeorr, she nipped in

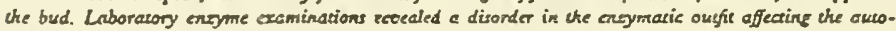
inmuniry and the neurooegctarive syscesi.
\end{abstract}

\section{Iatroduction}

Cases of hypescarotenemia are etcountered in the literature oxtly sporadicaliy. Case scudies have described the physical changes due to malnutition, demal changer, partioutady in childien but bave left the psychological states of these cases varecorded. ${ }^{1,2 . a-1}$ Illugher \& Worted uter wich byperceroteacenia es eariy as 1919 , refercace is made to it ia useic wosk The Orange prople? The subjests were two agricultural warkers strose dict had consieted predominantly of eacroes und inmatocs. Their skels was orange in colour. The study includes no deceription whatsoevec of their pryctiologieal statc. No reference is made so their furtber life bisturg.

In my mychiattic practice I have eacourtered three easos of hyperesfoteneatia, accompanied by irpical symptoms of drug depradeace.

\section{Aanlynia}

I catte across the first ease of chis kied at carly as 1951 in the Prugue poychistric clonic where 35- yearold womsa was hespicalised because of a neurotic disturtance and the wras consumiag epproxinazely I kg of suw carrors dzily. Hez skia as well as the selerae of ber eyes were coloured datk orsage. Casrocs were nost difficuls to procure in vinter bat she bad to get hold of them at any peice. Their lack made her suffer from typiesl wichdrawal sympeoms with a marked nervoriscess state. Afcee discharge from hospital, she was fort to follow-up.

Ic 1985, a 38-year-old nurse attended for help. Pacient A. L. was born in 1947 and maeked as a nurse. Stre had commenoed smokiag ac $i 8$ years of arc, stopped during pregancy and at preseatacioa the strioked 20 sigaretces daily. Stre coasumed alcohol ooly occasionally and also occesionally drank 2-3 cups of coffee daily whea ac work, but only one cup when at home. Ste is merried with oae daugher.

Sbe stared consuming carrots during bec, first pregancy in 1970 whea she sultered from eardialgie and execes acidity of acomzch fluids, eccompan- 
ied by hyperemesus. Being unable to rolerste fruirs, she touk to consuniug vegetables in large quantutier. Ia a forinight she consumed a bed of young carrots. She soon foucd that she rook plearure in it, or wo the said. Sbe ate carrors ia this maneer ead quectity throughout her pregnancy. After childbirch, the stopred eating carrnes and returned to normal. She extimared that she lad consumed two and a half sacks of eatrots during her pregnancy. She noted thot her skin becanic iutertsely yellow.

ller seomach troubles accompanied by occasional vumiting recurted in 1985. She resumed eating carcots regularly and in che course of a single week, the ste $1 \mathrm{~kg}$ of carrots daily. Carrots bad to be eaten raw. Cooked carrors failed to queach her eraving. Her desire became sn intense that sbe preserved the carrots peelings as a reserve supply. Io the winter months and particularly in sprine, when catrots lose much af their pleasant flavour and become racher bitter, she added sugaz to them. If she tan out of eerroe a itic wcekend, she would $25 \mathrm{k}$ a neighbour to give her some. Wben no caerout were available, she beeme desperacely nervous. Sometimes she would bite off a meuthful of carrot evea before washing is. In the mocring ste would feel desire for carrots and would peel and eat thean even oa her way to work. Her acquaintances began to make fun of her and even to seald her. She tbea resorted to purchasing and eacing carrots sectedy. Aaother cime, in the pecrtises of the herse-racing course where she often comes in company with her daughter, large enses loaded with earrots were delivered to the stables. She had nothing with her th pue the carrots is. IIer eraving for carrots was to interse that she weat to borrov a plascic bag and towk the carrots directly from the discharged cases. She had iried to reduce ber earrot consumpelon scveral times trat all her efforts have failed. Of iace, due to pour market supply of cirrots, she has actempted to cure herself of this habic. Sbe is psrtly successful and cruoches somethiag else instcad, is. radishes. At the same lime she is coasiderably nervous. Sthe has neciced tendeacy to more copious bleeding but ao other ditticulies sre invalved.

The naicat is subjected to a conesnuous folluw up. Duriog her last sheck-up khe impared the inforation that 2 ycart sto she for rid of ber depeudence un carrots-chess ste complacly left out of her menu. About Cibristmas 1090 , she iated carrots several rimes wheil cooking, and sain found thern appealing to ber palate. She realized that she rripht quickly become dependeot on them agzin. When this was broughu hame to hes, she maaged to stop taking carrula in lime. Al present she has no difficultics.

Somatoneurological fandings were wichin the aorm Ker skin is orange in colour, especially the undersurfaces of her fect and her paiuss. A complex examination of the level of teticol, carocenoids in general, ad beta-carotene in the rerum, as well us of same eazymatic systems including the deternins. cion of the enzymatic activicy of the following parametees was earried nut. The test battery applied hete was recomutiended after a consultation with speciallsts in interual diseases about the possibilicies of rentering certaio biological shanges. These teats corer the ztea of the description of livcr, cardiac and acurovegerative disezses recommended by the Ger. man Mcdical Chamber tor the purposes of eliuical diagnostics. In compliancs with the results of enzymatic rexts, mecabolle disorders in the enzyma. is pattem can be distinguished In great detail, and the patieat's metabolic condition as well as his disease can be monitored by mcthods non-agressive ia loag-term applieation.

Our material thow a macked impairment of the patieat's eazymex. A garticularly marked intesifieacion of activity bas been found in aldolese (AT.D) 25 well as cerebral creatinkinase (CK B) and lipase. Lower values in comparisnn with the norm were found in arglesternse (AE), alkaline phosphomonoexrecase (AP), ad ebolinesterase (CHS). Her bigh cartot ineake resulced in substantially higher vaiuea of retinol, bets-cacoteat and earotedoids in general A predouiazat cepresentation of lycopens and plant earotenoids were found in the serum.

In evaluacing the profile of the patient's enzymes, it oury be siated that clie patient's dependence on carroes lod ro a mecabolic imbalance. After 1 longteem monitoring of the patienc's condition, the decected changes were found to depend on the quantity of consumed carrous, and, afier a relatively long bstineres, they retuen to normal. In il probsbility, the changes involved are not persisteac.

Oue third case was a 40-year-old oran, J. T. who vas uadergoine treatment for multiple celeronis. In spolag 1983 , te turned up at an mati-smaking advice centre in Prpgue askiag for belp to stop smoking. II bed made nunkerous unaurcervful attenyets to stap liumall because of his coccerns for this general liealth. Ilis wife bad advised thus it was arcersary to replace cigareter wish somechiog elee and rec omracndad subsitute - iruit, or crunching some vegetables. She gave hiro carroes and he found that it helped hutn to forget abour cigareete: He was aoon cating cascols consunaly, consuming up to five 
bunclies 2 day, and as it was spriag he puc himself to considerable expense. Itis craving for earrors becarne as uigent as his previous cravlag for cigarertes Whenever the image of earrots entered his mind, of whenever he happeacd to eateb sight of them, be immediately inagined himself eacing them and started yesening for them. The cousumption of eartuls stopped his urge for something, and again be helped hizuself 10 carrots. If a sufGeicar amount of cartors were svailable, he would eruneh them in rapid succession-this perfecely supplanied the cigarettes and, in the same way, it was fixed in his consciousness. Ife ate che carrots at home but aiso could not resist eating them in public. Whea be went shopping, the felt compelled to eat the carrots he had ale eady bought on his way tome on the tsain.

The anti-smoking advice ceacee advised him - gainst such habirual cartol consumption. He irumediately seaseed doing his level best to give up carrots. Although the hathit was oor a: strong os the dependence on cigarettes, it rook birn a long time to suppress it compictely. He weat on buying castors throughout the summer-be was, however, canscious of the recessity to be oa his gursd. \&i was ody in autumn when cerrous became rare in the market that he slopped esting teen. In spriag 1989 he did not feel compelled to indulge in eating carrots any more, though he eoncinues to like them even aow.

After this visits to the adrice eenure be suceessfully scopped smoking and abreined from to for 4 months. However, he relaped aftes some stress situation at work.

\section{Diseuskion}

The thrce cases of raw-earrot abuse described bere are semarkable fur giving rise to a psychic depeadence, identical with drig addiction is defioed by the wiln (1969), in all the three allected persons -iwo women ad one man. The lsck of carrocs made them lapse iato a state of beighteand irritability, nervousness. The withdrawal syedrome is so intense that the afticted persons get bold of and consume carrots even in socialty quite uascoeprable situatious. In view of the fact that both the pasicats described in detril were also smokers, it was possible to discuss with them the inteasity of tbe depeadence. The patient A $L$ stated that the psychic diffieulties caused by a lack of carrots were far more Intensive than those called forth by a lact of cigarctes. The quality of difficulcies is the same as in the cese of amoking. The paticoe J. T. meacioced she same difficulties as the above patieat but evaluated their inteosity as somcwat leaser than in sunoking. This patieal, however, had oo: been consuming eartots for such a loog tirne as the patiene A. 6. The ascertainment chat raw catrots have the same elfects as drugs of the wicotine type see me thinking what substance in cerrors might be is. volved. The Gest to ence into consideration was the biologically active carotene.

For the ume being, howeves, I cannot discount ithe possibility that catrots may contain enother active substance conducive to drug addiction. In this atca, experimeatation seems necessary. This is why the aim of this communication is 20 dea competent specialist's attertien to this odd quality of earrots. A bighec carrn intake resulted in a mesabolic disorder particularty is the ares of the auto-imenuaity system, the neurovegeturive system and the central aervous system, as is the case is neuruses. The condition improved afeer giving up the coasuaption of carrots. Also the recurring relapse in pacieat o L L was iaterescing -it was similar to tbat found with other drus types.

\section{Refereoces}

1. Coner, L. B. (1985) Obacrvation on eerorencariz, Annuslis of Insmal Medicina, 18, pp. 239-227.

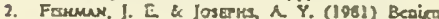
esroteoemia, Arehices of Diseases in Chistiond 56. p. 965 .

3. Ilucuns, J. D. \& $\nabla_{\infty}$ oren, R. L (1966) The orsage people, Joumal of the Ameriean Hedical Associatiom

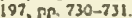

4. KnG, C \& Muruno, G. (1960) Mysterious diecary aypercarotenemin, Cinical kescarch, 28, p. 231.

5. uscus , A. D. (1981) Caroreocania, Cinical Pedie. irics, 20, p. 25.

6. PATter H. DUN, H. G. THater B of at (1973) Ceroceaemis is meatally recurded childrea, Conedlan Aredical Arociarion Joumai, 108, pp. 848-852.

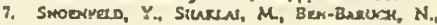
Ifikscrose, M. \& Pindunes, j. (1982) Neutropenie iuduced by hyperearorenerria, Lancet, it, p. 1245.

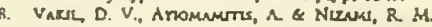
(1985) Hypercarotenemix, Nucritic Research, 5, Pp. 911-917. 
Mr. JAMES JOHNSTON. The facts are and the studies that are out there suggest that nicotine and caffeine have similar-that they are-in terms of effect and so forth on people-very similar in terms of how they effect the central nervous system and the fact that when you stop using the product, if you choose to do that, you may experience some symptoms of withdrawal, almost precisely the same ones from caffeine as from nicotine.

But we get to these characterizations of nicotine being like cocaine and heroin that are scary. They're scary because they may actually mislead people as to what the

Mr. MCMILLAN. If nicotine has those characteristics of addiction and there are people who are out there who are seeking to abuse the public by marketing excess amounts of it or, as we do, arguably, with respect to alcohol or other things, why isn't somebody out there producing a high nicotine product specifically to take advantage of the fact that it's presumably addictive?

Mr. JAMES JOHNSTON. If some of the suggestions that have been offered in the days leading up to this hearing were seriously taken, that's what we would all be producing. If we just chop up the tobacco and roll it into a piece of paper, the amount of nicotine then provided to smokers will go up 300 to 400 percent. Yet, we have this remarkable record of reducing nicotine and somehow we're challenged about it. I don't get it.

Mr. MCMillan. I would say that if the other side succeeds in banning the production and distribution of legal tobacco products in the United States, then precisely that kind of thing is likely to occur. It will go off-shore. It won't be taxed. It will find its way in the market. It will create an enormous crime apparatus through selling and distributing it, and it will probably have an extraordinarily high, artificially high content of additives to make it more appealing.

Mr. JAMES JOHNSTON. There is some indication that just that happened in Canada. When they went to very high taxes, not only was the contraband issue overwhelming, which is why they reduced the tax recently by 50 percent, but they found people drifting to higher tar, higher nicotine cigarettes because of the price.

Consumers naturally moved that way, saying I can smoke fewer cigarettes and that sort of thing. The crime element is what drove Canada to bring their taxes down. It should not be the policy of this government to say I will discourage you from smoking by making it too expensive for you.

That's the government knowing better than adults know. Let them make their choices. Let them make informed choices.

Mr. MCMILLAN. I don't think we're arguing here about full and adequate disclosure of what's in a cigarette or in alcohol. That's something that I think we can all get behind. Ard, also, what is above the normal terms of acceptable content. We allow extraordinary amounts of alcohol by proof in the consumer products that we sell.

What's important is that consumers understand how to regulate content. We come at that and deal with it in a different way. We have DUI laws to deal with alcohol in terms of the way it can be threatening to others. We don't have that driving under the influence of nicotine laws out there. 
I think that's an example of how we need to be sensible about dealing with this.

I had one other question for Dr. Spears and I wanted to clarify, if I might, because I'm not sure your response to the chairman's questions came across all that clearly.

Yesterday, you were accused publicly of making misrepresentations to this subcommittee the last time you appeared. Specifically, this charge arose from a 1981 article that you authored that told how the level of nicotine in a tobacco product can be changed by blending different types of tobacco which have differing nicotine contents.

This discussion from your article was presented as conclusive proof that cigarette manufacturers manipulate nicotine in cigarettes and you should stand accused of hiding this supposed "secret" fact.

Dr. Spears, if you would turn to your written statement from March 25, if you have it, and read the last sentence on the first page. If you don't have that, I-

Mr. SPEARS. I'm sorry. I do not have it.

Mr. MCiMillan. I would be glad to read that, and I quote, "The level of nicotine in the tobacco of our products is solely determined by the tobacco that we buy and blending of the different tobaccos during manufacturing. The tar and nicotine yields of our products are determined by a combination of the tobacco blends and the construction of the cigarette; that is, length, circumference, filter, tip ventilation, tobacco density, et cetera. The Federal Trade Commission has reported the results of tar and nicotine analysis by brand for years."

I will finish in just a minute, Mr. Chairman, if I may. Dr. Spears, in fact, you told the committee on March 25 what you said in your article, didn't you?

Mr. SPEARS. Yes, I did.

Mr. MCMillan. They were consistent.

Mr. SPEARS. They were consistent.

Mr. MCMILlan. I think that it's very clear, then, that some of the allegations that have been made with respect to your testimony, which, at that time, was perfectly clear, have been distorted and I simply wanted to interject that again to give you an opportunity to set the record straight on that point.

Mr. SPEARS. Thank you. I'd like to say something further on the concentration of nicotine in tobacco since that was one of the misinterpretations and statements made. I think Mr. Waxman stillhe is not a believer that there's no correlation between the concentration in tobacco and the FTC nicotine yield.

I'd like to read from this paper that I was handed from the New England Journal of Medicine by Neal Benowitz, the first paragraph under results. [See p. 724.] "Cigarette tobacco contained an average of 1.57 percent of nicotine. Neither the concentration of nicotine in the tobacco nor the total amount of nicotine in the cigarette correlated positively with the Federal Trade Commission machine delivery estimate.

"In fact, among the cigarette brands sampled, there was a significant inverse correlation between nicotine concentrations in tobacco and the nicotine delivered," which says, again, if a higher con- 
centration of tobacco-in this study, he found lower levels in the smoke.

I think, again, that's exactly what I said and what I've taken issue with in the chairman's press conference yesterday, a misstatement, not in this regard-in this regard.

Mr. WAXMAN. Thank you, Mr. McMillan. I think you're turning the world on its head, but it's not my turn to get into the questions. I'll get there in a minute. Mr. Wyden, your turn.

Mr. WydEN. Thank you, Mr. Chairman. Gentlemen, I'd like to turn again to the matter of children in our country smoking. I mentioned I've got young children. Millions of parents, of course, do, as well. I note that the Federal Government has found the Centers for Disease Control, and I quote, "Approximately 75 percent of current smokers become addicted to tobacco by age 18," generally before it was even legal for them to purchase tobacco products.

I'd like to start at this point by asking how many of you have children or grandchildren. If you would, just raise your hand, either children or grandchildren.

[Show of hands.]

Mr. WYDEN. Almost everybody. Good. My situation. I know that you all have been asked in the past about whether you would want your kids or your grand-kids to smoke and I have listened very carefully to the response that you've made.

In the past, when you all have been asked this question about whether you would want your kids or your grand-kids to smoke, the position of executives and others has been that this is an individual decision to be made by adults, and I have heard that stated on many occasions. I agree with you on that. No question about it. It is a decision that should be made by adults.

But I'm not going to ask you that question this morning. What I'd like to ask each of you with children is I'd like to ask each of you if you had your preference, would you want your kids or your grand-kids to smoke or not smoke? If you had your preference. Let's start with you, Mr. Campbell.

Mr. CAMPBELL. I have no preference.

Mr. WYDEN. It wouldn't bother you if your kids smoked.

Mr. CAMPBELL. Well, I think that in the end, the most important part, I've answered some of these questions earlier, is that the most important part is that our children be given information about all of these kinds of things, smoking and drugs and alcohol and sex and disease. I think that we're doing a good job of that and I think that the Congress of the United States is leading that.

Mr. WYDEN. But after all that information is given, it wouldn't bother you if your kids smoked.

Mr. CAMPBELL. I have to accept that my children are going to take risks, whether I like them to or not. I would prefer my kids have no risks.

Mr. JAMES JOHNSTON. Mr. Congressman, I do not want my children to smoke. I do not want your children to smoke or anyone else's children to smoke.

Mr. WYDEN. Thank you.

Mr. JAMES JOHNSTON. I want adults to smoke.

Mr. WYDEN. Thank you. I agree with that answer. 
Mr. TADDEO. I wouldn't want any children to use our product, any child.

Mr. Tisch. Mr. Wyden, I have stated in the past and I truly believe that smoking is an adult decision. I've got a 15-year-old son who is sitting in this room today and I have told him in the past that I would prefer that-first of all, I don't want him to make that decision until he's 18 years old and that when he's 18 years old, I want him to make a fully informed decision based on all the information available.

Mr. WYDEN. Mr. Tisch, with all due respect, the question I'm asking you is

Mr. TISCH. May I finish?

Mr. WYDEN. Please.

Mr. TiSCH. I think I will get to your question very quickly. I would prefer that he not smoke.

Mr. WYDEN. Thank you.

Mr. HORRIGAN. I have four children, all of whom are married. Neither my wife or I smoke. All of them smoke and they made their own decisions free and independent of any lifestyle that they saw in our home.

Mr. WYDEN. So you have no preference.

Mr. HORRIGAN. We have no preference.

Mr. WYDEN. All right.

Mr. SANDEFUR. I have no children.

Mr. WYDEN. All right. We'll let you off the hook.

Mr. DONALD JOHNSTON. I have two children who are adults. One is a smoker and one is not. I believe it's right that they should have the right to make their own choice and an informed choice. I would not have a preference for them to be smoking as children.

Mr. JAMES JOHNSTON. Mr. Congressman, I misspoke a moment ago. I'd like to correct it for the record. I said I want adults to smoke. That is not what I mean to communicate. I want adults to make that decision for themselves.

Mr. WYDEN. But you still don't want your child to smoke or I guess your grandchild, is that right?

Mr. JAMES JOHNSTON. I have three children, sir.

Mr. WYDEN. OK. Let me ask you, Mr. Johnston. I note that advertising age, for example, a publication that is truly committed to advertising, First Amendment and the like, in January of 1992, said that the Joe Camel ads encourage youngsters to smoke and urge that the ad be dropped.

Now, that is not exactly a - that's not even a health organ. That's an advertising organ. How do you react when even pro-advertising publications, publications that are dedicated to making money on advertising, say that you're zeroing in on kids?

Mr. JAMES JOHNSTON. Let's make sure that we're defining the term properly here. When I talk about children, it is those under the legal age to smoke. Just so we're clear on that.

Mr. WYDEN. But this publication said that your ad-this is not the American Medical Association. This is an advertising publication-said that it is zeroing in on kids and urged you to drop it.

Mr. JAMES JOHNSTON. My recollection is that was not the thrust of their editorial, but, rather, that those accusations would bring this reign of terror on cigarette advertising in general. So, there- 
fore, even if the company was right, they should cave in. And let me tell you it would be wrong and irresponsible for me if the facts don't support pulling that campaign, you know, I believe, and I know that this would not be the end of it. They would next go after the cowboy or the Newport advertiser or something else because the goal of the anti-smoking industry is to ban advertising so that we

Mr. WydEN. Sir, I'm not for banning cigarettes. I just want to make sure that youngsters don't get started, because the evidence shows that 75 percent of the smokers are hooked before they're 18 . You've got an advertising publication that makes its revenue on advertising and even they are saying that you all are zeroing in on it.

I guess your answer is, and let's keep it for the record and it's a clever one, that somehow this is going to lead to some wild reign of terror. But the fact of the matter is even publications that are dedicated to advertising revenue say that they are concerned that your practice is to go after kids.

The fact of the matter is we see it every day. You promote your products involving music and sports and parties. It's cool. There's an in-your-face kind of element. I just think now it's reached the point where even advertisers are having these concerns of conscience that I and other parents have. I hope that you all will get the message.

Mr. Chairman, let me, if I might-and I realize that this is unusual and out of order, but we have a young man with us today, Robert-I believe you pronounce his name Frenchis. He is a young man who testified at our hearing on second-hand smoke, about how he and other children don't want to be caught up in all this disease.

I think it would be very appropriate and very helpful if we could call this young man forward. I would realize it would have to be with the consent of all our members and we don't seem to have any on the other side, but I'd sure like to have these executives hear from this young man.

Maybe we could wait and obtain

Mr. WAXMAN. You have a few minutes left of your time.

Mr. WYDEN. That will be fine.

Mr. WAXMan. What will be fine?

Mr. WyDEN. Excuse me. I would like to have him come now. I do want to make it clear that I recognize this is unusual.

Mr. WAXMAN. You want him to make a very brief statement.

Mr. WYDEN. I would like that, yes.

Mr. WAXMAN. And take part of your time.

Mr. WydEN. Yes, please.

Mr. WAXMAN. Why don't we have him do that? Robert, why don't you come over? Why don't you speak right into that mike, if you'll turn it around, Mr. Sandefur. We're going to hear from Robert.

\section{TESTIMONY OF ROBERT FRENCHIS}

Mr. Frenchis. Hello. My name is Robert James Frenchis and I am 7 years old. I go to AMT Elementary School in Lake Ridge, Va., and I am in the first grade. I like to ice skate, play soccer and 
swim, but sometimes it is hard for me to do these things when I get sick with asthma and can't breathe very well.

This happens sometimes when I come in contact with tobacco smoke. When I smell it, I cough a lot and my eyes get red and real puffy. My breathing becomes more difficult and often my chest gets real sore. I also get headaches. After being around cigarettes, I usually have to take a lot of medicine to keep from getting worse and to get better.

Cigarette smoke keeps me from doing some of the things I'd like to do, like bowling. I can't go bowling because most alleys let people smoke. It hurts when I can't go bowling like other people.

It makes me feel different from my friends. I wish there were alleys where people can't smoke. Kids like me would have more fun and would not have to worry about getting sick.

There are some places I can go. I can go to shopping centers with mom and to most ball games. I can even go to some restaurants. When I go there, it's best if there is no smoking so I can stay well, because it hurts people like me who have asthma and can cause lung cancer, even in non-smokers.

If I could, I would tell the President to make it the law that no one smoke in public places. He should do the same thing with cigarettes that they are doing with guns. Turn them in for money or other things to get people off smoking.

I would also tell people who smoke it hurts them and especially other people, too. This is also important for parents who smoke at home to know, too. They need to realize what their smoking does to others around them.

I hope the government will help kids like me because growing up around cigarette smoke is hard. Clean air would help me to live like my friends and get to do all of those things that I would like to do.

Mr. WYDEN. Robert, you said it better than any Member of Congress could possibly have said it and thanks for coming and being here to speak up for all the kids. Thank you.

Mr. WAXMAN. Thank you, Robert. We're going to take a break for 10 minutes while we respond to a vote and give everybody a chance for a breather. So we'll reconvene as soon as we returm from the vote in 10 minutes.

[Brief recess.]

Mr. WAXMAN. The meeting will come to order. Mr. Bryant.

Mr. BRYANT. I will yield to my colleague from Oregon, Mr. Wyden.

Mr. Wyden. Thank you very much, Mr. Chairman and my colleague. As we heard from the young witness earlier, kids face a very serious health threat even if they don't smoke. There's overwhelming evidence that the cigarettes that you all make bring misery and disease to thousands of children across America, kids who didn't succumb to the advertising, children who don't smoke.

But their only mistake is to be near someone who does and to be too little and too powerless to stop this second-hand smoke. I'd like to know what each of you say to Robert, starting with you, Mr. Campbell.

Mr. CAMPBELL. I'd say people that smoke around you, Robert, are inconsiderate and you should always ask them not to smoke in 
your company and you should avoid smoke so that you feel well as much as you possibly can.

Mr. WYDEN. How can he do that if he's in a building, for example? This kid is 7 years old. How is he going to go out and clear out the building and tell everybody not to smoke?

Mr. CAMPBELL. I think that the majority of people in America are very considerate, and particularly smokers. In fact, I think you now know that smokers and non-smokers alike believe that they can get along with an accommodation policy, that there's restricted areas for smoking.

Mr. WYDEN. If everybody is so considerate, I don't know how it is that the Federal Government has found that the smoke causes more than 150,000 cases of lower respiratory disease, like bronchitis, in young kids less than 2 . What would you say to Robert, Mr. Johnston? I'd go to you next.

Mr. JAMES JOHNSTON. Robert is a delightful young man. I listenedvery carefully to what he had to say. I agree with Mr. Campbell that smokers will respect non-smokers. Are there a few rude smokers? Of course, there are, and there are rude non-smokers. But 70 percent of the American population believes that smokers and non-smokers working together can accommodate one another.

Mr. WydEN. But Robert is not causing cancer in the smokers. The smokers are causing the young people to get sick. I think this is all nice to kind of gloss it over and say let's all be happy to each other, but 7 years old, he doesn't have the power to stop this. It seems to me that you all are pretty indifferent to it, too. Sir, what would you say to Robert? He wants to stop it.

Mr. TADDEO. I'd have Robert talk to his parents and see if accommodations could be made to help him out.

Mr. WYDEN. His parents aren't the problem? The problem is the smokers around him. What? Is his parent going to go beat up somebody who smokes?

Mr. TADDEO. No. The place he was talking about, the bowling alley, certainly his parents could talk to the management of the bowling alley, tell them about Robert's situation, and make accommodations. That's what I would tell him.

Mr. WydEN. Mr. Tisch? It seems to me, too, if everybody respected each other the way you all advocate in this sort of wonderful world that doesn't exist, we wouldn't have this problem. We've got the problem because people don't go along with the kind of thing that you all are talking about. Mr. Tisch?

Mr. TisCH. Mr. Wyden, we also, and you'll not hear anything different from me, but we are in favor of an accommodation between smokers and non-smokers.

Mr. WYDEN. Do you support the Waxman legislation then to restrict smoking in these buildings?

Mr. Tisch. No, sir, I don't.

Mr. WYDEN. What kind of -all of this is happy talk. Robert doesn't want to get sick. All this business about accommodation is just great, but the fact of the matter is when the rubber hits the road, he's powerless. Mr. Waxman wants to give Robert and the other children in this country some power so they aren't going to get sick. 
You say you're opposed to it, but you're in favor of some accommodation. I think that's unfortunate. I hope your children and your grandchildren don't get sick as a result.

Mr. Horrigan?

Mr. HORRIGAN. I think over the years and since the issue has become more high profile, you have obviously seen a huge increase in the population, the smoking population, and their appreciation and respect for others. So I think that will continue. They will respect the rights of others. As Mr. Johnston said, there are rude non-smokers, as well, but I think it is a matter of accommodation.

I just happened to see Dave Thomas, the founder of Wendy's, yesterday in the hotel. He's a non-smoker and he said what's going to happen with all this prohibition of smoking in public places and restaurants. Are they managers or are they policemen? And he's a non-smoker, but he believes his customers who smoke have the right to smoke under the right circumstances, and that's my position, too.

Mr. WydEN. The Chain Restaurant Association supports the efforts of Mr. Waxman and the other supporters of the bill. Mr. Sandefur? Excuse me.

Mr. SANDEFUR. I would suggest that Robert's parents tell him that there are things in life that he's going to come in contact with in growing up that he doesn't have control over, because we live in a free society and we have choices to make and smokers have choices, as well as non-smokers to be around people who smoke.

Mr. WYDEN. What you said is it's more important for smokers to smoke-

Mr. SANDEFUR. I did not say it was more important.

Mr. WYDEN. But you said if it comes down to it, it's OK to let smokers smoke. So Robert is going to stay home from school because he's sick. I think that's unfortunate, as well. Mr. Johnston?

Mr. DONALD JOHNSTON. I listened carefully, too, to what Robert said and I, too, think it's an issue of accommodation and smokers and non-smokers accommodating each other.

I'm not convinced that further legislation is required to ensure that accommodation.

Mr. WydEN. Mr. Chairman, the gentleman from Texas has been very gracious to give me this time. I'd like to hear more about how your accommodations are going to work in the real world? I think what you all have done is reconstructed reality with respect to the smoking situation. The reality is it causes people to get sick. The reality is that it's addictive. The reality is that second-hand smoke is a problem and you've just reconstructed reality to say that this is really no big deal.

Mr. WAXMaN. Mr. Wyden, if you'll yield to me or Mr. Bryant will yield just to make one comment. I don't know if you're all aware of the fact that my legislation on environmental tobacco smoke would allow an accommodation for smokers in separately ventilated areas. In that way, the non-smoker is not forced to breathe in the tobacco smoke that's going to be permeating the same room and that a kid like Robert Frenchis is going to have a real difficult time if he's in the room with smokers. 
So while you've all said you want accommodations, I think the legislation does make those accommodations and I hope you'll take another look at it.

Mr. BRYANT. Thank you, Mr. Chairman. I think there is an anomaly that sort of surfaced in the questioning about kids a minute ago. Mr. Johnston, you and others said that you are working very hard to keep kids from smoking, or you are trying to avoid luring them into smoking.

I, frankly, think that the Joe Camel advertising campaign contradicts that very forcefully. But even if it is true, why are you working hard to keep kids from smoking if, indeed, smoking does not involve any risk to one's health?

Mr. JAMES JOHNSTON. Our market is adult smokers. I have a huge opportunity to increase my market share at these other people's expense. I need the ability to advertise in order to do that. Every time a kid lights up a cigarette, we get accused of luring kids in and tempting them into our products, and that results in calls for specific ads to be banned or all ads to be banned.

It would be stupid and crazy for me to threaten my ability to advertise by targeting kids.

Mr. BRYANT. But today we are having a hearing, though, and we are trying to find out what you say about your side of these issues. And you said very forcefully today "I don't want kids to smoke."

Mr. JAMES JOHNSTON. That's right.

Mr. BRYANT. I think Mr. Tisch said he doesn't want his kids to smoke. You say you do not want to lure kids into smoking. Why not? If smoking does not hurt your health, why not?

Mr. JAMES JOHNSTON. Let me be clear about that. I was talking about under-age kids.

Mr. BRYANT. I am talking about kids, anybody under, say, 18.

Mr. JAMES JOHNSTON. I have a 25-year-old kid, but I didn't mean-

Mr. BRYANT. We are using time up here unnecessarily. I am talking about kids, people under 18 years old.

Mr. JAMES JOHNSTON. Under age. Let's be specific. Smoking has health risk factors associated with it. It is very important for smoking or drinking or voting in this country that people be fully informed in order to exercise intelligent choices.

Mr. BRYANT. So you acknowledge that it does entail dangers to your health.

Mr. JAMES JOHNSTON. It entails clear health risks, yes. There are risk factors associated. I don't deny the statistical evidence. It is a risk factor, yes, sir.

Mr. BRYANT. You have talked about-I am going to ask Mr. Campbell about this one-about all the efforts that have been made to reduce nicotine in cigarettes. But if, indeed, nicotine is not addictive and it is not harmful, why is it helpful to your case that you are working hard and have succeeded in reducing levels of nicotine?

Mr. CAMPBell. We don't in any way imply that we just do what our consumers want. We did some polling, some research. They told us that they'd be interested in no-nicotine cigarettes, so we offered one. We've tried very hard to lower tar numbers over the past. 
Essentially, we're just responding to our consumers' expressed wants in the way of new products and that allows me the opportunity to try to get some of my colleagues' business.

Mr. BRYANT. Let me ask you about that. We have a chart thatit is Exhibit 13A, if we have it here, I would like you to see it, which shows the concentration of nicotine in three brands of your company's Merit cigarettes. The chart indicates that as the tar levels go down in your cigarettes, the nicotine concentration goes up. In fact, the highest tar brand of Merits, the regular Merit filters, actually has the lowest concentration of nicotine in the cigarettes.

[The exhibit follows:] 


\section{Percent Nicotine in Merit Cigarettes}

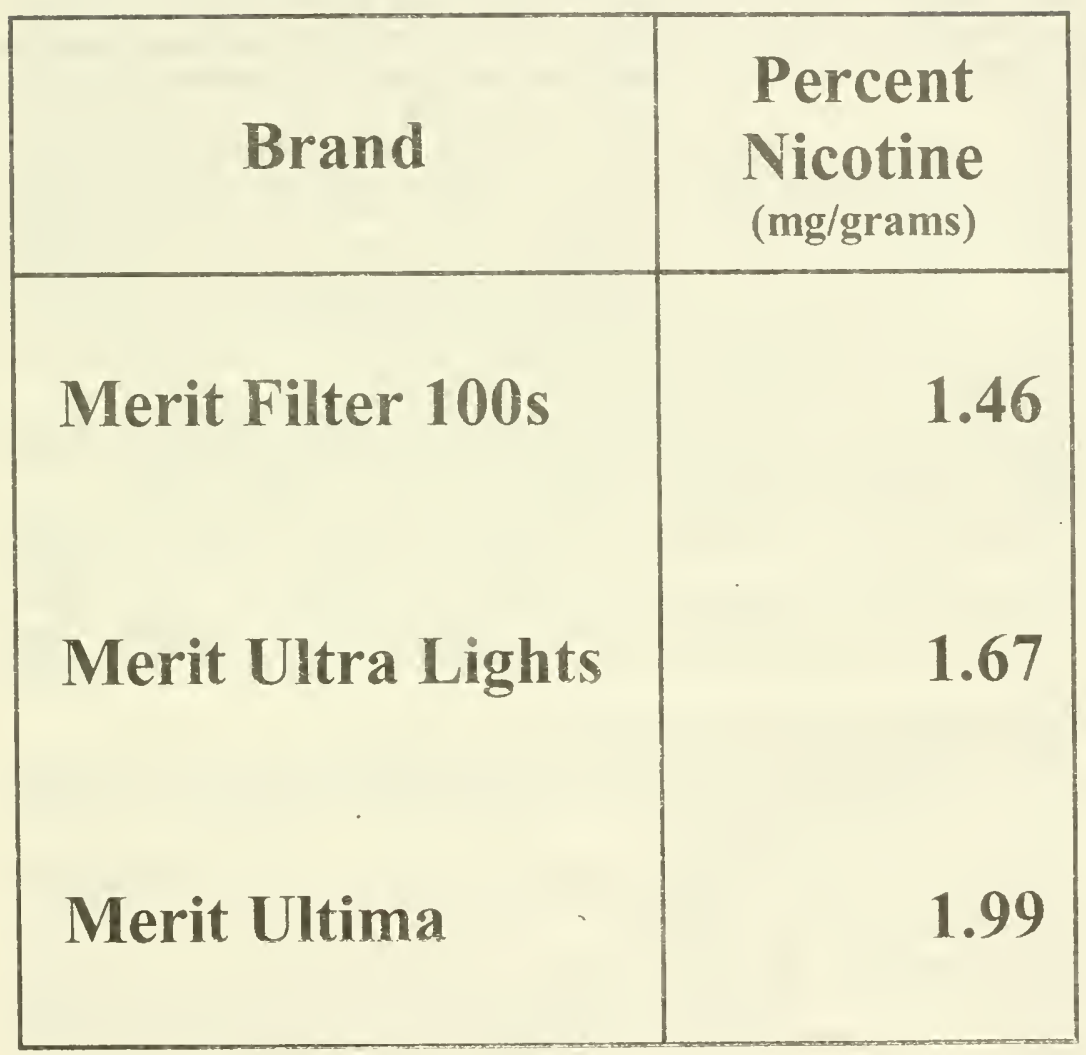

Source: FDA 
Mr. BRYANT. The lowest tar brand of Merits, the Ultima, actually has the highest concentration of nicotine, which would seem to imply that in making the Ultima, you use a tobacco blend with a higher concentration of nicotine than you used in making the Merit filters. Is that true?

Mr. CAMPBELL. We have been trying to get the background information to the equivalent of this chart from Dr. Kessler's office ever since it was published and we can't explain this data. We don't use this kind of measurement. So it's very difficult for us to answer.

Mr. BRYANT. You are in on the decisions about how to make the product. Did you use a tobacco blend with a higher concentration of nicotine in making Ultima than you used in making Merit filters?

Mr. CAmpBell. Absolutely not. In fact, I have a chart along with me, if you're willing to take the time to have my colleague $\mathrm{Mr}$. Burnely explain to you, for instance, the difference in how we make a Merit filter and a Merit Ultima and how we end up with 8 milligrams of tar and 0.6 milligrams of nicotine on a Merit filter and how we get it down to 1 milligram and 0.1 milligram of nicotine.

It will take a few minutes, but if you'd like to take the time, we'd be happy to explain to you how we do that.

Mr. BRYANT. What I am interested in is knowing whether or not you used a tobacco blend on purpose that has a higher concentration of nicotine in one cigarette than you did in another one.

Mr. CAMPBELl. No. We'd be happy to show you. What we do with the Merit Ultima is that we use some different grades of tobacco, but we only use 40 percent real tobacco, leaf tobacco, then we use reconstituted or processed tobacco and expanded tobacco. Then we-but the expanded tobacco means that you're taking the weight down.

Mr. BRYANT. The key question

Mr. CAMPBELl. So, in fact, you're taking the-there is no concentration of nicotine in these low tar cigarettes because of the way we've reduced the weight.

Mr. BRYANT. But the key question is whether you knowingly use a tobacco blend with a higher concentration of nicotine in one type than you do in another type.

Mr. CAMPBELl. We are not using-when it ends up, it is inside the rod and the way it is delivered to the consumer, we are delivering, in no uncertain terms, 1 milligram of tar and 0.1 milligrams of nicotine.

Mr. BRYANT. Let me just get a yes or no answer from you about this. Do you use a tobacco blend with a higher concentration of nicotine in making Ultima than you use in making Merit filters? Yes or no?

Mr. CAMPBELL. Are you taking into account both the leaf tobacco, the reconstituted and the expanded tobacco? The answer would be no.

Mr. BRYANT. Just the leaf tobacco.

Mr. CAMPBELL. That's only 40 percent of the tobacco.

Mr. BRYANT. OK. Well, with regard to that portion of the tobacco, yes or no?

Mr. CAMPBell. That tobacco is there for taste and flavor. We need the taste and flavor. 
Mr. BRYANT. I am just asking you. If you say it is 40 percent, then let us talk about 40 percent. With regard to that 40 percent of the cigarette that is leaf tobacco, do you use a tobacco blend with a higher concentration of nicotine in Ultima than you use in Merit filters?

Mr. Campbell. Yes, but it's irrelevant in terms of what the smoker gets in the end, because we use other tobaccos with lower nicotine to counteract that.

Mr. BRYANT. Mr. Sandefur, let me ask you a question about the Barclay cigarette that Brown \& Williamson makes. I think Barclay is marketed as a low tar cigarette, is that right?

Mr. SANDEFUR. Yes. It's marketed as an ultra-low tar cigarette, as agreed to by FTC and Federal Court.

Mr. BRYANT. I understand that the nicotine content of the tobacco used in Barclay cigarettes is 2.3 percent or higher. Is that correct?

Mr. SANDEFUR. 3.3 percent or higher.

Mr. BRYANT. 2.3 percent or higher.

Mr. RIEHL. That certainly sounds high to me.

Mr. BRYANT. Could you identify the gentleman who just spoke?

Mr. SANDEFUR. That was Mr. Riehl, in charge of our R\&D. You must understand that the FTC established the rating for Barclay. The machine that was used to measure Barclay, when we manufactured Barclay and we measured it, the machine, the FTC methodology measured it at 1 milligram tar. Exception was taken to that because of the design of the cigarette.

We took it to court. The court decided that we should talk with FTC and go with FTC, which we did, and the numbers are on the pack.

Mr. BRYANT. Let us stick with the Barclay cigarette. Are you saying that you do not know whether or not Barclay cigarette has a nicotine content from the tobacco of 2.3 percent or higher?

Mr. SANDEFUR. No, sir, I don't, because we don't-I don't make it a habit of looking at nicotine on my cigarettes.

Mr. BRYANT. The average nicotine content in tobacco is 1.7 percent. So if 2.3 percent is correct, 'it is 35 percent higher than the nicotine content in the average tobacco leaf. My question is do you deliberately mix the tobacco for the Barclay cigarette so that it will have a much higher concentration of nicotine?

Mr. SANDEFUR. I'm going to ask Mr. Riehl to answer that question. He is the blender on the cigarette.

Mr. RIEHL. No, sir. We blend for taste, not nicotine.

Mr. BRYANT. In order to obtain your goals with regard to taste, do you deliberately mix the tobacco for the Barclay cigarette so that it will have a much higher concentration of nicotine?

Mr. RIEHL. No, sir, we don't. We blend for taste.

Mr. BRYANT. Go ahead. I yield.

Mr. WAXMAN. I find this unbelievable. If you listen to what they're saying, they blend for taste, but they also say nicotine adds to the taste. So it seems to me that what's happening is you're blending the higher tobacco, the higher nicotine tobacco in some of these low tar cigarettes so it comes out, even though it may be low tar, with a higher nicotine label. 
And you may be right. You may think that's for taste, but it also produces a higher nicotine level. Isn't that what's happening in your products?

Mr. CAMPBEll. No, it isn't, sir, because we compensate. You're talking about milligrams per gram. We compensate in our ultra low tar cigarettes by using reconstituted tobacco and expanded tobacco. So that what the smoker gets is what we told-we say in our FTC advertisements, 0.1 milligram of nicotine.

But we basically, as I said, also, in my opening remarks, we do not blend for nicotine. Nicotine is a result. If you would join us, like the FDA experts did, you would find that we actually only ever measure nicotine in two places; one, before the tobacco enters the factory and then 18 months later after it's a finished product.

Mr. WAXMAN. Let me just usk you a factual question. Do you use a higher, a richer nicotine tobacco in your low tar cigarette products?

Mr. CAMPBELL. The total-there's only 484 milligrams of tobacco in an Ultima, in a Merit Ultima. There is 680 milligrams of tobacco in a full-fledged Merit. That's how the difference is-

Mr. WAXMAN. I'm not asking about tobacco. I'm asking about nicotine concentration. Is there a higher nicotine concentration in that tobacco because of blending?

Mr. CAMPBELl. Forty percent of the blend in a Merit Ultima has relatively higher alkaloid tobaccos. Then you have 60 percent of a Merit Ultima's blend is expanded and processed tobacco where the nicotine has been reduced.

So the consumer gets, in the end, 0.1 milligram of nicotine. We design cigarettes according to tar and that's why it's very difficult for all of us to express it as nicotine. We design in the early stages for tar.

Mr. WAXMAN. When you look at the concentration itself, which has a higher concentration, the Ultima or the regular?

Mr. CAMPBELL. That's a weight measurement. Weight measurement is not what the smoker gets, sir.

Mr. WAXMaN. My question is whether the nicotine concentration is higher? That should be an answer yes or no.

Mr. CAMPBELL. You are talking about concentration as if it'sthis is a-how we design a cigarette is we use a combination of weight and volume. What we're talking about is what the smoker actually gets.

Mr. WAXMAN. I'm asking about the concentration of nicotine in the tobacco. You have blended tobacco. I want to know if there's a higher concentration in that tobacco in the Ultima than there would be in the regular cigarette?

Mr. CAMPBELl. It's there for taste, yes, sir.

Mr. WAXMAN. Thank you very much.

Mr. BRYANT. Mr. Chairman, could I have-

Mr. WAXMAN. Yes.

Mr. BRYANT. Is it the fact that some tobacco leaf has a higher concentration of nicotine than another tobacco leaf?

Mr. CAMPBELl. Of course, yes.

Mr. BRYANT. Do you, when you are making cigarettes, ever choose a tobacco leaf with a higher concentration of nicotine on purpose? 
Mr. Campbell. We do not choose it for its nicotine, no, sir.

Mr. BRYANT. See, you always qualify the answers and that is why we get impatient and why we do what Mr. Horrigan does not like, we jump in and cut you off. I have asked you a simple yes or no question. It does not require a qualification.

Do you sometimes choose a tobacco leaf with a higher concentration of nicotine than at other times in order to make a specific cigarette?

Mr. CAMpbell. I can tell you under oath we blend for tar, sir. We do not blend for nicotine. I'm sorry. That's all I can answer.

Mr. BRYANT. Do you know which tobacco leaves have more nicotine than other tobacco leaves?

Mr. CAMPBELL. We know that from measurement, but we do not blend for it. I'm sorry. I really can't answer any further in that regard.

Mr. BRYANT. No need to apologize. Keep the microphone over there. You do not need to keep leaning back. I have some questions for you. You know some tobacco leaves have more nicotine than other tobacco leaves.

Mr. CAMPBELl. Yes, sir.

Mr. BRYANT. Is that correct?

Mr. CAMPBELL. Our people know that, yes.

Mr. BRYANT. For whatever reason, do you occasionally decide to use a higher nicotine content tobacco leaf to manufacture one brand than you do to manufacture another of your brands?

Mr. CAMPBELL. That's the end result. As I say, we do not design the product that way. We design the product for its category in the market, which is generally a tar category.

Mr. BRYANT. Why are you concerned about the implications of my question if nicotine is not addictive?

Mr. CAMPBELL. I think that this has been used extensively as if we have been undertaking some kind of sinister practice. We really resent that and we really have no sinister practices at all. We go about blending our cigarettes in order to make them competitive in the marketplace. And as I say, they're blended for tar.

Mr. BRYANT. Well, if nicotine is not addictive and it has no harmful characteristics in particular, why are you $\multimap$ or why is Mr. Johnston-somebody, suing $\mathrm{ABC}$ for alleging that you are manipulating the nicotine? If all you are really doing is manipulating it for the purposes of flavor, why do you not just say so-what if we are, it does not hurt anything. What is your answer to that?

Mr. CAMPBELL. The ABC charges are for the misrepresentation that we are spiking our products with nicotine.

Mr. BRYANT. My point is why bother to refute them if all you need to say is, well, so what, all we are doing is doing it for flavor, which is what you are saying to us today. If you are only doing it for flavor, why are you worried about the implications of that program?

Mr. CAMPBELL. We were very worried about the fact that our stock dropped the next day because there were some implications that we were doing something sinister.

Mr. BRYANT. My point is why not simply say there is nothing wrong? If you believe it, why do you not just say-there is nothing 
wrong with manipulating the levels of nicotine, if it is only for flavor?

Mr. CAMPBell. We don't do it. That's why I won't acknowledge it. I'm sorry.

Mr. BRYANT. I have just heard you say here that, yes, we do use tobacco leaves with varying levels of nicotine or to achieve a goal of a particular flavor. You have said that.

Mr. CAMPBELl. Yes, I have.

Mr. BRYANT. I rest my case. I do not think it adds up. I think I am over my time, Mr. Chairman.

Mr. CAMPBELL. Excuse me. Just one final point on that, Congressman Bryant. If we would have had available the FDA data on this brand family, we would have been able to do a better job of explanation. We have been asking repeatedly for this information, starting almost 2 weeks - as soon as we received the testimony, and we've just been unable to respond because we couldn't get the data.

So if you'd like a more-that doesn't help us answer your questions.

Mr. BRYANT. The data that would be necessary to answer my questions is exclusively in your possession, and that is-what kind of tobacco are you putting in your cigarettes. I do not think anybody else has that. I yield my time back.

Mr. WAXMAN. Thank you, Mr. Bryant. I'm going to try to clarify an issue that is getting to be very complicated and see if I can make it clear to everybody listening to this, although I think this panel understands it because I think what's happening is there's a manipulation of the information.

What this panel keeps on saying is that concentration is irrelevant to the FTC numbers. Dr. Spears cited Dr. Benowitz for that very conclusion. But the reason that the concentration is irrelevant to the FTC numbers is because the FTC numbers are irrelevant. The FTC numbers are, as Dr. Kessler testified before us, filled with difficulties because they can be distorted.

I have a chart that I think that would be the best way to talk about some of the distortions in the FTC numbers and why it's irrelevant.

The industry's argument is based on the FTC numbers and I would submit that the FTC numbers are meaningless. The tobacco industry has invented a variety of ways to manipulate the tests, according to Dr. Kessler. He went through many of these ways and here's a list of them. The FTC numbers are based on a smoking machine. That smoking machine could have two problems with it.

The smoking machine can distort what the actual smoker is receiving by way of nicotine because of the ventilation in the cigarette itself. The second thing that can be done to distort what the machine would take in is the faster burning cigarette. So if it's a faster burning cigarette, the machine will not take in as much nicotine. That's not what happens to smokers.

And Dr. Benowitz, rather than being quoted appropriately for Dr. Spears' proposition, concludes, and I want to read it, 'We conclude that smokers of low nicotine cigarettes do not consume less nicotine." That is our point. The reason they don't consume less nicotine is because the FTC numbers don't make any difference. It's 
what the smokers will actually take in, and that is related to concentrations.

I have a copy of an American Lung Association document, which I, without objection, will submit to the record, Exhibit 20.

This was a 1993 study. The study looked at the levels of continine, a biological mark of nicotine intake in the bodies of 300 smokers. The study found, and I quote, "Subject to smoked low yield brands at continued levels that were continine levels that were virtually indistinguishable from those of smokers using high yield brands."

Well, if that's the case, the smoker is getting as much nicotine from these so-called low tar/low nicotine cigarettes as someone using a regular cigarette, which it doesn't even pretend to be lower in nicotine.

I also wanted to make another point to illustrate this issue. We have a study by a tobacco industry consultant by the name of Dr. Gio Gori, and without objection, this will be introduced in the record as Exhibit 22.

[Testimony resumes on p. 791.]

[Exhibits 20 and 22 follow:] 


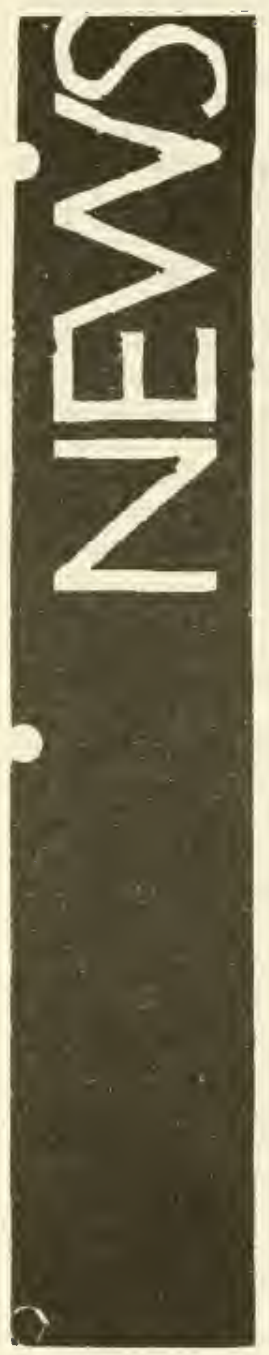

POR IMMEDLATE RELEASE

Aurust. 1993

Cusure: Joln Keanen

(212) $315-8746$

\section{DONT DELIEVE THE LABEL: STUDY 8HOWS MO BENEFT IN BMOKANC LOW.TAR AND NICOTINE CICARETIES}

NEW YORK, NY - The brund uf ciyusetles swokers choose bas little of nnining to do with their tre exposure to tar and vicotine.

In a now sndy published by the Amorican Lung Ascociation, researchers took salive and breath sumples from 300 smokers and measured them for ensbon monoxide $(C)$ and cotinine, a byproduct of olmrine. They fourd that on average, subjects who anoked low-ylelu bruids land $C O$ and cotinine levels that were barely dktingukhable from those of smokers using high-yleld brands.

The findiup iaise scrious questions about the ralovanes of tar and aicotine deta publithed by the Federal Trude Commission (FTC). These dus are often cited in tobecco odvortiuments implying that there ars bealth benofith astociated wilb low-tre and nicotine cigarates. A recent Gallup survoy, conducted for the Ameriean Iung Asonctation, the American Hean Asocintion, and the Amerficul Cancer Soclety, showed that most Americans interpret those ads to mean that low-yield broads are safer, bess addictive, and bentrier. 
This study cunfrers that there's no such thing as a safer type of cigarette," aid Lung Association President Dr. Alfred Munzer. "Ads touting low tan and aleotine yields are doosplive and ought to be basaed."

Tho oew findings are repored in the August American Revlow of Reypivasary Dlsass, an official joutod of tho Americas Thoracic Socicty, the Lung Aswetation's medical section"

"If you're tryisg is predien the ultimato exposure that people get from cigarente smoking l'd bay that the FTC data aren't at all usethl," says Dr. David Coultas lead author of the study and a professor at the University of New Mexico Scbool of Medicino.

"FTC dare are ebrained by smoklns muchioes, whicl snwke in a ver; srandardzed manner," said Dr. Coultes. "But people smoke to obtain ricotine, and they'll use various rechniques, either conssioutly or unconsciously, to ansure thoy get the levcl thoy want"

These techaiques may lndude inballng more smoke per puft, inbaling it mare deeply, holdiag smoke longer in the lings, and blocking the airholes on cigaretwo fitsors that difute the smoke entering the body.

Millions of smukers have been duped into thinking the hrande they nee are less hazardous," say6 Dr. Munzar. "Low-yicld brands give mokers a talso verse uf securlly, when the only safe option is quitung.

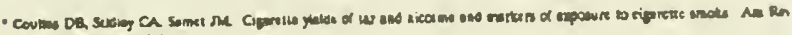
repir un ivis vesew. 
The sudy did and a siguifleant relationship between the number of ciguettes smoked and levele of cotinine and carbon monoxide to the body. It also found that meu amoked more clarettes un average than women. A large majonty of the sudy's participants were Hispanic Americans residlng near Nbuquerque.

Th. Amprioes Lung Assodation, the Amerivan Hear Asocietion, and the Americun Cancer Society, united as the Coalition on Smoting or Health, have peritionad the Fond and Drug Admiaistration and the Foderal Trade Comminalon to regulate ws "druga" those wbuccu products that make bealth claims and use advertisiog and promoslonal cempaigns to mislead consumers that some cigarettos are safor, bealthicr, and less addictive than others, The petition wus fled in February 1992, but neither agency bas yet responded to the rcquesh nor to follow-up letters frnm the Contition appoelling for action.

Tho New Merdeo study was coauthored by Dra. Christine Stldley and Joaathan Samet, who are alen affiliated with the Ualverdity of New Mexion School of Medicine.

Tor smokers wlu ueed belp in beatiag thetr toisacco addiction, the American Lung Assucistion provides Freedom From Smnking cliaís and self-holp matorials. For mon informution, coll 1.800-LUNG USA

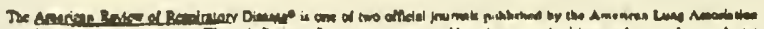

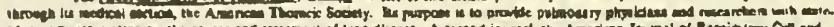

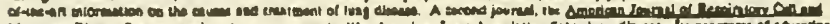

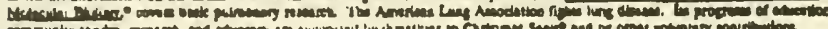

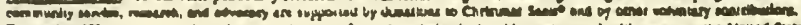

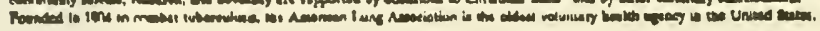




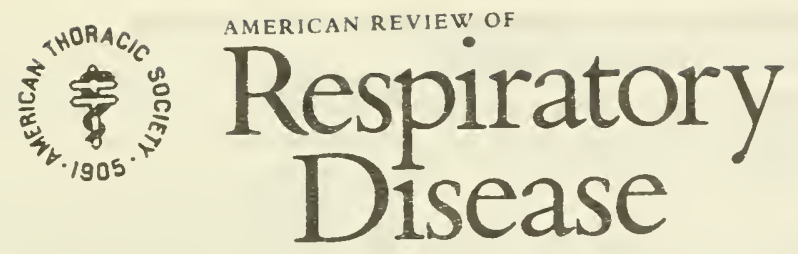

Volume $148 \cdot$ Number $2 \cdot$ August 1993

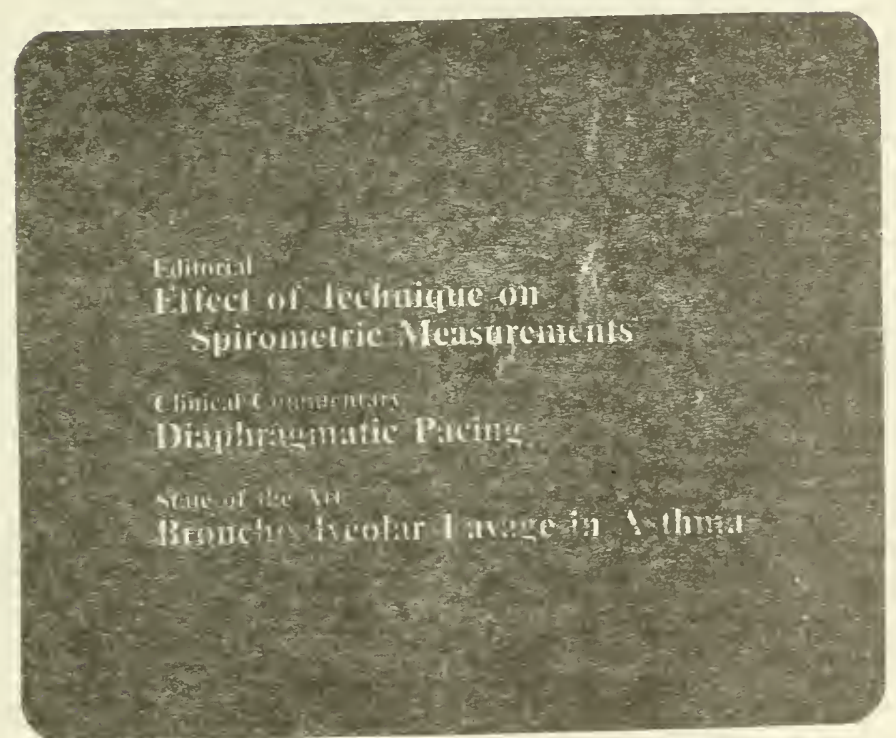

AN OFFICIAL JOURNAL OF THE AMERICAN THORACIC SOCIET MEDICAL SECTION OF THE AMERICAN LUNG ASSOCIATION 


\title{
Cigarette Yields of Tar and Nicotine and Markers of Exposure to Tobacco Smoke
}

\author{
DAVID B. COULTAS, Christine A. STIDLEY, and JONATHAN M. SAMET
}

Department of Medicine, Pulmonary and Critical Care Division, and the New Mexico Tumor Registry, Cancer Center, University of New Mexico School of Medicine, Albuquerque, New Mexico

\begin{abstract}
Although cigarette yields of tar and nicotine have been declining since the early 1970 s, litile information is available for the general population on the consequences of their use on exposure to tobacco combustion products. In a population-based sample of 298 smokers, the majority of whom were Hispanic, we examined the relationships between yields of cigerentes currently smoked and levels of salivary cotinine and end-expired carbon monoxide. Spearman correlation coefficients between the current number of cigarettes smoked end cotinine $(r=0.52)$ or carbon monoxide $(r=0.51)$ were higher than correlations between the Federal Trade Commission (FTC) nicotine data and these same markers, 0.12 and 0.05 , respectively. Corrolations between FTC tar and carbon monoxide yields and the biologic markers were similarty weak. In mul. tiple linear regression models, the current number of cigarettes smoked was the most important predictor of cotinine and carbon monoxide levels $(p<0.0001$ ). The eddition of FTC tar, nicotine, or carbon monoxide to the models explained little of the variability in cotinine or carbon monoxide levels. Because FTC yields of tar and nicotine are poor predictors of exposure to fobacco combustion products, subjects' reports of cigarerte brand should not be used as a primary marker of exposure in epiderniologic investigations. Furthermore, smokers need to be advised about the limitations of cigarette yield information for predicting the potential for adverse health effects of smoking. Couttas DB, Stldley CA, Samet JM. Clgarette ylalds of tar end nicotine and merkars of exposura to tobacco amoke. Am Rev Respir Dis 1993; 148:435-40.
\end{abstract}

Since the early 1970 s, tobacco manulacturers have marketed cigarettes with increasingly lower tar and nicotine yields (1). Marketers have implied that health benefits accrue from low-yield cigarettes, and switching to these cigarettes has been advocated for smokers unwilling to quit (2). These well-advertised changes in cigarettes have led to the belief by as many as $45 \%$ of smokers that lowyield cigarettes are less hazardous then other cigerettes (3). Because cigarette tar and nicotıne yields are determined with smok. ing machines, however, the data may nof accurately reflect the exposures to tobacco combustion products actually experienced by smokers (4). To develop effective preventive strategies for cigarette-related diseases, evidence is needed on the relationship between the reported yield to tar and nicotine and levels of biomarkers, which may provide a more biologically appropriate index of the doses of injurious substances.

Using date from a population-based survey of respiratory diseases and lung function in New Mexico Hispanics (5), we described the tar and nicotine yields of cigarettes smoked, based on respondents' reports of brands and Federal Trade Commission

(Recerved in ariginal form /une 29, 1992 ond in ievised form December 14, 1992) Supported by Crant No. HL-28120 from the Division of Lung Diseases, Navonal Hear, tung, and Blood institute and by Contract No. NO1-CN.S5426 from the Brometry Branch, National Cancer Institute

Correspondence and requests for repnnts should be addressed to David $B$. Coultas, M.D., University of New Mexico School of Medrine, New Mexico Tumor Registry, 900 Camino de Salud, Albuquerque, NM 87131.

Dr. Coultas is the recipient of Preventive Pulmonary Academic Award No. Ka7. HLO2474 from the Narional Heart, Lung, and Blood Institute.

Am Rev Resptr Ois Vol 148. pp 435-440, 1993
(FTC) data, and examined the relationships of measures of cigarette smoke exposure, including current number of cigarettes smoked per day and FTC cigarette yields, with tevels of salivary cotinine and end-expired cerbon monoxide. Our intent was to examine, in a population-based sample, the relationships between these biomarkers of exposure and the FTC values.

\section{METHOOS}

Data Collection

The study was conducted in a semirural city with a 1980 population of more than 11,000 localed near Albuquarqua, New Mexice. The methods of sample selection and data collection and the study questionnaires were described in detail by Samet and colleegues (5). in the period from July 1984 to November 1985, 733 Hispanic households were sempled in to populationbased provalenca survoy of respiratory disease. Househot aligiblitity was based on the presence of al least one selt-identifed Hispanic aduht. All persons residing in the household were considered eligibla to participate in the study regardless of ethnicity. Survey procedures relevant for this enaiysis included an intenviewer-administered smoking his tory for persons $18 \mathrm{yr}$ of age and older, andtidal carbon monoxide determination, end collection of a saliva sample at the time of deta collection.

End

End-expired samples of exhaled air wore obtaned for meesurement of carbon monoxids (8). Subjects inhaled to total lung capacity from func. tional residual capacity and hald the breath for $10 \mathrm{~s}$. The subjects than exhajed, and the fietd intervlewer collected the axhaled air close to tuncstonal residuel capecity in a 1-L anesthesia beg fitted with 9 on w way vatue. Within $2 \mathrm{~h}$ the end-expired ar samples were analyzed at the field otfice

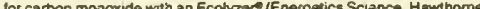
Th. Ny. which was calibrated daily with 40 ppm carbon monoxide stan
dard. An athanol filter wes used to prevent interference.

The salva was collected by expectoration of 1 to $2 \mathrm{ml}$ into a plastic 
tube. The specimens were trozen at $-20^{\circ} \mathrm{C}$ unt $\mathrm{l}$ the cotinine assays were performed, within 6 months of collection. The asseys were pertormed with out knowledge of the reported smoking status.

\section{Cotinine Assay}

Cotınine was quantified by double-antibody radioimmunoassay, es descnbed by Langone and coworkers (7). A specific antiserum produced In rabbris was supplied by De. Heien Ven Vunakis (Brandeis University). and afl assays were performed at the University of Now Mexico (8). Salive samples were diluted $1: 2$ or $1: 5$ for the assay, and an equal quentity of samples were dived 12 or 15 tor the acco products wos added to each standard. The ensituvty of the assay in our hands was 36 pg/ube or 0.78 $\mathrm{ng} / \mathrm{ml}$ saliva $\{4,204 \mathrm{pmol} / \mathrm{L}$ ). Imiraassay coefficients of verietion were 7.1 . 40 , snd $9.6 \%$ at low, miodle, and high concentrations of cotinine standard, respectively, and interassay coefficients of vanstion were $15.7,30.2$, and $8.4 \%$ at low, middle, and high concentrations of cotinine standard. respectively.

Statustical Analysis

The present analysis included participants $18 \mathrm{yr}$ of age and older, regardless of ethnicity, who identitied themsetves es curtent smokers, defined as smoxing cigarentes within 6 months of the interview Subjocts using chas se cigars, pipes, snult, or chewing these products elevates cotinine and/or carbon monoxide levels. We of these products elevetes cotinine and/or carbon monoxide levels. We carban monoxide levels.

We obtained information on current cigarefte brands, types of cigarettes currently smoked (nonfilter, filter, or rolled own), cigarette length, and number smoked per day. For each cigerente brand, type, end length. and number smailable FTC data for 1984 end 1985 on cigarene yields of war, micetine, end carben monoxids $(9,10)$ with the self-reported cigarotte tar, nicotine, end carben monoxids $(9,10)$ with the self-reported cigsrotte thet were not possible, we assigned them the closest length available Irom the FTC tables. We also ascertained inhalation pariems dunng smoking by asking whethar the subject inhaled into the mouth only, into the athe throat, into the top of the lungs, or deeply into the fungs.

To assess determinants of levels of carbon monoxide and salivary cothnine and numbers of crgarettes smoked daily, we calculated Sperman correlation coefficients ar 1 used muttiple lineer regression. Dependent vanables for the regression analysis included carbon monexsde level, cothnina level, and current number of cigarentes smoked per day as continu a calegoncal venables, sex, age (below or above $50 \mathrm{yr}$ ), ethnicity (Hispanic or nonHispenic), time since last cigaretto (less than $1 \mathrm{~h}$ or $1 \mathrm{~h}$ or more), and inhalation parterns (imo top of lungs or deeply into lungs versus into mouth only of into back of throat).

Deta analyses were pertormed with standard programs of the Statistical Analysis System (11).

\section{RESULTS}

A total of 298 current smokers, $39.6 \%$ males and $60.4 \%$ females. had sufficient data available for this analysis (table 1). An additional 51 smokers were excluded because they were currently using marijuana $(n=39$ ) or other tobacco products $(n=12)$. Of the available smokers, $91.5 \%$ of the males and $92.2 \%$ of the temales were Hispanic. The rematning 24 smokers were nonHispanic whites. For the Hispanic and non-Hispanic males, mean ages were 46.5 and 44.1 yr, respectively. Mean ages for the females were 39.9 and $35.7 \mathrm{yr}$, respectively.

In contrast to the 298 smokers included in Ihis analysis, the 51 smokers excluded wers largely male $(686 \%)$ an younger, with mean ages of $36.3 \mathrm{yr}$ for males and $25.9 \mathrm{yr}$ for females. The aver. age numbers of cigarettes smoked per day by those excluded were 21.2 and 15.7 for males and females, respectively.

Although 298 smokers were included, the numbers of subjects available for the various analyses varied widely. Information on numbers of cigarettes currently smoked, current cigarente brand. and current eigaret?e length were obtained from 96.3, 99.0, and $98.0 \%$ of the subjects, respectively. Based on this information we were able to determine FTC Lar and nicotine yields for $80.2 \%$. 80 cause of incomplele FTC data on carbon monoxide yields, how ever, we were able to determine this value in only $47.0 \%$ of the smokers Salivary cotinine levels were available for $89.6 \%$ and end-expired carbon monoxide levels in $983 \%$ of the subjects.

Patterns of reported smoking and levels of biomarkers vaned between males and females and between Hispanics and non Mispanics (table 1). For both ethnic groups, females smoked fewe cigarertes per day than males, and on average Hispanics smoked fewer cigarettes per day than non-Hispanics. Except for Hispanic males, $90.0 \%$ or more of the subjects smoked filter cigarettes. Among Hispanic males, $81.1 \%$ smoked cigarettes with high tar contents ( $15 \mathrm{mg}$ or greater) compared with $63.4 \%$ of Hispanic te males (figure 1). Similarly, for sell-reports on depth of inhelation of cigarette smoke, a higher proportion of Hispanic males (45.4\%) reported inhalation deeply into the lungs than Hispanic females (23.2\%). Although the subject numbers were much smaller, simitar smoking patterns were observed for the non-Hispanics. As for the self-reports on cigarette smoking practices, substantial difterences were observed for levels of salivary cotinine and end-expled carbon monoxide among the sex and ethnic groups.

Spearman correlation coefficients were used to examine the relationships among the various measures of exposure to ciga rette smoke. The correlation was highest between salivary cot!

TABLE

MEASURES OF CIGARETTE SMOKE EXPOSURE AMONO CUARENT SMOKEAS FACM A NEW MEXICO SAMPLE, 1984 TO 1985

\begin{tabular}{|c|c|c|c|c|}
\hline & \multicolumn{2}{|c|}{ Hispenics } & \multicolumn{2}{|c|}{ Non-Hrapankes } \\
\hline & $\begin{array}{c}\text { Male } \\
(n-100)\end{array}$ & $\begin{array}{l}\text { Fomele } \\
(n=186)\end{array}$ & $\begin{array}{c}\text { Malo } \\
(n-10)\end{array}$ & $\begin{array}{l}\text { Femaio } \\
\{n=14 \mid\end{array}$ \\
\hline $\begin{array}{l}\text { Meen number of cgersetes } \\
\text { smokediday I } \\
\text { stundard deviavon (SO) }\end{array}$ & $16.1(9.4)$ & $120(9.6)$ & $320(12.5)$ & $202(12.2)$ \\
\hline Current cigarente typea, to & & & & \\
\hline Finer & 87.0 & 946 & 90.0 & 928 \\
\hline Nonfiner & 11.1 & 2.4 & .10 .0 & 71 \\
\hline Roll own & 1.8 & 0.0 & - & - \\
\hline Unknown & - & 2.4 & - & - \\
\hline $\begin{array}{l}\text { Moean cotinine lovel. } \\
n g / m i=S O\end{array}$ & 350.3 (208.5) & 287.8 (181.9) & 553.0 (220.6) & $322.1(224.9)$ \\
\hline $\begin{array}{l}\text { Mean ondidel CO level. } \\
\text { pom } \pm \text { SO }\end{array}$ & $22.2(13.7)$ & $195(13 . \theta)$ & $36.9(179)$ & $27.7(18.8)$ \\
\hline
\end{tabular}




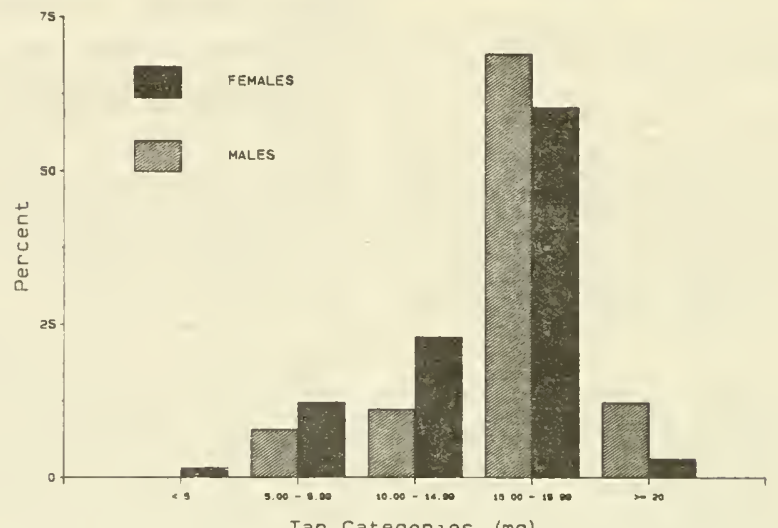

Tar Categories (mg)

Figure 1. Distributions of FTC cigarette tar yields in e general population semple of Hispanics, New Mexico. 1984 10 1985

nine and end-expired carbon monoxide levels, $r=0.64(\mathrm{~N}=264$ $p<0.0001$ ). For other measures of exposure (table 2), moderate levels of correlation were observed between current number of cigarettes smoked per day and the biologic markers salivary cotinine and end-expired carbon monoxide (ligures 2 and 3 ). There was a weak association between the tar level and the salivary coti. nıne level.

We developed multiple tinear regression models to character. ize further the predictors of selivary cotınine and end-expired carbon monoxide (tables 3 and 4). Several models were examıned using available independent variables as predictors of salivary cotinine and end-expired carbon monoxide levels (see METHODS). Current number of cigerettes per day and time since smoking the last cigarette were statisfically signilicant predictors in all model (tables 3 and 4). The current number of cigarettes smoked was consistently the most important predictor. Addition of FTC yields

TABLE 2

SPEARMAN CORRELATION COEFFICIENTS BETWEEN VARIOUS MEASURES OF CIGARETTE SMOKE EXPOSURE AMONG ACTIVE SMOKERS IN NEW MEXICO, 1984 TO 1985

\begin{tabular}{|c|c|c|}
\hline & N & A \\
\hline \multicolumn{3}{|l|}{ Selivery cotinine, ng/mi } \\
\hline Currant number of cigarettes smoked/day & 260 & 0.52 \\
\hline FTC ter, mg & 214 & 0.15 \\
\hline FTC nicotina, me & 214 & 012 \\
\hline FTC CO. ppm & 128 & 0.06 \\
\hline \multicolumn{3}{|l|}{ End-tidal carbon monoxide. pDm } \\
\hline Current number of chgarettes smokediday & 203 & 0.51 \\
\hline FTC tar, me & 234 & 007 \\
\hline FTC nicoline. mg & 234 & 0.05 \\
\hline FTC CO, ppm & 139 & 0.03 \\
\hline
\end{tabular}$$
i \begin{aligned}
& 0.00001 \\
& i=000
\end{aligned}
$$

to the models expleined only a small proportion of the variability in cotinine and carbon monoxidc levels. Modeis that included in. halation patterns as categorical variables 10 a into lop of lungs or deeply into lungs: 1 = into mouth only or into back of throat) showed tower levels of cotinıne $(B=-11.14 \mathrm{ng} / \mathrm{ml}, \mathrm{p}=0.65)$ and carbon monoxide levels $(B=-2.39 \mathrm{ppm}, p=0.16$ ) assuciated with reports of inhaling only into the mouth or throat, but the coeffi. cients were not statistically significant.

We also used multiple linear regression to examine predictors of the current number of cigarentes smoked per day, with sex, age, ethnicity, and FTC tar and nicotine yields as independent vari. ables. Significant predictors were sex (on average, males smoked 4.1 cigarettes more then femeleg, $p=0.002$ ), age (on average, subjects less than $50 \mathrm{yr}$ of age smoked 3.2 cigerettes more than those $50 \mathrm{yr}$ of age and older, $\mathrm{p}=0.02$ ), and ethnicity (on avsrage, Hispanics smoked 10.9 fewer cigarettes than non-Hispenics, $p<$ $0.0001)$. FTC tar and nicotine yields were not significant.

\section{DISCUSSION}

In this largely Hispanic community sample, some indices of exposure to tobacco smoke from active smoking veried widely be tween the sexes and ethnic groups. We found a broad renge of values for numbers of cigarettes, salivary cotinine levels, and endexpired carbon monoxide levels. However, types of cigarettes smoked were more narrowly distributed. Most subjects $(90 \%)$ smoked fitter cigarentes, end the majority smoked cigerentes of medium or high tar content ( $>10 \mathrm{mg} /$ cigarette). For all smokers. regardless of cigarette type, there was a moderate essocistin an between the current number of cigarettes smoked per day and levels of the biologic merkers salivery cotinine and end-expired carbon monoxide (table 2). In addition, our findings provide further documentation that FTC figures on cigarette yields of tar, nicotine, and carbon monoxide ere not strongly predictive of exposure 


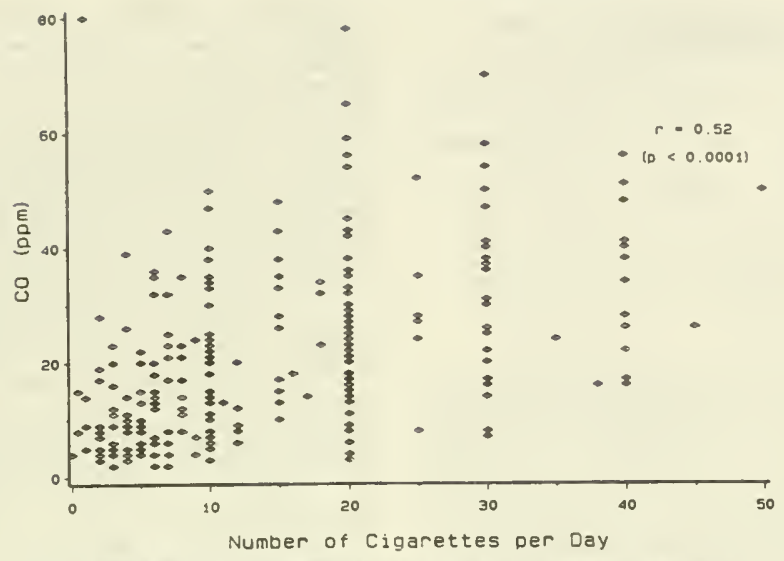

Figure 2. Scatter plot and Spearman correlation of the sell-reported number of cigaretes currently smoted per day and the end-tidal carbon monoxide level (ppm).

10 tobecco combustion products across the range of tar and nicotine yields of cigarettes mest often used in the general population. Several fimitetions must be considered in the interpretation of these results. Because we used self-reports of smoking habits, incorrect reports of brands may have resulted in misclassification of exposure. However, for current brands wo do not anticpate substantial bies. In y randomized trial to prevent heart dis ease emong factory workers in the United Kingdom, Peach and

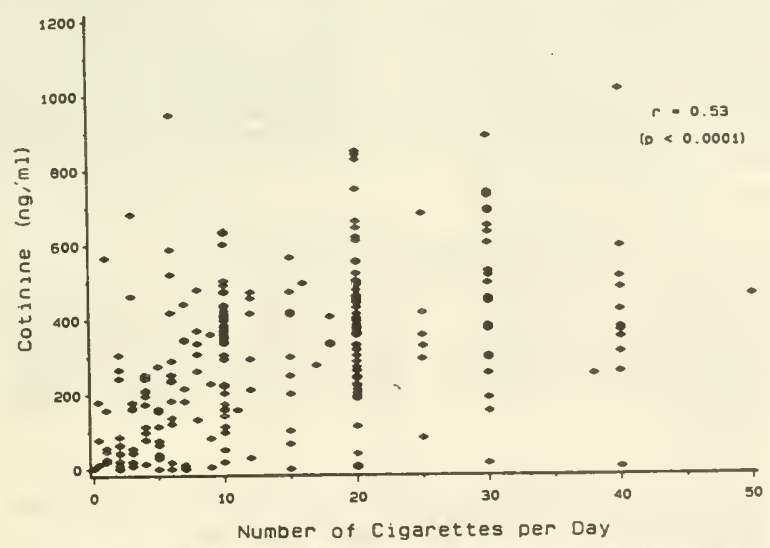

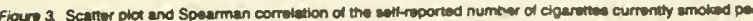
day and the selvery cocinino level (ng/mi). 
TABLE 3

MULTIPIE LINEAR REORESSION MOOELS* FOR PREDICTING SALIVARY COTININE LEVEL (NGMML)

\begin{tabular}{|c|c|c|c|}
\hline \multirow[b]{2}{*}{ Independent Variable } & \multicolumn{3}{|c|}{ Regression Coefficrents } \\
\hline & $\begin{array}{l}\text { Excluding FTC } \\
\text { Tay and Nicotine }\end{array}$ & $\begin{array}{l}\text { Including } \\
\text { FTC Tar }\end{array}$ & $\begin{array}{l}\text { Incluoing } \\
\text { FTC Nicotine }\end{array}$ \\
\hline Intercept & $173.02 \ddagger(2414)$ & $50.78(52.74)$ & $3928(6253)$ \\
\hline $\begin{array}{l}\text { Currem number of } \\
\text { cigerettes/day }\end{array}$ & $791 \pm(142)$ & $764^{t}$ (1 41) & $7.77 *(141)$ \\
\hline Time since last cigarenet & $5886+(28.10)$ & 5304 (27.75) & 52.23 (27 91) \\
\hline Tar yield, mg & - & 8617 (3 31) & - \\
\hline $\begin{array}{l}\text { Nicotine yietd. } \mathrm{mg} \\
\mathrm{R}^{x}\end{array}$ & $22.7 \ddagger^{-}$ & $25 \mathrm{st}^{-}$ & $\begin{array}{l}13955 \% \text { (60.31) } \\
249^{*}\end{array}$ \\
\hline
\end{tabular}

colleagues (12) compared questionnaire responses on current brand of cigarette smoked with an empty cigarette pack obtained within 2 wk of completing the questionnaire of 220 smokers who returned cigarette packs, the overall accuracy for reports on the current brand of cigarettes smoked was $74 \%$; most discrepancies were minor and did not result in misclassification of the usual brand smoked. The statistical power of our study for detecting significanf effects of FTC yields on levels of biomarkers may have also been limited by the small number of subjects using low-yield cigarettes (< $5 \mathrm{mg}$ tar/cigarette).

Although intormation is available on the prevalence of smok ing and on smoking habits in this study population (5) and other Hispanic populations (13-16), little is known about the types of cigarettes smoked (16). In New Mexico, the prevalence of smoking is similar for Hispanics and non-Hispanic whites, but on average Hispanics smoke fewer cigarettes per day (5). However, the prevalence of smoking may vary widely among different groups of Hispanics within the United States $(14,16)$.

The types of cigarettes smoked have been determined in sur. veys of smokers in the United Kingdom (17) and the United States (3. 18-21). Available data on the use of various cigaretie types in Hispanic populations of the United States are limited to brand without specific tar and nicotine information (16, 22). In 1986, a survey of U.S. smokers $17 \mathrm{yr}$ of age and older found that $41 \%$ reported smoking cigarettes with tar vields of $15 \mathrm{mg}$ or less (3). This proportion varied by racial group: $44 \%$ for whites, $22 \%$ for blacks, and $32 \%$ for "other" racial groups. The distributions of types of cigarettes smoked based on ter yield in our study (figure 1) are most similar to those of blacks and other racial groups in the 1986 nationwide survey.

The relationships among current smoking habits and various biologic markers of smoking have been examined in smokers at tempting to quit (23-25) and in population-based surveys of smokers $(21,26,27)$. Among 353 Australian cigarette smokers in a population survey, Pierce and coworkers (26) reported a corre lation coefficient of 0.33 between reported number of cigarettes smoked per day and salivary cotinıne. Using linear regression to predict salivary cotinine, with cigarettes smoked per day, time since last cigarette, and cigarette strength (filter or nonfilter) as independent variables, the model explained only $13.6 \%$ of the vari ability of the salivery cotinine level. Maron and Fortmann (21) examined data from 713 Calilornia smokers and found that sex and number of cigarettes smoked per day explained 28 and $22 \%$ of the variability in carbon monoxide and salivary thiocyanate, respectively. FTC nicotine yields explained only an additional 1 and $2 \%$ of the variability, respectively.

Failure to find a relationship between FTC yields and biologic markers of exposure to tobacco combustion products may be explained by several factors, including limitations of the method for determining FTC yields, variation in patterns of smoking among smokers, and individual differences in uptake and metabolism of tobacco combustion products. FTC yields are determined by machines that smoke with a constant pattern; the mechıne pattern of smoking may not accurately reflect actual smoking patterns or the variability of smoking patterns among humans $(4,23$ 28). Among smokers smoking the same type of cigarette, differences in smoking patterns (29). such as puff volume and inhala tion time and the practice of blocking the cigarette filter (30), may affect the doses of toxic components of smoke delivered to the lung. Furthermore, as smokers reduce the numbers of cigarettes smoked or change to lower yield cigarettes, levels of nicotine and of carbon monoxide decline, but less than predicted based on the decrease in the number ol cigarettes smoked (31) or the ciga retle tar yield (32). To maintain a constant nicotine level, changes in smoking patterns may follow reductions in the numbers of cigarettes smoked or switching to cigarettes with low nicotine yields (33). These finclings illustrate the difficulties in measuring exposura to tobacco combustion products and give evidence of the inaccuracy of measures obtained from FTC figures of cigarette yields. Other lactors that may contribute to variability in measures of ex.

TABLE 4

MULTIPLE LINEAR AEORESSION MODELS. FOR PREDICTING END-TIOAL CARBON MONOXIOE LEVEL (PPM)

\begin{tabular}{|c|c|c|c|c|c|}
\hline \multirow[b]{2}{*}{ Independent Veriable } & \multicolumn{5}{|c|}{ Regression Coefficients (SE) } \\
\hline & $\begin{array}{l}\text { Excluoding FTC } \\
\text { Tar, Nicotine, cot }\end{array}$ & $\begin{array}{l}\text { including } \\
\text { FTC Tar }\end{array}$ & $\begin{array}{l}\text { Including } \\
\text { FTC Nicotine }\end{array}$ & $\begin{array}{l}\text { Excluding FTC } \\
\text { Tas, Nicotine, cot }\end{array}$ & $\begin{array}{l}\text { Including } \\
\text { FTC CO }\end{array}$ \\
\hline intercept & 11 1s\$ (1.63) & $13.50^{*}(3.88)$ & $12.73^{t}(4.36)$ & $11.02^{ \pm}(2.43)$ & $6.47(690)$ \\
\hline Current number of crgarenes/day & $0.44 t(0.09)$ & $045 \pm(0$ s) & $0.45 \div(0.09)$ & $046^{t}(0.13)$ & $047 \pm(0.13)$ \\
\hline Time since last cigarattes & $1115+(186)$ & $1124 \div 11877$ & $11.22 \div(1.87)$ & $11.39 \div(2.63)$ & $11.30 *(265)$ \\
\hline Tar yield, $m g$ & - & $-0.18(0.23)$ & - & - & - \\
\hline Nicotine yeld. mg & - & - & $-123(418)$ & - & - \\
\hline CO neld, ppm & - & - & - & - & $178(446)$ \\
\hline $\mathbf{R}^{2}$ & 32.47 & $32.8 \ddagger$ & $32 \mathrm{~s} \$$ & $302 \ddagger$ & $30.3 \ddagger$ \\
\hline
\end{tabular}

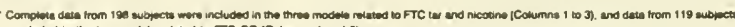

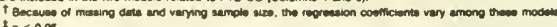

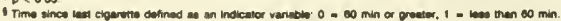


pasure, and for which there ere tew data, include individual difterences in the metabolism and excretion of tobacco combustion products (34).

Our results provide additional information on assessment of exposure to tobacco combustion products; the findings have practical implications for epidemiologic research on smoking and health and tor counseling smokers about yields of tar and nico tine. Because FTC yields are not strongly predictive of exposure to tobacco combustion products, subjects' reports of cigarente brand should not be used as a primary marker of exposure in epidemiologic investigations. The potential lor misclassification of exposure based on brand, and thus on FTC yields, is great and may largely explein inconsistent results among studies comparing health elfects in smokers of high-yieid cigarentes with those in smokers of lower yield cigarettes $(1,35)$.

Although many smokers percerve cigarettes labeled low in tar and in nicoline as less hazardous, our results suggest that FTC cigarette yields provide the smoker with inaccurate informalion on actual exposures to tobacco combustion products. Smokers need to be advised about the limitations of cigarente yield intor metion. Switching to lower yield cigarettes may not reduce a smoker's exposure to hazardous tobacco combustion products. and switching is unlikely to produce substantial health benefits compared with those that follow complete cessation.

Acknowledgment. The whters thank the interviewers and panicipanis in the Study and Jenniter Chavez, Carolyn Lara. and Rita Elliont for theor help in prepar. ing the manuscript.

\section{References}

1. U.S. Dopartment of Heath and Human Services. The heath consequences of emoking: the chenging cigarente. A report of the surgeon generat. Weshington, OC: U.S. Government Printing Ottica, OHHS (PHS) Publication No. 81.50158, 1961.

2. Participants of the Fourth Scarborough Conference, is there a future 10 lower-ter-yweid cioarentes 7 Lencet 1985: 2:1111-A.

3. U.S. Dapartmont of Health and Human Services. Redueing the heatth consequences of smoking: 25 yeere of progress. A reporn of the surgeon general. Washington, DC: Govern

4. Ricker WS, RODinson JC, Lawiese E. Limitations 10 potential usen for the date based on the machinas ornokung of cigarentes: cigarette dmoke conlents. In. Wald N. Frogatt P, ods. Nicotine, smoking and the 5. Samet JM. Coultas DB. How ard CA. Skipper Q. Respiratory diseases and cigaretio amoking in o Hispar

6. Jones RH, Ellicott MF, Cadigan J日, Gaeneler EA. The relationship be ween eveolas and blood carbon monoxida concentrations dunng breathholding. J Lab Clin Med 1958; $51 \cdot 553-64$.

7 Langone Ju, Gjike HB, Van Vunakie H. Nicotine and its metabolitea. R: dioimmunoassay for nicotine and cotunine. Biochemistry 1973; 12 5025-30.

a Coultas DB. Howard CA. Peake GT. Skipper BJ. Samel JM. Salivary coth nine levale and involuntary tobacco smoke exposure in children and adults in New Mexico. Am Rey Respir Ois 1987; $136.305-9$.

9. Federal Trede Commission. Aepon of "Tar," nicotine and carbon monoxide of the emoke of 207 vaneties of comestic cigarettes. Federal Trade Commisaion Report, 1884

10 Federat Trade Commission. Report of Tar," nicotine and carbon monoxide of the emoke of 207 vaneties of domestic cigarettes. Federal Trade Commission Repon, 1985.

11 SAS Institute inc. SAS users' guide ztatiaics. 5th ed. Cery. NC: SAS in strute. Inc., 1985
12. Poech H, Shah D, Morria RW. Velidity of smokerd' intormadon about presom and past cogarento brands - Implications for stuctes of the attects of falling ter yeides of cigarentes on neetth. Thores 1988; $41: 203-7$

13. Markides KS, Corell J, Ray LA. Smoking among Mexican Amencans: three-generation study. Am J Public Heakh 1987; 77 :708-11. 14 Escobedo LG. Remington PL. Birth cothort ansysis of prevalence of cig-
arette smokung among Hispenics in the United States. JAMA 1989; 261:68-9.

15. Marin G, Perez-Stable EJ, Marin BV. Cigarente emokung among San Fran crsco Hispenns: the role of acculturation and gender. Am J Public Health 1989. 79:196-9.

16. Haynes SO, Hanvey C. Montes H. Nickene H. Cohen BH. VIII. Patterns of agarotite smotung among Hispanics in the Unted States: results from HHanes 1992-84. Am J Public Health (Suppi) 1990; 80:47-54.

17. Jame M. Russet MAH. Tas and nicotine yelds of U.K. cigarettes 1972-1983: sales-weighted estmates trom non-industry sources. B J Addict 1985: $60: 429-34$.

18. Wymder EL, Goodman MT, Hoftmenn D. Demographic espects of the low yield cigarente: considerations in the evalitation of heatth risk. J Net

19 Folsom AR, Pechacek TF. Gaudemaris R. Luepker AV, Jacobs DR, GII lum RF. Consumption of "low-yelo' clgasenes: tts trequency and rele tionehip to serum throcyanate. Am J Public Heath 1984: 74:564-8.

20. Stellman SO, Gartinkal L. Smoking habits and ta levele in a now Amer. can Cancer Society prospective study of 1.2 million men and women. J Netl Cencer Inst 1986: 78:1057-63.

21. Maron D, Fortmann SP. Nicotine yiald and measurea of clgarette smoke exposure in a large population: arn lower-yield cigarentes salern Am $J$ Public Heasth

22. Cemtors for Oisense Control. Companison of the cigarente brand proterences of adult ene teeneged omokers - United Slates, 1989, and 10 U.S. Communtites. 1983 and 1990. JAMA 1992: 267:1893-8.

23. Benowitz NL, Hall SM, Herning RI, Jacob P III, Jones AT, Osman AL, Smokers of low-yrold clgarattes do not consumo less nicotins. N Engl

Russelt MAM. Jarvis MW. Feyerabend C. Salooleo Y. Reduction of tar nicotino and carbon monoxide intake in low ier amokers. J Epidem

25. Abrams OB, Follick M., Biener L, Carey KB, Hitw J. Selive cotinine as
Com a mesaurs of smoking auatus in field sentings. Am J Public Mealth 1987; $77.846-8$.

28. Pierce JP, Denyer T, Digiusto E. Carpenter T, Hannam C. Amin A, Yong C. Sartaty G, Burke N, and Oult for Life Steering Committee. Cotinine valideron of sott-reported amoting in cominercilly run cormunty sur. veys. J Chron Ois 1987; 10:389-95.

27. Wroctward M, Tunstat-Pedow H, Sm th WCS, Tavendaie R. Smoking che actensticy and intalation biochemistry in the Scotish population. $J \mathrm{Cl}$ Exidemiol 1991: 44.1405-10.

28. U S. Deparment of Heath and Humen Semose. Tha heath coneecuencee of moking: nucosine sddicion. A repon of the sumpeon canered. Westung ton. DC: U.S. Govemment Printing Ottics, 1989. DHHS (CDC) Publcation No. Beacos.

29. Woodman O, Nowman SP, Pavil O, Clarke SW. Inholed amoke volume and putt indices wrth cigerentes of different tar and nicoting lovets. Eur J Fespur Dis 1987; 70:187-92.

30. Kozlowski LT, Frecker AC, Khoum V. Pope MA. The masuse of Teses. hazardous" eigerettee and tas detection: hols blocking of ventlated filters. Am J Public Health 1990: $70: 1202-3$.

31. Benowiz NL. Jacob P III, Kozlowrski LT, Yu L. Intluence of moking tewer crgarettes on exosaure to tas, nicotina, and carbon monoxide. N Engl $J$ Med 1988; 315:1310-3.

32. Benowitz NL. Jecos P III, Yu L. Talcon A, Hell S, Jones AT. Aeduced tar, nicoline. and carbon monorode exposure while amoking ultralowbut not low-ylotd cigarettes. JAMA 1986; 256:241-6.

33. Aussell MAH. Nicotins and the solf-regulation of emoke intake. In: Wald N, Frogart P, edis. Nicotine, smoking and the low tar programme. Now York: Oxtord University Prose, 1989: 151-60.

34 ible JP. Titrating exposura to tobsccos smoke uaing cotinineof misunderstandinga. J Clin Epidemioh 1890; 43:313-7.

35. Semot JM. Less hazardous crgarentes and disoeses of the lung. Cheat 1905: $88: 602-3$ 


\title{
Exhibit 22
}

REGULATORY TOXSCOLOGY AND PHARMACOLOCY S, 314-326 (1985)

\section{Analytical Cigarette Yields as Predictors of Smoke Bioavailability'}

\author{
GIO B. GORI AND CORNELUUS J. LYNCH
}

The Frantlin Institule, Policy Analysis Cenier, 4701 Willard Avenue. Chevy Chase, Maryland 20815

Received April 26. 1985

\begin{abstract}
The smoke intake of 865 undisturbed smokers of over 10 cigarettes per day was measured using plasma nicotine and cotinine, and expired carton monoxide (CO) as markers. While nicotine yields, according to Federal Trade Commission (FTC) analycical standards varied 16-fold from 0.1 to $1.6 \mathrm{mg}$ cigarette, the corresponding plasma nicotine values varied from around 25 to 45 $\mathrm{ng} / \mathrm{ml}$, and extimated mean nicotine intake of smokers varied from around 0.75 to $1.25 \mathrm{mg}$ cigarene. Expired $\mathrm{CO}$ and plasma cotinine values atso raried in similar proportion, but mean daily cigarette consumption was independent of the FTC nicotine yield of the cigarettes smoked. The resulss indicate that pharmacodynamic satiation causes behavioral regulation, and that smokers of very high yield brands compensate downward, and vice vers. The ratio of tar vield to nicotine yield usually increases with increasing tar yeld: therefore tar intake is likely to increase at higher tar yieids, even though the increment of nicotine intake is smalt. It follows that FTC analytical determinations are poor predictors of relative intake of ajcotine, $\mathrm{CO}$, or tar, while rankings based on mean arto-nicotine ratio of a brand's smoke could be more meaningful. Moreover. the considerable variation of individual smoking behavior suggests that precise numerical rankings of cigarettes are not justified. An analogic ranking of cigarentes into a few broad clases would

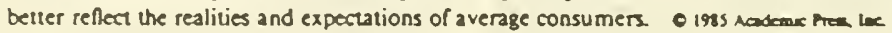

\section{INTRODUCTION}

In the United States, cigarette yields are determined by the Federal Trade Commission (FTC) according to standard procedures similar to methods used in other countries (30). The results of such tests do not represent the full behavioral range of individual smokers; as the FTC itself recognized, they simply indicate the relative yield position of brands according to a convention of analytical standards, but not actual conditions of smoke puffing or intake (13). While the prolonged public use of FTC ratings has fostered the belief that these values predict intake, several reports have challenged this belief, suggesting that official ranking methods may not offer reliable information to consumers $(3,7,9,12,16,27,34,35)$. The present study was

\footnotetext{
'? eliminary results of this study were first presented at the 21 st Annual Meeting of the American College of : europsychopharmacology, San Juan. P.R.. December 15-17, 1982.
} 
amed at further clarifing this issue, by measuring the undisturbed intake of individual smokers in relationship to the analytical FTC yjelds of tar, nicotine, and carton mon. oxide $(\mathrm{CO})$ of the cigareltes smoked.

Of the several thousand substances present in smoke, nicotine is obviousty a most specific marker, in plasma it has a half-life of some $120 \mathrm{~min}(5,6)$, and is steadystate levels reflect the input from cigarettes smoked during $8-10 \mathrm{hr}$ prior to ampling. ouinine, the principal metabolite of nicotine, has a terminal half-life around $15 \mathrm{hr}$ $.8,29)$. and it has been suggested as a better indicator of cumulative nicotine intake over a perion of several days (19-21).

Nicotine is delivered in close physical association with tar paricles (1T) Only a negligible amoun! mizrates as vapor, and at the average $p H$ of cigarette smoke most of it is rapidly absorbed in the lungs (2), white less soluble tar components are deposited on the lung surface or are partially exhaled (25). Thus, plasma nicotine and cotinine can be used to infer maximum tar intake potential, once the average ratio of tar to nicoune of a cigarette's smoke is known.

It should be kept in mind that plasma nicotine or cotinine values ate aot direct indicators of intake, and cannot be utilized as such to determine the validity of FTC cigarette rankings, which are expressed as yields per cigarette. To this end, they need to be transformed into estimates of mean nicotine intake per cigarette (MNIC), accounting for each subject's weight and cigarette consumption, and afier appropriate pharmacokinetic considerations.

Blood carboxyhemoglobin is quantitatively related to the amount of inhaled carbon monoxide and correlates with the concentration of $\mathrm{CO}$ in expired air (37). There are many external sources of $\mathrm{CO}$ besides cigarelte smoke, and endogenous formation is also possible (36). For these reasons, expired CO values can be interpreted ooly in the light of other more reliable markers, especially in studies utilizing free rangin smokers under field conditions.

\section{SUBJECTS AND METHODS}

\section{Subjects}

The subjects ( 397 men and 468 women) were approached randomly in five cities. They were at least 21 years of age and had been smoking only cigarettes of the same brand for at least 3 monihs and no less than 10 cigarettes per day. Only voluriteers who measured at least $15 \mathrm{ppm} C O$ of expired air were recruited, in order to eliminate noninhalers. To ensure an even coverage of marke: share over the FTC range, less than 10 subjects per brand were recruited (Fig. 1), with minor exceptions at very low yields where few brands are available. Subjects represenied predominanty white collar occupations and housewives.

Only individuals in good health under no medication were recruited lodividuals with akcoholic problems or exceeding $\pm 20 \%$ of ideal weight, or pregnant were excluded. Subjects reporned to the test facility and smoked one of his/her customary cigarettes. A venous blood sample was taken $10 \mathrm{~min}$ after the last puff to allow adequate time for frst compartment distribution (32). All subjects were sampled in midaftemoon on Wednesdays or Thursdays, and received nominal monetary compenation. 


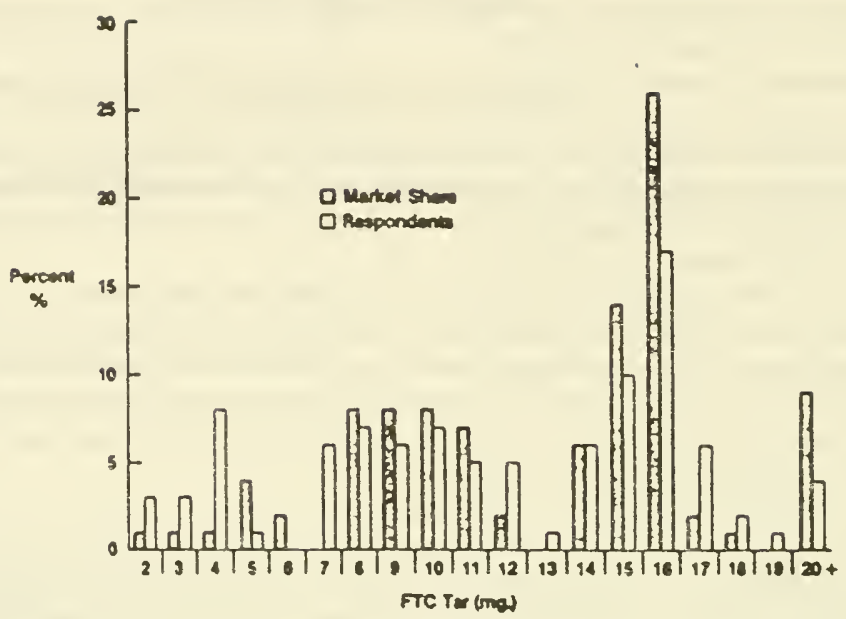

FKo. 1. Distribution of sampled smokers versus actual market share, based on FTC tar yiedd of cigareltes.

\section{Blood Samples}

Blood samples were drawn with EDTA as an anticoagulant; plasma was immediately frozen without preservatives. Samples were blind coded and stored frozen at $-20^{\circ} \mathrm{C}$ or below.

\section{Cigarette Consumption}

Volunteers reported the number of cigarettes smoked each day (CPD), by day of week. Approximately 20\% of the volunteers were asked to bring all cigarette butts from the previous day to the test facility, and the verbal reports were consistentiy verified. The overall CPD was taken as the daily average for all days of the week, rounded to the nearest integer.

\section{Cotinine and Nicotine Analysis}

Nicotine and cotinine levels in plasma were determined, using methods developed by Jacob et al. (26). Standard curves were constructed and repeated every 40 deter. minations, using the internal standards $N$-ethylnornicotine for nicotine, and $N-12$. methoxyethyl)norcotinine for counine. The peak height correlation was linear over the range 5 to $600 \mathrm{ng} / \mathrm{ml}$ for cotinine, and 1 to $100 \mathrm{ng} / \mathrm{ml}$ for nicotine. Throughout the procedure. precautions were taken to avoid exogenous contamination (15).

As a test of consistency, 167 samples were reanalyzed for nicotine and 88 separate samples reanalyzed for cotinine. The mean values for nicotine were $31.1 \mathrm{ng} / \mathrm{ml}$ for the original analyses and $31.5 \mathrm{ng} / \mathrm{ml}$ for duplicate analyses. The mean cifference of $0.4 \mathrm{ng} / \mathrm{ml}$ had a SEM of $0.2 \mathrm{ng} / \mathrm{ml}$. The corresponding values for cotinine were 244.7 
and 2:3.: $\mathrm{ng} / \mathrm{mi}$ for the original and dupicate samples. respectively. The mean dafference of $9.0 \mathrm{ng} / \mathrm{ml}$ had a SEM of $3.2 \mathrm{ng} / \mathrm{ml}$. There was no statistically signitiont pairuise difference between the original and duplicate values for either nicotine or cotinine, at the $5 \%$ level of significance.

In a previous study (19), utilizing the same methods of analysis for cotinine and :otine, interierences from other compounds were excluded after measuring a random Jup of samples by high-resolution gas chromalography and mass spectrometry.

\section{Expired Carbon Monoxide Determinations}

Expired air samples were obtained at the time of biood withdrawal by having the respondent loosen all tight fitring clothes, assume a standing position, take a full deep treath, hold it for $5 \sec$, and exhale all but the end tidal air, which was then collecred in a l-liter polyethylene sample bag. The $C O$ concentration was measured immedianely using a carbon monoxide analyzer (Ecolyzer, Energetics Sciences, Inc., Elmstead, $\checkmark$. Y.), with a sensitivity of $\pm 1 \mathrm{ppm}$, on the full scale from 0 to $100 \mathrm{ppm}$.

\section{RESULTS}

A very close similarity of data allowed a combined analysis for both sexes. Brand yields are those reported by the Federal Trade Commission (14). Because of wellknown production variations and seasonal drifts, the actual yields of the cigaretes smoked by the subjects might have been somewhat different from FTC figures. Data are presented graphically as a sequence of interval means. It is emphasized that this representation shows only the overall trend in the data; each mean, by itself, is cornprised of several data points. Ninety-five percent confidence bounds (broken bioes) indicate the extent of scattering. A scatter plot of the original plasma nicotine meajurements is given to illustrate the extent of variance, which is similar for plasma cotinine and expired $\mathrm{CO}$ data sets. Linear regression equations are given where desirable. However, it is clear that true functions involving nicotine or $\mathrm{CO}$ intake are nonlinear and must intersect $(0,0)$ coordinates.

\section{Plasma Nicotine and Cotinine as a Function of Cigaretie Yield}

Individual leveis of plasma nicotine are presented as measured to emphasize their pharmacodynamic significance, and are given in Fig. 2 as a function of FIC nicotine yields. The figure shows a close correspondence in slope and intercept with the mean sample trends of Fis 3. Plasma cotinine values correlated with FTC nicotine yields in a pattern similar to that of plasma nicotine $(Y=225.3+74.4 X, r=0.23, P<0.001)$ and their mean sample trends are also reported in Fig. 3.

\section{Nicotine Intake}

The transformation of plasma nicotine data according to cigarette consumption, body weight, volume of distribution, and clearance give an estimate of mean nicotine 


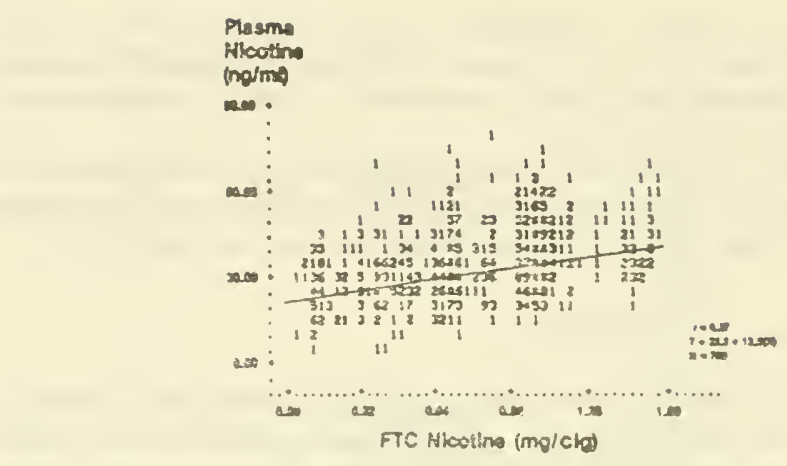

FIG. 2. Individual plasma nicotine values as a function of FTC nicutine vield of cigareties smoked. The digit in each data point indicatas the number of individual observations in the domain of that point. indicaies 10 or more obxervations The signiticance of $r$ is $P<0.001$.

bicavailability per cigarette. Published information on nicotine disposition in man $(5$, 6) estimates mean plasma nicotine half-life $h=120 \mathrm{~min}$, and mean volume of distribution $V_{d}=2600 \mathrm{ml} / \mathrm{kg}$. For each individual, the weight $W$ is known, and $d t=900$ $\min /(C P D-1)$ is the average interval between cigarettes smoked. Each individual was sampled in laie afterncon, 10 min after smoking a cizarette, giving plasma nicotine values at or near peak steady-state $P(N i c)$ s.s. On this basis, individual mean nicotine intake per cigarette I-MNIC œn be estimated as

$$
\text { I-MNIC }=P\left(\text { Nic s.s. }=W \cdot V_{0} *\left[1-(0.5)^{\mathrm{w} / \mathrm{h}}\right]\right.
$$

Because $V_{d}$ and $h$ are estimated population means, the l-MNIC values cannot be interpreted as precise individual estimates, but the statistical aggregate of their values is reasonably representative of sample trends.

This conclusion is ever more justified since published data (5) do not show correlation between half-life and dose, volume of distribution and dose, half-life and rolume of distribution, or half-life and plasma levels. Independent direst measure of mean nicotine intake in smokers has produced data consistent with the mean estimates of our study (9). Mean values of estimated ricotine intakes are reponted in Fig. 4, which also show's the mean trend of daily nicotine intake per kilogram of body weight, given here for its pharmacodynamic significance. In this regard it should be noted that in our sample the distribution of body weights was associated with less than 190 of the variation in the FTC nicotine yield of the cigarettes smoked $(Y=66.2+3.75 X ; r$ $=0.09, D<0.001$ ).

\section{Vicotine-Cotinine Relationship}

Pievious studies have shoun a good correlation of plasma nicotine and cotinine ( $r$ $=0.84)$. after accurate selection of subjects, and blood sampling timed to synchronize pharmacokinetic variables near steady-state values $(19,20)$. Recently, Benowitz el al. (8) and Linch (29) reported kinetic parameters for cotinine disposition in man, shourng no correlation between dose and half-life. nor between plasma leveis and half-life. 


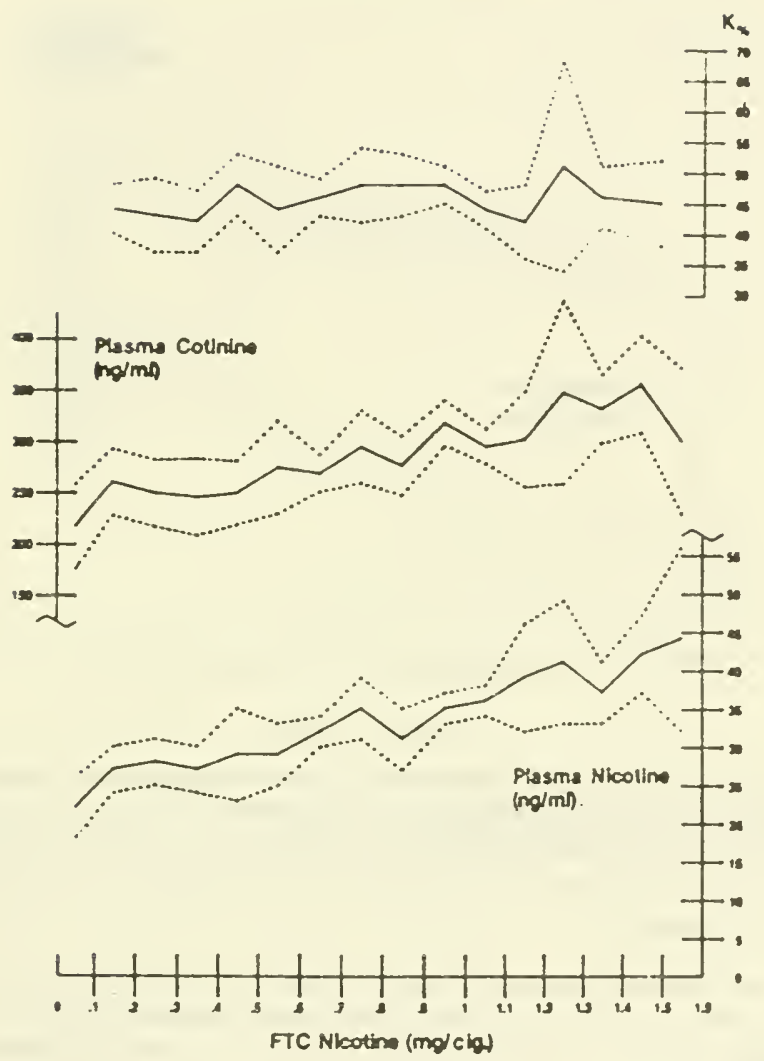

Fic. 3. Trends of man plasma nicotine, cotinine, and nicotine 10 cotinine conversion rate $\left(K_{\mathbf{4}}\right)$ as a function or FTC nicocine vield of cigarelles smoked (95\% confidence inlervals).

Such data open the possibility of estimating individual metabolic conversion rates (I$K_{\mathbf{3}}$ ) of nicotine to cotinine:

$$
I-K_{s}=100 \cdot P(\operatorname{Cot}) s . s \cdot W \cdot V_{d} \cdot\left[1-(0.5)^{d / h}\right] /(I-M N I C)
$$

where P(Cot)s.s is the plasma cotinine level measured in late afternoon as or near steady state for each individual, $W$ is the individual weight, $V_{c}=1100 \mathrm{~m} / \mathrm{hog}$ is the mean volume of distribution of cotinine, I-MNIC is the mean individual intake of nicoune per cigaretre as previously defined, $d t=900 \mathrm{~min} /(\mathrm{CPD}-1)$ is the individual mean interval between cigarettes smoked, and $h=900 \mathrm{~min}$ is the mean termival halflife for plasma cotinine (8). The estimated mean conversion rate $K_{3}$ is around 45\%; this value is obviously sensitive to the choice of parametric determinants, but not so for the slope of the relacionship, which appears independent of cigarette nicotioc yieid. as Fig. 3 shows. 


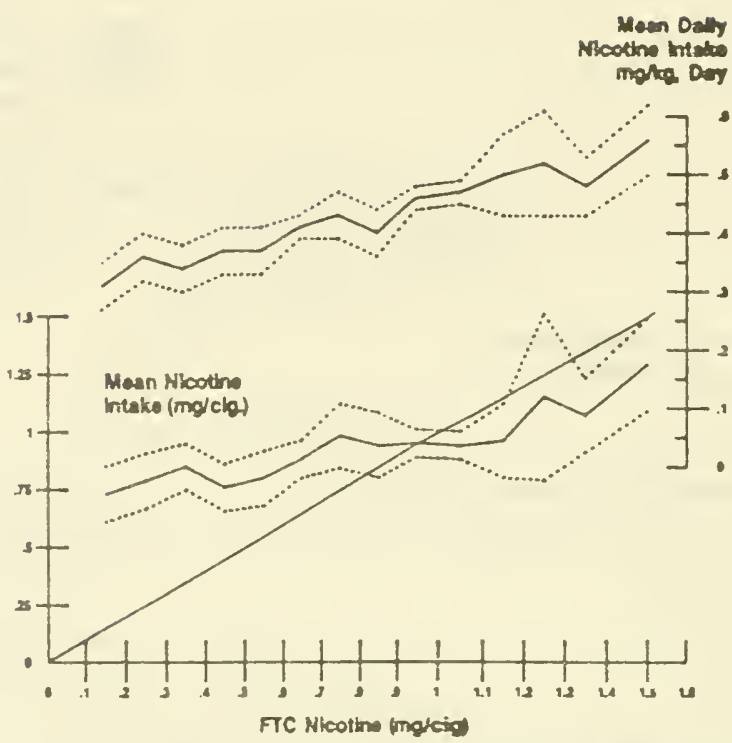

FiG. 4. Nicoline incake per cigarene and daily nicoline intake per kilogram of body weight: Mean trends as a function of FTC nicoline yield. The straight line represents expected values if mean intakes per cigarette were equivalent 10 FTC nicotine yields (958 confidence intervats).

\section{Cigarette Consumption}

Figure 5 indicates that mean daily cigarette consumption is not significantly affected by FTC nicotine yield for the sample of this study. Similarly, Fig. 6 indicates that mean plasma nicotine levels are poorly related to the number of cigarettes smoked daily, probably reflecting the absence of smokers of less than 10 cigarettes per day in our sample. For those smokers the relationship is likely to be more pronounced, as the beginning of the curve in Fig. 6 suggests.

\section{Expired CO}

Fizure 7 shows virtually no correlaion between FTC CO yieias and expired air CO $\because 2$ i.jes. The correlation of expired $\mathrm{CO}$ and plasma cotinine and nicotine was negligible even after correcting for FTC nicotine/CO ratios of the brands smoked ( $Y=26.8$ $+1.3 X, r=0.15, P<0.001$ ), suggesting strong interference from environmental sources of $\mathrm{CO}$ intake, other than cigarettes.

\section{DISCUSSION}

Nico:ine and $\mathrm{CO}$ inlake

The results show that in a sample of smokers representative of the entire market, mean cigarette consumption is unaffected by the FTC nicotine yield (Fig. 5) and that 


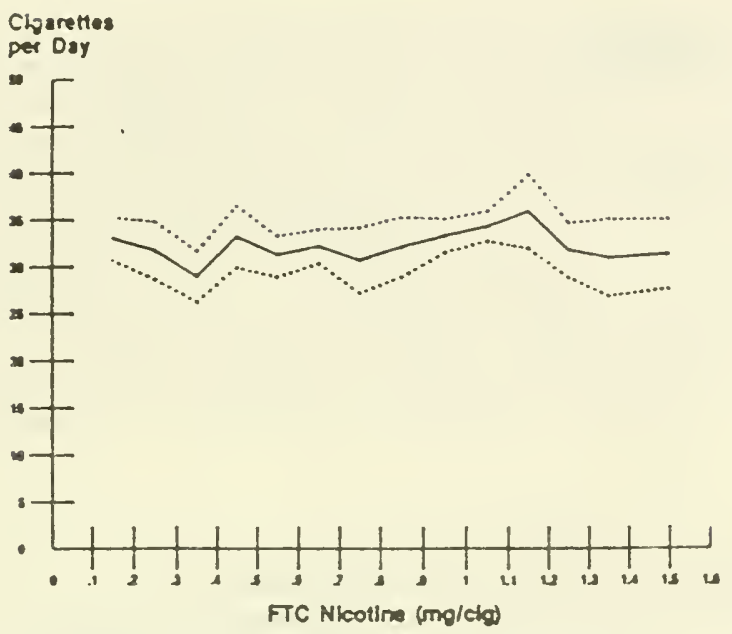

FKG. S. Mean values of cigarelles smoked per day as a function of FTC nicoline vield $195 \%$ cacitente intervals).

MNIC varies only between 0.75 and $1.25 \mathrm{mg} /$ cigarette (Fig. 4), corresponding to mean steady-state nicotine plasma levels between 25 and $45 \mathrm{ng} / \mathrm{ml}$ (Fig. 3), despite a much greater variation of FTC cigarette yields from approximaiely 0.1 to $1.6 \mathrm{mg}$ per cigaretre. The limiting factor is probably nicotine intake itself, since plasma nicotine and cainine values display similar ceilings, while the nicotine to cotinine conversion rate remains

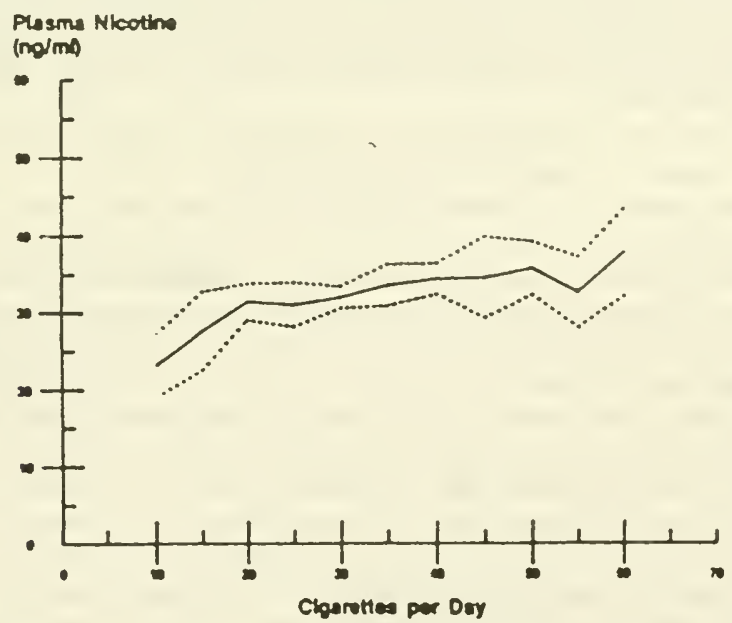

Fx. 6. Mean plasma nicotine values as a function of ciparettes smoked daily (95\% confidence interals). 


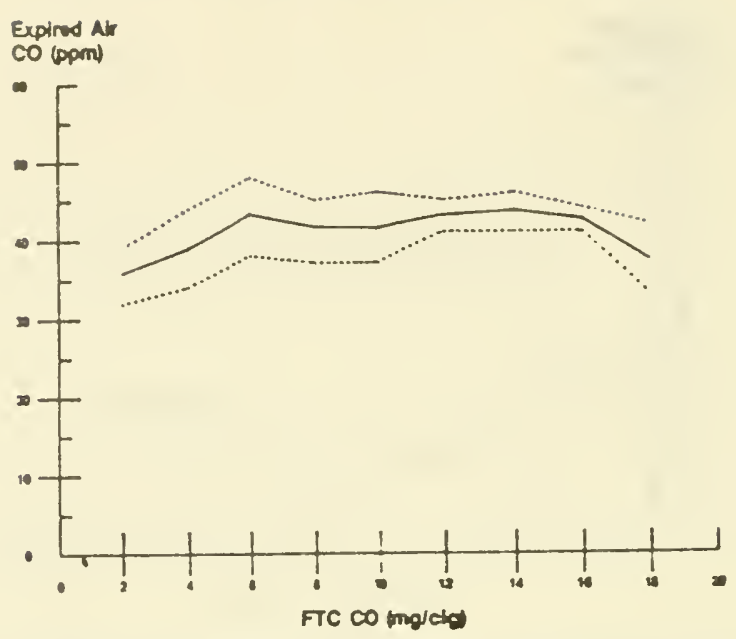

FrG. 7. Mean expired air carton monoxide ( $C O)$ valus as a function of FTC $C O$ yield of cigarelles smoked (95\% confidence intervals).

constant (Fig. 3). Daily nicotine intake per kilogram of body weight also displays a parallel ceiling (Fig. 4), and the mean plasma nicotine ceiling itself is not significantly exceeded even at high numbers of cigarettes smoked daily (Fig. 6). Expired CO levels also reach a ceiling corresponding to that of nicotine intake (Fig. 7), suggesting that either agent or both agents may be independently responsible for limiting intake. However, previous experience (37) suggests that $\mathrm{CO}$ is unlikely to have a primary role in the limitation of intake within the range of concentrations measured in this study. The results confirm earlier partial findings for nicotine, cotinine, and $\mathrm{CO}(3,4,7,9$. 12. 23, 24, 33, 34).

The parallel distributions of plasma nicotine and cotinine at all FTC levels argue azainst a metabolic explanation of the ceiling conditions observed, unless nicotine or ई-:ater proportions of a different metabolit: were excreted at faster rates, 3 intake increases. This possibility has not been obsened experimentally 15,9$)$, and it should be considered very unlikely, especially in vieu of the parallel and incependent stationary conditions of expired $\mathrm{CO}$ levels. Pharmacod!namic satiation and reiated behavioral determinants are the most probable reasons for the observed ceilings.

According to this thinking, smoke intake may be determined by individual nicotine demand. and to a lesser exten: $i$ the sapacisy of the cigarette to deliver nicotine. The former would influence behavioral factors, such as number of cigarettes smoked, modulation of the nicotine bolus effect by depth of inhalation, puff volume and frequency, and tampering with filtration and air dilution devices (22). At high FTC vields roughly equivalent amounts of nicotine may be extracted by individual smokers irom the daily average cigarette. At low yields most smokers compensate upward, although previous studies have shoun that at vields below $0.2-0.3 \mathrm{mg}$ FTC nicotine it will be progressively more difficult to physically extract smoke and nicotine from the cigarette no matter 
hn: much !amperng occurs. resulting ir. a linear correlation of yield and intak: (19). Brand preierences are probably established on the basis of organoleptic. phisiea' performance (e.g.. draw). promotional, and kinesthetic differences.

Figure 4 indicates that more smokers in our sample experienced intakes higher than FTC yields when smoking brands yielding less than $0.8-1.0 \mathrm{mg}$ of nicotine. and vice versa. Although these figures correspond closely with independent experimental neasures of nicotine intake (9). Fig. 4 should be interpreted only as a plausible approximation, owing to the variance of the parametric values utilized. Moreover. snokers of less than 10 cigarettes per day or with less than $15 \mathrm{ppm} C O$ in expired air were excluded from our sample; their inclusion would have given lower M.VIC escimates than reported in this study, which may be valid only for the majority of serious smokers, as direct measurements of compensation suggest (9).

\section{Tur Inlake Estima:es}

Retention of tar from inhaled smoke may be lower than that for nicotine (25); therefore. any evaluation of tar intake from nicotine intake estimates represents maximum possible tar intake and can be calculated from nicotine intake values. after :djusting for the tar-to-nicotine ratio (T/N) of the smoke inhaled.

For U. S. market cigarettes, the FTC T/N ratios of cigarette smoke increase with increasing FTC tar delivery (Fig. 8). In general. $\mathrm{T} / \mathrm{N}$ ratios are sensitive to blend composition, puff profile, volume, and duration, interval between puffs, tampering with ventilation devices, and environmental conditions (10). Methods of determining the $\mathrm{T} / \mathrm{N}$ ratio for individual smokers under free smoking conditions are not yet available. Vevertheless, available evidence indicates that the effects of ventilation on $T / N$ ratios of smoke may not be extreme (10), suggesting that average $T / N$ ratios based on FTC values might be close to mean field conditions. With this in mind, if we consider the range of MNIC in Fig. 4, and that of FTC T/N ratios of commercial cigarettes in Fig. 8, the probable tar intakes should range between 4 and $6 \mathrm{mg} /$ cigarette at the low end, and between 15 and $20 \mathrm{mg} /$ cigarette at the high end. Thus even though there is a small 0.6 -fold increase in nicotine intake between low and high yield cigarettes, the increase in tar intake could be in the order of 2.5 to 5 -fold.

\section{CONCLUSIONS}

In a large sample of relatively heavy smokers representative of market share, daily cigarette consumption is unaffected by the FTC nicotine yield of the cigarettes smoked, and MNIC for high yield cigarette consumers is only some $60 \%$ higher than for those of very low yield brands, even though the FTC ranking scale implies a $1600 \%$ increase. This intake ceiling is probably controlled by nicotine, it reflects upon $\mathrm{CO}$ intake and plasma cotinine levels, is not significantly affected by the number of cigareties consumed daily, and appears to be of pharmacodynamic and behavioral origin. In general these findings reinforce previous reports and suggest that FTC measures have dubious meaning to consumers, except perhaps for a small fraction of smokers (2-3\%) using very low yield cigarettes (19). The results also reinforce the desirability of cigarettes with low $T / N$ ratios $(18,38)$ and are consistent with epidemiologic evidence showing that duration of exposure is of greater significance than the type of cigarette smoked (II). 


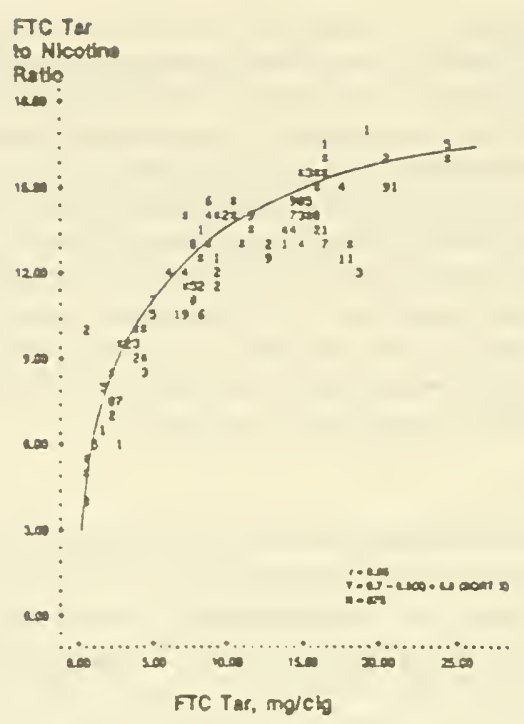

FIG. 8. FTC tar-10-nicotine ratios as a function of FTC ur yield of cigarelles smoked. The significance of $R$ is $P<0.001$.

The small variation of nicotine bioavailability in selation to FTC yield should not have appreciable biologic consequences $(1,22,31)$ and, thus, may not be a suitable criterion for cigarette ranking. On the other hand, tar intake is likely to vary over a broader range and can be estimated from the $\mathrm{T} / \mathrm{N}$ ratio of the smoke inhaled. In the light of our results, a cigarette ranking index should encourage low tar and thus low overall yields, and could be defined as $R=T(1+1 / N) / 5$ where $T$ and $N$ are the FTC tar and nicotine vields, and 5 is a normalizing factor. This index would give a range of approximately seven?old between the lowest and highest yield brands now on the market. probably close to real difierences in mean tar intake.

lowever, any ranking based on standardized and precise $=$ ialytical vields is boun 3 to retain a futile determir-istic pretense, given the individual variability in smoke demand and associated behavioral traits. Therefore, a better ranking index would simply give a message of relativity, graded into a iew broad categories or bands. For instance, a three-band sysiem would group cigarettes with $R$ values of less than 2 . ketween 2 and 4 . and greater than 4 . If such an approach were adopted. ma nu facturers could easily adjust vields to classify cigarettes unambiguously in any of these categories.

The broad meaning of such banding system has two main advantages. First, it uould make possible to change future classification criteria without altering the tasic public message, when better methods became ar zilable for predicting true tar to nicotine ratios and average intake. Second. its avoidance of numerical pretension will render it all the more realistic, credible, and informative. At the same time. consumers should be made aware that cigarette rankings have on! relative value. absolute intake being predominantly determined by personal behavior. 


\section{ACK.VOWLEDGME.VTS}

The authors acknow tedpe the asustance of Elrick-Lavdge Inc. in the superision and recruitung of voluntcers Jnd sampie collection: Dx. Roger A. Novak. Bornston Research Laboratories Inc.. for the analyses of plasma counine: Dr. Neal L. Benowiz and Dr. Pevion Jacob III. San Francisco General Medical Center, for the piasma nicotine analyses. The authors also thank Dr. J. Van Rossum. University of Nijmeger. The Nethertands: Dr. T. D. Darb! Lniversity of South Carolina; Dr. G. L Plaz. University of Montreal: Dr. L. Detth, L nversity of 3aset. Swizerland; and Dr. E. F. Domino, Unversity of Michigan.

\section{REFERENCES}

1. Anonymous (1984) Can we have less hazardous cigareltes? Lancet 2, 1167.

2. ARMTIACE, A. K. (1973). Some recent observations relating to the absorption of nicotise from tobacco smoke. In Smakug Behavior: Motives and Incentives (W. L. Dunn, ed.). Winston. Washington. D. C.

3. ASHTON, H., STEPSEY, R.. A.D THOMPSON, J. W. (1979). Self titration by cigarelle smokets. Brit. Med. $J 2,357-360$.

1. ASHTON, H., STEPIEY, R.. A.NO THO YPSON, J. W. (1981). Should intake of carton monoxide be used as a guide to incake of other smoke constituents? Brit. Wed. J 282. 10-13.

5. BE.NOWITZ. N. L., JACOB, P.. JONES, R. T., A.ND ROSENBERG. J. (1382). Interindividual variability in the metabolism and cardiovascular effects of nicotine in man. J. Pharmacol Exp Ther 221, 368372.

6. BENOWittz. N. L., KLYT, F.. A.ND JACOB. P. (1982). Circadian blood nicotine concentrations during cizarelle smokine Clin. Pharmacol. Ther. 32(6). 758-764

7. Be.Yohitz. N. L., HALL S. M.. HeRning, R. I., JaCOB, P., JONES, R. T., A.YO A Bdel-LATIF. O. (1983). Smokers of low rield cigareltes do not consume less nicotine. A Engl. J. Wed. 309. 139-142.

8. BENOWITZ N. L., KUYT, F., JACOB. P., JONES. R. T., AND ABDELLATF, O. (1983). Colinine disposition and effects. Clin. Pharmacol. Ther. 34, 604-611.

9. BENOWIZ N. L.. NND JACOB, P. (1984). Daily intake of nicotine during cigareule smoking Clin. Pharmacol. The 35, 499-504.

10. BROWNe, C. L. KETH, C. H. AND ALLe,, R. E. (1980). The effect of filter ventilation on the yield and composition of mainstream and sidestream smokes Beisr. Tabokforsch. Int. 10, 81-90.

11. DOLL, R. (1978). Ao epidemiological perspective of the biology of cancer. Cancer Res. 32, 3573-3583.

12. EBERT, R. V., MCNABa, MCE., MCCUSKER, K. T., AND S.NOW, S. L (1983). Amount of nicotine and carbon monoxide inhaled by smokers of low-tar, low-nicotine cigarette. J. Amer. .Med. Assoc. 250. $2840-2842$.

13. Federal Trade Commission (1967). Cigarettes: Testing for tar and nicotine content-Sutements of considerations. Fed. Regist. 3211178.

14. Federal Trade Commission (1983). "Tar, "Nicorine and Carbon. Monoxide of the Smake of 208 Varieries of Domestic Cigaretles. Gov. Printing Offce, Washington, D. C.

15. FEYERABEND. C.. AVD RUSSELL. M. A. H. (1980). Assay of nicocine in biological materals: Sources of contamination and their elimination. J. Pharm. Pharmacd. 32, 178-181.

16. Folsom, A. R., Pechacex, T. F. DeGaudemaris, R., LuepKer, R. V., Jacobs, D. R., and Billum, R. F. (1984). Consumption of "low-yield" cigaretses: lis frequency and relationship to serum thiocyanate. Amer. J. Public Healih 74, 564-568.

17. GEORGE, T. W.. AVD KETTH, C. H. (1967). The selective flitation of tobacco smoke. In Tobacco and Tobacco Smake (E. L Wynder and D. Holfmann, eds), Academic Press. New Yort.

18. GORI, G. B., AND BOCK. F. G. (1980). A Safe Cigaretle? Banioury Report No. 3. Cold Spring Harbor Laboratory, Cold Spring Hartor, N. Y.

19. GOR: G. B., AND LrixH, C. J. (1983). Smoker intake from ciesseltes in the 1-me Federal Trade Commission lar class. Regul. Toxicd. Pharmacd. 3, 110-120.

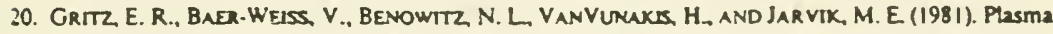
nicotine and cotinine concentrations in habitual smokeless tobecco users. Clin. Phamecol. Ther. 30, 201-209.

21. HALEY, N. J., AXezrod, C. M. AND TILTON, K. A. (1983). Validacion of self-reporing smoking behavior. Biochemical analysis of cotinine and thiocyanate. Amer. J. Public Health 37, 1204-1207. 
22. HesNingatLD, J. E. (1984). Behavioral pharmacology of cigarefte smoking. In Advances in Behavioral Phamocology (T. Thompson. P. B. Dews, and 1. E. Barreth ods), Vol. 4, pp. 132-210. Academic Presc. New York.

23. HILL P.. AND MARQUARDT, H. (1980). Plasma and urine changes after smoking different brands of cigarelles. Clin. Pharmacol. Ther. 27, 652-658.

4. HILL. P., HALEY, N. J., AND WrNDER, E. L. (1983). Cigaretle smoking: Carboxyhemoglobin. plasma nicotine counine and thiocyanate vs. self-reported smokung data and cardiovascular disease. J. Chronic Dis $36,439-449$.

25. HiNDS, W., FIRST, M. W., Huber, G. L., AND SHEA, J. W. (1983). A method for measuring respiratory deposition of cigaretie smoke during smoking. Amer. Ind. H/g Assoc. J. 4, 113-118.

26. JACOB, P., WILSON, M., AND BENOWITZ N. L. (1980). Improved gas chromatographic method for determination of nicotine and cotinine in biclogical fluids. $J$ Chromalogr 143, 203-206.

27. KOZlowski, L. T., RiCKert. W. S., POPE, M. A., ROBINSON, J. C., AND FreCKer, R. C. (1982). Esumating the seld to smokers of tar, nicocine and carbon monoxide from the lowest yield venulated filter cigarettes. Bnt. J. Addicr. 77, :59-165.

28. Krerematen, G. A., Damlano, M. D., DVorchix V. Hi., AND Vesell E. S. (!982). Smokinginduced change in nicotine disfosition: Application of a new HPLC assay for nicotine and its metabolues. Clin. Pharmacol. Ther. 32, 769-780.

29. LY.NCH. C. J. (1984). Half-lives of selected lobacco snoke exposure markers Eur J. Respir. Dis. Suppl. 133, 63-67.

30. PlLLSBURY, H. C., BRIGHT, C. C., OCONwOR, K. J. AND IRISt, F. W. (1969). Tar and nicotine in cigarelte er: oke. J Assoc. Anal. Chem. 52 458-462.

3!. RICHARDS. T (1984) Can we have safer cigareties? Brtt. Med J. 289, 1374-1375.

32. ROSENGERG, J. BENOWTR N. L. JACOB, P., AND Willson, K. M. (1980). Disposition kinetios and effects of intravenous nicoune. Clin. Phermacol. Ther. 28, $517-522$.

33. Rl'ssell M. A. H. Wilson, C., Patel U. A., Feterabend, C., and Cole P. V. (1975). Flasma nicoune levels afier smokıng eigare!res wh high, medium and low nicotine nelds. Brit .Med $\mathrm{J}$. $414-416$

34. RLSSELL M. A. H. JARVIS. M., IYER. R.. A.VD FEYERABE.ND, C. (1980). Relation of nicotine yeld of cigarettes to blood concentrations in smokess. Bru. Med J 280, 972-976.

is. SCHACHTER. S. (1981). Pharmacological and physiological determinants of smoking inn Intern. Hed. $88,104-114$.

36. Suostra.vd, T. L. (1951). The in uirc formation of arton monozide in blood. Acla Physiol. Scand. 24, 314-332

3? Stemiard. R. D. Stewart. R. S., Stamm, R. S.. Stamm. H'. avd Seele., R. P. (1976). Rapid estimation of carboxyhemoglobin level in fire fighters. J Amer . Ised Assoc. 235. 390-392.

i8. Surgeon General (1981). The health consequences of smoking: The changing cigarette. In Report of the Surgeon Geniral Department of Health and Human Services. Wiashington. D. C.

39 VESELL E. S., A\D PE\:TO, M. 8. (1983). Assessment of methods 10 identir! sources of intenndividual pharmacokinetuc iz ations. Cirn. Phormaconilnes 8. 378-409. 
Mr. Waxman. Like the American Lung Association and Dr. Benowitz, Dr. Gori found, and I quote, "FTC analytic determinations are poor predictors of relative intake of nicotine." So when this panel tells us that the FTC numbers show that nicotine rates are going down, they're relying on FTC numbers that they are able to affect, and which are not a predictor of what is happening to the smoker.

Now, if it's not a predictor of what's happening to the smoker, you would expect that maybe in smokers who have died, you can measure some of those nicotine levels. Dr. Gori's chart on page 318, showed that the individual plasma nicotine values as a function of FTC nicotine yield of cigarette smoke was not relevant and, in fact, plasma levels showed the same levels of nicotine.

This is relevant to the question of Dr. Spears' presentation in 1981, where he wrote that when the cigarettes were reduced for tar, the nicotine levels through a blending process could be greater and could result in a greater nicotine concentration.

Now, Dr. Spears says that concentration doesn't make any difference because it's the FTC numbers that make a difference. The FTC numbers do not make the difference. It's the concentration in the cigarettes because of the blending. If you have a higher concentration because of the blending in the cigarette which results in a higher nicotine level or concentration that is getting to the smoker, that is something the smoker will experience.

That will keep the smoker, if you accept the proposition, which this group does not, but which every other scientific- every other medical group that's looked at it would submit, nicotine is, in fact, addicting.

I was impressed by the statement that you blend tobacco for taste. You blend, as Mr. Suber, from the RJR Company, said, even though Mr. Johnston denies it, to achieve levels that the consumers have come to expect.

This is all a very slick way, in my estimation, of saying that it's really being done, you can say for other reasons, but for the levels of nicotine that consumers will experience. Mr. Suber said in order to deliver to the consumer a product that he wants, which contains a consistent level of nicotine, so we have to blend the tobaccos accordingly. So we do control it. They control it. They control the levels of nicotine by controlling the levels of concentration. This is one way we know that levels of nicotine can be manipulated.

Now, I want to ask a question of Mr. Johnston. You said that you want to advertise for adults to change brands. Well, I'll take you at your word, but tell me what this ad is all about. What adult is going to be influenced by this ad? "There's something for everyone at Joe's Place." There's Joe Camel. There's all these people having a wonderful time.

I'm an adult. I don't understand it. What do your advertising people have in mind when they produce have this ad to appeal to adults and not children?

Mr. JAMES JOHNSTON. The setting for that ad is a nightclub, a venue accessible ordinarily to people 21 years and older, who would understand what a nightclub is like and people having fun. The ad also talks about the smoothness of the product and it- 
Mr. WAXMAN. What is the message in a bunch of camels to an adult? These are cartoon figures.

Mr. JAMES JOHNSTON. It's fun, just like Snoopy the dog sells Met Life insurance, just like Garfield the cat sells Embassy Suites hotels. We're not accusing them of targeting kids, are we?

Mr. WAXMaN. Well, I think somebody ought to buy some life insurance if they're going to use this product.

Mr. JAMES JOHNSTON. Mr. Chairman, I think I can be helpful to this committee on the subject of what are smokers really getting when they smoke the full flavor and low tar and ultra-low tar. May I speak to that?

Mr. WAXMAN. I have some additional questions and believe you'll get to address these issues in the context of those questions. But first I want to question the assertion that the levels of nicotine have been going down since the 1950's.

Mr. Johnston, you wrote recently to Dr. Kessler that finished cigarettes contain between 1.5 percent and 2.5 percent nicotine. I have a copy of your letter here, which I will mark as Exhibit 23 and put in the record, but I assume you've seen that letter.

Did you send that letter?

Mr. JAMES JOHNSTON. I don't have it in front of me, but I did, indeed, send

Mr. WAXMAN. Let's get it to you.

Mr. JAMES JOHNSTON. I have a copy of it here with me. Yes, sir. That's my letter.

Mr. WAXMAN. The subcommittee has recently discovered evidence that the nicotine concentrations that you cited are actually higher than the concentrations of nicotine in tobacco in the 1950's.

Specifically, in 1952, a chemist for the FDA determined that nicotine levels in 1952 varied, on average, from 1.58 percent to 1.82 percent. His data is on an exhibit which I'd like to have marked 24 and put in the record.

[Exhibits 23 and 24 follow:] 


\section{Exh.bit23 -}

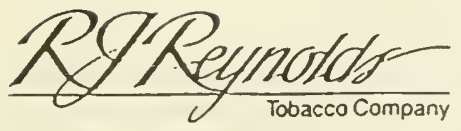

February 28, 1994

JAMES W. JOHNSTON

Chairman and

Chief Executive Otficer

Winston-Salem, N.C. 27102 919.741 .7925

David A. Kessler, M.D.

Commissioner of Food and Drugs

Food and Drug Administration

Department of Health \& Human Services

Rockville, MD 20887

\section{Dear Dr. Kessler.}

This letter is intended to clarify one simple fact that R.J. Reynolds Tobacco Company does not increase the nicotine in its cigarettes above what is found naturally in tobacco. In fact, our processes reduce the amount of nicotine in cigarettes when compared to unprocessed tobacco.

Reynolds manufactures and sells a broad range of cigarette products designed to appeal to the tastes of today's adult cigarette smokers. Smokers have increasingly demanded lower "tar" cigarettes. As a result of the processes used to lower "tar", nicotine has also been reduced. Over the past 40 years, the average "tar". and nicotine in cigarettes sold in the U.S. has declined by more than $60 \%$.

The variety of cigarettes available is, in large part, a result of blending techniques developed over a long history of cigarette manufacture and research. In addition to traditional tobacco blending techniques, various other techniques are available to cigarette manufacturers, including puffing of tobacco, filtration, air dilution, tobacco reconstitution and others, in order to enable manufacturers to reduce the "tar" and nicotine yields in their cigarettes. As a result of these various techniques, the sales weighted averages of "tar" and nicotine yields in the United States today are 11.5 milligrams and 0.8 milligram, respectively.

In the early 1950's the sales weighted averages of "tar" and nicotine yields were 36 milligrams and 27 milligrams, respectively. Most eigarette brands were in a narrow band around this average. Flue-cured tobacco naturally contains 2.5 to 3.5 percent nicotine, burley tobacco contains 2.75 to 4.0 percent nicotine, and Oriental tobacco contains 0.5 to 1.8 percent nicotine in the cured leaf. Finished cigarettes generally contain approximately 1.5 to $2.5 \%$ nicotine by weight, less than the natural cured teaf. 
Dr. David A. Kessler, M.D.

Page 2

February 28, 1994

The broad range of cigarette products available today provides smokers with a wide selection of tastes, "tar" and nicotine yields. The "tar" and nicotine yields in cigarettes are published by the Federal Trade Commission and the yields for each brand are provided in every advertisement for that brand in accordance with the law. The processing of certain tobaccos enables us to manufacture cigarettes consistent with the published "tar" and nicotine levels despite the nicotine variations from leaf to leaf and crop to crop.

Let me repeat, so that it is absolutely clear. R.J. Reynolds Tobacco Company does not increase the nicotine in the tobacco we use in the manufacture of our cigarettes.

Sincerely,

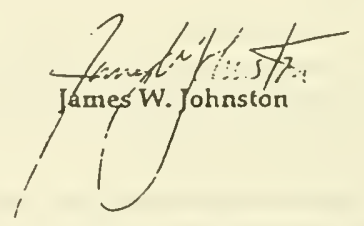


In the Matter of

LIGGETT \& MYERS TOBACCO COMPANY

\section{AFFIDAVIT OF CLARENCE D. WRIGHT}

DISTRICT OF COLUMBIA, ss.

Clarence D. Wright, first being duly sworn, states on oath as follows:

I am a resident of the District of colurbia and am employed as a chemist in the Food and Drug Administration, Federal security Agency, Washington, D. C. I hold the degrees of A.B. and Ph.D. and since 1912 have worked continuously as a food and drug analyst for the food and Drug Administration and 1ts predecessor agencles of the United States Government.

In the course of my official duties I recelved on August 14, 1952, fifteen cartons of cigarettes from Horatio Wales of the Division of Medical and Chemical Opinions of the Federal Trade Commission. Each carton bore en: urbroiken seai and was ldentlfled as shown in the attached photostatic copj of report marked Exhibit 1. The cartons remained in my possession until opened and the clgarettes contalned therein were then tested and analyzed as shown in sald report marked Exhibit 1. The results of the tests performed are shown in the attached photostatic 
copy of report marked Exhibit 2. Both exhibits are Incorporated herein by reference and made a part hereor.

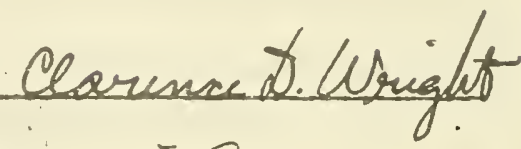

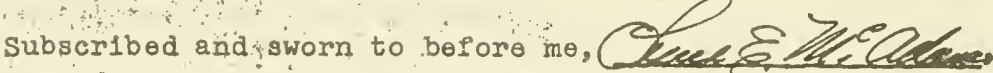

a Notary Public In and for the District of Columb1a, this Q 2 day of october, 1952.

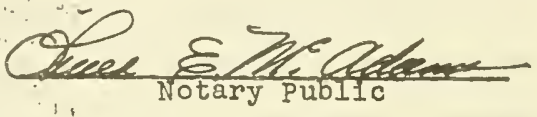

My comis ston expires

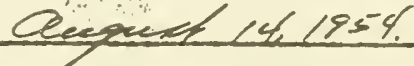




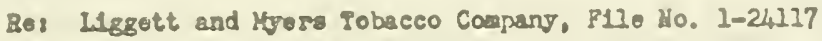

Sanplos: Meteen curtons of cigarettos, three of each of I1ve brands, were recelvod Irom Dr. H. Walas on Auguat 14, 1952. The cartons wore 1dent1sled as follors:

\begin{tabular}{|c|c|c|c|}
\hline $\begin{array}{r}\text { Buydos Mhibit A } \\
\text { B } \\
\text { C } \\
\text { D } \\
\text { B }\end{array}$ & & $\begin{array}{l}= \\
= \\
=\end{array}$ & $\begin{array}{l}\text { Luckg Strlke } \\
\text { Phillp Morr1s } \\
\text { Chestorf1sld } \\
\text { Cenol } \\
\text { 01d Gold }\end{array}$ \\
\hline Bakstran Bxhib1t & $\begin{array}{l}\text { A } \\
B \\
C \\
D \\
\text { E }\end{array}$ & $\begin{array}{l}- \\
\overline{-} \\
-\end{array}$ & $\begin{array}{l}\text { Chootorflold } \\
\text { Camol } \\
\text { Lucky Striko } \\
\text { Phllip Norrio } \\
\text { Old Gold }\end{array}$ \\
\hline LaRdrlere Ech1bit & $\begin{array}{l}A \\
B \\
C \\
D \\
E\end{array}$ & $\begin{array}{l}\overline{-} \\
\bar{z} \\
\overline{-}\end{array}$ & $\begin{array}{l}\text { Chooterfleld } \\
\text { Lucky Strike } \\
\text { Philip Morrie } \\
\text { 0ld Gold } \\
\text { Camel. }\end{array}$ \\
\hline
\end{tabular}

Each carton was treated as a separate sample, all determinations reported being made on samples consiating of ten clgarettas, one from each pack in the carton.

\section{Mo1sture.}

The papers were ramoved frora set of 10 clgarettes, and the contents placed in Rat aluminum dishes whth (t1ght fitting covers) which had provlously been wel ghed. The covered disher and contents were then welghed, the cover romoved and the dishes contalining the clgarette flller placed in a dessicator over concentratod sulfuric acld and allowed to stand at room temparature for two weeks. The papors wers welghed separately. After drylng, the d1shes wero covered and rowelghed, the loss boing reported as molsture (as recelved).

\section{Conditianing.}

Two sots of 10 elgarettos from each carton were placed in $50 \mathrm{cc}$ beakers and thase in a humidor over a saturated solution of amionfum nitrate. After standing for two woek at lesst, one sot was used for the swoking teots, the other was treated as doscribod under "lolstura" above, the loss belng reported as molsture after conditioping. 
Nicotine.

Welghed sets of 10 elgerettes (a recolved) were treated by the A.O.d.C. method for nicotine in tobecco and tobaceo products (Mothods of Analyals, 6.108). Results were corrected for the molsture content and for the paper waght, and reported on the dry besis.

\section{Smoking Teste.}

Sets of 10 conditloned afgarattes were unod in the eutomic apparatus provious 15 dereloped for reprodualble moking conditione, each cigarette requiring about 7 to 9 alnutes to be raked to a $23 \mathrm{~mm}$. butt. Tho agplrated smoko was dram through a eerlos of four oeparetory funnels each containing $12.5 \mathrm{oc}$. of chloroform and $12.5 \mathrm{cc}$ of $5 \%$ oulfurle ac1d, at half alnute intervale, each "drew" beling about 2 seconde duration. After the 10 elgarottes had been sooked suecessivelJ. the chloroform extract, Including washings, was ovaporated and driod at $100^{\circ}$ for 1-hour perlode unt1l the 10se was lese than .005 gram. The eopereted ac1d, aqueous solut1ons, and reshings were used for nicotine datarinations by the A.O.f.C. mothod.
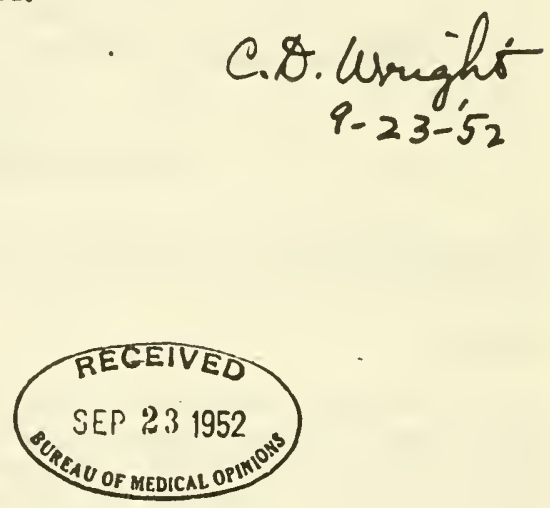


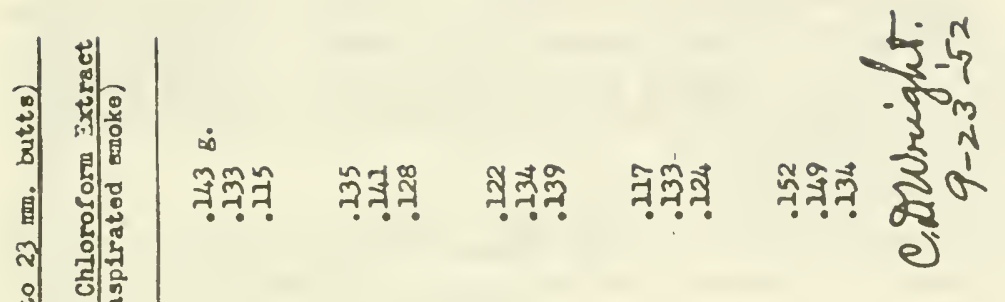

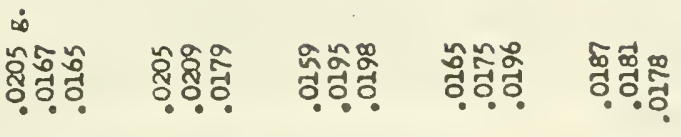

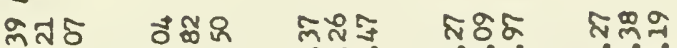

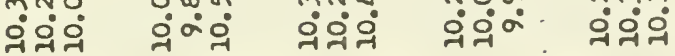

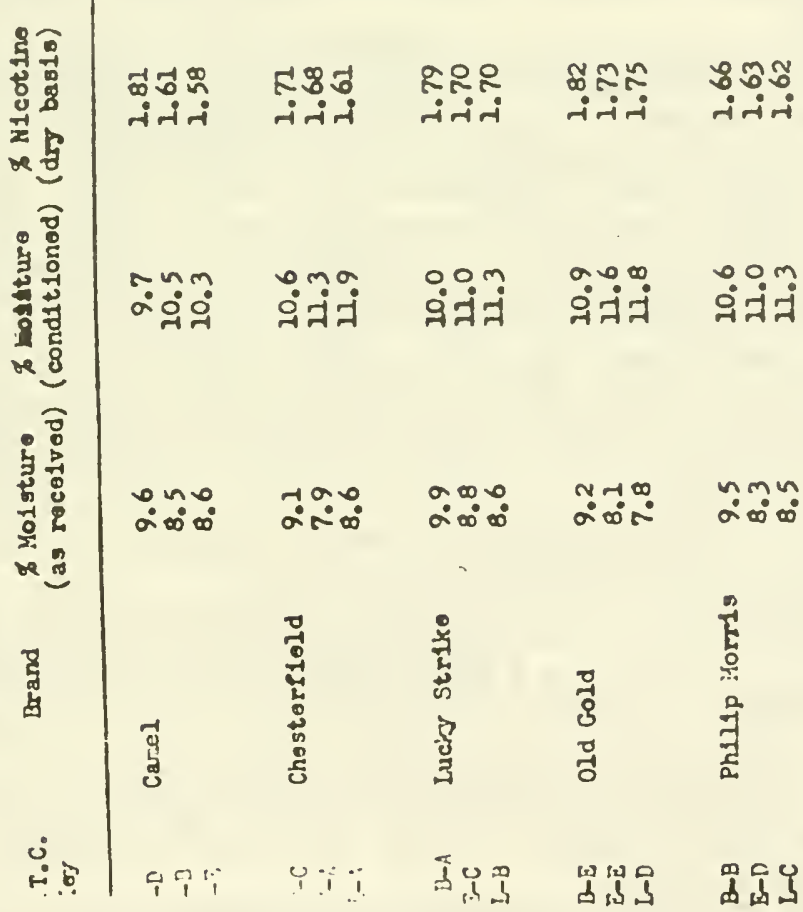


Mr. WAXMan. This chart compares two sets of data on nicotine concentrations. It shows a general trend toward the use of tobacco blends with higher nicotine concentrations over the last 40 years. So I would submit there's really no validity to your claim that nicotine levels are going down.

What do you say about that?

Mr. JAMES JOHNSTON. I would say, once again, I agree with the Surgeon General of the United States. We have gone back and recalculated the Surgeon General's numbers and we agree with them. Now, I don't agree with the Surgeon General on everything, but I agree with the Surgeon General on that.

This is information I have never seen before. I will take this very seriously. I will go back, analyze this, and I will submit, for the record, a response.

Mr. WAXMAN. Isn't it backwards to say that those numbers are really the Surgeon General's numbers that you're relying on? The Surgeon General's numbers are the FTC numbers.

Mr. JAMES JOHNSTON. They are worked through the FTC. Mr. Congressman, again, I believe I can be helpful to this committee on that subject.

Mr. WAXMAN. I appreciate that attitude because I want you to be helpful. I want all of you to be helpful. We've got a health crisis in this country causing an enormous amount of expense and loss of lives and pain and suffering and misery due to cigarettes.

I think we ought to work together to figure out a way to try to lessen that burden. I want you to be constructive, not simply to tell us you don't believe the health statistics that all the medical experts have submitted. You don't believe the Surgeon General's report on nicotine addiction. You don't believe anything but that which serves your purpose, the FTC numbers, which, I would submit, has been challenged by Dr. Kessler in a way that I think reasonable people have to wonder whether those FTC numbers mean anything, because they certainly don't correlate to what a smoker is ingesting through inhaling the smoke.

Have you done human studies to measure the nicotine levels in blood or related to nicotine addiction?

Mr. JAMES JOHNSTON. Mr. Chairman, we have done blood nicotine or continine studies. I would like to submit those to this committee for the record because I think they will be helpful. What those studies show-let's sort of back up to what I'd want to know as a smoker.

Some of the questions that have come up today might well scare me about am I getting more nicotine with a low tar cigarette, is this thing deceiving me, should I switch to a high tar cigarette. I don't believe that's the case.

Mr. WAXMAN. How about switching to no cigarette if you want to avoid the nicotine levels.

Mr. JAMES JOHNSTON. Absolutely.

Mr. WAXMAN. Would you submit to us these studies that you have done, human studies on the levels?

Mr. JAMES JOHNSTON. There is one-

Mr. WAXMAN. I want to ask whether the other Chief Executive Officers will be as cooperative as you are planning to be.

Mr. JAMES JOHNSTON. I'd like to share with you 
Mr. WAXMAN. Would you submit to us, as well, your

Mr. CAMPBELL. I don't know if we have anything available. I'd have to check.

Mr. WAXMAN. What we want are studies, human studies to measure nicotine levels on blood and studies relating to nicotine addiction. Do any of you refuse to give it or will you be willing to give us whatever you may have? You may not have studies, but if you do, we think we ought to get it and we think you ought to give it. Do any of you refuse?

Mr. SANDEFUR. Mr. Chairman.

Mr. WAXMaN. Yes, Mr. Sandefur.

Mr. SANDEFUR. The work on continine was done by Dr. Gori and that's been published. That's the work that we've done at Brown and Williamson.

Mr. WAXMAN. That one we have.

Mr. Donald Johnston. Mr. Chairman, we have not done any such studies on our own premises, but as I mentioned earlier, we were involved in grants with the Medical College of Virginia from the 1930's to the 1960's and if any of that information is necessary, fine, we'll cooperate.

Mr. WAXMAN. Mr. Horrigan?

Mr. HORRIGAN. We have done no such testing, but we'll continue to review and cooperate fully.

Mr. WAXMAN. Thank you. Mr. Tisch?

Mr. TISCH. We've done no such studies, but we'll be glad to give them to you.

Mr. WAXMAN. Mr. Taddeo?

Mr. TADDEO. We've done no such studies, but we'll cooperate.

Mr. WAXMAN. And the other two have said yes. Mr. Bliley, I'm going to let you take a turn.

Mr. BliLEY. Mr. Johnston, perhaps you can help us with this issue of the relationship between the amount of nicotine in the tobacco rod and the amount of nicotine in cigarette smoke. Which one is more important and why?

Mr. JAMES JOHNSTON. Clearly, as a smoker, I would say it's what's in the smoke and how much stays in my body. From the very limited-and I wouldn't call this a massive scientific study, but from the very limited work that we've done in this area, which we will provide to this committee.

Think of an FTC number as an EPA gas mileage number. If I drive my car fast, I get less gas mileage than what the sticker says. If I drive it easy, I get more. So it is with the FTC tar numbers. I may smoke one cigarette differently from another. Within a cigarette, I will get different tar and nicotine per puff, depending on how

Mr. Bliley. Are you saying that you could get different levels of nicotine from two cigarettes from the same pack?

Mr. JAMES JOHNSTON. Depending on how I smoke it. If I'm under stress-wait till you see the cigarette I light up after this hearing. It's probably going to be a high tar cigarette. It depends on how you smoke it. It depends on how you puff it. But here's the interesting thing we found; again, limited data, that among low tar smokers, the actual amount ingested as opposed to the FTC tar number, taking highs, lows, depending on how you smoke the ciga- 
rette, the average was a remarkable .97 correlation, meaning 97 percent accurate.

That's pretty darn good. Now, we have seen studies, and this is important for the chairman because I know he's interested in these studies that talk about smoker compensation. At the very lowest level of tar, I believe that there is evidence to suggest that smokers do compensate, that they do, on an ultra-low, lowest yield product, that they do, in general, compensate. But it's very important to understand that even with that compensation, someone smoking a lowest tar level or an ultra-low or lights or full flavor, each one going up, they ingest and intake less nicotine and tar at each level.

So if I'm smoking a low tar cigarette, could I physically puff it hard enough to get more tar? Yes. But based on the averages, it appears to line up, with some slighter compensation at the low end. I can't state that as a fact, but our review of the literature suggests that.

So a lowest level smoker still is getting less nicotine, but may be compensating up a little bit from what the published number is.

Mr. BLILEY. Do the rest of you agree with that or do you have any quarrel? Do any of you have any quarrel with that?

Mr. CAMPBELl. Absolutely not. The FTC, as Jim has indicated, has some significant constraints in terms of individuals, very much like the EPA mileage. However, it's a relative measurement. It's a good measurement from brand to brand. I think that, most importantly, people should realize that we talk about the dilution holes being covered, people smoking closer to the butt and all of these kinds of things. If you tore the filter off completely and smoked it as a plain-end cigarette, the Merit Ultima, which we sell as a 1 milligram of nicotine, it would still be a low tar cigarette.

So it's important to know that, yes, people do smoke in different ways, but as of this time, we haven't yet seen a better relative measurement.

Mr. BLILEY. The FTC, how do they test a cigarette? What do they actually do with a cigarette to test it for nicotine and tar?

Mr. JAMES JOHNSTON. I can give you a general explanation. I'm sure one of our scientists can give you a better one. But in general, it's inserted in a machine. There is a puff regimen, a puff in $30 \mathrm{sec}-$ onds, then a puff in 30 seconds. The tar and nicotine are registered on a pad and then chemically analyzed to determine the weight of tar and the weight of nicotine on that pad.

Mr. BLILEY. My purpose in asking the question is-then this machine, I assume, puffs at the same rate always. No difference, whatever the cigarette, whether it's an Uitima or whether it's a regular or whatever.

Mr. JAMES JOHNSTON. It is meant to predict an average that, again, from our very limited research into this, it appears to represent, at least in low tar cigarettes, the average may slightly underestimate the ultra-low.

Mr. BLILEY. If they wanted to, they could step it up, from what you appear to have said before or at least what I've gotten out of what you said before, that if they change that rate, instead of one puff every 30 seconds, that they would do three puffs every 30 seconds, they would get a different rate. They would get different results. 
Mr. JAMES JOHNSTON. Correct.

Mr. CAMPBELl. Absolutely.

Mr. Bliley. Mr. Campbell, the Federal Government is well aware of the ingredients you add to the tobacco in your cigarettes. Haven't you been providing HHS with an annual ingredients list for a number of years?

Mr. CAMPBEll. Yes. We started that back almost 15 years ago.

Mr. BLILEY. Has HHS at any time during this time period issued a report to Congress, as it is authorized to do, citing any health risks associated with any such ingredients?

Mr. CAMPBEll. No, they have not, sir.

Mr. BLILEY. Has HHS ever approached the industry with the results of any studies suggesting that any of the ingredients in cigarettes presented any health risks to smokers?

Mr. CAMPBELL. Absolutely no indications of health risks with our ingredients, sir.

Mr. BLILEY. Have you offered your cooperation to HHS and its review of ingredients?

Mr. CAMPBELL. Repeatedly we have offered our willingness to work with them.

Mr. BLILEY. What was their response?

Mr. CAMPBELl. There has been no response up to this time, sir.

Mr. BLILEY. If HHS had approached the industry with some of the allegations that have been bantered about recently in the press, what would have been your response?

Mr. CAMPBELl. Our response would have been that all of these are generally approved, but that we would be happy to look into these ingredients in any way that they wish to discuss them.

Mr. BLILEY. Is it your understanding that over 90 percent of the ingredients used by major cigarette companies in cigarettes manufactured in the United States are commonly used in food? They either have been approved by the Food and Drug Administration as food additives or they are included on lists of substances generally recognized as safe maintained by the FDA or the Flavor Extract Manufacturers Association?

Mr. CAMPBELL. That is absolutely correct.

Mr. BLILEY. Additionally, governmental bodies or affiliated orga. nizations in other countries, such as Great Britain, Germany France, Belgium, Switzerland and the Council of Europe, have evaluated the ingredients used in cigarettes and have come up with accepted lists of ingredients?

Mr. CAMPBELL. That's correct and that completes the U.S. domestic manufacturers list, I believe.

Mr. BLILEY. In short, all of the ingredients used by the major American cigarette manufacturers also can be found in one or more of these accepted lists.

Mr. CAMPBELL. That's correct, sir.

Mr. Bliley. Thank you very much. Thank you, Mr. Chairman.

Mr. WAXMaN. Mr. Synar.

Mr. SyNAR. Thank you, Mr. Chairman. Mr. Campbell, I'd lik to enter into the record Exhibit 14, if I could. Can the staff proride Exhibit 14 to $\mathrm{Mr}$. Campbell?

[Exhibit 14 follows:] 


\section{EXHIBIT 14}

\section{Times Newspapers Limited, SUnday TImes}

[September 19, 1993, Sunday]

\section{SMOKERS MAY Get A QUICK-FIX CIGARETTE}

[By Peter Victor]

With smokers increasingly banished from their workplaces to draughty corridors, the quick nicotine fix is set to get quicker. Industry sources say that Philip Morris, one of the world's biggest cigarette manufacturers, is developing a fast-smoking brand, understood to be code-named "Marlboro Express".

The idea behind Express is that smokers' craving for nicotine can be satisfied in half the time. It works by putting tobacco with a high nicotine yield in the outer end of the cigarette.

If successful, the Express could be worth millions of pounds in Britain. Although the country is increasingly hostile to smokers, 17 million are still hooked on tobacco, spending more than Pounds 10 billion on cigarettes last year.

Last week Philip Morris refused to comment "on stories about products in development".

But Dr. John Slade, addiction specialist at the University of Medicine and Dentistry of New Jersey, said patents confirm that the project is underway. "The patents would help them to produce a cigarette like the Marlboro Express."

Mr. SynaR. Mr. Campbell, this is an article from the Sunday Times of London, dated September 19, 1993. The article is about a new product Philip Morris is developing on the Mariboro Express. Let me read to you from the article, paragraph 1. Quote, "Industry sources say that Philip Morris is developing a fast-smoking brand understood to be code-name Marlboro Express. The idea behind Express is that smokers craving for nicotine can be satisfied in half the time. It works by putting tobacco with a high yield in the outer end of the cigarette."

Mr. Campbell, is Philip Morris now developing a fast-smoking brand of cigarettes, possibly named Marlboro Express?

Mr. CAMPBELL. If we had a project named Mariboro Express, I wouldn't tell my competitors. But we would not-we are not developing a fast-smoking product in any way.

Mr. SYNAR. Mr. Campbell, let me remind you you're under oath.

Mr. CAMPBELL. Absolutely.

Mr. SYNAR. At any time, now or in the past, have you ever tried to develop a fast-smoking brand?

Mr. CAMPBELl. No, sir, we have not.

Mr. SYNAR. In other words, what you're saying is that the story from the London Times is simply and completely untrue. Is that correct?

Mr. CAMPBELL. If we were to look at products like this, the tars and nicotines would be proportional to their size.

Mr. SYNAR. I didn't ask you that, Mr. Campbell. Let me repeat the question. You're saying the story from the London Times is simply and completely untrue, yes or no?

Mr. CAMPBELL. As it stands, it is untrue, yes.

Mr. SYNAR. Thank you. Mr. Tisch, I'd like to ask you about the 13 billion Kent Microlite cigarettes that Lorillard sold from 1952 to 1975. They were advertised as "Just what the doctor ordered" and which provided "maximum health protection."

That Microlite filter was a blend of 30 percent asbestos and 70 percent cotton and acetate. You are aware that 20 of the 36 workers who worked for Specialties, Incorporated which produced that 
cigarette paper and filter, died from asbestos poisoning and lung cancer. One woman died from simply washing her husband's overalls every day. Are you familiar with that?

Mr. TISCH. I am not familiar with those statistics, sir.

Mr. SYNAR. Is the advertising campaign that your corporation presently uses as inconsistent and untrue as it was from 1952 to 1957 ?

Mr. TISCH. Couid you repeat the full question, sir?

Mr. SYNAR. The question is-you advertised Kent Microlite cigarettes from 1952 to 1957 with the following advertising slogan, "Just what the doctor ordered" and "maximum health protection." That's not very honest advertising. Is that the same kind of advertising you all do today?

Mr. TisCH. I do not recall that campaign.

Mr. SYNAR. Mr. Johnston, you testified that if the FDA takes jurisdiction over cigarettes, it would result in the ban on those cigarettes. You are familiar with my bill. I'm sure you were briefed in anticipation of this hearing. You are familiar with the fact that my bill specifically prohibits the FDA from banning cigarettes, are you not?

Mr. JAMES JOHNSTON. I have been through your bill. I don't recall the exact details. I did read, however, a quote attributed to you in a national journal saying that FDA regulation would effectively mean the end of this industry.

Mr. SYNAR. Only if the FDA finds that the ingredients are not safe. Isn't that correct? Because the standard the FDA has is the safe and effective standard. Therefore, if the products are found unsafe, they would have no option but to ban it. Is that correct?

Mr. JAMES JOHNSTON. Based upon the view expressed by a number of members of this committee that this is-

Mr. SYNAR. Let's go back to square one. Are you familiar with my legislation? Mr. Johnston, are you aware that my legislation specifically directs the FDA not to ban cigarettes? Yes or no?

Mr. JAMES JOHNSTON. But it requires them to prove that the product is safe, as I recall.

Mr. SYNAR. No. It gives them the opportunity to review the product. You are assuming that once they take jurisdiction and review it, that they will find that the ingredients are unsafe. Is that not correct?

Mr. JAMES JOHNSTON. Based upon the view expressed by you and others on the committee that this product kills--

Mr. SYNAR. Are the ingredients safe in cigarettes, Mr. Johnston?

Mr. JAMES JOHNSTON. All of the ingredients that we add to our product have been thoroughly reviewed. They've been in the possession of the U.S. Government for 10 years. The Surgeon General of the United States testified before Congress saying he didn't see that ingredients were a significant problem.

But are you asking me to tell you that cigarettes are safe? Is that what you're saying?

Mr. SYNAR. That's correct.

Mr. JAMES JOHNSTON. No. I cannot say that. I have acknowledged, I believe, that cigarettes are a risk factor. 
Mr. SyNAR. You're familiar, also, Mr. Johnston, with the Synar amendment which would require States to enact and enforce bans on cigarette sales to minors, are you not?

Mr. JAMES JOHNSTON. Mr. Congressman, there are so many pieces of legislation affecting the industry

Mr. SYNAR. Mr. Johnston, I'm not new to this subject. You're familiar with my legislative career in this area, are you not?

Mr. JAMES JOHNSTON. I am, indeed.

Mr. SYNAR. OK. You're familiar with the legislation that would enforce the ban of cigarette sales to minors, yes or no? Mr. Campbell, are you familiar with it?

Mr. CAMPBELL. I, like Mr. Johnson, am only generally familiar and not specifically familiar.

Mr. SYNAR. Let's be real here, folks. You're the CEO's of major companies. This legislation, which passed last year, has a major impact on the distribution of your product to minors, and you're telling me as you sit there that you're only vaguely familiar with the legislation.

Let me ask you this. You said earlier today that the tobacco industry has been doing everything possible at the State legislative level to push for these kinds of minor bans from smoking. In order to make sure these laws are effective, why don't you all commit today to me to financing the State funding of sting operations of retail units? Will you commit to that today, Mr. Johnston, at this end?

The question is since you all are so committed to keeping cigarettes out of the hands of minors, will you commit to this subcommittee that you will help finance sting operations within States to try to catch minors who may be doing it? Will you help provide the money for sting operations on the State level by which to enforce the law?

Mr. DONALD JOHNSTON. I'm not sure that additional financing is required, other than the revenues that are already generated from-

Mr. SYNAR. I'll take that as a no. Mr. Sandefur?

Mr. SANDEFUR. No.

Mr. SYNAR. Mr. Horrigan?

Mr. HORRIGAN. I don't see that's our role.

Mr. SYNAR. Thank you. Mr. Tisch?

Mr. TISCH. No, sir.

Mr. SYNAR. Mr. Taddeo?

Mr. TADDEO. I don't think that's our role.

Mr. SYNAR. Mr. Johnston?

Mr. JAMES JOHNSTON. I have outlined our programs this morning. Smokers pay $\$ 13$ billion a year in excise taxes and some-

Mr. SYNAR. Mr. Johnston, will you provide money for sting operations within the State?

Mr. JAMES JOHNSTON [continuing]. Portion of that is-

Mr. SYNAR. Yes or no?

Mr. JAMES JOHNSTON. No.

Mr. SYNAR. OK. Mr. Campbell?

Mr. CAMPBELL. No.

Mr. SYNAR. A disingenuous commitment, I would say. From 1972, Mr. Johnston, there's a memo to the Tobacco Institute Presi- 
dent Horace Kornegay from Fred Panzer, who, I believe, was the Vice President of the Institute at that time. In fact, let me ask this of Mr. Campbell. It laid out the industry strategy and let me read you from that memorandum, Mr. Campbell.

It says "For nearly 20 years, this industry has employed a single strategy to defend itself on three major fronts-litigation, politics and public opinion." Is that the strategy that drove you to sue $\mathrm{ABC}$ ?

Mr. CAMpbell. No, sir.

[The memorandum referred to follows:] 
MEMORANDUM

To:

Horace R/́ Kornegay

TROM :

rred ponzer

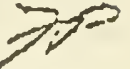

sur Jecr, The Roper Proposel

\section{GENERAL COMMYNTS}

Ie 1 a my etrong beldet thet we now have an opportun:ty to take the lnitiotive in the sigazetce contzoversy, ind otare to turn be seound.

Por nearby twenty yoart, thit induerry ha enployed - single serategy to dofend beselt on three magor stonta -.

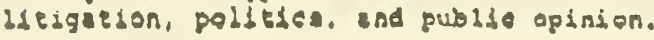

Whble the strategy was brillantby concedved and

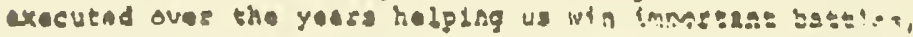
it da ondy fois to say that $1 \mathrm{t}$ is not nor was it latended to bo - vehiele yor vietory. OA the contrexy, it has a ways been holddng tersigy, consiating of

- craselng doube bout the hades charge whreut actueldy denythe it

- advocating the oublte's righe to snoke, whenout astudly uzoding then to take up the practese

- cosouragling objocejy ocdentitide researeh at the ondy way to gesolve the gueston of bader hased

on the Hitgation front for which the atrategy wa designod. se hes been succoseful. Thide we have not lont djasidity case, this ds not because jurter havo rajected the anthmmoxing aรgunants.

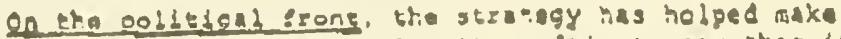

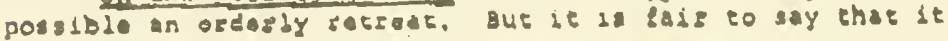

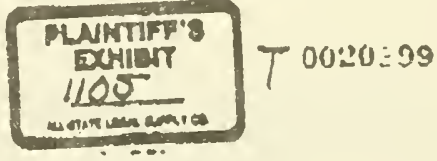


วงตุอ ว.

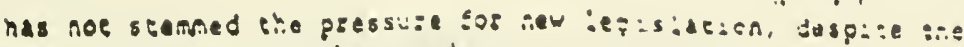
major concessior.s wa have nade.

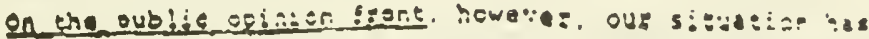

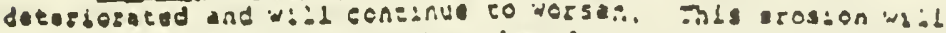

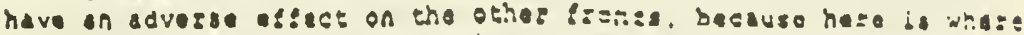

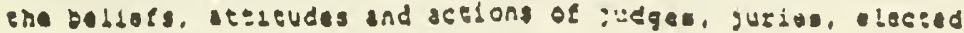
officluls and government empleyees are rerat.

\section{THE STQATEGIC IMPASSE}

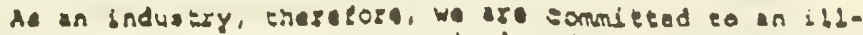
definse middle ground which i cresculared by vaziatsone on the cheme that, "the case is not proved." lis the resent

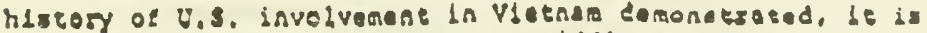
imposile to to hold th publle on aldd te sourse for any length of thas. There seene co be no way that sase pubdle oplndon can eneage In controyersy and ehoose an answer thas goes beyond the range of either/or.

In the slgerete conezoversy, the public - oppeladiy those who ite present and potontdsl supposeces (e.g. tobmeco

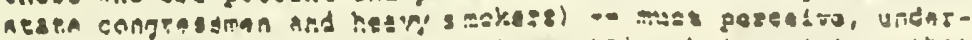
stand, and boliove da ovidence to suctatn sheiz oginond enat moking may not be ene eaudal latos.

A. endng stand, wo supply thea with to ditgle in the wey of sesdy-made erodble uleratsives.

\section{THE ALTERUATIVES}

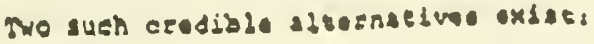

2) The Conselsytioned Mvpostiesh b.o. people who swoke tand to difloz laporeanely 500 people who do net, in thals heredity. da conatleutional makaup. in peeterns of dife. and in erie proesure under whber they dbve,

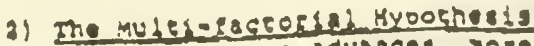
i.a, as ledence advancet, more and nose fucsers com under ouspleion as coneributing to the ldinestes for which mokling is blamod - is poblution, viruses. 
lood ateli:ives, ocejpationa:

hazares and stosses.

Our 1970 publif opinion survey shewed shat major::\% (S2x) tolieved that cigaretto axe only jne of ine monv caiss ol mokers havang mero ildnosses. It also showed chat hals of the poopla who taldoved thet smokers have mora dinesa than non-omokerg ecceptod the constidutions hypothesis the explanation.

Thus, there are millions of people who would be receptive to new moseage. stating,

\section{Clgarote smoklng muy not be the halth haxerd thot the antl-smoking pooplo say it is because other ilternotive ire it jese is probable}

The Ropas proposal would be a persunstre (1t not etgictly

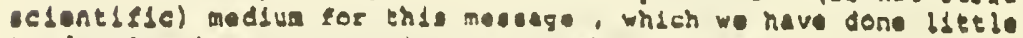
to develop in sycematio or emprehenstve way.

Poldowing is my outdine of the etopt ruqudsed to stare - chilt in pubdle opindon d: the roper proposed la accopend.

\section{A SCENARSE TOR ACTIOH.}

1) Seloct a panel of experta to consult on the destgn of the tudy. Idendly they would be prestige sigures who would initialdy have aodid contedbuedon to make and who would abo

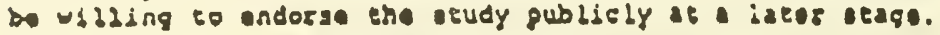

2) Conduct the pldot study.

3) IL Lavorable, present the sosults to earebuldy sedected monbers of the lollewing key groups!

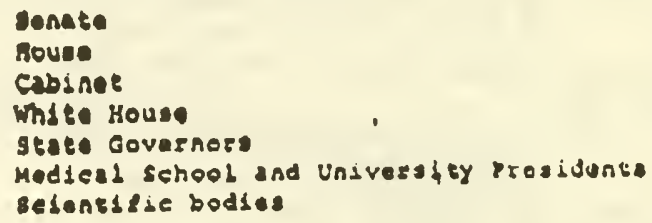




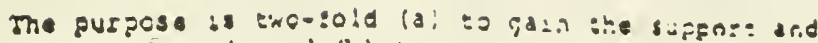

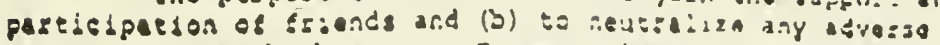

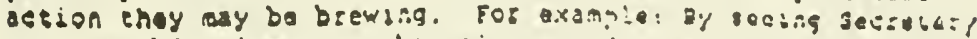

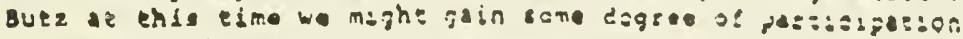

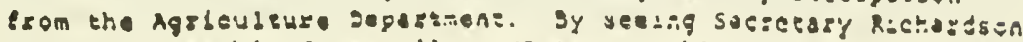
- might posibly forestald plis aned-smoking dy bve.

4) Concuce the tutl scate sugvey.

5) 18 the rasules are tavorable, robose them at - book in both hard cover ind pager back version, hopezulty published by legitimate house. In ofiect, lueh volume would be counter - Surgeon denerab's Repor:. The princlpel

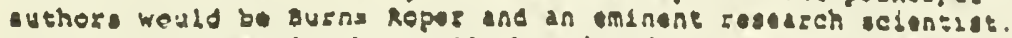
the edvisory panal-- hopesubly broedaried as a rasule of stop 3 -. would write the datzoduction. The induscry' tunding role would be sully acknew lodged.

6) Ad book the material would be marketed and promoted In all the meny way availables magerine vondenezion. TV and

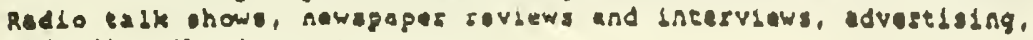
glet djetsbution, etc. ete.

And best of ald, dt would only have to be inen..- noe racd -a to be beldeved... juste dike the suggeon canerul' roport.

$88 / 10$

Ses H. Kaseenbeur

W. KLoepler, Jx. ; 
Mr. SYNAR. Mr. Campbell, earlier in questioning about the Joe Camel ads, I asked you whether or not you all had done any market research with respect to the impacts of the Jce Camel ad by your competitor. Your response at the time is "not specifically." What did you mean by that?

Mr. CAMPBELL. I don't know whether we've done any research of Joe Camel. If we have, I guess it would be available to you.

Mr. SYNAR. And you would tell us and provide that to the committee.

Mr. CAMPBell. Yes.

Mr. SYNAR. All right. And the same for all you gentlemen, even if it's not specifically involved with Joe Camel.

Mr. CAMPBELL. I'm sorry. I'm committing to a competitive act which I really can't do. I'm sorry.

Mr. SYNAR. Excuse me?

Mr. CAMPBELL. Well, as Mr. Johnston was saying before, I can't share competitive information without appropriate

Mr. SYNAR. I'm not asking for competitive information. I'm asking you for studies that you have done on the effectiveness of the Joe Camel advertising campaign.

Mr. CAMPBELL. I'll check into it. I don't know whether we have.

Mr. SYNAR. Will you or will you not provide that information for the committee?

Mr. CAMPBELl. These general requests are getting very broad. Can we not discuss

Mr. SYNAR. No. That's not broad at all, Mr. Campbell. I am asking you that with respect to the issue of Joe Camel, if your company has done some research with respect to the effect of that advertising campaign, will you provide that information to the committee?

Mr. CAMPBELl. We are extremely concerned about competitive activity in view of the fact that we-

Mr. SYNAR. Yes or no, Mr. Campbell?

Mr. CAMPBell. I will do my best, yes.

Mr. SYNAR. Mr. Chairman, that concludes this. May I take this opportunity as we come to a close of this hearing to say that I think I've learned a lot here today. I've learned, in particular, that when you're paid the exorbitant amounts of money that the seven of you are, you can create new reality, new reality of whether or not nicotine really is addictive, reality of whether or not $\$ 4$ billion is targeted towards children, and the new reality of whether or not you have any corporate responsibility to consumers.

I thank God that the rest of the corporate community in this country doesn't accept that same corporate responsibility. Thank you, Mr. Chairman.

Mr. WAXMAN. Thank you, Mr. Synar. I have some questions. This will be my last round of questions and I think Mr. Wyden may return with a few questions. I want to get some things on the record. But before I just ask some very specific questions for which you will be able to give, I think, specific answers, I do want to raise with you, Mr. Campbell, an issue in the State of California.

A letter has gone out to people all over the State asking that they sign a petition to restrict smoking in public places. The initiative that they're trying to get on the ballot is described as some- 
thing that will strictly protect the non-smokers, with strict regulations and tough smoking restrictions. But, in fact, this is a campaign paid for by the Philip Morris Company, which you can see on the small print. Californians for Statewide Smoking Restrictions, a committee of restaurants, hotels and Philip Morris, Inc.

What I understand this petition would put on the ballot is a preemption of all the local laws that do protect the non-smokers. In fact, it would weaken existing laws with a statewide standard. I want to express to you my concern about this. I don't know if you're familiar with it or not.

I would hope that you would see this as an inappropriate action on the part of your corporation to try to mislead people who want strict regulations into preempting stricter regulations at the local level by deception.

I ask that you look at this and I would hope that as you evaluate it, we can get a more favorable response. I would like to get a response from you for the record on that point.

Mr. CAMPBELL. I am somewhat familiar with the program. I think that the restaurant owners and people in the lodging and hotel business and things like that, they want standardization of smoking restrictions in the State and we are legitimately funding that work because the vast majority of Americans want smoking handled in an accommodative way.

I think you probably saw the Time Magazine poll this week that showed that most Americans want accommodation. They want separate smoking and non-smoking sections, and, yes, we support that.

Mr. WAXMAN. I, without objection, will put this document in the record with regard to what I consider a misrepresentation to people who sign it for the very purpose of getting the strongest regulation of EIS.

[The document follows:] 


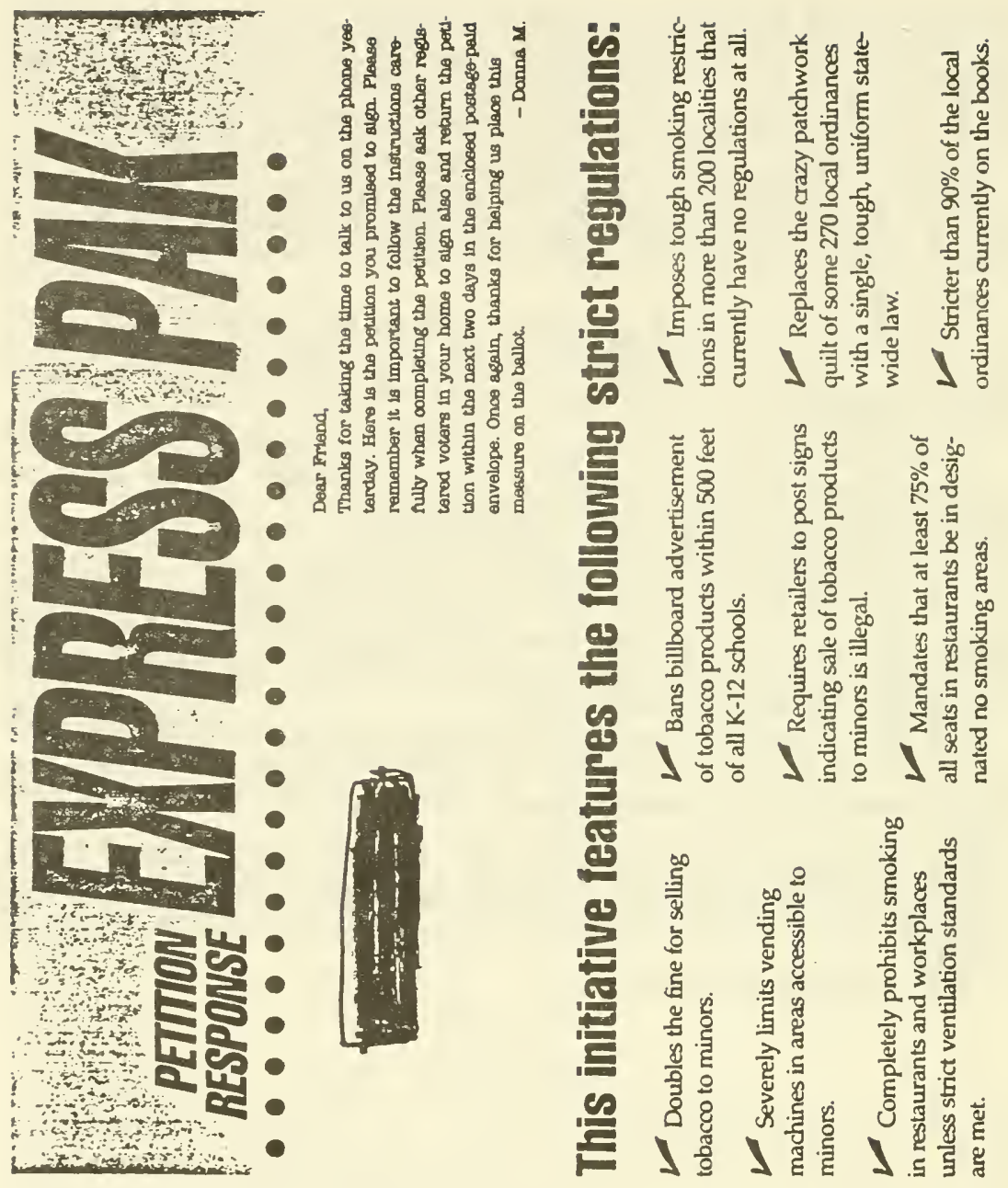




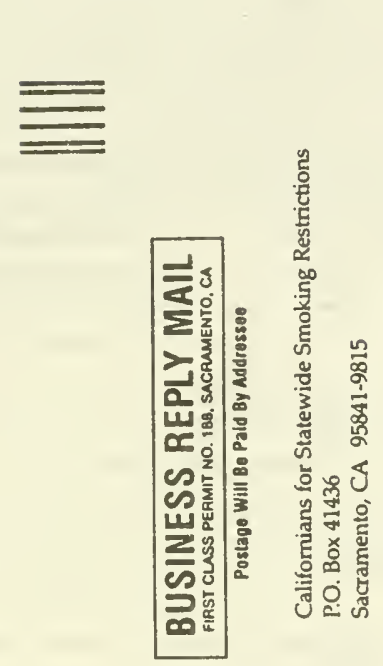

हe

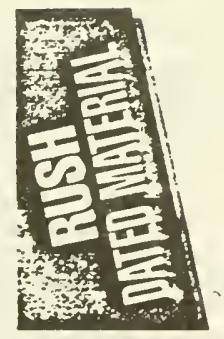

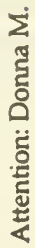


INITIATIVE MEASURE TO BE SUBMITTED DIRECTLY TO THE VOTERS

The Allorney General of Callfornis has prepared ethe following utte and summary of the chief purpose and points of the proposed measure: SMOKING AND TOBACCO PRODUCTS. STATEWIDE REGULATION. INITIATIVE STATUTE. EsLablishes statewide smoking and tobacco regulations. Repeals California Indoor Clean Air Act of 1976. Repeals and preempts local smoking and tobacco regulations. Bans public smoking with significant exceptions. Permits smoking sections in restaurants and employee cafeterias. Bars not regulated. Permits smoking in private offices, and business conference rooms with occupants' consent. Exempts from smoking regulations gaming clubs. bingo establishments, racetracks, sports facility private boxes and smoking lounges. Regulates location of tobacco vending machines and billboards. Increases penalties for tobacco purchases by minors. Permits amendment of tobacco regulations by two-thirds vote of Legislature. Summary of estimate by Legislative Analyst and Director of Finance of fiscal impact on state and local governments: Unknown effects on public-sector health care costs and state tobacco tax revenues, depending on the extent there are changes in the consumption of tobacco products and/or exposure to second-hand smoke. State costs to enforce the measure would be around \$1 million annually; local enforcement costs would probably not be significant.

NOTICE TO THE PUBLIC: THIS PETITION MAY BE CIRCULATED BY A PAID SIGNATURE GATHERER OR A VOLUNTEER. YOU HAVE THE RIGHT TO ASK.

All signers of this pettion must be regrstered in County

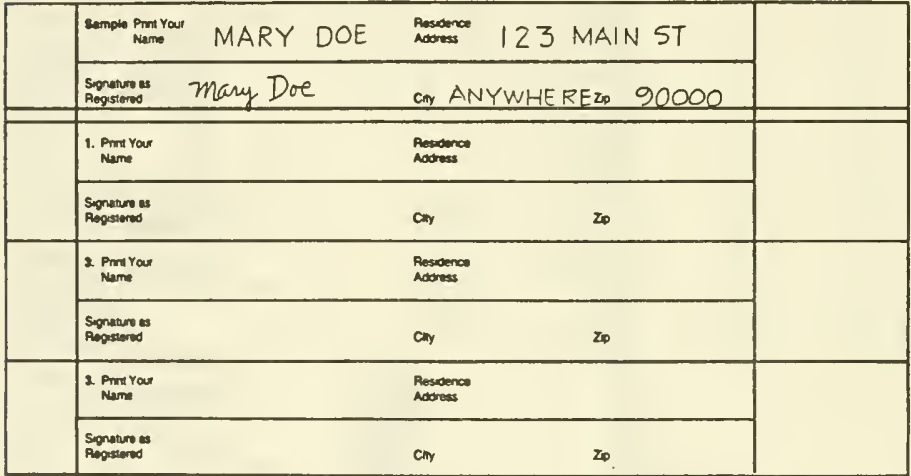

DECLARATION OF CIACULATOA (TO be completed sthet above signalures have been obtained.)

I am registered lo vole in the County (or City and County) of

I circulated this petition section end saw aach of the appended signatures on this petition being wrttan. Each signalure of this pettion is, 10 the best of my intormation and belief. the genuine signature of the person whose name in purponts to wil signalures on this pettion were obtained between and monoveryer

1 declare (or centify) under penaly of perjury under the laws of the Stale of Californa that the loregono is twe and correct

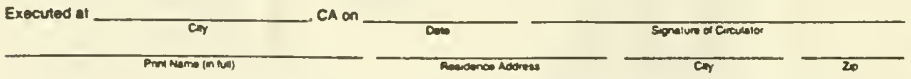

Find on m.

\footnotetext{
IMPORTANT - INSTRUCTIONS - PLEASE READ

1. Please complele the petition in all of the yellow shaded areas.

3. Get other registered volers in your household to sign as well but retum the petition night eway, even if yours is the only signature

2. Be sure to open the petition to page two and write in the name of your county in the shaded area.

4.Mail your signed petition in the postage-paid envelope TODAY
} 


\section{INITIATIVE MEASURE TO BE SUBMITTED DIRECTLY TO THE VOTERS}

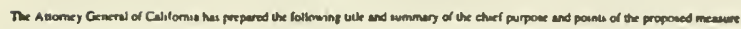

SMOKING AND TOBACCO PRODUCTS. STATEWIDE REGULATION. INITIATIVE STATUTE. ESLAblishes statewide smoking and tohacco regulations. Repeals Califomia Indoor Clean Air Act of 1976. Repeals and preempts local smoking and tobacco regulations. Bans public smoking with significant exceplions. Permits smoking sections in restaurants and employee cafeterias. Bars not regulated. Permits smoking in private offices, and business conference rooms with occupants' consent. Exempts from smoking regulations gaming clubs, bingo establishments, racetracks, sports facility private boxes and smoking lounges. Regulates location of tobacco vending machines and billboards. Increases penalties for tobacco purchases by minors. Permits amendment of tobacco regulations by two-thirds vote of Legislature. Summary of estimate by Legislative Analyst and Director of Finance of fiscal impact on state and local governments: Unknown effects on public-sector healih care costs and state tobacco tax revenues, depending on the extent there are changes in the consumption of tobacco products and/or exposure to second-hand smoke. State cosis to enforce the measure would be around $\$$. million annually; local enforcement costs would probably not be significant.

\section{TO THE HONORABLE SECRETARY OF STATE OF CALIFORNA}

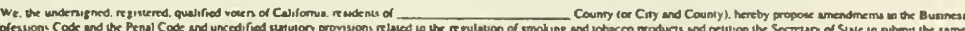
De

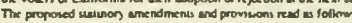

SECTON I The People of the Sule of Callomes find and dectere that

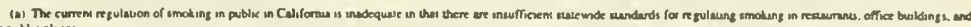
ouner putik pluces

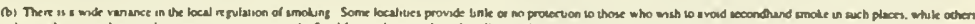

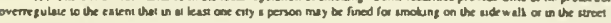

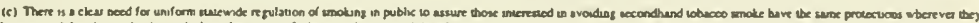

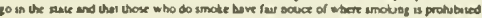

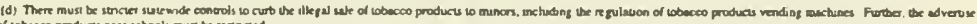

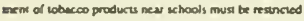

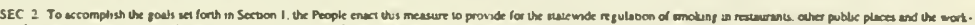

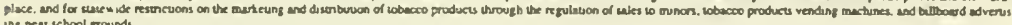
ing near sebrol fround

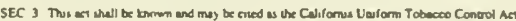

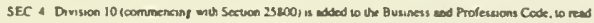

DIVISION 10 RECULA TDON OF SMOKNG

CHAPTER I GENERAL PROVISIONS.

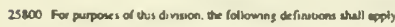

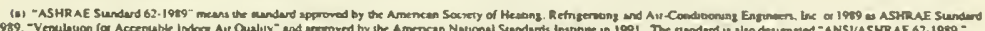

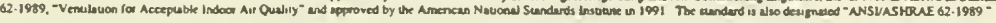

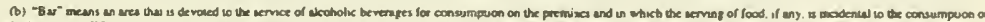

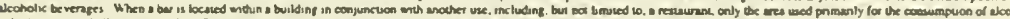

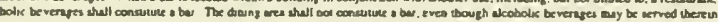

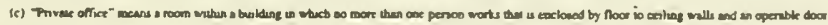

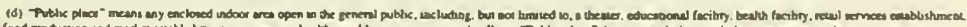

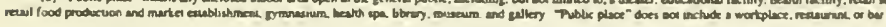

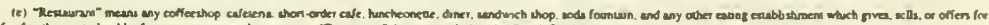

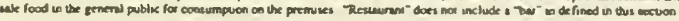

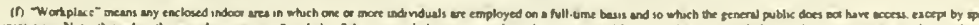

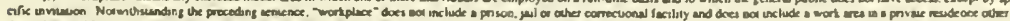

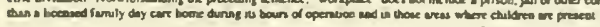

COAPTER ? RESTAURNTIS

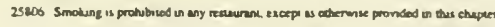

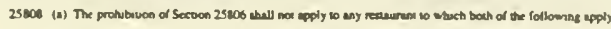

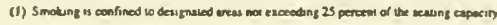

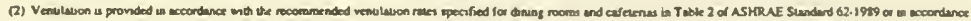




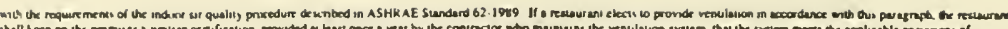

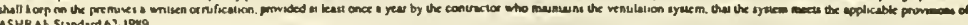
ASHRAt Scanderd 62.1909

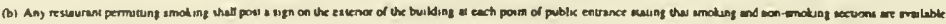

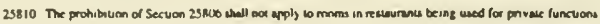

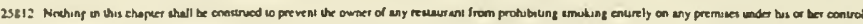
CHATTER 3 WORKPLACES

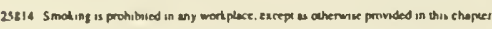

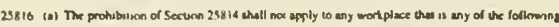

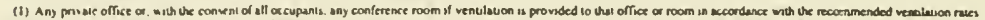

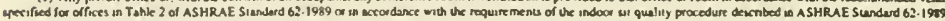

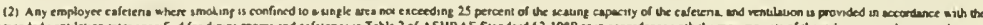

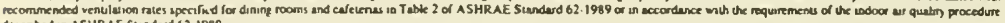
at sented in ASHRAE Sunderd 62.1989

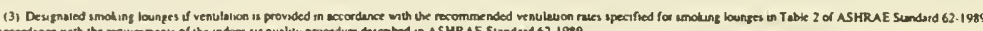

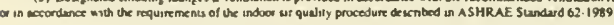

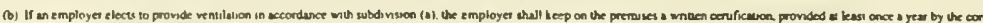

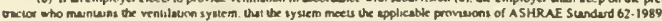

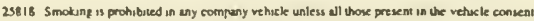

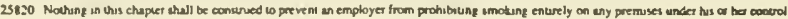

CHUPTER \& PUBLC PLACES

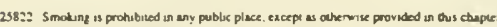

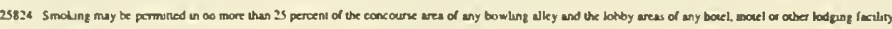

238:6 The prohibition of Soxuon $258: 2$ chall not apply wo any of the followne pleces

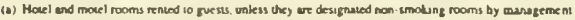

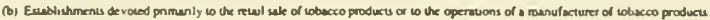

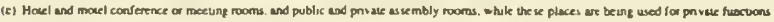

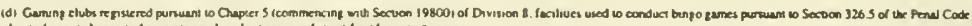

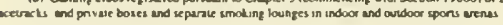

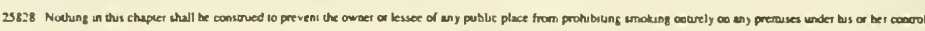
CHAPTER 5 SIGNS

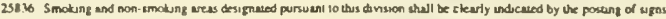

CHAPTER 6 VENDENG MACHENES

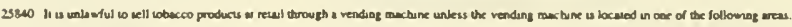

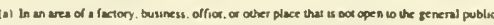

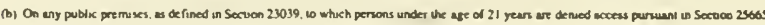

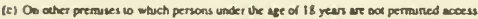

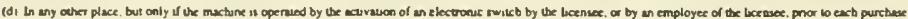

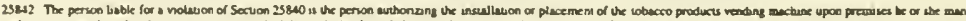

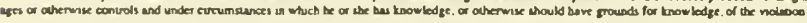

\section{CUPTER? BLLBOARS}

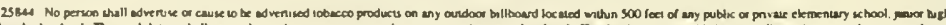

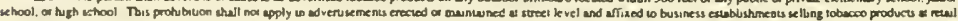

CHAPTER \& ENRORCEMENT

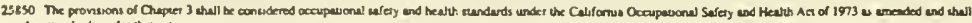
ox enforced es menderds undet the wet

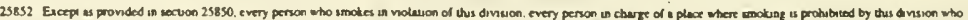

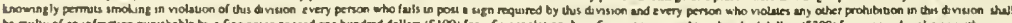

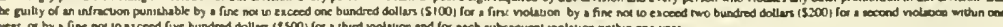

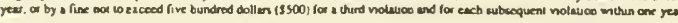

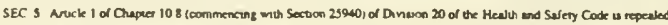

SEC 6 Section 25996 of the Healu and Sajery Cade in repealed

SEC 7 Serocos 300 of Uhe Penal Cad us anended wo read 


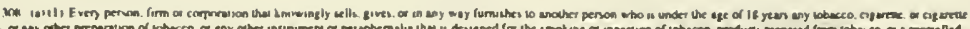

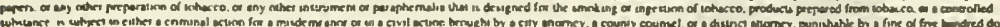

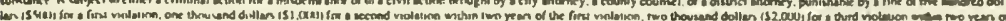

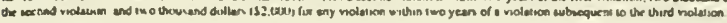

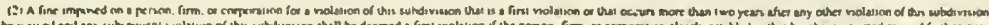

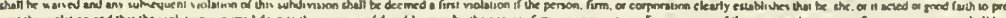

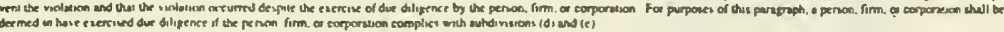

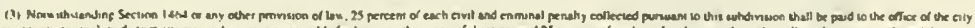

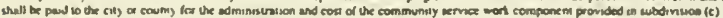

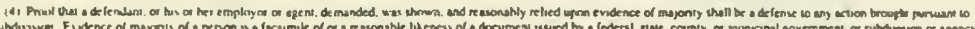

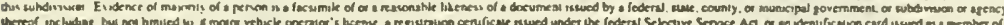

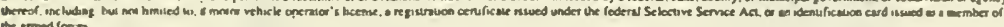
are ormedim

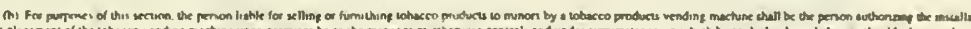

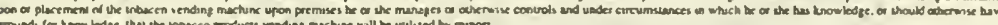

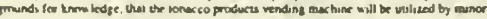

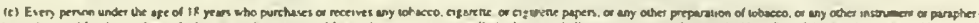

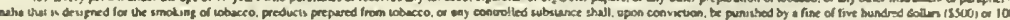

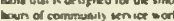

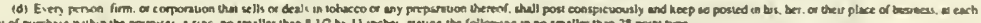

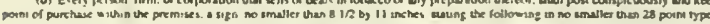

NOTCE - SECTOS 3OR OF THE PENAL CODE PROHIZITS THE SALE OF TOBACCO PRODUCTS TO PERSONS UNDER 18 VEARS OF AGE AND THE PURCHUSE OF TOBACCO PRODUCTS 8 Y PERSON'S UNDER 18 YEARS OF AGE

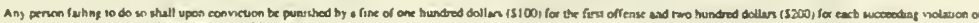

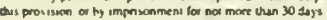
wame

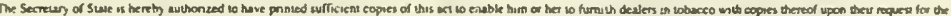

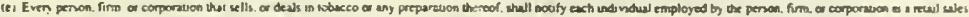

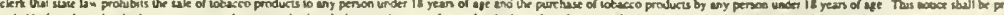

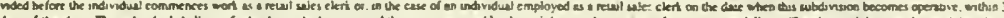

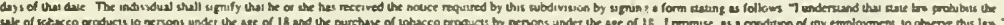

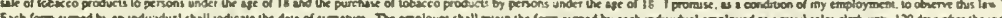

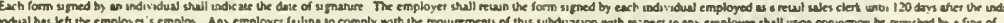

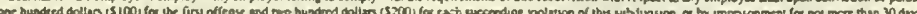

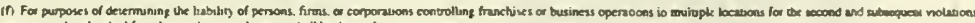

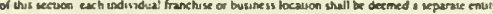

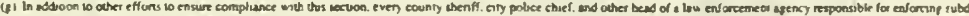

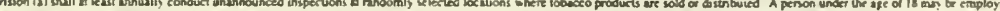

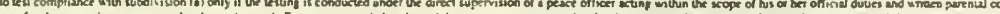

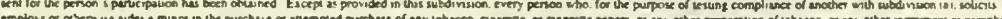

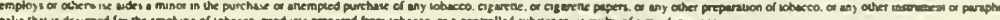

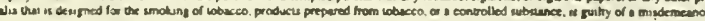

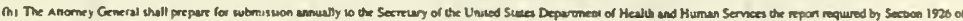

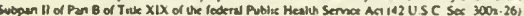

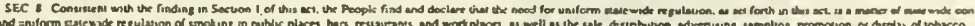

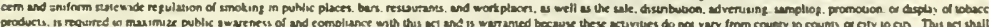

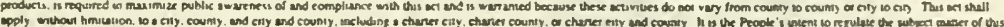

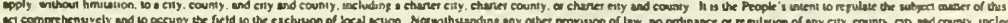

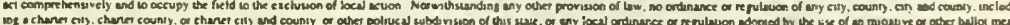

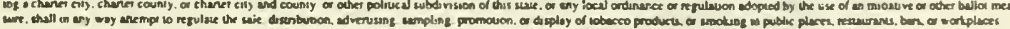

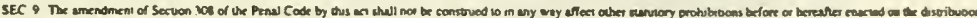

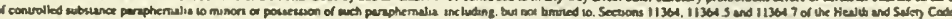

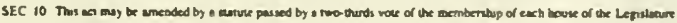

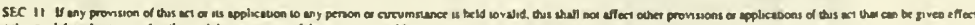

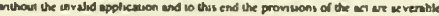

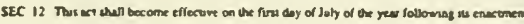




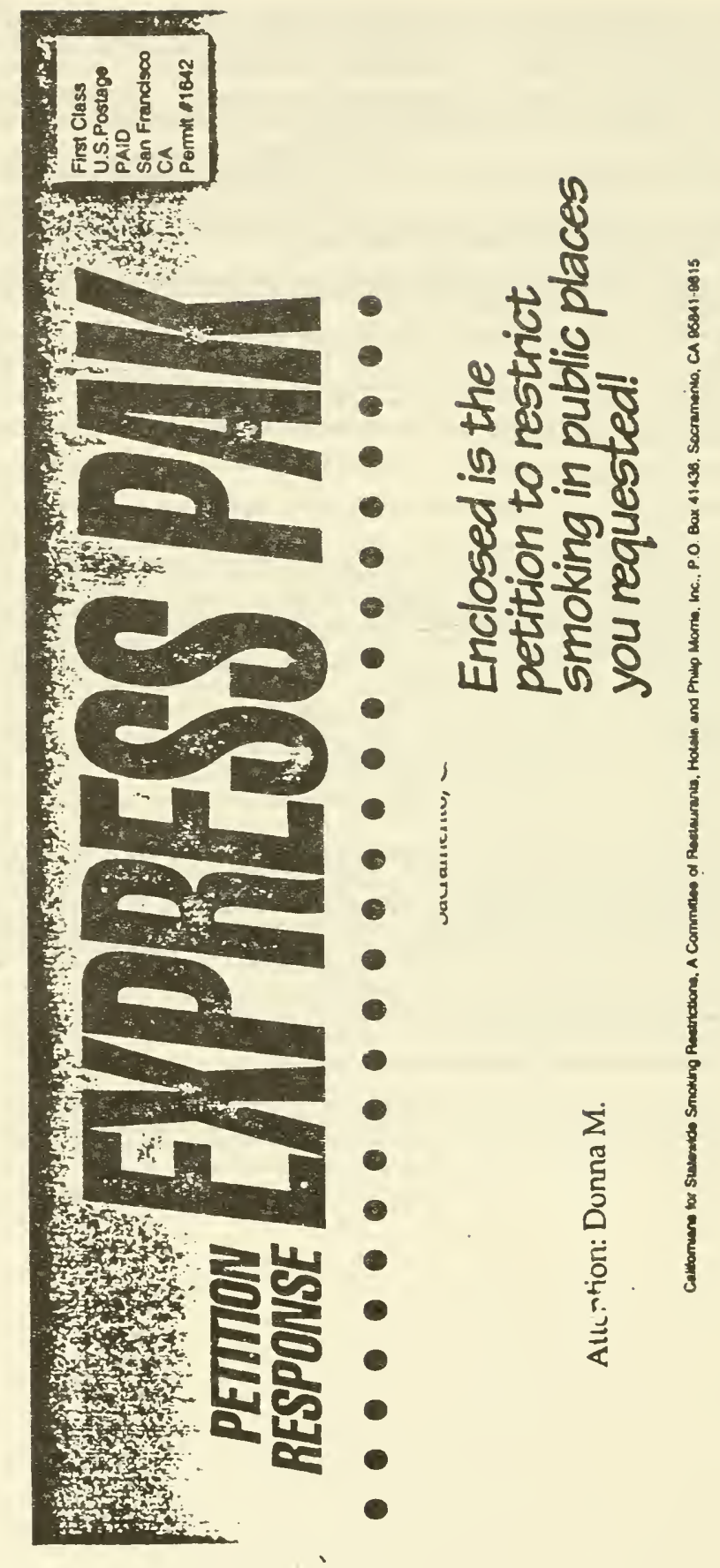


Mr. WAXMaN. And by the way, I do support uniform regulations so that we don't have one jurisdiction with one law and another jurisdiction with another or one business that tries to do something voluntarily, being placed at a competitive disadvantage. That's why I introduced H.R. 3434. That bill would say that smokers have the right to smoke in separately ventilated areas.

I would like to ask each of you to look at that legislation. If you really are sincere in your statement that you want to give smokers a choice to continue to smoke, you certainly ought to give those who don't want to smoke the choice not to have to breathe in someone else's tobacco smoke. I would add that this is especially important in light of the information from the Surgeons General back to the Nixon administration as well as the present Surgeon General and the Administrator of the Environmental Protection Agency, that ETS is not just a nuisance, but a threat to health.

Mr. Campbell, earlier you admitted that Dr. DeNoble's work was part of developing analogues that were reenforcing, but did not have peripheral effects. What was the point of this work, do you know?

Mr. CAMPBEll. I've tried to study up on it in general terms, but my colleague, Dr. Ellis, can be more specific, if you don't mind. Is that all right?

Mr. WAXMAN. Sure. Let's hear from her.

Ms. ELLIS. As you've already indicated, it's very important for a consumer products company to understand its product. The work that we have undertaken is-the goal of it was to do just that. The goal of the comparative psychology program and the nicotine analog program was to understand the cigarette and the product and to be able to deal with the issues and the opportunities that we might get from that. The program actually started in 1965 .

Mr. WAXMAN. Why would you look at those analogues? Were you trying to develop a compound that would mimic or take the place of and act as a substitute for nicotine?

Ms. ELLIS. We were looking at nicotine biochemistry, nicotine effects, and nicotine effects in a number of different industries. Our first interaction was with pharmaceutical companies and they did a lot of screening for us on all effects of these analogues, including agricultural uses.

Mr. WAXMAN. Were you trying to see if the analogues were reenforcing?

Ms. ELLIS. We were trying to look at the CNS effects of some of the analogues, yes.

Mr. WAXMAN. CNS means?

Ms. ELLIS. Central nervous system.

Mr. WAXMAN. Were you trying to find a nicotine substitute that wouldn't adversely affect the heart or any other part of the body?

Ms. ELLIS. If there were some in that category, definitely.

Mr. WAXMan. Thank you very much. Mr. Johnston, let me ask you about RJR's process for nicotine control. Specifically, do you monitor the nicotine levels in the tobacco leaves you use to make cigarettes?

Mr. JAMES JOHNSTON. Yes, we do.

Mr. WAXMAN. Speak into the mike. The answer is?

Mr. JAMES Johnston. Yes, Mr. Chairman, we do. 
Mr. WAXMAN. How carefully do you monitor nicotine and alkaloids during the production process? Could you identify each step during the production process, starting with the harvesting of the tobacco, at which RJR measures or otherwise monitors the nicotine or alkaloid levels in cigarettes?

Mr. JAMES JOHNSTON. Let me ask one of my associates if they can better answer that than I.

Mr. SCHINDLER. Could you repeat the question?

Mr. WAXMAN. What I want to know is how carefully you monitor nicotine and alkaloids during the production process, starting with the harvesting of the tobacco and other measures to monitor the nicotine or alkaloid levels in cigarettes?

Mr. SCHINDLER. In our stemery, which is where we take the leaf after we bring it in from the market, where we process the leaf to separate stems from the end product we call strips, we take samples of the bale of tobacco, of stripped tobacco, and identify sugars and nicotine level in those bales of tobacco.

From there, they are then moved to various storage sheds and they could be stored anywhere from 18 months to 2 years or so before they're actually used in the production process. The nicotine level and the sugars are identified in each of those bales.

Mr. WAXMAN. What use do you make of these measurements in the design and manufacture of cigarettes?

$\mathrm{Mr}$. SCHINDLER. Our cigarettes are designed to deliver a tar level and a taste to our consumers. Part of the taste profile is related to the nicotine. I don't know if you remember earlier I talked about how the moisture or the rainfall in a given year will determine the concentration of the nicotine in a leaf.

For example, in a year that's dry, you'll have a smaller leaf. You'll have the same weight of nicotine, but it will be on a smaller leaf and that has a much more bitter sharp taste to it. Because it's an agricultural product, it varies over the years. So the nicotine helps, in terms of its concentration, for the blending process to determine its smoothness and in terms of the target taste profile in the end product.

Mr. WAXMAN. Mr. Johnston, given RJR's interest in quality control, is there a point in the manufacturing process where nicotine which is lost due to processing is restored and could you identify each of the manufacturing procedures utilized by your company to adjust upwards, however incrementally, the nicotine level of your product?

Mr. SCHINDLER. Yes.

Mr. WAXMAN. I'm sorry.

Mr. SCHINDLER. We do not restore any nicotine anywhere in our process. We lose nicotine in the process. We lose nicotine, for example, in the reconstituted sheet process, which handles the byproducts from that stemery that I just discussed. Typically, the byproducts that enter into the reconstituted sheet process might have 1 percent nicotine and by the time they finish the reconstituted sheet process, they would be at 0.85 . There's somewhere around a 10 or 15 percent loss there.

So, generally, throughout the process, from the time we take our tobacco in, you will find a loss of nicotine and no where in that process is any nicotine being incrementally added into the process. 
I would like to point out that in previous answers to questions earlier, there was discussion about alcohol-

Mr. WAXMAN. That was mentioned in previous testimony and that's a minute amount. Is that correct?

Mr. SCHINDLER. Pardon me?

Mr. WAXMAN. That's a minute amount.

Mr. SCHINDLER. Yes. Minute.

Mr. WAXMAN. Let me just ask the others, and I'm going to ask you to submit this for the record, we would like to know each step during the production process where you monitor for nicotine, the nicotine or the alkaloids from the harvesting of the tobacco to the cigarettes themselves, the level in cigarettes. We'd also like to know whether there's a point in the manufacturing process where nicotine which is lost due to processing is restored, if you would all submit that for the record.

Also, identify each of the manufacturing procedures utilized by your company to adjust upwards, however incrementally, the nicotine level of your product.

Then I would ask each of you this question. Other than through blending or reconstitution, there are other methods that have been described for changing nicotine levels, using tobacco extract with nicotine or spraying on the tobacco or adding it to the filter or adding it to the paper or designing the filter so more nicotine gets to the smoker. I'd like to know which of these methods have you actually conducted research on and which of these methods are you actually using and which of these methods have you ever used in the past. Perhaps you can respond to that question.

We will ask you to submit that for the record, as well, rather than go through that now. We think it's important. Now, I'm assuming, since no one is standing up and saying no, that you're all going to cooperate and give us the answers to those points. Does anybody disagree?

Mr. SANDEFUR. Mr. Chairman, the explanation for the processing and measuring nicotine that Mr. Schindler outlined that R.J. Reynolds used is the same for my company.

Mr. WAXMAN. Perhaps you can tell us that for the record in writing. That shouldn't be any difficulty for you to put down. Has RJR done studies on how much nicotine is actually received by the smoker?

Mr. JAMES Johnston. Yes, Mr. Chairman. I brought that to your attention earlier. That is very limited information, but I think it could be of value to this committee in understanding the predictive value of the FTC.

Mr. WAXMAN. Can you make that available to us?

Mr. JAMES JOHNSTON. I would ask you if you would take that information.

[The information follows:] 


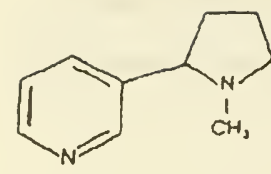

\section{INTERNATIONAL SYMPOSIUM ON NICOTINE The Effects of Nicotine on Biological Systems II}

Solellite Symposlum of the XIIth Interautional Cougress of Pharmacologr

Montreal, Canada

July 21-24, 1994

\section{ABSTRACT FORM \\ (Mkll absunct wicle reglstradod form)}

Send the original logether witt two copios by Fint Class mal. no faxes delease Colease uso cardboard bocking urben mailing) to Me. Anno Rousoll, Confarvaco Coardiator, Dept. of Pharmacolosy, 3655 Drummond Street, Monineal, Quebec, Canade H3G IY6

\section{INSTRUCITONS FOR PREPARATION OF ABSTRACTS (see semple on TEVEre)}

1. Do not type on or past border

2. Tille in CAPITAL LETTERS

3. Authars namee should be underlined

4. Address and institation where resetreh ives done

S. ... 3 spoce indentation for first lino
6. Entire abstract in 1 paragraph typod -inglompood no more then 6 lises per inch $(2.5 \mathrm{~cm})$ asing 12 point fort or equivelent.

7. DO NOT FOLD ABSTRACT

If this form is nol evalleble, please typo the abstract on plata white th a epece (18 $\mathrm{cm}$ hide by $11 \mathrm{~cm}$ hich) or xerox this form.

\section{DEADLINE FOR SUBMISSION OF ABSTRACTS: POSTMARK MAY 1, 1994}

\section{DNTBR-INDIVIDUAL VARIATION OF NICOTINE UPTAKR AMONG SMOKERS}

G. D. Byrd. J. H, Robinsoin, W. S. Caldwell, and D. J. deBetbizy, R. J. Reynolds Tobecco Company, Product Evaluation Group, Winston-Salem, NC 27102.

Cigarette smokers have a wide variety of "tar" and nicotine yicld products to choose from in the current market, maging from $0.5 \mathrm{mg}$ "ta" and less than $0.05 \mathrm{mg}$ uicotine to $27 \mathrm{mg}$ "tar" and $1.8 \mathrm{mg}$ nicotine by FTC method. To bette understand the relationstip between FTC nicotine yields and actual nicotine uptake in smokers, we tave studied aicotine uptake in 33 smokers that spanaed four groups: 1 mg "tar" (IMG), ultra-low "tar" (ULT), full-fikvor low "tar" (FRLT), and full flivor (FF) cigarette smokers. These cigarette categories had mean FTC nicotine yields of $0.14,0.49,0.67$ and 1.13 mg/cigaretre, respectively. The subjects smoked ad llbltum their usual braind of cigarette and submitted a $24 \mathrm{~h}$ urine sample for total ricotine uptake analysis over a period where the rumber of cigarettes smoked was racorded. Nicotine uptake was determined by monitoring urinary nicotine and its metabolites, including the glucuronide conjugates. Daily aicotine uptake was $9.1 \pm 7.3 \mathrm{mg}$ (range 1-21 $\mathrm{mg}$ ) for IMG, $19.2 \pm 10.0 \mathrm{mg}$ (range $4-42 \mathrm{mg}$ ) for ULT, $21.8 \pm 9.4 \mathrm{mg}$ (range 13-38 mg) for HFLT, and $37.1 \pm 14.4 \mathrm{mg}$ (range 21-60 mg) for FF smokers; on a per cigarette basis this equated to $0.23 \pm$ $0.11,0.56 \neq 0.23,0.60 \pm 0.18$, and $1.19 \pm 0.43 \mathrm{mg}$ nicotinc, respectively. Although the outnber of cubjocts in each group is limited, meano for the differeat groups showed that lower FTC yield cigarettes result in not only less nicotico uptake per $24 \mathrm{~h}$ period, but also per cigarette smoked. Thess data suggest that nicotine uptake is a function of individual smoking behavior within product decign limits. We conclude from these data that, while FTC yicld cannot preciscly predict niontine untake for an individual smoker, it is useful in oredicting and coinparing actual nicotine uptake by smokers who eclect cigaretten with a particular FTC yield. 


\section{EVIDENCE FOR URINARY EXCRETION OF GLUCURONIDE CONJUGATES OF NICOTNNE, COTININE, AND TRANS-3'-HYDROXYCOTININE IN SMOKERS}

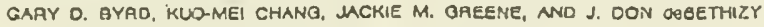

Phemecology Otrision. R J. Aoynords tooucoo Compiny

(fiteorver July 15. 1991; acomprod Octooer 22.19911

\section{ABSTAACT:}

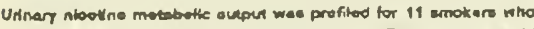

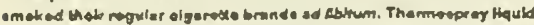
chrometoriaphy/mack epactromoty wal uevd to moritor nloodno

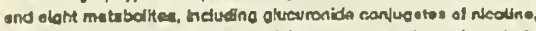
cothine, and trenes'shydroxycornte thel wore determined ind.

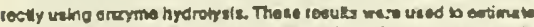
an ererage, elsidy-otste concentration in a 24 hif urino samote durtig ad fthoum smoldng and so issese huorladividual vedabtity in

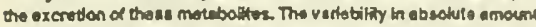
among the nire enalyted ranged from $\$ 5$ to $70 \%$ for these smokers. The gucuronids corfughtes constituted in erersge of $29 \%$ of ax

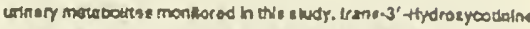

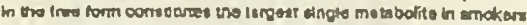

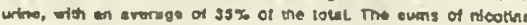

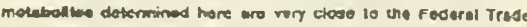
commiedon ylatde of noodine for the toul number of cygererte

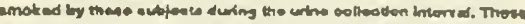
recults indicen thal a lerge propertion of the niactine beoctsed while

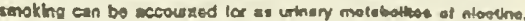

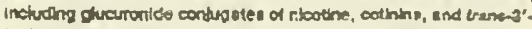
hydraxyoctinthe.
Althouth nicotinc disposition in smokers hes been studled for deondes with a namber of ractabolites reportod (1) the ability to wocourt for all of the ricotine cbrotied by smokers has been difficult becauce of a back of underatanding of whet the major mctabolites are and bow they vary from one individual to the Dext. Such an undertandies is of maricular importeros for biossenys that quantify exoorurc to xenobiotics lite nicotins (2) 3). Progress in analytical metbodolosy has made lt possible to deternine in bialogical fluids metabolite of ricotine that have a wide range of polarity. The relatively reant detemination of a maior metabolite trans-3'-hydroxycotirine (4, S), and the reports of glucuroaide conjugates of oicotise, cotinine, and urans3' hydroxycocinine (6-9) have siguificantly improved tbe potenlal for quanthying ricotine absorption in smoker.

Many analyucal methods sucb as GC (10), GCNS (11), HPLC (t), and caryme-linked Immunosorbent asays (12) have boto utilized to rooitor the dhsributios of ricotise and tis metabolites in bialogical huids HFLC with UY and radiomcuric derection ( $t$ ) is partionlarly usoful for determicing mass bulance from administered radiolsioled nicolioe However, it is no practical to introduce radiolabeled nicokins into enoken uto are absorting nicotirc utile smoluns their regulas brands ad libitum.

We have demonstrated the uility of a themospray LC/MS method for determinias ricotiac and many of its metabolites in the erine of humsn mokers, including the major metabolite irans-3'-bydroxyootinine and cotinine (13) and elucuronide conjugates of alootioe, trans-3'-hydroxyconinine, and cotinine (8). The major advanuages of thermospray LC/MS are its sbility to determine all major and severa! uninur neotioc mazbolita in a aogle chrometographic rus wihout derivargestion tochniques.

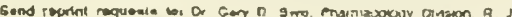

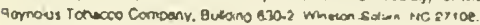

This study examines the amount and distribution of urinary aloolixc metabolites aroong if smokers who smoked their reqular cigarecte berids ad lisilum. Nicotioe and eight metabolites ur monisored using themospray LCMS, inctuding irans-3'. bydroxycotivioc, ootrine, alcodne-N-oxide, cotinizo-N-oxide, demethylcotining and tae chree glucuronlde confugates dinoribed previoushy. By looking at these major metabolltes in 24 be uriso cemples of II armokers, a survey of ricotine disposition

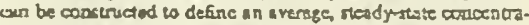

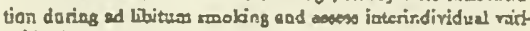
ability is the craction of these metabolisas.

\section{Muterts and Methed}

Meteriale SI-) Nicosiac tad (-Kotinipe were purchased commer disty (Stgers Chearical Co, St. Lovis MO). Deroetaylooticine pras

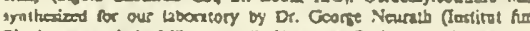

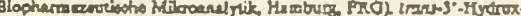

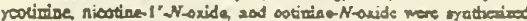
for our labenatory by Dr. Ptet Crooks (Undyerzily of Kentudy, Laxing lon). AD somples were asesed for purity ty GCMS, exoed for nicotine. $N^{\prime}$-oxide (which is themrolly usezetel and found to be at kear 99.35

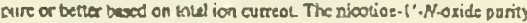

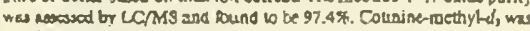

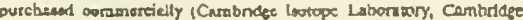

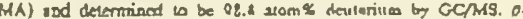
Glucuronidese from borioe liver 1624.000 Fishmun unies/8 rolid) wos muncturad commenislly (Sigms). HPLCGrade methasol, methylene chioride (American Burdick \& Jacloon, Muskeron, MII), and hieh-owrity

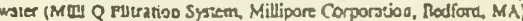
wore urod os rolverus. Reagetit grade a camonium ocetaic Mallinckradt,

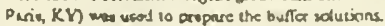

Mothots Sarple Precaration. Serriple propention was by o simpic meithod that bas been describod nreviously $(R, 13)$ Urias saraples wer thawnd just prot is use. Ore-militilica aliqunes were iranaferred to a

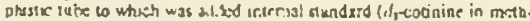

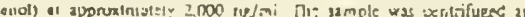

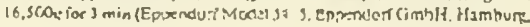




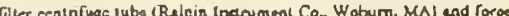

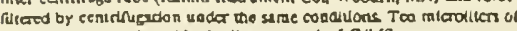
this filtnte were inveted in duplieate onto the $C C / M S$ system.

LC/NS. The thermospray LCAS method used in a andiliealion of

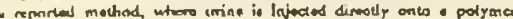

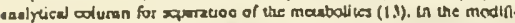
catlon, the water/reethand gradlent begins with $100 \%$ water and gocs to $10 \%$ methanol at $3.1 \mathrm{~min}$. $45 \%$ methaol at $S$ min. ar.d gor methenol 118 mia. Pockolumn adition of $0.1 \mathrm{M}$ exmunium ecernic bufter

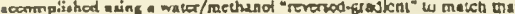
of the anabyal column. Tals orovido a consisteat composition of whter, methanol, and ammonium sorsic to the themospry iateriace.

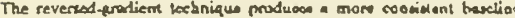

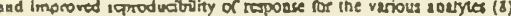

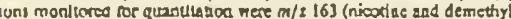

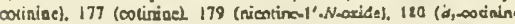
internul thedurd), and 19 ) (ootinioo-Noride and inans-3's hydrox yeocin ine), with a dwoll time of 0.25 roc $8 \pi$ act lon

Deteminarion of Conjuzares. In order to ceancify elucuporide cos

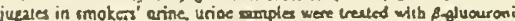
daw (14). Ution mamples were first djueted to $\mathrm{pH} 7.0$ by addidod of 4

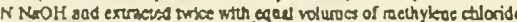

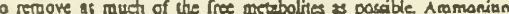

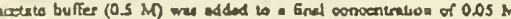

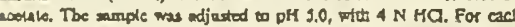
umple, triplicate $3 \mathrm{ml}$ eliquots were remored and 3,650 U B-elueuronidase were added to cach 53 moles ware incubeted for $24 \mathrm{hr}$ a $37^{\circ} \mathrm{C}$ -

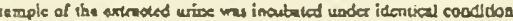

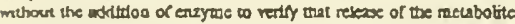

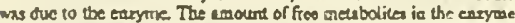

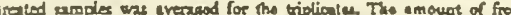

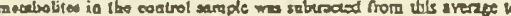

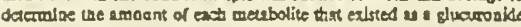
conjugute

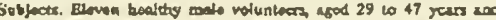

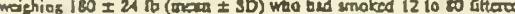

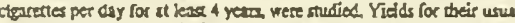
ciouctle braxts averiged $10.5 \pm 4.0$ (meas $\mathrm{E}$ SD) mg of "ter" aod 0.6

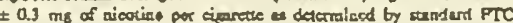

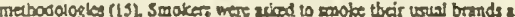
they would sormathy do orer a 24 hr period Thsy were atbed to reocm

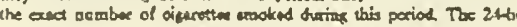

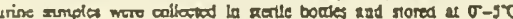
between colloction. Total 34 tr vrine volame and urine of were tneas

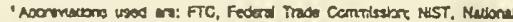
ins ruses of Stenatares and Terrolow.

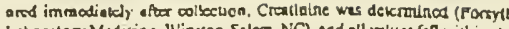
Laboratory Madicioe, Wieston-Satern, NC), and all ritues fell within the oormal rana a $0.6102 .8 \mathrm{z} / 24 \mathrm{hr}$. The enoust of niavioc cach amoke

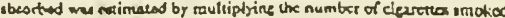

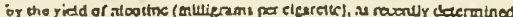
for diat ce eureste beand ty the FTC maitud (ISL. The acpound of absortod

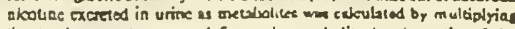

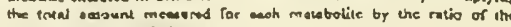

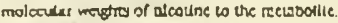

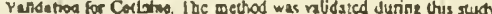
for cotinise asine NIST Reference Mutrial val4 "Cunine in Froem

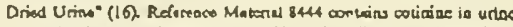

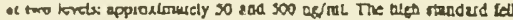
in the lomer part of our calbrated ranee. Trioliode mossurments made or thus meterial pave a value of $445+10 \mathrm{~nJ} / \mathrm{ml}$ whist is wittin $10 \%$ of Che NIST moomratedod alue of $4.93+4 /-10$ ng/In'.

Recalto

Trertment of urime eanplee. which had been extrectend with mathylane chloride, whit figlucuroniase tncressed the concentration of nicotine colinine, and trans-j'-hydreayeotinise (fis 1). The combined seloctod ion chroristogram in fie $\mid A$ is thas of unireatod unte collected from an individual molsex. The trans-3'-bydroxycoticine, cotinine, and nicotine peabs are cleary dixcruitle The chromatogran in $0 \mathrm{~g}, 1 \mathrm{~B}$ ts the same urine smols followine duplicate ertractions at $\mathrm{pH} 7$ aith motbylene chlorich More than $90 \%$ of the cotiniac and oloothe were removed, but les: than half of the trars-3'-hydroxycotinine was extricted becsure of its hydrophilicity. Tbe chromatogna in fig IC hons the seme extrect urioe sample following \&-glucuronidase trestorent as previously deacribed. Concatration of freo vicotine, octiniac, and trans-3' hydrwy yoticine in the extractod. urine incressed by f-ductronidse trearmere with cotinine

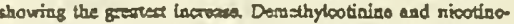
$N^{\prime}$-axide, as mel 2 cther nkcothe metsbolits wtrich were aot detectod in semolers' urize did not appens is glacuronido $\infty$ njugates within the detection limis of the mabod (20 to $200 \mathrm{ge} /$ ml). Iocubations of suokers' urine voder identical coaditions

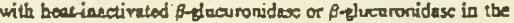
presenos of excturalactone yietded ao edditional niborite $\infty$ inine of tran 3' hy ytros yootinine.

Atrempes to ideatify the ducurontise confugates to the mass ranges thit would be expected were unsumersful Andivite of a modol glwouronide, A-aeptchylejucuronide, by thermaspay LCf

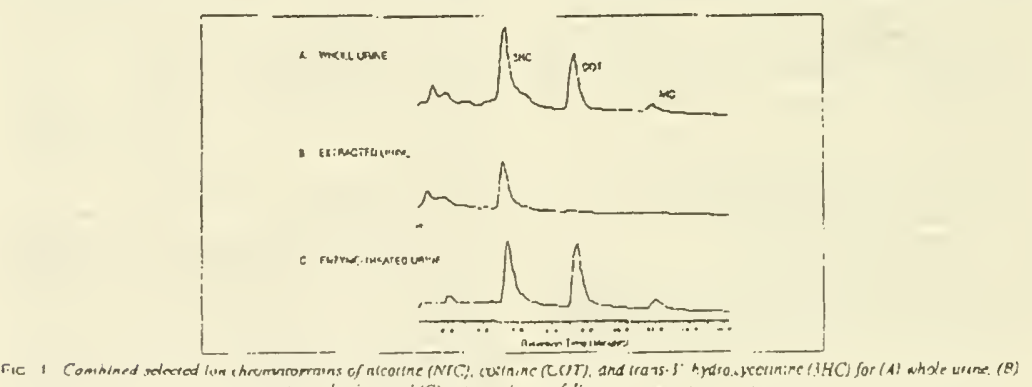

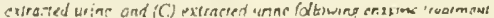


Mis using the condidons in this sudy grve $\left(M+N L_{4}\right)^{-}$at $m / 2$ 138. $\left(M+\mathrm{NH}_{<}-\mathrm{H}_{4} \mathrm{O}\right)^{-} \mathrm{m} \mathrm{m} / \mathrm{z} 320$, and the glucuronide iragment st $\mathrm{m} / x$ 194 that ajatctiod the mported bellayter for thls compound (i 7 ). T.wo nitroen-oontaining glucuronides 8-hyiruxyuvinuline glucuronid and o-aminophenyt glucuronide, gave very atrang $(M+H)^{*}$ innc at $\mathrm{m} / \mathrm{s} 322$ and 286, reppectivoly.

the amounts of each mearured metabolite exeneled in 124 be unne sample are listed in uble i for the 11 smoken. The variability of these absolute amounts in terms of tho coethoiont of varation rayes from 35\% for demethylootinise to $70 \%$ for nicotine ejucuronide conjugate. The distribetion of the major nicsabotices (nicotine, collnine, asd (rans-3'tiydroxycotigiue) beimeen the free and sonjugzted forms is showa in fogute 2 for the 11 imokers. Pleure 2 lliustrates that iree irans-3-bydroxycotinize wus uniformly the most sbudaht metatohit measured for all smnkers and acomented, os svenge, for $35 \%$ of the lous metsitolites detected The percent of each metabolite as ite glucurnardo conjugerto mised a groat deal for niootine (0 $1044 \%)$ and cotinise ( $d$ to $76 \%$ ) and wmswhat lex for tran $3^{\prime}$-hydroxyoutiaine ( 10 20 30\%).

to order to compare the relative dierribution of anezabolits anone smokes, the amount of each metabolite was converted to sicotine equivalente by multiplying by the ratio of the moisculat weights of nicotine to the coetsbolite. These nsults are also listed in table $I$ as percent of the total anount determined. These averases at the bottom of able 1 are plotted in fig. 3 in cridcr of docreaving abundance, witt errer bas to indieate the rtandard deviation among the 11 moicers. Frem this dete, the proportion of metabolites excreted as glucuroulse conjugates can be deretminoo. Tocal flucuronlóe condugates accounted for is $1037 \%$ of all ciessured membollter, with an average of $29 \%$ for the 11 smokers.

Nthough it has not bees demonstrated that all af the nicoline abeorbod while amoking cen be quantiestively rocoreced in urine as nicotine and ies ra stabolites, it is of Interent to doterminge rbat partion of FIC nicosine yield cae be recovered in wine Trble 2 lists the FIC cicotine vield for each emaker and the total nicotine couvivalenis determined in this study. The number of cigareties consumad the day of urine collecrion ranged from 12 1080 , and the total FTC nicotioe yield fos thete cigaretes varied rom 123 to 44,2 mg. Tabie 2 shows aicotine outpos in these smohers' uries ranged from a retio of 0.58 to 1.44 of the FTC yields, with an average of $0.96 \pm 0.29$.

\section{Dincasios}

1his study confirms cariter observaloas the nisotine can be metabolized to piucaronide confugates in humans (6-9). We present deta thet demonatrate only aicotinc, ouninine, ad irans-

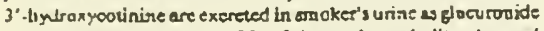
conjugates and oonutitute $29 \%$ of the total metabolites detected in line for the 11 smokors examined in tbis atudy. Uaing a themumay LCIMS uechnique developed in our laturatory that Dermits the simultancous determination nf ricotine aud 17 of its fioe metrbolites in human urite (13). we have determined that none of the ottier froe metabolites that sopear in snokes' urine ase excreted as glicuronide coniugates. Of ve numeruss froc metabolites of nicoline neported in vie licersture, only demeih:1colinine, nicoline- $N^{\prime}-n x i d e$ and oninine- $N$-exide wate cxeretad in measurable quantities (detetion limits 20 ic $2(0) \mathrm{ng} / \mathrm{ml}$ )

in corsmans. Cunall of a'. (6i, who studied aight:mukers,

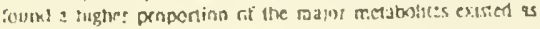

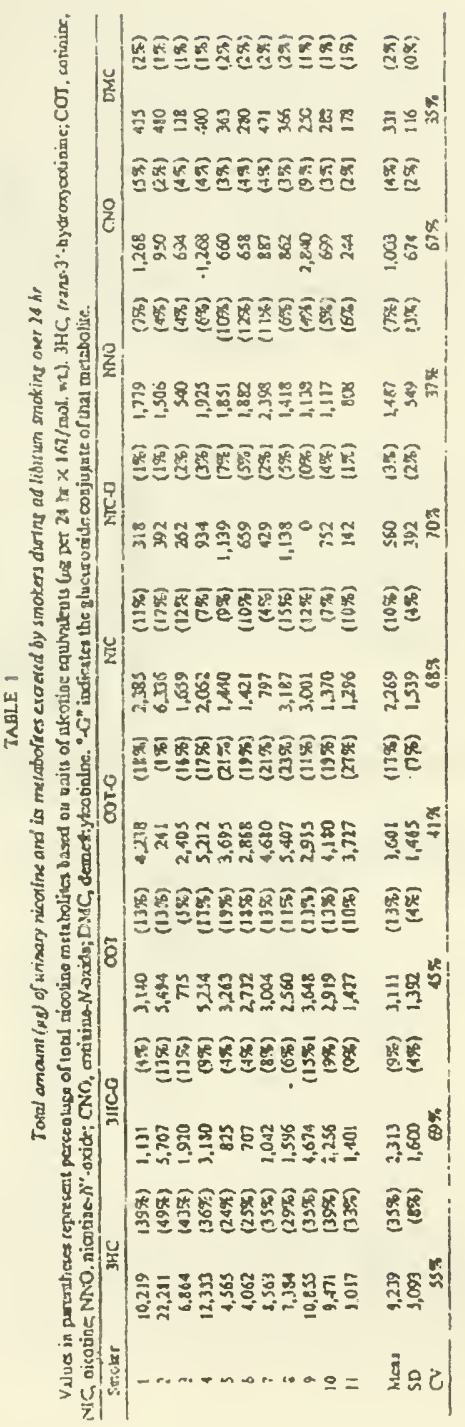




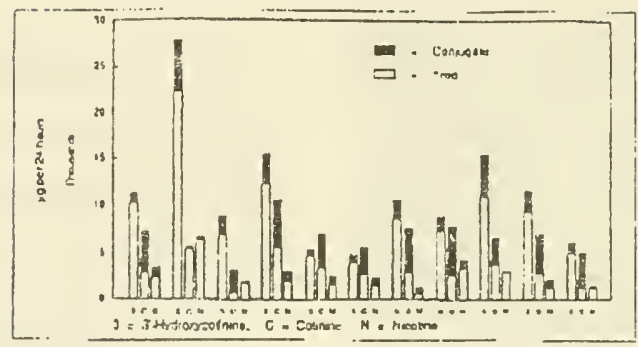

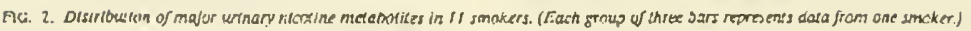

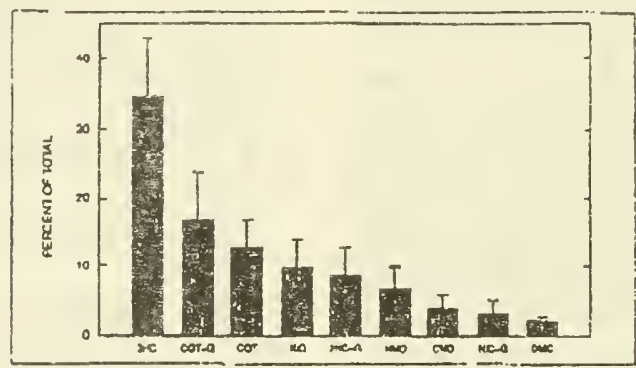

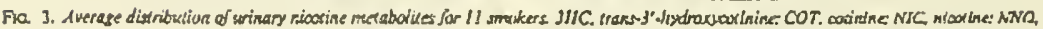

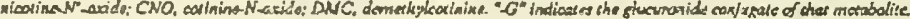

TARE 2

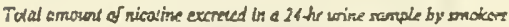
as nleothe and its major merabolites

\begin{tabular}{|c|c|c|c|}
\hline Smoker & $\begin{array}{l}\text { Toul } \\
\text { FTC } \\
\text { Niocine } \\
\text { Yind } \\
\text { (oter }\end{array}$ & 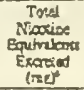 & $\begin{array}{l}\text { zerko } \\
\text { ovvir }\end{array}$ \\
\hline 1 & 37.2 & 22,2 & 0.60 \\
\hline 2 & 330 & 38.3 & 1.16 \\
\hline j & 129 & 13.5 & 1.04 \\
\hline 4 & 4.2 & 29.0 & 0.66 \\
\hline$s$ & 19.8 & 16.1 & 0.81 \\
\hline 6 & 123 & 138 & $t .12$ \\
\hline 7 & 20.2 & 20.6 & 1.02 \\
\hline 8 & 15.0 & 21.6 & $1 . \$ 4$ \\
\hline 9 & 19.8 & 25.4 & L.31 \\
\hline 10 & 35.1 & 204 & 252 \\
\hline \multirow[t]{2}{*}{11} & 16.5 & 12.7 & 0.77 \\
\hline & & & Mean $0.96=0.29$ \\
\hline
\end{tabular}

- Tolel FrC niogine yided from all ciosertes ov mumod during the 24hr pertod based oo tac yleid publistrod la res. 15.

- Sum of all urioary mestbolices determinod nemalizad w ricoxim equivileats as dexcrited in the Mas mlate and. Wushode.

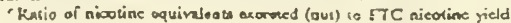
(1) conjugates. The average ratlos between fres and conjupalod

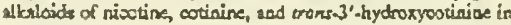
our sudy more 4,0,0.5, and 4.0, raspcocivdy, woeres Curvall reported nation of 1.0, 0.5. and 2.3. rapectively. Thus, we found

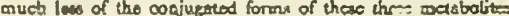
than Curvall reported In esrms of totaj amouns of frex and conjugated forms of these majer thros motebolites is conokers. re find $2.8,6.7$, and $11.6 \mathrm{mg}$ per 24 ir urtse temple for nicotire, cotiains, and irans-3' hydrozjotinine, resectively, compared with 2.1. 4.9, and 13.0 in the Currall study. The differcacos in gururonide proportion betwoe our results and Curvall's may neilect individual differeoces in nicotinn metabolism or may be due to differenos in the aarivical icciniques. Our method uses

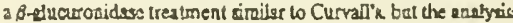
for niootiae, cotitine, ad /rets-3' hydroxyootinine is differeat Our method requles co extration or derivatization. as vas used by Cunvill for the decermination of the freo eadyos. in fart,

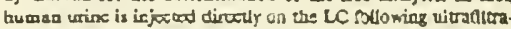
tion. This minimizes the porential for bas of materia! dutios carepta preparation and raduces the potertial for therral deconapustion.

Our eftors to deiect slucumaide conjupzes dirsctly usiag thermospray LC/MS in the rast ranes that wculd be expecaed wete laz'scoessill. We were able to deioct thre model slucum vide ocajugater i-eaphtb.tglacumaido, E-bydroryquinolin 
giucurunide and nrche-aminopticuyl glucuronide using themo spmu LC/MS operated under the comditions desconbed in this study. Homerer, the ebility of thermoepray LCMS to daver grucuranide cunjwates is varlable and very sependent on the structure of the zelvenne (18) Dired detemination of the efu. curoniden ntay have to wail untsl a mythetic alsadard is available fur uptimization of the therroospray system. Glucuronides o ertiary anomatic umince and aliphatle tertiary amines have been secared in urine by LC/MS, but only after the svailability of a synthelic slandard (19. 20). We are currently working on the tsolation and eharactenzation of those slucumnidos.

Kyerematen ef al. (9) reported the excetion of glucuronioe conjugater of nicatioc in smokers followirg intravenous edmin istratiun of " $\mathrm{C}$-labeled ractric aicotine The glucuronide observod in that stedy was crodominanlly trans. 3 ' -hydroxyootinine givcunotide, as judsyd by eppearance of free ${ }^{14} \mathrm{C}$-labeled trens 3 -hydroxycotininc collowlat incubation with oflucuronidais of the polar HPLC fraction crolaining the putative ducursaid peak. Ilıc finding that / razk-3'-kydroxyeotinine wes coajugeled 10 the greatest ratonl is puzzlioe considenng out findings an Curvall's findings. However, it murs be remernkered that Kyermaten administered a very low dose of radioblelod olcoulne to abruining smokers. II is posstbls thrt, under conditions wher the crrculatlog levels of cotininc have beer raduced by absention froro smokras the meater proportion of a low intravenous dose of ricotite is cooverted ta imma $3^{\prime}$-hydronycotiniae glusuroaid rather than colinine glocuroalde. Altentativay, bcoulse $50 \%$ of the aicolios adnioisterod in the Kyerematen atudy was $R+$ nicorine, the tessibility cxists that $R(t)$ niootioc is unetabolized to the fluarooides at s differeal rate than the $S-$ ) niootine.

Without cxception, unsonjugated enats 3 "-kydroxyootioine is the major uriosty metabollie for all smokess in this sady, constituting an average of $35 \%$ of all metsbolites mespred (Including the conjugared forms). Although first reportad many yeart aco is a vicotine meabolite in ramons (21) trans-3'bydroxyeotinine proved diflioult $w$ quentify in uriac bocauec it was aot readily extracted beanis of its hydropbilicily. The utermonpry LCMSS method used in this stady does not involve extraction and to weferited for the direct desermination of urinary tmans-3'shydrozypotininc. Pharmacokinetiz studies of crans-3'-hydroxycotinine bave shown thas is is fornos frow cotininc and furiber metsbolism is limitod (22). Thus it is aos surpriaing for it es be oosictently found as tha majoe urinery me'abotite.

Indindal respooses in nisotine mehbolic proples trifect lotcresting diffamos. Smoter 2, for exumple, is unusual corroared whth the others. in that much more fres trans 3 -hydroxycotinine, cotinine, and nicotino are feund in tir urine aod raver iess of the cotinine glucuronide. With the excepson of Smoka 2. the relzive nroportion of nicotine ercreted as ench mostbolite show variations iry faetors of 2 10 7 over the 10 remaiaios smokers. Smoker 9 has no devectable amount of the nicotine

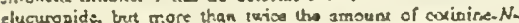
oxide than any orher stzoker. There observarlons suggert that certain melabolic pathu ays may be favorod ever cethers in some sunokers.

The data in mable 2 rearding somoking behavior of the undind. unds in this study are limicd in their ability to decribe the sctual Inneys of nucoline abrembeo by each sncker. The FTC Itseif has recontwised that FTC rated "milligran aicotine per cigarette" values do exis necessanly represent the actual aicutine vicided furing renokiun bi iny pracular individual (23). Thus, the aumber of cizaresies and their tout FTC. nientine yiald pravids If hert unly a general setise of nlarine absortxion for these smokers in a steady-staie syrtem. However, a majoc objective of this scudy wat tn quantify the wisl nicotine-dcrived meterial cxcreled in urin: uves a $24 \mathrm{hr}$ pened for smokers dunag thes reguiur smoking routine. Thus, the dat2 in lable 2 serve to cunnin that the subjoces are rofular smokers who consume berween onc-half and four orcks $x$ cigaretter $p x$ day.

Althoush the nicotioc out, in racion in lable 2 vary spproximately 3 -fold $(0.58$ to $i .44)$ rui these smoxeda, the cata indlate that on avorage, $96 \%$ of the FTC nicoline yield can be reosverod in urine as nicorinc cquivalents, basat on the analy tes determined in this study. We have as: useat the thermosoray LC'IMS method in quantify the amount of nicotias equivaients in humaos ad ministered a kmwn amount of nicollae intrzvenously; ter we do know that 81 \% of ('2C)oicotine adritnirtered intravenously ao te reoveral in the urine as metal wlites that cau de ditected by thermnairay LC/MS (9).

\section{Sumenters}

Themospray LCAIS tas beeo sucoessfully apolied to survey urloary nicotine metabnlic discribution io 11 susokns. For thes smoker, the variability in absolute amount anong the rune a deblyes canged from is $1070 \%$. This onethod confirms the presence of glucumnide conjugatos of alcodoc, codnire and Imac-3'-bydroxycosininc, canclitule 26 averate of $20 \%$ of the uriary metaboilies. trans-3'-Kvetroxycotinise in the froc form cosstitutes the larest sincle metubolite in smokers arine, with an averaze of 357 of the tolal The sum of aicolin moteboliter determinod hate is very close to the FTC yields for the clgerertes snoked by thac abjeat.

\section{Referoseco}

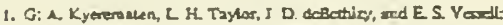

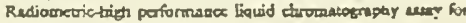

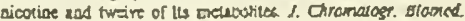
ipol 419. 191-203 (1987)

2 J. D. CoBsthizy, M. E. Bonending, D. J. Doolittla J. H. Robinese, ス T. Memonus, C. A. Rahne R. A Devis, O. T. Burger, J. R. Heres J. Il. Reyroke, and A. W. Hoyer. Cleonial and biol apiol

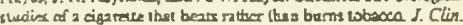
Fharnacol $34,755-i 63(1970)$.

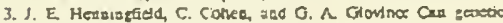

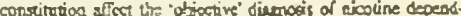
cnce? An \& Puttle Heaist 24, 1040-1041 (1990).

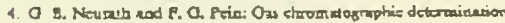

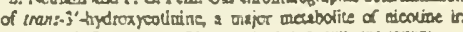

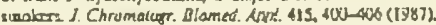

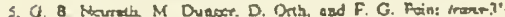
Hyaraxycotiales as a main caesubolice in uriac of reokers. Aneth Uccus. Entiron. Health \$9. 199-20! (1987)

6. M. Candil, E. $K$ Vale C. Endunsh and C. R Enzdl: Litinan

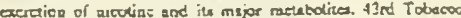

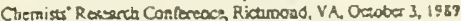

7. N. J. Haley. Y. Leurinzer. C. M. Axchad. and J. P. Ejehie Jt.

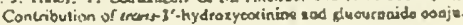

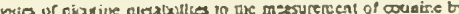
RiA. Imemseiond Sumrosium oa Niwane, Hambung Gerrany. June $28-30,1990$

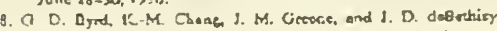
Determinrs:on of akotine and is metubolites in uriac by than

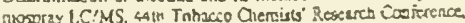

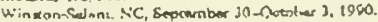

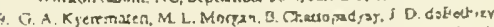

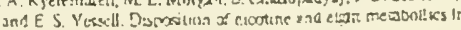


smokers and nonsmokere ldentifucausn ir. $3 \pi$ :okers of $t$ wa me1abulites that are longer lived tha a cotinine. Clln. Pharmacal Tier. 48, 641-651 (1990).

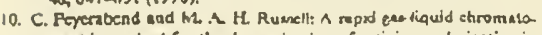
eraphio mathod for tha deceratination af cotiaine and aicctine in blolngial thids. J. Phan. Priarmacal. 42, 450.-1,12 (1990).

11. P. Daeacm, L Larulle, and K. Callowmer: Determination of cotiuge In biokded duids by capiliary gas shromatograpty-mese spec-

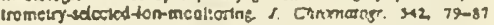
(1583).

12. R. J. B.entro, O. Cook, N. Ryehtik, H. Cjika, H. Van Vunskie and J. 1. Larzane Stereospccific monocional antiboules to nicotine and coriaine ad their use in erorme-liaked immunusurboat useys. J. Immenol. Seth, 90, 203-213 (1988).

13. K. T. MoMaous, J. D. deBetries, D. 4. Ganct, O. A Kjeremasea,

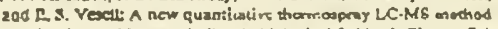

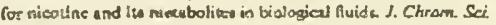
28, $510-516(1990)$

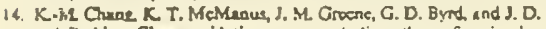
desechloy: Glecurodidation as a metubotic pathway for nicociuc retabotism. The Toxicologist 11, 4 h (abru.) (1991).

13. Tobseco Instirute Teating Leborsiory IN arker Simple 32 Tea Ropor, Rockville, MD, June 1S. 1990.

16. L. C. Spader and C. D. Byrd: A corinins in liescandried urins referenoc miknd, J. Res. NIST 94, I-5 (1989).

17. D. E. Games and B. lewe: Combinod liquid chromslogmphy mas apoctrometry of glyeosides, ducuronider sugar, and muclemsides Biomad. Vase Spectrone 7, 43]-438 (1480).

18. W. M. Draper, F R. Brown, R. Methem, ans M. J. Mitlle: Thermospmy mass yoctrometry and (nidera inos apectroriatry of polar, acinery messbolites and masbolic onnjugata. Uiumer. Envirun. Acass Specorom. 18. 767-774(1989).

19. M. W. Hins and A. F. Reorrool: Indation and eliswumenrization of

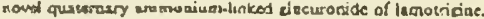
Drue Metab. Dispos. 19, 149-15\} (1991).

20. K Strasb, M. Davis, and A Hwang: Benameprine revisitedevidence for the formotion of noval amine complexts. Drug Ma tab. Dispor. 16, 399-106 (1925).

21 H. Mckeania Je, L B. Turabull, E, R. gomenan, and E. Tumato Ths myathecis of hydrosycaliolne and vedies on its stivcture. I Ons. Chom. 28. 383-387 (1963)

22 G. Scherer, 1 Jarzy 5 ,.-D. Helker, A. Biber, G. B. Neurath, und F. Adlkofer. Thamacokirecios of nicoline, cotininc, ad $y^{\prime}$-hy draxyoninise in cigarette srocher. Klen. Wuotenster. 60 (Sappl. Xil) I-11 (1S58)

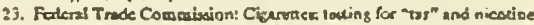
conteat-sintements of consuserntions. Fed. Res. $\Omega_{2} 11178$ (1967). 
Mr. WAXMAN. There's been a lot of interest in tobacco extract and whether nicotine is added by use of a tobacco extract. Mr. Johnston, has RJR ever used tobacco extract or any of its products sold domestically or abroad?

Mr. JAMES JOHNSTON. Not to my knowledge, Mr. Chairman.

Mr. WAXMAN. Maybe your research advisor.

Mr. JAMES Johnston. Pardon me. In Premier, there was a spray dried tobacco extract used. In our Winstons and Camels and so forth, that is not the case.

Mr. WAXMAN. Let me get for the record from each of you whether you've ever used tobacco extract and how much nicotine was in the tobacco extract. That means submit it to us in writing for the record. Mr. Wyden, you're the last one for questions.

Mr. WYDEN. Thank you, Mr. Chairman. Let me start this round on some matters involving the ingredient situation. Mr. Taddeo, and I hope I'm not doing violence to the pronunciation of -

Mr. TADDEO. Taddeo.

Mr. WyDEN. Excuse me. I noted yesterday that the ingredients from the smokeless tobacco industry were not included in the industry disclosure yesterday. Is your organization prepared to make your ingredient list public, as well, on the additives?

Mr. TADDEO. Mr. Wyden, you have to appreciate that that was a surprise to us yesterday. I haven't had a chance to speak to the other members of the industry, the smokeless tobacco industry. I can't speak for them. But I know we'll be meeting shortly on that subject.

Mr. WyDEN. Do you personally favor making smokeless tobacco additives public?

Mr. TADDEO. The ingredient list?

Mr. WYDEN. Yes.

Mr. TADDEO. I personally don't have a problem with it.

Mr. WYDEN. OK.

Mr. TADDEO. Nothing to hide.

Mr. WYDEN. Gentlemen, maybe this question directed to you, Mr. Johnston, if I could. Does the list of additives you supplied the Secretary of Health and Human Services include all additives to paper, filters and to non-tobacco smokable materials in the tobacco rods of cigarettes?

Mr. JAMES JOHNSTON. Please repeat the question. I didn't quite hear.

Mr. WYDEN. What we want to know is whether the list that you give the government includes all the additives to paper, filters, and non-tobacco smokable materials that are in the tobacco rods of your cigarettes.

Mr. JAMES JOHNSTON. I do not believe that it covers those. It may cover some, it may not. I will clarify that for the record.

Mr. WYDEN. That will be fine. Would you supply the committee with lists of these additives, if those aren't given over to the government?

Mr. JAMES JOHNSTON. I. see no reason why not. I would prefer that we do that on an industry basis so we're not revealing brandspecific data.

Mr. WYDEN. Let me ask you a couple of other quick questions with respect to the ingredients. A preliminary analysis of your 
most recent submissions reveal 13 ingredients that don't appear on the Food and Drug Administration's current list of everything added to food in the United States.

Mr. Chairman, at this time, I would ask unanimous consent that a report prepared at the subcommittee's request by the Centers for Disease Control on the toxicity of these ingredients be placed into the record.

Mr. WAXMAN. Without objection, that will be the order. [The information follows:] 
The Honorable Henry A. Waxman

Chairman, subcommittee on

Health and the Environment

Committes on Energy and Commerce

House of Representatives

washington, D.C. 20515-6118

Daar Mr. Waxam:

I am responding to your letter regarding ingradiente added to tobacco during the manufacture of cigarettes.

The 13 ingredients you reference were identified from the 1992 lists of ingredients added to tobacco during the manufacture of cigarettes abmitted by the cigarette manufacturers. A briaf description of the use of each of the 13 ingrediente and assoclated adverse health conditions is enclosed. We will coordinate with the Food and Drug Adninistration regarding specifle halth concerns which ight preclude the use of these substances as additive in food products under the Federal Food, Drug and Cosmetic Act.

Many of the approximately 700 ingredients added to tobacco could be causes of algeases or potantial advorse health effects, if a surficlently high dose lo ingested. Without information about the pecific dose, comblnation of ingredienta, and how and when ingredients are added during the manufacturing process, we are unable to determine health rloks that alght rasult from any of the ingredients. With respect to your question about the effects of combustion and inhalation, we do not know what potentially harmeul byproducts may be produced when tobacco additives are burned alone or in combination, as they are in clgarettes.

The Comprehensive smoking Education Act stipulates that cigerette ingredient information provided to the Department of Health and Human Services (HHS) be treated as trade eecret or confidential information subject to Section 552 (b) (4) of Title 5, United states code, and Section 1905 of Title 18 , Unitad state code. The enclosed information le being provided in accordance with the provisions of the act which authorize HHS to provide clgarette ingredient information to duly authorled comittees and subcomaltees of Congrese upon request.

Please let me know if we can be of further asiatance.

\section{sincerely,}

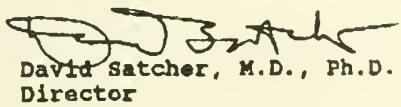


ATTACKABNT I

Conerel Characterlation*

of 13 Mon-enro Clgeretto Ingrodieate Iran the 1992 11et

$54-11-3$

idootine aulphate 10 an extramely toxic compound which 18 easily absorbed $\nabla$ ia all routes of exposure, including the dermal route. Toxic exposures can oocur in individuals that procesa tobacco a woll as ob1ldren who may eat tobacco products. Symptons of acute expogure Include extreme nausca, vomiting, evacuation of bowel and bladder, mantal confusion, twitching, and oonvuleiono. Repeated exposure to nIcotine has induced a wide variety of adverse reproductive effects in apimals (reduced offspring weighte and incroased kelotal defocta, cleft palates, and atilibirtb rates.) It 18 the ma1n precursor of euspect oarcinogento nitrosandne, $N$ nftrosonorn1cotine. The tobacco-specific nitrosandnes axe the only known carcinogens in snuff and may be the agents which caue an increased riek of oral cancer in snuff dippers.

$75-69-4$

Trichlorofluoramothane (fluorocarbon 11, FCl1) is only elightly toxic when the gas is acutely inhaled. Exposure to the ilguid does not reault in dermal absorption due to the rapid volatiliation of the product from the axin. The progressive effects induced followIng Bignificant aoute inhalation can include rapid and 1rregular reapiration, Increased activity, tremore, uncoordinated body movemente, and loss of consclousness. Repeated lower lovel exposuros excopt those above the osta celling value have resulted in cardiac sensitization an resultant death in some adronaline challonged dogs. Bffects on reproduction of fetal development were not cited in the Ilterature reviewed. Chronlc ingestion studies did not result in the induotion of cancer in FCli expoeod animale.

$7664-41-7$

M. nonle is a strongly hygroscopic gas of moderate ecuto toxiofty. The liquid can freeze contacted tissue and result in caustic burns. Dermally, it 18 poorly absorbed. The gas or vapor can also caura irritation and hes tho potentlal to ceuse caustic burns to contactad tissues. Inhelation of amnonia absorbed onto particles such as those found in tobacco emoke may regult in deeper ponetration of amonia lnto the lunge. Inhalation of increasing ooncontrat loas can lead to reddened mucou membanes, lacrimation, ooughing, sneering, and nasal discharge, bronchlolar damage, lveolar oongention, edema, dyspnea, atelectasis, hemorrhago, and emphysoma. Effects on reproduction, letal development, and carcinogenicity were not cited in the ilterature reviewed.

- MOT:

Thees aubtances were Identified by comparing the lagredients added during the manusacture of cigerettes, a eubinleted by the cigarette companion in 1992 , with thos ingrodionte appeering on the FDA ilst of approved food additives:

"sverything Added to rood In the united stakes." Because the olgarette ingrediat liete do not provide loformation on the quantity of ingrediente per cigarette. the following information describea general cherecteriatica of the substances. 


\section{Coneral Cheractorletion"

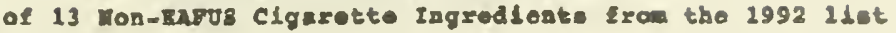

$10596-69-8$

Matheprea is a liquid and is acutely nontoxic to rodents v1a the oral or Inhalation routes of exposure but it moderately toxic to dogs. It 18 nonirittating to ocular and dermal tissues of exposed animais. Methoprene was also devold of adverse toxio endpolnts

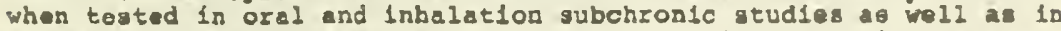
a teratology and thres-generation reproduction atudy in rats. No chronic or carcinogenicity toxicity data were lound in litezature reviewed.

$84961-66-0$

robacco laaf aqueous ertract, residue of a methylene ohloride extraction disolved in dimethylsulfoxide, was consumed by pregnant sows during the first trimester. The gows appeared unaffected by treatment. Arthrogryposis, a porsistent joint ourvature, was induced in thelr offsping, thereby confirming the teratogenic nature of tobacco leaf extract. None of the deformed offspring were able to tand. The spocific teratogenic agent in the extract was not Identifled. A carcinogenicity study was porformed in rats that rooived tobeooo leaf extract delly for 21 months. The treated animale developed lung adenothas (108) and gastio paplilomas (10\%) while an equal number of controla were devold of these tumor types.

$112-58-3$

ol-n-bexyl etber to a nontoxic liguid via the oral route of adminlstration and is poorly aboorbed through the skin. Animals exposed for eight hours to saturated vapors did not die. It 18 also a mild to moderate 1rpitant to contacted t1ssues. No reproductive, developmental, subchronlc, ohronic, or carcinogenioity toxicity data wero found in searchod data bases.

459-80-3

aerando eoid is a roderctoly toxio liguid wher ingested and of lower toxic potential via the dermal route of exposure. It is only moderately irritating when applied full strength to abraded skin. exposed human voluntoers did not develop sensitization reactions when challenged with this oompound. No reproductive,

developmental, subchronie, ohronle, or carcinogenicity toxicity data were found in the reviewad literature.

"NOTE:

Thers: ubstanoer were identifled by pompering the ingredlente addod durlng the

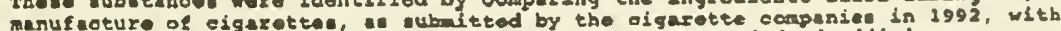
those ingrediente apponing on the rOA. Illt of epproved food additiven: "Bverythlag added to Food In the united states." seceuso the cigarette ingredient ilst do not provide information on the guantity ol ingrediente per oigarette, the following lalormation describes gederel characteristics of the aubstances. 


\section{of 13 Hop-zaros Cigaratt Ingrodieats froa the 1992 llet}

515-03-7

sclareol is an essential oll that 18 axtracted from the flower and ster of the plant Salvia sclarea. It is uged in the agricultural industry to control powdery mildew in crope, and by the perfumery industry as an odorant. No reproduct1vo, developinental, subchronic, chronic, or carcinogenicity toxiclty data were found in the reviewed ilterature.

$564-20-5$

eclareolide, derlvative of gclareol (515-03-7)1s used to enhance the sweetnese and flavors of condimonts, cheeses and other foods. No reproductive, developmental, subchronic, chronic, or oarcinogenioity toxioity data were lound in the reviewed literature.

\section{$585-88-6$}

Keltitol, when orally administered to pregnant rabbits, 1ncreased early resorptions and post-implantation losses. There were no adverse effects on the dams or teratologle effecto on surviving pups. No reproductive, developmental, subchronic, chronic, or carcinogenicity toxicity data were found in the reviewed literature.

$614-99-3$

Bthyl Furoate is a liquid with only alight irritant potent1al on contacted tisuas. It is severely toxic when parenterally adminlatered into rato. It has narcotic and anesthetic propertia but is epparently devold of convulsive potent1al. No reproduct1ve, developmental, ubchronic, chronio, or oarcinogenic1ty toxlcity data were found in the revlewed ilterature.

\section{$13215-88-8$}

4(2-Butengl1dene) -3,4,4-txdnotby1-e-cyolobexen-1-ore, also known as negastigmatrinone is a volatile, odorous substance, used to attract ineect pests that infest stored foods and tobacco. It is found in oigarette smoke condensate. No reproductive, developmenta1, subchronic, chronic, or carcinogenicity toxicity data were found in the reviewed ifterature.

$13341-72-5$

Dlmethyltetrabydrobenzofuranon is a mint derivative used as a flavorant in Europe, found in German tobacco products and Sw1sa toothpest. No reproductive. developmental, oubchronio, ohronic. or carcinogenicity toxic1ty data were found in the reviewed literature.

- NOT: 1

These ubetences wer Identifled by comparing the Ingredieote added durlag the

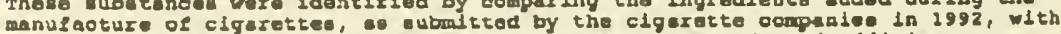

those lngredients appearing on the Fo' j1st of pproved lood additive

ingredient 11sts do not provide information on the quentity of lngrediente per elgarette, the following information describea ganexal characteriotica of the eubotances . 
Mr. JAMES JOHNSTON. I can be helpful on that issue, too, Mr. Congressman.

Mr. WYDEN. Mr. Johnston, one of these ingredients is nicotine sulfate. The CDC notes that this is a very toxic compound and it's the main precursor of a suspected carcinogenic nitrosamine. Have any of you, you or any of the others, used nicotine sulfate as an ingredient in the manufacture of cigarette products?

Mr. JAMES JOHNSTON. That issue has been addressed in every oral statement I heard, every written statement I heard, and probably a dozen questions today. I will repeat it again for the record.

Mr. WYDEN. Let's get it on the record.

Mr. JAMES JOHNSTON. We are required by the BATF to use that as the only thing we can use as a denaturing agent in alcohol. Alcohol is what carries flavors and deposits them on the tobacco. Its presence is not detectable in the final product. That is how little of it is used. It is vaporized-

Mr. WYDEN. Who says that? Who says that it's not detectable?

Mr. JAMES JOHNSTON. As you know, we have had six eminent independent toxicologists review these ingredients. I'd like to comment on this list of 13 ingredients. It is erroneous. Please let me say for the record that five of the items on that list are not used at all by the six major U.S. manufacturers.

Of the remaining ingredients, one is a processing agent that is not detectable in the finished product. Three are, in fact, approved for use in food. Others occur naturally in various food products and are present in cigarettes at trace levels, meaning parts per million.

Mr. WydEn. Let's be clear. What I have from the Centers for Disease Control was dated March 24 of this year. They said it was 13 based on the 1992 list, which is the last list given to the government. So I think we want to be clear that that's what the Centers for Disease Control said.

But more important, I think it needs to be noted, Mr. Johnston, that over the last 24 hours, the tobacco industry has declared once again that all is well, ingredients are safe, everybody doesn't have to worry, set it out of your mind. But let me read you what the Centers for Disease Control said on March 24.

They said, and I quote, "Without information about the specific dose, combination of ingredients and how and when ingredients are added during the manufacturing process, we are unable to determine health risks that might result from any of the ingredients."

Now, you all may have, in fact, been able in the last 24 hours to do a real sugar-coating job on this ingredient issue and try to convince people, including some in the press, that all is safe.

But the official declaration of the government, the Centers for Disease Control, in a letter, March 24, 1994, does not agree with that particular assertion. And until the government gets the specific quantity of the chemical involved, it is very clear that the government cannot ascertain safety.

I got my list yesterday. I was not given any specific dosage information, not given any dosage information on brands. I hope that that information will be forthcoming. You have, again, given us in your testimony a statement that there is nothing to worry about, we need not be concerned. 
I just hope that we can get specific dosage information so that independent scientists can make that declaration. I would be pleased if that was the case, but I will tell you, as one Member of Congress, I am not prepared to say just because some toxicologists that you all have hired, that does it.

The Centers for Disease Control says that that is not acceptable to them on the safety issue.

Mr. JAMES JOHNSTON. Did the CDC also tell you that additional information-we have provided it? The U.S. Government has had this information for 14 years and you're accusing us of hiding something. Ridiculous.

Mr. WYDEN. We don't question for a second that all through the 1980 's public health officials made little or no use of that list. We documented the number of requests. There were virtually none. But we've also been told, and Dr. Roper, the previous head of the CDC, said that he was not able under the law to get the quantity information.

Since he couldn't get quantity information, he felt research was really quite meaningless. You all can resolve this issue, it seems to me, by giving to Federal health officials quantity information about these ingredients. I hope that can be done. I think that is what is essential to really deal with this issue.

Mr. Chairman, I'd be happy to yield. I had one other area I did want to ask about.

Mr. WAXMAN. If you would do it briefly because your time has expired and I think we're ready to conclude the hearing. But I don't want to cut you off.

Mr. WYDEN. All right. I did want to ask one other question because it dealt with a matter Dr. Spears was involved with, as well. It may be appropriate for you, Mr. Tisch. This involves the fire-safe cigarette issue.

It seems to me that your industry is virtually outside the consumer protection laws overall, but it is certainly clear that that is the case in the fire-safe area.

Each year, cigarette-ignited fires cause $\$ 400$ million in property damage, 1,200 in death. We've got fire safety standards for sleepwear, children's sleepwear and a variety of other things. These standards are designed to protect the public from fires ignited by your products.

Yet, your industry opposes issuance of Federal standards in this area. Now, the tobacco industry has been able to delay consideration of Federal fire-safe cigarette standards through two Federal task forces.

Mr. Tisch, are you aware that in 1987, one of these Federal task forces included Dr. Spears and it determined-one of these task forces, with your staff person, Dr. Spears, determined that a firesafe cigarette was technically and economically feasible?

Mr. TisCH. I'm going to let Dr. Spears-

Mr. WydEN. But were you aware? He served. He works for your company. You're the CEO. Were you aware that he was on this task force that found you could make a fire-safe cigarette and we could keep a lot of folks from getting hurt?

Mr. TISCH. I may have been aware because I know that he's been very involved in the fire-safe cigarette issue for many, many years. 
Mr. Wyden. But you're not real sure.

Mr. TISCH. I'm not real aware.

Mr. Wyden. Mr. Campbell, one of these task forces also concluded that five cigarettes were less ignition-prone than other cigarettes on the market. Yet, the tobacco industry argues that fire-safe cigarettes are not feasible because they are too hard to draw on, they don't taste good and they don't have good mouth feel.

Mr. Campbell, I gather one of your brands, Virginia Slims, was one that the task forces said were less ignition-prone. Are you saying that your brand is too hard to smoke and doesn't taste good?

Mr. CAMPBElL. That particular brand is too hard to smoke and doesn't taste very good, but that's not the issue at hand. We're talking about people and loss of life in terms of fires. I must tell you that this industry and certainly my company is absolutely dedicated to trying to develop a fire-safe cigarette, if it's possible. We have not been able to do so up until this time, but we are diligently working on it and we'll continue to work on it.

Those five cigarettes which you spoke about, in the real word, on a real world test with real fabric, those results are reversed. So, unfortunately, we're not there yet, but we're working very hard with Chairman Moakley to develop a feasible test and from there we'll try to move on to develop products that will improve the firesafe situation.

Mr. WydEN. Mr. Campbell, I understand that your company is currently the subject of a potential antitrust action by the Department of Justice over your refusal to develop a fire-safe cigarette, is that correct?

Mr. CAMPBELL. I don't know of that, sir.

Mr. WYDEN. My understanding is that that was the case. You're not aware of that. You're not aware of whether the case-in fact, let's just ask about it-involves a previously secret research plan undertaken by Philip Morris called Project Hamlet.

Mr. CAMPBELL. I know of Project Hamlet. It's our fire-safe-it was our fire-safe ignition propensity project of the 1980's.

Mr. WYDEN. Do you admit that through Project Hamlet, Philip Morris developed the capability to manufacture a fire-safe cigarette that is acceptable to consumers and could have saved the lives of hundreds of children?

Mr. CAMPBELl. Absolutely not, sir. We could not accept ourselves if we had invented a fire-safe cigarette. We have not done so up until this time.

Mr. WydEN. Would you make Project Hamlet available to the public?

Mr. CAMPBELl. Project Hamlet?

Mr. WydEN. Yes. That's the research effort. That's what we're talking about.

Mr. CAMPBELl. This is very, very, very competitive information. We are trying very hard to develop a fire-safe cigarette.

Mr. WYDEN. Will you make any information available to either this subcommittee or the public in a fashion that would protect this gravely critical and private information?

Mr. CAMPBELL. I'm making the information public now. We have not yet developed a fire-safe cigarette. 
Mr. WyDEN. The fact of the matter is that these Federal task forces indicate that it is technically and economically feasible. I've heard the head of the Consumer Product Safety Commission express great frustration over the inability to get these products out.

Again, what we've got is a situation where independent experts say it can be done and people with a vested interest and economic interest say otherwise. That is of course, the pattern of what we have seen today. It started, I guess, Mr. Chairman, more than 6 hours ago, where we began to talk about whether nicotine was addictive. I brought out and our colleagues did all these studies, all these experts, saying nicotine was addictive.

What we found, lo and behold, is the one organized body of thought that says it's not are people with a financial interest to say that nicotine is not addictive. That pattern has continued through the day.

I'm hopeful that today's hearing will help us build support for the important legislation and work of the committee. Mr. Chairman, I want to thank you and the staff for a hearing of more than 6 hours and I think it's brought to light many important issues for the public.

Mr. Waxman. Thank you, Mr. Wyden. First of all, I want to ask unanimous consent that we leave the record open. We may have additional requests for documents, which we would like to put in the record. I'd like to ask this panel, if you would, to answer additional questions from members of the committee, should there be any, in writing for the record.

We will keep the record open for that purpose. I appreciated $\mathrm{Mr}$. Campbell's willingness to allow Dr. DeNoble to present scientific and medical information. I would request that if we have individuals who have conducted scientific or medical research in conjunction with your corporations, that you cooperate with us so that we will have the benefit of that information, as well as has Philip Morris done in regard to this one researcher.

Let me tell you, in closing, that it's been a long day. We've gone through many different subjects. These are important areas for inquiry. We haven't resolved, obviously, the disputes that we have, but I think we got a lot of information on the table and I hope a new basis for which we can work together to resolve those issues, where we will be able to agree in the future, because it's in the public interest.

Mr. Bliley?

Mr. BliLEY. I want to thank these gentlemen and their companies for coming. I think you've been most forthcoming with this committee and I know it's been a long day. Thank you, gentlemen.

Mr. WAXMAN. Thank you. That concludes our business for today and we stand adjourned.

[Whereupon, at 3:20 p.m., the subcommittee was adjourned, to reconvene at the call of the Chair.]

[The following letter was received for the record:] 


\section{1}

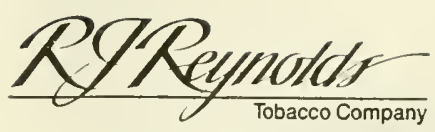

JAMES W. JOHNSTON

Chairman and

Chief Executive Otficer

May 3, 1994

Winston-Salem, N.C. 27102 919-741-7925

The Honorable Henry Waxinan

U. S. House of Representatives

Committee on Energy and Commerce

Subcommittee on Health and the Environment

2415 Rayburn House Office Building

Washington, DC 20515

Dear Mr. Chairman:

I attach for the record of your Subcommittee's hearing of Thursday, April 14, 1994, the following information:

1. Three charts referred to by Representative Thomas Bliley and by me at pages 78 through 81 of the transcript of the Subcommittee's proceedings. The first is entitled "1954-1986 SalesWeighted Average 'Tar' and Nicotine Yields" which Representative Bliley pointed out was taken from the 1989 Surgeon General's Report. The second entitled "Sales-Weighted Nicotine and 'Tar' Levels in Smoke As \% of 1982 Levels" was referred to by Representative Bliley as taken from Dr. Kessler's testimony before your Subcommittee on March 25, 1994. The third, entitled "Sales-Weighted Average 'Tar' and Nicotine As \% of 1982 Levels" is the chart referred to by me as reflecting calculations by R. J. Reynolds of the approximately 500 brand styles during the period 1982 through 1993.

Of the three charts, only Dr. Kessler's indicates an increase in nicotine levels over the past ten years. We have contacted the FDA and have offered to provide to them our data and calculations and have offered to meet and confer with them to resolve inconsistencies. To date, the FDA has not accepted our offer.

I ask that these three charts be inserted into the official record of this Subcommittee's proceedings at the point they were referred to during the course of testimony.

While we do not question that Dr. Kessler relied on data supplied by the Federal Trade Commission in preparing his chart, his chart apparently does not reflect the correct average sales-weighted "tar" and nicotine yields. This would explain the discrepancy between Dr. Kessler's chart and the chart that appears in the Surgeon General's 1989 report. as well as the chart that we prepared for the April 14 hearing. Both the Surgeon General's chart and our 
chart do reflect correct average sales-weighted "tar" and nicotine yields and are consistent with each other.

Dr. Kessler apparently derived the data for his chart as follows:

- First, Dr. Kessler divided all brand-styles into three categories ("full-flavor," "fullflavor low-tar," and "ultra low-tar").

- Second, Dr. Kessler found the average "tar" and nicotine yield for each year for each category. He did so by averaging the yields for all brand-styles within a category in a given year, but apparently not on a sales-weighted basis. That is, for purposes of determining the average yield for each category for any year, a high-yield brand-style with small market share counted as much as a low-yield cigarette with a large market share. In short, the average yield for each category was not a true sales-weighted average.

- Third, Dr. Kessler's chart is inaccurate because he did not conduct a brand-by-brand sales-weighted average analysis.

Because the average yields for each category derived by Dr. Kessler do not reflect the market share of the individual brand styles within the category, Dr. Kessler's chart does not accurately reflect trends in the marketplace.

It is important to remember that market share is a result of choices made by smokers, and is not directly determined by the manufacturers.

2. A chart entitled "Teens Who Associate Joe Camel With Cigarettes Have Uniformily Negative Views Of Smoking" and accompanying text which illustrates my testimony that a polling study conducted by Roper Starch Worldwide in November 1993 at our request revealed that teenagers who are aware of Joe Camel and associate him with Camel cigarettes have uniformly negative views of smoking. My testimony regarding this material occurred at page 172 of the transcript. At line 3961 , you indicated that these should be submitted for the record.

3. An article published in the British Journal of Addiction, referred to at pages 183-4, which reported that carrots could be evaluated as addictive, even more so than cigarettes. In the abstract to the article, the authors report that three patients evaluated their dependence on carrots as similar to that on tobacco and that two of the three patients evaluated their dependence on carrots as stronger than on cigarettes. The point of my testimony and the reason for submitting this article is not to suggest that one may become "addicted" to carrots, or to compare carrots to cigarettes, but rather to point out the danger of allowing persons to self-diagnose addiction and, more importantly, to underscore the fact that the meaning and concept of "addiction" has been so radically diluted that it can no longer be said to have real meaning. 
4. At page 169 of the transcript, in response to a request by Representative Synar, I indicated that we would make available documents with respect to our Joe Camel Advertising campaign. Over the course of the past 5 years, Reynolds has produced nearly 60,000 pages of documents and numerous other items to Congressional Committees and to the Federal Trade Commission. In May 1989, you and Congressman Synar launched an investigation, on behalf of your Subcommittee, of the "role of cigarette advertising and promotional activities in the incidence of tobacco usage among young people." At your request, we provided documents which "discuss the advertising and marketing strategies and goals for the" campaign. In March 1990, then Congressman Thomas A. Luken's Subcommittee on Transportation and Hazardous Materials of the House Committee on Energy and Commerce, requested, and, in response, we produced, information and documents relating tc whether or not the campaign "had the purpose and effect of gerting children to smoke." In August 1990, the Federal Trade Commission began its investigation and we understand that during the week prior to the April 14 Hearing of your Subcommittee, one of your senior aides, Ripley Forbes, reviewed a number of the documents produced by our company to the FTC. I believe the Subcommittee staff has continuing access to our submissions to the FTC.

Since so many copies of those documents with respect to our advertising campaign have been produced so many times to so many agencies and subcommittees, I would respectfully suggest that before yet another set is produced you or the Subcommittee staff might advise us whether the productions to date are sufficient.

5. At pages 180 and 181 of the transcript, Representative Synar read a letter from a Laura Sandefur indicating that cigarettes were being given away in a QuikTrip store in Oklahoma. I indicated that it would be contrary to my company's policy to be involved in a situation where cigarettes could be available to children and I committed to the Subcommittee that I would investigate and submit for the record my findings and what actions we took if our company was involved in any way. Attached for the record are copies of a letter I sent to the chairman and president of the QuikTrip Corporation the day following your Subcommittee's Hearing, together with a copy of a letter I received from him in response. I ask that both be submitted for the record.

In his response, Mr. Cadieux pointed out that distribution of the sample cigarettes was limited to adults and was closely monitored by store employees. The program was discontinued when some of their customers complained. As you can see from the response, neither Reynolds nor any of the other tobacco manufacturers who restified before your Subcommittee were involved in the QuikTrip program. Despite this, the tenor of the questions addressed during the course of the Subcommittee hearing implied that we were. This is precisely the point I was making to the Subcommittee when I testified that we do not advertise or market our products to children and we do not want children to smoke because when they do we are blamed and efforts are made to restrict our abiliky to advertise and market our products to our true market -- adult smokers of comperitive brands.

At page 251 of the cranscrips, I indicated that we had information that could be of value to your Subcommittee in understanding the predictive value of the FTC nicotine numbers. Artached are copies of an arricle published by Reynolds' scientists in a peer-reviewed journal 
and an abstract recently submitted to the International Symposium on Nicotine. This limited data indicates that there is a clear relationship between FTC nicotine yields and levels of nicotine found in smokers.

7. During the course of the hearing, you read to me statements made to the media by one of our employees, Dr. Robert Suber, and asked whether I agreed with that statement. Among other places, that testimony occurs at pages 150-151 of the transcript. At page 10 of our written statement submitted to the Subcommittee, we made the following point:

"The clear intent behind cigarette design developments has been and remains to manufacture and market a broad range of cigarette products in response to the demands and tastes of today's adult smokers and to ensure cigarette to cigarette and pack to pack consistency within a brand. Within the universe of cigarettes products, there is a range of "tar" and nicotine levels ..."

Dr. Suber's statement with respect to delivering a consistent level of nicotine clearly relates to the message contained in our written statement quoted ahove and to my testimony at page 149 , lines $3392-97$ to the effect that consumers expect and, indeed, the FTC requires, consistency in "tar" and nicotine levels. As stated, within the universe of cigarette products, there is a range of such levels and it was clearly not the intent of Dr. Suber to state that our company intends to deliver one "consistent level of nicotine." Indeed, the Subcommittee need only consider the broad range of "tar" and nicotine levels of all cigarette brands, as reflected in the FTC mandated disclosures to see that such an interpretation of Dr. Suber's statement is clearly wrong.

8. At pages 223-4 of the transcript, you referred to calculations by an FDA chemist regarding the concentrations of nicotine in tobacco in the 1950's. I advised that was information I had not previously seen. In order for us to analyze that data, we need the source of the information which is referred to on exhibit 24 at page 223 . Please have someone furnish to us the source of that data. Design techniques that have been developed since 1952, including filtration and air dilution, have resulted in a major reduction in the nicotine content of cigarette smoke. Therefore, the nicotine content of tobacco is not the major determinant of the nicotine content of the actual cigarette smoke which comes through the cigarette filter.

9. At various places during the course of my testimony I was asked questions relating to the purpose of cigarette advertising. As I attempted to make clear, study after study has shown that peer pressure and parental example are the primary reasons why youth begin smoking, while advertising plays little or no role. I want to be certain that the Subcommittee understands that the purpose of our cigarette advertising is to convince smokers of competitive brands to try our products, to promote brand loyalty among our own customers, and to convey information to smokers to allow them to make choices among the various brands and styles available now or in the future.

I have quickly reviewed the transcript of the Subcommittee's hearing on the 14th and there appear to be a number of typographical errors in it. By way of example, at page 118, line 2634, the question was being asked by either Representative Synar or by you; at page 178, line 4076 . the reference to "RJR" should be "PM;" at page 22, line 5157, the word quoted from my letter of February 28, 1994 was "finished," not "Finnish;" and at page 259, line 6027, the number should be "1,200" not " $\$ 1,200 ; "$ and at page 128 , line 2885 , the word "intent" should be "effect." The foregoing are onily examples where the record is inaccurate. I have not attempted to point out or correct all mistakes.

A copy of the transcript referred to above is attached for your reference.

Very truly yours,

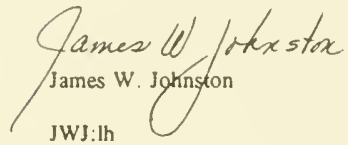



